\section{Bioterrorismus, infektiologische Aspekte}

\section{Ernst-Jürgen Finke, Herbert Tomaso, Dimitrios Frangoulidis}

"Alles, was sich als Waffe nutzen lässt, wird auch als Waffe verwendet."

(Stanislaw Lem 1921)

Infektionskrankheiten sind ständige Begleiter und gefürchtete Geißeln der Menschheit. Pest und Pocken versetzen als todbringende Seuchen die Menschen nicht erst seit dem Altertum in Schrecken (lat.: terror). Archaische Ängste und vor allem eine hohe Medienaufmerksamkeit sorgen immer wieder für Panik und irrationale Reaktionen: Im indischen Surat setzte im Herbst 1994 während eines ungewöhnlichen Pestausbruchs eine Massenflucht ein, nachdem die Presse den Verdacht auf Lungenpest und terroristische Anschläge verbreitet hatte. Über 800.000 Menschen, darunter auch zahlreiche Ärzte und Pflegekräfte, verließen daraufhin ihre Arbeitsplätze und Wohnorte. Allein die drastischen Flug- und Handelsbeschränkungen brachten Indien einen ökonomischen Schaden von etwa 3 Milliarden US \$.

Epidemien haben in der Vergangenheit oft Kriege entscheidend beeinflusst und nicht selten die Eroberung und Besiedlung neuer Territorien begünstigt. So soll im Jahre 1346 eine Pestepidemie die Verteidiger zur Übergabe ihrer von Tartaren belagerten Stadt Kaffa auf der Halbinsel Krim gezwungen haben. Pizarro konnte das Inkareich vermutlich nur deshalb erobern, weil mit seiner Truppe aus Europa neue Infektionskrankheiten, wie Pocken und Masern, eingeschleppt wurden. Diese dezimierten die immunologisch naive Bevölkerung, so dass kein nennenswerter Widerstand mehr möglich war.

\section{Die biologische Bedrohung}

Nur wenige Jahrzehnte nach ihrer Entdeckung wurde das militärische Potenzial von Mikroorganismen erkannt. In einigen europäischen Ländern, in den USA und Japan begann man nach dem 1 . Weltkrieg, verschiedene Mikroorganismen und Toxine systematisch auf ihre militärische Nutzbarkeit hin zu untersuchen. Nach dem Ende des 2. Weltkriegs wurde bekannt, dass Angehörige der japanischen Einheit 731 in der besetzten Mandschurei unter anderem die Wirkung von Pest-, Typhus-, Rotz- und Choleraerregern an Menschen getestet hatten. Außerdem wurden aus der Luft infizierte Flöhe ausgebracht, um in der chinesischen Zivilbevölkerung die Pest zu verbreiten [30].

Auch nach 1945 haben einige Staaten im Verlaufe des Kalten Krieges geheime B-Waffenprogramme betrieben. Dabei wurden unterschiedliche Arten biologischer (B-) Kampfstoffe entwickelt, produziert und als biologische (B-) Waffen (syn.: B-Kampfmittel) muniti- oniert. Bis zum Anfang der Siebzigerjahre war ein begrenztes Spektrum von Toxinen und Krankheitserregern identifiziert und in Labor- und Freilandversuchen erprobt worden, das oft als „Dirty dozen“ bezeichnet wird. Diese Agenzien erschienen aus militärischer Sicht für die taktische, operative und strategische biologische Kriegsführung als besonders geeignet $(\triangleright$ Tab. 1).

Eine Expertenkommission der WHO hat 1970 mögliche medizinische Folgen eines großflächigen AerosolLuftangriffs mit $50 \mathrm{~kg}$ Milzbrandsporen auf ein Ballungszentrum mathematisch modelliert [38]. Danach wären in einer Großstadt mit 500.000 ungeschützten Einwohnern bis zu 125.000 Personen erkrankt und 95.000 der Patienten verstorben.

Angesichts dieser Wirkungen werden biologische Waffen als Massenvernichtungsmittel betrachtet [30]. Um sie zu bannen, schlossen die USA und UdSSR am 10. April 1972 das Übereinkommen über das Verbot der Entwicklung, Herstellung und Lagerung bakteriologischer (biologischer) und von Toxinwaffen sowie über die Vernichtung solcher Waffen (BWÜ) ab, das am 26. März 1975 in Kraft trat. Leider verhinderte es in der Folgezeit nicht, dass biologische Kampfmittel insgeheim selbst durch Signatarstaaten des BWÜ weiter entwickelt und produziert wurden [32]. Dafür sprechen die offengelegten B-Waffen-Programme des Irak und der ehemaligen UdSSR zu Beginn der Neunzigerjahre.

Seitdem wuchs die Sorge, dass auch staatlich gestützte oder unabhängig agierende Gruppen des internationalen Terrorismus oder der organisierten Kriminalität, Sekten und Einzeltäter B-Kampfmittel erlangen könnten. Sogenannte Dual-Use-Technologien zur Massenvermehrung, zum Konzentrieren und Ausbringen von Mikroorganismen sind frei erhältlich. Viele der als potenzielle B-Kampfstoffe betrachteten Krankheitserreger und Toxine kommen weltweit natürlich vor oder wären in Untersuchungs- und Forschungslaboren sowie in bestimmten Pharmaunternehmen verfügbar.

Inwieweit jedoch nicht staatliche Akteure, wie zum Beispiel die Terrorgruppe Al-Qaida, über die nötige naturwissenschaftliche und technische Expertise, Logistik, Finanzmittel und Laborausstattung verfügen, um B-Kampfstoffe zu produzieren, ist gegenwärtig nur schwer abzuschätzen. Die japanische Sekte Aum Shinrikyo scheiterte noch in den Jahren 1990 bis 1994 trotz eines beachtlichen finanziellen und personellen Aufwandes bei ihren Versuchen, Anthraxsporen und Botulinumtoxine effizient auszubringen [24]. Andererseits gelang es offenbar einem spezialisierten, erfahrenen und zum Äußersten entschlossenen „Insider“, im Herbst 2001 in US-Großstädten mehrfach und gezielt speziell präparierte Sporenpulver eines hoch virulenten Bacillus -(B.-) anthracis-Stammes über das US-Postsystem zu verbreiten. In der Folge erkrankten 
22 Personen unerwartet an Milzbrand, wobei fünf von 11 der an Inhalationsanthrax Erkrankten starben.

Diese offiziell als Amerithrax-Ereignisse bezeichneten Anthraxausbrüche bewirkten in Verbindung mit den Terrorakten vom 11. September 2001, dass auch in Deutschland eine biologische Bedrohung stärker wahrgenommen wurde. Dazu trugen noch Tausende Fehlalarme und die Medienkampagnen bei, die eine stark verunsicherte Öffentlichkeit über mögliche biologische Risiken aufzuklären suchten. Aufgefordert durch die Europäische Kommission und die WHO, wurde der Schutz der Bevölkerung vor biologischen Gefahren verstärkt. So wurden u. a. das Zentrum für biologische Sicherheit am Robert Koch-Institut in Berlin und verschiedene regionale Kompetenzzentren eingerichtet und ein Bund-Länder-Rahmenkonzept zur Seuchenbekämpfung nach bioterroristischen Anschlägen erarbeitet. Spezielle Aus- und Fortbildungsangebote dienten dazu, Rettungs- und Ordnungskräfte, Angehörige des öffentlichen Gesundheitsdienstes sowie das medizinische Personal auf mögliche biologische Gefahrenlagen, speziell Bioterrorismus, vorzubereiten.

Im Folgenden wird biologische Bedrohung vereinfacht definiert als Produkt aus dem Risiko und der Absicht eines Angreifers, B-Waffen oder B-Kampfstoffe einzusetzen. Das biologische Risiko ergibt sich aus der Wahrscheinlichkeit und dem Ausmaß des Effekts eines biologischen Angriffs oder Terroranschlags [3].

Als Bioterrorismus wird gewöhnlich eine Drohung mit oder der Einsatz von biologischen Waffen, biologischen Kampfstoffen und vergleichbaren biologischen Agenzien durch Staaten, Gruppen oder Einzelpersonen aus politischen, militärischen, religiösen, ökonomischen oder anderen Beweggründen bezeichnet.

Angedrohte oder realisierte bioterroristische Anschläge verfolgen oft die Absicht, physische und psychische Schäden auszulösen und Bevölkerungsgruppen in Angst und Panik zu versetzen und zu demoralisieren. Damit wird bezweckt, eine Gesellschaft wirtschaftlich zu schwächen, politisch zu destabilisieren oder sogar $\mathrm{zu}$ paralysieren. Aber allein schon blinde Alarme („weißes Pulver") durch Trittbrettfahrer und gezielte Desinformation („Pockenpandemie“, „Bioterror") können ähnlich wirken und eine Massenhysterie auslösen.

Mit einem Massenanfall an Geschädigten wäre insbesondere zu rechnen, wenn B-Kampfmittel aus geheimen staatlichen B-Waffenarsenalen genutzt und extrem hohe Dosen „professioneller" biologischer Kampfstoffe ausgebracht würden.

Experten gehen davon aus, dass gegenwärtig eine derartige biologische Bedrohung sehr unwahrscheinlich ist. Dafür sprechen auch verschiedene historische Analysen von Ereignissen, bei denen biologische Agenzien gegen Personen eingesetzt wurden. So kam es im Zeitraum von 1900 bis 2001 weltweit lediglich zu
77 biologischen Ereignissen, wobei in den letzten 100 Jahren in den USA weniger als 10 Menschen durch biologische Anschläge getötet wurden [24].

\section{Biologische Kampfstoffe}

Biologische Kampfstoffe sind zu nicht friedlichen Zwecken produzierte vermehrungsfähige Organismen und daraus gewonnene physiologisch aktive Stoffe, die Tod oder Krankheit bei Mensch, Tier und Pflanze verursachen können.

Über 30 Arten und Typen von Krankheitserregern und Toxinen ( $\triangleright$ Tab. 1) gelten nach Ansicht internationaler Expertengremien und der US-amerikanischen Centers for Disease Control and Prevention (CDC) als potenzielle B-Kampfstoffe [9, 34, 36, 38]. Sie werden häufig auch als sogenannte „dual threat", „,critical“, ,,select" oder "biologische Agenzien“ bezeichnet. Einige der in Tab. 1 aufgeführten Agenzien sind aus bisher offengelegten B-Waffen-Programmen bekannt, wurden schon einmal waffenfähig gemacht oder bei terroristischen bzw. kriminellen Aktionen eingesetzt. Es handelt sich dabei um besonders wirksame mikrobielle, pflanzliche und tierische Toxine sowie hoch virulente Stämme verschiedener natürlich vorkommender human- und tierpathogener Bakterien-, Viren- und Pilzarten. Einige sind aufgrund ihrer Dauerformen (z. B. Sporen von B. anthracis) besonders umweltresistent und bleiben dadurch in Aerosolform in der Luft für mehrere Stunden infektiös.

Die Mehrzahl der als biologische Agenzien infrage kommenden Mikroorganismen sind Zoonoseerreger, von denen einige beim Menschen gefährliche, d. h. lebensbedrohliche und hoch ansteckende, Infektionskrankheiten verursachen können ( $\triangleright$ Tab. 1, 2 und 3). Sie treten in Deutschland normalerweise nicht oder sehr selten auf.

Infektionen mit den meisten dieser Krankheitserreger verlaufen überwiegend klinisch manifest. Unbehandelt weisen sie eine schlechte Prognose und relativ hohe Letalität auf. Abgesehen von Pocken, Lungenpest und bestimmten viralen hämorrhagischen Fiebern ist eine Übertragung von Mensch zu Mensch selten. Angesichts der fehlenden oder geringen Inzidenz derartiger "exotischer" Krankheiten kann eine valide Diagnostik nur in wenigen hoch spezialisierten Referenz-, Konsiliar- und Expertenlaboratorien der Schutzstufen 3 oder 4 gewährleistet werden. Wirksame Mittel zur kausalen Therapie und zur Immun- sowie Chemoprophylaxe sind entweder nicht oder nur begrenzt verfügbar. So könnten z. B. bestimmte, in Deutschland nicht zugelassene, Impfstoffe gegen Pest, Anthrax, Tularämie oder Pocken erst bei Eintritt eines biologischen Schadensereignisses freigegeben werden.

Daher würde ein Angriff mit Erregern gefährlicher Infektionskrankheiten aufgrund des hohen epidemischen Potenzials und der unzureichenden Immunität einer ungeschützt exponierten Bevölkerung schwer- 


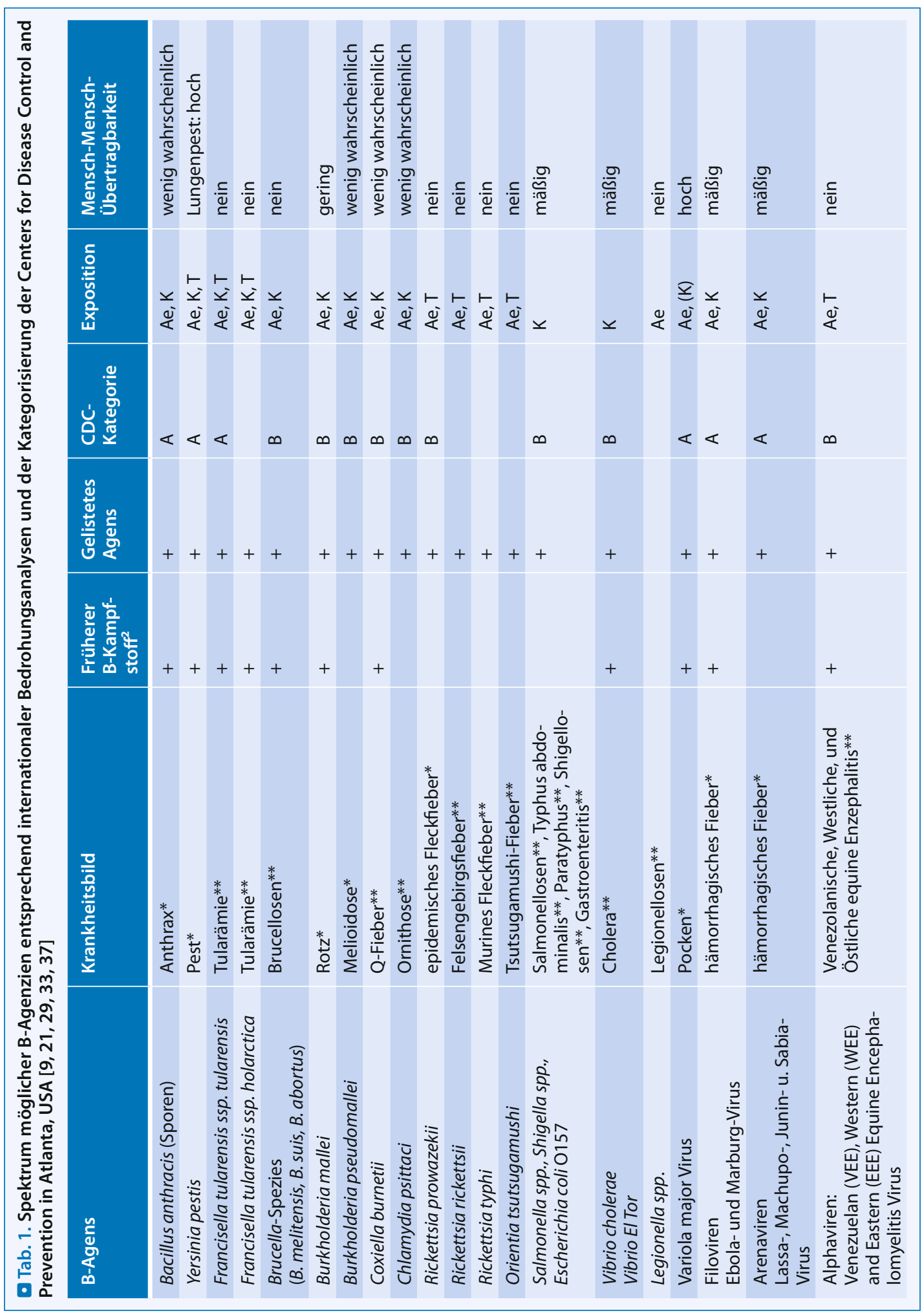




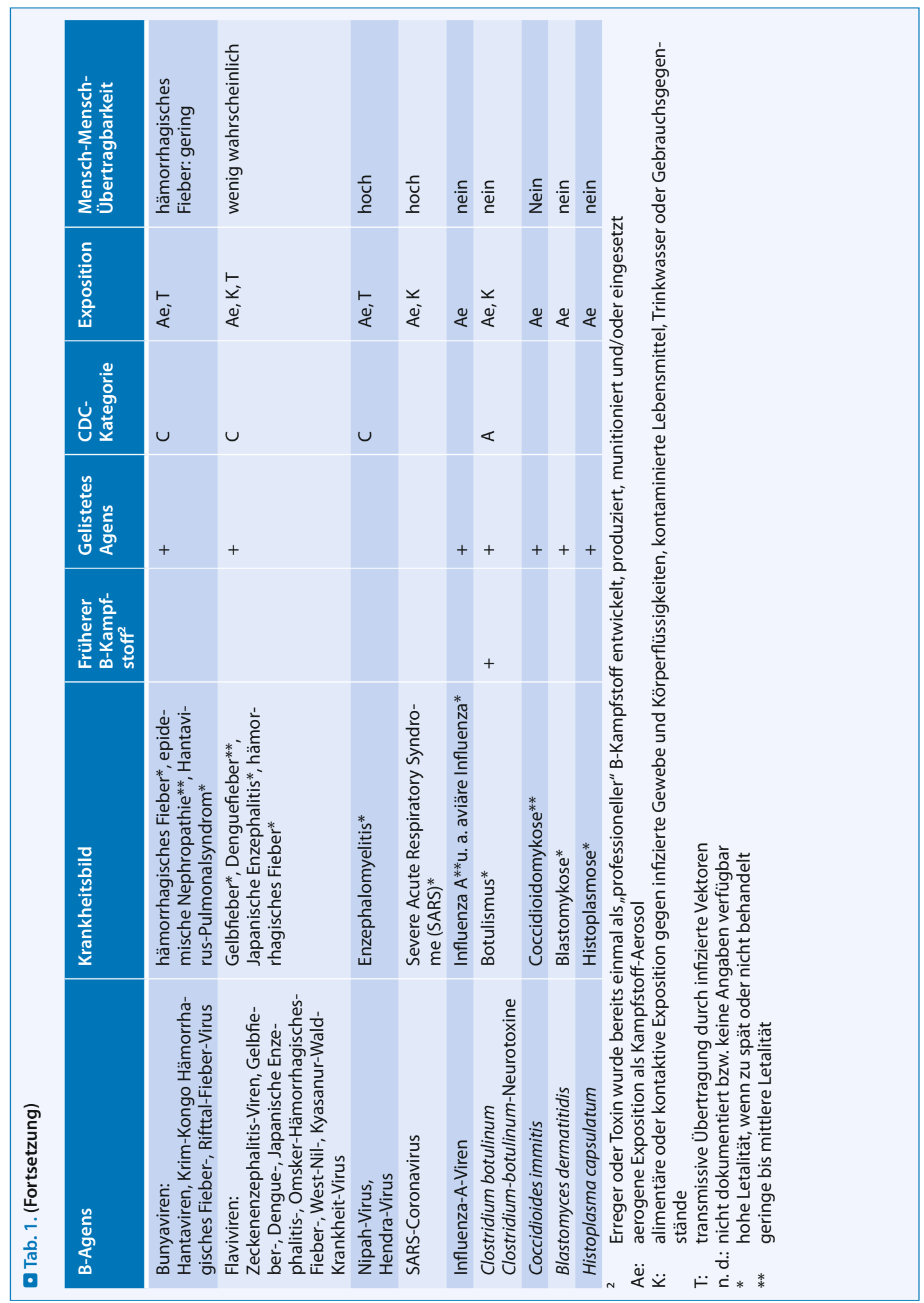


Tab. 2. Klinische Erscheinungsbilder von Krankheiten, die durch potenzielle biologische Agenzien ausgelöst werden können

\begin{tabular}{|c|c|}
\hline Syndrom & Krankheit \\
\hline $\begin{array}{l}\text { Fieberhaftes } \\
\text { gastrointestina- } \\
\text { les Syndrom }\end{array}$ & $\begin{array}{l}\text { Cholera } \\
\text { Shigellosen } \\
\text { Typhus abdominalis, Paraty- } \\
\text { phus A und B } \\
\text { Anthrax } \\
\text { Tularämie } \\
\text { Virale hämorrhagische Fieber } \\
\text { Venezolanische equine Enze- } \\
\text { phalitis, japanische Enzephali- } \\
\text { tis, West-Nil- Fieber } \\
\text { Staphylokokken-Enterotoxin- } \\
\text { B-, Rizin-Intoxikation }\end{array}$ \\
\hline $\begin{array}{l}\text { Meningitis, Me- } \\
\text { ningoenzephali- } \\
\text { tis, Enzephalitis, } \\
\text { Myelitis, Enze- } \\
\text { phalopathie }\end{array}$ & $\begin{array}{l}\text { Venezolanische, Westliche } \\
\text { und Östliche equine Enze- } \\
\text { phalitis } \\
\text { Zeckenenzephalitis, Japani- } \\
\text { sche Enzephalitis, Dengue- } \\
\text { Fieber, West-Nil Fieber } \\
\text { Virale hämorrhagische Fieber } \\
\text { Pocken } \\
\text { Pest } \\
\text { Anthrax } \\
\text { Q-Fieber } \\
\text { Brucellose } \\
\text { Tularämie } \\
\text { Rickettsiosen, u. a. epidemi- } \\
\text { sches und murines Fleckfie- } \\
\text { ber, Felsengebirgsfieber }\end{array}$ \\
\hline $\begin{array}{l}\text { Septikämie, } \\
\text { Sepsis, infek- } \\
\text { tiös-toxisches } \\
\text { Schocksyndrom }\end{array}$ & $\begin{array}{l}\text { Anthrax } \\
\text { Pest } \\
\text { Tularämie } \\
\text { Brucellose } \\
\text { Rotz/Melioidose } \\
\text { Rickettsiosen } \\
\text { Rizin-Intoxikation }\end{array}$ \\
\hline $\begin{array}{l}\text { „Influenza like } \\
\text { IIIness“ (ILI) }\end{array}$ & $\begin{array}{l}\text { Initialsyndrom bei nahezu } \\
\text { allen durch B-Agenzien ver- } \\
\text { ursachten Krankheiten, außer } \\
\text { Cholera und Botulismus }\end{array}$ \\
\hline
\end{tabular}

wiegende Auswirkungen auf das Leben und die Gesundheit der Betroffenen sowie auf das soziale Gefüge haben $[4,36]$.

Außer den in $>$ Tab. 1 und 3 aufgelisteten Agenzien sind bestimmte neu auftauchende Krankheitserreger, z. B. SARS-Coronaviren oder hochpathogene Influenza A-Virus-Subtypen, einzukalkulieren. Angesichts einer schwindenden Pockenimmunität der Bevölkerung kämen künftig auch animale Orthopockenviren, wie Affen- und Kuhpockenviren, in Betracht. Nach ei-
Tab. 2. (Fortsetzung)

\section{\begin{tabular}{l|l} 
Syndrom & Krankheit
\end{tabular}}

Fieber und Exan- Pocken theme

Virale hämorrhagische Fieber

Rickettsiosen

Pest, Q-Fieber, Brucellose

Tularämie

Typhus abdominalis, Paraty-

phus $A$ und $B$

Coccidioido- und Blastomy-

kose

\begin{tabular}{l|l}
$\begin{array}{ll}\text { Fieber, Pharyn- } \\
\text { gitis }\end{array}$ & Anthrax \\
& Pest \\
& Pocken \\
& Tularämie \\
& Rotz \\
& virale hämorrhagische Fieber \\
& Influenza
\end{tabular}

\begin{tabular}{l|l|}
\begin{tabular}{ll} 
Pneumonie, & Anthrax \\
ARDS & Pest \\
& $\begin{array}{l}\text { Tularämie } \\
\text { Q-Fieber } \\
\text { Rotz, Melioidose } \\
\text { Ornithose, Legionellose } \\
\text { Coccidioido- und Blastomyko- } \\
\text { se, Histoplasmose } \\
\text { Hantavirus-Pulmonal-Syn- } \\
\text { drom } \\
\text { Influenza }\end{array}$ \\
\hline $\begin{array}{l}\text { Fieber und } \\
\text { Lymphadenopa- } \\
\text { thie/Splenome- } \\
\text { galie }\end{array}$ & $\begin{array}{l}\text { Anthrax } \\
\text { Pest }\end{array}$ \\
$\begin{array}{l}\text { Tularämie } \\
\text { Rotz }\end{array}$ \\
Melioidose \\
Rickettsiosen \\
Ornithose
\end{tabular} \\
$\begin{array}{ll}\text { Virale hämorrhagische Fieber } \\
\text { Fieber und Blu- } \\
\text { tungen mit/ohne } \\
\text { Nephropathie }\end{array}$ & $\begin{array}{l}\text { Virale hämorrhagische Fieber } \\
\text { Pest } \\
\text { Anthrax } \\
\text { Rizin-Intoxikation }\end{array}$ \\
\hline
\end{tabular}

ner erfolgreichen weltweiten Elimination von Masern oder Poliomyelitis und dem Aussetzen der Impfungen würde auch von Masern- und Polioviren ein Risiko ausgehen. Zudem können biologische Agenzien derzeit schon mit Hilfe der Gentechnik und synthetischen Biologie rekombiniert (Interleukin-4-Insertion in Orthopockenviren), rekonstruiert (Influenza-A-Pandemie-Virus von 1918) oder de novo (Poliovirus) erzeugt werden [24]. Daraus resultiert die Sorge, dass solche Dual-Use-Technologien in die Hände von Ter- 


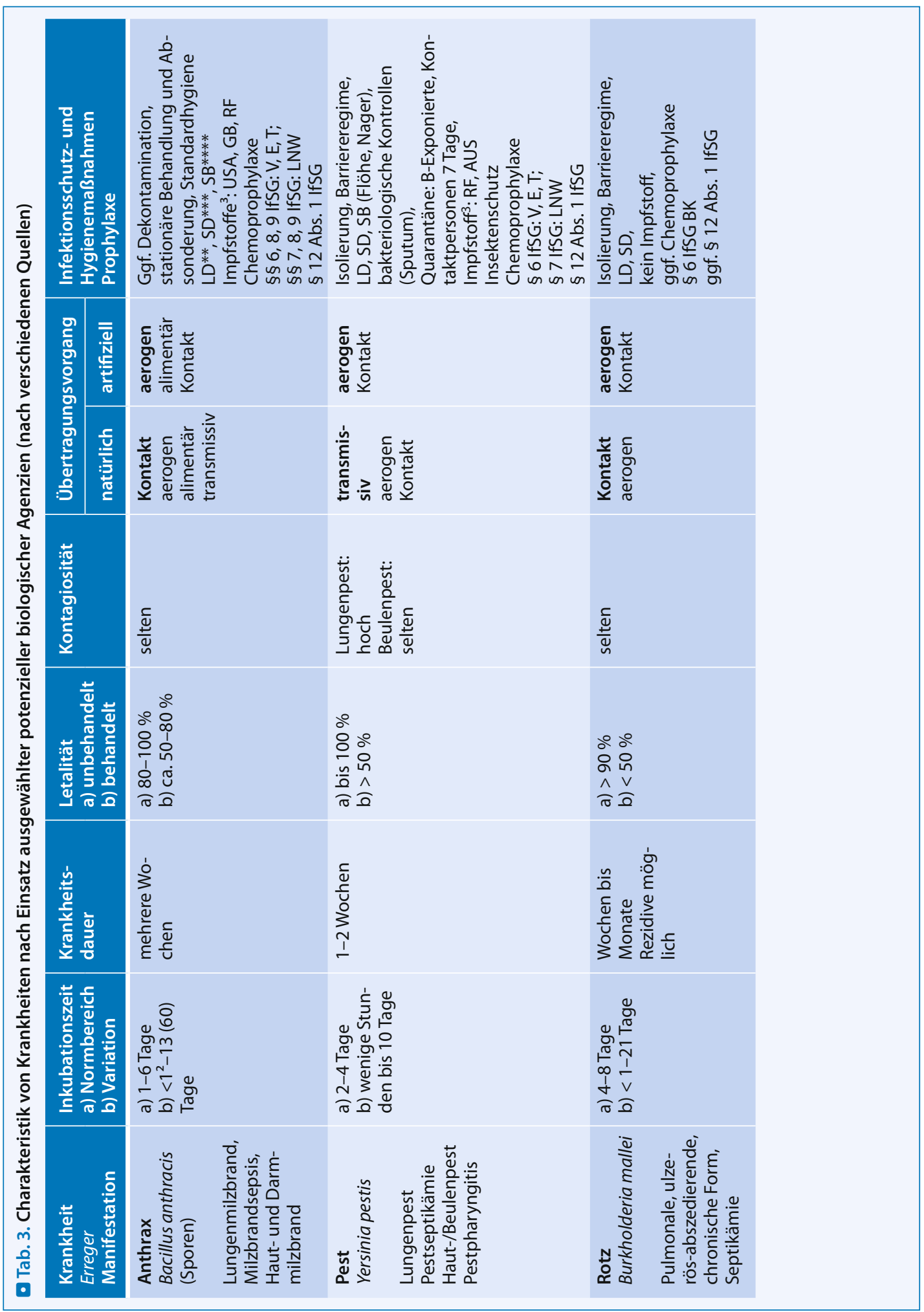




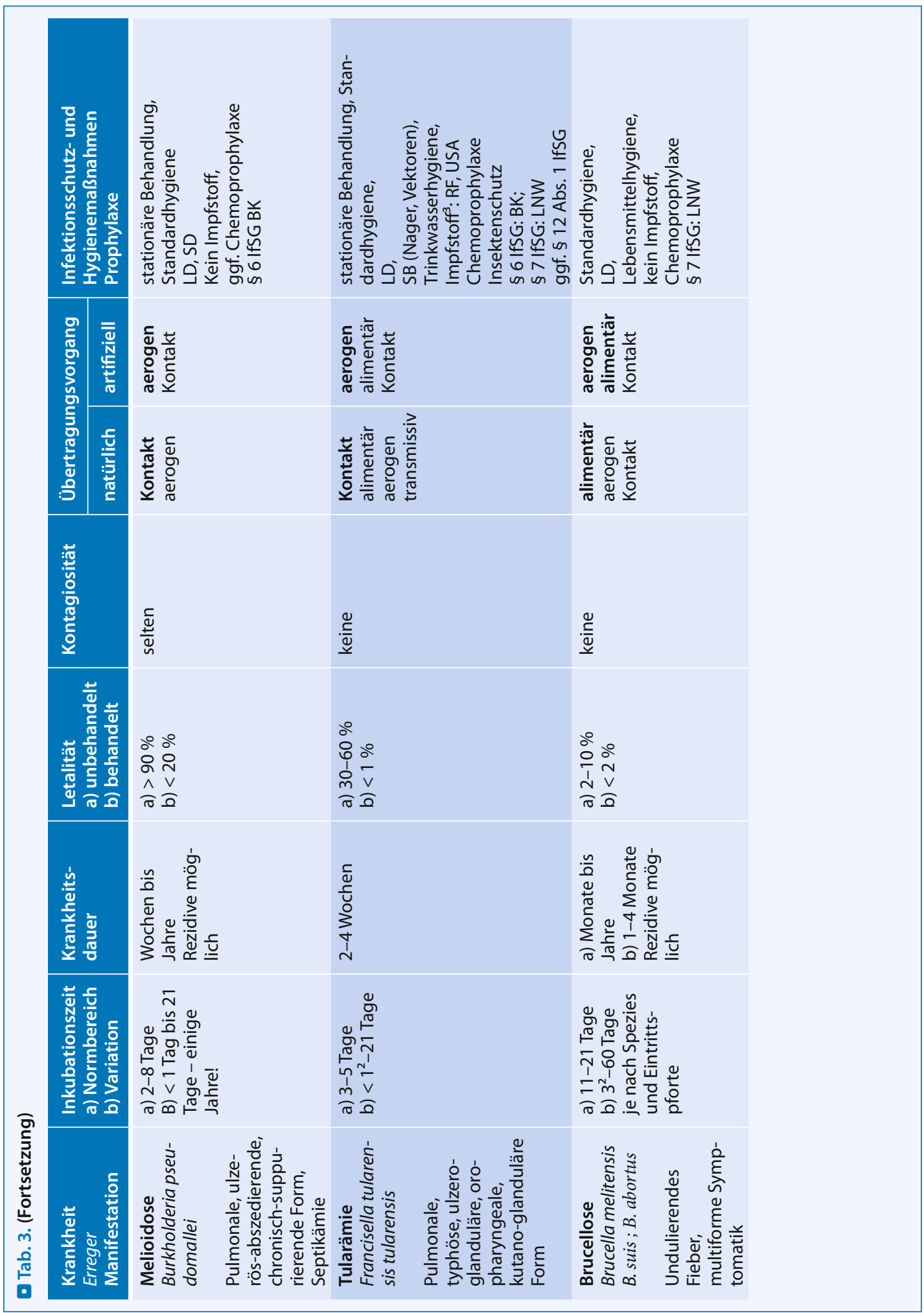




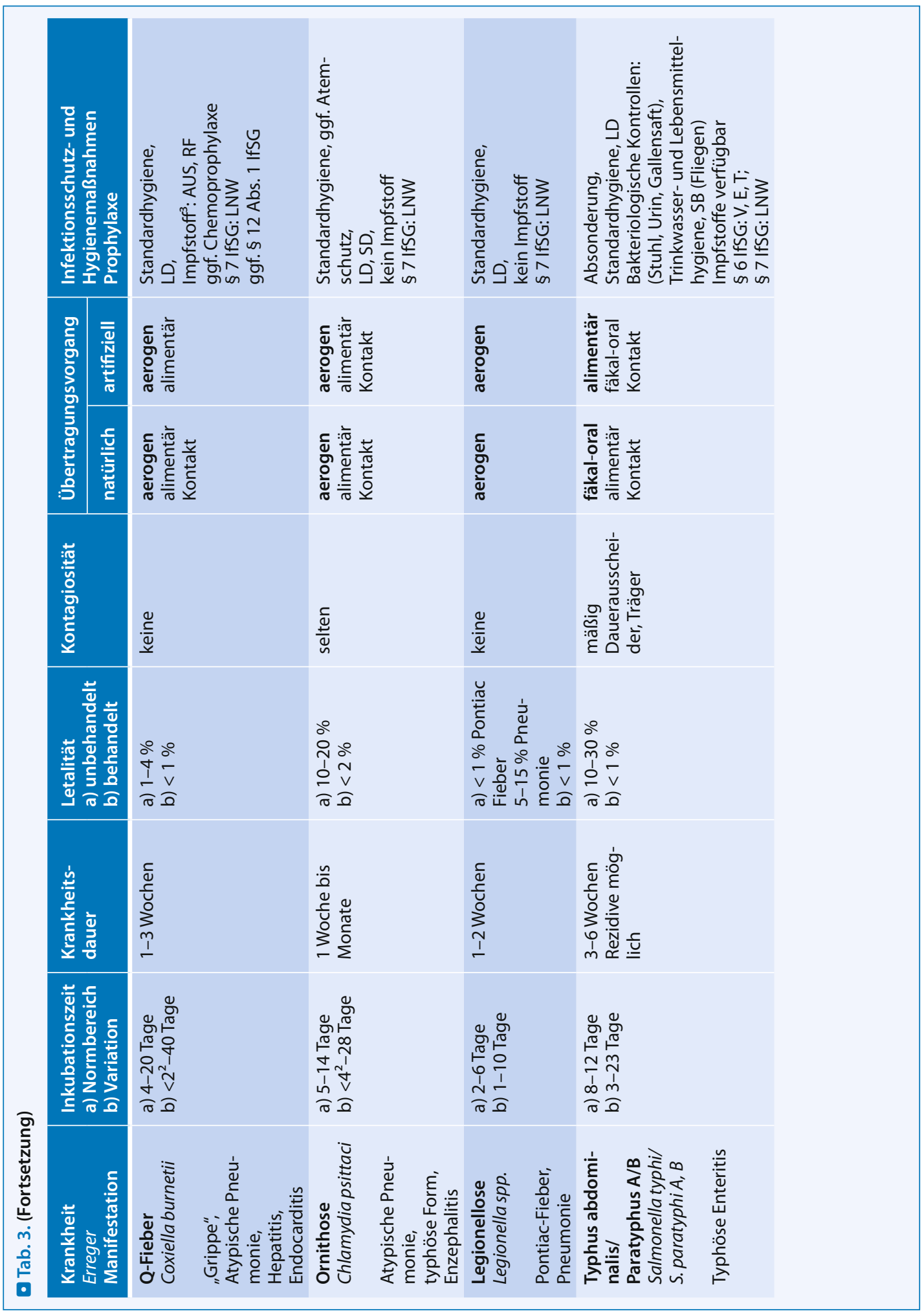




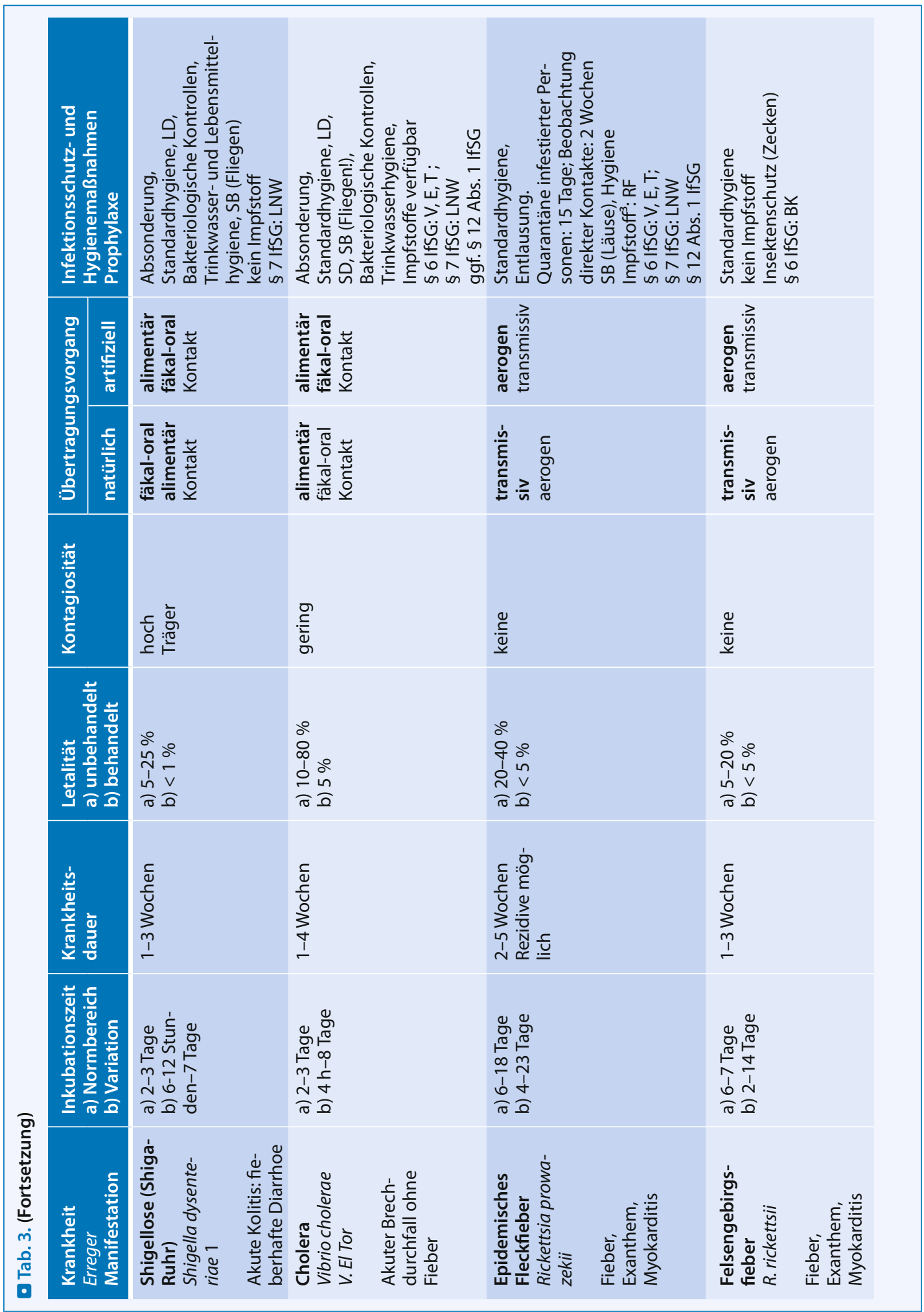




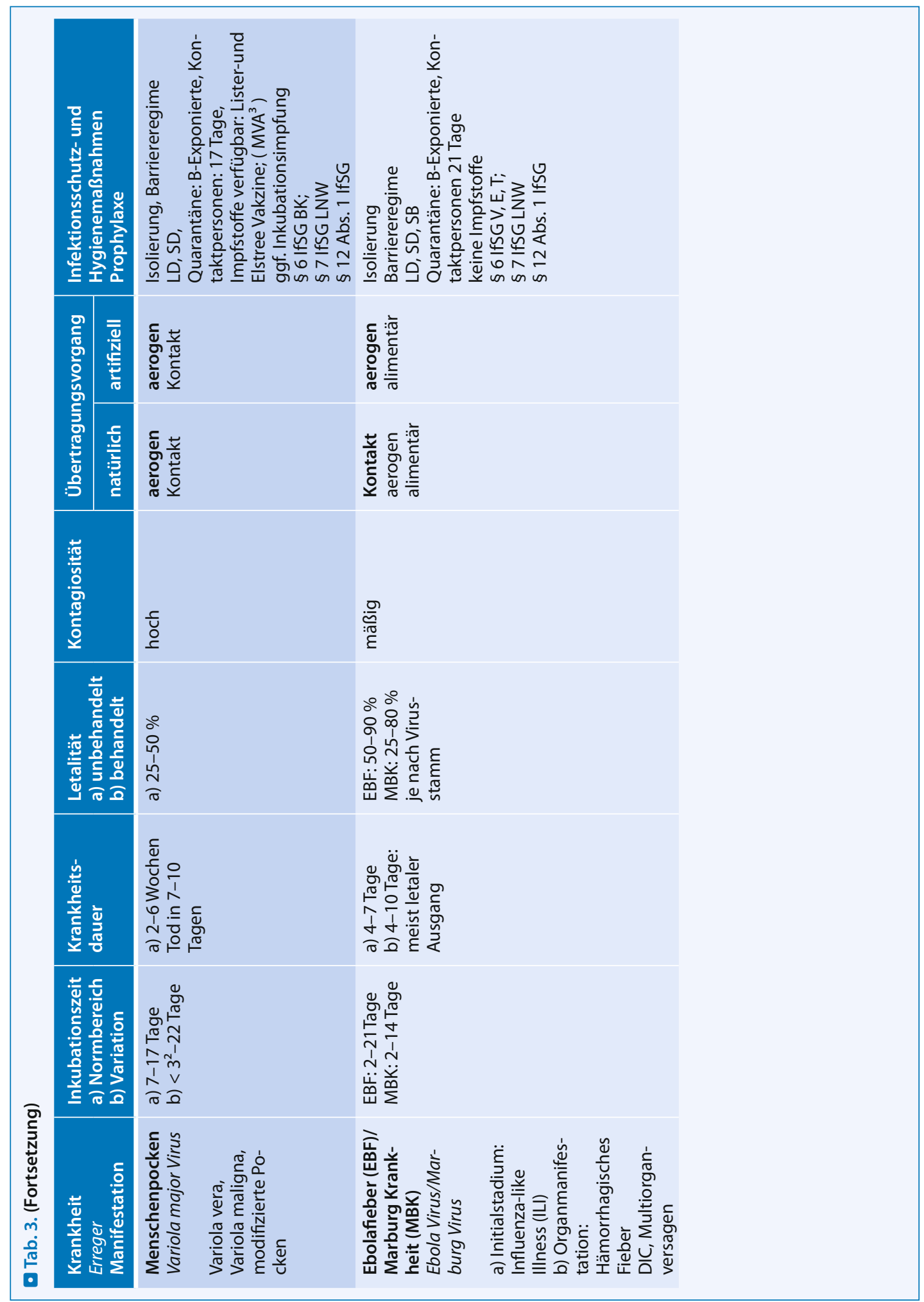




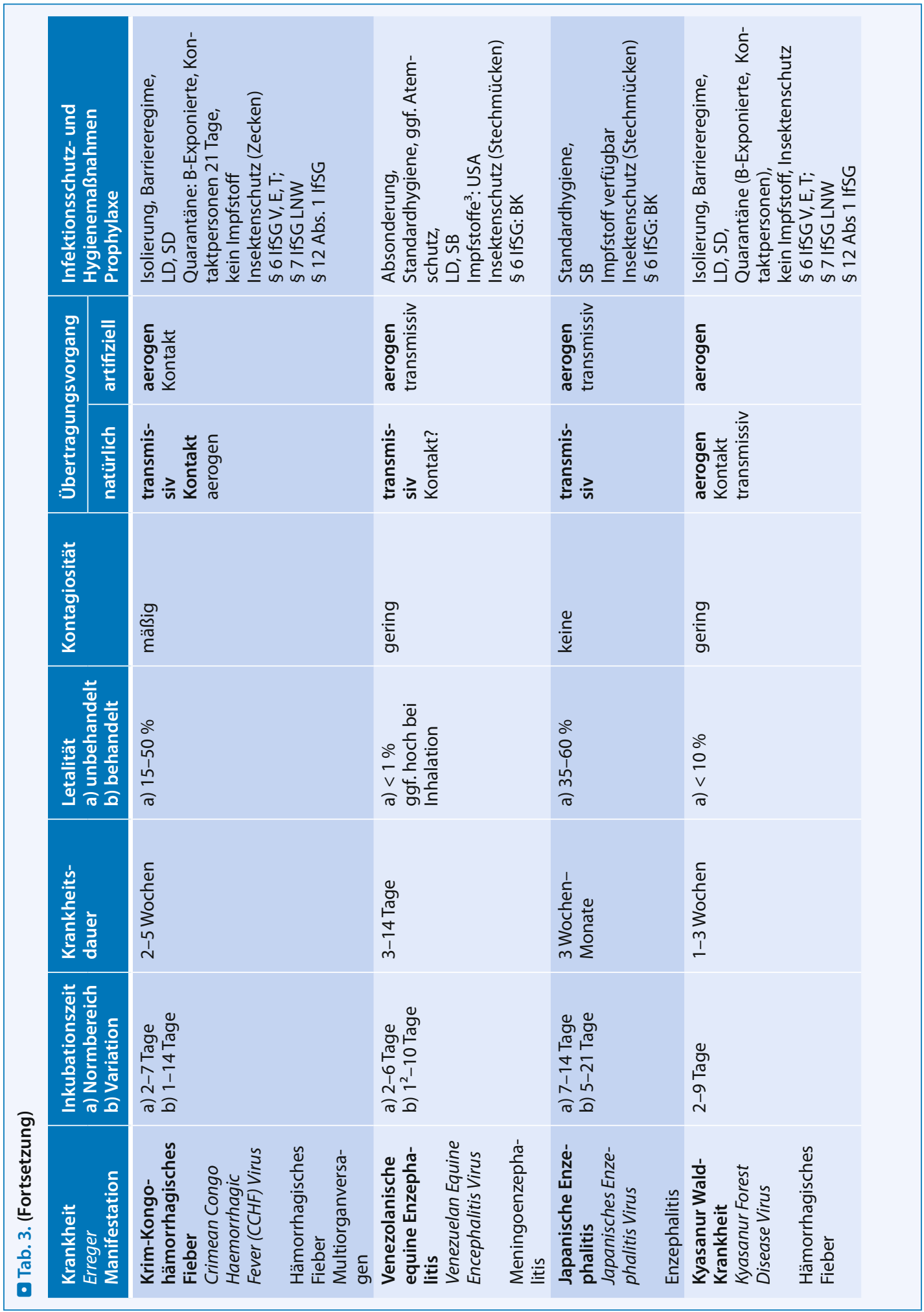




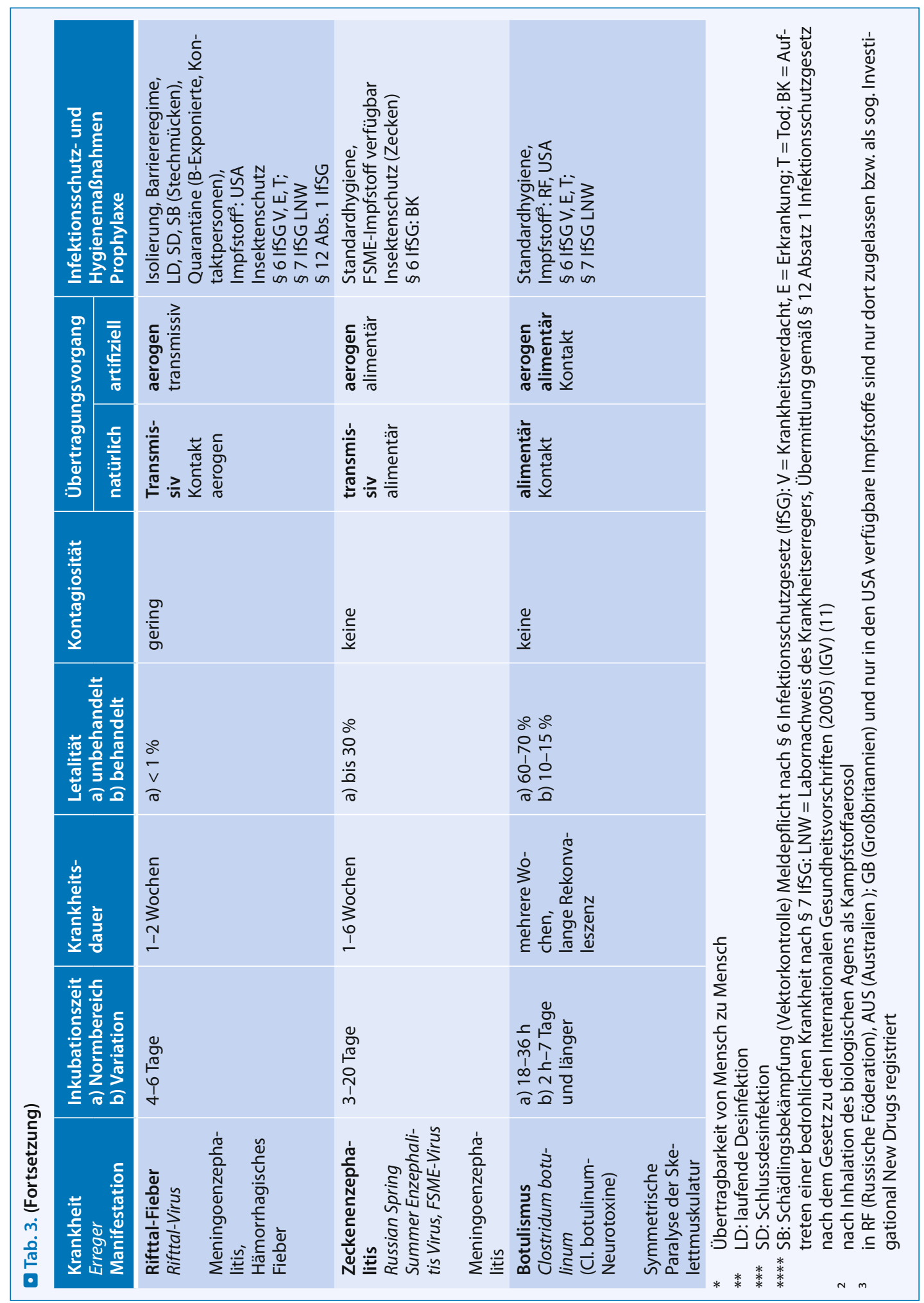


- Tab. 4. Diagnostik, Prophylaxe und Therapie ausgewählter potenzieller B-Gesundheitsstörungen (siehe auch $[5,6,34])$

\begin{tabular}{|c|c|c|c|}
\hline Krankheit & $\begin{array}{l}\text { Probengewinnung } \\
\text { für die Diagnostik* }\end{array}$ & Chemoprophylaxe & Therapie \\
\hline Anthrax & $\begin{array}{l}\text { Atemwegsekrete, } \\
\text { Pleurapunktat, Blut, } \\
\text { Liquor, Abstriche, } \\
\text { Stuhl }\end{array}$ & $\begin{array}{l}\text { Alternativ für } 60 \text { Tage } \\
\text { (sofern keine Impfung } \\
\text { möglich), bei gleichzei- } \\
\text { tiger Impfung } 30 \text { Tage: } \\
\text { - Ciprofloxacin } \\
\text { - Levofloxacin } \\
\text { - Ofloxacin } \\
\text { - Doxycyclin } \\
\text { - Amoxicillin }\end{array}$ & $\begin{array}{l}\text { Alternativ für } 60 \text { Tage } \\
\text { - Ciprofloxacin } \\
\text { - Doxycyclin } \\
\text { - Penicillin G } \\
\text { - Kombinationen von Doxycyclin oder } \\
\text { Gyrasehemmer mit Clindamycin } \\
\text { und ggf. anderen Antibiotika, z. B. } \\
\text { Rifampicin bei Lungen- und Darm- } \\
\text { milzbrand, Septikämie } \\
\text { Supportive Behandlung bei Sepsis, } \\
\text { ARDS }\end{array}$ \\
\hline Brucellose & $\begin{array}{l}\text { Blut, Knochenmark, } \\
\text { Urin, Liquor }\end{array}$ & $\begin{array}{l}\text { Über } 3 \text { Wochen: } \\
\text { - Doxycyclin + Rifam- } \\
\text { picin }\end{array}$ & $\begin{array}{l}\text { Alternativ für } 6 \text { Wochen: } \\
\text { - Doxycyclin + Rifampicin } \\
\text { - Doxycyclin + Streptomycin oder } \\
\text { Gentamicin } \\
\text { - Ofloxacin + Rifampicin }\end{array}$ \\
\hline Pest & $\begin{array}{l}\text { Blut, Atemwegsekrete, } \\
\text { Liquor, Bubonenpunk- } \\
\text { tate, Urin, Abstriche }\end{array}$ & $\begin{array}{l}\text { Alternativ über } 7 \text { Tage: } \\
\text { - Tetracyclin, } \\
\text { - Doxycyclin, } \\
\text { - Ciprofloxacin }\end{array}$ & $\begin{array}{l}\text { Über mindestens } 10 \text { Tage alternativ: } \\
\text { - Streptomycin } \\
\text { - Gentamicin } \\
\text { - Doxycyclin plus Chloramphenicol } \\
\quad \text { (bei Meningitis) } \\
\text { - Ciprofloxacin } \\
\text { Supportive Behandlung bei Sepsis, } \\
\text { ARDS }\end{array}$ \\
\hline Q-Fieber & $\begin{array}{l}\text { Blut, Atemwegsekrete, } \\
\text { Liquor }\end{array}$ & $\begin{array}{l}\text { Für 5-7 Tage (8-12 Tage } \\
\text { nach mutmaßlicher } \\
\text { Exposition) alternativ: } \\
\text { - Tetracyclin } \\
\text { - Doxycyclin }\end{array}$ & $\begin{array}{l}\text { Alternativ: } \\
\text { - Tetracyclin } \\
\text { - Doxycyclin } \\
\text { - Erythromycin + Rifampicin } \\
\text { - Tetrazyclin oder Doxycyclin + Chlo- } \\
\text { roquin/(Rifampicin) } \\
\text { Supportive Behandlung; ggf. Operati- } \\
\text { on bei Endokarditis }\end{array}$ \\
\hline $\begin{array}{l}\text { Rotz/Melioi- } \\
\text { dose }\end{array}$ & $\begin{array}{l}\text { Blut, Atemwegsekre- } \\
\text { te, Liquor, Punktate, } \\
\text { Abstriche, Urin }\end{array}$ & $\begin{array}{l}\text { Alternativ für } 7 \text { Tage: } \\
\text { - Doxycyclin } \\
\text { - TMP-SMX } \\
\text { - Ciprofloxacin }\end{array}$ & $\begin{array}{l}\text { Alternativ } \\
\text { - Ceftazidim + Gentamicin (bis } 4 \text { Wo- } \\
\text { chen) } \\
\text { - Imipenem } \\
\text { Anschließend: } \\
\text { - + TMP-SMX + Doxycyclin ( } 12 \text { Wo- } \\
\text { chen) } \\
\text { Supportive Behandlung bei Sepsis, ggf. } \\
\text { Operation }\end{array}$ \\
\hline Tularämie & $\begin{array}{l}\text { Blut, Atemwegsekrete, } \\
\text { Liquor, Punktate, Urin, } \\
\text { Abstriche }\end{array}$ & $\begin{array}{l}\text { Alternativ über } 14 \text { Tage: } \\
\text { - Doxycyclin } \\
\text { - Tetracyclin } \\
\text { - Ciprofloxacin }\end{array}$ & $\begin{array}{l}\text { Alternativ über 10-14 Tage: } \\
\text { - Streptomycin } \\
\text { - Gentamicin } \\
\text { - Tetracyclin } \\
\text { - Ciprofloxacin } \\
\text { Supportive Behandlung bei Sepsis, } \\
\text { ARDS }\end{array}$ \\
\hline
\end{tabular}


Tab. 4. (Fortsetzung)

\begin{tabular}{|c|c|c|c|}
\hline Krankheit & $\begin{array}{l}\text { Probengewinnung } \\
\text { für die Diagnostik* }\end{array}$ & Chemoprophylaxe & Therapie \\
\hline Botulismus & $\begin{array}{l}\text { Nasen-Rachen-Sekret, } \\
\text { Magen-Darm-Inhalt, } \\
\text { Blut }\end{array}$ & & $\begin{array}{l}\text { Intensivtherapie: } \\
\text { - Beatmung } \\
\text { - ggf. Antibiose } \\
\text { Sofern verfügbar: } \\
\text { - typenspezifische Antitoxine } \\
\text { Supportive Behandlung bei Atemläh- } \\
\text { mung }\end{array}$ \\
\hline Pocken & $\begin{array}{l}\text { Blut, Atemwegsekrete, } \\
\text { Hautmaterial }\end{array}$ & & $\begin{array}{l}\text { Nicht zugelassen: } \\
\text { - Cidofovir + Probenecid } \\
\text { ST-246 } \\
\text { Supportive Behandlung } \\
\text { bei Superinfektionen ggf. Antibiose }\end{array}$ \\
\hline $\begin{array}{l}\text { Virale hä- } \\
\text { morrhagi- } \\
\text { sche Fieber }\end{array}$ & $\begin{array}{l}\text { Blut, Atemwegsekrete, } \\
\text { Liquor, Hautmaterial, } \\
\text { Urin, Magen-Darm- } \\
\text { Inhalt }\end{array}$ & $\begin{array}{l}\text { Ribavirin bei CCHF, } \\
\text { Lassafieber }\end{array}$ & $\begin{array}{l}\text { Ribavirin (CCHF, Lassa Fieber) } \\
\text { Supportive Behandlung bei Nierenin- } \\
\text { suffizienz, hämorragischem Schock, } \\
\text { Multiorganversagen }\end{array}$ \\
\hline $\begin{array}{l}\text { Virale Me- } \\
\text { ningitis/En- } \\
\text { zephalitis }\end{array}$ & $\begin{array}{l}\text { Blut, Atemwegsekrete, } \\
\text { Liquor }\end{array}$ & & $\begin{array}{l}\text { Supportive Behandlung bei Fieber, } \\
\text { Paralysen, Krämpfe }\end{array}$ \\
\hline \multicolumn{4}{|c|}{$\begin{array}{l}\text { * bei Verstorbenen: Autopsiematerial (i. d. R. Blut, Leber, Milz, Lunge, Niere, auffällige Lymphknoten, Hirn, Punk- } \\
\text { tate (Abszesse, Pleura, Knochenmark, Liquor), Haut und Darmteile }\end{array}$} \\
\hline \multicolumn{3}{|c|}{$\begin{array}{l}\text { roristen oder Kriminellen gelangen und missbraucht } \\
\text { werden könnten. Daher werden im Rahmen des B- } \\
\text { Waffen-Übereinkommens effizientere Kontrollen der } \\
\text { Proliferation des kritischen Know-how, ein sogenann- } \\
\text { ter „Code of conduct“ für Biowissenschaftler und ver- } \\
\text { schärfte Sicherheitsvorschriften für die biomedizini- } \\
\text { sche Forschung und den Umgang mit kritischen bio- } \\
\text { logischen Agenzien angestrebt [3,32]. } \\
\text { B-Kampfstoffe können grundsätzlich nativ oder ent- } \\
\text { sprechend stabilisiert (z. B. mikroverkapselt) als Flüs- } \\
\text { sigkeit (Suspension) oder Trockensubstanz (Lyophili- } \\
\text { sat) genutzt werden. Als militärische Einsatzmittel } \\
\text { kommen u. a. Raketen, Bomben und Granaten, } \\
\text { Sprühtanks und Aerosol-Generatoren auf Luft-, Land- } \\
\text { oder Wasserfahrzeugen in Betracht, um biologische } \\
\text { Agenzien als lungengängige Aerosole (infektiöse Par- } \\
\text { tikel oder Tröpfchen < 5 } 4 \text { m) oder in Form feinster } \\
\text { Tröpfchen auszubringen [34, 38]. Das Beispiel der } \\
\text { Aum Shinrikyo-Sekte zeigt, dass Terroristen auch } \\
\text { tragbare Sprüh- und Vernebelungsgeräte sowie han- } \\
\text { delsübliche Zerstäuber aus der Medizin, Landwirt- } \\
\text { schaft, Fahrzeug- oder Haushaltstechnik verwenden } \\
\text { könnten. In geschlossenen Räumen könnten damit } \\
\text { prinzipiell sehr hohe Konzentrationen eines Agens er- } \\
\text { reicht werden. Im Freien haben UV-Strahlung, meteo- } \\
\text { rologische und geografische Gegebenheiten großen } \\
\text { Einfluss auf die Stabilität, Konzentration und Verbrei- } \\
\text { tung aerosolgetragener B-Agenzien. Durch stärkere }\end{array}$} & $\begin{array}{l}\text { Winde (> } 30 \mathrm{~km} / \mathrm{h}) \text { und Strömungseffekte im Be- } \\
\text { reich großer Gebäude bilden sich Wirbel, sodass die } \\
\text { Aerosolpartikel inhomogen verteilt werden. Dadurch } \\
\text { dürfte die Menge eines B-Agens im gleichen Gebiet } \\
\text { und somit auch der Expositionsgrad der Betroffenen } \\
\text { stark schwanken. Infolge der großen Schwankungs- } \\
\text { breite der aufgenommenen Erregermengen sind ne- } \\
\text { ben unterschiedlich schweren Krankheitsverläufen } \\
\text { auch asymptomatische Infektionen zu erwarten. Letz- } \\
\text { tere dürften meist unerkannt bleiben und würden erst } \\
\text { im Rahmen einer gezielten Serodiagnostik identifi- } \\
\text { ziert. } \\
\text { Außerdem lassen sich biologische (B-) Agenzien über } \\
\text { Trinkwassersysteme, Getränke, Lebens- und Genuss- } \\
\text { mittel, Postsendungen, kontaminierte Bedarfsgegen- } \\
\text { stände, selbst konstruierte Sprengsätze und infizierte } \\
\text { Haus- und Nutztiere sowie deren Vektoren verbreiten. } \\
\text { In Trinkwassersystemen ausgebrachte Krankheitser- } \\
\text { reger und Toxine unterliegen Verdünnungseffekten } \\
\text { und einer eventuellen Inaktivierung, wenn das Wasser } \\
\text { vor dem Verbrauch chloriert oder erhitzt wird. } \\
\text { Drogen könnten ebenfalls als Vehikel in Frage kom- } \\
\text { men, wie über } 45 \text { Anthraxfälle bei intravenösen Dro- } \\
\text { genabhängigen vermuten lassen, die in der ersten } \\
\text { Hälfte des Jahre } 2010 \text { im Vereinigten Königreich und } \\
\text { Deutschland auftraten. Das Beispiel der „Typhoid } \\
\text { Mary“ in New York am Ende des } 19 \text {. Jahrhunderts be- } \\
\text { weist, dass auch ansteckungsfähige Akteure, in diesem }\end{array}$ \\
\hline
\end{tabular}


Falle eine Dauerausscheiderin von Typhuserregern, Krankheitsausbrüche auslösen könnten.

Die meisten der potenziellen B-Agenzien sind als Aerosol hoch infektiös (aerogene Infektionsdosis: < 10100 Organismen). Aber mit Ausnahme der Erreger von Pocken, bestimmten Formen des viralen hämorrhagischen Fiebers, Influenza oder Lungenpest werden sie nicht oder nur selten von Mensch zu Mensch durch Aerosol-, Tröpfchen- oder Kontaktinfektion übertragen. Einige Zoonosen, wie z. B. Pest, Tularämie oder epidemisches Fleckfieber, können aber auch transmissiv durch infizierte Ektoparasiten übertragen und weiter verbreitet werden.

\section{Biologische Szenarien}

Alle bisher bekannt gewordenen biologischen Drohungen und Anschläge mit terroristischem oder kriminellem Hintergrund zeigen: Es ist nahezu unmöglich, rechtzeitig festzustellen, wer biologische Kampfstoffe besitzt oder anzuwenden gedenkt. Und selbst wenn man unmittelbar vor einem wahrscheinlichen biologischen Anschlag stünde, ist nicht exakt vorauszusagen, von wem, gegen wen, wann und wo welches B-Agens in welcher Menge, wie oft und auf welche Weise zum Einsatz käme. Aus infektiologischer und epidemiologischer Sicht sind daher folgende Aspekte beachtenswert:

Biologische Anschläge werden höchstwahrscheinlich unangekündigt und verdeckt ausgeführt.

Bei einer simultanen Infizierung größerer Personengruppen müssen nicht alle Exponierten in gleichem Maße geschädigt werden. Je nachdem, in welcher Menge, wann und wie oft biologische Agenzien eingesetzt werden, kann eine unterschiedlich große Zahl von Menschen entweder gleichzeitig oder zeitlich versetzt an demselben oder an unterschiedlichen Orten betroffen sein. Einmal als Aerosol oder durch Kontamination von Lebensmitteln und Trinkwasser ausgebracht, wären selbst extrem hohe Erregerkonzentrationen mit menschlichen Sinnen nicht erfassbar. Dabei würde eine nicht gewarnte und folglich ungeschützte Zielpopulation äußerst wirksam infiziert.

Sofern „professionelle" B-Kampfstoffe oder nicht endemische Erreger als B-Agenzien ausgebracht würden, träfen sie auf eine voll empfängliche Population, in der dann ein erheblicher Anteil der Exponierten erkranken dürfte. Nach Ablauf der minimalen Inkubationszeit würden sich eine oder mehrere primäre Explosivepidemien mit variierender Intensität entwickeln. Im Falle übertragbarer Krankheiten können in Abhängigkeit von der Kontaktrate und Empfänglichkeit der Exponierten weitere Epidemiewellen folgen.

Bei Erregern gefährlicher Infektionskrankheiten dürften nicht nur Infektionen durch Inhalation von BAgenzien fulminant verlaufen, sondern auch nach oraler Aufnahme von massiv kontaminierten Lebensund Genussmitteln oder Trinkwasser. Explosive Aus- bruchsgeschehen wären aber ebenso nach einer Exposition gegen einheimische Krankheitserreger, z. B. Salmonellen, Shigellen oder Noroviren, zu erwarten, gegen die zumeist keine belastbare Immunität bestünde.

So haben Anhänger der Rajneesh-Sekte in The Dallas (US-Staat Ohio) im Jahre 1984 unbemerkt Salatbüfetts einiger Restaurants mit Salmonella Typhimurium kontaminiert, um eine Gemeindewahl zu beeinflussen. Dadurch kam es zu mehreren Salmonellose-Ausbrüchen mit insgesamt 751 Erkrankten, von denen 45 stationär behandelt werden mussten. Im Jahre 1995 „beimpfte“ ein Mitarbeiter eines medizinischen Zentrums in Texas (USA) Gebäck mit Shigella dysenteriae Typ 2 und verursachte damit eine Shiga-Ruhr bei zwölf seiner Kollegen. Für ihre Straftaten nutzten die Täter übrigens Bakterienstämme aus den Laboratorien, in denen sie beschäftigt waren.

Fazit: Aufgrund der Vielzahl potenzieller B-Agenzien und Ausbringungsmöglichkeiten einerseits und der Heterogenität (Alter, Geschlecht, Immunität, Disposition) der gefährdeten Population andererseits ist mit einem außerordentlich großen Spektrum biologischer Szenarien und Krankheitsformen und -verläufen zu rechnen ( Tab.2). Daher können mögliche Szenarien nicht vorausgesagt und das Schadensausmaß eines biologischen Anschlags nur schwer abgeschätzt werden. Hinzu kommt, dass ohne Hinweise auf einen unmittelbar bevorstehenden oder erfolgten Angriff biologische Agenzien in der Umwelt, wenn überhaupt, erst sehr spät festzustellen sind. Aufgrund der biologischen und physikalischen Alterung vegetativer Bakterienformen und Viren bestünden Chancen für einen erfolgreichen Erregernachweis unmittelbar nach einem Anschlag und auch noch nach einigen Wochen bei Einsatz umweltresistenter Agenzien, z. B. Anthraxsporen oder Coxiella burnetii.

Ein biologischer Wirkungsherd (= potenziell verseuchte Räume, Objekte oder Gebiete einschließlich Flora, Personen, Tierbeständen, Technik) lässt sich daher anfangs kaum exakt lokalisieren und der Umfang der Kontamination nur mit einem enormen technischen und zeitlichen Aufwand bestimmen. Somit besteht die Gefahr, dass äußerlich kontaminierte oder schon infizierte Exponierte den Wirkungsherd ohne vorherige Dekontamination verlassen. Dabei könnten sie B-Kampfstoffe oder biologische Agenzien mit ihrer Kleidung oder über genutzte Verkehrsmittel weiter verbreiten und sekundär Infektionen an anderen Orten auslösen. Deshalb gilt es, frühzeitig einen „reinen“ Absperrbereich (grüne Zone) für die Behandlung und Betreuung der Betroffenen, einen Übergangsbereich (gelbe Zone) zur Dekontamination und zum Ausschleusen und einen „unreinen“ Gefahren- bzw. Kontaminationsbereich (rote Zone) festzulegen $[4,11]$.

Ein Einsatz von B-Kampfstoffaerosolen ist oft dadurch charakterisiert, dass Erkrankungen gehäuft in Wind- 
richtung lokalisiert sein werden, die zum Zeitpunkt des Angriffs vorherrschte. Dies traf z. B. für ein außergewöhnliches Anthraxgeschehen Anfang April 1979 in Sverdlovsk (heutiges Jekaterinburg, Russische Föderation) zu. Es wurde von sowjetischer Seite bis Anfang der 90iger Jahre als Darmmilzbrand nach dem Genuss von infiziertem Fleisch milzbrandkranker Tiere deklariert. In Wirklichkeit handelte es sich um eine Havarie in der geheimen militärmikrobiologischen Einheit 19, die Anthraxsporen in Pulverform für B-Waffen produzierte. Dabei traten größere Sporenmengen aus, die offenbar mit dem Wind ca. $70 \mathrm{~km}$ weit bis in die Vororte der Stadt gelangten $[1,43]$. Es erkrankten vor allem Personen, die in unmittelbarer Nähe der Havariestätte im Freien gearbeitet hatten oder in Stadtgebieten wohnten, in denen die Aerosolwolke eine besonders hohe Sporenkontamination hinterließ. Aufgrund der Mobilität der Exponierten gab es weitere Fälle auch in anderen Stadtteilen. Schon unmittelbar nach der Havarie kursierten Meldungen über Anthraxfälle bei Nutztieren aus Dörfern, die gleichfalls vom Aerosol betroffen waren.

Daraus leitet sich ab, dass ein biologischer Wirkungsherd nicht unbedingt mit dem Ort des Anschlags identisch sein muss und entsprechende Krankheitsfälle oder Epidemien regional oder überregional bei Mensch und Tier in Erscheinung treten können.

Im Falle einer gleichzeitigen Infizierung einer größeren Personengruppe durch B-Kampfstoff-Aerosole wären erste Erkrankte nach Ablauf der für das jeweilige Agens typischen minimalen Inkubationszeit zu erwarten. Daraufhin würde die Zahl der Krankheitsverdächtigen in Analogie zu trinkwasserbedingten Ausbrüchen exponentiell in Form einer Explosivepidemie ansteigen. Hierbei kann es sowohl primär durch die unmittelbare B-Exposition als auch sekundär durch Kontakt mit ansteckungsfähigen Patienten oder kontaminierten Objekten zu Krankheitsausbrüchen kommen.

Die Inkubationszeit der jeweiligen Krankheiten hängt wesentlich von der Art, Virulenz, Menge und Ausbringung des Agens und dem Grad der Empfänglichkeit der bedrohten Populationen ab. Sie könnte sich beim Einsatz hoch virulenter Stämme von z. B. Y. pestis, $B$. anthracis und F. tularensis oder massiver Mengen eines Erregers und bei erhöhter Disposition der Exponierten stark verkürzen. Dadurch würden erste Symptome schon innerhalb von wenigen Stunden, statt wie gewöhnlich bei natürlicher Infektion, erst nach einigen Tagen einsetzen.

In diesem Falle kann der weitere Krankheitsverlauf so schwer sein, dass jegliche Hilfe zu spät kommen dürfte. Bei einer Sichtung der Geschädigten unmittelbar nach einem Anschlag hätten somit auch scheinbar leicht erkrankte Exponierte eine schlechte Prognose. Solche Krankheitsverdächtigen (= B-Geschädigte) sollten daher sorgfältig medizinisch überwacht und möglichst rasch der stationären Versorgung zugeführt werden.

Im Gegensatz zu Bombenattentaten oder Anschlägen mit chemischen Agenzien und bestimmten Toxinen dürften allerdings die meisten Kranken und noch "gesunden" Exponierten nach biologischen Angriffen nicht mehr unmittelbar im Wirkungsherd anzutreffen sein. Sie werden vermutlich erst Tage später und an anderen Orten auffällig, wenn sie aufgrund ihrer Erkrankung ärztliche Hilfe suchen.

Des Weiteren ist es möglich, dass die freigesetzten BAgenzien gleichzeitig auf verschiedene Weise übertragen werden und sowohl bekannte als auch atypische klinische Manifestations- und Verlaufsformen bewirken können. So sind mehrere Formen einer Krankheit, z. B. pulmonale, typhöse, ulzero-glanduläre und oropharyngeale Tularämie, bei ein- und demselben Patienten oder in einer Gruppe Erkrankter nicht auszuschließen, wenn B-Agenzien sowohl inhaliert und verschluckt werden oder über Wunden in den Organismus gelangten.

Wie sich eine biologische Gefahrenlage entwickeln könnte, veranschaulicht der oben erwähnte Anthraxausbruch in Sverdlovsk [1,37]. Innerhalb von wenigen Wochen erkrankten etwa 88 Personen an Lungen-, Darm- und Hautmilzbrand sowie Milzbrandsepsis. Mindestens 68 der Erkrankten starben infolge eines akuten Atemnotsyndroms, Multiorganversagens oder infektiös-toxischen Schocks. Der Tod trat bei über $50 \%$ der Patienten, die vermutlich in unmittelbarer Nähe zur Havariestelle hohe Sporenmengen inhaliert hatten, meist schon innerhalb von 24 bis 72 Stunden nach Auftreten erster Influenza-ähnlicher Symptome ein. Die Infektion verlief oft foudroyant, sodass die Erkrankten quasi über Nacht oder auf dem Transport zum Krankenhaus verstarben. Wegen der ungewöhnlichen Klinik und Intensität des Ausbruchs wurde für die Krankheitsverdächtigen ein spezielles Krankenhaus evakuiert. Da primär eine Lungenpest nicht auszuschließen war, wurden alle Erkrankten in Isolierstationen mit dem erforderlichen Barrieremanagement abgesondert. Fahrzeuge und Fahrer wurden ausschließlich für diese Patientengruppe bereitgehalten Die Ärzte der Region waren informiert und angewiesen, jeden auffälligen Patienten nur in diese spezielle Klinik einzuweisen. Erst mehrere Tage später gelang es einem Moskauer Expertenteam, die Diagnose Milzbrand zu stellen und Bacillus anthracis als Erreger zu identifizieren. Daraufhin wurden die Patienten gezielt mit Antibiotika- und Anthrax-Serum behandelt. Durch eine rigorose Dekontamination kontaminierter Objekte und Postexpositionsprophylaxe (PEP) innerhalb der exponierten Bevölkerung (Penicillingabe, Massenimpfungen mit einer Lebendvakzine) wurde der Ausbruch eingedämmt. 


\section{Erkennung biologischer Schadensereignisse}

„Eine schwere Krankheit lässt sich anfangs leicht heilen, aber schwer erkennen. Wenn sie sich jedoch verstärkt, kann man sie leicht erkennen, aber nur schwer heilen."

(Nicolo Macchiavelli, 1449-1527)

Es ist wenig wahrscheinlich, dass biologische Anschläge rechtzeitig als solche erkannt werden, sofern kein automatisches Monitoring mit einem zuverlässigen Echtzeit-Nachweis von B-Agenzien existiert.

In der Praxis wird man erst durch einen ungewöhnlichen Krankheitsausbruch bzw. ein außergewöhnliches Seuchengeschehen in der Bevölkerung oder auch in Tierbeständen aufmerksam werden ( $>$ Tab. 5).

Ein Ausbruch stellt ein gehäuftes Auftreten von zwei und mehr Erkrankungs- oder Todesfällen in engem epidemiologischem Zusammenhang dar. Nicht selten bilden sie die Anfangsphase von Epidemien. Ungewöhnlich sind Ausbrüche dann, wenn sie in ihren ökologischen, epidemiologischen, infektiologischen und mikrobiologischen Merkmalen von der "Norm“ abweichen. Als „Norm“ gilt dabei das typische Auftreten einer Infektionskrankheit entsprechend dem erwartungsgemäßen saisonalen, geo- und demografischen Verteilungsmuster und dem bekannten klinischen Erscheinungsbild. Verdacht auf den Einsatz von B-Agenzien bzw. einen ungewöhnlichen Krankheitsausbruch besteht, wenn der Erreger nicht endemisch ist, die Krankheit wie im Fall der Pocken als ausgerottet gilt oder keine Exposition in einem Endemiegebiet im Ausland oder bei Labortätigkeiten stattgefunden haben kann.

Auffällig sind auch atypische, bei natürlicher Infektion unübliche, Krankheitsverläufe, z. B. Inhalationsmilzbrand und primäre Pestpneumonie, oder auffällig hohe Manifestations- und Letalitätsraten. Für eine nicht natürliche Ursache können auch extrem kurze Inkubationszeiten und der Nachweis ,exotischer" Erreger oder einer sonst nicht beobachteten Multiresistenz bei einer endemischen Erregerart sprechen.

Wichtige Kriterien für die Aufklärung der Ursachen können zusätzlich nachrichtendienstliche oder kriminalpolizeiliche Hinweise auf eine biologische Bedrohung bilden. Die Erkennung eines nicht natürlich verursachten Krankheitsgeschehens würde zusätzlich erschwert, wenn man bisher unbekannte bzw. gentechnisch manipulierte Agenzien oder endemisch vorkommende Erreger ausbrächte. Im letzteren Falle würden, analog zu den beiden o. a. Anschlägen mit Salmonellen und Shigellen, „natürliche“ Seuchengeschehen vorgetäuscht.

Deshalb sind eine kontinuierliche epidemiologische Überwachung von Infektionskrankheiten und konsequente Einhaltung der Meldepflicht nach $\$ \$ 6$ und 7 Infektionsschutzgesetz (IfSG) sowie der Übermittlung gemäß $\$ 12$ Abs. 1 des IfSG sowie bei Zoonosen gemäß der Tierseuchenerregerverordnung notwendig [40, 41]. Auf EU-Ebene bestehen zwei Frühwarnsysteme, das „Early Warning“-System für Infektionskrankheiten und das BICHAT-System (= Biological, Chemical and Atomic Threats). Darüber werden alle Mitgliedsstaaten per E-Mail unverzüglich bei besonderen Ereignissen informiert $[2,6]$. Hinweise auf das Vorkommen und die Ausbreitung ungewöhnlicher Krankheitsausbrüche bieten neben den Melde- und Frühwarnsystemen auch nationale und internationale Programme, Websites des Robert Koch-Instituts und der WHO, syndromorientierte und Laborsentinels sowie Netzwerke zur Überwachung (Surveillance) ausgewählter Infektionskrankheiten, z. B. Influenza, invasive Pneumokokken-Infektionen oder Gastroenteritiden [39]. Damit lassen sich relativ zeitnah untypische Anstiege in der Morbidität oder Mortalität, Abweichungen in der normalen demografischen, geografischen und saisonalen Verbreitung verfolgen. Außerdem können auch lokale oder regionale Häufungen (Cluster) und geno- oder phänotypische Besonderheiten endemischer, neu auftretender oder absichtlich freigesetzter Erreger erfasst werden

Das setzt aber voraus, dass Ärzte, Tierärzte und konsultierte Laboratorien entsprechend eingebunden, sensibilisiert und geschult sind, um derartige besondere Ereignisse wahrzunehmen und frühzeitig zu alarmieren.

Allerdings zeigen die bisherigen Erfahrungen, dass außergewöhnliche Seuchengeschehen nicht immer als biologische Anschläge erkannt werden. So wurde die nicht natürliche Genese der Salmonellen-Enteritisepidemie 1984 in den USA nur durch die Selbstanzeige eines Mitglieds der Rajneesh-Sekte, und zwar erst ein Jahr später, offenkundig.

Nicht immer ist damit zu rechnen, dass sich Infektionen mit einem bestimmten B-Agens in allen Alters-, Berufs- oder Geschlechtsgruppen gleichermaßen klinisch manifestieren bzw. gleich schwer verlaufen. Geschädigte dürften anfangs eine relativ unspezifische, zumeist Influenza-ähnliche Symptomatik oder Syndrome üblicher endemischer Infektionskrankheiten zeigen. Das erschwert die rechtzeitige Erkennung eines B-Angriffs erheblich. Hinzu kommt, dass Krankheitsfälle bei der gegenwärtig hohen Mobilität (Ausnahme: Zielgruppen in geschlossenen Einrichtungen) an unterschiedlichen Orten, zeitlich versetzt, vereinzelt oder gruppiert auftreten können. Die Schnelligkeit, mit der dann die richtige Diagnose gestellt und eine geeignete Therapie sowie präventive Maßnahmen eingeleitet werden, beeinflusst das weitere Schicksal der primär Erkrankten und der noch gesunden Exponierten sowie Kontaktpersonen. Dies gilt insbesondere, wenn es sich um eine gefährliche Infektionskrankheit oder ein Ereignis von möglicher internationaler Tragweite für die öffentliche Gesundheit, gemäß $\$ 12$ Abs. 1 IfSG nach dem Gesetz zu den Internationalen Gesundheitsvorschriften (2005) (IGV) handelt [11]. 
- Tab. 5. Indikatoren zur Früherkennung eines ungewöhnlichen Krankheitsausbruchs (modifiziert nach [4])

\begin{tabular}{|c|c|c|c|c|}
\hline \multirow[t]{2}{*}{ Indikatoren } & \multicolumn{4}{|c|}{ Indikator wahrnehmbar durch } \\
\hline & $\begin{array}{l}\text { Notärzte } \\
\text { niedergelassene } \\
\text { Ärzte/Tierärzte } \\
\text { Apotheker }\end{array}$ & $\begin{array}{l}\text { Kranken- } \\
\text { häuser/ } \\
\text { Tierkliniken }^{2}\end{array}$ & $\begin{array}{l}\text { Laborato- } \\
\text { rien }^{*^{3}}\end{array}$ & $\begin{array}{l}\text { ÖGD**/ } \\
\text { Veterinär- } \\
\text { wesen }\end{array}$ \\
\hline
\end{tabular}

Klinische Indikatoren

Ungewöhnliche/atypische Manifestation oder unerwartet fulminante Verläufe bekannter Krankheiten bei Menschen und/ oder Tieren

Fehlendes Ansprechen der Krankheit auf die übliche Therapie

Auftreten von Erkrankungen in geimpften Populationen (Mensch/Tier)

Ungewöhnliche/unerklärliche simultane Entwicklung verschiedener Syndrome in demselben Fall

Unerklärlicher Anstieg von Krankheits- und/ oder Todesfällen in menschlichen und/oder tierischen Populationen

Pathologisch-anatomische/-histologische Hinweise auf neu- oder wiederauftauchende bzw. nicht endemische Krankheiten

Lokale Häufung von Patienten mit unklarem Krankheitsbild, z. B. Fieber unbekannten Ursprungs, Fieber mit respiratorischen Symptomen, Exanthemen oder Lymphadenopathie, gastrointestinaler oder zentralnervöser Symptomatik mit oder ohne Fieber

Ungewöhnlicher Anstieg des Medikamentenverbrauchs

$+$

$(+)$

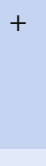

$(+)$

$(+)$

$(+)$

$(+)$

$(+)$

(+) +

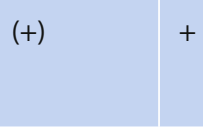

$(+)$

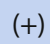

$(+)$

$(+)$

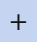

$+$

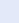

$(+)$

$+$

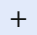

\section{Epidemiologische Indikatoren}

Plötzliches Auftreten bisher unbekannter/ nicht endemischer (importierter) oder eradizierter Krankheiten

Wiederauftauchen einer Krankheit in der Region nach längerer Zeit

Hinweise auf atypische Übertragungswege

Ungewöhnliche/atypische saisonale und geografische Verbreitung der Fälle

Explosivepidemien/-epizootien mit Hinweisen auf eine punktuelle Infektionsquelle

\begin{tabular}{|l|l|l|l|}
\hline+ & + & + & + \\
\hline+ & $(+)$ & + & + \\
\hline$(+)$ & $(+)$ & $(+)$ & + \\
\hline$(+)$ & $(+)$ & & + \\
\hline$(+)$ & $(+)$ & & + \\
\hline
\end{tabular}


- Tab. 5. (Fortsetzung)

\begin{tabular}{|c|c|c|c|c|}
\hline \multirow[t]{2}{*}{ Indikatoren } & \multicolumn{4}{|c|}{ Indikator wahrnehmbar durch } \\
\hline & $\begin{array}{l}\text { Notärzte } \\
\text { niedergelassene } \\
\text { Ärzte/Tierärzte } \\
\text { Apotheker }\end{array}$ & $\begin{array}{l}\text { Kranken- } \\
\text { häuser/ } \\
\text { Tierkliniken }{ }^{2}\end{array}$ & $\begin{array}{l}\text { Laborato- } \\
\text { rien }{ }^{3}\end{array}$ & $\begin{array}{l}\text { ÖGD**/ } \\
\text { Veterinär- } \\
\text { wesen }\end{array}$ \\
\hline Ungewöhnliche Häufung von Vektoren & $(+)$ & $(+)$ & & + \\
\hline $\begin{array}{l}\text { Gleichzeitiges Auftreten von Ausbrüchen: } \\
\text { - an verschiedenen Orten oder in einer } \\
\text { Windrichtung bzw. flussabwärts } \\
\text { - in menschlichen und tierischen Populati- } \\
\text { onen } \\
\text { - bevorzugt in oder außerhalb von Gebäu- } \\
\text { den/Räumen /Transportmitteln/Veran- } \\
\text { staltungen }\end{array}$ & $(+)$ & $(+)$ & & + \\
\hline $\begin{array}{l}\text { Hinweise auf eine gemeinsame Exposition } \\
\text { gegen kontaminierte/infizierte Umweltob- } \\
\text { jekte, u. a. Wasser, Staub, Aerosole, Pflanzen, } \\
\text { Tiere oder Gebrauchsgegenstände, } \\
\text { Lebens- oder Genussmittel (einschließlich } \\
\text { Drogen) und Trinkwasser }\end{array}$ & $(+)$ & $(+)$ & & + \\
\hline $\begin{array}{l}\text { Inzidenz, Morbidität und Letalität einer } \\
\text { bekannten Krankheit höher als erwartet }\end{array}$ & $(+)$ & $(+)$ & & $(+)$ \\
\hline \multicolumn{5}{|c|}{$\begin{array}{l}\text { - einschließlich human- und tierpathologische sowie rechtsmedizinische Institute, Landesuntersuchung- und } \\
\text { Tiergesundheitsämter } \\
\text { ** Öffentlicher Gesundheitsdienst einschließlich Sanitätsdienst der Bundeswehr } \\
{ }^{2} \text { Meldepflicht gemäß § } 6 \text { Infektionsschutzgesetz (IfSG) und Übermittlung gem.§ } 12 \text { Abs. } 1 \text { IfSG bzw. Meldung } \\
\text { nach Tierseuchenerreger-Verordnung } \\
{ }^{3} \text { Meldepflicht gemäß § } 7 \text { IfSG bzw. Tierseuchenerreger-Verordnung }\end{array}$} \\
\hline
\end{tabular}

Wie entscheidend frühzeitiges Erkennen biologischer Schadensereignisse für das Überleben der Exponierten sein kann, veranschaulichen die Anthraxanschläge im Jahre 2001 in den USA. Nachdem der Milzbrandverdacht bei den ersten Opfern bestätigt war, gelang es mithilfe modernster labordiagnostischer und bildgebender Verfahren, u. a. PCR beziehungsweise Computertomographie, weitere Fälle relativ rasch zu identifizieren. Dank der daraufhin eingeleiteten komplexen Antibiotika- und Intensivtherapie wurden sechs der elf Lungenmilzbrandkranken geheilt. Die Letalität war dadurch mit $40 \%$ wesentlich geringer als in Sverdlovsk (ca. $80 \%$ ), wo die Diagnose Milzbrand erst einige Tage nach Ausbruchsbeginn festgestellt werden konnte. Nach einem verdeckt ausgeführten biologischen Anschlag dürften nicht die ABC-Abwehr oder Ordnungskräfte als Erste mit den medizinischen Folgen konfrontiert werden. Ungewöhnliche Krankheitsausbrüche und plötzliche Todesfälle würden primär Rettungsdienste, Notärzte, niedergelassene Ärzte, Internisten, Tropenmediziner, Laborärzte, Mikrobiologen und Pathologen sowie das ärztliche und pflegerische
Personal in Ambulanzen, Notaufnahmen, Infektions-, Sonderisolier- oder Intensivstationen von Krankenhäusern alarmieren ( $\downarrow$ Tab. 5). Später werden auch Amtsärzte und Epidemiologen der Gesundheitsämter durch entsprechende Meldungen informiert und Ermittlungsbehörden sowie ggf. Ordnungskräfte einbezogen. Auch Apotheker würden bei einem plötzlichen Anstieg der Antibiotikaverordnungen auf ein besonderes Ereignis aufmerksam. Seuchengeschehen in Tierbeständen, die auch Ziel biologischer Anschläge sein könnten, würden zuerst durch die Tierhalter und niedergelassenen Tierärzte registriert und an die zuständigen Tiergesundheitsämter gemeldet. Erstgenannte könnten sich beim Umgang mit kranken oder toten Tieren und deren Ausscheidungen anstecken und selbst erkranken. Wie derartige Geschehen verlaufen könnten, veranschaulichen die außergewöhnlich schweren Q-Fieber-Ausbrüche, die seit 2008 in den Niederlanden seit der Massenhaltung von Ziegen beobachtet werden.

Bei plötzlichem Auftreten gefährlicher Infektionskrankheiten sind vor allem Rettungskräfte und medi- 
zinisches Personal während des Transports, der Notfallversorgung am Ort oder in der Praxis und bei der Aufnahme sowie Intensivbehandlung der ersten Erkrankten in den Krankenhäusern außerordentlich infektionsgefährdet. Zu diesem Zeitpunkt ist die Ansteckungsfähigkeit der Patienten gewöhnlich noch nicht bekannt. Es besteht aber ein intensiver Kontakt ohne ausreichenden persönlichen Schutz und damit ein besonders großes Infektionsrisiko, wie einschlägige Erfahrungen mit importierten Pocken Ende der Sechzigerjahre und nosokomiale Ausbrüche von viralem hämorrhagischem Fieber und SARS bestätigen.

Für die Differenzialdiagnose ist zu beachten, dass zwar die einzelnen als B-Kampfstoff infrage kommenden Erreger jeweils eine spezifische Krankheit bewirken. Aber nur selten existieren Agens-spezifische pathognomonische Symptome. Auch kommt es nach der Infektion durch einen bestimmten Erreger nicht nur zu unterschiedlichen Krankheitsformen, z. B. Pestseptikämie, Beulen-, Haut- oder Lungenpest, sondern innerhalb einer Form auch zu verschiedenen Verläufen. In Abhängigkeit von der Virulenz und Infektionsdosis des Erregers, dem Infektionsweg und der Disposition des Patienten, kann das Verhältnis von subklinischen zu klinisch manifesten Verläufen erheblich schwanken. Organmanifestationen können in der akuten und in der späten Krankheitsphase zudem völlig differieren. So kann sich Q-Fieber (Erreger: Coxiella burnetii) anfangs als leichter grippaler Infekte präsentieren und ausheilen oder später als atypische Pneumonie oder Hepatitis, seltener auch chronische Endokarditis, manifestieren.

Wie bei natürlicher Übertragung, wird sich die betreffende Infektion auch nach absichtlicher Ausbringung des jeweiligen biologischen Agens in ihren typischen Krankheitsstadien entwickeln: So würde sich das für Pocken charakteristische Exanthem nach einer unspezifischen fieberhaften Prodromalphase vom makulopapulösen, über das Bläschen- und Pustel- bis hin zum Krustenstadium ausprägen.

Sofern sehr große Mengen eines hoch virulenten Erregers auf einem für die natürliche Infektion unüblichen Wege, z. B. aerogen, aufgenommen wurden, können die Inkubationszeit und der Krankheitsablauf abnorm verkürzt sein. Außerdem sind atypische Manifestationsformen zu erwarten. Im Falle von Anthrax, Pest oder Tularämie träte der Tod sehr frühzeitig aufgrund perakuter primärer septikämischer bzw. pulmonaler Infektionen mit ZNS-Beteiligung und disseminierter intravasaler Koagulopathie (DIC) ein.

Die Differenzialdiagnostik ist insofern schwierig, als die meisten potenziellen biologischen Agenzien nach einer aerogenen Exposition im Initialstadium ein uncharakteristisches Krankheitsbild auslösen, das weitgehend mit einer sogenannten „Influenza-like Illness“ (ILI) identisch sein kann. Obwohl im Idealfall ein Leitsymptom bzw. ein pathognomonisches Muster von Symptomen definiert werden kann (u. a. bei Botulismus), ist es selbst für den infektiologisch ausgebildeten Arzt schwierig, im „Rauschen“ individuell ausgeprägter Krankheitszeichen ein solches „Signal” zu erkennen. Dazu trägt bei, dass die Mehrzahl der von potenziellen B-Kampfstoffen verursachten Krankheiten in Deutschland entweder nicht oder nur sehr selten auftritt und ihre klinischen Bilder nur wenigen Ärzten vertraut sind. So dürften jüngere Internisten keine Erfahrungen mehr im Erkennen der Pocken haben. Jedoch waren selbst in der Pocken-Ära Fehldiagnosen, z. B. im Falle von modifizierten Pocken (Variolois) bei Pockengeimpften, nichts Ungewöhnliches. Daher dürfte der Unsicherheitsfaktor in Bezug auf eine richtige Diagnose dieser Krankheit heute noch höher sein. Ähnlich würde auch bei Pestausbrüchen eine zuverlässige Diagnose oft zu spät zu erwarten sein. Sogar in bekannten Pestendemiegebieten, z. B. Indien, Madagaskar oder Südwesten der USA, werden insbesondere pulmonale und septikämische Formen aufgrund der uncharakteristischen Frühsymptome oft nicht rechtzeitig erkannt und enden, da inadäquat oder zu spät behandelt, in einem relativ hohen Prozentsatz tödlich [10].

Selbst wenn der Erstuntersucher die klinischen Merkmale aller potenziellen B-Agenzien und die dazu gehörenden Differenzialdiagnosen kennt, limitiert der Mangel an ad hoc verfügbaren Labormethoden die prompte Erkennung eines bioterroristischen Ereignisses. Folglich ließe sich eine Verdachtsdiagnose nur mit zeitlicher Verzögerung durch spezialisierte Konsiliaroder Referenzlaboratorien bestätigen. Ungewöhnliche Ausbrüche werden daher vermutlich vorrangig syndromorientiert zu erfassen sein. Mögliche Syndrome wären akutes Atemnotsyndrom mit und ohne Fieber, grippeähnliche Krankheit mit schwerem Krankheitsgefühl, akutes fieberhaftes Exanthem, Fieber mit hämorrhagischen Erscheinungen mit oder ohne Nephropathie, neurologische Symptomatik mit oder ohne Fieber, Fieber mit auffälliger Lymphadenopathie (z. B. Bubonen), hohes Fieber mit gastrointestinaler Symptomatik oder Septikämie bzw. infektiös-toxisches Schocksyndrom ( Tab. 2 und 3).

Der Erstuntersucher kann in solchen Fällen nur den Verdacht auf eine möglicherweise gefährliche Krankheit äußern und sollte dann die gesetzlich geforderten Meldungen machen [11]. Weiterhin sind labordiagnostische und epidemiologische Untersuchungen $\mathrm{zu}$ veranlassen. Die Isolierung und Identifizierung des Erregers und das Erstellen eines Antibiogramms sind notwendig für die nachfolgende kausale Therapie bei einer trotz PEP eingetretenen Erkrankung und zur forensischen Aufklärung des Geschehens. Dazu sind bei allen Krankheitsverdächtigen entsprechende Probenmaterialien so früh wie möglich, d. h. noch vor Behandlungsbeginn, zu entnehmen. Für die mikrobiologische Diagnostik eignen sich je nach Symptomatik 
außer Blut- und Abstrichproben noch Rachenspülflüssigkeit, broncho-alveoläre Lavagen, Punktate und Biopsiematerial, z. B. Lymphknoten, Stuhl, Harn und Liquor ( Tab. 4). Nach einer mutmaßlichen aerogenen Exposition sollten auch von Ansteckungsverdächtigen (= noch „gesunde“ B-Exponierte und Kontaktpersonen zu Krankheitsverdächtigen und potenziell kontaminierten Personen) baldmöglichst Venenblut und Nasen-/Rachenabstriche zum Nachweis biologischer Agenzien gewonnen werden [4, 5, 11]. Alle Probenmaterialien sind unter Einhaltung der gesetzlichen Vorschriften $\mathrm{zu}$ verpacken und der Untersuchungseinrichtung umgehend per Kurier zuzustellen. Der Transport ist dem empfangenden Labor rechtzeitig telefonisch anzukündigen.

Die mikrobiologische Labordiagnostik kann mehrere Tage erfordern. Untersuchungsergebnisse würden jedoch bei fulminanten Krankheitsverläufen zu spät vorliegen. Sofern verfügbar, lässt sich zwar eine vorläufige Diagnose mit modernen molekularbiologischen und immunologischen Schnellmethoden stellen. Allerdings ist die Schnelldiagnostik nur für ein begrenztes Spektrum von B-Agenzien verfügbar und nicht routinemäßig etabliert, sondern auf wenige spezialisierte Referenzlaboratorien beschränkt $[4,5]$. Diese sollten daher frühzeitig in das Management biologischer Schadensereignisse eingebunden werden.

\section{Medizinisches Management biologischer Schadensereignissen}

Sofern es keinerlei Drohungen oder Hinweise bezüglich eines bevorstehenden oder stattgefundenen biologischen Anschlags gibt, wird es bei einzelnen Erkrankungsfällen oder einem Krankheitsausbruch am Anfang kaum einen Verdacht auf einen B-Anschlag und demzufolge auch keine Schutzvorkehrungen geben. Somit wird gerade das mit der Sichtung, Dekontamination, medizinischen Notversorgung und dem Transport von Krankheitsverdächtigen betraute medizinische Personal als Kontaktpersonen besonders infektionsgefährdet sein. Unter diesen „First Respondern“ kann es daher ebenfalls zu Erkrankungen kommen, sofern sie "ungeschützt " eingesetzt würden. Für sie sollten geeignete persönliche Schutzausrüstungen (sog. Infektionsschutz-Sets) und gegebenenfalls Mittel zur prä- oder postexpositionellen Prophylaxe (PEP) bereitgestellt werden $[4,27]$.

Prinzipiell sind nach einem biologischen Anschlag alle Ansteckungsverdächtigen aktiv zu ermitteln, zu erfassen und zu sichten. Bei Bedarf sollten sie dekontaminiert werden und, sofern verfügbar, eine PEP und medizinische Beratung erhalten $[14,32]$. Eine behelfsmäßige (Not-) Dekontamination (Wechsel der Kleidung, Duschen) dieses Personenkreises sowie der Krankheitsverdächtigen kann entweder sofort im biologischen Wirkungsherd oder im Verlaufe von 24 Stunden auch noch im Rahmen einer ambulanten oder stationären Quarantäne bzw. Isolierung erfolgen $[11,27]$.

Krankheitsverdächtige (= B-Geschädigte), die innerhalb von 24 Stunden nach einer vermuteten B-Exposition in stationären Behandlungseinrichtungen eintreffen, sind ebenfalls vor der Aufnahmen zu dekontaminieren. Für einen Massenanfall an B-Geschädigten sollten gesonderte Dekontaminationsbereiche im Rahmen der Krankenhausalarmplanung vorgesehen werden $[4,11]$.

Eine Sichtung ist sinnvoll, wenn man das Schadenausmaß nicht voraussehen kann und bei begrenzten Ressourcen möglichst vielen Opfern helfen muss [11, 26, 29]. Dabei sind vorrangig diejenigen Patienten zu identifizieren, welche einer sofortigen Isolierung und/ oder dringenden Intensivbehandlung mit Beatmung bedürfen. Die Sichtungskriterien sind, der Lage angepasst, vom leitenden Notarzt festzulegen. Hier sollten auch Kinderärzte eingebunden werden, da sich sowohl die Pathophysiologie als auch die Klinik und Behandlung entsprechender Krankheiten bei Kindern wesentlich von der bei Erwachsenen unterscheiden. Frühzeitig ist eine Falldefinition zu erstellen, um Ersthelfern und Ärzten das Erkennen der jeweils vorliegenden Krankheit und die Differenzialdiagnostik zu erleichtern [41].

Da unter Umständen verschiedene B-Agenzien gleichzeitig oder zeitlich versetzt und auf unterschiedliche Weise (aerogen, alimentär) ausgebracht werden könnten, muss die Sichtung auch auf verschiedene Syndrome ausgerichtet sein ( $\downarrow$ Tab. 2). Die prozentualen Anteile der Erkrankten in den einzelnen Schweregradgruppen hängen primär von der Art und Menge des B-Agens, dem Expositionsgrad und der Empfänglichkeit sowie Disposition der Betroffenen ab.

Ansteckungsverdächtige, einschließlich ungeschütztes medizinisches Personal, sind bis zum Ausschluss einer gefährlichen Infektionskrankheit möglichst außerhalb des biologischen Wirkungsherdes unter Quarantäne abzusondern und täglich medizinisch zu überwachen (mindestens zweimal täglich Temperaturmessung und Inspektion). Bei Erkrankung müssen sie als ansteckungsfähig betrachtet und sofort isoliert werden.

Alle Krankheitsverdächtigen sollten im Zuge der Sichtung je nach Schwere und Syndrom in Kohorten zusammengefasst werden $[4,11,26]$. Solange der Verdacht auf eine gefährliche Infektionskrankheit besteht, sind sie räumlich isoliert unterzubringen und $\mathrm{zu}$ transportieren sowie unter Barrierebedingungen $\mathrm{zu}$ behandeln ( $\triangleright$ Tab. 3).

Sobald die Diagnose feststeht, richtet sich die weitere Unterbringung der Patienten im Krankenhaus primär nach ihrer Ansteckungsfähigkeit und dem Schweregrad der Erkrankung ( $\triangleright$ Tab. 3). Liegt keine übertragbare Krankheit vor, besteht nach der Dekontamination für das medizinische Personal keine Infektionsgefahr. Patienten mit nicht oder gering ansteckenden 
Infektionskrankheiten können dann grundsätzlich in normalen internistischen Abteilungen verlegt und dort weiter unter Standardhygienebedingungen versorgt werden.

Einzelne Patienten mit Verdacht auf Pocken, Lungenpest oder virales hämorrhagisches Fieber können in den Sonderisoliereinheiten der regionalen Kompetenz- und Behandlungszentren versorgt werden. Um eine Ausbreitung der Erreger über infektiöse Aerosole zu unterbinden, erfolgt hier eine Barrierebehandlung in Räumen, die mit Unterdruck, Luftfiltration und Schleusen ausgerüstet sind $[14,15,16]$.

Sofern diese überlastet sind, kann auch auf den üblichen Infektionsstationen ein provisorisches Barrieremanagement in einem räumlich abgetrennten Bereich mit strenger Zugangsbeschränkung und Behelfsschleusen eingerichtet werden. In jedem Falle erfordert die Betreuung solcher Patienten ein inneres Team für die Behandlung, Pflege, Diagnostik und Desinfektion, und ein externes Team zur Ver- und Entsorgung der Isoliereinheit. Das innere Team hat bei der Pflege und Behandlung von Patienten mit gefährlichen Infektionskrankheiten eine geeignete Schutzbekleidung $\mathrm{zu}$ nutzen. Folgende Mindestausstattung wird empfohlen: filtrierende Halbmasken der Schutzstufe FFP3 S (besser: Schutzanzug mit Filtergebläse), Schutzbrillen (oder Gesichtsschirm), flüssigkeitsdichter EinwegOverall, Einweg-Plastikschürzen, Einmal-Plastiküberschuhe und zwei Paar lange OP-Handschuhe. Handschuhe, Halbmaske und Brille sind mit dem Overall durch Klebeband dicht zu verbinden $[4,14,15]$.

Eine kalkulierte prä- oder post-expositionelle Prophylaxe (PEP) durch Breitbandantibiotika und deren Kombinationen sind bei einigen B-Agenzien möglich und sollten für alle Ansteckungsverdächtigen sowie bei Kontaktpersonen $\mathrm{zu}$ Krankheitsverdächtigen grundsätzlich vorgesehen werden $[5,11,17,34]$. Dabei müssen u. a. Alter, bestimmte Grundleiden, erworbene Immunsuppression oder Schwangerschaft, ähnlich wie im Falle von Pocken oder Influenzapandemien, bei der Auswahl der Chemoprophylaxe und -therapie oder bei Impfungen, berücksichtigt werden. Stets sollte das Risiko, an der Krankheit zu sterben, gegen mögliche Nebenwirkungen der Arzneimittel sorgfältig abgewogen werden. Zugelassene Impfungen gibt es in der Regel nicht ( $\downarrow$ Tab. 3). Manche Impfstoffe sind zwar als sogenannte „investigational new drugs“ in den USA erhältlich und z. T. von der Food and Drug Administration zugelassen, aber in Deutschland nicht ohne Weiteres verfügbar. Wenn keinerlei Informationen über den möglichen Erreger vorliegen, muss die Prophylaxe empirisch begonnen werden. Bei Erwachsenen mit mutmaßlichem Expositionsrisiko wird eine PEP mit Doxycyclin $(2 \times 100 \mathrm{mg} / \mathrm{d}$ p.o. $)$ und/oder Gyrasehemmern (z. B. Ciprofloxacin $2 \times 500 \mathrm{mg} / \mathrm{d}$ p.o.) empfohlen. Bei Kindern könnten Ciprofloxacin 20-30 mg/kg Körpergewicht oder Doxycyclin 5 mg/ kg Körpergewicht gegeben werden. Auf für Kinder weniger problematische Antibiotika kann übergegangen werden, wenn Empfindlichkeitsprüfungen deren Wirksamkeit belegt haben.

Bei akuten lebensbedrohenden Erkrankungen mit Hinweisen auf ein bakteriell bedingtes Geschehen, insbesondere Pest, Anthrax oder Rotz, muss frühzeitig mit einer kalkulierten Chemotherapie begonnen werden. Die Erregerdiagnostik ist zwar für eine nachfolgende kausale Therapie und zur forensischen Aufklärung des Geschehens erforderlich. Die Untersuchungsergebnisse dürfen aber nicht abgewartet werden, sofern sich dadurch die Prognose noch zusätzlich verschlechtern könnte.

Weitere detailliertere Empfehlungen und Hinweise zur PEP und kausalen antimikrobiellen Therapie sowie zum Management von durch potenzielle B-Agenzien bedingten Krankheiten finden sich unter [5, 6, 33, $34,39]$.

Unter der Kontrolle des Krankenhaushygienikers sollte die laufende und Schlussdesinfektion kontaminierter Gegenstände (Instrumente, Textilien, Mobiliar, Fußboden etc.) mit den jeweils erforderlichen Desinfektionsmitteln nach der VHA-Liste [35] durchgeführt werden. Abfälle und Patientenausscheidungen müssen anschließend durch Autoklavieren entsorgt werden. Dabei sind die nationalen Richtlinien für Krankenhaushygiene konsequent umzusetzen, um die Infektionsgefährdung des Personals und der Patienten zu reduzieren und Risiken für die Bevölkerung auszuschließen $[4,5,15]$.

Wie die Anthrax-Anschläge in den USA 2001 zeigten, ist die frühzeitige Einbeziehung von Psychologen und Kriseninterventionsteams notwendig, da nach einem mutmaßlichen biologischen Anschlag ein hoher Anteil von vermeintlich Geschädigten mit psychosomatischen Symptomen medizinische Hilfe suchen wird. Psychologen sind aber auch für die Betreuung der $\mathrm{Pa}-$ tienten, Angehörigen und beunruhigten Gesunden sowie des Personals sehr wichtig. Um Panik bei der Bevölkerung zu vermeiden, sollten durch die zuständigen Gesundheitsbehörden klare Handlungsabläufe für die Bevölkerung über die Medien vermittelt werden.

Über die Meldepflicht informierte Gesundheitsämter übernehmen primär die Koordination weiterer Maßnahmen. Sie können das Robert Koch-Institut und Sachverständige aus regionalen Kompetenz- und Behandlungszentren hinzuziehen, die über Sonderisolierstationen zur Behandlung einzelner Patienten mit gefährlichen Infektionskrankheiten verfügen. Die Kompetenzzentren unterstützen außerdem bei der Koordination antiepidemischer Maßnahmen, helfen bei Presse- und Öffentlichkeitsarbeit, beraten bei Fragen zur Diagnostik und Therapie seltener oder gefährlicher Infektionskrankheiten und organisieren Spezialtransporte. 
Das Vorgehen bei Pocken ist in Deutschland durch ein Bund-Länder-Rahmenkonzept zur Seuchenbekämpfung nach bioterroristischen Anschlägen mit Pockenviren und bei Influenzapandemien durch den Nationalen Influenzapandemieplan geregelt [25, 42]. Beide Pläne können prinzipiell auch als Muster für das Management und die Kontrolle anderer biologischer Schadensereignisse dienen.

Speziell im Falle eines erneuten Pockenausbruchs würden die meisten Länder der WHO-Strategie „search and contain" folgen Dabei untersuchen speziell ausgerüstete und geschulte Infektionsteams die Pockenverdachtsfälle und organisieren die aktive Suche nach Kontaktpersonen. Riegelungsimpfungen mit verfügbarem Pockenimpfstoff würden vom öffentlichen Gesundheitswesen organisiert werden. Sollte allerdings diese Strategie versagen, muss in letzter Konsequenz die Durchimpfung der gesamten Bevölkerung durchgeführt werden.

Eine Epidemie kann nur effizient bekämpft werden, wenn die Logistik für die Zufuhr von Reserven für die Prophylaxe und Dekontamination gesichert ist und die Lebensmittel- und Trinkwasserhygiene sowie Schädlingsbekämpfung und Vektorkontrolle konsequent durchgesetzt werden. Ergänzend dazu müssen die laufende und Schlussdesinfektion durchgeführt und die Wirksamkeit der therapeutischen, prophylaktischen und hygienisch-antiepidemischen Maßnahmen durch mikrobiologische Statuskontrollen, z. B. in Bezug auf Sporenkontamination, Dauerausscheider oder Antibiotikaresistenz, überwacht werden $(\downarrow$ Tab. 3 und $>$ Tab. 4). Erst nachdem die Sanierung biologischer Wirkungs- und Epidemieherde erfolgreich abgeschlossen ist, können etwaige Absonderungsmaßnahmen und Zutrittsbeschränkungen wieder aufgehoben werden.

\section{Zusammenfassung}

Bioterrorismus stellt künftig eine ernst zu nehmende Gefährdung dar, insbesondere wenn Erreger gefährlicher Infektionskrankheiten - oder hoch wirksame Toxine- als Aerosol gegen eine ungeschützte Population ausgebracht würden. Dies könnte zum Massenanfall an Geschädigten und zu erheblichen Panikreaktionen führen.

Die Folgen eines bioterroristischen Angriffs können je nach Art, Menge und Ausbringungsmodus des Agens und Anfälligkeit der Exponierten innerhalb von Stunden, Tagen oder Wochen einsetzen. Unmittelbar nach einem biologischen Anschlag gelten in einem biologischen Wirkungsherd grundsätzlich alle potenziell Exponierten bis zum Nachweis des Gegenteils als Ansteckungsverdächtige. Sie sind zu sichten, gegebenenfalls $\mathrm{zu}$ dekontaminieren, medizinisch zu beobachten und mit einer geeigneten postexpositionellen Prophylaxe $\mathrm{zu}$ versorgen. Alle Krankheitsverdächtigen gelten bis zum Ausschluss einer gefährlichen Infektionskrank- heit als hoch ansteckungsfähig und dringend behandlungsbedürftig. Sie sind nach der Sichtung eventuell notfallmedizinisch zu versorgen, umgehend $\mathrm{zu}$ isolieren und unter Barrierebedingungen zu versorgen.

Bei einem biologischen Schadensereignis besteht für ungeschützte Ersthelfer ein besonderes Infektionsrisiko, das nicht nur von Krankheitsverdächtigen und "noch gesunden“"kontaminierten B-Exponierten, sondern auch von kontaminierten Umweltobjekten ausgeht. Deshalb sind rechtzeitig persönliche Schutzausstattungen zu nutzen und entsprechende Dekontaminationsmaßnahmen vorzusehen, um gefahrlos mit Patienten und Exponierten umzugehen, die weitere Verschleppung biologischer Agenzien zu verhindern und biologische Wirkungs- bzw. Epidemieherde zu kontrollieren.

Prophylaxe- und Therapieschemata sollten sich anfänglich syndromorientiert nach der klinischen Verdachtsdiagnose richten, da akute Verläufe keinen Behandlungsaufschub erlauben. Eine frühzeitige Kontaktaufnahme mit den Gesundheits- und Ermittlungsbehörden sowie Untersuchungseinrichtungen trägt dazu bei, dass erforderliche hygienisch- antiepidemische Maßnahmen rasch und koordiniert durchgeführt und die Ursachen des Ereignisses aufgeklärt werden. Nur durch eine rechtzeitige adäquate Erkennung, effiziente Behandlung und Prophylaxe sowie geeignete Hygienemaßnahmen ist es möglich, die Morbidität und Mortalität zu senken und eine weitere Ausbreitung übertragbarer Krankheiten zu verhüten. Dies ist stets bei der Planung der Prävention, des Managements und der Kontrolle biologischer Schadensereignisse zu berücksichtigen.

Bioterrorismus hat in erster Linie auch Psychoterror zum Ziel. Deshalb sind eine frühzeitige, wissenschaftlich fundierte und auf höchster Ebene abgestimmte, Information der Öffentlichkeit und ständige Kommunikation mit allen Akteuren beim Management einer biologischen Gefahrenlage sehr wichtig. Ständig aktualisierte Informationsangebote auf den Websites des Robert Koch-Instituts, der WHO und der CDC sind dafür hilfreich.

Wie anfällig eine Gesellschaft für bioterroristische Anschläge sein wird, hängt zudem von weiteren Faktoren ab. Dazu gehören vor allem intakte Ökosysteme und Infrastrukturen einschließlich Hygienebarrieren in Form einer effizienten Trink- und Abwasser-, Lebensmittel-, Tier-, Kommunal-, persönlichen und Krankenhaushygiene sowie der biologischen Sicherheit. Hinzu kommen eine qualifizierte, flächendeckende, ambulante und stationäre medizinische Versorgung, ein ausgewogenes Netz an Rettungsdiensten, qualifizierten Katastrophenschutz- und Ordnungskräften, adäquate Wohn- und Ernährungsbedingungen sowie eine belastbare kollektive Immunität gegen endemische Infektionskrankheiten. 


\section{Weiterführende Literatur}

1. Abramova FA, Grinberg LM, Yampolskaya IV, Walker DH (1993) Pathology of inhalational anthrax in 42 cases from the Sverdlovsk outbreak of 1979. Proc Natl Acad Sci USA 90:2291-2294

2. Anonymus (2003) Entscheidung der Kommission zur Änderung der Entscheidung 2119/98/EG des Europäischen Parlaments und des Rates und der Entscheidung 2000/96/EG hinsichtlich der in dieser Entscheidungen aufgeführten übertragbaren Krankheiten und zur Änderung der Entscheidung 2002/253/EG hinsichtlich der Festlegung von Falldefinitionen für übertragbare Krankheiten. K (2003) 2302

3. Beck V (2010) Biologische Waffen Bedrohung, Risiken und Herausforderungen. Wehrmed Monatsschrift 3:7479

4. Bundesamt für Bevölkerungsschutz und Katastrophenhilfe (2007) Biologische Gefahren I. Handbuch zum Bevölkerungsschutz. 3. Auflage, Bonn

5. Bundesamt für Bevölkerungsschutz und Katastrophenhilfe (2007) Biologische Gefahren II. Entscheidungshilfen zu medizinisch angemessenen Vorgehensweisen in einer B-Gefahrenlage 1. Auflage, Bonn

6. Bossi P, Van Loock F, Tegnell A, Gouvras G (2004) Bichat clinical guidelines for bioterrorist agents. Euro Surveill 9 (12):E1-E2

7. Bryan JL, Fields HF (1999) An ounce of prevention is worth a pound of cure - shoring up the public health infrastructure to respond to bioterrorist attacks. Am J Infect Control 27:465-467

8. Centers for Disease Control and Prevention (1988) Management of patients with suspected viral hemorrhagic fever. MMWR 37 (Suppl 3):1-16

9. Centers for Disease Control and Prevention (2000) Biological and chemical terrorism: strategic plan for preparedness and response. Recommendations of the CDC Planning Workgroup. MMWR 49 (RR-4):1-14

10. Crook LD, Tempest B (1992) Plague: a clinical review of 27 cases. Arch Int Med 152:1253-1256

11. Domres BD, Finke E-J, Kekulé A Großschadenslagen durch biologische Agenzien. In: Schutzkommission beim Bundesministerium des Innern (2010) Leitfaden für die ärztliche Versorgung im Katastrophenfall. 5. völlig neu überarbeitete Auflage, München, S. 266-302

12. Dove A (2001) Is investment in bioterrorism research warranted? Nature 1:9

13. Fidler DP (1999) Facing the global challenges posed by biological weapons. Microbes and Infection 1:1059-1066

14. Fock R et al. (1999) Management und Kontrolle lebensbedrohender hoch kontagiöser Infektionskrankheiten. Bundesgesundheitsbl Gesundheitsforsch Gesundheitsschutz 5:389-401

15. Fock R, Koch U, Finke E-J, Niedrig M, Wirtz A, Peters M, Scholz D, Fell G. Bußmann H, Bergmann H, Grünewald T, Fleischer K, Ruf B (2000) Schutz vor lebensbedrohenden importierten Infektionskrankheiten. Strukturelle Erfordernisse bei der Behandlung von Patienten und antiepidemische Maßnahmen. Bundesgesundheitsbl Gesundheitsforsch Gesundheitsschutz 43:891-899

16. Fock R, Koch U, Wirtz A, Peters M, Ruf B, Grünewald T (2001) Erste medizinische und antiepidemische Maßnahmen bei Verdacht auf virales hämorrhagisches Fieber. Med Welt 52:126-132
17. Franz DR et al. (1997) Clinical recognition and management of patients exposed to biological warfare agents. JAMA 278:399-411

18. Garner JS et al. (1996) Guideline for isolation precautions in hospitals. Infect Control Hosp Epidemiol 17:7688576905

19. Henderson DA (1999) The looming threat of bioterrorism. Science 283:1279-1282

20. Heymann DL (2008) Control of Communicable Diseases Manual. 19th Edition, American Public Health Association, Washington

21. Kaufmann AF, Meltzer MI, Schmid GP (1997) The economic impact of a bioterrorist attack: are prevention and post attack intervention programs justifiable? Emerg Infect Dis 3:83-94

22. Keim M, Kaufman AF (1999) Principles for emergency response to bioterrorism. Ann Emerg Med 34:183-190

23. Leitenberg, M (2004) The Problem of Biological Weapons. Swedish National Defence College-Acta B27 Stockholm

24. Macintyre AG, Christopher GW, Eitzen E, Gum R, Weir S, DeAtley C, Tonat K, Barbera JA (2000) Weapons of mass destruction events with contaminated casualties. JAMA 283 (2):242-249

25. Riedmann K, Sasse J (2003) Das Bund-Länder-Rahmenkonzept zu notwendigen fachlichen Vorbereitungen und Maßnahmen zur Seuchenbekämpfung nach bioterroristischen Anschlägen mit Pocken. Der Mikrobiologe 13 (4):123-130.

26. Rose G (1999) It could happen here: facing the new terrorism. For Affairs 78:131-137

27. Rotz LD, Khan AS, Lillibridge SR, Ostroff SM, Hughes JM (2002) Public Health assessment of potential biological terrorism agents. Emerg Infect Dis 8 (2):225-229

28. Sefrin P, Weidringer JW, Weiss W (2003) Katastrophenmedizin. Sichtungskategorien und deren Dokumentation. Einigung von Experten aus Deutschland sowie einigen europäischen Staaten. Dtsch Ärztebl 100 (31-32):16151616

29. Sewell DA (2003) Laboratory safety practices associated with potential agents of biocrime or bioterrorism. J Clin Microbiol 41 (7):2801-2809

30. Sidell FR, Takafuji ET, Franz DR (1997) Medical aspects of chemical and biological warfare. Part I. Textbook of Military Medicine. Washington DC: Office of The Surgeon General, Borden Institute, Walter Reed Army Medical Center; United States Army

31. Snyder JW (2003) Role of the hospital-based microbiology laboratory in preparation for and response to a bioterrorism event. J Clin Microbiol 41:1-4

32. Sohns T (2000) Die Proliferation von Massenvernichtungswaffen: Herausforderungen für Entscheidungsträger. Notfallvorsorge 2:1-15

33. Tomaso H, Al Dahouk S, Fock RRE, Treu TM, Schlögel R, Strauss R, Finke E-J (2003) Management in der Behandlung von Patienten nach Einsatz biologischer Agenzien. Notfall \& Rettungsmedizin 8:603-614

34. USAMRIID`s (2001) Medical Management of Biological Casualties Handbook, 4th edn. United States Army Medical Research Institute of Infectious Diseases, Frederick, Md.

35. Verbund für angewandte Hygiene e. V. (VHA). http:// www.vah-online.de

36. Weinstein RS, Alibek K (2003) Biological and Chemical 
Terrorism. A Guide for Healthcare Providers and First Responders. Thieme New York, Stuttgart

37. Walker DH, Yampolska L, Grinberg LM (1994) Death at Sverdlovsk: What have we learned? Am J Pathol 144:11351141

38. World Health Organization (1970) Health aspects of chemical and biological weapons: Report of a WHO group of consultants. Geneva, Switzerland

39. http://www.int/csr/delibepidemic
40. http://www.rki.de 07.04.2010, Meldeformulare zu Infektionsschutzgesetz (IfSG)

41. http://www.rki.de>infektionsschutz> RKI-Falldefinitionen

42. http://www.rki.de/DE/Content/InfAZ/I/Influenza/Influenzapandemieplan.html

43. Zilinskas RA (1983) Anthrax in Sverdlovsk? Bull At Sci Jun/Jul:24-27

\section{BK-Virus (BKV)}

- Polyomaviren

\section{Black-Creek-Canal-Virus}

Hantaviren

\section{Blasenbilharziose}

Schistosomen

\section{Blastocystis sp.}

Erreger

Synonym(e)

Blastocystis enterocola (1911).

\section{Erregerspezies}

Blastocystis sp. Subtypen 1-9 (evtl. 10), vormals: Blastocystis hominis.

\section{Taxonomie}

Lange Zeit galt Blastocystis sp. als (Hefe-)Pilz. Zierdt (1983) gelang es, den Mikroorganismus zu den Protozoen zu gruppieren. Die Analyse der kleinen rRNAUntereinheiten-Sequenz hat ergeben, dass Blastocystis sp. mit den Stramenopiles verwandt ist. So wird Blastocystis sp. heute zum Stamm der Sarcomastigophora, in die Ordnung Blastocystea und in die Familie Bastocystidae gestellt. Die Erregerspezies wird aktuell nicht mehr als Blastocystis hominis sondern als Blastocystis. sp. Subtyp $\mathrm{n}$ bezeichnet.

\section{Historie}

Blastocystis sp. wurde bereits 1911 von Alexeieff und 1912 von Brumpt beschrieben.

\section{Morphologie}

Blastocystis sp. ist ein sehr variabler, 5-150 $\mu \mathrm{m}$ großer, polymorpher, meist kugeliger Organismus. Vakuoläre, amöboide, granuläre, avakuoläre, multivakuoläre Formen sowie Zysten sind bekannt. Meist weist Blastocystis sp. im Inneren eine große sphärische, zentrale Vakuole (oder einen Zentralkörper) auf, mit einem dünnen, peripheren Zytoplasma-Ring einschließlich Granula und Kernen. Die Mitochondrien-ähnlichen Organellen sind derzeit Ziel molekularbiologischer Untersuchungen.

\section{Genom}

Blastocystis sp. besitzt eine hohe genetische Diversität (DNA-Polymorphismus) und wird in mindestens 9 Subtypen unterteilt (Subtyp 10 bislang nicht beim Menschen isoliert). Es handelt sich um einen typischen Eukaryonten mit ITS1- und ITS2-Regionen.

\section{Vermehrung}

Die Vermehrung erfolgt durch einen Abschnürungsprozess, wobei 1-2 Tochterorganismen abgeschnürt werden. Plasmotomie konnte in vitro ebenfalls beobachtet werden.

\section{Pathogenität / Virulenz / Antigenvariabilität}

Bis in die 1970er Jahre galt Blastocystis sp. als apathogen. Für eine humanpathogene Relevanz scheint z. B. zu sprechen, dass sich Blastocystis sp. bei Auslandsrückkehrern mit gastroenteritischer Symptomatik signifikant häufiger als in der Normalpopulation nachweisen lässt. Virulenzfaktoren sind bislang noch nicht bekannt. Lebensgefährliche Infektionen sind sehr selten. Auch die Subtypen konnten bislang nicht sicher bezüglich ihrer Pathogenität eingestuft werden, obwohl sich aus einigen epidemiologischen Studien Hinweise auf Pathogenitäts-Assoziationen ergaben. Blastocystis sp. besitzt eine hohe Proteaseaktivität, die wichtig für die Pathogenese ist.

\section{Erkrankung}

Darminfektion durch Blastocystis sp.

\section{Synonym(e)}

Blastozystose.

\section{Inkubationszeit}

Über die Inkubationszeit ist nicht viel bekannt, beim Menschen ist sie wohl sehr variabel. 


\section{Leitsymptome}

Diarrhoe, chronische Diarrhoe

\section{Symptome}

Die klinischen Erscheinungen sind variabel und unspezifisch; meist verläuft eine Infektion asymptomatisch. Wässrige Diarrhoe, Abdominalschmerzen, Übelkeit, Krämpfe, Erbrechen, Flatulenz, Völlegefühl und Appetitlosigkeit sowie perianaler Pruritus sind berichtete Symptome. Selbst fieberhafte Verläufe mit Arthralgien sind beschrieben. Auch die Reizdarmsymptomatik ist mit Blastocystis sp. ätiologisch in Verbindung gebracht worden.

\section{Pathophysiologie}

Es handelt sich um lokal begrenzte Dickdarmentzündungen, die zu einem mukösen Ödem mit lymphoplasmazellulären Infiltraten führt. Die intestinale Permeabilität war bei Patienten mit einer Blastocystis-sp.Infektion erhöht. Beschrieben ist, dass Blastocystis sp. Zerstörungen an der Darmwand anrichtet, wobei keine Invasion des Epithels vorliegt.

\section{Immunantwort}

Offenbar bildet ein Teil der mit Blastocystis sp. infizierten Personen Antikörper gegen Oberflächenantigene des Parasiten. Spezifische IgA-, IgG- und IgM-Antikörper wurden im Serum Infizierter nachgewiesen.

\section{Differenzialdiagnose}

Die Ursachen gastrointestinaler Beschwerden umfassen eine Vielzahl internistischer Differenzialdiagnosen. Neben den infektiösen gibt es auch ähnlich verlaufende nicht infektiöse Erkrankungen, wie z. B. Colitis ulcerosa/Morbus Crohn, Malabsorptionssyndrome oder unerwünschte Arzneimittelwirkungen.

\section{Diagnostik}

\section{Untersuchungsmaterial}

Zur Untersuchung auf Blastocystis sp. eignet sich Frischstuhl (Zeit bis zur Untersuchung maximal 30 $\mathrm{min}$ ), nativer oder fixierter Stuhl in geeigneten Transportbehältnissen bzw. speziellen Transportsystemen.

\section{Diagnostische Verfahren}

Bei Verdacht auf Blastocystis sp. ist der direkte Nachweis durch lichtmikroskopische Verfahren nach Anreicherung (z. B. MIFC, SAF) anzustreben. Eine dreifache Stuhluntersuchung erhöht die Sensitivität maßgeblich.

\section{Befund / Interpretation}

Der Nachweis von Blastocystis sp. ist ein häufiger Befund im Rahmen einer parasitologischen Stuhluntersuchung. Die lange Zeit gültige Meinung, dass geringen Konzentrationen von Blastocystis sp. im Stuhl (weniger als 5 Organismen pro Gesichtsfeld bei 40facher Vergrößerung) keine klinische Bedeutung zu- komme, fand ihren Ursprung in klinisch-diagnostischen Beobachtungen. Inzwischen tendiert man dazu, den Nachweis stets in Zusammenschau mit den klinischen Symptomen sowie den übrigen Untersuchungsergebnissen zu bewerten. Eine Therapieindikation ergibt sich nur dann, wenn bei bestehenden Beschwerden außer dem Nachweis von Blastocystis sp. keine plausible Ursache eruierbar ist.

\section{Therapie}

\section{Therapeutische Maßnahmen}

Die Therapieindikation ist zurückhaltend $\mathrm{zu}$ stellen (siehe Befund/Interpretation). Entscheidet man sich zur Behandlung, wird Metronidazol als Mittel der Wahl empfohlen (verschiedene Therapieansätze sind beschrieben, z. B. $3 \times 750 \mathrm{mg}$ oder $4 \times 500 \mathrm{mg}$ täglich über 5-7 Tage). Iodoquinol, Imidazol-Derivate, Cotrimoxazol sowie Tetrazyclin sollen ebenfalls wirksam sein. Auch Trimethoprim/Sulfmethoxazol und Nitazoxamid werden als Therapeutika diskutiert.

\section{Resistenz}

Über Resistenzen gibt es kaum Berichte; Beobachtungen deuten jedoch darauf hin, dass sich in einigen Fällen die Blastocystis-Populationen nach der Gabe von Metronidazol rasch wieder erholten.

\section{Epidemiologie}

\section{Verbreitung}

Blastocystis sp. kommt weltweit vor und wird in den Tropen und in Entwicklungsländern häufiger gefunden (in Thailand z. B. Prävalenzen bis zu $50 \%$ ), bevorzugt bei Kindern. Studien an Urlaubsrückkehrern aus tropischen Ländern zeigten eine Häufung des Blastocystis-Nachweises bei Indienurlaubern. Die Verbreitung der Subtypen ist regional sehr unterschiedlich.

\section{Wirtsbereich / Reservoir}

Alle Subtypen des Menschen wurden auch bei Tieren gefunden, was auf eine niedrige Wirtsspezifität hinweist. Übertragungen vom Tier auf den Menschen sowie vom Menschen zum Tier werden angenommen, was auf ein zoonotisches Reservoir schließen lässt.

\section{Risikogruppen}

Aufgrund der oft schlechteren hygienischen Verhältnisse besteht insbesondere bei Reisen in Entwicklungsländer oder Länder mit niedrigen hygienischen Standards und unzureichenden sanitären Anlagen ein erhöhtes Infektionsrisiko. Bei immungeschwächten Patienten (z. B. AIDS-Patienten) können die Verläufe einer Blastocystis-Infektion fulminant sein. Bei Annahme eines zoonotischen Potenzials stellt auch der (enge) Kontakt zu infizierten Tieren ein Risiko dar.

\section{Transmission / Vektoren}

Die Übertragung erfolgt fäkal-oral. Die infektionsfähigen Stadien (Zysten) werden in der Regel mit Was- 
ser oder Nahrung aufgenommen. Gehäufte Koinfektionen mit Giardia lamblia weisen auf ähnliche Übertragungswege der beiden Erreger hin.

\section{Prävention / Impfstoffe}

Einen Impfstoff gegen Blastocystis sp. gibt es nicht. Die strikte Einhaltung der Maßnahmen zur Nahrungshygiene bietet in Ländern mit niedrigem Hygienestandard einen gewissen Schutz. Insbesondere AIDS-Patienten sollten den Kontakt mit Human- und Tierfäzes meiden.

\section{Meldepflicht}

Eine Meldepflicht besteht nicht.

\section{Weiterführende Informationen}

\section{Referenzzentren / Expertenlaboratorien}

- Als fachlich qualifiziert anzusehen sind parasitologische und tropenmedizinische Institutionen.

\section{Web-Adressen}

- Centers for Disease Control and Prevention (CDC): http://www.dpd.cdc.gov/dpdx/HTML/Blastocystis.htm

\section{Schlüsselliteratur}

1. Souppart L et al. (2010) Subtype analysis of Blastocystis isolates from symptomatic patients in Egypt. Parasitol Res 106:505-511

\section{Blastomyces dermatitidis}

\section{Erreger}

\section{Synonym(e)}

Blastomycoides dermatitidis, Oidium dermatitidis, Cryptococcus dermatitis, Cryptococcus gilchristi, Endomyces dermatitidis, Zymonema dermatitidis, Zymonema gilchristi u. a.

\section{Erregerspezies}

B. dermatitidis ist die einzige Spezies der Gattung Blastomyces.

\section{Taxonomie}

Klasse: Euascomycetes; Ordnung: Onygenales; Familie: Onygenaceae; Gattung: Blastomyces, Teleomorph: Ajellomyces dermatitidis

\section{Historie}

Die Blastomykose wurde erstmals im Jahre 1876 von Philippe E. L. Van Tiegherm, einem französischen Botaniker, beschrieben. Zwanzig Jahre später publizierten T. C. Gilchrist und W. R. Stokes im „Boulletin of the Johns Hopkins Hospital, Baltimore“ die erste Fallbeschreibung eines „Peudolupus vulgaris“ und stellten die Verbindung zwischen dem Erreger (Oidium) und der Hauterkrankung her. Die erste Beschreibung der
Erkrankung als Systemmykose erfolgte danach durch Walker und Montgomery im Jahre 1902.

\section{Morphologie}

B. dermatitidis ist ein dimorpher Pilz, der abhängig von der Temperatur und anderen Umweltfaktoren entweder als Hefe oder als Hyphomyzet existiert. Bei $37{ }^{\circ} \mathrm{C}$ wächst der Pilz als eine runde dickwandige Hefezelle von 8-15 $\mu \mathrm{m}$ Durchmesser, wobei die Tochterzelle der Mutterzelle breitbasig aufsitzt. Bei $24{ }^{\circ} \mathrm{C}$ bildet der Pilz Hyphenzellen sowie ovale 2-10 $\mu$ m große Konidien, die aus kurzen Stielzellen lateral oder terminal an der Hyphe hervorgehen.

\section{Genom}

B. dermatitidis hat ein Genom, welches aus 25 Millionen DNA-Paaren besteht. Die geschätzte Genomgröße beträgt 28 MB. B. dermatitidis ist haploid mit zwei Geschlechtsformen.

\section{Vermehrung}

Von B. dermatitidis ist ein sexueller Vermehrungszyklus bekannt, weshalb die Zuordnung zu den Ascomyceten erfolgte.

\section{Pathogenität / Virulenz / Antigenvariabilität}

Nach Inhalation erfolgt eine Transformation der Konidien in Hefezellen (temperatur- und nährstoffabhängiger Dimorphismus). Die Hefezellen werden von Alveolarmakrophagen phagozytiert und können intrazellulär persistieren und sich sogar vermehren. BAD-1 (Blastomyces adhesin 1), ein 120-kDa-Protein wird für die Fähigkeit im Makrophagen zu überleben, verantwortlich gemacht. BAD-1 supprimiert die Makrophagenaktivität und versorgt den Erreger mit Kalzium.

\section{Erkrankung}

\section{Blastomykose}

\section{Synonym(e)}

Gilchrist-Rixford-Krankheit, Gilchrist's Disease, Maladie de Chicago, Zymonematose.

\section{Inkubationszeit}

3 Wochen bis ca. 100 Tage.

\section{Leitsymptome}

Fieber, Pneumonie, blutiger Auswurf, ulzerierende Hautläsionen, Gewichtsverlust, seltener Osteomyelitis.

\section{Symptome}

Die primäre Lokalisation der Blastomykose findet sich entweder in der Lunge oder in der Haut.

- Primäre pulmonale Form: grippeähnliche Infektion der Atemwege mit Fieber, trockenem Husten, Glieder- und Thoraxschmerzen. Diese Symptoma- 
tik kann entweder nach wenigen Wochen rückläufig sein oder sich zu einer Pneumonie mit blutigem Auswurf und Pleuraerguss entwickeln.

- Primäre kutane Form: nach Hautinokulation entzündlicher, ulzerierender Primäraffekt mit regionaler Lymphadenitis. Unabhängig von der Ausprägung der primären Symptomatik kann eine hämatogene Aussaat meist vom pulmonalen Primärherd ausgehend erfolgen.

- Disseminierte Form: Die Streuung erfolgt in die Haut, seltener in andere Organe wie ZNS, Prostata, Nebenhoden, Nieren und Knochen. Die Hautläsionen manifestieren sich bevorzugt an Gesicht, Armen und Händen. Aus erythematösen Papeln entwickeln sich eitrige Granulome mit randständigen Mikroabszessen und Fisteln. Die Patienten erleiden einen Gewichtsverlust, haben subfebrile Temperaturen und ein allgemeines Schwächegefühl. Aus den pulmonalen Infiltraten können sich ähnlich wie bei einer Tuberkulose Kavernen bilden. Die disseminierte Blastomykose verläuft unbehandelt letal.

\section{Pathophysiologie}

Nach Inhalation keimen die Konidien in den Lungenalveolen zu Hefezellen aus. Sie persistieren in phagozytischen Zellen und können sich darin sogar solange vermehren, bis die zelluläre Abwehr greift. Bei Insuffizienz zellulärer Immunmechanismen, insbesondere bei erniedrigten T-Helferzellzahlen und dadurch beeinträchtigter Makrophagenaktivität, kommt es zur Dissemination der Pilze aus der Lunge in andere Organsysteme, wobei besonders Haut und Knochen befallen werden.

\section{Immunantwort}

Die zelluläre Abwehr ist entscheidend. Die Konidien werden von Alveolarmakrophagen phagozytiert, aber nicht abgetötet. Dazu müssen T-Helferlymphozyten die Makrophagen erst aktivieren. Targetantigen für TLymphozyten ist vermutlich das Adhäsin BAD-1. Eine humorale Immunantwort wird induziert, schützt jedoch nicht vor einer Reinfektion.

\section{Differenzialdiagnose}

Pulmonale Form: Tuberkulose, Infektion mit anderen dimorphen Pilzen (Histoplasma capsulatum, Coccidioides immitis, Paracoccidioides), Infektionen mit anderen Erregern einer Pneumonie, Sarkoidose.

Kutane Form: Tuberkulose, Chromomykose, Coccidiodomykose, Sporotrichose, Syphilis, Granuloma venereum.

Disseminierte Form: Tuberkulose, Syphilis, Neoplasmen.

\section{Diagnostik}

\section{Untersuchungsmaterial}

Sputum, Bronchialsekret, BAL, Biopsate, Punktate.

\section{Diagnostische Verfahren}

- Kultur: Anzucht des Erregers auf Spezialnährmedien (z. B. Hirn-Herz-Agar); bei $24{ }^{\circ} \mathrm{C}$ Wachstum von Kolonien mit weißem, filzigem Myzel; bei $37{ }^{\circ} \mathrm{C}$ ledrige, stark gefurchte Hefekolonien.

- Histologie: runde, dickwandige Hefezellen in PASgefärbten Gewebeschnitten, granulomatöse Veränderungen mit Riesenzellen.

- PCR aus Direktmaterial.

- Tests für Antikörpernachweis nicht kommerziell verfügbar.

\section{Befund / Interpretation}

Der histologische, kulturelle oder genetische Nachweis des Pilzes aus Biopsiematerial und Körperflüssigkeiten ist pathognomonisch. Der Nachweis von Antikörpern bei Bewohnern von Endemiegebieten zeigt eine Durchseuchung an, keine Infektion. Bei Patienten außerhalb der Endemiegebiete ist ein Antikörpertiter aussagekräftiger, aber nicht beweisend für eine Blastomykose.

\section{Therapie}

\section{Therapeutische Maßnahmen}

Mittel der Wahl ist Itraconazol, bei disseminierter Blastomykose entweder Voriconazol oder initial Amphotericin B, dann Itraconazol.

\section{Resistenz}

Unbekannt.

\section{Epidemiologie}

\section{Verbreitung}

USA: Mississippibecken, Ost- und Nordstaaten, Kanada, Mittelamerika, Afrika, Indien, Israel, Saudi-Arabien.

\section{Wirtsbereich / Reservoir}

Mensch, Hund, Katze und andere Wirbeltiere. Der Pilz wurde isoliert aus sandigem, mit organischem Material angereichertem Boden in Nähe von Wasser.

\section{Risikogruppen}

Farmer, Waldarbeiter, Touristen in Endemiegebieten, Immunsupprimierte.

\section{Transmission / Vektoren}

Sporen von B. dermatitidis werden mit dem Staub verbreitet. Die Übertragung auf den Menschen erfolgt bei Inhalation des kontaminierten Staubes, durch direkte Inokulation in die Haut bei Hautverletzungen oder durch kontaminierte Gegenstände und Pflanzenbestandteile, z. B. Dornen, Holzspäne. Eine Übertragung von Mensch zu Mensch ist wenig wahrscheinlich.

\section{Prävention / Impfstoffe}

Eine spezifische Prophylaxe ist nicht möglich. Immunsupprimierte sind besonders anfällig eine disseminierte Blastomykose zu entwickeln, weshalb Reisen in Endemiegebiete gemieden werden sollten. 


\section{Ausbruchsmanagement}

Nationale Surveillance-Programme erfassen Infektionen in Endemiegebieten.

\section{Meldepflicht}

Keine.

\section{Weiterführende Informationen}

\section{Referenzzentren / Expertenlaboratorien}

- Konsiliarlabor:Robert-Koch-Institut, Nordufer 20, D-13353 Berlin

- National Centers for Disease Control, Mycotic Diseases Branch, Atlanta, GA 30333, USA

\section{Web-Adressen}

- http://www.cdc.gov

\section{Schlüsselliteratur}

1. Baumgardner DJ, Paretsky DP (1999) The in vitro isolation of Blastomyces dermatitidis from a woodpile in North central Wisconsin, USA. Med Mycol 37:163-168

2. De Groote MA, Bjerke R, Smith H, Rhodes IL (2000) Expanding Epidemiology of Blastomycosis: Clinical Features and Investigation of 2 Cases in Colorado. Clin Infect Dis 30:582-584

3. Larone DH (1995) Medically Important Fungi - A Guide to Identification, $3^{\text {rd }}$ edn. ASM Press, Washington, D.C

4. Li RK, Ciblak MA, Nordoff N, Pasarell L, Warnock DW, McGinnis MR (2000) In vitro activities of voriconazole, itraconazole, and amphotericin B against Blastomyces dermatitidis, Coccidioides immitis and Histoplasma capsulatum. Antimicrob Agents Chemother 44:1734-1736

5. McCullough MJ,DiSalvo AF, Clemons KV, Park P, Stevens DA (2000) Molecular epidemiology of Blastomyces dermatitidis. Clin Infect Dis 30:328-335

\section{Blastomykose}

Blastomyces dermatitidis

\section{Blastomykose, brasilianische}

- Paracoccidioides brasiliensis

\section{Blastomykose, europäische}

- Cryptococcus neoformans

\section{Blastomykose, südamerikanische}

- Paracoccidioides brasiliensis

\section{Blastozystose}

- Blastocystis sp.

\section{Bocavirus}

Parvoviren

\section{Body-Cavity-Based Lymphoma (BCBL)}

- Humanes Herpesvirus 8 (HHV-8)

\section{Bordetella}

\section{Erreger}

HANS-GÜNTHER SonNTAG

Bordetella pertussis, B. parapertussis, B. ansorpii, B. avium, B. bronchiseptica, B. hinzii, B. holmesii, B. petrii, B. trematum

\section{Erregerspezies \\ B. pertussis, B. parapertussis}

\section{Taxonomie}

Genus:Alcaligeneaceae; Spezies: B. pertussis, B. parapertussis

\section{Historie}

Der Keuchhusten ist ein lange bekanntes eigenständiges Krankheitsbild, die Erstbeschreibung erfolgte 1518 durch Guilleaume de Baillou. Die infektiöse Genese als „contagium animatum“ wurde im 18.Jahrhundert von Rosen von Rosenstein aufgegriffen. Bordet und Gengou gelang 1906 mithilfe eines speziellen Nährmediums die Anzucht der Bakterien, die zunächst Haemophilus pertussis hießen. Zu Ehren Jules Bordets wurden die Bakterien 1940 in ein eigenes Genus Bordetella eingeordnet. Ein ähnliches Bakterium wurde 1953 als B. parapertussis klassifiziert.

\section{Morphologie}

$B$. pertussis ist ein kleines, bekapseltes gramnegatives Stäbchen, das keine Sporen bildet.

\section{Genom}

Die Genome von $B$. pertussis mit einer Länge von 4,09 Mio. nt, wie auch von B. parapertussis, B. bronchiseptica, B. avium und B. petrii sind vollständig sequenziert und in Genomdatenbanken zugänglich.

$B$. pertussis und B. parapertussis sind weitgehend DNA-homolog. Weitere Informationen: http://www. genedb.org. bzw. http://www.genomesonline.org.

\section{Vermehrung}

Bordetella wächst nur unter aeroben Bedingungen. Die Bakterien zeigen ein langsames Wachstum und sind empfindlich gegen Umweltfaktoren wie Kälte, Fettsäuren und Magnesiumionen.

Pathogenität / Virulenz / Antigenvariabilität

B. pertussis zeichnet sich durch eine Vielzahl mehr 
oder minder gut charakterisierter Virulenzfaktoren aus: Die Fimbrien vom Typ 2 und Typ 3 dienen als Adhäsine, wie auch das Filamenthämagglutinin (FHA) und das Pertactin. FHA wird von den Bakterien sezerniert und ist auch bei anderen Bakterien (Pneumokokken, Haemophilus influenzae) als Adhäsin bekannt.

Ein für die Symptomatik des Keuchhustens wesentlicher Virulenzfaktor ist das Pertussis-Toxin (PT) (Synonyme: Lymphozytose produzierender Faktor, Histamin sensibilisierender Faktor, Inselzell aktivierendes Protein), das nach dem A-B-Modell bakterieller Toxine aufgebaut ist und Ähnlichkeiten zum Cholera-, Shiga- und Diphtherietoxin aufweist. Die A-Untereinheit besitzt enzymatische Aktivitäten einer ADP-Ribosyltransferase für G-Proteine (Signaltransduktion in der Epithelzelle).

Adenylatcyclasetoxin hemmt phagozytierende Effektorzellen des Wirtsorganismus. Trachea-Cytotoxin, ein dem Peptidoglykan der Zellwand ähnlicher kleinmolekularer Virulenzfaktor, führt zur Nekrose von zilientragenden Epithelzellen.

Die Bedeutung weiterer Virulenzfaktoren (hitzelabiles Toxin, BrkA u. a.) bei der Pathogenese des Keuchhustens ist bisher nicht abgeklärt.

Polymorphismen im Genom und entsprechend in den Virulenzfaktoren kommen im Vergleich zu anderen bakteriellen Spezies eher selten vor, sind aber wegen des möglichen Einflusses auf die Wirksamkeit von Impfstoffen von Bedeutung.

\section{Erkrankungen}

\section{Krankheitsbezeichnung}

B. pertussis $\left(\mathrm{A} 37.0^{\star}\right)$ und B. parapertussis $\left(\mathrm{A} 37.1^{*}\right)$ sind die Erreger des Keuchhustens $($ A37.9*) beim Menschen. B. bronchiseptica verursacht respiratorische Symptome bei Tieren und selten beim Menschen. B. avium wird bei respiratorischen Erkrankungen von Geflügel gefunden. Nur sehr selten wurden andere Spezies, wie B. ansorpii, B. hinzii, B. holmesii und B. trematum $\left(\mathrm{A} 37.8^{\star}\right)$ aus Untersuchungsmaterialien von immunsupprimierten Patienten isoliert.

* Klassifikation nach ICD-10

\section{Synonym(e)}

„100-Tage-Husten“.

\section{Inkubationszeit}

Circa 10 Tage (6-28).

\section{Leitsymptome}

Länger dauernder Husten, anfallsartiger Husten mit Würgen oder Erbrechen, inspiratorischer Stridor, Apnoe bei Säuglingen, paroxysmale Hustenattacken.

\section{Symptome}

Die Krankheit verläuft beim Ungeimpften in drei Phasen:
1. Katarrhalstadium, Dauer etwa 1 Woche mit uncharakteristischen Symptomen einer Rhinitis und Tracheitis.

2. Konvulsivstadium drei bis sechs (maximal 40) Wochen mit charakteristischen paroxysmalen Hustenattacken.

3. Rekonvaleszenzstadium, ein bis mehrere Wochen mit langsamem Rückgang von Frequenz und Intensität der Hustenattacken.

Der Verlauf ist bei ungeimpften Säuglingen häufig atpyisch mit Apnoen. Ältere (geimpfte) Kinder, Adoleszente und Erwachsene zeigen als klinische Symptomatik häufig nur länger dauernden Husten.

Komplikationen: Pneumonie, Enzephalopathie, Otitis media, Bahnung von Superinfektionen, Komplikationen aufgrund der mechanischen Beanspruchung durch die Hustenattacken (z. B. Rippenbrüche, Leistenhernien).

\section{Pathophysiologie}

Die Erreger haften und vermehren sich ausschließlich an den Schleimhäuten der Atemwege.

\section{Immunantwort}

Nach Infektionskrankheit ca. 10 Jahre.

\section{Differenzialdiagnose}

Infektionen durch Adenoviren, Respiratory-syncytial Virus, Rhinoviren und andere Erreger akuter respiratorischer Infektionen sind bei Jugendlichen und Erwachsenen häufig von Keuchhusten nicht zu unterscheiden.

\section{Diagnostik}

\section{Untersuchungsmaterial \\ Nasopharyngealabstrich.}

\section{Diagnostische Verfahren}

Direktnachweis: Die Kultur von B. pertussis und B. parapertussis ist aus Nasopharyngealabstrichen oder -sekreten möglich. Die Abstrichtupfer (Material: Calciumalginat oder Dacron) müssen in geeigneten Transportmedien (z. B. REGAN-LOWE-Medium) verschickt werden. Die Anzucht erfolgt auf speziellen Medien (Holzkohle-Blut-Agar) mit einer Bebrütungsdauer von sieben Tagen bei $37^{\circ} \mathrm{C}$. Eine Differenzierung erfolgt nach Morphologie, Gram-Verhalten, Oxidase-Reaktion (positiv bei B. pertussis, negativ bei B. parapertussis) sowie durch Reaktion mit spezifischen Antiseren. Der kulturelle Nachweis ist lediglich bei Säuglingen und Ungeimpften im Frühstadium hinreichend sensitiv.

Andere Bordetella spp. werden auf üblichen Medien angezüchtet und wie gramnegative nicht fermentierende Stäbchen differenziert.

B. pertussis und B. parapertussis können aus Nasopharyngealabstrichen (Dacron-Tupfer ohne Transport- 
medium) oder -sekreten mittels verschiedener PCRFormate nachgewiesen werden; die Methode ist vor allem bei Geimpften, Adoleszenten und Erwachsenen empfindlicher als der kulturelle Nachweis. Der Nachweis der Bakterien mittels direkter Immunfluoreszenz ist obsolet.

Serologische Diagnostik: Nach etwa 2-4 Wochen Symptomatik können mithilfe von ELISA IgG-und IgA-Antikörper gegen PT, FHA und andere Antigene nachgewiesen werden. Ein Titeranstieg zwischen Akut- und Rekonvaleszenzserum sichert die Diagnose. Ein einzelner über der altersentsprechenden Referenz (meist 100-125 EU/ml bezogen auf ein Referenzpräparat der FDA) liegender IgG-Antikörperspiegel gegen PT kann die Infektion mit $~ 80 \%$ Sensitivität und $95 \%$ Spezifität wahrscheinlich machen. Für 1-3 Jahre nach einer Impfung mit azellulären Impfstoffen ist der Antikörpernachweis diagnostisch nicht zu verwerten.

\section{Befund/Interpretation}

Definitionen: CDC- bzw. WHO-Definition: 14 bzw. 21 oder mehr Tage dauernder paroxysmaler Husten, jeweils mit einer Bestätigung durch Nachweis des Erregers, Titeranstieg spezifischer Antikörper oder Kontakt (innerhalb 28 Tagen) zu einem kulturell bestätigten Fall.

RKI-Definition: Klinisches Bild vereinbar mit Keuchhusten mit anfallsartigem Husten und/oder inspiratorischem Stridor und/oder Erbrechen nach Anfall für $\geq 14$ Tage. Klinisches Bild mit Apnoen bei Säuglingen. Laborbestätigung durch Kultur, PCR, Serologie oder Kontakt zu einem bestätigten Fall.

\section{Therapie}

\section{Therapeutische Maßnahmen}

Die Behandlung erfolgt mit Erythromycin (7 Tage) bei Säuglingen und Kleinkindern oder mit anderen Makroliden (Azithromycin, Clarithromycin) bei älteren Kindern, Jugendlichen und Erwachsenen. Die Therapie reduziert die Infektiosität, beeinflusst jedoch die Symptomatik nicht oder nur wenig. Ungeimpfte Kontaktpersonen, insbesondere Säuglinge, sollten eine Makrolid-Prophylaxe (Erythromycin bei Säuglingen; Azithromycin, Clarithromycin bei anderen Kontaktpersonen) erhalten.

Wegen der geringen Wirksamkeit der antibiotischen Therapie auf die Symptomatik gewinnt die Prophylaxe durch aktive Schutzimpfung (Prävention/Impfstoffe) besondere Bedeutung.

In Gemeinschaftseinrichtungen für Kinder ist bei Fällen von Pertussis eine Wiederzulassung nach fünftägiger antibiotischer Therapie möglich.

\section{Resistenz}

Keine Resistenzentwicklung gegenüber Makrolidantibiotika.

\section{Epidemiologie}

\section{Verbreitung}

Der Keuchhusten ist bei Ungeimpften eine typische Kinderkrankheit mit einem Altersgipfel um vier Jahre. Etwa $10 \%$ der Kinder erkranken als Säuglinge, während etwa 5-10 \% der Patienten Erwachsene sind. In impfenden Ländern zeigt sich eine Konzentration von bis zu 50\% der Fälle im ersten Lebensjahr, die anderen Fälle treten bei älteren Kindern, Jugendlichen und im Erwachsenenalter auf. Mädchen und Jungen erkranken gleich häufig.

Die Inzidenz der gemeldeten Keuchhustenfälle schwankt zwischen 10-25/100.000 und Jahr. In Studien zeigte sich eine Inzidenz bei Erwachsenen zwischen $150-500 / 100.000$ und Jahr.

\section{Wirtsbereich / Reservoir}

$B$. pertussis ist bisher nur beim Menschen gefunden worden, $B$. parapertussis neben dem Menschen auch bei Schafen.

B. bronchiseptica hat große veterinärmedizinische Bedeutung für eine Vielzahl von Spezies. B. avium und $B$. hinzii kommen vor allem bei Geflügel vor.

Die Ökologie von B. ansorpii, B. holmesii, B. petrii und B. trematum ist nicht genau bekannt.

\section{Risikogruppen}

Die Empfänglichkeit ist universell, ein Nestschutz existiert nicht oder nur sehr begrenzt. Komplikationen und Letalität sind in den ersten sechs Lebensmonaten am größten. Etwa 5-20 Jahre nach durchgemachtem Keuchhusten besteht erneut eine Empfänglichkeit. Die Schutzdauer einer aktiven Schutzimpfung ist gleichfalls begrenzt, für die azellulären Impfstoffe wird eine Schutzdauer von 5-8 Jahren angenommen.

\section{Transmission / Vektoren}

Die Übertragung erfolgt durch bakterienhaltige ausgehustete Tröpfchen, wobei bereits etwa 100 Bakterien ausreichen, um einen Keuchhusten zu induzieren. Völlig asymptomatische Träger spielen keine Rolle. Geimpfte ältere Kinder, Jugendliche und Erwachsene scheinen das Hauptreservoir des Erregers in impfenden Ländern darzustellen.

\section{Prävention / Impfstoffe}

Die aktive Schutzimpfung im Säuglingsalter (ab 3. Lebensmonat) mit azellulären Impfstoffen zählt in Kombination mit anderen Antigenen (Diphtherie- und Tetanustoxoid, Hib-PRP, HBs-Antigen, Polioviren) zu den empfohlenen Säuglingsimpfungen. Azelluläre Impfstoffe $(\mathrm{Pa})$ sind gleich wirksam wie die früher verwendeten Ganzzellimpfstoffe, haben jedoch weniger Nebenwirkungen. Kombinationsimpfstoffe mit reduziertem Antigengehalt (Tdap) werden zur Auffrischimpfung im Vorschulalter, und bei Jugendlichen zwischen 11 und 18 Jahren von der STIKO empfohlen. Mitarbeiter in Kinderkliniken, KITAs und Kindergär- 
ten sollten gleichfalls durch Impfung gegen Pertussis geschützt werden. In verschiedenen Ländern (USA, Kanada) wird die universelle Impfung aller Erwachsenen empfohlen.

\section{Ausbruchsmanagement}

Nicht erforderlich.

\section{Meldepflicht}

Keine Meldepflicht nach InfSG.

\section{Weiterführende Informationen}

\section{Referenzzentren / Expertenlaboratorien}

- Konsiliarlabor: Prof Dr. CH Wirsing von König, Institut für Hygiene und Laboratoriumsmedizin, Klinikum Krefeld, Lutherplatz 40, 47805 Krefeld; www.klinikum-krefeld.de/Hygiene/index.html

\section{Webadressen}

- Impfempfehlungen der STIKO: www.rki.de/GESUND/ IMPFEN/IMPFEN.HTM

- US-Impfempfehlungen des ACIP: www.cdc.gov/nip/ publications/ACIP-list.htm

\section{Schlüsselliteratur}

1. Edwards KM, Decker MD (2004) Pertussis Vaccines. In: Plotkin SA, Orenstein WA (eds) Vaccines, $4^{\text {rd }}$ edn. WB Saunders, Philadelphia, pp 471-528

2. Loeffelholz M (2003) Bordetella. In: Murray PR, Baron EJ, Pfaller MA, Jorgensen JH, Yolken RH (eds) Manual of Clinical Microbiology, $8^{\text {th }}$ edn. ASM, Washington, pp 780-788

3. Versteegh FGA, Schellekens JFP, Fleer A, Roord JJ (2005) Pertussis: a conscise historircal review including diagnosis, incidence, clinical manifestatios and the role of treatment and vaccination in management, Rev.Med.Microbiol 16 (3): 79-89

\section{Borna-Virus}

\section{Erreger}

Synonym(e)

Bornavirus.

\section{Erregerspezies}

Borna disease virus (BDV)

Subspezies: Avian Bornavirus (ABV)

\section{Taxonomie}

BDV: Familie Bornaviridae; Ordnung: Mononegavirales. Genom: Einzelsträngige, unsegmentierte RNA negativer Polarität, 8910 Nukleotide und sechs ORFs. Replikation im Kern; ein ORF (X-Protein) nur bei der Familie Bornaviridae zu finden. Hauptproteine: Nund P-Protein (sog. s-(soluble-)Antigen). Wie die an-

\footnotetext{
\# Der Beitrag gibt ausschließlich die persönliche Auffassung der Autorin wieder.
}

deren Mononegavirales besitzt BDV eine L-Polymerase und ein klassisches Glykoprotein (G-Protein). Ungewöhnlich, M-Protein kommt mit Zuckeranteil vor, scheint jedoch strukturell kein Glykoprotein zu sein. RNA-Genom enthält drei Introns. Replikation zeichnet sich durch komplizierte Splicing-Mechanismen aus, findet im Gegensatz zu allen anderen Mononegavirales im Kern statt. Ungewöhnlich stark konservierte Genomstruktur von BDV bei Tier und Mensch lässt es als evolutionär sehr alt erkennen. Neue Untersuchungen an Genomfragmenten, eingebaut in das Erbgut von Mensch und Tier, unterstützen diese Annahme $[4,5]$.

Weitere Detailbeschreibungen zur Taxonomie, siehe Schlüsselliteratur [7]. Kürzlich Entdeckung eines neuen Vogelvirus, genannt aviäres Bornavirus (ABV) [6]. Könnte wegen der Unterschiede zu BDV als Subspezies eingestuft werden.

\section{Historie}

Die Borna-Krankheit, ursprünglich beim Pferd und Schaf beschrieben, wird seit 100 Jahren nach der Amtshauptmannschaft Borna (bei Leipzig) benannt. Dort kam es gehäuft zu seuchenhaftem Pferdesterben. Natürliche Infektionen wurden bei Rind, Katze, Hund und Straußen beschrieben [8]. Für die aviäre proventrikuläre Dilatationskrankheit (PDD) ist ursächlich das $A B V$ verantwortlich gemacht worden [6]. Große Bedeutung hat BDV erlangt, als serologische Befunde auf menschliche Infektionen hingewiesen hatten und dann Virusantigen (N- und P-Protein) und Nukleinsäure in peripheren weißen Blutzellen nachgewiesen [2] sowie Humanisolate gewonnen wurden. Inzwischen existieren 5 Isolate von psychiatrischen Patienten, davon 4 von unserer Berliner Gruppe charakterisiert: 2 Patienten mit manisch-depressiver Erkrankung (engl.: Bipolar Disorder), 1 Patient mit einer chronischen Zwangserkrankung (engl.: Obsessive Compulsive Disorder; OCD), 1 depressiver Patient mit dem chronischen Müdigkeitssyndrom (engl.: Chronic Fatigue Syndrome; CFS) und ein Gehirnisolat aus Autopsiematerial eines Schizophrenie-Patienten (japanische Gruppe). Mit der Entdeckung neuer Laborparameter (zirkulierende Immunkomplexe und PlasmaAntigen) ließen sich Zusammenhänge einer aktivierten BDV-Infektion mit bestimmten Erkrankungsbildern (vor allem psychiatrischer Art) aufzeigen [3]. Die Entdeckung, dass BDV Genomanteile in das Wirtserbgut eingebaut werden [5], unterstreicht die Risiken mentaler Störungen bei persistent infizierten Menschen [4].

\section{Morphologie}

EM-Aufnahmen zeigen $90 \mathrm{~nm}$ große eingehüllte $\mathrm{Vi}$ ren und $60 \mathrm{~nm}$ große ikosaedrische Partikel, die Nukleokapside oder defekte Virusstrukturen darstellen. Dass es sich bei BDV um ein ikosaedrisches, eingehülltes Virus handelt, wurde in Japan bestätigt. Struk- 
turelle und molekulare Verwandtschaftsbeziehungen $\mathrm{zu}$ anderen Mononegavirales werden werden in Ref. [7] aufgeführt.

\section{Genom}

Das BDV-Genom ist zuerst aus gereinigten Virionen (animaler Referenzstamm: Stamm V) als nicht segmentierte, einzelsträngige RNA mit negativer Polarität, bestehend aus 8910 Nukleotiden, charakterisiert worden. Auf dem Genom liegen sechs Leserahmen (Gene) für die Proteine p40, 24, 10, 16, 56 und 190 (N-, P-, X-, M-, G-Protein und L-Polymerase), in die 3 Introns eingebaut sind [7]. Neben dem G-Protein gibt es Hinweise, dass auch das M-Protein ähnlich wie ein Glykoprotein $\mathrm{zu}$ funktionieren scheint, jedoch mit strukturellen Unterschieden (Stoyloff, Bode, Ludwig et al., 2005, unpublizierte Daten).

Das G-Protein besitzt in glykosylierter Form ein Molekulargewicht von $94 \mathrm{kDa}$ und hat eine dominante Furinspaltstelle. Es wird als wichtiges Hüllprotein in vergleichsweise geringen Mengen produziert, mit dem Ergebnis oft fehlender neutralisierender Antikörper. Die Hauptgenprodukte stellen das N- und P-Protein dar, die während der Replikation im Überschuss produziert werden (s-Antigen).

BDV besitzt ein ungewöhnlich hoch konserviertes Genom mit > 95 \% Sequenzhomologie - ein Hinweis auf ein evolutionär sehr altes Virus. Die Genome der neu entdeckten $\mathrm{ABV}$ s besitzen eine Gesamthomologie mit BDV von rund 60\% [6]. Die Teilsequenzen der Humanisolate sind untereinander und mit BDV-Referenzstamm $\mathrm{V}$ eng verwandt, weisen allerdings individuelle Mutationen auf, die nicht bei Tierstämmen gefunden wurden [3].

\section{Vermehrung}

Beim Menschen kann analog zur tierischen Infektion angenommen werden, dass sich BDV auch im limbischen System (Hippocampus, Amygdala, Hypothalamus, limbischer Cortex etc.) vermehrt. Virale RNA konnte in Hirnautopsie-Proben Verstorbener mit psychiatrischen Vorerkrankungen amplifiziert werden [7]. Virusantigene im Liquor cerebrospinalis konnten bisher als Ausdruck einer zumindest transienten Virusvermehrung im Gehirn nur bei Patienten mit rezidivierender Major Depression, nicht bei anderen psychiatrischen Störungen nachgewiesen werden $[1$, S17].

In Zellkulturen verschiedener Spezies lässt sich BDV als persistente Infektion ohne CPE halten [1,S15]. Die Vermehrung des Virus findet im Gegensatz zu allen anderen Mononegavirales im Kern statt, wo auch die RNPs zusammengebaut werden [7]. Generell werden nur wenige infektiöse Einheiten (eine oder weniger) per Zelle gebildet und freigesetzt. Die Hauptantigene $(\mathrm{N}$ - und P-Protein) werden allerdings in großer Menge nicht nur in Zellkultur, sondern auch im infizierten Organismus gebildet [8].

\section{Pathogenität / Virulenz / Antigenvariabilität}

Die Pathogenität von BDV wird bei Mensch und Tier durch Eigenschaften des Virusstammes und die individuelle Resistenz/Vulnerabilität des entsprechenden Wirts bestimmt. Asymptomatische Infektionen können bei 30\% erwachsener Menschen vorkommen (BDV-spezifische Immunkomplexe), bei Pferden in Mitteleuropa durchschnittlich doppelt so häufig. Mindestens $5 \%$ (Pferde $10 \%$ ) der Gesamtbevölkerung haben aufgrund häufiger und/oder stärkerer Antigenämiephasen ein signifikant erhöhtes Erkrankungsrisiko oder sind bereits manifest erkrankt. Das klinische Spektrum - am besten bekannt beim Pferd [8] - reicht von episodischen Verhaltens-, Bewegungs- und Fressstörungen (Apathie, Panikattacken, Lern- und Leistungsschwäche, Zwangsbewegungen, Gangunsicherheit, Appetitlosigkeit u. a.) bis zu fatalen neurologischen Verläufen (letztere selten).

Beim Menschen wird angenommen, dass neben genetisch prädisponierenden Faktoren chronischer Stress und/oder geminderte Stressresistenz die Aktivierung latenter BDV-Infektionen fördern und damit zu dem komplexen Szenario mutmaßlicher multifaktorieller Pathogenese-Effekte von Wirts- und Virusseite beitragen [3].

Das Morbiditätsrisiko durch eine BDV-Infektion ist bei prädisponierten Personen wahrscheinlich als hoch, bei nicht vorbelasteten Personen dagegen eher als gering einzuschätzen. Diagnostisch sind häufige und/ oder längere Antigenämiephasen (Plasma-Antigen plus BDV-Immunkomplexe) als Aktivierungszustände (engl.: ,state marker") interpretierbar, die ein gegenüber dem „latenten“ Zustand (serologisch nur Antikörper) gestiegenes individuelles Erkrankungsrisiko signalisieren. Auch infizierte Personen mit fehlendem genetischen Risikoprofil für Affektstörungen können solche Infektionsphasen entwickeln (z. B. durch medikamentöse Immunsuppression) und damit ihr Krankheitsrisiko für eine mentale Störungen steigern.

Über die Kontagiosität des humanen Virus ist bisher nichts bekannt. Ob und in welchem Umfang Virusaktivitätsphasen auf Reaktivierungen bereits bestehender Infektionen beruhen oder auf Neuinfektionen mit einem virulenteren oder Antigen veränderten Stamm zurückzuführen sind, ist bisher nicht unterscheidbar Eine Impfprophylaxe ist nicht in Sicht. Vielmehr sollte die bereits existierende gut verträgliche antivirale Amantadin- Therapie für Symptomträger als Option erachtet werden. Amantadin reduziert in vitro die Titer humaner und equiner Wildviren (jedoch nicht Laborviren) signifikant und dosisabhängig [3] und führt in vivo zu einer klinischen Besserung sowie Reduktion der Infektionsmarker bei etwa 70-80 \% der Patienten [1, S62-64].

Aufgrund des sehr konservierten BDV-Genoms ist die Antigenvariabilität gering. Die zum Antigennachweis eingesetzten monoklonalen Antikörper erkennen spe- 
ziesübergreifend N- bzw. P-Protein des Borna-Virus [3].

\section{Erkrankungen}

Die Borna-Krankheit ist für unsere Haustiere gut definiert [8]. Beim Menschen wird von Borna-Virus-Infektionen mit Risikopotenzial für die mentale Gesundheit gesprochen. Aktivierte Infektionen können zu primären und sekundären psychiatrischen Störungen beitragen [3; 1, S27-32].

\section{Major Depressionen und Bipolare Störungen, Zwangserkrankungen.}

\section{Synonym(e)}

Major Depressive Disorder and Bipolar Typ I and II Disorders (DSM IV No. 296.xx) and OCD (DSM IV No. $300.3[1, \mathrm{~S} 62]$.

\section{Inkubationszeit}

Die Inkubationszeiten lassen sich beim Menschen bisher nicht eingrenzen. Im Tierexperiment am adulten Individuum treten Krankheitssymptome nach ca. 2 bis 3 Wochen auf (Kaninchen). Beim infizierten Neonaten (Ratte, Maus) entsteht eine tolerante Infektion, bei der ohne Angabemöglichkeiten zur Inkubationszeit, Verhaltensänderungen und Lernstörungen zu beobachten sind.

\section{Leitsymptome}

Manische und depressive Symptomatik, i. d. R. ohne psychotische Anteile, kognitive Defizite und anhaltende Minderung der intellektuellen Leistungsfähigkeit häufig bei infizierten Patienten. Verlauf zu Beginn episodenhaft mit symptomfreien Intervallen, später mit zunehmender Tendenz zur Chronifizierung.

Zwangshandlungen und Zwangsgedanken, einzeln oder kombiniert, mit frühzeitiger Chronifizierung und erheblicher Behinderung und Einbußen der Lebensqualität [3].

\section{Symptome}

Die BDV-Infektion persistiert in der Regel lebenslang, mit symptomlosen Verläufen in allen Wirtsspezies. Zum besseren Verständnis der Symptomatik beim Menschen sei auf die gut dokumentierten Symptomenkomplexe beim Tier hingewiesen. Mortalität kommt entgegen früheren Annahmen jedoch nur sporadisch bei Tieren vor [8].

Beim Menschen ist eine Koinzidenz von aktivierter Virusinfektion mit akuten psychiatrischen Krankheitsbildern offensichtlich, vor allem für rekurrierende „endogene“ Depressionen (Major Depression, unipolar und bipolar) [3]. In der Remission geht auch die Virusaktivität zurück bzw. ist nicht mehr nachweisbar. Auch ein Teil der Zwangserkrankungen kann mit chronischer Virusaktivierung zusammenhängen. Hier konnten sogar BDV-Immunkomplexe im Blut mit krankheitsbezogenen Abweichungen von Gehirnpotenzialen signifikant korreliert werden [1, S18].

Auch bei dem heterogenen chronischen Müdigkeitssyndrom (CFS/ME) konnte bei einem Teil der Patienten ein deutlich erhöhter BDV-Antigentiter gemessen werden. Wegen der Behandlungsoption mit Amantadin für infizierte Patienten macht es Sinn, bei CFS/ME differenzialdiagnostisch auf Borna-Virus zu untersuchen. Die (aktivierte) BDV-Infektion ist als wichtiger Faktor zu bewerten, der - zusammen mit genetischer Prädisposition und das Immunsystem beeinflussenden Stressfaktoren (vulnerable HPA-Achse) - das klinische Bild rekurrierender Gemütsstörungen beeinflusst [3; 1, S62]. Nach der DSM-IV-Klassifikation (American Psychiatric Association) sollten insbesondere Störungen der Diagnose-Nummern 296.xx und 300.3 , sowie zusätzlich $311,300.4$ und 295.70 differenzialdiagnostisch berücksichtigt werden. Darüber hinaus kann eine aktivierte BDV-Infektion auch mit anderen Krankheitsbildern, die auf eine funktionelle Fehlsteuerung im limbischen System hinweisen, einhergehen (z. B.. ADHS; engl.: Attention Deficit Hyperactivity Disorder Syndrom; DSM IV No. 314.9).

\section{Pathophysiologie}

Humanes BDV ist erstmalig aus peripheren weißen Blutzellen isoliert worden, d. h. es hat Zielzellen außerhalb des Gehirns [3]. Virale RNA konnte durch RTPCR in Hirnautopsie-Proben Verstorbener mit psychiatrischen Vorerkrankungen amplifiziert [7] und Virusantigene im Liquor cerebrospinalis als zumindest transiente Virusaktivität im Gehirn (nur bei Patienten mit Major Depression) nachgewiesen werden $[3,8]$.

\section{Immunantwort}

Antikörper sind im Serum/Plasma nachweisbar, allerdings (methodenabhängig) nicht zu jedem Zeitpunkt der persistenten Infektion. Dies ist erklärbar mit der Bildung von Immunkomplexen, die im Blut zirkulieren und als Folge von Antigenschüben entstehen. Die Antikörper sind bei Mensch und Tier vor allem gegen das $\mathrm{N}$ - und P-Protein gerichtet und haben keine Schutzwirkung [3]. Neutralisierende Antikörper (bisher nur bei Tieren nachgewiesen) sind erheblich seltener [8]. Sie erkennen vor allem das G-Protein, teilweise allerdings auch das M-Protein. Die zelluläre Immunantwort ist bisher nur gründlich im experimentellen Tiermodell (Ratte) untersucht [7]. Immunpathologische Ereignisse treten gegenüber den ätiopathogenetisch bedeutsamen Balancestörungen im Neurotransmitter-Netzwerk in den Hintergrund oder spielen zumindest keine initiale Rolle bei Verhaltensänderungen.

\section{Differenzialdiagnose}

Erkrankungen des peripheren und zentralen Nervensystems mit negativem BDV-Blutbefund, z. B. Enzephalitiden viraler Genese sowie die Frühstadien von 
nvCJD und möglicherweise auch die Frühsymptomatik der Alzheimer-Krankheit; außerdem die Borreliose-Infektion (Neuroborreliose), bei der ein heterogenes Symptomenbild angenommen wird, das sich wenig mit der Ausprägung einer (BDV-spezifischen) Dysfunktion im limbischen System deckt.

\section{Psychiatrische Störungen}

Sekundär bedingte psychiatrische Störungen, in Folge von organischen Erkrankungen, die mit einer pathologischen Veränderung des Immunsystems einhergehen (Autoimmunkrankheiten, onkologische Erkrankungen, HIV-Infektion/AIDS u. a.) oder für deren Behandlung medikamentöse Immunsuppression erforderlich ist (Transplantationsmedizin, MS-Behandlung u. a.).

\section{Synonym(e)}

Kognitive Spätfolgen bei Kindern mit ausgeheilter Leukämie nach Knochenmarktransplantation, Depressionen bei Tumorpatienten, Depressionen bei MS-Patienten.

\section{Inkubationszeit \\ - Erkrankung 1}

\section{Leitsymptome}

Auffälligkeiten im Verhalten, Aufmerksamkeits- und Lernstörungen (Kinder), Depressionen bei Patienten mit soliden Tumormetastasen, Depressionen bei Patienten mit MS nach Behandlung eines akuten Schubs.

\section{Symptome}

Ausgehend von Langzeituntersuchungen bei Kindern, die erfolgreich von Leukämien geheilt worden waren und später Auffälligkeiten im Verhalten oder Aufmerksamkeits- und Lernstörungen in der Schule zeigten, wurden in einer Pilotstudie ca. 300 Plasmen von 18 Kindern mit Leukämie vor und nach der Transplantation auf BDV untersucht, mit dem Ergebnis, dass mehr als die Hälfte kurz nach Transplantation viele Wochen dauernde Antigenämiephasen durchlief und damit ein signifikant erhöhtes Risiko für die potenzielle Entwicklung einer Lernstörung entwickelt hatte (Greil, Bode, Niethammer, unpubl.). In einer weiteren Studie mit erwachsenen onkologischen Patienten $(\mathrm{N}=55)$, die sich in einem fortgeschrittenen Stadium (IV) mit soliden Tumormetastasen befanden, zeigten Patienten, die eine Major Depression entwickelt hatten $(\mathrm{N}=26)$, einen signifikanten Anstieg von BDV-Antigen und Antikörpern im Plasma im Vergleich zu nicht depressiven Tumorpatienten (Jehn, Pfeiffer, Bode, Possinger et al., unpubl.).

\section{Pathophysiologie}

Starke Antigenämie im Plasma nach medikamentöser Immunsuppression (Leukämiekinder), veränderte
HPA-Achse bei Depressionspatienten mit BDV-Infektion.

\section{Immunantwort \\ - Erkrankung 1}

\section{Differenzialdiagnose}

Jegliche anderen ätiopathogenetisch denkbaren Ursachen für die Ausprägung dieser klinischen Bilder.

\section{Entwicklungsstörungen im Kindesalter \\ - Schlüsselliteratur [1, S86; Scholbach und Bode, un- publ.] \\ BDV-assozierte Entwicklungsstörungen.}

\section{Synonym(e)}

Nicht organische Gedeihstörung (engl.: Non-Organic Failure to Thrive; NOFT) und sonstige Verhaltensauffälligkeiten insbesondere beim Kleinkind (bis 3 Jahre).

\section{Inkubationszeit \\ - Erkrankung 1}

\section{Leitsymptome}

Nahrungsverweigerung, oft kombiniert mit Schreikrämpfen, Gewichtsentwicklung unterhalb der altersgemäßen Perzentile, auffällige Abweichungen vom Normalverhalten.

\section{Symptome}

Deutliche Abneigung gegenüber dem Essen (Ernährung über Magenschlundsonde). Kinder nehmen nicht zu und drohen zu verhungern (immer Hospitalisierung). Im Alterssegment der Ein- bis Dreijährigen waren Nahrungsverweigerung und NOFT hochsignifikant mit BDV-Antigenämie, Immunkomplexen und Antikörpern korreliert. Die bisher als unbehandelbar geltenden Störungen konnten mit Amantadin-Gaben erfolgreich therapiert werden (Scholbach, Bode, Ludwig et al., unpubl.).

Ein bestimmter Prozentsatz von Kindern mit einem Hyperaktivitätssyndrom (ADHS) und Virusbelastung deutet auf ähnliche Zusammenhänge hin.

\section{Pathophysiologie}

Das NOFT-Syndrom hat gravierende Entwicklungsstörungen des Gehirns zur Folge. Beim Hyperaktivitätssyndrom wird vermutet, dass ähnliche, die Entwicklung des ZNS störende Einflüsse, durch verstärkte BDV-Aktivität mit beeinflusst werden könnten. Experimentelle Infektionen von kleinen Nagern, bei denen, wie japanische Forscher zeigen konnten, die Synapsen-Aussprossung und die Funktion des "nerve out growth factors" durch BDV-Infektion inhibiert werden konnten, unterstützen diese Annahme [7].

\section{Immunantwort}

- Erkrankung 1 


\section{Differenzialdiagnose}

Sonstige Agens-bedingte oder Umwelt-verursachte Noxen, die die Entwicklung des Gehirns beeinflussen.

\section{Diagnostik}

\section{Untersuchungsmaterial}

Citratblutproben (ca.10 ml) sind optimal geeignet, vor allem im Plasma, aber auch in Leukozyten, Infektionsparameter zu überwachen. Beim Tier kommt post mortem Gehirnmaterial des limbischen Systems hin$\mathrm{zu}$.

\section{Diagnostische Verfahren}

Die Labor-Diagnostik der BDV-Infektion wurde über Jahrzehnte von der Fluoreszenz-Antikörper Technik beherrscht. Ein negativer Befund schließt aber eine Infektion nicht aus [3]. Neu entdeckte Laborparameter erlauben eine sichere Diagnose [3]. Benötigt werden eine oder mehrere Citratblut-Proben $(10 \mathrm{ml})$, möglichst während akuter Krankheitsepisoden entnommen, aus denen Plasma und weiße Blutzellen getrennt gewonnen werden. Im Plasma werden mit ELISA-Techniken, die auf spezifischen Epitop-definierten monoklonalen Antikörpern basieren [1, S3031] zirkulierende BDV-spezifische Immunkomplexe (CICs) sowie virale Proteine (Plasma-Antigen) und ggf. Antikörper (3 Teste) gemessen. BDV-CICs sind die am häufigsten nachweisbaren Infektionsmarker und eignen sich optimal für Suchtests [3]. In den Blutzellen können zeitweise ebenfalls Virusproteine (intrazelluläres Antigen) sowie Virusnukleinsäure (mit nested RT-PCR) gefunden werden [2]. Bei schweren psychiatrischen Erkrankungen, aber auch bei normalen Blut-(Spender)Proben mit hohen Antigenwerten bei gleichzeitiger CIC-Präsenz kann der BDV-spezifische Nukleinsäurenachweis direkt aus Plasma (Serum) gelingen [3].

Die Diagnostik der humanen BDV-Infektion (die Tierinfektion einschließend) wird gegenwärtig nur von wenigen Forschungslaboratorien im In- und Ausland (Italien, Tschechoslowakei, Ungarn, Iran, China), eine aussagekräftige Serologie unter Einschluss von Antigen und CICs [3], in Deutschland nur von dem unten erwähnten Referenzlabor angeboten.

\section{Befund / Interpretation}

Der Laborbefund kann allein über die quantitativen CIC-Werte erstellt werden. Zusätzlich ist der Antigentest hilfreich. Dies gilt auch für eine präventive Abklärung erhöhter Gesundheitsrisiken bei bislang symptomfrei infizierten Personen (Tieren) mit geschwächter Immunabwehr. Die Antikörpertestung spielt eher eine untergeordnete Rolle und bleibt ohne Aussagewert für Prophylaxe, Prognose und Therapie BDV-assoziierter Krankheitsprozesse. Die drei labordiagnostisch erhobenen Parameter gemeinsam erlauben jedoch eine Prognostik für die Krankheit [3].

\section{Therapie}

\section{Therapeutische Maßnahmen}

Nach tierexperimentellen Untersuchungen an Ratten hat BDV vermutlich einen kompetitiv-inhibierenden oder modulatorischen Effekt auf das Neurotransmitter-Netzwerk im limbischen System [1, S54]. Es ist nicht bekannt, ob die üblichen Psychopharmaka die Aktivität von BDV beeinflussen, weil aktivierte Infektionen in ihrer Gegenwart nachweisbar sind. Die von uns kürzlich entdeckte antivirale (virostatische) Wirksamkeit von Amantadinsulfat (2-4 mg/kg KG/d oral, Einnahmezeit durchschnittlich 12 Wochen), wurde bisher durch zwei offene klinische Studien, sowie eine Placebo kontrollierte Doppelblindstudie an Humanpatienten gestützt [1, S63-64]. Die erfolgreiche Behandlung zahlreicher Pferde mit typischen Symptomen einer BDV-Infektion unterstreicht diese These (mindestens $\mathrm{N}=500$ mit kontrolliertem Verlauf) [1, S42]. Eine beachtliche, über die Behandlungsdauer hinaus anhaltende antidepressive Wirksamkeit (ca. 70 \% Responder) konnte bei BDV-infizierten Patienten mit Major Depression beobachtet werden, die gegenüber konventioneller Medikation bereits weitgehend therapieresistent waren. Die erfolgreiche Behandlung der Manie mit Amantadin (Pilotstudie; [1, S64]) bestärkt die Hypothese, dass hier gleiche (Virus-geschädigte) neurophysiologische Regelmechanismen angesprochen werden. Die antivirale Wirkung von Amantadinsulfat gegen BDV konnte auch in vitro an den verschiedenen Human- und Pferde-Isolaten erfolgreich nachgewiesen werden, nicht jedoch bei Laborstämmen [3].

\section{Resistenz}

BDV ist durch UV, Hitze und die üblichen Desinfektionsmittel (wie die anderen Mononegavirales) leicht zu inaktivieren [7]. Gegen die einzige bisher als spezifisch erkannte antivirale Substanz, Amantadin, sind Wildstämme (nicht Laborstämme) empfindlich. Resistenzen gegen Amantadin (wie bei Influenza-Viren üblich) sind bisher nicht bekannt.

\section{Epidemiologie}

\section{Verbreitung}

BDV ist beim Menschen weltweit verbreitet [1]. Die equine Virusinfektion ist in vielen Ländern Europas und Asiens endemisch, nicht jedoch in Australien (Prävalenz von $<1 \%$ ).

Die Infektionsprävalenz bei gesunden Menschen (d. h. auch Blutspendern) liegt bei 20-30 \%, gegenüber einer Prävalenz von über $90 \%$ bei Akutpatienten mit Major Depression, beides basierend auf dem Nachweis von BDV-CICs [3]. Nicht nur klinische Studien, sondern auch epidemiologische Untersuchungen gesunder Bevölkerungsgruppen (und gesunder Tierbestände) werden durch ein „BDV-CIC“-Screening zukünftig wesentlich erleichtert werden. 


\section{Wirtsbereich / Reservoir}

Das ungemein breite Wirtsspektrum umfasst Pferd, Schaf, Rind, Katze, Hund, Straußenvögel sowie den Menschen. Die neu entdeckten aviären Bornaviren $(\mathrm{ABV})$, die bei Proventrikulärer Dilatationskrankheit (PDD) vorkommen, sind vor allem bei exotischen Vögeln nachgewiesen worden [6]. Das Mammalier-BDV kann experimentell auf zahlreiche Tierspezies übertragen sowie an deren Zellen in Kultur adaptiert werden. In Bezug auf einen Organtropismus in vivo muss die Lokalisation im limbischen System (Gehirn) als Prädilektionsstelle hervorgehoben werden. Bei allen Spezies gibt es aber auch Zielzellen (z. B. weiße Blutzellen) in der Peripherie des Körpers. Über das $\mathrm{Zu}$ sammenspiel von Gehirn- und Blutzell-Virus ist bisher nichts bekannt. Spekulationen zu Reservoiren in der Natur können ausgeschlossen werden. Bei einer 30\%igen Durchseuchung der Menschen und 60\%igen der Pferde Mitteleuropas müssen beide Spezies als natürliche Reservoire angesehen werden.

\section{Risikogruppen}

Bezüglich der Verbreitung von BDV ist keine Prävalenz für bestimmte ethnische Gruppen bekannt. Das Risiko häufiger Virusaktivitätsschübe besteht nach heutigem Wissensstand bei „endogenen“ Affekterkrankungen (mit und ohne genetische Prädisposition) und wird durch zusätzliche Stressoren (besondere persönliche Belastungen) als Einwirkung auf die HPAAchse und herabgesetzte immunologische Resistenz deutlich verstärkt. Parallele BDV-Aktivität mit klinischer Symptomatik konnte bei akuten rekurrierenden „endogenen“ Depressionen gezeigt werden [3]. Neue Aspekte haben sich bei Kindern ergeben mit besonderen Risiken für Entwicklungsstörungen in der Altersgruppe der Ein- bis Dreijährigen [1, S83]. Für onkologische Patienten gibt es erhöhte Risiken sekundärer psychiatrischer Störungen (unpubl.).

$\mathrm{Ob}$ ein Gefährdungspotenzial für Empfänger von Blutplasma besteht, ist strittig, nachdem bei $1 \%$ der Spender zeitweise eine hohe Belastung durch infektiöse BDV-Strukturkomponenten nachgewiesen wurde [3; 1, S91].

\section{Transmission / Vektoren}

Über die natürlichen Übertragungswege von BDV ist wenig bekannt. Ebenso bleibt offen, ob infizierte Tiere ein relevantes Ansteckungsrisiko für den Menschen darstellen. Allerdings muss von der zoonotischen Potenz des Virus ausgegangen werden. Eine mögliche Eintrittspforte stellen die Nasenschleimhäute dar. Bei Mensch und Tier ist die Übertragung Mutter-Kind nachgewiesen $[1$, S84].

Virusausscheidung findet vermutlich während längerer Virusaktivierungsphasen (Antigenämie) statt. Es ist andererseits bekannt, dass die Hauptantigene im Überschuss gebildet werden. Das heißt, dass Antigenämie nicht zwingend mit der Präsenz infektiöser Par- tikel gleichzusetzen ist. Ein positiver Antikörperstatus oder geringe Konzentrationen von CICs im Blut sind vermutlich selten mit Ausscheidung verbunden. Eine Übertragung des Borna-Virus mittels Vektoren kann dagegen ausgeschlossen werden.

Die Gefahr einer iatrogenen Transmission durch Blutspenden (Plasma) muss dringend weiter abgeklärt werden, nachdem in Deutschland und Australien unabhängig bei normalen Blutspenden $1 \%$ mit hoher Antigen- und CIC-Belastung gefunden worden sind, wobei auch Nukleinsäure nachweisbar war. In Australien wurde bei multitransfundierten Patienten ein erhöhtes Maß an BDV-Markern mit Korrelation zur Art der Blutspende gemessen [3, 1 S91].

\section{Prävention / Impfstoffe}

Das Bestehen einer aktivierten Infektion kann in einer einzigen Blutprobe (10 ml Citratblut) über BDV-Immunkomplexe und Antigen im Plasma abgeklärt werden, eine latente Infektion über Antikörper. Für einen sicheren Nachweis/Ausschluss einer BDV-Infektion sind die Untersuchungen mehrerer Parameter während akuter Krankheitsphasen unbedingt empfehlenswert sowie mindestens zwei Untersuchungen im Krankheitsverlauf [3]. Infizierte Patienten können vermutlich von den therapeutischen Interventionsmöglichkeiten durch Amantadin profitieren. Monatliche Blutuntersuchungen sollten die virologische Behandlungseffizienz kontrollieren.

Die Impfung hat sich beim Tier nicht bewährt und steht beim Menschen nicht in Aussicht.

\section{Ausbruchsmanagement}

Gute hygienische Maßnahmen stellen eine angemessene Vorbeugung dar. Neben der Diagnose klinisch Erkrankter sind epidemiologische Untersuchungen zur Erfassung gesunder Träger bei Familienmitgliedern und in Tierbeständen erstrebenswert. Hierdurch können Verbreitungsdaten erhalten, zukünftig Infektketten aufgeklärt und individuell erhöhte Risiken bei symptomfrei Infizierten rechtzeitig erkannt werden. Ein zoonotischer Transfer des Virus von Tier auf Mensch oder vice versa erscheint möglich. Die neuen diagnostischen Verfahren bieten hierzu erstmalig optimale Voraussetzungen.

Als konventionelles eingehülltes Virus ist BDV mit den üblichen Desinfektionsmitteln inaktivierbar.

\section{Meldepflicht}

Das Infektionsschutzgesetz (IfSG) schreibt keine Meldepflicht vor. Die bisher geltende Meldepflicht für die Borna-Krankheit (post mortem) bei Pferden sowie den Nachweis des Erregers bzw. seiner Bestandteile (intra vitam) wurde in der Neufassung der tierseuchenrechtlichen Verordnung vom 11.02.2011 gestrichen. 


\section{Weiterführende Informationen}

\section{Referenzzentren / Expertenlaboratorien}

- Da bisher kein offizielles nationales oder internationales Referenzzentrum existiert, wurden entsprechende Aufgaben, humane und tierische Borna-Virus-Infektionen betreffend, bis Ende 2005 von der Arbeitsgruppe am Robert Koch-Institut (RKI; PD Dr. Liv Bode) und am Institut für Virologie der Freien Universität Berlin (Prof. Dr. H. Ludwig) wahrgenommen. Die umfangreiche Referenzproben- und Datensammlung (Borna-Biobank) wird ab 2011 stufenweise an eine neue Trägerinstitution übergeben. Bei DIAMEDIS (Labormedizin), Dunlopstr. 50, 33689 Bielefeld (Ansprechpartner Univ.-Prof. Dr. H. Ludwig und Dr. A. Kuhlencord) werden die BDV-Diagnostik und ein Konsiliarlabor weitergeführt.

\section{Web-Adressen}

- Habilitationsschrift Bode: http://library.vetmed.fu-berlin. de/resources/global/contents/2654808/bode_habil.pdf

- VDW: http://www.vdw-ev.de

- http://www.diamedis.eu

\section{Schlüsselliteratur}

1. APMIS (2008) The International Berlin Symposium on Bornavirus Infections- from animals to man - 50 years of development (Norrild B, ed.), Suppl 124, 116:14-97

2. Bode L, Zimmermann W, Ferszt R, Steinbach F, Ludwig H (1995) Borna disease virus genome transcribed and expressed in psychiatric patients. Nature Med 1 (3):232236

3. Bode L, Ludwig H (2003) Borna disease virus infection, a human mental-health risk. Clin Microbiol Rev 16 (3):534-545

4. Feschotte C (2010) Bornavirus enters the genome. Nature 463:39-40

5. Horie H, Honda T, Suzuki Y, Kobayashi Y, Daito T, Oshida T, Ikuta K, Jern P, Gojobori T, Coffin JM, Tomonaga K (2010) Endogenous non-retroviral RNA virus elements in mammalian genomes. Nature 463:84-87

6. Kistler AL, Gancz A, Clubb S, Skewes-Cox P, Fischer K, Sorber K, Chiu C Y, Lublin A, Mechani S, Farnoushi Y, Greninger A, Wen CC, Karlene SB, Ganem D, DeRisi JL (2008) Recovery of divergent avian bornaviruses from cases of proventricular dilatation disease: identification of a candidate etiologic agent.Virol J, 5:88 doi:10.1186/ 1743-422X-5-88

7. Lipkin WI, Briese T. Bornaviridae (2007). In: Knipe DM, Howley PM, editors. Field's Virology. 5th edition. Vol 2. Philadelphia, Pa, USA: Lippincott Williams \& Wilkins, pp 1829-1851

8. Ludwig H, Bode L (2000) Borna disease virus: new aspects on infection, disease, diagnosis and epidemiology. Rev sci tech Off int Epiz 19 (1):259-288

\section{Bornholm-Krankheit}

$>$ Coxsackieviren

\section{Borrelien}

\section{Erreger}

LOTHAR ZÖLLER

\section{Erregerspezies}

Borrelia recurrentis, $B$. duttonii, $B$. hispanica, B. crocidurae, $B$. persica, B. caucasica, B. latyschewii, $B$. hermsii, B. turicatae, B. parkeri, B. mazzottii, B. graingeri, $B$. venezuelensis, B. burgdorferi sensu lato, B. burgdorferi sensu stricto, B. garinii, B. afzelii, B. spielmanii, B. lonestari, B. anserina

\section{Taxonomie}

Ordnung: Spirochaetales; Familie: Spirochaetaceae; Genus: Borrelia (weitere Genera in der Familie: Treponema, Spirochaeta, Serpulina, Cristispira, Brachyspira, Brevinema). Prototypspezies des Genus Borrelia ist B. anserina, Erreger der Borreliose bei Vögeln. Das Genus umfasst die folgenden humanpathogenen Spezies ( Tab. 1): (1) B. recurrentis: Erreger des Läuserückfallfiebers, (2) B. duttonii und weitere Borrelia spp.: Erreger des Zeckenrückfallfiebers, (3) B. burgdorferi sensu lato: Erreger der Lyme-Borreliose.

B. burgdorferi s.l. wird heute in mindestens 11 verschiedene Genospezies unterteilt. Davon sind mindestens vier gesichert humanpathogen (B. burgdorferi sensu stricto, B. garinii, B. afzelii, B. spielmanii), wobei die drei erstgenannten mit Abstand die häufigsten Infektionen beim Menschen verursachen. B. valaisiana und B. bissettii sind vermutlich ebenfalls humanpathogen, worauf positive PCR-Befunde aus menschlichen Untersuchungsmaterialien hinweisen. Borrelia lusitaniae wurde nur ein einziges Mal aus menschlichem Untersuchungsmaterial isoliert, nämlich aus der Haut eines portugiesischen Patienten.

Die taxonomische Zuordnung der aus der Schildzeckenart Amblyomma americanum isolierten Spezies B. lonestari, die das im Süden der USA auftretende, als STARI (Southern Tick Associated Rash Illness) bezeichnete Krankheitsbild auslöst, ist noch nicht sicher geklärt. Daneben gehören zum Genus Borrelia einige tierpathogene Borrelia spp. (B. anserina, B. coriaceae).

\section{Historie}

Die erste gut dokumentierte Läuserückfallfieberepidemie trat 1739 in Irland auf. Während des ersten Weltkriegs wurden zahlreiche Ausbrüche in Militär- und Gefangenenlagern beobachtet. Das Zeckenrückfallfieber wurde erstmals 1857 beschrieben. Die Lyme-Borreliose wurde 1975 durch Allan Steere als nosologische Entität definiert, nachdem er eine ungewöhnliche Häufung juveniler Arthritiden in Lyme (Connecticut, USA) epidemiologisch untersucht hatte. Das Erythema migrans war allerdings schon 1909 durch Afzelius beschrieben worden, der auch bereits den ätiologischen Zusammenhang mit Zeckenstichen erkannt hatte. B. burgdorferi wurde erst 1983 durch Willy Burg- 
Tab. 1. Charakteristika der humanpathogenen Borrelia spp.

\begin{tabular}{l|l|l|l} 
B.sp. & Überträger & Hauptreservoir & Verbreitung
\end{tabular}

1. Erreger des Läuserückfallfiebers

\begin{tabular}{|c|c|c|c|}
\hline B. recurrentis & Pediculus humanus ${ }^{1)}$ & Mensch & $\begin{array}{l}\text { Geografisch begrenzte Herde in Ostafrika } \\
\text { (Äthiopien, Sudan), Nord- u. Zentralafrika, } \\
\text { Asien, Südamerika; potenziell weltweit }\end{array}$ \\
\hline \multicolumn{4}{|c|}{ 2. Erreger des Zeckenrückfallfiebers } \\
\hline B. duttonii & Ornithodoros ${ }^{2)}$ moubata & Mensch & Afrika (Zentral-, Ost-, Süd-) \\
\hline B. hispanica & Ornithodoros erraticus & Nager & $\begin{array}{l}\text { Spanien, Portugal, Marokko, Algerien, Tu- } \\
\text { nesien }\end{array}$ \\
\hline B. crocidurae & Ornithodoros erraticus & Nager & $\begin{array}{l}\text { Marokko, Libyen, Ägypten, Iran, Türkei, } \\
\text { Senegal, Kenia }\end{array}$ \\
\hline B. persica & Ornithodoros tholozani & Nager & $\begin{array}{l}\text { Westl. China und Kaschmir bis zum Irak und } \\
\text { Ägypten, GUS-Staaten, Indien }\end{array}$ \\
\hline B. caucasica & Ornithodoros verrucosus & Nager & Kaukasus bis zum Irak \\
\hline B. latyschewii & Ornithodoros tartakowskyi & Nager & Iran, Zentralasien \\
\hline B. hermsii & Ornithodoros hermsii & Nager & Westl. USA \\
\hline B. turicatae & Ornithodoros turicata & Nager & Südwestl. USA \\
\hline B. parkeri & Ornithodoros parkeri & Nager & Westl. USA \\
\hline B. mazzottii & Ornithodoros talaje & Nager & Südl. USA, Mexiko, Zentral- und Südamerika \\
\hline B. graingeri & Ornithodoros graingeri & Nager & Ostafrika \\
\hline B. venezuelensis & Ornithodoros rudis & Nager & Zentral- u. Südamerika \\
\hline
\end{tabular}

3. Erreger der Lyme-Borreliose

\begin{tabular}{l|l|l}
$\begin{array}{l}\text { B. burgdorferi } \\
\text { (sensu lato) }\end{array}$ & Ixodes $^{3)}$ spp. & $\begin{array}{l}\text { Nager, Rehwild, } \\
\text { andere Säuge- } \\
\text { tiere }\end{array}$
\end{tabular}

\begin{tabular}{l|l|l}
$\begin{array}{l}\text { B. burgdorferi } \\
\text { sensu stricto }\end{array}$ & USA, Europa \\
\hline
\end{tabular}

\begin{tabular}{l} 
B. garinii \\
B. afzelii \\
B. spielmanii \\
(B. lusitaniae) ${ }^{4)}$ \\
(B. valaisiana) \\
(B. bissettii) \\
\hline
\end{tabular}

\section{Europa, Asien}

Europa, Asien

Europa

(Südwest)-Europa

Europa, Asien

USA, Europa

\section{Erreger der STARI}

B. lonestari Amblyomma $\quad$ Amp.

${ }^{1}$ Kleiderlaus; ${ }^{2}$ Lederzecken; ${ }^{3}$ Schildzecken; ${ }^{4}$ Spezies in Klammern: Humanpatogenität nicht gesichert 
dorfer im Darm von Schildzecken entdeckt. Der Zusammenhang zwischen Erreger und Krankheitsbild wurde erst serologisch und später durch kulturellen Nachweis der Spirochäten aus Material von Borreliose-Patienten gesichert.

\section{Morphologie}

Schraubenförmige, bewegliche Bakterien, 5-25 $\mu \mathrm{m}$ lang, 0,2-0,5 $\mu \mathrm{m}$ breit. Der Zellwandaufbau entspricht im Prinzip dem gramnegativer Bakterien. In einer Tasche der äußeren Membran befindet sich ein axiales Flagellenbündel. Jeweils 7-30 Flagellen sind an den Enden des Zellleibs in „basal knobs“ verankert, überlappen in der Mitte und verleihen den Spirochäten ihre charakteristische Beweglichkeit. Die Zellen sind nach Giemsa anfärbbar und ungefärbt im Dunkelfeldmikroskop darstellbar.

\section{Genom}

B. burgdorferi besitzt 853 Gene. Zahlreiche Nukleotidund Aminosäuresequenzen von Borrelia spp. sind in den einschlägigen Genbanken niedergelegt und auf folgender Internetseite abrufbar: http://www.ncbi. nlm.nih.gov.

\section{Vermehrung}

Borrelien vermehren sich durch transversale binäre Zellteilung. Die Generationszeit der Borrelien ist lang und beträgt im artifiziellen Medium 8-24 h. Die optimale Inkubationstemperatur beträgt $33^{\circ} \mathrm{C}$. Auf halbfesten Medien lassen sich nach langer Inkubationszeit Mikrokolonien beobachten.

\section{Pathogenität / Virulenz / Antigenvariabilität}

Die äußeren Membranproteine von Borrelien (für B. burgdorferi: Outer surface proteins, Osp, und Variable major protein-like sequence, expressed, VlsE; für Rückfallfieber-Borrelien: Variable major proteins, Vmp) besitzen eine hohe Variabilität. Für B. burgdorfe$r i$ sensu lato wurden dementsprechend über die Definition der verschiedenen Spezies hinaus für die drei in Europa vorkommenden humanpathogenen Spezies sieben verschiedene OspA-Typen beschrieben. Für Rückfallfieber-Borrelien (B. hermsii) wurde gezeigt, dass sich die äußeren Membranproteine (Vmp) während der Infektion im Wirtsorganismus fortlaufend ändern. Offenbar ist dafür ein Gen-Switch verantwortlich, bei dem präexistente $v m p$-Gene von linearen Plasmiden auf ein Expressionsplasmid transferiert werden. Pro Zelle wird nur ein $v m p$-Gen transkribiert. Bis zu 30 verschiedene Serotypen wurden aber als Nachkommenschaft eines einzelnen Organismus beobachtet. Diese Antigene werden in zwei Familien unterteilt, die man als „Variable large proteins (Vlp, $36 \mathrm{kDa}$ )“ bzw. „Variable small proteins (Vsp, $20 \mathrm{kDa}$ )“ bezeichnet. Sie determinieren nicht nur die Immunantwort ( $\triangleright$ Immunantwort) gegen die Spirochäten, sondern auch deren Organtropismus. In ganz ähnli- cher Weise spielt das VlsE eine Schlüsselrolle in der Überlebensstrategie von B. burgdorferi im Wirt. Das Protein unterteilt sich in mehrere Abschnitte: konservierte Bereiche, die als Transmembran-Domänen das VlsE in der Borrelienmembran verankern, sowie variable und invariable Regionen. Die variablen Regionen des VlsE weisen nach außen und werden durch Rekombination ständig variiert, wodurch das angreifende Immunsystem immer wieder veränderte Antigenepitope antrifft. Die invariablen Regionen werden durch die variablen Regionen verdeckt und sind bei lebenden Borrelien dem direkten Zugriff des Immunsystems entzogen.

Die verschiedenen Genospezies von B. burgdorferi haben offenbar einen etwas unterschiedlichen Organtropismus. Während B. burgdorferi sensu stricto vornehmlich mit Arthritiden assoziiert ist, verursacht B. afzelii häufiger Hautsymptome und ist der einzige Erreger, der bei der Acrodermatitis chronica atrophicans gefunden wird. B. garinii wird gehäuft bei der Neuroborreliose gefunden.

\section{Erkrankungen}

1. Rückfallfieber, Läuserückfallfieber, Zeckenrückfallfieber

\section{Inkubationszeit}

5-15 (im Mittel 8) Tage.

\section{Leitsymptome}

Intermittierendes Fieber, Hepatomegalie, Splenomegalie, Purpura.

\section{Symptome}

Nach Ablauf der Inkubationszeit kommt es zu Fieberperioden von 2-9 Tagen Dauer, die sich mit afebrilen Phasen von 2-4 Tagen Dauer abwechseln. Die Zahl der Rückfälle beträgt in der Regel zwischen 1 und 10 . Das Läuserückfallfieber dauert meist zwischen 13 und 16 Tagen, das Zeckenrückfallfieber hält länger an und verläuft schwerer. 5-10 Tage nach der Infektion beginnen die Manifestationen plötzlich mit schwerem Schüttelfrost und Kopfschmerzen. In mehr als der Hälfte der Fälle treten Photophobie, Gelenkschmerzen und Husten auf, bei einem Viertel der Patienten findet man Blutungskomplikationen in Form von Epistaxis oder Purpura. Beim Läuserückfallfieber wird eine ZNS-Beteiligung in $30 \%$, beim Zeckenrückfallfieber in $9 \%$ der Fälle beobachtet. Während der Fieberphasen werden Temperaturen bis $40^{\circ} \mathrm{C}$ entwickelt. Meist finden sich Spleno- und Hepatomegalie sowie die klinischen Zeichen einer hepatozellulären Nekrose. Die Fieberphase endet mit einer Krise, die sich gelegentlich durch ein makulopapulöses Exanthem ankündigt. Ein schwerer Erschöpfungszustand kennzeichnet die Intervallphase zwischen den Fieberschüben. Todesfälle sind beim sporadischen Rückfallfieber selten, aber bei epidemischen Ausbrüchen und entsprechender 
Disposition der betroffenen Bevölkerung können Mortalitätsraten von bis zu 30\% erreicht werden. Als seltenere Komplikationen der Rückfallfieber wurden Milzruptur, gastrointestinale Blutungen, Iritis und Iridocyclitis, Hirnnerven- und periphere Lähmungen sowie Myokarditis beschrieben.

\section{Pathophysiologie}

Nach der Transmission kommt es zu einer massiven Spirochätämie. Die Borrelien invadieren das Gefäßendothel, was zu einer disseminierten intravaskulären Gerinnung und zur Thrombozytopenie führen kann. Einige der Symptome werden durch komplementvermittelte Lyse und durch die Freisetzung von Endotoxinen hervorgerufen.

\section{Immunantwort}

Die durch die $v m p$-Gene kodierten Lipoproteine werden in großer Menge produziert und in der äußeren Membran verankert. Die Immunantwort richtet sich jeweils gegen den dominierenden Serotyp. Durch die Antikörperproduktion kommt es dann zum Verschwinden dieses Serotyps aus dem Blut. Indem sich dann ein anderer Serotyp durchsetzt, kommt es zum Wiederauftreten der klinischen Symptomatik.

\section{Differenzialdiagnose}

Läuse- und Zeckenrückfallfieber sind klinisch nicht voneinander zu unterscheiden. In der epidemischen Situation ist die Diagnose des Läuserückfallfiebers recht eindeutig. Bei der Differenzialdiagnose des Zeckenrückfallfiebers ist in erster Linie an die Malaria und durch Zecken übertragene Rickettsiosen, aber auch an Hepatitis, Leptospirose oder Dengue-Fieber zu denken.

\section{Lyme-Borreliose}

\section{Synonym(e)}

Borreliose, Zeckenborreliose, Lyme-Krankheit.

\section{Inkubationszeit}

Die Inkubationszeit beträgt bei der Lyme-Borreliose 5-48 Tage für das Stadium I, 2-10 Wochen für das Stadium II und Monate bis Jahre für das Stadium III.

\section{Leitsymptome}

Erythema migrans, Neuroborreliose, Fazialisparese, Meningitis, Meningopolyneuroradikulitis, M. Bannwarth, lymphozytäre Pleozytose, Oligoarthritis, LymeArthritis, Acrodermatitis chronica atrophicans, Lymphadenosis cutis benigna, AV-Block.

\section{Symptome}

- Tab. 2 gibt die heute allgemein akzeptierte Stadieneinteilung der Lyme-Borreliose wieder. Das Stadium I, das bei ca. $80 \%$ der Infizierten Tage bis Wochen nach der Inokulation des Erregers auftritt, ist typischerweise gekennzeichnet durch das Erythema mig-

\section{Tab. 2. Stadieneinteilung der Lyme-Borreliose}

\begin{tabular}{|c|c|c|}
\hline \multicolumn{2}{|c|}{ Stadien } & \\
\hline \multirow[t]{2}{*}{ frühe } & $\begin{array}{l}\text { I. lokalisierte } \\
\text { Infektion }\end{array}$ & \\
\hline & $\begin{array}{l}\text { Il. dissemi- } \\
\text { nierte Infek- } \\
\text { tion }\end{array}$ & $\begin{array}{l}\text { Manifestationen } \\
\text { Erythema migrans, un- } \\
\text { spez. Allgemeinsympto- } \\
\text { me, Lymphadenosis cutis } \\
\text { benigna (LABC) } \\
\text { Meningopolyneuroradi- } \\
\text { kulitis (M. Bannwarth), } \\
\text { Fazialisparese, periphere } \\
\text { Mononeuritis, Arthritis/ } \\
\text { Arthralgie (akut), Kardi- } \\
\text { tis, LABC }\end{array}$ \\
\hline späte & $\begin{array}{l}\text { III. persistie- } \\
\text { rende Infek- } \\
\text { tion }\end{array}$ & $\begin{array}{l}\text { Acrodermatitis chronica } \\
\text { atrophicans (ACA), Ar- } \\
\text { thritis (chronisch), Ence- } \\
\text { phalomyelitis, LABC }\end{array}$ \\
\hline
\end{tabular}

rans, eine schmerzlose, zentral abblassende, peripher wandernde, ringförmige Hautrötung, die im Mittel nach vier Wochen spontan abheilt. Es wird in 10-30 \% der Fälle von unspezifischen Allgemeinerscheinungen wie subfebrilen Temperaturen, Kopfschmerzen oder Arthralgien begleitet. Bei der überwiegenden Mehrzahl der Patienten (ca. $90 \%$ ) heilt die Borrelia-Infektion im Stadium I spontan aus. Circa $20 \%$ aller Infizierten erreichen das Disseminationsstadium (II), das Wochen bis Monate nach Beginn der Infektion auftritt. Symptome vonseiten des Zentralnervensystems, der Gelenke oder des Herzens stehen dabei im Vordergrund. Das Vollbild der ZNS-Manifestationen wird als Meningopolyneuroradikulitis (M. Bannwarth) bezeichnet. Häufig finden sich aber nur Fragmente, wie z. B. eine isolierte Hirnnervenlähmung (am häufigsten Fazialisparese) oder eine periphere Mononeuritis. Bei ca. $80 \%$ der Fälle mit ZNS-Manifestationen findet man im Liquor eine lymphozytäre Pleozytose. Die Gelenkbeteiligung ist im Gegensatz zu den Gelenkmanifestationen des Stadiums III passager. Meist handelt es sich um Arthralgien, gelegentlich um akute Monooder Oligoarthritiden. Relativ selten ist die Myokardbeteiligung, die sich in der Regel als akutes AV-Blockbild und klinisch als Schwindel, Synkopen oder Palpitationen manifestiert. Eine typische Manifestation des Stadiums II ist die Lymphadenosis cutis benigna (Borrelienlymphozytom). Es handelt sich um eine gutartige Proliferation des dermalen lymphoretikulären Gewebes, die sich am häufigsten als blaurote, tumorartige, erhabene Infiltration am Ohrläppchen, in der Perimamillar- oder Genitalregion manifestiert. Die Stadien I und II werden wegen der Ähnlichkeit der in ihrem Verlauf zu beobachtenden Immunantwort als Frühstadien, das Stadium III als Spätstadium bezeichnet. Die Erreger erreichen trotz Antikörperbildung verschiedene Organe und können dort persistieren. Das 
Stadium der persistierenden Infektion (III), das Monate bis Jahre nach Infektionsbeginn auftreten kann, wird allerdings nur von einem kleinen Teil der Infizierten ausgebildet $(2-3 \%)$. Es ist gekennzeichnet durch chronische Manifestationen an der Haut (Acrodermatitis chronica atrophicans Herxheimer), an den Gelenken (Lyme-Arthritis) oder - selten - im Bereich des ZNS (progressive Borrelienenzephalomyelitis). Die Arthritiden verlaufen schubweise als chronische Mono- oder asymmetrische Oligoarthritis, bevorzugen Knie- und Ellbogengelenke und gehen oft mit Ergussbildung einher. Die Lyme-Borreliose kann in jedem Krankheitsstadium spontan ausheilen. Jedes klinische Stadium kann im Krankheitsverlauf übersprungen werden, sodass z. B. das Auftreten einer Stadium-III-Manifestation nicht notwendigerweise ein vorangegangenes Erythema migrans oder ein Stadium-II-Symptom voraussetzt. Die Häufigkeit der einzelnen Manifestationen, bezogen auf die Gesamtzahl der Erkrankten, ist daher unterschiedlich und hängt außerdem von der Prädominanz verschiedener Genotypen in unterschiedlichen geografischen Regionen ab (Erythema migrans: 65-75 \%; Lymphadenosis cutis benigna: 1-3\%; Acrodermatitis chronica atrophicans: 1-2 \%; Neuroborreliose: 10-12 \%; Lyme-Arthritis: Europa $8 \%$, USA $30 \%$; Karditis: 0,2-4\%). Darüber hinaus gibt es eine Vielzahl uncharakteristischer Manifestationen, die ebenso wie ein Teil der Hauptsymptome nach klinischen Kriterien nur schwer von anderen Erkrankungen abzugrenzen sind.

\section{Pathophysiologie}

Bei der Lyme-Borreliose reagieren die durch den $\mathrm{Ze}$ ckenstich inokulierten Borrelien mit zahlreichen Wirtsfaktoren. Sie adhärieren an das Bindegewebe und lösen durch die Interaktion mit Makrophagen und die dadurch bedingte Ausschüttung proinflammatorischer Zytokine wie TNF- $\alpha$ und IL- $1 \beta$ eine starke entzündliche Reaktion aus. Durch die entzündungsbedingte Erhöhung der vaskulären Permeabilität gelangen die Erreger ins Gefäßlumen und disseminieren. Über die Mechanismen ihrer Gefäßevasion und des Organtropismus gibt es augenblicklich noch keine Erkenntnisse.

\section{Immunantwort}

Bei der Lyme-Borreliose tritt ungefähr ab der dritten Woche nach Infektionsbeginn eine systemische IgMImmunantwort auf, gefolgt von der IgG-Antikörperbildung etwa ab der sechsten Woche. Im zweiten Stadium sind meist auch IgG-Antikörper vorhanden. Im Stadium III findet man fast immer hohe IgG-Antikörpertiter. IgM-Antikörper lassen sich dann nur noch selten nachweisen. B. burgdorferi besitzt zahlreiche immunologisch relevante Antigene. Die nach ca. 3 Wochen einsetzende Antikörperbildung richtet sich in der Regel zuerst gegen das Flagellenprotein (Flagellin, Molekulargewicht (MW 41.000) und das mit der äußeren Membran assoziierte OspC (MW 21.000). Im Stadium II der Erkrankung werden allmählich auch gegen weitere Proteine Antikörper gebildet. Im Stadium III findet man dann meist Antikörper gegen ein breites Spektrum verschiedener Proteine. Sehr charakteristisch und spezifisch für die späte Immunantwort ist die Reaktion gegen das p83-100. Nicht alle Immunreaktionen sind speziesspezifisch. Verschiedene Borrelia-Proteine weisen Antigenverwandtschaften mit Proteinen anderer Spirochäten oder sogar anderer Bakterienfamilien auf. Eine Borrelia-Infektion kann eine lang anhaltende Immunität hinterlassen, die jedoch nicht sicher vor Reinfektionen schützt. Eine Reinfektion kann z. B. durch einen anderen Genotyp von B. burgdorferi erfolgen.

\section{Differenzialdiagnose}

Die Lyme-Borreliose ist aufgrund ihrer mannigfaltigen Symptome von zahlreichen anderen Erkrankungsbildern abzugrenzen. So ist das Erythema migrans nicht selten von einer allergischen Reaktion auf den Zeckenspeichel $\mathrm{zu}$ unterscheiden. In letzterem Fall liegt starker Juckreiz vor, die zentrale Abblassung fehlt, und der Umfang der Läsion bleibt meist unter $5 \mathrm{~cm}$.

Insbesondere bei der Lyme-Arthritis ist die Differenzialdiagnose zu Erkrankungen des rheumatischen Formenkreises oft nicht einfach, da ein positiver Antikörpernachweis eine zwar notwendige, aber nicht hinreichende Bedingung für die Diagnose darstellt. Wichtig ist es daher, die Ausschlussdiagnostik für klinisch ähnliche Krankheitsbilder wie die reaktive Arthritis sorgfältig durchzuführen.

Die Diagnose einer Lyme-Borreliose ist letztlich immer klinisch unter Beachtung der veröffentlichten (z. B. MIQ > Diagnostik) Falldefinitionskriterien, die klinische und labordiagnostische Befunde einschließen, zu stellen.

\section{Diagnostik}

\section{Untersuchungsmaterial}

Rückfallfieberborreliosen

Direktnachweis: EDTA-Blut oder Ausstrich auf Objektträger.

Serologie: Vollblut ohne Zusätze oder Serum.

\section{Lyme-Borreliose}

Kultureller Erregernachweis und PCR: geeignete Untersuchungsmaterialien sind Liquor sowie Haut-, Gelenk- oder Synovia-Bioptate.

Serologie: Vollblut ohne Zusätze oder Serum.

\section{Diagnostische Verfahren}

\section{Rückfallfieberborreliosen}

Direktnachweis im Blut: Methode der Wahl; In der febrilen Phase lassen sich in gefärbten (Giemsa, MayGrünwald, Wright) Blutausstrichen oder dunkelfeldmikroskopisch in Nativpräparaten Borrelien nachweisen, ggf. nach Anreicherung durch Zentrifugation. 
Kultur: Borrelien lassen sich in vivo (Nager) oder in vitro (Barbour-Stoenner-Kelly (BSK)-Medium) anzüchten. Nachteil der diagnostischen Kultivierung ist die lange Generationszeit der Keime, die eine Bebrütung über mehrere Wochen erforderlich macht.

Antikörpernachweis: Antikörper gegen Rückfallfieber-Borrelien lassen sich am zuverlässigsten mit dem Indirekten Immunfluoreszenztest nachweisen. Da aber nicht von allen Borrelia spp. Antigene zur Verfügung stehen, sind die Tests nicht sehr empfindlich. Eine akute Infektion wird anhand eines IgG-Titeranstiegs oder hilfsweise eines über einen definierten Grenzwert hinaus erhöhten Einzeltiters diagnostiziert.

\section{Lyme-Borreliose}

Mikroskopische Verfahren: Die dunkelfeldmikroskopische Untersuchung von Nativmaterial eignet sich zum Nachweis von Borrelien im Zeckendarm. In Gewebsmaterial können die Erreger durch immunhistologische Färbung mit monoklonalen Antikörpern oder mithilfe der Silberfärbung dargestellt werden. Die Methoden besitzen aber nur eine sehr geringe Sensitivität. Sie sind für die Routinediagnostik an $\mathrm{Pa}$ tientenproben ungeeignet.

Kultur: Zwar können Borrelien in vitro in speziellen Medien angezüchtet werden, doch ist die Empfindlichkeit der Kultur bei Anzucht aus Patientenmaterial nur gering. Häufig lassen sich die Erreger erst nach mehrwöchiger Bebrütung und mehrfacher Blindpassage nachweisen. Die besten Ergebnisse erhält man, wenn das Untersuchungsmaterial (z. B. Liquor) sofort nach der Entnahme in das Medium verimpft wird. Als Routineverfahren ist die Kultur wenig geeignet.

PCR: Die Polymerasekettenreaktion ist im Hinblick auf die Sensitivität etwa der Kultur äquivalent, aber der Serologie unterlegen. Deutliche Sensitivitätsvorteile gegenüber der Kultur weist die PCR lediglich bei der Untersuchung von Gelenk- bzw. Synovia-Bioptaten auf. Diagnostisch ist sie nur bei speziellen Indikationen anzuwenden. So kann ein positiver IgG-Antikörper-Nachweis durch eine positive PCR aus einem Gelenk- oder Synovia-Bioptat mit der klinischen Diagnose einer Lyme-Arthritis assoziiert werden. Nicht empfohlen wird die PCR aus Urin.

Serologie/Antikörper-Nachweis: Die Labordiagnostik der Infektion durch B. burgdorferi beruht im Wesentlichen auf dem Nachweis spezifischer Antikörper. Als Testmethoden werden heute vor allem Enzymimmuntests (ELISA) und der Immunblot eingesetzt. Gesamtantigene von Borrelia spp., Detergenzien-Extrakte und rekombinante Proteine werden in den Tests als Antigene verwendet. Die Möglichkeit von Kreuzreaktionen ist bei den verschiedenen Antigenen unterschiedlich stark ausgeprägt und bei der Interpretation der Testergebnisse zu berücksichtigen. Beim Immunblot fließen die diagnostische Sensitivität und Spezifität der einzelnen als Banden dargestellten reaktiven Proteinantigene in die Interpretation ein, die nach de- finierten Regeln erfolgt. Die Verwendung definierter rekombinanter Antigene beim Immunblot erleichtert dessen Interpretation. Zum Nachweis der Neuroborreliose werden Liquor-/Serum-Paare mit den oben genannten Methoden untersucht, um eine intrathekale Antikörperproduktion gegen B. burgdorferi nachzuweisen.

\section{Befund / Interpretation}

Die Borreliose-Serodiagnostik wird als Stufendiagnostik durchgeführt, bei der zunächst ein IgG- und ein IgM-ELISA als Screeningtests und bei positivem Ergebnis ein IgG- und ein IgM-Immunblot als Bestätigungstests eingesetzt werden. Das Gesamtergebnis hat bei Einhaltung dieser Vorgehensweise und bei optimaler Testeinstellung einen hohen prädiktiven Wert. Ein positiver Antikörpernachweis ist aber nicht gleichbedeutend mit der klinischen Diagnose einer LymeBorreliose. Da IgG- wie auch IgM-Antikörper nach zurückliegender - ausreichend behandelter oder spontan ausgeheilter Infektion - langfristig persistieren können, kann eine Assoziation mit der beim Patienten bestehenden Symptomatik nur nach klinischen Kriterien erfolgen. Expertengruppen haben dazu Empfehlungen in Form von Falldefinitionskriterien veröffentlicht (EUCALB Homepage und [1]). $\mathrm{Zu}$ beachten ist auch, dass der Antikörpernachweis bei Patienten mit kurzer Krankheitsdauer noch negativ sein kann. Ein klinisch eindeutiges Erythema migrans ist auch bei negativer Serologie diagnostisch und stellt eine Therapieindikation dar.

\section{Therapie}

\section{Therapeutische Maßnahmen}

\section{Rückfallfieberborreliosen}

Trotz einer breiten in-vitro-Sensibilität gegenüber zahlreichen Antibiotika sind Tetrazykline Mittel der Wahl für die antibiotische Behandlung (z. B. Tetrazyklin $4 \times 500 \mathrm{mg}$ p.o. über 7-10 Tage). Dabei kann es zu schweren Jarisch-Herxheimer-Reaktionen kommen.

\section{Lyme-Borreliose}

$B$. burgdorferi ist in vitro gegenüber einer Reihe von Antibiotika hochempfindlich. Bei Therapiestudien wiesen jedoch für die verschiedenen Stadien der Borreliose unterschiedliche Regime die jeweils beste Wirksamkeit auf. Mittel der Wahl für die Behandlung der Borreliose im frühen Stadium sind Doxycylin in einer Dosierung von $2 \times 100 \mathrm{mg} / \mathrm{d}$ oder Amoxycillin $(3 \times 500-1000 \mathrm{mg} / \mathrm{d})$, jeweils über $14-21$ Tage. Alternativen sind Penicillin V $(3 \times 1,0-1,5$ Mio E) oder Cefuroximaxetil $(2 \times 500 \mathrm{mg} / \mathrm{d})$. Bei Kindern unter 8 Jahren wird Amoxycillin (25-50 mg/kg KG über 1421 Tage) gegeben. Bei Penicillinallergie oder Tetrazyklinunverträglichkeit kann auch auf Roxithromycin oder Azithromycin ausgewichen werden. Bei der Neuroborreliose wird mit Cephalosporinen der dritten Generation (z. B. Ceftriaxon $1 \times 2 \mathrm{~g} / \mathrm{d}$ oder Cefotaxim 
$3 \times 2 \mathrm{~g} / \mathrm{d}$ über 14-30 Tage), alternativ mit Doxycyclin $(2 \times 100 \mathrm{mg} / \mathrm{d}$ über $14-30$ Tage $)$ oder Penicillin G (20 Mio E/d über 14-30 Tage) behandelt, bei der Lyme-Arthritis gibt man primär Doxycyclin $(2 \times 100 \mathrm{mg} / \mathrm{d}$ über 14-30 Tage), alternativ Amoxicillin $(3 \times 500-1000 \mathrm{mg} / \mathrm{d}$ über 14-30 Tage) oder Ceftriaxon $(1 \times 2 \mathrm{~g} / \mathrm{d}$ über 14-30 Tage).

Das Auftreten Herxheimer-ähnlicher Reaktionen im Initialstadium der intravenösen Therapie mit Cephalosporinen ist beschrieben.

\section{Resistenz}

Borrelien sind primär resistent gegen Aminoglykoside, Trimethoprim/Sulfamethoxazol und Chinolone. In vitro sind Makrolide und Drittgenerations-Cephalosporine, gefolgt von Doxycyclin und Amoxycillin am effektivsten.

\section{Epidemiologie}

\section{Verbreitung}

Die durch Läuse übertragene Rückfallfieberborreliose tritt epidemisch auf, meist im Zusammenhang mit dem engen Zusammenleben von Menschen unter schlechten hygienischen Bedingungen (z. B. Flüchtlingslager), während das endemische Vorkommen charakteristisch ist für die durch Zecken übertragenen Borreliosen. Das Läuserückfallfieber kommt nur noch in begrenzten geografischen Regionen der Erde vor. Demgegenüber sind die durch Zecken übertragenen Borreliosen weit verbreitet ( $>$ Tab. 1). Die Lyme-Borreliose ist die häufigste durch Zecken übertragene Erkrankung in der nördlichen Hemisphäre. In den USA ist nur B. burgdorferi s.s. endemisch, während in Europa die Spezies B. burgdorferi s.s., B. garinii, B. afzelii und B. spielmanii vorkommen. In Europa liegt die Inzidenz der Lyme-Borreliose schätzungsweise zwischen 16 und 140/ 100.000 Einwohner und Jahr ( $\triangleright$ Abb. 1 und $>$ Abb. 2).

\section{Wirtsbereich / Reservoir}

Läuserückfallfieber

Der Mensch ist durch die strikte Wirtsspezifität des Vektors (Pediculus humanus) einziger Wirt.

\section{Zeckenrückfallfieber und Lyme-Borreliose}

Die Erreger haben einen großen Wirtsbereich unter wild lebenden Tieren, insbesondere Nagern. Ausnahme ist $B$. duttonii. Für diese Spezies scheinen Mensch und Zecke die einzigen Wirte zu sein. Zecken und tierische Reservoirwirte unterhalten den Infektionszyklus der Borrelien und damit die Naturherde. Die Zecken selbst sind dabei ebenfalls als Reservoir wirksam, da die Keime transstadiell und transovariell weitergegeben werden. In Endemiegebieten sind bis zu 40\% der Zecken mit B. burgdorferi infiziert.

\section{Risikogruppen}

Läuserückfallfieber

Menschen in Lagern.

\section{Zeckenrückfallfieber, Lyme-Borreliose}

Ein erhöhtes Erkrankungsrisiko entsteht durch eine besondere Exposition gegenüber Zecken in den Endemiegebieten. Daraus lassen sich auch berufliche Risikogruppen ableiten (z. B. Waldarbeiter).

\section{Transmission / Vektoren \\ Zeckenrückfallfieber}

Die Blutmahlzeit dauert bei Weichzecken nur kurze Zeit und die Borrelien werden (im Gegensatz zu B. burgdorferi) nach dem Stich innerhalb von Minuten auf den Wirt übertragen. Die Übertragungsmöglichkeit durch Bluttransfusion ist nachgewiesen.

\section{Läuserückfallfieber}

Die Übertragung erfolgt durch Kontamination der Stichwunde beim Zerquetschen der infizierten Laus (z. B. beim Kratzen). Da sich die Spirochäten in der Hämolymphe befinden, erfolgt die Übertragung nicht direkt beim Stich der Laus.

\section{Lyme-Borreliose}

B. burgdorferi wird durch den Zeckenstich übertragen, allerdings erst Stunden nach Beginn des Saugaktes der Zecke. Durch den Kontakt mit dem aufgenommenen Blut kommt es bei den im Mitteldarm der Zecke befindlichen Borrelien zu einem Switch der Osp-Produktion von OspA, das die Adhärenz an das Darmepithel vermittelt, zu OspC. Dadurch gelingt es den Spirochäten, aus dem Darm aus- und über die Hämolymphe in die Speicheldrüse einzuwandern. Über den Speichel der Zecke gelangen die Erreger dann in die Stichwunde. Selten erfolgt die Übertragung vermutlich auch durch den Stich von Fliegen, Mücken, Flöhen.

\section{Prävention / Impfstoffe}

Für B. burgdorferi wurde gezeigt, dass Antikörper gegen das OspA vor einer Infektion schützen können. Die hohe Osp-Variabilität stellt allerdings ein Problem für die Impfstoffentwicklung dar. Ein Impfstoff gegen $B$. burgdorferi auf der Basis des gentechnisch hergestellten OspA der Spezies B.b. sensu stricto war in den USA unter dem Handelsnamen Lymerix ${ }^{\circledR}$ zugelassen, wurde aber 2003 vom Hersteller zurückgezogen. Aufgrund umstrittener Nebenwirkungen war der Impfstoff kaum noch angewendet worden. Insbesondere für Europa, wo die Borrelia-Stämme überdies eine starke OspA-Heterogenität aufweisen, ist derzeit kein Impfstoff in Sicht. Als einzige Präventionsmaßnahme verbleibt daher die Expositionsprophylaxe. Die Gefahr, Zecken zu akquirieren, besteht bei Freilandaufenthalten mit Kontakt zu bodennahen Pflanzen (hohes Gras, Kraut, Farne, Strauchwerk). Das Tragen geschlossener Kleidung und die Anwendung von Repellentien kann das Risiko deutlich mindern. Nach entsprechender Exposition sollte der Körper sorgfältig nach Zecken abgesucht werden. Bei Zeckenbefall muss 


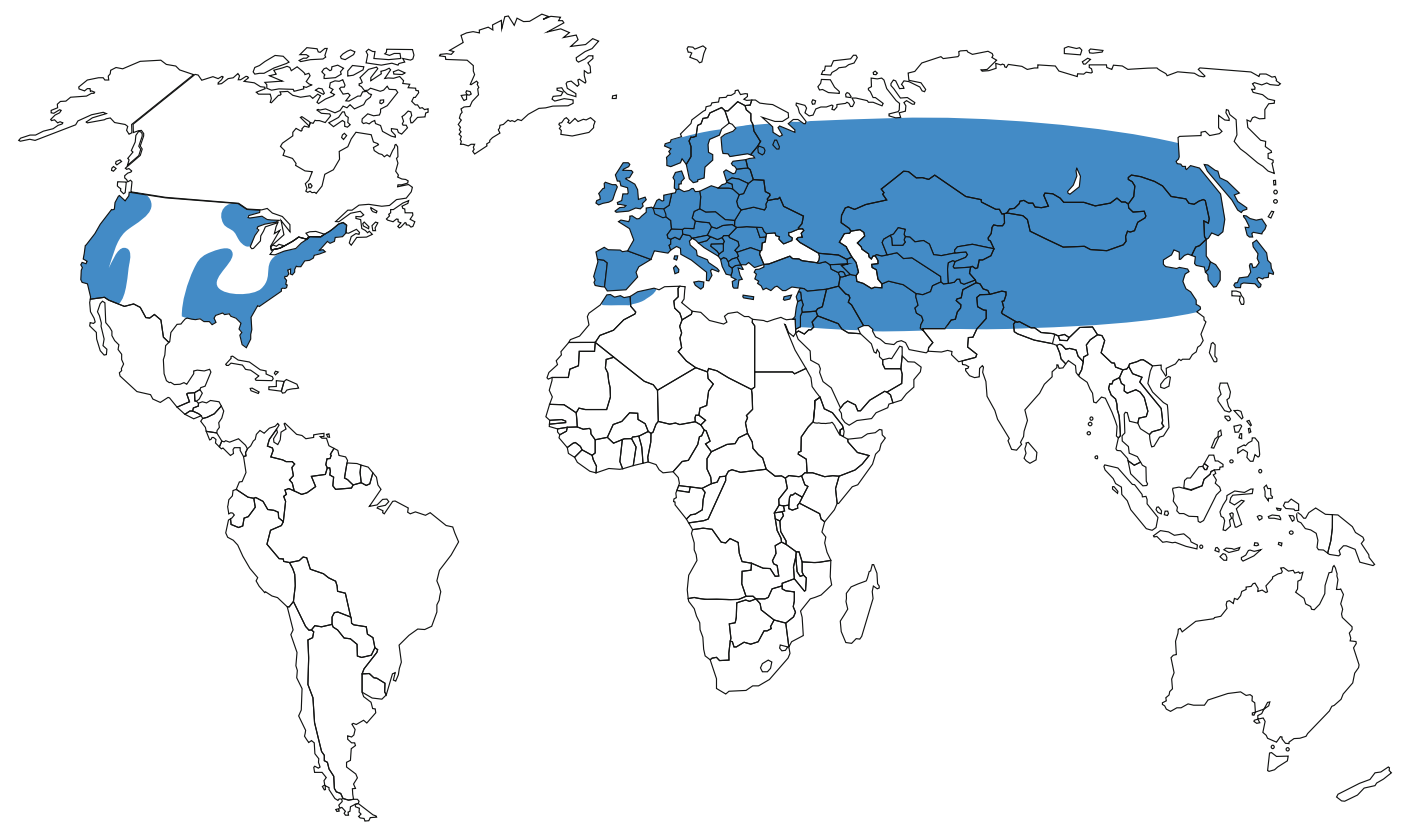

- Abb. 1. Geografische Verbreitung der Lyme-Borreliose

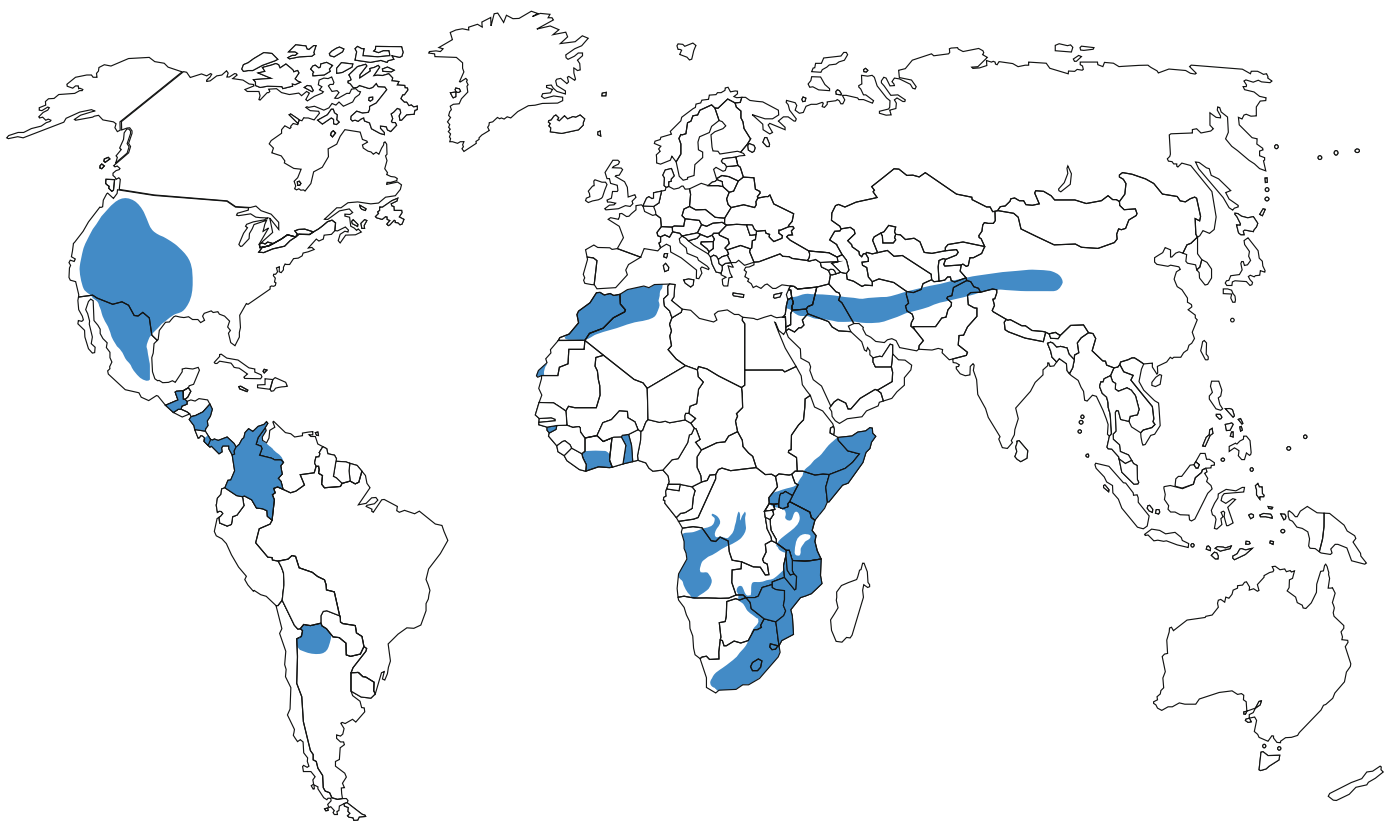

- Abb. 2. Geografische Verbreitung des Zeckenrückfallfiebers

die Zecke umgehend entfernt und die Wunde desinfiziert werden.

\section{Ausbruchsmanagement}

Läuserückfallfieber

Entlausung, Imprägnierung der Kleidung Gefährdeter mit Insektiziden, Verbesserung der Lebensbedingungen.

\section{Zeckenrückfallfieber, Lyme-Borreliose}

Vermeidung der Zeckenexposition in Naturherden, Tragen geschlossener Kleidung in Zeckenhabitaten, 
Anwendung von Zeckenrepellentien auf der Basis von DEET.

\section{Meldepflicht}

Der Nachweis von $B$. recurrentis ist nach $\$ 7$ Infektionsschutzgesetz meldepflichtig.

Für die Lyme-Borreliose besteht nach dem Infektionsschutzgesetz keine Meldepflicht. Allerdings haben einige Bundesländer eine eigene Meldepflicht eingeführt.

\section{Weiterführende Informationen}

\section{Referenzzentren / Expertenlaboratorien}

- Nationales Referenzzentrum für Borrelien (Leitung: Dr. Volker Fingerle),

- Ansprechpartner: Dr. V. Fingerle, Bayerisches Landesamt für Gesundheit und Lebensmittelsicherheit, Veterinärstr. 2, 85764 Oberschleißheim, Tel. 089/31560-870, Telefax 089/31560-844, Email: volker.fingerle@lgl.bayern.de

\section{Web-Adressen}

- EUCALB Home Page (European Union Concerted Action on Lyme Borreliosis): http://meduni09.edis.at/ eucalb/cms/index.php

- MiQ 12/2000: Quality Standards for the Microbiological Diagnosis of Infectious Diseases: http://nrz-borrelien. lmu.de/miq-lyme/index.html

- NRZ Borrelien: http://www.lgl.bayern.de/gesundheit/ nrz_borrelien/

\section{Schlüsselliteratur}

1. Cunha BA (Hrsg) (2000) Tickborne Infectious Diseases. Diagnosis and Management. Marcel Dekker, New York

2. Johnson RCB (1998) In: Collier L, Balows A, Sussmann M (Hrsg) Topley \& Wilson's Microbiology and Microbial Infections, vol 2, $9^{\text {th }}$ edn. Arnold, London, pp1277-1286

3. Oschmann P, Kraicy P, Halperin J, Brade V (Hrsg) (1999) Lyme-Borreliosis and Tick-borne Encephalitis. Uni-Med Verlag, Bremen

4. Wilske B, Zöller L, Brade V, Eiffert U, Göbel UB, Stanek G (2000) Lyme-Borreliose. In: Mauch H, Lütticken R (Hrsg), MIQ (Qualitätsstandards in der mikrobiologisch-infektiologischen Diagnostik) 12. Urban \& Fischer, München

\section{Borreliose}

Borrelien

\section{Botulismus}

$\checkmark$ Clostridium botulinum

\section{Branhamella catarrhalis}

\footnotetext{
- Moraxella catarrhalis
}

\section{Brasilian Purpuric Fever (BPF)}

Haemophilus aegyptius

\section{Brasilianisches Fleckfieber}

Rickettsien

\section{Breakbone Fever}

$>$ Dengueviren

\section{Brucella}

HANS-GÜNTHER SONNTAG

\section{Erreger}

\section{Synonym(e)}

Erreger des Malta-, Gibraltar-, Mittelmeer-Fiebers oder undulierenden Fiebers für Brucella melitensis sowie Erreger der Bang'schen Krankheit oder des Morbus Bang für Br. Abortus.

\section{Erregerspezies}

Offiziell anerkannte Spezies sind Br.melitensis (Hauptwirt Schaf und Ziege), Br. abortus (Hauptwirt Rind), Br. suis (Hauptwirt Schwein), Br. ovis (Hauptwirt Schaf), Br. neotomae (Hauptwirt Wüstenratte) und Br. canis (Hauptwirt Hund). Neue Spezies wie Br. ceti und Br.pinnepedialis, konnten bei Delphinen und anderen Meeressäugern, Br. microti im Microtus arvalis und $\mathrm{Br}$ inopinata in einem Brustimplantat nachgewiesen werden,

\section{Taxonomie}

Derzeit wird die Gattung Brucella taxonomisch teilweise noch der Familie Brucellaceae zugeordnet. Aufgrund von DNA-Hybridisierungen wird neuerdings vorgeschlagen in der Gattung nur noch die Spezies $B r$. melitensis aufzuführen, während die bisher bekannten Spezies, inkl. Biotypen, als deren Biovare gelten sollen.

\section{Historie}

Der britische Militärarzt D. Bruce isolierte 1897 auf Malta aus der Milz eines an den Symptomen von Malta-Fieber verstorbenen Soldaten Bakterien, die als „Micrococcus melitensis“ bezeichnet wurden. 1897 gelang in Dänemark dem Veterinärpathologen B. Bang aus Untersuchungsmaterial von abortierten Rinderfeten die Anzüchtung von Bakterien, die als „Bacillus abortus infektiosus" bezeichnet wurden. Beide Erreger erwiesen sich in Vergleichsuntersuchungen des amerikanischen Bakteriologin A. Evans (1918) als nahezu identisch und daher erfolgte ihre Umbenennung in Brucella melitensis und Br. abortus sowie deren Ein- 
ordnung in die Gattung Brucella. Eine Erweiterung der Gattung erfolgte durch Br. suis, erstmals 1914 in den USA von J. Traum aus abortierten Schweinefeten isoliert und 1970 durch $\mathrm{Br}$. neotomae, bislang nur bei amerikanischen Wüstenratten gefunden. Sowie durch Br. ovis (einziges Erregerreservoir Schaf) und seit 1978 Br. canis (Hauptwirt Hund) als weitere offiziell anerkannte eigenständige Brucella-Spezies.

\section{Morphologie}

Brucellen sind gramnegative, unbewegliche, kokkoide oder kurze Stäbchen (Größe: 0,5-0,7 × 0,6-1,5 $\mu \mathrm{m}$ ) ohne Kapsel und Sporen, die einzeln sowie gelegentlich paarweise oder in kurzen Ketten bzw. in kleinen Anhäufungen vorliegen.

\section{Genom}

Der Prozentsatz Guanin und Cytosin (GC \%) beträgt bei Brucellen 57,9 \% und das Molekulargewicht des DNA-Genoms 2,61 $\times 10^{9}$. Die Genome aller genannten Spezies sind sequenziert (http://www.genomesonline. org)

\section{Vermehrung}

Die Vermehrung von Brucella-Spezies erfolgt intrazellulär. Nach neueren Untersuchungen (Science 2007) wird die Reproduktion von Brucella besonders durch die blaue Phase des natürlichen Lichts angeregt und die Infektiosität gefördert.

\section{Pathogenität, Virulenz, Antigenvariabilität}

Nur die S-Formen von Brucellen (Br. abortus, Br. melitensis, Br. suis) besitzen ein Lipid A, das in seiner endotoxischen Wirkung dem der Enterobacteriaceae entspricht. Br. abortus und Br. melitensis weisen die charakteristischen Oberflächenantigene „A“ und „ $\mathrm{M}$ “ auf. Diese sind in unterschiedlicher Menge in allen S-Formen von Brucellen vorhanden. Raue Brucellen-Spezies, wie Br. ovis und Br. canis sowie die R-Formen von $\mathrm{Br}$. abortus, Br. melitensis und Br. suis besitzen keine "A“- und „M“-Antigene, sondern enthalten andere Antigene auf LPS-Basis.

Ferner liegen in der Zellwand von Brucellen antileukozytär wirkende Faktoren vor. Diese stellen einen Schutz gegen intrazelluläre Bakterizide dar und ermöglichen das Überleben und die Vermehrung von Brucellen in Leukozyten und Makrophagen

\section{Erkrankung}

Brucellose

\section{Synonym(e)}

Malta-Fieber, Mittelmeer-Fieber, Bang'sche Krankheit, Morbus Bang.

\section{Inkubationszeit}

Die Inkubationszeit beträgt 1-3 Wochen; nach Infektionen mit Br. melitensis u. U. bis zu 3 Monaten.

\section{Leitsymptome}

Undulierendes Fieber (morgens subfebril, abends $>39^{\circ} \mathrm{C}$ ).

\section{Symptome}

Die klinischen Erscheinungsbilder der durch die verschiedenen Brucella-Spezies verursachten Brucellosen sind beim Menschen weitgehend ähnlich, obwohl sie sich sehr vielgestaltig darstellen können. Den schwersten Krankheitsverlauf zeigen Infektionen mit Br. melitensis (syn. Malta-Fieber, Mittelmeer-Fieber). Etwas milder gehen Infektionen mit Br. suis einher, dann folgen in der Schwere Br-abortus-Infektionen (syn. Bang'sche Krankheit, Morbus Bang) und deutlich milder Br. canis. Br. neotomae, Br. ovis, Br. ceti und Br.pinnepedialis sind beim Menschen als Krankheitserreger noch nicht nachgewiesen worden.

Prodromalerscheinungen äußern sich in Form von Appetitlosigkeit, Übelkeit, Müdigkeitsgefühl, Fieber, Nachtschweiß, Kopf-, Gelenk- und Muskelschmerzen oder gastrointestinalen Beschwerden. Schwellungen der Leber, Milz oder tastbare Lymphknoten können auftreten. Für den weiteren Krankheitsverlauf ist eine normale oder subfebrile Morgentemperatur charakteristisch, die sich mit hohen Abendtemperaturen $\left(39^{\circ} \mathrm{C}\right.$ und höher), verbunden mit Schüttelfrost, abwechselt. Dieses undulierende Fieber, das einen wellenförmigen Verlauf von 7-21 Tagen Dauer, unterbrochen von 2bis 5-tägigen fieberfreien Intervallen, zeigt, ist bei Infektionen mit $\mathrm{Br}$. melitensis besonders ausgeprägt. Etwa $5 \%$ der Brucellose-Patienten erleiden einen Rückfall, der noch 2 Jahre nach stattgefundener Erkrankung auftreten kann.

Bei einer Krankheitsdauer von mehr als 1 Jahr (chronische Brucellose) kommt es zu Organmanifestationen, die mit uncharakteristischen Symptomen, aber i. d. R. mit pathologischen Veränderungen einhergehen: Hepatitis, Orchitis, Pyelonephritis sowie Arthritiden, insbesondere Spondylarthritis. Auch chronische Bronchopneumonie, Endokarditis oder Meningoenzephalitis (Neurobrucellose) sind möglich. Alle diese Krankheitserscheinungen sind häufig begleitet von Depressionen und/oder Schlafstörungen.

\section{Pathophysiologie}

Nichts bekannt.

\section{Immunantwort}

Nach Infektion kommt es zur Ausbildung sowohl einer humoralen als auch zellulären Immunität. Der IgM-Antikörperspiegel kann längere Zeit bestehen bleiben. Nach antibiotischer Behandlung verschwinden die IgG-Antikörper rasch, allerdings ist deren Nachweis ein Hinweis für das Vorliegen einer aktiven Infektion.

\section{Differenzialdiagnose}

Im akuten Stadium sind grippaler Infekt, Ornithose, 
Q-Fieber, Typhus, Paratyphus, Malaria, Miliartuberkulose, Kala-Azar und infektiöse Mononukleose differenzialdiagnostisch auszuschließen. Im chronischen Stadium ist differenzialdiagnostisch u.a. an Virusmeningoenzephalitis, rheumatisches Fieber, Endokarditis lenta, Kollagenose, Lymphogranulomatose, Morbus Marie-Strümpell-Bechterew, Wirbelsäulen-Tuberkulose, Spondylose oder Hepatitis zu denken.

\section{Diagnose}

\section{Untersuchungsmaterial}

Citratblut, Gelenk-, Leberpunktat.

\section{Diagnostische Verfahren}

Wichtige diagnostische Hinweise geben vor allem Antworten auf die Fragen nach beruflichem oder akzidentiellem Kontakt vorwiegend mit landwirtschaftlichen Nutztieren (Rind, Schaf, Ziege, Schwein) sowie nach Genuss von Rohmilch oder daraus hergestellten Produkten (z. B. Schaf-, Ziegenkäse), insbesondere bei Aufenthalten im Ausland ( $\triangleright$ Epidemiologie).

Kultur: Im akuten Stadium mit Citratblut (wichtig mehrfache Probenentnahmen während eines Fieberanfalls oder einer Fieberperiode, BACTEC 9240-System), ferner Sternal-, Gelenkspunktat, exzidierte Lymphknoten sowie Biopsiematerial von Leber, Milz oder Knochenmark. Im chronischen Krankheitsstadium erweist sich der kulturelle Erregernachweis als ziemlich aussichtslos. Die Anzüchtung von Brucellen erfolgt unter Verwendung von flüssigen Nährböden (Anreicherung), wie z. B. Brain-Heart-Infusion-, Tryptose- oder Albimi-Bouillon sowie von festen Nährböden, wie z. B. Tryptose-Blut-, Tryptose-Soya- oder Albimi-Agar. Die Anreicherungen werden bis zu 4 Wochen bei $37^{\circ} \mathrm{C}$ in $5-10 \%$ iger $\mathrm{CO}_{2}$-Atmosphäre sowie aerob bebrütet, in regelmäßigen Abständen auf feste Nährböden ausgestrichen und diese bis zu 8 Tage (in 5-10 \%iger $\mathrm{CO}_{2}$-Atmosphäre bei $37^{\circ} \mathrm{C}$ sowie aerob) bebrütet. Brucellen-PCR aus Blut.

Identifizierung: Langsam wachsende Kolonien (3-5 Tage), die eine positive Oxydase- sowie rasche UreaseReaktion (Ausnahme Br. ovis), eine negative Fermentation von Glukose und Laktose zeigen, sowie in der Objektträgeragglutination mit Brucella-Antiserum positiv reagieren, gelten als verdächtig für Brucellen. Deren endgültige Spezies-Differenzierung bleibt i. d. R. entsprechend eingerichteten Laboratorien vorbehalten, ebenso die Bestimmung der Biovare, die von epidemiologischem Interesse ist.

Antikörpernachweis: Für die Brucellen-Serodiagnostik stehen mehrere Untersuchungsverfahren zur Verfügung. In der Routine wird am häufigsten die Langsamagglutination (Widal-Reaktion) im Röhrchen oder das Mikrotiterverfahren eingesetzt. Ein Agglutinationstiter von 1:160 oder höher bzw. ein 4-facher Titeranstieg in Wiederholungsuntersuchungen, jeweils im Abstand von 10-14 Tagen, erlaubt eine diagnostische Aussage. Bei chronischen Organbrucellosen oder latenten Infektionen sind Agglutinationstiter von 1:80 bis herunter zu 1:10 oder sogar ein negativer Ausfall der Langsamagglutination möglich.

Die Komplementbindungsreaktion führt ab der 3.-4. Krankheitswoche zu positiven Resultaten und wird bei rechtzeitig begonnener Therapie früher negativ als die Langsamagglutination. Liegt eine chronische Brucellose vor, so fällt die Komplementbindungsreaktion positiv aus, obwohl in solchen Fällen die Langsamagglutination zu negativen Ergebnissen führt.

Zunehmend wird auch die ELISA-Technik in der Serodiagnostik der Brucellose eingesetzt. Mit dieser Untersuchungsmethode ist die Erfassung von IgM- (frische Infektion) und IgG-Antikörpern (länger zurückliegende bzw. chronische Infektion) möglich. Bei der klinischen Auswertung der mit Br.-abortus-, Br.-melitensis oder Br.-suis-Antigenen erhaltenen serologischen Befunde muss berücksichtigt werden, dass diese drei Brucella-Arten Antigengemeinschaften, vor allem mit Yersinia enterocolitica O:9 aufweisen, die mit den serologischen Untersuchungsverfahren zu nahezu homologen und heterologen Titern führen. Ferner bestehen Antigengemeinschaften mit Francisella tularensis, Escherichia coli O 157 : H7, Salmonellen der Serogruppe O:30 (z. B. Salmonella godesberg) sowie Vibrio cholerae, die ebenfalls zu serologischen Kreuzreaktionen führen.

Die serologische Erfassung von Br.-Canis-Infektionen bedarf eines eigens hergestellten Br.-canis-Antigens, das in manchen veterinärmedizinischen Untersuchungslaboratorien zur Verfügung steht.

\section{Befund / Interpretation}

Vor dem Erregernachweis steht die serologische Diagnostik in Kombination mit der klinischen Symptomatik im Vordergrund.

\section{Therapie}

\section{Therapeutische Maßnahmen}

Von der WHO wird nach wie vor die Verabreichung einer Kombination von Tetrazyklin (täglich $2 \mathrm{~g}$ oral, 4 Wochen lang) - zur Verhinderung des Auftretens einer Herxheimer-Reaktion wird in den ersten Tagen nur die halbe Dosis gegeben - und Streptomycin (täglich $1 \mathrm{~g}$ i.m., 1-2 Wochen lang) empfohlen. Trotzdem ist mit Therapieversagern zu rechnen. Alternativ kann in einer Langzeittherapie Doxycyclin (täglich 0,2 g oral, 6 Wochen lang; Kinder täglich $4 \mathrm{mg} / \mathrm{kg} \mathrm{KG}$ ) in Kombination mit Gentamicin (täglich $5 \mathrm{mg} / \mathrm{kg} \mathrm{KG}, 3$ Wochen lang) oder Rifampicin (täglich 0,6-0,9 g, 6 Wochen lang) verabreicht werden.

\section{Resistenz}

Brucellen weisen in der Umwelt sowie in Lebensmitteln eine relativ hohe Widerstandsfähigkeit auf. Sie bleiben z. B. in Heu länger als 5 Monate, in Kot bis zu 75 Tagen, in eingepökeltem Schweinefleisch bis zu 2 Monate, in Butter bis zu 4 Monate sowie in frischem 
Schaf- und Ziegenkäse sogar bis zu 6 Monate lebensfähig. Brucellen werden in der Milch durch Pasteurisierung sicher abgetötet.

\section{Epidemiologie}

\section{Verbreitung}

Das Auftreten der Brucellose beim Menschen ist eng mit dem Vorkommen und der Verbreitung der Erreger bei Tieren, insbesondere bei landwirtschaftlichen Nutztieren, verbunden. In Europa kommen Tierbrucellosen in westeuropäischen und mediterranen Ländern (z. B. Irland, Frankreich, Portugal, Spanien, Malta, Griechenland, Türkei) noch gehäuft vor, ferner in Osteuropa sowie in Ländern Afrikas, Asiens und Lateinamerikas (hier insbesondere Brasilien und Mexiko).

\section{Wirtsbereich / Reservoir}

Brucellen können außerhalb des Menschen bei zahlreichen Tierarten, insbesondere bei landwirtschaftlichen Nutztieren (Rind, Schaf, Ziege, Schwein), aber auch bei Haustieren (Br. canis beim Hund) sowie bei Jagd- und Wildtieren (Hase, Wildschwein u.a.) vorkommen.

\section{Risikogruppen}

Besonders gefährdet sind Tierärzte, Landwirte, Tierpfleger, Melker, Schäfer, Schlachthofpersonal, Abdecker, Laboratoriumspersonal sowie Touristen, Gastarbeiter oder Entwicklungshelfer in Ländern (Epidemiologie) mit Tierbrucellosen.

\section{Transmission / Vektoren}

Brucellen-Infektionen des Menschen nehmen ihren Ausgang stets von infizierten Tieren oder tierischen Lebensmittelprodukten (Zoonose). Durch direkten Kontakt mit Ausscheidungen (z. B. Nachgeburt, Abortmaterial) infizierter Tiere können Brucellen über kleinste Hautläsionen oder über Konjunktiven in den Organismus gelangen. Auch ist der orale Infektionsweg, z. B. Genuss von Rohmilch und daraus hergestellten Lebensmittelprodukten (z. B. Schaf-, Ziegenkäse) möglich. Auch über Aerosole (z. B. im Schlachthof) können Brucellen in den Organismus gelangen.

\section{Prävention / Impfstoffe}

Beruflich exponierte Personen ( $\downarrow$ Risikogruppen) sollten sich beim Umgang mit infizierten Tieren oder deren Ausscheidungen durch Tragen von Schutzhandschuhen, insbesondere bei Vorliegen auch von kleinsten Hautläsionen, sowie durch Gesicht- und Mundschutz vor Kontakt und Schmierinfektionen schützen. Im Ausland ( $\triangleright$ Epidemiologie) kein Genuss von Rohmilch und daraus hergestellten Produkten (z. B. Schaf-, Ziegenkäse). Auch im Labor erfordert der Umgang mit Brucellen oder verdächtigem Untersuchungsmaterial besondere Vorsichtsmaßnahmen, um Laborinfektionen (meist über Schmier- oder Tröpfcheninfektion) zu vermeiden. Keine Impfstoffe vorhanden.
Ausmerzen Brucellose-infizierter Tiere aufgrund veterinärpolizeilicher Bestimmungen; keine Therapie erlaubt.

\section{Ausbruchsmanagement}

Staatliche Maßnahmen zur Bekämpfung und Überwachung der Brucellose bei landwirtschaftlichen Nutztieren (Rind, Schaf, Ziege und Schwein). In diese Überwachung sollten auch Wildtiere (Schwarzwild, Hase) mit einbezogen werden. Bei Verdacht einer menschlichen Ansteckung sind regelmäßig serologische Kontrollen durchzuführen (Titerverlaufskontrollen).

\section{Meldepflicht}

In Deutschland sind nach $₫ 7$ des IfSG Brucellen nach direktem oder indirektem Nachweis beim Menschen namentlich zu melden, soweit ein entsprechender Nachweis auf eine akute Infektion hinweist.

Nach dem Tierseuchengesetz unterliegt in Deutschland die Brucellose der Rinder, Schafe, Ziegen und Schweine der Anzeigepflicht.

\section{Weiterführende Informationen}

\section{Referenzzentrum / Expertenlaboratorium:}

- Nationales veterinärmedizinisches Referenzlabor für Brucellose, Bundesinstitut für gesundheitlichen Verbraucherschutz und Veterinärmedizin, Diedersdorfer Weg 1, 12277 Berlin, Tel.: 01888/412-2053, Fax:01888/412-2000, E-Mail: k.noeckler@bgvv.de

\section{Web-Adressen}

- http://yellow-fever.rki.de/INFEKT/STECKBRF/ STBR_B/BRUCEL.HTM

- http://yellow-fever.rki.de/GESUND/MBL/MBL_PR1.HTM

- http://www.bgvv.de/presse/1996/pr_96_11.htm

- http://netdoktor.at/Krankheiten/Fakta/brucellose.htm

\section{Schlüsselliteratur}

1. Corbel MJ (1997) Brucellosis an overview. Emerg Infect Dis 3:213-221

2. Deadly in the Daylight, August 23, 2007 in Science NOW Daily news. Assessed Sept. 8, 2007

3. Plommet M, Diaz R, Verger JM. (1998) Brucellosis. In: Palmer SR, Soulsby L, Simpson DIH Zoonoses. Oxford University Press, pp 23-36

4. Shapiro DS, Wong JD (1999) Brucella. In: Murray PR (ed) Manual of Clinical Microbiolgy, 7th edn. ASM Press, Washington, pp 625-631

5. Solera J, Lozano E, Martinez-Alfaro E., Espinosa A, Castillejos MJ, Abad L (1999) Brucellar spondylitis: review of 35 cases and literature survey 29:1440-1449

6. Young EJ (1995) An overview of human brucellosis. Clin Infect Dis 21:283-290

\section{Brucellose}

Bioterrorismus, infektiologische Aspekte

- Brucella 


\section{Brugia}

ACHIM HÖRAUF

Erreger

\section{Synonym(e)}

Filaria malayi, Brugia-Filarie (beide nicht gebräuchlich).

\section{Erregerspezies}

Brugia malayi, Brugia timori.

\section{Taxonomie}

Klasse: Nematoda; Ordnung: Spirurida; Familie: Onchocercidae

\section{Historie}

Mikrofilarien von B. malayi wurden erstmals von Lichtenstein auf Sumatra beobachtet und 1927 als zu einer neuen Filarienart gehörend von Brug beschrieben. Erst 1940 gelang Rao und Maplestone der Nachweis von adulten Würmern dieser Spezies. 1965 fanden David und Edeson bei Bewohnern der Insel Timor einen anderen Mikrofilarientyp, für den erst 1970 Partono und Mitarbeiter durch Infektionsexperimente anhand der dabei gewonnenen Adulten den Artstatus als B. timori sichern konnten.

\section{Morphologie}

Weißliche, fadenförmige Würmer (Filarien). Männchen 13-25 mm lang und bis zu 0,09 mm dick, Weibchen 40-60 mm lang und 0,13-0,19 mm dick. Die Weibchen gebären sogenannte Mikrofilarien, die von einer Scheide (ursprüngliche Eihülle) umgeben sind. Mikrofilarien von B. malayi sind $220 \mu$ m (240$298 \mu \mathrm{m})$ lang und ca. $6 \mu \mathrm{m}$ dick. Mikrofilarien von B. timori sind länger $(310 \mu \mathrm{m})$.

\section{Genom}

Das „Filarial Genome Project“ wurde im Jahre 1994 durch die WHO und das „United Nations/World Bank/ WHO Special Program for Research and Training in Tropical Diseases (TDR) in Angriff genommen. B. malayi wurde als der Modellorganismus ausgewählt, da dieser Erreger sowohl humanpathogen ist als auch in Labornagetieren angezüchtet und damit in größerer Menge in allen Stadien (Adulte, Mikrofilarien) produziert werden kann. Das Genom ist unter Federführung der Firma TIGR mittlerweile durchsequenziert und weitestgehend annotiert ( $\downarrow$ WebAdressen). Es besteht aus ca. $100 \mathrm{MBp}$ und ist damit dem Genom des frei lebenden Nematoden C. elegans vergleichbar. Es enthält, ähnlich C. elegans, ca. 19.000 Protein-kodierende Gene.

\section{Vermehrung}

Die beiden Brugia-Arten sind Helminthen mit einem zweiwirtigen Entwicklungszyklus. Die einzige Ver- mehrungsphase ist dabei die geschlechtliche Vermehrung im Endwirt (Mensch, auch Affe, Katze $>$ oben). Die Weibchen produzieren während ihres ca. 5 Jahre währenden Lebens mehrere Millionen Mikrofilarien, die lebend geboren werden. Die Mikrofilarien treten periodisch oder subperiodisch im peripheren Blut des Endwirts auf und werden durch den Zwischenwirt bzw. Überträger (vor allem Stechmücken der Gattung Mansonia) beim Saugakt aufgenommen. Dort penetrieren sie die Magenwand und wandern in die Thoraxmuskulatur der Mücke ein. Nach zweimaliger Häutung innerhalb von 10 Tagen wachsen sie zur $1,4 \mathrm{~mm}$ langen Infektionslarve (L3) heran und wandern in die Stechborstenscheide ein. Beim nachfolgenden Saugakt der Mücke wandern die L3 auf die Haut des Endwirts und dringen aktiv durch den Stichkanal ein. Im Endwirt wandern sie in die Lymphgefäße, dort erfolgt über mehrere Monate die Häutung und das Heranwachsen zu Adultwürmern. Das erste Auftreten von Mikrofilarien im peripheren Blut (Präpatenz) geschieht nach 70-120 Tagen.

\section{Pathogenität / Virulenz / Antigenvariabilität}

Die Pathogenität wird hauptsächlich durch das adulte Stadium hervorgerufen. Beim Absterben von adulten Würmern kommt es zu einer plötzlichen Freisetzung von großen Mengen von Antigen. Dies führt zu einer fieberhaften Lymphangitis und Lymphadenitis („Filarienfieber").

Neben den Wurmantigenen, die eine klassische Eosinophilenreaktion mit nachfolgender Makrophagenantwort hervorrufen, scheinen auch die mit den Filarien in Symbiose lebenden Wolbachia-Endobakterien eine pathogenetische Rolle zu spielen; Letztere induzieren die Freisetzung u. a. von TNF aus Makrophagen. Dies hat wiederum die Ausschüttung von Angiogenese- und Lymphangiogenesefaktoren (z. B. VEGF, bFGF, u. a.) zur Folge, wodurch es zu einer proliferativen Veränderung des Lymphendothels kommt.

Mikrofilarien enthalten eine Gamma-Glutamyl-Transpeptidase; Homologe dieses Proteins sind als Immunogene bzw. Allergen bekannt. Hyperreaktivität gegen dieses Protein scheint eine Immunantwort hervorzurufen, die erfolgreich Mikrofilarien abtöten kann; solchermaßen angegriffene Mikrofilarien können aber im Kapillarbett der Lunge die Tropische Pulmonale Eosinophilie (TPE) auslösen.

\section{Erkrankungen}

\section{Lymphangitis/Lymphadenitis}

\section{Synonym(e)}

Filarienfieber.

\section{Inkubationszeit}

Einige Jahre (Absterben der adulten Würmer, mittlere Lebenszeit 5 Jahre). 


\section{Leitsymptome}

Lymphknotenschwellung, Fieber, Schmerzen im befallenen Bereich (meist Arm oder Bein, einseitig).

\section{Symptome}

Akut auftretendes Fieber $>38{ }^{\circ} \mathrm{C}$, verbunden mit Schmerzen und Überwärmung bevorzugt im Bereich der vergrößerten Lymphknoten, Rötung der Lymphbahnen. Insbesondere der femorale Lymphknoten kann dabei abszedieren und nach außen durchbrechen. Typisch sind bleibende große Narben. Die Fieberattacken können mehrmals pro Jahr auftreten und dauern mehrere Tage, meist aber nicht länger als eine Woche.

Bei Brugia-Infektionen verweilen die Adulten im Gegensatz zur Lymphatischen Filariose durch Wuchereria bancrofti ( $\triangleright$ Wuchereria) nicht in der Genitalregion, entsprechend beschränken sich Lymphadenitis und Lymphangitis auf die Region der Extremitäten (gelegentlich sind die Mammae betroffen).

\section{Pathophysiologie}

Die Symptome entstehen durch das (natürliche oder durch Medikamente induzierte) Absterben von adulten Würmern. Der lokal in den Lymphbahnen auftretende Entzündungsreiz führt zur Entzündung der Lymphgefäße (Lymphangitis) wie auch der zugehörigen Lymphknoten (Lymphadenitis).

\section{Immunantwort}

Das Absterben der Würmer führt zu einer Freisetzung sowohl von „klassischen“ Wurmantigenen, welche eine Antikörper-abhängige zelluläre Zytotoxizitätsantwort (ADCC) mit Beteiligung von Eosinophilen und Makrophagen induzieren, als auch von Antigenen der Wolbachia-Endobakterien, die eine typische Sofortreaktion (Toll-like-Rezeptor-vermittelt) gegen Bakterien, ähnlich einer Sepsis, hervorrufen. Wichtige Mediatoren sind hier TNF, IL-6, IL-1, und IL-8.

\section{Differenzialdiagnose}

Lymphangitis und Lymphadenitis bakterieller Genese, z. B. durch Streptokokken bzw. Chlamydia trachomatis. Da Bakteriennachweise (zumal in den abgelegenen Gebieten in den Tropen) schwierig sind, wird die Diagnose zum einen klinisch unter Berücksichtigung der Endemizität, zum anderen parasitologisch zum Beweis einer Infektion mit Brugia spp. ( $\downarrow$ unten) gestellt. Allerdings schließt ein negatives parasitologisches Ergebnis (keine Mikrofilarien im Blut) die Diagnose Brugiasis nicht aus.

\section{Elephantiasis}

\section{Synonym(e)}

Filarienbedingtes Lymphödem.

\section{Inkubationszeit}

5-20 Jahre, vereinzelt länger.

\section{Leitsymptome}

Lymphödem.

\section{Symptome}

Ödematöse Schwellung der Gliedmaßen, meist der Beine. Im Gegensatz zur Filariose durch W. bancrofti keine Ödeme des Genitales, da sich Brugia spp. dort nicht aufhalten.

\section{Pathophysiologie}

Durch die wiederkehrenden Entzündungsantworten in den Lymphbahnen kommt es bei genetisch prädisponierten Infizierten (familiäre Häufung!) zu einer entzündlichen Proliferation des Lymphendothels mit Erweiterung der Lymphgefäße, deren Klappen durch die Erweiterung insuffizient werden, so dass der Lymphfluss gestört ist, d. h. er erfolgt nicht mehr in Richtung des Herzens, sondern entsprechend der Schwerkraft retrograd. Langsam entwickelt sich ein (wegen des hydrostatischen Druckes häufiger an den Beinen als an den Armen zu findendes) Lymphödem. Wie bei Lymphödemen anderer Genese gilt auch hier, dass bei einer Vorschädigung des Lymphsystems andere exogene infektiöse Erreger, insbesondere Streptokokken der Gruppe A, die durch kleinste Hautverletzungen eindringen, ebenfalls zu Fieberattacken mit weiterer Entzündung führen können, sodass sich das Geschehen auch ohne den ursprünglichen Erreger verselbstständigt und progredient verläuft.

\section{Immunantwort}

Die Freisetzung von Antigenen des Wurms und der Wolbachia-Endobakterien in den Lymphbahnen geschieht nicht nur akut beim Absterben von Adulten, sondern wohl auch chronisch durch Freisetzung degenerierter Mikrofilarien (ca. 30 \% der produzierten Mikrofilarien), die von Eosinophilen und Makrophagen abgeräumt werden. Dies führt zu einer chronischen Induktion von inflammatorischen Zytokinen (TNF etc. $>$ oben, Immunantwort der Lymphangitis) und in der Folge von Wachstumsfaktoren für Angiogenese und Lymphangiogenese (VEGF u. a.).

Es wird diskutiert, ob die beobachteten familiären Häufungen ihre Ursache in allelischen Varianten der VEGFs haben, die eine stärkere Lymphproliferation induzieren würden. Auch eine genetisch fixierte stärkere Immunabwehr gegenüber heranwachsenden Würmern wird angenommen, da Lymphödem-Patienten nicht selten Würmer kontrollieren und keine Infektionszeichen außer einer Serumnarbe mehr haben. Eine Variante im IL-18 Gen, die zu einer stärkeren IL-18-vermittelten Th1- und Th2-Antwort führt, ist bei Lymphödempatienten häufiger zu finden. Die familiäre (genetische) Belastung ist schon länger bekannt.

\section{Differenzialdiagnose}

Lymphödeme anderer (nicht infektiöser) Genese (Verletzungen, iatrogen); in Gegenden mit vulkani- 
schem Boden kann es durch Aufnahme von Silikaten zur sogenannten Podokoniose kommen. Die Lymphödeme sind klinisch kaum von den Filarien-induzierten zu unterscheiden. Hier muss die Diagnose wiederum unter Zuhilfenahme des Labors gestellt werden. Hierbei steht allerdings die serologische Diagnose (Serumnarbe) im Vordergrund, da die stärkere Immunabwehr $(\triangleright$ oben) dieser Patienten die Parasiten meist unter die Nachweisgrenze drückt oder neue Infektionen sogar ganz verhindert. Nicht selten haben Patienten, die ein Lymphödem ursächlich durch Brugia bekommen haben, bei oder kurz nach der klinischen Manifestation keine Parasiten mehr. Allerdings scheint eine PCR aus Plasma/Serum, die eine B.-malayi-spezifische repetitive Filarien-Gensequenz erkennt (s. u.), bei den meisten dieser Patienten positiv zu sein.

\section{Tropische Pulmonale Eosinophilie, TPE}

\section{Synonym(e)}

Okkulte Filariose, Tropisches eosinophiles Asthma, Weingartner-Syndrom.

\section{Inkubationszeit}

Monate bis Jahre nach Infektion.

\section{Leitsymptome}

Asthmoide Bronchitis.

\section{Symptome}

Asthmoide Bronchitis, Husten, Störung des Allgemeinbefindens, radiologisch Lungeninfiltrate mit vergrößerten Lymphknoten, laborchemisch hochgradige Eosinophilie (i. d. R. > $20 \%$ und mehr). Bei langem Verlauf kommt es zur Lungenfibrose.

\section{Pathophysiologie}

Es handelt sich um eine Hypersensitivitätsreaktion gegen Mikrofilarien, die bei nur wenigen genetisch prädisponierten Personen auftritt. Eine starke Antikörper-vermittelte Abwehrreaktion gegenüber Mikrofilarien lässt diese wahrscheinlich schon im peripheren Blut bzw. im Lymphsystem degenerieren oder abtöten. Solchermaßen veränderte Mikrofilarien werden im Kapillarbett der Lunge festgehalten und abgebaut. Dadurch werden zwar die Mikrofilarienlasten deutlich reduziert und können sogar negativ werden, es kommt aber zu einer weiteren Verstärkung der Immunantwort und des gesamten Hypersensitivitäts-Prozesses.

\section{Immunantwort}

Es handelt sich um eine genetisch mitbedingte, starke Immunreaktion auf Mikrofilarien. Hauptantigen ist dabei die Gamma-Glutamyl-Transpeptidase, ein Protein mit Homologie zu bekannten Allergenen. Es entwickelt sich eine sehr starke Th2-Antwort gegen Mikrofilarien, mit hohem IgE (bzw. allgemein Ig-Titern) und Eosinophilie. Durch ADCC ( $\triangleright$ oben) werden Mikrofilarien abgetötet, was zu einer weiteren AntigenFreisetzung und Immunstimulation führt.

\section{Differenzialdiagnose}

Lungenerkrankungen anderer Genese, infektiöse (Tbc) wie nicht infektiöse (Tumoren). Hinweisgebend ist die hohe Eosinophilie sowie IgE-Titer auf Filarienantigene.

\section{Diagnostik}

\section{Untersuchungsmaterial}

Eine sichere Diagnose der Brugiasis ist nur durch den Direktnachweis der Mikrofilarien im Blut mittels Mikroskopie oder PCR möglich. Antikoaguliertes Blut (bei PCR nicht heparinisiert, sondern EDTA-Blut!) ist deshalb auch das Material der Wahl. Die Blutentnahme zum Mikrofilariennachweis muss je nach Endemiegebiet und Periodizität der Mikrofilarien erfolgen. Bei der weitaus häufigsten „Microfilaraemia nocturna" schwärmen die Mikrofilarien nachts in das periphere Blut aus, verschwinden dagegen während des Tages fast völlig und sind dann nur bei sehr starkem Befall (> $1000 \mathrm{MF} / \mathrm{ml})$ nachweisbar. Die günstigste Zeit für die Blutentnahme liegt zwischen 21 und 2 Uhr (bei Übertragung durch Aedes dagegen zwischen 15 und $17 \mathrm{Uhr}$ ). Durch eine Provokation mittels einer oralen Gabe von 100 mg Diäthylcarbamazin-Citrat erhöht sich die Mikrofilariämie nach 30-60 min. Die Blutentnahme für die Serologie kann jederzeit erfolgen.

Zur Anreicherung für Mikrofilarien eignen sich 3 Verfahren:

- Mikrohämatokritverfahren: Hämatokritröhrchen werden zentrifugiert, die Mikrofilarien sind unter dem Mikroskop in der „Buffy-Coat"-Schicht (an der Blut-Plasma-Grenze) durch ihre Bewegungsaktivität zu erkennen. Dieses Verfahren verbindet Screening und Anreicherung; keine Speziesdiagnostik möglich.

- Anreicherung durch Lyse von Erythrozyten: Antikoaguliertes Blut wird mit $10 \mathrm{ml}$ einer Lösung (Gemisch aus 9,5 ml einer 5 \%igen wässrigen Lösung von Formalin mit $0,5 \mathrm{ml}$ Eisessig und $0,2 \mathrm{ml}$ einer 4 \%igen alkoholischen Gentianaviolettlösung) versetzt, welche die Erythrozyten lysiert und die Mikrofilarien färbt und gleichzeitig fixiert. Nach $5 \mathrm{~min}$. Zentrifugation bei $400 \mathrm{U} / \mathrm{min}$., Waschen mit Aqua dest und erneuter Zentrifugation kann das Sediment bei 10facher Vergrößerung mikroskopiert werden. Im positiven Fall findet man tote, violett gefärbte Mikrofilarien und Leukozyten.

- Anreicherung durch Filter: Je nach erwarteter Mikrofilariendichte werden 1-10 $\mathrm{ml}$ anti-koaguliertes Blut durch einen Polycarbonatfilter (z. B. Nucleopore $^{\circledR}$ ) von 3-5 $\mu \mathrm{m}$ Porendurchmesser gedrückt. Dieser lässt Blutzellen weitgehend passieren, hält aber die Mikrofilarien zurück. Anschließend Färbung mithilfe eines üblichen Verfahrens, z. B. Giemsa-Färbung. 


\section{Diagnostische Verfahren}

Mikroskopische Diagnostik

- Nativpräparat mit Citratblut: eine einfache Nachweismöglichkeit. Mikrofilarien sind durch ihre Beweglichkeit schon bei schwacher Vergrößerung zu erkennen; keine Speziesdiagnostik möglich.

- Dicker Tropfen; Methode - Plasmodien.

- Die Delafield'sche Färbung anstelle der GiemsaFärbung erlaubt oft eine bessere Visualisierung der Kerne im Schwanzbereich der Mikrofilarien, was für die Differenzialdiagnose wichtig ist. BrugiaMikrofilarien lassen sich von denen der Mansonellen durch die sie umgebende Scheide und von allen Filarienarten durch das lange fast kernfreie Schwanzende mit lediglich 2 Kernen unterscheiden, die als auffallende Ausbeulung an der Schwanzspitze erkennbar sind.

PCR: Wenn speziesspezifische Primer verwendet werden, erlaubt dies eine Speziesdifferenzierung auch für den in der Mikroskopie nicht geübten Untersucher. "In-house-Tests" sind beschrieben (Einsendung an Speziallabore). Bedeutung könnte die PCR in Zukunft bei der Detektion latenter Infektionen (nur Adultwürmer, keine Mikrofilarien) erlangen, da die Verfahren zum Nachweis von adulten Würmern (Ultraschall und "circulating filarial antigen“, CFA) im Gegensatz zu Infektionen mit $W$. bancrofti bei Brugia-Infektionen nicht funktionieren. Eine PCR, die den repetitiven Genabschnitt Hha nachweist, kann im Tierversuch latente bzw. präpatente Infektionen nachweisen und ist bei Patienten mit Lymphödem positiv, auch wenn diese keine Mikrofilarien haben.

Serologische Diagnostik: Mittels ImmunfluoreszenzTest (IFT; Gefrierschnitte von adulten Filarien als Antigen, es können auch tierische Filarien verwendet werden) oder ELISA.

Weitere Diagnostik: Die Untersuchung auf sich bewegende Würmer in Lymphbahnen mittels Ultraschall des männlichen Skrotalbereiches, der bei Wuchereria bancrofti bei Männern regelhaft positive Ergebnisse bringt, ist bei Brugia-Infektionen negativ, da sich die Würmer nicht dort aufhalten.

\section{Befund / Interpretation}

Das klinische Bild in Zusammenhang mit der Herkunft des Patienten lässt eine Verdachtsdiagnose zu. Klinisch liefern rekurrierende Lymphangitiden und Lymphadenitiden unter Berücksichtigung der Herkunft des Patienten weitere wichtige Verdachtshinweise auf eine Brugia-Infektion, ebenso eine Elephantiasis bei Patienten aus Endemiegebieten.

Beweisend für eine Brugia-Infektion ist der Nachweis von Mikrofilarien in der Mikroskopie oder durch PCR, da es keine Möglichkeit zum Nachweis von zirkulierendem Antigen gibt, welches bei Wuchereria aber doppelt so viele Infektionen nachweist wie die Bestimmung der Mikrofilarien.
Die Resultate beider serologischer Verfahren sind filarien-, jedoch nicht artspezifisch und somit geeignet zur Abgrenzung von Infektionen mit anderen Würmern. Die Serologie ist der 1. Schritt der Stufendiagnostik bei Tropenrückkehrern im Sinne des Suchtests; ein negatives Ergebnis schließt eine Infektion mit Filarien aus. Da man nach neuen Befunden ähnlich wie bei der Wuchereria-bancrofti-Infektion auch bei Brugiasis von vielen Infektionen ohne Mikrofilarämie ausgehen muss, kommt der Serologie für den Nachweis von okkulten Brugia-Infektionen eine besondere Bedeutung zu.

Bei der Elephantiasis ist der Mikrofilarien-Befund in der Regel, bei der TPE meistens negativ. Immunologische Ergebnisse lassen den Schluss zu, dass eine inverse Relation besteht zwischen der Menge der Mikrofilarien und dem Ausmaß an inflammatorischer immunologischer Reaktivität bzw. dem Auftreten von Pathologie und Krankheitszeichen.

\section{Therapie}

\section{Therapeutische Maßnahmen}

Diäthylcarbamazin (DEC) gilt als Mittel der Wahl. Es ist sowohl gegen Mikrofilarien als auch partiell gegen Adultwürmer wirksam, wobei aber keine 100 \%ige Eliminierung der Parasiten gelingt. Folgendes Behandlungsschema wird empfohlen: 1 . Tag $1 \times 50 \mathrm{mg}$; 2. Tag $3 \times 50 \mathrm{mg} ; 3$. Tag $3 \times 100 \mathrm{mg}$; ab dem 4 . Tag $3 \times 150 \mathrm{mg}$. In der Regel wird eine Gesamtdosis von $36 \mathrm{mg} / \mathrm{kg} \mathrm{KG}$ als ausreichend betrachtet. Die Häufigkeit des Auftretens von Lymphangitiden und Lymphadenitiden geht nach DEC-Gabe deutlich zurück. Ebenso bessert sich nach Behandlung mit DEC das klinische und hämatologische Bild bei Patienten mit Tropischer Pulmonaler Eosinophilie. Als weitgehend unwirksam erweist sich DEC beim Lymphödem; dies ist auch nicht anders zu erwarten, da diese Patienten meistens keine Wurminfektion mehr haben ( $\triangleright$ oben). Neue Daten zeigen, dass - ähnlich wie bei der Wuchereria-bancrofti-Infektion - eine Depletion der Wolbachia-Endobakterien zur Unfruchtbarkeit der weiblichen Würmer führt, sodass entsprechend behandelte Patienten, wenn sie nicht Neu-Infektionen erwerben, mikrofilarienfrei bleiben. Da es keinen sicheren Nachweis einer okkulten Infektion nur durch erwachsene Würmer gibt, kann -anders als bei W. bancrofti - keine Aussage zu einer makrofilariziden Wirkung von Doxycyclin bei Brugia-Infektionen des Menschen getroffen werden. Doxycyclin ist aber makrofilarizid in Tiermodellen mit Brugia malayi.

Gegen Lymphödem sind supportive Maßnahmen (Fuß hochlagern, Fußhygiene, Vermeidung des Eindringens von Erregern durch Hautläsionen) indiziert. Es ist nicht untersucht, ob Doxycyclin die Progredienz des Lymphödems aufhält, so wie dies für das Lymphödem durch W. bancrofti gezeigt ist. Es ist aber wahrscheinlich, dass Doxycyclin ähnlich wirkt. 


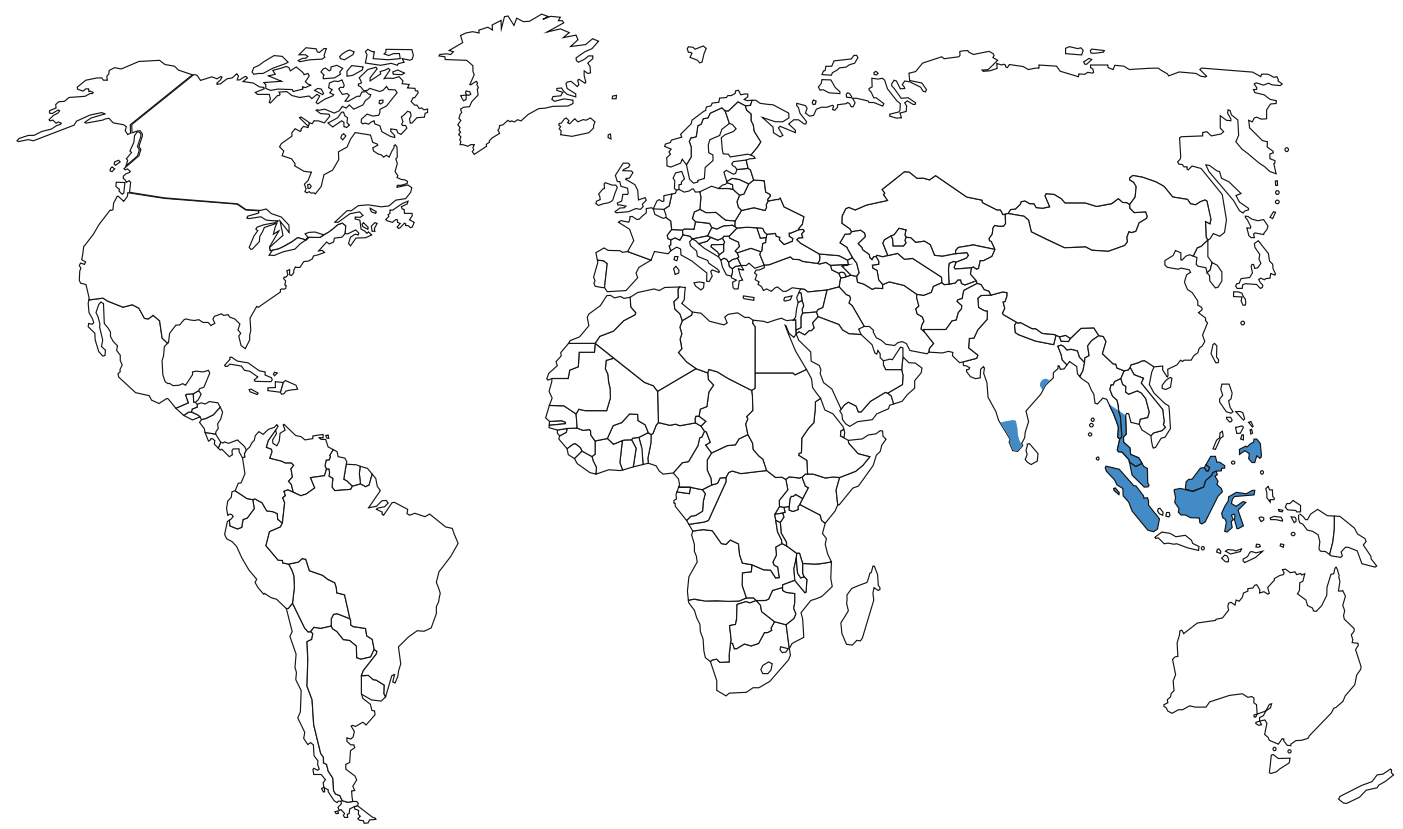

- Abb. 1. Verbreitung von Brugia malayi

\section{Resistenz}

Es gibt derzeit keine Hinweise auf Resistenz gegen DEC.

\section{Epidemiologie}

\section{Verbreitung}

Die Endemiegebiete von B. malayi liegen in Süd-, Südost- und Ostasien (östliches Indien, äußerster Süden Thailands, Malaysia, Indonesien außer Sumatra und Java) sowie im westlichen pazifischen Raum; das Verbreitungsareal von B. timori ist auf die kleinen SundaInseln wie z. B. Timor, Alor und Flores beschränkt $(\triangleright$ Abb. 1$)$.

\section{Wirtsbereich / Reservoir}

Die nachtperiodische Form wird wahrscheinlich nur von Mensch zu Mensch übertragen, während die seltene subperiodische Form ein Reservoir in Affen und Carnivoren (z. B. Hauskatzen) hat.

\section{Risikogruppen}

Voraussetzung für den Erwerb einer Brugia-Infektion ist der Aufenthalt in einem Endemiegebiet mit zusätzlicher Mückenexposition. Besonders gefährdet ist die ländliche, in Gewässernähe lebende Bevölkerung der Endemiegebiete, da die Larven- und Puppen-Entwicklung der Überträger an das Wasser gebunden ist. In gewässernahen Gebieten ist die Überträgerdichte besonders hoch, was die Voraussetzung für die Transmission von Brugia ist. Sind Mansonia-Arten die
Überträger, dann setzt dies eine reiche Wasservegetation voraus. Mansonia-Larven und -Puppen sind auf Wasserpflanzen als Sauerstoffquelle angewiesen.

\section{Transmission / Vektoren}

Die Übertragung von Brugia erfolgt ausschließlich durch Stechmücken, in erster Linie der Gattung Mansonia (B. malayi) bzw. Anopheles (B. timori), deren Aktivitätsphasen weitgehend mit dem rhythmischen Auftreten der Mikrofilarien im peripheren Blut zusammenfallen. Periodische oder sub- bzw. semiperiodische Präsenz ist vom Endemiegebiet und den jeweiligen Überträgern abhängig. Bei ausgeprägter Periodizität treten Mikrofilarien ausschließlich nachts oder in den späten Abendstunden im Blut auf, bei Subperiodizität auch tagsüber.

\section{Prävention / Impfstoffe}

Insgesamt gilt, dass die Übertragung von Filariosen mit weitaus weniger Effizienz verläuft als z. B. die Übertragung von Plasmodien. Dies ist einer der Gründe, warum Filariosen von normalen Reisenden selten importiert werden. Schutz vor Mückenstichen durch Anwendung von Repellentien und Moskitonetzen sowie geeignete Kleidung kann die Übertragung von infektiösen Larven verhindern. Es ist außerdem aus verschiedenen Tiermodellen bekannt, dass die Chemotherapeutika Ivermectin und Doxycyclin die Reifung von infektiösen Larven zu adulten Würmern verhindern können. Eine Malariaprophylaxe mit Doxy- 
cyclin verhindert also mit ziemlicher Sicherheit auch eine Infektion mit B. malayi.

\section{Ausbruchsmanagement}

Plötzliche Ausbrüche kommen nicht vor und bedürfen deshalb auch keines speziellen Managements. Generell wird versucht, die Transmission von Filariosen durch Massenchemotherapie mit mikrofilariziden Substanzen (hier: DEC) zu verhindern. Die „Global Alliance for the Elimination of Lymphatic Filariasis" bezieht sich allerdings explizit nur auf die Lymphatische Filariose durch $W$. bancrofti, da nur diese eine reine Anthroponose darstellt.

\section{Meldepflicht}

Keine.

\section{Weiterführende Informationen}

\section{Referenzzentren / Expertenlaboratorien}

Das Bernhard-Nocht-Institut für Tropenmedizin (BernhardNocht-Str. 74, 20359 Hamburg) ist Referenzzentrum der Dt. Gesellschaft f. Hygiene u. Mikrobiologie (DGHM) für alle tropischen Erreger; als fachlich qualifiziert anzusehen sind aber sämtliche parasitologische und tropenmedizinische Institutionen, wie z. B.:

- Abteilung für Infektions- und Tropenmedizin, Leopoldstr. 5, 80802 München

- Hygiene-Institut, Abteilung Öffentl. Gesundheit, Im Neuenheimer Feld 324, 69120 Heidelberg

- Institut für Medizinische Mikrobiologie, Immunologie und Parasitologie, Sigmund-Freud-Str. 25, 53105 Bonn

- Institut für Tropenmedizin, Wilhelmstr. 31, 72074 Tübingen

- Landesinstitut für Tropenmedizin, Engeldamm 62/64, 10179 Berlin

\section{Web-Adressen}

- Nematoden-Genomseite der Universität Edinburgh: www.nematodes.org/

- WHO - World Health Organization: http://www.who. int/topics/filariasis/en/

\section{Schlüsselliteratur}

1. Hoerauf A (2008) Filariasis: new drugs and new opportunities for lymphatic filariasis and onchocerciasis. Curr Opin Infect Dis 21:673-681.

2. Löscher T, Burchard G (Hrsg) (2010) Tropenmedizin in Klinik und Praxis. 4. Aufl. Georg Thieme Verlag, Stuttgart New York

3. Lucius R, Loos-Frank B (2008) Biologie von Parasiten. 552 pages. Springer-Verlag Berlin, Heidelberg, New York.

4. Nutman TB (ed) (2000) Lymphatic filariasis. Tropical Medicine: Science and Practice, Vol. 1. Imperial College Press, London

5. Taylor MJ, Bandi C, Hoerauf A (2005) Wolbachia bacterial endosymbionts of filarial nematodes. Adv Parasitol 60:245-284

6. Taylor MJ, Hoerauf A, Bockarie M (2010) Lymphatic filariasis and onchocerciasis. Lancet, in press. Review.

7. Turner JD, Mand S, Debrah AY, Muehlfeld J, Pfarr K, McGarry HF, Adjei O, Taylor MJ and Hoerauf A (2006) A randomized, double-blind clinical trial of a 3-week course of doxycycline plus albendazole and ivermectin for the treatment of Wuchereria bancrofti infection. Clin Infect Dis 42:1081-1089.

8. WHO Expert Committee on Filariasis (1992) Lymphatic filariasis: the disease and its control. Fifth report of the WHO Expert Committee on Filariasis. WHO Tech Rep Ser 821

9. WHO Model Prescribing Information (1995) Drugs used in parasitic diseases. 2nd Ed. World Health Organization, Geneva; kann unter der Website http://apps.who.int/medicinedocs/en/d/Jh2922e/ kostenlos heruntergeladen werden!

\section{B-Streptokokken}

Streptococcus agalactiae

\section{Bubonenpest}

Yersinien

\section{Bunyamwera-Virus}

$>$ Bunyaviren

\section{Bunyaviren}

\section{Erreger}

\section{Humanpathogene Erregerspezies}

Caraparu-Virus, Itaqui-Virus, Madrid-Virus, Marituba-Virus, Murutucu-Virus, Nepuyo-Virus, OribocaVirus, Restan-Virus, Bunyamwera-Virus, Fort-Sherman-Virus, Germiston-Virus, Ilesha-Virus, Ngari-Virus, Shokwe-Virus, Tucunduba-Virus, Tensaw-Virus, Wyeomyia-Virus, Xingu-Virus, Bwamba-Virus, Pongola-Virus, California-Enzephalitis-Virus, Guaroa-Virus, Inkoo-Virus, Jamestown-Canyon-Virus, Snowshoe-hare-Virus, LaCrosse-Virus, Tahyna-Virus, TrivittatusVirus, Cache-Valley-Virus, Catu-Virus, Guama-Virus, GanGan-Virus, Oropouche-Virus, Shuni-Virus, Anopheles-A-Virus, Sandfliegenfieber-Virus Neapel-Typ, Sandfliegenfieber-Virus Sizilien-Typ, Toscana-Virus, Punta-Toro-Virus, Rift-Valley-Virus, Alenquer-Virus, Candiru-Virus, Chagres-Virus, Nairobi-Schafkrankheit-Virus, Dugbe-Virus, Krim-Kongo-Virus, BanguiVirus, Bhanja-Virus, Issk-Kul-Virus, Kasokero-Virus, Nyando-Virus, Tamdy-Virus, Tataguine-Virus, Wanowrie-Virus.

\section{Taxonomie}

In der Familie Bunyaviridae sind fünf Genera beschrieben: Orthobunyavirus, Hantavirus, Nairovirus, Phlebovirus, Tospovirus. Auf Genusebene erfolgt die weitere Unterteilung in Serotypen (genetische Grup- 
Tab. 1. Taxonomie der medizinisch relevanten Vertreter der Familie Bunyaviridae

\begin{tabular}{l|l|l}
$\begin{array}{l}\text { Genus/Serogruppe/ } \\
\text { Virus }\end{array}$ & $\begin{array}{l}\text { Krankheit beim } \\
\text { Menschen }\end{array}$ & Verbreitungsgebiet \\
\hline
\end{tabular}

Orthobunyavirus

Anopheles-A-Gruppe

Anopheles-A-Virus

Tacaiuma-Virus

Stechmücken

Fieber

Südamerika

Stechmücken

Fieber

Südamerika

\section{Gruppe C}

Apeu-Virus

Caraparu-Virus

Stechmücken

Fieber

Südamerika

Stechmücken

Fieber

Südamerika

Itaqui-Virus

Stechmücken

Fieber

Südamerika

Madrid-Virus

Stechmücken

Fieber

Panama

Marituba-Virus

Stechmücken

Fieber

Südamerika

Murutucu-Virus

Stechmücken

Fieber

Südamerika

Nepuyo-Virus

Stechmücken

Fieber

Oriboca-Virus

Stechmücken

Fieber

Süd- u. Mittelamerika

Ossa-Virus

Stechmücken

Fieber

Südamerika

Restan-Virus

Stechmücken

Fieber

Panama

Trinidad

\section{Bunyamwera-Gruppe}

Batai-Virus

Fort-Sherman-Virus

Bunyamwera-Virus

Germiston-Virus

Ilesha-Virus

Ngari-Virus

Shokwe-Virus

Tucunduba-Virus

Tensaw-Virus

Wyeomyia-Virus

Xingu-Virus

\section{Bwamba-Gruppe}

Bwamba-Virus

Pongola-Virus

\begin{tabular}{l|l} 
Stechmücken & Fieber
\end{tabular}

Stechmücken

Stechmücken

Stechmücken

Unbekannt

Stechmücken

Stechmücken

Stechmücken

Stechmücken

Stechmücken

Unbekannt

Stechmücken

Stechmücken
Fieber

Fieber

Fieber

Fieber, Exanthem

Fieber, Hämorrhagien

Fieber

Enzephalitis

Enzephalitis

Fieber

Fieber, Hepatitis

Fieber, Exanthem

Afrika

Fieber
Europa, Asien

Mittelamerika

Afrika

Afrika

Afrika

Afrika

Afrika

Brasilien

Nordamerika

Südamerika, Panama

Brasilien 
Tab. 1. (Fortsetzung)

\begin{tabular}{|c|c|c|c|}
\hline $\begin{array}{l}\text { Genus/Serogruppe/ } \\
\text { Virus }\end{array}$ & Überträger & $\begin{array}{l}\text { Krankheit beim } \\
\text { Menschen }\end{array}$ & Verbreitungsgebiet \\
\hline \multicolumn{4}{|l|}{ California Gruppe } \\
\hline Cache-Valley-Virus & Stechmücken & Enzephalitis & USA, Kanada \\
\hline $\begin{array}{l}\text { California-Enzephalitis- } \\
\text { Virus }\end{array}$ & Stechmücken & Enzephalitis & USA \\
\hline Guaroa-Virus & Stechmücken & Fieber & Südamerika, Panama \\
\hline Inkoo-Virus & Stechmücken & Fieber & Skandinavien \\
\hline Jamestown-Canyon-Virus & Stechmücken & Enzephalitis & USA, Kanada \\
\hline Snowshoe-hare-Virus & Stechmücken & Enzephalitis & $\begin{array}{l}\text { USA, Kanada, China, } \\
\text { Russland }\end{array}$ \\
\hline LaCrosse-Virus & Stechmücken & Enzephalitis & $\begin{array}{l}\text { USA (Norden, Osten), } \\
\text { Kanada }\end{array}$ \\
\hline Tahyna-Virus & Stechmücken & Fieber & Europa, Afrika \\
\hline Trivittatus-Virus & Stechmücken & Fieber & Nordamerika \\
\hline \multicolumn{4}{|l|}{ Guama-Gruppe } \\
\hline Catu-Virus & Stechmücken & Fieber & Südamerika \\
\hline Guama-Virus & Stechmücken & Fieber & Südamerika \\
\hline \multicolumn{4}{|l|}{ Mapputta Gruppe } \\
\hline GanGan-Virus & Stechmücken & Fieber, Arthritis & Australien \\
\hline \multicolumn{4}{|l|}{ Simbu-Gruppe } \\
\hline Oropouche-Virus & Stechmücken & Fieber & $\begin{array}{l}\text { Brasilien, Trinidad, Peru, } \\
\text { Panama }\end{array}$ \\
\hline Shuni-Virus & Stechmücken & Fieber & Afrika, Asien \\
\hline
\end{tabular}

Phlebovirus

Phlebotomus-Fieber-Gruppe

\begin{tabular}{l|l|l|l|}
$\begin{array}{l}\text { Sandfliegenfieber-Virus } \\
\text { Neapel-Typ }\end{array}$ & Phlebotomen & Fieber & $\begin{array}{l}\text { Südeuropa, Afrika, Mitt- } \\
\text { lerer Osten, Pakistan }\end{array}$ \\
\hline $\begin{array}{l}\text { Sizilien-Typ } \\
\text { Toscana-Virus }\end{array}$ & Fieber & $\begin{array}{l}\text { Südeuropa, Afrika, Mitt- } \\
\text { lerer Osten, Pakistan }\end{array}$ \\
\hline $\begin{array}{l}\text { Punta-Toro-Virus } \\
\text { Rift-Valley-Virus }\end{array}$ & Phlebotomen & Meningitis & Norditalien \\
\hline Alenquer-Virus & Stechmücken & Fieber & Fieber, Hämorrhagien, \\
Candiru-Virus & Unbekannt & Fieber & Afrika \\
\hline Chagres-Virus & Unbekannt & Fieber & Südamerika \\
\hline & Phlebotomen & Fieber & Südamerika \\
\hline
\end{tabular}


Tab. 1. (Fortsetzung)

\begin{tabular}{|c|c|c|c|}
\hline $\begin{array}{l}\text { Genus/Serogruppe/ } \\
\text { Virus }\end{array}$ & Überträger & $\begin{array}{l}\text { Krankheit beim } \\
\text { Menschen }\end{array}$ & Verbreitungsgebiet \\
\hline \multicolumn{4}{|l|}{ Nairovirus } \\
\hline $\begin{array}{l}\text { Nairobi-Schafkrankheit- } \\
\text { Virus }\end{array}$ & Zecken & Fieber & Afrika, Indien \\
\hline Dugbe-Virus & Zecken & Fieber & Afrika \\
\hline Krim-Kongo-Virus & Zecken & Hämorrhagisches Fieber & $\begin{array}{l}\text { Europa, Afrika, Zentrala- } \\
\text { sien, Mittlerer Osten }\end{array}$ \\
\hline \multicolumn{4}{|l|}{ Hantavirus* } \\
\hline Tospovirus & \multicolumn{3}{|c|}{ Keine humanmedizinisch relevanten Vertreter } \\
\hline \multicolumn{4}{|l|}{ Unklassifizierte Viren } \\
\hline Bangui-Virus & Unbekannt & Fieber, Exanthem & Afrika \\
\hline Bhanja-Virus & Zecken & Fieber, Enzephalitis & Afrika, Europa, Asien \\
\hline Issk-Kul-Virus & Zecken & Fieber & Asien \\
\hline Kasokero-Virus & Unbekannt & Fieber & Afrika \\
\hline Nyando-Virus & Stechmücken & Fieber & Afrika \\
\hline Tamdy-Virus & Zecken & Fieber & Russland \\
\hline Tataguine-Virus & Stechmücken & Fieber, Exanthem & Afrika \\
\hline Wanowrie-Virus & Zecken & Fieber, Hämorrhagien & Mittlerer Osten, Asien \\
\hline
\end{tabular}

* Hantaviren $\triangleright$ gesondertes Kapitel

pen) und Subtypen. Es handelt sich um die größte Familie von RNA-Viren mit mehr als dreihundert serologisch oder molekulargenetisch unterscheidbaren Viren, von denen über 60 Erkrankungen beim Menschen verursachen. Bunyaviren der Gattungen Orthobunyavirus, Phlebovirus und Nairovirus werden durch Arthropoden übertragen und damit epidemiologisch den Arboviren zugeordnet. Viren der Gattung Hantavirus werden durch Nagetiere übertragen. Die medizinisch relevanten Viren der Familie Bunyaviridae mit Ausnahme der Hantaviren ( gesondertes Kapitel) sind in $>$ Tab. 1 zusammengestellt.

\section{Historie}

Das Prototypvirus des Genus Nairovirus (NairobiSchafkrankheit-Virus) wurde 1911 durch E. Montgomery in Material eines erkrankten Schafes identifiziert. Das Hantaan-Virus (Prototypstamm des Genus Hantavirus) wurde 1976 durch Ho Wang Lee aus Apodemus agrarius (Brandmaus) isoliert. 1930 wurde das Rift-Valley-Virus gefunden, das eine Epidemie bei Mutterschafen und Lämmern ausgelöst hatte. Im Epi- demiegebiet erkrankten auch Menschen an einem akuten Influenza-ähnlichen Krankheitsbild. Ausbrüche unter Schafen und Rindern wurden ab 1950 aus vielen Ländern südlich der Sahara berichtet. 1977/78 trat das Virus erstmals in Ägypten auf. Im bislang größten Ausbruch erkrankten 200.000 Menschen, wovon 600 starben. Seit 1981 ist das Rift-Valley-Virus in Ägypten nicht mehr aufgetreten, wenngleich es regelmäßig in den südlich der Sahara gelegenen Ländern Ausbrüche hervorruft. Das Sandfliegenfieber war bereits während der napoleonischen Kriege unter der Bezeichnung Mittelmeerfieber beschrieben worden. In Italien war es als Pappataci-Fieber bekannt. 1905 wurde gezeigt, dass die Infektion durch Phlebotomen übertragen wird. Epidemien von Sandfliegenfieber traten 1943/44 während des Zweiten Weltkriegs bei den alliierten Truppen in Italien auf.

\section{Morphologie}

Bunyaviren sind sphärische, behüllte Virionen mit einem Durchmesser von ca. 80-120 nm. Die in drei Segmente geteilte Einzelstrang-RNA mit negativer Polari- 
tät bildet zusammen mit dem viralen Nukleokapsidprotein und der anhaftenden RNA-abhängigen RNAPolymerase (L-Protein) das virale Nukleokapsid. In die aus einem Lipidbilayer bestehende Hülle sind zwei Glykoproteine (G1, G2) integriert, die typspezifische antigene Determinanten tragen. Im Gegensatz zu den anderen Minus-Einzelstrang-RNA-Virusfamilien (Orthomyxoviridae, Paramyxoviridae, Rhabdoviridae) fehlt ein internes Matrixprotein. Jeweils charakteristische Oberflächenstrukturen wurden für repräsentative Viren der verschiedenen Genera beschrieben. Phleboviren besitzen $10 \mathrm{~nm}$ große Glykoprotein-Spikes. Eher fransenähnliche Oberflächenstrukturen findet man hingegen bei den Nairoviren. Während bei Hantaviren elektronenmikroskopisch eine regelmäßige Netzstruktur erkennbar wird, scheinen Virionen des Genus Orthobunyavirus eine aus knopfähnlichen Untereinheiten aufgebaute Hülle zu besitzen.

\section{Genom}

Bunyaviren besitzen ein Minus-Einzelstrang-RNAGenom, das aus drei Segmenten besteht (L- [= Large], M- [= Medium] und S- [= Small $]$ Segment). Diese bilden mit dem durch das S-Segment kodierten Nukleokapsidprotein $(\mathrm{N})$ separate Nukleokapsidstrukturen. Alle drei RNA-Spezies haben eine Genus-homologe gemeinsame Konsensus-Sequenz am 3'-Ende und eine komplementäre Sequenz am 5'-Ende, die es ihnen erlaubt, stabile ringförmige Sekundärstrukturen $\mathrm{zu}$ bilden. Das L-Segment kodiert für eine virale Polymerase, die das Negativstrang-Genom in PlusstrangMessenger-RNA transkribiert. Das M-Segment kodiert für zwei Hüllglykoproteine (G1, G2) in einem einzigen offenen Leserahmen, dessen Genomprodukt als Polyprotein translatiert und beim Membrandurchtritt in die einzelnen Komponenten prozessiert wird. Neben den Strukturproteinen und der viralen Polymerase, die bei den verschiedenen Genera unterschiedliche Molekulargewichte aufweisen, werden von einigen Genera kleinere Nichtstrukturproteine mit unterschiedlichen Kodierungsstrategien exprimiert. Phleboviren benutzen eine sogenannte „AmbisenseStrategie", bei der ein Nichtstrukturprotein auf dem S-Segment entgegen der Leserichtung des viralen Genomstranges kodiert wird. Bei Viren des Genus Orthobunyavirus kodiert der virale S-Segment-Strang ein Nichtstrukturprotein, wobei der offene Leserahmen den des N-Proteins überlappt. Die verschiedenen Genera kodieren auch für unterschiedliche Nichtstrukturproteine auf den M-Segmenten. Bei den Bunyaviridae wurde die Fähigkeit zum Austausch von Genomsegmenten zwischen serologisch eng verwandten Virusstämmen (Reassortantenbildung) nachgewiesen. Kürzlich wurde gezeigt, dass Ngari-Virus eine Reassortante des Bunyamwera-Virus ist. Die in Genbanken hinterlegten und veröffentlichten Nukleotid- und Aminosäuresequenzen von Bunyaviren sind auf fol- gender Internet-Seite abrufbar: http://www.ncbi.nlm. nih.gov/.

\section{Vermehrung}

Die meisten Bunyaviren lassen sich in Zellkulturen (z. B. Vero E6, BHK-21) vermehren. Die virale Proteinsynthese findet im rauen endoplasmatischen Retikulum statt, die Morphogenese erfolgt durch Knospung (Budding) in die Zisternen des Golgi-Apparates (Golgi-Targeting) der Wirtszelle. Im Vertebratenwirt findet die Virusvermehrung vornehmlich in den entsprechenden Zielorganen statt. In den Invertebratenwirten werden zum Teil persistierende Infektionen hervorgerufen.

\section{Pathogenität / Virulenz / Antigenvariabilität}

Mit Ausnahme der Hantaviren verursachen Bunyaviren in ihrem Vertebraten-Wirt zytolytische Infektionen, hingegen kaum oder keine zytopathologischen Effekte in den als Überträger fungierenden Invertebraten. Primäre Replikationsorte beim Menschen können das vaskuläre Endothel, die Haut oder regionale Lymphknoten sein. Nach einer Inkubationszeit von einigen Tagen kommt es zur Virämie, die nach Eintreten einer humoralen Immunreaktion sistiert. Die Infektion verläuft oft inapparent. Einige Infizierte entwickeln jedoch Fieber. Organmanifestationen leiten sich aus den direkten Effekten des Virus auf die Zielorgane (z. B. Leber, Gehirn, Lunge, Gefäßendothel) ab. Bei den Hantavirus-Infektionen ist die Pathogenese vermutlich immunvermittelt.

\section{Erkrankungen}

\section{Fieber, arbovirales}

\section{Synonym(e)}

Rift-Valley-Fieber, Oropouche-Fieber, Wanowrie-Fieber, Sandmückenfieber, Nairobi-Schafkrankheit.

\section{Inkubationszeit}

Die Inkubationszeit beträgt mehrere Tage, beim RiftValley-Fieber und bei den Sandmücken-Fiebern sind es meist 2-6 Tage.

\section{Leitsymptome}

Fieber, Exanthem, Meningoenzephalitis, Hämorrhagien.

\section{Symptome}

Stechmücken-übertragene Fieber

Erreger: Bunyamwera-Virus, Bwamba-Virus, Rift-Valley-Virus, Gruppe-C-Viren, Oropouche-Virus, GuamaViren und andere $(\triangleright$ Tab. 1$)$.

Es handelt sich um eine Gruppe fieberhafter viraler Erkrankungen, die in der Regel einige Tage bis eine Woche dauern und häufig Dengue-artig und durchaus schwer verlaufen können. Die Krankheitsbilder beginnen gewöhnlich mit Kopfschmerzen, allgemeinem Krankheitsgefühl, Arthralgien oder Myalgien, gelegentlich Übelkeit und Erbrechen. Häufig treten Kon- 
junktivitis und Photophobie auf. Das Fieber kann biphasisch verlaufen. Bei einigen Erregern kann ein Exanthem hinzutreten ( $\triangleright$ Tab. 1). Die Infektion durch das Oropouche-Virus kann durch eine Meningoenzephalitis kompliziert werden. Beim Rift-Valley-Fieber können sich eine Enzephalitis, eine Hepatitis, Hämorrhagien oder eine Retinitis entwickeln. Ngari-Virus wurde in Ostafrika auch von Fällen mit Hämorrhagischem Fieber isoliert, die im Rahmen größerer Ausbrüche aufgetreten waren.

\section{Phlebotomen-übertragene Fieber}

Erreger: Sandmücken-Fieber-Viren der Naples- und der Sicilian-Gruppe ( Tab. 1).

Es handelt sich um grippeartige Krankheitsbilder mit einer Fieberperiode von 3-4 Tagen, häufig einhergehend mit allgemeinem Krankheitsgefühl, retrobulbären Schmerzen, Injektion der Skleren, Glieder- und Rückenschmerzen. Nicht selten ist die Symptomatik alarmierend. Todesfälle wurden nur vereinzelt beschrieben. Nach einer Infektion durch Toscana-Virus kann sich eine Meningo-Enzephalitis entwickeln. Gelegentlich ist die Rekonvaleszenz verzögert.

\section{Zecken-übertragene Fieber}

Erreger: Nairobi-Schafkrankheit-Virus, Bhanja-Virus, Dugbe-Virus und andere ( $>$ Tab. 1).

Es handelt sich um akute, Dengue-artige, oft biphasisch verlaufende, in der Regel leichte bis mittelschwere Krankheitsbilder. Bei Bhanja-Virus-Infektionen können neurologische Komplikationen auftreten, $\mathrm{Wa}$ nowrie-Virus wurde aus dem Gehirn eines Patienten mit Enzephalitis isoliert.

\section{Pathophysiologie}

Die Organmanifestationen ergeben sich aus den Zielorganen des jeweiligen Virus. Eine disseminierte intravasale Koagulopathie kann bei schweren Erkrankungen mit hämorrhagischen Manifestationen (RiftValley-Fieber, Wanowrie-Fieber, Ngari-Fieber) vorkommen.

\section{Immunantwort}

Die initiale Antwort des Körpers auf eine BunyavirusInfektion ist die Produktion von Interferon, das die Infektion bereits wirksam bekämpfen kann. Bei allen Bunyavirus-Infektionen entwickelt sich sodann eine typische humorale Immunantwort, die die Virämie begrenzt und in den meisten Fällen klinisch zur Genesung führt. Anfangs überwiegen IgM-, später IgGAntikörper. Die zelluläre Immunantwort und die Rolle der Zytokine sind wenig erforscht. Die Antikörperantwort richtet sich hauptsächlich gegen die Strukturproteine N, G1 und G2. Gewöhnlich ist das Nukleokapsidprotein $(\mathrm{N})$ das immundominante Antigen. Die Hüllglykoproteine G1 und G2 sind die neutralisationsrelevanten Antigene, die bei der Ausbildung einer Immunität von Bedeutung sind.

\section{Differenzialdiagnose}

Differenzialdiagnostisch sind - je nach Leitsymptom und geografischer Anamnese - zahlreiche andere Infektionskrankheiten, z. B. die Influenza oder Malaria, zu berücksichtigen. Die Diagnose von Bunyavirus-Infektionen kann wegen der wenig spezifischen Krankheitsbilder, die sie verursachen, nicht allein nach klinischen Kriterien erfolgen, sondern bedarf eines spezifischen labordiagnostischen Nachweises. Richtungsweisend ist neben den Organsymptomen die Expositionsanamnese. Da die Endemiegebiete geografisch determiniert sind, ergibt sich daraus bereits eine Eingrenzung der in Frage kommenden Erreger.

\section{Hämorrhagisches Krim-Kongo-Fieber}

\section{Inkubationszeit}

Die Inkubationszeit beträgt beim Hämorrhagischen Krim-Kongo-Fieber ca. 3-12 Tage nach dem Zeckenstich.

\section{Leitsymptome}

Fieber, Hämorrhagien, Thrombozytopenie.

\section{Symptome}

Die Erkrankung beginnt plötzlich mit Fieber, allgemeinem Krankheitsgefühl, Reizbarkeit, Kopf-, Glieder- und Lendenschmerzen sowie Appetitlosigkeit. Gelegentlich kommt es zu Erbrechen, abdominellen Schmerzen und Diarrhoe. Früh entwickeln sich ein Erythem im Gesicht und auf der Brust sowie eine konjunktivale Injektion. Meist findet man ein hämorrhagisches Enanthem der Mund- und Pharynxschleimhäute sowie ein feines petechiales Exanthem, das sich ausgehend von Brust und Bauch über den Körper ausbreitet. Blutungen unterschiedlichen Ausmaßes können Zahnfleisch, Nasenschleimhäute, Lungen, Uterus und Darm betreffen. Charakteristisch sind flächenhafte Hautblutungen (Ecchymosen). Oft sind sie assoziiert mit einer schweren Begleithepatitis. Hämaturie und Albuminurie sind häufig, aber gewöhnlich nicht sehr ausgeprägt. Das Fieber bleibt für 5-12 Tage konstant erhöht oder verläuft biphasisch. Häufig findet man eine Leukopenie, Lymphozytopenie und Thrombozytopenie. Die Letalität beträgt zwischen 2 und $30 \%$. Schätzungsweise kommt es in jedem fünften Infektionsfall zu hämorrhagischen Manifestationen.

\section{Pathophysiologie}

Die Infektion des Gefäßendothels führt zu Hämorrhagien und zur disseminierten intravasalen Gerinnung mit Verbrauchskoagulopathie.

\section{Immunantwort}

Die Immunantwort entspricht der von fieberhaften Bunyavirus-Infektionen. Das Hämorrhagische KrimKongo-Fieber verläuft manchmal perakut, so dass keine Immunantwort beim Patienten nachweisbar ist. 


\section{Differenzialdiagnose}

Unter Berücksichtigung des jeweiligen Endemiegebietes ist das Hämorrhagische Krim-Kongo-Fieber von anderen hämorrhagischen Fiebern (Gelbfieber, Hämorrhagisches Fieber mit Renalem Syndrom durch Hantaviren, Ebola- und Marburg-Fieber) abzugrenzen. Überdies sind differenzialdiagnostisch zu beachten: bakterielle Septitiden (insbesondere Meningokokken-Sepsis), die Leptospirose und - in entsprechenden Verbreitungsgebieten - Malaria und Rickettsiosen.

\section{Enzephalitis, arbovirale}

\section{Synonym(e)}

LaCrosse-Enzephalitis, Jamestown-Canyon-Enzephalitis, California-Enzephalitis, Cache-Valley-Enzephalitis.

\section{Erreger}

LaCrosse-Virus, Jamestown-Canyon-Virus, CaliforniaEnzephalitis-Virus, Cache-Valley-Virus, Snowshoe-hare-Virus, Tahyna-Virus u. a.

\section{Inkubationszeit}

Die Inkubationszeit bei der LaCrosse-Enzephalitis beträgt ca. 7 Tage.

\section{Leitsymptome}

Fieber, Meningoenzephalitis.

\section{Symptome}

Es handelt sich um akute, kurz andauernde Virusinfektionen mit entzündlicher Beteiligung des ZNS, des Rückenmarks und der Meningen. Die Symptome der verschiedenen Krankheitsbilder sind ähnlich, Schwere und Verlauf jedoch unterschiedlich. Die meisten Infektionen verlaufen asymptomatisch oder mit blanden klinischen Symptomen (Kopfschmerzen, aseptische Meningitis). Schwere Infektionen beginnen in der Regel plötzlich und können im Verlauf zu Desorientiertheit, Stupor, Koma, spastischen Paresen und gelegentlich zu Krampfanfällen führen. LaCrosse-Virus-Infektionen treten bevorzugt bei Kindern unter 15 Jahren auf und können epileptische Anfälle auslösen.

\section{Pathophysiologie}

Meist findet man bei diesen Erkrankungen eine leichte Leukozytose. Im Liquor findet man in der Regel eine lymphozytäre Pleozytose mit 50-500/3 Zellen.

\section{Immunantwort}

- Fieber, arbovirales (Erkrankung 1)

\section{Differenzialdiagnose}

Bunyavirus-Meningoenzephalitiden sind klinisch von anderen viralen Meningoenzephalitiden nicht zu unterscheiden. In Frage kommen differenzialdiagnostisch primär Infektionen durch Herpesviren und Cox- sackieviren, aber auch durch andere Arboviren, die im jeweiligen Gebiet vorkommen. Ätiologisch klärend ist letztlich der spezifische labordiagnostische Erregernachweis.

\section{Diagnostik}

\section{Untersuchungsmaterial}

Die Diagnostik der Bunyaviridae-Infektionen ist weitgehend auf Speziallaboratorien beschränkt. Geeignete Untersuchungsmaterialien sind Vollblut, EDTA-Blut, Hirnbioptat und Liquor für den Virusnachweis (Zellkultur, PCR, Elektronenmikroskopie) oder Vollblut für den serologischen Antikörper-Nachweis.

\section{Diagnostische Verfahren}

Virusanzucht: Bei den meisten Infektionen entsteht lediglich eine kurz andauernde Virämie-Phase mit niedriger Viruslast, sodass die Virusanzucht aus Blut nur selten gelingt. Bei bestimmten Bunyavirus-Infektionen, u. a. dem Oropouche-Fieber, den Sandmückenfiebern oder dem Rift-Valley-Fieber dauert die Virämiephase ausreichend lang und ist die Viruslast ausreichend hoch, sodass die Virusanzucht aus Blut des akut erkrankten Patienten in den ersten Erkrankungstagen erfolgversprechend ist. Beim Zecken-übertragenen Hämorrhagischen Krim-Kongo-Fieber ist ebenso wie beim Rift-Valley-Fieber durch hohe Viruskonzentrationen im Blut und im Gewebe sowie in Exkreten und Sekreten eine Direktübertragung durch Kontakt mit diesen Materialien möglich. In diesen Fällen kann die Virusisolierung aus Blut oder Gewebe mittels Babymaus oder Zellkultur auch diagnostisch genutzt werden. Für die direkte Virusanzucht eignen sich bei Patienten mit ZNS-Infektionen auch Leber-, Milzoder Hirnbioptate. Gelegentlich kann Virus auch im Liquor nachgewiesen werden.

Serologische und elektronenmikroskopische Direktnachweismethoden: Neben der Virusanzucht sind als direkte Nachweismethoden die Elektronenmikroskopie sowie serologische (Antigen-capture-Enzymimmuntests) und immunhistologische Methoden gebräuchlich.

Nukleinsäureamplifikationstests: Für einige Erreger (Oropouche-Virus, Sandfliegenfieber-Viren, Rift-Valley-Virus, Hantaviren) wurden PCR-Methoden für den Direktnachweis aus Blut oder Gewebe etabliert.

Antikörpernachweis: Die Diagnostik beruht hauptsächlich auf den serologischen Verfahren. Zum IgMNachweis wurden für verschiedene Erreger (z. B. Hantaviren, Krim-Kongo-Virus, Sandfliegenfieber-Viren, Rift-Valley-Virus) sensitive $\mu$-capture-ELISAs beschrieben. Daneben werden Enzymimmuntests zum Nachweis von IgG-Antikörpern, indirekte Immunfluoreszenztests und Neutralisationsteste eingesetzt.

\section{Befund / Interpretation}

Diagnostisch ist der direkte Virusnachweis, der Nachweis von IgM-Antikörpern oder ein vierfacher Titer- 
anstieg in IgG-spezifischen oder nicht Immunglobulinklassen-differenzierenden Tests (Neutralisationstest). Kreuzreaktionen innerhalb der serologischen Gruppen (z. B. Phlebotomen-Fieber-Gruppe, Nairoviren) sind zu beachten.

\section{Therapie}

\section{Therapeutische Maßnahmen}

Da eine kausale Therapie nicht existiert, stehen symptomorientierte Maßnahmen im Vordergrund der Behandlung. Beim Hämorrhagischen Krim-Kongo-Fieber kann eine frühzeitig einsetzende Therapie mit Ribavirin Schweregrad und Dauer der Manifestationen günstig beeinflussen. Beim Rift-Valley-Fieber ist die Effektivität einer Ribavirin-Therapie bisher nicht eindeutig nachgewiesen. Bei schweren Verläufen sollte daher ein entsprechender Therapieversuch unternommen werden. Auch die frühzeitige Behandlung mit hochtitrigem Rekonvaleszentenplasma wurde beim Hämorrhagischen Krim-Kongo-Fieber als nützlich beschrieben.

\section{Resistenz}

Resistenzen gegen Ribavirin spielen bisher keine Rolle.

\section{Epidemiologie}

\section{Verbreitung}

Die Verbreitungsgebiete sind $\mathbf{~ T a b . ~} 1$ zu entnehmen. Die meisten Bunyaviren verursachen in definierten geografischen Regionen endemische, d.h. sporadisch auftretende Infektionen. Rift-Valley-Virus und KrimKongo-Virus besitzen wegen der direkten Übertragungsmöglichkeit durch infizierte Gewebe oder Blut außerdem ein epidemisches Potenzial. Auch Erreger, die ausgeprägte Virämien hervorrufen, wie das Oropouche-Virus oder die Sandfliegenfieber-Viren, können Ausbrüche mit mehreren Tausend Fällen verursachen. Im Jahr 2000 sind erstmals Ausbrüche von Rift-Valley-Fieber außerhalb Afrikas auf der arabischen Halbinsel aufgetreten. Insgesamt wurden 857 Erkrankungen und 119 Todesfälle aus Saudi-Arabien gemeldet. Auch zahlreiche Tiere (Schafe, Ziegen, Kamele) erkrankten. Gleichzeitig trat im benachbarten Jemen ein Ausbruch auf: 1.087 Erkrankungsfälle und 121 Todesfälle wurden beobachtet. Die Letalität betrug somit bei diesen Ausbrüchen durchschnittlich etwa $11 \%$. Die wichtigste Bunyavirus-Infektion in den Vereinigten Staaten ist die LaCrosse-Enzephalitis. Man findet sie in Kanada sowie im Norden und Osten der USA. Seit 1960 sind mehr als 1.000 Fälle aufgetreten. Überwiegend sind Kinder unter 15 Jahren betroffen $(\triangleright$ Abb. 1$)$.

\section{Wirtsbereich / Reservoir}

Die verschiedenen Viren besitzen unterschiedlich breite Wirtsspektren. Rift-Valley-Virus infiziert zahlreiche Stechmückenspezies und viele Haus- und Nutztierarten. Als natürliche Reservoire der Bunyaviren $(\triangleright$ Tab. 2) fungieren Vertebraten, überwiegend Nager (Hantaviren, Bunyaviren), aber auch Schafe und andere Haustiere (Rift-Valley-Virus, Krim-Kongo-Virus) sowie Vögel (LaCrosse-Virus, Krim-Kongo-Virus). Die

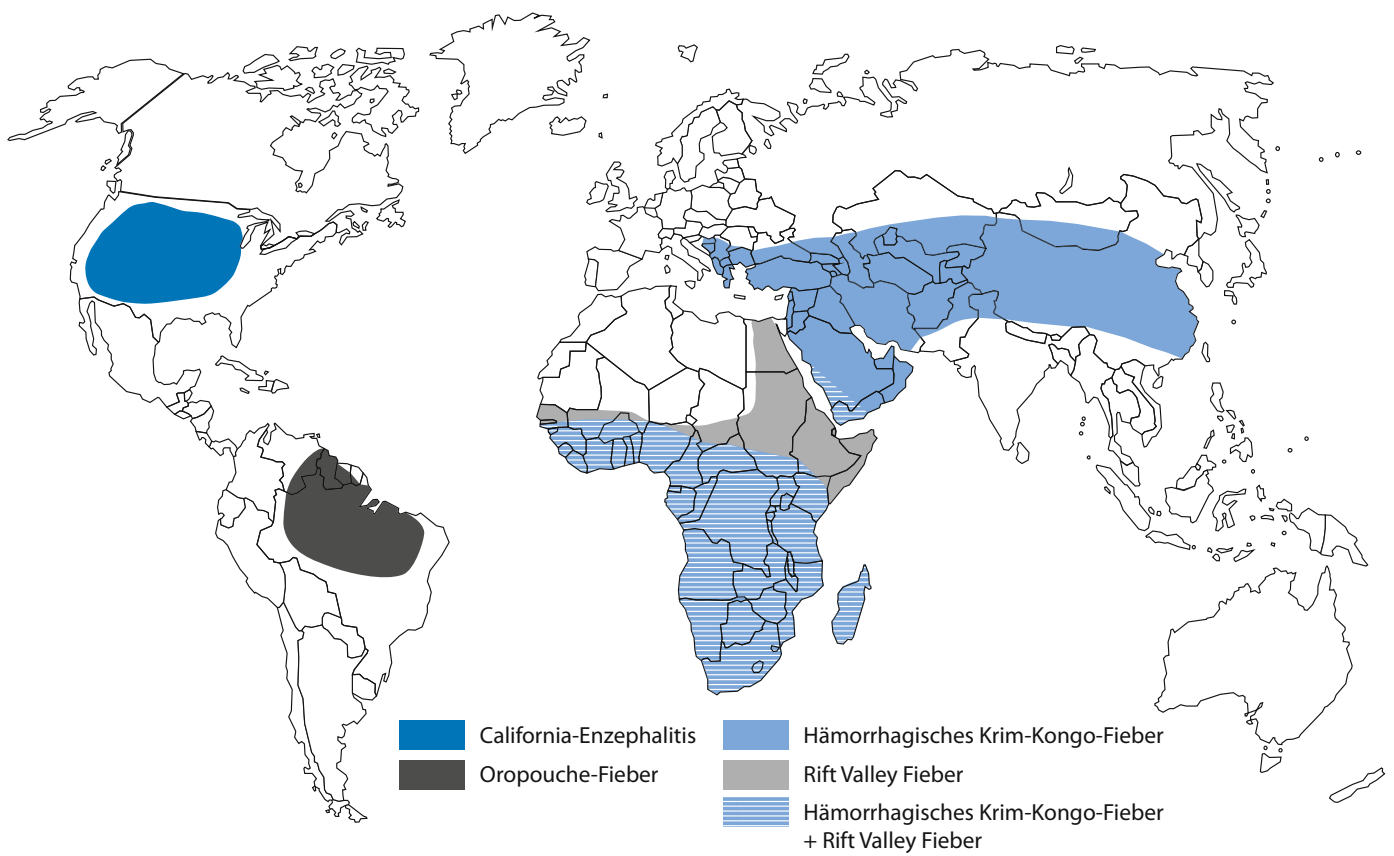


Tab. 2. Ökologische Charakteristika der Bunyaviridae

\begin{tabular}{|c|c|c|c|}
\hline Genus/Virus & Überträger & Reservoirwirt & Übertragungsmechanismus \\
\hline \multicolumn{4}{|l|}{ Orthobunyavirus } \\
\hline LaCrosse-Virus & Aedes triseriatus (t.o.*) & Nager (akut) & Insektenstich \\
\hline Bunyamwera-Virus & Aedes spp. & Nager (akut) & Insektenstich \\
\hline \multicolumn{4}{|l|}{ Phlebovirus } \\
\hline Rift-Valley-Virus & $\begin{array}{l}\text { Stechmücken (versch. } \\
\text { Genera, Aedes spp., } \\
\text { Culex spp., t.o.*) }\end{array}$ & $\begin{array}{l}\text { Schafe, Ziegen, zahl- } \\
\text { reiche Haus- u. Nutz- } \\
\text { tiere (akut) }\end{array}$ & $\begin{array}{l}\text { Insektenstich, infizierte Ge- } \\
\text { webe, Blut }\end{array}$ \\
\hline Sandfliegenfieber-Virus & Phlebotomus spp. (t.o.*) & Unbekannt & Insektenstich \\
\hline Hantavirus & keine & Nager (persistierend) & aerosolisierte Exkretionen \\
\hline \multicolumn{4}{|l|}{ Nairovirus } \\
\hline Krim-Kongo-Virus & Ixodes, Hyalomma spp. & $\begin{array}{l}\text { Herbivoren (akut), Vö- } \\
\text { gel, Nager, Haustiere }\end{array}$ & $\begin{array}{l}\text { Zeckenstich, infizierte Gewe- } \\
\text { be, Blut }\end{array}$ \\
\hline
\end{tabular}

* t.o. $=$ transovarielle Übertragung

Viren können in den Reservoirwirten persistierende (Hantaviren) oder akute (alle anderen Genera) Infektionen hervorrufen. Beim Sandfliegenfieber-Virus ist ein tierisches Wirtsreservoir bisher nicht identifiziert. Hauptreservoir scheinen die Sandfliegen und, im Ausbruchsgeschehen, der Mensch zu sein.

\section{Risikogruppen}

Ein erhöhtes Erkrankungsrisiko ergibt sich aus einer besonderen Exposition gegenüber den übertragenden Arthropoden, im Falle der Hantaviren gegenüber den Reservoirwirten bzw. beim Rift-Valley-Virus und beim Krim-Kongo-Virus durch Exposition gegenüber virushaltigem Gewebsmaterial, Blut oder Milch. Durch Zecken übertragene Virusinfektionen haben ihre höchste Inzidenz in Gebieten, in denen der Mensch mit zahlreichen infizierten Zecken in Kontakt kommt, nämlich im Allgemeinen in ländlichen oder bewaldeten Regionen. Die Erkrankungswahrscheinlichkeit hängt auch von einer eventuell bereits bestehenden (Durchseuchungs-)Immunität ab. So tritt z.B. das Sandfliegenfieber bevorzugt bei militärischen Truppen und bei Reisenden aus Nichtendemiegebieten auf. Ausgesprochen berufliche Risikogruppen ergeben sich beim Rift-Valley-Fieber durch die Exposition gegenüber infiziertem Gewebsmaterial bei Metzgern, Schlachtern, sowie bei medizinischem Personal. Beim Hämorrhagischen Krim-Kongo-Fieber sind bevorzugt Viehzüchter (Übertragung durch Zecken) und medizinisches Personal (nosokomiale Übertragung durch Blut und Gewebe) betroffen. Zu Risikogruppen für Hantavirus-Infektionen $>$ Hantaviren. Das Krim-Kongo-Virus und Hantaviren zählen überdies zu den potenziellen Biokampfstoffen.

\section{Transmission / Vektoren}

Mit Ausnahme der Hantaviren erfolgt die Übertragung der Bunyaviridae durch Arthropoden (Stechmücken - vorwiegend Aedes-Arten -, Phlebotomen, Zecken, $\triangleright$ Tab. 1). In den Überträgern findet man in der Regel eine transstadielle und transovarielle Übertragung ( $\triangleright$ Tab. 2). So nimmt man beispielsweise an, dass LaCrosse-Virus hauptsächlich in Aedes-Eiern überwintert. Hantaviren werden durch aerosolisierte Exkretionen der Nagerwirte übertragen ( $\triangleright$ Hantaviren). Rift-Valley-Virus kann auch durch Kontakt mit Gewebsmaterial oder Milch von infizierten Tieren (z.B. beim Schlachten) übertragen werden. Darüber hinaus scheint eine mechanische Übertragung durch hämatophage Fliegen sowie durch Aerosole möglich. Eine Kontaktübertragung durch Blut oder infiziertes Gewebe ist auch beim Hämorrhagischen Krim-KongoFieber möglich, was die epidemische Ausbreitung begünstigt.

\section{Prävention / Impfstoffe}

Zum Schutz vor dem Rift-Valley-Fieber wurde eine Vakzine aus Formalin-inaktivierten, auf foetalen diploiden Rhesusaffenlungenzellen angezüchteten Viren beschrieben. Sie ist nicht allgemein zugelassen, kann aber bei Laborpersonal, Tierärzten, Entwicklungshelfern und militärischem Personal, das in Endemiegebieten eingesetzt werden soll, angewandt werden. Studien belegen die hohe Immunogenität und gute Verträglichkeit der Vakzine. Allerdings wurde die Produktion durch den Hersteller jüngst eingestellt, so dass nur noch Restbestände zur Verfügung stehen. Eine attenuierte Lebendvakzine befindet sich in der Entwicklung und ist bei Epizootien schon im Einsatz. 
Im Übrigen richten sich persönliche protektive Maßnahmen in Endemiegebieten auf die Vermeidung der Exposition gegenüber den relevanten Vektoren (z. B. durch die Anwendung von Repellentien, Bettnetzen u. ä.), den Reservoirwirten (Hantaviren) bzw. Blut oder Gewebe infizierter Tiere oder Menschen (RiftValley-Virus, Krim-Kongo-Virus).

\section{Ausbruchsmanagement}

Maßnahmen der Vektorkontrolle umfassen die Vernichtung von Stechmücken-Brutplätzen oder das „Residual Spraying" in menschlichen Behausungen. Wegen der Möglichkeit der Virusübertragung durch Blut (Krim-Kongo-Virus, Rift-Valley-Virus) sind im Krankenhausbereich besondere Schutzmaßnahmen zu ergreifen. Dazu gehört die Desinfektion von Blut oder blutigen Ausscheidungen, das Tragen von Schutzkleidung, Handschuhen, Mundschutz etc. Das Krankenhaus- und Laborpersonal muss über die Ansteckungsgefahr informiert werden.

\section{Meldepflicht}

Der direkte oder indirekte Nachweis von Hantaviren oder von Erregern virusbedingter hämorrhagischer Fieber im Zusammenhang mit einer akuten Infektion ist nach $₫ 7$, der Krankheitsverdacht, die Erkrankung oder der Tod an einem virusbedingten hämorrhagischen Fieber nach $\$ 6$ Infektionsschutzgesetz (IFSG) meldepflichtig. Darüber hinaus ist nach $\$ 6$ IFSG jede bedrohliche Krankheit oder Krankheitshäufung zu melden, wenn dies auf eine schwerwiegende Gefahr für die Allgemeinheit hinweist.

\section{Weiterführende Informationen}

\section{Referenzzentren / Expertenlaboratorien}

- Nationales Referenzzentrum für tropische Infektionserreger (NRZ) am Bernhard-Nocht-Institut für Tropenmedizin, Bernhard-Nocht-Straße 74, 20359 Hamburg, Tel.: 040428 18-401, Fax: 040428 18-400, E-Mail: Labordiagnostik@bni-hamburg.de, Homepage: http://www.bnihamburg.de/

\section{Web-Adressen}

- Centers for Disease Control and Prevention: http://www. cdc.gov

- All the Virology (mit weiteren Link: http://www.tulane. edu/ dmsander/garryfavwebindex.html

\section{Schlüsselliteratur}

1. Fauquet CM, Mayo MA, Maniloff J, Desselberger U, Ball LA (eds.) (2005) Virus Taxonomy. Eighth Report of the International Committee on Taxonomy of Viruses. Elsevier Academic Press, San Diego, London.

2. Heyman DL (2004) (Hrsg) Control of Communicable Diseases Manual, 18. Ausgabe. American Public Health Association, Washington

3. Nichol ST, Bunyaviruses. In: Knipe PM et al. (Hrsg), Fields Virology, Philadelphia 4. Ausgabe, vol 2. Lippincott-Raven Publishers, pp 1603-1634

4. Schmaljohn CS, Hooper J, (2001) Bunyaviridae: The Vi- ruses and their Replication. In: Knipe PM et al. (Hrsg), Fields Virology, Philadelphia 4. Ausgabe, vol 2. LippincottRaven Publishers, pp 1581-1602

5. Tidona CA, Darai G (eds) (2001) The Springer Index of Viruses. Springer Berlin, Heidelberg, New York, Tokio

\section{Burkholderia, Ralstonia}

Michael Hogardt, Isabel Späth

\section{Erreger}

\section{Erregerspezies}

Burkholderia-cepacia-Komplex (17 Spezies), B. gladioli, B. mallei und B. pseudomallei. Die Gattung Burkholderia enthält mehr als 60 Spezies, jedoch nur die genannten Arten haben eine humanpathogene Bedeutung. Die Gattung Ralstonia umfasst die 5 Spezies R. pickettii, R. mannitolilytica, R. insidiosa, R. solanacearum, R. syzygii (nur die beiden Erstgenannten verursachen Infektionen beim Menschen).

\section{Taxonomie}

Familie: Burkholderiaceae; Gattung: Burkholderia; Typspezies: B. cepacia (ehemals B. cepacia Genomovar I); Gattung: Ralstonia; Typspezies R. picketii; sowie 9 weitere Gattungen (z. B. Pandoraea, Cupriavidus etc.). Der B.-cepacia-Komplex (BCK) umfasst eine Gruppe phänotypisch ähnlicher und ursprünglich einheitlich als B. cepacia benannter Spezies. Anfangs waren diese nur auf genomischer Ebene unterscheidbar und wurden als B.-cepacia-Genomovare (I-IX) bezeichnet. Typspezies ist B. cepacia oder exakter B. cepacia sensu stricto (Genomovar I). Die weiteren Spezies des BCK (B. cepacia sensu lato) sind B. multivorans (II), B. cenocepacia (III, mit den Subtypen A-D), B. stabilis (IV), B. vietnamensis (V), B. dolosa (VI), B. ambifaria (VII), B. anthina (VIII) und B. pyrrocinia (IX). Ohne ehemalige Genomovar-Klassifizierung, da erst kürzlich beschrieben, sind B. ubonensis, B. latens, B. diffusa, B. arboris, B. seminalis, B. metallica, B. contaminans und B. lata.

\section{Historie}

B. cepacia (ehemals Pseudomonas cepacia) wurde erstmals 1950 von W. H. Burkholder beschrieben. Das lateinische Wort „cepia“ bedeutet Zwiebel, denn die u. a. phytopathogenen Bakterien sind Verursacher der Zwiebelfäule. B. gladioli (ehemals Pseudomonas gladioli) wurde von Severini 1913 beschrieben. B. mallei wurde 1882 von F. Loeffler entdeckt und als Bacillus, Pfeifferella, Mallomyces, Loefflerella und Pseudomonas mallei klassifiziert. B. pseudomallei wurde erstmals 1912 von Whitmore als Erreger der Melioidose beschrieben (Bacillus pseudomallei). Spätere Bezeichnungen waren Pfeifferella, Malleomyces, Loefflerella und Pseudomonas pseudomallei. Die Einordnung der genannten Spezies 1992 durch Yabuuchi in die Gattung Burkholderia erfolgte v. a. aufgrund von Unter- 
schieden in der 16S rRNA-Gensequenz (Pseudomonas RNA-Homologiegruppe II).

R. pickettii (1964 von King erwähnt) wurde $1973 \mathrm{zu}$ nächst von Ralston als Pseudomonas pickettii klassifiziert, 1992 dann als Burkholderia pickettii und 1995 der Gattung Ralstonia zugeordnet.

\section{Morphologie}

Burkholderia spp./Ralstonia spp. sind bewegliche (Ausnahme B. mallei), 0,5-1 × 1-5 $\mu \mathrm{m}$ große Stäbchenbakterien.

\section{Genom}

Für viele Burkholderia spp. liegen Genomsequenzen vor. Das Genom des bei Cystischer Fibrose (CF) besonders pathogen eingestuften B.-cenocepacia-Stammes J2315 (IIIA) ist 8,06 Mb groß und besteht aus 3 zirkulären Chromosomen, die mehrere Genominseln beinhalten. $21 \%$ der Genomsequenz sind im Vergleich zu seltener bei Infektionen aber häufiger in der Umwelt vorkommenden B.-cenocepacia-Isolaten (IIIBIIID) stammspezifisch, was als besondere Anpassung an das Humanhabitat gewertet wird.

\section{Pathogenität / Virulenz / Antigenvariabilität}

Die Erforschung der Virulenzfaktoren der Burkholderien konzentriert sich v. a. auf BCK (bei 2-8 \% der CFPatienten), B. pseudomallei und B. mallei (potenzielle B-Agenzien). Mehrere Virulenzfaktoren sind bekannt, wenn auch deren Rolle für die Infektionspathogenese nicht genau geklärt ist. B. cenocepacia verfügt über die Fähigkeit der Zellkommunikation (Quorum-sensing), der Biofilmbildung, ein Pilin (,cable pilin'), Exopolysaccharid, Lipopolysaccharid, Phospholipase C, Proteasen und spezielle Sekretionssysteme (z. B. Typ III, IV und VI). In den 80er Jahren wurden BCK-Spezies erstmals bei CF nachgewiesen. Selten traten schwere Verläufe (sog. „Cepacia-Syndrom“) und in den 90er Jahren epidemieartige Ausbrüche auf, wie man heute weiß v. a. durch B. cenocepacia IIIA. Für die Virulenz von B. pseudomallei und B. mallei scheint ein kapsuläres Polysaccharid mit antiphagozytärer Wirkung, ein Exopopolysaccharid, Quorom-sensing, ein Typ III-/ Typ VI-Sekretionssystem von Bedeutung zu sein. Beide Burkholderia-Spezies sind fakultativ intrazellulär und können in Phagozyten überleben und replizieren.

\section{Erkrankungen}

\section{Chronische Pneumonie bei CF-Patienten}

Hervorgerufen durch BCK.

\section{Leitsymptome}

Pneumonie, Exazerbationen, Hämoptysen, Sepsis, respiratorische Insuffizienz.

\section{Symptome}

Die Symptome entsprechen einer chronischen Pneu- monie mit rezidivierenden Exazerbationen und Verschlechterung der Gesamtprognose. Selten tritt das sog. „Cepacia-Syndrom“ auf, das mit nekrotisierender Pneumonie mit septischem Verlauf, rapider Verschlechterung der Lungenfunktion und hoher Mortalität einhergeht. CF-Patienten mit einer B.-cenocepacia-Infektion zeigen nach Lungentransplantation eine signifikant schlechtere Prognose.

\section{Differenzialdiagnose}

Pneumonie durch andere CF-Erreger, v. a. P. aeruginosa.

2. Nosokomiale Infektionen bei Nicht-CF-Patienten Hervorgerufen durch BCK, B. gladioli (Pneumonie, Harnwegsinfekt, Kathetersepsis, Peritonitis) bzw. R. pickettii (Meningitis, Endokarditis, Osteomyelitis, Kathetersepsis).

\section{Leitsymptome}

Die klinische Symptomatik manifestiert sich in Abhängigkeit der Lokalisation.

\section{Differenzialdiagnose}

Infektionen durch andere nosokomiale Erreger.

\section{Melioidose (Pseudorotz)}

Hervorgerufen durch B. pseudomallei.

\section{Inkubationszeit}

2-14 Tage (selten Jahre).

\section{Leitsymptome}

Pneumonie, Hautinfektion, Organabszesse, Wundinfektion, Sepsis

\section{Symptome}

Nach Inhalation/Aspiration erregerhaltigen Materials manifestiert sich die Melioidose als primäre Pneumonie. Das klinische Bild variiert von asymptomatischen Infektionen, milden Bronchitiden, akuten nekrotisierenden/abszedierenden Pneumonien (Fieber, produktiver Husten) bis hin zu einer chronischer Pneumonie mit Granulom- und Kavernenbildung (DD: Lungentuberkulose). Nach einer Infektion über Hautverletzungen oder Wunden treten v. a. lokalisierte, eitrige Hautinfektionen mit knotiger Lymphangitis und regionaler Lymphadenitis auf. Sowohl Lungen- als auch Hautmanifestationen können septikämisch verlaufen, z. B. mit multipler Abszessbildung in Organen. In manchen (chronischen) Fällen kann die Melioidose erst nach Jahren (intrazelluläres Überleben) klinisch manifest werden.

\section{Differenzialdiagnose}

Pneumonie durch andere Erreger.

\section{Rotz}

Hervorgerufen durch B. mallei. 


\section{Inkubationszeit}

1-5 Tage bei Hautinfektionen, 10-14 Tage bei Lungeninfektionen.

\section{Leitsymptome}

Haut- und Schleimhautinfektion, Pneumonie, Sepsis

\section{Symptome}

Der Rotz ist primär eine Erkrankung, die bei Einhufern (Pferden, Eseln, Maultieren) vorkommt. Bei engem Tierkontakt kann eine Übertragung auf den Menschen stattfinden. Auch Laborinfektionen sind beschrieben. Hauptmanifestationen sind eitrige Hautund Schleimhautinfektionen, Pneumonie, multiple Abszesse und Sepsis.

\section{Diagnostik}

\section{Untersuchungsmaterial}

Respiratorische Materialien, Blutkulturen, Liquor, Urin, Aszites, Wundabstriche

\section{Diagnostische Verfahren}

Die kulturelle Isolierung gelingt aerob auf Blut- und MacConkey-Agar bei $37^{\circ} \mathrm{C}$. Zum Nachweis von BCK (Wachstumsoptimum bei $30-35{ }^{\circ} \mathrm{C}$ ) und B. pseudomallei (Wachstumsoptimum bei $40{ }^{\circ} \mathrm{C}$ ) sind Selektivnährmedien, die Polymyxin enthalten, anzuraten. B. mallei wächst nicht immer auf MacConkey-Agar. Verlängerte Bebrütungszeiten von mehreren Tagen sind einzuhalten.

BCK-Spezies wachsen auf Blutagar in Kolonien von butterartiger Konsistenz, meist ohne Pigmentierung. Kolonien von B. gladioli sind häufig gelb pigmentiert. B. mallei wächst unter Bildung glatter, weißlicher bis cremefarbener Kolonien. Typisch ist die Unbeweglichkeit von B. mallei. B. pseudomallei bildet hellorange- bis cremefarbene Kolonien mit erdigem Geruch, die meist eine Radiärfaltung aufweisen und mit Kolonien von $P$. stutzeri verwechselt werden können. Ralstonia-Kolonien wachsen langsam und unpigmentiert. Die meisten Isolate der genannten Spezies sind oxidase-positiv. Die biochemische Identifizierung gelingt, ist aber wenig verlässlich, weswegen die molekularbiologische Bestätigung auf Basis einer 16S-rDNA Sequenzierung bzw. von Polymorphismen im recA-Gen (BCK) oder fliC-/fliP-Gen (B. pseudomallei, B. mallei) erfolgen sollte. Die Diagnose Melioidose kann mittels Antikörpernachweis bestätigt werden.

\section{Befund / Interpretation}

Der Nachweis von BCK bei CF-Patienten ist immer relevant (Prognoseverschlechterung, Kohortierung). Werden BCK, B. gladioli oder Ralstonia spp. bei NichtCF-Patienten nachgewiesen, muss die klinische Relevanz (Besiedelung oder Infektion) im Einzelfall abgewogen werden. Der in Europa äußerst seltene Nachweis von B. mallei bzw. B. pseudomallei ist immer ernst zu nehmen, da beide Erreger hoch infektiös sind (L3Erreger) und schwerste Erkrankungen hervorrufen.

\section{Therapie}

\section{Therapeutische Maßnahmen}

Für klinisch relevante Infektionen mit BCK, B. gladioli oder Ralstonia spp. erfolgt eine antibiotische Therapie nach Resistenztestung. Mit BCK infizierte CF-Patienten erhalten meist eine Kombinationstherapie (Ceftazidim, Meropenem, Temocillin und TrimethoprimSulfamethoxazol bzw. Doxycyclin). Die Behandlung der Melioidose umfasst Ceftazidim oder ein Carbapenem in Kombination mit Trimethoprim-Sulfamethoxazol oder Amoxicillin/Clavulansäure. Im Anschluss an die Akuttherapie folgt die orale Erhaltungstherapie über Monate z. B. mit Doxycyclin und TrimethoprimSulfamethoxazol.

\section{Resistenz}

Burkholderia spp. zeigen eine breite intrinsische Antibiotikaresistenz (z. B. gegenüber Aminoglykosiden, Polymyxin). Ralstonia spp. sind ebenfalls Polymyxinresistent.

\section{Epidemiologie}

\section{Verbreitung}

BCK und Ralstonia spp.: weltweit; B. pseudomallei :Südostasien (insbesondere in Nord-Thailand) und Nordaustralien; B. mallei; endemisch als Tierseuche in Asien, Südamerika und Afrika. Der letzte in Deutschland dokumentierte humane Rotzfall war 1959. Bei CF-Patienten wurden bisher alle bekannten BCK-Spezies nachgewiesen, wobei über 90-95\% der Infektionen auf $B$. multivorans (60-80\%) und B. cenocepacia (20-40 \%) zurückzuführen sind.

\section{Wirtsbereich / Reservoir}

Burkholderia spp und Ralstonia spp. sind ubiquitär vorkommende Umweltkeime (Oberflächengewässer, Erdboden, Pflanzen) mit einer Vorliebe für Feuchthabitate.

\section{Risikogruppen}

CF-Patienten (BCK); hospitalisierte Patienten (BCK; Ralstonia spp.); Südostasien-Reisende v. a. bei Langzeitaufenthalten (B.pseudomallei)

\section{Transmission / Vektoren}

Bei CF-Patienten bleibt die Infektionsquelle für BCKSpezies meist unklar. Übertragungen von Patient zu Patient waren früher häufig (private Kontakte oder im Krankenhaus, Kuren, Freizeiten) sind heute aber durch strenge Hygienemaßnahmen sehr selten (z. B. Kohortierung). BCK-Spezies, B. gladioli sowie Ralstonia spp. können im Krankenhaus über verunreinigte Vernebler-, Inkubator-, Respirator- oder Waschflüssigkeiten auf Patienten übertragen werden.

B. mallei wird durch engen Tierkontakt (Pferde, Esel) 
auf den Menschen übertragen, meist über kleine Hautverletzungen oder Wunden. Die Übertragung von $B$. pseudomallei findet meistens über den Kontakt mit kontaminiertem Oberflächenwasser statt.

\section{Meldepflicht}

Meldepflicht nach IfSG bei nosokomialen Häufungen ( 6 Abs. 1, Nr. 2).

\section{Weiterführende Informationen}

\section{Referenzzentren / Expertenlaboratorien}

B.-cepacia-Komplex

Konsiliarlaboratorien für Mukoviszidose Bakteriologie:

- Max von Pettenkofer-Institut für Hygiene und Medizinische Mikrobiologie der LMU München, Pettenkoferstr. 9a, 80336 München, Tel.: 089/5160-5201, Email: heesemann@mvp.uni-muenchen.de

- Institut für Medizinische Mikrobiologie und Krankenhaushygiene, Medizinische Hochschule Hannover, 30623 Hannover, Tel.: 0511/5326769, Email: suerbaum.sebastian@mh-hannover.de

B. pseudomallei/B. mallei

- Institut für Mikrobiologie der Bundeswehr, Neuherbergstr. 11, 80937 München, Tel.: 089/3168-3981, Email: institutfuermikrobiologie@bundeswehr.org

\section{Web-Adressen}

- http://go.to/cepacia

- http://www.ncbi.nlm.nih.gov/sites/entrez?db=genomeprj

\section{Schlüsselliteratur}

1. Lynch JP (2009) Burkholderia cepacia complex: impact on the cystic fibrosis lesion. Semin Respir Crit Care Med 30:596-610

2. Mahenthiralingam E, Baldwin A, Dowson CG (2008) Burkholderia cepacia complex bacteria: opportunistic pathogens with important natural biology. J Appl Microbiol 104:1539-1551.

3. Mandell GL, Bennett JE, Dolin R (eds) (2009) Mandell, Douglas, and Benett's Principles and Practices of Infectious Diseases. Seventh edition, Elsevier Churchill Linvingstone

\section{Burkitt-Lymphom}

Epstein-Barr-Virus

\section{Buschfieber}

Rickettsien

\section{Buschke-Löwenstein-Tumor}

- Humane Papillomviren (HPV)

\section{Busse-Buschke'sche Krankheit}

- Cryptococcus neoformans

\section{B-Virus}

Kerstin Borchers

\section{Erreger}

\section{Synonym(e)}

Herpesvirus simiae, Herpesvirus B, Cercopithecines Herpesvirus 1, CeHV-1, monkey B-Virus, Simian Herpesvirus B.

\section{Erregerspezies}

Macacine Herpesvirus 1 (McHV1)

\section{Taxonomie}

Das B-Virus ist der Ordnung Herpesvirales, der Familie Herpesviridae und der Subfamilie Alphaherpesvirinae zugeordnet. Das B-Virus gehört wie HSV-1 und HSV-2 zum Genus Simplexvirus.

\section{Historie}

Die erste dokumentierte B-Virusinfektion eines Menschen ereignete sich 1932, als Dr. William Bartlet Brebner von einem klinisch unauffälligen Affen der Gattung Macaca mulatta (Rhesusaffe) gebissen wurde. Er entwickelte eine progressive Encephalitis und starb nach 15 Tagen. Gay und Holden (1933) sowie Sabin und Wright (1934) konnten nach Inokulation von Gehirnmaterial des Patienten in Kaninchen das gleiche Krankheitsbild auslösen und den Erreger als Herpesvirus charakterisieren. Der Patient William Bartlet Brebner war Namen gebend für das Virus.

\section{Morphologie}

Das B-Virus stellt ein 120-180 nm großes behülltes DNA-Virus dar. Das ikosaedrische Kapsid besteht aus 162 Kapsomeren und ist von einem Tegument und einer doppelschichtigen äußeren Lipidmembran mit Oberflächenprojektionen umgeben.

\section{Genom}

Das Virusgenom ist linear, doppelsträngig, 156.789 bp groß und hat mit 74,5 \% einen sehr hohen G/C-Gehalt. Es ist wie HSV-1 und -2 strukturiert (E-Typ-Genom) und weist eine 31 \%ige Homologie zu HSV-1 auf. Das Virusgenom des Stammes E2490 ist komplett sequenziert (Accessionnumber AF533768). Das Genom beinhaltet 6 Replikationsursprünge und 74 Gene. Das Gen ICP34,5 (Neurovirulenzfaktor) fehlt im Genom des B-Virus.

\section{Vermehrung}

Wie bei HSV findet die akute Virusvermehrung in der Haut oder Schleimhaut des Respirations- und Genitaltraktes statt. Nach Replikation in Epithelzellen wird das Virus durch Zelllyse freigesetzt und infiziert weitere Zellen oder dringt in die lokalen Nervenendigungen ein. Das Virus kann Neuronen auch direkt infizieren ohne vorherige Replikation. Aus experimentell 
infizierten Mäusen ist bekannt, dass das B-Virus intraxonal und transsynaptisch zu den Nervenzellen sensorischer Ganglien, wie dem Trigeminalganglion und den Spinalganglion gelangt. In vitro lässt sich das B-Virus u. a. auf HeLa-Zellen, Kaninchennierenzellen oder Affennierenzellen vermehren. Nach 1-2 Tagen zeigt sich ein zytophatischer Effekt mit Polyokaryozytenbildung, Abrundung und/oder ballonartigen Vergrößerungen.

\section{Pathogenität / Virulenz / Antigenvariabilität}

B-Virusinfektionen in Makaken verlaufen in der Regel asymptomatisch. In anderen Affenspezies und dem Menschen zeigen B-Viursinfektionen einen schweren Verlauf und enden zu einem hohen Prozentsatz (70$80 \%)$ tödlich. Genetisch und antigenetisch sind alle bekannten B-Virusisolate eng verwandt und serologisch kreuzreaktiv. Einige Proteine wie Glykoprotein $\mathrm{G}$ und $\mathrm{J}$ tragen stammspezifische Epitope.

\section{Erkrankung}

Herpes-Simiae-Encephalitis

\section{Synonym(e)}

Keine.

\section{Inkubationszeit}

Die Inkubationszeit beim Menschen beträgt je nach den Umständen (Infektionsart und Infektionsdosis) 2 Tage bis zu 5 Wochen nach Exposition.

\section{Leitsymptome}

Bläschenbildung um die Hautwunde, grippeähnliche Symptome (Gliederschmerzen, Fieber und Schüttelfrost), starke Kopfschmerzen, Verwirrtheit, lokales Taubheitsgefühl, Lähmungserscheinungen an den betroffenen Extremitäten

\section{Symptome}

Im natürlichen Wirt bleibt die B-Virusinfektion in der Regel asymptomatisch und führt nur gelegentlich, meist unter Stress und Immunsuppression zu rekurrenten Infektionen. Bei Rhesusaffen ist das Krankheitsbild dem der HSV-Infektion des Menschen sehr ähnlich und geht mit Bläschen und Ulzerationen an den Lippen, der Mundhöhle, Zunge sowie Konjunktiven, selten an den genitalen Schleimhäuten einher. Fatal endende Infektionen kommen selten vor und dann bei jungen Tieren. Bei anderen Affenarten (z. B. Husarenaffe, Mantelaffe, Kapuzineraffe) und dem Menschen kommt es zu lokaler Entzündung mit Lymphangitis. Charakteristisch ist der Befall des Gehirns (Enzephalitis) und der Meningen (Meningitis), selten auch des Rückenmarks (Myelitis).

\section{Pathophysiologie}

Beim Menschen kommt es nach einer B-Virusinfektion zu einer schweren aufsteigenden nekrotisierenden Myleoenzephalitis mit Einschlusskörperchen in den
Nerven- und Gliazellen. Der Befall des Gesamthirns mit hämorrhagischen Nekrosen ist ein differentialdiagnostisch wichtiger Befund im Vergleich zur HSV Enzephalitis.

\section{Immunantwort}

Obwohl HSV-spezifische Serumantikörper das B-Virus in vitro neutralisieren, bieten HSV-Antikörpertiter keinen protektiven Schutz gegen eine B-Virusexposition oder -infektion des Menschen.

\section{Differenzialdiagnose}

Im natürlichen Wirt sind andere Herpesvirusinfektionen der Altweltaffen, wie SA8, Herpesvirus papio 2 oder Rhesus CMV, serologisch bzw. molekularbiologisch auszuschließen. Beim Menschen muss eine schnelle Abgrenzung zu HSV-1, HSV-2 oder anderen neurotropen Virusinfektionen erfolgen.

\section{Diagnostik}

\section{Untersuchungsmaterial}

Bei Infektionsverdacht des Menschen, insbesondere bei Biss- oder Kratzwunden durch Makaken, ist das verursachende Tier auf Virusausscheidung zu untersuchen. Hierfür eignen sich Augen-, Nasensekret, Speichelproben, Bläschenflüssigkeit oder Abstriche von Schleimhäuten. Falls möglich, sollte auch von der Wunde der betroffenen Person Material entnommen werden. Ein Problem für den diagnostischen Nachweis des B-Virus im natürlichen Wirt ist die Tatsache, dass das B-Virus in sensorischen Ganglien latent vorliegt und nur in unregelmäßigen Abständen, meist unbemerkt ausgeschieden wird. Ein eindeutiger Virusnachweis ist daher häufig erst postmortal an nervalem Gewebe möglich. Neben Spinalganglien und Trigeminalganglien sind Gehirn- sind Rückenmarksproben geeignet.

In Serumproben können Antikörpertiter gegen das BVirus ermittelt werden, wobei eine serologische Kreuzreaktion mit nahverwandten Vertretern der Simplexviren wie HSV oder SA8 berücksichtigt werden muss. Der Umgang mit B-Virus haltigem Proben- und Untersuchungsmaterial ist nur in entsprechend ausgerüsteten Laboratorien der Sicherheitsstufe 3 zulässig.

\section{Diagnostische Verfahren}

Die PCR ist die Methode der Wahl, um schnell, spezifisch und sensitiv das Virusgenom nachzuweisen. Eine Aussage über die Infektiosität des Erregers ist damit nicht möglich.

Eine serologische Testung von Einzeltieren oder als Bestandskontrolle mittels ELISA hilft Virusträger zu identifizieren. Verlaufsuntersuchungen an Serumpaaren im Abstand von 3-6 Wochen ermöglichen Rückschlüsse auf eine erfolgte Infektion oder Reaktivierung bei Affen aber auch Menschen. 


\section{Befund / Interpretation}

Selbst bei einem negativen PCR- oder ELISA-Befund kann nicht mit hundertprozentiger Sicherheit von einer Virusfreiheit eines Tieres ausgegangen werden. Es sollte daher auch bei negativem Testergebnis grundsätzlich davon ausgegangen werden, dass Makaken latente Virusträger sind und Virus ausscheiden können.

\section{Therapie}

\section{Therapeutische Maßnahmen}

$\mathrm{Zu}$ den wichtigsten Sofortmaßnahmen nach Exposition gehört die intensive (ca. $15 \mathrm{~min}$ ) Wundreinigung mit Seife oder Detergenzienlösungen. Schleimhäute sollten unter fließendem Wasser ausreichend lange (ca. $15 \mathrm{~min}$ ) gespült werden. Nach ärztlicher Untersuchung sollte über eine unverzügliche und ausreichend dosierte und andauernde (bis zu 14 Tagen) orale antivirale Therapie z. B. mit Aciclovir, Famciclovir oder Valacyclovir entschieden werden. Bei einer bereits ausgebrochenen und diagnostizierten B-Virusinfektion ist eine intravenöse antivirale Behandlung z. B. mit Gangciclovir zu empfehlen.

\section{Resistenz}

Es sind keine therapieresistenten Virusmutanten bekannt.

\section{Epidemiologie}

\section{Verbreitung}

Das B-Virus ist weit verbreitet bei Altweltaffen und hier enzootisch bei asiatischen Makaken wie Rhesusaffen und Javaneraffen. Untersuchungen an in Gefangenschaft gehaltenen Makaken zeigten, dass 70-100 \% der adulten Tiere seropositiv sind und damit latente Virusträger darstellen. Aufgrund des Einsatzes von Affen und Affenzellkulturen in der biomedizinischen Forschung sowie der Haltung von Makaken in Zoologischen Gärten ist die Virusverbreitung weltweit.

\section{Wirtsbereich / Reservoir}

Asiatische Makaken sind der natürliche Wirt des BVirus und sollten als potentielle Ansteckungsquelle für andere Primaten betrachtet werden.

\section{Risikogruppen}

Tierhändler, Tierärzte, Tierpfleger, Forscher, Laborpersonal. Bei den etwa 45 dokumentierten Fällen von $\mathrm{B}$-Virusinfektionen beim Menschen handelt es sich in erster Linie um Personen, die mit Labor Makaken direkten Umgang hatten. Während Kinder häufiger als Erwachsene von als Haustieren gehaltenen Makaken infiziert wurden.

\section{Transmission / Vektoren}

Die B-Virusinfektion kann zwischen Tieren durch direkten Kontakt, Biss-, Kratzwunden und Geschlechtsverkehr übertragen werden. Das B-Virus muss zu den
Zoonoseerregern gezählt werden, da Kontaktinfektionen von Menschen durch infizierte Affen, wenn auch verhältnismäßig selten, beschrieben sind. Die bisher beim Menschen bekannten B-Virus Infektionen gingen in den meisten Fällen von klinisch unauffälligen Rhesus-Makaken aus. Eine Übertragung durch Affenbiss (Speichel), Kratzwunden, Nadelstiche, Verletzungen an kontaminierte Gegenstände (Käfiggitterstäbe), Kontakt mit Zellmaterial, Gewebeproben und Körperflüssigkeiten und sogar durch Direktübertragung von Mensch zu Mensch ist bekannt. In etwa der Hälfte der bekannten Fälle haben sich Personen, die mit Affenzellkulturen oder Blutbestandteilen gearbeitet haben infiziert. In Europa sind bisher keine B-Virusinfektionen des Menschen dokumentiert.

\section{Prävention / Impfstoffe}

Personenschutzmaßnahmen (Schutzanzug, Gesichtsschutz, Augenschutz, Handschuhe), regelmäßige Mitarbeiterschulungen, Betriebsanweisung, Hygieneplan, Notfallplan und Gesundheitsüberwachung sowie der Einsatz von spezifisch Pathogen freien Affen sollten zum Schutz vor Ansteckung beim Menschen Beachtung finden. Eine Vakzine existiert nicht.

\section{Ausbruchsmanagement}

Richtlinien zur Prävention, für den Notfall und zur Postexpositionsprophylaxe wurden publiziert (Cohen et al., 2002; Reme et al., 2009) und sollten für jeden Betrieb entsprechend angepasst werden.

\section{Meldepflicht}

Es besteht keine Meldepflicht nach dem Infektionsschutzgesetz.

\section{Weiterführende Informationen}

\section{Referenzzentren / Expertenlaboratorien}

- Prof. Dr. F.-J. Kaup: 0551-3851-241 (Fkaup@gwdg.de)

- Dr. Klaus Dieter Jentsch, Deutsches Primatenzentrum Göttingen, Kellnerweg 4, D-37077 Göttingen, Tel. $+49(0) 551-3851-157$

- Dr. C. Coulibaly, Paul-Ehrlich Institut, Bundesamt für Serum und Imfpstoffe, Paul-Ehrlich-Str. 51-59, 63225 Langen, Tel. +49(0)6103778002

\section{Web-Adressen}

- Allgemeine Informationen: http://www.cdc.gov/ncidod/ diseases/bvirus.htm

- Epidemiologie: http://www.cdc.gov/mmwr/preview/ mmwrhtml/00000920.htm

- Prävention: http://www.cdc.gov/mmwr/preview/ mmwrhtml/00015936.htm

- Prävention und Behandlung: http://www.cdc.gov/mmwr/ preview/mmwrhtml/00035805.htm

\section{Schlüsselliteratur}

1. Cohen JI, Davenport Ds, Stewart JA, Scott D, Hilliard JK, Chapman LE (2002) Recommendations for Prevention of and therapy for exposure to B-Virus (Cercopithecine Herpesvirus 1). CID 35, 1191-1203 
2. Gay FP, Holden M (1933) The herpes encephalitis problem. J Infect Dis 53:287-303

3. Hilliard JK, Munoz RM, Lipper SL, Eberle R (1986) Rapid identification of herpesvirus simiae (B-Virus) DNA from clinical isolates in nonhuman primate colonies. J Virol Meth 13:55-62

4. Huff JL, Barry PA (2003) B-virus (Cercopithecine herpesvirus 1) infection in humans and macaques: potential zoonotic disease. Emerging Infectious Diseases 9:246250

5. Ludwig H, Pauli G, Gelderblom HR, Darai G, Koch RM, Flugel B, Norrild B, Daniel MD (1983) B-Virus (Herpesvirus simiae). In: Roizman B (ed) The herpesviruses, Plenum Press, New York, vol 2, pp 385-428

6. Miranda, MB, Handermann M, Darai G (2005) DNA polymerase gene locus of Cercopithecine herpesvirus 1 is a suitable target for specific and rapid identification of viral infection by PCR technology. Virus Genes 30:307-322

7. Perelygina l, Zhu L, Zurkuhlen H, Mills R, Borodovsky M, Hilliard J (2003) Complete sequence and comparative analysis of the genome of Herpes B-Virus (Cercopithecine Herpesvirus 1) from a Rhesus monkey. JVirol 77:61676177

8. Reme T, Jentsch KD, Steinmann J, Kenner S, Buse E, Sauerbrei A, Kaup JF (2009) Recommendations for post exposure prophylaxis after potential exposure to herpes BVirus in Germany. J Occup Med Toxicol 4: 29

9. Sabin AB, Wright WM (1934) Acute ascending meyelitis following a monkey bite, with the isolation of a virus capable of reproducing the disease .J Exp Med 59:115-136

10. Slomka, MJ, Brown DW, Clewley JP, Bennet AM, Harrington L, Kelly DC (1993) Polymerase chain reaction for detection of herpesvirus simiae (B-Virus) in clinical specimens. Arch Virol 131: 89-99

\section{Bwamba-Virus}

\section{- Bunyaviren}




\section{Cache-Valley-Virus}

Bunyaviren

\section{California-Enzephalitis}

Bunyaviren

\section{California-Enzephalitis-Virus}

Bunyaviren

\section{Calliphora spp.}

Myiasis-Erreger

\section{Campylobacter}

Bernhard SteinbrüCKNER

\section{Erreger}

\section{Synonym(e)}

Entfällt.

\section{Erregerspezies}

C. coli, C. concisus, C. curvus, C. fetus ssp. fetus, C. fetus ssp. venerealis, C. gracilis, C. helveticus, C. hominis, C. hyointestinalis ssp. hyointestinalis, C. hyointestinalis ssp. lawsonii, C. insulaenigrae, C. jejuni ssp. doylei, C. jejuni ssp. jejuni, C. lanienae, C. lari, C. mucosalis, C. rectus, C. showae, C. sputorum biovar faecalis, C. sputorum biovar paraureolyticus, C. sputorum biovar sputorum, C. upsaliensis

\section{Taxonomie}

Familie: Campylobacteraceae

Gattung: Die Familie Campylobacteraceae enthält neben den Gattungen Arcobacter und Sulfurospirillum die Gattung Campylobacter mit derzeit 17 Spezies.

\section{Historie}

1886 wurden von Th. Escherich erstmals spiralförmige Bakterien bei durchfallkranken Säuglingen und Katzen mikroskopisch beobachtet. Dabei handelte es sich wahrscheinlich um C. jejuni bzw. C. coli. Eine Anzucht gelang damals nicht und die Entdeckung geriet in Vergessenheit. Erste Beschreibung eines vibrioähnlichen
Erregers (wahrscheinlich C. fetus ssp. fetus) als Ursache für das „fieberhafte Verwerfen“ bei Schafen durch McFadyean und Stockmann 1909. Erste Anzucht 1913 aus dem Schaf, Erstisolation beim Menschen durch Vinzent 1947 („Vibrio fetus“). Der Zusammenhang mit Durchfallerkrankungen des Menschen wurde über 70 Jahre nach Escherich durch King erneut hergestellt. 1963 Einführung der Gattungsbezeichnung durch Sebald und Veron. Seit 1977 (Einführung von antibiotikahaltigen Selektivmedien) ist die Anzucht ein Routineverfahren in der mikrobiologischen Untersuchung von menschlichen Stuhlproben bei Durchfallerkrankungen. 1991 Abgrenzung der Gattung Arcobacter (selten beim Menschen als Infektionserreger isoliert). Die Gattung Sulfurospirillum wurde 1993 eingeführt, eine humanpathogene Bedeutung ist derzeit nicht bekannt. In den letzten Jahren wurden zahlreiche neue Spezies und Subspezies vorgeschlagen, von welchen bislang nur $C$. insulaenigrae allgemein akzeptiert wurde.

\section{Morphologie}

Gebogene, spiral- oder S-förmige gramnegative Stäbchen, $0,2-0,9 \mu \mathrm{m}$ dick, $0,5-5 \mu \mathrm{m}$ lang, von älteren Kulturen oder nach Sauerstoffexposition auch kokkoid. Aufgrund ihrer Schlankheit sind sie in der Gram-Färbung häufig nur schwer zu erkennen. Charakteristisch ist eine gute Beweglichkeit (oft „windradartig“), welche vor allem bei Phasenkontrastbetrachtung oder in der Dunkelfeld-Mikroskopie deutlich erkennbar wird. Die Beweglichkeit wird durch je eine uni- oder bipolare Geißel vermittelt, welche aber auch fehlen kann.

\section{Genom}

Im Jahr 2000 wurde die Sequenzierung des Genoms von C. jejuni NCTC 11168 abgeschlossen, mittlerweile ist das Genom von 8 Campylobacter spp. sequenziert. Das ringförmige Chromosom von C. jejuni hat einen GC-Anteil von 30,6 \% und ist mit 1,64 Megabasen relativ klein. Es kodiert für etwa 1.600 Proteine. Auffällig sind der geringe Anteil von Insertionen und RepeatSequenzen sowie das Auftreten von hypervariablen Regionen. Mehrere mit der Pathogenität assoziierte Plasmide wurden beschrieben, u. a. pVir bei blutigen Diarrhoen.

\section{Vermehrung}

In vitro: Unter Laborbedingungen benötigen die meisten Arten der Gattung Campylobacter zum Wachstum eine mikroaerobe Atmosphäre $\left(5 \% \mathrm{O}_{2}, 10 \% \mathrm{CO}_{2}\right.$, $85 \% \mathrm{~N}_{2}$ ). Für das Wachstum einiger Arten (C. sputorum, C. concisus, C. mucosalis, C. curvus, C. rectus und 
C. hyointestinalis) ist ein Wasserstoffanteil von ca. $6 \%$ in der Kulturatmosphäre erforderlich. C. gracilis wächst ausschließlich unter anaeroben Bedingungen. Die thermophilen Campylobacter-Spezies (v. a. C. jejuni, C. coli, C. lari) vermehren sich sehr gut auch bei Temperaturen bis $43^{\circ} \mathrm{C}$. Diese Eigenschaft wurde vor der Einführung effektiver Selektivmedien häufig zur verbesserten Selektivität bei der Anzucht genutzt. Zur Anzucht sind zahlreiche unterschiedliche blut- und nicht-bluthaltige Selektivnährmedien verfügbar. Auch Filtrationsmethoden mit Anzucht auf nicht-selektiven Medien sind beschrieben, werden aufgrund des hohen Aufwandes aber nur selten in der Diagnostik eingesetzt. Je nach eingesetztem Medium wachsen Campylobacter spp. meist in flachen, unregelmäßig begrenzten Kolonien. Das Koloniematerial erscheint nach Abnahme mit der Öse oft leicht rötlich. Auf bluthaltigen Medien tritt keine Hämolyse ein.

In vivo: Die Vermehrung findet v.a. im Gastrointestinaltrakt kolonisierter Wirtstiere statt, welche selbst nicht erkranken (z. B. Geflügel, Rind, Schaf, Schwein). Bei einer Infektion des Menschen vermehren sich die Erreger im Jejunum, Ileum und Colon. Für die bei $\mathrm{Pa}$ rodontitis auftretenden Spezies C. concisus, C. rectus, C. curvus und C. showae ist der Mensch das einzige bekannte Reservoir.

\section{Pathogenität / Virulenz / Antigenvariabilität}

Minimale Infektionsdosis ab ca. 500 Bakterien, meist sind jedoch mindestens $10^{4}$ Bakterien zur Auslösung einer Infektion nötig. Über die Pathogenese ist, nicht zuletzt aufgrund eines fehlenden Tiermodells, noch relativ wenig bekannt. Motilität und Spiralform scheinen eine Rolle beim Durchdringen der Schleimschicht von Jejunum, Ileum und Colon zu spielen. In der Folge vermitteln Oberflächenstrukturen, u.a. der Geißeln, sowie Polysaccharide Adhäsion an das Darmepithel und Kolonisation. Invasion in Darm-Epithelzellen sowie Translokation in die Submukosa wurden beschrieben, Häufigkeit und pathogenetische Bedeutung dieser Vorgänge sind jedoch unbekannt. Wesentliche Pathogenitätsfaktoren sind die Geißeln sowie verschiedene Adhäsine (u. a. PEB1, JIpA, CadF). Etwa 1,5 je 1.000 Fälle sollen mit einer Bakteriämie einhergehen. Tödliche Verläufe sind sehr selten, kommen jedoch vor. Über Campylobacter-Toxine wurde eine Vielzahl oft widersprüchlicher Arbeiten publiziert. Wahrscheinlich können Campylobacter-Stämme unterschiedliche Toxine wie das CDT (cytolethal distending toxin) produzieren, deren pathogenetische Bedeutung jedoch noch weitgehend unklar ist. Klassische Enterotoxine wie Shiga-Toxin oder Cholera-Toxin wurden bisher nicht nachgewiesen. C. fetus und C. rectus synthetisieren ein S-(surface-)Layer-Protein, welches über Hemmung der C3b-Bindung zu Serum- und damit zu Phagozytoseresistenz führt. Die hohe Antigenvariabilität wird bei der Serotypisierung basierend auf hitzelabilen (HL-) Antigenen nach Lior und hitzesta- bilen O-Antigenen nach Penner genutzt (160 HL- und 65 O-Serotypen).

C. jejuni und C. coli, seltener C. helveticus, C. lari und C. upsaliensis sind Erreger von Enteritis und Enterokolitis. C. fetus verursacht, v. a. bei Immunsupprimierten, extraintestinale Infektionen mit Bakteriämie bzw. Sepsis und Absiedlung der Erreger in unterschiedlichen Lokalisationen (Harnwegsinfekte, Meningitis, Endokarditis, Peritonitis, Pankreatitis, reaktive Arthritis, Abort und Neugeborenensepsis sind beschrieben). C. sputorum wurde aus Abszessen isoliert, während C. curvus, C. rectus, C. gracilis und C. showae mit der Pathogenese der Parodontitis in Zusammenhang gebracht werden.

\section{Erkrankung \\ Campylobacter-Enteritis \\ Synonym(e) \\ Campylobacteriose.}

\section{Inkubationszeit}

Die Inkubationszeit beträgt 2-10 Tage, meist 2-5 Tage.

\section{Leitsymptome}

Fieberanstieg bis über $40{ }^{\circ} \mathrm{C}$, abdominelle Krämpfe, wässrige Diarrhoen, in bis zu $50 \%$ der Fälle auch schleimig oder mit Blutbeimengung.

\section{Symptome}

Der eigentlichen akuten Phase der Erkrankung gehen unspezifische Krankheitserscheinungen voran (Prodromalstadium): Kopfschmerzen, Myalgien, Arthralgien sowie allgemeines Krankheitsgefühl. Fieberanstieg, abdominelle Krämpfe und Kreislaufbeschwerden kennzeichnen den Beginn der Erkrankung. Erbrechen ist selten. Hauptsymptom sind die zahlreichen (oft mehr als 10/d) wässrigen, oft auch schleimigen Diarrhoen, teils mit Blutbeimengung. Diese halten meist wenige Tage bis zu einer Woche an und sind üblicherweise selbstlimitierend. Bei Immunsupprimierten kommen länger dauernde Verläufe vor, Dauerausscheider sind außer bei AIDS-Patienten sehr selten.

\section{Pathophysiologie}

Am häufigsten finden sich C. jejuni (ca. 90 \% der Fälle) und C. coli, selten C. helveticus, C. lari und C. upsaliensis. In Stuhlproben Erkrankter sind häufig zahlreiche Granulozyten nachweisbar. Zahlreiche Daten sprechen für die Invasivität der Erreger durch Überwindung der tight junctions des Darmepithels. Die eigentliche pathophysiologische Ursache des Leitsymptoms Diarrhoe ist nach wie vor unklar, wahrscheinlich jedoch durch mehrere, z. T. auch wirtsabhängige Faktoren bedingt. Die Erreger werden insgesamt meist für 2 bis 3 Wochen mit dem Stuhl ausgeschieden. 


\section{Immunantwort}

Anstieg von spezifischen IgG-, IgM- und IgA-Antikörpern im Serum sowie von IgA-Antikörpern im Stuhl nach Infektion. Abfall auf Ausgangswerte bei unkompliziertem Verlauf innerhalb von ca. 4 Wochen. Die Immunität schützt nicht vor Neuinfektionen, die Erkrankung kann jedoch milder verlaufen. Die Antikörper spielen eine wesentliche Rolle bei Folgeerkrankungen: Ca. 3 Wochen nach Beginn der Erkrankung können aseptische reaktive Arthritis, Reiter-Syndrom (Arthritis, Konjunktivitis, Urethritis) oder eine PolyNeuroradikulitis (Guillain-Barré-Syndrom, aufsteigende Parese bis zur Atemlähmung) auftreten. Letztere beruht auf einer Antigenverwandtschaft von Strukturen der Core-Region des Lipooligosaccharides von Campylobacter (Assoziation mit bestimmten Serotypen, z. B. Penner O:19, O:41) mit Gangliosiden (u.a. GM1, GD1a, GD3) der Schwann'schen Scheiden.

\section{Differenzialdiagnose}

Differenzialdiagnostisch sind infektiöse Enteritiden durch andere bakterielle (z. B. Salmonellen, Shigellen, Yersinien) oder virale (z. B. Rota-, Adeno-, Noro-Viren) Erreger zu berücksichtigen

\section{Diagnostik}

\section{Untersuchungsmaterial}

Enteritis: Stuhlprobe, zur Erhöhung der Nachweissicherheit möglichst kurze Transportzeit zum Labor; extraintestinale Infektionen: in Abhängigkeit von der Lokalisation z. B. Blutkultur, Liquor, Abszesspunktat, Urin; Antikörpernachweis: Serum

\section{Diagnostische Verfahren}

Mikroskopie: Morphologie.

Kulturelle Anzüchtung: Erfolgt über Filtration auf Blutplatten oder spezielle bluthaltige oder -freie Selektivmedien. Inkubation für $48 \mathrm{~h}$ bei $37^{\circ} \mathrm{C}$ in mikroaerobem Milieu $\left(5 \% \mathrm{O}_{2}, 10 \% \mathrm{CO}_{2}, 85 \% \mathrm{~N}_{2}\right)$, für einige Campylobacter spp. kann $\mathrm{H}_{2}$-Zusatz erforderlich sein ( Vermehrung).

Kulturelle und biochemische Identifizierung: Nachweis von Oxidase und Katalase, Kohlenhydrate werden weder fermentiert noch oxidiert. Differenzierungsmerkmale sind $\mathrm{H}_{2} \mathrm{~S}$-Bildung, Hippurathydrolyse, Indoxylacetathydrolyse, Nitratreduktion und Wachstum bei 25 und $42^{\circ} \mathrm{C}$. Die Prüfung des Resistenzverhaltens gegen Nalidixinsäure kann bei zunehmender Chinolon-Resistenz nicht mehr als Differenzierungsmerkmal empfohlen werden. Aufgrund der geringen Anzahl zur Verfügung stehender biochemischer Reaktionen sind weitere Differenzierungsmethoden wie die gaschromatographische Auftrennung der Gesamtzellfettsäuren, molekularbiologische Verfahren (PCR, Hybridisierung) oder MALDI-TOF von besonderer Bedeutung.

Typisierung: Serotypisierung nach den Schemata von Lior und Penner (nur in wenigen spezialisierten Labo- ratorien verfügbar). Molekularbiologische Typisierung mittels Pulsfeld-Gelelektrophorese, RFLP, multilocus sequence typing $u$. a.

Antigennachweis: Testverfahren zum Nachweis von Campylobacter-Antigen in Stuhlproben sind verfügbar. Vorteil: Gegenüber der Kultur schnelleres Vorliegen des Ergebnisses, Nachteil: z. T. geringere Sensitivität.

Molekularbiologie: Verschiedene Nachweisverfahren (z. B. PCR, FISH) sind beschrieben, werden aber nicht in der Routinediagnostik eingesetzt.

Antikörpernachweis: Nur bei Folgeerkrankungen (reaktive Arthritis, Guillain-Barré-Syndrom) indiziert. KBR, ELISA und Western Blot stehen zur Verfügung, sind aber noch wenig standardisiert.

\section{Befund / Interpretation}

Der Nachweis von enteropathogenen Campylobacter spp. im Stuhl bei Enteritis und Fehlen des gleichzeitigen Nachweises anderer Enteritiserreger kann als beweisend für die Ätiologie gewertet werden. Gleiches gilt für den Nachweis anderer Campylobacter-Arten aus primär sterilen Materialien (z. B. Blutkultur, Abszesspunktat).

\section{Therapie}

\section{Therapeutische Maßnahmen}

Enteritis: Bei unkompliziertem Verlauf lediglich symptomatische Therapie (Volumen- und Elektrolytsubstitution). Bei schwerem (hohes Fieber, blutige Diarrhoe) oder lang anhaltendem Verlauf (> 7 Tage) Gabe von Makroliden. Alternativ Ciprofloxacin oder Tetrazyklin (bei Kindern kontraindiziert). Keine Gabe von Motilitätshemmern!

Extraintestinale Infektionen und Bakteriämie (v. a. C. fetus): Ampicillin (bei schweren Verläufen zusätzliche Gentamicin), Carbapeneme.

Guillain-Barré-Syndrom: Gabe von Immunglobulinen, Plasmapherese

\section{Resistenz}

Ca. 90 \% der C.-coli- und über $95 \%$ der C.-jejuni-Isolate sind sensibel gegen Makrolide, häufig aber resistent gegen Penicilline und Cephalosporine. In den letzten Jahren starke Zunahme der Resistenz gegen Chinolone (10-20\% in Mitteleuropa, über $50 \%$ in Südeuropa und Asien). Extraintestinale Infektionen durch C. fetus können mit Ampicillin, ggf. in Kombination mit einem Aminoglykosid behandelt werden. Insgesamt ist die Methodik der Resistenztestung noch schlecht standardisiert.

\section{Epidemiologie}

\section{Verbreitung}

Campylobacter spp. sind weltweit verbreitet, in Deutschland ist Campylobacter der häufigste bakterielle Durchfallerreger (2008 wurden 64.731 Erkran- 
kungen gemeldet; zum Vergleich Salmonellosen: 42.909 Fälle), was einer Inzidenz von 78,7 Erkrankungen je 100.000 Einwohnern entspricht. Der jahreszeitliche Gipfel der Erkrankungen liegt in den Sommermonaten. Die Altersverteilung der Erkrankten zeigt zwei Schwerpunkte bei unter 5- und 25- bis 29-Jährigen.

\section{Wirtsbereich / Reservoir}

Wichtigstes Erregerreservoir und häufigste Infektionsquelle sind besiedelte, meist asymptomatische Tiere, v. a. Geflügel, aber auch Rind, Schwein, Schaf, Hund, Katze und Vögel.

\section{Risikogruppen}

Risikogruppen sind Kleinkinder, junge Erwachsene, Touristen, v. a. bei Reisen in warme Länder mit niedrigem hygienischen Standard, sowie Beschäftigte in Tierzucht- oder tierverarbeitenden Betrieben.

\section{Transmission / Vektoren}

Die Übertragung erfolgt hauptsächlich über kontaminierte Lebensmittel, insbesondere Schlachtgeflügel und Rohmilch. Andere tierische Lebensmittel (Rind-, Schweinefleisch) sind aufgrund der anderen Verarbeitungsprozesse seltener Quelle einer Infektion. Eine sekundäre Keimvermehrung in Lebensmitteln ist selten. Berichtet wurden auch Erkrankungen nach Kontakt mit an Diarrhoe erkrankten Katzen und Hunden, Ausscheidungen von Wildvögeln oder Aufnahme von Oberflächenwasser.

\section{Prävention / Impfstoffe}

Campylobacter-freie Nutztierbestände werden z. T. angestrebt, sind aber in der Praxis nur schwer zu verwirklichen. Wichtigste Maßnahmen zur Prävention sind Verwendung von einwandfreiem Trinkwasser, strenge Küchenhygiene, Durchgaren von Fleisch und Verzicht auf Rohmilch (zuverlässige Abtötung durch Pasteurisieren). Ein Impfstoff steht nicht zur Verfügung.

\section{Ausbruchsmanagement}

Da die Übertragung meist über kontaminierte Lebensmittel erfolgt ( $\$$ Transmission / Vektoren) und eine direkte Infektionskette von Mensch zu Mensch selten ist, sind an das Ausbruchsmanagement keine über das übliche Maß hinausgehende Anforderungen zu stellen. Übliche Hygienemaßnahmen zur Unterbindung fäkal-oraler Übertragung.

\section{Meldepflicht}

Der direkte oder indirekte Nachweis darmpathogener Campylobacter ist nach $\$ 7$ (1) IfSG namentlich zu melden. Weiter ist nach $\$ 6$ (1) IfSG der Verdacht auf oder die Erkrankung an einer Campylobacter-Enteritis meldepflichtig, sofern eine Person betroffen ist, die in lebensmittelverarbeitenden Bereichen beschäftigt ist oder zwei oder mehr gleichartige Erkrankungen auftreten, bei denen ein epidemiologischer Zusammenhang wahrscheinlich ist oder vermutet wird.

\section{Weiterführende Informationen}

\section{Referenzzentren / Expertenlaboratorien}

- Nationales Referenzzentrum für Salmonellen und andere bakterielle Enteritiserreger am Robert Koch-Institut (Bereich Wernigerode), FG 11 - Bakterielle Infektionen, Burgstr. 37, 38855 Wernigerode; Leitung: Frau PD Dr. A. Flieger, Tel.: 03018 754-2522, -4206; Fax: 03018 754-4207, E-Mail: fliegera@rki.de

\section{Web-Adressen}

- http://www.rki.de/cln_169/nn_196658/DE/Content/ InfAZ/C/Campylobacter/Campylobacter.html? nnn=true

- http://www.cdc.gov/nczved/divisions/dfbmd/diseases/ campylobacter/

- http://www.who.int/topics/campylobacter/en/

\section{Schlüsselliteratur}

1. Allos BM, Blaser MJ (2010) Campylobacter jejuni and related species. In: Mandell GL, Bennett JE, Dolin R (Hrsg.) Mandell, Douglas, and Bennett's Principles and Practice of Infectious Diseases. 7th ed. Elsevier Philadelphia, pp 2793-2802

2. Fitzgerald C, Nachamkin I. (2007) Campylobacter and Arcobacter. In: Murray PR, Baron EJ, Jorgensen JH, Landry ML, Pfaller MA (Hrsg.) Manual of Clinical Microbiology. 9th ed. ASM Press, Washington, pp 933-946

3. Kist M (2001) Die Gattungen Streptobacillus, Campylobacter, Arcobacter und Helicobacter. In: Köhler W, Eggers HJ, Fleischer B, Marre R, Pfister H, Pulverer G (Hrsg.) Medizinische Mikrobiologie, Urban\&Fischer Verlag München pp 368-375

4. Kist M (2009) Campylobacter und Arcobacter spp. In: Neumeister B, Geiss HK, Braun RW, Kimmig P (Hrsg.) Mikrobiologische Diagnostik. 2.Aufl., Georg Thieme Verlag Stuttgart, pp 565-573

\section{CA-MRSA}

- Staphylococcus aureus

\section{Canaliculitis lacrimalis}

Aktinomyzeten mit fermentativem Kohlenhydratmetabolismus

- Propionibakterien

\section{Candida}

Marianne Kretschmar, Paul Schnitzler

\section{Erreger}

\section{Synonym(e)}

Mehr als 150 Synonyme für C. albicans, C. tropicalis, 
ca. 20-50 Synonyme für C. parapsilosis, C. guilliermondii und C. krusei. Bekanntestes Synonym für C. glabrata: Torulopsis glabrata.

\section{Erregerspezies}

C. albicans, C. dubliniensis, C. tropicalis, C. parapsilosis, C. guilliermondii, C. glabrata, C. krusei, sonstige Candida-Spezies.

\section{Taxonomie}

Division: Ascomycota; Klasse: Endomycetes; Familie: Endomycetaceae; Gattung: Candida; Arten: C. albicans (Robin) Berkhout; Teleomorph nicht bekannt. C. tropicalis (Castellani) Berkhout; Teleomorph nicht bekannt. C. parapsilosis (Ashford) Langeron \& Talice; Teleomorph nicht bekannt. C. guilliermondii (Castellani) Berkhout var. guilliermondii; Teleomorph: Pichia guilliermondii Wickerham. C. guilliermondii var. membranifaciens Lodder \& Kreger-van Rij; Teleomorph: Pichia ohmeri. C. glabrata (Anderson) S. A. Meyer \& Yarrow; Teleomorph nicht bekannt. C. dubliniensis; Teleomorph nicht bekannt.

Familie: Sacharomycetaceae: C. krusei (Castellani) Berkhout; Teleomorph: Issatchenkia orientalis Kudryavtsev.

\section{Historie}

Erste Erwähnung des Mundsoor von Hippokrates im 4. Jahrhundert vor Christus. Erste Beschreibung der Ösophagus-Candidose 1835 von Véron, der zerebralen Candidose 1862 von Zenker. Abgrenzung der Art C. dubliniensis von C. albicans 1995 durch Sullivan.

\section{Morphologie}

- C. albicans: auf Sabouraud-Glucose-Agar (SGA) bei $37^{\circ} \mathrm{C}$ cremefarbene, meist glatte Kolonien. Mikroskopisch: sprossende Hefezellen 3-8 $\times 2-7 \mu \mathrm{m}$. Auf zuckerarmen Substraten bei $24^{\circ} \mathrm{C}$ : reichlich Pseudomyzel, echtes Myzel und Chlamydosporen.

- C. dubliniensis: Kulturmorphologie wie C. albicans, jedoch auf Guizotiaabbyssinica-Kreatinin-Agar (Staib-Agar) raue Kolonien mit reichlich Chlamydosporen.

- C. tropicalis und C. parapsilosis: auf SGA bei $37^{\circ} \mathrm{C}$ Kolonien, Hefezellen und Pseudomyzel ähnlich wie C. albicans; kein echtes Myzel, keine Chlamydosporen.

- C. guilliermondii: auf SGA bei $37^{\circ} \mathrm{C}$ Kolonien ähnlich wie C. albicans. Sprossende Hefezellen 3-6× 2-4 $\mu \mathrm{m}$. Pseudomyzel spärlich.

- C. glabrata: auf SGA bei $37^{\circ} \mathrm{C}$ Kolonien ähnlich wie C. albicans. Sprossende Hefezellen 2-4 $\times$ 3-6 $\mu \mathrm{m}$. Kein Pseudomyzel.

- C. krusei: auf SGA bei $37{ }^{\circ} \mathrm{C}$ cremefarbene, raue Kolonien. Hefezellen deutlich ellipsoid bis zylindrisch, $4-5 \times 2-5 \mu \mathrm{m}$. Pseudomyzel robust. Wirtsgewebe: Rundzellen mit Sprossungen, meist größer als in Kultur; Pseudomyzel, bei C. albicans und C. dubliniensis auch echtes Myzel.

\section{Genom}

Diploider Chromosomensatz bei C. albicans; ca. 800900 Gene; ein sexueller Vermehrungszyklus wird angenommen. Chromosomen bei C. albicans: R 1, 2, 3, 4, $5,6,7$. Von C. albicans ist das komplette mitochondriale Genom sequenziert.

Candida-Spezies sind meist haploid, sexuelle Vermehrungszyklen zum Teil bekannt, weshalb Zuordnung zu den Ascomyceten erfolgte. Die Sequenzierung des Genoms von C. albicans, C. glabrata und C. tropicalis erfolgt im Rahmen des NCBI Genome Project (Project ID 9526, 12362 bzw. 12494).

\section{Vermehrung}

Vermehrung erfolgt intra- und extrazellulär durch Spross- und Hyphenzellen; Generationszeiten von C. albicans kürzer als von anderen Spezies.

\section{Pathogenität / Virulenz / Antigenvariabilität}

Candida sp. sind opportunistische Krankheitserreger. C. albicans besitzt das größte Pathogenitätspotenzial. Zur Virulenz beitragende Eigenschaften: Dimorphismus (C. albicans, C. dubliniensis); Adhäsion an Epithel- und Endothelzellen, Plastikadhärenz; Sekretion lytischer Enzyme: Aspartatproteinasen, Phospholipasen, Lipasen; Variation von Oberflächenantigenen (Phenotypic Switching); Expression wirtsähnlicher Moleküle wie Komplementrezeptoren (Antigenic Mimikry). Expression der einzelnen Faktoren variabel, z. T. in Abhängigkeit der Erregerlokalisation, Infektionsphase sowie Immunstatus.

\section{Erkrankungen}

\section{Oberflächliche Candidose}

\section{Synonym(e)}

Intertriginöse, genitale, perineale, interdigitale Candidose, Candidose der Schleimhaut, Soor der Mundschleimhaut, Soorösophagitis, Vaginitis, Vulvitis, Kolpitis, Balanitis.

\section{Inkubationszeit}

Unbekannt, da meist endogene Infektion.

\section{Leitsymptome}

Weißliche Beläge in Hautfalten oder auf Schleimhäuten.

\section{Symptome}

Intertriginöse Candidose: Juckreiz, Rötung und Erosionen in Hautfalten, interdigital oder in Zehenzwischenräumen; Paronychie: schmerzhafte Rötung und Schwellung des Nagelwalls mit Entleerung eines eitrigen Sekretes, Übergang auf die Nagelplatte möglich. Vulvovaginale Candidose: Juckreiz oder Brennen und weißliche Beläge auf geröteter Vaginalschleimhaut, Fluor. Beim Mann Candida-Balanitis mit Rötung der Eichel und Vorhaut. Mundsoor/Soorösophagitis: abstreifbare, schmierig-weißliche Beläge der Mund- und 
Ösophagus-Schleimhaut, andernfalls rote scharf begrenzte Läsionen am harten Gaumen und Zungengrund. Anguläre Cheilitis: Fissuren mit Auflagerungen in Mundwinkel. Bei Soorösophagitis Rötung und Schwellung der Schleimhaut mit weißen Auflagerungen, Sodbrennen, retrosternaler Schmerz, Dysphagie.

\section{Pathophysiologie}

Candidose der Haut entwickelt sich bevorzugt in Arealen mit hoher Feuchtigkeit und mechanischer Belastung (submammär, interdigital, im Inguinalbereich, Windelbereich). Massenhafte Vermehrung der Pilzzellen auf und in der Epidermis lässt durch lokale entzündliche Reaktionen nässende Erytheme mit leichter oberflächlicher Schuppung entstehen sowie Maculae am Herdrand. Histologisch finden sich neben Hefezellen auch Hyphenzellen, die in die meist vorgeschädigte Epidermis invadieren. Eitrige, pustuläre Veränderungen sind Hinweis auf eine bakterielle Superinfektion.

Vulvovaginale Candidose: Diabetes, Schwangerschaft sowie orale Kontrazeptiva begünstigen eine massenhafte Vermehrung von Pilzzellen. Durch Sekretion gewebelytischer Enzyme, insbesondere saurer Aspartatproteasen Schädigung des Vaginalepithels und lokale entzündliche Reaktion, ödematöse Schwellung und Rötung der Vulva.

Mundsoor/Soorösophagitis: Der ansonsten zur normalen Mundflora gehörende Pilz entfaltet sein pathogenetisches Potenzial bei Störung der Schleimhautbarriere, Stoffwechselerkrankungen, die u. a. die Sekretbeschaffenheit beeinflussen, bei anatomischen Veränderungen und Immunsuppression. Pilzzellen vermehren sich auf der Schleimhaut und invadieren in Hyphenform das Plattenepithel. Es entstehen intraund subepitheliale Mikroabszesse, Gewebenekrosen und Fibrinbeläge.

\section{Immunantwort}

Keine wirksame Immunreaktion nach Infektion.

\section{Differenzialdiagnose}

Ausschlüsse von Erkrankungen bakterieller, parasitärer oder viraler Genese sind bei oberflächlichen Candidosen notwendig, da die Krankheitsbilder wenig spezifisch sind. Die Art der Prädisposition oder Grundkrankheit kann richtungsweisend sein.

\section{Intraabdominelle Candidose}

Synonym(e)

Tiefe Candidose, tertiäre Peritonitis.

\section{Inkubationszeit}

Unbekannt, da oft endogene Infektion.

\section{Leitsymptome}

Peritonitis.

\section{Symptome}

Peritonitis.

\section{Pathophysiologie}

Meist tertiäre Peritonitis nach Darmoperation, Perforation oder bei CAPD via besiedelte Peritonealkatheter.

\section{Immunantwort}

Keine wirksame Immunreaktion nach Infektion.

\section{Differenzialdiagnose}

Andere, Peritonitis verursachende Erreger.

\section{Systemisch disseminierte Candidose \\ Inkubationszeit \\ Unbekannt, da meist endogene Infektion.}

\section{Leitsymptome}

Fieber, uncharakteristisches Krankheitsbild.

\section{Symptome}

Sepsis mit möglicher Absiedelung in Auge (Endophthalmitis, Chorioretinitis), Hirn (basale Meningitis, Meningitis mit intraparenchymalen Abszessen, Enzephalitis), Knochen (Osteomyelitis), Leber (chronische Entzündung mit multiplen Abszessen), Nieren (interstitielle Nephritis), Herz (Endokarditis mit Besiedelung der Herzklappen, Perikarditis). Besiedelung von Plastikimplantaten (Katheter, Herzklappen etc.) mit Gefahr der Dissemination.

\section{Pathophysiologie}

Nach Einschwemmung der Pilze in die Blutbahn Absiedelung in allen Organen möglich, insbesondere aber in Nieren, Gehirn, Myokard, Auge, Milz und Leber. Im Gewebe entstehen multiple Mikroabszesse.

\section{Immunantwort}

Granulozyten sind wichtige Abwehrzellen, mitentscheidend für Prävention der systemischen Dissemination. Mononukleäre Phagozyten müssen aktiviert werden (IFN $\gamma$ - hauptsächlich aus $\mathrm{CD} 4+$, aber auch CD8+ und NK-Zellen), um phagozytierte CandidaZellen abtöten zu können. Reduktion der CD4+ Zellen mit Auftreten von Soorösophagitis korreliert. Antikörperproduktion bei immunkompetenten Menschen vorhanden, Unterscheidung zwischen Schleimhautbesiedelung, Infektion und Dissemination kaum möglich, Protektion durch Antikörper fraglich.

\section{Differenzialdiagnose}

Andere opportunistische Infektionen.

\section{Diagnostik}

\section{Untersuchungsmaterial}

Je nach Lokalisation Abstriche, Gewebeproben, Blutkulturen (spezielle Medien), Katheterspitzen, Urin, Trachealsekret etc. 


\section{Diagnostische Verfahren}

Bei Materialien aus nicht sterilen Kompartimenten muss bakterielle Begleitflora eliminiert werden (Antibiotika im Kulturmedium). Kultur und Mikroskopie - Morphologie. Artdifferenzierung nach mikroskopischen und biochemischen Merkmalen.

Antigen-Nachweis im Blut: Kommerzialisierter Test, Detektion von zirkulierendem $\beta-1,5$ Oligomannosid von C. albicans; für Screening von Risikopatienten einsetzbar, negativer Testausfall schließt disseminierte bzw. Organmykose aber nicht aus.

Nachweis systemischer Candida-Infektionen mittels PCR wird heute in den Zentren angeboten.

Antikörper-Nachweis. Kommerzialisierte Tests: Indirekter Hämagglutinationstest (HAT), Indirekter Immunfluoreszenz (IFT). HAT und IFT erfassen wegen Antigengemeinschaft Antikörper gegen Zellwandmannane von C. albicans, C. dubliniensis, C. tropicalis, C. parapsilosis und C. glabrata. Präzipitationsreaktionen weisen AK gegen intrazelluläres Proteinantigen nach. ELISA zum Nachweis von Antikörpern verfügbar.

Candida-Serologie ist zum Monitoring von lebensbedrohlichen Candidosen bei Patienten mit regelrechter Immunantwort hilfreich, bei immunsupprimierten Patienten sowie in der Dermatologie und Gynäkologie verzichtbar.

\section{Befund / Interpretation}

Histopathologischer und kultureller Pilznachweis aus Sterilkompartimenten ist pathognomonisch. Ätiologische Bedeutung aus Nichtsterilkompartimenten ist wegen des Candida-Kommensalismus beim Menschen kritisch zu bewerten, hier Quantifizierung sinnvoll und individuelle Beurteilung notwendig.

\section{Therapie}

\section{Therapeutische Maßnahmen}

Candidosen der Haut: lokal Nystatin, Azole (Clotrimazol, Miconazol, Bifonazol u. a.), Ciclopiroxolamin, Naftifin; begünstigende Faktoren beseitigen (abgeschlossenes feucht-warmes Milieu).

Genitalcandidose: lokal Nystatin, Azole, Ciclopiroxolamin, Povidon-Jod; systemisch Fluconazol $(1 \times 150 \mathrm{mg})$ oder Itraconazol $(2 \times 200 \mathrm{mg})$. Partnermitbehandlung. Mundsoor: lokal Nystatin-Suspension (100.000 E alle 3-6 Stunden), Lutschtabletten mit Amphotericin B oder Miconazol.

Bei AIDS und Soorösophagitis systemische Therapie mit Fluconazol oder Itraconazol, Dosierung in Abhängigkeit von nachgewiesener Spezies und Azol-Empfindlichkeit oder mit Caspofungin (70 mg am Tag 1, danach $50 \mathrm{mg} / \mathrm{d}$ ). Systemisch disseminierte oder invasive Candidosen: Fluconazol $(400 \mathrm{mg} / \mathrm{d})$ oder Itraconazol $(400 \mathrm{mg} / \mathrm{d})$ bei C. albicans u. a. empfindlichen Spezies. Fluconazol (600-800 mg/d) bei C. tropicalis, C. lusitaniae, C. parapsilosis und C. glabrata, später Korrektur entsprechend Antimykogramm. C. krusei ist Fluconazol und oft Flucytosin resistent. Voriconazol bei Fluconazol resistenten Spezies $(2 \times 200 \mathrm{mg}$ i.v. bzw. 3-4 mg/kg $2 \times$ täglich, bei Körpergewicht $<40 \mathrm{~kg}$ $2 \times 100 \mathrm{mg} / \mathrm{d}$; loading dose: $2 \times 6 \mathrm{mg} / \mathrm{kg}$. Caspofungin bei nicht neutropenischen Patienten (70 mg am Tag 1, danach $50 \mathrm{mg} / \mathrm{d}$ ). Besiedelte Plastikimplantate (Herzklappen, Katheter) sollten entfernt werden.

\section{Resistenz}

Diverse Resistenzen gegen die Azole sind durch Austestung zu ermitteln.

\section{Epidemiologie}

\section{Verbreitung}

Besiedelung des Menschen mit C. albicans während und kurz nach Geburt beginnend. Infektion erfolgt deshalb meist endogen bei entsprechender Disposition. Oft nosokomiale Infektionen, bei prädisponierender Grundkrankheit hohe Morbidität und Mortalität.

\section{Wirtsbereich / Reservoir}

C. albicans und wahrscheinlich auch C. dubliniensis existiert auf Haut und Schleimhaut des Menschen als Kommensale. C. guilliermondii, C. tropicalis, C. parapsilosis, C. krusei und C. glabrata primär in der Natur vorkommend, zeitweilig Kommensalen bei Mensch und anderen Warmblütern. Terrestrisches und aquatisches Habitat vieler Candida-Spezies außer C. albicans.

\section{Risikogruppen}

Für Haut- und Schleimhaut-Candidosen: Früh- und Neugeborene, Kleinkinder (Windelbereich), Patienten mit konsumierender Grundkrankheit und/oder Abwehrschwäche, unter Antibiotikatherapie, mit großflächigen Hautverletzungen (bes. Verbrennung), Diabetiker, Atopiker.

Für tief lokalisierte und disseminierte Candidosen: Neutropenie jedweder Genese, infektabwehrgeminderte Patienten vielfältiger Genese (bes. Transplantierte), Patienten in Intensivtherapie mit Antibiotikatherapie, Beatmung und/oder zentralem Venenkatheter, Herzchirurgie (künstliche Klappen), Abdominalchirurgie, CAPD.

\section{Transmission / Vektoren}

Candidosen entwickeln sich bei Störungen der Barrierefunktion von Haut bzw. Schleimhaut größtenteils aus dem patienteneigenen kommensalen Reservoir (endogene Infektion), seltener durch Einbringen extern kontaminierter Materialien (z. B. Infusionslösungen) oder durch andersartige Schmierinfektionen (exogene Infektion).

\section{Prävention / Impfstoffe}

Bei Risikopatienten, Fieber unklarer Genese und Nichtansprechen auf Antibiotika, zusätzlich Therapie mit Antimykotika. Prophylaxe in Neutropeniephase 
$\left(<1.000 / \mathrm{mm}^{3}\right)$ und in anderen Risikosituationen (z. B. Abdominalchirurgie) z. B. mit Fluconazol.

\section{Meldepflicht}

Keine Meldepflicht des Erregers. Ausnahme: Erfassungspflicht besonderer Antimykotikaresistenzen in Krankenhäusern.

\section{Weiterführende Informationen}

\section{Referenzzentren / Expertenlaboratorien}

- NRZ für Systemische Mykosen an der Universitätsklinik Göttingen, Abteilung für Bakteriologie, Kreuzbergring 57, 37075 Göttingen

\section{Web-Adressen}

- http://www.bakteriologie.uni-goettingen.de/

- http://www.cathouse4.freeserve.co.uk/mycol.htm

- http://alces.med.umn.edu/ candida.htm

- http://www.dsmz.de/species/gn300167.htm

- http://www.nlm.nih.gov/medlineplus/candidiasis.html

- http://hivinsite.ucsf.edu

- http://www.current-drugs.com/news/ICAAC40R9.htm

- http://www-cme.erep.uab.edu/ onlineCourses/fungal/ ID0047.html

\section{Schlüsselliteratur}

1. Coleman DC, Sullivan DJ, Bennett DE, Moran,GP, Barry HJ, Shanley DB (1997) Candidiasis: the emergence of a novel species, Candida dubliniensis. AIDS. 11:557-567

2. Costanzo MC, Arnaud MB, Skrzypek MS, Binkley G, Lane C, Miyasato SR, Sherlock G (2006) The Candida Genome Database: facilitating research on Candida albicans molecular biology. FEMS Yeast Res.6, pp 671-684

3. Jones T et al. 2004. The diploid genome sequence of Candida albicans. Proc Natl Acad Sci USA 101(19):73297334

4. Tzung KW et al. (2001) Genomic evidence for a complete sexual cycle in Candida albicans. Proc Natl Acad Sci USA 98(6):3249-3253

5. Wahyuningsih R., Freisleben H.-J., Sonntag H.-G., Schnitzler P. (2000). Simple and rapid detection of Candida albicans DNA in serum by PCR for diagnosis of invasive candidiasis. J Clin Microbiol 38:3016-3021.

\section{Candidiasis}

$>$ Candida

\section{Candiru-Virus}

- Bunyaviren

\section{Canicola-Fieber}

- Leptospiren

\section{Capillaria spp.}

Nematoden, seltene Arten

\section{Capillariasis}

- Nematoden, seltene Arten

\section{Capnocytophaga}

Mardjan Arvand

\section{Erreger}

\section{Synonym(e)}

Frühere Bezeichnungen von C. ochraceae sind u. a. Fusiformis nucleatus var. ochraceus, Bacteroides oralis var. elongatus, Bacteroides ochraceus und Ristella ochracea.

\section{Erregerspezies}

C. ochraceae, C. gingivalis, C. sputigena, C. haemolytica, C. granulosa, C. canimorsus und C. cynodegmi.

\section{Taxonomie}

Familie Flavobacteriaceae. Die Gattung Capnocytophaga besteht aus 7 Arten.

\section{Historie}

C. ochraceae wurde erstmals 1956 von Prévot an zwei Isolaten aus eitrigem Sputum und aus dem Abszess einer Katze beschrieben.

\section{Morphologie}

Schlankes fusiformes oder fadenförmiges gramnegatives Stäbchen, teilweise gebogen oder coccoid, gleitende (taumelnde) Beweglichkeit.

\section{Genom}

Die komplette Genomsequenz von C. canimorsus ist in GenBank unter der Accession-Nr. CP001632.1 hinterlegt.

\section{Vermehrung}

Langsames Wachstum auf Blut- oder Kochblut-Agar in anaerober oder mikroaerophiler Atmosphäre (5$10 \% \mathrm{CO}_{2}$ ). Nach 2-4 Tagen kleine, flache, raue, teilweise gelblich pigmentierte Kolonien, in den Agar eingesunken, mit unregelmäßigem Rand und Schwärmzonen oder mit glattem Rand und glatter Oberfläche.

\section{Pathogenität / Virulenz / Antigenvariabilität \\ Keine Daten verfügbar.}

\section{Erkrankungen}

\section{Haut- und Weichteilinfektionen}

Haut- und Weichteilinfektionen nach Hunde- bzw. 
Katzenbiss oder -kontakt, meist durch C. canimorsus. Davon ausgehend können sich Sepsis (häufig bei splenektomierten Patienten), Endokarditis, Meningitis, Augeninfektionen etc. entwickeln. C. ochracea und andere Capnocytophaga species wurden vereinzelt als Erreger von Sepsis, Endokarditis, Peritonitis und Osteomyelitis isoliert.

\section{Inkubationszeit}

Keine Daten verfügbar.

\section{Leitsymptome}

- Wundinfektion, Endokarditis.

\section{Symptome}

- Wundinfektion, Endokarditis.

\section{Pathophysiologie}

Capnocytophaga ist Bestandteil der Schleimhautflora von Mensch und Tier und kann nach hämatogener Verbreitung Infektionen an Herzklappen, Meningen und weiteren Organen verursachen.

\section{Immunantwort}

Keine Daten verfügbar.

\section{Differenzialdiagnose}

- Wundinfektion, Endokarditis durch andere Erreger.

\section{Paradontitis}

C. ochraceae, C. gingivalis, C. sputigena sind mit Parodontitis assoziiert.

\section{Synonym(e)}

Parodontitis.

\section{Inkubationszeit}

- Parodontitis (Aggregatibacter).

\section{Leitsymptome}

- Parodontitis (Aggregatibacter).

\section{Symptome}

- Parodontitis (Aggregatibacter).

\section{Pathophysiologie}

- Parodontitis (Aggregatibacter).

\section{Immunantwort}

Keine Daten verfügbar.

\section{Differenzialdiagnose}

Parodontitis durch andere Erreger.

\section{Diagnostik}

\section{Untersuchungsmaterial}

Blutkultur bei Endokarditis, Sepsis, Osteomyelitis und anderen systemischen Infektionen. Liquor cerebrospi- nalis und Blutkultur bei Meningitis. Gewebeprobe, Punktat bzw. Abstrich bei lokalen Infektionen.

\section{Diagnostische Verfahren}

Mikroskopie: Direkter Nachweis des Erregers im Grampräparat. Kultur stellt das Routineverfahren im mikrobiologischen Labor dar. Capnocytophaga wächst auf Blut- oder Kochblut-Agar, nicht aber auf McConkey-Agar. Oxidase- und Katalasereaktion variabel, indolnegativ, schwache Fermentation von Kohlenhydraten. Molekularbiologische Methoden zum Nachweis und zur Identifizierung der bakteriellen DNA (Nukleinsäureamplifikation, Sequenzierung) finden in besonderen Fällen Anwendung.

\section{Befund / Interpretation}

Nachweis aus primär sterilen Untersuchungsmaterialien wie Blut, Herzklappe, Abszesspunktat spricht für die kausale Rolle des Erregers, während der Nachweis aus mit Normalflora besiedelten Proben meist eine Kolonisation anzeigt.

\section{Therapie}

\section{Therapeutische Maßnahmen}

In vitro häufig empfindlich gegen Breitspektrum-Cephalosporine, Carbapeneme, Fluorchinolone, Chloramphenicol, Erythromycin, Clindamycin.

\section{Resistenz}

Teilweise resistent gegen Cotrimoxazol und Aminoglykoside, i. d. R. resistent gegen Metronidazol und Aztreonam.

\section{Epidemiologie}

\section{Verbreitung}

Der Erreger kommt weltweit vor.

\section{Wirtsbereich / Reservoir}

Einige Capnocytophaga Arten gehören der physiologischen Rachenflora des Menschen an. C. canimorsus und C. cynodegmi besiedeln den Rachenraum von Hunden und Katzen.

\section{Risikogruppen}

Immunsupprimierte, v. a. Patienten mit Granulozytopenie oder Asplenie. Ein erhöhtes Risiko für Endokarditis besteht bei Vorschädigung der Herzklappen, Trägern künstlicher und biologischer Herzklappen und Conduits, nach Shuntanlage sowie nach durchgemachter bakterieller Endokarditis.

\section{Transmission / Vektoren}

Die Infektion ist i. d. R. endogen bei den Spezies, die zur physiologischen Standortflora des Menschen gehören. Andere Arten können durch Hund- bzw. Katzenbiss oder Speichel übertragen werden.

\section{Prävention / Impfstoffe}

Bei vorgeschädigten Herzklappen wird eine antibioti- 
sche Endokarditisprophylaxe bei chirurgischen bzw. zahnärztlichen Eingriffen empfohlen.

\section{Ausbruchsmanagement}

Keine Daten verfügbar.

\section{Meldepflicht}

Keine.

\section{Weiterführende Informationen}

\section{Referenzzentren / Expertenlaboratorien \\ Keine.}

\section{Web-Adressen}

- http://leitlinien.dgk.org/images/pdf/leitlinien_ volltext/2004-10_s2_endokarditis.pdf

- http://www.chirurgie-portal.de/zahnmedizin/ parodontose-parodontitis.html

\section{Schlüsselliteratur}

1. Pers C, Gahrn-Hansen B, Frederiksen W (1996) Capnocytophaga canimorsus septicemia in Denmark, 19821995: review of 39 cases. Clin Infect Dis 23:71-75. Review

2. Steinberg JP, Del Rio C (2005) Other gram-negative and Gram-variable bacilli. In: Mandell, Douglas and Bennett's (eds) Principles and Practice of Infectious Diseases, $6^{\text {th }}$ edn. Churchill Livingstone, New York

\section{Carajas-Virus}

- Vesiculovirus

\section{Caraparu-Virus}

- Bunyaviren

\section{Cardiobacterium}

\section{Erreger}

Mardjan Arvand

\section{Erregerspezies}

Cardiobacterium hominis, C. valvarum.

\section{Taxonomie}

Genus Cardiobacterium gehört der Familie Cardiobacteriaceae an. C. hominis gehört der HACEK-Gruppe an.

\section{Historie}

C. hominis wurde 1964 von Slotnick und Dougherty als Erreger von Endokarditis beschrieben und war lange die einzige Art der Gattung Cardiobacterium. C. valvarum wurde erstmalig 2004 von Han et al. als Endokarditiserreger beschrieben.

\section{Morphologie}

Schlankes, gramnegatives Stäbchen mit grampositiv erscheinenden Polkappen, pleomorph, einzeln, in Paaren, Ketten oder Rosetten gelagert. Unbeweglich.

\section{Genom}

Die Sequenz des 16S rRNA-Gens ist in GenBank unter der Accession-Nr. M35014 verfügbar.

\section{Vermehrung}

Cardiobacterium wächst unter mikroaerophilen (5$10 \% \mathrm{CO}_{2}$ ) oder anaeroben Bedingungen auf Blutbzw. Kochblutagar. Nach 2-4 Tagen kleine konvexe, runde Kolonien, opaleszierend ohne oder mit leichter $\beta$-Hämolyse, die später flach und trocken werden, netzartig konfluieren und in den Agar einsinken.

\section{Pathogenität / Virulenz / Antigenvariabilität \\ Keine Daten verfügbar.}

\section{Erkrankung}

C. hominis ist meist mit Endokarditis assoziiert, seltener mit Meningitis oder anderen eitrigen Infektionen. Der Erreger wurde ferner aus dentalen Plaques und bei Parodontitis isoliert.

\section{Synonym(e)}

Keine Daten verfügbar.

\section{Inkubationszeit}

Keine Daten verfügbar.

\section{Leitsymptome}

Fieber und neu aufgetretenes Herzgeräusch bei Endokarditis.

\section{Symptome}

Weitere Symptome der Endokarditis können eine Splenomegalie, Petechien, Hämaturie und andere Zeichen der Embolisation sowie eine Anämie sein.

\section{Pathophysiologie}

Cardiobacterium ist Bestandteil der Schleimhautflora des Menschen und kann nach hämatogener Verbreitung Infektionen der Herzklappen, Meningen, etc. verursachen.

\section{Immunantwort}

Keine Daten verfügbar.

\section{Differenzialdiagnose}

Endokarditis durch andere Erreger.

\section{Diagnostik}

\section{Untersuchungsmaterial}

Blutkultur bei Endokarditis und Sepsis. Liquor cerebrospinalis und Blutkultur bei Meningitis. Gewebeprobe, Punktat bzw. Abstrich bei lokalen Infektionen. 


\section{Diagnostische Verfahren}

Mikroskopie: Direkter Nachweis des Erregers im Gram-Präparat. Kultur stellt das Routineverfahren im mikrobiologischen Labor dar. Cardiobacterium wächst auf Blut- oder Kochblut-, nicht aber auf McConkey-Agar und ist i. d. R. katalasenegativ und oxidasepositiv. Indol wird produziert (teilweise nur schwach), Glucose und andere Kohlenhydrate werden fermentiert. Molekularbiologische Methoden zum Nachweis und zur Identifizierung der bakteriellen DNA (Nukleinsäureamplifikation, Sequenzierung) finden in besonderen Fällen Anwendung.

\section{Befund / Interpretation}

Nachweis aus primär sterilen Untersuchungsmaterialien wie Blut, Herzklappe, Abszesspunktat spricht für die kausale Rolle des Erregers, während der Nachweis aus mit Normalflora besiedelten Proben meist eine Kolonisation anzeigt.

\section{Therapie}

\section{Therapeutische Maßnahmen}

Normalerweise besteht gute in-vitro-Empfindlichkeit gegen viele Antibiotika. Zur empirischen Therapie der Endokarditis werden Cephalosporine der 3. Generation (Ceftriaxon, Cefotaxim), z. T. in Kombination mit Aminoglykosiden empfohlen.

\section{Resistenz}

$\beta$-Laktamase produzierende Stämme wurden beschrieben.

\section{Epidemiologie}

\section{Verbreitung}

Der Erreger kommt vermutlich weltweit vor.

\section{Wirtsbereich / Reservoir}

Bestandteil der physiologischen Standortflora des oberen Respirationstrakts des Menschen.

\section{Risikogruppen}

Ein erhöhtes Risiko für Endokarditis besteht bei Vorschädigung der Herzklappen, Trägern künstlicher und biologischer Herzklappen und Conduits, nach Shuntanlage sowie nach durchgemachter bakterieller Endokarditis.

\section{Transmission / Vektoren}

Die Infektionen entstehen i. d. R. endogen, d. h. sie gehen von der körpereigenen Normalflora aus.

\section{Prävention / Impfstoffe}

Bei vorgeschädigten Herzklappen wird eine antibiotische Endokarditisprophylaxe bei chirurgischen bzw. zahnärztlichen Eingriffen empfohlen.

\section{Ausbruchsmanagement}

Keine Daten verfügbar.

\section{Meldepflicht}

Keine.

\section{Weiterführende Informationen}

\section{Referenzzentren / Expertenlaboratorien}

Keine.

\section{Web-Adressen}

- http://leitlinien.dgk.org/images/pdf/leitlinien volltext/2004-10_s2_endokarditis.pdf

\section{Schlüsselliteratur}

1. Han XY, Meltzer MC, Woods JT, Fainstein V (2004) Endocarditis with Ruptured Cerebral Aneurysm Caused by Cardiobacterium valvarum sp. nov. Journal of Clinical Microbiology 42:1590-1595

2. Steinberg JP, Del Rio C (2005) Other gram-negative and Gram-variable bacilli. In: Mandell, Douglas and Bennett's (eds) Principles and Practice of Infectious Diseases, $6^{\text {th }}$ edn. Churchill Livingstone, New York

\section{Cardioviren}

Hans-Peter Grunert, Heinz Zeichhardt

\section{Erreger}

\section{Erregerspezies}

Enzephalomyokarditis-Virus und Theilovirus

\section{Taxonomie}

Genus Cardiovirus in der Familie der Picornaviridae mit den weiteren Genera: Enterovirus, Rhinovirus, Aphthovirus, Hepatovirus, Parechovirus, Erbovirus, Kobuvirus und Teschovirus. Für eine kurze Übersicht zu Infektionen des Menschen durch Aphthoviren (Maulund Klauenseuche-Virus) und Kobuviren (Aichivirus) - Enterovirus 68-71 und andere Enteroviren. Nach dem Eighth Report of the International Committee on Taxonomy of Viruses (2005) werden die Cardioviren in die Spezies Enzephalomyokarditis-Virus und Theilovirus eingeteilt. Zur Spezies Enzephalomyokarditis-Virus zählen die Stämme Columbia-SKVirus, Enzephalomyokarditis-Virus (EMCV), MausElberfeld-Virus und Mengovirus. Zur Spezies Theilovirus gehören die Stämme Theiler's-Murine-Enzephalomyelitis-Virus (TMEV mit GDVII, FA, Ask-1, TO, BeAn, DA), Vilyuisk-Human-Enzephalomyelitis-Virus, Saffold-Viren (SAFV) und Theiler-like virus of rats.

Die taxonomische Einteilung basiert u. a. auf den Aminosäure-Identitäten in den Regionen $\mathrm{P} 1$ sowie $2 \mathrm{C}$ und 3CD (jeweils $>70 \%$ ). Bezogen auf das gesamte Virusgenom besteht zwischen den einzelnen Spezies des Genus Cardiovirus eine Sequenzhomologie von $>50 \%$.

picorna: von pico $=$ piccolo, klein; $r n a=$ RNA, ribonucleic acid cardio: von griech. kardia $=$ Herz 


\section{Historie}

Ab dem Jahr 1939 wurden bei den Anzüchtungsexperimenten in Tieren zum Nachweis des Erregers der Poliomyelitis u. a. von Jungeblut, Sanders und Dalldorf verschiedene tierpathogene Viren gefunden, die in Mäusen, Hamstern, Affen und anderen Tieren u. a Enzephalitis und Paralyse hervorriefen. 1945 wurde aus Affen mit Myokarditis durch Helwig und Schmidt/ USA ein Virus isoliert, das in inokulierten Mäusen fatale Paralyse und Myokarditis hervorrief. Diese neuen Virusisolate wurden als Enzephalomyokarditis-Viren (EMCV) bezeichnet und ließen sich durch ihre gemeinsamen antigenen Eigenschaften als eigener EMCV-Serotyp von den Theiloviren abgrenzen. 1948 und 1949 wurden zwei weitere EMCV-Stämme gefunden: Das Mengovirus wurde in Entebbe (Mengo District, Uganda) aus gefangenen Rhesusaffen isoliert, die an einer Paralyse litten. In Elberfeld (Deutschland) wurde aus Mäusen das Mouse-Enzephalomyelitis-Virus (= Maus Elberfeld Virus) nachgewiesen.

Max Theiler isolierte 1933 ein Virus, das in Mäusen eine Enzephalomyelitis hervorruft. Dieses Virus wurde ursprünglich als murines Poliovirus und später als Theiler's-Murine-Enzephalomyelitis-Virus (TMEV) bezeichnet. Später wurden von Theiler ursprünglich gefundene Isolate als TO (Theiler's original) Stämme bezeichnet. Vilyuisk-Human-Enzephalomyelitis-Virus (VHEV) wird für ein gehäuftes Auftreten von neurodegenerativen Erkrankungen bei der yakutischen Bevölkerung im Vilyuy-Flusstal in Sibirien verantwortlich gemacht. VHEV gehört zu den Theiloviren und wurde zwischen 1954 und 1957 aus dem Liquor eines Patienten isoliert und in Mäusen vermehrt. $\mathrm{Ab}$ 2007 wurden Infektionen mit Saffold-Virus (SAFV), einem neuen Theilovirus, vorwiegend bei Kindern mit fiebrigen respiratorischen und gastrointestinalen Symptomen, in einigen Fällen auch mit Polio-ähnlichen Paresen, in Deutschland, Brasilien, Kanada sowie Südund Südostasien beschrieben.

\section{Morphologie}

Cardioviren sind wie alle anderen Picornaviren kleine, sphärische und unbehüllte RNA-Viren (Durchmesser $30 \mathrm{~nm}, 156 \mathrm{~S}, 1,34 \mathrm{~g} / \mathrm{ml}$ Dichte in CsCl). Das Viruskapsid mit seinen vier nichtglykosylierten Viruskapsidproteinen VP1-VP4 umgibt ein Molekül der genomischen Plus-Strang-RNA (einzelsträngig), die auch als mRNA dient ( $\triangleright$ Polioviren). Die Kapsidoberfläche wird durch die Proteine VP1-VP3 gebildet, wobei die Proteine VP1 und VP3 zusammen ein Loch (Pit, 2,2 $\mathrm{nm}$ tief und $3 \mathrm{~nm}$ breit) als Erkennungsstelle für den virusspezifischen Rezeptor bilden.

Cardioviren sind wie Enteroviren an die Bedingungen bei der Passage des Magen-Darmtraktes angepasst (bis $\mathrm{pH} 3$ stabil). Viren des TMEV-Serotyps sind über den gesamten Bereich von $\mathrm{pH}$ 3-9,5 resistent. Viren des EMCV-Serotyps sind dagegen im pH-Bereich 5-7 sehr labil, wenn das umgebende Medium 0,1 M Chlorid oder Bromid enthält. Cardioviren sind wie Polioviren wegen der fehlenden Lipidhülle resistent gegen lipidlösende Mittel. Zur Inaktivierung $>$ Polioviren.

\section{Genom}

Die Genomorganisation der einzelsträngigen PlusStrang-RNA gleicht im Wesentlichen der von den Entero- und Rhinoviren, die Cardioviren enthalten jedoch zusätzlich eine Leadersequenz ( $\triangleright$ Abb. 1). Die virale RNA kodiert als polycistronische mRNA für ein Leader- (L-) Protein, die Kapsidproteine VP4, VP2, VP3 und VP1 sowie funktionelle Proteine mit Polymerase- und Proteaseaktivität(en). Die genomische RNA von Enzephalomyokarditis-Virus (EMCV) ist ca. 7.840 Nukleotide und die von Theiler's-MurineEnzephalomyelitis-Virus (TMEV) ca. 8.100 Nukleotide lang. In der 5'-terminalen nichttranslatierten Region (5'-NTR, 833 Nukleotide bei EMCV und 1.064 Nukleotide bei TMEV) hat EnzephalomyokarditisVirus einen Poly-Cytosin-Abschnitt (Poly-C-Tract; 80-250 Cytosine).

Für Einzelheiten zur Genomstruktur und Prozessierung der viralen Proteine Abb. 1.

Die Enteroviren (Poliovirus, Coxsackieviren, Echoviren und Enteroviren 68-71 und andere Enteroviren) und die humanen Rhinoviren haben eine gleiche Genomorganisation, besitzen jedoch keine Leader (L)Sequenz und können in der Länge der kodierenden und nicht kodierenden Bereiche der jeweiligen RNAs voneinander abweichen ( $\triangleright$ Polioviren). Für Nukleinsäuresequenzen von einzelnen Enteroviren siehe GenBank, National Institute of Health: http://www.ncbi. nlm.nih.gov/sites/entrez? $\mathrm{db}=$ nucleotide; Picornavirus Study Group: http://www.picornastudygroup.com/.

Die Genomkarte zeigt die einzelsträngige virale PlusStrang-RNA (EMCV ca. 7.840 Nukleotide, TMEV ca. 8.100 Nukleotide) mit den kodierenden Bereichen (Kästen) und den nichttranslatierten Regionen am 5' -

\section{Kapsidproteine}

\section{Funktionelle Proteine}

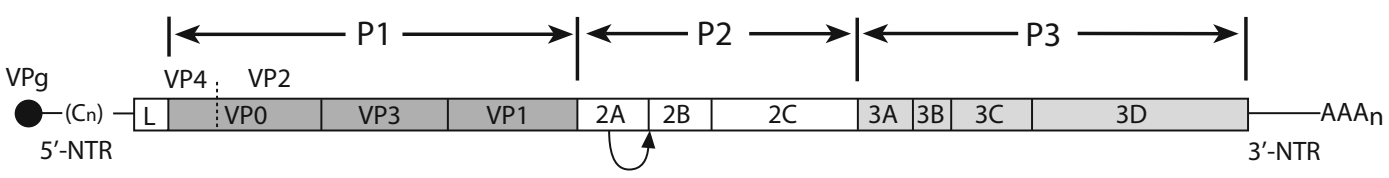


und $3{ }^{\prime}$-Terminus ( 5 '-NTR und 3 '-NTR) (siehe Rueckert, 1996). An das $5^{\prime}$-terminale Uracil der RNA ist das kleine hydrophobe Protein VPg (Virus Protein Genome Linked, 2,4 kDa) kovalent gebunden. In der 5'-NTR (EMCV 833 Nukleotide und TMEV 1064 Nukleotide) befindet sich mit einer ausgeprägten Sekundärstruktur der Initiationsort der Translation (Internal Ribosome Entry Site = IRES) und bei EMCV eine Poly-Cytosin-Region (Poly-C-Tract; 80-250 Cytosine). Die $3^{\prime}$-NTR ist in unterschiedlicher Länge polyadenyliert. Während der Proteinbiosynthese wird der kodierende Bereich der polycistronischen mRNA in ein Polyprotein übersetzt, das im Vergleich zu den Enteroviren am N-Terminus zusätzlich ein LeaderProtein aufweist. Die Region P1 enthält die Kapsidproteine VP0 (Vorläufer von VP4 und VP2), VP3 und VP1. Die Regionen P2 und P3 enthalten funktionelle Proteine (u. a. $2 \mathrm{~A}=$ Protease, $3 \mathrm{~B}=\mathrm{VPg}, 3 \mathrm{C}=$ Protease, $3 \mathrm{D}=\mathrm{RNA}$-Polymerase). Die Prozessierung der Proteine wird durch 3 Proteasen bewirkt. Protease 2A (Pfeil; nur zusammen mit $2 \mathrm{~B}$ proteolytisch aktiv) setzt ein Vorläuferprotein L-P1-2A frei. Die Protease 3C spaltet das Vorläuferprotein an den L-P1 und P1-2A Schnittstellen und setzt das Vorläuferprotein P1 für die Kapsidproteine frei. Die Protease 3C übernimmt auch die meisten übrigen proteolytischen Spaltungen vor dem Zusammenbau des Virus (Assembly). Im Viruskapsid wird nach Aufnahme der viralen RNA das Vorläuferprotein VP0 in die Kapsidproteine VP2 und VP4 gespalten, wobei für Enteroviren eine Beteiligung der RNA postuliert wird.

Die Enteroviren (Poliovirus, Coxsackieviren, Echoviren und Enteroviren 68-71) und die humanen Rhinoviren haben eine gleiche Genomorganisation, besitzen jedoch keine Leader (L)-Sequenz und können in der Länge der kodierenden und nichtkodierenden Bereiche der jeweiligen RNAs voneinander abweichen $(\triangleright$ Polioviren).

\section{Vermehrung}

Die akute Virusvermehrung findet in den Epithelzellen des Darms statt. Es wird davon ausgegangen, dass analog zur Poliovirus-Infektion ( $>$ Polioviren) das Virus über eine Virämie zum Erfolgsorgan (z. B. ZNS) transportiert wird.

\section{Pathogenität / Virulenz / Antigenvariabilität}

Der Reproduktionsmechanismus von Cardioviren ist erst ansatzweise aufgeklärt. Da Cardioviren in ihren strukturellen und funktionellen Eigenschaften teilweise den Enteroviren gleichen, ist für Cardioviren eine Vermehrungsstrategie wie bei Enteroviren anzunehmen ( $\triangleright$ Polioviren). Der Zelltropismus wird durch virusspezifische Rezeptoren geregelt. Für EMC-Viren sind Glykophorin A auf Erythrozyten und VCAM-1 (Vascular Cellular Adhesion Molecule-1, Immunglobulin-Superfamilie) auf Endothelzellen als Rezeptoren charakterisiert worden. Für TME-Viren kommt ein bislang nicht näher untersuchtes $34 \mathrm{kDa}$-Protein als Rezeptor in Betracht. In Analogie zu Polioviren und humanen Rhinoviren der Major-Gruppe dient das Loch (Pit), das auf der Kapsidoberfläche durch die Virusproteine VP1 und VP3 gebildet wird, als Anhaftungsstelle für den Rezeptor. Die wesentlichen Schritte des viralen Reproduktionszyklus zeigen für EMC-Virus Übereinstimmung mit dem Vermehrungsmechanismus von Polioviren. Der zytopathische Effekt (z. B. durch Maus-Elberfeld-Virus) zeigt sich durch extreme Membranausstülpungen der Zelloberflächenmembran. Die Stärke der Neurovirulenz von EMC-Viren ist von der Länge vom Poly-C-Tract in der 5'-NTR abhängig. Über den Reproduktionsmechanismus von TME-Viren ist vergleichsweise wenig bekannt.

\section{Erkrankungen}

1. Erkrankung beim Menschen
- Tab. 1 .

- Tab. 1. Klinische Syndrome der Infektionen mit Cardioviren beim Menschen

\begin{tabular}{|l|l|}
\hline $\begin{array}{l}\text { Klinische Syndrome beim } \\
\text { Menschen (selten) }\end{array}$ & $\begin{array}{l}\text { Viren } \\
\text { (Stämme) }\end{array}$ \\
\hline $\begin{array}{l}\text { Drei-Tage-Fieber } \\
\begin{array}{l}\text { Aseptische Meningitis, } \\
\text { polioähnliche Paralyse }\end{array}\end{array}$ & EMCV \\
\hline $\begin{array}{l}\text { Guillain-Barré Syndrom } \\
\text { Fieberhafte Erkrankungen mit } \\
\text { ZNS-Beteiligung (Enzephalitis) }\end{array}$ & EMCV \\
\hline $\begin{array}{l}\text { Neurodegenerative Erkrankungen } \\
\text { Fieberhafte respiratorische } \\
\text { Erkrankung }\end{array}$ & VHEV \\
\hline $\begin{array}{l}\text { Gastroenteritis } \\
\text { Polio-ähnliche Parese }\end{array}$ & SAFV \\
\hline
\end{tabular}

\section{Inkubationszeit}

Da Infektionen mit Cardioviren beim Menschen selten auftreten, fehlen detaillierte Angaben zur Inkubationszeit.

\section{Leitsymptome}

Fieberhafte Infekte und Erkrankungen des zentralen Nervensystems beim Menschen.

\section{Symptome}

Infektionen mit Enzephalomyokarditis-Viren können zu fieberhaften Erkrankungen führen. 1945-1946 trat bei Soldaten der US-Truppen auf den Philippinen gehäuft ein „Drei-Tage-Fieber" auf, das (ohne kardiale Beteiligung) mit starken Kopfschmerzen, erhöhten 
Temperaturen für 2-3 Tage, Pharyngitis, steifem Nacken und Starre der Gesäß- und Oberschenkelmuskeln (Kernig-Zeichen) einher ging. Neutralisationstests mit Serumpaaren zeigten einen Titeranstieg bei den Erkrankten. G. Dick, der als erster 1948 in Uganda das Mengovirus bei gefangenen paralytischen Rhesusaffen isolierte, erlitt selbst eine akute fieberhafte Erkrankung mit Enzephalitis (Virusnachweis aus dem Blut und signifikanter Titeranstieg von neutralisierenden Antikörpern). Danach wurde mehrfach EMC-Virus bei Patienten mit aseptischer Meningitis, einer Poliomyelitis-ähnlichen Paralyse oder Guillain-BarréSyndrom nachgewiesen. Das Vilyuisk-Human-Enzephalomyelitis-Virus (VHEV) wird für ein gehäuftes Auftreten von neurodegenerativen Erkrankungen in Sibirien bei Yakuten verantwortlich gemacht. Fiebrige respiratorische und gastrointestinale Symptome, in einigen Fällen auch Polio-ähnliche Paresen, wurden in den letzten Jahren bei Kindern in Deutschland, Brasilien, Kanada sowie Süd- und Südostasien mit SaffoldVirus-(SAFV-) Infektionen assoziiert.

\section{Pathophysiologie}

$\checkmark$ Vermehrung und $>$ Pathogenität.

\section{Immunantwort}

Für die Antigenität und Immunantwort bei Cardiovirus-Infektionen des Menschen liegen nur wenige Ergebnisse vor. Es zeigt sich, dass nach Infektion mit EMC-Viren die humorale Immunantwort ähnlich wie nach Poliovirus-Infektionen abläuft ( $\triangleright$ Polioviren). Im Tiermodell wurde für Mengovirus gezeigt, dass Epitope der Virusproteine VP1, VP2 und VP3 auf der Kapsidoberfläche für die Erkennung durch neutralisierende Antikörper verantwortlich sind. Für die zellvermittelte Immunität sind Bereiche von VP2 und VP3 als T-Zell-Epitope bekannt.

TME-Viren induzieren in Mäusen lebenslang nachweisbare neutralisierende Antikörper. Murine CD4+ T-Zellen (Th1) sind für eine Überempfindlichkeitsreaktion vom verzögerten Typ (DTH = Delayed Type Hypersensitivity) verantwortlich (MHC II-Restriktion), die durch Epitope von VP2 bewirkt wird. Die virusspezifische T-Zellantwort, DTH und Makrophagen vermittelte Demyelinisierung werden für die der Multiplen Sklerose ähnliche Krankheit in Mäusen verantwortlich gemacht.

Als Ursache für die dauerhafte Persistenz von TMEV werden zwei Mechanismen vorgeschlagen: In Makrophagen persistiert TMEV mit herunterregulierter Virusvermehrung. TMEV unterläuft in infektiösen Virus-Antikörper-Komplexen bzw. Virusaggregaten oder an zelluläre Membranen gebunden die Immunüberwachung.

\section{Differenzialdiagnose}

Fieberhafte Erkrankungen mit ZNS-Beteiligung wie aseptische Meningitis und Poliomyelitis ähnliche $\mathrm{Pa}$ - ralyse können auch durch Enteroviren hervorgerufen werden. Zur Differenzialdiagnostik > Polioviren, - Coxsackieviren, $>$ Echoviren und Parechoviren sowie Enteroviren 68-71 und andere Enteroviren. Zur Differenzierung von Meningitis bzw. Paralyse, für die andere Viren verantwortlich sein können, sind Mumpsvirus, Herpes-simplex-Viren und (seltener) andere Viren der Herpesvirusfamilie, FrühsommerMeningoenzephalitis-Virus sowie das Lymphozytäre Choriomeningitis-Virus in Betracht zu ziehen.

\section{Erkrankung bei Nagetieren, Affen und anderen}

Tieren

$>$ Tab. 2.

Enzephalomyokarditis-Viren rufen in oral infizierten Mäusen, Ratten und Meerschweinchen häufig Infektionen hervor, die asymptomatisch oder mit geringen klinischen Zeichen verlaufen. Orale Infektionen mit hohen Virusdosen und vor allem intrazerebrale Inokulationen führen zu starken ZNS-Manifestationen mit Enzephalitis sowie Paralyse (schlaffe Lähmungen der hinteren Extremitäten) und in der Folge zum Tode $(\triangleright$ Tab. 2). Anders als beim Menschen sind EMC-Viren bei der Maus auch für eine Myokarditis verantwortlich. EMC(D), das eine Variante von EMCV ist, infiziert in Labormäusen die Insulin produzierenden B-Zellen des Pankreas und induziert Diabetes mellitus. EMC(D) hat im Vergleich zum Wildtypvirus eine Mutation im Viruskapsidprotein VP1. Es wird postuliert, dass EMC(D) dadurch für einen Rezeptor auf BZellen erkennbar wird. Folge sind Virusaufnahme und Virusvermehrung mit zytopathischem Effekt der BZellen.

Bei Affen rufen verschiedene EMCV-Stämme eine Paralyse und Myokarditis hervor. Bei erwachsenen Schweinen steht die Myokarditis im Vordergrund. Intrauterine Infektionen können beim Schwein zu Totgeburten führen. Lebend geborene Schweine versterben im Allgemeinen an einer interstitiellen Pneumonie, Meningoenzephalitis und/oder Myokarditis.

Die Virusstämme von Theiler's-Murine-Enzephalomyelitis-Virus sind für Mäuse neurovirulent. Die hochvirulenten Stämme (z. B. GDVII, FA, Ask-1) vermehren sich in Mäusen nach intrazerebraler Inokulation in Gehirn und Rückenmark und rufen eine Enzephalitis oder Enzephalomyelitis mit nachfolgender Paralyse hervor. Zielzellen sind Neuronen und Gliazellen. Die schwachvirulenten Stämme (z. B. TO, BeAn, DA, Vilyuisk) führen zu einer biphasischen ZNS-Erkrankung. Zu Beginn zeigt sich ein Poliomyelitis-ähnliches Krankheitsbild mit Paralyse (schlaffe Lähmung der hinteren Extremitäten = Mäuse-Poliomyelitis). Während dieser frühen Krankheitsphase sind vor allem die motorischen Neuronen im Hirnstamm und Rückenmark betroffen. Wochen später kommt es zu einer chronischen und entzündlichen Erkrankung mit demyelinisierenden Prozessen. Die weiße Substanz 
Tab. 2. Klinische Syndrome der Infektionen mit Cardioviren beim Tier (Syndrome bei ${ }^{1}$ Affe, ${ }^{2}$ Maus, ${ }^{3}$ Ratte, ${ }^{4}$ Meerschweinchen, ${ }^{5}$ Schwein)

\begin{tabular}{|c|c|}
\hline $\begin{array}{l}\text { Klinische Syndrome } \\
\text { beim Tier }\end{array}$ & $\begin{array}{l}\text { Encephalomyocarditis- } \\
\text { Virus (Stämme) }\end{array}$ \\
\hline $\begin{array}{l}\text { Pneumonie, pulmona- } \\
\text { les Ödem }{ }^{2,5}\end{array}$ & EMCV \\
\hline Paralyse ${ }^{1,2,4}$ & $\begin{array}{l}\text { EMCV, Columbia SK, } \\
\text { Mengovirus }\end{array}$ \\
\hline Meningoenzephalitis ${ }^{5}$ & EMCV \\
\hline Myokarditis ${ }^{1,2,5}$ & EMCV \\
\hline Diabetes mellitus ${ }^{2}$ & EMCV (D) \\
\hline Totgeburt ${ }^{5}$ & EMCV \\
\hline $\begin{array}{l}\text { Klinische Syndrome } \\
\text { beim Tier }\end{array}$ & $\begin{array}{l}\text { Theiler's Murine } \\
\text { Encephalomyelitis-Virus } \\
\text { (Stämme) }\end{array}$ \\
\hline \multicolumn{2}{|l|}{ Intestinale Infekte $e^{2,3}$} \\
\hline Paralyse $^{2}$ & Hochvirulente Stämme: \\
\hline Enzephalitis ${ }^{2}$ & GDVII, FA, Ask-1 \\
\hline \multicolumn{2}{|l|}{ Enzephalomyelitis ${ }^{2}$} \\
\hline Mäuse-Poliomyelitis & $\begin{array}{l}\text { Schwachvirulente } \\
\text { Stämme: }\end{array}$ \\
\hline $\begin{array}{l}\text { Demyelinisierung (Mul- } \\
\text { tiple Sklerose-ähnlich) }\end{array}$ & TO, DA, Vilyuisk \\
\hline
\end{tabular}

von Gehirn und Rückenmark zeigt Infiltrate, wobei zuerst Lymphozyten und danach Makrophagen auftauchen. Mit der Infiltration von Makrophagen beginnt der Myelinzerfall. Als Ursache für den chronischen Verlauf wird u. a. die Persistenz von TMEV in Makrophagen angesehen. Wie Lipton (1994) zusammenfasst, ist die TMEV-induzierte demyelinisierende Erkrankung der Maus ein anerkanntes Tiermodell für die Multiple Sklerose (MS). Dafür spricht weiterhin, dass die Krankheit unter Kontrolle von Genen des Haupt-Histokompatibilitäts-Komplexes (MHC II) steht und der Myelinzerfall durch einen Immunpathogenitätsmechanismus hervorgerufen wird.

\section{Diagnostik}

\section{Untersuchungsmaterial}

Zur Virusisolierung eignen sich je nach Organmanifestation Stuhl, Nasopharynxabstrich, Liquor und Serum, die in der akuten Krankheitsphase gewonnen werden, und bei fatalen Fällen weiterhin Biopsie-/Au- topsiematerialien von Gehirn, Rückenmark, Myokard und Milz.

\section{Diagnostische Verfahren}

Virusnachweis: Der Virusnachweis steht in Speziallaboratorien im Vordergrund. Zum molekularbiologischen Nachweis von Cardioviren ist die RT-PCR mit Primern aus verschiedenen Genombereichen geeignet. Für eine Unterscheidung der verschiedenen Stämme ist eine Sequenzierung notwendig. Für umfangreiches Screening von Patientenmaterialien auf Cardioviren werden zunehmend Oligonukleotid-Arrays angewendet.

Die klassische Virusanzüchtung ist entweder durch intrazerebrale Inokulation von Mäusen bzw. Beimpfung von embryonierten Hühnereiern möglich oder durch die Anzüchtung in Zellen von Mensch und Nagetieren. Beispiele für humane Zelllinien: HeLa- und HEp-2-Zellen. Beispiele für Nagerzelllinien: Primäre murine embryonale Fibroblasten, Ehrlich oder Krebs Ascites Tumorzellen von murinen L-929 Fibroblasten, Baby Hamster Kidney (BHK) Zellen. Die Virustypisierung erfolgt im Neutralisationstest (NT).

Antikörpernachweis: Virustypspezifische Antikörper lassen sich im Neutralisationstest (NT) bestimmen, dagegen werden gruppenspezifische Antikörper in experimentellen ELISAs nachgewiesen.

\section{Befund / Interpretation}

Wegen des seltenen Auftretens von EMC-Virus- und Theilovirus-Infektionen beim Menschen sind Virusund Antikörpernachweise weltweit auf wenige Speziallaboratorien beschränkt. Bei negativem Befund, aber passendem klinischen Bild und entsprechender epidemiologischer Anamnese sollte eine Kontrollprobe erneut untersucht werden.

\section{Therapie}

\section{Therapeutische Maßnahmen}

Eine antivirale Therapie steht nicht zur Verfügung.

\section{Epidemiologie}

\section{Verbreitung}

Bei den Cardioviren handelt es sich primär um Viren von Nagetieren, die auf den Menschen und andere Säugetiere wie Affen, Schweine, hasenartige Tiere, Pferde, Rinder und Elefanten übertragen werden können.

Einige Fälle von klinisch apparenten Cardiovirus-Infektionen beim Menschen sind für Viren des EMCVSerotyps und für das Vilyuisk-Human-Enzephalomyelitis-Virus beschrieben und beziehen sich hauptsächlich auf Untersuchungen in den Vierziger- und Fünfzigerjahren des letzten Jahrhunderts ( Tab. 1). EMCV-spezifische neutralisierende Antikörper sind bei Tierpflegern nachzuweisen, die Kontakt zu Nagetieren haben. Im Gegensatz zu den humanpathogenen En- 
teroviren ist über die Verteilung, Pathologie und Histopathologie von EMC-Viren beim Menschen wenig bekannt. In Analogie zu infizierten Affen gelten auch beim Menschen viszerale Organe als Hauptvermehrungsorte für EMC-Viren.

Epizoonotische Ausbrüche von EMCV-Infektionen wurden in New South Wales (Australien) 1986 in Schweinezuchten beobachtet. Infektionen über Ausscheidungen von Nagetieren werden für das „DreiTage-Fieber" verantwortlich gemacht, das 1945-1946 bei Soldaten der US-Truppen auf den Philippinen auftrat ( $\triangleright$ Erkrankung 1: Erkrankungen beim Menschen). Eine Prävalenzstudie für EMCV in Hawai 1978 ergab, dass Ratten zu 36 \% sowie Schweine und Kühe zu ca. $20 \%$ durchseucht waren. Für Menschen wurde eine Durchseuchung von $6 \%$ festgestellt.

Fiebrige respiratorische und gastrointestinale Symptome, in einigen Fällen auch Polio-ähnliche Paresen, sind in Untersuchungen vor allem bei Kindern in Deutschland, Brasilien, Kanada sowie Süd- und Südostasien nachgewiesen worden. Ein neues Theilovirus, das Saffold-Virus (SAFV), wird dafür verantwortlich gemacht.

Ein Cardiovirus-ähnliches Virus, das „common-stoolassociated-picornavirus“ (Cosa-Virus), ließ sich im Jahr 2008 bei Kindern in Südasien mit einer akuten schlaffen Lähmung nachweisen (nicht-Polio akute schlaffe Lähmung = non-polio acute flaccid paralysis). Das Cosa-Virus kommt auch bei gesunden Kindern in Pakistan vor. In Australien sind Fälle akuter Diarrhoe bei Kindern mit Cosa-Virus-Infektionen assoziiert.

\section{Wirtsbereich / Reservoir}

Als natürliches Reservoir für Cardioviren gelten Nagetiere (vor allem Maus und Ratte). Der Wirtsbereich der Theiloviren ist im Wesentlichen auf Nager beschränkt. Eine Ausnahme bilden VHEV und SAFV, die auch Menschen infizieren. Viren des EMCV-Serotyps können auch auf Menschen, Affen, hasenartige Tiere, Schweine und andere Haustiere sowie Vögel übertragen werden. Als mögliche Träger von EMCV werden u. a. auch Moskitos diskutiert. Maus oder Ratte werden für ausgewählte Fragestellungen zum Nachweis von EMC-Viren durch Anzüchtung verwendet. Zelllinien von Mensch und Nagetieren eignen sich zur Propagierung von EMC-Viren ( $\triangleright$ Diagnostische Verfahren). Der Nachweis von TME-Viren in Zellkulturen ist problematisch.

\section{Risikogruppen}

Trotz der in den letzten Jahren beschriebenen Cardiovirus-assoziierten Erkrankungen beim Menschen mit VHEV und SAFV, ist das Risiko für den Menschen als gering anzusehen. Personen, die mit Ausscheidungen infizierter, frei lebender Tiere in Kontakt kommen (z. B. Soldaten) oder Materialien mit konzentrierten EMC-Viren bearbeiten (z. B. Personal in wissenschaftlichen Laboratorien), können sich infizieren.

\section{Transmission / Vektoren}

Tierexperimente ergaben, dass Cardioviren enteritisch übertragen werden (selten auch respiratorisch). Für EMC-Viren wurde gezeigt, dass oral infizierte Schweine EMCV im Darm vermehren und über Fäzes ausscheiden. Auch Mäuse und Ratten sind oral infizierbar und werden als Hauptüberträger von EMCV-Infektionen angesehen.

Cardiovirus-Infektionen können vereinzelt beim Menschen nach direktem Kontakt mit infizierten Tieren auftreten und verlaufen überwiegend asymptomatisch.

\section{Prävention / Impfstoffe}

Die Vermeidung von Kontakten mit infizierten Tieren (speziell Nagetieren) dient der Krankheitsvorbeugung. Eine aktive und passive Immunisierung gegen Cardioviren sowie eine antivirale Therapie stehen nicht zur Verfügung.

\section{Weiterführende Informationen \\ Referenzzentren / Expertenlaboratorien}

Keine.

\section{Web-Adressen}

- Picornaviridae.com: www.picornaviridae.com

- Picornaviridae study group: www.picornastudygroup.com

- The big picture book of viruses: www.mirrorservice.org/ sites/www.virology.net/Big_Virology/BVHomePage.html

- Genbank, National Institute of Health: www.ncbi.nlm. nih.gov/Genbank/index.html

\section{Schlüsselliteratur}

1. Lipton HL (1994) Theiler's Viruses. In: Webster RG, Granoff A (eds) Encyclopedia of Virology, vol 3. Academic Press, San Diego, pp 1423-1430

2. Racaniello VR, Picornaviridae (2007) The Viruses and Their Replication. In: Knipe DM et al (eds) Fields Virology, vol 1, $5^{\text {th }}$ edn. Wolters Kluwer Lippincott Williams \& Wilkins, Philadelphia, pp 795-838

3. Rueckert RR (1996) Picornaviridae. The Viruses and Their Replication. In: Fields BN et al (eds) Virology, vol 1, $3^{\text {rd }}$ ed. Lippincott-Raven, Philadelphia, pp 609-654.

4. Scraba DG (1994) Cardioviruses. In: Webster RG, Granoff A (eds) Encyclopedia of Virology, vol 1. Academic Press, San Diego, vol 1, pp 205-213

5. Stanway G et al. (2005) Picornaviridae. In: Fauquet CM et al (eds) Virus Taxonomy, Classification and Nomenclature of Viruses, Eighth Report of the International Committee on Taxonomy of Viruses. Elsevier, Amsterdam, pp 757-778

6. Warren J (1979) Miscellaneous Viruses: Encephalomyocarditis. In: Lennette EH, Schmidt NJ (eds) Diagnostic Procedures for Viral, Rickettsial and Chlamydial Infections, $5^{\text {th }}$ edn. American Public Health Association, Inc, pp 1010-1013

7. Zeichhardt H, Grunert, H-P (2010) Picornaviren - Klinik, Diagnostik und Prävention. In: Doerr HW, Gerlich WH (Hrsg) Medizinische Virologie, 2. Aufl. Thieme, Stuttgart New York, S 468-489 


\section{Catu-Virus}

Bunyaviren

\section{Ceratophyllus spp.}

- Ektoparasiten, sonstige (Stechmücken, Trombiculiden, Flöhe, Wanzen, Zecken)

\section{Cervikale intraepitheliale Neoplasie (CIN)}

- Humane Papillomviren (HPV)

\section{Cestoden, seltene Arten}

\section{Erreger}

\section{Synonym(e)}

Dipylidium caninum, Gurkenkernbandwurm; Spirometra, Diphyllobothriiden-Larven im Menschen, Spargana.

\section{Erregerspezies}

Dipylidium caninum; Plerozerkoide der Gattung Spirometra (Spargana).

\section{Taxonomie}

D. caninum Unterklasse: Eucestoda; Ordnung: Cyclophyllidea; Familie: Dipylidiidae; Spirometra Ordnung: Diphyllobothriidea

\section{Vermehrung}

D. caninum: Der Gurkenkernbandwurm von Hund und Katze wird etwa $15-20 \mathrm{~cm}$ lang und weist bis $\mathrm{zu}$ 175 Proglottiden auf. Die Proglottide enthält 10-30 Eier. Obligatorische Zwischenwirte sind Mallophagen (Federlinge) oder Flöhe, in denen sich das Cysticercoid entwickelt.

Spirometra: Eine vollständige Entwicklung findet nicht statt. Die infektiösen Prozerkoide werden im Menschen zu den Plerozerkoiden und verharren in diesem Entwicklungsstand.

\section{Erkrankungen}

\section{Dipylidiasis}

Synonym(e)

Gurkenkernbandwurm.

\section{Symptome}

In der Regel asymptomatischer Verlauf, selten gastrointestinale Symptome, perianaler Juckreiz.

\section{Sparganose}

\section{Synonym(e)}

Larva migrans.

\section{Inkubationszeit}

Unbekannt.

\section{Leitsymptome}

Abhängig von der Lokalisation, schmerzhafte Hautund Bindehautschwellungen.

\section{Symptome}

Abhängig von der Lokalisation, entzündlicher Tumor.

\section{Pathophysiologie}

Der Mensch ist Fehlzwischenwirt. Die Larve wandert durch diverse Organe des Körpers und kann bis zu $30 \mathrm{~cm}$ lang werden.

\section{Diagnostik}

\section{Untersuchungsmaterial}

D. caninum: Stuhlprobe; Spirometra (Sparganum): Biopsiematerial.

\section{Diagnostische Verfahren}

Stuhlmikroskopie bzw. Histologie.

\section{Befund / Interpretation}

Die Proglottiden des Gurkenkernbandwurms lassen sich leicht von anderen Bandwürmern unterscheiden, da sie in der Mitte breiter sind als an den schmalen Enden, was ihnen das Aussehen von Gurkenkernen verleiht.

Spirometra: Die Spargana können bis zu $36 \mathrm{~cm}$ lang werden.

\section{Therapie}

\section{Therapeutische Maßnahmen}

Einmalbehandlung mit Praziquantel oder Niclosamid.

\section{Epidemiologie}

\section{Verbreitung}

D. caninum: Weltweite Verbreitung, seltene Infektion des Menschen. Sparganose kommt in Ost- und Südostasien, selten in Afrika, Mittelamerika und Südeuropa vor.

\section{Wirtsbereich / Reservoir}

Katzen und wild lebende Carnivore.

\section{Risikogruppen \\ Kinder.}

\section{Transmission / Vektoren}

Akzidentieller Verzehr von infizierten Flöhen, unsauberes Trinkwasser, Verzehr von Schlangen- oder Froschfleich. Infektion auch durch Auflegen von rohem Schlangen- oder Froschfleisch auf Wunden oder Auge (tradionelle Medizin in Asien).

\section{Prävention / Impfstoffe}

Regelmäßige Entwurmung der Hauskatzen und gele- 
gentliche Behandlung mit Insektiziden, um die Ektoparasiten abzutöten.

\section{Meldepflicht}

Eine Meldepflicht besteht nicht.

\section{Weiterführende Informationen}

\section{Referenzzentren / Expertenlaboratorien}

- Nationale Referenzzentren gibt es nicht. Als fachlich qualifiziert anzusehen sind sämtliche parasitologischen und tropenmedizinischen Institutionen.

\section{Web-Adressen}

- CDC-Center for Disease Control and Prevention: http:// www.cdc.gov/ncidod/dpd/parasites/dipylidium/default. htm

\section{Schlüsselliteratur}

1. Beaver PC, Jung RC, Cupp EW (1984) Clinical Parasitology. $9^{\text {th }}$ edn. Lea $\&$ Febiger, Philadelphia

2. Guerrant RL, Walker DH, Weller PF (2010) Tropical Infectious Diseases; Principles, Pathogens, \& Practice. Third edition, Elsevier Churchill Livingstone Inc, Philadelphia

3. Löscher T, Burchard GD (Hrsg) (2010) Tropenmedizin in Klinik und Praxis. 4. Aufl. Georg Thieme Verlag, Stuttgart

4. Lucius R, Frank-Loos B (2008) Biologie von Parasiten. Springer-Verlag Berlin, Heidelberg

5. Mehlhorn H, Eichenlaub D, Löscher T, Peters W (1995) Diagnostik und Therapie der Parasitosen des Menschen. 2. Aufl. Gustav Fischer Verlag, Stuttgart

\section{Chagas-Krankheit}

- Trypanosoma cruzi

\section{Chagom}

Trypanosoma cruzi

\section{Chagres-Virus}

Bunyaviren

\section{Chancroid}

- Haemophilus ducreyi

\section{Chandipura-Virus}

- Vesiculovirus

\section{Chikungunya-Fieber}

Alphaviren

- Chikungunya-Virus

\section{Chikungunya-Virus}

Gerhard Dobler

\section{Erreger}

\section{Taxonomie}

Das Chikungunya-Virus wird in das Genus Alphavirus der Familie Togaviridae eingruppiert. O'nyongnyong-Virus gilt als Subtyp des Chikungunya-Virus.

\section{Historie}

Chikungunya-Virus wurde 1952 in Tansania während eines Ausbruchs mit Fieber und Gelenkschmerzen isoliert und beschrieben. Der Name "chikungunya“ stammt aus der Sprache der einheimischen Bevölkerung (Suaheli: „das was sich aufkrümmt“, nach den durch die Gelenkschmerzen bedingten Körper- und Gliedmaßenkrümmungen der Patienten). Chikungunya-Fieber eine der wichtigsten Arbovirus-Erkrankungen und rangiert unter den drei wichtigsten sogenannten „emerging infections“.

\section{Morphologie}

Chikungunya-Virus hat den typischen AlphavirusAufbau mit einem Durchmesser von rund 60-70 nm. Das Nukleokapsid ist aus 240 Kapsomeren in einer $\mathrm{T}=4$ Ikosaeder-Symmetrie aufgebaut. Die Membran besteht aus einer Lipidhülle, die 2 Hüllproteine (E1, E2) enthält, die durch Interaktion mit dem Nukleokapsid-Protein (C-Protein) das Viruspartikel stabilisieren. Die Hüllproteine sind für verschiedene biologische Eigenschaften des Virus (u. a. Immunität, Pathogenität, Übertragbarkeit durch Stechmücken) von Bedeutung.

\section{Genom}

Das Genom des Chikungunya-Virus besteht aus einzelstängiger RNA positiver Polarität mit einer Länge von etwa 11.500 Nukleotiden. Die vier Nichtstrukturproteine (nsP1, nsP2, nsP3, nsP4) sind am 5'-Ende und die fünf Strukturproteine (C, E3, E2, 6K, E1) am 3'Ende des Genoms angeordnet. Die genomische virale RNA dient primär als mRNA zur Produktion der Nichtstruktur-Proteine. Diese sind für die Produktion der Strukturproteine, das capping der viralen RNAs (nsP1), die Initiierung der Transkription in komplementäre RNA (nsP2) sowie Protease- und HelikaseFunktionen (nsP3, nsP4, nsP1-4-Komplex) wichtig. Sie sind für den strukturellen Aufbau des Virions essentiell. 


\section{Vermehrung}

Chikungunya-Virus vermehrt sich in vielen Zellen. Zur Anzucht werden Verozellen (Grüne Meerkatze) oder BHK-21-Zellen (Hamster) verwendet. Diese zeigen innerhalb von Stunden bis wenigen Tagen nach Infektion eine Abrundung, gefolgt vom Zelltod (Apoptose). In Stechmückenzellen (C6/36, Aedes albopictus) vermehrt sich das Chikungunya-Virus ohne zytopathischen Effekt. Die Vermehrung des Virus findet ausschließlich im Zytoplasma statt. Dort werden die Hüllproteine gebildet und an die Zytoplasma-Membran transportiert. Das Nukleokapsid wird im Zyptoplasma gebildet und über Exozytose als komplettes umhülltes Viruspartikel ausgeschleust.

\section{Pathogenität/Virulenz/Antigenvariabilität}

Im Vertebraten-Wirt verursachen Chikungunya-Viren zytolytische Infektionen vor allem in Fibroblasten der Haut und der Synovia. In der Phase der primären Virusvermehrung lässt sich eine Virämie mit Virustitern bis $10^{6} / \mathrm{ml}$ nachweisen. Nach Eintreten der Antikörperbildung kann Chikungunya-Virus für Wochen innerhalb von Makrophagen in Gelenken persistieren und eine Entzündungsreaktion induzieren. Unterschiede in der Virulenz oder Antigen-Variabilität einzelner Virustypen sind nicht bekannt. O'nyong-nyongVirus ist serologisch und genotypisch ein Subtyp des Chikungunya-Virus.

\section{Erkrankung}

Chikungunya-Fieber

\section{Synonym(e)}

Keine.

\section{Inkubationszeit}

4-7 Tage.

\section{Leitsymptome}

Fieber, Kopfschmerz, makulopapuläres Exanthem, Arthritis, Arthralgie.

\section{Symptome}

Chikungunya-Fieber ist eine akute Infektion, die sich nach einer Inkubationszeit von 4 bis 7 Tagen mit hohem Fieber (bis zu $40{ }^{\circ} \mathrm{C}$ ), Schüttelfrost und charakteristischen, starken symmetrischen Gelenkschmerzen und Entzündungen der kleinen Gelenke äußert. Das Fieber verläuft häufig zweigipfelig mit einem Fieberabfall von 24 bis 48 Stunden nach 3 bis 4 Tagen. Ein Teil der Patienten entwickelt ein makulopapulöses, häufig juckendes Exanthem, das sich vom Rumpf auf Gesicht, Arme und Beine, einschließlich der Handund Fußflächen ausbreitet. Daneben treten auch starke Kopf- und Muskelschmerzen auf. Die Akutsymptomatik dauert meist 7 bis 10 Tage. Bei einem Teil der Patienten (v. a. HLA B27 positive) persistieren die Gelenkschmerzen über Monate. Kinder zeigen atypische Verläufe mit Kopfschmerz, Erbrechen, Übelkeit, oder sogar ZNS-Anfällen (Fieberkrämpfe?). Erstmalig wurden in aktuellen Ausbrüchen vereinzelt Fälle von Meningoenzephalitis beobachtet.

\section{Pathophysiologie}

Durch die primäre Vermehrung des ChikungunyaVirus in Fibroblasten und anschließend in Langerhans-Zellen und Makrophagen und die weitere Vermehrung in den lokalen Lymphknoten werden Zytokine (u. a. IL-1 $\beta$, IL6, TNF- $\alpha$ ) freigesetzt, die für die primäre Fiebersymptomatik verantwortlich zeichnen. Die sekundäre Vermehrung in den synovialen Fibroblasten führt zu deren Apoptose mit reaktiver Zellvermehrung und Angiogenese, die im Verlauf zur hyperplastischen Synoviabildung führen. Chikungunya-Virus konnte über Monate in Gewebe-Makrophagen nachgewiesen werden, wodurch die teilweise monatelangen Arthralgien und Arthritiden erklärbar sind.

\section{Immunantwort}

Etwa ab dem 7. Erkrankungstag werden IgM-Antikörper gebildet, die etwa für 40 bis 60 Tage nachweisbar bleiben. Ab dem 10. bis 14. Erkrankungstag sind auch IgG-Antikörper nachweisbar, die meist über Jahre persistieren. Die höchsten IgG-Antikörper-Titer werden etwa 4 Wochen nach Erkrankungsbeginn gefunden.

\section{Differenzialdiagnose}

Als Differenzialdiagnose kommen virale Infektionen mit Arthralgie oder Arthritis in Frage, die im Verbreitungsgebiet des Chikungunya-Fiebers vorkommen. In Südostasien sind dies insbesondere das Dengue-Fieber, das Zika-Fieber und in Neuguinea die Epidemische Polyarthritis (Ross-River-Virus). In Afrika sind neben dem Dengue-Fieber weitere Arbovirus-Infektionen (verursacht durch West-Nil-Virus, WesselsbronVirus, Spondweni-Virus, Zika-Virus u. a.) zu nennen. Daneben sind andere Ursachen der Arthritis, bei protrahierten Verlausformen auch aus dem rheumatischen Formenkreis, abzuklären,

\section{Diagnostik}

\section{Untersuchungsmaterial}

Blut, Serum, Plasma.

\section{Diagnostische Verfahren}

Ein Anfangsverdacht ergibt sich bei Reiserückkehrern aus Ländern mit endemischem Vorkommen oder einer epidemischen Situation. In den ersten 5 bis 7 Erkrankungstagen kann Chikungunya-Virus im Blut der Patienten molekularbiologisch (Echtzeit-PolymeraseKettenreaktion), durch Virusisolierung (Zellkultur, Tierversuch) nachgewiesen werden. Als Untersuchungsmaterial kommen Serum oder EDTA-Plasma in Frage.

Der serologische Nachweis ist erst ab dem 7. Erkrankungstag Erfolg versprechend. Dazu sind ELISA, IFT 
und Neutralisationstest verfügbar. ELISA und IFT sind sensitive Teste, die allerdings mit anderen Alphaviren kreuzreagieren können. Der Neutralisationstest ist spezifisch und zum Ausschluss von Kreuzreaktionen mit anderen Alphaviren geeignet.

\section{Befund/Interpretation}

Der Nachweis von Chikungunya-Virus-RNA mittels molekularbiologischer oder kultureller Nachweismethoden ist beweisend für ein akutes ChikungunyaFieber. Ab dem 7. Erkrankungstag gilt der spezifische Nachweis von IgM-Antikörpern als hinweisend und der signifikante IgG-Titeranstieg oder der neutralisierenden Antikörper-Ansteig in zwei aufeinander folgenden Serum-/Plasmaproben als beweisend für eine akute Chikungunya-Virusinfektion.

Kreuzreaktionen zu anderen Alphaviren (u. a. Mayaro-Virus, Sindbis-Virus, O'nyong-nyong-Virus, RossRiver-Virus) können, soweit sie nicht anamnestisch ausgeschlossen werden können, nur mittels Neutralisationstest durch Speziallaboratorien abgeklärt werden.

\section{Therapie}

\section{Therapeutische Maßnahmen}

Als Therapie kommen symptomatische Maßnahmen u. a. mit nicht-steroidalen Antirheumatika in Frage. Daneben ist auch Chloroquin-Phosphat wirksam.

\section{Epidemiologie}

Chikungunya-Virus wird von Stechmücken auf Primaten übertragen. Es werden ein sylvatischer, ein urbaner (epidemischer) und ein urbaner (pandemischer) Übertragungszyklus unterschieden. Für den urbanen Übertragungszyklus spielen Menschen die einzige Rolle als Wirte. Vektoren sind anthropophile Aedes-Arten. Im sylvatischen Übertragungszyklus zirkuliert das Virus in West- und Zentralafrika in nicht-humanen Primatenarten und Regenwald-Stechmückenarten.

\section{Verbreitung}

Chikungunya-Virus ist auf den gesamten afrikanischen Kontinent südlich der Sahara einschließlich der an der Ostküste im Indischen Ozean vorgelagerten Inseln, auf dem Indischen Subkontinent und in Teilen Südostasiens (Indonesien, Philippinen, Malaysia, Thailand und Singapur) verbreitet ( $\triangle$ Abb. 1). Die Situation in den daran angrenzenden Ländern ist unklar.

\section{Wirtsbereich/Reservoir}

Chikungunya-Virus konnte bisher ausschließlich in Primaten nachgewiesen werden. Im Rahmen des urban-epidemischen und pandemischen Zyklus spielt ausschließlich der Mensch eine Rolle als natürlicher Wirt des Virus. Im sylvatischen Viruszyklus sind verschiedene Affenarten, u. a. Husarenaffen (Erythrocebus patas) und Guinea-Paviane (Patio patio) als natürliche Wirte involviert.

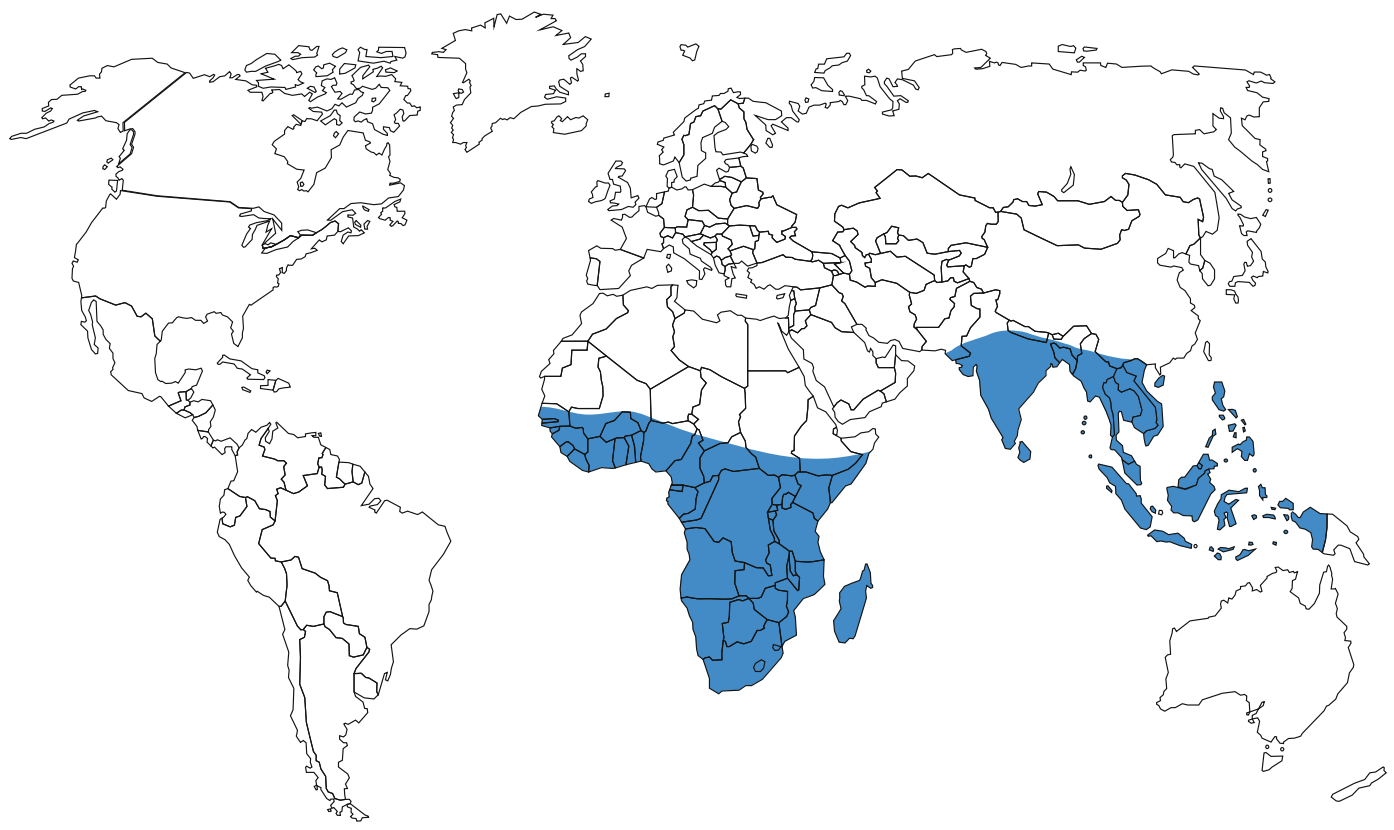




\section{Risikogruppen}

In den großen Epidemien der letzten Jahre konnten bei älteren Patienten und Patienten mit Grunderkrankungen vereinzelt tödliche Verläufe beobachtet werden. Atypische Verläufe (Enzephalitis, Hepatitis) konnten keinen spezifischen Risikogruppen zugeordnet werden. Kleinkinder zeigen häufiger atypische Verlaufsformen mit Fieber und Exanthem ohne die typischen Gelenksbeschwerden.

\section{Transmission/Vektoren}

Chikungunya-Virus wird in der Natur überwiegend durch Stechmücken der Gattung Aedes übertragen. Am sylvatischen Zyklus sind unterschiedliche Stechmücken-Arten (u. a. Aedes furcifer-taylori, Aedes luteocephalus, Aedes dalzieli u. a.), am urbanen Zyklus sind hauptsächlich Aedes aegypti und Aedes albopictus beteiligt.

\section{Prävention/Impfstoffe}

Bisher sind keine Impfstoffe verfügbar. Einzige Möglichkeit der Prävention ist damit die individuelle Stechmücken-Expositionsprophylaxe.

\section{Ausbruchsmanagement}

Ausbrüche mit Chikungunya-Fieber können im persönlichen Umfeld durch Entfernen aller für Stechmücken-Brutplätze geeigneten Gegenstände eingedämmt werden. In einer Ausbruchssituation können großflächige Ausbringungen von Insektiziden (Larvizide, Adultizide) eine Epidemie kurzfristig eindämmen, jedoch erfahrungsgemäß nicht stoppen.

\section{Meldepflicht}

Der Erregernachweis und der serologische Nachweis einer akuten Chikungunya-Virusinfektion sind namentlich meldepflichtig gemäß $₫ 7$ IfSG unter der Rubrik „Virale hämorrhagische Fieber - sonstige Formen".

\section{Weiterführende Informationen}

\section{Referenzzentren/Expertenlaboratorien}

- Nationales Referenzzentrum für tropische Infektionserreger am Bernhard-Nocht-Institut für Tropenmedizin, Bernhard-Nocht-Straße 74, 20359 Hamburg, Tel. 040-428 18 401, Fax: 040-428 18 400, email: mzd@bni-hamburg. de, Homepage: http://www.bni-hamburg.de/

\section{Web-Adressen}

- Bernhard-Nocht-Institut für Tropenmedizin: www.bnihamburg.de

- Robert-Koch-Institut: www.rki.de

- Centers für Disease Control, Atlanta: www.cdc.gov

\section{Schlüsselliteratur}

1. Cavrini F, Gaibani P, Pierro AM, Rossini G, Landini MP, Sambri V (2009) Chikungunya: an emerging and spreading arthropod-borne viral disease. J Infect Dev Ctries 3:744-752

2. Griffin DE. Alphaviruses. In: Knipe PM et al. (Hrsg) Fields
Virology, Philadelphia 4. Ausgabe vol 1 Lippincott-Raven Publishers, S 917-962

3. Her Z, Kam Y-W, Lin RTP, Ng LFP (2009) Chikungunya: a bending reality. Microb Infect 11:1165-1176

4. Jaffar-Bandjee MC, Das T, Hoarau JJ, Trotot PK, Denizot M, Ribera A, roques P, Gasque P (2009) Chikungunya virus takes centre stage in virally induced arthritis: possible cellular and molecular mechanisms to pathogenesis. Microb Infect 11:1206-1218

5. Jupp PG, McIntosh BM. Chikungunya virus disease. In: Monath T (Hrsg.) The Arboviruses: Epidemiology and Ecology, Boca Raton, vol. 2. CRC Press Inc, S 137-158

6. Kam Y-W, Ong EKS, Renia L, tong J-C, Ng LFP. Immunobiology of chikungunya and implications for disease intervention. Microb Infect 11:186-1196

\section{Chilomastix mesnili}

- Darmflagellaten

\section{Chinesischer Darmegel}

- Leberegel - Opisthorchis, Clonorchis

\section{Chlamydia}

Andreas Essig

\section{Erreger}

Synonym(e)

Chlamydien.

\section{Erregerspezies}

Chlamydia trachomatis, Chlamydia pneumoniae, Chlamydia psittaci, Chlamydia abortus.

\section{Taxonomie}

Familie Chlamydiacea, Gattung Chlamydia. 1999 wurde, basierend auf phylogenetischen Analysen der 16S und $23 \mathrm{~S} \mathrm{rRNa}-\mathrm{Gene}$, eine Revision der bisherigen taxonomischen Einteilung der Chlamydien vorgeschlagen [8]. Danach wurde die bisher einzige Gattung Chlamydia der Familie Chlamydiaceae in die Gattungen Chlamydia (C) und Chlamydophila unterteilt. Allerdings konnte sich die vorgeschlagene neue Gattungsbezeichnung Chlamydophila (Cp.) nicht durchsetzen, da nach Ansicht führender Experten wichtige biologische und funktionelle Aspekte nicht berücksichtigt wurden [25, 27]. Die vorgeschlagenen neuen Spezies Cp. pneumoniae, Cp. psittaci und Cp. abortus finden sich daher in der Literatur überwiegend als C. pneumoniae, C. psittaci und C. abortus wieder. C. psittaci enthält nun vorwiegend aviäre Stämme, die beim Menschen eine Ornithose verursachen. Als $C$. abortus wird der frühere C.-psittaci-Serotyp 1 bezeichnet, der bei Wiederkäuern aber auch schwangeren 
Frauen zum Abort führen kann. Ferner gingen aus dem früheren C. psittaci-Taxon noch die tierpathogenen Spezies C. felis und C. caviae hervor, die beim Menschen jedoch kaum Infektionen verursachen.

Bei der Spezies C. trachomatis haben sich keine wesentlichen taxonomischen Änderungen ergeben. Derzeit beinhaltet $C$. trachomatis basierend auf den antigenen Eigenschaften des „major outer membrane protein (MOMP) “ die Serotypen A-C (Trachom), D-K (urogenitale Infektionen) und L1-L3 (Lymphogranuloma venereum)

\section{Historie}

Beschreibungen einer trachomähnlichen Erkrankung des menschlichen Auges finden sich bereits in Überlieferungen aus dem Altertum. 1907 konnten Halberstädter und von Prowazek zeigen, dass das Krankheitsbild des Trachoms vom Menschen auf Menschenaffen experimentell übertragbar ist: Mittels GiemsaFärbung identifizierten sie in Zellen von Konjunktivalabstrichen intrazytoplasmatische Vakuolen, die sie als Ursache des Trachoms interpretierten. In den Folgejahren wurden ähnliche Einschlusskörper in Konjunktivalabstrichen von Neugeborenen mit Konjunktivitis, in Zervixabstrichen ihrer Mütter sowie in Harnröhrenabstrichen von Männern gefunden. Aufgrund ihrer mangelnden Kultivierbarkeit auf künstlichen Nährböden wurden die Erreger damals fälschlicherweise als Viren eingestuft. Der bis dahin sogenannte "Trachomavirus" wurde erstmals 1977 von einer chinesischen Arbeitsgruppe mithilfe von Dottersackkultivierungstechniken aus bebrüteten Hühnereiern isoliert. Dank der Verfügbarkeit von Zellkulturtechniken und elektronenmikroskopischer Techniken wurde ab Mitte der 1960er Jahre klar, dass Chlamydien keine Viren, sondern Bakterien sind. Mit dem Einsatz von nichtkulturellen Nachweisverfahren, insbesondere der Nukleinsäureamplifikation in den 1990er Jahren zeigte sich, dass C. trachomatis global zu den häufigsten sexuell übertragbaren Erregern gehört.

Der Zusammenhang zwischen Vogelexposition und schwer verlaufenden Allgemeininfektionen mit Pneumonie wurde bereits 1879 von Ritter bei einem Ausbruch in der Schweiz erkannt und als Pneumotyphus bezeichnet. 1930 wurden die kausalen Erreger in verschiedenen Laboratorien erstmals nachgewiesen. Die Bezeichnung Psittakose leitet sich von dem griechischen Wort für Papagei ab.

1965 wurde ein atypischer Chlamydia-Stamm erstmals aus dem Konjunktivalabstrich eines Kindes in Taiwan angezüchtet. Nachdem 1983 in Seattle, USA ein gleichartiger Stamm von einem Studenten mit akuter respiratorischer Infektion angezüchtet wurde, wurde der Erreger zunächst mit dem Akronym TWAR bezeichnet, bevor er 1989 als eigene Chlamydienspezies C. pneumoniae anerkannt und als Erreger oberer und unterer Atemwegsinfektionen beschrieben wurde [11].

\section{Morphologie}

- Chlamydien sind obligat intrazelluläre Bakterien, die sich in zwei morphologisch und funktionell unterschiedlichen Formen präsentieren:

- Die 0,2-0,3 $\mu \mathrm{m}$ großen Elementarkörperchen sind in der Lage extrazellulär für eine eng begrenzte Zeit zu überleben, an potenzielle Wirtszellen zu adhärieren und diese zu infizieren.

Die 1,0-1,5 $\mu \mathrm{m}$ großen, metabolisch aktiven, jedoch nicht infektiösen Retikularkörperchen replizieren sich intrazellulär durch Zweiteilung innerhalb eines sogenannten Einschlusskörpers.

Innerhalb des Einschlusskörpers finden sich, insbesondere am Ende des Entwicklungszyklus, sowohl Elementar- als auch Retikularkörperchen, die ultramorphologisch im Elektronenmikroskop voneinander unterschieden werden können.

\section{Genom}

Chlamydien besitzen verhältnismäßig kleine Genome, die zwischen 1,04 Mio bp (C. trachomatis) und 1,2 Mio bp (C. pneumoniae) groß sind. Die Genomsequenzen von C. trachomatis, C. pneumoniae, C. abortus sind bekannt. C. trachomatis besitzt ein 7,5 kbp großes kryptisches Plasmid, das in ca. 4-7 Kopien vorhanden ist, und von einigen kommerziell verfügbaren Nukleinsäureamplifikationsassays als Ziel-Gen genutzt wird. Vergleichende Sequenzanalysen zwischen C. trachomatis und C. pneumoniae lieferten wichtige Hinweise auf speziesübergreifende biologische Prozesse, die für das Überleben der Bakterien in Säugetierzellen wichtig sind. Dazu gehörten unter anderem ein Typ-IIISekretionssystem, eine neue Familie polymorpher äußerer Membranproteine, drei Serin/Threonin-Proteinkinasen, Phospholipase-D-ähnliche Proteine und zusätzliche Purin- und Biotin-Synthesekapazität [14]. Die bisher aus unterschiedlichen Regionen gewonnenen Isolate von C. pneumoniae sind genotypisch und phänotypisch nahezu identisch. Die Genomsequenz eines aviären C.-psittaci-Stammes wurde bisher nicht publiziert.

\section{Vermehrung}

Alle Chlamydien-Spezies sind obligat intrazelluläre Bakterien, die einen charakteristischen Entwicklungszyklus gemeinsam haben, wobei die zugrunde liegenden molekularen Mechanismen nur im Ansatz verstanden sind. Nach Eintritt in die Wirtszelle erfolgt die Differenzierung der Elementarkörperchen in metabolisch aktive Retikularkörperchen, die sich durch Zweiteilung innerhalb von sogenannten Einschlusskörpern (engl. inclusion bodies) vermehren. Anhand von Genexpressionsstudien für verschiedene Stadien des Chlamydien-Entwicklungszyklusses konnten Chlamydien-Gene identifiziert werden, die partiell eukaryotischen Ursprungs sind und den hoch spezialisierten intrazellulären Differenzierungsprozess koordinieren 
könnten [2]. Am Ende des 48-72 Stunden umfassenden Entwicklungszyklus entwickeln sich die Retikularkörper wieder zurück zu infektiösen Elementarkörperchen, die dann zu mehreren Hunderten aus der Wirtszelle freigesetzt werden und somit wieder neue Wirtszellen infizieren können [12].

In vivo gelten die Epithelzellen der Zervix, der Urethra sowie der Konjunktiven als Zielzellen von C. trachomatis. Die C.-trachomatis-Serotypen L1-L3 beinhalten invasive C.-trachomatis-Stämme, da sie auch Lymphozyten und Makrophagen infizieren können. Epithelzellen des Respirationstraktes gelten als Zielzellen für C. pneumoniae und für C. psittaci. C. psittaci kann sich offenbar auch in Monozyten und Makrophagen vermehren, wodurch es dann zur systemischen Erregerdisseminierung kommt. C. abortus kann in der Plazenta von trächtigen Muttertieren in hohen Konzentrationen nachgewiesen werden.

Alle humanpathogenen Chlamydienspezies können inzwischen im Labor mithilfe von Zellkulturtechniken kultiviert werden. Üblicherweise werden dafür permanente Monolayerkulturen wie McCoy- oder Hela229-Zellkulturen eingesetzt. C. pneumoniae ist sehr empfindlich und extrem schwierig aus Patientenmaterial anzuzüchten. Die beste Ausbeute wird mit HEp-2-, HL- und HeLa229-Zellen erzielt.

\section{Pathogenität / Virulenz / Antigenvariabilität}

Allen Chlamydien-Arten ist gemeinsam, dass sie in vitro durch Behandlung mit Interferon-Gamma oder Betalaktam-Antibiotika in ein so genanntes Stadium der Persistenz getrieben werden. Dabei unterliegen sie reversiblen Veränderungen in ihrer Ultramorphologie, metabolischen Aktivität und Infektiosität. Persistierende Chlamydienformen sind gekennzeichnet durch aberrante, vergrößerte Retikularkörperchen mit einer veränderten Gen- und Antigenexpression, die in einem viablen, jedoch nichtinfektiösem Stadium verharren [1]. Damit entgehen sie möglicherweise der Immunantwort des Wirtes und einer antibiotischen Therapie, sodass persistierende Chlamydien für das Auftreten von chronischen oder rezidivierenden Chlamydieninfektionen verantwortlich gemacht werden. Allerdings ist die klinische Relevanz persistierender Chlamydienformen immer noch umstritten, da bislang noch keine diagnostischen Verfahren verfügbar sind, um sie im menschlichen Untersuchungsmaterial detektieren zu können. Darüber hinaus konnte für alle Chlamydien-Arten gezeigt werden, dass sie in der Lage sind durch eine Modulation der Wirtszellapoptose ihr intrazelluläres Überleben in einer für sie potentiell feindlichen Umgebung zu sichern [3]. Eine Schlüsselrolle für die Pathogenese chlamydialer Infektionen scheinen Typ-3-sezernierte Proteine zu spielen, die in die Wirtszelle injiziert werden, wobei sie im Unterschied zu anderen gramnegativen Bakterien nicht auf so genannten Pathogenitätsinseln lokalisiert sind [19]. Darüber hinaus wurde ein chlamydialer Faktor mit Proteaseaktivität (CPAF) beschrieben, der offenbar dazu führt, dass Transkriptionsfaktoren für die MHC restringierte Antigenpräsentation degradiert werden und somit die infizierte Zelle, dem Zugriff der zellulären Immunantwort möglicherweise entgeht [31]

Chlamydien können bis dato genetisch nicht transformiert werden. Daher stehen die klassischen Instrumente der bakteriologischen Virulenzforschung nicht zur Verfügung.

C. trachomatis besitzt eine vergleichsweise große antigene Variabilität, die vor allem durch variable Domänen des MOMP determiniert wird und zur Ausprägung von derzeit 18 unterschiedlichen Serotypen mit unterschiedlicher Gewebespezifität führt. So führen Infektionen mit den Serotypen A-C zum Trachom, die Serotypen D-K zu weit verbreiteten sexuell übertragbaren Erkrankungen wie Urethritis und Zervizitis einschließlich Ihrer Folgeerkrankungen und die Serotypen L1-L3 zum ebenfalls durch Sexualkontakte übertragbaren Lymphogranuloma venereum.

Spezielle Pathogenitätsfaktoren von C. pneumoniae sind nicht definiert. Insbesondere konnten bisher keine bakteriellen Faktoren identifiziert werden, die für einen besonderen Gefäßtropismus des Erregers stehen. Im Unterschied zu C. trachomatis und C. psittaci sind bisher keine unterschiedlichen Serotypen von C. pneumoniae bekannt.

Die Antigenvariabilität von C.psittaci beruht auf Sequenzunterschieden des „major outer membrane proteins (MOMP)“, was zur Einteilung von C. psittaci in bisher 6 Serovare (A-F) geführt hat. Bei C. abortus wurden hochvariable Proteinfamilien wie TMH/INC und PMP-Familien gefunden, die möglicherweise für den Wirtstropismus verantwortlich sind [28].

\section{Erkrankungen}

\section{Trachom}

\section{Synonym(e)}

Keine.

\section{Inkubationszeit}

Die Primärinfektion entwickelt sich innerhalb von einigen Tagen klinisch als Konjunktivitis und betrifft in Endemiegebieten vor allem Kleinkinder. Die fortgeschrittenen Stadien sowie das Endstadium der Erkrankung entwickeln sich im Lauf von mehreren Jahren

\section{Leitsymptome}

In den initialen Stadien manifestiert sich das Trachom als eine chronische follikuläre Konjunktivitis mit papillärer Hypertrophie und entzündlicher Infiltration. In den fortgeschrittenen Stadien finden sich Entropium, Trichiasis, Hornhautulzera, Visusverlust, Erblindung. 


\section{Symptome}

Initial konjunktivitistypische Symptomatik mit Hyperämie, Fremdkörpergefühl und mukopurulentem Ausfluss. Die initiale Infektion kann spontan ausheilen oder zu klinisch unterschiedlich schweren Verläufen führen. Die WHO schlägt basierend auf der Ausprägung der Symptomatik die Einteilung des Trachoms in 5 klinische Stadien vor [26]:

1. Follikuläre trachomatöse Entzündung bei 5 oder mehr Follikeln der Konjunktiva des Oberlides,

2. Starke trachomatöse Entzündung bei ausgeprägter inflammatorischer Verdickung der Konjunktiva des Oberlides,

3. Trachomatöse, konjunktivale Vernarbung bei sichtbaren Narben der Konjunktiva des Oberlides,

4. Trachomatöse Trichiasis bei Reiben von mindestens einer Wimper auf dem Augapfel,

5. Korneale Trübung.

\section{Pathophysiologie}

Durch Infektion der Konjunktiva mit den C.-trachomatis-Serotypen A-C wird die Erkrankung initiiert. Sofern die Erkrankung nicht spontan ausheilt, kann es im Rahmen einer chronisch-anhaltenden inflammatorischen Reaktion zu einem fibrotischen Umbau des betroffenen Gewebes mit Bildung konjunktivaler Narben kommen. Die Primärinfektion bei kleinen Kindern kann für mehrere Jahre aktiv sein. Relativ häufig werden diese verkompliziert durch bakterielle Superinfektionen oder durch Reinfektionen. Durch Vernarbungsprozesse der inneren Konjunktiven kommt es zu Entropium, Trichiasis und konsekutiven Hornhautabschürfungen, die bis hin zu Ulzeration, kornealer Vernarbung mit Hornhauttrübung und im Extremfall zur Erblindung führen können.

\section{Immunantwort}

Da Reinfektionen möglich und auch häufig sind, hinterlässt die Primärinfektion offenbar keine protektive Immunität. Möglicherweise spielt eine überschießende Immunantwort, die vor allem gegen das innerhalb der Chlamydiaceae stark konservierte „heat shock protein 60 (cHsp60)" gerichtet ist, eine pathogenetisch entscheidende Rolle. Zumindest bei Affen führte die wiederholte experimentelle Inokulation der Konjunktiven mit cHsp60 zu einem dem Trachom sehr ähnlichen Krankheitsbild. Da cHsp60 Homologien zu humanen "heat shock“ Proteinen zeigt, wird auch ein Autoimmungeschehen diskutiert.

\section{Differenzialdiagnose}

In den Frühstadien der Erkrankung (Einschluss-) Konjunktivitis durch die C.-trachomatis-Serotypen D-K sowie durch Viren.

\section{Unspezifische Urogenitalinfektionen}

Bei Frauen typischerweise Zervizitis; bei Männern Urethritis.

\section{Synonym(e)}

Sexuell übertragbare Erkrankungen (engl. sexually transmitted disease, STD). Nicht-gonorrhoische Urethritis (NGU).

\section{Inkubationszeit}

Bei Urethritis und Zervizitis ca. 7-14 Tage. Bei aufsteigenden Infektionen vermutlich Wochen bis Monate. Unerkannte genitale-Infektionen bei werdenden Müttern können zur Erregerübertragung auf das Neugeborene während der Passage durch den Geburtskanal führen, sodass es nach der Geburt innerhalb von 5-12 Tagen zur Neugeborenen-Konjunktivitis und innerhalb 2-8 Wochen zur Säuglings-Pneumonie kommen kann.

\section{Leitsymptome}

Die Mehrheit der Primärinfektionen verläuft asymptomatisch. Bei symptomatischen Männern primär Urethritis mit Dysurie und Ausfluss, der im Gegensatz zur Gonorrhoe weniger purulent und manchmal sogar klar sein kann. Bei Frauen manifestiert sich die Primärinfektion üblicherweise als mukopurulente Zervizitis u. U. mit postkoitalen Blutungen und Dysurie.

\section{Symptome}

Bei Frauen führen aufsteigende Infektionen zur Endometritis, Salpingitis oder Pelveoperitonitis (engl. pelvic inflammatory disease). Die klinische Symptomatik kann dabei akut und schwer sein und von einem Aszites begleitet werden. Allerdings kommen subklinische Formen, die sehr milde und nahezu asymptomatisch verlaufen, offenbar weitaus häufiger vor. Spätfolgen von aufsteigenden Infektionen bei Frauen umfassen vor allem die Tubarsterilität, ektopische Schwangerschaft und ein chronisches Schmerzsyndrom des kleinen Beckens (PID).

Durch Schmierinfektion kann es zur so genannten Einschlusskonjunktivitis des Erwachsenen kommen mit akuter follikulärer mukopurulenter Konjunktivitis und Fremdkörpergefühl

Säuglinge von Müttern mit unerkannten C.-trachomatis-Infektionen können eine Neugeborenen-Konjunktivitis und/oder eine Säuglings-Pneumonie mit einem überwiegend moderaten und afebrilen Verlauf entwickeln. Die Kinder werden symptomatisch durch nasale Obstruktion mit Ausfluss, Tachypnoe und Husten [22].

Aufsteigende Infektionen führen beim Mann zur unilateralen Epididymitis, die in der akuten Phase mit einer Oligospermie assoziiert sein kann. Es finden sich einseitig geschwollene (Neben-) Hoden, Dysurie, Fieber und gelegentlich Schüttelfrost. Bei Befall des Rektums findet sich insbesondere bei homosexuellen Männern eine Proktitis und/oder Proktokolitis mit den Symptomen analer Pruritus und mukopurulenter Ausfluss. In der Folge einer Urethritis kann es insbe- 
sondere bei HLA B27-positiven Männern zu einer reaktiven Arthritis kommen. Ein sogenannter Morbus Reiter liegt vor bei der Symptomentrias Urethritis, Konjunktivitis und Arthritis.

\section{Pathophysiologie}

Die Infektionen werden durch Befall der entsprechenden Schleimhautepithelzellen mit C. trachomatis der Serovare D-K ausgelöst. Der Großteil der Infektionen verläuft insbesondere bei Frauen oligosymptomatisch bzw. gänzlich asymptomatisch. Als Folge unerkannter Infektionen können chronisch Verläufe mit irreversiblen Folgeschäden entstehen. Die pathophysiologischen Details sind dabei nicht vollständig aufgeklärt. Offenbar führt jedoch die aufsteigende Chlamydieninfektion der Adnexe zu chronisch inflammatorischen Prozessen mit fibrotischem Umbau des Gewebes und tubaler Okklusion. Persistente Chlamydienformen mit modifizierter Gen- und Antigen-Expression könnten dabei eine wichtige Rolle spielen.

\section{Immunantwort}

Die natürliche Infektion verleiht nur eine partielle Immunität. Reinfektionen, insbesondere durch unterschiedliche Serovare sind möglich. Tierexperimentelle Daten weisen daraufhin, dass die Th-1 vermittelte zelluläre Immunantwort kritisch für die Erregererradikation ist. Hohe Titer C.-trachomatis-spezifischer Antikörper korrelieren nicht mit der Beseitigung der Infektion sondern im Gegenteil mit schweren Folgeerkrankungen oder invasiven Infektionen wie Pelveoperitonitis, Tubarinfertilität oder dem LGV. Dabei werden auch Antikörper gegen Virulenz-assoziierte Proteine induziert [9]. Bei umschriebenen lokalen Infektionen wie der Urethritis oder Konjunktivitis kommt es häufig zu keiner serologisch messbaren humoralen Immunantwort.

\section{Differenzialdiagnose}

Gonorrhoe sowie andere Erreger der nicht-gonorrhoischen Urethritis wie Ureaplasma urealyticum, Trichomonas vaginalis, Mycoplasma genitalium und Herpes simplex-Virus.

\section{Lymphogranuloma venereum}

Synonym(e)

LGV.

\section{Inkubationszeit}

7-14 Tage.

\section{Leitsymptome}

Genitalulkus mit schmerzhafter Lymphadenopathie, Proktitis.

\section{Symptome}

Im Stadium I der Infektion zeigt sich an der Genitalschleimhaut oder angrenzenden Haut eine Primärläsi- on in Form einer kleinen Papel oder eines schmerzlosen herpetiformen Ulkus. Dabei kommt es häufig zur Abheilung des Ulcus ohne Narbenbildung. In Abhängigkeit der Sexualpraktiken kann sich die Primärläsion auch als Proktitis oder Pharyngitis klinisch manifestieren. Im Stadium II unilaterale, manchmal beidseitige, in der Regel inguinale schmerzhafte Lymphadenopathie. Im fortgeschrittenen Verlauf Einschmelzung der Lymphknoten mit sogenannter Bubobildung (fluktuierende Lymphknoten) und Fistelbildung. Im Stadium III Lymphabflussstörungen mit Elephantiasis. Die lokale Symptomatik wird häufig von Allgemeinsymptomen wie Fieber, Abgeschlagenheit und Krankheitsgefühl begleitet.

\section{Pathophysiologie}

Das Lymphogranuloma venereum wird durch die C.trachomatis-Serovare L1-L3 verursacht. Initial werden die Epithelzellen des Genitaltraktes befallen. Die Eintrittspforte stellen kleinere Hautabschilferungen oder Verletzungen dar. Die Erreger gelangen in die drainierenden Lymphknoten, wo sie in Monozyten und Lymphozyten replizieren und zur Abszess-(Bubo-)Bildung führen. Die Rupturierung eingeschmolzener Lymphknoten kann zur Fistelbildung führen. Bei Unbehandelten entwickelt sich eine chronisch granulomatöse Entzündung mit fibrotischem Umbau und Verlegung der Lymphabflussgefäße.

\section{Immunantwort}

Es kommt insbesondere ab dem zweiten Erkrankungsstadium zu einer messbaren humoralen Immunantwort.

\section{Differenzialdiagnose}

Andere ulzerierende Erkrankungen des Genitaltraktes wie Herpes genitales, Syphilis, Ulcus molle und Granuloma inguinale.

\section{Respiratorische Infektionen durch \\ C. pneumoniae \\ Sinusitis, Pharyngitis, Bronchitis und Pneumonie.}

\section{Synonym(e)}

TWAR-Pneumonie.

\section{Inkubationszeit}

Die exakte Inkubationszeit ist unbekannt, vermutlich 1-3 Wochen.

\section{Leitsymptome}

Typische Leitsymptome für C.-pneumoniae-Infektionen fehlen.

\section{Symptome}

Bei C.-pneumonie-Infektionen der oberen Atemwege ähneln die Symptome denen eines grippalen Infektes, mit initial unspezifischen Befunden wie Rhinitis, Halsschmerzen und Heiserkeit. Ein Großteil der Infektionen des oberen Respirationstraktes verläuft ver- 
mutlich oligo- bzw. asymptomatisch. Die Entwicklung eines trockenen Hustens und einer Dyspnoe weisen auf eine Pneumonie hin. Der radiologische Befund ist dabei variabel. Die Entzündungsmarker können stark erhöht sein, aber auch im Normalbereich liegen [30]. Fieber wird anamnestisch bei C.-pneumoniae-Infektionen eher seltener genannt. Die Symptomatik kann trotz adäquater Therapie ausgesprochen prolongiert sein und sich in monatelanger Abgeschlagenheit und Krankheitsgefühl äußern.

Chronische Infektionen mit C. pneumoniae wurden von Patienten mit chronisch obstruktiver Lungenerkrankung und auch als Ursache von Exazerbationen bei Patienten mit Asthma bronchiale berichtet. Daneben wurde C. pneumoniae kasuistisch auch bei extrapulmonalen Erkrankungen wie Endokarditis, Myokarditis, Meningitis, Erythema nodosum und reaktive Arthritis nachgewiesen.

\section{Pathophysiologie}

Für C.-pneumoniae-Infektionen ist ein biphasischer Verlauf beschrieben. Unklar ist jedoch, wie häufig sich aus initial milden Infektionen der oberen Luftwege eine Bronchitis oder eine Pneumonie entwickelt und was die auslösenden Faktoren dafür sind.

Eine ätiologische Rolle von C. pneumoniae in der Atherogenese wird seit 1988 diskutiert, als Saikku und Mitarbeiter aufgrund serologischer Daten eine Assoziation zwischen C. pneumoniae und der koronaren Herzkrankheit sowie des akuten Myokardinfarktes postulierten [24]. In den Folgestudien wurden die Erreger in atherosklerotischen Läsionen von Patienten mittels Kultur, PCR, Immunhistochemie und Transmissions-Elektronenmikroskopie detektiert. Dabei wurde diskutiert, ob der Erreger bzw. einzelne Bestandteile (Antigene, Nukleinsäuren) durch das Monozyten-Makrophagensystem aus dem Respirationstrakt in die Gefäßwand gelangen. In-vitro-Studien weisen darauf hin, dass die Präsenz hochimmunogener Chlamydien-Antigene wie heat shock-Protein 60 sowie das chlamydiale LPS eine entscheidende Rolle bei der Induktion proinflammatorischer Prozesse in der Gefäßwand spielen könnten. Die Diskrepanz der publizierten Daten, einschließlich der tierexperimentellen Befunde sowie das Scheitern groß angelegter Therapiestudien [4] hat dazu geführt, dass die ätiologische Relevanz des Erregers bei der Arteriosklerose zunehmend kritisch diskutiert wird [13].

\section{Immunantwort}

Die C.-pneumoniae-Infektion induziert eine spezifische humorale und zelluläre Immunantwort, die jedoch offenbar nicht vollständig vor Reinfektionen schützt. Frühestens 2 Wochen nach Primärinfektion finden sich spezifische IgM-Antikörper, frühestens 4 Wochen nach Primärinfektion spezifische IgG-Antikörper. Tierexperimentelle Daten weisen darauf hin, dass eine effektive Th1-vermittelte Immunantwort un- ter Beteiligung von CD8-positiven Zellen entscheidend für die Erregerradikation ist.

\section{Differenzialdiagnose}

In Frage kommen vor allem andere Erreger atypischer Pneumonien und des oberen Respirationstraktes insbesondere respiratorische Viren sowie Mycoplasma pneumoniae, C. psittaci und Legionella pneumophila.

\section{Psittakose}

\section{Synonym(e)}

Papageienkrankheit, Ornithose. Der Begriff „Ornithose" ist eigentlich die korrekte Krankheitsbezeichnung, denn dadurch wird deutlich, dass nicht nur Papageien, sondern viele unterschiedliche Vogelarten als Erregerreservoir in Frage kommen.

\section{Inkubationszeit}

Variabel, zwischen 1 und 4 Wochen.

\section{Leitsymptome}

Initial grippeähnliche Symptomatik die typischerweise in eine atypische Pneumonie mündet. Oft wird die Infektion initial verkannt, da keine gezielte Anamnese (Vogelkontakt) erhoben wurde oder die Infektion als systemische Allgemeininfektion imponiert.

\section{Symptome}

Hohes Fieber, Gliederschmerzen und starke Kopfschmerzen finden sich in Verlaufsformen mit und ohne respiratorische Beteiligung. Unproduktiver Husten (im Erkrankungsverlauf oft spät), Dyspnoe sowie Infitrate im Röntgen-Thorax weisen auf eine Pneumonie hin, die auch einen karnifizierenden Verlauf nehmen kann [7]. In der präantibiotischen Ära verlief die Psittakose oft tödlich.

Durchfall, Übelkeit und Erbrechen können den Verdacht anfangs auf eine Gastroenteritis und bei Ikterus und Hepatomegalie auf eine Hepatitis lenken. Eine kardiale Beteiligung kann sich als Perikarditis, Myokarditis und kulturnegative Endokarditis manifestieren. Bei ZNS-Beteiligung relativ häufig meningoenzephalitische Symptomatik mit Somnolenz und Verwirrung. Die nicht selten auftretenden Exantheme können vielgestaltig sein, typischerweise kommt es zur Ausbildung eines roseolenähnlichen makulo-papulären Erythems.

\section{Pathophysiologie}

Die Psittakose oder Ornithose wird durch C. psittaci (aviäre Serovare ) verursacht. Unklar ist, welche Determinanten auf Wirts- und Erregerseite für den variablen klinischen Verlauf verantwortlich sind. In-vitroStudien sowie die rasche systemische Ausbreitung deuten darauf hin, dass C. psittaci sich auch in Monozyten vermehren kann.

\section{Immunantwort}

Bisher kaum charakterisiert. Bei klinisch manifester 
Ornithose in der Regel ausgeprägte humorale Immunantwort gegen das Chlamydien-Lipopolysaccharid und weitere bisher schlecht charakterisierte Antigene.

\section{Differenzialdiagnose}

Bei atypischer Pneumonie kommen vor allen Dingen respiratorische Viren, Coxiella burnetii, Legionella pneumophila, Mycoplasma pneumoniae und C. pneumoniae differenzialdiagnostisch in Frage. Bei systemischem Verlauf ohne Lungenbeteiligung sind differenzialdiagnostisch die Ursachen des Fiebers unklarer Genese zu bedenken.

\section{Septischer Abort}

Synonym(e)

Keine.

\section{Inkubationszeit \\ Unklar.}

\section{Leitsymptome}

Spontanabort, unklares Fieber und Sepsis in der Schwangerschaft.

\section{Symptome}

Die Infektion mit C. abortus in der Schwangerschaft kann zunächst zu einer influenzaähnlichen Symptomatik führen. Schwere und lebensbedrohliche Verläufe sind beschrieben worden, die mit einem Multiorganversagen (Niere, Leber) und disseminierter intravasaler Gerinnung einhergehen [29].

\section{Pathophysiologie}

Die Erkrankung wird durch C. abortus verursacht, dem Erreger einer insbesondere bei Schafen und Ziegen weit verbreiteten Zoonose, die bei diesen Tieren zum Abort führen kann. Offenbar besitzt C. abortus einen Tropismus zu den Plazentaepithelien. Falls schwangere Frauen z. B. in der Landwirtschaft gegenüber C. abortus infizierten Nutztierbeständen (v. a. Schafen) exponiert sind, insbesondere aber wenn sie Kontakt mit Abortmaterial von infizierten Tierbeständen, kann es aufgrund einer schweren Plazentitis zum Verlust des Feten kommen. Infektionen bei Männern wurden bisher noch nicht beschrieben.

\section{Immunantwort}

Es wird vermutet, dass eine Th2-vermittelte zelluläre Antwort bei der Interferon- $\gamma$ herunterreguliert ist, möglicherweise zur raschen Ausbreitung des Erregers beiträgt.

\section{Differenzialdiagnose}

Q-Fieber.

\section{Diagnostik}

\section{Untersuchungsmaterial}

Da es sich bei Chlamydien um obligat intrazellulär re- plizierende Bakterien handelt, ist bei der Entnahme der Untersuchungsproben grundsätzlich auf die Gewinnung möglichst zellreicher Materialien zu achten. In Abhängigkeit der im untersuchenden Labor eingesetzten Verfahren zum Direktnachweis der Erreger ist die Verwendung spezieller Abstrichbestecke und Transportmedien erforderlich. Sofern der zellkulturelle Nachweis angestrebt wird, muss das Untersuchungsmaterial in einem speziellen Chlamydien-Transportmedium möglichst unverzüglich nach Entnahme gekühlt ins Labor gebracht werden.

Für den serologischen Nachweis wird eine Serummonovette entnommen. Oft ermöglicht erst eine Verlaufsuntersuchung im Abstand von ca. 2 Wochen eine zuverlässige Interpretation der serologischen Befunde.

C. trachomatis: Erststrahlurin und (selbst entnommene) Vaginalabstriche bei unkomplizierten urogenitalen Infektionen. Für Screening-Untersuchungen bei jungen Frauen sind in Deutschland laut G-BA Beschluss nur Urinproben vorgesehen. Weitere geeignete Untersuchungsmaterialien in Abhängigkeit des klinischen Bildes umfassen Konjunktival-, Urethral-, Zervikal-, Rektalabstriche, bei V. a. LGV darüber hinaus Abstriche vom Ulkusgrund sowie Buboaspirat [6].

C. pneumoniae: Für den direkten Erregernachweis kommen primär respiratorische Materialien wie $\mathrm{Na}-$ sen-Rachen-Spülflüssigkeiten (insbesondere bei Kindern), Rachenabstriche, Sputum, Bronchialsekrete sowie bronchoalveoläre Lavage (BAL)-Flüssigkeit in Frage. Für den indirekten Erregernachweis sollte eine gepaarte Serumprobe, die im Abstand von 2 Wochen entnommen wurde, untersucht werden.

C. psittaci: Bei Verdacht auf Psittakose: Serum für den Antikörpernachweis und ggf. respiratorische Sekrete wie bronchoalveoläre Lavageflüssigkeit (BAL) für den Direktnachweis.

C. abortus: Unklar; Serum, Abortmaterial, Vaginalausfluss von Schwangeren.

\section{Diagnostische Verfahren}

C. trachomatis: Diagnostische Verfahren der Wahl zum Nachweis von C.-trachomatis-Infektionen sind kommerziell verfügbare Nukleinsäureamplifikationsverfahren (NAT) die auch die Untersuchung von nicht invasiv gewonnenen Untersuchungsmaterialien wie Urin z. B. im Rahmen von Screening-Untersuchungen erlauben [6]. Antigennachweisverfahren wie ELISA oder direkter Immunfluoreszenztest haben an Bedeutung verloren, weil sie hinsichtlich Sensitivität und Spezifität den Nukleinsäureamplifikationsverfahren unterlegen sind und sie nur an invasiv gewonnenen Materialien wie Zervikal- und Urethralabstrichen durchgeführt werden können. Aufgrund des beträchtlichen technischen Aufwandes werden zellkulturelle Verfahren zum Nachweis von C. trachomatis nur noch in wenigen Speziallaboratorien angeboten. Der Nachweis C.-trachomatis-spezifischer Antikörper kann bei 
einigen Indikationen wie Infektionen des oberen Genitaltraktes, Neugeborenen-Pneumonie und LGV hilfreich sein.

C. pneumoniae: In vielen Laboratorien verbreitet sind so genannte in-house-PCR-Verfahren, die jedoch wenig standardisierte und daher oft schwer reproduzierbare Befunde liefern [15]. Der zellkulturelle Erregernachweis ist aufwändig und technisch schwierig und wird nur von wenigen Speziallaboratorien angeboten. Als goldener Standard für die Serodiagnostik gilt nach wie vor der Mikroimmunfluoreszenztest auf der Basis von gereinigtem C.-pneumoniae-Elementarkörperchen. Die Beurteilung des Tests erfordert Erfahrung und ist nicht frei von subjektiven Einflüssen. Kommerziell verfügbare, standardisierbare Verfahren auf Basis von ELISA- bzw. Immunoblot-Techniken sind überwiegend noch in der Phase der Evaluierung.

C. psittaci: PCR- und kultureller Nachweisverfahren sind in Speziallaboratorien verfügbar [23]. Zum Schutz vor Laborinfektionen sind beim Umgang mit den Erregern gemäß Biostoffverordnung Sicherheitsmaßnahmen der Schutzstufe 3 vorgeschrieben. Nachweis hoher Antikörpertiter mittels Mikroimmunfluoreszenztest oder Ornithose-KBR (cave: Kreuzreaktionen).

C. abortus: Nukleinsäureamplifikationsverfahren und serologische Verfahren sind nur in Speziallaboratorien etabliert.

\section{Befund / Interpretation}

Kommerziell verfügbare Nukleinsäureamplifikationsverfahren erlauben den Nachweis von urogenitalen C. trachomatis-Infektionen mit hoher Zuverlässigkeit. Diese Nachweisverfahren können jedoch noch bis zu 3 Wochen nach abgeschlossener Therapie positiv bleiben. Bei der Interpretation serologischer Verfahren ist auf Speziesspezifiät des Testes zu achten. Hohe C.trachomatis-spezifische Antikörper finden sich bei aufsteigenden C.-trachomatis-Infektionen des kleinen Beckens und beim Lymphogranuloma venereum.

Der direkte Nachweis von C. pneumoniae mittels Kultur oder PCR weist auf eine aktive behandlungsbedürftige Infektion hin. Allerdings ist zu berücksichtigen, dass selbst in Speziallaboratorien mit einer beträchlichen Variabilität insbesondere der PCR-Befunde zu rechnen ist. Ein IgM-Titer von $1 \geq 16$ und/oder ein IgG-Titer von $1 \geq 512$ gelten neben einem 4 fachen Titeranstieg in gepaarten Serumproben als diagnostisch hinweisend auf eine aktive Infektion. Allerdings sollte ein IgG-Titer von $1 \geq 512$ in einer einzelnen Serumprobe mit Vorsicht interpretiert werden, da erhöhte IgG-Titer u. U. mehrere Jahre auch ohne klinisch-apparente Symptomatik persistieren können. IgG-Titer zwischen 1:16 und 1:256 weisen auf eine zurückliegende Infektion hin. Der diagnostische Nutzen von spezifischen IgA-Antikörpern ist unklar [5]. Es gibt ganz offensichtlich einen Mangel an standardisierten und evaluierten kommerziell verfügbaren
Nachweisverfahren, was die Beurteilung der klinischen Relevanz von C. pneumoniae erheblich erschwert [15].

Die verfügbaren serologischen Nachweisverfahren erlauben keinen Nachweis speziesspezifischer Antikörper gegen C. psittaci und C. abortus [6]. Daher ist zu bedenken, dass ein erhöhter KBR-Titer auch durch eine Infektion mit einer anderen Chlamydienspezies zustande kommen kann. Beim Nachweis hoch positiver (häufig mit anderen Chlamydienspezies kreuzreagierender) Antikörper ist bei entsprechender klinischer Symptomatik die gezielte Erhebung der Anamnese hinsichtlich einer möglichen Exposition des Patienten gegenüber den natürlichen Wirten diagnostisch wegweisend.

\section{Therapie}

\section{Therapeutische Maßnahmen}

Tetracycline, Makrolide und Chinolone werden zur Antibiotika-Therapie von Chlamydieninfektionen üblicherweise eingesetzt.

Bei unkomplizierter Urethritis und Zervizitis durch C. trachomatis ist die Einmalgabe von Azythromicin ebenso effektiv wie die standardmäßige 7-tägige Behandlung mit Doxycyclin. Alternativ kommt eine Therapie mit Erythromycin oder Levofloxacin für 7 Tage in Frage [10]. Bei der Neugeborenen-Konjunktivitis und -Pneumonie durch C. trachomatis wird die systemische Therapie mit Erythromycin empfohlen. Das Lymphogranuloma venereum wird 21 Tage mit Doxycyclin behandelt [16].

Bisher gibt es keine klinischen Studien zur Antibiotikatherapie von C.-pneumoniae-Infektionen. Die Behandlungsdauer, wenn mit Doxycyclin oder Makroliden behandelt wird, sollte zwischen 2 und 3 Wochen liegen. Bei klinischem Therapieversagen kann eine Ausdehnung der Therapie oder ein Wechsel der Substanzklasse erforderlich sein.

Bei klinischem und anamnestischem Verdacht auf Psittakose muss umgehend eine parenterale Therapie mit Doxycyclin oder Makrolid-Antibiotika eingeleitet werden.

Bei unklarem Fieber während der Schwangerschaft und Exposition zu potenziell infizierten Tierbeständen, insbesondere Schafherden unverzügliche Einleitung einer Therapie mit einem Makrolid-Antibiotikum, wegen der Gefahr einer Plazentitis durch C. $a b$ ortus.

\section{Resistenz}

Resistenzen von Chlamydien gegen empfohlene Antibiotika sind selten und beschränken sich auf wenige C.-trachomatis-Isolate. Allerdings wurde immer wieder über rezidivierende und chronisch anhaltende Infektionen trotz adäquater Therapie berichtet. Die Beurteilung von Resistenz und möglichem klinischen Therapieversagen wird eingeschränkt durch den Mangel an standardisierten Tests zur Empfindlichkeitsprü- 
fung von Chlamydien. Die Durchführung von Empfindlichkeitsprüfungen bei Chlamydien-Infektionen erfordert die zellkulturelle Isolierung des Erregers und ist nur in wenigen Speziallaboratorien verfügbar.

\section{Epidemiologie}

\section{Verbreitung}

C. trachomatis: Das Trachom ist weit verbreitet in unterentwickelten Gebieten Afrikas, des Nahen Ostens, Asiens, Südamerikas. Nach Schätzungen der WHO sind weltweit rund 1,3 Mio. Menschen durch den Erreger erblindet. Urogenitalinfektionen der C.-trachomatis-Serovare $\mathrm{D}-\mathrm{K}$ gehören global zu den häufigsten sexuell übertragbaren Erkrankungen. Da für Deutschland keine Meldepflicht besteht, liegen keine genauen Daten zur Prävalenz vor. Anhand der wenigen vorliegenden Studien ist davon auszugehen, dass in der Altersgruppe der 15-bis 25-Jährigen ca. 4-10\% infiziert sind. In den USA sind die Erreger für mindestens 1 Mio. Neuinfektionen pro Jahr verantwortlich. In Schweden hatte sich in den vergangenen Jahren eine C.-trachomatis-Variante ausgebreitet, die dem Nachweis durch einige kommerziell verfügbare Nukleinsäureamplifikationsverfahren, aufgrund einer 377-bpDeletion im kryptischen Plasmid, entging [20]. Inzwischen haben sich die meisten Testhersteller darauf eingestellt und die klinische und epidemiologische Relevanz dieser Variante außerhalb von Schweden scheint gering zu sein. Das LGV hat sich in den vergangenen Jahren vor allem unter homosexuellen, HIV-positiven Patienten in den Großstädten Europas und Nordamerikas wieder ausgebreitet [18]. Außerdem ist das LGV noch in einigen Teilen Afrikas, Asiens, Südamerikas und der Karibik endemisch.

C. pneumoniae: Seroepidemiologische Studien weisen darauf hin, dass bei einer Durchseuchungsrate zwischen $50-70 \%$ im Erwachsenenalter sich nahezu jeder im Laufe seines Lebens zumindest einmal mit C. pneumoniae infiziert. Die Primärinfektion erfolgt vermutlich im Kindes- bzw. Jugendlichenalter. Frühere Studien identifizierten C. pneumoniae in 10-15\% der Fälle als Ursache der ambulant erworbenen Pneumonie sowohl bei Erwachsenen als auch bei Kindern. Neuere Studien mit Prävalenzraten von unter $1 \%$ für C. pneumoniae weisen allerdings darauf hin, dass die Bedeutung des Erregers bei der ambulant erworbenen Pneumonie derzeit eher gering ist [30].

C. psittaci: C. psittaci ist in mehr als 130 Vogelarten weltweit verbreitet. Dagegen sind humane C.-psittaciInfektionen mit deutlich weniger als 100 Fällen pro Jahr in Deutschland sehr selten geworden [21].

C. abortus: Infektionen beim Menschen wurden bisher nur sporadisch beschrieben.

\section{Wirtsbereich / Reservoir}

Der Mensch ist das einzige Erregerreservoir für alle C.-trachomatis-Serovare.

Für C. pneumoniae galt der Mensch bisher als einzig bekanntes Erregerreservoir. Inzwischen wurde C. pneumoniae jedoch auch bei einer Reihe von Säugetieren (Koalabären, Pferde) Amphibien und Reptilien nachgewiesen und es wird vermutet, dass die heutigen humanen Stämme sich aus zoonotisch erworbenen Isolaten adaptiert haben [17].

Typischerweise stellen Ziervögel (insbesondere Papageien und Wellensittiche) das klassische Erregerreservoir für die Psittakose dar. Das natürliche Reservoir bildet jedoch eine Vielzahl von Wildvögeln, die den Erreger auch auf Nutzgeflügel (Truthahn und Enten) übertragen können [21].

Für C. abortus stellen Wiederkäuer, insbesondere Schafe und Ziegen das wichtigste Erregerreservoir dar.

\section{Risikogruppen}

Kinder unter 2 Jahren, die in Endemiegebieten extrem schlechten sozioökonomischen Bedingungen ausgesetzt sind, haben das größte Erkrankungsrisiko für das Trachom. Bei den Urogenitalinfektionen der C.-trachomatis-Serovare $\mathrm{D}-\mathrm{K}$ ist die Altersgruppe der 15-30-Jährigen vor allem betroffen. Die jüngsten Ausbrüche von LGV in Europa betrafen vor allem homosexuelle HIV-positive Männer [18].

Risikogruppen, die für C.-pneumoniae-Infektionen prädestiniert sind, wurden bisher nicht beschrieben. Ambulant erworbene Pneumonien durch C. pneumoniae betreffen eher jüngere Patienten [30].

Halter von Ziervögeln, Beschäftigte in Zoohandlungen und der geflügelverarbeitenden Industrie kommen als Risikogruppen für die Ornithose in Frage [7, 21].

C.-abortus-Infektionen wurden bisher nur bei schwangeren Frauen, die gegenüber infizierten Tierbeständen exponiert waren, beschrieben. Bei Männern sind C.abortus-Infektionen bisher nicht bekannt.

\section{Transmission / Vektoren}

Die Weiterverbreitung des Trachoms innerhalb der Familie erfolgt durch Schmierinfektion unter schlechten hygienischen Bedingungen. Fliegen, die sich von mukopurulenten Konjunktivalsekreten ernähren, können dabei die Erreger von Mensch zu Mensch über relativ lange Distanzen übertragen. Die C.-trachomatis-Serovare D-K sowie das Lymphogranuloma venereum werden in der Regel durch Sexualkontakte übertragen. Die adulte Anschlusskonjunktivitis erfolgt oft durch Autoinokulation bei Menschen mit genitaler C.-trachomatis-Infektion. Die Neugeborenen-Konjunktivitis entsteht durch Kontaktinfektion bei der Passage des Kindes durch den infizierten Geburtskanal.

Die Übertragung von C. pneumoniae erfolgt vermutlich durch Tröpfcheninfektion.

Die Elementarkörperchen von C. psittaci gelten als hochinfektiös und werden sowohl von symptomatischen als auch gesunden Vögeln ausgeschieden. Der 
Mensch infiziert sich durch Inhalation infektiöser Aerosole bzw. infektiösem Vogelstaub.

Die Infektion mit C. abortus erfolgt vermutlich auch durch Einatmung infektiöser Aerosole aus Abortmaterial.

\section{Prävention / Impfstoffe}

Ein Impfstoff gegen C. trachomatis steht nicht zur Verfügung. Beim Trachom bestehen die präventiven Maßnahmen in der von der WHO verfolgten sogenannten SAFE-Strategie (Surgery, Antibiotics, Facial Cleaning, Environment = Verbesserung der sozioökonomischen und hygienischen Gegebenheiten). Zur Senkung der Prävalenz und Vermeidung schwerer Komplikationen der urogenitalen C.-trachomatis-Infektionen werden in Deutschland seit 2008 ScreeningUntersuchungen für die Altersgruppe der 15-bis 25 -jährigen jungen Frauen angeboten. Bei nachgewiesenen Infektionen sollte unbedingt eine Partnermitbehandlung erfolgen und bis zum Abschluss der Therapie sexuelle Abstinenz eingehalten werden. Wie auch bei anderen sexuell übertragbaren Krankheiten senkt der Gebrauch von Kondomen das Infektionsrisiko.

Spezielle präventive Maßnahmen zur Senkung des Infektionsrisikos für C. pneumoniae sind nicht bekannt. Die Prävalenz der Ornithose konnte vor allem durch veterinärhygienische Maßnahmen, insbesondere auch beim Import von Ziervögeln (Quarantänemaßnahmen, prophylaktische Antibiotikabehandlung der Tiere) gesenkt werden.

Ganzkörperzellimpfstoffe sind für C. abortus im veterinärmedizinischen Bereich verfügbar.

\section{Ausbruchsmanagement}

Für das LGV wurde in den letzten Jahren Ausbrüche unter HIV-positiven, homosexuellen Männern beobachtet. Da keine spezielle Meldepflicht besteht, sollte insbesondere von $\$ 6$ IfSG Absatz $1 \mathrm{Nr}$. 5b Gebrauch gemacht werden, wenn eine ungewöhnliche Häufung von Fällen beobachtet wird

Ausbrüche von C.-pneumoniae-Infektionen wurden in den vergangenen Jahren eher selten beobachtet. Eine ungewöhnliche Häufung von C.-pneumoniaeFällen sollte daher Anlass sein, mit dem Konsiliarlabor für Chlamydieninfektionen Kontakt aufzunehmen. Für das Ausbruchsmanagement ist zu beachten, dass die Übertragung vermutlich durch Aerosole erfolgt und Erkrankte das Erregerreservoir darstellen.

Für die zonotischen Chlamydien C. psittaci und C. $a b$ ortus kommt es beim Ausbruchsmanagement auf eine rasche Identifizierung der infizierten Tierbestände an. Danach erfolgen spezielle Maßnahmen wie Quarantäne, Expositionsschutz von Beschäftigten, Behandlung infizierter Bestände mit Chlortetrazyklin. Eine Übertragung von Mensch zu Mensch ist theoretisch denkbar, wurde jedoch nie bewiesen.

\section{Meldepflicht}

Der direkte und indirekte Nachweis von C psittaci ist gemäß $₫ 7$ Infektionsschutzgesetz namentlich meldepflichtig.

\section{Weiterführende Informationen}

\section{Referenzzentren / Expertenlaboratorien}

- Konsiliarlabor für Chlamydien-Infektionen: Prof. Dr. Eberhard Straube, Institut für Medizinische Mikrobiologie der Friedrich-Schiller-Universität Jena, Erlanger Allee 101, 07747 Jena, Tel. Tel.: +49-3641-9-393500. Email: eberhard.straube@med.uni-jena.de

- Nationales Referenzlabor für Psittakose. Dr. Konrad Sachse, Institut für bakterielle Infektionen und Zoonosen. Bundesforschungsanstalt für Tiergesundheit, FriedrichLöffler Institut Jena, E-mail: konrad.sachse@fli.bund.de

\section{Web-Adressen}

- www.chlamydiae.com

\section{Schlüsselliteratur}

1. Belland RJ, Nelson DE, Virok D, Crane DD, Hogan D, Sturdevant D, Beatty WL, Caldwell HD (2003) Transcriptome analysis of chlamydial growth during IFN-gammamediated persistence and reactivation. Proc Natl Acad Sci USA 100:15971-15976

2. Belland RJ, Zhong G, Crane DD, Hogan D, Sturdevant D, Sharma J, Beatty WL, Caldwell HD (2003) Genomic transcriptional profiling of the developmental cycle of Chlamydia trachomatis. Proc Natl Acad Sci USA 100:84788483

3. Byrne GI, Ojcius DM (2004) Chlamydia and apoptosis: life and death decisions of an intracellular pathogen. Nat Rev Microbiol 2:802-808

4. Cannon CP, Braunwald E, McCabe CH, Grayston JT, Muhlestein B, Giugliano RP, Cairns R, Skene AM (2005) Antibiotic treatment of Chlamydia pneumoniae after acute coronary syndrome. N Engl J Med 352:1646-1654

5. Dowell SF, Peeling RW, Boman J, Carlone GM, Fields BS, Guarner J, Hammerschlag MR, Jackson LA, Kuo CC, Maass M, Messmer TO, Talkington DF, Tondella ML, Zaki SR (2001) Standardizing Chlamydia pneumoniae assays: recommendations from the Centers for Disease Control and Prevention (USA) and the Laboratory Centre for Disease Control (Canada). Clin Infect Dis 33:492-503

6. Essig A (2011) Chlamydia. In: Murray PR, Baron EJ, Jorgensen JH, Landry ML, Pfaller MA (eds) Manual of Clinical Microbiology, 10th Edition

7. Essig A, Zucs P, Susa M, Wasenauer G, Mamat U, Hetzel M, Vogel U, Wieshammer S, Brade H, Marre R (1995) Diagnosis of ornithosis by cell culture and polymerase chain reaction in a patient with chronic pneumonia. Clin Infect Dis 21:1495-1497

8. Everett KD, Bush RM, Andersen AA (1999) Emended description of the order Chlamydiales, proposal of Parachlamydiaceae fam. nov. and Simkaniaceae fam. nov., each containing one monotypic genus, revised taxonomy of the family Chlamydiaceae, including a new genus and five new species, and standards for the identification of organisms. Int J Syst Bacteriol 49 Pt 2:415-440

9. Forsbach-Birk V, Simnacher U, Pfrepper KI, Soutschek E, Kiselev AO, Lampe MF, Meyer T, Straube E, Essig A (2009) Identification and evaluation of a combination of chla- 
mydial antigens to support the diagnosis of severe and invasive Chlamydia trachomatis infections. Clin Microbiol Infect

10. Geisler WM (2007) Management of uncomplicated Chlamydia trachomatis infections in adolescents and adults: evidence reviewed for the 2006 Centers for Disease Control and Prevention sexually transmitted diseases treatment guidelines. Clin Infect Dis 44 Suppl 3:S77-S83

11. Grayston JT, Campbell LA, Kuo CC, Mordhorst CH, Saikku P, Thom DH, Wang SP (1990) A new respiratory tract pathogen: Chlamydia pneumoniae strain TWAR. J Infect Dis 161:618-625

12. Hybiske K, Stephens RS (2007) Mechanisms of host cell exit by the intracellular bacterium Chlamydia. Proc Natl Acad Sci USA 104:11430-11435

13. Ieven M M, Hoymans VY (2005) Involvement of Chlamydia pneumoniae in atherosclerosis: more evidence for lack of evidence. J Clin Microbiol 43:19-24

14. Kalman S, Mitchell W, Marathe R, Lammel C, Fan J, Hyman RW, Olinger L, Grimwood J, Davis RW, Stephens RS (1999) Comparative genomes of Chlamydia pneumoniae and C. trachomatis. Nat Genet 21:385-389

15. Kumar S, Hammerschlag MR (2007) Acute respiratory infection due to Chlamydia pneumoniae: current status of diagnostic methods. Clin Infect Dis 44:568-576

16. McLean CA, Stoner BP, Workowski KA (2007) Treatment of lymphogranuloma venereum. Clin Infect Dis 44 Suppl 3:S147-S152

17. Myers GS, Mathews SA, Eppinger M, Mitchell C, O'Brien KK, White OR, Benahmed F, Brunham RC, Read TD, Ravel J, Bavoil PM, Timms P (2009) Evidence that human Chlamydia pneumoniae was zoonotically acquired. J Bacteriol 191:7225-7233

18. Nieuwenhuis RF, Ossewaarde JM, Gotz HM, Dees J, Thio $\mathrm{HB}$, Thomeer MG, den Hollander JC, Neumann MH, van der Meijden WI (2004) Resurgence of lymphogranuloma venereum in Western Europe: an outbreak of Chlamydia trachomatis serovar 12 proctitis in The Netherlands among men who have sex with men. Clin Infect Dis 39:996-1003

19. Peters J, Wilson DP, Myers G, Timms P, Bavoil PM (2007) Type III secretion a la Chlamydia. Trends Microbiol 15:241-251

20. Ripa T, Nilsson P (2006) A variant of Chlamydia trachomatis with deletion in cryptic plasmid: implications for use of PCR diagnostic tests. Euro Surveill 11:E061109

21. Rohde G, Straube E, Essig A, Reinhold P, Sachse K (2010) Chlamydial zoonoses. Dtsch Arztebl Int 107:174-180

22. Rours IG, Hammerschlag MM, Van Doornum GG, Hop WW, de Groot RR, Willemse DH, Verbrugh HH, Verkooyen RR (2009) Chlamydia trachomatis respiratory infection in Dutch infants. Arch Dis Child

23. Sachse K, Laroucau K, Vorimore F, Magnino S, Feige J, Muller W, Kube S, Hotzel H, Schubert E, Slickers P, Ehricht R (2009) DNA microarray-based genotyping of Chlamydophila psittaci strains from culture and clinical samples. Vet Microbiol 135:22-30

24. Saikku P, Leinonen M, Mattila K, Ekman MR, Nieminen MS, Makela PH, Huttunen JK, Valtonen V (1988) Serological evidence of an association of a novel Chlamydia, TWAR, with chronic coronary heart disease and acute myocardial infarction. Lancet 2:983-986

25. Schachter J, Stephens RS, Timms P, Kuo C, Bavoil PM, Birkelund S, Boman J, Caldwell H, Campbell LA, Chernesky
M, Christiansen G, Clarke IN, Gaydos C, Grayston JT, Hackstadt T, Hsia R, Kaltenboeck B, Leinonnen M, Ojcius D, McClarty G, Orfila J, Peeling R, Puolakkainen M, Quinn TC, Rank RG, Raulston J, Ridgeway GL, Saikku P, Stamm WE, Taylor-Robinson DT, Wang SP, Wyrick PB (2001) Radical changes to chlamydial taxonomy are not necessary just yet. Int J Syst Evol Microbiol 51:249-253

26. Solomon AW, Peeling RW, Foster A, Mabey DC (2004) Diagnosis and assessment of trachoma. Clin Microbiol Rev 17:982-1011, table

27. Stephens RS, Myers G, Eppinger M, Bavoil PM (2009) Divergence without difference: phylogenetics and taxonomy of Chlamydia resolved. FEMS Immunol Med Microbiol 55:115-119

28. Thomson NR, Yeats C, Bell K, Holden MT, Bentley SD, Livingstone M, Cerdeno-Tarraga AM, Harris B, Doggett J, Ormond D, Mungall K, Clarke K, Feltwell T, Hance Z, Sanders M, Quail MA, Price C, Barrell BG, Parkhill J, Longbottom D (2005) The Chlamydophila abortus genome sequence reveals an array of variable proteins that contribute to interspecies variation. Genome Res 15:629640

29. Walder G, Hotzel H, Brezinka C, Gritsch W, Tauber R, Wurzner R, Ploner F (2005) An unusual cause of sepsis during pregnancy: recognizing infection with chlamydophila abortus. Obstet Gynecol 106:1215-1217

30. Wellinghausen N, Straube E, Freidank H, von Baum H, Marre R, Essig A (2006) Low prevalence of Chlamydia pneumoniae in adults with community-acquired pneumonia. Int J Med Microbiol 296:485-491

31. Zhong G, Fan P, Ji H, Dong F, Huang Y (2001) Identification of a chlamydial protease-like activity factor responsible for the degradation of host transcription factors. J Exp Med 193:935-942

\section{Chlamydia pneumoniae}

Chlamydia

\section{Chlamydia psittaci}

Chlamydia

\section{Chlamydia trachomatis}

Chlamydia

\section{Chlamydophila pneumoniae}

Chlamydia

\section{Chlamydophila psittaci}

Chlamydia 


\section{Cholangitis}

- Ascaris lumbricoides

- Bacteroides

- Echinokokken

- Escherichia coli

- Fasciola hepatica

\section{Cholera}

- Vibrio

\section{Cholezystitis}

- Bacteroides

- Bilophila

- Clostridien der Gasbrandgruppe

- Enterobacter

- Escherichia coli

- Mikrosporidien

- Salmonella

\section{Chorioamnionitis}

- Mycoplasma hominis

- Ureaplasma urealyticum

\section{Chorioretinitis}

- Candida

- Cytomegalievirus

- Herpes-simplex-Virus (HSV)

- Onchocerca volvulus

- Varicella-zoster-Virus (VZV)

\section{Chryseobacterium spp.}

- Flavobacterium

\section{Chrysomyia spp.}

$\checkmark$ Myiasis-Erreger

\section{Cimex spp.}

- Ektoparasiten, sonstige (Stechmücken, Trombiculiden, Flöhe, Wanzen, Zecken)

\section{Citrobacter}

UWE ULLMANN

\section{Erreger}

Synonym(e)

Nicht bekannt.

\section{Erregerspezies}

Citrobacter freundii (C.-freundii-Komplex mit 11 Spezies), C. koseri, C. amalonaticus

\section{Taxonomie}

Familie: Enterobacteriaceae; Gattung: Citrobacter: Spezies: Citrobacter freundii

\section{Historie}

Erstbeschreibung durch Werkmann und Gillen: J Bacteriol 1932, 23:167-182. Der Name leitet sich ab von Citrus (Zitrone), Bacter (griech.: Stäbchen).

\section{Morphologie}

Gramnegative peritrich begeißelte Stäbchenbakterien.

\section{Genom}

Genom vollständig sequenziert, siehe auch www.ncbi. nlm.nih.gov.

\section{Vermehrung}

Fakultativ anaerob, Wachstum innerhalb von 24 Stunden auf Nährmedien.

\section{Pathogenität / Virulenz / Antigenvariabilität}

Von C. freundii wurden hitzelabile und hitzestabile Enterotoxine beschrieben, deren Wirkungsweise jedoch noch nicht endgültig erforscht ist. Bei C.-koseriIsolaten von Patienten mit Meningitis wurde ein äußeres Membranprotein beobachtet, das bei anderen Citrobacter-Spezies nicht vorhanden ist.

\section{Erkrankungen}

\section{Lokalisierte Prozesse}

Sporadisch Diarrhoe bei kleinen Kindern, Erreger von Harnwegsinfektionen, Wundinfektionen, Infektionen des Respirationstraktes, Meningitis, Otitis; C. koseri ist gelegentlich auch Erreger von Meningitiden und Hirnabszessen bei Neugeborenen.

\section{Synonym(e)}

Nicht bekannt.

\section{Inkubationszeit}

Nicht bekannt.

\section{Leitsymptome}

Der jeweiligen Erkrankung entsprechend.

\section{Symptome}

Der jeweiligen Erkrankung entsprechend. 


\section{Pathophysiologie}

Fakultativ pathogener opportunistischer Erreger, Infektion bei Standortwechsel.

\section{Immunantwort}

Nicht bekannt.

\section{Differenzialdiagnose}

Abgrenzung von anderen Krankheitsauslösenden Erregern.

\section{Generalisierte Erkrankungen}

Durch Einschwemmen von Citrobacter sp. in die Blutbahn kann es zur Sepsis und extrem selten zur Endokarditis kommen.

\section{Synonym(e)}

Nicht bekannt.

\section{Inkubationszeit}

Nicht bekannt.

\section{Leitsymptome}

Fieber.

\section{Symptome}

Fieber.

\section{Pathophysiologie \\ - Lokalisierte Prozesse (Erkrankung 1) \\ Immunantwort \\ Nicht bekannt.}

\section{Differenzialdiagnose}

- Lokalisierte Prozesse (Erkrankung 1)

\section{Diagnostik}

\section{Untersuchungsmaterial \\ - Enterobacter}

\section{Diagnostische Verfahren}

Kulturelle Anzüchtung: $>$ fakultativ pathogene E. coli. (Escherichia coli).

Biochemische Differenzierung:

- Citrat kann als alleinige Kohlenstoffquelle verwertet werden.

- Nitrat wird zu Nitrit reduziert.

- Glukose wird abgebaut zu Säure und Gas.

- Methylrotreaktion ist positiv.

- Anwesenheit von Betagalaktosidase.

- Fermentation von Arabinose, Zellobiose, Maltose, L-Rhamnose, Trehalose, D-Xylose, D-Mannit, DSorbit, Glyzerol.

- H2S-Bildung durch C. freundii

Bei C. freundii können $42 \mathrm{O}$ - und mehr als $90 \mathrm{H}$-Antigene unterschieden werden.

\section{Befund / Interpretation}

Erregernachweis ausschlaggebend.

\section{Therapie}

Therapeutische Maßnahmen

Mehrfach-resistente Stämme werden beobachtet. Die Therapie entsprechend dem Antibiogramm wird empfohlen. Wirksam sind häufig Ureidopenicilline, Cefotaxim, Cefmenoxim, Ceftriaxon, Carbapeneme, Chinolone und Aminoglykoside.

\section{Resistenz}

Nicht bekannt.

\section{Epidemiologie}

\section{Verbreitung}

Eine epidemische Ausbreitung von Citrobacter sp. im Rahmen von nosokomialen Infektionen wurde bisher nicht beobachtet.

\section{Wirtsbereich / Reservoir}

Angehörige des Genus Citrobacter finden sich in Faezes von Menschen und Tieren, in Wasser, Abwasser und Abfall.

\section{Risikogruppen}

Säuglinge, Immunsupprimierte, Karzinom- und Transplantationspatienten.

\section{Transmission / Vektoren}

Citrobacter spp. werden durch direkten Kontakt oder auch indirekt über Gegenstände oder Lebensmittel übertragen.

\section{Prävention / Impfstoffe}

- Fakultativ pathogene E. coli (Escherichia coli).

\section{Ausbruchsmanagement}

Nicht erforderlich.

\section{Meldepflicht}

$\$ 23$ IfSG Abs. 1: Multiresistenz ist zu dokumentieren.

\section{Weiterführende Informationen}

Referenzzentren / Expertenlaboratorien

- Nicht benannt.

\section{Web-Adressen}

- www.cdc.gov/

\section{Schlüsselliteratur}

1. Blaser MJ, Smith PhD, Ravdin JI, Greenberg HB, Guerrant RL (1995) (eds) Infections of the Gastrointestinal Tract. Raven Press, New York

2. Hahn H, Kaufmann SHE, Schulz, ThF, Suerbaum, S (Hrsg) (2009) Medizinische Mikrobiologie und Infektiologie. 6. Aufl. Springer Verlag Berlin, Heidelberg, New York

3. Kist M, Bockemühl J, Aleksic S, Altwegg M, Autenrieth IB, Bär W, Beutin L, Gerten B, Heintschel von Heinegg E, 
Karch H, Lehmacher A, Mehnert F, Sonnenborn U, Tschäpe H, v. Eichel-Streiber C (2000) Infektionen des Darmes: MiQ 9. Urban und Fischer, München, Jena

4. Konemann EW, Allen HD, Janda WM, Schreckenberger PC, Winn WC (eds) (1997) Diagnostic Microbiology, $5^{\text {th }}$ edn. Lippincott, Philadelphia, New York

\section{Clonorchiasis}

Leberegel - Opisthorchis, Clonorchis

\section{Clonorchis sinensis}

- Leberegel - Opisthorchis, Clonorchis

\section{Clostridien der Gasbrand-Gruppe}

\section{Erreger}

HeIDI SCHÜTt-GerowitT

\section{Synonym(e)}

Gasbranderreger, Welch-Fraenkel-„Bazillus“ (C. perfringens $=C$. welchii), Prarauschbrand-„Bazillus“ (=C. septicum).

\section{Erregerspezies}

Clostridium perfringens, C. septicum, C. histolyticum, C. novyi sowie einige andere Clostridien-Arten.

\section{Taxonomie}

Familie: Bacillaceae; Gattung Clostridium (anaerob)

\section{Historie}

Bereits im Altertum wurde das Krankheitsbild Gasbrand von Hippokrates u. a. beschrieben und auch aus dem Mittelalter liegen Berichte darüber vor. Eine exakte Beschreibung des klinischen Bildes stammt aus der Zeit des Krimkrieges von Pirogoff. 1892 fanden Welch und Nuttal in den Blutgefäßen Verstorbener grampositive, gasbildende Stäbchen, die sich schnell vermehrten. Welch und Flexner erkannten 1896 die ätiologische Bedeutung dieses Erregers für das Krankheitsbild des Gasbrandes. Die mikrobiologische Erstbeschreibung von $C$. perfringens erfolgte 1898 durch Veillon und Zuber. Vor der antiseptischen Ära war das Krankheitsbild auch unter der Bezeichnung Hospitalbrand bekannt und gefürchtet. Zum gehäuften Auftreten kam es in Kriegszeiten: Im ersten Weltkrieg starben mindestens 100.000 Soldaten an Gasbrand.

Die Enteritis necroticans, hervorgerufen durch C. perfringens Typ C, wurde in Deutschland nach dem zweiten Weltkrieg beschrieben und in den 1960er Jahren in Neuguinea.

\section{Morphologie}

C. perfringens: grampositive "plumpe“ Stäbchen, un- beweglich, in Präparaten von Kulturen und Patientenmaterial keine Spore sichtbar.

C. septicum: grampositive, mittelgroße Stäbchen, stark beweglich, subterminale, ovale Spore.

C. histolyticum: grampositive, kleine Stäbchen, beweglich, subterminale Spore.

C. novyi: grampositive, lange schlanke Stäbchen, beweglich, subterminale ovale Spore.

\section{Genom}

Genom teilweise sequenziert, siehe auch www.ncbi. nlm.nih.gov

\section{Vermehrung}

Die meisten Gasbranderreger können sich nur unter streng anaeroben Bedingungen vermehren, C. histolyticum und einzelne Stämme von C. perfringens sind jedoch aerotolerant.

\section{Pathogenität / Virulenz / Antigenvariabilität}

Pathogenitäts- bzw. Virulenzfaktoren der Gasbranderreger sind Exotoxine bzw. Exoenzyme, die zell- und gewebsschädigende Wirkungen haben und zum Muskelzerfall mit Ödem- und Gasbildung führen sowie die Zerstörung von Leukozyten und Erythrozyten bewirken. Haupttoxin ist die Phospholipase C (Lecithinase, $\alpha$-Toxin); außerdem werden Kollagenase, Hyaluronidase, Hämolysine und Proteasen gebildet. C. perfringens kommt in verschiedenen Typen vor: Typ A ist für die überwiegende Zahl der Gasbrandfälle verantwortlich sowie für die Lebensmittelvergiftung, wenn er Enterotoxin bildet. C. perfringens Typ C ruft durch das von ihm gebildete $\beta$-Toxin die Enteritis necroticans hervor.

\section{Erkrankungen}

\section{Gasbrand}

\section{Synonym(e)}

Gasödem, Gasgangrän.

\section{Inkubationszeit}

Nur beim exogenen Infektionsweg kann die Inkubationszeit angegeben werden; sie beträgt meist 1-4 Tage, eventuell auch länger.

\section{Leitsymptome}

Weichteilinfektion mit Gasbildung im Gewebe, Zellulitis, Myonekrose.

\section{Symptome}

Gasbrand kann traumatisch (exogen, Wundinfektion) oder nicht traumatisch (endogen) entstehen. Primäre Symptome sind Schmerzen und ödematöse Schwellung, es kommt zur Gasbildung im Gewebe, die bei der subkutanen Infektion (Zellulitis) im Vordergrund steht. Sie kann durch bildgebende Verfahren sichtbar gemacht werden und ist eventuell bei Berührung durch Knistern wahrnehmbar. Bei weiterem Fort- 
schreiten oder primär greift die Infektion auf das Muskelgewebe über und führt zu dessen Zerstörung (Myonekrose). Die Haut ist blass, später bronzefarben, die Muskulatur sieht wie gekochter Schinken aus. Es ist ein süßlicher Geruch wahrnehmbar. Die Gasbrandinfektion kann klinisch auch als Peritonitis oder als retroperitoneale Infektion (starke Gasbildung) sowie als gangränose Cholezystitis mit entsprechender klinischer Symptomatik und oft foudroyantem, septischen Verlauf in Erscheinung treten. Die Symptomatik ist bei den verschiedenen Gasbranderregern unterschiedlich: C. septicum kommt wegen seiner hohen Invasivität vor allem beim nicht traumatischen Gasbrand vor; er ist auch Erreger einer Enterocolitis (Fieber, blutiger Durchfall), die speziell bei neutropenischen Patienten auftreten kann. Bei Infektionen durch C. novyi bilden sich vor allem Ödeme; Gas tritt im Gewebe nur selten auf. Allgemeine Symptome sind Fieber, Tachykardie (evtl. auch ohne entsprechende Temperaturerhöhung) und Hypotonie. Es fällt besonders die Ängstlichkeit des Patienten auf. Im weiteren Verlauf kommt es zur intravasalen Hämolyse, Hypotonie und Nierenversagen, letztlich zum Tod im septischen Schock. Die Letalität beträgt $20-25 \%$.

\section{Pathophysiologie}

Das klinische Bild des Gasbrandes entwickelt sich nur in hypoxischem Gewebe. Ursachen für die Hypoxie sind schlechte Durchblutung aufgrund von Gefäßerkrankungen, Kälte, Schock, straffen Verbänden oder Abschnüren von Extremitäten, eingedrungenen Fremdkörpern sowie Mischinfektionen mit Sauerstoff verbrauchenden Bakterien. Der wichtigste Pathogenitätsfaktor ist die Phospholipase $\mathrm{C}$, die durch ihre membranschädigende Wirkung Zellen zerstört und somit zur Ödembildung führt. In Abhängigkeit von den gebildeten proteolytischen Enzymen kommt es zur Auflösung des Muskelgewebes, die besonders bei Infektionen durch C. histolyticum im Vordergrund steht. Die im Gewebe entstehenden Gase sind Endprodukte des Kohlenhydratstoffwechsels der Bakterien.

\section{Differenzialdiagnose}

Nekrotisierende Fasziitis, Streptokokken-Fasziitis, Infektionen mit anderen gasbildenden Bakterien.

\section{Enteritis necroticans}

\section{Synonym(e)}

Darmbrand, Pig-Bel, nekrotisierende Enterokolitis.

\section{Inkubationszeit}

1-2 Wochen nach dem Ernährungsfehler ( $\triangleright$ unten).

\section{Symptome}

Bauchschmerzen, Erbrechen, blutiger Durchfall.

\section{Pathophysiologie}

Unter der Einwirkung des von C. perfringens gebildeten $\beta$-Toxins kommt es zu Nekrosen im Jejunum. Jedoch ist nicht der Erreger allein die Ursache für die Erkrankung: Das Krankheitsbild wird bzw. wurde vor allem bei Kindern mit Fehlernährung (Verzehr von großen Mengen Fleisch) beobachtet.

\section{Differenzialdiagnose}

Andere Durchfallerreger.

\section{Lebensmittelvergiftung}

\section{Synonym(e)}

Gastroenteritis.

\section{Inkubationszeit}

7-30 Stunden nach Aufnahme des Lebensmittels.

\section{Symptome}

Bauchkrämpfe, wässriger Durchfall, Übelkeit, Erbrechen. Die Erkrankung verläuft in der Regel selbstlimitierend und dauert 2-3 Tage. Wahrscheinlich tritt sie viel häufiger auf als sie diagnostiziert wird, da die Patienten entweder gar nicht zum Arzt gehen oder die Stuhlproben nicht auf diesen Erreger untersucht werden.

\section{Pathophysiologie}

Wenn Enterotoxin bildende Stämme von C. perfringens Typ A in großer Zahl $\left(10^{6}-10^{7}\right.$ Bakterien) in den Dünndarm gelangen, beginnen sie in dem alkalischen Milieu zu sporulieren und setzen dabei das Toxin frei. Seine Bindung an Rezeptoren der Darmzellen führt zur Permeabilitätsstörung der Zellen: Sie werden durchlässig für Wasser und Elektrolyte. Die für die Erkrankung notwendige große Zahl von Erregern setzt deren Vermehrung im Lebensmittel voraus. Infektionsquellen sind vor allem ungenügend gekochtes Fleisch und Reisgerichte, in denen die Sporen von C. perfringens die Zubereitung überdauert haben. Werden die Speisen dann nach der Zubereitung ungekühlt aufbewahrt, tritt eine starke Vermehrung der Bakterien ein.

\section{Differenzialdiagnose}

Andere Durchfallerreger.

\section{Diagnostik}

\section{Untersuchungsmaterial}

Bei Verdacht auf Gasbrand muss Punktionsmaterial oder ein tief entnommener Abstrich eingesandt werden. Blutkulturen sollten in jedem Fall - nicht nur bei Sepsis-Verdacht - abgenommen werden. Sie sind das alleinige Untersuchungsmaterial bei Verdacht auf neutropenische Clostridien-Sepsis.

Wenn die klinische Symptomatik an eine Lebensmittelvergiftung durch $C$. perfringens denken lässt, ist Stuhl als Untersuchungsmaterial einzusenden. Auch 
bei Verdacht auf Enteritis necroticans kann eine Stuhlprobe eingesandt werden.

\section{Diagnostische Verfahren}

Typischerweise zeigt das Grampräparat vom Wundsekret bei einer Gasbrandinfektion durch C. perfringens grampositive plumpe Stäbchen ohne Sporen, jedoch oft keine Leukozyten. Bei der kulturellen Anzüchtung des Erregers im anaeroben Milieu ist in flüssigen Medien die starke Gasbildung charakteristisch sowie auf bluthaltigen festen Medien eine Doppelhämolyse. Bei Infektionen durch C. histolyticum und C. novyi sind im Grampräparat kleinere bzw. schlankere Stäbchen mit Sporenbildung sichtbar. Die endgültige Identifizierung aller Arten erfolgt mittels biochemischer Verfahren, durch Gensequenzierung oder masspenspektrometrisch. In Blutkulturen muss der mikroskopische Nachweis grampositiver plumper Stäbchen immer zuerst an Gasbranderreger denken lassen, denn bei $15 \%$ der Gasbrand-Fälle werden die Clostridien auch im Blut nachgewiesen, bei der neutropenischen Clostridien-Sepsis erfolgt der Nachweis immer aus Blutkulturen.

Die Lebensmittelvergiftung durch C. perfringens wird durch den Nachweis des C. perfringens-Enterotoxins in der Stuhlprobe mittels Enzymimmunoassay bewiesen.

Die Diagnose Enteritis necroticans wird überwiegend klinisch-anamnestisch gestellt; es ist jedoch prinzipiell möglich, den Nachweis von C. perfringens Typ F aus einer Stuhlprobe mittels PCR zu führen.

\section{Befund / Interpretation}

Der mikrobiologische Nachweis der Gasbranderreger von Abstrichen oder Punktaten bedeutet nicht die Diagnose Gasbrand. Eine Befundinterpretation ist somit nur im Zusammenhang mit dem klinischen Befund möglich, während der Nachweis im Blut eine Clostridien-Bakteriämie beweist und der Enterotoxinnachweis eine Lebensmittelvergiftung durch $C$. perfringens.

\section{Therapie}

\section{Therapeutische Maßnahmen}

Für die Therapie des Gasbrandes ist das chirurgische Vorgehen am wichtigsten: breite Eröffnung der Wunde bzw. großzügiges Debridement, ggf. frühzeitige Amputation bzw. Hysterektomie. Antibiotika: Penicillin 10-30 Millionen Einheiten pro Tag, dazu Metronidazol und/oder Clindamycin bzw. Tetrazykline, Erythromycin oder Rifampicin; bei Penicillin-Unverträglichkeit: Imipenem. Die Effektivität der hyperbaren Sauerstofftherapie wird nicht einheitlich beurteilt, sie hat sich jedoch in einigen Fällen als vorteilhaft erwiesen.

Die Therapie der Lebensmittelvergiftung ist symptomatisch. Bezüglich der Therapie der Enteritis necroticans muss im Einzelfall entschieden werden.

\section{Resistenz}

C. perfringens weist in ca. 40 \% der Fälle eine Resistenz gegen Tetrazykline auf, andere Resistenzen spielen bisher keine Rolle, insbesondere ist hervorzuheben, dass die Clostridien der Gasbrandgruppe weiterhin empfindlich für Penicillin $\mathrm{G}$ sind.

\section{Epidemiologie}

\section{Verbreitung}

Die Sporen der Gasbranderreger sind weltweit im Erdboden zu finden. In Deutschland treten jährlich ca. 100 Fälle der Gasbranderkrankung auf.

\section{Wirtsbereich / Reservoir}

C. perfringens ist Bestandteil der Dickdarmflora von $90 \%$ der Menschen sowie auch von Tieren; seine Sporen sind im Erdboden in hoher Zahl vorhanden. Von den übrigen Gasbranderregern kommt C. septicum bei $2 \%$ der Menschen vor. Die Sporen der übrigen Gasbranderreger sind in der Umwelt seltener zu finden.

\section{Risikogruppen}

Gefährdet für den exogen bedingten Gasbrand sind Verletzte mit Gewebszertrümmerung, offenen Frakturen oder Schusswunden und - früher häufig - Patientinnen nach kriminellem Abort. Risikofaktoren für den endogen entstehenden Gasbrand sind Patienten mit diabetischem Fußsyndrom, arteriellem Verschlussleiden, Kolonchirurgie, Kolonkarzinom und neutropenische Patienten.

Der Risikofaktor für das Krankheitsbild Enteritis necroticans ist die oben erwähnte Fehlernährung.

\section{Transmission / Vektoren}

Die Infektion durch Gasbranderreger erfolgt in ca. der Hälfte der Fälle exogen traumatisch, wenn die Sporen aus der Umwelt in tiefe Wunden gelangen; die übrigen Fälle entstehen endogen.

In die Lebensmittel gelangen die Sporen von C. perfringens aus der Umwelt.

\section{Prävention / Impfstoffe}

Eine Prävention der exogen erworbenen Gasbranderkrankung ist nur dadurch möglich, dass primär eine gute Wundversorgung durchgeführt wird bzw. bei einer beginnenden Symptomatik ein großzügiges Debridement vorgenommen wird. Der endogen entstehenden Gasbranderkrankung kann nur durch die Beseitigung der Risikofaktoren vorgebeugt werden.

Präventionsmaßnahme bezüglich der Enteritis necroticans ist das Vermeiden der Fehlernährung. Der Lebensmittelvergiftung durch C.-perfringens-Enterotoxin kann nur durch Einhaltung aller Maßnahmen der Lebensmittelhygiene vorgebeugt werden.

\section{Weiterführende Informationen}

\section{Referenzzentren / Expertenlaboratorien}

- Konsiliarlaboratorium für anaerobe Bakterien: Zentrum 
für Infektionsmedizin, Institut für Medizinische Mikrobiologie und Infektionsmedizin, Universität Leipzig, Herr Professor Dr. A. C. Rodloff, Liebigstr. 24, 04103 Leipzig

\section{Schlüsselliteratur}

1. Hahn H, Kaufmann S, Schulz Th (Hrsg) (2009) 6. Auflage Springer Verlag, Heidelberg

2. Mandell GL, Bennet JE, Dolin R (eds) (2009) Principles and Practice of Infectious Disease, 7 th ed. Churchill Livingstone Inc, London

3. Murray PR, Baron EJ, Jorgensen JH, Pfaller MA, Yolken RH (eds) (2009) Manual of Clinical Microbiology 8th edn. ASM Press, Washington

\section{Clostridium botulinum}

\section{Erreger \\ Erregerspezies \\ Clostridium botulinum}

\section{Taxonomie}

Familie: Bacillaceae; Gattung: Clostridium (anaerob)

\section{Historie}

Der erste Nachweis erfolgte 1896 durch van Ermengem aus einem ranzigen Schinkenrest und dem Mageninhalt des Patienten, der nach Verzehr des Schinkens gestorben war. Die Symptome dieses Patienten entsprachen der von Kerner 1820 beschriebenen und Botulismus (Wurstvergiftung) genannten Erkrankung. Das Bakterium erhielt daher den Namen C. botulinum. Später wurden weitere Erkrankungen durch C. botulinum beschrieben: 1943 der Wundbotulismus, 1976 der Säuglingsbotulismus und 1986 der Botulismus „ungeklärter Ursache“.

\section{Morphologie}

Grampositive kurze Stäbchen mit subterminaler Spore.

\section{Genom}

Die für den Menschen pathogenen Toxintypen sind chromosomal kodiert, während andere (tierpathogene) Typen phagenkodiert sind.

\section{Vermehrung}

C. botulinum vermehrt sich nur in einer streng anaeroben Atmosphäre, z. B. in luftdicht verpackten Lebensmitteln.

\section{Pathogenität / Virulenz / Antigenvariabilität}

Der Pathogenitätsfaktor von C. botulinum ist ein Exotoxin (Neurotoxin), von dem es acht verschiedene Typen gibt. Die Typen A, B, E und F sind für den Menschen pathogen.

\section{Erkrankung}

Botulismus: lebensmittelbedingt, Wundbotulismus, Säuglingsbotulismus, Botulismus „ungeklärter Ursache"

\section{Synonym(e)}

Wurstvergiftung.

\section{Inkubationszeit}

Nach oraler oder aerogener Aufnahme des Toxins treten die Symptome nach 8 Stunden bis einigen Tagen auf, bei den übrigen Formen lässt sich keine Inkubationszeit angeben.

\section{Leitsymptome}

Schlaffe Lähmungen, insbesondere Doppelbilder sehen.

\section{Symptome}

Beim „klassischen“ Botulismus, d. h. der Aufnahme des Toxins mit dem Lebensmittel, können schon nach 8 Stunden, eventuell erst später, gastrointestinale Symptome auftreten: Übelkeit, Erbrechen, Bauchkrämpfe, Obstipation oder Diarrhoe. Beim Fortschreiten der Erkrankung treten symmetrisch absteigende schlaffe Lähmungen auf. Die typische neurologische Symptomatik beginnt meist mit der Lähmung der Augenmuskeln, die zum Sehen von Doppelbildern, zu Akkommodationsschwäche, Lichtscheu, Flimmern vor den Augen und Pupillenstarre führt. Weitere Symptome sind Mundtrockenheit, Schluckbeschwerden, Schwindel, Parästhesien und später Dyspnoe. Der Tod tritt durch Lähmung der Atemmuskulatur ein. Das Bewusstsein bleibt erhalten. Fieber tritt bei der Intoxikation nicht auf. Beim Wundbotulismus entstehen keine gastrointestinalen Symptome; aufgrund der Wundinfektion kommt aber Fieber dazu. Die neurologischen Symptome sind gleich. Säuglingsbotulismus und Botulismus „ungeklärter Ursache“ beginnen mit Mattigkeit, Obstipation, Schluckbeschwerden und Muskelschwäche, der Tod tritt durch plötzlichen Atemstillstand ein.

\section{Pathophysiologie}

Die Aufnahme des Botulismus-Toxins erfolgt oral (Lebensmittelvergiftung) oder aerogen (Versprühen in terroristisch-kriegerischer Absicht) oder es wird im Körper des Menschen im Sinne einer Toxiinfektion gebildet (Wundbotulismus, Säuglingsbotulismus, Botulismus „ungeklärter Ursache“). Nach seiner Resorption gelangt das Toxin ins Blut und wird zu den peripheren Nervenendigungen transportiert, wo es die Freisetzung von Azetylcholin an der motorischen Endplatte hemmt und somit die neuromuskuläre Erregungsübertragung blockiert.

Das Botulismus-Toxin, insbesondere Typ A, ist das stärkste mikrobiell gebildete Gift: Die letale Dosis für den Menschen beträgt bei oraler Aufnahme $1 \mu \mathrm{g}$, bei aerogener Aufnahme noch weniger. 


\section{Immunantwort}

Es kommt im tierischen und menschlichen Organismus zu einer humoralen Immunität gegen den jeweiligen Toxintyp. Die Antikörperbildung in Tieren wird für die Produktion der therapeutisch und diagnostisch verwendeten Antiseren benutzt.

\section{Differenzialdiagnose}

Guillain-Barré-Syndrom, Intoxikation durch Atropin oder Methylalkohol, paralytische Poliomyelitis; bezüglich der gastrointestinalen Symptome: Lebensmittelvergiftung durch Staphylokokken-Enterotoxin.

\section{Diagnostik}

\section{Untersuchungsmaterial}

Patientenserum, Mageninhalt, Stuhlproben oder/und das Lebensmittel zum Toxinnachweis, letzteres auch zum kulturellen Nachweis; tiefer Wundabstrich bei Verdacht auf Wundbotulismus; Stuhlproben bei Verdacht auf Säuglingsbotulismus und Botulismus „, ungeklärter Ursache“.

\section{Diagnostische Verfahren}

Die sicherste Methode für den Toxinnachweis ist der Mäuse-Toxin-Antitoxin-Schutzversuch. Hierbei erhält eine Maus das Material, in dem das Toxin nachgewiesen werden soll, eine weitere Maus erhält das Material und dazu das Antitoxin. Da dies eine sehr aufwändige Methode ist, werden in neuerer Zeit auch andere Verfahren - verschiedene Techniken der Enzymimmunoassays - verwendet. Beim kulturellen Nachweis muss außer der konventionell nicht einfachen Identifizierung immer der Toxinnachweis aus dem Kulturüberstand erfolgen.

\section{Befund / Interpretation}

Wenn die für Botulismus typischen klinischen Symptome vorliegen und der Toxinnachweis aus dem Patientenmaterial oder dem Lebensmittel gelingt, ist der Befund eindeutig, während der kulturelle Nachweis von C. botulinum aus Stuhlproben zwar beweisend für den Säuglingsbotulismus ist, jedoch bei den übrigen Formen nicht.

\section{Therapie}

\section{Therapeutische Maßnahmen}

Bei allen Formen sofortige Gabe von polyvalentem Antitoxin, bei der Lebensmittelvergiftung außerdem Magenspülung, Abführen; keine Antibiotika.

Bei Wundbotulismus: nach Antitoxingabe breite Eröffnung der Wunde, Gabe von 10-20 Millionen Einheiten Penicillin G pro Tag.

Wichtig ist in allen Fällen der rechtzeitige Beginn der künstlichen Beatmung.

\section{Epidemiologie}

\section{Verbreitung}

Die Sporen von C. botulinum sind weltweit im Erdboden verbreitet. Für die Lebensmittelvergiftung sind vor allem die C.-botulinum-Toxintypen A und B verantwortlich, für den Säuglingsbotulismus der Toxintyp F. Die Typenverteilung weist geografische Unterschiede auf, in Deutschland kommt überwiegend Typ B vor. Die Anzahl der gemeldeten Fälle beträgt in Deutschland 10-20 pro Jahr, die in neuerer Zeit auch durch Verzehr von vakuumverpackten, unsachgemäß gelagerten Lebensmitteln (z. B. Forellenfilets) hervorgerufen werden. 1998 wurden in Russland 500 Fälle mit 48 Toten registriert. Auch in anderen Ländern treten sporadisch Ausbrüche auf. In den USA ist eine $\mathrm{Zu}$ nahme des Wundbotulismus bei Drogenabhängigen festzustellen und auch in Deutschland werden zunehmend Fälle beschrieben.

\section{Wirtsbereich / Reservoir}

C.-botulinum-Stämme, die die Toxintypen C und D produzieren, kommen im Darm von Säugetieren und Vögeln vor und führen bei Vögeln auch zur Erkrankung; C.-botulinum-Stämme, die andere Toxintypen produzieren, sind Umweltbakterien.

\section{Risikogruppen}

Bezüglich des Wundbotulismus stellen Drogenabhängige eine Risikogruppe dar. Menschen, die eigene Konserven (Hülsenfrüchte, Fleisch) im Haushalt herstellen und verzehren, gehen ebenfalls ein Risiko ein. Für Säuglinge würde ein Risiko bestehen, wenn sie mit Honig gesüßten Tee bekämen.

\section{Transmission / Vektoren}

Da die Sporen von C. botulinum ubiquitär verbreitet sind, erfolgt die Kontamination von Lebensmitteln bzw. Wunden aus der Umwelt.

\section{Prävention / Impfstoffe}

Eine Impfung gegen Botulismus gibt es nicht. Für die Prävention ist es am wichtigsten, verdächtige Speisen $\mathrm{zu}$ meiden - auch nicht probieren! Konservendosen, die eine Bombage aufweisen, nicht öffnen. Zuverlässigster Schutz für vakuumverpackte Lebensmittel, insbesondere Fisch, ist die durchgängige Einhaltung von Temperaturen unter $7{ }^{\circ} \mathrm{C}$, besser unter $3^{\circ} \mathrm{C}$, bei Lagerung und Transport. Alle Toxintypen sind hitzelabile Proteine, die durch 15-minütiges Kochen zerstört werden. Dennoch sollten verdächtige Speisen keinesfalls aufbereitet werden. Die Toxinbildung in Lebensmitteln kann nur bei pH-Werten über 4,6 erfolgen; von Konserven, die saures Obst enthalten geht somit keine Gefahr aus. Die Prävention des Säuglingsbotulismus ist durch die Warnung, Säuglingstee nicht mit Honig zu süßen, gelungen.

Bei den Laborarbeiten mit dem auf Botulismus-Toxin 
zu untersuchenden Material und mit den Kulturen sind besondere Sicherheitsmaßnahmen zu beachten. Aufgrund der beschriebenen Eigenschaften steht das Botulismus-Toxin ganz oben auf der Liste der für biologische Kriegführung bzw. Bioterrorismus missbrauchten Agenzien.

\section{Meldepflicht}

Nach dem Infektionsschutzgesetz beseht Meldepflicht für Verdacht, Erkrankung und Tod an Botulismus $(\$ 6)$ sowie für den Nachweis des Erregers und/oder des Toxins $(\$ 7)$.

\section{Weiterführende Informationen}

\section{Referenzzentren / Expertenlaboratorien}

- Konsiliarlaboratorium für anaerobe Bakterien: Zentrum für Infektionsmedizin, Institut für Medizinische Mikrobiologie und Infektionsmedizin, Universität Leipzig, Herr Professor Dr. A. C. Rodloff, Liebigstr. 24, 04103 Leipzig

\section{Schlüsselliteratur}

1. Hahn H, Kaufmann S, Schulz Th (Hrsg) (2009) 6. Auflage Springer Verlag, Heidelberg

2. Mandell GL, Bennet JE, Dolin R (eds) (2009) Principles and Practice of Infectious Disease, 7 th ed. Churchill Livingstone Inc, London

3. Murray PR, Baron EJ, Jorgensen JH, Pfaller MA, Yolken RH (eds) (2009) Manual of Clinical Microbiology 8th edn. ASM Press, Washington

4. www. rki.de Infektionskrankheiten von A-Z

\section{Clostridium difficile}

\section{Erreger}

\section{Erregerspezies}

Clostridium difficile

\section{Taxonomie}

Familie: Bacillaceae; Gattung: Clostridium (anaerob)

\section{Historie}

Seltene Fälle von Antibiotika-assoziierter Kolitis wurden von 1960 bis 1970 bei Patienten beobachtet, die mit Lincomycinen oder Breitspektrum-Antibiotika behandelt wurden. Seit 1970 trat dieses Krankheitsbild häufiger auf und 1977 wurde erkannt, dass ein Exotoxin von $C$. difficile dafür verantwortlich ist.

\section{Morphologie}

C. difficile sind grampositive, bis zu $17 \mu \mathrm{m}$ lange Stäbchen, die subterminale Sporen ausbilden.

\section{Genom}

Die für die Bildung der Toxine A und B kodierenden Gene können mittels PCR nachgewiesen werden. Deletionen wurden gefunden, die dazu führen, dass es Stämme gibt, die nur eins der beiden Toxine bilden können. Stämme denen ein regulatorisches Gen fehlt, können Überproduzenten des Toxins sein.

\section{Vermehrung}

C. difficile kann sich - wie alle Clostridien - nur unter anaeroben Bedingungen vermehren.

\section{Pathogenität / Virulenz / Antigenvariabilität}

Von C. difficile werden zwei Toxine - A und B - gebildet. Beide wirken zytotoxisch, Toxin A wirkt außerdem als Enterotoxin und ist vor allem für die Symptomatik verantwortlich. Jedoch zeigen neuere Beobachtungen, dass auch C.-difficile-Stämme, die nur das Toxin B bilden, die Ursache schwer verlaufender Erkrankungen sein können. Außerdem kommen auch nicht toxische C.-difficile-Stämme vor sowie die bereits erwähnten Toxin-Überproduzenten.

\section{Erkrankung}

Antibiotika-assoziierte Kolitis, pseudomembranöse Kolitis, Clostridium difficile assoziierte Diarrhoe (CDAD)

\section{Inkubationszeit}

Nicht eruierbar, meist abhängig von der Antibiotikagabe bzw. der Gabe anderer Medikamente (sieheRisikopatienten)

\section{Leitsymptome}

Blutig-schleimige Durchfälle mit Fieber und krampfartigen Bauchschmerzen.

\section{Symptome}

Die CDAD tritt meist einige Tage - eventuell aber auch Wochen - nach dem Beginn einer antibiotischen oder antineoplastischen Therapie auf. Symptome sind leichte bis schwere z. T. blutig-schleimige Durchfälle mit Fieber und krampfartigen Bauchschmerzen. Die Diagnose der schwersten Verlaufsform, der pseudomembranösen Kolitis, wird aufgrund des endoskopischen Bildes gestellt, wobei eine ödematös veränderte Darmschleimhaut mit charakteristischen gelblichweißen Plaques und Pseudomembranen zu sehen ist. Als weitere Komplikation kann ein toxisches Megakolon auftreten und es kann zu einer Darmperforation kommen.

\section{Pathophysiologie}

C. difficile kann in geringer Zahl im Darm des Menschen vorkommen und aufgrund seiner Resistenzeigenschaften selektioniert werden, wenn durch eine antibiotische Therapie die übrige Darmflora zerstört wird. Im Prinzip können alle Antibiotika sowie auch einige andere Medikamente dieses Krankheitsbild auslösen, am häufigsten wird es aber bei bzw. nach der Gabe von Ampicillin, Amoxicillin, Clindamycin und Cephalosporinen beobachtet. In seltenen Fällen kann auch die Stagnation des Darminhaltes (z. B. postope- 
rativ) die Ursache für die Vermehrung von C. difficile sein.

\section{Immunantwort}

Nicht bekannt.

\section{Differenzialdiagnose}

Differenzialdiagnostisch kommen die enteropathogenen Erreger in Betracht.

\section{Diagnostik}

\section{Untersuchungsmaterial}

Stuhlproben, die möglichst innerhalb von 2 Stunden zum Labor gelangen sollten.

\section{Diagnostische Verfahren}

Das meist verwendete diagnostische Verfahren ist der Nachweis der Toxine A und B mittels Enzymimmunoassay. Wegen der Bedeutung des Toxins B sollten Tests, die allein das Toxin A nachweisen, nicht verwendet werden. Außerdem kann C. difficile auf Spezialkulturmedien selektiv angezüchtet werden. Dann muss im zweiten Schritt der nachgewiesene Stamm auf sein Toxinbildungsvermögen untersucht werden. Ein alleiniger kultureller Nachweis von $C$. difficile lässt keine Aussage über die ätiologische Bedeutung zu. Die kulturelle Untersuchung ist aber notwendig, um Aussagen über die Besiedelungshäufigkeit machen zu können. Ferner existiert ein Schnelltest, der auf dem Nachweis der Glutamatdehydrogenase beruht. Dieser Test hat einen hohen negativen prädiktiven Wert, aber seine Spezifität ist so gering, dass im positiven Fall immer weitere Tests erforderlich sind. Außerdem kann auch eine PCR zum Nachweis von C. difficile durchgeführt werden. In schweren Fällen soll immer ein kultureller Nachweis erfolgen, um ggf. eine Stammtypisierung durchführen zu können.

\section{Befund / Interpretation}

Die Befunde müssen immer in Verbindung mit der klinischen Symptomatik gesehen werden, da C. diffici$l e$ und seine Toxine auch bei klinisch gesunden Menschen vorhanden sein können. Eine Therapieüberwachung mittels der Laboruntersuchungen hat keinen Aussagewert.

\section{Therapie}

\section{Therapeutische Maßnahmen}

Eventuell kann allein das Absetzen einer noch laufenden antibiotischen Therapie die Symptome stoppen; bei schwer verlaufenden Fällen muss Metronidazol oder ggf. Vancomycin oral gegeben werden.

\section{Resistenz}

Die Resistenzeigenschaften von C. difficile sind die Ursache für seine Selektionierung und somit für die Erkrankung überhaupt. Resistenzen gegen die zur The- rapie eingesetzten Antibiotika Metronidazol und Vancomycin sind bisher nicht beobachtet worden.

\section{Epidemiologie}

\section{Verbreitung}

C. difficile kommt in geringer Zahl im Darm von Menschen und Tieren vor. 3-15 \% der Erwachsenen, jedoch 30-50 \% der Säuglinge sind mit $C$. difficile besiedelt. Die Sporen von C. difficile sind auch im Boden und in Gewässern weltweit verbreitet.

\section{Wirtsbereich / Reservoir \\ $\checkmark$ Verbreitung.}

\section{Risikogruppen}

Vor allem ältere Patienten und Kinder, die eine antibiotische oder antineoplastische Therapie bekommen, sowie seltener Patienten, bei denen es postoperativ oder aus anderen Gründen zu einer Stagnation des Darminhaltes gekommen ist. Auch für Patienten, die mit Protonenpumenhemmern, H2-Rezeptor-Antagonisten oder nicht steroidalen Antiphlogistika behandelt werden, besteht ein erhöhtes Risiko einer CDAD. Es gibt jedoch auch Fälle, bei denen eine CDAD bei jungen Menschen ohne Risikofaktoren auftritt. Die Untersuchung der hierfür verantwortlichen Clostridien-Stämme führte zu der Entdeckung der ToxinÜberproduzenten (z. B. Ribotyp 027).

\section{Transmission / Vektoren}

In der Regel handelt es sich um ein endogenes Geschehen, jedoch kann eine nosokomiale Übertragung im Sinne einer cross infection erfolgen, z. B. durch die Hände des Pflegepersonals. Ausbrüche auf Stationen kommen immer wieder vor, so dass $C$. difficile jetzt als einer der wichtigsten Verursacher nosokomial erworbener Diarrhoen anzusehen ist. Dazu trägt bei, dass die Sporen von C. difficile sehr resistent gegen Umwelteinflüsse und auch gegen Desinfektionsmittel sind.

\section{Prävention / Impfstoffe}

Um dieser schweren Erkrankung vorzubeugen, ist es wichtig, dass Antibiotika nur unter strenger Indikationsstellung gegeben werden. Eine Impfung gibt es nicht.

\section{Ausbruchsmanagement}

Patienten, bei denen C.-difficile-Toxine nachgewiesen sind, müssen isoliert werden, um eine weitere Übertragung zu vermeiden, da bei ihnen $C$. difficile in groBer Zahl im Darm vorhanden ist.

\section{Meldepflicht}

Es besteht keine Meldepflicht nach dem Infektionsschutzgesetz, außer wenn es sich um einen nosokomialen Ausbruch (zwei oder mehr Patienten, bei denen 
ein epidemiologischer Zusammenhang wahrscheinlich ist) handelt.

\section{Weiterführende Informationen}

\section{Referenzzentren / Expertenlaboratorien}

- Konsiliarlaboratorium für Clostridium difficile: Institut für Medizinische Mikrobiologie und Hygiene, Herr PD Dr. Chr. von Eichel-Streiber, Obere Zahlbacher Str. 63, 55101 Mainz

- Konsiliarlaboratorium für gastrointestinale Infektionen (bakteriell): Institut für Medizinische Mikrobiologie und Hygiene, Klinikum der Universität Freiburg, Herr Professor Dr. med. M. Kist, Hermann-Herder-Str. 11, 79104 Freiburg

\section{Schlüsselliteratur}

1. Hahn H, Kaufmann S, Schulz Th (Hrsg) (2009) 6. Auflage Springer Verlag, Heidelberg

2. Mandell GL, Bennet JE, Dolin R (eds) (2009) Principles and Practice of Infectious Disease, $7^{\text {th }}$ ed. Churchill Livingstone Inc, London

3. Murray PR, Baron EJ, Jorgensen JH, Pfaller MA, Yolken RH (eds) (2009) Manual of Clinical Microbiology $8^{\text {th }}$ edn. ASM Press, Washington

4. www. rki.de Infektionskrankheiten von A-Z

\section{Clostridium tetani}

\section{Erreger}

\section{Synonym(e)}

Wundstarrkrampf-Erreger.

\section{Erregerspezies}

Clostridium tetani

\section{Taxonomie}

Familie: Bacillaceae; Gattung: Clostridium (anaerob)

\section{Historie}

Berichte aus Ägypten und Griechenland lassen erkennen, dass das Krankheitsbild Tetanus schon im Altertum bekannt war. Der Erreger wurde in menschlichem Untersuchungsmaterial erstmalig 1886 durch Rosenbach beschrieben, seine Anzüchtung erfolgte 1889 durch Kitasato. 1890 wurde durch Faber der Toxinnachweis erbracht, und es folgte im selben Jahr die Gewinnung von antitoxischem Tetanusserum von Pferden und Kaninchen durch Faber, von Behring und Kitasato.

\section{Morphologie}

C. tetani sind grampositive schlanke lange Stäbchen, die endständige runde Sporen ausbilden; die Zellen haben in der Phase der Sporenbildung ein trommelschlegelförmiges Aussehen.

\section{Genom}

Das Gen für den Virulenzfaktor Tetanospasmin liegt in einem Plasmid.

\section{Vermehrung}

Wie alle Clostridien kann sich C. tetani nur unter anaeroben Bedingungen vermehren.

\section{Pathogenität / Virulenz / Antigenvariabilität}

Die vegetativen Zellen des C. tetani bilden zwei Toxine: das Tetanolysin (Hämolysin) und das neurotoxische Tetanospasmin, das die Erkrankung auslöst, indem es die Freisetzung von erregungshemmenden Neurotransmittern (Glycin, Gammaaminobuttersäure) hemmt.

\section{Erkrankung}

Tetanus

\section{Synonym(e)}

Wundstarrkrampf.

\section{Inkubationszeit}

4-14 Tage, evtl. länger; je kürzer die Inkubationszeit ist, desto schlechter ist die Prognose.

\section{Leitsymptome}

Tonuserhöhung der Kaumuskulatur: Risus sardonicus, Opisthotonus durch Befall der Nacken- und Rückenmuskulatur, tonisch-klonische Krämpfe.

\section{Symptome}

Beim generalisierten Tetanus kommt es zuerst zu einer Tonuserhöhung der Kaumuskulatur: Der Mund kann nicht geöffnet werden, es treten Sprech- und Schluckschwierigkeiten auf; durch die Kontraktion der mimischen Muskulatur bekommt das Gesicht ein grinsendes Aussehen, das schon im Altertum als Risus sardonicus beschrieben wurde. Die Tonuserhöhung führt dann zur schmerzhaften Dauerkontraktion weiterer Muskeln (Opisthotonus durch Befall der Nacken- und Rückenmuskulatur) und es kommt außerdem zu tonisch-klonischen Krämpfen, die durch optische, akustische und taktile Reize ausgelöst werden. Das Bewusstsein bleibt ungetrübt. Aufgrund der Lähmung von Glottis, Schlund- und Zwerchfellmuskulatur tritt schließlich der Erstickungstod ein.

Eine leichtere Verlaufsform ist der lokalisierte Tetanus, bei dem es nur in begrenzten Bereichen zu einer Muskelstarre kommt, aber nicht zu Krämpfen.

Der Tetanus neonatorum geht von einer Nabelschnurinfektion aus. Symptome sind Schwäche und Unfähigkeit zur trinken, später kommen Spasmen dazu.

\section{Pathophysiologie}

C. tetani ist nicht invasiv. Bei der Erkrankung handelt es sich um eine Toxiinfektion.

Die am häufigsten auftretende Verlaufsform ist der generalisierte Tetanus. Hierbei wird das Toxin über 
Lymphbahnen und Blut im ganzen Körper verteilt und breitet sich dann entlang der Nervenbahnen bis zu den Vorderhörnern des Rückenmarks aus. Beim selten auftretenden lokalisierten Tetanus gelangt das Toxin intraaxonal durch periphere motorische Neuronen aufwärts an die Zellen des Rückenmarks, die die kontraktilen Muskeln eines begrenzten Bereiches innervieren.

\section{Immunantwort}

Gegen das Tetanustoxin bzw. das zur Impfung verwendete Tetanus-Toxoid entsteht eine antitoxische humorale Immunität.

\section{Differenzialdiagnose}

Differenzialdiagnostisch ist an eine Strychninvergiftung zu denken.

\section{Diagnostik}

\section{Untersuchungsmaterial}

Serum, Wundabstrich.

\section{Diagnostische Verfahren}

Tetanus ist vor allem eine klinische Diagnose. Durch Laboruntersuchungen kann man ihn weder beweisen noch ausschließen. Prinzipiell kann ein Toxinnachweis im Tierversuch (Maus) durchgeführt werden, er bleibt aber meist erfolglos. Die kulturelle Anzüchtung des Erregers ist mit den üblichen Methoden der Anaerobier-Diagnostik möglich, sie hat aber praktisch keine Bedeutung.

\section{Befund / Interpretation}

Aufgrund der typischen Symptomatik.

\section{Therapie}

\section{Therapeutische Maßnahmen}

Wichtig ist eine sorgfältige Wund,,toilette“. Auch wenn bereits klinischer Verdacht auf Tetanus besteht, muss die Eintrittspforte exzidiert werden, um eine weitere Vermehrung und die dabei erfolgende Toxinbildung zu unterbinden. Die Gabe von Antibiotika hat keinen Einfluss auf den Krankheitsverlauf. Wenn klinische Symptome vorliegen, die für Tetanus sprechen, sind in der Regel intensivmedizinische Maßnahmen erforderlich. Wenn der Impfstatus unklar ist oder die letzte Impfung mehr als 10 Jahre zurückliegt, muss auch bei kleinen Verletzungen eine passive Immunisierung mit Tetanus-Antitoxin i. m. und gleichzeitig die aktive Immunisierung durchgeführt werden („Simultanimpfung“). Die Antitoxingabe muss so früh wie möglich erfolgen, da die Antikörper nur das noch nicht gebundene Toxin neutralisieren können. Wenn die letzte Tetanusimpfung zwischen 5 und 10 Jahre zurückliegt, muss bei einer Verletzung eine aktive Impfung gegeben werden. Keine Maßnahmen sind erforderlich, wenn die letzte Tetanusimpfung weniger als 5 Jahre zurückliegt.

\section{Resistenz}

Die Sporen von C. tetani haben eine hohe Umweltresistenz.

\section{Epidemiologie}

\section{Verbreitung}

C. tetani kommt im Darm von Tieren, selten auch des Menschen vor und ist weltweit im Erdboden und im Staub verbreitet. Die Erkrankung ist in Deutschland wegen des guten Impfstatus der Bevölkerung selten, in den Entwicklungsländern Asiens und Afrikas kommt sie jedoch immer noch häufig vor. In diesen Ländern sterben jährlich auch heute noch Tausende Neugeborene an Nabelschnur-Tetanus.

\section{Wirtsbereich / Reservoir}

Darm von Tieren, Staub.

\section{Risikogruppen}

Risikogruppen sind alle nicht oder unvollständig geimpften bzw. nicht adäquat „aufgefrischten“ Menschen.

\section{Transmission / Vektoren}

Die Sporen von C. tetani dringen über Wunden - auch Bagatellverletzungen - in den Körper ein. Durch Tierbisse kann die vegetative Form übertragen werden.

\section{Prävention / Impfstoffe}

Die wichtigste Präventionsmaßnahme ist die aktive Immunisierung. Sie soll nach der Grundimmunisierung, die in der Regel bereits im ersten Lebensjahr erfolgt, alle 10 Jahre aufgefrischt werden. Bei adäquat durchgeführter Impfung sind andere Präventionsmaßnahmen nicht notwendig. Die aktive Immunisierung erfolgt mit dem Tetanus-Toxoid.

\section{Ausbruchsmanagement \\ Nicht erforderlich.}

\section{Meldepflicht}

Keine Meldepflicht nach IfSG.

\section{Weiterführende Informationen}

\section{Referenzzentren / Expertenlaboratorien}

- Konsiliarlaboratorium für anaerobe Bakterien: Zentrum für Infektionsmedizin, Institut für Medizinische Mikrobiologie und Infektionsmedizin, Universität Leipzig, Herr Professor Dr. A. C. Rodloff, Liebigstr. 24, 04103 Leipzig

\section{Schlüsselliteratur}

1. Hahn H, Kaufmann S, Schulz Th (Hrsg) (2009) 6. Auflage Springer Verlag, Heidelberg

2. Mandell GL, Bennet JE, Dolin R (eds) (2009) Principles and Practice of Infectious Disease, $7^{\text {th }}$ ed. Churchill Livingstone Inc, London

3. Murray PR, Baron EJ, Jorgensen JH, Pfaller MA, Yolken RH (eds) (2009) Manual of Clinical Microbiology $8^{\text {th }}$ edn. ASM Press, Washington

4. www. rki.de Infektionskrankheiten von A-Z 


\section{CMV-Colitis}

- Cytomegalievirus

\section{CMV-Mononukleose}

- Cytomegalievirus

\section{CMV-Pneumonie}

- Cytomegalievirus

\section{Cocal-Virus}

- Vesiculovirus

\section{Coccidien}

Isospora belli

- Sarcocystis

\section{Coccidioides immitis}

\section{Erreger}

Marianne Kretschmar, Paul Schnitzler

\section{Synonym(e)}

Posadasia esteriformis, Geotrichum immite, Trichosporon proteolyticum, Blastomycoides immitis, Pseudococcidioides mazzai.

\section{Erregerspezies}

Zur Gattung Coccidioides gehören zwei Spezies: Coccidioides immitis und C. posadasii. C. posadasii wurde vor der molekularbiologischen Abtrennung von C. immitis als non-California $C$. immitis bezeichnet.

\section{Taxonomie}

Klasse: Hyphomycetes; Ordnung: Onygenales; Familie: Onygenaceae; Gattung: Coccidioides; Teleomorph: nicht bekannt

\section{Historie}

Erste Fallberichte aus Argentinien von Posadas und Wernicke 1892, aus Kalifornien von Rixford und Thorne 1894. Identifizierung als Pilz durch Ophulus and Moffitt 1900. Erste Isolierung aus dem Erdboden durch Stewart and Mayer 1932.

\section{Morphologie}

C. immitis ist ein dimorpher Pilz, der abhängig von der Temperatur und anderen Umweltfaktoren entweder als runde Zellen (Sporangiosporen) oder als Hyphomyzet existiert. Im Wirtsgewebe bildet der Pilz dick- wandige 15-60 $\mu \mathrm{m}$ große Gebilde, die sogenannten Sphärulen aus, die bis zu 100 Sporangiosporen beherbergen. Reife Sporangiosporen haben einen Durchmesser von 2-5 $\mu \mathrm{m}$ und werden aus den Sphärulen freigesetzt. In der Umwelt wächst der Pilz als Hyphomyzet, bei dem sich jede zweite Hyphenzelle zu Arthrokonidien umwandelt. Die Arthrokonidien haben eine Größe von 3-8 × 3,5-4,5 $\mu \mathrm{m}$, sind kurz-zylindrisch bis tonnenförmig und glattwandig. An beiden Enden finden sich rüschenartige Reste der benachbarten, zugrunde gegangenen Zellen.

\section{Genom}

C. immitis hat eine Genomgröße von ca. $28 \mathrm{Mb}$; vier Chromosomen. Ein sexueller Vermehrungszyklus ist nicht bekannt.

\section{Vermehrung}

Vermehrung in der Umwelt erfolgt durch asexuelle Arthrosporen, im Gewebe durch asexuelle Sporangiosporen, die aus den Sphärulen freigesetzt wiederum neue Sphärulen ausbilden können.

\section{Pathogenität / Virulenz / Antigenvariabilität}

Arthrosporen sind hoch infektiös; die Infektion erfolgt bei hoher Erregerdichte in der Luft unabhängig vom Immunstatus. Mit Virulenz assoziierbare Faktoren sind Chitinasen (Zellwandlyse bei Endosporulation), Ornithindecarboxylasen (Morphogenese), Proteinasen (Gewebelyse).

\section{Erkrankung \\ Kokzidioidomykose}

\section{Synonym(e)}

Valley Fever, San Joaquin Fever, Wüstenrheumatismus, Wüstengrippe, Posadas-Wernicke-Krankheit.

\section{Inkubationszeit}

1-4 Wochen nach Inhalation des Arthrosporen enthaltenden Staubes.

\section{Leitsymptome}

Fieber, trockener Husten, Thoraxschmerz, Pneumonie, Pleuritis, Fisteln und Abszesse an Haut und Knochen, Meningitis.

\section{Symptome}

Etwa die Hälfte aller Infektionen mit C. immitis verläuft klinisch inapparent.

- Primäre pulmonale Form: Einfache "Grippe“ bis schwere Bronchopneumonie mit Pleurabeteiligung, eine Chronifizierung ist möglich. Remittierendes Fieber, Schüttelfrost, Unwohlsein, intensive Thoraxschmerzen, Kopfschmerzen, meist trockener Husten, Arthritis. Bei ca. 20 \% der Betroffenen entwickelt sich ein Erythema nodosum oder Erythema multiforme, eine Urtikaria und Konjunkti- 
vitis. Bei immungesunden Menschen heilt die primäre Form der Kokzidioidomykose meist aus.

- Primär kutane Form: Sehr selten nach Verletzung.

- Disseminierte Form: Die hämatogene Disseminierung aus aktiven, latenten oder residualen Lungenherden kann auch noch Jahre nach der Primärinfektion erfolgen. In Haut, Peritoneum und Knochen entstehen granulomatöse Herde und Abszesse, im ZNS kann sich eine chronisch verlaufende Meningitis entwickeln. Unbehandelt verläuft die disseminierte Kokzidioidomykose letal.

\section{Pathophysiologie}

Nach Inhalation der Arthrosporen wandeln sich diese in hefeähnliche Zellen um (Gewebeform). Die Hefezellen vermehren sich in den Alveolen und werden von einer Hülle umgeben. Diese Gebilde nennt man Sphärulen. Aus reifen Sphärulen werden die Pilzzellen, auch Endosporen genannt, in das benachbarte Gewebe freigesetzt. Die Endosporen können dann in andere Organsysteme via Blutstrom disseminieren.

\section{Immunantwort}

Zellwandantigene induzieren eine humorale und zelluläre Immunantwort. Nach überstandener Infektion lebenslange Immunität, jedoch ist eine Reaktivierung nicht austherapierter Herde bei Immunschwäche möglich.

\section{Differenzialdiagnose}

Pulmonale Form: Tuberkulose, Infektion mit anderen dimorphen Pilzen (Histoplasma capsulatum, Blastomyces dermatitidis, Paracoccidioides), Infektionen mit anderen Erregern einer Pneumonie, insbesondere Pneumocystis carinii, Sarkoidose.

Disseminierte Form: Tuberkulose, Kryptokokkose, Blastomykose.

\section{Diagnostik}

\section{Untersuchungsmaterial}

Sputum, Bronchialsekret, BAL, Punktate, Exsudate, Biopsiematerial.

\section{Diagnostische Verfahren}

Mikroskopischer Nachweis von Sphärulen in Sputum, BAL, Punktaten, Exsudaten.

Kultur: Anzucht des Erregers auf Spezialnährmedien (z. B. Hirn-Herz-Agar): bei $24^{\circ} \mathrm{C}$ Wachstum von watteartigen Myzelkulturen nach 3-7 Tagen, bei $37^{\circ} \mathrm{C}$ nach 3-7 Tagen lederartige Kulturen. Cave: Kulturen müssen unter L3-Bedingungen gehandhabt werden!

Histologie: Runde, dickwandige Hefezellen in PAS gefärbten Gewebeschnitten, granulomatöse Veränderungen mit Riesenzellen.

PCR aus Direktmaterial.

Serologie: Antikörpernachweis mittels Immundiffusion oder Western Blot, im Akutstadium auch KBR.

\section{Befund / Interpretation}

Der mikroskopische/histologische Nachweis von Sphärulen sowie der Nukleinsäurenachweis ist pathognomonisch. Antikörpernachweise mittels Immundiffusion sind noch Monate bis Jahre nach Infektion positiv. KBR ist geeignet zur Quantifizierung und Titerverlaufskontrolle.

\section{Therapie}

\section{Therapeutische Maßnahmen}

Eine klinisch symptomatische pulmonale Infektion sollte mit Itraconazol behandelt werden. Bei disseminierter Kokzidioidomykose kann entweder Voriconazol eingesetzt werden oder initial Amphotericin B, danach Itraconazol.

\section{Resistenz}

Unbekannt.

\section{Epidemiologie}

\section{Verbreitung}

Trockene und wüstenartige Gebiete im Südwesten der USA, Mittel- und Südamerika.

\section{Wirtsbereich / Reservoir}

Mensch, Wild- und Nutztiere in Endemiegebieten; Seeottern.

\section{Risikogruppen}

Landarbeiter, Archäologen und Touristen in Endemiegebieten, Immunsupprimierte.

\section{Transmission / Vektoren}

Die infektiösen Arthrokonidien werden mit der stauboder sandhaltigen Luft übertragen, insbesondere bei Sandstürmen. Sehr selten erfolgt die Übertragung durch Mikrotraumata direkt in das Gewebe. Keine Übertragung von Mensch zu Mensch.

\section{Prävention / Impfstoffe}

Eine spezifische Prophylaxe ist nicht möglich. Expositionsprophylaxe für Immunsupprimierte.

\section{Ausbruchsmanagement}

Nationale Surveillance-Programme erfassen Infektionen in Endemiegebieten.

\section{Meldepflicht}

Keine.

\section{Weiterführende Informationen}

\section{Referenzzentren / Expertenlaboratorien}

- Konsiliarlabor: Robert-Koch-Institut, Nordufer 20, FG212, D-13353 Berlin

- National Centers for Disease Control, Mycotic Diseases Branch, Atlanta, GA 30333, USA

- HIV-Infektion und Coccidioidomykose: University of California San Francisco and San Francisco General Hospital 


\section{Web-Adressen}

- http://www.cdc.gov

- http://yellow-fever.rki.de/INFEKT/STECKBRF/STBR. HTM

- http://www.cdc.gov/ncidod/dbmd/diseaseinfo/ coccidioidomycosist.htm

- http://www.astdhpphe.org/infect/valley.html,

- http://vfce.arl.arizona.edu/vermain.htm

- http://hivinsite.ucsf.edu

\section{Schlüsselliteratur}

1. Ampel NM, Ryan KJ, Carry PJ, Wieden MA, Schifman RB (1986) Fungemia due to Coccidioides immitis. Medicine 65:312-321

2. Fisher MC, Koenig GL, White TJ, San-Blas G, Negroni R, Alvarez IG, Wanke B, Taylor JW (2001) Biogeographic range expansion into South America by Coccidioides immitis mirrors New World patterns of human migration. Proc Natl Acad Sci USA 98:4558-4562

3. Galgiani JN, Ampel NM, Catanzaro A, Johnson RH, Stevens DA, Williams PL (2000) Practice guidelines for the treatment of coccidioidomycosis. Clin Infect Dis 30:658661

4. de Hoog GS, Guarro J, Gene J, Figueras MJ (2000) Atlas of Clinical Fungi, $2^{\text {nd }}$ edn, vol 1. Centraalbureau voor Schimmelcultures, Utrecht, The Netherlands

5. Li RK, Ciblak MA, Nordoff N, Pasarell L, Warnock DW, McGinnis MR (2000). In vitro activities of voriconazole, itraconazole, and amphotericin B against Blastomyces dermatitidis, Coccidioides immitis and Histoplasma capsulatum. Antimicrob. Agents Chemother 44:1734-1736

\section{Cochliomyia spp.}

Myiasis-Erreger

\section{Colorado-Tick-Fever-Virus}

$>$ Coltivirus

\section{Colorado-Zeckenfieber}

$>$ Coltivirus

\section{Coltivirus}

\section{Erreger}

\section{Erregerspezies}

Colorado-Tick-Fever-Virus

\section{Taxonomie}

Aufgrund morphologischer, serologischer und physikochemischer Eigenschaften dieser Virusgruppe wurde das Genus Coltivirus eingeführt. Die Einführung eines neuen Genus innerhalb der Familie Reoviridae wird auch durch die Übertragung dieser Viren durch Arthropoden untermauert.

\section{Historie}

$\mathrm{Zu}$ Beginn dieses Jahrhunderts beschrieben Ärzte in Montana und Colorado eine mild verlaufende Krankheit ohne Ausschlag, die dort nach Zeckenstich auftrat. Erst 1930 beschrieb Becker das Colorado-TickFieber. Florio isolierte das Virus 1944 aus menschlichem Blut. Dieser Virusstamm ist der Prototyp des Colorado-Tick-Fever-Virus. Freiwillige wurden mit Seren von infizierten Personen inokuliert und zeigten die gleiche Symptomatik wie natürlich infizierte Personen. Danach wurde das Virus an Mäuse und Hühnerembryonen adaptiert und konnte durch Inokulation von Babymäusen isoliert werden. Ursprünglich wurde diese Gruppe von Reoviren als Arboviren klassifiziert, weil sie von Arthropoden übertragen werden. Allerdings unterscheiden sie sich stark von Arboviren in ihrer Resistenz gegen organische Lösungsmittel.

\section{Morphologie}

Das Coltivirus ist ein sphärisches Partikel mit ikosaedrischer Symmetrie, sein Durchmesser liegt bei ca. 60-80 nm. Das Virion besteht aus einer äußeren Hülle und einem inneren Core. Das Nukleokapsid ist von einer diffusen Proteinschicht umgeben; dieses äußere Kapsid besitzt keine klaren morphologischen Untereinheiten. Der Durchmesser des Colorado-Tick-FeverVirus beträgt $80 \mathrm{~nm}$ bei negativer Färbung, die Kapsomere sind bei dieser Art der Darstellung ringförmig angeordnet. Die äußere Kapsidhülle ist eine diffuse Schicht, die im Vergleich zu anderen Reoviren eher zerbrechlich wirkt. Das Coltivirus besitzt kein Envelope, aber ein segmentiertes doppelsträngiges RNA-Genom. Die Morphogenese und Ausbildung neuer Viruspartikel findet im Zytoplasma der infizierten Zelle statt, was an den Einschlusskörperchen zu erkennen ist. Diese Einschlusskörper sind Orte der Virusreplikation und des Zusammenbaus von neuen Viruspartikeln. Das virale Genom besteht aus zehn doppelsträngigen RNA-Segmenten, die einzige Ausnahme ist das Colorado-Tick-Fever-Virus mit zwölf doppelsträngigen RNA-Segmenten.

\section{Genom}

Die Mitglieder der Familie Reoviridae besitzen ein segmentiertes Genom mit einer variablen Anzahl von Gensegmenten aus doppelsträngiger RNA. Das Genom des Colorado-Tick-Fever-Virus besteht aus zwölf doppelsträngigen RNA Molekülen, hat eine Masse von $18 \times 10^{6} \mathrm{D}$ und ist damit größer als das Genom anderer Reoviren.

\section{Vermehrung}

Infektionen mit dem Colorado-Tick-Fever-Virus sind mit einer Virämie assoziiert, die mehrere Monate dauern kann. Das Virus befindet sich in Erythozyten und 
ist somit für eine Immunantwort schlecht zugänglich. Die Morphogenese und Ausbildung neuer Viruspartikel findet im Zytoplasma der infizierten Zelle statt, was an den Einschlusskörperchen zu erkennen ist. Diese Einschlusskörper sind Orte der Virusreplikation und des Zusammenbaus von neuen Viruspartikeln.

\section{Pathogenität / Virulenz / Antigenvariabilität}

CTFV verursacht eine febrile Erkrankung und Enzephalitis beim Menschen. Über die Pathologie beim Menschen ist nur sehr wenig bekannt. Leukopenie mit einer Abnahme von Granulozyten und Lymphozyten sowie Thrombozytopenie sind die häufigsten hämatologischen Veränderungen. Zwei fatale Fälle mit Enzephalitis und Nierenversagen mit Hämorrhagien wurden bei Kindern berichtet. Symptome waren hier Petechien der Haut, Schwellen des Endothels sowie Nekrosen der Leber, Milz und des Gehirns.

\section{Erkrankung \\ Colorado-Tick-Fever-Virus-Erkrankung \\ Synonym(e) \\ Bergfieber.}

\section{Inkubationszeit}

Die Inkubationszeit beträgt ungefähr vier Tage.

\section{Leitsymptome}

Fieber, Schüttelfrost, Kopfschmerz, Myalgien und Photophobie, unter Umständen Diarrhoe, Enzephalitis.

\section{Symptome}

Das Colorado-Tick-Fever-Virus (CTFV) verursacht eine febrile Erkrankung und Enzephalitis beim Menschen. Dermacentor andersoni ist die Zecke, die dieses Virus in den Rocky Mountains und in Nordwestkanada überträgt. Die Krankheit, die durch das ColoradoTick-Fever-Virus beim Menschen hervorgerufen wird, wird wegen der recht unspezifischen Symptome auch als Bergfieber bezeichnet und wird immer noch mit einer Anzahl von anderen Erkrankungen verwechselt. Die Krankheit beginnt mit Fieber, Schüttelfrost, Kopfschmerz, Myalgien und Photophobie, unter Umständen Diarrhoe. Die akute Krankheitsphase dauert fünf bis zehn Tage.

\section{Pathophysiologie}

Über die Pathologie beim Menschen ist nur sehr wenig bekannt. Leukopenie mit einer Abnahme von Granulozyten und Lymphozyten sowie Thrombozytopenie sind die häufigsten hämatologischen Veränderungen.

\section{Immunantwort}

Patienten mit CTF zeigen eine verminderte Produktion des Kolonie stimulierenden Faktors, der zirkulierende Inhibitor könnte Interferon sein. Ein großer Teil der CTF-Patienten hat einen hohen Spiegel an zirkulierendem Interferon-alpha während der ersten zehn Tage der Erkrankung. Der Interferonspiegel korreliert mit dem Fieber, aber nicht mit der Häufigkeit oder dem Schweregrad der Symptome. Komplementbindende und neutralisierende Antikörper werden spät, d. h. etwa zwei bis drei Wochen nach Beginn der Symptomatik gebildet.

\section{Differenzialdiagnose}

Das Colorado-Tick-Fieber kann wegen der Übertragung durch Zecken mit einer Lyme-Borreliose verwechselt werden. Bei europäischen Formen der Infektion kommt differenzialdiagnostisch eine Frühsommermeningoenzephalitis (FSME) in Betracht.

\section{Diagnostik}

\section{Untersuchungsmaterial}

Das Colorado-Tick-Fever-Virus kann leicht aus infizierten Patienten isoliert werden. Infektiöses Virus ist in zirkulierenden Erythrozyten nachweisbar. Das am besten geeignete Untersuchungsmaterial ist Heparinblut, da das Virus zellassoziiert ist. Erythrozyten müssen vor einer Untersuchung gut gewaschen werden, um sie vom Serum und den darin enthaltenen Antikörpern zu befreien. Die Probe sollte gekühlt transportiert und gelagert werden, Einfrieren ist zu vermeiden.

\section{Diagnostische Verfahren}

Das sensitivste Nachweissystem zur Isolierung des Virus ist die intrazerebrale Inokulation von Babymäusen. Ein Antigennachweis mittels Immunfluoreszenz ist auch möglich.

Zum serologischen Nachweis einer Colorado-TickFieber-Infektion werden die Komplementbindungsreaktion und der IgM-Nachweis eingesetzt. Komplementbindende Antikörper werden bei einem Viertel der Patienten nicht gebildet. Neutralisierende Antikörper werden spät, d. h. etwa zwei bis drei Wochen nach Beginn der Symptomatik gebildet. Infizierte Vero- oder BHK-21-Zellen werden zum Nachweis von Antikörpern gegen das CTFV in der Immunfluoreszenz benutzt. Die IgM-Antikörperantwort, die ca. vier bis fünf Wochen nach der Infektion ihren höchsten Titer erreicht, wird im ELISA gemessen.

\section{Befund / Interpretation}

Die Isolierung des CTFV aus Patientenmaterial sowie ein positiver IGM-Nachweis sind beweisend für eine Infektion.

\section{Therapie}

\section{Therapeutische Maßnahmen}

Es gibt keine spezifische Behandlung. Eine Therapie kann daher nur die Senkung des Fiebers und das Lindern der Schmerzen zum Ziel haben. Ribavirin inhibiert das Wachstum des CTFV in Zellkultur und 
schützt Mäuse gegen eine Infektion durch intrazerebrale Inokulation.

\section{Resistenz}

Da keine antivirale Therapie existiert, sind keine Angaben zur Resistenz gegen Virostatika möglich.

\section{Epidemiologie}

\section{Verbreitung}

Das Colorado-Tick-Fieber-Virus kommt in den Rocky Mountains und im Nordwesten Kanadas in einer Höhe zwischen 1.000 und 3.000 m vor. Dies entspricht der natürlichen Verbreitung des Vektors, Dermacentor andersoni. Bei Personen in Südkorea wurden ebenfalls neutralisierende Antikörper gegen CTFV nachgewiesen.

Das Colorado-Tick-Fieber tritt vor allem zwischen April und Juli auf. Im Mai und Juni, wenn die adulten Zecken am aktivsten sind, ist die Inzidenz am höchsten.

\section{Wirtsbereich / Reservoir}

CTFV kommt beim Menschen und bei der Zecke Dermacentor andersoni in den Rocky Mountains und in Nordwestkanada vor.

\section{Risikogruppen}

Insbesondere Personen, die sich häufig im Freien in den Rocky Mountains und im Nordwesten Kanadas aufhalten, sind durch die vermehrte Exposition zu infizierten Zecken stärker gefährdet. Hierzu zählen in erster Linie Jäger, Camper und Bergsteiger. Über 70 \% der Colorado-Tick-Fieber-Fälle werden bei Erwachsenen verzeichnet, die höchste Inzidenz liegt in der Altersgruppe von 20-29 Jahren. Unter den Infizierten sind etwa dreimal mehr Männer als Frauen.

\section{Transmission / Vektoren}

CTFV verursacht eine febrile Erkrankung und Enzephalitis beim Menschen. Dermacentor andersoni ist die Zecke, die dieses Virus in den Rocky Mountains und in Nordwestkanada überträgt.

\section{Prävention / Impfstoffe}

Der beste Schutz gegen eine Infektion durch das CTFV ist das Tragen einer sachgemäßen Bekleidung für diejenigen Personen, die häufig in den genannten Gebieten diesen Zecken exponiert sind. Dieser Personenkreis sollte auf jeden Fall darauf achten, dass Zecken, die sich auf der Haut anheften, sofort entfernt werden.

\section{Meldepflicht}

Nach dem Infektionsschutzgesetz besteht keine Meldepflicht.

\section{Weiterführende Informationen}

\section{Referenzzentren / Expertenlaboratorien}

- Ein Referenzzentrum für Coltivirus in der Bundesrepublik Deutschland ist nicht bekannt.

\section{Web-Adressen}

- http://www.iah.bbsrc.ac.uk/virus/Reoviridae/

\section{Schlüsselliteratur}

1. Roy P (1995) Orbiviruses and their replication. In: Fields BN, Knipe DM, Howley PM Virology. Raven-Lippincott Publishers, Philadelpia, New York, pp 1709-1734

\section{Common Cold}

- Coxsackieviren

$\checkmark$ Rhinoviren

\section{Community-Acquired MRSA (CA-MRSA)}

- Staphylococcus aureus

\section{Condylomata acuminata}

- Humane Papillomviren (HPV)

\section{Condylomata lata}

Ureaplasma urealyticum

\section{Conidiobolomykose}

- Conidiobolus

\section{Conidiobolus}

\section{Erreger}

\section{Erregerspezies}

Conidiobolus coronatus, C. incongruus, C. lamprauges

Reinhard Kappe, Dagmar Rimek

\section{Taxonomie}

Abteilung: Zygomycota; Klasse: Zygomycetes; Ordnung: Entomophthorales; Familie: Anylistaceae; Gattung: Conidiobolus

\section{Historie}

Die erste humane Conidiobolomykose wurde 1965 von Bras et al. bei einem Mann aus der Karibik berichtet.

\section{Morphologie}

- Wirtsgewebe: unseptiertes oder sehr selten septier- 
tes Myzel, rechtwinklige Verzweigungen (wie Basidiobolomykose).

- Kultur: gutes Wachstum bei $37^{\circ} \mathrm{C}$. Kolonien raumgreifend, wachsartig mit radiären Furchen, Oberseite zunächst weiß, später beige-braun, bald Satellitenkolonien.

- Mikroskopisch: Hyphen 6-15 $\mu \mathrm{m}$ breit. Sporophoren 60-90 $\mu \mathrm{m}$ hoch, basales Septum, sich zur Spitze hin leicht verjüngend, apikale Produktion einzelner Konidiosporen. Primäre Sporen $40 \mu \mathrm{m}$ groß, mit herausragender, warzenförmiger Basis, später haarähnliche Anhängsel ausbildend. Die Konidien werden aktiv in Richtung von Lichtquellen abgestoßen.

\section{Genom}

Conidiobolus spp. sind eukaryonte Organismen, über deren Genomgröße und Chromosomenzahl noch keine Daten vorliegen. Es sind bisher nur Teile der Genome sequenziert. Für die taxonomische Einordnung wichtige Sequenzen sind die der $18 \mathrm{~S}, 5,8 \mathrm{~S}$ und $28 \mathrm{~S}$ ribosomalen RNA-Gene sowie der internen transkribierten Spacer 1 und 2.

\section{Vermehrung}

In vitro zeichnen sich alle Conidiobolus-Arten durch rasches Wachstum bei $37^{\circ} \mathrm{C}$ aus (Thallusgröße $>1 \mathrm{~cm}$ in $24 \mathrm{~h}$ ). C. coronatus ist heterothallisch und bildet selten Zygosporen, C. incongruus ist homothallisch.

\section{Pathogenität / Virulenz / Antigenvariabilität}

Eingeordnet in Risikogruppe 2. Aufgrund der geringen Fallzahl an Erkrankungen weltweit wird eine niedrige Virulenz der Erreger angenommen. Die Thermotoleranz mit Wachstum bei $37^{\circ} \mathrm{C}$ könnte einen Virulenzfaktor darstellen. Es besteht eine Antigengemeinschaft mit Basidiobolus ranarum.

\section{Erkrankung}

\section{Conidiobolomykose}

\section{Inkubationszeit}

Die Inkubationszeit der humanen Conidiobolomykose ist unbekannt.

\section{Leitsymptome}

Nasale Obstruktion, nasales Granulom, subkutane Knoten.

\section{Symptome}

Die Infektion beginnt in der Submukosa der Nase und breitet sich nach beiden Seiten auf die Haut von Nase, Glabella, Wange, Oberlippe, Nasennebenhöhlen und Pharynx aus. Die Erkrankung kann mit nasalen Symptomen oder einem harten schmerzlosen Knoten in der Nasenhaut in Erscheinung treten. Das häufigste nasale Symptom ist Obstruktion, aber auch Rhinorrhoe und Epistaxis können auftreten. Wie bei der Basidiobolomykose bleibt auch hier der Knochen ver- schont und die Haut intakt. Der Allgemeinzustand bleibt unbeeinträchtigt. Selten kann eine hämatogene Aussaat auftreten.

\section{Pathophysiologie}

Inhalierte Sporen von Conidiobolus spp. penetrieren die traumatisch veränderte Nasenschleimhaut und führen zu lokaler Infektion mit Granulombildung.

\section{Immunantwort}

Lokale Ausbildung eines Granuloms, das viele eosinophile Leukozyten enthält.

\section{Differenzialdiagnose}

Basidiobolomykose, Zygomykose, Sarkom.

\section{Diagnostik}

\section{Untersuchungsmaterial}

Schleimhautbiopsie der Nase oder subkutane Gewebebiopsie.

\section{Diagnostische Verfahren}

Röntgenaufnahmen der Nasennebenhöhlen zeigen das Ausmaß des Befalls dieser Region. Rhinoskopie mit Biopsie oder Hautbiopsie sind die angezeigten diagnostischen Maßnahmen.

Direktmikroskopie: Im $\mathrm{KOH}$ - oder Calcofluorweiß$\mathrm{KOH}$-Präparat einer Biopsie sind breite, nicht oder spärlich septierte Hyphen mit lichtbrechenden Wänden und granulären Einschlüssen zu sehen.

Kultur: Auf Sabouraud-Glukose-Agar wachsen bei $37^{\circ} \mathrm{C}$ nach $2-5$ Tagen wachsartige weiße Kolonien mit radiären Furchen. Diese werden mikromorphologisch identifiziert $(\triangleright$ Morphologie).

Serologie: Ein Immundiffusionstest zur AntikörperDiagnostik wurde entwickelt, ist aber nicht kommerziell verfügbar.

\section{Befund / Interpretation}

Eine Biopsie des Granuloms mit Kultur und Histopathologie ist diagnostisch. Der mikroskopische Nachweis großer, nicht oder spärlich septierter, kurzer Hyphen, umgeben von hyalinem eosinophilem Material ist sehr charakteristisch, muss aber durch den kulturellen Erregernachweis bestätigt werden.

\section{Therapie}

\section{Therapeutische Maßnahmen}

Es gibt keine Standardtherapie, die Heilungsraten sind nicht sehr hoch, nur wenige Infektionen heilen spontan. Eine Submucosektomie schafft nur zeitweilige Erleichterung. Medikamente, die teilweise erfolgreich eingesetzt wurden, sind Kaliumjodid, TrimethoprimSulfamethoxazol, Amphotericin B, Ketoconazol, Itraconazol und Kombinationen dieser Medikamente.

\section{Resistenz}

In vitro-Daten sind sehr begrenzt. C. coronatus weist 
hohe MHK-Werte für Flucytosin, Amphotericin B, Fluconazol, Itraconazol, Ketoconazol und Miconazol auf.

\section{Epidemiologie}

\section{Verbreitung}

Bis 1991 wurden weltweit ca. 150 Fälle von Conidiobolomykose beschrieben. Geografische Verbreitung: Zentralamerika, Äquatorialafrika, Indien.

\section{Wirtsbereich / Reservoir}

Conidiobolus-Arten kommen weltweit in abgestorbener Vegetation und im Erdboden vor. Hohe Keimzahlen finden sich vor allem im feucht-warmen Klima der tropischen Regionen. C. coronatus wurde in Insekten und im Darminhalt von Eidechsen und Kröten gefunden. Nasale Infektionen wurden auch bei Pferden, Schafen, Hunden und Wild beschrieben.

\section{Risikogruppen}

Im Gegensatz zur Basidiobolomykose sind überwiegend gesunde männliche Erwachsene betroffen. Es sind keine prädisponierenden Grunderkrankungen oder beruflichen Risikofaktoren bekannt.

\section{Transmission / Vektoren}

Es wird angenommen, dass inhalierte Sporen von Conidiobolus spp. die traumatisch veränderte Nasenschleimhaut penetrieren.

\section{Prävention / Impfstoffe}

Keine Daten verfügbar.

\section{Ausbruchsmanagement}

Die Erkrankung ist nicht von Mensch zu Mensch übertragbar. Ausbrüche kommen nicht vor.

\section{Meldepflicht}

Nach dem Infektionsschutzgesetz besteht für die Conidiobolomykose in Deutschland keine Meldepflicht.

\section{Weiterführende Informationen}

\section{Referenzzentren / Expertenlaboratorien}

- Centraalbureau voor Schimmelcultures, PO Box 85167, NL-3508 AD Utrecht, The Netherlands. Tel.: +31-302122600, Fax: +31-30-2512097, E-Mail: info@cbs.knaw.nl

\section{Web-Adressen}

- DoctorFungus Corporation: http://www.doctorfungus. org/thefungi/Conidiobolus.htm

- Centraalbureau voor Schimmelcultures, Niederlande: http://www.cbs.knaw.nl

\section{Schlüsselliteratur}

1. de Hoog GS, Guarro J, Gene J, Figuera MJ (2000) Atlas of Clinical Fungi, $2^{\text {nd }}$ edn. Centraalbureau voor Schimmelcultures, Utrecht, Conidiobolus, pp 118-124

2. Kwon-Chung KJ, Bennett JE (1992) Medical Mycology, $2^{\text {nd }}$ edn, Lea \& Febiger, Philadelphia, London. Chapter 17: Entomophthoramycosis, pp 447-463

3. Ribes JA, Vanover-Sams CL, Baker DJ (2000) Zygomycetes in human disease. Clin Microbiol Rev 13:236-301

4. Richardson MD, Koukila-Kähkölä P (2007) Rhizopus, Rhizomucor, Absidia, and other agents of systemic and subcutaneous zygomycoses. In: Murray PR, Baron EJ, Jorgensen JH, Landry ML, Pfaller MA (eds) Manual of Clinical Microbiology, vol 2, $9^{\text {th }}$ edn. ASM Press, Washington DC, Chapter 122

\section{Cordylobia spp.}

\section{$\checkmark$ Myiasis-Erreger}

\section{Coronavirus, humanpathogenes}

\section{Erreger}

\section{Synonym(e)}

Humanes Coronavirus.

\section{Erregerspezies}

Humanpathogene Coronaviren $\mathrm{HCoV}-229 \mathrm{E}, \mathrm{HCoV}-$ OC43, HCoV-NL63, HCoV-NH, HCoV-HKU1.

\section{Taxonomie}

Genus: Coronavirus in der Familie: Coronaviridae; als Mitglieder der Ordnung Nidovirales klassifiziert. Spezies: Fünf humanpathogene Serotypen, die folgenden Gruppen zuzuordnen sind:

Gruppe 1: HCoV-229E, Typ HCoV-NL-63, bzw. NH Gruppe 2: HCoV-OC43, HCoV-HKU1. Als Typ-Spezies gilt das Coronavirus der Aviären infektiösen Bronchitis (IBV).

\section{Historie}

Die Erstbeschreibung animaler Coronaviren (IBV) erfolgte durch Schalk und Hawn (1931), die von humanpathogenen Coronaviren (B814) durch Tyrrell und Bynoe (1965), Erstisolation und Kultivierung durch Hamre und Procknow (1967). Klassifikation als Coronaviridae aufgrund der Morphologie und der charakteristischen Anordnung von Oligomeren des S-Glykoproteins (ähnlich der solaren „Korona“). Die Genomsequenz der Prototypen ist ermittelt, u. a. Herold et al. (1993). 2004 erfolgt die Identifikation des Serotyps NL-63 durch Berkhout et al. und HCoV-NH (2005) von Esper und Mitarbeitern. Letzteres wurde für einige Zeit mit dem Kawasaki-Syndrom in Verbindung gebracht. Neuere Untersuchungen können diesen Befund nicht bestätigen.

\section{Morphologie}

Virionen von Coronaviren sind umhüllt und von pleomorpher, in der Regel sphärischer Struktur (120$160 \mathrm{~nm}$ ). Das virale Genom (ss-RNA, Plus-Strang, ca. 
$30 \mathrm{~kb}$ ) bildet mit dem viralen Nukleokapsidprotein (N) ein helikales Nukleokapsid. Die Virushülle setzt sich aus zwei bis vier Proteinen zusammen, dem SProtein, das zu trommelschlegelförmigen Oligomeren aggregiert, dem M-Protein und bei verschiedenen Spezies und Serotypen (z. B. HCoV-OC43) dem Hämagglutinin-Esterase-Protein (HE).

\section{Genom}

Das nicht-segmentierte, einzelsträngige RNA-Genom mit Plusstrang-Polarität von 27-31 kb, wird monocistronisch transkribiert. Translatiert werden i. d .R drei Glykoproteingene, das Gen des HE-Proteins und das des Nukleokapsidproteins. Das virale Genom besitzt am 5'-Ende eine Cap-Strukur und ist am 3'-Ende polyadenyliert. Die komplette Ribonukleotidsequenz und Proteinsequenz des HCoV-229E ist abrufbar unter GENBANK \# AF304460; NCBI \# NC002645; Medline 21262210; Pubmed 11369870, die von Isolat NL63 unter NCBI \# 471450. Weitgehend identisch ist Isolat NH. CoV HKU1 ist abrufbar unter NCBI \# AY 597011.

\section{Vermehrung}

Die Vermehrung findet meist in den Epithelialzellen des oberen Respirationstraktes statt. Seltener erfolgt eine Replikation in den Epithelien des Pharynx und des Broncho-Alveolartraktes. Der Primärkontakt an Zielzellen erfolgt über das Spike-Protein.

\section{Pathogenität / Virulenz / Antigenvariabilität}

Die meisten Infektionen gehen mit einer milden respiratorischen Symptomatik einher, jedoch sind auch schwerere respiratorische Infekte, sowie Entzündungen des Kehlkopfes häufig. HCoV-229E und HCoVOC43 infizieren meist Flimmerpithelzellen des Nasopharyngealraumes. Der 229-E-Gruppe angehörende Viren adsorbieren mit dem S-Protein an die Aminopeptidase $\mathrm{N}$ der Zielzellen, wogegen Vertreter der OC43-Gruppe an das CE-Antigen andocken

\section{Erkrankungen}

1. Erkrankungen des oberen Respirationstraktes HCoV-229E und HCoV-OC43 führen zu akuten Erkrankungen des oberen Respirationstraktes. Diese treten saisonal gehäuft im Winter und Frühjahr auf. Je nach Erhebung wird davon ausgegangen, dass 5-30 \% aller Erkältungskrankheiten durch humane Coronaviren hervorgerufen werden. Als Komplikationen sind Erkrankungen des unteren Respirationstraktes, Bronchitis, sowie Pneumonien bei Kindern beschrieben. Letzteres kann insbesondere, ebenso wie Myokarditis, bei Immunsupprimierten auftreten. Die Beteiligung von Coronaviren an enterischen Infektionen beim Menschen, wird nach wie vor kontrovers diskutiert, da Coronavirus-Like-Particles (CVLP) in den Fäzes von Diarrhoe-Patienten ebenso wie bei Gesunden nachweisbar sind. Neuere Berichte deuten aber auf eine
Beteiligung von Coronaviren an Gastroenteritiden beim Menschen hin. Auch das Auftreten von nekrotisierenden Enterocolitiden bei Neugeborenen wird diskutiert. Gesicherte Gastroenteritiden, hervorgerufen durch tierpathogene Coronaviren, sind in verschiedenen Tierspezies beobachtet worden. Die ätiologische Rolle von Coronaviren bei der Entstehung neurologischer Erkrankungen, u. a. der Multiplen Sklerose, ist weiterhin unklar. Aus dem Hirn einiger MS-Patienten konnte humanes Coronavirus isoliert, oder CVLP durch Elektronenmikroskopie dargestellt werden.

\section{Synonym(e)}

Schnupfen.

\section{Inkubationszeit}

Die Inkubationszeit ist mit 2-5 Tagen geringfügig länger als die von Rhinoviren, die Dauer der Erkrankung (2-20 Tage) vergleichbar.

\section{Symptome}

Husten, Schnupfen, Heiserkeit allgemein. Bronchiolitis, Bronchopneumonie und Pneumonie, vor allem hervorgerufen durch neuere Isolate.

\section{Pathophysiologie \\ - Vermehrung}

\section{Differenzialdiagnose}

Bei Verdacht auf Bronchitis sind abzuklären:

- Infektion mit Influenza und Parainfluenza

- Respiratory-Syncycial-Virus

- Metapneumovirus

- Adenovirus

- Coxsackie-Viren und ECHO-Viren

- Rhinoviren

\section{Symptome}

Die Symptomatik von respiratorischen Coronavirusinfektionen ähnelt in ihrem klinischen Verlauf stark der von Rhinoviren und anderen Erregern des oberen Respirationstraktes. Diese können durch klinische Diagnostik zumeist nicht klar differenziert werden. Allgemein treten Abgeschlagenheit, Kopfschmerzen, Husten, Schnupfen, rauer Hals, Halsschmerzen, Schüttelfrost, vereinzelt Fieber auf. Schwerere Verläufe von respiratorischen Infekten sind in 5-10 \% der Fälle beobachtbar. Selten erfolgt eine Ausbreitung auf den unteren Respirationstrakt. Ein schwererer Verlauf chronischer Bronchitiden bei Erwachsenen und die Induktion von Asthmaanfällen bei Kindern kann infolge einer akuten Coronavirusinfektion beobachtet werden. Die Isolate NL63, NH und HK-U1 verursachen möglicherweise häufiger Infektionen des unteren Respirationstraktes, als bisher bei den bekannten Isolaten beobachtet. Weitere Symptomatiken $>$ Erkrankungen 2 und 3. 


\section{Immunantwort}

Es besteht kein lang andauernder immunologischer Schutz vor Coronaviren nach Infektion.

\section{Broncheolitis, Krupp (Pseudokrupp) \\ Durch Coronavirus NL 63.}

\section{Synonym(e)}

New-Haven-Coronavirus.

\section{Inkubationszeit}

Ähnlich wie bei HMPV 3-6 Tage, zumeist zunächst mit Beteiligung der oberen Atemwege.

\section{Leitsymptome}

Bellender Husten, Heiserkeit, eventuell eine respiratorische Vorerkrankung des oberen Respirationstraktes, ansteigende oder anfallartige Atemnot bisweilen Fieber. Bei der klinischen Symptomatik des Krupp und inspiratorischer Stridor, Stenosierungsprozess in Larynx und Trachea, auch mit Beteiligung des Bronchialtraktes, seltener alveolärer Bereiche. Kinder, erleiden nach Infektion mit CoV-NL mit sechsfach erhöhter Wahrscheinlichkeit einen Krupp-Anfall.

\section{Symptome}

Anschwellen der Schleimhäute im Bereich des Pharynx, unterhalb der Stimmbänder.

Krupp (Pseudokrupp) imponiert mit Heiserkeit, seltener bellendem Husten, Aphonie und Stridor. Das klinische Bild zeigt eine stenosierende Laryngo-Tracheobronchitis, in schweren Fällen mit Dyspnoe, Ateminsuffizienz, Zyanose und Erstickungsgefahr, ferner Bradykardie und Somnolenz.

\section{Differenzialdiagnose}

Diphterie, Keuchhusten, Kehlkopfdeckelentzündung, Influenza, Parainfluenza.

\section{SARS}

- SARS-Coronavirus (SARS-CoV)

\section{Diagnostik}

\section{Untersuchungsmaterial}

Aufgrund des überwiegend leichten Verlaufs der Erkrankungen erfolgt zumeist keine Labordiagnose. Für die Diagnostik wird vielfach noch Hämagglutinationshemmtest (Cave: erfasst nur HCV-Stämme mit Hämagglutinin) und Komplement-Bindungsreaktionstestung angewendet. Immer mehr Verbreitung findet aber der Virusnachweis durch RT-PCR. In jüngster Zeit hat die Etablierung neuer Zelllinien die Grundlage für einen verbesserten Direktnachweis in der Zellkultur geschaffen.

\section{Diagnostische Verfahren}

Der Nachweis von Coronaviren erfolgt aus Rachenbzw. Nasenabstrichen oder Rachenspülwasser durch
Anzüchtung in Zellkultur. Nachweise mittels RT-PCR sind in vielen Labors etabliert.

\section{Therapie}

\section{Therapeutische Maßnahmen}

Die Behandlung nach Diagnosestellung Krupp erfolgt symptomatisch und supportiv, je nach Schweregrad des Verlaufs der Infektion.

Eine antivirale Therapie nach klinischen Verläufen einer HMPV-Infektion steht zurzeit nicht zur Verfügung. Experimentelle Daten zeigen eine Sensitivität der neuen Coronaviren gegen $\beta$-D-N4-Hydroxycitidin und 6-Azauridin. Die Gabe von Ribavirin scheint weniger geeignet zu sein. Intensivmedizinische Betreuung kann, vor allem bei entsprechender medizinischer Prädisposition, angezeigt sein.

Bei Pseudokrupp infolge von Coronavirus NL 64 zeigen Gaben von Epinephrin Prednison und Prednisolon positive Wirkung.

Reicht die Gabe eines systemisch applizierten Kortikosteroids nicht aus, ist es u. U. sinnvoll, zusätzlich ein Adrenalin-Präparat inhalativ zu applizieren. Eine Herzfrequenz von 180 Schlägen/Minute sollte dabei nicht überschritten werden.

\section{Epidemiologie}

\section{Verbreitung}

Humane Coronaviren, auch die neueren Isolate, sind weltweit verbreitet. Studien belegen, dass 20-80\% der Bevölkerung gegen Coronavirus seropositiv sind. Für verschiedene Coronavirus-Serotypen kann ein mehr oder weniger ausgeprägter Zweijahres-Zyklus mit hohem Auftreten von Infektionen beobachtet werden. Die neuen Virusisolate NL64 und NH sind in allen Altersgruppen der nördlichen Hemisphäre anzutreffen, wobei der klinische Verlauf der Infektion oft in Schwere und Verlauf einer solchen durch Parainfluenzaviren ähnelt.

\section{Wirtsbereich / Reservoir}

Coronaviren, sofern sie in diesem Kapitel Erwähnung finden, sind speziesspezifisch, eine Übertragung auf andere Spezies ist bisher nicht beobachtet worden.

\section{Risikogruppen}

Erkrankungen treten bei Personen aller Bevölkerungsschichten und jeden Alters auf. Komplikationen nach Coronavirusinfektionen treten selten, aber gehäuft bei Kindern, älteren Personen sowie Personen mit unzureichendem Immunstatus auf. Bei Infektionen mit neuen Coronaviren ist bei Personen, insbesondere bei Kindern, mit asthmatischer Grunderkrankung besondere Aufmerksamkeit geboten.

\section{Prävention / Impfstoffe}

Die Entwicklung einer Immunprophylaxe ist schwierig, da Schutzimpfungen nur einen zeitlich begrenzten Schutz gegen Viren des gleichen Serotyps bewirken. 
Experimentelle Therapieansätze mit Inhibitoren gegen die virale RNA-Polymerase zeigen ansatzweise eine positive Beeinflussung des klinischen Verlaufs einer Coronavirus-Erkrankung.

Eine wirksame Immunprophylaxe existiert nicht. Natürliche Infektionen mit Coronaviren verleihen einen bedingten Schutz über einen Zeitraum von etwa $1 \mathrm{Jahr}$ gegenüber einer Reinfektion mit dem betreffenden Coronavirus-Serotyp. Prophylaktische intranasale Applikation mit alpha-Interferon führt zu einer Reduzierung der Virusreplikation und einer scheinbaren Verminderung klinischer Symptome, jedoch ist mit allergischen Reaktionen zu rechnen. Der experimentelle Einsatz von Nukleosidanaloga gegen die Replikation, vor allem der neuen Coronaviren, erscheint Erfolg versprechend.

\section{Meldepflicht}

Es besteht keine Meldepflicht bei Verdacht oder gesicherter Diagnose auf Coronavirusinfektion, außer SARS-Coronavirus, $>$ SARS-Coronavirus.

\section{Weiterführende Informationen}

\section{Referenzzentren / Expertenlaboratorien} Keine.

\section{Web-Adressen}

- www.rki.de

\section{Schlüsselliteratur}

1. Antimicrob Agents Chemother 2006, 50(6):2000-2008

2. Lai MMC, PerlmanS, Anderson LJ (2007) Coronaviridae:. In: Knipe DM et al (eds) Fields Virology, 5th edn. Lippincott-Raven Publ, pp 1305-1337

3. Pyrik K, Berchout B, lVan der Hoek L, David Cavanagh (2004) Coronaviruses and Toroviruese in: Zuckerman et al (eds) Principles and Practice of Clinical Virology 5 th edn, pp 375-397

4. White DO, Fenner FJ (eds) (1994) Coronaviridae. In: Medical Virology, Academic Press, San Diego, pp 451-455

\section{Corynebacterium diphtheriae}

Hans-GÜNTHer SonNtag

\section{Erreger}

Synonym(e)

Diphtheriebakterium.

\section{Erregerspezies}

C. diptheriae.

\section{Taxonomie}

Familie Actinomycetales, Gattung (Genus) Corynebacterium

\section{Historie}

Die Darstellung des Krankheitsbildes der Diphtherie findet sich bereits im Corpus Hippocraticum. Auf Epi- demien von „Halskrankheit“ größeren Ausmaßes und in Intervallen von etwa 25 Jahren wird aber erst im 16. Jahrhundert hingewiesen. 1821 beschrieb Bretonneau erstmals die typischen klinischen Merkmale. Klebs wies 1883 in mikroskopischen Präparaten von diphtherischen Membranen neben Kokken in Ketten Stäbchen nach. 1984 isolierte Loeffler das Diphtheriebakterium erstmals in Reinkultur, induzierte damit experimentell in Meerschweinchen eine Diphtherie und bewies damit die Ätiologie der Diphtherie. Roux und Yersin zeigten 1888, dass selbst bakterienfreie Kulturfiltrate für Meerschweinchen tödlich waren und gaben damit den ersten Hinweis auf die Wirkung des Diphtherietoxins, was durch von Behring über den Nachweis des Antiserums gegen das Toxin und dessen Schutzwirkung im Tierversuch gegen die tödlich wirkende Intoxikation eine Bestätigung fand. Roux konnte 1894 durch die therapeutische Applikation von Pferdeimmunserum gegen Diphtherietoxin bei Diphtherieerkrankten die Letalität um $50 \%$ reduzieren. Smith und von Behring gelang die erfolgreiche aktive Immunisierung von Kindern erstmals mit einer Mischung von Toxin und Antitoxin. 1923 wurde von Ramon formalininaktiviertes Toxin („Toxoid“) für die aktive Impfung eingeführt und in der Folge zwischen 1930 bis 1945 in den meisten westlichen Ländern im Rahmen von Impfprogrammen bei Kindern verwendet, was zu einer deutlichen Reduktion der Inzidenz der Diphtherie führte.

\section{Morphologie}

C.-diphtheriae-Bakterien sind - wie praktisch alle anderen Corynebakterien - grampositive, unbewegliche, schlanke Stäbchen, oft leicht gekrümmt und mit keulenförmiger Auftreibung. Auch kurze und kokkoide Formen sind möglich. Charakteristisch ist die V- oder Y-förmige Lagerung. Mit der Färbung nach Neisser stellen sich im Präparat von auf Blutagar oder Loeffler-Serum gezüchteten $C$. diphtheriae in den gelbbraun gefärbten Stäbchen schwarz-blaue Polkörperchen, sogenannte methachromatische Granula dar, die allerdings nicht spezifisch für C. diphtheriae sind.

\section{Genom}

Das Genom von C. diphtheriae ist vollständig sequenziert (http://www.genomesonline.org) Das Diphtherietoxin-Gen ist mittels PCR nachweisbar.

\section{Vermehrung}

C. diphtheriae vermehrt sich auf den Schleimhäuten des oberen Atemtraktes und führt dabei zu lokalen Reaktionen (Pseudomembranen, Schwellungen). Der Erreger ist gut auf Selektivnährmedien anzüchtbar.

\section{Pathogenität, Virulenz, Antigenvariabilität}

C. diphtheriae ist nicht invasiv. Seine Pathogenität beruht auf dem Diphtherietoxin, einem Exotoxin als alleinigem Virulenzfaktor. Die genetische Information 
für die Toxinbildung liegt auf dem Genom eines Bakteriophagen, der sich in die DNA der Wirtszelle integriert. Nur lysogene Stämme haben die Fähigkeit zur Toxinbildung und können sie bei Verlust des Phagen verlieren. Das Diphtherietoxin ist ein sehr potenter Inhibitor der Proteinsynthese in eukaryontischen, nicht aber in prokaryontischen (Bakterien-) Zellen. Zusammen mit einer Induktion der Apoptose führt seine Wirkung zum Zelltod.

\section{Erkrankung}

\section{Diphtherie}

(Die Hautdiphtherie bleibt in der Regel lokalisiert und kommt vor allem in den Tropen, aber auch in westlichen Ländern, insbesondere bei gesellschaftlichen Randgruppen: Obdachlose, Alkoholiker, Drogensüchtige, vor.)

\section{Synonym(e)}

Keine.

\section{Inkubationszeit}

Nach einer Inkubationszeit von 2-5 Tagen erkranken ca. $20 \%$ der nicht immunen infizierten Personen (maximale Variabilität: 1-10 Tage).

\section{Leitsymptome}

Tonsillitis oder Pharyngitis mit Pseudomembranen.

\section{Symptome}

Die klinischen Manifestationen der Diphtherie können lokal begrenzt bleiben, typischerweise in Form von Pseudomembranen im Nasopharyngealraum, laryngeal oder tracheobronchial.

Wesentliche Symptome sind:

- Tonsillitis oder Pharyngitis mit grau-braunen Belägen mit Ausdehnung auf die Uvula und den weichen Gaumen,

- Lymphknoten- und Halsschwellung, verbunden mit einer pseudomembranösen Pharyngitis und Zeichen einer systemischen Toxizität (Blässe, Ödeme, Erbrechen),

- Heiserkeit und Stridor,

- Gaumensegellähmung,

- blutig seröser Nasenausfluss mit Schleimhautbelägen.

\section{Pathophysiologie}

Lokal treten Nekrotisierung, Gefäßdilatation, Ödembildung, Blutungen und Fibrinausscheidung auf. Die dadurch entstehenden Pseudomembranen enthalten Fibrin, Leukozyten, Erythrozyten, abgetötete Epithelzellen und Bakterien. Unter den Membranen ist die Submucosa ödematös geschwollen. Eine toxische Fernwirkung kann die Organe Herz (Myokarditis), Nervensystem (Demyelinisierung) und die Niere (tubuläre Nekrose) betreffen. Die tödliche Dosis des Toxins beträgt $0,1 \mathrm{mg}$ pro Kilogramm Körpergewicht.

\section{Immunantwort}

Eine überstandene Diphtherie hinterlässt in der Regel eine lang anhaltende Immunantwort gegenüber der Intoxikation

\section{Differenzialdiagnose}

Differenzialdiagnostisch kommen andere Erkrankungen des Rachenraumes in Betracht, wie

- Infektiöse Mononukleose: Im Unterschied zur Diphtherie breiten sich die Membranen nicht über die Tonsillen hinaus aus, bleiben hell und bluten nicht.

- Streptokokkenangina: Es werden keine Membranen ausgebildet, der Rachen ist stark gerötet und es besteht hohes Fieber.

- Angina Plaut-Vincenti: meist einseitige, nekrotisierende Angina, die sich mikroskopisch durch den Nachweis von Schraubenbakterien und Fusobakterien abgrenzen lässt.

- Epiglottitis: in der Regel durch Haemophilus hervorgerufen, verläuft sie akuter; die Epiglottis ist hellrot ohne Membranauflagerung.

\section{Diagnostik \\ Untersuchungsmaterial \\ Rachenabstrich.}

\section{Diagnostische Verfahren}

Mikroskopie: Ein Direktnachweis von Corynebakterien aus dem Originalmaterial ist nicht diagnostisch verwertbar, da der Erreger mikroskopisch von anderen apathogenen Corynebakterien nicht abgegrenzt werden kann.

Kultur: Abstrichmaterial wird auf Schafblutagar (optimalerweise mit einem Fosfomycin-Blättchen zwecks Hemmung der Begleitflora), auf Rinderserum-Platten nach Loeffler, dem Cystein und Tellurit enthaltenden Tinsdale-Agar oder auf Clauberg-III-Agar, einem selektiven Medium zur Unterdrückung der Begleitflora, ausgestrichen. Der Clauberg-Agar nutzt die Telluritresistenz von $C$. diphtheriae aus; verdächtig sind die durch Telluriteinlagerung schwarz gefärbten Kolonien, die von einem blauen Hof umgeben sind.

Identifikation: Verdächtige Kolonien (gräuliche Kolonien mit evtl. schwachem Hämolysehof auf Blutplatten, schwarze oder braune Kolonien auf Tellurit haltigen Medien) werden nach Gram gefärbt. Liegen grampositive coryneforme Stäbchen vor, werden Subkulturen auf Blutagar und Loeffler-Serum angelegt. Die biochemische Identifikation erfolgt über die positive Katalasereaktion, die negative Ureasereaktion (im Gegensatz zu C. ulcerans und C. pseudodiphtheriticum), den fermentativen Abbau von Glukose (nicht Saccharose) und die Nitradreduktion. Aufgrund der unterschiedlichen Koloniemorphologie, dem Hämolysevermögen und der Fähigkeit Glykogen und Dextrin abzubauen werden die drei Biovare mitis, intermedius und gravis unterschieden. 
Toxinnachweis: C. diphtheriae hat (von seltenen Fällen bei C. ulcerans und C. pseudotuberculosis abgesehen) die einzigartige Fähigkeit, durch so genannte Lysogenisierung mit einem Phagen das Diphtherietoxin zu produzieren. Der Nachweis der Toxinbildung erfolgt im Präzipitationstest nach Elek. Mit DiphtherieAntitoxin getränkte Filterpapierstreifen werden in den Agar eingelegt und der zu prüfende Stamm aufgeimpft. Das produzierte Toxin diffundiert in den Nährboden und reagiert mit den Antikörpern, was zur Bildung einer weißen Präzipitationslinie führt. Eine weitere Möglichkeit ist der Nachweis des Toxin-Gens mittels PCR.

\section{Befund/Interpretation}

Allein der positive Toxinnachweis ist ausschlaggebend für die Bestätigung einer Diphtherie.

\section{Therapie}

\section{Therapeutische Maßnahmen}

Bei Vorliegen einer klinischen Diphtheriesymptomatik ist der Patient zunächst nach seinem Impfstatus zu befragen. Ist dieser unklar oder liegt definitiv keine Auffrischungsimpfung vor, so muss zur schnellen Eindämmung der Toxinwirkung eine passive Immunisierung, d. h. die Gabe von Diphtherieantitoxin in Form von humanem Diphtherieantiserum erfolgen. Diese ist so früh wie möglich durchzuführen, da nur freies, extrazelluläres, noch nicht von der Zielzelle aufgenommenes Toxin durch Antiserum inaktiviert werden kann. Je nach Schwere des Krankheitsbildes hat eine Therapie mit 500-2000 IE Antitoxin pro kg Körpergewicht $\mathrm{zu}$ erfolgen. Bei Verwendung von tierischem Antiserum muss eine bereits vorliegende Allergisierung durch einen Intrakutantest ausgeschlossen werden.

Erst an zweiter Stelle steht die Gabe von Antibiotika (Penicillin G oder Erythromycin). Bei der LarynxDiphtherie sind unter Umständen nur die rechtzeitige Intubation und die operative Entfernung der verlegenden Membranen lebensrettend.

\section{Resistenz}

Es besteht eine hohe Empfindlichkeit gegenüber Penicillin bzw. Erythromycin, aber auch gegen andere Antibiotika, wie Tetrazykline, Rifampicin und Clindamycin. C. diphtheriae ist relativ resistent gegen Umwelteinflüsse; z. B. gegenüber Austrocknung an Oberflächen und Gegenständen, was für die Erregerübertragung von Bedeutung ist.

\section{Epidemiologie}

\section{Verbreitung}

C. diphtheriae ist der Erreger einer der klassischen Seuchen der Menschheitsgeschichte. Bei einem saisonalen Morbiditätsgipfel im Winter und im Frühjahr trat die Diphtherie mit einer Periodizität alle 30-40
Jahre in seuchenhafter Dimension auf. Während noch zu Anfang des letzten Jahrhunderts vor allem Kinder unter 15 Jahren betroffen waren, sind in neueren Epidemien Erkrankungen bei Erwachsenen vorherrschend. Infektionen durch C. diphtheriae können weltweit beobachtet werden. Die asymptomatischen Träger perpetuieren die endemische wie die epidemische Form der Diphtherie. Die Inzidenz und das Muster des Auftretens der Diphtherie haben sich in den letzten 50-75 Jahren dramatisch verändert. In der östlichen Welt sank sie von 150 auf weit unter 1 Erkrankung pro 100.000 Einwohner pro Jahr. In der Dritten Welt ist zwar ein Rückgang zu beobachten, jedoch ist die Krankheit immer noch endemisch. In Russland und Teilen der früheren Sowjetunion ist in den letzten Jahren ein beunruhigender Anstieg zu verzeichnen gewesen. Raten von bis zu 17 Erkrankungen pro 100.000 Einwohner pro Jahr wurden in Moskau und in Sankt Petersburg verzeichnet, wobei Erwachsene und Kinder gleichermaßen betroffen waren. Die Ursache mag ein unzulänglicher Impfschutz sein.

\section{Wirtsbereich / Reservoir}

Das Erregerreservoir für C. diphtheriae ist ausschließlich der Mensch.

\section{Risikogruppen}

Obwohl die Impfung das Risiko an Diphtherie zu erkranken nicht völlig eliminiert, sind vor allem ungeimpfte Individuen oder solche, bei denen der Impfschutz im Erwachsenenalter nicht aufgefrischt wurde, gefährdet. Circa $50 \%$ der deutschen Bevölkerung weist im Erwachsenenalter einen ungenügenden Impfschutz auf. In westlichen Ländern sind in Armut und schlechten hygienischen Verhältnissen lebende Menschen sozialer Randgruppen (Alkoholiker, Drogensüchtige) gefährdet an Diphtherie zu erkranken. Aber auch Reisende in tropische und subtropische Länder oder Russland oder mit Asylbewerbern in Kontakt kommende Bürger westlicher Länder haben ein erhöhtes Risiko.

\section{Transmission / Vektoren}

C. diphtheriae wird durch Aerosole, die von hustenden Diphtherieerkrankten oder asymptomatischen Trägern ausgestoßen werden oder über die Hände übertragen. Bei der Hautdiphtherie steht die Übertragung durch Schmierinfektion im Vordergrund.

\section{Prävention / Impfstoffe}

Die Prophylaxe gegen Diphtherie besteht in einer aktiven Immunisierung mittels formalinbehandeltem Toxin (Toxoid). Zum Aufbau der Immunität beginnt man im Säuglingsalter (2.-3. Lebensmonat) mit zwei intramuskulären Injektionen im Abstand von vier Wochen, einer Booster-Impfung nach etwa einem Jahr und im 6. Lebensjahr. Alle weitere zehn Jahre wird eine Auffrischimpfung empfohlen. 


\section{Ausbruchmanagement}

Bei Auftreten von Erkrankungen müssen die Infizierten bis zum Nachweis der Elimination von C. diphtheriae isoliert werden. Keimträger werden aufgrund von Umgebungsuntersuchungen identifiziert und saniert.

\section{Meldepflicht}

Nach dem IfSG sind Krankheitsverdacht, Erkrankung und Tod an Diphtherie sowie der direkte und indirekte Nachweis von toxinbildenden C. diphtheriae meldepflichtig.

\section{Weiterführende Informationen}

\section{Referenzzentren/ Expertenlaboratorien}

- Dr. G. Funke, Institut für Medizinische Mikrobiologie der Universität Zürich, Gloriastrasse 32, CH-8028 Zürich

\section{Web-Adressen}

- http://www.astdhpphe.org/infect/dip.html

- http://www.cdc.gov/nip/publications/pink/dip.pdf

- http://www.medicine.com/EMERG/topic138.htm

\section{Schlüsselliteratur}

1. Burkhardt F (Hrsg) (1992) Mikrobiologische Diagnostik. Georg Thieme Verlag, Stuttgart

2. Köhler W, Eggers HJ, Fleischer B, Marre R, Pfister H, Pulverer G (Hrsg) (2001) Medizinische Mikrobiologie. 8. Aufl. Urban und Fischer, München, Jena

3. Mandell G, Douglas RG, Bennett JE. (Hrsg) (1995) Principles and Practice of Infectious Diseases, $4^{\text {th }}$ edn. Churchill Livingstone, New York

4. Murray PR, Baron EJ, Pfaller MA, Tenover FC, Yolken RH (Hrsg) (1995) Manual of Clinical Microbiology, $6^{\text {th }}$ edn. ASM Press, Washington DC

\section{Corynebacterium jeikeium}

- Corynebacterium, sonstige Spezies

\section{Corynebacterium pseudotuberculosis}

Corynebacterium, sonstige Spezies

\section{Corynebacterium, sonstige Spezies}

\section{Erreger}

\section{Synonym(e)}

Actinomyces (Corynebakterium) pyrogenes, Arcanobacterium (Corynebacterium) hämolyticum, Rhodococcus (Corynebacterium) equi, Corynebacterium ovis.

\section{Erregerspezies}

Weltweit sind mehr als 500 verschiedene Corynebacterium-Spezies beschrieben worden, (http://www. ncbi.nlm.nih.gov) von denen hier nur die humanpathogenen berücksichtigt werden sollen.

Corynebacterium amycolatum, C. jeikeium, C. pseudotuberculosis, C. striatum, C. urealyticum, C. xerosis.

\section{Taxonomie}

Familie: Actinomycetales; Gattung: Corynebacterium

\section{Historie}

C. pseudotuberculosis wurde Anfang der 90er Jahre des 19. Jahrhunderts aus den nekrotischen Nieren eines Schafes isoliert und nach seinen Entdeckern PreißNocard-Bazillus genannt. Man weiß seit langem, dass C. pseudotuberculosis bei verschiedenen Tieren (Pferde, Rinder, Ziegen und Wild) käsig-eitrige, granulomatöse Infektionen verursacht. Der Erreger produziert ein dermonekrotisches Toxin, das bereits 1912 gefunden und eingehend untersucht wurde. Eine Infektion beim Menschen wurde erstmals 1966 von Lopez beschrieben. C. ulcerans (lat. ulcerare: geschwürig/ zerfallen) wurde erstmals 1926 von Gilbert und Stewart beschrieben, als sie eine der Diphtherie ähnliche Krankheit untersuchten. Später wurden seine Pathogenität beim Menschen sowie die Fähigkeit, u. a. Diphtherietoxin zu produzieren, nachgewiesen. C. urealyticum wurde erstmals 1972 von King beschrieben. Seit einigen Jahren werden aus der Gruppe coryneformer Mikroorganismen, die als Teil der Hautflora in der Inguinal- und Perinealregion vorkommen, besonders bei hospitalisierten Patienten als Krankheitserreger nachgewiesen.

\section{Morphologie}

Grampositive, kokkoide bis pleomorphe Stäbchen in der Färbung nach Loeffler oder Neisser mit z.T. metachromatischen Granula.

\section{Genom}

Das Genom ist bei den meisten Spezies sequenziert. Weitere Informationen unter http://www.genedb.org. bzw. http://www.genomesonline.org

\section{Vermehrung}

Langsames Wachstum auf Blutagar bzw. auf Selektivnährmedien entsprechend C. diphtherieae

\section{Pathogenität, Virulenz, Antigenvariabilität}

Die meisten Stämme bilden ein dermonekrotisches Toxin (Phospholipase D) und können - unabhängig davon - manchmal auch Diphtherietoxin (C.ulcerans) bilden.

\section{Erkrankungen}

Lymphadenitis, Pneumonie (C. pseudotubercuosis); Endocarditis, Sepsis entsprechend Organmanifestation (C. jeikeium); Rachenentzündung, der Diphtherie ähnliche Erkrankung (C. ulcerans); Alkalische enkrustierende Zystitis (C. urealyticum) 


\section{Synonym(e)}

C. urealyticum: chronisch lokal ulzerierende Zystitis. Sonst nicht bekannt.

\section{Inkubationszeit}

Nicht bekannt.

\section{Leitsymptome}

C. pseudotuberculosis: Granulomatöse Lymphadenitis, eosinophile Pneumonie. Diphtherieähnliche Rachenentzündung.

C. urealyticum: Zystitis, Harnwegsinfektion.

Sonst dem jeweiligen Krankheitsbild entsprechend.

\section{Symptome}

C. pseudotuberculosis kann eitrige, abszedierende Infektionen bei Rind, Pferd, Schaf, Ziege, Wild und sehr selten beim Menschen verursachen. Bisher wurden wenige Fälle mit eitriger granulomatöser Lymphadenitis bzw. von eosinophiler Pneumonie beschrieben.

C. ulcerans verursacht hauptsächlich Mastitiden bei Rindern. Infektionen bei Menschen verlaufen überwiegend als milde, manchmal diphtherieähnliche Rachenentzündung. Schwere diphtherieähnliche Erkrankungen wurden jedoch beschrieben.

C. urealyticum ist beteiligt an der Pathogenese der alkalischen enkrustierenden Zystitis, einer chronischen lokal ulzerierenden Zystitis mit Ablagerungen von Ammonium-Magnesiumphosphat (Struvit), assoziiert mit Harnstoff spaltenden, den Urin alkalisierenden Organismen (z. B. Proteus spp.). In einer vorgeschädigten Blase kann C. urealyticum auch primärer Erreger einer Harnwegsinfektion sein.

Bei älteren oder immungeschwächten Patienten sind Pneumonien, hervorgerufen durch C. urealyticum, wie auch Peritonitiden, Septikämien, Endokarditiden, Osteomyelitiden und Wundinfektionen, beschrieben worden.

C. amycolatum, C. jeikeium, C. striatum und C. xerosis wurden verschiedentlich aus Blut, Liquor und infizierten Wunden von abwehrgeschädigten Patienten sowie bei Endokarditis und nach Herzoperationen isoliert. Sie wurden ebenfalls bei Patienten mit kontinuierlicher ambulanter Peritonealdialyse (CAPD) gefunden (Katheterkontamination als Ursache für Sepsis).

\section{Pathophysiologie}

Nicht bekannt.

\section{Immunantwort}

Bei C.-pseudotuberculosis-Infektionen scheint zumindest bei Schafen die Erkrankung zu einer Immunität $\mathrm{zu}$ führen, zumal diese Tiere möglicherweise durch Impfung gegen die Erkrankung geschützt werden können. Bei C. ulcerans hinterlässt eine Erkrankung eine langjährige Immunität sowohl gegenüber dem dermonekrotischen Toxin wie auch dem Diphtherietoxin. Bei den sonstigen Spezies nicht bekannt.

\section{Differenzialdiagnose}

Bei C. pseudotuberculosis Tuberkulose, abszedierende Infektionen, bedingt durch andere Erreger. Bei den anderen Spezies wegen der geringen Häufigkeit von Erkrankungen im Menschen keine Aussage möglich.

\section{Diagnostik}

\section{Untersuchungsmaterial}

Punktate, Abstriche.

\section{Diagnostische Verfahren}

Mikroskopie: Wegen der Ähnlichkeit zu einer Vielzahl coryneformer Mikroorganismen lässt sich das mikroskopische Präparat aus dem Primärmaterial nicht für eine Differenzialdiagnose verwenden.

Kultur: C. jeikeikum: Langsames Wachstum auf Blutagar ohne Hämolyse bzw. auf Tinsdale-Medium Wachstum ohne schwarz-braunen Hof.

Identifizierung: C. jeikeikum: Glukose wird erst nach mehrtägiger Bebrütung im serumhaltigen Milieu gespalten. Weitere Zucker werden nicht gespalten. Urease-negativ, Nitrat-negativ, Katalase-positiv, Betahämolyse nicht bekannt.

Kultur: C. pseudotuberculosis: Wachstum auf BlutAgar in kleinen, trockenen, gelblichen Kolonien mit meist schwacher Betahämolyse, auf Tinsdale in schwarzen Kolonien, gelegentlich mit braunem Hof, ähnlich C. ulcerans.

Identifikation: C. pseudotuberculosis und C. ulcerans: Katalase-positiv, Urease-positiv, fermentiert Glukose und Maltose. Die Nitratreduktion ist variabel. Wie C. ulcerans - und im Unterschied zu den übrigen Corynebakterien - produziert C. pseudotuberculosis eine Phospholipase D (dermonekrotisches Toxin), zudem zeigt es ein umgekehrtes CAMP-Phänomen. Stärke wird nicht fermentiert.

Kultur: C. ulcerans: Gutes Wachstum auf Loeffler- und Tinsdale-Medien sowie Tellurit-Agar. Auf Blutagar sind die Kolonien etwas größer und opaker als jene von $C$. diphtheriae. Sie haben häufig eine feine Hämolyse-Zone. Auf Tinsdale-Agar sind die von einem bräunlichen Hof umgebenen braun-schwarzen Kolonien nicht von C. diphtheriae zu unterscheiden.

Identifikation: C. ulcerans ist Katalase-positiv und - im Gegensatz zu C. diphtheriae - Urease-positiv, reduziert Nitrat nicht und spaltet Eskulin. Es fermentiert Glukose, Maltose und (langsam) Trehalose.

Kultur: C. urealyticum: Wie C. jeikeium wächst C. urealyticum nur langsam auf Schafblutagar und wird daher bei der üblichen bakteriologischen Urinuntersuchung häufig übersehen. Der CAMP-Test ist negativ. Wegen der Lipophilie kann das Wachstum durch $\mathrm{Zu}-$ satz von $0,1 \%$ Tween 80 oder Serum zum Medium unterstützt werden.

Identifikation: Die Katalse ist positiv, Nitrat wird nicht reduziert. Im Gegensatz zu C. jeikeium wird aus Kohlenhydraten keine Säure produziert. Die Ureasereaktion ist stark positiv. 
Toxinnachweis: Diphtherietoxin wie bei $>$ C. diphtherieae.

\section{Befund / Interpretation}

Alleiniger Keimnachweis bzw. Toxinnachweis relevant für Krankheitsursache.

\section{Therapie}

\section{Therapeutische Maßnahmen}

C. pseudotuberculosis: Antibiotische Therapie mit Erythromycin oder Tetrazyklin sowie chirurgische Intervention.

C. ulcerans: Wenn klinisch eine Diphtherie vorliegt oder die Bildung von Diphtherietoxin nachgewiesen wurde, muss Antitoxin gegeben werden. Der Keim ist gegenüber den meisten Antibiotika sensibel. Aufgrund klinischer Erfahrung scheint Erythromycin das Therapeutikum der Wahl zu sein.

C. urealyticum ist wie C. jeikeium häufig multiresistent, vor allem, wenn es bei hospitalisierten Patienten isoliert wird. Bis zum Vorliegen eines Antibiogramms sollte daher mit Vancomycin bzw. Rifampizin behandelt werden.

\section{Resistenz}

Hohe primäre Antibiotikaresistenz bei C. jeikeium und C. urealyticum. Einzige antibiotische Therapie durch Glykopeptidantibiotika möglich.

\section{Epidemiologie}

\section{Verbreitung}

C. urealyticum ist als Bestandteil der normalen Hautflora zuzuordnen und kann insbesondere auf der Haut hospitalisierter bzw. immungeschwächter Patienten gefunden werden, von wo aus (generalisierte) Infektionen ihren Ausgang nehmen können.

Infektionen, hervorgerufen durch C. pseudotuberculosis sind Zoonosen. Sie kommen typischerweise bei Nutztieren und Wild vor. Infektionen des Menschen sind selten und wurden vor allem in Australien beschrieben.

C. ulcerans ist gewöhnlich ein Kommensale bei Rind, Pferd und beim Menschen. Infektionen des Menschen treten bei uns selten auf. C. ulcerans kann auch aus dem Rachen asymptomatischer Träger isoliert werden, weshalb die klinische Relevanz nicht immer eindeutig ist.

C. urealyticum ist als Bestandteil der normalen Hautflora zuzuordnen und kann insbesondere auf der Haut hospitalisierter bzw. immungeschwächter Patienten gefunden werden, von wo aus (generalisierte) Infektionen ihren Ausgang nehmen können

\section{Wirtsbereich / Reservoir}

Menschliche Hautflora. Infektionen, verursacht durch C. pseudotuberculosis, kommen bei Schafen, Ziegen, Pferden, Rindern, Wild und selten bei Menschen vor. Reservoir für C. ulcerans sind Rind und Pferd. Das
Vorkommen des Keimes beim Menschen, z. B. bei asymptomatischen Trägern ist äußerst selten.

C. urealyticum kann beim Menschen, aber auch beim Tier (enkrustierende Zystitis beim Hund) gefunden werden. Auch bei Tieren gehört er wohl zum Bestandteil der normalen Hautflora.

\section{Risikogruppen}

C. pseudotuberculosis: In der Landwirtschaft tätige Menschen, Metzger, Jäger, die mit erkrankten Tieren, Schlachtabfällen oder Tierhäuten in Berührung kommen oder frische Milch erkrankter Tiere trinken.

Ländliche Bevölkerungen mit Kontakt zu Vieh,v. a. bei fehlender Immunität gegen das Diphtherietoxin.

Als Risikogruppen für C. urealyticum und C. jeikeium sind hospitalisierte, immungeschwächte, vorwiegend ältere Patienten anzusehen, bei denen die natürlichen Schutzfunktionen von Haut und Schleimhäuten z. B. durch Katheter durchbrochen sind. Die Gefahr für Harnwegsinfektionen ist auch nach Nierentransplantation, nach urologischen Eingriffen und bei Anwendung von (Dauer-)Kathetern erhöht.

\section{Transmission / Vektoren}

C. pseudotuberculosis: Die Übertragung der Krankheit erfolgt unter Tieren, wahrscheinlich durch ihre Ausscheidungen, während Menschen durch direkte Berührung erkrankter Tiere oder von Teilen davon (Schlachtabfälle, Tierhäute, Genuss roher Milch) angesteckt werden.

Infektionen bei Menschen mit C. ulcerans, meist Pharyngitiden, sind Anthropozoonosen. Die Übertragung erfolgt gewöhnlich vom Rind über kontaminierte Milch auf den Menschen. Eine Übertragung von Mensch zu Mensch ist bisher nicht beschrieben worden.

Bei C. urealyticum wie bei C. jeikeium wird angenommen, dass hospitalisierte Patienten vermehrt von Keimen besiedelt werden, die durch eine über längere Zeit andauernde Antibiotikatherapie aufgrund ihrer Resistenzeigenschaften selektiert worden sind. Mögliche Besiedlung von Katheter- oder anderen Plastikmaterialien als Ausgangspunkt für eine Infektion.

\section{Prävention / Impfstoffe}

Häufiger Katheterwechsel bei immunsupprimierten und abwehrgeschädigten sowie CAPD-Patienten. Bei C. urealyticum sind neben üblichen krankenhaushygienischen Maßnahmen keine spezifischen bekannt. Aktive Immunisierung gegen das Diphtherietoxin bietet gleichsam Schutz gegen Intoxikationen verursacht durch C. ulcerans. Möglicherweise können Tiere (Schafe) durch Impfung mit entsprechenden Toxoiden gegen die Erkrankung geschützt werden. Genuss von ausschließlich pasteurisierter, gekochter Milch.

\section{Ausbruchmanagement}

Wegen Einzelerkrankungen nicht erforderlich. 


\section{Meldepflicht}

Nur bei Diphtherietoxinnachweis, sonst keine Meldepflicht.

\section{Weiterführende Informationen}

\section{Referenzzentren, Expertenlaboratorien}

- Dr. G. Funke, Institut für Medizinische Mikrobiologie, Universität Zürich, Gloriastrasse 32, CH-8028 Zürich

\section{Web-Adressen}

- http://www.astdhpphe.org/infect/dip.html

- http://www.cdc.gov/nip/publications/pink/dip.pdf

- http://www.emedicine.com/EMERG/topic138.htm

- http://www.nfid.org/factsheets/diphtadult.html

\section{Schlüsselliteratur}

1. Burkhardt F (Hrsg) (1992) Mikrobiologische Diagnostik. Georg Thieme Verlag, Stuttgart

2. Köhler W, Eggers HJ, Fleischer B, Marre R, Pfister H, Pulverer G (Hrsg) (2001) Medizinische Mikrobiologie. 8. Aufl. Urban und Fischer, München, Jena

3. Mandell GL, Douglas RG, Bennett JE (Hrsg) (1995) Principles and Practice of Infectious Diseases, $4^{\text {th }}$ edn. Churchill Livingstone, New York

4. Murray PR, Baron EJ, Pfaller MA, Tenover FC, Yolken RH (Hrsg) (1995) Manual of Clinical Microbiology, $6^{\text {th }}$ edn. ASM Press Washington DC

\section{Corynebacterium ulcerans}

- Corynebacterium, sonstige Spezies

\section{Corynebacterium urealyticum (CDC-Gruppe D2)}

- Corynebacterium, sonstige Spezies

\section{Corynespora cassiicola}

- Eumyzetom (Madurella mycetomatis u.v.a.)

\section{Coxiellen}

\section{Erreger}

\section{Erregerspezies}

Coxiella spp.

\section{Taxonomie}

Divisio: Proteobacteria; Klasse: Gammaproteobacteria, Ordnung: Legionellales; Familie: Coxiellaceae

\section{Historie}

Edward Holbrook Derrick beschrieb 1937 bei Schlachthausarbeitern in Brisbane, Queensland, Australien den Ausbruch einer unbekannten Krankheit.
Augrund der bis dato ungeklärten (fraglich $=$ „query“) Krankheitsursache nannte er die Erkrankung Q-Fieber. Der australische Arzt Frank Macfarlane Burnet isolierte 1937 aus den Patienten ein Bakterium, das zunächst der Rickettsien-Spezies zugeordnet wurde. Nachdem 1938 H. R. Cox und Davis den selben Erreger aus Zecken in Montana, USA isoliert und den Übertragungsweg beschrieben hatten, wurde der Erreger „Coxiella burnetii“ genannt. Seit Kurzem gehört Coxiella burnetii nicht mehr zu den Rickettsien.

\section{Morphologie}

C. burnetii ist ein gramnegatives Bakterium, dessen Erscheinungsbild von kokkoid bis zur kurzen Stäbchenform variieren kann. Die Länge beträgt ca. 0,2$0,3 \mu \mathrm{m}$. Die obligat intrazellulär lebenden Coxiellen treten in 2 Formen auf: einer kleinen, sporenähnlichen Form, die eine hohe Resistenz gegenüber Umwelteinflüssen besitzt, und einer größeren, vegetativen Form.

\section{Genom}

Molekularbiologische Analysen zur Phylogenetik von C. burnetii führten zu der systematischen Zuordnung $\mathrm{zu}$ den Legionellen und nicht mehr zu den Rickettsien.

Coxiella burnetii RSA 493, complete genome; DNA; circular; Length: 1,995,281 nt: NC_002971

Coxiella burnetii CbuK_Q154, complete genome, DNA; circular; Length: 2,063,100 nt NC_011528

Coxiella burnetii CbuG_Q212, complete genome, DNA; circular; Length: 2,008,870 nt NC_011527

Coxiella burnetii Dugway 5J108-111, complete genome, DNA; circular; Length: 2,158,758 nt, NC_009727

\section{Vermehrung}

C. burnetii lebt obligat intrazellulär und infiziert sowohl Säugetiere als auch Arthropoden. Zecken infizieren sich durch Blutsaugen an einem infizierten Säugetier. C. burnetii kann durch transovarielle und transtadiale Übertragung über Jahre in einer Zeckenpopulation fortbestehen.

\section{Pathogenität / Virulenz / Antigenvariabilität}

In Abhängigkeit von den Umweltfaktoren zeigt C. burnetii eine Antigenphasen-Variation. Der Erreger des Q-Fiebers besitzt auf der Zelloberfläche zwei Hauptantigene (Lipopolysaccharide) - das Phase 1-Antigen und das Phase-2-Antigen.

Lipopolysaccharid (LPS)-Moleküle der Phase 1 schützt vor Lyse in den Phagolysosomen der Makrophagen. Die Bakterien sind getarnt und somit dem Immunsystem nicht oder nur unzureichend zugänglich. Kommt vor bei

- niedrigen Passagezahlen in der Kultur (unter 10),

- chronischen Coxiella-Infektionen.

LPS-Moleküle der Phase 2 sind immunogener als Phase-1-Antigene und kommen vor

- nach hohen Passagezahlen in der Kultur, 
- bei akuter und chronischer Q-Fieber-Erkrankung (zunächst IgM- und später auch IgG-Antikörper).

Die Antigenphasen-Variation ist reversibel. Durch Passagen im Tier verändern sich die avirulenteren Phase 2-Coxiellen wieder zum virulenteren Phase-ITyp. Die Virulenz scheint daher abhängig vom Wirtstyp zu sein.

\section{Erkrankung \\ Q-Fieber}

\section{Synonym(e)}

Queensland-Fieber oder Query-Fieber (daher: Q-Fieber), Balkan-Grippe, Euboea-Fieber, Kretafieber, Krim-Fieber, Pneumorickettsiose, Schlachthausfieber, Siebentagefieber, Wüstenfieber.

\section{Inkubationszeit}

2-4 Wochen.

\section{Leitsymptome}

Fieber, grippeähnliche Beschwerden, atypische Pneumonie, Hepatitis.

\section{Symptome}

Generell verlaufen viele Q-Fieber-Infektionen, möglicherweise bis zu $50 \%$, asymptomatisch bzw. subklinisch. In einigen Fällen sind die Folgen einer Infektion weniger harmlos: Die Infektion beginnt durch die Inhalation des Erregers C. burnetii in der Lunge. Nach der Inkubationszeit von ca. 30 Tagen kann es zu einer atypischen Pneumonie kommen, die mit hohem Fieber und heftigen retroorbitalen Kopfschmerzen einhergeht. Seltener tritt eine Hepatitis auf. Ein Großteil der Infektionen äußert sich jedoch in Form eines grippalen Infekts und endet selbstlimitierend nach 1-2 Wochen. In seltenen Fällen ( $\leq 1 \%)$ kann es aber auch $\mathrm{zu}$ einer persistierenden Infektion kommen, die über Jahre hinweg zu wiederholten Erkrankungsausbrüchen führen (chronisches Q-Fieber). Bei chronischen Verläufen kommt es in erster Linie zur Endokarditis. Eine akute Infektion in der Schwangerschaft bzw. die Reaktivierung persistierender Erreger kann für schwangere Frauen und deren Leibesfrucht eine Gefahr darstellen. Coxiellen können sich in der Plazenta vermehren und den Feten infizieren. Zwar verläuft die Infektion bei etwa der Hälfte der Fälle asymptomatisch; bei einer symptomatischen Infektion kann es jedoch zur Frühgeburtlichkeit oder Abort kommen. Bei der Geburt eines infizierten Kindes muss die Infektionsgefahr im Kreißsaal und in der Umgebung beachtet und das pflegerische und ärztliche Personal rechtzeitig über Schutzmaßnahmen informiert werden. Diese umfassen u. a. bedingt durch die ausgeprägte Resistenz des Erregers gegenüber Umwelteinflüssen insbesondere individuelle Schutzmaßnahmen (Mund-Nasen-Schutz, Handschuhe), die gesonderte Behandlung der Wäsche als "Infektionswäsche“ und lückenlose Desinfektionsmaßnahmen. In Holland startete März 2010 eine große prospektive Studie zur relevanz eines Q-Fieber-Antikörper- Screenings in Schwangeren aus Hochrisikogebieten.

\section{Pathophysiologie}

C. burnetii werden von Makrophagen aufgenommen und vermehren sich zunächst in den Phagolysosomen.

\section{Immunantwort}

Antikörper nachweisbar ca. 14 Tage nach Krankheitsbeginn.

\section{Differentialdiagnose}

Chlamydien-Infektionen, Viruspneumonien, Mykoplasmenpneumonie, Legionellose, Leptospirose.

\section{Diagnostik}

\section{Untersuchungsmaterial}

2 Serumproben im Abstand von 2-3 Wochen, EDTABlut, Knochenmark, Biopsiematerial (Herzklappe, Lymphknoten, Haut), Plazenta.

\section{Diagnostische Verfahren}

Erregerisolierung: kulturell (z. B. in Zellkultur, Brutei); Nukleinsäurenachweis. (Die PCR ist jedoch nur in der frühen Phase der Infektion positiv.)

Serologischer Nachweis: IgG- und IgM-Antikörpernachweis gegen Phase-2-Antigene bei akuter Infektion (z. B. IFT, ELISA, MIF; deutliche Änderung zwischen zwei Proben oder einmaliger deutlich erhöhter Wert), zusätzliche positiver IgG/IgA -Antikörpernachweis gegen Phase-1-Antigene bei chronischer QFieber-Erkrankung.

\section{Befund / Interpretation}

Serologischer Nachweis: Bei einer akuten Q-FieberInfektion werden (fast) ausschließlich Phase-2-Antikörper gebildet. Beginnende oder bestehende chronische Infektionen sind durch hohe Anti-Phase-2-Antikörpertiter und erhöhte Anti-Phase-1-Antikörper charakterisiert.

Phase I/II-IgG neg und IgM neg: Bisher kein auffälliger serologischer Befund. Falls kürzlicher Krankheitsbeginn, sollte zur Verlaufskontrolle eine weitere Blutprobe untersucht werden.

IgM-Antikörper isoliert positiv: Verdacht auf akute Infektion, weitere Blutprobe zur Verlaufskontrolle untersuchen.

Phase 1-IgG pos/IgM pos: chronische Infektion, Verlaufskontrolle sollte durchgeführt werden.

Phase 2-IgG pos/IgM (schwach)pos: (kürzliche) akute Infektion, Verlaufskontrolle sollte durchgeführt werden.

Erregernachweis: Positiver Befund mittels PCR bestätigt den Verdacht auf Q-Fieber. 


\section{Therapie}

\section{Therapeutische Maßnahmen}

Mittel der Wahl ist die Gabe von Doxycyclin über einen Zeitraum von 2-3 Wochen. Bei Risikopersonen gilt bei akuter Infektion mit C. burnetii folgende Empfehlung: Patienten mit Herzklappenanomalien sollten für die Dauer von 12 Monaten $200 \mathrm{mg} / \mathrm{Tag}$ Doxycyclin und $600 \mathrm{mg} / \mathrm{Tag}$ Hydroxichloroquin erhalten. Bei Schwangeren sollte bis zur Entbindung täglich mit 160/800 mg Trimethoprim-Sulfamethoxazol therapiert werden. Postpartal sollten die Frauen auf eine chronische Infektion getestet werden. Bei Vorliegen einer solchen erfolgt für $1 \mathrm{Jahr}$ eine Behandlung mit Doxycyclin und Hydroxychloroquin. Mütter mit akutem Q-Fieber in der Schwangerschaft sollten nicht stillen, da C. burnetii mit der Muttermilch übertragen werden könnte.

\section{Resistenz}

C. burnetii weist eine hohe Tenazität auf. Durch die hohe Resistenz der sporenähnlichen Form gegen Austrocknung kann die Infektiosität des Erregers bis zu 2 Jahre lang in kontaminiertem Staub, in Heu, Wolle usw. erhalten bleiben.

\section{Epidemiologie}

\section{Verbreitung}

Das Q-Fieber kommt - mit Ausnahme von Neuseeland - weltweit vor. In Deutschland haben seit 1995 die Erkrankungen zugenommen. Im Frühsommer 2003 gab es im westfälischen Landkreis Soest eine Kleinepidemie mit 299 Erkrankungen und im Sommer 2005 in Jena mit ca. 300 Erkrankungen. Während der Q-Fieberausbruch im Kreis Soest durch die Geburt zweier Lämmer auf einem Bauernmarkt verursacht wurde, war die Ursache in Jena eine Wanderschafherde, die direkt neben einem Wohngebiet weidete. Im Umkreis von 50 Metern kam es durch einen starken Wind zu einer Übertragung und einer daraus folgenden Infektion von 12 \% der Bewohner; ca. 22 der an Q-Fieber erkrankten Patienten mussten stationär wegen einer atypischen Pneumonie behandelt werden. Seit 2007 kommt es im Süden der Niederlanden immer wieder zu Q-Fieber-Ausbrüchen. Allein im Jahre 2008 wurden 1000 Q-Fieber-Fälle registriert. Ursache für die exponentielle Zunahme ist die dichte Besiedelung bei gleichzeitig intensiver landwirtschaftlicher Nutzung, in diesem Falle die Haltung von Milchziegen für Ziegenkäseherstellung.

\section{Wirtsbereich / Reservoir}

Q-Fieber ist eine Zoonose mit einem ausnehmend großen Wirtsspektrum. Wirtstiere sind Nager, Wild, Vögel; die meisten Haustiere (Rinder, Ziegen, Schafe) und der Mensch dienen dem hochkontagiösen Erreger C. burnetii als Reservoir. Die symptomlos erkrankten Tiere scheiden die Erreger in großen Mengen in
Kot, Urin, Milch und anderen Exkreten (PlazentaMaterial) aus. Als Vektoren fungieren Zecken, von denen experimentell mehr als 50 Arten infiziert werden konnten.

\section{Risikogruppen}

Potenziell gefährdend sind alle Tätigkeiten, die den Umgang mit Schafen oder Rindern bedingen: Tierhalter, Schlachter, veterinärmedizinisches Personal, Laborpersonal.

\section{Transmission / Vektoren}

Da C. burnetii äußerst resistent gegen Austrocknung ist, erfolgt die Übertragung meist aerogen. Ein direkter Kontakt des Menschen zu Tieren ist daher nicht nötig. Die Übertragung von Mensch zu Mensch kommt eher selten vor.

\section{Prävention / Impfstoffe}

Kontrolle der Nutztierbestände; Verarbeiten der tierischen Produkte unter hygienisch adäquaten Bedingungen; Pasteurisieren von Milchprodukten. In Australien und Holland werden Nutztierbestände geimpft. In einigen Ländern steht beruflich exponierten Personen eine Impfung zur Verfügung, ist aber in Deutschland nicht zugelassen.

\section{Ausbruchsmanagement}

Mit Ausbrüchen ist auf Höfen mit Tierhaltung, insbesondere Schafherden, zu rechnen. Durch konsequentes Einhalten der Hygiene- und Verhaltensregeln - so sollten Schafherden weder zum Weiden noch zum Ablammen näher als $500 \mathrm{~m}$ an ein Wohngebiet kommen - kann die Zahl der Erkrankungen reduziert werden.

\section{Meldepflicht}

Gemäß $₫ 7$ Abs. 1 Nr. 9 IfSG ist der direkte oder indirekte Nachweis von C. burnetii, soweit er auf eine akute Infektion hinweist, meldepflichtig. Für den Arzt beteht nach $\$ 6$ IfSG die Meldpflicht für Krankheitsverdacht, Erkrankung und Tod.

\section{Weiterführende Informationen}

\section{Referenzzentren / Expertenlaboratorien}

- Konsiliarlaboratorium für Coxiella burnetii, Landesgesundheitsmat Baden-Württemberg, Wiederholdstrasse 15, 70174 Stuttgart, Frau PD Dr. S. Fischer, Frau Dr. C. Wagner-Wiening, Tel.: 0711 904-39 301 oder -39 304, Fax: 0711 904-38 326

\section{Web-Adressen}

- Robert-Koch-Institut: http://www.rki.de

- Eurosurveillance www.eurosurveillance.org

- Centers for disease control and prevention http://www. cdc.gov

- WHO World Health Organization: http://www.who.int

- National center for biotechnology information: http:// www.ncbi.nlm.nih.gov

- International society for infectious disease: http://www. promedmail.org 


\section{Schlüsselliteratur}

1. Hamm H (2004) Q-Fieber: Eine seltene Infektionskrankheit mit variabler Klinik, Pneumologie 58:285-286

2. RKI-Ratgeber Infektionskrankheiten - Merkblätter für Ärzte: Q-Fieber, aktualisierte Fassung vom Juli 2009; Erstveröffentlichung im Epidemiologischen Bulletin $37 / 2002$

3. Schimmer B. [2009] Sustained intewnsive transmission of Q fever in the south of the Netherlands, 2009. Eurosurveillance 14 (19):1-3

\section{Coxsackieviren}

Hans-Peter Grunert, Heinz Zeichhardt

\section{Erreger}

\section{Synonym(e)}

Humanes Coxsackievirus A1-A22 und A24, Humanes Coxsackievirus B1-B6.

\section{Erregerspezies}

Humanes Enterovirus A (Coxsackievirus A2-A8, A10, A12, A14 und A16), Humanes Enterovirus B (Coxsackievirus B1-B6 und A9), Humanes Enterovirus C (Coxsackievirus A1, A11, A13, A17, A19-A21 und A24).

\section{Taxonomie}

Genus Enterovirus in der Familie der Picornaviridae mit den weiteren Genera: Rhinovirus, Cardiovirus, Aphthovirus, Hepatovirus, Parechovirus, Erbovirus, Kobuvirus und Teschovirus. Für eine kurze Übersicht zu Infektionen des Menschen durch Aphthoviren (Maulund Klauenseuche-Virus) und Kobuviren (Aichivirus) siehe $>$ Enterovirus 68-71 und andere Enteroviren. Historisch wurden Coxsackieviren $(\mathrm{CV})$ u. a. wegen ihrer Krankheitsbilder von den übrigen Enteroviren abgegrenzt ( $\downarrow$ Historie). CVA15, CVA18 und CVA23 sind keine eigenen Typen mehr: CVA15 und CVA18 sind gleich und entsprechen CVA11; CVA23 ist Echovirus 9. Mit dem Eighth Report of the International Committee on Taxonomy of Viruses (2005) wurden die Coxsackieviren der Gruppen A und B basierend auf den Aminosäure-Identitäten in den Regionen P1 sowie $2 \mathrm{C}$ und 3CD (jeweils $>70 \%$ ) den Spezies Humanes Enterovirus A-C zugeordnet (Pallansch and Roos, 2007) ( Erregerspezies).

Coxsackieviren werden häufig wie Echoviren auch als Nicht-Polio-Enteroviren bezeichnet.

Coxsackieviren der Gruppen A und B wurden früher durch experimentelle Infektionen in neugeborenen Mäusen unterschieden. Coxsackieviren der Gruppe A: typischerweise generalisierte Myositis mit Lähmung; selten Veränderungen im ZNS. Coxsackieviren der Gruppe B: typischerweise Befall des ZNS mit Enzephalitis und Infektionen des Herzens, des Pankreas und des braunen Fetts; Myositis häufig herdförmig. picorna: von pico = piccolo, klein; $r n a=$ RNA, ribonucleic acid. entero: von griech. enteron $=$ Darm, Eingeweide. Coxsackie: Ort im Staat New York, USA.

\section{Historie}

Coxsackieviren wurden erstmalig von Dalldorf und Sickles (1948) aus dem Stuhl von zwei Kindern mit einem poliomyelitisähnlichen Krankheitsbild isoliert. Das Virus, anzüchtbar in neugeborenen Mäusen, war jedoch durch poliovirusspezifische Patientenseren nicht zu neutralisieren (Benennung des neuen Virus nach Ort der Erstisolierung: Coxsackie (N.Y., USA); erstes Virus der Gruppe A). Das erste Coxsackievirus der Gruppe B wurde 1949 von Melnick und Mitarbeitern isoliert. Weiteres $>$ Erkrankungen/Symptome.

\section{Morphologie}

Humane Coxsackieviren sind wie alle anderen Picornaviren kleine, sphärische und unbehüllte RNA-Viren (Durchmesser $30 \mathrm{~nm}, 156 \mathrm{~S}$, Dichte 1,34 g/ml in CsCl). Das Viruskapsid mit seinen vier nichtglykosylierten Viruskapsidproteinen VP1-VP4 umgibt ein Molekül der genomischen Plus-Strang-RNA (einzelsträngig), die auch als mRNA dient. Coxsackieviren ähneln in Struktur, Genomorganisation, physikochemischen Eigenschaften und Empfindlichkeit gegen Inavktivierungsmaßnahmen stark den Polioviren sowie den anderen Enteroviren ( $\triangleright$ Polioviren).

\section{Genom}

Die Genomorganisation der einzelsträngigen PlusStrang-RNA von Humanen Coxsackieviren gleicht im Wesentlichen der von anderen Enteroviren ( $\triangleright$ Polioviren). Abweichungen können für die Länge der genomischen RNA (z. B. 7.395 Nukleotide für CVB3) und die Molekulargewichte der einzelnen Virusproteine auftreten. Für Nukleinsäuresequenzen von einzelnen Enteroviren siehe GenBank, National Institute of Health: http://www.ncbi.nlm.nih.gov/sites/entrez? $\mathrm{db}=$ nucleotide; Picornavirus Study Group: http://www.picornastudygroup.com/.

\section{Vermehrung}

Coxsackieviren vermehren sich in den Epithelien und lymphoiden Organen des Rachens und Darms und in allen Organen, in denen die Infektion zu Krankheitszeichen führt ( $\triangleright$ Erkrankungen/Symptome). Es wird davon ausgegangen, dass das Virus über eine Virämie zum Erfolgsorgan (z. B. ZNS) transportiert wird ( $\triangleright$ Polioviren).

\section{Pathogenität / Virulenz / Antigenvariabilität}

Der Pathogenitätsmechanismus ist wie bei den Polioviren und den anderen Enteroviren vor allem durch den Zelltropismus über die Interaktion mit spezifischen Rezeptoren auf empfänglichen Zellen bedingt. Bekannte Rezeptoren sind: Intercellular Adhesion Molecule-1 (ICAM-1, CD54, Immunglobulin-Superfamilie) für CVA13 und CVA21; die Integrine av $\beta 3$ 
(Vitronectin) sowie avß6 für CVA9; Decay Accelerating Factor (DAF, CD55) für CVA21, CVB1, CVB3 und CVB5; Coxsackievirus-Adenovirus-Rezeptor (CAR) für CVB1-CVB6. Zusätzlich wurden verschiedene Integrine und immunglobulinähnliche Moleküle als Corezeptoren postuliert. Einige der Rezeptoren werden auch von humanen Rhinoviren und Echoviren benutzt. Die wesentlichen Schritte des viralen Reproduktionszyklus zeigen Übereinstimmung mit dem Vermehrungsmechanismus von Polioviren. Weiteres $\checkmark$ Polioviren.

\section{Erkrankungen}

\section{Inkubationszeit}

Die mittlere Inkubationszeit beträgt 7-14 Tage (2-35 Tage).

\section{Leitsymptome}

- Tab. 1

\section{Symptome}

Coxsackieviren verursachen wie alle anderen Enteroviren überwiegend asymptomatische Infektionen (90$95 \%$ ) unter Ausbildung von neutralisierenden Antikörpern (stille Feiung). Nach der Vermehrung im Intestinaltrakt kann das Virus durch die abführenden Lymphbahnen in den Blutkreislauf gelangen und zu einer zyklischen Infektion mit Virämie sowie Ausbreitung auf die Zielorgane führen. Im Vergleich zu Polioviren haben Coxsackieviren einen verminderten $\mathrm{Neu}-$ rotropismus, zeigen jedoch ein breiteres Krankheitsspektrum. Coxsackieviren können neben dem Verdauungstrakt, die Meningen, das ZNS (u. a. Befall der motorischen Vorderhornzellen und verschiedener Hirnzentren), das Myokard und Perikard, die quergestreifte Muskulatur, den Respirationstrakt und die Haut infizieren. Paralysen sind im Allgemeinen seltener und weniger stark ausgeprägt als nach PoliovirusInfektionen. Coxsackieviren sind meistens stärker pathogen als Echoviren. Charakteristische pathologische Veränderungen bestehen in fokalen Nekrosen, einhergehend mit Infiltrationen von Lymphozyten und polymorphkernigen Leukozyten. Läsionen sind häufig im Herzen und auch in Gehirn, Rückenmark, Leber, Niere und Nebenniere zu finden. Tab. 1 zeigt die Virustypen, die unter den Coxsackieviren Hauptverursacher der folgenden klinischen Syndrome sind (einzelne Viren können mehrere Syndrome gleichzeitig verursachen):

Meningitis und Paralyse. Mit nahezu allen Coxsackieviren der Gruppen A und B können Infektionen mit Meningitis und (seltener) Parese bzw. Paralyse auftreten (poliomyelitisähnlich, im Allgemeinen jedoch mit besserer Prognose). Schwere Paralyse kann durch CVA7 und CVA9 sowie CVB2-CVB5 hervorgerufen werden. Ein Ausbruch mit CVB5-bedingter Meningitis (> 220 erkrankte Personen) trat 1996 auf Zypern auf.
Tab. 1. Klinische Syndrome der Coxsackievirus-Infektionen (nach Melnick, 1996; Pallansch and Roos, 2007).

\begin{tabular}{|l|l} 
Klinische Syndrome & $\begin{array}{l}\text { Coxsackievirus } \\
\text { A-Typen }\end{array}$
\end{tabular}

Herpangina (vesikuläre Pha-

$2,3,4,5,6,8,10$ ryngitis)

Akute lymphatische Pharyngitis

10

(Lymphknotenbeteiligung)

Aseptische Meningitis

$2,4,7,9,10$

Paralyse (selten)

7,9

Myokarditis, Perikarditis

$4,14,16$

Exantheme

$4,5,6,9,16$

Hand-, Fuß- und Mundkrankheit

$5,10,16$

Pneumonitis bei Kindern

9,16

Common Cold und Sommer-

21,24

grippe

Hepatitis

4,9

Diabetes

9

Diarrhoe (vor allem bei Kindern)

$18,20,21,22,24$

Akute hämorrhagische Kon24

junktivitis

Uncharakteristische fieberhafte

Erkrankung

Klinische Syndrome

verschiedene Typen

Coxsackievirus B-Typen

Pleurodynie

$1,2,3,4,5$

Bornholm-Krankheit (epidemische Pleurodynie oder akute epidemische Myalgie)

Aseptische Meningitis

$1,2,3,4,5,6$

Paralyse (selten)

Schwere systemische Infektion bei Kindern, Meningoenzephalitis und Myokarditis

Myokarditis, Perikarditis

$1,2,3,4,5$

Infektionen des oberen Respira-

4,5 tionstraktes und Pneumonie

Exanthem

$2,3,4,5$

$1,2,3,4,5$

Hepatitis

5

Pankreatitis

5

Diabetes

1,2

Uncharakteristische fieberhafte

Erkrankung
$1,2,3,4,5$

$1,2,3,4,5,6$ 
Pleurodynie (epidemische Myalgie, BornholmKrankheit). Pleurodynie wird hauptsächlich durch CVB1-CVB5 ausgelöst. Rasch ansteigendes Fieber, Myalgie und stechende Schmerzen im Thorax (Teufelsgriff) und Bauchbereich (besonders beim Einatmen) sind charakteristisch (häufig generalisierte Muskelhypotonie meist bei Kindern und Jugendlichen). Die Epidemien auf der Insel Bornholm (1930-1932) führten zum Namen „Bornholm-Krankheit“ für die epidemische Pleurodynie oder Myalgie (Epidemien meist im Spätsommer und Frühherbst).

Herpangina. Herpangina wird vor allem durch CVA2-A6, A8 und A10 hervorgerufen (häufig bei Kleinkindern mit plötzlichem Fieber, Schluckbeschwerden, Erbrechen und abdominalen Beschwerden). Typisch sind stecknadel- bis linsengroße Bläschen (vorderer Gaumenbogen, Uvula, Tonsillen und manchmal Pharynx, weicher Gaumen und Zunge). Eine lymphatische Pharyngitis kann durch CVA10 verursacht werden.

Hand-, Fuß- und Mundkrankheit. Vor allem CVA5, A10 und A16 rufen die Hand-, Fuß- und Mundkrankheit hervor (vesikuläres Exanthem an Händen und Füßen). Neben einer Herpangina können auf der Mundschleimhaut generalisierte vesikulo-ulzerierende Läsionen auftreten.

Infektionen des Respirationstraktes und uncharakteristische fieberhafte Erkrankung. Verschiedene Typen der Coxsackieviren A und B führen zu Infektionen mit schwachen Krankheitszeichen im oberen und unteren Respirationstrakt (selten fatale Pneumonien). Häufig werden uncharakteristische fieberhafte Erkrankungen u. a. mit schnupfenähnlichem Bild (Common Cold) im Sommer durch Coxsackieviren hervorgerufen (Sommergrippe). Influenzaähnliche Zeichen können nach Infektion mit Swine Vesicular Disease Virus (verwandt mit CVB5) auftreten.

Konjunktivitis. Konjunktivitis kann durch CVA24 verursacht werden (im Allgemeinen lokale Infektion mit vorübergehender epithelialer Keratitis). 19691971 führte eine Variante von CVA24 zu einer Epidemie von akuter hämorrhagischer Konjunktivitis vor allem in Singapur und Hongkong. Nach Ausbreitung in Südostasien trat die akute hämorrhagische Konjunktivitis 1986 erstmals außerhalb von Asien in Amerikanisch-Samoa auf (47 \% der Population infiziert). Akute hämorrhagische Konjunktivitis kann auch durch Enterovirus 70 bedingt sein ( $\triangle$ Enteroviren 68-71 und andere Enteroviren).

Myokarditis und Perikarditis. Vor allem Infektionen mit Coxsackieviren der Gruppe B können zu Myokarditis, Perikarditis oder dilatativer Kardiomyopathie führen, jedoch sind auch Fälle beschrieben, in denen Coxsackieviren der Gruppe A (z. B. CVA4, A14, A16) oder Echoviren beteiligt waren $(\triangleright$ Echoviren und $\mathrm{Pa}$ rechoviren). Coxsackieviren können im Myokard, Endokard und in der Perikard-Flüssigkeit nachgewiesen werden. Das Myokard zeigt Ödeme, diffuse fokale Ne- krosen und Zeichen einer akuten Entzündung. Gelegentlich kommt es zu Meningismus und Konvulsionen. Für Säuglinge hat die Myokarditis in etwa 50 \% der Fälle einen letalen Ausgang. Die Perikarditis tritt überwiegend bei älteren Kindern und jungen Erwachsenen auf und zeigt einen günstigeren Verlauf. Begleitend können Pleuritis oder Pleuro-Pneumonie auftreten.

Chronisch kardiovaskuläre Erkrankung. Es können chronische Coxsackievirus-Infektionen (vor allem CVB2-B5) mit rekurrenter Perikarditis auftreten, wobei persistierende virusspezifische IgM-Titer nachgewiesen werden. Fibroblasten im Myokard gelten als Ort der RNA-Persistenz von Coxsackie-B-Viren. Eine Störung der angeborenen Immunität wird als Ursache chronisch kardiovaskulärer Erkrankungen diskutiert ( $\triangleright$ Immunantwort).

Neonatale Erkrankungen. Gefährdet sind Neugeborene unter anderem durch nosokomiale Coxsackievirus-Infektionen, die zu einer generalisierten Erkrankung führen können (vor allem Gruppe B-Viren; - Risikogruppen). In schweren Fällen kommt es innerhalb von 8 Tagen nach der Geburt zu fulminanten Infektionen mit sepsisähnlicher Erkrankung, akuter Myokarditis oder Perikarditis sowie Enzephalitis. Eine Hepatitis, häufig einhergehend mit Hämorrhagien und Nierenversagen, verläuft häufig tödlich. Durchfälle bewirken bei den Kindern massive Störungen des Wasser- und Elektrolythaushaltes (häufige Todesursache). Intrauterine Infektionen durch transplazentale Übertragung und eine Infektion des Kindes im Geburtskanal werden diskutiert. Nach bisher nicht generell bestätigten Beobachtungen werden Infektionen mit einigen Coxsackieviren (A9, B2, B3 und B4) im ersten Trimenon der Schwangerschaft mit Fehlbildungen beim Föten (z. B. urogenitale, gastrointestinale, kardiovaskuläre und zentralnervöse Defekte) assoziiert. Das potenzielle teratogene Risiko wird kontrovers diskutiert, jedoch als eher gering eingeschätzt.

Gastrointestinale Erkrankungen. Coxsackievirus-Infektionen können neben anderen unspezifischen klinischen Symptomen zu einer Diarrhoe führen. Eine Hepatitis kann Folge einer generalisierten Coxsackievirus-Infektion sein (gefürchtet bei Neugeborenen). Verschiedene Coxsackieviren der Gruppe B werden mit Pankreatitis in Verbindung gebracht.

Exantheme. Ein rötelnähnliches Exanthem kann durch verschiedene Coxsackieviren der Gruppen A und B vor allem bei Kleinkindern hervorgerufen werden.

Diabetes. In einigen Fällen wird eine Coxsackievirus B-Infektion, unter Umständen persistierend, mit juvenilem insulinabhängigem Diabetes mellitus in $\mathrm{Zu}-$ sammenhang gebracht, was vor allem durch tierexperimentelle Ergebnisse unterstützt wird. Wie für chronisch kardiovaskuläre Erkrankungen wird für Typ 1 Diabetes eine Störung der angeborenen Immunität diskutiert. 


\section{Pathophysiologie}

- Vermehrung und $>$ Pathogenität.

\section{Immunantwort}

Die humorale Immunität wird durch serotypspezifische Antikörper der IgG-, IgM- und IgA-Klassen bedingt, wodurch die hämatogene Virusausbreitung zu den jeweiligen Zielorganen verhindert wird. 7-10 Tage nach der Infektion erscheint typspezifisches IgM und persistiert mindestens 4 Wochen (in $90 \%$ der Fälle). Einige Tage verzögert werden typspezifisches IgG und IgA gebildet, wobei das IgG häufig für Jahre nachweisbar ist. Die Immunantwort gleicht der von Polioviren ( $\triangleright$ Polioviren). Wegen des Vorhandenseins diaplazentar übertragbarer Antikörper der IgG-Klasse sind Säuglinge seropositiver Mütter in den ersten Lebensmonaten gegen eine Infektion mit dem entsprechenden Coxsackievirustyp geschützt (Nestschutz durch Leihantikörper). Die zellvermittelte Immunität ist bislang erst unvollständig untersucht.

Für die durch Coxsackie-B-Viren bedingten Kardiomyopathien wird Autoimmunität durch „Molecular Mimicry" als Ursache angenommen (ähnliche antigene Determinanten von Coxsackievirus B3 und Myozyten bewirken eine immunologische Kreuzreaktion und dadurch eine Abwehrreaktion gegen Herzgewebe).

Es wird diskutiert, dass die angeborene antivirale Immunität u. a. durch Toll-like Rezeptoren (z. B. TLR-3) vermittelt ist. Wird die TLR-3 vermittelte Typ-1-Interferon-Signalkette (z. B. durch Mutation von TLR-3) eingeschränkt, kann die Viruseliminierung unterdrückt und das Risiko kardialer Schäden verstärkt sein.

\section{Differenzialdiagnose}

Wie einige Coxsackieviren der Gruppen A und B können auch Polioviren, die meisten Echoviren und einige Parechoviren eine Meningitis und eine Paralyse bewirken. Coxsackie- und Echoviren führen verschiedentlich zu gleichen Krankheitsbildern. Neben CVA24 kann auch Enterovirus 70 für eine akute hämorrhagische Konjunktivitis verantwortlich sein. Zur Differenzialdiagnostik Polioviren, Echoviren und $\mathrm{Pa}$ rechoviren sowie $>$ Enteroviren 68-71 und andere Enteroviren. Zur Differenzierung von Meningitis bzw. Paralyse, für die andere Viren verantwortlich sein können, sind Mumpsvirus, Herpes-simplex-Viren und (seltener) andere Viren der Herpesvirusfamilie, Frühsommer-Meningoenzephalitis-Virus sowie das Lymphozytäre Choriomeningitis-Virus in Betracht zu ziehen.

\section{Diagnostik}

\section{Untersuchungsmaterial}

Zum Routinenachweis von Coxsackieviren wird wie bei allen anderen Enteroviren Rachenabstrich und Stuhl verwendet ( $\triangleright$ Polioviren sowie Echoviren und
Parechoviren). In Abhängigkeit der Organmanifestation eignen sich zusätzlich Konjunktival-, Rektal- und andere Abstriche, Rachenspülwasser, Nasensekret, Urin, Liquor, Biopsie- oder Autopsiematerialien von Herz und/oder Gehirn.

\section{Diagnostische Verfahren}

Virusnachweis: Der Virusnachweis steht im Vordergrund. Als Screeningtest ist die RT-PCR geeignet (häufig Primer-Zielsequenzen in der 5'-NTR). 5'-NTRPrimer erlauben wegen der hohen Sequenzhomologie in diesem Bereich keine Differenzierung zwischen verschiedenen Serotypen. Zur molekularen Typisierung durch Sequenzierung von PCR-Amplifikaten ist die Analyse der genomischen Bereiche für die Viruskapsidproteine (z. B.VP1) notwendig. Neben der konventionellen Sanger-Sequenzierung wird zunehmend auch das schnellere und kostengünstigere Pyrosequenzierungsverfahren eingesetzt. Zur Identifizierung und Charakterisierung neuer Virusisolate kann eine randomisierte Amplifikation mittels Partikel-assoziierter Nukleinsäure-PCR (PAN-PCR) und anschließender Sequenzierung eingesetzt werden.

Zur Virusisolierung werden Monolayer-Zellkulturen vom Menschen und Affen verwendet. Beispiele für humane Zelllinien: primäre embryonale Haut- und Lungenfibroblasten, permanente Fibroblasten (z. B. MRC-5-Zellen), permanente Amnionzellen (z. B. FLZellen) und transformierte Zellen (z. B. KB-, HeLa-, HEp-2-Zellen). Beispiele für Affen-Zelllinien: primäre oder permanente Affennieren-Zelllinien vor allem von Rhesusaffen und afrikanischen grünen Meerkatzen (z. B. BGM- und Vero-Zellen). Alle Coxsackieviren der Gruppe B und einige der Gruppe A (A7, A9, A11, A13, A16, A20, A21, A24) lassen sich in einer oder mehreren der o. g. Zelllinien propagieren. Verschiedene Coxsackieviren der Gruppe A replizieren sich nur in humanen Rhabdomyosarkom-Zellen oder neugeborenen Mäusen (Anzüchtung von CVA1, A19 und A22 nur in neugeborenen Mäusen möglich). Verschiedene Coxsackieviren der Gruppen A und B haben hämagglutinierende Eigenschaften, deshalb ist ein Hämagglutinationstest und Hämagglutinationshemmtest möglich.

Neben der molekularen Virustypisierung wird auch die immunologische Typisierung im Neutralisationstest (NT) mit Antiseren bekannter Spezifität eingesetzt, z. B. mit 8 Hyperimmunserum-Pools nach LimBenyesch-Melnick (LBM-Antiserum-Pools, erhältlich über Statens Serum Institut, Kopenhagen) oder RIVM/ Bilthoven-Antiserum-Pools (erhältlich über Rijksinstituut vor Volksgezondheid en Milieu, Bilthoven, Niederlande) Referenzzentren. Eine Sonderstellung nimmt der Nachweis von Coxsackievirus A24 bei Patienten mit akuter hämorrhagischer Konjunktivitis ein. Dabei wird der Virusnachweis vornehmlich in abgeschabtem Konjunktivalmaterial mittels indirektem Immunfluoreszenztest durchgeführt (Speziallabor). 
Antikörpernachweis: Zum serologischen Nachweis einer frischen Infektion ist entweder die Untersuchung eines Serumpaares (min. 4facher Titeranstieg im NT bei zwei Seren, die im Abstand von 7-14 Tagen gewonnen sind) oder die Bestimmung virusspezifischer IgM-Antikörper notwendig. Der Nachweis von virustypspezifischen Antikörpern kann nur im NT geführt werden (im NT werden ausschließlich Epitope der Virusoberfläche durch Antikörper erkannt). Wegen immunologischer Kreuzreaktion sind kommerzielle und selbsthergestellte Enzymimmunassays dazu nicht geeignet (Antikörper erkennen auch kreuzreagierende Epitope aus dem Virusinneren, weil denaturiertes Antigen verwendet wird).

\section{Befund / Interpretation}

Da Coxsackievirus-Infektionen in der Mehrzahl der Fälle klinisch inapparent oder als uncharakteristische fieberhafte Erkrankungen verlaufen und zudem Virus vor allem im Stuhl über Monate ausgeschieden werden kann, sollte die Diagnostik in engem ätiologischen Zusammenhang des Virusnachweises mit einem definierten Krankheitsbild erfolgen. Beweisend für eine Infektion mit Coxsackieviren ist der Virus-RNANachweis bzw. die Virusanzucht. Der signifikante Titeranstieg neutralisierender Antikörper $(\geq 4$ facher Titeranstieg; 10-14 Tage Abstand zwischen beiden Blutabnahmen) ist weiterhin beweisend für eine frische Coxsackievirus-Infektion.

\section{Therapie}

\section{Therapeutische Maßnahmen}

Eine in-vivo-Therapie mit antiviralen Substanzen ist nur begrenzt möglich. Die Substanz Pleconaril, die durch Interkalation im Viruskapsidprotein VP1 eine Kapsidstabilisierung bewirkt und so zu einer Blockierung des viralen Uncoatings und/oder der Rezeptorerkennung führt, zeigte in randomisierten, doppelblind und Plazebo kontrollierten Phase-3-Studien für Enterovirus bedingte Meningitis eine Reduzierung der mittleren Infektionsdauer (in Deutschland nicht zugelassen) ( $\triangleright$ Polioviren).

\section{Epidemiologie}

\section{Verbreitung}

Coxsackievirus-Infektionen kommen weltweit vor (in gemäßigten Zonen mehrheitlich im Sommer, in wärmeren Ländern das ganze Jahr über). Wegen des fehlenden Immunschutzes sind Kleinkinder Hauptausscheider. Ungünstige hygienische und sozioökonomische Bedingungen erhöhen das Infektionsrisiko. Coxsackievirus-Infektionen können gleichzeitig mit anderen Enterovirus-Infektionen auftreten (z. B. Polioviren und Echoviren), wobei die Virusreproduktion eines der Viren durch Interferenz unterdrückt sein kann.

\section{Wirtsbereich / Reservoir}

Reservoir für Humane Coxsackieviren ist der Mensch.
In ihrem Wirtsbereich unterscheiden sich Coxsackieviren untereinander und von anderen Enteroviren. Charakteristisch für alle Coxsackieviren ist ihre Infektiösität für neugeborene Mäuse ( $\triangleright$ Diagnostik).

\section{Risikogruppen}

Von Coxsackievirus-Infektionen sind Kinder am häufigsten betroffen. Bei immunsupprimierten Patienten sind die Krankheitszeichen verstärkt. Infektionen mit Coxsackieviren der Gruppe A zeigen bei Kindern im Allgemeinen einen leichteren Verlauf als bei Erwachsenen. Durch Infektionen mit Coxsackieviren der Gruppe B sind Kinder vergleichsweise stark gefährdet. Bei Neugeborenen können diese Infektionen zu einem sepsisähnlichen Bild mit tödlichem Verlauf führen (u. a. mit Myokarditis oder Enzephalitis). Coxsackieviren der Gruppe B stehen im Verdacht, bei Neugeborenen eine Myokarditis durch intrauterine Infektion hervorzurufen (Ausbrüche vor allem auf Neugeborenenstationen). Nach bisher nicht generell bestätigten Beobachtungen werden Infektionen mit einigen Coxsackieviren im ersten Trimenon der Schwangerschaft mit Fehlbildungen beim Föten assoziiert. Das potenzielle teratogene Risiko wird eher als gering eingeschätzt ( $\triangleright$ Erkrankungen/Symptome).

\section{Transmission / Vektoren}

Coxsackieviren werden wie die anderen Enteroviren hauptsächlich fäkal-oral übertragen( $\triangleright$ Polioviren). Schon kurz nach Infektionsbeginn kommt es zu massiver Virusausscheidung im Stuhl, die mehrere Wochen andauern kann. Fäkale Kontaminationen (Finger, Gegenstände, Lebensmittel) sind die Hauptursachen für die Virusverbreitung. Wegen der primären Virusvermehrung in den Rachenepithelien wird das Virus auch respiratorisch kurz nach Infektion übertragen. Bei der durch Coxsackievirus A24 bedingten hämorrhagischen Konjunktivitis besteht eine erhöhte Übertragungsgefahr durch Schmierinfektion mit Konjunktivalflüssigkeit. Coxsackievirus-Infektionen sind in Ländern mit niedrigem sozioökonomischem Status besonders häufig, wobei die Übertragung durch kontaminiertes Abwasser eine wesentliche Bedeutung hat.

\section{Prävention / Impfstoffe}

Eine aktive Immunisierung gegen Coxsackieviren kann nicht durchgeführt werden.

\section{Ausbruchsmanagement}

Nosokomiale Coxsackievirus-Infektionen können von klinischem Personal durch Vernachlässigung der üblichen Hygiene übertragen werden. Wegen der fulminanten Verläufe sind Infektionen mit Coxsackieviren der Gruppe B auf Neugeborenenstationen besonders gefürchtet. Wesentliche Präventionsmaßnahmen sind die hygienische Händedesinfektion, die fachgerechte Windelentsorgung und der Kittelwechsel. Gegebenen- 
falls ist eine räumliche Trennung der infizierten Patienten vorzunehmen.

\section{Meldepflicht}

Es besteht keine Meldepflicht.

\section{Weiterführende Informationen}

\section{Referenzzentren / Expertenlaboratorien}

- Nationales Referenzzentrum für Poliomyelitis und Enteroviren und Regionales Referenzlabor der WHO/EURO für Poliomyelitis, Dr. Sabine Diedrich, Robert Koch-Institut, Nordufer 20, D-13353 Berlin, Tel.: +49-(0)30-18754 2378, Fax: +49-(0)30-18754 2617, E-Mail: DiedrichS@rki. de; www.rki.de.

- Statens Serum Institut, 5, Artillerivej, DK-2300 Kopenhagen S, Dänemark; Dr. Mette B. Kern, Tel.: +45-4829-9178, Fax: +45-4829-9179, E-Mail: ivdorders@ssi.dk; www.ssi.dk.

- National Institute for Public Health and the Environment, RIVM - Rijksinstituut vor Volksgezondheid en Milieu, Dept. Virology, PO Box 1, NL 3720 BA Bilthoven, The Netherlands; www.rivm.nl

\section{Web-Adressen}

- Picornaviridae.com: www.picornaviridae.com

- Picornaviridae study group: www.picornastudygroup.com

- The big picture book of viruses: www.mirrorservice.org/ sites/www.virology.net/Big_Virology/BVHomePage.html

- Genbank, National Institute of Health: www.ncbi.nlm. nih.gov/Genbank/index.html

\section{Schlüsselliteratur}

1. Melnick J (1996) Enteroviruses: Polioviruses, Coxsackieviruses, Echoviruses, and Newer Enteroviruses. In: Fields $\mathrm{BN}$ et al. (eds) Fields Virology, $5^{\text {th }}$ edn. Lippincott-Raven, Philadelphia, vol 1, pp 655-712

2. Pallansch M, Roos R (2007) Enteroviruses: Polioviruses, Coxsackieviruses, Echoviruses, and Newer Enteroviruses. In: Knipe DM et al. (eds) Fields Virology, $5^{\text {th }}$ edn. Wolters Kluwer Lippincott Williams \& Wilkins, Philadelphia, vol 1, pp 839-893

3. Racaniello VR (2007) Picornaviridae: The Viruses and Their Replication. In: Knipe DM et al. (eds) Fields Virology, $5^{\text {th }}$ edn. Wolters Kluwer Lippincott Williams \& Wilkins, Philadelphia, vol 1, pp 795-838

4. Stanway G et al. (2005) Picornaviridae. In: Fauquet CM et al. (eds) Virus Taxonomy, Classification and Nomenclature of Viruses, Eighth Report of the International Committee on Taxonomy of Viruses. Elsevier Academic Press, Amsterdam, pp 757-778

5. Zeichhardt H, Grunert HP (2003) Enteroviruses: polioviruses, coxsackieviruses, echoviruses and enteroviruses 68-71. In: Cohen J, Powderly WG, Opal SM (eds) Infectious Diseases, $2^{\text {nd }}$ edn. Elsevier Health Sciences, London, chapter 213, pp 1993-2006

6. Zeichhardt H, Grunert, H-P (2010) Picornaviren - Klinik, Diagnostik und Prävention. In: Doerr HW und Gerlich WH (Herausgeber) Medizinische Virologie, 2. Aufl, Thieme Verlag, Stuttgart New York, Kapitel 42, S 468-489

\section{Creutzfeld-Jakob-Erkrankung}

$>$ Prione

\section{Cryptococcus neoformans}

\author{
Marianne Kretschmar, Paul Schnitzler
}

\section{Erreger}

\section{Synonym(e)}

Saccharomyces neoformans, Torulopsis neoformans, Cryptococcus meningitidis, Blastomyces lithogenes, Debaryomyces hominis $\mathrm{u}$. a.

\section{Erregerspezies}

Zur Gattung Cryptococcus gehören über 30 Arten, wovon C. neoformans die humanpathogene Spezies ist. Von C. neoformans var. grubii sind drei Serotypen bekannt, A und D sowie eine Kreuzung beider Organismen, Serotyp AD. Selten sind Infektionen durch C. gatti, ehemals eine Varietät von C. neoformans. Humanmedizinisch wenig relevante Spezies sind u. a.: C. albidus, C. laurentii, C. terreus, C. uniguttulatus, C. luteolus, C. gastricus.

\section{Taxonomie}

Klasse: Heterobasidiomycetes; Ordnung: Filobasidiales; Familie: Filobasidiaceae; Gattung: Cryptococcus; Art: Cryptococcus neoformans (Sanfelice); Vuillemin C. neoformans var. neoformans und var. grubii, Teleomorph: Filobasidiella neoformans Kwon-Chung var. neoformans; C. neoformans var. gattii Vanbreuseghem und Takashio, Teleomorph: Filobasidiella bacillispora Kwon-Chung.

\section{Historie}

Erste Fallbeschreibung und Erregerisolierung von O. Busse 1894 in Greifswald, weitere Arbeiten von A. Buschke 1895 und F. Sanfelice 1895. Wichtige systematische Arbeiten wurden von K. J. Kwon-Chung durchgeführt.

\section{Morphologie}

C. neoformans ist ein pigmentierter Hefepilz. Im mikroskopischen Präparat finden sich multilateral sprossende, runde 3,5-7,5 × 3-7 $\mu \mathrm{m}$ große Hefezellen, die von einer Kapsel variabler Größe umgeben sind, keine Hyphen oder Pseudomyzelien.

Makromorphologie der Kultur nach 2-3 Tagen: glänzende Kolonien, schleimig, cremefarben bis hellbraun.

\section{Genom}

Das Genom von C. neoformans ist ca. 20,2 Mb groß, es enthält 14 haploide Chromosomen einer Größe von $0,8-2,3 \mathrm{Mb}$.

\section{Vermehrung}

Die Vermehrung der Pilze erfolgt durch Blastokonidien. Ein sexueller Vermehrungszyklus ist bekannt. Hier entwickelt sich bei entsprechenden Umweltbedingungen ein Basidium, welches Basidiosporen freisetzt. 
Eine Vermehrung von C. neoformans im Wirt im ruhenden Makrophagen ist möglich.

\section{Pathogenität / Virulenz / Antigenvariabilität}

C. neoformans verfügt im Unterschied zu den anderen Cryptococcus-Arten über Faktoren, die es ihm ermöglichen, im Wirtsorganismus zu persistieren, sich zu vermehren und Abwehrmechanismen zu umgehen. Nach Inhalation gelangen die Pilzzellen bis in die Alveolen, dort erfolgt die Adaptation an die Körpertemperatur (temperaturabhängiger Dimorphismus) und die Regeneration der Polysaccharidkapsel aus Glucuroxylomannan, Galactoxylomannan und Mannoprotein. Die Kapsel schützt die Pilzzelle vor Phagozytose und Abtötung durch Alveolarmakrophagen. Mit der Phenoloxidase kann der Pilz Katecholamine zu Melanin abbauen. Melanin und Mannitol verleihen Schutz vor oxidativen Abwehrmechanismen. Bei einer Infektion persistiert C. neoformans oft lebenslang, indem Abwehrmechanismen umgangen werden können: herabregulierender Effekt der Kapselbestandteile auf zellvermittelte Immunität, Antigenvariabilität (Veränderungen der Kapselstruktur und Membransterole) und genetische Variabilität (Instabilität des Karyotyps).

\section{Erkrankung \\ Kryptokokkose}

Synonym(e)

Europäische Blastomykose, Busse-Buschke'sche Krankheit.

\section{Inkubationszeit}

Mehrere Wochen.

\section{Leitsymptome}

Kopfschmerzen, neurologische Auffälligkeiten, Meningoenzephalitis.

\section{Symptome}

Primärstadium: Die Infektion der Lunge ist häufig klinisch inapparent, der Verlauf kann chronisch progredient sein.

Sekundärstadium: Mit der hämatogenen Disseminierung aus der Lunge kann der Pilz in alle parenchymatösen Organe gelangen. Auch Augen, Haut, Knochen und Gelenke können betroffen sein. Bei Disseminierung in die Haut zeigen sich Papeln, Pusteln und Ulzera. Häufigste Manifestation ist die zerebrale Kryptokokkose mit Meningoenzephalitis, sensiblen und motorischen Ausfällen, heftigen Kopfschmerzen, psychischen Veränderungen und Hörstörungen.

\section{Pathophysiologie}

Primärstadium: Nach Inhalation kontaminierten Staubes kaum pathologische Befunde der Lunge. Bei vorliegendem Defekt der T-Zell-abhängigen Abwehr Übertritt in die Blutbahn und hämatogene Streuung.
Sekundärstadium: Bevorzugtes Absiedelungsgebiet ist das Gehirn mit den Hirnhäuten. In den Meningen granulomatöse Entzündungsreaktion mit Makrophagen und Riesenzellen, die Kryptokokken enthalten. Im Hirnparenchym zystische gelatinöse Pilzhaufen ohne entzündliche Reaktion, besonders im Bereich der Basalganglien und kortikalen grauen Substanz. Zerebrales Ödem. Unbehandelt verläuft die zerebrale Kryptokokkose tödlich.

\section{Immunantwort}

Reduzierte Immunantwort aufgrund verminderter Migration von Granulozyten zum Infektionsort, supprimierter T-Lymphozytenaktivierung und Antikörperproduktion durch zirkulierende Kapselbestandteile.

\section{Differenzialdiagnose}

Tuberkulose, Histoplasmose, Kokzidioidomykose, Brucellose, Toxoplasmose und andere Erreger einer Meningitis bzw. Meningoenzephalitis.

\section{Diagnostik}

\section{Untersuchungsmaterial}

Liquor, Blut, Urin, Prostataexprimat, Sputum, Bronchialsekret, Punktate, Biopsiematerial.

\section{Diagnostische Verfahren}

Mikroskopie: von Liquorsediment: Hefezellen, zum Teil sprossend, mit Kapsel variabler Größe. Darstellung der Polysaccharidkapsel mit Tusche.

Kultureller Nachweis: aus Liquor, Punktaten und Biopsiematerialien; makroskopische und mikroskopische Merkmale $>$ Morphologie.

Antigen-Nachweis: Cryptococcus-Kapselantigen in Liquor und Serum. Antigen-Titerkinetik im Serum ermöglicht Therapiekontrolle und prognostische Aussagen.

Serologie: Antikörper-Bildung nicht regelhaft oder unterdrückt.

\section{Befund / Interpretation}

Mikroskopischer Nachweis bekapselter Hefezellen im Liquorsediment, kultureller Nachweis von C. neoformans und/ oder positiver Antigentest sind beweisend für eine Infektion.

\section{Therapie}

\section{Therapeutische Maßnahmen}

Amphotericin B (0,3-0,6 mg/kg KG/d) kombiniert mit Flucytosin (100-150 mg/kg KG/d in 4 Einzeldosen) und Fluconazol (400-800 mg/d) oder Itraconazol (400 g/d). Nach klinischer Ausheilung bei Personen mit Immunsuppression lebenslange Erhaltungsdosis von $100-200 \mathrm{mg} / \mathrm{d}$ Fluconazol sinnvoll.

\section{Resistenz}

Eine Resistenzentwicklung gegen Flucytosin ist möglich (Testung sinnvoll). 


\section{Epidemiologie}

\section{Verbreitung}

Weltweit.

\section{Wirtsbereich / Reservoir}

Natürliches Habitat des Pilzes ist der mit Vogelfäkalien kontaminierte Erdboden und Staub. Vögel, insbesondere Tauben und Papageien sind Träger, zeigen aber selbst keine Krankheitssymptome.

\section{Risikogruppen}

Immunsupprimierte Patienten mit T-Zell-Defekt, insbesondere bei AIDS im Vollstadium. Seltener Personen mit anderen Prädispositionen, z. B. nach Organtransplantation, bei malignen Tumoren unter einer Chemotherapie oder Langzeit-Steroidmedikation. Einzelne Fallberichte von Kryptokokkosen bei Patienten ohne bekannte Prädisposition.

\section{Transmission / Vektoren}

Übertragung erfolgt durch Inhalation kontaminierten Staubes. Keine Übertragung von Mensch zu Mensch.

\section{Prävention / Impfstoffe}

Eine spezifische Prophylaxe ist nicht möglich. Bei Risikopatienten, insbesondere bei Patienten mit $<50$ $\mathrm{CD} 4^{+}$T-Lymphozyten $/ \mathrm{mm}^{3}$ Prophylaxe mit Fluconazol bedenkenswert.

\section{Ausbruchsmanagement}

Wird nicht benötigt. Es handelt sich um Einzelerkrankungen.

\section{Meldepflicht}

Keine gesetzliche Meldepflicht. Eine Meldung an das Konsiliarlabor für Cryptococcus neoformans am Robert-Koch Institut ist aber erwünscht.

\section{Weiterführende Informationen}

\section{Referenzzentren / Expertenlaboratorien}

- Konsiliarlabor: Robert-Koch Institut, Nordufer 20, D-13353 Berlin

- Institut Pasteur, Unité de Mycologie, 25, rue du Docteur Roux, F-75724 Paris Cedex 15, France.

\section{Web-Adressen}

- http://hivinfo.de/handbuch/kryptok.htm

- http://www.cdc.gov

- http://www.uni-leipzig.de/ immun/scrypto.htm

- http://hivinsite.ucsf.edu

\section{Schlüsselliteratur}

1. Casadevall A, Perfect JR (1998) Cryptococcus neoformans. American Society for Microbiology, Washington DC

2. Kurtzman CP, Fell JW (1998) The Yeasts, A Taxonomic Study. Elsevier Science BV, Amsterdam

3. Kwong-Chung KJ, Bennett JW (1992) Medical Mycology. Lea \& Febiger, Philadelphia

4. Loftus BJ et al. (2005) The genome of the basidiomycet- ous yeast and human pathogen Cryptococcus neoformans. Science 307(5713):1321-1324

5. Veron V, Simon S, Blanchet D, Aznar C. Real-time polymerase chain reaction detection of Cryptococcus neoformans and Cryptococcus gattii in human samples. Diagn Microbiol Infect Dis. 2009, 65(1):69-72

\section{Cryptosporidium cayetanensis}

Cyclospora cayetanensis

\section{Ctenocephalides canis}

- Ektoparasiten, sonstige (Stechmücken, Trombiculiden, Flöhe, Wanzen, Zecken)

\section{Ctenocephalides felis}

Ektoparasiten, sonstige (Stechmücken, Trombiculiden, Flöhe, Wanzen, Zecken)

\section{Culex spp.}

Ektoparasiten, sonstige (Stechmücken, Trombiculiden, Flöhe, Wanzen, Zecken)

\section{Culiseta spp.}

Ektoparasiten, sonstige (Stechmücken, Trombiculiden, Flöhe, Wanzen, Zecken)

\section{Cunninghamella bertholletiae}

Mucorales

\section{Curvularia spp.}

- Eumyzetom (Madurella mycetomatis u.v.a.)

\section{Cyclospora cayetanensis}

\section{Erreger}

\section{Synonym(e)}

CLB-bodies (engl.: cyanobacteria-like-bodies (CLB) oder coccidia-like-bodies); Cryptosporidium-murislike; Cryptosporidium cayetanensis Tauxe, 1997; Cyclospora cayetenensis Duluol, Heyer, Beaugerie, und Chatelet, 1996, lapsus; Cyclospora sp. Ortega et al. 1994; Isospora sp. Ashford, 1979. 


\section{Erregerspezies}

Cyclospora cayetanensis, C. cercopitheci, C. colobi, C. papionis, Cyclospora cayetanensis ist die derzeit einzige humanpathogene Art der Gattung Cyclospora.

\section{Taxonomie}

Stamm: Alveolata; Unterstamm: Apicomplexa; Klasse: Coccidea; Ordnung: Eimeriida; Familie: Eimeridae; Gattung: Cyclospora.

\section{Historie}

Das Auftreten von durch Cyclospora verursachten Krankheitsfällen des Menschen wurde zunächst in $\mathrm{Pa}$ pua Neuguinea beobachtet. Im Stuhl der Patienten wurden kugelige Oozysten entdeckt, die zunächst für Cyanobakterien oder Isospora belli gehalten wurden. Seit 1980 häufen sich Infektionen mit C. cayetanensis bei Personen mit Aufenthalten in endemischen Gebieten (z. B. Fernreisende oder Soldaten und Angehörige von Hilfsorganisationen mit Einsätzen im Ausland). Zunehmend sind auch immunkomprimierte Patienten (vor allem AIDS-Patienten) und Kinder mit Mangelernährung betroffen.

1983 wurde über einen Ausbruch auf Haiti berichtet, der als „Big Crypto“ beschrieben wurde, und 1985 wurde der erste Fall in Peru und der Erreger als Cryptosporidium-muris-ähnlich beschrieben. 1986 wurde bei 4 Urlaubern, die aus Haiti und Mexico in die USA zurück gekehrt waren, Cyclosporiasis diagnostiziert. Der erste Ausbruch in den USA wurde 1990 in Chicago dokumentiert. 1991 wurde von einer Krankheit berichtet, deren Erreger als Cyanobakteria-like body bzw. Coccidian-like body (CLB) beschrieben wurde. 1993 wurden diese Organismen erstmalig als Coccidien bestätigt. 1994 wurde für den Erreger der Name Cyclospora cayetanensis vorgeschlagen und im gleichen Jahr kam es zum Ausbruch einer wasserbürtigen Epidemie in Nepal. Ein Jahr später wurde die Effektivität von Trimethroprim-Sulfamethoxazol als Chemotherapeutikum aufgezeigt. Die phylogenetische Verwandtschaft zu den Eimerien wurde 1996 beschrieben. Der Trivialname ist von der Cayetano Heredia Universität in Lima, Peru, abgeleitet. Die ersten Cyclosporiasis Infektionen in Deutschland wurden 1997 dokumentiert und der erste dokumentierte Ausbruch in Deutschland wurde im Jahr 2002 publiziert. Die Infektion bei diesem Ausbruch erfolgte durch den Verzehr von importiertem Kopfsalat aus Italien.

\section{Morphologie}

Das zur Infektion führende Verbreitungsstadium des Parasiten ist die Oozyste. Dieses sphärische Dauerstadium hat einen Durchmesser von etwa 8 bis $10 \mu \mathrm{m}$ und ist von einer gegen Umwelteinflüsse widerstandsfähigen, derben Hülle umschlossen. Die Oozysten enthalten zwei Sporozysten mit je zwei Sporozoiten, deren Größe etwa 9 x 1,5 $\mu$ m beträgt. Die Oozysten sind Desinfektionsmittel-unempfindlich.

\section{Vermehrung}

Der monoxene Entwicklungszyklus gleicht dem von Cryptosporidium parvum. Die Entwicklung findet nach oraler Aufnahme der Oozysten und Freisetzung der Sporozoiten intrazellulär im Dünndarm statt. Die genauen Abläufe beim Menschen sind jedoch noch nicht vollständig aufgeklärt.

\section{Pathogenität / Virulenz}

Menschen in jedem Alter sind gefährdet und die Infektionen sind weltweit verbreitet. Hohe Pathogenität besteht bei immunkompromittierten oder geschwächten Personen. Die Virulenz ist beträchtlich und der von Kryptosporidien vergleichbar.

\section{Erkrankung \\ Cyclosporiasis}

\section{Synonym(e)}

Cyclosporidiose, AIDS-related Diarrhea, Traveller's Disease.

\section{Inkubationszeit}

Die Inkubationszeit beträgt 2 bis 7 Tage (in Ausnahmefällen bis zu 18 Tagen).

\section{Leitsymptome}

Diarrhoen (wässrige Diarrhoen).

\section{Symptome}

Drei- bis viermal täglich wässrige Durchfälle, Übelkeit, Anorexie, Appetitlosigkeit, Gewichtsverlust, Magenkrämpfe, abdominale Schmerzen, Blähungen, Muskelschmerzen, Müdigkeit, Schwäche, Fieber und Schüttelfrost, Elektrolytverlust.

\section{Pathophysiologie}

Histopathologisch werden mäßige bis massive Erytheme bei Infektionen mit C. cayetanensis im distalen Duodenum beobachtet. Weiterhin treten reaktive Hyperämie mit vaskulärer Dilatation, Zottenkapillarkongestion, asexuelle und sexuelle Stadien enthaltende parasitophore Vakuolen im Darmepithel, Kryptenhyperplasie sowie partielle Villusatrophie auf. In elektronenmikroskopischen Aufnahmen sind intrazelluläre sporozoitenähnliche Partikel sichtbar.

\section{Immunantwort}

Eine Neuinfektion ist trotz durchlaufener Krankheit möglich. Aus Patientenseren wurden Cyclospora-spezifische Antikörper isoliert, jedoch sind die Vorgänge der Immunantwort auf Cyclospora noch nicht vollständig geklärt und ob sich eine Immunität entwickelt, ist fraglich.

\section{Differenzialdiagnose}

Differenzialdiagnostisch ist die Cyclosporiasis von anderen Erkrankungen durch die Parasiten Isospora, 
Microspora, Giardia lamblia und Cryptosporidium spp. zu unterscheiden. Enteritiden durch Bakterien und Viren sind abzugrenzen. Die Oozysten von C. cayetanensis sind deutlich größer (Faktor 2) als die der Kryptosporidien (5-6 $\mu \mathrm{m}$ ) und kleiner als die von Isospora belli $(20-33 \times 10-19 \mu \mathrm{m})$. Außerdem enthalten die Oozysten von Isospora acht Sporozoiten. Die infektiösen Stadien der Mikrosporidien sind einzellige kleine Sporen, die einen Polfaden aufweisen.

\section{Diagnostik}

\section{Untersuchungsmaterial \\ Stuhl}

\section{Diagnostische Verfahren}

Darstellung der Oozysten mittels mikroskopischer Untersuchung bei 400facher Vergrößerung nach säurefester Färbung (z. B. modifizierte Ziehl-NeelsenFärbung). In SAF- oder Formalin-fixierten Stuhlproben sind die Oozysten leicht zu übersehen. Cyclospora-Oozysten leuchten unter UV-Licht blau (Autofluoreszenz). Wegen der unregelmäßigen Ausscheidung der Oozysten ist eine Mehrfachuntersuchung des Stuhls notwendig. Sensitivität und Spezifität der PCR liegen bislang unter denen des Goldstandards (mikroskopische Untersuchung von Stuhlproben).

\section{Befund / Interpretation}

Mehrfache Stuhluntersuchungen sind unerlässlich. Bereits der positive Nachweis von wenigen Oozysten stellt eine Indikation zur Therapie dar. Eine routinemäßige Stuhluntersuchung beinhaltet nicht obligatorisch den Nachweis von Cyclospora-Oozysten, es sei denn, dies wird ausdrücklich angefordert. Bei den meisten Ärzten ist allerdings die Cyclosporiasis unbekannt.

\section{Therapie}

\section{Therapeutische Maßnahmen}

Bei immunkompetenten Patienten ist Cotrimoxazol (Sulfamethoxazol $800 \mathrm{mg}$ und Trimethoprim $160 \mathrm{mg}$ ) das Mittel der Wahl. Dosierung: 2 Dosen täglich über 7 Tage. Heilung in 90 \% der Erkrankungsfälle. In besonders hartnäckigen Fällen führt eine Fortsetzung der Therapie um weitere drei Tage zur Genesung nahezu aller Patienten. Bei Patienten mit einer Intoleranz gegen Cotrimoxazol kann Ciprofloxacin gegeben werden, das jedoch eine geringere Effektivität aufweist. Kindern werden über 7 Tage jeweils 2 Dosen Trimethoprim von $5 \mathrm{mg} / \mathrm{kg}$ Körpergewicht und Sulfamethoxazol von $25 \mathrm{mg} / \mathrm{kg}$ Körpergewicht verabreicht. Wird die Erkrankung nicht behandelt, kann die Infektion für mehrere Wochen oder sogar Monate persistieren, begleitet von Erschöpfungssyndrom und Unbehagen.

\section{Epidemiologie}

\section{Verbreitung}

Der Erreger ist weltweit verbreitet, zumeist aber in tropischen und subtropischen Ländern. $\mathrm{Zu}$ den Endemiegebieten zählen vor allem Südamerika, Asien sowie Teile Afrikas und des Nahen Ostens. Die Verbreitung erfolgt in erster Linie durch den Verzehr kontaminierter Lebensmittel und Wasser. Über die direkte Übertragung von Mensch zu Mensch liegen derzeit keine genauen Erkenntnisse vor. Cyclosporiasis-Epidemien in den Industrieländern gehen meist auf importierte kontaminierte frische Lebensmittel (Salate) zurück.

\section{Wirtsbereich / Reservoir}

C.-cayetanensis-Infektionen treten ausschließlich beim Menschen auf. Keine der 16 tierpathogenen Cyclospora-Spezies (Primaten, andere Mammalia, Reptilien) ist humanpathogen. Tiere stellen demnach kein Reservoir für C. cayetanensis dar.

\section{Risikogruppen}

Immunsupprimierte Patienten (HIV/AIDS, nach Transplantation oder Chemotherapie) und Kleinkinder. Die Diagnosestellung ist bei erstgenanntem Personenkreis von besonderer Bedeutung, da mit einem schwereren, verlängerten und möglicherweise extraintestinalen Krankheitsverlauf gerechnet werden muss. Zudem treten häufig Rezidive auf. Bei Immunkompetenten ist die Erkrankung in der Regel selbstlimitierend.

\section{Transmission/Vektoren}

Die Übertragung findet durch die orale Aufnahme der Oozysten in kontaminierter Nahrung (Wasser oder Gemüse) statt.

\section{Prävention / Impfstoffe}

Ein Impfstoff existiert derzeit nicht. Reisende sollten die Präventionsmaßnahmen für sauberes Trinkwasser berücksichtigen.

\section{Meldepflicht}

Keine.

\section{Weiterführende Informationen}

\section{Referenzzentren / Expertenlaboratorien}

- Offizielle Referenzzentren existieren nicht. Alle parasitologischen und tropenmedizinischen Einrichtungen haben ausreichend Expertise.

\section{Web-Adressen}

- CDC (Center for Disease Control and Prevention): http:// www.cdc.gov

- Identifikation/Diagnose: www.dpd.cdc.gov/dpdx

Schlüsselliteratur

1. Chacín-Bonilla L (2010) Epidemiology of Cyclospora 
cayetanensis: A review focusing in endemic areas. Acta Trop. Apr 9. [Epub ahead of print]

2. Garcia LS (2001) Diagnostic Medical Parasitology, 4th ed. ASM Press, Washington

3. Karanis P, Kourenti C, Smith H (2007) Waterborne transmission of protozoan parasites: a worldwide review of outbreaks and lessons learnt. J Water Health 5:1-38

4. Manson's Tropical Diseases. 20th Edition, G.C. Cook. WB Saunders Company Ltd

5. Ortega YR, Sanchez R (2010) Update on Cyclospora cayetanensis, a food-borne and waterborne parasite. Clin Microbiol Rev. 23:218-234

\section{Cyclosporiasis}

- Cyclospora cayetanensis

\section{Cylindrocarpon destructans}

Eumyzetom (Madurella mycetomatis u.v.a.)

\section{Cysticercose}

Taenien

\section{Cysticercus cellulosae}

Taenien

\section{Cysticercus racemosus}

Taenien

\section{Cytomegalievirus}

Hartmut Hengel

\section{Erreger}

Synonym(e)

Humanes Cytomegalievirus (HCMV).

\section{Erregerspezies}

Humanes Herpesvirus 5 (HHV-5).

\section{Taxonomie}

Das Genus Cytomegalovirus ist in der Familie Herpesviridae der Subfamilie der Betaherpesvirinae zugeordnet. Sub- oder Serotypen werden nicht unterschieden.

\section{Historie}

Mit der Entwicklung von Zellkulturtechniken gelang es erstmals 1956, das Cytomegalievirus (griech. kytos, Zelle und megas, groß) zu isolieren. Bereits Anfang des 20. Jahrhunderts sind die typischen Eulenaugen- zellen mit ihren charakteristischen Einschlusskörpern von Histopathologen in fetalen Geweben beschrieben worden, wurden aber irrtümlich Protozoen zugeschrieben.

\section{Morphologie}

Das Virion weist die typische Struktur der Herpesviren aus Kapsid, Tegument und äußerer Membranhülle auf. Dementsprechend ist das Kapsid ikosaedrisch, besteht aus 162 Kapsomeren und enthält ein doppelsträngiges DNA-Genom mit $235 \mathrm{kbp}$. Das Kapsid wird von dem amorph erscheinenden Tegument umgeben. In die äußere Membranhülle sind virale Glykoproteine integriert, die für die Anheftung und die Fusion der Virushülle mit der Wirtszelle verantwortlich sind.

\section{Genom}

Das virale Genom ist ein lineares, doppelsträngiges DNA-Molekül mit ca. $235 \mathrm{kbp}$ (Gensequenz von HCMV Stamm AD169 Acc. No. NC_001347). Es besteht aus zwei kovalent miteinander verbundenen Komponenten, unique long (UL) und unique short (US). Der GC-Gehalt der CMV-DNA liegt bei $58 \%$. Das CMV-Genom beinhaltet ca. 200 offene Leserahmen, wobei die Funktion der meisten Genprodukte bisher noch unbekannt ist. Die Mehrzahl der Gene ist für die Replikation in vitro nicht essenziell. Diese Gene besitzen jedoch entscheidende Bedeutung für die Virusvermehrung in vivo. Laborstämme haben im Vergleich zu Wildisolaten Genfunktionen durch Deletionen oder Punktmutation eingebüßt.

\section{Vermehrung}

Die CMV-Infektion zeichnet einen breiten Zelltropismus aus, der Epithel-, Endothel-, glatte Muskelzellen, Fibroblasten und myeolmonozytäre Zellen (Monozyten, Makrophagen, Granulozyten, CD34+-Vorläuferzellen, Megakaryozyten) einschließt. In vitro vermehrt sich HCMV in Fibroblastenkulturen besonders effizient. Hierbei tritt ein zytopathischer Effekt (CPE) und Plaquebildung auf. Der Replikationszyklus beansprucht mindestens 3 Tage. Dabei durchläuft HCMV wie alle Herpesviren drei Replikationsphasen (,immediate early“, „early“ und „late“). Bei der Primärinfektion des Patienten kann keine präzise Inkubationszeit angegeben werden. Das Auftreten von klinischen Symptomen und der Beginn der Virusausscheidung können zwischen wenigen Wochen und Monaten liegen. Wie alle Herpesviren kann HCMV in vivo eine latente, nicht produktive Infektionsform mit episomaler Lokalisation der viralen DNA etablieren, aus der die produktive Virusvermehrung reaktiviert werden kann. Das intakte Immunsystem kann die CMV-Replikation beenden, das Virus jedoch nicht aus dem Organismus eliminieren. Als Latenzort von CMV werden unterschiedliche Zelltypen diskutiert, u. a. monozytäre Vorläufer- und Endothelzellen. Exogene oder endokrine Faktoren, die zur Reaktivierung der 
CMV-Replikation führen, sind bisher schlecht definiert (z. B. Stress). Immundefizienz begünstigt das Ausmaß der reaktivierten Infektion. Diese führt zur Virusausscheidung über Körpersekrete. Vermehrt findet man Episoden der Virusausscheidung während der Schwangerschaft und Stillperiode.

\section{Pathogenität / Virulenz / Antigenvariabilität}

Für das Verständnis der CMV-Infektion ist eine Unterscheidung der CMV-Erkrankung mit vielfältigen klinischen Manifestationsmöglichkeiten einerseits von der CMV-Infektion mit Virusausscheidung bei fehlender Symptomatik andererseits notwendig. Ausmaß und Verlauf der aktiven CMV-Infektion sind in hohem Maße vom Immunstatus des Patienten bestimmt. Dabei kommt der zellulären Immunität die entscheidende Rolle zu. Antikörper haben eine unterstützende Funktion. Primär asymptomatische Infektionen können bei ungenügender immunologischer Kontrolle im weiteren Verlauf zu allgemeinen und organspezifischen Symptomen führen. Hierbei findet sich eine starke Virusreplikation und Virämie. In produktiv infizierten Zellen wirkt die CMV-Infektion lytisch. Histologisch resultieren Veränderungen einzelner Zellen (z. B. „Eulenaugenzellen“) und von Zellverbänden (z. B. Endothelschäden, Ulzera der gastrointestinalen Mucosa, Retinits etc.). Multiple genetische Funktionen befähigen das Virus, sich der Immunkontrolle partiell zu entziehen. So ist das Virus in der Lage, die MHC-vermittelte Antigenpräsentation zu kontrollieren und damit der T-Zell-Kontrolle entgegenzuwirken. Ebenso attenuiert CMV die Erkennung infizierter Zellen durch Natürliche Killerzellen (NK). Schließlich unterbricht das Virus zahlreiche intrazelluläre Signalkaskaden und so die Wirkung von Interferonen und antiviralen Zytokinen. Die virale Immunevasion kann durch spezifische Funktionen des Immunsystems kompensiert werden. Dies setzt aber eine intakte zelluläre Immunität voraus. Die Antigenität ist stabil. Sub- und Serotypen werden nicht unterschieden. Mithilfe von molekulargenetischen Analysen lassen sich CMV-Isolate genotypisch unterscheiden. Die klinische Bedeutung der genetischen Variabilität ist bislang unklar.

\section{Erkrankungen}

\section{CMV-Mononukleose}

\section{Inkubationszeit}

2-6 Wochen.

\section{Leitsymptome}

Lymphadenopathie, Hepatosplenomegalie, Fieber, Lymphozytose.

\section{Symptome}

Die CMV-Primärinfektion verläuft in der Mehrzahl der Fälle asymptomatisch. Auch bei immunkompetenten Personen können jedoch uncharakteristische
Symptome auftreten: Fieber, Lymphknotenschwellungen, Hepatosplenomegalie, Lymphozytose. Ca. $20 \%$ aller Fälle mit infektiöser Mononukleose sind durch CMV verursacht. In seltenen Fällen kann die CMVPrimärinfektion durch Komplikationen wie Ikterus, Myokarditis, interstitielle Pneumonie, Thrombozytopenie oder ein Guillain-Barré-Syndrom in Erscheinung treten.

\section{Pathophysiologie}

Vermutlich sind eine ausgeprägte Aktivierung des Immunsystems und die Lyse virusinfizierter Zellen für das Fieber, die Lymphadenopathie und die Gewebsentzündung verantwortlich.

\section{Immunantwort}

Es finden sich aktivierte T-Lymphozyten, CMV-spezifisches IgM und IgA sowie die IgG-Serokonversion.

\section{Differenzialdiagnose}

Infektiöse Mononukleose durch EBV, maligne Erkrankungen mit B-Symptomatik.

\section{CMV-Pneumonie}

\section{Synonym(e) \\ CMV-Infektion der Lunge.}

\section{Inkubationszeit}

Die Symptome entwickeln sich in Abhängigkeit von der Immundefizienz unterschiedlich schnell, in der Regel innerhalb weniger Tage.

\section{Leitsymptome}

Dyspnoe, röntgenologisch interstitielle Pneumonie.

\section{Symptome}

Husten, Fieber, Tachypnoe.

\section{Pathophysiologie}

Gefährdet sind insbesondere Patienten nach Knochenmark- oder Stammzelltransplantation. Es besteht eine massive Virusreplikation und Inflammation in der Lunge mit nachfolgender Hypoxie. Diskutiert wird ein pathophysiologischer Zusammenhang mit der Graft-versus-Host-Disease.

\section{Immunantwort}

Die antivirale Immunantwort in der Lunge ist ungenügend.

\section{Differenzialdiagnose}

Interstitielle Pneumonien anderer Ursache.

\section{CMV-Retinitis}

Synonym(e)

CMV-Netzhautentzündung. 


\section{Inkubationszeit}

Die Symptome entwickeln sich in Abhängigkeit von der Immundefizienz und Netzhautlokalisation innerhalb von Tagen bis Wochen.

\section{Leitsymptome}

Visusverlust, Sehstörungen, Erblindung.

\section{Symptome}

Funduskopisch imponieren weiße exsudative und schließlich nekrotische Netzhautbezirke (cotton wool spots). Eine Papillitis ist ebenfalls möglich. Dazu können perivaskuläre Hämorrhagien treten. Die CMVInfektion des Auges ist schmerzlos und kann bei peripherer Netzhautlokalisation längere Zeit unbemerkt bleiben.

\section{Pathophysiologie}

Die CMV-Replikation in der Retina führt zu Entzündung, Schwellung und Einblutung. Ohne frühzeitige antivirale Behandlung tritt innerhalb von Monaten die Erblindung ein.

\section{Immunantwort}

Die CMV-Retinits tritt am häufigsten bei HIV-Patienten mit fortgeschrittenem CD4-T-Zellverlust ( $<100$ Zellen/ $\mu \mathrm{l}$ ) ein. Risiko, Ausmaß und Prognose hängen vom Immunstatus ab.

\section{Differenzialdiagnose}

Retinitis bei Toxoplasmose, HSV, VZV, Bartonellose, Candidose.

\section{CMV-Colitis und-Ösophagitis}

\section{Synonym(e)}

CMV-Infektion des Gastrointestinaltraktes.

\section{Inkubationszeit}

Die Symptome entwickeln sich in Abhängigkeit von der Immundefizienz unterschiedlich schnell, in der Regel innerhalb weniger Tage.

\section{Leitsymptome}

Diarrhoe, Schmerzen, Schluckbeschwerden.

\section{Symptome}

Bei Colitis meist wässrige, gelegentlich auch blutige Durchfälle und Fieber. Möglich sind CMV-Infektionen im Rektum und Proktitis. Bei Ösophagitis schmerzhafte Schluckbeschwerden.

\section{Pathophysiologie}

Wird in der Regel nur bei immundefizienten Patienten beobachtet. Die CMV-Replikation in der Epithelschicht von Speiseröhre bzw. Darm führt zu zunächst flachen Defekten der Mucosa, aus denen sich tiefere, meist scharfbegrenzte Ulzerationen mit Pseudomembranen entwickeln.

\section{Immunantwort}

Die zelluläre Immunantwort in Speiseröhre bzw. Darm ist ungenügend. In der Regel sind die Patienten virämisch.

\section{Differenzialdiagnose}

Enterokolitis durch Cryptosporidien, Mikrosporidien, Mykobakterien, Adenovirus.

\section{Kongenitales CMV-Syndrom}

Synonym(e)

Angeborene CMV-Infektion.

\section{Inkubationszeit}

In Abhängigkeit vom Schweregrad zeigen sich die Schäden bereits in utero. Entwickeln sich ausschließlich Schäden des ZNS, zeigen sich diese erst im Laufe des ersten Lebensjahres.

\section{Leitsymptome}

Innenohrschwerhörigkeit, Hepatosplenomegalie, Blutbildveränderungen.

\section{Symptome}

Hepatosplenomegalie, intra- oder extrahepatische Gallengangsatresie, Chorioretinitis, Mikrozephalie, Enzephalitis (mit oder ohne periventrikuläre Verkalkungen), Hydrozephalus, Sprachstörungen, Krampfanfälle, Retinitis, Thrombozytopenie, Anämie und selten auch kardiovaskuläre Defekte. Oligosymptomatische Formen mit passagerer viszeraler Symptomatik sind häufiger als das Vollbild. Fetopathien sind häufiger als Embryopathien, das Risiko einer schwerwiegenden Infektion ist in der ersten Schwangerschaftshälfte erhöht. Die Spätschäden sind in Form von geistigen und körperlichen Entwicklungsrückständen, Intelligenzdefiziten, Taubheit und Sprachstörungen erheblich.

\section{Pathophysiologie}

Die diaplazentare Transmission von der Schwangeren auf den Embryo/Fetus kann bei primärer wie reaktivierter CMV-Infektion der Schwangeren erfolgen. Allerdings sind die klinischen Folgen für das Kind bei einer Primärinfektion sehr viel schwerwiegender. Die Organschäden (z. B. Innenohr, Leber, Retina, Knochenmark) werden durch die zytopathogenen Effekte des Virus und eine mangelnde Immunkontrolle der Virusreplikation erklärt.

\section{Immunantwort}

Infolge der immunologischen Unreife des Feten ist die zelluläre Immunantwort ungenügend. CMV-IgM-Antikörper sind nur in einem Teil der Fälle nachweisbar.

\section{Differenzialdiagnose}

Kongenitale und perinatale Infektionen anderer Ursa- 
che (z. B. Toxoplasmose, Röteln), Gendefekte, Stoffwechselerkrankungen.

\section{Diagnostik}

\section{Untersuchungsmaterial}

Serum, Blut-Leukozyten, Plasma, Trachealsekret, Urin, Liquor, Stuhl, Fruchtwasser, Nabelschnurblut, Augenkammerwasser, Gewebebiopsien.

\section{Diagnostische Verfahren}

Der direkte Virusnachweis erfolgt am schnellsten und empfindlichsten durch PCR. Quantifizierende Nachweisverfahren eignen sich auch zur Therapiesteuerung. Die Virusanzucht gelingt mittels humaner Fibroblastenkulturen. Der Antigenämietest wird mit monoklonalen Antikörpern gegen das intranukleäre pp65-Antigen durchgeführt.

Indirekter Virusnachweis durch den Nachweis CMVspezifischer IgG- bzw. IgM-Antikörper mittels ELISA oder IFT. Mithilfe der Aviditätsbestimmung CMVspezifischer IgG-Antikörper kann der Infektionszeitpunkt frischer Infektionen näher eingegrenzt werden. Western Blot und Neutralisationstest werden nicht routinemäßig durchgeführt.

Bei Verdacht auf Resistenzentwicklung gegen Ganciclovir und Foscarnet genotypische Analyse (Sequenzierung) der Gene UL97 bzw. UL54.

\section{Befund / Interpretation}

Positive CMV-DNA-Befunde belegen eine aktive Infektion, der CMV-DNA-Nachweis im Blut bzw. in Blutzellen eine Virämie. Der Nachweis von IgM-Antikörpern deutet auf eine primäre oder reaktivierte Infektion. Er ist bei immundefizienten Patienten und Neugeborenen häufig falsch negativ.

\section{Therapie}

\section{Therapeutische Maßnahmen}

Ganciclovir, Foscarnet und Cidofovir werden bei organ- oder lebensbedrohlichen Infektionen intravenös verabreicht, ihre grundsätzliche Wirksamkeit ist in Studien belegt. Valganciclovir wird oral eingesetzt. Die Auswahl der eingesetzten Medikamente wird durch die teilweise erhebliche Toxizität der Mittel bestimmt. Die Wirksamkeit von CMV-Hyperimmunglobulin ist bei spezifischen Indikationen nachgewiesen.

\section{Resistenz}

Resistenzbildung gegen die genannten Medikamente tritt gelegentlich auf.

\section{Epidemiologie}

\section{Verbreitung}

$\mathrm{CMV}$ ist weltweit verbreitet.

\section{Wirtsbereich / Reservoir}

Mensch.

\section{Risikogruppen}

Die Durchseuchung in Deutschland beträgt bei Erwachsenen in Abhängigkeit von der sozialen Herkunft im Durchschnitt $50 \%$. In Asien, Afrika und Südamerika ist die Durchseuchung deutlich höher. Bei spezifischen Bevölkerungs- und Patientengruppen wurde eine Durchseuchung von $>90 \%$ ermittelt (z. B. AIDSPatienten, homosexuelle Männer).

\section{Transmission / Vektoren}

Das Virus wird bei engen zwischenmenschlichen Kontakten über Speichel, Genitalsekrete und Muttermilch übertragen. Es bestehen Infektionsgipfel im Kleinkindesalter und in der Adoleszenz. Iatrogene Übertragungswege sind die Organtransplantation und die Bluttransfusion, sofern die weißen Blutzellen nicht entfernt werden. In Deutschland wird etwa $1 \%$ der Neugeborenen mit einer kongenitalen CMV-Infektion geboren. 10-15 \% dieser Kinder entwickeln eine dauerhafte Schädigung.

\section{Prävention / Impfstoffe}

Wirksame Impfstoffe sind nicht verfügbar. Die Immunprophylaxe kongenitaler CMV-Erkrankungen durch CMV-Hyperimmunglobulinpräparate in der Schwangerschaft scheint wirksam, muss aber durch weitere klinische Studien bestätigt werden. Bei immundefizienten Transplantationspatienten hat sich eine befristete Chemoprophylaxe mit Valganciclovir oder Aciclovir bewährt.

\section{Ausbruchsmanagement}

Seronegative Schwangere mit Haushaltskontakten zu Kleinkindern, die CMV-Ausscheider sind, können mithilfe spezifischer Hygienemaßnahmen eine wirksame Reduktion des Infektionsrisikos erreichen. Frühgeborene CMV-seropositiver Mütter sollten virusinaktivierte Muttermilch erhalten.

\section{Meldepflicht}

Besteht nicht.

\section{Weiterführende Informationen}

\section{Referenzzentren / Expertenlaboratorien}

- Konsiliarlaboratorium: Prof. Dr. Thomas Mertens, Universität Ulm, Abteilung Virologie, Albert-Einstein-Allee 11, 89081 Ulm; Tel.: 0731/502-3341, Fax: 0731/502-3337

- Konsiliarlaboratorium für kongenitale CMV-Infektionen: Prof. Dr. G. Jahn, Universität Tübingen, Institut für Med. Virologie, Calwerstr. 7/6, 72076 Tübingen, Tel.: 07071/2984921, Fax: 07071/29-5790

\section{Web-Adressen}

- Introduction to virology: http://www-micro.msb.le.ac. uk/109/Introduction.html

- All the virology on the WWW: http://www.virology.net

- Virus databases on-line: http://life.anu.edu.au/viruses/

- The big picture book of viruses: http://www.virology.net/ Big_Virology/BVHomePage.html 
- National center of biotechnology information: http:// www.ncbi.nlm.nih.gov/

- Links to further information on viruses: http://www2.rki. de/INFEKT/ENIVD/RS1.HTM

- The International Committee on Taxonomy of Viruses: http://www.ncbi.nlm.nih.gov/ICTV/

- The World of Human Cytomegalovirus (HCMV) and the Human Cytomegalovirus webring: http://www.biografix. $\mathrm{de} / \mathrm{cmv} /$ welcomeie.htm

\section{Schlüsselliteratur}

1. Crumpacker C (1996) Ganciclovir. N Engl J Med 335:721729
2. Ludwig A, Hengel H (2009) Epidemiological impact and disease burden of congenital cytomegalovirus infection in Europe. Euro Surveill. 14:26-32

3. Mocarski ES (2002) Immunomodulation by cytomegaloviruses: manipulative strategies beyond evasion. Trends in Microbiology 10:332-339

4. Mocarski ES, Shenk T, Pass RF (2007) Cytomegalovirusrd. In: Knipe DM, Holey PM (eds) Fields Virology, $5^{\text {th }}$ edn. Lippincott Williams \& Williams, Philadelphia, pp 27012771

5. Reddehase MJ (ed) (2006) Cytomegaloviruses. Molecular Biology and Immunology. Caister Academic Press, Norfolk, pp 49-61 


\section{Dakar-bat-Virus}

Flaviviren, seltene humanpathogene

\section{Darmamöben, apathogen}

\section{Erreger}

\section{Synonym(e)}

Amöboide Darmprotozoen, Darmkommensalen.

\section{Erregerspezies}

Entamoeba dispar; Entamoeba coli; Entamoeba hartmanni; Endolimax nana; Iodamoeba bütschlii; Entamoeba gingivalis (im Mundbereich); Entamoeba moshkovskii; nur selten: Entamoeba polecki; Entamoeba chattoni; für Dientamoeba fragilis $>$ Darmflagellaten

\section{Taxonomie}

System: Protozoa; Stamm: Sarcomastigophora; Unterstamm: Sarcodina (Rhizopoda); Ordnung: Amoebidae; Familie Entamoebidae

\section{Historie}

Die Untersuchungen über Amöben als Parasiten des Menschen begannen mit der Entdeckung des franzö- sisch-russischen Gelehrten Gros, der 1849 die Mundamöbe E. gingivalis beschrieb. Von den im Darm lebenden Arten wurde Entamoeba coli 1870 in Indien von Lewis entdeckt, E. histolytica jedoch erst 1875 von F. Lösch beschrieben. Erst 1993 schlugen Clark und Diamond E. dispar als eigenen Namen für nicht pathogene E. histolytica-Stämme vor, wobei Brumpt bereits 1925 eine Einteilung in zwei Spezies, eine pathogene und eine apathogene, favorisierte. Zur Unterscheidung zwischen E. histolytica und E. dispar - Entamoeba histolytica.

\section{Morphologie}

Eine Auswahl der morphologischen Kriterien ist - Tab. 1 zu entnehmen.

\section{Genom}

Die in Genbanken hinterlegten und veröffentlichten Nukleotid- und Aminosäuresequenzen, z. B. von E. dispar, sind auf folgender Internetseite zu finden: http://www.ncbi.nlm.nih.gov.

\section{Vermehrung}

Die Vermehrung der Darmamöben erfolgt durch Teilungsvorgänge.

\section{Pathogenität / Virulenz / Antigenvariabilität}

Die hier beschriebenen Darmamöben gelten generell

Tab. 1. Darmamöbenarten des Menschen

\begin{tabular}{|c|c|c|c|c|c|c|}
\hline Erreger & $\begin{array}{l}\text { Entamoea } \\
\text { dispar } \\
\text { (morpho- } \\
\text { logisch } \\
\text { ähnlich: E. } \\
\text { moshkovskii) }\end{array}$ & $\begin{array}{l}\text { Entamoeba } \\
\text { coli }\end{array}$ & $\begin{array}{l}\text { Entamoeba } \\
\text { hartmanni }\end{array}$ & $\begin{array}{l}\text { Endolimax } \\
\text { nana }\end{array}$ & $\begin{array}{l}\text { lodamoeba } \\
\text { bütschlii }\end{array}$ & $\begin{array}{l}\text { Entamoeba } \\
\text { gingivalis }\end{array}$ \\
\hline $\begin{array}{l}\text { Morpholo- } \\
\text { gie } \\
\text { Trophozoit }\end{array}$ & $\begin{array}{l}\text { ca. 10-20 } \mu \mathrm{m} ; \\
\text { Kern mit } \\
\text { zentralem } \\
\text { Karyosom }\end{array}$ & $\begin{array}{l}\text { ca. 15-40 } \mu \mathrm{m} \text {; } \\
\text { Kern mit ex- } \\
\text { zentrischem } \\
\text { Karyosom }\end{array}$ & $\begin{array}{l}\text { ca. 4-10 } \mu \mathrm{m} \text {; } \\
\text { Kern mit } \\
\text { großem Kary- } \\
\text { osom }\end{array}$ & $\begin{array}{l}\text { ca. 6-20 } \mu \mathrm{m} \text {; } \\
\text { Kern schei- } \\
\text { benförmig } \\
\text { mit großem } \\
\text { Karyosom }\end{array}$ & $\begin{array}{l}\text { ca. } 8-15 \mu \mathrm{m} ; \\
\text { mit großem } \\
\text { zentralen } \\
\text { Karyosom }\end{array}$ & $\begin{array}{l}10-20 \mu \mathrm{m} ; \\
\text { Mundhöh- } \\
\text { lenbewohner }\end{array}$ \\
\hline $\begin{array}{l}\text { Morpholo- } \\
\text { gie } \\
\text { Zyste }\end{array}$ & $\begin{array}{l}\text { ca. } 10-18 \mu \mathrm{m} ; \\
4 \text { Kerne }\end{array}$ & $\begin{array}{l}\text { ca. } 10- \\
30 \mu \mathrm{m} ; \text { ovoid } \\
\text { bis kugelig; } 8 \\
\text { Kerne }\end{array}$ & $\begin{array}{l}\text { ca. } 5-10 \mu \mathrm{m} \text {; } \\
\text { ovoid bis } \\
\text { kugelig; } 1-4 \\
\text { Kerne; meist } \\
4 \text { Kerne }\end{array}$ & $\begin{array}{l}\text { ca. } 5-14 \mu \mathrm{m} \text {; } \\
\text { kugelförmig, } \\
\text { oft oval; } 1-4 \\
\text { Kerne; schei- } \\
\text { benförmig }\end{array}$ & $\begin{array}{l}\text { ca. 5-20 } \mu \mathrm{m} ; \\
\text { unregelmä- } \\
\text { ßige Form; } \\
\text { einkernig mit } \\
\text { großer durch } \\
\text { Jod anfärb- } \\
\text { barer Glyko- } \\
\text { genvakuole }\end{array}$ & $\begin{array}{l}\text { nicht be- } \\
\text { kannt }\end{array}$ \\
\hline
\end{tabular}


als apathogen. Pathogene Arten sind gesondert beschrieben $(\square$ E. histolytica) und müssen in der Diagnostik von den apathogenen Darmamöben abgegrenzt werden. In einer Publikation aus dem Jahr 1998 wurde Entamoeba hartmanni mit Arthritis in Zusammenhang gebracht. E. dispar soll bei Versuchstieren in Einzelfällen kleine, lokale, intestinale Läsionen verursacht haben. Infektionen mit apathogenen Darmamöben persistieren meist längerfristig, die Parasiten können aber nach einiger Zeit spontan wieder eliminiert werden. Reinfektionen sind bei erneuter Exposition jederzeit möglich. Aus Australien kamen in jüngster Zeit Meldungen über ein mögliches pathogenes Potenzial von E. moshkovskii.

\section{Diagnostik}

\section{Untersuchungsmaterial}

Zum Nachweis intestinaler Amöben (durch mehrfache Stuhluntersuchungen) eignet sich als Untersuchungsmaterial Frischstuhl (Zeit bis zur Untersuchung maximal $30 \mathrm{~min}$ ), nativer Stuhl oder fixierter Stuhl in geeigneten Transportbehältnissen bzw. speziellen Transportsystemen.

\section{Diagnostische Verfahren}

Mikroskopische Diagnostik:

- Zur Untersuchung auf intestinale Amöben ist der direkte Nachweis von Trophozoiten oder Zysten durch mikroskopische Verfahren (z. B. Sedimentationsverfahren, MIFC, SAF) anzuwenden. Eine dreifache Stuhluntersuchung erhöht die Sensitivität maßgeblich.

- Bei der Frischstuhluntersuchung werden die beweglichen Trophozoiten direkt nachgewiesen. Hierbei werden die Lokomotionsstadien der Darmamöben anhand ihrer für Amöben typischen Bewegung erkannt.

- Insbesondere die Abgrenzung zu E. histolytica ist von besonderer Wichtigkeit; die Differenzierung der morphologisch identischen Spezies E. histolytica und E. dispar erfolgt mithilfe eines ELISA oder molekularbiologischer Verfahren $(\mathrm{PCR} \triangleright$ E. histolytica).

\section{Befund / Interpretation}

Der Nachweis von apathogenen Darmamöben (inkl. Artangabe) führt nicht zur Therapie. Er dient aber indirekt als Indikator für die hygienischen Verhältnisse (Feststellung des Hygienestandards), in denen der Träger lebt. Da der Übertragungsweg der apathogenen intestinalen Amöben der gleiche ist, wie der von E. histolytica und anderen Parasiten, deutet ihr Nachweis auf eine mögliche Infektkette für fäkal-orale Parasitosen hin. Der Nachweis der apathogenen Arten ist im Befund anzugeben, insbesondere zur Abgrenzung und dem sicheren Ausschluss einer E.-histolytica-Infektion. Möglicherweise ist der Nachweis dieser Darm- kommensalen auch als Hinweis auf eine Störung der Kolonisationsresistenz beim Träger zu werten.

\section{Therapie}

\section{Therapeutische Maßnahmen}

Der Befall mit apathogenen Amöben wird nicht therapiert.

\section{Resistenz}

Über Resistenzen gibt es demzufolge keine Berichte.

\section{Epidemiologie}

\section{Verbreitung}

Darmamöben kommen weltweit vor. Ihre Häufigkeit korreliert mit den lebensmittel- und wasserhygienischen Bedingungen. Während die meisten apathogenen Darmamöben im menschlichen Intestinaltrakt vorkommen, ist E. gingivalis im Mund zu finden. E. moshkovskii wurde auch aus limnischen Sedimenten und Klärschlamm isoliert.

\section{Wirtsbereich / Reservoir}

Von E. gingivalis ist bekannt, dass auch Primaten, Hunde und Katzen befallen werden können. Iodamoeba bütschlii wurde ebenfalls bei anderen Primaten sowie bei Schweinen gefunden. E. histolytica/dispar konnte bei Hunden, Schweinen sowie Affen nachgewiesen werden.

\section{Risikogruppen}

Aufgrund der oft schlechteren hygienischen Verhältnisse besteht insbesondere bei Reisen in Entwicklungsländer oder Länder mit niedrigem hygienischen Standard eine erhöhtes Infektionsrisiko.

\section{Transmission / Vektoren}

Die infektionsfähigen Zysten werden in der Regel fäkal-oral übertragen. Fliegende und kriechende Arthropoden können die Zysten taktil (mechanisch) verbreiten (z. B. Anheftung an den Tarsen). Praktisch alle in diesem Kapitel behandelten Amöbenzysten werden durch die Aufnahme kontaminierten Wassers oder den Verzehr kontaminierter Lebensmittel übertragen.

\section{Prävention / Impfstoffe}

Die Prävention besteht in der persönlichen Hygiene zur wirksamen Unterbrechung der Infektkette. Insbesondere die strikte Einhaltung der Maßnahmen zur Nahrungshygiene bietet in Ländern mit niedrigem Hygienestandard einen gewissen Schutz.

\section{Meldepflicht}

Es besteht keine Meldepflicht.

\section{Weiterführende Informationen}

\section{Referenzzentren / Expertenlaboratorien}

- Als fachlich qualifizierte Ansprechstellen gelten praktisch 
alle parasitologischen und tropenmedizinischen Institutionen.

\section{Web-Adressen}

- Identifikation/Diagnose: www.dpd.cdc.gov/dpdx

- Atlas of Medical Parasitology: www.cdfound.to.it/HTML/ atlas.htm

\section{Schlüsselliteratur}

1. Garcia LS (2001) Diagnostic Medical Parasitology, $4^{\text {th }}$ edn. ASM Press, Washington

2. Mehlhorn H (2007) Encyclopedia of Parasitology, $3^{\text {nd }}$ edn. Springer-Verlag, Berlin

3. Mehlhorn H, Eichenlaub D, Löscher T, Peters W (1995) Diagnostik und Therapie der Parasitosen des Menschen, 2. Aufl. Fischer-Verlag, Stuttgart

\section{Darmbilharziose}

Schistosomen

\section{Darmbrand}

- Clostridien der Gasbrand-Gruppe

\section{Darmegel}

\section{Erreger}

\section{Synonym(e)}

Riesendarmegel, großer Darmegel (Fasciolopsis buski): Erreger der Fasciolopsiasis; Zwergdarmegel für kleinere Formen (s. u.).

\section{Erregerspezies}

Fasciolopsis buski, Metagonimus yokogawai, Heterophyes heterophyes, Echinostoma ilocanum, Gastrodiscoides hominis, Watsonius watsoni.

\section{Taxonomie}

Stamm: Plathelminthes; Klasse: Trematoden, Digenea; Ordnung: Fasciolopsidae; Familie: Fasciolopsoidae; Echinostomatidae; Heterophyidae; Gattungen: Fasciolopsis, Watsonius, Echinostoma, Gastrodiscoidaes, Heterophyes.

\section{Historie}

Die Erstbeschreibung von Fasciolopsis buski geht auf Lankester im Jahre 1857 zurück. Der Name Fasciolopsis buski leitet sich aus den Wörtern opsis (griech.) = Aussehen, Erscheinung und lat. fascia-ae= Band oder Binde ab, also eine Trematodenart, die im Aussehen der Gattung Fasciola ähnelt.

\section{Morphologie}

F. buski besitzt im äußeren Erscheinungsbild größte
Ähnlichkeit mit F. hepatica. F. buski wird etwa $7,5 \times 2 \mathrm{~cm}$ groß und besitzt kleine Dornen im Tegument, die zu der Darmepithelschädigung beitragen. Die größten Exemplare sollen $10 \mathrm{~cm}$ erreichen. Echinostomen sind mit 7,5 × 1,5 mm viel kleiner und bilden im Hals-Kragenteil des Wurmkörpers artspezifische Dornen aus. Die noch kleineren Arten Metagonimus yokogawai $(\mathrm{L}=2,5 \mathrm{~mm} \times 0,4=0,7 \mathrm{~mm})$ und Heterophyes heterophyes $(2 \times 0,4 \mathrm{~mm})$ weisen auf der gesamten Oberfläche Dornen auf. Gastrodiscoides hominis und Watsonius watsoni sind mit 5-10 mm bzw. 4-5 mm wiederum etwas größer.

\section{Genom}

Das Genom dieser Spezies ist nicht intensiv untersucht, alle Arten sind (meist) diploide Zwitter, gelegentlich treten haploide/triploide Formen auf.

\section{Vermehrung}

Gelangen die im Darm des Wirtes von den adulten Egeln abgesetzten Eier mit dem Kot ins Wasser, so entwickelt sich eine Mirazidium-Larve. Die Entwicklung bei F. buski verläuft wie bei F. hepatica, denn die Zerkarien heften sich an Pflanzen und werden zu Metazerkarien. Dies gilt auch für Gastrodiscoides hominis und Watsonius watsoni, Metagonimus, Echinostoma und Heterophyidae. Darmegel benutzen Fische als zweite Zwischenwirte. F. buski ist die größte beim Menschen im Darm vorkommende Trematodenart.

\section{Pathogenität/Virulenz}

Schäden treten bei Massenbefall auf. Die Egel produzieren eine große Anzahl von gelblich gefärbten Eiern (pro Tag bis 20000).

\section{Erkrankung \\ Fasciolopsiasis}

\section{Synonym(e)}

Intestinal fluke disease.

\section{Inkubationszeit}

Die Präpatenzperiode bis zu Beginn der Eiausscheidung beim Menschen beträgt ca. 3 Monate. Die adulten Würmer leben im Darm ca. ein Jahr.

\section{Leitsymptome}

Uncharakteristische Magen-Darm-Symptome; abdominale Schmerzen.

\section{Symptome}

Die meisten Infektionen verlaufen leicht oder asymptomatisch. Bei schwerem Befall (Massenbefall) treten gastrointestinale Symptome (Diarrhoe, Obstipation, Übelkeit, Appetitlosigkeit, Blähungen) auf. Es kann zu Aszites, Abmagerung, und allgemeinen Kräfteverfall kommen. Akute intestinale Obstruktion, Anämie und allergische Reaktionen können auftreten. Die Symptome sind auf Stoffwechselprodukte zurückzuführen, da 
die Würmer sich vorwiegend vom Darminhalt und weniger vom Wirtsgewebe ernähren. Gelegentlich kann es zur Darmperforation oder bei Massenbefall auch zum Tod des Wirtes kommen.

\section{Immunantwort}

Die durch Darmegel hervorgerufene Immunantwort führt weder zur Abtötung des Parasiten noch schützt sie vor Reinfektionen.

\section{Differentialdiagnose}

Darmbeschwerden anderer Provenienz (z. B. Entzündungen, Amoebiasis, Bandwurmbefall)

\section{Diagnostik}

\section{Untersuchungsmaterial}

Unfixierter Stuhl.

\section{Diagnostische Verfahren}

Stuhluntersuchung. Mikroskopischer Nachweis der Eier im Stuhl (Sedimentation bei großen Formen bzw. Flotation bei kleinen Stadien). Die Eier von Fasciolopsis buski sind gedeckelt, breit-ellipsoid; sie sind 130$150 \mu \mathrm{m}$ lang $\times 60-90 \mu \mathrm{m}$ breit. Sie werden unembryoniert mit dem Stuhl abgesetzt.

\section{Befund/Interpretation}

Zur Diagnose führen Anamnese und Klinik sowie der Nachweis von Wurmeiern im Stuhl. Die mikroskopische Identifizierung der Eier und selten der adulten Würmer im Stuhl oder im Erbrochenen erlaubt die spezifische Diagnose. Die Eier sind von Fasciola-hepa-
tica-Eiern schwer zu unterscheiden. Der Nachweis einer größeren Anzahl von Eiern stellt eine Therapieindikation dar.

\section{Therapie}

\section{Therapeutische Verfahren}

Die Therapie erfolgt mit Praziquantel. Alternativ: Niclosamid, Bithionol, Bitoscanat.

\section{Resistenz}

Nicht bekannt.

\section{Epidemiologie}

\section{Verbreitung}

F. buski ist in ländlichen Regionen in folgenden Ländern Südostasiens zu finden: zentrales und südliches China, Bangladesch, Kambodscha, Taiwan, Vietnam, Thailand, Indien, Borneo, Indonesien, Laos, Malaysia, Pakistan. Menschen sind vor allem in ländlichen Gebieten infiziert ( $\downarrow$ Abb. 1). Die Übertragung erfolgt durch Verzehr von Wasserpflanzen. Es wird vermutet, dass ca. 10 Millionen Menschen in Ost-Asien mit diesem Egel infiziert sind (Verbreitungsgebiete der kleinen Arten nicht angegeben).

\section{Wirtsbereich/Reservoir}

Wasserschnecken (z. B. Planorbis) dienen als Zwischenwirt. Als zweiter Zwischenwirt fungieren Wasserpflanzen und deren Früchte. Endwirt sind Schweine und der Mensch, wobei das Schwein in manchen Gegenden als natürliches Reservoir dieser Parasiten

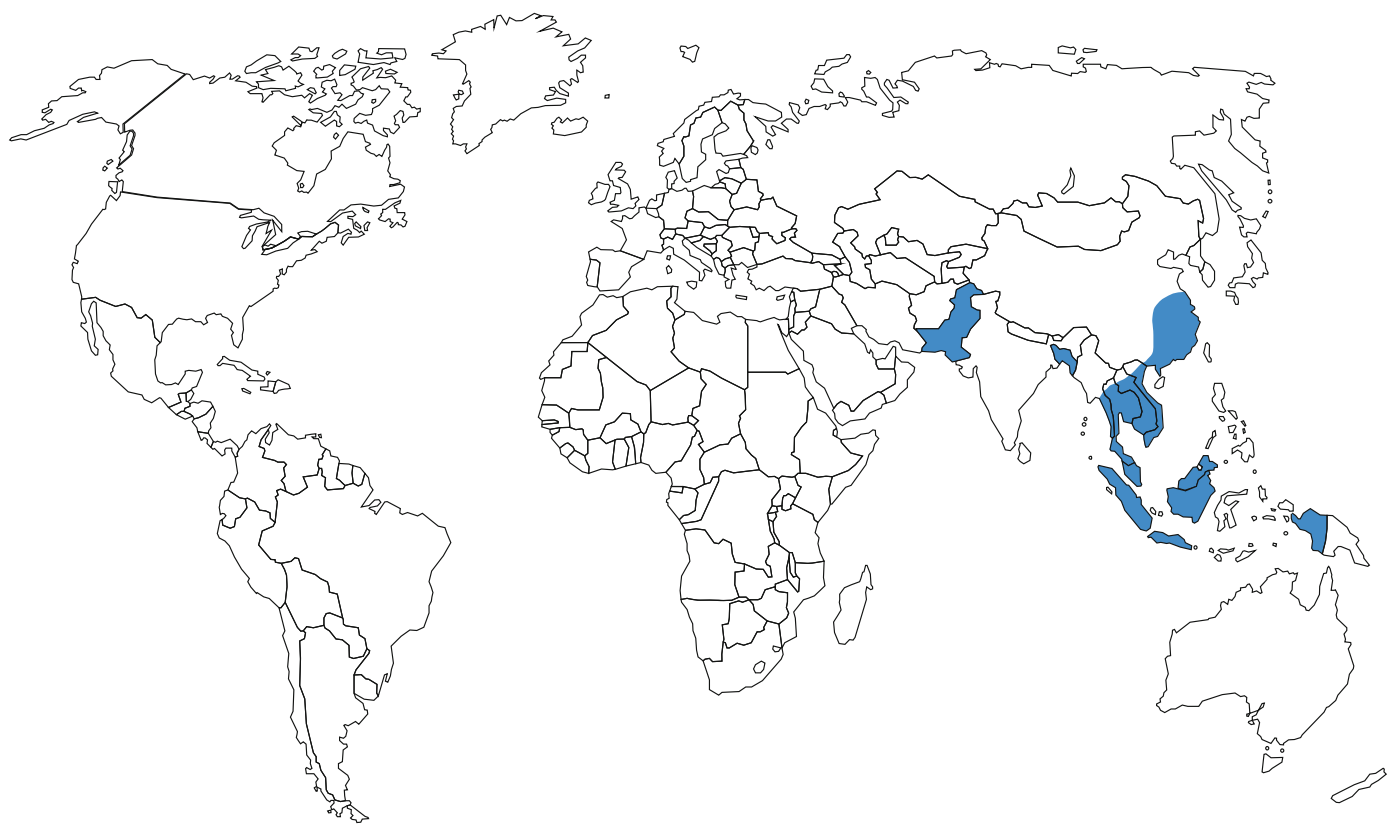


gilt. Die Riesendarmegel können auch Hunde und Kaninchen infizieren.

\section{Risikogruppen}

Es wird geschätzt, dass 750 Millionen Menschen dem Infektionsrisiko mit nahrungsübertragenen Trematoden (Clonorchis sinensis, Fasciola gigantica, Fasciola hepatica, Opisthorchis felineus and Opisthorchis viverrini), Lungenegel (Paragonimus spp.), und Darmegel (z. B. Echinostoma spp., Fasciolopsis buski und Heterophyidae) ausgesetzt sind. Gefährdet sind Menschen, die in Verbreitungsgebieten der Erreger leben, vor allem Kinder im Schulalter von 10-14 Jahren. Es handelt sich insbesondere um die asiatischen Länder China, Taiwan, Süd-Ost Asien, Malaysia und Indien, wo landestypische Ernährungsgewohnheiten und hygienische Bedingungen die Verbreitung der Erreger begünstigen.

\section{Transmission/Vektoren}

Die Fasciolopsiasis zählt zu den nahrungsbedingten Parasitosen. Der Mensch nimmt den Darmegel oral meist als Metazerkarien auf, die sich in stehenden Gewässern auf zur menschlichen Ernährung bestimmten Wasserpflanzen oder Sumpfpflanzen befinden. Dazu zählen besonders die Wassernuss (Trapa natans), die Wasserkastanie, sowie wahrscheinlich die Lotuswurzel, der Wasserspinat sowie der Mandschurische Wildreis (Zizania latifolia), dessen verpilzte Stängel auch roh als Gemüse gegessen werden. Die Metazerkarien sind gegen Austrocknung sehr empfindlich. Die Infektionskette wird permanent aufrechterhalten, weil die Fäkalien von Mensch und Schwein ins Wasser gelangen. Schweine, die sich in Suhlen aufhalten, geben dort ihren Kot ab und fressen zugleich die Wassernüsse.

\section{Prävention}

Wirksame Vorbeugemaßnahmen sind das Erhitzen von Trinkwasser aus Oberflächengewässern, das Überbrühen der Wassernüsse oder Wasserpflanzen mit kochendem Wasser vor dem Verzehr (Abtötung der Metazerkarien), die Kontrolle der Abwässer von Mensch und Tier sowie die Kontrolle der Zwischenwirte (Schnecken). Ökologische und demographische Veränderungen können die geografischen Ansprüche des Erregers beeinflussen.

\section{Meldepflicht}

Eine Meldepflicht besteht nicht.

\section{Weiterführende Informationen}

\section{Referenzzentren / Expertenlaboratorien}

- Offizielle Referenzzentren existieren nicht. Alle parasitologischen und tropenmedizinischen Einrichtungen haben ausreichend Expertise.

\section{Weblinks}

- http://www.dpd.cdc.gov/dpdx/HTML/Fasciolopsiasis. htm
- http://www.stanford.edu/class/humbio $103 /$ ParaSites2002/fasciolopsiasis/fasciolopsiasis.html

- http://tmcr.usuhs.mil/tmcr/chapter21/otherfas.htm

- http://www.dpd.cdc.gov/dpdx/images/ParasiteImages/ A-F/Fasciolopsiasis/Fasciolopsis_LifeCycle.gif

\section{Darmflagellaten}

\section{Erreger}

\section{Synonym(e)}

Darmbewohnende begeißelte Protozoen, begeißelte Darmkommensalen.

\section{Erregerspezies}

Chilomastix mesnili; Dientamoeba fragilis; Enteromonas hominis; Pentatrichomonas hominis; Retortamonas intestinalis; Trichomonas tenax (im Mundbereich).

\section{Taxonomie}

System: Protozoa; Stamm: Sarcomastigophora; Unterstamm: Mastigophora (Flagellata); Ordnung: Trichomonadida; Familie: Trichomonadidae (Pentatrichomonas hominis und Trichomonas tenax); Familie: Monocercomonadidae (Dientamoeba fragilis);

Ordnung: Retortamonadida; Familie: Retortamonadidae (Chilomastix mesnili, Retortamonas intestinalis); Ordnung: Enteromonadida; Familie: Enteromonadidae (Enteromonas intestinalis)

\section{Historie}

Dientamoeba fragilis, der einzige potenziell pathogene Flagellat, der in diesem Kapitel beschrieben ist, wurde 1909 erkannt und erstmals 1918 von Jepps und Dobell beschrieben. Erst aufgrund elektronenmikroskopischer Untersuchungen wurde D. fragilis zu den Flagellaten und nicht mehr zu den Amöben gestellt. Ockert hat $1972 \mathrm{im}$ Selbstversuch die Übertragung von D. fragilis via Enterobius-vermicularis-Eier bestätigt. Die erste Beschreibung von Trichomonas hominis erfolgte 1854 durch Davaine.

\section{Morphologie}

- Tab. 1 .

\section{Genom}

Hinweise auf die Existenz mehrerer genetisch unterschiedlicher Varianten von D. fragilis sind publiziert. Zwei Genotypen von D. fragilis wurden von Johnson und Clark nach Untersuchung von Untereinheiten des rRNA-Gens gefunden, wobei einer vorwiegend in Australien vorkommt.

\section{Vermehrung}

Die Vermehrung der Darmflagellaten erfolgt durch Teilungsvorgänge (Zweiteilung). 
Tab. 1. Morphologie der Darmflagellaten-Arten des Menschen sowie von T. tenax

\begin{tabular}{|c|c|c|c|c|c|c|}
\hline Erreger & $\begin{array}{l}\text { Chilomastix } \\
\text { mesnili }\end{array}$ & $\begin{array}{l}\text { Dientamoe- } \\
\text { ba fragilis }\end{array}$ & $\begin{array}{l}\text { Enteromonas } \\
\text { hominis }\end{array}$ & $\begin{array}{l}\text { Pentatri- } \\
\text { chomonas } \\
\text { (Trichomo- } \\
\text { nas) hominis }\end{array}$ & $\begin{array}{l}\text { Retortamo- } \\
\text { nas intesti- } \\
\text { nalis }\end{array}$ & $\begin{array}{l}\text { Trichomo- } \\
\text { nas tenax } \\
\text { (Mund- } \\
\text { bereich!) }\end{array}$ \\
\hline $\begin{array}{l}\text { Morphologie } \\
\text { Trophozoit }\end{array}$ & $\begin{array}{l}\text { ca. 6-20 } \mu \mathrm{m} \\
\text { lang, } \\
3-10 \mu \mathrm{m} \\
\text { breit; bir- } \\
\text { nenförmig; } \\
\text { einkernig; } \\
\text { mit } 3 \text { freien, } \\
\text { nach vorn } \\
\text { gerichteten } \\
\text { Geißeln und } \\
1 \text { Geißel, die } \\
\text { innerhalb des } \\
\text { Zytostoms } \\
\text { verläuft }\end{array}$ & $\begin{array}{l}\text { ca. } 3-15 \mu \mathrm{m} ; \\
\text { amöbenähn- } \\
\text { licher Habi- } \\
\text { tus; } 1 \text { oder } 2 \\
\text { Kerne; meist } \\
2 \text { fragmen- } \\
\text { tierte Kerne; } \\
\text { Zytoplasma } \\
\text { fein granu- } \\
\text { liert und } \\
\text { vakuolisiert; } \\
\text { Trophozoiten } \\
\text { variieren in } \\
\text { Größe und } \\
\text { Aussehen }\end{array}$ & $\begin{array}{l}\text { ca. 4-10 } \mu \mathrm{m} ; \\
\text { 3-6 } \mu \text { m breit; } \\
\text { mit } 3 \text { vorde- } \\
\text { ren Geißeln } \\
\text { und einer } \\
\text { am Körper } \\
\text { nach hinten } \\
\text { ziehenden, } \\
\text { dann frei } \\
\text { endenden } \\
\text { Geißel; ein- } \\
\text { kernig; Zys- } \\
\text { ten ähneln } \\
\text { denen von } \\
\text { Endolimax } \\
\text { nana }\end{array}$ & $\begin{array}{l}\text { ca. } 5-14 \mu \mathrm{m} \text {; } \\
7-10 \mu \mathrm{m} \\
\text { breit; mit } 4 \\
\text { (3-5) freien } \\
\text { Geißeln am } \\
\text { Vorderende } \\
\text { und einer } \\
\text { weiteren, die } \\
\text { nach hinten } \\
\text { gerichtet } \\
\text { ist, eine } \\
\text { undulierende } \\
\text { Membran } \\
\text { aufweist und } \\
\text { frei endet; } \\
\text { einkernig }\end{array}$ & $\begin{array}{l}\text { ca. 4-9 } \mu \mathrm{m} \\
\text { lang; 3-5 } \mu \mathrm{m} \\
\text { breit; mit } \\
2 \text { Geißeln, } \\
\text { von denen } \\
\text { die kürzere } \\
\text { nach vorn, } \\
\text { die längere } \\
\text { nach hinten } \\
\text { gerichtet ist; } \\
\text { einkernig; } \\
\text { prominentes } \\
\text { Zytostom; } \\
\text { Zysten } \\
\text { ähneln } \\
\text { denen von } \\
\text { Chilomastix } \\
\text { mesnili }\end{array}$ & $\begin{array}{l}\text { ca. 5-12 } \mu \mathrm{m} \\
\text { lang; 6,5- } \\
7,5 \mu \mathrm{m} \text { breit; } \\
\text { einkernig; } \\
\text { birnenför- } \\
\text { mig; mit } 4 \\
\text { freien nach } \\
\text { vorn gerich- } \\
\text { teten Geißeln } \\
\text { und einer } \\
\text { Schleppgei- } \\
\text { ßel mit un- } \\
\text { dulierender } \\
\text { Membran } \\
\text { ohne freies } \\
\text { Ende, mit di- } \\
\text { ckem, deut- } \\
\text { lich über das } \\
\text { Hinterende } \\
\text { herausragen- } \\
\text { dem Axostyl }\end{array}$ \\
\hline $\begin{array}{l}\text { Morphologie } \\
\text { Zyste }\end{array}$ & $\begin{array}{l}\text { ca. 7-10 } \mu \mathrm{m} \\
\text { lang; 4-6 } \mu \mathrm{m} \\
\text { breit; birnen- } \\
\text { bis zitronen- } \\
\text { förmig; mit } \\
\text { hyalinem } \\
\text { „Höcker" }\end{array}$ & $\begin{array}{l}\text { kein Zys- } \\
\text { tenstadium } \\
\text { bekannt }\end{array}$ & $\begin{array}{l}\text { ca. } 6-8 \mu \mathrm{m} \\
\text { lang; } 4-6 \mu \mathrm{m} \\
\text { breit; vierker- } \\
\text { nig }\end{array}$ & $\begin{array}{l}\text { kein Zys- } \\
\text { tenstadium } \\
\text { bekannt }\end{array}$ & $\begin{array}{l}\text { Ca. } 4-7 \mu \mathrm{m} \\
\text { lang; } 3-4 \mu \mathrm{m} \\
\text { breit; einker- } \\
\text { nig }\end{array}$ & $\begin{array}{l}\text { kein Zys- } \\
\text { tenstadium } \\
\text { bekannt }\end{array}$ \\
\hline
\end{tabular}

\section{Pathogenität / Virulenz / Antigenvariabilität}

Humanmedizinisch relevante Arten sind gesondert beschrieben ( $\triangleright$ z. B. Giardia lamblia). Dientamoeba fragilis wird zu den fakultativ pathogenen Arten gestellt und daher hier näher beschrieben, wobei die genetische Variante wohl die Pathogenität mitbestimmt. Die sonstigen hier beschriebenen Darmflagellaten werden derzeit als apathogen eingestuft. Lediglich Chilomastix mesnili soll im Einzelfall auch wässrige Stühle verursachen können.

Infektionen mit Darmflagellaten persistieren meist längerfristig, die Parasiten können aber nach einiger Zeit spontan wieder eliminiert werden. Reinfektionen sind bei erneuter Exposition jederzeit möglich.

\section{Erkrankung}

Infektion durch D. fragilis

\section{Inkubationszeit}

Variabel, nur fakultativ pathogen.

\section{Leitsymptome}

Intermittierender Durchfall mit abdominalen Schmerzen.

\section{Symptome}

Die Symptome wie Durchfall, abdominale Schmerzen, Erbrechen, abdominale Krämpfe, Müdigkeit, Eosinophilie, Urtikaria, Flatulenz und Pruritus sind vor allem bei Kindern beschrieben. Auch die Reizdarmsymptomatik wird mit $D$. fragilis in Verbindung gebracht. Meist treten die Symptome chronisch auf.

\section{Differenzialdiagnose}

Andere infektiöse und nicht infektiöse Ursachen einer chronisch intermittierenden Diarrhoe.

\section{Diagnostik}

\section{Untersuchungsmaterial}

Zum Nachweis intestinaler Flagellaten ist nativer (unfixierter) oder fixierter Stuhl in geeigneten Transport- 
gefäßen bzw. speziellen Transportsystemen einzusenden. Eine Frischstuhluntersuchung (Untersuchung des nativen Stuhls innerhalb einer halben Stunde nach Gewinnung) zum Nachweis der beweglichen Trophozoiten ist immer anzustreben.

\section{Diagnostische Verfahren}

Mikroskopische Diagnostik:

- Bei Verdacht auf intestinale Flagellaten ist der direkte Nachweis der beweglichen Trophozoiten oder der Zysten durch mikroskopische Verfahren anzustreben. Geeignet sind die Frischstuhluntersuchung auf bewegliche Stadien, Sedimentationsverfahren, MIFC, SAF. Eine dreifache Stuhluntersuchung erhöht die Sensitivität maßgeblich. Zum Nachweis der nicht zystenbildenden $D$. fragilis sollten Fixanzien eingesetzt werden.

- Insbesondere die Abgrenzung der Darmflagellaten zu Giardia lamblia ist von besonderer Wichtigkeit.

- Der Nachweis von D.-fragilis-Trophozoiten, die leicht degenerieren, kann durch spezielle Färbungen (z. B. Trichrom-Färbung) erleichtert werden. Auch kulturelle Methoden und In-house-PCRVerfahren sind entwickelt.

\section{Befund / Interpretation}

Der Nachweis von apathogenen Darmflagellaten (inkl. Artangabe) führt nicht zur Therapie.

Er dient aber indirekt als Indikator für die hygienischen Verhältnisse (Feststellung des Hygienestandards), in denen der Träger lebt. Da der Übertragungsweg der apathogenen intestinalen Flagellaten der gleiche ist wie der von Giardia lamblia und anderen Parasiten, deutet ihr Nachweis auf eine mögliche Infektkette für fäkal-orale Parasitosen hin. Der Nachweis der apathogenen Arten ist im Befund anzugeben, insbesondere zur Abgrenzung und dem sicheren Ausschluss einer G.-lamblia-Infektion. Möglicherweise ist der Nachweis dieser Darmkommensalen auch als Hinweis auf eine Störung der Kolonisationsresistenz beim Träger zu werten.

Beim Nachweis von $D$. fragilis ist insbesondere der klinische Befund für eine Therapieentscheidung maßgeblich.

\section{Therapie}

\section{Therapeutische Maßnahmen}

Infektionen durch apathogene Flagellaten werden nicht therapiert. Für die Therapie von Infektionen durch $D$. fragilis werden Metronidazol, Doxycyclin, Tetracyclin, Paromomycin oder halogenierte Hydroxychinoline empfohlen.

\section{Epidemiologie}

\section{Verbreitung}

Weltweit.

\section{Wirtsbereich / Reservoir}

Bei den meisten Darmflagellaten ist der Mensch das einzige bekannte Reservoir. $D$. fragilis wurde auch bei Affen gefunden, Chilomastix mesnili bei Affen und Schweinen.

\section{Risikogruppen}

Bei Reisen in Entwicklungsländer oder in Länder mit niedrigen hygienischen Standards besteht ein erhöhtes Infektionsrisiko. Immunkompromittierte Menschen sind prädisponiert.

\section{Transmission / Vektoren}

Praktisch alle in diesem Kapitel behandelten Flagellaten werden durch die Aufnahme kontaminierten Wassers oder den Verzehr kontaminierter Lebensmittel übertragen.

Fliegende und kriechende Arthropoden können die Zysten taktil (mechanisch) verbreiten (z. B. Anheftung an den Tarsen).

Die Übertragung von $D$. fragilis mit Eiern von Enterobius vermicularis oder Ascaris sp. ist zwar oft beschrieben, aber umstritten ( $\downarrow$ Historie). Eine Mensch-zuMensch-Übertragung wird für $D$. fragilis ebenfalls diskutiert, der Transmissionsweg ist jedoch noch nicht aufgeklärt.

\section{Prävention / Impfstoffe}

Die Prävention von Darmflagellaten-Infektionen besteht in der persönlichen Hygiene zur wirksamen Unterbrechung der Infektkette. Insbesondere die strikte Einhaltung der Maßnahmen zur Nahrungshygiene bietet in Ländern mit niedrigem Hygienestandard einen gewissen Schutz. Zur Eliminierung sowie zur Prävention der Trichomons-tenax-Besiedlung genügt eine Verbesserung der Mundhygiene.

\section{Meldepflicht}

Es besteht keine Meldepflicht.

\section{Weiterführende Informationen}

\section{Referenzzentren / Expertenlaboratorien}

- Als fachlich qualifizierte Ansprechstellen gelten alle parasitologischen und tropenmedizinischen Institutionen.

\section{Web-Adressen}

- Identifikation/Diagnose: www.dpd.cdc.gov/dpdx

- Atlas of Medical Parasitology: www.cdfound.to.it/HTML/ atlas.htm

\section{Schlüsselliteratur}

1. Mehlhorn H (2007) Encyclopedia of Parasitology, $3^{\text {nd }}$ edn. Springer-Verlag, Berlin

\section{Darmkokzidiose}

Isospora belli 


\section{Darmmilzbrand}

- Bacillus anthracis

\section{Deer Fly Fever}

- Francisella tularensis

\section{Dekubitalgeschwür}

- Aktinomyzeten mit fermentativem Kohlenhydratmetabolismus

\section{Dellwarze}

Molluscum Contagiosum Virus (MCV)

\section{Deltahepatitis}

- Hepatitis D Virus (HDV)

\section{Dematiaceae}

- Phaeohyphomycetes

\section{Demodex spp.}

- Haarbalgmilben

\section{Demodikose}

$\checkmark$ Haarbalgmilben

\section{Dengue-Fieber}

$\checkmark$ Dengueviren

\section{Dengue-hämorrhagisches-Fieber (DHF)}

Dengueviren

\section{Dengue-Schock-Syndrom (DSS)}

- Dengueviren

\section{Dengueviren}

\section{Erreger}

\section{Erregerspezies}

Denguevirus 1 (DENV 1), Denguevirus 2 (DENV 2), Denguevirus 3 (DENV 3), Denguevirus 4 (DENV 4)

\section{Taxonomie}

DENV 1-4 bilden eine eigene Untergruppe innerhalb des Genus Flavivirus (Familie Flaviviridae).

\section{Historie}

Der Ausdruck „Dengue“ entstand aus dem Versuch, die Phrase „ki denga pepo“ (kommt aus dem Swahili und bedeutet so viel wie „Krampfähnliche Anfälle verursacht durch einen bösen Geist") in die spanische Sprache zu integrieren. Ausbrüche von Dengue-Fieber wurden erstmals 1779 in Batavia (heute Jakarta) und Kairo registriert. Danach traten Epidemien in Intervallen von 10-30 Jahren in tropischen und subtropischen Gebieten auf. Erst 1944 konnte Albert Sabin Dengueviren von Soldaten isolieren, die in Kalkutta, auf Neuguinea und auf Hawaii erkrankt waren.

\section{Morphologie}

Dengueviren gleichen morphologisch dem Gelbfiebervirus.

\section{Genom}

Die Sequenzierung einer Region des HüllproteinGens hat gezeigt, dass die Serotypen DENV 1-4 weiter in Genotypen unterteilt werden können. Die Genome von DENV 1-4 sind ähnlich wie dasjenige des Gelbfiebervirus organisiert. GenBank-Nr.: M23027 (DENV 1), M19197 (DENV 2), A34774 (DENV 3), M14931 (DENV 4).

\section{Vermehrung}

Nach der Übertragung durch einen infizierten Moskito vermehrt sich das Virus in den regionalen Lymphknoten und verbreitet sich über Lymphe und Blut. Als weitere Replikationsorte werden Endothelzellen und Zellen im Knochenmark diskutiert. Das Virus konnte auch aus Leber, Lunge, Nieren, Lymphknoten, Gehirn und Gastrointestinaltrakt isoliert werden. Die Vermehrung im retikuloendothelialen System und der Haut führt schließlich zur Virämie. Außerdem infizieren Dengueviren dendritische Zellen des Immunsystems, welche die angeborene und adaptive Immunantwort überbrücken.

\section{Pathogenität / Virulenz / Antigenvariabilität}

Alle 4 Serotypen verursachen identische Krankheitsbilder. Die meisten Infektionen mit Dengueviren verlaufen jedoch asymptomatisch. 


\section{Erkrankungen}

\section{Klassisches Dengue-Fieber}

\section{Synonym(e)}

„Breakbone fever".

\section{Inkubationszeit}

Die Inkubationszeit beträgt 4-7 Tage (in Einzelfällen bis zu 14 Tage).

\section{Symptome}

Das klassische Dengue-Fieber beginnt mit plötzlichem Fieberanstieg, schweren Kopfschmerzen (typischerweise frontal lokalisiert), Schwindel und Erbrechen. Charakteristischerweise treten Muskelschmerzen, Knochenschmerzen („Breakbone fever“) und Arthralgien auf. Besonders das Rückgrat ist davon betroffen. Vor der Rekonvaleszenzphase tritt in $50 \%$ der Fälle ein diffus verteiltes, makulopapuläres Exanthem auf. Es dauert 2 bis 4 Tage und kann von Pruritus und Schälen der Haut begleitet sein. Trotz der schweren klinischen Symptomatik und zum Teil langwieriger Rekonvaleszenz ist die Prognose günstig.

\section{Pathophysiologie}

Dem Immunsystem, wird eine wichtige Rolle bei der Entstehung von Symptomen zugeschrieben (Immunpathogenese).

\section{Immunantwort}

Nach Infektion mit einem Serotyp gibt es nur kurzzeitig eine gruppenspezifische Immunität, langfristig bleibt nur ein typenspezifischer Immunschutz.

\section{Differenzialdiagnose}

Eine sichere klinische Diagnose der apparenten Infektionen mit Dengueviren ist oft nicht möglich. Das klassische Dengue-Fieber unterscheidet sich kaum von anderen Erkrankungen, die ebenfalls mit plötzlichem Fieber einhergehen. Allerdings sollten schwere Muskel- und Knochenschmerzen an Dengueviren denken lassen. Infektionen mit anderen Arboviren (z. B. West-Nil-Virus, Rift-Valley-Fieber-Virus und Sandmückenfiebervirus) sowie Malaria und Leptospirose sind auszuschließen.

\section{Dengue-Hämorrhagisches-Fieber (DHF) / Dengue-Schock-Syndrom (DSS) \\ Inkubationszeit}

DHF/DSS beginnt 4-7 Tage nach Auftreten der ersten Krankheitsphase.

\section{Symptome}

Die erste Krankheitsphase verläuft ähnlich wie beim klassischen Dengue-Fieber. Danach kommt es zu einer kurzen Remission. Bauchschmerzen, Erbrechen, Unruhe, Bewusstseinsstörungen oder ein plötzlicher Wechsel von Fieber zur Hypothermie können den Be- ginn des DHF ankündigen. Schließlich tritt eine plötzliche Verschlechterung auf, die durch Blutdruckabfall und Kreislaufkollaps gekennzeichnet ist. In Haut und Schleimhäuten zeigen sich Petechien (Thrombozyten$\mathrm{zahl}<10^{5} / \mathrm{mm}^{3}$ ). Gastrointestinale Blutungen und hämorrhagische Pneumonien können folgen. Bei sehr ungünstigem Verlauf des DHF kommt es zum DSS mit meist letalem Ausgang.

\section{Pathophysiologie}

Das Auftreten von DHF wird u. a. durch zwei Wirtsfaktoren begünstig: Alter $<15$ Jahre und frühere Infektion mit Dengueviren. Über 90 \% der Patienten mit DHF hatten bereits eine frühere Denguevirus-Infektion mit einem anderen Serotyp. Bei etwa 1-2 \% aller Sekundärinfektionen tritt ein DHF auf. Die erkrankten Personen sind in der Regel nicht älter als 15 Jahre. Beim DHF und seiner schwersten Komplikation, dem DSS, spielt das so genannte „Immunoenhancement" eine Rolle. Dabei binden nichtneutralisierende Antikörper, die sich nach einer früheren Infektion mit einem anderen Serotyp gebildet haben, an Dengueviren, ohne diese unschädlich zu machen. Die so entstandenen Immunkomplexe binden schließlich über den FcTeil der IgG-Antikörper an Fc-Rezeptoren (insbesondere an Fc $\gamma$ RI wegen dessen hoher Avidität) auf Monozyten/Makrophagen und werden dann in das Zellinnere aufgenommen. Über diesen Mechanismus können Dengueviren leichter in mononukleäre Zellen eindringen. Daraus resultiert im infizierten Organismus eine größere Anzahl von infizierten Zellen, die eine größere Menge an Viruspartikel produzieren. Daher ist die Zirkulation von mehreren verschiedenen Serotypen in einem Endemiegebiet eine wesentliche Voraussetzung für das Auftreten des DHF/DSS.

\section{Immunantwort}

- Pathophysiologie

\section{Differenzialdiagnose}

Das DHF ist kaum von anderen Ursachen des hämorrhagischen Fiebers abgrenzbar. Thrombozytopenie und die Zeichen einer leichten Verbrauchskoagulopathie deuten in Richtung Dengueviren.

\section{Diagnostik}

\section{Untersuchungsmaterial \\ Serum, Plasma.}

\section{Diagnostische Verfahren}

Wichtigste Nachweismethode ist die RT-PCR. Im amplifizierten Material kann dann mit Hilfe der Sequenzierung der Subtyp bestimmt werden. Die Virusisolierung ist schwierig. Zu diesem Zweck werden am besten Moskito-Zelllinien inokuliert. Etwa 2-3 Tage später kann das Virus nach Anfärbung mit spezifischen monoklonalen Antikörpern in der Immunfluoreszenz identifiziert werden. Zum Nachweis von virusspezifi- 
schen Antikörpern werden KBR, HHT und NT eingesetzt. ELISA-Verfahren zum Nachweis von virusspezifischen IgM-Antikörpern sind erhältlich, werden aber erst 4-5 Tage nach Beginn der Symptome positiv.

\section{Befund / Interpretation}

Bei der Interpretation der Serologie sind mögliche Kreuzreaktionen mit anderen Flaviviren (u. a. auch bei Impfung gegen Gelbfieber oder Japanische Enzephalitis) zu berücksichtigen. IgM-Antikörper können bis zu 3 Monaten nach Infektion persistieren. Die Reiseanamnese ist sehr wichtig, da aufgrund der Inkubationszeit eine Denguevirus-Infektion unwahrscheinlich wird, wenn die Symptome mehr als 2 Wochen nach Verlassen eines Endemiegebiets für Dengueviren auftreten. Fieber, welches länger als 10 Tage persistiert, ist in der Regel nicht auf eine Denguevirus-Infektion zurückzuführen.

\section{Therapie}

\section{Therapeutische Maßnahmen}

Eine spezifische antivirale Therapie, deren Wirksamkeit zweifelsfrei nachgewiesen wurde, gibt es noch nicht. Das klassische Dengue-Fieber ist eine selbstlimitierende Erkrankung, welche durch Antipyretika, Analgetika und andere supportive Maßnahmen behandelt werden kann. Für das DHF/DSS hat die WHO Richtlinien für die Behandlung ausgearbeitet. Die vitalen Funktionen des Patienten und insbesondere der Hämatokrit müssen eng überwacht werden. Auf dieser
Basis muss parenterale Flüssigkeitszufuhr den Verlust an Plasmavolumen ersetzen. Bei disseminierter Koagulopathie kann eine Heparin-Therapie indiziert sein. Bluttransfusionen sind nur bei schweren Blutungen notwendig. Auf keinen Fall dürfen Salizylate oder hepatotoxische Medikamente verabreicht werden.

\section{Epidemiologie}

\section{Verbreitung}

In den letzten 40 Jahren haben die Inzidenz von Infektionen mit Dengueviren und ihre geografische Verbreitung dramatisch zugenommen ( $\triangleright$ Abb. 1). Alle Subtypen von Dengueviren sind in bisher nicht betroffene Gebiete eingeschleppt worden und mittlerweile weltweit zu finden (tropische Gebiete und warme Bereiche der gemäßigten Zonen). Sie verursachen die meisten Arbovirus-Infektionen und stellen ein globales Gesundheitsproblem dar. Über 2 Milliarden Menschen bewohnen Risikogebiete. Die höchste Inzidenz findet sich in Südostasien, Indien und in tropischen Gebieten Amerikas. Jährlich treten weltweit ungefähr 100 Millionen Fälle von Dengue-Fieber und etwa 250.000 Fälle von DHF auf. Die Gründe für diese Entwicklung sind unkontrollierte Urbanisierung und Massenwanderungen der Landbevölkerung in die Slums am Rande von großen Städten. Armut und kriegerische Handlungen haben diese Situation noch verschärft. Der sprunghaft angestiegene Reiseverkehr mit dem Flugzeug und internationaler Handel haben ebenfalls zur Weiterverbreitung der Dengueviren bei-

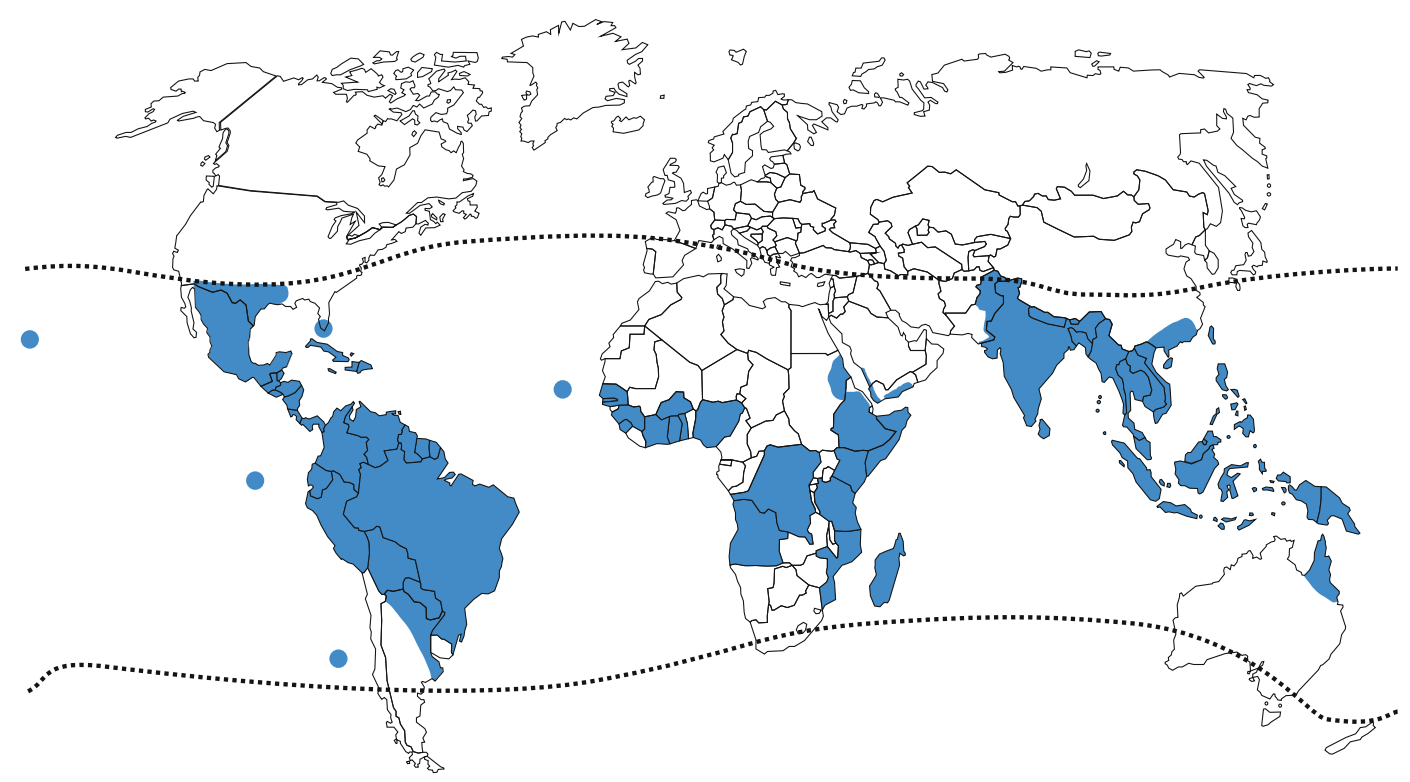

Abb. 1. Verbreitung von Dengue-Erkrankungen. Hochrisiko-Länder sind blau markiert. Die beiden Linien geben die Januar- und Juli-Isotherme $\left(10^{\circ} \mathrm{C}\right)$ wieder. Das dadurch eingegrenzte Areal entspricht dem Lebensraum von Aedes aegypti (Hauptvektor von Dengueviren). (Quelle: WHO, International Travel and Health, 
getragen. Insbesondere der Massentourismus in ferne Länder ist für importierte Fälle von Dengue-Fieber verantwortlich. Häufig findet der Rückflug während der Inkubationszeit statt, sodass die Krankheit erst im Heimatland ausbricht. Dort denken die Ärzte oft nicht an diese Infektionsmöglichkeit und die Diagnose wird zunächst verzögert. In solchen Fällen ist die Reiseanamnese ein wertvoller Hinweis. Auch klassische Fernreiseziele wie Thailand (z. B. Pukhet oder Ko Samui) bergen die Gefahr einer Denguevirus-Infektion. Etwa 50 bis 100 solcher eingeschleppten Fälle von DengueFieber werden jährlich in den USA und Europa registriert.

\section{Wirtsbereich / Reservoir}

Die einzigen Vertebraten, die als Wirte für Dengueviren fungieren, sind der Mensch und mehrere Arten von asiatischen und afrikanischen Primaten. Babymäuse können nur sehr schwer infiziert werden.

\section{Risikogruppen}

Pathophysiologie

\section{Transmission / Vektoren}

Dengueviren werden hauptsächlich durch den Stich des Moskitos Aedes aegypti auf den Menschen übertragen. Dieser ist bei Tage aktiv und hält sich in der Nähe von menschlichen Behausungen auf. Andere, für die Infektion von Menschen wichtige Vektoren sind besonders in Asien und Ozeanien - Aedes albopictus, Aedes polynesiensis und Aedes scutellaris. Als Infektionsquelle für Moskitos fungieren Menschen in der virämischen Phase. Nach der Aufnahme von infiziertem Blut muss sich das Virus noch im Moskito 1-2 Wochen vermehren, bis der Vektor die Infektion an andere Menschen weitergeben kann. Ähnlich wie beim Gelbfiebervirus existieren im Wesentlichen zwei verschiedene Übertragungszyklen: ein silvatischer und ein urbaner. Im Unterschied zum Gelbfiebervirus ist jedoch bei den Dengueviren der urbane Zyklus für Epidemien und Endemien am wichtigsten.

\section{Prävention / Impfstoffe}

Eine Vakzine ist zum jetzigen Zeitpunkt noch nicht verfügbar. Daher ist das Vermeiden von Moskitostichen (adäquate Kleidung, Gebrauch von Moskito-Repellentien und Moskitonetzen) hier besonders wichtig. Gegenwärtig ist der vielversprechendste Impfstoffkandidat eine rekombinante Lebendvakzine, die auf dem erfolgreichen 17D-Impfstoff gegen Gelbfieber basiert und immunogene Proteine der Dengueviren enthält. Sie wird zurzeit klinisch getestet.

\section{Ausbruchsmanagement}

Die einzige mögliche Kontrolle besteht gegenwärtig in der Elimination von Aedes-Brutstätten in der Nähe von menschlichen Siedlungen. Endemische Länder sollten ein Labor-gestütztes Überwachungssystem aufbauen, welches eine zumindest grobe Vorhersage der epidemiologischen Situation liefert.

\section{Meldepflicht}

Nach $₫ 6$ des Infektionsschutzgesetzes (IfSG) ist vom feststellenden Arzt bei Krankheitsverdacht, Erkrankung sowie Tod an virusbedingtem hämorrhagischen Fieber der Patient namentlich dem Gesundheitsamt zu melden (unverzüglich, spätestens innerhalb von 24 Stunden). Außerdem ist nach $₫ 7$ jeder direkte oder indirekte (serologische) Nachweis von Dengueviren durch das Labor dann namentlich zu melden, wenn er auf eine akute Infektion hinweist. Diese Meldungen werden entsprechend $\$ 11$ über die zuständigen Landesbehörden an das Robert-Koch-Institut übermittelt. Zusätzlich ist das Auftreten einer Erkrankung auch nach $\$ 12$ IfSG übermittlungspflichtig. Dies bedeutet, dass - zusätzlich zum Übermittlungsweg nach $\$ 6$ und 7 - bestätigte hämorrhagische Verläufe von Denguevirus-Infektionen vom Gesundheitsamt aus unverzüglich an die zuständige oberste Gesundheitsbehörde und von dort unverzüglich an das Robert Koch-Institut zu übermitteln sind, welches dann die Informationen an die WHO weitergibt. Weiterführende Informationen zum IfSG und zur Falldefinition für Gesundheitsämter sind auf der unten aufgeführten Web-Adresse des Robert-Koch-Instituts zu finden.

\section{Weiterführende Informationen}

\section{Referenzzentren / Expertenlaboratorien}

- Deutschland, Nationales Referenzzentrum für tropische Infektionserreger, Bernhard-Nocht-Institut für Tropenmedizin, Bernhard-Nocht-Straße 74, 20359 Hamburg, Tel.: +49-40-42818-401 bzw. 400, E-Mail: MZD@bnihamburg.de

\section{Web-Adressen}

- Robert-Koch-Institut (RKI): http://www.rki.de

- Bernhard-Nocht-Institut für Tropenmedizin (Hinweise auf Tropen-Viruskrankheiten): http://www.bni-hamburg. de/

- Gesellschaft für Virologie: http://www.g-f-v.org/

- Deutsche Vereinigung zur Bekämpfung der Viruskrankheiten e.V.: http://www.dvv-ev.de/

- Centers for disease control and prevention (Empfehlungen und Standards in der Kontrolle und Diagnostik von Infektionen): http://www.cdc.gov/

- Veterinary Public Health (Tierärztliche Hochschule Hannover): http://www.veterinary-public-health.de/home_d/ aufgaben/zoonosen/viren.htm

- WHO World Health Organization (Aktuelles über Infektionskrankheiten, Empfehlungen und Programme der WHO): http://www.who.int/

\section{Schlüsselliteratur}

1. Gubler DJ, Kuno G, Markoff L (2007). Flaviviruses. In: Knipe, DM, Howly, PM (eds) Fields Virology (5th edition), pp. 1153-1252. Philadelphia: Lippincott Williams and Wilkins.

2. Halstead SB (2007) Dengue. Lancet 370:1644-52

3. Schoub BD, Venter M (2009). Flaviviruses. In: Zuckerman 
AJ, Banatvala JE, Pattison JR, Griffiths PD, Schoub BD, Mortimer P (eds) Principles and practice of clinical virology (6th edition), Chichester, John Wiley, pp 669-698

Dermacentor marginatus
Ektoparasiten, sonstige (Stechmücken, Trombiculi-
den, Flöhe, Wanzen, Zecken)

\section{Dermatitis exfoliativa neonatorum Ritter von Rittershain}

Staphylococcus aureus

\section{Dermatobia spp.}

Myiasis-Erreger

\section{Diabetes}

- Coxsackieviren

- Hepatitis C Virus (HCV)

\section{Diarrhoe}

- Acanthocephala

- Balantidium coli

- Blastocystis sp.

- Campylobacter

- Citrobacter

- Clostridium botulinum

- Coxsackieviren

- Cyclospora cayetanensis

- Cytomegalievirus

$\checkmark$ Darmegel

- Darmflagellaten

- Dicrocoelium dendriticum

- Dientamoeba fragilis

- Echoviren und Parechoviren

- Entamoeba histolytica

- Enterobacter

- Escherichia coli

- Giardia lamblia

- Hakenwürmer

- Hepatitis A Virus (HAV)

$\checkmark$ Hymenolepis

- Isospora belli

- Kluyvera, Koserella (Yokenella), Leclercia, Leminorella, Moellerella

- Kryptosporidien

- Leberegel - Opisthorchis, Clonorchis

Legionella

Leishmanien
- Listeria monocytogenes

- Masernvirus

- Mikrosporidien

$\checkmark$ Neisseria meningitidis

- Noroviren

- Plesiomonas

- Rotavirus

- Sarcocystis

- Schistosomen

- Shigella

- Staphylococcus aureus

- Strongyloides stercoralis

- Taenien

- Trichinella spiralis

- Trichuris trichiura

- Vibrio

\section{Diarrhoe, blutige}

- Leberegel-Opisthorchis, Clonorchis

\section{Diarrhoe, blutig-schleimige}

- Entamoeba histolytica

- Escherichia coli (EHEC)

$>$ Shigella

\section{Diarrhoe, chronische}

- Blastocystis sp.

- Trichuris trichiura

\section{Dicrocoeliose}

- Dicrocoelium dendriticum

\section{Dicrocoelium dendriticum}

\section{Erreger}

\section{Synonym(e)}

Dicrocoelium lanceolatum, Lanzettegel, Kleiner Leberegel.

\section{Erregerspezies}

Dicrocoelium dendriticum.

\section{Taxonomie}

Überstamm: Protostomia (Urmünder); Stamm: Plathelminthes (Plattwürmer); Klasse: Trematoda (Saugwürmer); Unterklasse: Digenea; Ordnung: Plagiorchiida; Familie: Dicrocoeliidae 


\section{Historie}

Die Erstbeschreibung des Lanzettegels geht auf Rudolphi (1819) zurück; Mattes (1936), Neuhaus (1939), Krull und Mapes (1952/53) trugen wesentlich zu seiner weiteren Charakterisierung bei.

\section{Morphologie}

Es handelt sich um 5-15 mm lange und 1,5-2,5 mm breite, transparente Saugwürmer (Trematoden) von dorso-ventral abgeplattetem lanzettförmigem Bau, die mit zwei Saugnäpfen und blind endendem Gabeldarm ausgestattet sind. Die Eier sind ausgesprochen resistent gegenüber Hitze, Kälte, Trockenheit und können bis zu 20 Monate infektiös bleiben.

\section{Vermehrung}

Die Ausscheidung der Eier erfolgt mit den Fäzes des Endwirtes. Nach oraler Aufnahme der Eier durch den 1. Zwischenwirt (Landlungenschnecken: Zebrina, Helicella und weitere; insgesamt sind bis zu 100 Landschneckenarten beschrieben) schlüpfen erste Larvenstadien (Miracidium; voll entwickelte Wimpernlarven), und weitere Larven entwickeln sich (Sporozyste I, II und Zerkarie). Der Ausscheidung der Zerkarien in Schleimballen folgen die orale Aufnahme durch den 2. Zwischenwirt (Ameisen, z. B. Formica) und die Entwicklung zur Metazerkarie. Das Eindringen einer Metazerkarie in das Unterschlundganglion der Ameise führt durch eine Beeinflussung des Nervensystems zu einer Verhaltensänderung der Ameise, in deren Folge diese sich an Grashalmen oder anderen Pflanzen festbeißt und durch den Endwirt aufgenommen wird, in dessen Gallengängen schließlich der adulte Wurm heranwachsen kann. Die Eiausscheidung beginnt ca. 9 Wochen p.i. (= Präpatenz, Präpatenzperiode). Kleine Leberegel können bis zu 6 Jahren im Endwirt überleben. Ein kompletter Zyklus dauert ca. 6 Monate. Aus einem Ei können theoretisch bis $\mathrm{zu}$ 400.000 adulte Würmer hervorgehen.

\section{Erkrankung}

Dicrocoeliose

\section{Inkubationszeit}

Bislang unbekannt.

\section{Leitsymptome}

Bauchschmerzen, Verdauungsstörungen, Konstipation, Diarrhoe, Erbrechen.

\section{Symptome}

Krankheitserscheinungen beim Menschen (v. a. abdominelle Symptome wie Bauchschmerzen, Erbrechen, Stuhlunregelmäßigkeiten) sind selten, da das zufällige Verschlucken von Ameisen in der Regel nicht zu massivem Befall führt. Bei entsprechender Befallstärke kann D. dendriticum als Gallengangparasit eine Erweiterung der Gallengänge, Hypertrophie des Epithels und Wandverdickungen verursachen, mitunter vergesellschaftet mit Blut-Eosinophilie und erhöhten Bilirubin- und IgE-Werten im Serum.

\section{Differenzialdiagnose}

Differenzialdiagnostisch sind eine Opisthorchose sowie Gallenwegerkrankungen anderer Genese zu bedenken.

\section{Diagnostik \\ Untersuchungsmaterial \\ Stuhl.}

\section{Diagnostische Verfahren}

Die Labordiagnose stützt sich auf den mikroskopischen Nachweis der mit dem Stuhl ausgeschiedenen dunkelbraunen, ovalen und gedeckelten Eier von 38$45 \times 22-30 \mu \mathrm{m}$ Größe.

\section{Befund/Interpretation}

Der positive Befund aufgrund einer einzigen Stuhluntersuchung ist noch nicht beweisend für einen tatsächlichen Befall mit D. dendriticum (Ausschluss eines Pseudoparasitismus bei Darmpassage durch Verzehr befallener Schafleber).

\section{Therapie}

\section{Therapeutische Maßnahmen}

Eine gezielte Therapie ist unbekannt; möglicherweise kommen Praziquantel, Albendazol oder Triclabendazol in Frage.

\section{Epidemiologie}

\section{Verbreitung}

Die Dicrocoeliose ist als Zoonose weltweit, vor allem aber in Eurasien und Nordafrika verbreitet. In Europa sind vor allem die kalkhaltigen Mittelgebirge und das Alpenvorland betroffen.

\section{Wirtsbereich}

Lanzettegel sind in erster Linie Parasiten der Wiederkäuer und anderer herbivorer Säugetiere. Der Mensch stellt nur einen akzidentiellen Endwirt dar.

\section{Risikogruppen}

Die Dicrocoeliose wird nur selten beim Menschen beobachtet. Gehäuft tritt sie bei Hirten und Feldarbeitern auf, Einzelfälle bei HIV-Infizierten und bei einem Patienten mit Morbus Crohn unter immunsuppressiver Therapie sind in der Literatur beschrieben.

\section{Transmission}

Eine Übertragung auf den Menschen kann akzidentiell durch die orale Aufnahme infizierter Ameisen zustande kommen, die sich an Grashalmen und anderen Pflanzen befinden. 


\section{Prävention}

Eine Dicrocoelium-Infektion ist allein dadurch vermeidbar, dass keine an Gräsern oder Vegetabilien befindlichen Ameisen verschluckt werden.

\section{Meldepflicht}

Eine Meldepflicht nach dem Infektionsschutzgesetz besteht nicht.

\section{Weiterführende Informationen}

\section{Referenzzentren, Expertenlaboratorien}

- Offizielle Referenzzentren existieren nicht; als fachlich qualifiziert anzusehen sind parasitologische und tropenmedizinische Institutionen.

\section{Web-Adressen}

- CDC-Center for Disease Control and Prevention: http:// www.dpd.cdc.gov/dpdx/html/Dicrocoeliasis.htm

\section{Schlüsselliteratur}

1. Magi B, Frati E, Bernini L, Sansoni A, Zanelli G (2009) Dicrocoelium dendriticum: a true infection? Infez Med 17:115-116

2. Manga-González MY, González-Lanza C (2005) Field and experimental studies on Dicrocoelium dendriticum and dicrocoeliasis in Northern Spain. J Helminthol 79:291-302

3. Rack J, Adusu E, Jekinek T (2004) Human infection with Dicrocoelium dendriticum. Dtsch Med Wochenschr 129:2538-2540

4. Rommel M et al. (Hrsg) (2000) Veterinärmedizinische Parasitologie. Paul Parey, Berlin

5. Schweiger F, Kuhn M (2008) Dicrocoelium dendriticum infectioin in a patient with Crohn's disease. Can J Gastroenterol 22:571-573

\section{Dientamoeba fragilis}

- Darmflagellaten

\section{Diphtherie}

Corynebacterium diphtheriae

\section{Diphtheriebakterium}

- Corynebacterium diphtheriae

\section{Diphyllobothriasis}

- Diphyllobothrium

\section{Diphyllobothrium}

Peter Kern

\section{Erreger}

\section{Synonym(e)}

Diphyllobothrium latum, Dibothriocephalus latus, Bothriocephalus latus, Breiter Fischbandwurm, Fischbandwurm.

\section{Erregerspezies}

Diphyllobothrium latum.

\section{Taxonomie}

Unterklasse: Eucestoda; Ordnung: Diphyllobothriidae

\section{Historie}

D. latum wurde erstmals 1592 durch Thadeus Dunus in Locarno beschrieben. Später, 1819, findet sich eine detaillierte Beschreibung mit der Bezeichnung Bothriocephalus latus im Lehrbuch der Helminthologie von Johann Gottfried Bremser. In Infektionsversuchen erkannte Maximilian Braun 1880/83 in verschiedenen Fischarten die Träger der Plerozerkoide und damit die Infektionsquelle für den Menschen. Die derzeit gültige Bezeichnung geht auf Maximilian Lühe zurück.

\section{Morphologie}

Der Bandwurm ist 8-20 m lang und 15-20 mm breit. Fingerförmiger Skolex mit beiderseits je einer Sauggrube; die Gliederkette (Strobila) besteht aus bis zu 4.000 Proglottiden, die breiter als lang sind; Uterus der reifen Proglottiden rosettenförmig mit Öffnung (Tocotrema), durch die die Eier ins Darmlumen entlassen werden. Die Eier sind ca. $65 \times 45 \mu \mathrm{m}$ groß gelb-braun und sind von Trematodeneiern kaum zu unterscheiden.

\section{Genom}

Nicht entschlüsselt.

\section{Vermehrung}

D. latum gehört zu den triheteroxenen Helminthen (mit Endwirt und zwei Zwischenwirten). Entwicklungszyklus: Ausscheidung der Eier mit dem Stuhl des Endwirts $\rightarrow$ Weiterentwicklung nur im Süßwasser $\rightarrow$ Schlüpfen des 1. Larvenstadiums (Korazidium) $\rightarrow$ Aufnahme der Korazidien durch den 1. Zwischenwirt (Kleinkrebse: Copepoden) und Weiterentwicklung zum 2. Larvenstadium (Prozerkoid) $\rightarrow$ Aufnahme der Prozerkoide durch den 2. Zwischenwirt (planktonfressende Fische) und Weiterentwicklung zum infektiösen 3. Larvenstadium (Plerozerkoid, Synonym Sparganum) $\rightarrow$ orale Aufnahme der Plerozerkoide durch den Endwirt und Ansiedlung im Darmtrakt. Neben den 2. Zwischenwirten spielen für die Infektion des Endwirts als paratenische Wirte fungierende Fische eine 
besondere Rolle; dabei handelt es sich um Raubfische, die sich von infizierten Friedfischen ernähren, sodass es in ihnen zur „Anreicherung“ von Plerozerkoiden kommt (Stapelwirte). Nach Aufnahme befallenen Fried- oder Raubfischfleisches durch den Menschen siedelt sich der Wurm bevorzugt im vorderen Dünndarm an und wächst sehr schnell heran. Der Mensch beherbergt meist nur einen Wurm, der 10-20 Jahre leben kann.

\section{Pathogenität / Virulenz / Antigenvariabilität}

Der Bandwurm reichert selektiv Vitamin B12 an, das er jedoch für den eigenen Stoffwechsel nicht benötigt. Infolge Vitaminmangels kann sich daher beim Menschen eine lebensgefährliche perniziöse Anämie entwickeln.

\section{Erkrankung \\ Fischbandwurm-Infektion}

Synonym(e)

Diphyllobothriasis.

\section{Inkubationszeit}

Die Präpatenzzeit ist kurz und beträgt 3 bis 6 Wochen. Die Zeit bis zum Auftreten der Symptome einer megaloblastären Anämie oder neurologischer Folgeerscheinungen infolge Vitaminmangels kann sich über Wochen und Jahre erstrecken.

\section{Leitsymptome}

Asymptomatisch, abdominelle Beschwerden, VitaminB12-Mangelanämie, Mattigkeit, Schwindel.

\section{Symptome}

Die Infektion bleibt meist symptomlos. Gelegentlich sind uncharakteristische abdominelle Beschwerden vorhanden. D.-latum-Befall kann sich als megaloblastäre Anämie äußern infolge der selektiven Aufreicherung von Vitamin B12 im Bandwurm, für den jedoch Vitamin B12 nicht essenziell ist. Bei anhaltender Infektion können neurologische Erscheinungen des Vitamin-B12-Mangels entstehen (Neuropathien mit Parästhesien und Sensibilitätsstörungen). Neurologische Symptome kommen gelegentlich auch ohne manifeste Anämie vor.

\section{Differenzialdiagnose}

Andere Wurmerkrankungen, konsumierende Erkrankungen, megaloblastäre Anämie anderer Ursache, Malabsorptionszustände, Folsäuremangel.

\section{Diagnostik}

Untersuchungsmaterial

Stuhlprobe.

\section{Diagnostische Verfahren}

Stuhl: Anreicherungsverfahren (MIF- oder SAF-Anreicherung).
Blut: Diskrete Eosinophilie. Serologische Verfahren sind nicht etabliert.

Bildgebende Diagnostik: Nicht hilfreich.

\section{Befund / Interpretation}

Nachweis der charakteristischen ovalen, gedeckelten, goldgelben Eier, typische Morphologie der Bandwurmanteile.

\section{Therapie}

\section{Therapeutische Maßnahmen}

Therapie der Wahl ist Praziquantel in einer Einmaldosis von $10 \mathrm{mg} / \mathrm{kg} \mathrm{KG}$. Alternativ kann Niclosamid in einer Einmaldosis von $2 \mathrm{~g}$ gegeben werden. Die Heilungsraten liegen bei 90-100\%. Da der Skolex gelegentlich eine Behandlung überleben kann, sind mehrere Stuhlkontrollen nach frühestens 3-4 Wochen empfehlenswert. Die Vitaminsubstitution ist zur Beherrschung der vorliegenden Anämie und der neurologischen Auswirkungen erforderlich.

\section{Epidemiologie}

\section{Verbreitung}

D. latum war in den nördlichen Seengebieten von Europa sehr verbreitet, kommt sporadisch auch im Donaudelta und an den südalpinen Seen in Oberitalien, Frankreich und der Westschweiz vor, außerdem in Russland, Japan, Nord- und sogar Südamerika. Man rechnet mit ca. 20 Mio. infizierten Menschen weltweit. In Finnland waren noch in den 70er Jahren mehr als $10 \%$ der Bevölkerung befallen, heute werden nur noch ca.20 Fälle pro Jahr erfasst. Starke Verbreitung weiterhin in Ostsibirien, in bestimmten Seengebieten wird eine Prävalenz von bis zu 3,0 \% erreicht.

\section{Wirtsbereich / Reservoir}

Neben dem Menschen fungieren fischfressende Säugetiere (Hund, Katze und Bär) als Endwirt von D. latum.

\section{Risikogruppen}

Personen, die Fische in rohem oder nur in schwach gesalzenem Zustand verzehren.

\section{Transmission / Vektoren}

Ein D.-latum-Befall des Menschen kommt ausschließlich durch den Verzehr von rohem oder ungarem Fleisch von Raubfischen wie Hecht, Aalquappe, Barsch oder Kaulbarsch, seltener der Äsche zustande. Verbreitung weltweit, besonders entlang der Küsten. Süß- und Meerwasserfische können infiziert sein.

\section{Meldepflicht}

Es besteht keine Meldepflicht.

\section{Weiterführende Informationen}

\section{Referenzzentren / Expertenlaboratorien}

- Offizielle Referenzzentren existieren nicht; als fachlich 
qualifiziert anzusehen sind sämtliche parasitologischen und tropenmedizinischen Institutionen.

\section{Web-Adressen}

- Dt. Gesellschaft für Tropenmedizin und Internationale Gesundheit:http://www.dtg.org

- Deutsche Gesellschaft für Parasitologie: http://www. dgparasitologie.de

- Deutsche Veterinärmedizinische Gesellschaft: http:// www.dvg.net

- CDC-Center for Disease Control and Prevention: http:// www.cdc.gov/

- WHO-World Health Organization: http://www.who.int/

\section{Schlüsselliteratur}

1. Beaver PC, Jung RC, Cupp EW (1984) Clinical Parasitoloy. $9^{\text {th }}$ edn. Lea \& Febiger, Philadelphia

2. Bonsdorff B von (1977) Diphyllobothriasis in man. Academic Press, London

3. Despommier DD, Gwadz RW, Hotez PJ (1995) Parasitic Diseases. $3^{\text {rd }}$ edn. Springer-Verlag, New York

4. Löscher T, Burchard GD (Hrsg) (2010) Tropenmedizin in Klinik und Praxis. 4. Aufl. Georg Thieme Verlag, Stuttgart

5. Mehlhorn H, Eichenlaub D, Löscher T, Peters W (1995) Diagnostik und Therapie der Parasitosen des Menschen. 2. Aufl. Gustav Fischer Verlag, Stuttgart

6. Scholz $\mathrm{T}$ et al. Update on the human broad tapeworm (Genus Diphyllobotrium), including clinical relevance. Clin Microbiol Reviews (2009) 22:146-160

\section{Dipylidiasis}

Cestoden, seltene Arten

\section{Dipylidium caninum}

- Cestoden, seltene Arten

\section{Dobrava-Virus}

$>$ Hantaviren

\section{Dracunculose}

$\rightarrow$ Dracunculus medinensis

\section{Dracunculus medinensis}

Erreger

Synonym(e)

Guineawurm, Medinawurm.

\section{Erregerspezies}

Dracunculus medinensis.

\section{Taxonomie}

Klasse: Nematoda, Ordnung: Camallianida, Familie: Dracunculidae

\section{Historie}

Der Guineawurm war bereits im Altertum bekannt. Seine Erstbeschreibung geht auf Linné (1758), die Aufklärung des Entwicklungszyklus auf Fedtschenko (1870) zurück. Die Extraktion des weiblichen Wurmes durch Aufrollen auf ein Holzstäbchen diente vermutlich als Vorbild für den Äskulapstab.

\section{Morphologie}

Dracunculus ist ein weißlicher, fadendünner Rundwurm mit für Nematoden typischem Aufbau: Kutikula, Subkutikula (Hypodermis) und Längsmuskulatur, Pseudozoel und durchgehendem Darm. Die Weibchen erreichen eine Länge von bis $\mathrm{zu} 80 \mathrm{~cm}$ bei einem Durchmesser von 0,7-1,7 mm. Die sehr viel kleineren Männchen sind lediglich 1-4 cm lang mit einem Durchmesser von ca. 0,4 mm. Larven sind 500-700 $\mu \mathrm{m}$ groß.

\section{Vermehrung}

Die Infektion beginnt mit der oralen Aufnahme von kleinen Süßwasserkrebsen der Gattung Cyclops durch kontaminiertes Trinkwasser. Diese werden im Magen zerstört und setzen Wurmlarven frei, die die Darmwand penetrieren. Sie wandern durch die Bauchhöhle zu subkutanen Geweben und wachsen dort aus. Dieser Prozess dauert ca. 40 Tage. Nach geschlechtlicher Vermehrung stirbt das kleinere Männchen. Das Weibchen wandert zu Hautstellen, die Kontakt zu Wasser haben (meist Füße und Beine), und produziert ca. 3 Millionen Embryonen, die ca. 10-14 Monate nach Infektion an die Umgebung abgesetzt werden, indem das Weibchen bei Wasserkontakt die Haut durchbohrt. Die Larven sind im Wasser einige Tage bis Wochen überlebensfähig.

\section{Pathogenität/Virulenz/Antigenvariabilität}

Das Weibchen induziert - wohl durch eine Vielzahl von Antigenen (von denen allerdings wegen des Fehlens eines geeigneten Tiermodells nicht bekannt ist, ob sie sezerniert werden), eine Th2-vermittelte Immunreaktion, die zur Gewebsauflösung und zu einer flüssigkeitsgefüllten Blase führt, die der Wurm leichter durchbohren kann. Freisetzung von Wurmlarven durch vorzeitiges Absterben der Weibchen oder deren Zerstörung bei der Extraktion führt zu einer Verstärkung der Th2-abhängigen Symptome (s. u.). Über Antigenvariabilität ist nichts bekannt.

\section{Erkrankung \\ Dracunculose}

\section{Leitsymptome}

Fieber, Übelkeit, Erbrechen, Urtikaria, schmerzhafte Schwellungen. 


\section{Symptome}

Nach ca. 10-14 Monaten entstehen im Bereich der im Unterhautbindegewebe angesiedelten DracunculusWeibchen (zu $90 \%$ an den unteren Extremitäten) schmerzhafte Schwellungen. Über dem oberflächlich gelegenen Vorderende des Parasiten bildet sich ein flüssigkeitsgefülltes Bläschen, das schließlich platzt und das Vorderende freisetzt. Meist heilt das entstandene Ulkus komplikationslos ab; in vielen Fällen (ca. 30 \%) kommt es jedoch zu bakteriellen Sekundärinfektionen mit dem Bild einer Phlegmone. Außerdem kann das Ulkus auch die Eintrittspforte für eine Tetanusinfektion werden. Kurz vor dem Platzen der Blase können Fieber, Urtikaria, Übelkeit, und Erbrechen und manchmal auch eine Dyspnoe auftreten.

\section{Immunantwort}

Die Infektion ruft eine starke Th2-vermittelte Immunantwort mit Eosinophilie, IgE- und IgG-Antikörperproduktion hervor. Sie hinterlässt keinen Schutz gegen Neuinfektionen.

\section{Differenzialdiagnose}

Die uncharakteristischen Begleitsymptome bei Durchbruch der Dracunculus-Weibchen nach außen lassen Differenzialdiagnosen wie Wund- bzw. Hautinfektionen anderer Genese zu.

\section{Diagnostik}

\section{Untersuchungsmaterial}

Nach Bläschenbildung und Durchbruch des Dracunculus-Weibchens nach außen wird sein Vorderende sichtbar, so dass die Diagnose keine Schwierigkeiten bietet.

\section{Diagnostische Verfahren}

Makroskopische Inspektion der Haut.

\section{Therapie}

\section{Therapeutische Maßnahmen}

Die einzige therapeutische Maßnahme besteht in der Extraktion des weiblichen Wurmes. Zur Vorbereitung der Extraktion kann durch gleichzeitige Therapie mit Metronidazol (400 mg/d für 10-20 Tage) oder Thiabendazol erleichtert werden. Für die Extraktion selbst provoziert man das Heraustreten des Wurmvorderendes durch ein kaltes Wasserbad, klemmt das Vorderende in ein gespaltenes Stäbchen, zieht den Wurm vorsichtig wenige Zentimeter heraus und wickelt ihn auf das Stäbchen. Dieses Vorgehen wird solange täglich wiederholt, bis der Wurm komplett entfernt ist, was ca. 2-4 Wochen dauert. Zusätzlich hat eine antiseptische Wundbehandlung zu erfolgen. Phlegmonen und Abszesse erfordern eine chirurgische Behandlung.

\section{Epidemiologie}

\section{Verbreitung}

Die Dracunculose ist eine tropische Wurminfektion, deren Verbreitungsareal noch vor Jahren vom Senegal in Westafrika bis nach Indien in Südasien reichte. Mittlerweile wurde diese Infektion jedoch durch ein Eradikationsprogramm (WHO, im Verbund mit dem Carter-Center, Atlanta, USA) weit zurückgedrängt (5000 gemeldete Fälle in 2008) und betrifft derzeit nur noch einige Länder in regenarmen Regionen des subsaharischen Afrika (Sudan, Ghana, Nigeria, Niger, Mali, Äthiopien). In Asien ist die Infektion ausgerottet. Die Infektion tritt in der Regel streng saisongebunden auf: in regenreichen Gebieten mit maximaler Inzidenz in der Trockenzeit, wenn Reste von Gewässern zurückbleiben, in regenarmen Gebieten jedoch in der Regenzeit, wenn sich Tümpel füllen und zur Trinkwassergewinnung benutzt werden ( $\triangleright$ Abb. 1$)$.

\section{Wirtsbereich/Reservoir}

Neben dem Menschen können Hunde, Pferde, Kühe, Affen und andere Tiere infiziert werden. Als Zwischenwirte dienen zahlreiche Spezies von Copepoden (Wasserkrebsen).

\section{Risikogruppen}

Ein erhöhtes Infektionsrisiko besteht in den Endemiegebieten, vor allem für diejenigen Bevölkerungsgruppen, die ihr Trinkwasser aus freien Gewässern beziehen müssen und dieses weder durch Kochen noch durch Filtrieren aufbereiten.

\section{Transmission/Vektoren}

Die Übertragung von Dracunculus auf den Menschen kommt allein durch Verschlucken infizierter Kleinkrebse mit dem Trinkwasser zustande.

\section{Prävention/Impfstoffe}

Wichtigste Präventionsmaßnahme ist das Filtrieren (Maschenweite 0,15 mm) oder Abkochen des Trinkwassers. Die von der Weltgesundheitsorganisation (WHO) entwickelten erfolgreichen Strategien zur Bekämpfung der Dracunculose umfassen die Aufklärung und Versorgung der Bevölkerung mit sicherem Trinkwasser.

\section{Meldepflicht}

Eine Meldepflicht nach dem Infektionsschutzgesetz besteht nicht.

\section{Weiterführende Informationen}

\section{Referenzzentren, Expertenlaboratorien}

- Offizielle Referenzzentren existieren nicht; als fachlich qualifiziert anzusehen sind parasitologische und tropenmedizinische Institutionen. 


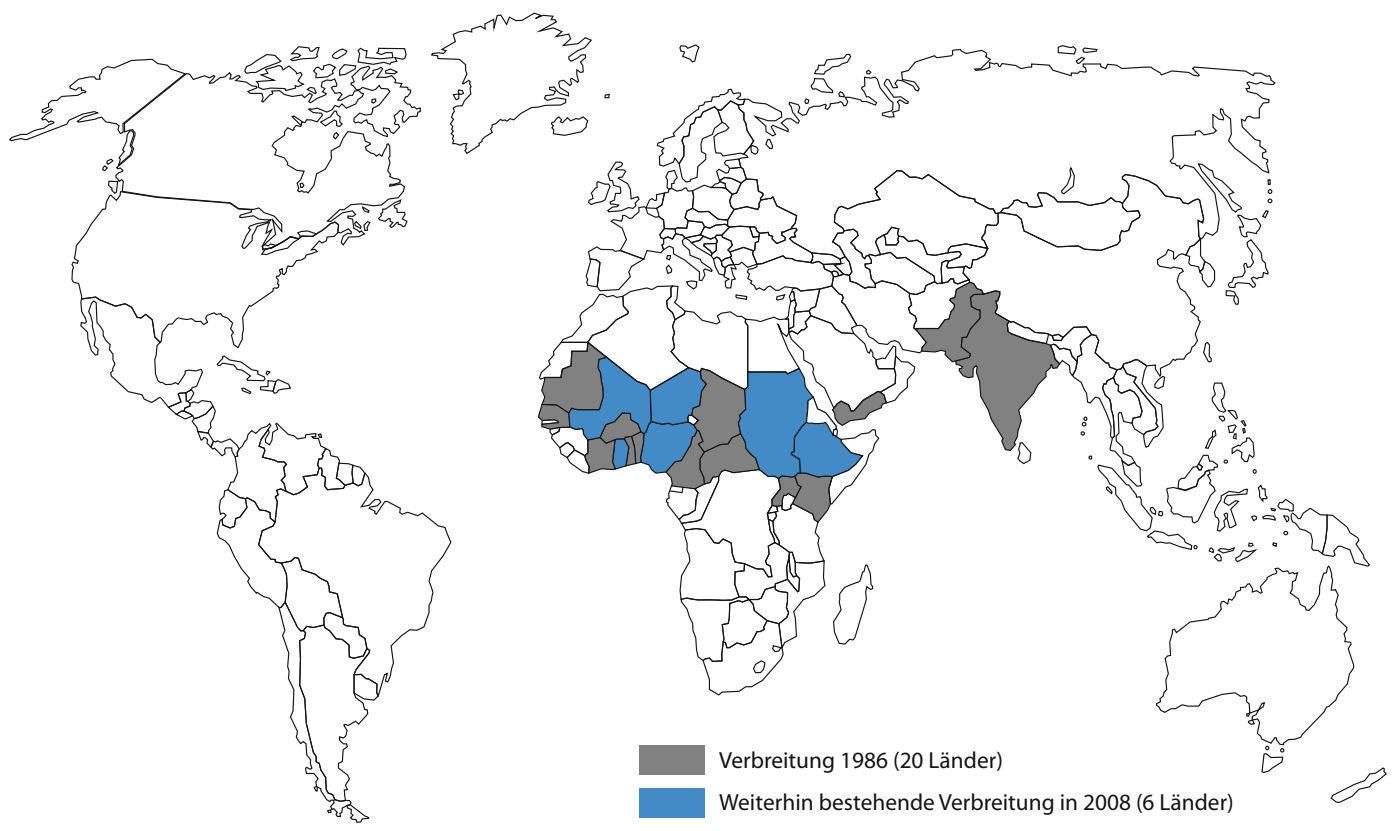

- Abb. 1. Verbreitungsgebiet von Dracunculus

Web-Adressen

- CDC-Center for Disease Control and Prevention: http:// www.cdc.gov/guineaworm/

- WHO-World Health Organization: http://www.who.int/ topics/dracunculiasis/en/

\section{Schlüsselliteratur}

1. Beaver PC, Jung RC, Cupp EW (1984) Clinical Parasitology, 9th edn. Lea \& Febiger, PhiladelphiaDysurie-Syndrom, 231

2. Despommier DD, Gwadz RW, Hotez PJ (1995) Parasitic Diseases. 3rd edn. Springer-Verlag, New York

3. Ruiz-Tiben E, Hopkins DR (2006). Dracunculiasis (Guinea worm disease) eradication. Adv Parasitol 61:275-309

\section{Dreitagefieber}

- Cardioviren

- Humanes Herpesvirus 6 (HHV-6)

\section{Dugbe-Virus}

> Bunyaviren

\section{Dysurie-Syndrom}

Staphylococcus (koagulasenegativ) 


\section{Early-onset-Sepsis}

- Streptococcus agalactiae

\section{Eastern-Equine-Enzephalitis-Virus}

Alphaviren

\section{Ebolavirus}

Filoviren

\section{Echinokokken}

\section{Erreger}

Peter Kern

\section{Synonym(e)}

Echinococcus (Rudolphi, 1801); Hundebandwurm, Echinococcus granulosus (Batsch, 1786); Kleiner Fuchsbandwurm; Echinococcus multilocularis (Leukart, 1863); Echinococcus oligarthus (Diesing, 1863); Echinococcus vogeli (Rausch und Bernstein, 1972); Echinococcus shiquicus.

\section{Erregerspezies}

Echinococcus granulosus (Genotypen G1-G10 u. a. mit den vorläufigen Artbezeichnungen E. granulosus sensu strictu [G1-G3, Zwischenwirt Schaf], E. equinus [G4, Zwischenwirt Pferd], E. ortleppi [G5, Zwischenwirt Rind], E. canadensis [G6-G9, Zwischenwirt Schwein], sowie der möglichen neuen Art E. felidis);

E. multilocularis; E. shiquicus (neue in China/Tibet beschriebene Art);

E. oligarthrus und E. vogeli, die südamerikanischen Erreger

\section{Taxonomie}

Klasse: Cestoda; Ordnung: Cyclophyllidea; Familie: Taeniidae; Gattung Echinococcus

\section{Historie}

Die zystische Echinokokkose war schon im Altertum als Erkrankung bei Menschen und Tieren bekannt; für die wassergefüllten Zysten in der Leber hat sich im 19. Jh. der Begriff „Hydatide“ eingebürgert (Rudolphi 1810). Die Herkunft der Zysten aus tierischem Gewebe wurde 1760 von Pallas (Leiden) erkannt, und wurde 1782 endgültig durch Goeze (Quedlinburg) nach- gewiesen, der bei Zysten aus Tieren und Menschen die Protoskolizes beschrieb und als Bandwurmköpfe erkannte. Nachdem der Entwicklungszyklus des Parasiten durch die Infektion von Hunden mit Zysten aus Schafen von v. Siebold 1852 (Breslau) aufgeklärt war, wurde 1864 von Naunyn (Berlin) die Ätiologie der menschlichen Erkrankung durch Infektion von Hunden mit Material aus infizierten menschlichen Lebern bewiesen. Die chirurgische Entfernung der Zysten war schon im 16. Jahrhundert erstmalig erfolgreich. Bei günstiger Lokalisation der Zysten in Leber, Lunge oder anderen Organen galt die Krankheit schon früh als prinzipiell heilbar. Die eigentliche Erforschung begann daher im 19. Jahrhundert und geht auf die Untersuchungen von Siebold, Haubner, Leuckart, Küchenmeister u. a. zurück. Dabei stellte sich heraus, dass die im Menschen sowie in herbivoren und omnivoren Säugetieren parasitierenden Larven derselben Art angehören und dass für diese in erster Linie der Haushund als Endwirt dient. Seitdem wurden zahlreiche Subspezies und Varianten beschrieben, so der E. granulosus sensu strictu mit dem Haushund als Endwirt und domestischen Ungulaten als Zwischenwirt, der sich in Europa entwickelte und dann weltweite Verbreitung erfuhr. Im arktischen Nordamerika kommt E. granulosus mit dem Endwirt Wolf und wild lebenden Wiederkäuern als Zwischenwirt vor. McManus und Thompson (2008) haben vorgeschlagen, die unterschiedlichen biologischen und genetischen Eigenschaften von E. granulosus weiter aufzugliedern. Danach werden der Granulosus-Gruppe als weitere (Sub-)Arten E. ortleppi, (G5, Zwischenwirt Rind), E. equinus (G4, Zwischenwirt Pferd) und E. canadensis (G7, Zwischenwirt Schwein) zugeordnet. E. felidis ist eine neue Art, die 2009 beschrieben wurde. Eine abschließende taxonomische Zuordnung für den gesamten Komplex steht noch aus.

E. multilocularis ist seit ca. 150 Jahren bekannt. „Unitarier" und "Dualisten" stritten sich lange Zeit um die Frage, ob der „alveoläre Echinococcus“ lediglich eine besondere Wuchsform der Larve von E. granulosus repräsentiert oder es sich um eine eigene Spezies handelte. Erst durch die Untersuchungen von Rausch in Alaska und Vogel auf der Schwäbischen Alb vor etwa 60 Jahren konnte die Eigenständigkeit des E. multilocularis als eigene Art nachgewiesen und damit der Streit beendet werden. Zwei weitere Arten treten in Südamerika auf (E. oligarthus und E. vogeli), kürzlich wurde eine neue Art in Shiqu/Tibet (E. shiquicus) identifiziert. 


\section{Morphologie}

Sehr kleine Bandwürmer (Länge 1,2-7 mm) mit zweiwirtigem Entwicklungszyklus. Die im Darmtrakt des Endwirts parasitierenden adulten Bandwürmer besitzen einen mit vier Saugnäpfen und zwei Hakenkränzen am Rostellum ausgestatteten Skolex. Die Adulti der verschiedenen Arten unterscheiden sich in Körperlänge, Anzahl, Länge und Form der Haken, Anzahl der Proglottiden und Testes u. a. Merkmalen. Die Larven (Finnen, bei E. granulosus auch Hydatiden genannt) sind Organparasiten der Zwischenwirte (herbivore und omnivore Säugetiere, Mensch) und unterscheiden sich morphologisch (zystisch, alveolär oder polyzystisch). Im Inneren der blasenförmigen Finnen entwickeln sich die Protoskolizes, aus denen im Endwirt die Adultwürmer hervorgehen.

E. granulosus: 2-7 mm langer Bandwurm mit 2-7 mm langer Strobila, im Darm des Hundes u. a. Carnivoren, mit 37-42 $\mu \mathrm{m}$ langen großen und 29-34 $\mu \mathrm{m}$ langen kleinen Haken am Rostellum, 3-4 (-6) Proglottiden und einem Uterus mit seitlichen Aussackungen.

E. multilocularis: 1,2-3,7 mm langer Bandwurm im Darm von Rotfuchs (Vulpes vulpes) und anderen Carnivoren, mit ca. $31 \mu \mathrm{m}$ langen großen und ca. $27 \mu \mathrm{m}$ langen kleinen Haken am Rostellum, 4-5 (2-6) Proglottiden und einem sackförmigen Uterus. Die Larve vom alveolären Typ stellt ein Gebilde aus vielen kleinen Kämmerchen (multi loculus) dar, das infiltrativ durch exogene Sprossung weiter wuchert. Einzelbläschen sind nur wenige Millimeter groß, bestehen aus einer gallertartigen Matrix im Inneren und enthalten die von der Keimschicht gebildeten Protoskolizes.

E. oligarthrus: Kleine Bandwürmer von 1,9-2,9 mm Länge mit drei Proglottiden; gravide Proglottide mit sackförmigem Uterus.

E. vogeli: 3,9-5,6 mm langer Bandwurm mit drei Proglottiden und gravidem Uterus ohne Seitenzweige oder Aussackungen.

\section{Genom}

Das Echinococcus-Genom ist weitgehend entschlüsselt. (Hinweise zu den Netzwerken $>$ Web-Adressen).

\section{Vermehrung}

Die im Darm des Endwirts parasitierenden adulten Würmer enthalten in ihren graviden Proglottiden 500-1000 Eier vom Taenientyp $(32-39 \times 24-26 \mu \mathrm{m})$. Die Anzahl der Eier hängt von der Wirtsspezies und vom Alter der Infektion ab; diese beträgt bei jungen Würmern 200-500/Glied, geht später aber drastisch zurück. Nach Ausscheidung der Eier mit dem Kot und oraler Aufnahme durch einen Zwischenwirt schlüpft die Larve (Onkosphäre) und dringt in die Darmwand ein. Aus der Onkosphäre entwickelt sich ein blasenförmiges Gebilde, das expansiv zur Zyste heranwächst und im Inneren Protoskolizes enthält. Die weitere Vermehrung erfolgt erregerabhängig durch endogene bzw. exogene Sprossung. Der Endwirt infiziert sich durch Verzehr von Protoskolizes enthaltenden Zysten. Infertil ist eine Zyste, wenn keine Brutkapseln gebildet werden. In seinem Darmtrakt entsteht aus jedem Protoskolex ein adulter Bandwurm.

\section{Pathogenität / Virulenz / Antigenvariabilität}

Die erwachsenen Würmer verursachen im Endwirt keine nennenswerten Symptome. Mit einer immunologisch inerten Lamellarschicht kapselt sich die Larve vollständig im jeweiligen Wirtsorgan ab und wird daher vom Immunsystem nur erkannt, wenn die Integrität dieser Hülle (Endozyste) verletzt ist. Der Wirt umschließt die sich bildende Blase mit Granulationsgewebe. Das Wachstumsverhalten der Larve im Zwischenwirt ist bei jeder Art verschieden. Kennzeichen der E.-granulosus-Larve ist das benigne Wachstum durch endogene Sprossung, während die E.-multilocularis-Larve durch exogene Sprossung infiltrativ in das befallende Organ und das benachbarte Gewebe einwuchert und über Blut- oder Lymphwege Fernmetastasen setzt. Die Aufteilung in separate Krankheitsbilder begründet sich daher mit dem biologischen Verhalten des Erregers im Zwischenwirt.

\section{Erkrankungen}

\section{Alveoläre Echinokokkose}

\section{Synonym(e)}

E.-multilocularis-Infektion; Die Bezeichnung E. alveolaris ist veraltet und sollte auch im klinischen Kontext nicht mehr verwendet werden.

\section{Inkubationszeit}

Die Inkubationszeit beträgt wahrscheinlich mehr als 10-15 Jahre.

\section{Leitsymptome}

Hepatomegalie, Oberbauchbeschwerden, Ikterus; Zeichen einer konsumierenden Erkrankung.

\section{Symptome}

Primärer Ansiedlungsort der E. multilocularis-Larve beim Menschen ist in $98 \%$ der Fälle die Leber. Das langsame Wachstum der Geschwulst verursacht in der Regel keine Symptome. Typisch ist daher, dass die Erkrankung häufig zufällig festgestellt wird. In fortgeschrittenen Stadien bestehen Allgemeinsymptome (BSymptome, z. B. Nachtschweiß, Gewichtsabnahme, Müdigkeit). Diese erwecken den Verdacht auf eine maligne Erkrankung. Mit der Kompression wichtiger Gefäße in der Leber können weitere Symptome (Ikterus, Ösophagusvarizen, Caput Medusae) hinzutreten. Das Einwuchern in benachbarte Organe verursacht weitere Krankheitszeichen (Zwerchfell, Perikard, Mammae, Haut u. a.). Auch drainierende Lymphknoten werden besiedelt. Bei hämatogener oder lymphogener Streuung kann eine Ansiedlung in allen Organen (zentrales und peripheres Nervensystem, Knochen, Herz u. a.) erfolgen. Die Ausdehnung der parasi- 
tären Geschwulst in der Leber und in weiteren Organen wird mit der PNM-Einteilung (WHO-Klassifikation der alveolären Echinokokkose) erfasst. In Anlehnung an das TNM-System für Lebertumore wird das anatomische Ausbreitungsmuster beschrieben. P 1-4 bezeichnet die parasitäre Läsion in der Leber, $\mathrm{N}$ die Beteiligung benachbarter Organe, einschließlich der Lymphknoten und $\mathrm{M}$ den Befall weiterer Organe durch Fernmetastasierung. Die Stadieneinteilung I-IV gruppiert die unterschiedlichen Ausprägungen.

\section{Pathophysiologie}

Nach dem Schlüpfen der Onkosphäre im Dünndarm gelangt die Larve über die Vena porta in die Leber und siedelt sich häufig im rechten Leberlappen an. Über viele Jahre entwickeln sich eine oder mehrere Läsionen, die jeweils aus vielen winzigen Bläschen (Durchmesser 1-3 mm) bestehen, im Schnittpräparat kompakt imponieren und morphologische Ähnlichkeit mit Alveolen haben. Die Hohlräume sind angefüllt mit einer gallertigen Masse. Wesentliches Kennzeichen ist das infiltrative Wachstum der Larve und die geringe Abwehr seitens des Wirtsorganismus. Beim Menschen finden sich sehr selten Protoskolizes. In der modernen Bildgebung (Magnet-Resonanz-Tomographie) sind die traubenförmigen Formationen charakteristisch. Eingebettet und durchzogen wird die Geschwulst von derbem, wenig strukturiertem Bindegewebe mit Fremdkörper-Riesenzellen und einem schmalen Lymphozytensaum. Am Rande sind Kalkeinlagerungen häufig. Mit pilzähnlichen Fortsätzen wuchert die Larve durch den Bindegewebspanzer hindurch in das noch unbeteiligte Gewebe ein und durchbricht die Organgrenze. Die Größe der Läsion kann sehr unterschiedlich sein, z. B. kleine, weit über die Leber verteilte Knötchen (Durchmesser 1-2 cm) bis zum riesigen Konglomerattumor, der sich über mehrere Lebersegmente erstrecken kann. Bei einem Teil der Patienten entsteht im Zentrum der Läsion eine Zerfallshöhle, die in der Bildgebung als „Pseudozyste“ imponiert. Der Inhalt besteht aus Zelldetritus und Galleflüssigkeit, selten kann die Nekrosehöhle auch sekundär bakteriell besiedelt sein. Ein besonderes Kennzeichen der äußerst widerstandsfähigen, vitalen Larve von E. multilocularis ist daher ihre ungebremste Proliferation am Rande des an Größe zunehmenden Tumors. Dies kann indirekt durch die verstärkte Aufnahme von Fluorodesoxyglukose in der Positronen-Emissionstomographie (FDG-PET) visualisiert werden. Unter der spezifischen Therapie mit Benzimidazolen (Albendazol oder Mebendazol) unterbleibt die Proliferation und die Glukoseaufnahme im PET verschwindet. Somit gibt die Untersuchung Hinweise auf die Vitalität der Larve. Leider ist die Penetration der Benzimidazole in den alveolären "Tumor“ eingeschränkt, so dass es nach Absetzen der Therapie häufig zum Rückfall kommt.

\section{Immunantwort}

In den vergangenen Jahren wurden wesentliche neue
Erkenntnisse zu molekularen Vorgängen am Modell der E.-multilocularis-Infektion erarbeitet. Dabei nutzt der Parasit Wachstumssignale des Wirts für die eigene Proliferation und moduliert die Wirtsantwort. Aufgrund des infiltrativen Wachstums ist in der Regel eine humorale Immunantwort nachweisbar. Die zelluläre Immunantwort wird blockiert. Es findet sich eine extrem starke IL-10-Expression, welche möglicherweise die langfristige Persistenz des Erregers erklärt. Eine effektive Immunabwehr ist nur in seltenen Fällen belegt. In diesen Fällen erfasst man morphologisch eine abgestorbene Läsion („died-out-lesion“). Es ist allerdings unklar, unter welchen Bedingungen der Wirt den Erreger in dieser Weise abwehren kann. Das Vorkommen bestimmter HLA-Merkmale scheint dabei eine Rolle zu spielen. Ein defektes Immunsystem lässt die ungebremste Proliferation der Larve und Ausbreitung im Wirtsorganismus zu. Patienten mit HIV-Infektion oder anderen Immundefekten sterben an der alveolären Echinokokkose. Eine falsch positive humorale Immunantwort findet sich bei Personen in typischen Endemiegebieten, ohne dass der bildmorphologische Nachweis einer Echinokokkus-Läsion geführt werden kann. Ob dies Ausdruck der Immunität ist oder lediglich die höhere Schwelle der betroffenen Personengruppen im Testsystem widerspiegelt, ist unklar.

\section{Differenzialdiagnose}

Hepatozelluläres Karzinom, große Lebermetastasen mit Verkalkungen und zentralen Nekrosehöhlen. Frühe Manifestationen können als Hämangiom imponieren. Vollständig verkalkte Läsionen werden extrem selten beobachtet. Der makroskopische und histopathologische Nachweis der E.-multilocularis-Larve ist beweisend. Moderne molekulare Verfahren helfen heute bei der Differenzierung der Spezies. Eine diagnostische Punktion ist nicht nur wegen der Möglichkeit der Verschleppung von Larvengewebe obsolet, die Punktionsausbeute ist immer gering, da der umschließende Bindegewebspanzer die Punktionsnadel abgleiten lässt und geeignetes Material nicht gewonnen werden kann.

\section{Zystische Echinokokkose}

\section{Synonym(e)}

E.-granulosus-Infektion; Hydatidose. Die Bezeichnung E. cysticus ist veraltet und sollte auch im klinischen Kontext nicht mehr verwendet werden.

\section{Inkubationszeit}

Eine Inkubationszeit von mehr als 5 Jahren wird angenommen.

\section{Leitsymptome}

Hepatomegalie, Druckgefühl im rechten Oberbauch, Lungenrundherde; durch Kompression wichtiger Strukturen oder Gefäße organspezifische Symptome, z. B. Ikterus, Hämoptysen. 


\section{Symptome}

Primärer Ansiedlungsort der E.-granulosus-Larve ist in $75 \%$ der Fälle die Leber, in weiteren $20 \%$ die Lunge, jedes weitere Organ kann jedoch singulär betroffen sein. Häufig wird die Zyste zufällig bemerkt. Je nach Zahl, Größe und Lokalisation der Zysten ist das Krankheitsbild äußerst vielfältig. Die Organmanifestation erklärt daher die im Vordergrund stehende Symptomatologie und kommt in eigenen Krankheitsbezeichnungen zum Ausdruck: z. B. Leberechinokokkose, Lungenechinokokkose, Knochenechinokokkose. Es können solitäre, aber auch multiple Zysten in einem Organ festgestellt werden und es können mehrere Organe gleichzeitig befallen sein. Fieberhafte Sekundärinfektionen, Abszesse, Fistelungen können auftreten. Gefürchtet ist die Zystenruptur, die zudem zu einer „sekundären Echinokokkose" führt, da sich aus den freigesetzten Protoskolizes neue Zysten bilden können.

Zystische Leberechinokokkose: Pathognomonisch sind scharf begrenzte Zysten mit wabenförmiger Binnenstruktur im Ultraschallbild. Die sonografischen Stadien kennzeichnen den unterschiedlichen Entwicklungsstand der Zyste und bilden die Basis für die weitverbreitete WHO-Klassifikation der Leberzysten (CL, CE1 bis CE5). Hierbei werden aktive, transitorische und inaktive Zysten unterschieden. Bei Ruptur der Zysten in die Bauchhöhle kann sich eine lebensbedrohliche Peritonitis entwickeln. Kompression der ableitenden Gallenwege führt zum posthepatischen Ikterus, bei Ruptur einer Zyste in das Gallenwegssystem kommt es zur Entleerung des Zysteninhalts und bei Passage von kleinen Tochterzysten durch die Papilla Vateri zum Nachweis von gelblichen, weintraubenähnlichen Zysten im Stuhl. Bei Keimaszension entwickelt sich häufig eine sekundär bakterielle Cholangitis.

Zystische Lungenechinokokkose: Die tennisball- bis kindskopfgroßen Zysten sind scharf begrenzt und verursachen selten klinische Symptome. Diese treten bei Anschluss einer Zyste an das Bronchialsystem auf, z. B. hohes Fieber, Eosinophilie, pulmonale Infiltrate, langwierige Hämoptysen.

Manifestation in anderen Organen: Bei Befall von Knochen und Muskulatur treten pathologische Frakturen auf. Kardiale Symptome bei Herzbefall, neurologische Symptome bei ZNS-Befall.

\section{Pathophysiologie}

Nach dem Schlüpfen der Onkosphäre im Dünndarm gelangt die Larve in die Leber bzw. in die Lunge. Langsam wächst der Parasit zu einer Zyste heran und wird von einer Wirtskapsel umschlossen. In den bildgebenden Verfahren imponiert daher die scharf begrenzte Raumforderung. In den Wandabschnitten kann es zur Kalkeinlagerung kommen. Gemeinsames Kennzeichen ist das langsame, expansive Wachstum von wenigen Zentimetern Durchmesser bis zur Größe eines
Kindskopfes. Die Zyste enthält eine wasserklare Flüssigkeit und steht unter beträchtlichem Druck. In der Zyste bilden sich Tochterzysten. Bei ungünstiger Lage, spontan oder nach Trauma können die Zysten rupturieren. Der Austritt der antigenreichen Flüssigkeit führt zu einer anaphylaktischen Reaktion, die lebensgefährlich werden kann. Bei Ruptur der Zysten kollabiert die Endozyste. Zysten imponieren als „Wasserlilien", wenn Luft in die bindegewebige Kapsel eindringt. Die Perizyste besteht aus bindegewebigen Lagen des Wirts, die sich konzentrisch um den Parasiten zu einer festen Hülle formen. Man rechnet grob mit einem $\mathrm{Zu}$ wachs des Zystendurchmessers von etwa $1 \mathrm{~cm} / J a h r$. Nicht selten kommt es aber spontan zu einem Sistieren des Wachstums, dem Absterben der Larve und zu regressiven Veränderungen mit vollständiger Verkalkung. Im Gegensatz zur alveolären Echinokokkose ist eine verstärkte Glukoseaufnahme in der Perizyste mittels PET-CT nicht darstellbar.

\section{Immunantwort}

Es ist derzeit unbekannt, warum die humorale Immunantwort bei lange bestehender Infektion und ausgeprägtem Befall so träge reagiert. Erst bei Platzen einer Zyste und nachfolgender allergischer Reaktion werden hochtitrige Antikörper nachweisbar. Die zelluläre Immunantwort ist bislang bei der persistierenden Infektion widersprüchlich.

\section{Differenzialdiagnose}

Leberzysten: Benigne Leberzysten können mit den WHO-Stadien CL und CE1 verwechselt werden. Stadium CE2 ist pathognomonisch für die zystische Echinokokkose. Beim transitorischen Stadium CE3 bestehen gleichzeitig degenerierte neben viablen Anteilen. In den Stadien 4 und 5 ist die Degeneration unterschiedlich weit fortgeschritten. Die Differenzialdiagnose schließt daher verkalkte Hämatome oder Abszesse, aber auch Leberfiliae ein.

Lungenzysten: Form und Struktur des Rundherdes sind typisch, nach Ruptur kann sich eine Luftsichel bilden und als Kaverne imponieren. Nach Ruptur kommt es zur eosinophilen Pneumonie.

\section{Polyzystische Echinokokkose}

Synonym(e)

E.-ligarthrus-Infektion, E.-vogeli-Infektion.

\section{Inkubationszeit}

Unbekannt.

\section{Leitsymptome}

Hepatomegalie, abdominelle Symptome.

\section{Symptome}

Kennzeichen dieser seltenen, nur in Mittel- und Südamerika auftretenden Echinokokkose ist die polyzystische Ausprägung in den hauptsächlichen Manifesta- 
tionsorganen Leber und Abdomen. Die Erkrankung wurde nur im fortgeschrittenen Stadium diagnostiziert.

\section{Pathophysiologie}

Echinococcus oligarthrus: Die Larve im Zwischenwirt gehört wie diejenige von $E$. vogeli zum polyzystischen Typ, besitzt die Tendenz zur Septierung und Vielkammrigkeit. Die bis zu $5 \mathrm{~cm}$ messenden Einzelbläschen sind von Flüssigkeit gefüllt und enthalten Protoskolizes. Befallen werden in erster Linie innere Organe und Muskulatur. Bisher wurden Finnen erst einmal bei einem Menschen (Fehlzwischenwirt) in Venezuela nachgewiesen, bei dem sich die Finne intraorbital entwickelt hat.

Echinococcus vogeli: Die Finnen sind polyzystisch und ähneln denjenigen von E. oligarthrus. Differenzialdiagnostisch lassen sich die Finnen durch die Größe der Haken am Rostellum der Protoskolizes unterscheiden. Die großen Haken von E. vogeli haben Abmessungen von 39,1-43,9 $\mu \mathrm{m}$, die kleinen von 30,4$36,5 \mu \mathrm{m}$, während die entsprechenden Werte für E. oligarthrus 25,9-27,9 $\mu \mathrm{m}$ und 22,6-29,5 $\mu \mathrm{m}$ betragen. Die Infektion des Menschen (Fehlzwischenwirt) mit E. vogeli ist beschrieben. Bevorzugter Ansiedlungsort der Finnen ist die Leber. Diagnostisch können bildgebende Verfahren hilfreich sein; serologische Verfahren sind bisher nicht verfügbar.

\section{Differenzialdiagnose}

Unklare Lebertumore, hepatozelluläres Karzinom.

\section{Diagnostik}

\section{Untersuchungsmaterial}

Serum für die Antikörperdiagnostik, Biopsiematerial zur mikroskopischen bzw. molekularen Diagnostik, Zysteninhalt.

\section{Diagnostische Verfahren}

\section{E.-multilocularis-Infektion}

Allgemeine Labordiagnostik: Das Blutbild ist selten diagnostisch aufschlussreich. Eine Eosinophilie findet sich nicht. Bei fortgeschrittenen Läsionen besteht ein Transaminasenanstieg. Die globalen Leberfunktionen sind nicht beeinträchtigt. Hingegen kann die Erhöhung des Gesamt-IgE Hinweis auf eine aktive Infektion oder fortbestehende Aktivität der Larve sein.

Bildgebende Diagnostik: Bildgebende Verfahren sind für die Diagnose entscheidend. Im Ultraschall, Computer- oder im Kernspintomogramm stellt sich die Läsion als traubenförmiger Tumor mit spritzerartigen Randverkalkungen dar. Typischerweise ist der Herd unscharf vom übrigen Lebergewebe abgegrenzt und wuchert ggf. in das benachbarte Gewebe ein. Man unterscheidet die tumorartige, solide Wuchsform, die der alveolären Echinokokkose den Namen gegeben hat und die ebenfalls tumorartige, jedoch zentral nekrotische Läsion. Der Eindruck der zystischen Raumforde- rung führt immer wieder zur Verwechslung mit der zystischen Echinokokkose. Häufig wird zunächst ein hepatozelluläres Karzinom oder eine zerfallende Lebermetastase vermutet. Vor einer diagnostischen Punktion sollte dringend eine serologische Abklärung erfolgen. Das kombinierte PET-CT kann Aufschlüsse über die Aktivität und damit auch Vitalität des Parasiten geben. Die Untersuchung eignet sich zur Verlaufskontrolle unter Therapie.

Immundiagnostik: In mehr als $90 \%$ der Fälle lassen sich mit unterschiedlichen Testbestecken (indirekter Hämagglutinationstest, ELISA, Immunoblot unter Verwendung von Rohantigen, chromatographisch gereinigtem Em2 oder rekombinanten Antigenen Em10, Em18 oder EmII/3-10) spezifische Antikörper nachweisen. Meist gelingt auch die Speziesdifferenzierung. Kreuzreaktionen mit anderen Helminthen-Antigenen kommen vor.

Molekulare Verfahren: Verschiedene Gensonden stehen zur Verfügung und erlauben heute eine Differenzierung der unterschiedlichen Spezies. Die Validierung für die klinische Diagnostik steht jedoch noch aus.

Makro- und mikroskopische Untersuchung: Das Operationspräparat erweckt den Eindruck einer malignen Geschwulst. Erst die mikroskopische Untersuchung mit PAS-Reaktion identifiziert die Larve zweifelsfrei. Im Menschen als Fehlzwischenwirt entwickelt die Larve selten Protoskolizes und bleibt daher ,infertil“. Häkchen können daher im Punktat oder im Operationspräparat mikroskopisch nicht nachgewiesen werden.

\section{E.-granulosus-Infektion}

Allgemeine Labordiagnostik: Das Blutbild kann diagnostisch aufschlussreich sein. Häufig findet sich eine moderate Eosinophilie, nach Zystenruptur imponiert eine Hypereosinophilie mit zugleich starker Vermehrung des Gesamt-IgE. Leberenzymveränderungen und Hyperbilirubinämie werden bei ausgedehntem Befall oder ungünstiger Lokalisation beobachtet. Die Lungenfunktion kann bei der Lungenechinokokkose eingeschränkt sein.

Bildgebende Diagnostik: Bei der zystischen Echinokokkose sind bildgebende Verfahren für die Diagnose entscheidend. Im Ultraschall, Computer- oder im Kernspintomogramm kann die Zyste in den unterschiedlichen Stadien dargestellt werden. Hilfreich für die Einteilung der Leberzysten ist die WHO-Klassifikation. Danach werden aktive von inaktiven Zysten unterschieden. Beide Formen können in der Leber parallel nebeneinander bestehen. Bei der Übergangsform (CE3) können neue Zysten bzw. Tochterzysten heranwachsen oder aber regressive Veränderungen eintreten.

Immundiagnostik: Nur in etwa $60 \%$ der Fälle lassen sich mit unterschiedlichen Testbestecken (indirekter Hämagglutinationstest, ELISA, Immunoblot unter 
Verwendung von Rohantigen [Hydatidenflüssigkeit] oder rekombinantem Antigen B) spezifische Antikörper nachweisen. Gerade bei Lungenzysten bleibt die Serologie bis zur Ruptur der Zyste negativ. Falsch positive serologische Reaktionen finden sich regelmäßig bei der alveolären Echinokokkose.

Molekulare Verfahren: Verschiedene Gensonden stehen zur Verfügung und erlauben heute die Differenzierung der unterschiedlichen Spezies. Die Validierung für die klinische Diagnostik steht jedoch noch aus.

Makro- und mikroskopische Untersuchung: Die wasserklare Flüssigkeit in der Zyste ist pathognomonisch für eine Echinokokkuszyste (E. granulosus). Mit der mikroskopischen Untersuchung werden Protoskolizes nachgewiesen. In Material aus degenerierten Zysten können nativ und mittels PAS-Reaktion Häkchen nachgewiesen werden. Selten sind die Zysten infertil. Dann können Häkchen mikroskopisch nicht nachgewiesen werden.

\section{Befund / Interpretation}

E.-multilocularis-Infektion: Die Interpretation der bildgebenden Befunde ist in ausgewiesenen Behandlungszentren unkritisch. Das weite Spektrum der morphologischen Veränderungen kann gut eingegrenzt werden. Das seltene Auftreten der Erkrankung erschwert jedoch die Interpretation andernorts und verleitet zur unsachgemäßen invasiven Diagnostik.

Der Immundiagnostiker ist mit der alleinigen Interpretation der serologischen Befunde überfordert. Die Speziesdifferenzierung ist nur in Kenntnis der klinischen und der morphologischen Befunde möglich.

E.-granulosus-Infektion: Bildgebende Befunde bei der Ultraschalluntersuchung der Leber sind pathognomonisch für die Erkrankung (WHO-Stadien CE1 und CE2). Bei anderen Stadien sind Vorkenntnisse und nähere klinische Angaben erforderlich. Die Morphologie der Zysten in anderen Organen gleicht den Leberzysten, dennoch ist die Befundinterpretation nur mit den genauen klinischen Angaben möglich. Bei akzidentieller Punktion einer Zyste trägt die wasserklare Flüssigkeit mit mikroskopischem Nachweis von Protoskolizes zur eindeutigen Diagnosestellung bei. Der Anteil von Bilirubin gibt Aufschluss über die eingetretene Arrosion der Gallengänge. Immundiagnostisch stellt die zystische Echinokokkose eine Herausforderung dar. Denn häufig finden sich bei morphologisch klaren Befunden negative Resultate. Beweisend ist die makroskopische und mikroskopische Untersuchung des Operationspräparates.

E.-oligarthus-Infektion und E.-vogeli-Infektion: Es sind nur wenige Krankheitsfälle in der Weltliteratur beschrieben. Für die Diagnose sind die bildgebenden Befunde und die moderne molekulare Diagnostik entscheidend.

\section{Therapie}

\section{Therapeutische Maßnahmen}

\section{Alveoläre Echinokokkose}

Operation: Therapie der Wahl ist die radikale Operation bei umschriebener, eher peripher liegender Läsion in der Leber. Der Absetzungsrand sollte $2 \mathrm{~cm}$ im Gesunden liegen. Die medikamentöse Nachbehandlung mit Albendazol oder Mebendazol über ein Minimum von 2 Jahren vermindert das Rezidivrisiko. Palliative Operationen sind zu vermeiden, da die alleinige dauerhafte medikamentöse Therapie zu einer guten Stabilisierung führt und Folgeschäden nach Operation vermeidet.

Medikamentöse Therapie (anti-infektive Therapie): Die alleinige Therapie mit Albendazol oder Mebendazol führt bei Inoperabilität zur Konsolidierung und Regression durch Sistieren des Parasitenwachstums. Beide Medikamente wirken ausschließlich parasitostatisch. Die Therapie muss nach derzeitigem Kenntnisstand daher lebenslang fortgesetzt werden. Von einer Behandlung in Zyklen wird abgeraten, da das Larvenwachstum nur unter dauerhafter medikamentöser Suppression unterbunden wird.

Interventionelle Behandlung: Bei ausgedehntem Organbefall und Komplikationen sind minimal-invasive Maßnahmen entscheidend. Hierzu zählen u. a. die Einlage von Stents, die Entlastung von Nekrosehöhlen oder die Versiegelung neu gebildeter Hohlräume.

Lebertransplantation: Eine Lebertransplantation ist nur bei zusätzlicher Leberschädigung durch andere Erkrankungen zu erwägen. Bei einem sehr ausgedehnten Befall der Leber (auch ohne Übergreifen auf andere Organe) bietet die Transplantation keinen zusätzlichen Vorteil gegenüber der alleinigen Chemotherapie und ist durch die notwendige Immunsuppression mit einem hohen Rezidivrisiko behaftet. Die dauerhafte Nachbehandlung mit Benzimidazolen ist erforderlich.

\section{Zystische Echinokokkose}

In den vergangenen 10 Jahren hat sich ein erheblicher Wandel der therapeutischen Strategien bei der zystischen Leberechinokokkose ergeben. Während früher die Operation als Behandlung der ersten Wahl galt, wird sie heute nur noch in Ausnahmefällen bei bestimmten morphologischen Zystenstadien oder Komplikationen durchgeführt.

Bei gut zugänglichen Leberzysten und bestimmten morphologischen Zystenstadien (CL und CE1) kann die so genannte Punktion-Aspiration-InstillationReaspirationsmethode (PAIR) nach Filice und Brunetti (1997) zur Anwendung kommen. Die Technik wurde weiterentwickelt, sodass auch Zysten im Stadium CE2 mit dieser minimal-invasiven Technik behandelt werden können: Zunächst erfolgt die ultraschallgesteuerte Punktion der Zyste, die Entnahme und parasitologische Analyse des Zysteninhalts, das Einbringen der skoliziden Lösung (70-90 \%iger Alko- 
hol oder 15-20 \%ige NaCl-Lösung) und die Reaspiration nach kurzer Inkubationszeit. Die verwendeten Punktionsinstrumente und Katheter variieren je nach vorliegendem Befund. Die Behandlung sollte ausschließlich in ausgewiesenen Zentren erfolgen. Die medikamentöse Therapie der zystischen Echinokokkose mit Mebendazol oder Albendazol ist ein weiterer wesentlicher Pfeiler des therapeutischen Konzeptes. Nach einer kurativen Operation wird die Behandlung für drei Monate empfohlen. Die medikamentöse Therapie ist zwingend vor, während und nach dem PAIRVerfahren durchzuführen.

Auch die alleinige medikamentöse Therapie ist in verschiedenen Behandlungszentren möglich und führt nach Monaten zur Degeneration der Zyste und zur Ausheilung der Erkrankung. Beide Anthelmintika sind in der Lage, die Keimschicht des Parasiten und die Protoskolizes abzutöten. Eine Behandlungsphase von 3-6 Monaten mit Albendazol in einer Tagesdosis von $10-15 \mathrm{mg} / \mathrm{kg} \mathrm{KG}$ wird empfohlen. Es besteht die Auffassung, dass mit der medikamentösen Therapie der hohe Binnendruck in der Zyste vermindert werden kann und damit das Risiko einer Aussaat während eines Eingriffs verhindert werden kann. Dies ist jedoch nicht durch Studien belegt, so daß die WHOEmpfehlung weiterhin Gültigkeit hat, die präoperative/präinterventionelle Vorbehandlung mit Anthelmintika auf wenige Tage zu beschränken (WHO 1996). Je nach Organlokalisation kann eine langfristige Dauerbehandlung erforderlich sein (Knochen- und Weichteilechinokokkose). Zur Therapiekontrolle können Spiegelbestimmungen der Anthelmintika durchgeführt werden. Allerdings ist nicht nachgewiesen, inwieweit die Medikamentendosis mit einer effektiven Kontrolle des Parasitenwachstums in vivo korreliert. Die Kombinationstherapie mit Praziquantel wird seit Kurzem in einigen Zentren favorisiert. Praziquantel hat jedoch keinen Einfluss auf die Endozyste, daher erscheint diese Therapie nicht ausreichend begründet.

\section{Resistenz}

E. multilocularis: Benzimidazole entfalten bei der E.multilocularis-Infektion eine ausschließlich parasitostatische Wirkung. Die zellulären Zielmoleküle für Benzimidazole sind Tubuline als essenzielle Komponenten des Zytoskeletts. Eine unterschiedliche Empfindlichkeit des Echinococcus-Tubulins für Benzimidazole könnte Anlass für eine Medikamentenresistenz sein, spielt aber klinisch keine Rolle.

E. granulosus: Eine Resistenz gegenüber Benzimidazolen ist bisher nicht beschrieben.

\section{Epidemiologie}

\section{Verbreitung}

Die durch E. multilocularis verursachte Zoonose ist in ihrer Verbreitung auf die Nordhalbkugel beschränkt. $\mathrm{Zu}$ den klassischen Endemiegebieten in Europa zählen Ostfrankreich, die Nordschweiz, Süddeutschland und der Westen Österreichs. Neue Regionen sind Tschechien, Slowakei, Polen und die baltischen Staaten. Über Bulgarien und die Türkei erstreckt sich das Endemiegebiet nach Osten bis nach Sibirien. Zentralasien sowie China/Tibet sind stark betroffen (höchste Prävalenzraten weltweit, regional bis zu $8 \%$ ). Weiterhin ist der Erreger auf Hokkaido in Japan, in Alaska und Kanada beheimatet. Auch die zentral gelegenen nördlichen Staaten der USA gelten als Verbreitungsgebiet. Krankheitsfälle sind dort aber nie aufgetreten. Der aktuelle Trend zeigt die Zunahme der infizierten Fuchspopulationen in Europa, so dass das Infektionsrisiko für den Menschen zunehmen könnte ( $>$ Abb. 1 und $>$ Abb. 2).

Als Zoonose weist die durch E. granulosus verursachte Form der zystischen Echinokokkose eine weltweite Verbreitung auf. Nach dem Rückgang der Inzidenzen in den Mittelmeerländern sowie in Mittel- und Südamerika weisen aktuelle Berichte auf eine hohe Infektionsrate in China/Tibet hin. Autochthone Infektionen kommen auch in Mitteleuropa vor. Mit Spannung wird die Auftrennung in unterschiedliche Genotypen und deren Bedeutung für die Infektionsrate beim Menschen erwartet.

Die zwei weiteren humanpathogenen Erreger (E. vogeli bzw. E. oligarthrus) sind auf Lateinamerika beschränkt. In der Weltliteratur sind nur ca.150 Infektionen beim Menschen dokumentiert.

\section{Wirtsbereich / Reservoir}

E. multilocularis: In Mitteleuropa ist der Rotfuchs (Vulpes vulpes) der Hauptendwirt mit Befallsraten für E. multilocularis, die in den Endemiegebieten die $50 \%$-Marke weit übersteigen. In arktischen Gebieten spielt der Eisfuchs (Alopex lagopus) eine wichtige Rolle. Daneben fungieren Haushund und Katze, aber auch andere Caniden (Marderhund, Wolf u. a.) als Endwirt. Geeignete Zwischenwirte sind Nagetiere aus der Familie Cricetidae (Feldmaus, Microtus arvalis) als der in Mitteleuropa wichtigsten Art. Andere Microtus-Arten, Rötelmäuse, Bisamratte, Lemminge, aber auch Hausmaus, Wanderratte und andere Nagetiere sind ebenfalls suszeptibel für das Larvenstadium von E. multilocularis. Füchse sind äußerst anpassungsfähig und haben sich inzwischen in den Großstädten etabliert. Nach jüngsten Untersuchungen nimmt die Befallsrate der Stadtfüchse mit E. multilocularis deutlich zu.

E. granulosus: Wichtigster Endwirt ist der Haushund. Daneben können Wölfe, Kojoten, Dingos, Hyänen, Schakale und andere carnivore Säugetiere den adulten E. granulosus beherbergen. Zwischenwirte sind Wiederkäuer, die sich herbivor oder omnivor ernähren. Wichtigste Nutztiere sind Rind, Schaf, Ziege, Schwein, Kamel und Pferd. Aber auch zahlreiche Wildtiere (z. B. Büffel, Bison, Antilope, Gazelle, Elch, Rentier) sind empfänglich für das Larvenstadium.

E. oligarthrus: Der Entwicklungszyklus ist wie bei allen Echinococcus-Arten zweiwirtig mit Feliden (Puma, 


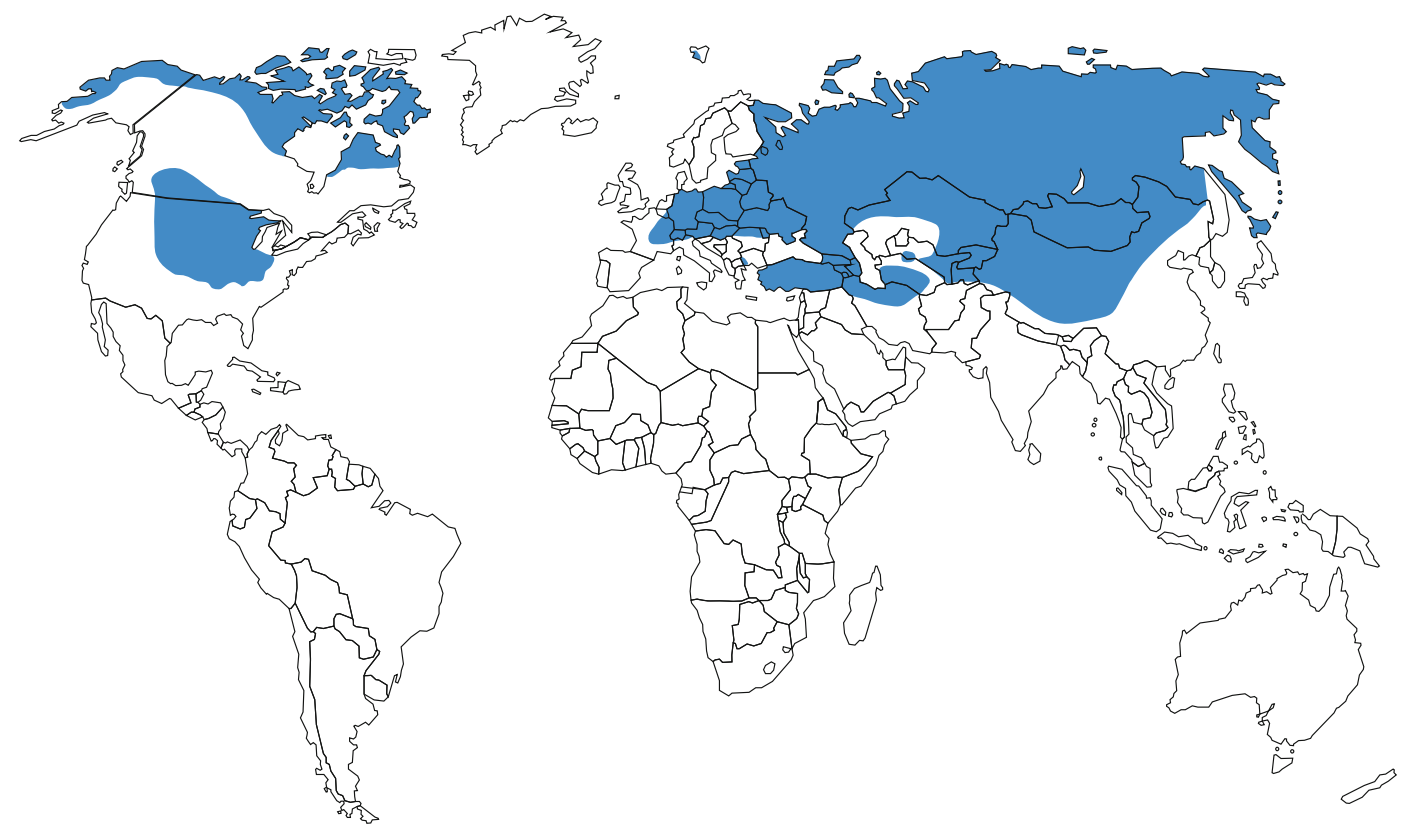

- Abb. 1. Weltweite Verbreitung von Echinococcus multilocularis. Modifiziert nach Eckert und Deplazes, mit freundlicher Genehmigung des Instituts für Parasitologie der Universität Zürich

Jaguar, Jaguarundi) als End- und dem Aguti sowie anderen Nagetieren als Zwischenwirt.

E. vogeli: Parasitiert im Waldhund (Speothus venaticus), kommt aber auch beim Haushund vor. Im zweiwirtigen Entwicklungszyklus fungieren Pakas und vermutlich auch andere Nagetiere als Zwischenwirt.

\section{Risikogruppen}

E. multilocularis: Alle in der Land- und Forstwirtschaft der Endemiegebiete tätigen Personen sind als stärker gefährdet anzusehen. Einige Berufsgenossenschaften erkennen die alveoläre Echinokokkose als entschädigungsfähige Berufskrankheit an. Ebenso zählen Hundehalter zur Risikogruppe. Dies gilt im besonderen Maß für ländliches Gebiet in China/Tibet.

E. granulosus: Hunde, die mit finnenhaltigen Fleischabfällen gefüttert werden, stellen ein hohes Infektionsrisiko dar. Die gesetzliche Fleischbeschau verhindert, daß zystenhaltiges Fleisch als Hundefutter abgegeben wird.

\section{Transmission / Vektoren}

E. multilocularis: Die Infektion erfolgt nach oraler Aufnahme der Eier von E. multilocularis, die aus dem Kot von Rotfüchsen oder anderen Endwirten (Haushund, Katze) ausgeschieden werden. Für den Menschen sind Hunde vermutlich die entscheidenderen Glieder in der Infektionskette. Die Übertragung durch kontaminierte Waldfrüchte (Blaubeeren, Erdbeeren oder Fallobst etc.) ist wissenschaftlich nicht belegt. Inwieweit Oberflächenwasser und Staub, der bei der
Feldarbeit aufgewirbelt wird, zur Übertragung beiträgt, ist völlig unklar. Die Eier sind bei niedrigen Temperaturen lange haltbar.

E. granulosus: Die Übertragung auf den Menschen (und andere Zwischenwirte) erfolgt als Schmutzinfektion. Der Hund ist das wichtigste Glied in der Übertragungskette.

\section{Prävention / Impfstoffe}

E. multilocularis: In den Endemiegebieten wird die regelmäßige Entwurmung der Haustiere empfohlen. In einigen Gebieten Süddeutschlands wird der Fuchsbestand durch regelmäßiges Ausbringen von Praziquantel-haltigen Ködern systematisch entwurmt. Eine Reduktion der hohen Fuchsbefallsrate von E. multilocularis ist belegt. Inwieweit sich dies auf die mögliche Infektion des Menschen auswirken wird, ist allerdings unklar.

E. granulosus: Die Fleischbeschau und die Vernichtung von finnenhaltigem Fleisch sind entscheidende Faktoren, um eine Infektion des Menschen zu verhindern. Liegt jedoch eine Infektion des Hundes vor, dann muss dessen Kot sofort vernichtet werden und der befallene Hund unter Quarantäne einer Wurmkur unterzogen werden. Praziquantel ist hierbei das Mittel der Wahl. In Australien wird derzeit ein Impfstoff gegen Echinokokkose entwickelt, um den ökonomischen Schaden durch Ausfall der Schlachttiere (Schafe) zu reduzieren. 


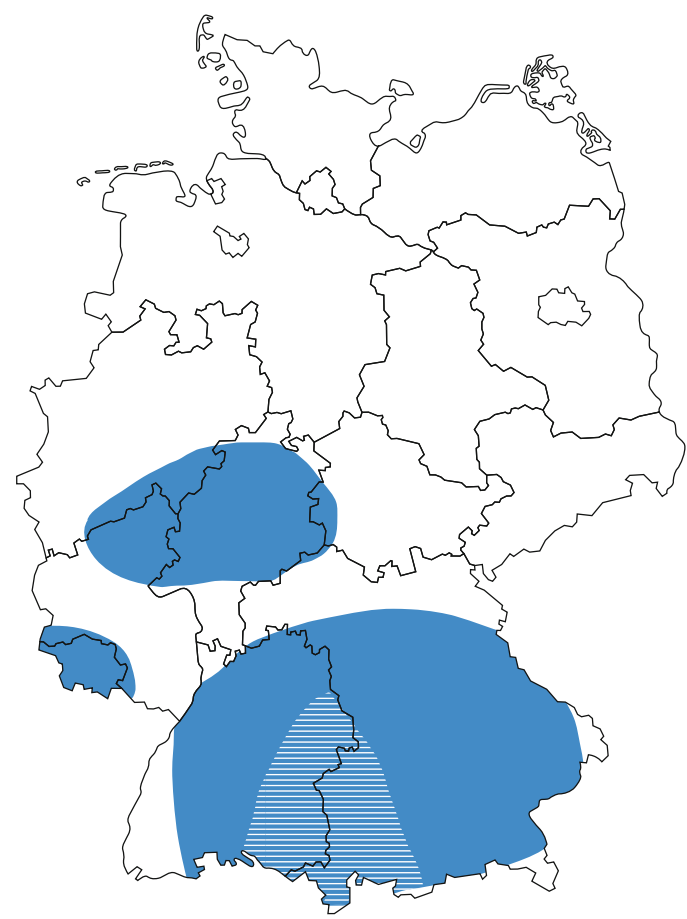

- Abb. 2. Alveoläre Echinokokkose in Deutschland: im Echinokokkose-Register Ulm gemeldete Fälle ( $n=300$ Patienten, Stand Mitte 2010). Die markierten Regionen kennzeichnen die Gebiete, aus denen die Patienten stammen. „Schraffierung“: Region mit starker Häufung. Außerhalb dieser Regionen wurden zudem weitere einzelne Fälle gemeldet $(n=8)$.

\section{Meldepflicht}

Nach dem Infektionsschutzgesetz (IfSG) ist die Echinokokkose in Deutschland eine meldepflichtige Erkrankung. Der direkte oder indirekte Labornachweis ist nach $\$ 7$ (Abs. 3) an das Robert-Koch-Institut in Berlin zu melden.

\section{Weiterführende Informationen}

\section{Referenzzentren / Expertenlaboratorien}

- Das Europäische Echinokokkose-Register Ulm kann Hilfestellung zu medizinischen Anfragen vermitteln (Institut für Biometrie, Universität Ulm, Schwabstraße 13, 89075 Ulm, Fax: 0731/50-26902, E-Mail: echinoreg@uni-ulm. de).

- Das Konsiliarlaboratorium für Echinokokken ist im Institut für Hygiene und Mikrobiologie der Universität Würzburg, Josef-Schneider-Str. 2, 98070 Würzburg angesiedelt. Ansprechpartner sind Prof. M. Frosch, Prof. K Brehm, Dr. Tappe, Tel: 0931/201-5161,E-Mail: mfrosch@ hygiene.uni-würzburg.de.

- Fachlich qualifiziert sind darüber hinaus sämtliche parasitologischen und tropenmedizinischen Institutionen. www.dtg.org.

\section{Web-Adressen}

- AG Echinokokkose der Paul-Ehrlich-Gesellschaft: http:// www.p-e-g.org/econtext/sektionen/\#echinokokkose

- Hinweise zu Genomprojekten: http://www.sanger.ac.uk/ Projects/Echinococcus/

\section{Schlüsselliteratur}

1. Ammann, RW, Eckert, J. Parasitic Diseases of the liver and intestine: Cestodes, Echinococcus. Gastroenterol Clin North Am 1996;25:655-89

2. Brunetti E, Junghanss T. Update on cystic hydatid disease. Review. Curr Opin Infect Dis. 2009 Oct;22(5):497-502

3. Brunetti E, Kern P, Vuitton DA et al. Expert consensus for the diagnosis and treatment of cystic and alveolar echinococcosis in humans. Acta Trop 2010; 114:1-16

4. Craig P (2003) Echinococcus multilocularis. Curr Opin Infect Dis 16:434-437

5. Guerrant RL Walker DH, Weller PF (eds) (2010)Tropical Infectious Diseases; Principles, Pathogens, and Practice (Third Edition), Elsevier, Churchill, Livingstone, Philadelphia

6. McManus DP, Zhang W, Li J, Bartley PB. Echinococcosis. Review. Lancet. 2003 Oct 18;362(9392):1295-304

7. Moro P, Schantz PM. Echinococcosis: a review. Int J Infect Dis 2009;13(2):125-33

8. Pawlowski ZS, Eckert J, Vuitton DA, et al. (2001) WHO/ OIE Manual on Echinococcosis in Humans and Animals. Chapter 2: Echinococcosis in Humans. WHO, Geneva, pp 20-71

9. Thompson RCA, Murdoch University, Australia and Lymbery AJ, Western Australian Department of Agriculture (1995) Echinococcus und Hydatid Disease. CAB International, Wallingford, UK

10. [Thompson RCA (2008) The taxonomy, phylogeny and transmission of Echinococcus. Experimental Parasitology 119:439-446

\section{Echinokokkose}

Echinokokken

\section{Echinokokkus-Zyste}

Echinokokken

\section{Echinostoma ilocanum}

Darmegel

\section{Echoviren und Parechoviren}

Heinz Zeichhardt, Hans-Peter Grunert

\section{Erreger}

\section{Synonym(e)}

Humanes Echovirus 1-7, 9, 11-21, 24-27 und 29-33;

Humanes Parechovirus 1-8 


\section{Erregerspezies}

Genus: Enterovirus, Spezies: Humanes Enterovirus $B$ (Echovirus 1-7, 9, 11-21, 24-27 und 29-33); Genus: Parechovirus, Spezies: Humanes Parechovirus (Parechovirus 1-8)

\section{Taxonomie}

Die Familie der Picornaviren umfasst neben dem Genus Enterovirus (mit den Echoviren) das neue Genus Parechovirus (mit den Parechoviren 1-8) und die weiteren Genera: Rhinovirus, Cardiovirus, Aphthovirus, Hepatovirus, Erbovirus, Kobuvirus und Teschovirus. Für eine kurze Übersicht zu Infektionen des Menschen durch Aphthoviren (Maul- und KlauenseucheVirus) und Kobuviren (Aichivirus) $>$ Enteroviren 6871 und andere Enteroviren.

Mit dem „Eighth Report of the International Committee on Taxonomy of Viruses" (2005) wurde eine neue Einteilung für die Echoviren innerhalb der Familie der Picornaviren vorgenommen. Im Genus Enterovirus werden die Echoviren 1-7, 9, 11-21, 24-27 und 29-33 der Spezies Humanes Enterovirus B zugeordnet. Die Grundlage dafür waren vor allem Aminosäure-Identitäten in den Regionen P1 sowie 2C und $3 \mathrm{CD}$ (jeweils $>70 \%$ ) sowie der Wirtsbereich und die virusspezifischen Wirtszellrezeptoren. Bezogen auf das gesamte Virusgenom besteht zwischen den einzelnen Enteroviren untereinander sowie zwischen den beiden Genera Enterovirus und Rhinovirus eine RNA-Sequenzhomologie von $>50 \%$.

Für einige andere Echoviren wurde bereits früher folgende Reklassifizierung vorgenommen: Echovirus 8 ist identisch mit Echovirus 1 und wird nicht mehr als eigener Serotyp geführt. Echovirus 10 wurde als Reovirus Typ 1, Echovirus 28 als humanes Rhinovirus Typ 1A und Echovirus 34 als Coxsackievirus A24 identifiziert. Coxsackievirus A23 wurde als Echovirus 9 reklassifiziert.

Die humanen Echoviren werden wie die Coxsackieviren der Gruppen A und B häufig auch als Nicht-PolioEnteroviren bezeichnet.

In der neuen Taxonomie werden die Echoviren 22 und 23 in einem eigenen Genus Parechovirus als Parechovirus 1 und 2 erfasst, da ihre Proteinsequenzen nur maximal 30 \% Homologie zu allen anderen Picornaviren aufweisen. Diesem Genus wurden zusätzlich die kürzlich gefundenen Parechoviren 3-8 zugeordnet. picorna: von pico = piccolo, klein; $r n a=$ RNA, ribonucleic acid.

entero: von griech. enteron = Darm, Eingeweide.

Echovirus: Abk. für „Enteric Cytopathogenic Human Orphan Virus" (orphan = engl. Waisenkind, weil diese Viren nach ihrer Entdeckung zunächst keinem Krankheitsbild zuzuordnen waren).

lat. $p a r=$ gleich.

\section{Historie}

Nachdem es durch Einführung der Zellkulturtechnik durch Enders und Mitarbeiter (1949) möglich war, Polioviren zu isolieren, wurden 1951 von Robbins, Enders und Mitarbeitern aus dem Stuhl von zwei Kindern mit den Symptomen einer nicht paralytischen Poliomyelitis Viren isoliert, die sich serologisch von Polioviren und Coxsackieviren unterschieden. In den folgenden Jahren wurden weltweit weitere Virusisolate mit gemeinsamen Eigenschaften gewonnen. Da diesen enteritischen Viren häufig keine Krankheitsbilder zugeordnet werden konnten, wurde diese neue Virusgruppe 1956 von Duran-Reynals als Orphan Viren (= Waisenviren) bezeichnet. Später erhielt diese Virusgruppe den Namen Echoviren (= Enteric Cytopathogenic Human Orphan Viruses). Typischerweise sind Echoviren im Gegensatz zu Coxsackieviren apathogen für neugeborene Mäuse. Sequenzvergleiche führten zu einer Reklassifizierung der Echovirus Typen 22 sowie 23 im Genus Parechovirus als humanes Parechovirus $1(\mathrm{HPeV} 1)$ und HPeV2. Im Jahr 1999 wurde bei einem 1-jährigen japanischen Mädchen mit transienten Paralysen, Fieber und Diarrhoe HPeV 3 erstmals isoliert. Anschließend wurden $\mathrm{HPeV}$ 4-8 identifiziert - Symptome.

\section{Morphologie}

Echoviren und Parechoviren sind wie alle anderen Picornaviren kleine, sphärische und unbehüllte RNAViren (Durchmesser $30 \mathrm{~nm}, 156 \mathrm{~S}$, Dichte $1,34 \mathrm{~g} / \mathrm{ml}$ in $\mathrm{CsCl}$ ). Das Viruskapsid mit seinen vier nichtglykosylierten Viruskapsidproteinen VP1-VP4 umgibt ein Molekül der genomischen Plus-Strang-RNA (einzelsträngig), die auch als mRNA dient. Echoviren ähneln in Struktur, Genomorganisation und physikochemischen Eigenschaften stark den Polioviren sowie den anderen Enteroviren. Für eine detaillierte Beschreibung $>$ Taxonomie und $>$ Polioviren. Abweichungen können für die Länge der genomischen RNA und die Molekulargewichte der einzelnen Virusproteine auftreten. Für Säurestabilität und Inaktivierbarkeit von Echoviren und Parechoviren $>$ Polioviren.

\section{Genom}

Die Genomorganisation der einzelsträngigen PlusStrang-RNA von Echoviren und Parechoviren gleicht im Wesentlichen der von anderen Enteroviren und Rhinoviren ( $\triangleright$ Polioviren). Abweichungen können für die Länge der genomischen RNA (z. B. 7.339 Nukleotide für Echovirus 9, 7.500 Nukleotide für Echovirus 12 und 7.321 Nukleotide für Parechovirus 3) und die Molekulargewichte der einzelnen Virusproteine auftreten. Für Nukleinsäuresequenzen von einzelnen Enteroviren und Parechoviren siehe: GenBank, National Institute of Health, http://www.ncbi.nlm.nih.gov/ sites/entrez? $\mathrm{db}=$ nucleotide; Picornavirus Study Group: http://www.picornastudygroup.com/.

\section{Vermehrung}

Echoviren und Parechoviren vermehren sich in den 
Epithelien und lymphoiden Organen des Rachens und Darms und in allen Organen, in denen die Infektion zu Krankheitszeichen führt ( $\triangleright$ Erkrankungen/Symptome). Es wird davon ausgegangen, dass analog zur Poliovirus-Infektion ( $\triangleright$ Polioviren) das Virus über eine Virämie zum Erfolgsorgan (z. B. ZNS) transportiert wird.

\section{Pathogenität / Virulenz / Antigenvariabilität}

Der Pathogenitätsmechanismus ist wie bei den Polioviren und den anderen Enteroviren vor allem durch den Zelltropismus bedingt, wobei die Viruserkennung durch spezifische Rezeptoren geregelt wird. Bislang ist erst für einige Echovirustypen der Rezeptor bekannt. Darunter sind: Decay Accelerating Factor (DAF, CD55) für Echovirus 3, 6, 7, 11-13, 20, 21, 24, 29 und

Tab. 1. Klinische Syndrome der Echovirus- und Parechovirus-Infektionen (nach Melnick, 1996; Pallansch and Roos, 2007; Harvala et al., 2010).

\begin{tabular}{|c|c|}
\hline Klinische Syndrome & Echovirus-Typen \\
\hline Aseptische Meningitis & $\begin{array}{l}1-7,9,11,13-21,25 \\
27,30,31\end{array}$ \\
\hline Paralyse (selten) & $\begin{array}{l}4,6,9,11,30 \\
\text { wahrscheinlich } \\
1,7,13,14,16,18,31\end{array}$ \\
\hline $\begin{array}{l}\text { Enzephalitis, Ataxie oder } \\
\text { Guillain-Barré Syndrom }\end{array}$ & $\begin{array}{l}2,6,9,19 \\
\text { wahrscheinlich } \\
3,4,7,11,14,18\end{array}$ \\
\hline Exantheme & $\begin{array}{l}2,4,6,9,11,16,18 \\
\text { wahrscheinlich } \\
1,3,5,7,12,14,19,20\end{array}$ \\
\hline $\begin{array}{l}\text { Respirationstraktinfekte (u. } \\
\text { a. Sommergrippe) }\end{array}$ & $\begin{array}{l}4,9,11,20,25 \\
\text { wahrscheinlich } \\
1-3,6-8,16,19\end{array}$ \\
\hline Konjunktivitis & 7,11 \\
\hline Myalgie (selten) & $1,6,9$ \\
\hline $\begin{array}{l}\text { Myokarditis und Perikardi- } \\
\text { tis (selten) }\end{array}$ & $1,6,9,19$ \\
\hline Hepatitis & 4,9 \\
\hline Diarrhoe & verschiedene Typen \\
\hline $\begin{array}{l}\text { Sepsis-ähnliche Erkran- } \\
\text { kung (häufig neonatal) }\end{array}$ & 11 \\
\hline $\begin{array}{l}\text { Uncharakteristische fieber- } \\
\text { hafte Erkrankung }\end{array}$ & verschiedene Typen \\
\hline Klinische Syndrome & Parechovirus-Typen \\
\hline $\begin{array}{l}\text { Aseptische Meningitis } \\
\text { (häufig neonatal) }\end{array}$ & $1,2,3$ \\
\hline Transiente Paralyse & 1,3 \\
\hline
\end{tabular}

33; Very Late Activation Antigen-2 (VLA-2, $\alpha 2 \beta 1$, Integrin) für Echovirus 1 und 8; die Integrine $\alpha v \beta 1, \alpha v \beta 3$ (Vitronectin) und $\alpha v \beta 6$ für Parechovirus 1. DAF und Vitronectin werden auch von einigen Coxsackieviren als Rezeptor benutzt. Die wesentlichen Schritte des viralen Reproduktionszyklus zeigen Übereinstimmung mit dem Vermehrungsmechanismus von Polioviren. Weiteres $\triangleright$ Polioviren.

\section{Erkrankung}

Inkubationszeit

Die mittlere Inkubationszeit beträgt 7-14 Tage (2-35 Tage).

\section{Leitsymptome \\ - Tab. 1.}

Tab. 1. Fortsetzung

Klinische Syndrome Echovirus-Typen

Nicht-Polio-bedingte aku- $\quad 1,3,6,7$ te schlaffe Lähmungen

\begin{tabular}{|c|c|}
\hline $\begin{array}{l}\text { Enzephalitis (häufig neo- } \\
\text { natal) }\end{array}$ & 1,3 \\
\hline Enzephalomyelitis & 1,3 \\
\hline Meningoenzephalitis & 3 \\
\hline $\begin{array}{l}\text { Ataxie oder Guillain-Barré- } \\
\text { Syndrom }\end{array}$ & 1 \\
\hline Reye-Syndrom & 5,6 \\
\hline $\begin{array}{l}\text { Milde respiratorische Er- } \\
\text { krankungen }\end{array}$ & $1-8$ \\
\hline Otitis media & 1 \\
\hline Myositis & 3 \\
\hline Myokarditis & 1 \\
\hline Diarrhoe & $1,2,3,8$ \\
\hline $\begin{array}{l}\text { Milde gastroenteritische } \\
\text { Erkrankung }\end{array}$ & $1-8$ \\
\hline $\begin{array}{l}\text { Hepatitis (häufig neonatal, } \\
\text { z.T. mit Koagulopathie und } \\
\text { Thrombozytopenie) }\end{array}$ & 3 \\
\hline $\begin{array}{l}\text { Nekrotisierende Entero- } \\
\text { kolitis }\end{array}$ & 1 \\
\hline $\begin{array}{l}\text { Hämolytisch-urämisches } \\
\text { Syndrom (HUS) }\end{array}$ & 1 \\
\hline $\begin{array}{l}\text { Sepsis-ähnliche Erkran- } \\
\text { kung (häufig neonatal) }\end{array}$ & 3 \\
\hline Lymphadenitis & 4 \\
\hline $\begin{array}{l}\text { Uncharakteristische fieber- } \\
\text { hafte Erkrankung }\end{array}$ & $1-8$ \\
\hline
\end{tabular}




\section{Symptome}

Echoviren verursachen wie alle anderen Enteroviren überwiegend asymptomatische Infektionen (90-95\%) unter Ausbildung von neutralisierenden Antikörpern (stille Feiung). Nach der Vermehrung im Intestinaltrakt kann das Virus durch die abführenden Lymphbahnen in den Blutkreislauf gelangen und zu einer zyklischen Infektion mit Virämie sowie Ausbreitung auf die Zielorgane führen. Im Vergleich zu Polioviren haben Echoviren einen verminderten Neurotropismus, zeigen jedoch ein breiteres Krankheitsspektrum. Echoviren können neben dem Verdauungstrakt, die Meningen, das ZNS, das Myokard und Perikard, die quergestreifte Muskulatur, den Respirationstrakt und die Haut infizieren. Paralysen sind im Allgemeinen seltener und weniger stark ausgeprägt als nach Poliovirus-Infektionen. Da Echovirus-Infektionen im Vergleich zu Infektionen mit Polio- und Coxsackieviren im Allgemeinen zu schwächeren Krankheitsverläufen und seltener zum Tode führen, sind die Kenntnisse über die Pathologie und Histopathologie der Echovirus bedingten Krankheiten eingeschränkt. Die morphologischen Veränderungen bei ZNS-Manifestation sind denen der Poliomyelitis sehr ähnlich. Die Schädigung der motorischen Vorderhornzellen ist jedoch geringer, wodurch die Beeinträchtigungen normalerweise vorübergehend sind. Bei den übrigen Organmanifestationen (auch bei den generalisierten EchovirusInfektionen von Säuglingen) treten gleiche pathologische Veränderungen wie nach Infektionen mit Coxsackieviren auf. Weiteres $>$ Polioviren und Coxsackieviren.

Die Parechoviren 1-8 zeigen wie die Enteroviren ein sehr breites Spektrum von klinischen Syndromen. Gefürchtet sind Infektionen bei Neugeborenen und Kleinkindern, die oft mit schweren, sepsis-ähnlichen Verläufen einhergehen können.

- Tab. 1 zeigt die Virustypen, die unter den Echoviren und Parechoviren Hauptverursacher der folgenden klinischen Syndrome sind, wobei die einzelnen Viren mehrere Syndrome gleichzeitig bewirken können.

Infektionen des Zentralen Nervensystems. Die meisten Echoviren und die Parechoviren 1-3 und 5-7 können mit Infektionen des ZNS assoziiert sein. Echovirus 9 war 1955-1960 für eine Pandemie von aseptischer Meningitis verantwortlich. In seltenen Fällen kommt es zur Paralyse, die im Vergleich zu PoliovirusInfektionen häufig schwächer und nur vorübergehend ist. Verschiedentlich bewirken Echovirus-Infektionen Enzephalitis, Ataxie und das Guillain-Barré-Syndrom. Für HPeV1-3 sind Fälle von aseptischer Meningitis, für $\mathrm{HPeV} 1$ und 3 Enzephalitis, Enzephalomyelitis, und Paresen beschrieben worden. HPeV3 kann zusätzlich zu einer Meningoenzephalitis führen. Akute schlaffe Lähmung (nicht Polio-bedingte Parese) wird durch HPeV1, 3, 6 und 7 hervorgerufen. Reye-Syndrom mit akuter, nichtentzündlicher Enzephalitis und Fettleberhepatitis sind für HPeV5 und 6 beschrieben.
Exantheme. Einige Echovirustypen können vor allem bei Kindern nicht juckende Exantheme (u. a. makulopapulös, teilweise masern- und rötelnähnlich) hervorrufen, die einem anfänglich unklaren fieberhaften Infekt folgen und von einer Pharyngitis begleitet werden können. Für das sogenannte Boston-Exanthem ist Echovirus 16 verantwortlich. Die aseptische Meningitis ist häufig von einem Exanthem begleitet. Für Infektionen mit Parechovirus 3 ist beschrieben, dass es bei Kleinkindern zu Exanthemen (teilweise makulopapulös) verbunden mit hohem Fieber und Tachypnoe kommen kann.

Respirationstraktinfekte und uncharakteristische fieberhafte Erkrankung. Für verschiedene Typen der Echoviren und für die meisten Parechoviren sind Infektionen mit uncharakteristischer fieberhafter Erkrankung und schwachen Krankheitszeichen im oberen Respirationstrakt beschrieben. Häufig werden schnupfenähnliche Bilder (Common Cold) durch Echoviren im Sommer hervorgerufen und deshalb als Sommergrippe bezeichnet.

Konjunktivitis. Echovirus 7 und 11 können eine Konjunktivitis hervorrufen. Für Echovirus 7 wurde in Schweden 1977 eine epidemische Ausbreitung der Konjunktivitis beschrieben. Diese Form der Konjunktivitis ist von der akuten hämorrhagischen Konjunktivitis zu unterscheiden, die durch Coxsackievirus A24 und Enterovirus 70 verursacht wird.

Myalgie. Echovirus-Infektionen führen vereinzelt $\mathrm{zu}$ Muskelschmerzen, die vor allem im Bereich der unteren Extremitäten auftreten. Betreffen diese Myalgien die Interkostalmuskulatur, kommt es zu Zeichen einer Pleurodynie. Für sporadisch auftretende Fälle von Pleurodynie sind Echovirus 6 und 9 verantwortlich.

Myokarditis und Perikarditis. Seltener als Coxsackieviren können Echoviren zu akuter Myokarditis, Perikarditis oder dilatativer Kardiomyopathie führen. Infektionen des Herzens sind vor allem bei Neugeborenen gefürchtet. Echoviren können im Myokard und in der Perikard-Flüssigkeit nachgewiesen werden. Für Parechovirus 1 sind Fälle von Myokarditis beschrieben.

Gastrointestinale Erkrankungen. Echovirus- und Parechovirus-Infektionen können neben anderen unspezifischen klinischen Symptomen zu einer Diarrhoe führen, die bei Neugeborenen fatale Folgen haben kann. Eine Hepatitis kann Folge einer generalisierten Echovirus-Infektion sein.

Neonatale Infektionen. Echovirus-Infektionen, oft nosokomial erworben, können bei Neugeborenen zu einer generalisierten Erkrankung führen. Ausbrüche auf Neugeborenenstationen sind für verschiedene Echoviren bekannt. Durchfälle bewirken bei den Kindern massive Störungen des Wasser- und Elektrolythaushaltes, was häufig zum Tode führt. Besonders schwere Fälle ruft Echovirus 11 hervor. Innerhalb von wenigen Tagen nach der Geburt kommt es zu fulminanten Infektionen mit sepsisähnlichem Verlauf, aku- 
ter Myokarditis oder Perikarditis sowie Enzephalitis. Eine Hepatitis, einhergehend mit Hämorrhagien und Nierenversagen, verläuft häufig tödlich.

Die höchste Gefährdung durch Parechovirus-Infektionen besteht für Neugeborenen und Kleinkinder. Untersuchungen zeigen Prävalenzen von bis zu 90 \% für mindestens einen Parechovirustyp für die Altersgruppe bis zu 2 Jahren (geringere Prävalenz bei Jugendlichen und Erwachsenen). Wie bei Enteroviren findet nach der Vermehrung im Respirations- und MagenDarmtrakt mit anschließender Virämie eine Ausbreitung auf die Zielorgane statt. Insbesondere für Parechovirus 3 sind schwere Verläufe mit hohem Fieber, sepsisähnlichem Bild, Enzephalitis und Hepatitis beschrieben.

\section{Pathophysiologie \\ - Vermehrung und $\triangleright$ Pathogenität.}

\section{Immunantwort}

Antigene Determinanten der Virusproteine auf der Kapsidoberfläche sind für die Serotypspezifität der einzelnen Echoviren und Parechoviren verantwortlich. Einige Echoviren zeigen untereinander partielle Kreuzreaktion (Typen 1 und 8, Typen 12 und 29 sowie Typen 6 und 30). Die humorale Immunität wird durch typspezifische Antikörper der IgG-, IgM- und IgAKlassen bedingt, wodurch die hämatogene Virusausbreitung $\mathrm{zu}$ den jeweiligen Zielorganen verhindert wird. 7-10 Tage nach der Infektion erscheint typspezifisches IgM und persistiert mindestens 4 Wochen (in 90 \% der Fälle). Einige Tage verzögert werden serotypspezifisches IgG und IgA gebildet, wobei das IgG häufig für Jahre nachweisbar ist. Die Immunantwort gleicht der von Polioviren ( $>$ Polioviren). Wegen des Vorhandenseins diaplazentar übertragbarer Antikörper der IgG-Klasse sind Säuglinge seropositiver Mütter in den ersten Lebensmonaten gegen eine Infektion mit dem entsprechenden Virustyp geschützt. Die im Vergleich niedrigere Prävalenz bei Erwachsenen könnte bedingen, dass die Parechovirus-Infektionen bei Neugeborenen und Kleinkindern durch fehlende Leihimmunität nach der Geburt zu den schweren Verläufen führen.

Die zellvermittelte Immunität ist bislang erst unvollständig untersucht.

\section{Differenzialdiagnose}

Da Echoviren teilweise ähnliche Krankheitsbilder wie die anderen humanpathogenen Enteroviren hervorrufen können, wird zur Differenzialdiagnostik auf die Kapitel: $>$ Polioviren, $>$ Coxsackieviren und $>$ Enteroviren 68-71 und andere Enteroviren verwiesen. Parechovirus-Infektionen sind aufgrund des Krankheitsbildes klinisch nicht von den meisten anderen Enterovirus-Infektionen zu unterscheiden. Zur Differenzierung von Meningitis bzw. Paralyse, für die andere Viren verantwortlich sein können, sind Mumpsvirus,
Herpes simplex-Viren und (seltener) andere Viren der Herpesvirusfamilie, Frühsommer-Meningoenzephalitis-Virus sowie das Lymphozytäre-ChoriomeningitisVirus in Betracht zu ziehen.

\section{Diagnostik}

\section{Untersuchungsmaterial}

Zum Routinenachweis von Echoviren und Parechoviren wird wie bei allen anderen Enteroviren Rachenabstrich und Stuhl verwendet ( $\triangleright$ Polioviren und Coxsackieviren). In Abhängigkeit der Organmanifestation eignen sich zusätzlich Konjunktival-, Rektal- und andere Abstriche, Rachenspülwasser, Nasensekret, Urin, Liquor, Biopsie- oder Autopsiematerialien von Herz und/oder Gehirn.

\section{Diagnostische Verfahren}

Virusnachweis: Für Echoviren und Parechoviren stehen heute wie für die anderen Picornaviren molekularbiologische Methoden zum Virusgenomnachweis und zur Typisierung mittels Sequenzierung (VP1-Region) im Vordergrund. Die Diagnostik von Parechovirus-Infektionen ist auf Speziallaboratorien beschränkt (Parechovirus-spezifische RT-PCR). Parechoviren sind auf Grund der genetischen Unterschiede mit den routinemäßig verwendeten 5'NTR-spezifischen Enterovirus-RT-PCRs nicht nachzuweisen. Zum Parechovirus-Nachweis und zur Abgrenzung von anderen Enteroviren werden Parechovirus-spezifische RTPCRs verwendet (mit Primern gegen hochkonservierte Bereiche der Parechovirus-5'NTR). Molekulare Typisierung wird durch Sequenzierung vorgenommen (in genomischen Bereichen der Viruskapsidproteine, z. B. VP1).

Zur Isolierung von Echoviren und teilweise auch $\mathrm{Pa}$ rechoviren dienen Monolayer-Zellkulturen vom Menschen und Affen. Beispiele für humane Zelllinien: Primäre embryonale Haut- und Lungenfibroblasten, permanente Fibroblasten (z. B. MRC-5-Zellen), permanente Amnionzellen ( $\mathrm{z}$. B. FL-Zellen) und transformierte Zellen (z. B. KB-, HeLa-, HEp-2-Zellen). Beispiele für Affen-Zelllinien: primäre oder permanente Affennieren-Zelllinien, vor allem von Rhesusaffen und afrikanischen grünen Meerkatzen (z. B. BGMund Vero-Zellen). Eine Ausnahme bildet Echovirus 21, das sich auf Affennierenzellen nicht anzüchten lässt. Verschiedene Echoviren haben hämagglutinierende Eigenschaften und sind im Hämagglutinationstest bzw. Hämagglutinationshemmtest nachweisbar.

Die Virusidentifizierung im Neutralisationstest erfolgt für Echoviren mit Antiseren bekannter Spezifität, z. B. mit 8 Hyperimmunserum-Pools nach Lim-BenyeschMelnick (LBM-Antiserum-Pools, erhältlich über Statens Serum Institut, Kopenhagen $\boldsymbol{\nabla}$ Referenzzentren). Eine Sonderstellung nimmt der Nachweis von Echovirus 7 bei Konjunktivitis ein. Abgeschabtes Konjunktivalmaterial ist $u$. a. für den indirekten Immunfluoreszenztest gut geeignet. 
Antikörpernachweis: Zum serologischen Nachweis einer frischen Infektion ist entweder die Untersuchung eines Serumpaares (min. 4 facher Titeranstieg im NT bei zwei Seren, die im Abstand von 7-14 Tagen gewonnen sind) oder die Bestimmung virusspezifischer IgM-Antikörper notwendig. Der Nachweis von virustypspezifischen Antikörpern kann nur im NT geführt werden (im NT werden ausschließlich Epitope der Virusoberfläche durch Antikörper erkannt). Wegen immunologischer Kreuzreaktion sind kommerzielle und selbsthergestellte Enzymimmunassays dazu nicht geeignet (Antikörper erkennen auch kreuzreagierende Epitope aus dem Virusinneren, weil denaturiertes Antigen verwendet wird).

\section{Befund / Interpretation}

Da Echo- und Parechovirus-Infektionen in der Mehrzahl der Fälle klinisch inapparent oder als uncharakteristische fieberhafte Erkrankungen verlaufen und zudem Virus vor allem im Stuhl über Monate ausgeschieden werden kann, sollte die Diagnostik in engem ätiologischen Zusammenhang des Virusnachweises mit einem definierten Krankheitsbild erfolgen. Beweisend für eine Infektion mit diesen Viren ist der VirusRNA-Nachweis bzw. die Virusanzucht. Der signifikante Titeranstieg neutralisierender Antikörper $(\geq 4 \mathrm{fa}$ cher Titeranstieg; 10-14 Tage Abstand zwischen beiden Blutabnahmen) ist weiterhin beweisend für eine frische Infektion mit Echo- und Parechoviren.

\section{Therapie}

\section{Therapeutische Maßnahmen}

Eine In-vivo-Therapie mit antiviralen Substanzen ist nur begrenzt möglich. Die Substanz Pleconaril, die durch Interkalation im Viruskapsidprotein VP1 eine Kapsidstabilisierung bewirkt und so zu einer Blockierung des viralen Uncoatings und/oder der Rezeptorerkennung führt, zeigte in randomisierten, doppelblind und Plazebo kontrollierten Phase-3-Studien für Enterovirus-bedingte Meningitis eine Reduzierung der mittleren Infektionsdauer (in Deutschland nicht zugelassen) ( $>$ Polioviren). Gegen Parechoviren zeigt Pleconaril in In-vitro-Experimenten keine antivirale Wirksamkeit.

\section{Epidemiologie}

\section{Verbreitung}

Echovirus-Infektionen kommen weltweit vor. In den gemäßigten Zonen findet die Mehrzahl der Infektionen im Sommer, in wärmeren Ländern das ganze Jahr über statt. Wegen des fehlenden Immunschutzes sind Kleinkinder Hauptausscheider. Ungünstige hygienische und sozioökonomische Bedingungen führen zu einem hohen Infektionsrisiko. Echovirus-Infektionen können gleichzeitig mit anderen Enterovirus-Infektionen auftreten (z. B. Polioviren und Coxsackieviren), wobei die Virusreproduktion eines der Viren durch
Interferenz unterdrückt sein kann. Verschiedene Typen (Echovirus 3, 4, 6, 9, 11 und 16) sind mit großen Epidemien verbunden. Echovirus 9 führte 1955-1960 zu einer Pandemie von aseptischer Meningitis. Anfang der Fünfzigerjahre des letzten Jahrhunderts trat in Massachusetts gehäuft ein fieberhaftes Exanthem (makulopapulös) durch Echovirus 16 auf, das seitdem auch als Boston-Exanthem bezeichnet wird. Für verschiedene Echovirustypen sind zyklische Ausbrüche berichtet, die z. B. für Echovirus 9 in verschiedenen Gegenden im Abstand von 3-4 Jahren auftraten. In den letzten Jahren wurden gehäuft Echovirus 13-Ausbrüche beobachtet (44 Meningitis-Fälle in Deutschland von Mai bis Juni 2000; 38 Meningitis-Fälle in England und Wales im ersten Halbjahr 2000; 50 Meningitisfälle in den USA von März-Juni 2001). Ein Echovirus-30-Ausbruch trat im Raum Frankfurt am Main im Jahr 1997 auf. Häufige Infektionen mit Echovirus 30 wurden auch in Ost-Brandenburg, Niedersachsen und im Würzburger Raum berichtet. Zusätzlich wurden im Jahr 2000 gehäufte Infektionen mit Echovirus 13 in Sachsen-Anhalt und Sachsen beobachtet. Im August 2001 wurde ein durch Echovirus 30 bedingter Meningitisausbruch in Nordhessen im $\mathrm{Zu}-$ sammenhang mit dem Besuch eines Kleinbadeteiches berichtet.

Die ersten Parechovirus-Infektionen wurden zu Beginn der 1960er Jahre beschrieben. Auf Grund von genetischen Untersuchungen wurden Parechovirus 1 (HPeV1) und HPeV2 als erste Viren dem eigenen Genus Parechovirus zugeordnet $>$ Taxonomie. Folgende neue Parechoviren wurden isoliert: $\mathrm{HPeV} 3 \mathrm{im} \mathrm{Jahr}$ 1999 von einem japanischen einjährigen Kind mit transienter Paralyse; HPeV4 im Jahr 2002 von einem niederländischen Neugeborenen mit fieberhafter Erkrankung; HPeV5 im Jahr 1986 von einem US-amerikanischen zweijährigen Kind mit hohem Fieber; HPeV6 aus dem Liquor von einem japanischen einjährigen Mädchen mit fatalem Reye-Syndrom; $\mathrm{HPeV} 7$ aus dem Stuhl eines gesunden pakistanischen zweijährigen Jungen (Kontakt zu Patienten mit Nicht-Poliobedingter akuter schlaffer Lähmung) und $\mathrm{HPeV} 8$ bei der Untersuchung von Stuhlproben einer Studienkohorte von brasilianischen Kindern unter sechs Jahren.

\section{Wirtsbereich / Reservoir}

Reservoir für Echoviren und Parechoviren ist der Mensch. Im Gegensatz zu Coxsackieviren sind die meisten Echoviren für neugeborene Mäuse apathogen. Eine Ausnahme bilden einige Stämme von Echovirus 9, die in infizierten neugeborenen Mäusen zu Lähmungen mit histologischen Veränderungen in der quergestreiften Muskulatur führen können (ähnlich wie Coxsackievirus A23). Typischerweise sind Echoviren auch für Affen apathogen. Einige Echoviren können in Affen nach intrazerebraler und intraspinaler Inokulation schwache Läsionen im ZNS verbunden mit Paralyse hervorrufen. Zelllinien vom Mensch und 
Affen werden zur Virusanzüchtung verwendet $(\triangleright$ Diagnostik).

\section{Risikogruppen}

Infektionen mit Echoviren zeigen bei Kindern im Allgemeinen einen leichteren Verlauf als bei Erwachsenen. Immunsupprimierte Patienten und Neugeborene sind durch Echovirus-Infektionen vergleichsweise stark gefährdet. Bei Neugeborenen können diese Infektionen zu schweren Durchfällen führen. Speziell bei Echovirus 11 kommt es zu tödlichen Verläufen mit Manifestationen im ZNS und Herzen sowie Hepatitis (teilweise hämorrhagisch). Ausbrüche mit Echoviren können vor allem auf Neugeborenenstationen vorkommen. Perinatale Echovirus-Infektionen werden diskutiert ( $\triangleright$ Erkrankungen/Symptome).

Durch Infektionen mit Parechoviren sind Neugeborene und Kleinkinder stark gefährdet. Typisch sind Fieber mit respiratorischen und gastroentestinalen Symptomen. Fatale Infektionen zeigen häufig einen sepsisähnlichen Verlauf mit Enzephalitis und Hepatitis.

\section{Transmission / Vektoren}

Echoviren und Parechoviren werden wie Enteroviren hauptsächlich fäkal-oral übertragen. Schon kurz nach Infektionsbeginn kommt es zu massiver Virusausscheidung im Stuhl, die mehrere Wochen andauern kann. Fäkale Kontaminationen (Finger, Gegenstände, Lebensmittel) sind die Hauptursachen für die Virusverbreitung. Wegen der primären Virusvermehrung in den Rachenepithelien wird das Virus auch respiratorisch kurz nach Infektion übertragen. Echovirus-Infektionen sind in Ländern mit niedrigem sozioökonomischem Status besonders häufig, wobei die Übertragung durch kontaminiertes Abwasser eine wesentliche Bedeutung hat. Weiteres $>$ Polioviren.

\section{Prävention / Impfstoffe}

Eine aktive Immunisierung gegen Echoviren und $\mathrm{Pa}$ rechoviren ist nicht verfügbar.

\section{Ausbruchsmanagement}

Nosokomiale Echovirus- und Parechovirus-Infektionen können von klinischem Personal durch Vernachlässigung der üblichen Hygiene übertragen werden. Wegen der fulminanten Verläufe sind Infektionen mit Echoviren wie auch mit Coxsackieviren auf Neugeborenenstationen besonders gefürchtet. Wesentliche Präventionsmaßnahme ist die fachgerechte Windelentsorgung und Kittelwechsel. Gegebenenfalls ist eine räumliche Trennung der infizierten Patienten vorzunehmen. Die aktuellen Maßnahmen zur hygienischen Händedesinfektion sind unbedingt einzuhalten.

\section{Meldepflicht}

Es besteht keine Meldepflicht.

\section{Weiterführende Informationen}

\section{Referenzzentren / Expertenlaboratorien}

- Nationales Referenzzentrum für Poliomyelitis und Enteroviren und Regionales Referenzlabor der WHO/EURO für Poliomyelitis, Dr. Sabine Diedrich, Robert Koch-Institut, Nordufer 20, D-13353 Berlin, Tel.: +49-(0)30-18754 2378, Fax: +49-(0)30-18754 2617, E-Mail: DiedrichS@rki. de; www.rki.de.

- Statens Serum Institut, 5, Artillerivej, DK-2300 Kopenhagen S, Dänemark; Dr. Mette B. Kern, Tel.: +45-4829-9178, Fax: +45-4829-9179, E-Mail: ivdorders@ssi.dk; www.ssi. $\mathrm{dk}$.

- National Institute for Public Health and the Environment, RIVM - Rijksinstituut vor Volksgezondheid en Milieu, Dept. Virology, PO Box 1, NL 3720 BA Bilthoven, The Netherlands; www.rivm.nl

\section{Web-Adressen}

- Picornaviridae.com: http://www.picornaviridae.com

- Picornaviridae study group: http://www.picornastudy group.com

- The big picture book of viruses: http://www.tulane. edu/ dmsander/Big_Virology/BVRNApicorna.html

- Genbank, National Institute of Health: http://www.ncbi. nlm.nih.gov/Genbank/index.html

\section{Schlüsselliteratur}

1. Harvala H, Wolthers KC and Simmonds P (2010) Parechoviruses in children: understanding a new infection. Curr Opp Infect Dis 23, pp 224-230

2. Melnick J (1996) Enteroviruses: Polioviruses, Coxsackieviruses, Echoviruses, and Newer Enteroviruses. In: Fields $\mathrm{BN}$ et al. (eds) Fields Virology, 5th edn. Raven, Philadelphia, vol 1, pp 655-712

3. Pallansch M, Roos, R (2007) Enteroviruses: Polioviruses, Coxsackieviruses, Echoviruses, and Newer Enteroviruses. In: Knipe DM et al. (eds) Fields Virology, 5th edn. Wolters Kluwer Lippincott Williams \& Wilkins, Philadelphia, vol 1, pp 2839-2893

4. Stanway G et al (2005) Picornaviridae. In: Fauquet CM et al. (eds) Virus Taxonomy, Classification and Nomenclature of Viruses, Eighth Report of the International Committee on Taxonomy of Viruses. Elsevier Academic Press, Amsterdam, pp 757-778

5. Zeichhardt H, Grunert HP (2003) Enteroviruses: polioviruses, coxsackieviruses, echoviruses and enteroviruses 68-71. In: Cohen J, Powderly WG, Opal SM (eds) Infectious Diseases, 2nd edn. Elsevier Health Sciences, London, chapter 213, pp 1993-2006

6. Zeichhardt H, Grunert, H-P (2010) Picornaviren - Klinik, Diagnostik und Prävention. In: Doerr HW und Gerlich WH (Herausgeber) Medizinische Virologie, 2. Aufl, Thieme Verlag, Stuttgart New York, Kapitel 42, S 468-489

\section{Edwardsiella}

UWE ULLMANN

\section{Erreger}

\section{Synonym(e)}

Keine bekannt. 


\section{Erregerspezies}

Edwardsiella ictaluri, Edwardsiella hoshinae

\section{Taxonomie}

Familie Enterobacteriaceae, Gattung: Edwardsiella, Spezies: E. tarda

\section{Historie}

Edwardsiella ist benannt nach dem amerikanischen Bakteriologen P.R. Edwards. Weitere Arten, die jedoch beim Menschen bisher nicht als Krankheitserreger in Erscheinung getreten sind, sind Edwardsiella ictaluri (fischpathogen) und Edwardsiella hoshinae.

\section{Morphologie}

Gramnegative Stäbchenbakterien, beweglich durch peritriche Begeißelung.

\section{Genom}

Genom vollständig sequenziert, siehe auch www.ncbi. nlm.nih.gov.

\section{Vermehrung}

Fakultativ anaerob, Wachstum innerhalb von 24 Stunden.

\section{Pathogenität / Virulenz / Antigenvariabilität}

Endotoxin.

\section{Erkrankungen}

1. Lokalisierte Prozesse: sehr selten Leberabszess, Meningitis, Weichteilinfektionen, Gastroenteritis.

\section{Synonym(e)}

Keine bekannt.

\section{Inkubationszeit}

Nicht bekannt.

\section{Leitsymptome}

Dem Krankheitsbild entsprechend.

\section{Symptome}

Dem Krankheitsbild entsprechend.

\section{Pathophysiologie}

Fakultativ pathogener opportunistischer Erreger, Infektion bei Standortwechsel.

\section{Immunantwort}

Opsonisierung durch Antikörper, Phagozytose.

\section{Differenzialdiagnose}

Ausschluss anderer Infektionserreger.

2. Generalisierte Prozesse: extrem selten Sepsis.

\section{Inkubationszeit}

Nicht bekannt.

\section{Leitsymptome}

Fieber.

\section{Symptome}

Fieber.

\section{Pathophysiologie}

- Lokalisierte Prozesse (Erkrankung 1)

Immunantwort

- Lokalisierte Prozesse (Erkrankung 1)

Differenzialdiagnose

- Lokalisierte Prozesse (Erkrankung 1)

\section{Diagnostik}

\section{Untersuchungsmaterial}

- Enterobacter

\section{Diagnostische Verfahren}

Biochemische Differenzierung:

- Katalase-positiv

- Nitratreduktion

- $\mathrm{H}_{2} \mathrm{~S}$-positiv/Schwefelwasserstoffbildung

- intrinsic'sche Resistenz gegen Colistin

Serologische Differenzierung: Für Edwardsiella tarda beschrieben Edwards und Ewing ein Schema mit 49 $\mathrm{O}$-Antigen und $37 \mathrm{H}$-Antigenen.

\section{Befund / Interpretation}

Erregernachweis ausschlaggebend.

\section{Therapie}

\section{Therapeutische Maßnahmen}

Fluorochinolon, Ampicillin, Cefalosporine, Aminoglykoside.

\section{Epidemiologie}

\section{Verbreitung}

Weltweit, Gastroenteritis in tropischen und subtropischen Klimazonen, häufig einhergehend mit dem Nachweis von Entamoeba histolytica.

\section{Wirtsbereich / Reservoir}

Nachweis in Faeces vom Menschen, Haustieren, Ratten, Fröschen, Vögeln, Fischen.

\section{Risikogruppen}

Immunsupprimierte und abwehrgeschwächte Patienten, Reisende in warme Klimazonen.

\section{Transmission / Vektoren}

Endogen, Schmierinfektion.

\section{Prävention / Impfstoffe}

Siehe obligat pathogene E.-coli-Stämme und fakultativ pathogene E.-coli-Stämme. \ Escherichia coli.

\section{Ausbruchsmanagement}

Nicht erforderlich. 


\section{Meldepflicht}

$\S 23$ IfSG Abs. 1: Multiresistenz ist zu dokumentieren.

\section{Weiterführende Informationen}

\section{Referenzzentren / Expertenlaboratorien \\ Keine.}

\section{Web-Adressen}

- www.cdc.gov/

\section{Schlüsselliteratur}

1. Blaser MJ, Smith D, Ravdin JI, Greenberg HB, Guerrant RL (eds) (1995) Infections of the Gastrointestinal Tract, Raven Press New York

2. Hahn H, Kaufmann SHE, Schulz TF, Suerbaum S (Hrsg) (2009) Medizinische Mikrobiologie und Infektiologie. 6. Auflage, Springer Verlag Berlin, Heidelberg, New York, Barcelona, Hongkong, London, Mailand, Paris, Singapur, Tokyo

3. Kist M, Bockemühl J, Aleksic S, Altwegg M, Autenrieth IB, Bär W, Beutin L, Gerten B, Heintschel E, Heinegg, Karch H, Lehmacher A, Mehnert F, Sonnenborn U, Tschäpe H, von Eichel-Streiber C (2000) Infektionen des Darmes: MiQ 9, Urban und Fischer, München, Jena

4. Mandell GL, Bennett JE, Dolin R (eds) (2000) Mandell, Douglas, and Bennett's Principles and Practice of Infectious Diseases. 5th Ed. Churchill-Livingstone, Philadelphia, London, Toronto, Montreal, Sydney, Tokyo, Edinburgh

\section{Eggerthella lentum}

Eubakterien

\section{Ehrlichia}

Volker Fingerle, ANdreas Sing

\section{Erreger}

\section{Synonym(e)}

Humane monozytäre Ehrlichiose (HME), Humane granulozytäre Anaplasmose (HGA, früher humane granulozytäre Ehrlichiose, HGE), humane ewingii Ehrlichiose (HEE).

\section{Erregerspezies}

Anaplasma phagocytophilum, Ehrlichia chaffeensis, Ehrlichia ewingii

\section{Taxonomie}

Innerhalb der Familie Anaplasmataceae (a-Proteobacteria) werden (nach 16S rDNA und groESL Analyse) E. chaffeensis und E. ewingii dem Genus Ehrlichia, A. phagocytophilum dem Genus Anaplasma zugeordnet.

\section{Historie}

Schon in der ersten Hälfte des 20sten Jahrhunderts wurden Ehrlichien als Erreger fieberhafter Erkran- kungen bei Hunden und Wiederkäuern beschrieben. Die zunächst als Rickettsien bezeichneten Erreger wurden $1945 \mathrm{zu}$ Ehren von Paul Ehrlich in E. canis und E. phagocytophila umbenannt. Der erste Fall einer durch Zeckenstich übertragenen humanen Ehrlichiose wurde 1986 in den USA bekannt. Nachdem zunächst $E$. canis als Erreger vermutet wurde, gelang 4 Jahre später die Isolierung und Charakterisierung einer neuen Ehrlichia-Spezies aus dem Blut eines Soldaten der Kaserne Chaffee, Arkansas, die als E. chaffeensis bezeichnet wurde. Im Jahr 1994 wurde dann der Erreger der HGE zunächst an der amerikanischen Ostküste entdeckt und 1997 wurde der erste Fall aus Europa (Slowenien) berichtet. Als bislang letzte Spezies wurde 1999 aus Amerika E. ewingii als Ursache fieberhafter Erkrankungen primär bei Immundefizienten beschrieben.

\section{Morphologie}

Es sind kleine $(0,2-2 \mu \mathrm{m})$, obligat intrazelluläre, gramnegative, unbewegliche, kokkoide bis pleomorphe Bakterien mit dreischichtiger Zellwand, die als intrazytoplasmatische Vakuolen (Morula) in Granulozyten (A. phagocytophilum, E. ewingii) oder Monozyten/Makrophagen (E. chaffeensis) nachweisbar sind. In Zellkultur zeigen sich bei A. phagocytophilum und E. chaffeensis zu Beginn der Infektion aufgelockerte retikuläre Formen, im weiteren Verlauf Verdichtung der einzelnen Bakterien.

\section{Genom}

A. phagocytophilum und E. chaffeensis besitzen ein einzelnes zirkuläres Genom mit einer Größe von etwa $1,5 \mathrm{Mb}$ (A. phagocytophilum) bzw. 1,2 Mb (E. chaffeensis) mit zahlreichen repeats. Bei E. chaffeensis fanden sich 1.115 open reading frames, bei $A$. phagocytophilum 1.369. Der GC-Gehalt ist $41,6 \%$ bei A. phagocytophilum und $30,1 \%$ bei E. chaffeensis. Das bemerkenswertes genetisches Inventar für Oberflächenproteine aus der OMP-1/MSP2/P44 Familie umfasst für E. chaffeensis 22 omp-Paraloge, für A. phagocytophilum mehr als $100 \mathrm{Gene}$ dieser Familie. Es finden sich nur wenige regulatorische und alternative metabolische Pathways. Sie sind auxotroph für 14-17 Aminosäuren, können aber alle wichtigen Vitamine sowie die meisten KoFaktoren und Nukleotide selbst synthetisieren. Gene für die Biosynthese von Lipopolysaccharid und Peptidoglykan fehlen.

\section{Vermehrung}

Der Vermehrungszyklus der Erreger ist noch weitgehend unklar. Im Menschen vermehren sich A. phagocytophilum und E. ewingii in Granulozyten, E. chaffeensis in Monozyten durch Zweiteilung innerhalb einer Morula. A. phagocytophilum kann wahrscheinlich auch Endothelzellen infizieren. Ob die Infektion neuer Zellen über Zytolyse oder andere Mechanismen funktioniert ist noch unklar. In der Zecke I. scapularis 
scheint A. phagocytophilum in den sekretorischen Acini der Speicheldrüsen zu persistieren. In vitro wachsen A. phagocytophilum in HL60- und E. chaffeensis in DH82 Zellen

\section{Pathogenität / Virulenz / Antigenvariabilität}

Die differenzielle Expression von Oberflächenproteinen der OMP-1/MSP2/P44 Familie ermöglicht wahrscheinlich eine Anpassung an die unterschiedlichen Lebensräume Zecke und Säugetier, antigenetische Variationen eine persistierende Infektion im Wirt.

Bei A. phagocytophilum und E. chaffeensis wurden ein Typ-Iva-Sekretionssystem sowie Komponenten eines Typ-I-Sekretionssystems nachgewiesen. Das gp120 von E. chaffeensis gilt als Adhäsin.

\section{Erkrankung}

Humane granulozytäre Anaplasmose (HGA), Humane monozytäre Ehrlichiose (HME), Humane ewingii Ehrlichiose (HEE)

\section{Synonym(e)}

Humane granulozytäre Ehrlichiose (HGE)

\section{Inkubationszeit}

Meist 1-2 Wochen, kann von wenigen Tagen bis zu 4 Wochen schwanken.

\section{Leitsymptome}

Akut beginnende, influenzaartige Symptome nach Zeckenstich: Fieber, Kopf-, Muskel- und Gelenkschmerzen sowie Abgeschlagenheit

\section{Symptome}

Schwindel, Erbrechen, Durchfall, Bauchschmerzen, Husten und Nackensteife. Exanthem (petechial, makulös, makulopapulös bis zu diffusen Erythemen) bei etwa $30 \%$ der HME-Fälle, nur ausnahmsweise bei HGA. Auch Handflächen und Fußsohlen können betroffen sein.

Komplikationen bei HGE und HME: akutes Abdomen, akutes Nierenversagen, opportunistische Infektionen, Gerinnungsstörungen, Hämorrhagien, Hepatitis, Hirnnervenlähmungen und Tod (0,5-1 \% bei HGE, $3 \%$ bei HME); bei HME interstitielle Pneumonie, Lungenödem, Herzversagen, Ataxie und Meningoenzephalitis; bei HGE Toxic Shock Like Syndrom, Acute Respiratory Distress Syndrom (ARDS), atypische Pneumonie, Myokarditis, Rhabdomyolyse und demyelinisierende Polyneuropathie.

\section{Pathophysiologie}

Wirtszellen sind für E. chaffensis Monozyten und Makrophagen, für E ewingii Granulozyten und für A phagozytophilum Granulozyten und Endothelzellen. Hämophagozytose in Knochenmark und Lymphknoten zeigt eine breite Makrophagen-Aktivierung. Lokal Anhäufung von Makrophagen und Histiozyten, bei
HME auch nicht verkäsende Granulome. In der Leber fokal apoptotischen Hepatozyten bis zu lobulärer Hepatitis und Nekrose. In der Lunge interstitielle Pneumonie mit Makrophagen-dominierten intraalveolären Infiltraten. Der zugrunde liegende Mechanismus ist weitgehend unklar. Die Veränderungen sind wahrscheinlich zytokininduziert, da in den Organen kaum Pathogene nachweisbar sind. In infizierten Wirtszellen wird die Produktion inflammatorischer Zytokine und Chemokine induziert bzw. durch Verhinderung der Apoptose eine verlängerte Degranulation der infizierten Zellen verursacht. Eine wichtige Rolle wird für IFN- $\gamma$ und IL10 vermutet.

\section{Immunantwort}

Der Ablauf der Immunantwort sowie die Beiträge von humoraler und zellulärer Immunität für die Erregerelimination sind weitgehend unklar. Eine überstandene Infektion hinterlässt im Normalfall einen erhöhten IgG-Titer. Ob diese Antikörper vor einer Neuinfektion schützen, ist nicht bekannt. Als immundominant wurden für E. chaffeensis Proteine mit 120, 66, 58, $55,44,29,28$ und $22 \mathrm{kDa}$, für A phagocytophilum Proteine mit 100, 75, 56, $42-49$ und $44 \mathrm{kDa}$ beschrieben. Immunevasionsmechanismen: Die Erreger besitzen weder Lipopolysaccharid noch Peptidoglykan, ein möglicher Schutzmechanismus vor der Erkennung durch Pattern-recognition-Rezeptoren wie z. B TLR, und damit Schutz vor Abwehrmechanismen des angeborenen und vor der Induktion des erworbenen Immunsystems. A phagocytophilum und E. chaffeensis werden über Caveolae vermittelte Endozytose in primäre Abwehrzellen aufgenommen und befinden sich dann in einem membranumschlossenen zytoplasmatischen Kompartment, das die Phagolysosomenbildung umgeht. Beide Erreger verhindern Zusammenbau und Aktivierung des NADPH-Oxidase-Komplexes und beschleunigen dessen Abbau. Beide Erreger scheinen IFN- $\gamma$-Signalwege zu hemmen und den Eisenmetabolismus zu beeinflussen.

Über Hemmung der Wirtszell-Apoptose wird eine relevante Vermehrung der Erreger erst ermöglicht. A. phagocytophilum hemmt die Kaspase-3-Aktivierung, erhöht die Transkription und verhindert den spontanen Abbau der mRNA des antiapoptotisch wirksamen bfl-1 und blockiert den anti-FAS (CD95/ Apo-1)-induzierten Zelltod. E. chaffeensis scheint generell Apoptose-Inhibitoren wie IER3 (immediately early response 3 ), NF- $\kappa \mathrm{B}$ oder BirC3 (baculoviral IAP repeatcontaining protein 3 ) zu induzieren, dagegen Induktoren der Apoptose wie BIK (BCL2-interacting killer) oder BNIP3L (BCL2/adenovirus E1B 19-kDa interacting protein 3-like) zu hemmen und blockiert ebenfalls den anti-FAS induzierten programmierten Zelltod.

\section{Differenzialdiagnose}

Differenzialdiagnostisch kommt ein sehr breites Spek- 
trum infektiöser und nicht infektiöser fieberhafter Erkrankungen in Betracht.

Nach Zeckenstich:

- Frühsommer-Meningoenzephalitis (FSME): In der frühen Phase der Erkrankungen zeigt die HGA signifikant häufiger Myalgien, Arthralgien, erhöhtes CRP und erhöhte LDH.

- Lyme-Borreliose: Fieberhafter Verlauf selten. In der Mehrzahl der Fälle ist ein Erythema migrans vorhanden. Mögliche Ko-Infektion mit beiden Erregern beachten.

- Babesiose: Sehr seltene humane Erkrankung. Diagnostisch wegweisend ist der Nachweis intraerythrozytärer Babesien. Mögliche Ko-Infektion mit beiden Erregern beachten.

Weiterhin sind u. a. in Betracht zu ziehen: Q-Fieber, Leptospirose, Tularämie, Rocky Mountain Spotted Fever, Bruzellose, Rückfallfieber, Typhus, Paratyphus, fieberhafte virale Infektionen (z. B. Influenza, verschiedene Enteroviren), Autoimmunerkrankungen, Leukämien oder Arzneimittelraktionen.

\section{Diagnostik}

\section{Untersuchungsmaterial}

Akutstadium: EDTA-Blut, Knochenmark für den Direktnachweis der Erreger (Ausstrich und PCR für alle Erreger) und kulturellen Nachweis (HGA und HME). Luftgetrocknete Blutausstriche werden am besten sofort nach Entnahme angefertigt. Liquor bei neurologischer Symptomatik (insbesondere HME) für PCR und Kultur. Alle Materialien für den kulturellen oder direkten Erregernachweis (EDTA-Blut, Liquor, ggf. Biopsate) sollen das Labor innerhalb von 2 Tagen erreichen, sonst das Material bei $4{ }^{\circ} \mathrm{C}$ halten.

Serumprobe zum Nachweis erregerspezifischer Antikörper im Akutstadium und 14-21 Tage später.

\section{Diagnostische Verfahren}

Mikroskopie: Nachweis der typischen Morulae in Monozyten bei HME, in Granulozyten bei HGE und HEE im nach Giemsa oder Wright gefärbten Ausstrich von Blut, Knochenmark oder Liquorsediment. Wenigstens 800-1.000 Zellen sollen mikroskopisch beurteilt werden. Die Sensitivität (Blutausstrich, Akutstadium) für HGA wird mit 25-80 \%, für HME mit 1-38 \% angegeben.

Kultur: In der Akutphase Anzucht von E. chaffeensis in der Histiozytom-Zelllinie DH82 vom Hund (ATCC CR5L-10389) und A. phagocytophilum in der humanen promyelozytären Leukämie Zelllinie HL60 (ATCC CCL240) aus EDTA-Blut oder Buffy Coat, ggf. auch Knochenmark und Liquorsediment. Der Nachweis intrazytoplasmatischer Erreger (CytoSpin-Präparate) frühestens 2-7 Tage nach Inokulation, dauert aber oft mehrere Wochen. Identifizierung des Erregers obligat über PCR und Sequenzierung. Die Anzucht wird wegen des hohen Zeit-, Material- und Arbeitsaufwandes nur von Speziallaboratorien durchgeführt. E. ewingii konnte bislang nicht angezüchtet werden.

PCR: Sie gilt für alle Erreger in der Akutphase als die sensitivste Methode. Geeignetes Material ist EDTABlut, ggf. Liquor und Knochenmark. Standardisierte Verfahren stehen nicht zur Verfügung. Zielgene für die PCR sind u. a. rrs oder groESL für alle Erreger, msp2 oder ankA für HGA und p28 für HME oder HEE. Die Sensitivität wird mit 60-100 \% für E. chaffeensis und 48-95\% für A. phagocytophilum angegeben. Antikörpernachweis: Der Nachweis erregerspezifischer IgG- und IgM-Antikörper ist mit dem indirekten Immunfluoreszenztest (E. chaffeensis-Antigen bei HME- und HEE-, A.-phagocytophilum-Antigen bei HGE-Verdacht) möglich. ELISAs mit rekombinanten Antigenen und Immunoblot sind in Entwicklung.

\section{Befund / Interpretation}

$\mathrm{Da}$ alle angesprochenen Erkrankungen selten sind und nur A. phagocytophilum autochthon in Europa vorkommt, ist die Bewertung positiver Befunde schwierig, da bei niedriger Prävalenz der Erkrankung der positive prädiktive Wert einer Untersuchung gering ist. Es sollten deshalb mehrere Testverfahren ggf. auch mehrfach zur Anwendung kommen. Positive Befunde müssen im Gesamtbild aus klinischen, epidemiologischen, mikrobiologischen und laborchemischen Daten zum Patienten interpretiert werden. Da chronische Verlaufsformen bei den beschriebenen Erkrankungen praktisch nicht vorkommen, ist die Diagnostik für diese Fragestellung meist wertlos.

Im Akutstadium kann ein gefärbter Blutausstrich über den Nachweis intrazytoplasmatischer Morula schnell einen ersten wichtigen Hinweis geben. Die Beurteilung soll durch eine erfahrene Person erfolgen, um falsch positive Befunde z. B. durch toxische Granulation, Färbeartefakte, Döhle-Körperchen oder aufgelagerte Thrombozyten zu vermeiden. Die Diagnosesicherung erfolgt über die PCR mit Spezifizierung über Sonden oder Sequenzierung.

Die Anzucht des Erregers soll bei entsprechendem Verdacht durchgeführt werden, allerdings steht sie nur in wenigen Laboratorien zur Verfügung. Für die Routinediagnostik ist die PCR wegen der Schnelligkeit, breiteren Verfügbarkeit und höheren Sensitivität dem kulturellen Nachweis vorzuziehen.

Antikörpernachweis. Zu Beginn der Erkrankung ist in mehr als $60 \%$ der Fälle mit einem negativen Befund zu rechnen. Etwa 80 \% der Erkrankten entwickeln im Verlauf der Krankheit diagnostische Antikörpertiter, die nachträglich - durch Serokonversion oder signifikanten Titeranstieg (mindestens 4fach) im Rekonvaleszenzserum - eine Bestätigung der Diagnose ermöglichen. Deshalb sollte immer ein Akutphaseserum und ein Rekonvaleszenzserum untersucht werden, da die Serologie als sensitivste Methode für die nachträgliche Diagnosesicherung gilt. Erhöhte Antikörpertiter können nach Infektion über Jahre persistieren. Es beste- 
hen Kreuzreaktionen zwischen Anaplasma und Ehrlichia. So kann auch die serologische Diagnostik der HEE mit E.-chaffeensis-Antigen durchgeführt werden. Unspezifische Reaktionen können bei akuter Bartonellen-Endokarditis, Q-Fieber, Typhus, Brucellose, EBV, Lyme-Borreliose und Autoimmunerkrankungen auftreten.

\section{Therapie}

\section{Therapeutische Maßnahmen}

Therapie der Wahl ist Doxycyclin $2 \times 100 \mathrm{mg} /$ Tag für 10-14 Tage. Die meisten Patienten werden innerhalb von 1-3 Tagen fieberfrei. Bei nicht Ansprechen der Therapie innerhalb dieses Zeitraums muss die Diagnose in Frage gestellt werden. Die antibiotische Therapie soll bis mindestens 3 Tage nach Entfieberung fortgesetzt werden. Nach In-vitro-Daten für HGA und HME ist auch Rifampicin $1 \times 600 \mathrm{mg} / \mathrm{Tag}$ einsetzbar. Bei $A$. phagocytophilum waren in vitro auch Ciprofloxacin, Levofloxacin und Chloramphenicol wirksam, belastbare klinische Erfahrungen fehlen.

\section{Resistenz}

Resistenzen gegen Doxycyclin oder Tetracyclin wurden nicht beschrieben.

In vitro und z. T. in vivo wurden Resistenzen gegen $\beta$-Laktame, Makrolide, Aminoglykoside und Cotrimoxazol für E. chaffeensis und A. phagocytophilum beschrieben. E. chaffeensis ist auch gegen Fluoroquinolone resistent (Mutation im gyrA Gen).

\section{Epidemiologie}

\section{Verbreitung}

Das Verbreitungsgebiet der HME und der HEE liegt im Süden der USA (Schwerpunkt Osten und zentral) entsprechend dem Verbreitungsgebiet der Zecke Amblyoma americanum, das der HGA in den USA (Nordosten, Mittelwesten und Nord-Kalifornien) sowie Nord- und Zentraleuropa (Verbreitungsgebiet von $I$. ricinus I. persulcatus Komplex Schildzecken). Von 2003-2008 wurden in den USA für HGA und HME je ca. 300-800 Fälle pro Jahr gemeldet. Für HEE liegen nur einzelne Fallbeschreibungen vor.

A. phagocytophilum wurde in Zentral- und Nordeuropa in Schildzecken und Säugern nachgewiesen. In seroepidemiologischen Studien waren in Risikopopulationen bei bis zu $21 \%$ Antikörper nachweisbar, dagegen nur bei 0\%-2,9\% der Blutspender. Gut definierte Fälle wurden aus Slowenien, Schweden, Norwegen, Österreich, Holland, Kroatien, Spanien, Polen, Italien und Frankreich berichtet (insgesamt < 100 Fälle). Aus Deutschland liegt noch keine Fallbeschreibung vor.

\section{Wirtsbereich / Reservoir}

Das vermutete Erregerreservoir sind für A. phagocytophilum Schafe, Ziegen, Rinder, Pferde, Weißwedelhirsche, Hunde, Katzen und Kleinsäuger, für E. chaffeen- sis Weißwedelhirsche, Ziegen, Hunde, Koyoten und Weißfußmäuse und für E. ewingii Weißwedelhirsche und Hunde.

\section{Risikogruppen}

Beruflich (z. B. Forstarbeiter, Soldaten) oder in der Freizeit (Pilzsammler, Golfspieler, u. a.) vermehrt zeckenexponierte Personen. Männer sind häufiger betroffen. Die HGE betrifft am häufigsten 60-69 jährige-, die HME > 70-jährige Personen. Immunsuppression, z. B. durch HIV-Infektion oder medikamentös, ist ein weiterer Risikofaktor. HEE wurde bisher nahezu nur bei Immunsupprimierten beobachtet.

\section{Transmission / Vektoren}

Die Erreger werden von Schildzecken während des Saugaktes über die Speicheldrüsen übertragen. A. phagocytophilum wird durch Zecken aus dem I. ricinus/ I. persulcatus Komplex übertragen, in Mitteleuropa durch I. ricinus (gemeiner Holzbock), in den USA durch I. scapularis und I. pacificus. E. chaffeensis und E. ewingii werden durch Amblyoma americanum (lone-star tick) übertragen. Da die Erreger innerhalb der Zecken nur transstadiell, nicht transovariell, übertragen werden, sind nur Nymphen und adulte Zecken als potenziell infektiös zu betrachten.

Möglicherweise können Ehrlichien auch perinatal oder durch infiziertes Blut übertragen werden.

\section{Prävention / Impfstoffe}

Ein Impfstoff steht nicht zur Verfügung. Schutz vor Zeckenstichen durch das Meiden zeckendurchseuchter Gebiete, Tragen geschlossener, heller Kleidung (darauf lassen sich die Zecken einfacher entdecken) und Anwendung von Repellents: DEET vertreibt Zecken durch olfaktorische Belästigung, Permethrin wirkt als Kontaktgift. Nach Aufenthalt im Freien sollte der Körper nach Zecken abgesucht werden. Zecken so schnell wie möglich entfernen, da die Übertragung mit der Dauer des Saugaktes zunimmt (Übertragung von A. phagocytophilum durch I. scapularis benötigt 2448 Stunden). Dafür fasst man die Zecke mit spitzer Pinzette oder Zeckenkarte dicht über der Haut und zieht sie langsam heraus. Das „Herausschrauben“ der Zecke führt häufiger zum Abreißen des Stechrüssels. Abschließend die Wunde desinfizieren. Bei Resten in der Wunde handelt es sich um den Stechrüssel i.S. eines intrakutanen Fremdkörpers, der keine spezifische Infektionsgefahr besitzt. Eine antibiotische Prophylaxe nach Zeckenstich wird in Europa nicht empfohlen.

\section{Ausbruchsmanagement}

Aufgrund der an Schildzecken gebundenen Übertragungsweise sind Ausbrüche nicht zu erwarten.

\section{Meldepflicht}

Es besteht keine Meldepflicht. 


\section{Weiterführende Informationen}

\section{Referenzzentren / Expertenlaboratorien}

- Dr. V. Fingerle, PD Dr. Dr. A. Sing, Konsiliarlabor für Ehrlichien, Landesamt für Gesundheit und Lebensmittelsicherheit, Veterinärstr. 2, 85764 Oberschleißheim; Tel.: 8935160870, E-Mail: Volker.Fingerle@LGL.Bayern.de

\section{Web-Adressen}

- http://www.cdc.gov/mmwr/preview/mmwrhtml/ rr5504a1.htm

- http://www.cdc.gov/ticks/index.html

\section{Schlüsselliteratur}

1. Brouqui P et al (2004) ESCMID Study Group on Coxiella, Anaplasma, Rickettsia and Bartonella. European Network for Surveillance of Tick-Borne Diseases. Guidelines for the diagnosis of tick-borne bacterial diseases in Europe. Clin Microbiol Infect 10(12):1108-1132

2. Dumler JS et al (2001) Reorganization of genera in the families Rickettsiaceae and Anaplasmataceae in the order Rickettsiales: unification of some species of Ehrlichia with Anaplasma, Cowdria with Ehrlichia and Ehrlichia with Neorickettsia, descriptions of six new species combinations and designation of Ehrlichia equi and „HGE agent" as subjective synonyms of Ehrlichia phagocytophila Int J Syst Evol Microbiol 51:2145-2165

3. Hotopp JCD et al (2006) Comparative genomics of emerging human ehrlichiosis agents. PLOS 2:208-223

4. Rikihisa Y (2010) Anaplasma phagocytophilum and Ehrlichia chaffeensis: subversive manipulators of host cells. Nat Rev Microbiol. 8(5):328-339

5. Thomas RJ et al. (2009) Current management of human granulocytic anaplasmosis, human monocytic ehrlichiosis and Ehrlichia ewingii ehrlichiosis. Expert Rev Anti Infect Ther. 7(6):709-22

\section{Ehrlichiose}

Ehrlichia

\section{Eikenella}

\section{Erreger}

\section{Synonym(e)}

Früher Bacteroides corrodens bzw. Ristella corrodens.

\section{Erregerspezies}

Eikenella corrodens

\section{Taxonomie}

Familie: Neisseriaceae, Gattung: Eikenella, einzige Spezies E. corrodens. Eikenella wird der HACEK-Gruppe zugeordnet.

\section{Historie}

Erstisolierung 1948 durch Henriksen, 1958 Klassifikation durch Eiken als Bacteroides corrodens, seit 1972 neue Zuordnung und Bezeichnung als E. corrodens.
Morphologie

Kleine, regelmäßige, gramnegative Stäbchen. Manche Isolate zeigen eine gleitende (taumelnde) Beweglichkeit, während andere unbeweglich sind.

Genom

Die komplette Sequenz des 16S rRNA-Gens steht in GenBank unter der Accession-Nr. M22512 zur Verfügung.

\section{Vermehrung}

Anzucht in mikroaerophiler Atmosphäre (5-10 \% $\mathrm{CO}_{2}$ ) auf Blut- oder Kochblutagar. Nach 2-3 Tagen sehr kleine $(1 \mathrm{~mm})$, weißlich-grau oder gelblich gefärbte Kolonien, die in den Nährboden eindringen (korrodieren), nach dem Wegwischen einen Abdruck hinterlassen und von einem Saum umgeben sind. Daneben gibt es nicht korrodierende Stämme.

\section{Pathogenität / Virulenz / Antigenvariabilität}

E. corrodens Lectin-ähnliche Substanz (EcLS) ist ein potenzieller Virulenzfaktor, der die Adhäsion an Wirtszellen vermittelt und als Hämagglutinin fungiert. Typ-IV-Pili sind ein weiterer potenzieller Virulenzfaktor und für die Phasenvariation verantwortlich.

\section{Erkrankungen}

\section{Infektionen im Mundbereich}

Eitrige Infektionen im Mundbereich wie Parodontitis.

\section{Synonym(e)}

> Parodontitis

\section{Inkubationszeit}

- Parodontitis (Aggregatibacter)

\section{Leitsymptome}

- Parodontitis (Aggregatibacter)

\section{Symptome}

- Parodontitis (Aggregatibacter)

\section{Pathophysiologie \\ - Parodontitis (Aggregatibacter)}

\section{Immunantwort}

Keine Daten verfügbar.

\section{Differenzialdiagnose \\ - Parodontitis durch andere Erreger}

\section{Wund- und Weichteilinfektionen}

Eitrige Wund- und Weichteilinfektionen, v. a. nach chirurgischen Eingriffen oder Verletzungen durch Menschenbiss, pleuropulmunale Infektionen, Osteomyelitis, Arthritis, Meninigitis, Hirnabszess, Endokarditis und Sepsis. 


\section{Diagnostik}

\section{Untersuchungsmaterial}

Gewebeprobe, Punktat bzw. Abstrich bei lokalen Infektionen. Blutkultur bei Endokarditis, Sepsis, Osteomyelitis und anderen systemischen Infektionen. Liquor cerebrospinalis und Blutkultur bei Meningitis.

\section{Diagnostische Verfahren}

Mikroskopie: Direkter Nachweis des Erregers im Grampräparat. Kultur stellt das Routineverfahren im mikrobiologischen Labor dar. E. corrodens wächst auf Blut- oder Kochblut-, nicht aber auf McConkey-Agar und ist Oxidase-positiv und Katalase-negativ. Kohlenhydrate werden nicht fermentativ abgebaut. E. corrodens kommt häufig in Mischkulturen mit fakultativ oder obligat anaeroben Erregern vor. Nachweis der bakteriellen DNA mittels Nukleinsäureamplifikation findet in besonderen Fällen Anwendung.

\section{Befund / Interpretation}

Nachweis aus primär sterilen Untersuchungsmaterialien wie Blut, Herzklappe, Abszesspunktat spricht für die kausale Rolle des Erregers, während der Nachweis aus mit Normalflora besiedelten Proben meist eine Kolonisation anzeigt.

\section{Therapie}

\section{Therapeutische Maßnahmen}

E. corrodens ist in vitro empfindlich gegen Penicillin, Aminopicilline, Acylureidopenicilline, Cephalosporine der 2. und 3. Generation, Carbapeneme, Fluorochinolone und Tetrazykline. Die In-vivo-Wirksamkeit von Aminopenicillinen, auch in Kombination mit $\beta$-Laktamaseinhibitoren, ist jedoch umstritten.

\section{Resistenz}

Resistenz besteht häufig gegen Cephalosporine der 1 . Gerneration, Erythromycin, Clindamycin und Metronidazol.

\section{Epidemiologie}

\section{Verbreitung}

Der Erreger kommt vermutlich weltweit vor.

\section{Wirtsbereich / Reservoir}

E. corrodens ist physiologischer Bestandteil der Rachenflora und kommt vermutlich auch auf anderen Schleimhäuten des Menschen vor.

\section{Risikogruppen}

Personen mit Menschenbissverletzungen, z. B. nach Faustschlag (clenched fist injury).

\section{Transmission / Vektoren}

Der Erreger kann durch Bissverletzung übertragen werden. Endogene Infektionen sind auch möglich.

\section{Prävention / Impfstoffe}

Keine Daten verfügbar.

\section{Ausbruchsmanagement}

Keine Daten verfügbar.

\section{Meldepflicht}

Keine.

\section{Weiterführende Informationen}

\section{Web-Adressen}

- http://www.emedicine.com/med/byname/human-biteinfections.htm

- http://www.dgk.org/leitlinien/LL_Endokarditis_S2.pdf

\section{Schlüsselliteratur}

1. Paul K, Patel SS (2001) Eikenella corrodens Infections in Children and Adolescents: Case Reports and Review of the Literature. J Infect Dis 33:54-61

2. Steinberg JP, Del Rio C (2005) Other gram-negative and Gram-variable bacilli. In: Mandell, Douglas and Bennett's (eds) Principles and Practice of Infectious Diseases, $6^{\text {th }}$ edn. Churchill Livingstone, New York

3. Von Grävenitz A, Zbinden R, Mutters R (2003) Actinobacillus, Capnocytophaga, Eikenella, Kingella, Pasteurella, and other fastidious or rarely encountered gram-negative rods. In: Murray PR, Baron EJ, Jorgensen JH, Pfaller MA, Tenover FC, Yolken HY (eds), Manual of Clinical Microbiology, $8^{\text {th }}$ edn. ASM Press, Washington DC

\section{Einschlusskonjunktivitis}

Chlamydia

\section{Ektoparasiten, sonstige (Stechmücken, Trombiculiden, Flöhe, Wanzen, Zecken)}

\section{PATRICK SCHEID}

\section{Erreger}

\section{Synonym(e)}

Für Stechmücken: Moskitos; für Trombiculiden: Herbstgrasmilben, Herbstmilben; Erntemilben; für Bettwanzen: Tapetenflundern; für Raubwanzen: Kissing Bugs.

\section{Erregerspezies (Auswahl)}

Flöhe: Pulex irritans (Menschenfloh), Ctenocephalides felis (Katzenfloh), Ctenocephalides canis (Hundefloh), Ceratophyllus sp. (Vogelflöhe), Xenopsylla cheopis (Ratten- oder Pestfloh), Tunga penetrans (Sandfloh, - Tunga penetrans)

Zecken: Ixodes ricinus (Holzbock), Rhipicephalus sanguineus (Braune Hundezecke), Dermacentor marginatus (Schafzecke), Argas reflexus (Taubenzecke), Hyalomma sp.

Trombiculiden: Neotrombicula autumnalis (Herbstmilben), Leptotrombidium sp., Trombicula akamushi, Sarcoptes scabiei ( Krätzmilben)

Wanzen: Cimex lectularius (Bettwanze), Cimex hemipterus (trop. Bettwanzen), selten: Leptocimex boueti, 
Reduviidae (Raubwanzen): Triatoma infestans, Rhodnius prolixus

Stechmücken: Anopheles sp., Aedes sp. (Stegomyia sp.), Culex sp., Mansonia sp., Culiseta sp.

\section{Taxonomie}

Trombiculiden: Stamm: Arthropoda, Unterstamm: Chelicerata, Klasse: Arachnida (Acari), Unterklasse: Acarina, Ordnung: Prostigmata, Familie: Trombiculidae (Laufmilben)

Flöhe: Stamm: Arthropoda, Unterstamm: Tracheata, Klasse: Insecta, Unterklasse: Pterygota, Ordnung: Siphonaptera (Aphaniptera), verschiedene Familien, z. B. Pulicidae, Xenopsyllidae

Wanzen: Stamm: Arthropoda, Unterstamm: Tracheata, Klasse: Insecta, Unterklasse: Pterygota, Ordnung: Rhynchota (Hemiptera), Familie: Reduviidae (Raubwanzen) oder Cimicidae (Plattwanzen, Bettwanzen)

Zecken: Stamm: Arthropoda, Unterstamm: Chelicerata, Klasse: Arachnida, Unterklasse Acarina, Ordnung Metastigmata, Familie: Ixodidae und Argasidae

Stechmücken: Stamm: Arthropoda, Unterstamm: Tracheata, Klasse: Insecta, Unterklasse: Pterygota, Ordnung Diptera, Unterordnung: Nematocera, Familie: Culicidae

\section{Historie}

Die sekundär apterigoten, in beiden Geschlechtern saugenden Flöhe gab es bereits vor 60 Millionen Jahren. In der Geschichte haben Flöhe als Krankheitsüberträger eine enorme Bedeutung erlangt, vor allem als Überträger der Pesterreger (im 14. Jahrhundert starb ein Viertel der Bevölkerung Europas an der Pest). Erst 1898 kam Simond auf die Bedeutung der Flöhe bei einer Beulenpest-Epidemie. Die erste Epidemie der durch Flöhe auf den Menschen übertragenen Pest dürfte die Pest der Philister aus dem ersten Buch Samuels sein. Bereits im Mittelalter wurden besonders konstruierte Flohfallen verwendet. 1693 beschrieb Leuwenhoek den Entwicklungszyklus von Pulex irritans.

Den Bettwanzen verwandte Arten sollen bereits mit den ersten Höhlenmenschen in Afrika vergesellschaftet gewesen sein. Das durch Milben übertragene Tsutsugamushi-Fieber wurde erstmals vor ca. 2.000 Jahren in China beschrieben. Schon 450 Jahre vor der Zeitenwende wusste man im alten Rom, dass das Trockenlegen von Sümpfen zur Verhütung von Malaria notwendig ist. Insbesondere der Gang militärischer Handlungen wurde in der Geschichte durch ektoparasitäre Stechmücken bzw. durch sie übertragene Erreger, die nicht selten zu den Endoparasiten gehören, geprägt (Vietnamkrieg). Schon 1854 hatte Beauperthuy die Rolle von Aedes-Mücken bei der Übertragung des Gelbfiebers geahnt. Finley bestätigte dies 1881. Der Bau des Panamakanals musste wegen der hohen Todesfallrate unter den Arbeitern durch Moskito-übertragene Infektionen (Malaria, Gelbfieber) zeitweise eingestellt werden. Mit der Entdeckung des (mittlerweile in einigen Ländern verbotenen) DDT (Dichlor-Diphenyl-Trichlor-Methylmethan) 1939 wurde die Bekämpfung von Ektoparasiten revolutioniert. Immer mehr Ektoparasiten wurden in den letzten Jahrzehnten als Überträger von z. T. unbekannten oder wieder aufkommenden („emerging“ und „reemerging") Infektionserregern erkannt.

\section{Morphologie}

Die Morphologie ist sehr unterschiedlich, da unter die Ektoparasiten sowohl Spinnentiere (Zecken und Milben) als auch Insekten (Insecta, Hexapoda) gestellt werden. Zecken sind bis zu $2 \mathrm{~cm}$ große, dorsoventral abgeplattete Ektoparasiten (Familienzuordnung abhängig von dem Vorhandensein oder Fehlen eines Rückenschilds: Schildzecken bzw. Lederzecken/Weichzecken), die am ersten Beinpaar ein spezielles Sinnesorgan, das Haller'sche Organ, zum Aufspüren von Wirten besitzen. Der Körper des Weibchens schwillt beim Blutsaugen enorm an. Die Larven der Zecken und Milben besitzen sechs Beine, die Nymphen und adulten Tiere acht. Flöhe sind $2-4 \mathrm{~mm}$ große, meist sprunggewaltige, lateral abgeplattete, flügellose Insekten mit arttypischen Beborstungen. Stechmücken sind zarte, langbeinige, fliegende Nematocera mit langen Stechborsten, deren Genital- und Fühlermorphologie Auskunft über Geschlecht und Artzugehörigkeit gibt. Sie besitzen ein Flügelpaar, Halteren und fadenförmige Antennen. Bettwanzen sind bis max. $1 \mathrm{~cm}$ große, dorsoventral abgeflachte, rotbraune, behaarte Insekten, deren rudimentäre Vorderflügel schuppenförmig sind und denen Hinterflügel fehlen. Raubwanzen sind mit bis zu $3 \mathrm{~cm}$ deutlich größer ( $\triangleright$ Trypanosoma cruzi).

\section{Vermehrung}

Der Entwicklungszyklus ist temperaturabhängig. Die Vermehrung erfolgt durch Kopulation von Männchen und Weibchen. Die dorsoventral abgeplatteten Zecken machen ebenso wie die Läuse, Milben und Wanzen eine hemimetabole Entwicklung durch. Stechmücken und Flöhe durchlaufen eine holometabole Entwicklung. Aus dem Ei schlüpft eine Larve, die sich zur Nymphe weiterentwickelt und nach Häutungen zur Imago heranreift. Zur Eireifung benötigen die Ektoparasiten eine Blutmahlzeit.

\section{Pathogenität / Virulenz / Antigenvariabilität}

Die Reaktion der menschlichen Haut auf die Speichelinjektion der Ektoparasiten ist wahrscheinlich auf die Wirkung von Eiweißfraktionen, die als Antikoagulans, Haemolysin oder als Nervengift fungieren, zurückzuführen. Bei Zecken kann es durch neurotoxisch wirkende Substanzen im Zeckenspeichel zur Zeckenparalyse kommen, die sogar letal ausgehen kann. Durch toxisch wirkende Speicheldrüsensekrete können auch Hämorrhagien und Ödeme an den Einstichstellen 
oder systemische Reaktionen wie Fieber, Lähmungen oder Krämpfe ausgelöst werden. Darüber hinaus führt die allergische Reaktion auf die in die Stichwunde abgegebenen Antigene zu klinischen Manifestationen.

\section{Erkrankung \\ Insekten-, Zecken-, Wanzen-, Floh-, Milbenstich}

\section{Synonym(e)}

Arthropodenstich, Stich von Blutsaugern, bei Trombiculiden: Trombidiose.

\section{Leitsymptome}

Rötung, Schmerzen, Juckreiz, v. a. an der Einstichstelle.

\section{Symptome}

Innerhalb weniger Minuten bildet sich um die (Arthropoden-) Stichstelle ein unterschiedlich weit ausgedehntes Erythem (Hautrötung) aus, das eine zentrale Quaddel aufweisen kann und mehr oder weniger stark juckt (kutane Sofortreaktion IgE, Typ 1). Nach einiger Zeit (kutane Spätreaktion, T-Zell-Typ, meist innerhalb 24 Stunden) entsteht daraus vielfach eine Papel (Knötchen), die ebenfalls juckt und lange erhalten bleiben kann. Selten treten Vesikel oder Pusteln auf. Symptome wie Juckreiz, Schmerzen, Überempfindlichkeitsreaktionen, Entzündungen etc. können durch den Stich von Dipteren verursacht werden. Schmerzen und Juckreiz treten nicht beim Stich selbst, sondern erst später auf. Insbesondere bei Lederzecken (z. B. Taubenzecke) ist eine deutliche punktförmige Hämorrhagie (Blutaustritt) an der Einstichstelle beschrieben. Die durch Zeckenbefall direkt hervorgerufenen Symptome, wie z. B. Ödeme oder Fieber und Krämpfe, werden hauptsächlich durch das toxisch wirkende Speicheldrüsensekret ausgelöst. Zeckenparalysen beginnen mit Symptomen wie Schwindel, Kopfschmerzen, Erbrechen und allgemeiner Muskelschwäche, bis hin zur aufsteigenden Lähmung, Sprachstörungen und Tod durch Lähmung der Atemmuskulatur. Raubwanzen stechen oft ins Gesicht („Kissing Bug“) Aufgrund der systemischen Reaktion auf ihre Stiche sind Todesfälle beschrieben. Bei längerer Exposition gegenüber Bettwanzen können Asthma, Schockzustände und Beeinträchtigung des Sehvermögens folgen. Charakteristisch für Flohstiche ist, dass sie perlschnurartig in Reihe angeordnet sind (Probestiche). Zudem tritt hierbei zunächst eine punktförmige Hämorrhagie mit hellrotem Hof direkt am Floheinstich (Roseola pilicosa) auf, der nach einiger Zeit einem blauroten kleinen Fleck (Purpura pulicosa) weicht. Bei jedem erneuten Einstich eines Flohs jucken auch die früheren Stichstellen (Repetieren). Bei Milbenstichen kann es (durch den als Allergen wirkenden Speichel) zur sogenannten Gebüschkrätze (scrub itch) sowie zur Bildung einer schwarzen Kruste (tache noir) kommen. Die Trombi- diose tritt vorwiegend im Herbst auf, die auftretenden Entzündungen gehen mit heftigem Juckreiz einher.

\section{Pathophysiologie}

Es handelt sich bei den Hautreaktionen auf Stiche von Ektoparasiten weniger um Reaktionen auf die mechanische Verletzung als auf Komponenten des in den Stichkanal injizierten Speichels. Dementsprechend fallen die Reaktionen je nach Ektoparasit bzw. auch je nach Wirt (Mensch) unterschiedlich aus (bis hin zum anaphylaktischen Schock). Sekundärschäden können auftreten, wenn durch Kratzen an den juckenden Einstichstellen Hautläsionen und damit Eintrittspforten für Erreger (Sekundärinfektionen) geschaffen werden.

\section{Immunantwort}

Die Sensibilisierung gegen die in die Stichwunde abgegebenen Antigene kann heftige allergische Reaktionen bewirken, die sich z. B. in Fieber, Kopfschmerzen, Lymphadenitis etc. äußern. Bei Bettwanzen reagiert das Immunsystem ebenfalls auf das Fremdeiweiß des Wanzenspeichels. Bei längerem Befall kann eine Immunisierung erfolgen. Bei Flöhen spricht man von allergischer Dermatitis. IgG- und IgE-Antikörperreaktionen gegen Antigene von Ektoparasiten sind vielfach beschrieben.

\section{Differenzialdiagnose}

Abzugrenzen sind die Stiche der beschriebenen Arthropoden von denen anderer Arthropoden (z. B. Läuse, Fliegen, Sandmücken, Kriebelmücken, Krätzemilben). Auch Dermatitiden (z. B. durch Bakterien oder Pilze) anderer Genese bei Mensch und Tier sind von Stichreaktionen zu unterscheiden. Eine mechanische Übertragung von Krankheitserregern ist durch die Mundwerkzeuge der Arthropoden möglich. Dadurch möglicherweise ausgelöste lokale Infektionen sind von den reinen Stichreaktionen abzugrenzen.

\section{Diagnostik}

\section{Untersuchungsmaterial}

Die Krankheitsbilder nach Arthropodenstichen werden in der Regel rein klinisch diagnostiziert. Der $\mathrm{Zu}-$ sammenhang zu einem Arthropodenstich ergibt sich aus der noch sichtbaren Einstichstelle oder der anamnestischen Angabe des Patienten. Bei feststellbarem Befall durch Arthropoden (z. B. Zecken, Läuse, Milben) ist die Artdiagnose anzustreben. Vor allem die adulten Tiere, oft auch die Eier und Larven, eignen sich zur sicheren Bestimmung. Hierzu sind diese an den bevorzugten Stellen des Körpers, ggf. auch des Haustieres oder der Umgebung zu suchen.

\section{Diagnostische Verfahren}

Mikroskopische Artbestimmung: Die gefundenen Eier, Larven, Nymphen oder adulten Tiere werden unter dem Mikroskop anhand spezieller morphologi- 
scher Merkmale beurteilt, die der einschlägigen Bestimmungsliteratur zu entnehmen sind.

Makroskopisch kann die Anordnung der abgelegten Eier im Bruthabitat bei Stechmücken zur Artdifferenzierung hilfreich sein. Adulte Flöhe werden z. B. beim Sprung erkannt, die Larven erscheinen als weiße Pünktchen.

\section{Befund / Interpretation}

Eine Speziesdifferenzierung ist essenziell, um geeignete, der Biologie der jeweiligen Ektoparasiten folgende, Bekämpfungs- oder Prophylaxemaßnahmen durchführen zu können. Eine Gefährdungsanalyse ist vor allem auch anhand der durch die Ektoparasiten übertragenen endemischen Erreger in dem jeweiligen Gebiet vorzunehmen.

\section{Therapie}

\section{Therapeutische Maßnahmen}

Zur Behandlung von Mückenstich-Reaktionen helfen Eiswürfel oder kühle Kompressen. Zur Linderung des Juckreizes und zur Verhinderung von Sekundärinfektionen sollte eine Desinfektion der Stichstellen erfolgen (Alkohol, lokal!). Lokale und orale Antiallergika (Antihistaminika, in schweren Fällen auch Kortikosteroide) können bei allergischen Reaktionen topisch (Gel oder Creme) oder systemisch appliziert werden. Die Bekämpfung der Ektoparasiten sollte von erfahrenen Fachleuten mithilfe von Insektiziden oder Akariziden durchgeführt werden.

\section{Resistenz}

Mannigfaltige Resistenzen der genannten Ektoparasiten gegen Insektizide sind bekannt. So werden beispielsweise Resistenzen gegen Pyrethroide (z. B. Permethrin und Alphacypermethrin) bei Bettwanzen beschrieben.

\section{Epidemiologie}

\section{Verbreitung}

Saugende und stechende Arthropoden findet man weltweit in den jeweiligen arttypischen Habitaten bzw. Klimazonen. Insbesondere die Stechmücken sind auf Biotope angewiesen, die ihnen geeignete Brutmöglichkeiten bieten, z. B. die Umgebung stehender oder sehr langsam fließender Gewässer oder auch temporäre Wasseransammlungen, Neotrombicula autumnalis und verwandte Arten kommen vor allem in Mitteleuropa vor. Ctenocephalides felis ist die in Mitteleuropa häufigste Flohart (> 80\%).

\section{Wirtsbereich / Reservoir}

Die hier behandelten Arten besitzen im Gegensatz zu den Läusen ( $\triangleright$ Läuse) keine Wirtsspezifität und können sowohl an Tieren als am Menschen Blut saugen. Sie finden ihren Wirt mittels chemischer und optischer Signale.

\section{Risikogruppen}

Ein Risiko besteht für alle, die sich in den Habitaten der Ektoparasiten während deren Aktivitätszeiten ungeschützt aufhalten (meist in der Dämmerung, nachts). Befinden sich die Ektoparasiten in der häuslichen Umgebung, sind praktisch alle Bewohner gefährdet.

\section{Transmission / Vektoren}

Meist sind es bei den Ektoparasiten die weiblichen Tiere, die Blut saugen, damit ihre Eier heranreifen können. Die in diesem Kapitel behandelten Arthropoden sind potenzielle Überträger (engl: vectors) von Krankheitserregern (z. B. Endoparasiten, Tab. 1). Oft fungieren sie jedoch nicht nur als reine Überträger sondern zugleich auch als Endwirte, wie z. B. Anopheles sp. für die Plasmodien. Die Übertragung von Krankheitserregern erfolgt z. B. über die stechendsaugenden Mundwerkzeuge, entweder durch Regurgitation der Erreger aus dem Darmbereich oder durch ihr Einwandern in die Speicheldrüsen und ihre Abgabe in die Stichwunde mit dem Speichelsekret. Die Chagas-Krankheit wird durch das Einkratzen des Raubwanzenkots in die Stichstelle übertragen (siehe Kapitel Trypanosoma cruzi). Die Ektoparasiten selbst, bzw. deren Stadien, können anthropogen weiterverbreitet werden, wie es von Aedes-Larven in gebrauchten Autoreifen oder ähnlichen wassergefüllten „Behältnissen" beschrieben ist.

\section{Prävention / Impfstoffe}

Moskitonetze, die z. B. mit Permethrin imprägniert werden, und korrekt getragene, helle Kleidung etc. bieten einen gewissen Schutz gegen die blutsaugenden Ektoparasiten (persönliche Schutzmaßnahmen). Auf die Haut aufgetragene Repellents, wie z. B. DEET- oder Icaridin-haltige Mittel, stellen einen Schutz gegen zahlreiche blutsaugende Arthropoden dar. Gute Wirksamkeit wird auch oft von neu entwickelten Formulierungen mit sekundären Pflanzenstoffen berichtet. Die Vermeidung bzw. Beseitigung von Brutstätten (auch kleinste Wasseransammlungen) stellt eine flankierende Maßnahme im Rahmen der Habitatveränderung dar. Haustiere sind z. B. zur Vermeidung einer Flohplage ebenfalls in die Maßnahmen mit einzubeziehen. Die Beachtung der bevorzugten Stechzeiten (und von präferierten Orten) hilft bei der Vermeidung von Stichen durch Ektoparasiten ebenfalls. Der Einsatz von Räucherspiralen, Verdampfern, Sprays etc. muss sehr vorsichtig erfolgen, eine intensive Nutzung in geschlossenen Räumen vermieden werden. Gaze am Fenster schützt vor dem Eindringen vieler Ektoparasiten. Aufklärung und Verhaltensänderungen- bzw. Anpassungen sowie die Meidung von befallenen Gebieten (Expositionsprophylaxe) sind weitere Eckpfeiler einer Stichvermeidung. Menschen, die allergisch auf Stiche von Ektoparasiten reagieren, sollten stets ein Antihistaminikum griffbereit haben. 


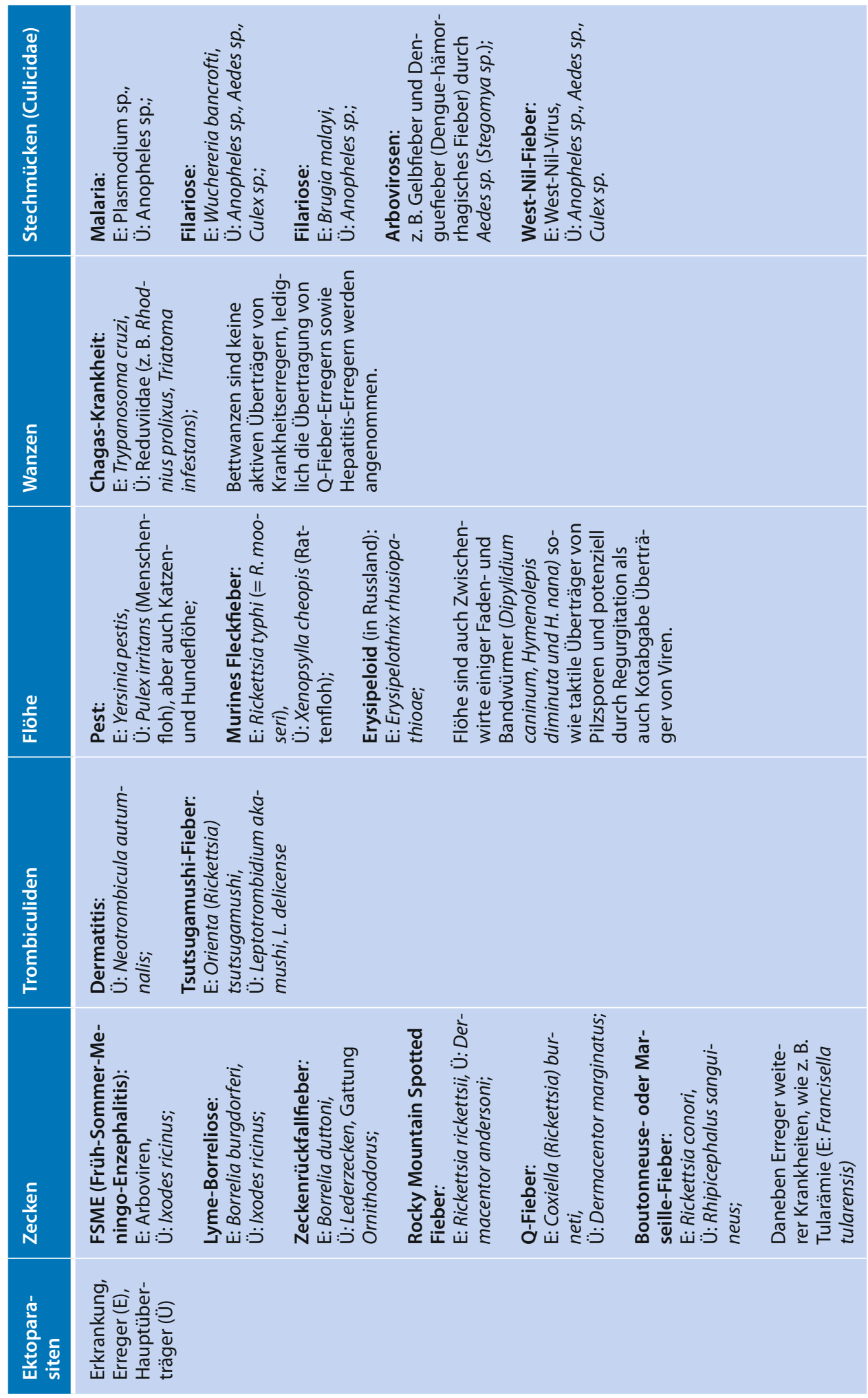




\section{Ausbruchsmanagement}

Die Bekämpfung der Ektoparasiten (im Rahmen des "Integrated Pest Management") ist ein Eckpfeiler bei der Eindämmung der durch sie übertragenen Krankheiten. Bekämpfungsmaßnahmen sind, falls aus epidemiologischen Gründen erforderlich, nur nach einer Artbestimmung gezielt durchzuführen (Schädlingsmonitoring mit Befallsanalyse). Bei Flöhen ist insbesondere die Larvenbekämpfung (Mittel zur Häutungsverhinderung, Wachstumsregulatoren) an den Lagerstätten der Haustiere wichtig. Die Bekämpfung von Zecken- und Milbenplagen ist recht schwierig und wird ebenfalls mit Insektiziden (z. B. Malathion) durchgeführt. Bettwanzen und Raubwanzen werden mit Insektiziden (z. B. Pyrethroide) bekämpft. Bei der Stechmückenbekämpfung wird zwischen der Larvenbekämpfung und der Bekämpfung der adulten Tiere unterschieden. Während die Larven im Wasser z. B. mit BTI (Bacillus thuringiensis var. israelensis) bekämpft werden können, müssen gegen die adulten Tiere Insektizide wie z. B. Pyrethroide eingesetzt werden. Residualanwendungen von Insektiziden durch das Besprühen der Innenwände von Behausungen werden in Endemiegebieten ebenfalls erfolgreich angewandt. Der Einsatz von natürlichen Feinden (Prädatoren, Parasiten) ist im Einzellfall nützlich (z. B. Einführung von Gambusien gegen Anopheleslarven). Zur Entfernung der stationär saugenden Zecken werden Zeckenzangen, Zeckenkarten o. ä. angeboten.

Die Vernebelung oder ULV (Ultra Low volume)-Ausbringung von Insektiziden sind fachkundigem Personal zu überlassen.

Auch die konsequente und fachgerechte Bekämpfung der natürlichen Reservoire (z. B. Nager) stellt eine Maßnahme zur Eindämmung von Ausbrüchen dar.

\section{Meldepflicht}

Eine Meldepflicht nach dem Infektionsschutzgesetz kann sich für spezielle, durch Ektoparasiten übertragene Erkrankungen ergeben $>$ jeweilige Krankheitserreger.

\section{Weiterführende Informationen}

\section{Referenzzentren / Expertenlaboratorien}

- Als fachlich qualifizierte Ansprechstellen gelten praktisch alle parasitologischen und tropenmedizinische Institutionen.

\section{Web-Adressen}

- Deutsche Gesellschaft für Tropenmedizin und Internationale Gesundheit: http://www.dtg.org

- CDC (Center for Disease Control and Prevention): http:// www.cdc.gov

\section{Schlüsselliteratur}

1. Mehlhorn H (2007) Encyclopedia of Parasitology, 3. Ausgabe, Springer-Verlag, Berlin

\section{Ekzema herpeticum}

Herpes-simplex-Virus (HSV)

\section{Elefantiasis}

$\checkmark$ Brugia

- Wuchereria

\section{Elektronenmikroskopie in der}

\section{Erregerdiagnostik}

- Optische und Elektronenmikroskopische Detektion - Erregerschnelldiagnostik, hochauflösende Lichtmikroskopie und Live-Cell-Imaging

\section{El-Moro-Canyon-Virus}

- Hantaviren

\section{Empyem}

Aktinomyzeten mit fermentativem Kohlenhydratmetabolismus

- Bacteroides

- Legionella

- Moraxella catarrhalis

- Pasteurella multocida

- Porphyromonas

- Shewanella

- Staphylococcus aureus

\section{Encephalitozoon spp.}

- Microsporidien

\section{Endokarditis}

Aggregatibacter

- Arcanobacterium

- Bacteroides

- Bartonella

- Capnocytophaga

- Cardiobacterium

- Chlamydia

- Citrobacter

- Corynebakterien, sonstige Spezies

- Coxiellen

$\checkmark$ Ehrlichia

- Eikenella

- Enterokokken 


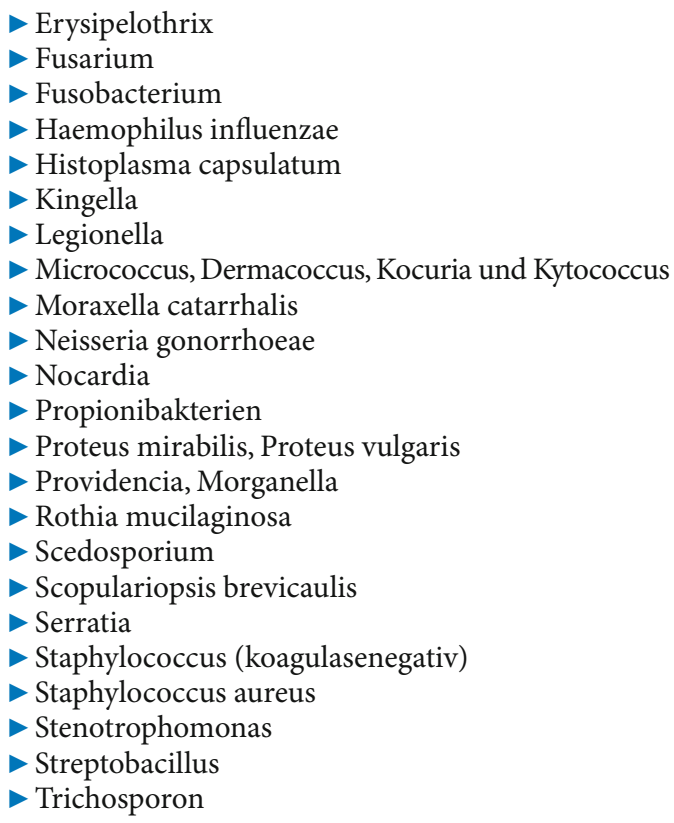

\section{Endokarditis, infektiöse}

Björn Plicht, Christoph K. Naber

\section{Definition}

Die infektiöse Endokarditis (IE) ist eine endovaskuläre, vorzugsweise durch Bakterien verursachte Infektion kardiovaskulärer Strukturen. Vorrangig sind native Herzklappen betroffen, aber auch intrakardial implantierte Fremdmaterialien (Klappenprothesen, Schrittmacherelektroden, etc.).

\section{Erregerspektrum}

Häufigste Erreger einer infektiösen Endokarditis (IE) sind grampositive Kokken: in der Reihenfolge der Häufigkeit S. aureus und Koagulase-negative Staphylokokken, Streptokokken der so genannten ViridansGruppe und Enterokokken, meist E. faecalis. Seltener finden sich Infektionen mit Gram-negativen Mikroorganismen wie Erregern der HACEK-Gruppe (Haemophilus spp., Actinobacillus actinomycetemcomitans, Cardiobacterium hominis, Eikenella corrodens, Kingella spp.). Infektionen mit Chlamydia spp., Coxiella spp., Brucella spp., Bartonella spp. treten in Nordeuropa weniger häufig auf. Pilzinfektionen sind selten.

\section{Epidemiologie}

Die Inzidenz der IE liegt bei etwa 3-10 Episoden/100.000 Personenjahre $[1,2]$. Sie nimmt abhängig vom Alter zu und beträgt bei Patienten zwischen 70 und 80 Jahren 14,5/100.000 Personenjahre.

Prädisponierende Faktoren sind ein vorbestehendes Vitium, Klappenprothesen, i.v.-Drogenabusus, rheu- matisches Fieber oder frühere Endokarditis in der Anamnese.

Trotz aller diagnostischen und therapeutischen Fortschritte weist die Erkrankung eine hohe Morbidität und eine Letalität zwischen $15 \%$ und $30 \%$ [2] auf. Eine chirurgische Intervention wird bei mehr als $30 \%$ der Erkrankten durchgeführt.

\section{Beschreibung des Krankheitsbildes}

Grundsätzlich unterscheidet man langsame, chronische Verlaufsformen, die über Monate oligosymptomatisch und daher häufig unerkannt bleiben. Bei anderen Patienten ist der Verlauf akut bis perakut. Oft ist dies Ausdruck der Virulenz des zugrundeliegenden Erregers.

Leitsymptome der IE sind Fieber und das neu aufgetretene oder aggravierte Herzgeräusch. Unspezifische Symptome, z. B. subfebrile Temperaturen, Gewichtsverlust, Nachtschweiß, Abgeschlagenheit oder Myalgien, können gerade bei älteren Patienten auf eine IE hinweisen.

Typische, allerdings selten beobachtete Zeichen sind Osler-Knoten als Ausdruck vaskulärer und immunologischer Phänome (subkutane, hämorrhagische Knötchen i. S. einer Immunkomplexvaskulitis), Splinter-Hämorrhagien (Einblutungen unter den Fingernägeln), Janeway-Läsionen (Hämorrhagien der Handflächen und Fußsohlen durch Immunkomplexe) oder Immunkomplex-Glomerulonephritiden.

Wichtig ist die frühe Erkennung klinischer Komplikationen: z. B. progrediente Dyspnoe als Hinweis auf eine Klappendestruktion mit kardialer Volumenbelastung oder neurologische Symptome bedingt durch zerebrale septische Embolien.

Typische Laborveränderungen sind bedingt durch die systemische Inflammation: Leukozytose mit Linksverschiebung, Erhöhung des C-reaktiven Proteins (CRP) und des Procalcitonins (PCT). Ihr Wert in der Verlaufsbeobachtung ist jedoch umstritten, da sie nicht direkt mit der Ausprägung des Lokalbefundes korrelieren.

\section{Zielorgan(e) und Immunreaktion}

Vorrangig ist im Rahmen infektiöser Endokarditiden das Endothel nativer Herzklappen betroffen. Das normale Endothel gesunder Herzklappen ist resistent gegenüber Kolonisation und Infektion durch zirkulierende Bakterien.

Endothelschäden können mechanisch (durch turbulenten Blutfluss, Elektroden oder Katheter), entzündlich (bei rheumatischer Karditis), oder degenerativ bedingt sein. Eine mechanische Verletzung des Endothels resultiert in einer Freisetzung extrazellulärer Matrixproteine, der Produktion von Gewebefaktor und der Ablagerung von Fibrin und Thrombozyten als normaler Heilungsprozess. Degenerative Klappenveränderungen sind echokardiographisch bei bis zu $50 \%$ asymptomatischer Patienten über 60 Jahre zu finden. 
Die durch oben beschriebene Mechanismen verursachte lokale Entzündung triggert Endothelzellen zur Expression von Integrinen (transmembrane Proteine, die extralluläre Faktoren mit dem Zytoskelett verbinden) der b1-Familie (Very Late Antigen), die zirkulierendes Fibronektin an die endotheliale Oberfläche knüpfen. S. aureus und einige andere Erreger der IE tragen ihrerseits Fibronektin-bindendene Proteine. Damit bilden aktivierte Endothelzellen, die Fibronektin binden, eine adhäsive Oberfläche für im Blut zirkulierende Staphylokokken. Einmal gebunden, triggert S. aureus seine aktive Internalisation in die Klappenendothelzelle, wo er persistieren und den Abwehrmechanismen des Körpers und Antibiotika entgehen kann.

Die klassischen Pathogene der IE (S. aureus, Streptococcus spp., Enterococcus spp.) teilen die Fähigkeit, an geschädigte Herzklappen anzuheften, die lokale prokoagulatorische Aktivität zu steigern und infektiöse Vegetationen zu bilden. Dabei sind Gram-positive Bakterien resistent gegenüber Komplement. Jedoch sind sie Ziel von thrombozytären mikrobiozidalen Proteinen („platelet microbicidal proteins“/PMP), mit denen aktivierte Thrombozyten Mikroorganismen durch Störung der Plasmamembran vernichten können. Allerdings sind Bakterienstämme von Patienten mit IE regelmäßig resistent gegenüber Angriffen mit PMP, während vergleichbare Bakterien bei Infektionen anderer Organe PMP-empfindlich sind. Damit scheint eine PMP-Resistenz ein typisches Charakteristikum von IE-verursachenden Mikroorganismen zu sein [2].

\section{Pathophysiologie / Molekulare Basis der Organschäden}

Die Pathophysiologie der Endokarditis wird bestimmt durch hämodynamische Veränderungen bedingt durch die Destruktion der Herzklappen oder durch eine systemische Inflammationsreaktion im Sinne einer Sepsis. Diese sind Ursache der im Rahmen der IE auftretenden Organschäden, sofern sie nicht direkt durch septische Embolisation verursacht werden.

\section{Diagnostische Maßnahmen}

Zur erreger- und resistenzgerechten Einleitung einer antimikrobiellen Therapie ist der blutkulturelle Nachweis des auslösenden Pathogens essentiell. Der Befund eines Erregers in mindestens zwei Blutkulturen ist bei echokardiographischem Nachweis einer Endokardbeteiligung diagnostischer Goldstandard. Blutkulturen sind grundsätzlich vor Einleitung einer antimikrobiellen Therapie zu entnehmen. Für die IE ist eine kontinuierliche Bakteriämie charakteristisch, daher können Blutkulturen unabhängig von Fieberspitzen akquiriert werden. Insgesamt werden 3 bis 5 Blutkultursets (aerob/anaerob) innerhalb einiger Stunden durch Punktion der Kubitalvene entnommen.

In 10-30 \% der Fälle bleibt die Blutkultur negativ. Ur- sache ist zu ca. 50 \% eine Vorbehandlung mit Antibiotika, gefolgt von einer Infektion mit schwer anzüchtbaren Mikroorganismen. Bei Patienten mit antimikrobieller Vorbehandlung ist bei klinischer Stabilität eine Unterbrechung der Antibiotikatherapie zu erwägen, um die Wahrscheinlichkeit des Erregernachweises zu verbessern. Bei Verdacht auf schwer anzüchtbare Erreger sind entsprechende serologische Nachweisverfahren indiziert. Die mikrobiologische bzw. molekularbiologische Untersuchung von intraoperativ entnommenem Klappengewebe oder Gewebe aus peripheren Abszessen kann hilfreich sein. PCR-Untersuchungen aus Vollblut- oder Serumproben sind für die Diagnose der infektiösen Endokarditis noch von unklarem klinischem Wert.

Bei jedem klinisch begründeten Verdacht ist die rasche Durchführung einer echokardiographischen Untersuchung zwingend erforderlich. Dabei ist die transösophageale Echokardiographie (TEE) i. d. R. der transthorakalen Untersuchung (TTE) überlegen. Bei schlechter Bildqualität der TTE, prothetischem Klappenersatz oder verdächtigen Strukturen sollte in jedem Fall eine TEE durchgeführt werden. Da bei morphologischen Klappenveränderungen differenzialdiagnostisch immer auch nicht-infektiöse Ursachen, z. B. Degeneration, kardiale Tumoren oder Thromben in Betracht kommen, ist für die Diagnosestellung die Integration echokardiographischer, klinischer und mikrobiologischer Parameter entscheidend. Zur Diagnosefindung haben sich diesbezüglich die „Duke-Kriterien" [3], die heute in modifizierter Form vorliegen [4], als hilfreich erwiesen. Sie können jedoch in keinem Fall eine klinische Beurteilung ersetzen.

\section{Therapie und Prävention}

Grundsätzlich sollte die Therapie der IE unter stationären Bedingungen mittels parenteraler Gabe bakterizider Antibiotika erfolgen. Bei Infektionen durch Penicillin-empfindliche Streptokokken mit unkompliziertem Verlauf ist im Anschluss an eine 14-tägige stationäre Initialbehandlung eine ambulante Fortführung der Therapie möglich. Bei akuten Erkrankungsformen und bei hämodynamischer Instabilität, wird nach Akquisition von Blutkulturen umgehend eine kalkulierte antimikrobielle Therapie eingeleitet. Bei klinisch stabilen Patienten kann oft das Ergebnis der mikrobiologischen Diagnostik abgewartet werden. Bezüglich der spezifischen Erreger- und Resistenzgerechten Therapie sei auf die aktuellen Leitlinien verwiesen [2].

Frühzeitig sind Herzchirurgen hinzuzuziehen, um im Falle nicht-kontrollierbarer Infektionen eine rasche chirurgische Sanierung zu ermöglichen. Nach neurologischen Ereignissen sollte es bei bestehender Indikation zu keiner Verzögerung der Operation kommen, sofern die neurologische Prognose gut ist. Nach intrakraniellen Blutungen jedoch sollte der Operationszeit- 
punkt um mindestens einen Monat prolongiert werden, sofern möglich.

Postoperativ sollte die präoperative Antibiotikatherapie fortgesetzt werden, wobei die Gesamtdauer der Behandlung durch den ersten Tag der effektiven Therapie, nicht durch den Zeitpunkt der Operation festgelegt wird, außer bei positivem kulturellem Erregernachweis von den operierten Herzklappen. Hier ist ein neuer, Erreger- und Resistenz-gerechter Kurs zu beginnen.

Ein Konzept zur Verhinderung einer IE bei Eingriffen mit Bakteriämierisiko ist die prophylaktische Einnahme von Antibiotika. Aufgrund einer schwachen Evidenzlage empfehlen die aktuellen Leitlinien [5] diese nur für Patienten mit einem hohen Risiko für einen besonders schweren Verlauf oder einen letalen Ausgang einer IE (als Einmalgabe von Amoxicillin, alternativ Clindamycin, 30 bis 60 Minuten vor dem Eingriff). Die Definition der Risikoeingriffe beschränkt sich auf zahnärztliche Eingriffe mit Manipulation der Gingiva, der periapikalen Zahnregion oder mit Perforation der oralen Mukosa. Da bereits alltägliche orale Manipulationen (Zähneputzen, Verwendung von Zahnseide oder Kauen der Nahrung), besonders in Abhängigkeit vom Zahnstatus, zu transitorischen Bakteriämien führen, wird eine generelle Empfehlung für die Einhaltung einer guten Mundhygiene ausgesprochen.

\section{Schlüsselliteratur}

1. Durack DT, Lukes AS, Bright DK (1994) New criteria for diagnosis of infective endocarditis: utilization of specific echocardiographic findings. Duke Endocarditis Service. Am J Med 96:200-209

2. Habib G, Hoen B, Tornus P, et al (2009) Guidelines on the prevention, diagnosis, and treatment of infective endocarditis (new version 2009). European Heart Journal 30:2369-2413

3. Hoen B, Alla F, Selton-Suty C, Beguinot I et al (2002) Association pour l'Etude et la Prevention de l'Endocardite Infectieuse (AEPEI) Study Group. Changing profile of infective endocarditis: results of a 1-year survey in France. JAMA 288:75-81

4. Li JS, Sexton DJ, Mick N et al (2000) Proposed modifications to the Duke criteria for the diagnosis of infective endocarditis. Clin Infect Dis 30: 633-638

5. Naber CK, Al-Nawas B, Baumgartner H, et al.: Prophylaxe der infektiösen Endokarditis. Kardiologe 2007; 1:243250

\section{Wichtige Webseiten und Links}

- http://www.p-e-g.de/

- http://leitlinien.dgk.org/

- http://www.escardio.org/guidelines-surveys/escguidelines/Pages/GuidelinesList.aspx

\section{Endolimax nana}

- Darmamöben, apathogen

\section{Endometritis}

Prevotella

\section{Endophthalmitis}

- Bacillus-Arten (fakultativ bzw. opportunistisch pathogen)

- Candida

- Fusarium

- Moraxella catarrhalis

- Pasteurella multocida

- Plesiomonas

- Rothia mucilaginosa

- Scedosporium

- Scopulariopsis brevicaulis

- Sporothrix schenkii

- Staphylococcus (koagulasenegativ)

\section{Entamoeba histolytica}

EGBERT TANNICH

\section{Erreger}

\section{Synonym(e)}

Darmamöbe, Ruhramöbe.

\section{Erregerspezies}

Entamoeba histolytica

\section{Taxonomie}

Amöben gehören in die Gruppe der Protozoen (einzellige, heterotrophe Eukaryonten) und werden wegen des Besitzes von unstrukturierten Pseudopodien den Rhizopoden (Wurzelfüßer) zugeordnet. Innerhalb der Rhizopoden bilden die Entamoeben ein eigenes Taxon. Entamoeba histolytica ist die einzige humanpathogene Art.

\section{Historie}

Erstbeschreibung von Amöben als Auslöser von Dysenterien durch F. A. Lösch (1875). Die Namensgebung (histolytica) erfolgte durch Schaudinn (1903) aufgrund der Fähigkeit, Gewebe mit hoher Effektivität zu zerstören. Abgrenzung von apathogenen Darmamöben, insbesondere von Entamoeba dispar durch E. Brumpt (1925).

\section{Morphologie}

Der Lebenszyklus von Entamoeba histolytica umfasst zwei morphologisch klar zu unterscheidende Entwicklungsstadien, das Vegetativstadium, auch Trophozoit genannt, und das Zystenstadium. Durch Aufnahme von Erythrozyten können die charakteristischen hämatophagen Trophozoiten entstehen, die im deutschen Schrifttum aufgrund ihrer Größe auch als „Ma- 
gnaformen" bezeichnet werden. Die reifen Zysten haben einen Durchmesser von 10-16 $\mu \mathrm{m}$ und besitzen immer vier Kerne mit einem zentralen Karyosom. Zysten von Entamoeba histolytica und den kommensalisch im Darm des Menschen vorkommenden Arten Entamoeba dispar und Entamoeba moshkovskii lassen sich morphologisch nicht unterscheiden.

\section{Genom}

Das Genom von Entamoeba histolytica ist weitgehend aufgeklärt (http://pathema.jcvi.org/cgi-bin/Entamoeba/PathemaHomePage.cgi). Nach dem aktuellen Kenntnisstand umfasst es etwa 24 Megabasen, die auf 14 Chromosomen verteilt sind. Bisher wurden knapp 10.000 offene Leserahmen identifiziert. Nur etwa ein Viertel aller Protein-kodierenden Gene ist durch Introns unterbrochen und nur $6 \%$ der Gene besitzen mehr als ein Intron.

\section{Vermehrung}

Die Vermehrung von Entamoeba histolytica findet im Dickdarm statt. Nach oraler Aufnahme infektionstüchtiger Zysten, die im Gegensatz zu den Trophozoiten über Monate an der Außenwelt stabil bleiben können und resistent gegenüber dem sauren Millieu des Magens sind, entwickeln sich im Dünndarm die einkernigen, teilungsfähigen Trophozoiten, die vor allem den oberen Dickdarm besiedeln. Im distalen Kolon kommt es zur erneuten Enzystierung mit zwei anschließenden Kernteilungen. Eine infizierte Person kann bis zu 500 Millionen Zysten pro Tag ausscheiden.

\section{Pathogenität / Virulenz / Antigenvariabilität}

Die Pathogenität von Entamoeba histolytica beruht primär auf der Fähigkeit des Parasiten, Wirtsgewebe und Zellen zu lysieren. Hierbei spielen Oberflächenrezeptoren, Cysteinproteinasen und porenbildende Peptide der Amöben eine entscheidende Rolle. In Abhängigkeit von der Stärke der Expression dieser Moleküle, kann die Virulenz einzelner Amöbenisolate variieren. Antigenvariabilität konnte bisher bei Entamoeba histolytica nicht nachgewiesen werden. Allerdings verlaufen die meisten Infektionen mit Entamoeba histolytica asymptomatisch (nicht invasive Amöbiasis). Nur in etwa 10 \% der Fälle kommt es zur Invasion in das Gewebe (invasive Amöbiasis), wobei sowohl der Darm (intestinale Amöbiasis) als auch andere Organe (extraintestinale Amöbiasis), vornehmlich die Leber, betroffen sind (Amöbenleberabszess).

\section{Erkrankungen}

\section{Intestinale Amöbiais}

\section{Synonym(e)}

Amöbenruhr, Amöben-Colitis, Amöben-Dysenterie, Amöbom.

\section{Inkubationszeit}

Sehr variabel, zwischen wenigen Tagen und mehreren Monaten.

\section{Leitsymptome}

Blutig-schleimige Diarrhoe.

\section{Symptome}

Enteritis oder Kolitis von variablem Schweregrad, Diarrhoe, Fieber, Tenesmen, druckdolenter Oberbauch.

\section{Pathophysiologie}

Für die Pathologie der intestinalen Amöbiasis sind die Amöben direkt verantwortlich. Durch eine kontaktabhängige Lyse von Darmgewebe verursacht Entamoeba histolytica tiefe Ulzerationen der Darmschleimhaut. Amöbom $=$ sehr seltene, durch Entamoeba histolytica hervorgerufene tumorartige granulomatöse Entzündungsreaktion des Dickdarms.

\section{Immunantwort}

In mehr als $90 \%$ aller Fälle mit invasiver Amöbiasis finden sich zum Zeitpunkt der klinischen Symptomatik signifikante Serum-Antikörpertiter gegen Entamoeba-histolytica-Antigen.

\section{Differenzialdiagnose}

Andere infektiöse Darmerkrankungen, insbesondere durch Shigellen und invasive Escherichia coli, sowie nicht infektöse Darmerkrankungen wie Colitis ulcerosa oder Morbus Crohn.

\section{Extraintestinale Amöbiasis}

Synonym(e)

Amöbenleberabszess.

\section{Inkubationszeit}

Sehr variabel, im Mittel 3-5 Monate, in Einzelfällen mehrere Jahre.

\section{Leitsymptome}

Fieber, Schmerzen im rechten Oberbauch.

\section{Symptome}

Hepatomegalie, Übelkeit, Erbrechen, Schmerzen in der rechten Schulter (abhängig von der Lokalisation des Abszesses), Ikterus, Diarrhoe (nur in $10 \%$ der Fälle!).

\section{Pathophysiologie}

Nach Invasion in die Darmschleimhaut können die Amöben hämatogen in andere Organe gestreut werden und dort ausgedehnte Abszesse induzieren. Diese finden sich in erster Linie in der Leber. Amöbenleberabszesse führen häufig zu Transsudaten der Pleura und zu Atelektasen der Lunge, können aber gelegentlich auch je nach Lokalisation in die Lunge oder das Perikard rupturieren. Primäre Amöbenabszesse au- 
ßerhalb der Leber, wie etwa in der Lunge oder dem Gehirn, sind eine Rarität.

\section{Immunantwort}

Amöbenleberabszesse führen regelmäßig zur Bildung von Serum-Antikörpern gegen Entamoeba-histolytica-Antigene. Sie sind bei über $90 \%$ der Patienten bereits zu Beginn der klinischen Symptomatik nachweisbar.

\section{Differenzialdiagnose}

Bakterielle Leberabszesse, Echinokokkuszyste, primäre Leberzyste, einschmelzender Tumor.

\section{Diagnostik}

\section{Untersuchungsmaterial}

Die Diagnostik der invasiven Amöbiasis richtet sich nach dem Manifestationsort der Erkrankung:

- Bei der intestinalen Amöbiasis stehen der rektoskopische oder koloskopische Nachweis entsprechender Schleimhautveränderungen sowie der Direktnachweis des Erregers im Vordergrund. Letzteres geschieht durch Stuhluntersuchungen oder den histologischen Nachweis von Amöben im Biopsiematerial.

- Bei der extraintestinalen Amöbiasis bedient man sich vor allem bildgebender Verfahren wie Sonographie und Computertomographie zum Nachweis entsprechender Organmanifestationen und Strukturdefekte. Gleichzeitig ist der serologische Nachweis spezifischer Antikörper gegen Entamoeba histolytica ein wichtiges, oftmals richtungweisendes diagnostisches Hilfsmittel.

\section{Diagnostische Verfahren}

\section{Mikroskopie}

Nativpräparat: Dient dem Nachweis der beweglichen Trophozoiten, die im Falle von blutigen Diarrhoen typischerweise phagozytierte Erythozyten enthalten und eine typische Bewegung mit Pseudopodienbildung zeigen. Zur Herstellung der Präparate werden Stuhl und Schleimbeimengungen getrennt auf verschiedene Objektträger aufgebracht. Schleimflocken werden ohne Zusatz direkt mikroskopiert. Stuhlpräparate werden vor dem Mikroskopieren zu einem Teil mit physiologischer Kochsalzlösung vermischt, ein anderer Teil kann mit Lugol'scher Lösung versetzt werden, zur besseren Darstellung der Zellstruktur. CharakteristischistdieAusbildungvon Bruchsackpseudopodien, die aus einem hyalinen ektoplasmatischen Teil bestehen, der leicht von dem gekörnten endoplasmatischen Anteil unterschieden werden kann.

Dauerpräparat: Kann ein Stuhl nicht sofort untersucht werden oder finden sich in den Nativpräparaten keine Amöben, so sollte die Probe mit einer Formalin-Lösung (MIF, SAF) fixiert und mögliche Zysten über eine Konzentrierungsmethode, wie z. B. MIFC angereichert werden. Zur Herstellung des Präparates wird das Sedi- ment direkt auf den Objektträger aufgebracht und nach Abdecken mit dem Deckglas bei mindestens 400facher Vergrößerung mikroskopiert. Wichtig ist die Verwendung eines Okulars mit Mess-Skalierung zur exakten Größenbestimmung, da nur EntamoebaZysten mit einem Durchmesser von 10-16 $\mu \mathrm{m}$ verdächtig sind für das Vorliegen einer Entamoeba-histolytica-Infektion.

\section{Koproantigen-ELISA}

Immunodetektionsverfahren mithilfe monoklonaler Antikörper zum spezifischen Nachweis von Entamoeba-histolytica-Antigen aus Stuhlproben. Verschiedene konfektionierte Test-Kits sind kommerziell erhältlich.

\section{Nukleinsäurenachweis}

Nukleinsäureamplifikationsverfahren auf der Basis der Polymerasekettenreaktion (PCR) sind gegenwärtig die empfindlichsten Methoden, um Entamoeba histolytica in Stuhlproben nachzuweisen. Diese Techniken erlauben die Detektion von weniger als einer Amöbe pro Gramm Stuhl und sind damit allen anderen Nachweisverfahren wie Mikroskopie oder Koproantigen-ELISA deutlich überlegen. Als Zielsequenz für den Amöbennachweis verwendet man typischerweise den rDNS-Locus, der im Genom von Entamoeba histolytica in 200-400 Kopien vorkommt und somit eine sehr empfindliche Detektion erlaubt.

\section{Serologie}

Bei Verdacht auf eine Entamoeba-histolytica-Infektion, insbesondere bei extraintestinaler Amöbiasis (z. B. Amöbenleberabszess) sind serologische Untersuchungen auf spezifische Antikörper indiziert. Verschiedene Tests zum Nachweis von Serumantikörpern gegen Entamoeba histolytica sind kommerziell erhältlich und zeigen in der Regel eine relativ gute Sensitivität und Spezifität, wobei zur Diagnostik einer Amöbiasis nach Möglichkeit zwei unabhängige Verfahren kombiniert eingesetzt werden sollten, wie etwa die Immunfluoreszenz und der ELISA.

\section{Befund / Interpretation}

Der mikroskopische Nachweis hämatophager Trophozoiten in Stuhlproben oder der histologische Nachweis von Amöben in Biopsiematerial gilt als pathognomonisch für das Vorliegen einer invasiven intestinalen Amöbiaisis. Der Nachweis entsprechender Zysten oder nicht hämatophager Trophozoiten in Stuhlproben bedarf hingegen weiterer Abklärung mittels Antigentest oder PCR. Infektionen mit E. dispar sind wesentlich häufiger als Infektionen mit Entamoeba histolytica. Daher ist insbesondere bei asymptomatischen Amöbenausscheidern eine solche Diagnostik angezeigt, vor allem da die Kosten der Diagnostik (einschließlich der PCR) deutlich unter den Therapiekosten liegen. Im Gegensatz zur intestinalen Amöbiasis basiert die Diagnose einer extraintestinalen Amö- 
biasis in aller Regel auf indirekten Nachweisverfahren. Die Kombination aus Fieber, hypodenser Raumforderung in der Leber und positiver Amöbenserologie gilt aber als ausreichend sicher für das Vorliegen eines Amöbenleberabszesses.

\section{Therapie}

\section{Therapeutische Maßnahmen}

Jede Infektion mit Entamoeba histolytica ist grundsätzlich behandlungsbedürftig. Bei asymptomatischen intestinalen Infektionen erfolgt die Behandlung mit Paromomycin $(3 \times 500 \mathrm{mg}$ über 10 Tage $)$. Der Therapieerfolg sollte frühestens 14 Tage nach Abschluss der Behandlung durch entsprechende Stuhluntersuchungen überprüft werden. Bei allen Entamoeba-histolytica-Infektionen mit invasiven intestinalen oder extraintestinalen Manifestationen erfolgt die Behandlung zunächst mit Metronidazol (30 mg/kg KG/Tag verteilt auf drei Tagesdosen über 10 Tage). Metronidazol wird größtenteils im Dünndarm resorbiert und wirkt vor allem auf Amöben, die bereits in das Gewebe eingedrungen sind. Zur Elimination möglicher intraluminal verbliebener Parasiten folgt im Anschluss an die Metronidazoltherapie immer eine Therapie mit dem nicht resorbierbaren Paromomycin. Amöbenleberabszesse heilen unter adäquater medikamentöser Therapie vollständig aus. Im Gegensatz zu bakteriellen Abszessen ist eine Punktion oder Drainage des Abszessinhaltes nur in Ausnahmefällen indiziert.

\section{Resistenz}

Medikamentenresistenzen gegen Metronidazol wurden in Einzelfällen vermutet, sind aber bisher nicht wissenschaftlich belegt. Versuche, Metronidazol-resistente Amöben in vitro zu generieren, blieben ohne Erfolg.

\section{Epidemiologie}

\section{Verbreitung}

Entamoeba histolytica kommt weltweit vor, ist aber vor allem in Gegenden mit niedrigem Hygienestandard endemisch. Die Ausbreitung hängt von der Zahl der Zystenausscheider und den hygienischen Bedingungen ab. Unter den hygienischen Verhältnissen, wie sie in Westeuropa Standard sind, ist eine Ausbreitung nicht gegeben.

Wirtsbereich / Reservoir

Die natürliche Infektion mit Entamoeba histolytica beschränkt sich auf den Menschen und einige Affenarten.

\section{Risikogruppen}

Hauptrisikogruppen sind Personen, die unter schlechten hygienischen Bedingungen in den entsprechenden Endemiegebieten des Erregers leben (vor allem Tropen und Subtropen), darüber hinaus Reisende in sol- che Länder sowie männliche Homosexuelle, Kanalarbeiter und Bewohner von Behindertenheimen.

\section{Transmission / Vektoren}

Die Übertragung von Entamoeba histolytica erfolgt in der Regel fäkal-oral durch Ingestion infektiöser Zysten (kontaminierte Nahrungsmittel), ist aber auch durch entsprechende homosexuelle Praktiken möglich. Vektoren als Überträger sind nicht belegt.

\section{Prävention / Impfstoffe}

Maßnahmen zur Verhinderung einer Amöbeninfektion bestehen derzeit in der Expositionsprophylaxe durch entsprechende Körperhygiene, Nahrungsmittel- und Trinkwasseraufbereitung sowie der Erkennung und Therapie von Ausscheidern. Eine medikamentöse Prophylaxe wird nicht empfohlen, ein geeigneter Impfstoff steht bisher nicht zur Verfügung.

\section{Ausbruchsmanagement}

Ausbrüche von Amöbiasis wurden bisher nur in Einzelfällen im Zusammenhang mit Unzulänglichkeiten bei der Trinkwasseraufbereitung beschrieben. Das Ausbruchsmanagement besteht in der konsequenten Sanierung der Infektionsquelle und der Behandlung infizierter Personen. Eine Isolierung ist in der Regel nicht erforderlich.

\section{Meldepflicht}

Nach $₫ 6$, Abs. 1 IfSG ist die Erkrankung nur meldepflichtig, sofern zwei oder mehr gleichartige Erkrankungen auftreten, bei denen ein epidemischer Zusammenhang wahrscheinlich ist oder vermutet wird.

\section{Weiterführende Informationen}

\section{Referenzzentren / Expertenlaboratorien}

- Nationales Referenzzentrum für Tropischen Infektionserreger, Bernhard-Nocht-Institut für Tropenmedizin, Bernhard-Nocht-Str. 74, 20359 Hamburg, Tel.: 040/4281811, http://www.bnitm.de

\section{Web-Adressen}

- Bernhard-Nocht-Institut für Tropenmedizin: http:// www.bnitm.de

- AWMF Leitlinien Diagnostik und Therapie der Amöbenruhr: http://leitlinien.net/042-002.htm

- AWMF Leitlinien Diagnostik und Therapie des Amöbenleberabszesses: http://leitlinien.net/042-003.htm

- The Entamoeba homepage: http://homepages.lshtm. ac.uk/entamoeba/

\section{Schlüsselliteratur}

1. Burchard GD, Tannich E (2004) Epidemiologie, Diagnostik und Therapie der Amöbiasis. Dtsch Aerztebl 101:A3036-A-3040

2. Haque R, Huston CD, Hughes M, Houpt E, Petri WA (2003) Amebiasis. N Engl J Med 17:1565-1573

3. Löscher T, Burchrd RD (2010) Tropenmedizin in Klinik und Praxis, 4. Aufl. Thieme, Stuttgart

4. Stanley SL (2003) Amoebiasis. Lancet 361:1025-1034 
5. Tannich E (2004) The laboratory diagnosis of Entamoeba histolytica-infections. J Lab Med 28:491-497

\section{Entamoeba spp.}

Darmamöben, apathogen

\section{Enteritis necroticans}

- Clostridien der Gasbrand-Gruppe

\section{Enterobacter}

\section{Erreger}

Synonym(e)

\section{Erregerspezies}

Enterobacter cloacae, -aerogenes, -agglomerans, -sakazakii sowie mehrere andere Spezies, die bisher nicht als Krankheitserreger beim Menschen beobachtet wurden.

\section{Taxonomie}

Familie Enterobacteriaceae, Gattung: Enterobacter

\section{Historie}

Einteilung der Gattung durch E. Hormaeche and P. R. Edwards (1960) A Proposed Genus Enterobacter. Int. Vol. Bacterial. Nomen. Taxon. 10:71-74.

Leitet sich ab aus dem griech. Enteron (Darm) und Bacter (Stäbchen).

\section{Morphologie}

Gramnegative Stäbchenbakterien, beweglich durch peritriche Begeißelung. Kapselbildung fakultativ.

\section{Genom}

Genom vollständig sequenziert, siehe auch www.ncbi. nlm.nih.gov.

\section{Vermehrung}

Fakultativ anaerob, Wachstum innerhalb von 24 Stunden.

\section{Pathogenität / Virulenz / Antigenvariabilität} Endotoxin.

\section{Erkrankungen}

\section{Lokalisierte Prozesse}

Ca. $10 \%$ aller nosokomialen Infektionen, postoperative Wundinfektionen nach abdomineller und vaginaler Hysterektomie, Meningitis, Gastroenteritis, Harnwegsinfektionen

\section{Synonym(e)}

Keine.

\section{Inkubationszeit}

Nicht bekannt.

\section{Leitsymptome}

Dem jeweiligen Krankheitsgeschehen entsprechend.

\section{Symptome}

Dem jeweiligen Krankheitsgeschehen entsprechend.

\section{Pathophysiologie}

Fakultativ pathogene opportunistische Infektionserreger, Infektion bei Standortwechsel.

\section{Immunantwort}

Opsonisierung durch Antikörper, Phagozytose.

\section{Differenzialdiagnose}

Ausschluss anderer Infektionserreger.

\section{Generalisierte Prozesse}

Durch Einschwemmung von Enterobacter spp. in die Blutbahn kann es zur Sepsis kommen

\section{Synonym(e)}

Keine.

\section{Inkubationszeit}

Nicht bekannt.

\section{Leitsymptome}

Fieber.

\section{Symptome}

Fieber.

\section{Pathophysiologie}

- Lokalisierte Prozesse (Erkrankung 1)

\section{Immunantwort}

- Lokalisierte Prozesse (Erkrankung 1)

\section{Differenzialdiagnose}

- Lokalisierte Prozesse (Erkrankung 1)

\section{Toxische Prozesse}

Bei Enterobacter-cloacae-Isolaten aus tropischen Ländern wurde eine Enterotoxin-ähnliche Aktivität nachgewiesen, daher selten auch Durchfallerreger

\section{Synonym(e)}

Keine.

\section{Inkubationszeit}

Nicht bekannt.

\section{Leitsymptome}

Durchfall. 


\section{Symptome}

Durchfall.

\section{Differenzialdiagnose}

Ausschluss anderer Infektionserreger.

\section{Diagnostik}

\section{Untersuchungsmaterial}

Wundabstrich, Urin, Faeces, Blutkultur, Liquor.

\section{Diagnostische Verfahren}

Kulturelle Anzüchtung: Siehe Fakultativ pathogene E. coli

Biochemische Differenzierung: Ist durch umfangreiche Untersuchungen zwischen den einzelnen Spezies möglich.

Serologische Differenzierung: Für Enterobacter cloacae wurden $53 \mathrm{O}$-Antigene und $56 \mathrm{H}$-Antigene beschrieben.

\section{Befund / Interpretation}

Erregernachweis ausschlaggebend.

\section{Therapie}

\section{Therapeutische Maßnahmen}

Möglichst nach Antibiogramm. Wirksam sind häufig Ureidopenicilline sowie Cefotaxim, Ceftazidim, Carbapeneme, Chinolone und auch Aminoglykoside.

\section{Resistenz}

Chromosomale Betalaktamase, die induzierbar ist oder konstitutiv.

\section{Epidemiologie}

\section{Verbreitung}

Teil der normalen Darmflora. Als Erreger von krankenhauserworbenen Infektionen gefürchtet, da eine durch Betalaktam-Antibiotika induzierbare Breitspektrum-Betalaktamase zu Multiresistenz führt.

\section{Wirtsbereich / Reservoir}

Enterobacter aerogenes wird isoliert aus Faezes von Mensch und Tieren, ebenso E. sakazakii, der zusammen mit E. agglomerans als freilebende Saprophyten aus Erdreich und Wasser nachgewiesen wird. E. cloacae hat eine zunehmende Bedeutung als Erreger von Hospitalinfektionen. E. agglomerans wird auch aus Blutkulturen isoliert, nach invasiven Eingriffen.

\section{Risikogruppen}

Enterobacter-spp.-Infektionen betreffen vor allem abwehrgeschwächte, langzeitbeatmete ältere Patienten.

\section{Transmission / Vektoren}

Die Übertragung erfolgt durch direkten Kontakt oder indirekt auch über Gegenstände und möglicherweise auch über Lebensmittel.

\section{Prävention / Impfstoffe}

Nicht bekannt.

\section{Ausbruchsmanagement}

Nicht erforderlich.

\section{Meldepflicht}

$\S 23$ IfSG Abs. 1: Multiresistenz ist zu dokumentieren.

\section{Weiterführende Informationen}

\section{Web-Adressen}

- www.cdc.gov/

\section{Schlüsselliteratur}

1. Blaser MJ, Smith PD, Ravdin JI, Greenberg HB, Guerrant RL (eds) (1995) Infections of the Gastrointestinal Tract, Raven Press New York

2. Hahn H, Kaufmann SHE, Schulz TF, Suerbaum S (Hrsg) (2009) Medizinische Mikrobiologie und Infektiologie. 4. Auflage, Springer Verlag Berlin, Heidelberg, New York, Barcelona, Hongkong, London, Mailand, Paris, Singapur, Tokyo

3. Kist M, Bockemühl J, Aleksic S, Altwegg M, Autenrieth IB, Bär W, Beutin L, Gerten B, Heintschel von Heinegg E, Karch H, Lehmacher A, Mehnert F, Sonnenborn U, Tschäpe H, v. Eichel-Streiber C (2000) Infektionen des Darmes: MiQ 9, Urban und Fischer, München, Jena

4. Konemann EW, Allen HD, Janda WM, Schreckenberger PC, Winn EC (eds) (1997) Diagnostic Microbiology, 5th Ed, Lippincott, Philadelphia, New York

\section{Enterobiasis}

Enterobius vermicularis

\section{Enterobius vermicularis}

Peter Kimmig

\section{Erreger}

\section{Synonym(e)}

Oxyuris vermicularis, Madenwurm, Pfriemenschwanz, Kinderwurm, Pinworm.

\section{Erregerspezies}

Enterobius vermicularis

\section{Taxonomie}

Klasse: Nematoda; Ordnung: Oxyurida; Familie: Oxyuridae

\section{Historie}

Madenwürmer sind seit dem Altertum bekannt. Die Namensgebung und definierte Erstbeschreibung erfolgte 1758 durch Linné, die eindeutige Klassifizierung und Unterscheidung von anderen Oxyuriden wurde aber erst 1824 durch Johann Bremser vorgenommen. 


\section{Morphologie}

Die Weibchen haben ein spitz ausgezogenes Hinterende (Pfriemenschwanz) und erreichen eine Länge von ca. 9-12 mm. Die Männchen sind nur 3-5 mm lang: sie sterben bald nach der Begattung ab und sind daher nur selten im Stuhl zu finden.

\section{Genom}

Derzeit liegen Sequenzen von ribosomalen und mitochondrialen Genen sowie von Strukturgenen vor, die für den molekularbiologischen Nachweis verwendet werden können. Jedoch existieren bisher keine Daten bezüglich des Gesamtgenoms.

\section{Vermehrung}

Die adulten Würmer leben vorwiegend im unteren Dünndarm, Blinddarm, Wurmfortsatz und oberen Dickdarm. Die Weibchen produzieren nach der Kopulation ca. 10.000 befruchtete Eier; zur Eiablage wandern sie - besonders nachts - zum Anus, legen ihre gesamte Eilast in den Analfalten ab, und sterben dann ab. Zur Weiterentwicklung müssen die embryonierten (nach 6-8 Std!) Eier vom Menschen verschluckt werden. Die Larven schlüpfen im Magen oder im Zwölffingerdarm; sie häuten sich hier zweimal und wandern dann darmabwärts in den unteren Dünndarm und oberen Dickdarmbereich ein, wo sie das Adultstadium erreichen. Die Gesamtentwicklung dauert vermutlich mindestens 1 Monat.

\section{Pathogenität / Virulenz / Antigenvariabilität}

Durch die Wanderung der weiblichen Adultwürmer und die abgelegten Eier kommt es zu mechanischen, durch Wurmsekrete zu chemischen Reizungen der Analschleimhaut.

\section{Erkrankung}

\section{Enterobiasis}

\section{Synonym(e)}

Oxyuriasis, Madenwurminfektion.

\section{Inkubationszeit}

Eine Inkubationszeit lässt sich nicht präzise definieren, da das Entstehen von Krankheitserscheinungen von der Zahl der - in der Regel akkumulativ - aufgenommenen infektiösen Eier und der Dauer der Infektion abhängt. Die Präpatenz beträgt ca. 4 Wochen.

\section{Leitsymptome}

Analpruritus.

\section{Symptome}

Ein großer Teil der Madenwurminfestationen verläuft asymptomatisch. Ansonsten ist analer (ggf. auch vaginaler) Pruritus das Hauptsymptom, der bei Kindern häufig zu Schlafstörungen führt.

\section{Pathophysiologie}

Bei einem großen Teil der Betroffenen führt die Infektion zu keiner Erkrankung. Bei ausgeprägten Infektionen finden sich im Darm geringfügige entzündliche Reizungen, vorherrschend sind jedoch allergische Reaktionen der Analschleimhaut, die durch die auswandernden graviden Weibchen und die abgelegten Eier verursacht werden; über Kratzen kann es zu bakteriellen Superinfektionen kommen.

Bei Einwandern der Würmer in die Vagina sind auch Kolpitiden möglich, als seltene Komplikationen sind Appendizitiden beschrieben.

\section{Immunantwort}

Die durch Madenwürmer hervorgerufene Immunantwort führt weder zur Abtötung des Parasiten noch schützt sie vor Reinfektionen. Inwieweit der altersbedingte Rückgang der Empfänglichkeit immunogener Natur ist, muss noch geklärt werden.

\section{Differenzialdiagnose}

Differenzialdiagnostisch ist - besonders bei Erwachsenen - perianaler Pruritus anderer Genese in Betracht zu ziehen: Analekzem, Proktitis, Hämorrhoiden, Analmykose, Strongyloidiasis.

\section{Diagnostik}

\section{Untersuchungsmaterial}

Analabdruck: Das Material zum Nachweis der Oxyuren-Eier sollte am besten morgens gewonnen werden. Eine vorhergehende Reinigung der Perianalregion ist unbedingt zu unterlassen!

\section{Diagnostische Verfahren}

Der Befund eines Madenwurmbefalles kann makroskopisch durch Identifizierung der Würmer in der Analregion oder im Stuhl erfolgen, i. d .R. wird die Diagnose durch den mikroskopischen Ei-Nachweis gestellt. $\mathrm{Zu}$ diesem Zweck werden die Eier mithilfe eines Klebestreifens von den Analfalten abgenommen. Die $50-60 \times 20-30 \mu \mathrm{m}$ großen Eier sind von ovaler, einseitig abgeflachter Form.

Serologische Verfahren sind wegen der geringen oder fehlenden Immunantwort nicht etabliert.

\section{Befund / Interpretation}

Der Nachweis der Eier bzw. der Würmer selbst ist für einen Oxyuren-Befall beweisend. Falsch negative Resultate können durch eine unkorrekte Entnahmetechnik zustande kommen.

\section{Therapie}

\section{Therapeutische Maßnahmen}

Zur Behandlung der Enterobiasis kommen zurzeit folgende vier verschiedene Substanzen in Frage, die alle nach einmaliger oraler Applikation wirksam sind: Mebendazol $(1 \times 100 \mathrm{mg})$, Albendazol $(1 \times 400 \mathrm{mg})$ (Kinder unter 2 Jahren $14 \mathrm{mg} / \mathrm{kg} \mathrm{KG}$ ); Pyrantelembonat 
$(1 \times 10 \mathrm{mg} / \mathrm{kg} \mathrm{KG})$, Pyrviniumembonat $(1 \times 2,5 \mathrm{mg} /$

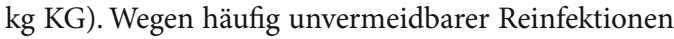
(z. B. durch die sogenannten Staubeier) ist die Behandlung im Abstand von ca. 2 Wochen und ca. 4 Wochen zu wiederholen. Darüber hinaus sollten bei Auftreten der Enterobiasis alle Angehörige einer Wohngemeinschaft behandelt werden.

\section{Resistenz}

Bei „therapieresistenten“ Infektionen handelt es sich i. d. R. nicht um Resistenzen, sondern um Reinfektionen durch sogenannte Staubeier bzw. um Gruppeninfektionen.

\section{Epidemiologie}

\section{Verbreitung}

Oxyuren sind weltweit verbreitet mit einer durchschnittlichen Prävalenz von ca. 10 \%. Typische Übertragungsorte sind Kindergärten, Grundschulen, Behindertenheime sowie der familiäre Bereich, in dem die Infektion durch direkten (Schmierinfektion) und indirekten Kontakt (Staub, kontaminierte Gegenstände) weitergegeben wird.

\section{Wirtsbereich / Reservoir}

Hauptwirt von E. vermicularis ist der Mensch; daneben wurden gelegentlich Menschenaffen infiziert gefunden.

\section{Risikogruppen}

Befallen sind in erster Linie Kinder oder Behinderte. Verhaltensbedingt (vermutlich aber auch aufgrund von Immunreaktionen) ist die Infestation im Erwachsenenalter in Mitteleuropa selten.

\section{Transmission / Vektoren}

Die Übertragung erfolgt auf oralem Wege über die Eier, die direkt über Schmierinfektion (Eier unter den Fingernägeln! Finger-After-Mund-Weg) oder indirekt über aufgewirbelten Staub (Aufschütteln der Bettwäsche) aufgenommen werden.

\section{Prävention / Impfstoffe}

Eine eigentliche Prävention ist kaum möglich, lediglich therapieunterstützende Maßnahmen können eingesetzt werden (z. B. Kurzhalten der Fingernägel, Bestreichen des Anus mit einer die Eier fixierenden Salbe, tägliches Waschen von Unterwäsche und Bettwäsche.

Impfstoffe gegen Oxyuriasis sind derzeit nicht verfügbar und nicht in Entwicklung.

\section{Ausbruchsmanagement}

Trotz des direkten Übertragungswegs kommt es nicht zu Ausbruchsgeschehen, allenfalls zu einem gehäuften Auftreten, gegen das die o. g. Präventionsmaßnahmen ausreichend sind.

\section{Meldepflicht}

Nach dem Infektionsschutzgesetz (IfSG) vom 1.1.2001 ist bei einer Oxyuriasis weder die Erkrankung noch der Erregernachweis meldepflichtig.

\section{Weiterführende Informationen}

\section{Referenzzentren / Expertenlaboratorien}

- Offizielle Referenzzentren existieren nicht, als fachlich qualifiziert anzusehen sind sämtliche parasitologischen und tropenmedizinischen Institutionen.

\section{Web-Adressen}

- CDC-Center for Disease Control and Prevention: http:// www.cdc.gov/ncidod/dpd/parasites/pinworm/default. htm

\section{Schlüsselliteratur}

1. Beaver PC, Jung RC, Cupp EW (1984) Clinical Parasitology. 9th edn. Lea \& Febiger, Philadelphia

2. Burkhardt F (Begr), Neumeister B, Geiss K, Braun R, Kimmig P (Hrsg) (2009) Mikroskopische Diagnostik: Bakteriologie, Mykologie, Virologie, Parasitologie. Georg Thieme Verlag, Stuttgart

3. Despommier DD, Gwadz RW, Hotez PJ, Knirsch CA (2005) Parasitic diseases. 5th edn. Springer Verlag, New York

4. Janitschke K, Kimmig P, Seitz HM, Frosch M, Groß U, Hlobil H, Reiter-Owona I (1998) MIQ, Qualitätsstandards in der mikrobiologisch-infektiologischen Diagnostik. 4, Parasitosen. Gustav Fischer, Stuttgart

5. Löscher T , Burchard G D (Hrsg) (2010): Tropenmedizin in Klinik und Praxis,4. Aufl. Georg Thieme Verlag, Stuttgart

6. Mehlhorn H, Eichenlaub D, Löscher T, Peters W (1995) Diagnostik und Therapie der Parasitosen des Menschen. 2. Aufl. Gustav Fischer Verlag, Stuttgart

\section{Enterocytozoon bieneusi}

- Microsporidien

\section{Enterokokken}

Matthias Maiwald

\section{Erreger}

\section{Synonym(e)}

Streptococcus spp. (alte Gattungsbezeichnung), Fäkalstreptokokken (Trivialname).

\section{Erregerspezies}

Enterococcus faecalis, Enterococcus faecium, Enterococcus durans, Enterococcus avium, Enterococcus casseliflavus, Enterococcus gallinarum, Enterococcus mundtii und weitere Spezies

\section{Taxonomie}

Phylum: Firmicutes (grampositive Bakterien mit niedrigem GC-Gehalt); Klasse: Bacilli; Ordnung: Lactoba- 
cillales, Familie Enterococcaceae; Gattungen: Bavariicoccus, Catellicoccus, Enterococcus, Melissococcus, Pilibacter, Tetragenococcus, Vagococcus

\section{Historie}

Der Name Streptococcus geht auf Billroth (1874) zurück, der kettenförmig aneinandergereihte Kugelbakterien in Eiter fand. Streptococcus pyogenes wurde als erste Art der Gattung von Rosenbach (1884) beschrieben. Als erste Spezies der heutigen Enterokokken wurde "Streptococcus faecalis" von Andrewes und Horder (1906) beschrieben. Aufgrund chemotaxonomischer Unterschiede zu den übrigen Streptokokken wurde 1984 von Schleifer und Kilpper-Bälz der Gattungsname Enterococcus für $E$. faecalis und E. faecium vorgeschlagen und von Collins et al. (1984) wurden weitere Spezies in die neugeschaffene Gattung überführt.

\section{Morphologie}

Grampositive Kokken, angeordnet in Ketten, jedoch mit Tendenz zu kürzeren Ketten als bei Streptokokken. Einzelne Kokken erscheinen eher oval als kugelförmig.

\section{Genom}

Mehrere Genomsequenzen existieren für E. faecalis, E. faecium, E. casselliflavus und E. gallinarum. Die Genomgrößen betragen zwischen ca. 2,7 Mbp (E. faecium, E. faecalis) und 3,4 Mbp (E. casselliflavus) mit etwas Größenvariabilität zwischen verschiedenen Spezies und Stämmen einer Spezies (Stand 2010; http:// www.ncbi.nlm.nih.gov).

\section{Vermehrung}

Enterokokken sind schnell wachsende Bakterien. Wachstum in Kultur erfolgt meist über Nacht.

\section{Pathogenität / Virulenz / Antigenvariabilität}

Entsprechend ihrer Zugehörigkeit zur normalen Flora sind Enterokokken opportunistische Erreger mit relativ niedriger Virulenz. Dennoch sind Enterokokken wichtige Erreger von Krankenhausinfektionen sowie Infektionen bei Patienten mit schwerwiegenden Grundleiden. Mehrere Eigenschaften von Enterokokken wirken begünstigend für Infektionen, dazu gehören ein Zytolysin (Hämolysin), verschiedene Proteasen, eine Aggregationssubstanz und mehrere Adhäsine. Es spielt jedoch kein einzelner dieser Pathogenitätsfaktoren eine herausragende Rolle bei Enterokokken-Infektionen. Antigenvariabilität zwischen einzelnen Spezies oder Stämmen besitzt keine praktische Bedeutung. Das Gruppenantigen D, welches nach Lancefield (1933) auch Verwendung zur Einteilung von Streptokokken findet, ist bei den meisten Enterokokken vorhanden.

\section{Erkrankung \\ Enterokokken-Infektion \\ Synonym(e) \\ Enterococcus-Infektion.}

\section{Inkubationszeit}

$\mathrm{Zu}$ den Inkubationszeiten der verschiedenen Enterokokken-Infektionen gibt es keine dezidierten Daten; nach Eindringen in sterile oder prädisponierte anatomische Kompartimente ist aber von kurzen Inkubationszeiten von wenigen Tagen auszugehen.

\section{Leitsymptome}

Harnwegsinfektionen, Endokarditiden, Weichteilinfektionen, intraabdominelle Infektionen, postoperative Wundinfektionen, Gefäßkatheter-Infektionen, Abszesse, Dekubitalulzera sowie verschiedene andere Infektionen.

\section{Symptome}

Enterokokken verursachen kein einzelnes, umschriebenes Krankheitsbild, sondern eine Reihe verschiedener Infektionen in mehreren Organsystemen. Enterokokken gehören nach den Enterobacteriaceae zu den wichtigsten Erregern von Harnwegsinfektionen; Risikogruppe sind hospitalisierte Patienten oder solche mit Abnormalitäten der ableitenden Harnwege. Bei Frauen sind rekurrierende Harnwegsinfektionen häufig assoziiert mit vulvovaginaler Kolonisation durch Enterokokken. Komplizierte oder chronische Harnwegsinfektionen sowie Nierenabszesse oder Nierenstein-Infektionen sind eher selten. Enterokokken gehören zu den wichtigsten Erregern von Endokarditiden, dabei können sowohl vorgeschädigte als auch nicht veränderte Herzklappen und ebenso Herzklappenprothesen betroffen sein. Der Verlauf dieser Endokarditiden ist in der Regel nicht so stürmisch wie der einer Staphylococcus-aureus-Endokarditis, aber auch nicht so langwierig wie der einer Endocarditis lenta durch vergrünende oder nicht-hämolysierende Streptokokken. Enterokokken-Endokarditiden kommen bevorzugt bei älteren Personen vor, ebenso bei Drogenabhängigen. Ausgangspunkte sind beispielsweise Harnwegsinfektionen, Weichteilinfektionen, intraabdominelle Infektionen oder infizierte Venenkatheter. Obwohl Enterokokken nicht zu den häufigen Sepsiserregern gehören, werden Bakteriämien und gelegentlich auch Sepsen bei hospitalisierten und/oder abwehrgeschwächten Patienten oder Neugeborenen beobachtet. Ebenfalls bei Neu- und Frühgeborenen kommen Meningitiden mit Enterokokken vor, nach der Neugeborenenperiode sind diese eine Rarität. Bei anderen Infektlokalisationen werden Enterokokken immer wieder als Bestandteil von Mischinfektionen gefunden. Dazu gehören Wundinfektionen und Abszesse, Dekubitalulzera, sowie intraabdominelle Infektionen und Infektionen der weiblichen Beckenorgane. 
Durch Enterokokken verursachte Pneumonien sind eine Rarität.

\section{Pathophysiologie}

Enterokokken-Infektionen entstammen zumeist der körpereigenen Flora oder werden als Kontakt- oder Schmierinfektionen übertragen. Häufige Voraussetzungen sind schwere Grunderkrankungen, Immobilität und/oder die Verletzung anatomischer Körperbarrieren, z. B. durch Urin- oder Venenkatheter. Dies führt zur Keimaszension entlang Schleimhäuten (z. B. Urethra) oder zum Eindringen in sterile Körperhöhlen.

\section{Immunantwort}

Bei der Abwehr von Enterokokken-Infektionen spielt die Phagozytose durch neutrophile Leukozyten eine wichtige Rolle, daneben das Vorhandensein von Antikörpern und Komplement. Antikörper vermitteln jedoch keine dauerhafte Immunität und besitzen keine serodiagnostische Relevanz.

\section{Differenzialdiagnose}

Bei Harnwegsinfektionen spielen vor allem gramnegative Bakterien der Familie Enterobacteriaceae eine Rolle, aber auch Staphylococcus saprophyticus. Bei Endokarditiden kommen vor allem Staphylokokken und Streptokokken in Frage, aber auch viele andere grampositive und gramnegative Erreger; dies ebenso bei Sepsis. Bei Abdominal- und Beckenorgan-Infektionen vor allem Mischinfektionen unter Beteiligung von Anaerobiern.

\section{Diagnostik}

\section{Untersuchungsmaterial}

Prinzipiell sind alle Materialien geeignet, die normalerweise zur kulturellen Erregerdiagnostik eingesetzt werden, inklusive Abstriche, (unfixierte) Gewebeproben und Blutkulturen. An manchen Institutionen (insbesondere in englischsprachigen Ländern) wird ein Screening auf das Trägertum von Vancomycin-resistenten Enterokokken (VRE) durchgeführt; dazu eignen sich z. B. Analabstriche oder Stuhlproben. Abgesehen vom VRE-Screening hat die Diagnostik aus Stuhlproben, Mund-/Rachenabstrichen oder Hautabstrichen keine Bedeutung.

\section{Diagnostische Verfahren}

Die Kultur von Enterokokken gelingt zuverlässig in den meisten flüssigen sowie festen Nährmedien. Für Routinezwecke können Thioglykolatbouillon und Schafblutagar verwendet werden. Enterokokken wachsen unter aeroben und anaeroben Bedingungen, Katalasereaktion und Oxidasereaktion sind negativ. Zur Isolierung aus kontaminierten Materialien können Selektivmedien verwendet werden, z. B. Azid-GlukoseBouillon oder Kanamycin-Äskulin-Agar. Wachstum (1 Tag, $37^{\circ} \mathrm{C}$ ) erfolgt in Kolonien, die auf Schafblut- agar nicht-hämolysierend (gamma-Typ) oder alphahämolysierend sind. E. faecalis bildet typischerweise etwa $1,5 \mathrm{~mm}$ große, gewölbte, nicht hämolysierende, grauweißliche Kolonien. E. faecium, E. durans und E. avium sind alpha-hämolysierend, wenn auch meist nicht so ausgeprägt wie orale vergrünende Streptokokken. E. mundtii und E. casselliflavus bilden gelbliches Pigment. E. gallinarum und E. casselliflavus sind beweglich, alle anderen Enterokokken-Spezies sind unbeweglich. Fast alle Enterokokken besitzen das Gruppenantigen D nach Lancefield. Dies ist jedoch kein definitives Merkmal, da echte Streptokokken (z. B. Streptococcus bovis und Streptococcus suis) dieses Antigen auch besitzen können. Die Abgrenzung gegenüber Streptokokken gelingt durch weitere Tests. Dazu gehört die Pyrrolidonyl-Aminopeptidase(PYR-)Reaktion, die bei fast allen Enterokokken positiv ist, sowie die so genannten Sherman-Kriterien (Äskulin-Spaltung, Wachstum bei pH 9,6 und in 6,5\% $\mathrm{NaCl}$ ) und das Wachstum in Gegenwart von $40 \%$ Galle und bei $10^{\circ} \mathrm{C}$. Die Unterscheidung verschiedener Enterokokken-Spezies gelingt durch weitere Tests. Für die Isolierung Vancomycin-resistenter Enterokokken können Selektivmedien verwendet werden, z. B. Äskulin-Galle-Azid-(Enterococcosel-)Bouillon oder Agar mit Zusatz von Vancomycin. Serologische Verfahren besitzen keine Bedeutung für die Diagnostik von Enterokokken-Infektionen. Molekulare Diagnostik (PCR) kann zum VRE-Screening mittels Nachweis von Vancomycin-Resistenzgenen (z. B. vanA, vanB Gene) eingesetzt werden.

\section{Befund / Interpretation}

Der Nachweis von Enterokokken aus Gewebe oder sterilen Körperflüssigkeiten ist beweisend für eine Infektion. Nicht so die Isolierung von Haut, Schleimhäuten und aus Stuhl; hier gehören Enterokokken zur normalen Flora oder transienten Besiedlung. Der Nachweis Vancomycin-resistenter Enterokokken (VRE) ist in der Regel eine Indikation zur KontaktIsolierung in Einzelzimmern.

\section{Therapie}

\section{Therapeutische Maßnahmen}

Enterokokken-Infektionen können zumeist mit Aminopenicillinen (z. B. Ampicillin, Amoxicillin), Acylaminopenicillinen (z. B. Mezlocillin, Azlocillin, Piperacillin), Carbapenemen (z. B. Imipenem), Glykopeptiden (z. B. Vancomycin, Teicoplanin), Chinolonen (z. B. Moxifloxacin), Linezolid oder Tigecyclin behandelt werden. Auch Penicillin G ist geeignet, aber aufgrund höherer minimaler Hemmkonzentrationen (als bei Aminopenicillinen) sind hohe Dosen erforderlich. Eine Resistenztestung ist auf jeden Fall anzustreben, da Empfindlichkeiten variabel sind. Therapie der Wahl für schwere Enterokokken-Infektionen (z. B. Endokarditis) ist eine Kombination von Amoxicillin oder Ampicillin mit einem Aminoglykosid (z. B. Gentamicin), 
da trotz intrinsischer low-level Aminoglykosid-Resistenz der Enterokokken diese Kombination synergistisch wirkt.

\section{Resistenz}

Enterokokken besitzen intrinsische Resistenz gegenüber einigen Antibiotika, die ansonsten bei grampositiven Bakterien wirksam sind. Nicht geeignet zur Therapie sind Cephalosporine, Makrolide, Linco-/Clindamycin und Trimethoprim-Sulfamethoxazol (Cotrimoxazol). Eine intrinsische low-level-Resistenz besteht gegenüber Aminoglykosiden, die eine Monotherapie unmöglich macht, aber dennoch einen Synergismus bei Kombination mit Penicillinen oder Carbapenemen ermöglicht. Bei Stämmen mit high-level Aminoglykosid-Resistenz ist kein Synergismus vorhanden; deshalb sollte bei schweren Infektionen eine Testung auf high-level Resistenz vorgenommen werden. Resistenzen gegenüber Penicillinen, Carbapenemen und Glykopeptiden sind in Zunahme begriffen, diese sind bei $E$. faecium wesentlich häufiger als bei $E$. faecalis . Glykopeptid-Resistenz (Vancomycin-Resistenz) lässt sich in mehrere Phänotypen (VanA bis VanG, mit assoziierten Genotypen) einteilen. Der VanA-Phänotyp besitzt high-level Resistenz gegen Vancomycin und Teicoplanin, VanB eine mittlere bis high-level Resistenz gegen Vancomycin, aber nicht Teicoplanin. Sowohl VanA als auch VanB kommen in variabler Häufigkeit bei E. faecalis und E. faecium vor und sind klinisch die wichtigsten Typen, da sie zur nosokomialen Ausbreitung tendieren. Der VanC-Phänotyp ist als Spezies-Merkmal bei E. gallinarum und E. casseliflavus vorhanden und vermittelt eine intrinsische lowlevel Resistenz gegen Vancomycin, aber nicht Teicoplanin.

\section{Epidemiologie}

\section{Verbreitung}

Enterokokken sind weltweit verbreitet. Genaue Zahlen über die Häufigkeit von Enterokokken-Infektionen existieren aber nicht. Aufgrund von Daten aus den USA werden Enterokokken als zweithäufigste Erreger von Krankenhaus-Infektionen eingeschätzt. Der Anteil von Enterokokken an Harnwegsinfektionen wird auf etwa $4 \%$ geschätzt und kann bei hospitalisierten Patienten beträchtlich höher liegen (ca. $15 \%)$. An Endokarditiden sind Enterokokken in ca. 5-15\% beteiligt. E. faecalis ist der häufigste Erreger menschlicher Enterokokken-Infektionen (ca. 80-90 \% der klinischen Enterokokken-Isolate), gefolgt von E. faecium; die anderen Spezies werden seltener gefunden.

\section{Wirtsbereich / Reservoir}

Enterokokken kommen beim Menschen und einer Vielzahl anderer Warmblüter-Spezies vor. Dabei werden für einzelne Enterokokken-Spezies bevorzugte Wirte beobachtet. Bei Menschen sind E. faecalis und E. faecium am häufigsten. E. durans wird bei Menschen und Hühnern gefunden, E. gallinarum bei Hühnern und E. avium entgegen der Namensgebung bei verschiedenen Säugern. Enterokokken können selten auch Infektionen bei Haustieren verursachen.

\section{Risikogruppen}

Risikogruppen für Enterokokken-Infektionen sind vor allem hospitalisierte Patienten mit allgemein geschwächter Abwehrlage, invasiven Behandlungen oder Operationen. Als Risikofaktoren für Infektionen der ableitenden Harnwege gelten Dauerkatheter oder Harnwegsabnormalitäten, das Risiko für Endokarditiden ist bei vorbestehenden Herzklappenschäden, Klappenprothesen sowie intravenösem Drogenkonsum erhöht. Operationen im Bauchraum oder gynäkologische Operationen stellen ein Risiko für abdominale Mischinfektionen mit Enterokokken dar. Dekubitalgeschwüre können Ausgangspunkt für Weichteilinfektionen sein. Früh- und Neugeborene sind, wenn auch seltener als durch andere Erreger, ebenfalls durch Enterokokken-Infektionen bedroht.

\section{Transmission / Vektoren}

Enterokokken sind weit verbreitete Bewohner des Darmtrakts von Warmblütern, kommen in geringeren Keimzahlen auch in der Mundhöhle vor und können bei Frauen den Vulvovaginalbereich kolonisieren. Dementsprechend ist die Mehrzahl der Infektionen endogen durch die körpereigene Flora bedingt. Die Übertragung auf andere Personen findet durch Schmier- oder Kontaktinfektion statt, seltener durch kontaminierte Gegenstände. Dadurch können Enterokokken in Krankenhäusern verbreitet werden; gefürchtet sind insbesondere Vancomycin-resistente oder multiresistente Stämme.

\section{Prävention / Impfstoffe}

Abgesehen von der Kontakt-Isolierung von Patienten, bei denen Vancomycin-resistente Enterokokken nachgewiesen wurden, gibt es keine spezifischen Präventionsmaßnahmen. Allgemeine Maßnahmen zur Prävention endogener Infektionen sind die Vermeidung unnötig langer Liegedauern von Harnwegskathetern oder Venenkathetern, die Beachtung aseptischer Techniken bei Operationen sowie die Vermeidung unnötigen Gebrauchs von Cephalosporinen (Selektion von Enterokokken). Die Prävention von exogenen Infektionen (Schmierinfektionen, Übertragung durch Gegenstände) erfolgt durch die Beachtung allgemeiner hygienischer Maßnahmen (z. B. Händehygiene etc.).

\section{Ausbruchsmanagement}

In Krankenhäusern kann es zu Fallserien mit gehäuftem Auftreten von Enterokokken-Infektionen kommen, die bei mangelhafter Hygiene durch Schmierinfektionen weiterverbreitet werden. Gefürchtet sind in diesem Zusammenhang Vancomycin-resistente Enterokokken. Solche Infektketten können durch Einzel- 
zimmer-Isolierung und strenge Hygienemaßnahmen unterbrochen werden. Infektketten können durch molekulare Typisierung der Enterokokken-Stämme aufgeklärt werden.

\section{Meldepflicht}

Es besteht keine Meldepflicht.

\section{Weiterführende Informationen}

\section{Referenzzentren / Expertenlaboratorien}

- Nationales Referenzzentrum für Streptokokken, Dr. M. van der Linden, Institut für Medizinische Mikrobiologie der RWTH Aachen, Pauwelsstr. 30, 52057 Aachen.

\section{Web-Adressen}

- Nationales Referenzzentrum:http://www.nrz-streptococcus. de

\section{Schlüsselliteratur}

1. Kalka-Moll WM, Reinert RR (2009) Enterokokken. In: Neumeister B, Geiss HK, Braun RW, Kimmig P. Mikrobiologische Diagnostik, 2. Aufl. Georg Thieme-Verlag, Stuttgart, pp 325-330

2. Moellering RC (2005) Enterococcus species, Streptococcus bovis, and Leuconostoc species. In: Mandell GL, Bennett JE, Dolin R (eds) Mandell, Douglas, and Bennett's principles and practice of infectious diseases, 6th edn. Elsevier Churchill Livingstone, Philadelphia, pp 2411-2421

3. Podbielski A, Lütticken R (2001) Die Familie der Streptococcaceae. In: Köhler W, Eggers HJ, Fleischer B, Marre R, Pfister H, Pulverer G. (Hrsg) Medizinische Mikrobiologie, 8. Aufl. Urban \& Fischer, München pp 260-276

4. Teixeira LM, Facklam RR (2005) Enterococcus. In: Borriello SP, Murray PR, Funke G (eds) Topley \& Wilson's microbiology \& microbial infections. Bacteriology, 10th edn. Hodder Arnold, London, pp 882-902

5. Teixeira LM, Carvalho MGS, Facklam RR (2007) Enterococcus. In: Murray PR, Baron EJ, Jorgensen JH, Landry ML, Pfaller MA (eds) Manual of clinical microbiology, 9th edn. American Society for Microbiology, Washington, DC pp 430-442

\section{Enterokolitis, hämorrhagische}

$\checkmark$ Escherichia coli

\section{Enterokolitis, nekrotisierende}

- Clostridien der Gasbrand-Gruppe

\section{Enteromonas hominis}

Darmflagellaten

\section{Enteroviren 68-71 und andere Enteroviren}

\author{
Hans-Peter Grunert, Heinz Zeichhardt
}

\section{Erreger}

\section{Synonym(e)}

Humanes Enterovirus (EV) 68-71 sowie andere humane Enteroviren 73-91, 96, 97, 100, 101 und weitere, deren endgültige Klassifizierung noch aussteht.

\section{Erregerspezies}

Humanes Enterovirus A (EV 71,76, 89, 90 und 91), Humanes Enterovirus B (EV 69,73-75,77-88, 97, 100 und 101), Humanes Enterovirus $C$ (EV 96) und Humanes Enterovirus D (EV 68 und 70)

\section{Taxonomie}

Genus Enterovirus in der Familie der Picornaviridae mit den weiteren Genera: Rhinovirus, Cardiovirus, Aphthovirus, Hepatovirus, Parechovirus, Erbovirus, Kobuvirus und Teschovirus. Mit dem Eighth Report of the International Committee on Taxonomy of Viruses (2005) wurde eine neue Einteilung für Enteroviren und damit für die Humanen Enteroviren 68-71 und andere Enteroviren in die Spezies Humanes Enterovirus $A-D$ vorgenommen (Pallansch and Roos, 2007) ( $\triangleright$ Erregerspezies). Die Grundlage dafür waren vor allem Aminosäure-Identitäten in den Regionen P1 sowie $2 \mathrm{C}$ und $3 \mathrm{CD}$ (jeweils $>70 \%$ ) sowie der Wirtsbereich und die virusspezifischen Wirtszellrezeptoren. Dabei variiert die genomische Basenzusammensetzung $(\mathrm{G}+\mathrm{C})$ nicht mehr als 2,5\%. Humanes Enterovirus 68 und Humanes Rhinovirus 87 werden seit Kurzem als ein einheitlicher Serotyp klassifiziert (HRV 87 wird nicht mehr als Humanes Rhinovirus geführt). Enterovirus 72 wurde als Hepatitis-A-Virus (1 Serotyp) reklassifiziert und taxonomisch dem eigenen Genus Hepatovirus zugeordnet. Weiteres $>$ Hepatitis-AVirus.

picorna: von pico = piccolo, klein; rna = RNA, ribonucleic acid.

entero: von griech enteron $=$ Darm, Eingeweide .

\section{Historie}

Historisch wurden die humanen Enteroviren 68-71 mit aufsteigender Nummerierung bezeichnet, sofern die Isolate eigene Serotypen darstellten und unabhängige Eigenschaften von Polio-, Coxsackie- und Echoviren hatten. Enterovirus 68 wurde 1962 aus einem Rachenabstrich eines Kindes in Kalifornien isoliert, das an einem Infekt des oberen Respirationstraktes erkrankt war. Enterovirus 69 wurde erstmals 1959 in Tocula, Mexico, aus dem Rektalabstrich eines gesunden Kindes isoliert. Enterovirus-69-Isolate sind im Allgemeinen nicht mit einer Krankheit assoziiert. Enterovirus 70 wurde 1971 als einer der Erreger von akuter hämorrhagischer Konjunktivitis identifiziert, als 1969-1971 in Südostasien eine Variante von Coxsa- 
ckievirus A24 epidemische Ausbrüche von akuter hämorrhagischer Konjunktivitis verursachte. Enterovirus 70 war zur selben Zeit für eine Pandemie verantwortlich, die neben Südostasien auch Japan, Indien und Afrika betraf. Enterovirus 71 wurde erstmals in Kalifornien 1969-1973 als Erreger von aseptischer Meningitis und Enzephalitis identifiziert. Zusätzlich gefundene neue Enterovirus-Isolate (Enteroviren 7391, 96, 97, 100 und 101) wurden ebenfalls mit aufsteigenden Nummern bezeichnet. Für die neueren Enteroviren mit höheren Nummern steht die endgültige taxonomische Zuordnung noch aus.

Humanpathogene Viren der Genera Aphthovirus und Kobuvirus : Die nachfolgenden Viren werden hier zur Abgrenzung von den humanpathogen Enteroviren kurz aufgeführt.

Maul- und Klauenseuche-(MKS-)Virus: Insgesamt 7 Serotypen des MKS-Virus gehören zum Genus Aphthovirus. MKS-Virus infiziert vornehmlich Klauentiere wie Rinder, Schafe und Ziegen, auch Schweine und gelegentlich Kamele und Elefanten. Das MKS-Virus wird in seltenen Fällen zoonotisch vom infizierten Tier auf den Menschen durch direkten Kontakt oder Kontakt mit virushaltigen Materialien (z. B. bei Stallpersonal, Melkern, Veterinären und Laborpersonal) oder möglicherweise durch den Genuss von unpasteurisierter Milch übertragen.

MKS-Virus-Infektionen verlaufen beim Menschen (hauptsächlich MKS-Virustyp O, gefolgt von Typ C und seltener Typ A) im Allgemeinen klinisch inapparent (selbst limitierend). Eine Übertragung von Mensch zu Mensch ist nicht beschrieben. Im Jahr 2001 wurden in Großbritannien bei einem MKS-Ausbruch bei Tieren 21 Verdachtsfälle beim Menschen gemeldet (ohne positiven PCR-Nachweis). Klinische Manifestationen sind bei Kindern stärker als bei Erwachsenen (Inkubationszeit 2-6 Tage) und verlaufen mit anfänglicher Mattigkeit sowie Hals-, Kopf-, Kreuz- und Gliederschmerzen mit häufig mäßigem Fieber (virushaltige Primärblasen an der Eintrittspforte, z. B. im Mund nach Infektion durch Milch oder an der Hand nach Infektion beim Melken). Bläschen mit einem roten Hof können 1-2 Tage später an Lippen, Wangenschleimhaut, Rachen und Zunge sowie an Fingern und Zehen, an der Innenhand, den Fußsohlen und den Fußrändern Bläschen auftreten.

Aichi-Virus: Aichi-Virus, dem Genus Kobuvirus zugeordnet, wurde 1989 in Japan bei Menschen mit einer nichtbakteriellen Gastroenteritis (nach Austernverzehr) isoliert. Antikörperprävalenzstudien zeigen für Japan eine Durchseuchung mit diesem Virus von ca. $80 \%$ bis zum 35. Lebensjahr (in Frankreich 85 \% Antikörperpositivität in der Altersgruppe der 30- bis 39-Jährigen). Auch für Pakistan und Bangladesh sowie für Südostasien (Indonesien, Thailand, Vietnam und Malaysia) wurden Aichi-Virus-Infektionen im $\mathrm{Zu}$ sammenhang mit Gastroenteritis beschrieben. Die Diagnostik erfolgt durch Erregernachweis mittels RT-
Tab. 1. Klinische Syndrome der Infektionen mit Enterovirus 69-71 und anderen Enteroviren (nach Pallansch and Roos, 2007)

\begin{tabular}{|l|l|}
\hline Klinische Syndrome & $\begin{array}{l}\text { Enterovirus 68-71 und } \\
\text { andere Enteroviren- } \\
\text { Typen }\end{array}$ \\
\hline $\begin{array}{l}\text { Bronchiolitis und Pneu- } \\
\text { monie }\end{array}$ & 68 \\
\hline $\begin{array}{l}\text { Akute hämorrhagische } \\
\text { Konjunktivitis }\end{array}$ & 70 \\
\hline $\begin{array}{l}\text { Aseptische Meningitis } \\
\text { Akute schlaffe Läh- } \\
\text { mung }\end{array}$ & $\begin{array}{l}71 \\
97,100\end{array}$ \\
\hline $\begin{array}{l}\text { Meningoenzephalitis } \\
\text { Hand-, Fuß- und Mund- } \\
\text { krankheit }\end{array}$ & 70,71 \\
\hline
\end{tabular}

PCR mit anschließender Sequenzierung. Zur Virusanzüchtung eignen sich BS-C-1 oder Vero-Zellen. Experimentelle Enzymimmunassays und Mikroneutralisationsteste werden zum Nachweis Aichi-Virus-spezifischer Antikörper eingesetzt.

\section{Morphologie}

Die Enteroviren 68-71 sind wie alle anderen Enteroviren (Polio-, Coxsackie- und Echoviren) kleine, sphärische und unbehüllte RNA-Viren (Durchmesser $30 \mathrm{~nm}$, 156S, 1,34 g/ml Dichte in CsCl). Das Viruskapsid mit seinen vier nichtglykosylierten Viruskapsidproteinen VP1-VP4 umgibt ein Molekül der genomischen PlusStrang-RNA (einzelsträngig), die auch als mRNA dient. In Struktur, Genomorganisation und physikochemischen Eigenschaften gleichen die Enteroviren 68-71 den anderen Enteroviren $>$ Polioviren.

\section{Genom}

Die Genomorganisation der einzelsträngigen PlusStrang-RNA von Enteroviren 68-71 gleicht im Wesentlichen der von anderen Enteroviren und Rhinoviren ( $\triangleright$ Polioviren). Abweichungen können für die Länge der genomischen RNA (z. B. 7.390 Nukleotide für Enterovirus 70) und die Molekulargewichte der einzelnen Virusproteine auftreten. Für Nukleinsäuresequenzen von einzelnen Enteroviren siehe GenBank (National Institute of Health: http://www.ncbi.nlm. nih.gov/sites/entrez? $\mathrm{db}=$ nucleotide), Picornavirus Study Group (http://www.picornastudygroup.com/) sowie Pallansch und Roos (2007).

\section{Vermehrung}

Die Humanen Enteroviren 68-71 und anderen En- 
teroviren vermehren sich in allen Organen, in denen eine Infektion mit diesen Viren Krankheitszeichen bedingt ( $\triangleright$ Erkrankungen/Symptome).

\section{Pathogenität / Virulenz / Antigenvariabilität}

Der Pathogenitätsmechanismus der Enteroviren 6871 und anderer Enteroviren ist bislang wenig untersucht. Wegen der ähnlichen strukturellen und biologischen Eigenschaften ist davon auszugehen, dass diese Enteroviren eine gleiche Vermehrungsstrategie wie Polio-, Coxsackie- und Echoviren haben. Weiteres $>$ Polioviren.

\section{Erkrankung}

\section{Inkubationszeit}

Die mittleren Inkubationszeiten betragen 7-14 Tage (2-35 Tage). Im Gegensatz zu allen anderen Enteroviren haben Infektionen mit Enterovirus 70 eine sehr kurze Inkubationszeit (mittlere Inkubationszeit 24 Stunden; 12-72 Stunden).

\section{Leitsymptome}

- Tab. 1 .

\section{Symptome}

Die Enteroviren 68-71 verursachen wie alle anderen Enteroviren überwiegend asymptomatische Infektionen unter Ausbildung von neutralisierenden Antikörpern (stille Feiung). Enterovirus 69 konnten bislang keine eindeutigen Symptome zugeordnet werden. Nach der Vermehrung im Intestinaltrakt können Enterovirus 68 und 71 durch die abführenden Lymphbahnen in den Blutkreislauf gelangen und zu einer zyklischen Infektion mit Virämie sowie Ausbreitung auf die Zielorgane führen. Enterovirus 70 führt hauptsächlich zu lokalen Infektionen des Auges. Die Krankheitszeichen, die durch Infektionen mit Enterovirus 68, 70 und 71 hervorgerufen werden können, sind in - Tab. 1 zusammengefasst. Die Organmanifestationen der Enteroviren 68-71 gleichen denen der anderen Enteroviren. Weiteres $>$ Polioviren, $>$ Coxsackieviren sowie $>$ Echoviren und Parechoviren.

Respirationstraktinfekte. Vor allem bei Kindern sind Enterovirus 68 mit Pneumonie und Bronchiolitis und Enterovirus 71 mit einer influenzaähnlichen Krankheit assoziiert.

Akute hämorrhagische Konjunktivitis. Diese Form der epidemischen Konjunktivitis durch Enterovirus 70 trat erstmals 1969-1971 in Afrika, Südostasien (inkl. Singapur), Japan und Indien mit mehreren Millionen Erkrankten auf. Nach sporadischen Ausbrüchen in Französisch Polynesien (1982) wurde das Virus in die USA eingeschleppt. Zeitgleich kam es in Singapur und Hongkong zu Ausbrüchen von akuter hämorrhagischer Konjunktivitis, die durch ein anderes Enterovirus, eine Variante von Coxsackievirus A24, hervorgerufen wurde ( $\triangleright$ Coxsackieviren). Typischerweise bleibt die Enterovirus-70-Infektion auf die Augen be- schränkt, jedoch können auch ZNS-Manifestationen auftreten (teilweise poliomyelitisähnliche Paralyse). Im Gegensatz zu allen anderen Enteroviren haben Infektionen mit Enterovirus 70 eine sehr kurze Inkubationszeit ( Inkubationszeit). Die Konjunktivalflüssigkeit ist hochinfektiös.

Aseptische Meningitis, Meningoenzephalitis und akute schlaffe Lähmung. Enterovirus-71-Infektionen können gemeinsam mit Hand-, Fuß- und Mundkrankheit eine aseptische Meningitis oder Meningoenzephalitis verursachen. Bei epidemischen Ausbrüchen kann gehäuft eine poliomyelitisähnliche Paralyse auftreten. Eine ZNS-Manifestation mit poliomyelitisähnlichem Bild wird vereinzelt auch bei der durch Enterovirus 70 verursachten akuten hämorrhagischen Konjunktivitis beobachtet. Das Bild einer akuten schlaffen Lähmung wurde beobachtet bei Infektionen mit den Enteroviren 70, 71, 85-91, 96, 97 und 100 .

Hand-, Fuß- und Mundkrankheit. Ausbrüche mit Enterovirus 71 wurden erstmals 1969-1973 beobachtet. Hauptkrankheitszeichen ist das Auftreten von virushaltigen Vesikeln an Händen und Füßen. Weiterhin tritt ein Enanthem auf den Mundschleimhäuten (teilweise ulzerierend) auf.

\section{Pathophysiologie}

$\checkmark$ Vermehrung und $\triangleright$ Pathogenität.

\section{Immunantwort}

Wie bei den anderen Enteroviren determiniert die Viruskapsidoberfläche die Antigenität ( $\triangleright$ Polioviren). Die Enteroviren 68-71 und anderen Enteroviren induzieren jeweils typspezifische neutralisierende Antikörper und stellen sich dadurch als eigene Serotypen dar. Für Enterovirus 70 ließ sich zeigen, dass Virusisolate von einem Ausbruch im Jahr 1980 antigene Veränderungen im Vergleich zum Prototypvirus aufweisen, das 1971 isoliert wurde. Die für Enteroviren charakteristische humorale Immunantwort mit serotypspezifischem IgG, IgM und IgA sowie die Induktion von sekretorischem IgA ist im Allgemeinen auch für Infektionen mit den Enteroviren 68-71 charakteristisch. Die Immunität gegen Enterovirus 70 ist offensichtlich nur von kurzer Dauer, da in definierten Regionen Asiens ca. alle fünf Jahre wiederholte Ausbrüche von akuter hämorrhagischer Konjunktivitis zu beobachten sind. Wegen des Vorhandenseins diaplazentar übertragbarer Antikörper der IgG-Klasse sind Säuglinge seropositiver Mütter in den ersten Lebensmonaten gegen eine Infektion mit dem entsprechenden Enterovirustyp geschützt. Über die Immunitätslage nach Infektionen mit den anderen Enteroviren (EV 73-91, 96, 97, 100 und 101) liegen bislang keine eindeutigen Ergebnisse vor. Generell gilt für alle humanen Picornaviren, dass die zellvermittelte Immunität bislang erst unvollständig untersucht ist.

\section{Differenzialdiagnose}

Neben Enterovirus 71 können auch Coxsackieviren 
der Gruppe A eine Hand-, Fuß- und Mundkrankheit hervorrufen. Für eine akute hämorrhagische Konjunktivitis kann außer Enterovirus 70 auch Coxsackievirus A24 verantwortlich sein. Respirationstraktinfekte durch Enterovirus 68 und 71 treten im Gegensatz zu Infekten mit Rhinoviren, Parainfluenzaviren, Respiratory Syncytial Virus, Influenzaviren und Adenoviren vornehmlich in der warmen Jahreszeit auf. Zur Differenzialdiagnostik der durch andere Enteroviren bedingten ZNS-Erkrankungen Polioviren, $>$ Coxsackieviren sowie $>$ Echoviren und Parechoviren. Zur Differenzierung von Meningitis bzw. Paralyse, für die andere Viren verantwortlich sein können, sind Mumpsvirus, Herpes-simplex-Viren und (seltener) andere Viren der Herpesvirusfamilie, FrühsommerMeningoenzephalitis-Virus sowie das LymphozytäreChoriomeningitis-Virus in Betracht zu ziehen.

\section{Diagnostik}

\section{Untersuchungsmaterial}

Zum Virusnachweis eignen sich am besten Stuhl und Rachenabstrich bzw. -spülwasser und in Abhängigkeit von der Organmanifestation auch Liquor, Bläscheninhalt und Konjunktivalabstrich.

\section{Diagnostische Verfahren}

Virusnachweis. Der Virusnachweis steht im Vordergrund. Als Screeningtest ist die RT-PCR geeignet (häufig Primer-Zielsequenzen in der 5'-NTR). 5 '-NTRPrimer erlauben wegen der hohen Sequenzhomologie in diesem Bereich keine Differenzierung zwischen verschiedenen Serotypen. Zur molekularen Typisierung durch Sequenzierung von PCR-Amplifikaten ist die Analyse der genomischen Bereiche für die Viruskapsidproteine (z. B. VP1) notwendig. Zur Identifizierung und Charakterisierung neuer Virusisolate kann eine randomisierte Amplifikation mittels Partikel-assoziierter Nukleinsäure-PCR (PAN-PCR) und anschließender Sequenzierung eingesetzt werden.

Zur Virusanzucht werden verschiedene Zelllinien vom Menschen und Affen verwendet (z. B. humane fötale diploide Lungen- und Nierenzellen, HeLa-Zellen, Rhabdomyosarkomzellen und primäre Affennierenzellen). Die Virustypisierung erfolgt im Allgemeinen im Neutralisationstest (NT) mit serotypspezifischen Antiseren. Erleichtert wird die Typisierung von Enterovirus 71, wenn das Virus filtriert bzw. mit Chloroform oder Natrium-Deoxycholat vorbehandelt wird. Eingeschränkt ist der Nachweis von Enterovirus 70, da es nur sehr kurz im Prodromalstadium im Stuhl zu isolieren ist.

Der direkte Virusnachweis aus dem Stuhl durch Elektronenmikroskopie (Negativ-Kontrastierung) ist möglich, jedoch wegen der geringen Virusgröße problematisch. Diese Methode wird deshalb nur von wenigen Speziallaboratorien - häufig kombiniert mit der Immun-Elektronenmikroskopie - durchgeführt $(\triangleright \mathrm{Po}-$ lioviren).
Antikörpernachweis. Zum Nachweis von typspezifischen Antikörpern wird im Allgemeinen der Neutralisationstest (NT) verwendet. Der Enzymimmunoassay (EIA) ist wegen der Kreuzreaktion zwischen den verschiedenen Enteroviren nur bedingt einsetzbar.

\section{Befund / Interpretation}

$\mathrm{Da}$ davon auszugehen ist, dass Infektionen mit den Enteroviren 68-71 und anderen Enteroviren (EV 7391, 96, 97, 100 und 101) in der Mehrzahl der Fälle klinisch inapparent oder als uncharakteristische fieberhafte Erkrankungen verlaufen, sollte die Diagnostik in engem ätiologischen Zusammenhang des Virusnachweises mit einem definierten Krankheitsbild erfolgen. Beweisend für eine Infektion mit den o. g. Enteroviren ist z. B. bei ZNS-Manifestation der Virus-RNA-Nachweis bzw. Virusanzucht aus dem Liquor. Der Virusnachweis im Stuhl ist dabei sehr nützlich. Der signifikante Titeranstieg neutralisierender Antikörper $\geq 4 \mathrm{fa}$ cher Titeranstieg; 10-14 Tage Abstand zwischen beiden Blutabnahmen) ist weiterhin beweisend für eine frische Infektion mit den o. g. Enteroviren.

\section{Therapie}

\section{Therapeutische Maßnahmen}

Eine In-vivo-Therapie mit antiviralen Substanzen ist nur begrenzt möglich. Ob die neue antivirale Substanz Pleconaril (in Deutschland nicht zugelassen) auch gegen Infektionen mit den Enteroviren 68-71 und anderen Enteroviren eingesetzt werden kann, ist bislang nicht belegt. Die Substanz Pleconaril zeigte in randomisierten, doppelblind und plazebokontrollierten Phase-3-Studien für Enterovirus-bedingte Meningitis eine Reduzierung der mittleren Infektionsdauer.

\section{Epidemiologie}

\section{Verbreitung}

Infektionen mit den Enteroviren 68-71 kommen weltweit vor. Gehäufte Infektionen treten bei mangelhaften hygienischen Bedingungen in Populationen mit hoher Bevölkerungsdichte und niedrigem sozioökonomischem Status auf. Infektionen mit Enterovirus 70, die bevorzugt in warmen und feuchten Küstenregionen auftreten, breiteten sich von 1969-1971 in Asien und Afrika explosionsartig aus, wobei das klinische Bild dieser akuten hämorrhagischen Konjunktivitis erstmals in Ghana beobachtet wurde. Nach erneuten Ausbrüchen 1981-1982 wurde Enterovirus 70 in den karibischen Raum, in die USA und nach Mittel- und Südamerika eingeschleppt. Ausbrüche mit Enterovirus 71 sind seit 1969 wiederholt auf jedem Kontinent mit unterschiedlichen Krankheitsbildern aufgetreten. 1973 führte dieses Virus in Japan zu mehr als 3.200 Fällen von Hand-, Fuß- und Mundkrankheit und (teilweise) aseptischer Meningitis. 1973 war Enterovirus 71 in Bulgarien und 1975 in Ungarn für jeweils Hunderte Fälle von aseptischer Meningitis und Me- 
ningoenzephalitis, vereinzelt mit poliomyelitisähnlichem Bild, verantwortlich. Infektionen mit Enterovirus 71 führten 1998 in Taiwan zu einer schweren Epidemie von Hand-, Fuß- und Mundkrankheit (geschätzt werden zwischen 60.000 und 300.000 Krankheitsfälle), in deren Verlauf 271 Fälle von aseptischer Meningitis und Enzephalitis sowie 55 Todesfälle verzeichnet wurden. Von den schweren Verläufen und Todesfällen waren zu ca. 90 \% Kinder unter 6 Jahren betroffen. Mehrere der anderen Enteroviren (EV 76, 89, 90, 91) wurden zwischen 1999 und 2002 in Bangladesh bei Patienten mit akuter schlaffer Lähmung isoliert. Im Jahr 2008 verursachten Enterovirus-71-Infektionen in China eine Epidemie von Hand-, Fuß- und Mundkrankheit mit 488.955 registrierten Krankheitsfällen und 126 Todesfällen.

\section{Wirtsbereich / Reservoir}

Reservoir für die Humanen Enteroviren 68-71 und andere Enteroviren (EV 73-91, 96, 97, 100 und 101) ist der Mensch. Neugeborene Mäuse sind mit Enterovirus 71 infizierbar. Enterovirus-70-Infektionen können im Affen ZNS-Läsionen hervorrufen. In vitro lassen sich die Enteroviren 68-71 auf diversen Zelllinien vom Mensch und Affen propagieren. Die in Bangladesh isolierten anderen Enteroviren (EV 76, 89, 90, 91) können in humanen Rhabdomyosarkom-Zellen vermehrt werden.

\section{Risikogruppen}

Infektionen mit den Enteroviren 68-71 treten ebenso wie bei den anderen Enteroviren vornehmlich bei Kindern auf. Im Allgemeinen sind Neugeborene durch diaplazentar übertragene Antikörper gegen Infektionen mit diesen Viren geschützt. Eine Einschränkung besteht dabei für Enterovirus 70, das nach der hämorrhagischen Konjunktivitis nur einen vorübergehenden Immunschutz bewirkt. Patienten in Augenkliniken haben während einer Epidemie mit Enterovirus 70 ein erhöhtes Risiko für eine nosokomiale Infektion, wenn das Virus bei Vernachlässigung von Hygiene und Desinfektionsmaßnahmen durch kontaminierte Finger und Utensilien (Tonometer, Handtücher) übertragen wird. Wie bei den anderen Non-Polio-Enteroviren (Coxsackie- und Echoviren) ist auch für diese Enteroviren davon auszugehen, dass die Krankheitsverläufe bei Immunsupprimierten verstärkt sind.

\section{Transmission / Vektoren}

Die Übertragung der Enteroviren 68-71 und anderen Enteroviren erfolgt hauptsächlich fäkal-oral und respiratorisch. In Abhängigkeit der Organmanifestation kann auch eine Übertragung durch direkten oder indirekten Kontakt vorkommen (z. B. über Bläscheninhalt und Konjunktivalflüssigkeit). Bei Ausbrüchen mit akuter hämorrhagischer Konjunktivitis durch Enterovirus 70 sind Übertragungen über kontaminierte Finger und Utensilien bei normalen Haushaltskontakten (z. B. Handtücher und Spielzeug) ebenso wie in $\mathrm{Au}-$ genkliniken häufig.

\section{Prävention / Impfstoffe}

Aktive und passive Vakzinationen gegen die Enteroviren 68-71 und anderen Enteroviren stehen nicht zur Verfügung. Allein hygienische Maßnahmen sind wirksam zur Prävention.

\section{Ausbruchsmanagement}

Zur Verhinderung der nosokomialen Übertragung der akuten hämorrhagischen Konjunktivitis durch Enterovirus 70 (vor allem in Augenkliniken) ist der Gebrauch von Handschuhen, Papierhandtüchern und -taschentüchern und die Einhaltung der vorgeschriebenen Desinfektionsmaßnahmen angeraten. Zur Vermeidung von nosokomialen Infektionen ist bei Fällen der akuten schlaffen Lähmung bis zum labordiagnostischen Ausschluss einer durch Poliovirus bedingten Kinderlähmung eine räumliche Abtrennung der Patienten erforderlich. Zur Vermeidung von Schmierinfektionen sind die hygienischen Maßnahmen inklusive hygienische Händedesinfektion und Kittelwechsel dringend notwendig. Das zuständige nationale Referenzzentrum ist in die Diagnostik und Beratung unmittelbar mit einzubeziehen.

\section{Meldepflicht}

Es besteht keine Meldepflicht.

\section{Weiterführende Informationen}

\section{Referenzzentren / Expertenlaboratorien}

- Nationales Referenzzentrum für Poliomyelitis und Enteroviren und Regionales Referenzlabor der WHO/EURO für Poliomyelitis, Dr. Sabine Diedrich, Robert Koch-Institut, Nordufer 20, D-13353 Berlin, Tel.: +49-(0)30-18754 2378, Fax: +49-(0)30-18754 2617,E-Mail: DiedrichS@rki. de; www.rki.de.

\section{Web-Adressen}

- Picornaviridae.com: www.picornaviridae.com

- Picornaviridae study group: www.picornastudygroup.com

- The big picture book of viruses: www.mirrorservice.org/ sites/www.virology.net/Big_Virology/BVHomePage.html

- Genbank, National Institute of Health: www.ncbi.nlm. nih.gov/Genbank/index.html

\section{Schlüsselliteratur}

1. Melnick JL (1996) Enteroviruses: Polioviruses, Coxsackieviruses, Echoviruses, and Newer Enteroviruses. In: Fields $\mathrm{BN}$ et al. (eds) Fields Virology, 5th edn. Lippincott-Raven, Philadelphia, vol 1, pp 655-712

2. Mertens Th, Haller O, Klenk H-D (Hrsg) (2004) Diagnostik und Therapie von Viruskrankheiten - Leitlinien der Gesellschaft für Virologie, 2. Aufl. Urban \& Fischer, S 5764

3. Pallansch M, Roos R (2007) Enteroviruses: Polioviruses, Coxsackieviruses, Echoviruses, and Newer Enteroviruses. In: Knipe DM et al. (eds) Fields Virology, $5^{\text {th }}$ edn. Wolters Kluwer Lippincott Williams \& Wilkins, Philadelphia, vol 1, pp 839-893 
4. Stanway G et al. (2005) Picornaviridae. In: Fauquet CM et al. (eds) Virus Taxonomy, Classification and Nomenclature of Viruses, Eighth Report of the International Committee on Taxonomy of Viruses. Elsevier Academic Press, Amsterdam, pp 757-778

5. Zeichhardt H, Grunert, H-P (2003) Enteroviruses: polioviruses, coxsackieviruses, echoviruses and enteroviruses 68-71. In: Cohen J, Powderly WG,Opal, SM Infectious Diseases, 2nd edn. Elsevier Health Sciences, London, chapter 213, pp 1993-2006

6. Zeichhardt H, Grunert, H-P (2010) Picornaviren - Klinik, Diagnostik und Prävention. In: Doerr HW und Gerlich WH (Herausgeber) Medizinische Virologie, 2. Aufl., Thieme Verlag, Stuttgart New York, Kapitel 42, S 468-489

\section{Enterovirus}

Echoviren und Parechoviren

\section{Enzephalitis}

- Adenoviren

- Alphaviren

- Amöben, frei lebende (Naeglerien, Acanthamöben, Balamuthia, Amöben als Vehikel pathogener Mikroorganismen)

- Arenaviren

- Bioterrorismus, infektiologische Aspekte

- Brucella

- Bunyaviren

B-Virus

- Candida

- Cardioviren

- Coltivirus

$\checkmark$ Coxsackieviren

- Cryptococcus neoformans

- Cytomegalievirus

Echoviren und Parechoviren

- Ehrlichia

- Enteroviren 68-71 und andere Enteroviren

- Flaviviren, seltene humanpathogene

- Frühsommer-Meningoenzephalitis-Virus und Russisches Frühjahrs-Sommer-Enzephalitis-Virus

- Fusarium

- Gelbfiebervirus

$\checkmark$ Hendra-Virus

- Herpes-simplex-Virus (HSV)

- Japanisches Enzephalitis-Virus

- Lassa-Virus

- Legionella

- Leptospiren

$\checkmark$ Listeria monocytogenes

- Loa loa

- Lyssavirus

- Masernvirus

- Meningitis/Enzephalitis

$\rightarrow$ Mumpsvirus
- Mycoplasma pneumoniae

- Nematoden, seltene Arten

- Nipah-Virus

- Parvoviren

- Pockenviren, zoonotische

$\checkmark$ Polioviren

- Polyomaviren

- Reoviren

- Rickettsien

- Rötelnvirus

- Schistosomen

- Toxocara

- Toxoplasma gondii

- Trypanosoma brucei

- Trypanosoma cruzi

- Varicella-zoster-Virus (VZV)

- Variola- und Vaccinia-Virus

- Vesiculovirus

$>$ West-Nil-Virus

\section{Enzephalomyokarditis-Virus}

- Cardioviren

\section{Epidermodysplasia verruciformis}

- Humane Papillomviren (HPV)

\section{Epidermophyton floccosum}

Marianne Kretschmar, Paul Schnitzler

\section{Erreger}

\section{Synonym(e)}

Acrothecium floccosum Harz, 1871; Epidermophyton inguinale (Sabouraud) Sabouraud, 1910; Epidermophyton cruris (Castellani) Castellani \& Chalmers, 1910.

\section{Erregerspezies}

Epidermophyton floccosum (Harz) Langeron et Milochevitch, 1930 (Fadenpilz, anthropophiler Dermatophyt)

\section{Taxonomie}

Abteilung: Ascomycota; Klasse: Euascomycetes; Ordnung: Onygenales; Familie: Arthrodermataceae; Spezies: Anamorph: Epidermophyton floccosum

Teleomorph: Unbekannt

\section{Historie}

Erstbeschreibung als Trichophyton floccosum durch Harz 1870.

\section{Morphologie}

Makroskopisch: E. floccosum ist ein raschwüchsiger 
Dermatophyt, der aufgrund typischer Merkmale frühzeitig erkannt werden kann.

Kolonie: Oberseite gelb, olivgrün bis bräunlich, samtig oder zart gipsig mit radiärer Faltenbildung. Kolonierand ausgefranst. Sehr früh bilden sich weiße watteähnliche pleomorphe Myzelien auf der Kolonieoberseite (danach Bezeichnung „floccosum“); Unterseite gelb bis gelbbraun.

Mikromorphologie der Kulturform: Wichtigstes Merkmal sind die zahlreichen dünn- und glattwandigen, keulenförmigen Makrokonidien mit 2-4, selten bis zu 9 Kammern und breiter Basis. Mikrokonidien werden nicht gebildet. Reichlich terminale und interkalare Chlamydosporen in älteren Kulturen. Spiralhyphen selten.

\section{Genom}

Das mitochondriale Genom von E. floccosum wurde von Tambor JH (2006) sequenziert.

\section{Vermehrung}

Vermehrung des Pilzes erfolgt durch Ausbildung asexueller Makrokonidien, die sich vom Myzel abgetrennt in der Kultur zu neuen Kolonien entwickeln. Im keratinhaltigen Gewebe erfolgt Vermehrung durch Hyphenzellen und Arthrosporen.

\section{Pathogenität / Virulenz / Antigenvariabilität}

E. floccosum hat eine Affinität zur unbehaarten Haut. Die Sporen adhärieren z. B. mit Zellwandmannanen an Keratinozyten und wachsen zu Hyphen aus, die in die keratinhaltigen Zellen eindringen. Die vom Pilz sezernierten Keratinasen bauen das Keratin des Stratum corneum ab. Keratin reicht als hauptsächliche Kohlenstoff- und Stickstoffquelle für den Stoffwechsel des Pilzes aus.

\section{Erkrankung}

Besonders häufig Tinea cruris und T. pedis, wobei E. floccosum im Vergleich zu Trichophyton rubrum wesentlich seltener eine T. pedis hervorruft. T. corporis, T. manus und T. unguium sind seltene Krankheitsbilder durch E. floccosum.

\section{Inkubationszeit}

Die Inkubationszeit bei Infektion beträgt 1-3 Wochen.

\section{Leitsymptome}

Rötliche, schuppende und juckende Hauterscheinungen.

\section{Symptome}

Tinea cruris: gerötete Hautaerale mit follikulären schuppenden und juckenden Knötchen im Inguinalbereich, an der Innenseite der Ober- und Unterschenkel.

Tinea pedis: Rötung, Schuppung, Erosionen, Mazeration, besonders in den Zehenzwischenräumen. Aus- bildung von Fissuren und Übergang auf die Zeh- und Fußunterseite sind möglich, meist starker Juckreiz. Übergang auf den Nagel ist ebenfalls möglich.

\section{Pathophysiologie}

Nur die glatte Haut und die Nägel werden befallen, niemals das Haar. Prädilektionsstellen sind feuchte und mechanisch beanspruchte Regionen wie der Inguinalbereich, die Innenseiten der Oberschenkel und der Zwischenzehenbereich, wo die physiologische Hautbarriere leichter überwunden werden kann. Die Infektion bleibt auf das Stratum corneum der Haut beschränkt und verläuft chronisch fortschreitend. Sie ruft eine mäßige entzündliche Reaktion hervor. Die Infektion führt zu einer gesteigerten Desquamation der Haut, insbesondere am Herdrand.

\section{Immunantwort}

Es wird eine spezifische zelluläre Immunantwort beim Patienten ausgelöst. Die Zellwandantigene triggern Th1- und Th2-Zellantworten, wodurch weitere Abwehrmechanismen in Gang gesetzt werden. Der Pilz wird häufig nicht ausreichend eliminiert, woraus chronische rekurrente Infektionen resultieren. Spezifische humorale Antikörper der Klasse IgG treten bei chronischen Verlaufsformen auf. Sie haben aber keinen protektiven und diagnostischen Wert.

Bei entzündlichen Tinea-Formen wird eine verzögerte Überempfindlichkeitsreaktion vom Typ IV durch Bildung von spezifischem IgE induziert.

\section{Differenzialdiagnose}

Ausschluss weiterer Dermatophyten und anderer Pilze sowie Bakterien als Erreger der Tinea pedis und Tinea cruris. Weitere Differenzialdiagnosen: Psoriasis, ekzematöse Erkrankungen, Seborrhoe, Pyodermien, Karbunkel, Lupus erythematodes.

\section{Diagnostik}

\section{Untersuchungsmaterial}

Hautgeschabsel, Deckhäutchen von Pusteln, Nagelgeschabsel.

\section{Diagnostische Verfahren}

Die mykologische Diagnostik erfolgt durch den mikroskopischen und kulturellen Pilznachweis. Mikroskopische Untersuchung: Hautschuppen und Nagelspäne im KOH-Deckglaspräparat. Diese sind von verzweigten, septierten Hyphen durchzogen.

Kulturelle Anzüchtung: Auf speziellen festen Nährböden innerhalb von 2 Wochen bei $22-30^{\circ} \mathrm{C}$. Differenzierung: anhand der Kolonieform und der Mikromorphologie. Abgrenzung von Trichophyton- und Mikrosporum-Arten durch Fehlen von Mikrokonidien.

\section{Befund / Interpretation}

Der Nachweis von Pilzelementen im relevanten Untersuchungsmaterial sowie die typische Kultur sind beweisend für eine Infektion mit E. floccosum. 


\section{Therapie}

\section{Therapeutische Maßnahmen}

Therapie der Tinea cruris lokal mittels antimykotikahaltiger Salben, Cremes, Tinkturen. Geeignete Wirkstoffe sind: Azole (Clotrimazol, Miconazol, Econazol u. a.), Hydroxypyridone (Ciclopiroxolamin), Allylamine (Naftifin, Terbinafin), Morpholine (Amorolfin). Bei Versagen topischer Therapie Kombination lokaler mit systemischer Therapie: Griseofulvin mikrofein, Itraconazol, Fluconazol, Terbinafin.

Therapie der Tinea pedis analog, bei Beteiligung der Nägel zusätzlich atraumatische Nagelentfernung mit harnstoffhaltiger Salbe (20-40 \%) oder Einsatz von Nagellack mit Ciclopirox oder Amorolfin, woraus diese Wirkstoffe kontinuierlich in den Nagel diffundieren. Unterstützende Maßnahmen durch Trockenhalten der Zwischenzehenbereiche und Inguinalfalten.

\section{Resistenz}

Resistent gegen Polyen-Antimykotika (Amphotericin, Nystatin).

\section{Epidemiologie}

\section{Verbreitung}

Der Mensch ist Wirt und Infektionsquelle. In der menschlichen Population ist der Pilz weltweit verbreitet. In Europa sind Infektionen selten geworden.

\section{Wirtsbereich / Reservoir}

E. floccosum ist ein anthropophiler Dermatophyt, der an intertriginöse Bereiche des menschlichen Körpers adaptiert ist.

\section{Risikogruppen}

Junge Erwachsene in Gemeinschaftsquartieren. Sportler (enges Schuhwerk, Druckstellen und Verletzungen an Füßen). Übergewichtige (feuchte Hautfalten submammär, periumbilical etc.). Männer sind häufiger befallen als Frauen.

\section{Transmission / Vektoren}

Exogene Infektion. Direkte und indirekte Übertragung von Mensch zu Mensch.

\section{Prävention / Impfstoffe}

Einhaltung eines persönlichen Hygieneregimes. Verringerung des Infektionsrisikos durch antimykotische Behandlung von Fuß- und Inguinalmykosen. Während antimykotischer Therapie Desinfektion der Schuhe und Strümpfe sinnvoll. Regelmäßige Desinfektions- und Reinigungsmaßnahmen in gemeinschaftlich genutzten Wohn-, Bade- und Sporteinrichtungen.

\section{Meldepflicht}

Keine.

\section{Weiterführende Informationen}

Referenzzentren / Expertenlaboratorien

- Centraalbureau voor Schimmelcultures (CBS), Padualaan 8, Utrecht, NL-3584 CT, The Netherlands

- Institut Pasteur, Unité de Mycologie, 25 Rue du Docteur Roux, F-75015 Paris, Frankreich

- Konsiliarlaboratorium für Dermatophyten in Deutschland, Klinik und Poliklinik für Hautkrankheiten, Mykologisches Labor, Universität Münster, von-Esmarch-Straße 56, D-48149 Münster

- Klinik und Poliklinik für Dermatologie und Allergologie, Mykologisches Labor, Universität München, Frauenlobstraße 9-11, D-80337 München

- Hautklinik des Universitätsklinikums Leipzig AöR, Mykologisches Labor, Stephanstraße 11, D-04103 Leipzig

- Institut für Mikrobiologie und Hygiene (Charité), Abt. Parasitologie (Genotypische Bestimmung von Pilzen), Dorotheenstraße 96, D-10117 Berlin

\section{Web-Adressen}

- http://www.cbs.knaw.nl

- http://www.ridom.hygiene.uniwuerzburg.de

- http://www.purl.oclc.org/net/ridom

- http://www.uni-duesseldorf.de/AWMF//11/013-003.htm

\section{Schlüsselliteratur}

1. Borman AM, Campbell CK, Fraser M, Johnson EM (2007) Analysis of the dermatophyte species isolated in the British Isles between 1980 and 2005 and review of worldwide dermatophyte trends over the last three decades. Med Mycol 45:131-141

2. De Hoog GS, Bowman B, Graser Y, Haase G, El Fari M, Van den Ende A, Melzer-Krick B, Untereiner WA (1998) Molecular phylogeny and taxonomy of medically important fungi. Med Mycol 36:52-56

3. De Hoog GS, Guarro J, Gené J, Figueras MJ (2000) Atlas of clinical fungi, $2^{\text {nd }}$ edn. Centraalbureau voor Schimmelcultures, Utrecht, The Netherlands / Universitat Rovira I Virgili, Reus, Spain

4. Hahn H et al (2000) Medizinische Mikrobiologie und Infektiologie. 3. Aufl. Springer-Verlag Berlin, Heidelberg, New York, pp 719-725

5. Kwon-Chung KJ, Bennett JE (1992) Medical Mycology, $2^{\text {nd }}$ edn. Lea \& Febiger, Philadelphia, London, Chapter 6: Dermatophytoses, pp 105-161

\section{Epididymitis}

- Neisseria gonorrhoeae

- Ureaplasma urealyticum

\section{Epiglottitis}

- Haemophilus influenzae

- Pasteurella multocida

\section{Epithelioma contagiosum}

- Molluscum Contagiosum Virus (MCV) 


\section{Epstein-Barr-Virus}

Angela Rösen-WolfF

Erreger

Synonym(e)

Epstein-Barr-Virus (EBV); Humanes Herpesvirus 4 (HHV-4).

\section{Erregerspezies}

Herpesvirus

\section{Taxonomie}

Gammaherpesvirinae, Humanes Herpesvirus 4

\section{Historie}

Im Jahr 1958 beschrieb Burkitt eine endemisch in Äquatorialafrika auftretende Krebserkrankung bei Kindern, die in Folge Burkitt-Lymphom genannt wurde. Einige Jahre später fanden Epstein, Barr und Achong herpesvirusähnliche Partikel in lymphoiden Zellen aus Burkitt-Tumorproben. Erst 1968 konnte gezeigt werden, dass im Verlauf der infektiösen Mononukleose eine Serokonversion gegen EBV-Antigene auftrat. Daraus konnte geschlossen werden, dass EBV das auslösende Agens dieser seit Langem bekannten Infektionskrankheit war.

\section{Morphologie}

Das Virion besteht aus einem ikosaedrischen Kapsid (100-110 nm) mit 162 Kapsomeren, das das virale Genom beherbergt. Das ganze umhüllte Virion misst $150-220 \mathrm{~nm}$. Innerhalb des Nukleokapsids ist das virale Genom verpackt, das aus einer linearen doppelsträngigen DNA von ca. 170.000 Basenpaaren Länge besteht.

\section{Genom}

Das Genom des EBV besteht aus einer linearen doppelsträngigen DNA mit einer kurzen und einer langen nicht repetitiven "unique " Region $\left(\mathrm{U}_{\mathrm{S}}\right.$ und $\left.\mathrm{U}_{\mathrm{L}}\right)$, die durch eine große interne Repetitionsregion $\left(\mathrm{IR}_{\mathrm{I}}\right)$ getrennt sind. Diese Repetitionsregion besteht aus 6-12 direkten Repetitionen einer 3-kb-Sequenz. Auch an den Enden des Genoms sind terminale Repetitionen lokalisiert. Während der Latenzphase liegt das Genom episomal in zirkulärer Form vor. Die lytische Vermehrung des Virus erfordert die Interaktion der DNA-Polymerase mit den Replikationsursprüngen OriLyt, die zweimal auf dem EBV-Genom lokalisiert sind. Während der Latenz dient OriP als Replikationsursprung. Das EBV-Genom kodiert für 50-70 Proteine, deren Expression während der latenten Phase der Infektion stark eingeschränkt ist. Mindestens zehn virale Proteine werden während der Latenzphase exprimiert.

Die Nukleotidsequenz des gesamten Genoms des EBV ist unter der Genebank Accession-Nr. NC 001345 erhältlich.

\section{Vermehrung}

In vivo vermehrt sich das Virus vorwiegend in epithelialen Zellen. Nur in einer kleinen Fraktion der B-Zellen kommt es ebenfalls zur lytischen Infektion.

\section{Pathogenität / Virulenz / Antigenvariabilität}

Immunologische Studien EBV-infizierter B-Zellen ergaben, dass EBV generell reife B-Zellen transformiert, die komplette Immunglobuline sezernieren. Frühere B-Zellstadien können jedoch auch infiziert werden. Im Gegensatz zu B-Zellen von Mononukleose-Patienten beherbergen B-Zellen aus Burkitt-Lymphomen in 90 \% der Fälle reziproke Translokationen mit Beteiligung des langen Arms der Chromosomen 8 und 14. Die involvierte Region des Chromosoms 8 beherbergt das c-myc-Protoonkogen.

EBV ist in der Lage, latente Infektionen zu induzieren, die zu einem lebenslangen Verbleib des Virus im Wirt führen. Diese latente Infektion kann durch verschiedene Stimuli reaktiviert werden. Es wird vermutet, dass der Persistenzort im Körper ruhende B-Zellen sind. Von den etwa 100 viralen Genen werden während der Latenz in vitro nur 10 exprimiert. Zwei Arten nicht translatierter RNA, sechs Kernproteine und zwei Membranproteine werden während der Latenz exprimiert. Diese eingeschränkte virale Genexpression reduziert die Anzahl der viralen Proteine, die die Erkennung der infizierten Zellen durch zytotoxische T-Zellen erlaubt. Das EBV nuclear antigen (EBNA) 1 Protein bindet an die virale DNA und erlaubt dem EBV-Genom auf diese Weise als zirkuläre DNA episomal vorzuliegen. EBNA-2 reguliert die Expression der EBV latent membrane Proteine 1 (LMP-1) und LMP-2 herauf. LMP-1 wirkt als Onkogen und Expression dieses Proteins in transgenen Mäusen resultiert in der Entwicklung von B-Zell-Lymphomen.

\section{Erkrankungen}

Infektionen mit EBV können unter sehr unterschiedlichen Krankheitsbildern verlaufen. Die meisten Infektionen verlaufen inapparent. Die Inkubationszeit beträgt 5-15 Tage, kann aber auch länger sein.

\section{Infektiöse Mononukleose}

Beginn meist schleichend mit Prodromalzeichen wie Müdigkeit, Übelkeit, Erbrechen, Kopf- und Bauchschmerzen. Später kommt es zu Fieber, Tonsillitis mit weißen oder graugelben Belägen und zur generalisierten oder lokalisierten Lymphknotenschwellung, vor allem am Hals, inguinal und axillär. Die Lymphknoten sind druckdolent und von einem Ödem umgeben. Die Milz ist vergrößert, teilweise kommt es zur Hepatomegalie, selten zu Ikterus. Morbilliforme oder petechiale Exantheme und Lidödeme sind möglich. Die Dauer der Erkrankung beträgt wenige Tage bis viele Wochen. Die Patienten klagen über Müdigkeit und eingeschränkte Leistungsfähigkeit.

Bei der lytischen Infektion vermehrt sich das Virus zu- 
Tab. 1. Übersicht über die EBV-assoziierten malignen Erkrankungen

\begin{tabular}{|c|c|c|c|c|}
\hline Tumor & Subtyp & $\begin{array}{l}\text { Typische } \\
\text { Latenzperiode }\end{array}$ & EBV positiv & Antigen Expression \\
\hline Burkitt-Lymphom & $\begin{array}{l}\text { Endemisch } \\
\text { Sporadisch } \\
\text { AIDS-assoziiert }\end{array}$ & $\begin{array}{l}\text { 3-8 Jahre post EBV } \\
\text { 3-8 Jahre post EBV } \\
\text { 3-8 Jahre post EBV }\end{array}$ & $\begin{array}{r}100 \% \\
15-85 \% \\
30-40 \%\end{array}$ & EBNA1+ \\
\hline $\begin{array}{l}\text { Nasopharyng. } \\
\text { Karzinom }\end{array}$ & $\begin{array}{l}\text { Wenig/nicht } \\
\text { differenziert }\end{array}$ & > 30 Jahre post EBV & $100 \%$ & LMP2+, EBNA1+, LMP1+/- \\
\hline M. Hodgkin & $\begin{array}{l}\mathrm{mc} / \mathrm{ld} \\
\mathrm{ns}\end{array}$ & $\begin{array}{l}>30 \text { Jahre post EBV } \\
>10 \text { Jahre post EBV }\end{array}$ & $\begin{array}{r}80-90 \% \\
30 \%\end{array}$ & EBNA1+, LMP1+, LMP2+ \\
\hline T-Zell-Lymphom & & 6 Monate post EBV & $100 \%$ & $?$ \\
\hline $\begin{array}{l}\text { Immunoblast. } \\
\text { Lymphome }\end{array}$ & & 6 Monate bis $1 \mathrm{Jahr}$ & $100 \%$ & EBNA1,2,3A,3B,3C,0-, LP+ \\
\hline
\end{tabular}

nächst im lymphatischen Rachenring in reifen BLymphozyten. Hämatogen erfolgen die Ausbreitung und der Befall weiterer B-Lymphozyten, die zu Lymphoblasten transformiert werden. Die ungehinderte Proliferation wird aber durch spezifische T-Lymphozyten (Killer-Zellen) begrenzt.

\section{Schwere chronische Infektionen}

Selten kommt es zu persistierenden oder reaktivierten EBV-Infektionen, die zu Dysfunktionen verschiedenster Organe führen können. So kann es im Verlauf einer persistierenden EBV-Infektion zur Knochenmarksaplasie, Pneumonitis, rekurrierenden febrilen Episoden, Dysgammaglobulinämien, Hepatitis oder neurologischen Abnormalitäten kommen.

\section{Lymphoproliferative Erkrankungen}

Patienten mit X-linked lymphoproliferative disease, sind nicht in der Lage, EBV-Infektionen zu kontrollieren. Von 161 bekannten Patienten mit dieser Erkrankung verstarben $57 \%$ an einer infektiösen Mononukleose, 29 \% entwickelten eine Hypogammaglobulinämie und $24 \%$ hatten malige Lymphome. Das mutierte Gen auf dem X-Chromosom wurde als SAP (signaling lymphocyte activation molecule [SLAM] associated protein) identifiziert. Die Abwesenheit des funktionellen SAP scheint die Interaktion zwischen T- und BZellen zu schädigen.

Immundefiziente Patienten haben ein erhöhtes Risiko infolge einer EBV-Infektion an einer lymphoproliferativen Erkrankung wie einem T-Zell-Lymphom zu erkranken. Bei HIV-Infektionen kommt es zur Haarleukoplakie. HIV-infizierte Kinder können eine lymphoide interstitielle Pneumonitis entwicklen. Außerdem können EBV-positive Non-Hodgkin-Lymphome bei diesen Patienten detektiert werden.
Das Burkitt-Lymphom ist eine EBV-assoziierte Erkrankung vorwiegend bei Kindern in Zentralafrika und Papua-Neuginea, bei der die EBV-Infektion als Ko-Faktor der Tumorentstehung anzusehen ist. Das in Süd-China auftretende EBV-assoziierte Nasopharyngeal-Karzinom betrifft hauptsächlich Erwachsene. - Tab. 1 gibt eine Übersicht über die EBV-assoziierten malignen Erkrankungen.

\section{Synonym(e)}

Pfeifersches Drüsenfieber.

\section{Inkubationszeit}

Die Inkubationszeit beträgt bei Kindern etwa 10 Tage, bei Jugendlichen zwischen 30 und 50 Tagen.

\section{Leitsymptome}

Lymphknotenschwellung, Hepatosplenomegalie.

\section{Symptome}

Beginn meist schleichend mit Prodromalzeichen wie Müdigkeit, Übelkeit, Erbrechen, Kopf- und Bauchschmerzen. Später kommt es zu Fieber, Tonsillitis mit weißen oder graugelben Belägen und zur generalisierten oder lokalisierten Lymphknotenschwellung vor allem am Hals, inguinal und axillär. Die Lymphknoten sind druckdolent und von einem Ödem umgeben. Die Milz ist vergrößert, teilweise kommt es zur Hepatomegalie, selten zu Ikterus. Morbilliforme oder petechiale Exantheme und Lidödeme sind möglich. Die Dauer der Erkrankung beträgt wenige Tage bis viele Wochen. Die Patienten klagen über Müdigkeit und eingeschränkte Leistungsfähigkeit.

\section{Pathophysiologie}

Infizierte B-Lymphozyten werden „immortalisiert“. 
Ohne Virusvermehrung werden die B-Zellen durch die persistierende Infektion zu lymphoblastoiden Zellen transformiert. Diese können in vitro zu fortwährendem Wachstum stimuliert werden. Durch zytotoxische T-Zellen wird die Zahl der infizierten B-Zellen bis zur Einstellung eines Gleichgewichts zwischen BZell-Proliferation und Lyse reduziert. Die Infektion geht dann in das latente Stadium über. EBNA-1 wird bei der Lyse der B-Lymphozyten durch die T-Zellen freigesetzt und führt dann zu einer reaktiven Antikörperbildung.

\section{Immunantwort}

- Diagnostik

\section{Differenzialdiagnose}

Andere Viruserkrankungen wie Zytomegalie, Hepatitis, Mumps, Röteln, Toxoplasmose, StreptokokkenTonsillitis aber auch Leukämie.

\section{Diagnostik}

\section{Untersuchungsmaterial}

Serum.

\section{Diagnostische Verfahren}

IgM und IgG-Antikörper gegen Viruskapsid-Antigen (VCA), ,early-antigen“ (EA) oder „Epstein-Barr nuclear antigen“ (EBNA) können im Immunfluoreszenztest oder ELISA nachgewiesen werden. Frische EBVInfektionen zeichnen sich meist durch die Anwesenheit von IgM- und IgG-Antikörpern gegen VCA, Serokonversion gegen EA und die Abwesenheit von Anti-EBNA-Antikörpern aus, die meist erst im späteren Verlauf der Infektion auftreten.

Das Blutbild weist erhöhte Lymphozytenzahlen auf, mikroskopisch können monozytoide Lymphozyten (Pfeifferzellen) nachgewiesen werden.

Der bei Erwachsenen gebräuchliche Paul-Bunnel-Test (Nachweis heterophiler Antikörper) gibt bei Erwachsenen in $80-85 \%$ der Fälle ein positives Resultat, ist aber bei Kindern in 50 \% der Fälle negativ.

\section{Befund / Interpretation}

Frische EBV-Infektionen zeichnen sich meist durch die Anwesenheit von IgM- und IgG-Antikörpern gegen VCA, Serokonversion gegen EA und die Abwesenheit von Anti-EBNA-Antikörpern aus, die meist erst im späteren Verlauf der Infektion auftreten.

\section{Therapie}

\section{Therapeutische Maßnahmen}

Es sind keine kausalen Therapieoptionen bekannt. Bei chronisch aktiven EBV-Infektionen wurden Behandlungsversuche mit Acyclovir, Ganciclovir, IFN, IL-2 und Vidarabin beschrieben.

\section{Resistenz}

Keine Daten verfügbar.

\section{Epidemiologie}

\section{Verbreitung}

Weltweit.

\section{Wirtsbereich / Reservoir}

EBV ist durch einen starken Lymphotropismus gekennzeichnet und infiziert vorwiegend B-Lymphozyten. Die Infektion erfolgt wahrscheinlich über den C3d-Rezeptor. Außer seinem natürlichen Wirt, dem Menschen, können auch Affenzellen infiziert werden.

\section{Risikogruppen}

Es sind keine Risikogruppen bekannt. Menschen können in jedem Lebensalter erkranken, wobei der Infektionsgipfel im Kindes- bzw. Jugendalter liegt. Keine Prävalenz für bestimmte Bevölkerungsgruppen.

\section{Transmission / Vektoren}

Die Übertragung erfolgt über Tröpfcheninfektion, setzt aber einen sehr engen Kontakt voraus (z. B. Küssen). Auch durch Bluttransfusionen ist das Virus übertragbar.

\section{Prävention / Impfstoffe}

Kein Impfstoff erhältlich.

\section{Ausbruchsmanagement}

Keine Daten verfügbar.

\section{Meldepflicht}

Keine.

\section{Weiterführende Informationen}

\section{Referenzzentren / Expertenlaboratorien}

- Konsiliarlaboratorium für EBV, HHV 6, 7, 8, Erreger: Epstein-Barr-Virus, humanes Herpes-Virus 6, 7, 8; Institution: Institut für Virologie Haus 47 Universitätskliniken, Homburg/Saar 66421 Homburg/Saar; Ansprechpartner: Herr Prof. Dr. N. Müller-Lantzsch Frau Prof. Dr. B. Gärtner, Telefon: 068 41.1 62-39 31 oder -39 50, Telefax: 068 41.162-39 80,E-Mail: vinmue@uniklinikum-saarland.de, E-Mail: vibgae@uniklinikum-saarland.de

\section{Web-Adressen}

- All the virology on the WWW: http://www.virology.net

- National Center of biotechnology information: http:// www.ncbi.nlm.nih.gov

\section{Schlüsselliteratur}

1. Cohen JI (2000) Epstein-Barr Virus Infection. New England Journal of Medicine 343:481-492

2. Epstein MA, Achong BG (1979) The Epstein Barr Virus. Springer, Berlin

3. Rickinson AB, Kieff E (2001) Epstein-Barr Virus. In: Fields BN, Knipe DM, Howley PM (eds) Fields Virology, 4th edn. Lippincott-Raven Publishers, Philadelphia, pp 2575-2627

4. Young LS, Rickinson AB (2004) Epstein-Barr-Virus: 40 years on. Nat Rev Cancer 4 (10):757-768 


\section{Equines Morbillivirus}

Hendra-Virus

\section{Erbgrind}

Trichophyton schoenleinii

\section{Erntefieber}

Leptospiren

\section{Erntemilben}

- Ektoparasiten, sonstige (Stechmücken, Trombiculiden, Flöhe, Wanzen, Zecken)

\section{Erworbenes Immundefektsyndrom}

Humane Immundefizienzviren (HIV)

\section{Erysipeloid}

- Erysipelothrix

\section{Erysipelothrix}

\section{Erreger}

Synonym(e)

Rotlaufbakterien.

\section{Erregerspezies}

Erysipelothrix rhusiopathiae

\section{Taxonomie}

Genus Erysipelothrix

\section{Historie}

E. rhusiopathiae wurde 1882 von Loeffler beim Schweinerotlauf entdeckt und 1884 von Rosenbach als Erysipeloid-Erreger des Menschen erkannt.

\section{Morphologie}

Unbewegliches, schlankes, grampositives, zuweilen gramlabiles Stäbchen mit Ketten- und Fadenbildung.

\section{Genom}

Das Genom ist in Teilbereichen sequenziert. Weitere Informationen unter http://www.genedb.org.

\section{Vermehrung}

Langsames Wachstum auf Nährmedien.
Pathogenität, Virulenz, Antigenvariabilität

Über Virulenzfaktoren ist nichts bekannt.

\section{Erkrankung}

Erysipeloid

Inkubationszeit

Die Inkubationszeit beträgt 1-4 Tage.

\section{Leitsymptome}

An der Eintrittspforte der Haut juckende schmerzende Schwellung.

\section{Symptome}

E. rhusiopathiae, der Erreger des Rotlaufs ruft insbesondere Erkrankungen beim Schwein, seltener beim Pferd, Rind, Geflügel und Fisch hervor. Es handelt sich dabei meistens um lokale Hauterkrankungen und nur selten um systemische Erkrankungen wie Arthritis, Endokarditis oder Sepsis.

Beim Menschen kann E. rhusiopathiae auch zu lokalen Infektionen (Erysipeloid) und seltener zu systemischen Infektionen (Endokarditis) führen. Über kleine Verletzungen, meist an den Händen führt der Kontakt mit infizierten Tieren, bzw. deren Fleisch zur Infektion, dem Erysipeloid, einer juckenden, schmerzenden Schwellung mit blau-rötlicher Verfärbung, die als kutane Manifestation in der Regel nach ca. 2-3 Wochen unter Schuppung abheilt. Die besondere Bedeutung von E. rhusiopathiae bei Menschen ist in der hohen Letalität der Endokarditis begründet.

\section{Differenzialdiagnose}

Entsprechende Hautveränderungen bzw. Endokardititen durch andere Erreger.

\section{Diagnostik}

\section{Untersuchungsmaterial}

Biopsiematerial, Gewebeflüssigkeit, bei Sepsis Blutkulturen.

\section{Diagnostische Verfahren}

Mikroskopie: Direktpräparate sind wegen geringer Erregerdichte wenig Erfolg versprechend.

Kultur: Biopsiematerial, Gewebeflüssigkeit (unmittelbar in dextrosehaltiges Medium geben) und bei septischem Erscheinungsbild Blutkulturen sind adäquate Proben. Probenmaterial wird auf glukosehaltigem Blutagar ausgeimpft und mehrere Tage bei $36^{\circ} \mathrm{C}$ und 5-8 \% $\mathrm{CO}_{2}$-Spannung inkubiert. E. rhusiopathiae wächst in kleinen, glatten, grau-weißen Kolonien mit leichter Hämolyse. Rauformen bilden größere Kolonien mit unregelmäßigem Rand.

Identifikation: Der definitive Nachweis von E. rhusiopathiae wird geführt durch biochemische Merkmale: in der bunten Reihe (insbesondere Glukose/Saccharose-Methabolismus), fehlende Katalaseaktivität, $\mathrm{H}_{2} \mathrm{~S}$ Bildung (Leitreaktion). 


\section{Befund / Interpretation}

Nachweis des Erregers ausschlaggebend für die Erkrankungsursache.

\section{Therapie}

\section{Therapeutische Maßnahmen}

Das Antibiotikum der Wahl bei der kutanen und arthritischen Form der Erkrankung ist Penicillin G (3-4 Mega-Einheiten pro Tag). Endokarditis und Sepsis durch E. rhusiopathiae werden hochdosiert mit $30 \mathrm{Me}-$ ga-E pro Tag Penicillin G und langfristig therapiert. Bei Penicillinallergie sind Erythromycin oder Clindamycin angezeigt. Gegen Vancomycin ist E. rhusiopathiae resistent.

\section{Resistenz}

E. rhusiopathiae ist recht gut empfindlich gegenüber Penicillinen, Cephalosporin, Makroliden, Clindamycin. Resistenz besteht gegenüber Glykopeptidantibiotika.

\section{Epidemiologie}

\section{Verbreitung}

Infektionen, hervorgerufen durch E. rhusiopathiae sind Zoonosen. Sie kommen typischerweise bei Nutztieren und Fischen vor. Infektionen des Menschen sind selten und werden nur bei entsprechenden Risikopersonen gesehen.

\section{Wirtsbereich / Reservoir}

Das Reservoir für E. rhusiopathiae sind Tiere, und hier insbesondere Schweine, seltener Pferde, Rinder, Geflügel und Fisch. Es handelt sich hierbei um eine Zoonose, die auf den Menschen übertragen werden kann.

\section{Risikogruppen}

Risikogruppen sind Tierärzte sowie Arbeiter in der Fleisch und Fisch verarbeitenden Industrie. Infektionen können allerdings auch im häuslichen Milieu beim Umgang mit tierischen Produkten auftreten.

\section{Transmission / Vektoren}

Die Übertragung der Krankheit erfolgt meistens über kleine Verletzungen an der Haut und im Kontakt mit infizierten Tieren, bzw. ihrem Fleisch.

\section{Prävention / Impfstoffe}

Präventionsmaßnahmen bestehen in der Vermeidung des Kontakts mit infizierten Tieren, bzw. deren Produkten. Impfschutz ist nicht gegeben.

\section{Ausbruchmanagement}

Wegen des Vorkommens als seltene Einzelerkrankung ist ein Ausbruchsmanagement nicht erforderlich.

\section{Weiterführende Informationen}

\section{Referenzzentren, Expertenlaboratorien}

- Dr. G. Funke, Institut für Medizinische Mikrobiologie der Universität Zürich, Gloriastr. 32, CH-8028 Zürich

\section{Web-Adressen}

- http://www.astdhpphe.org/infect/dip.html

- http://www.cdc.gov/nip/publications/pink/dip.pdf

- http://www.emedicine.com/EMERG/topic138.htm

- http://www.nfid.org/factsheets/diphtadult.html

\section{Schlüsselliteratur}

1. Friedrich B (Hrsg) (1992) Mikrobiologische Diagnostik. Georg Thieme Verlag, Stuttgart

2. Köhler W, Eggers HJ, Fleischer B, Marre R, Pfister H, Pulverer G (Hrsg) (2001) Medizinische Mikrobiologie. 8. Aufl. Urban und Fischer, München, Jena

3. Mandell GL, Douglas RG, Bennett JE (Hrsg) (1995) Principles and Practice of Infectious Diseases, $4^{\text {th }}$ edn. Churchill Livingstone, New York

4. Murray PR, Baron EJ, Pfaller MA, Tenover FC, Yolken RH (Hrsg) (1995) Manual of Clinical Microbiology, $6^{\text {th }}$ edn. ASM Press, Washington DC

\section{Erythema infectiosum}

Parvoviren

\section{Erythema nodosum}

Chlamydia

\section{Erythroblastophenie}

- Parvoviren

\section{Erythroblastophthise}

> Parvoviren

\section{Erythroblastose}

Parvoviren

\section{ESBL}

- Escherichia coli

- Klebsiella

- Kluyvera, Koserella (Yokenella), Leclercia, Leminorella, Moellerella

\section{Meldepflicht}

Es besteht keine Meldepflicht nach IfSG. 


\section{Escherichia coli}

UwE UlLMANN

Erreger

\section{Erregerspezies}

Escherichia coli

\section{Taxonomie}

Familie Enterobacteriaceae

Gattungen: Escherichia, Shigella, Salmonella, Citrobacter, Klebsiella, Enterobacter, Yersinia, Serratia, Erwinia, Hafnia, Edwardsiella, Proteus, Providencia, Morganella, Obesumbacterium, Xenorhabdus, Kluyvera, Rahnella, Cedecea, Tatumella

\section{Historie}

Als Bacterium coli commune erstmals von dem Pädiater Theodor Escherich 1894 angezüchtet und beschrieben und von Castellani und Chalmers 1919 als Escherichia coli nach seinem Entdecker benannt.

\section{Morphologie}

Gramnegative Stäbchenbakterien erscheinen einzeln oder in Paaren, manche Stämme besitzen Kapseln oder Mikrokapseln. Beweglich durch peritriche Begeißelung oder auch unbeweglich.

\section{Genom}

4,7 Millionen Basenpaare (siehe auch www.ncbi.nlm. nih.gov).

\section{Vermehrung}

Fakultativ anaerob, Wachstum innerhalb von $24 \mathrm{~h}$.

\section{Pathogenität / Virulenz / Antigenvariabilität}

\section{Fakultativ pathogene E.-coli-Stämme}

Besitzen als Virulenzfaktoren Endotoxine, Hämolysine, Mannose-resistente Fimbrien (Typ-2-Fimbrien), das K1-Antigen sowie Resistenz gegenüber dem komplementvermittelten bakteriziden Effekt von Serum. Stämme, die eine Pyelonephritis auslösen, besitzen neben den MR-Fimbrien auch sog. P-Pili, die eine besondere Affinität für das Epithel des oberen Genitaltraktes besitzen.

\section{Obligat pathogene E.-coli-Stämme}

EPEC-Stämme: Kolonisation des Dünndarmes erfolgt durch ein Membranprotein, dessen Produktion sowohl chromosomal als auch plasmidkodiert ist, den sog. ,,Bundle-forming Pilus“ (BFP), sowie durch ein als „Intimin“ bezeichnetes Protein. Der Nachweis kann durch Adhärenz an HEp-2-Zellen erfolgen. Sie produzieren in der Regel kein Enterotoxin, manche in geringen Mengen ein Shiga-like-Toxin. Der entscheidende pathogenetische Faktor ist die Fähigkeit der Adhärenz an den Epithelzellen und die Zerstörung der Mikrovilli.
Die EHEC-Stämme bilden Cytotoxine, die wegen ihres zytopathischen Effektes auf Verozellkulturen auch als Verotoxine (VT) bezeichnet werden. Synonym sind die Begriffe Shiga like toxin I und II (SLT) aufgrund ihrer Ähnlichkeit mit dem von Shigella dysenteriae produzierten Toxin. Die Zytotoxinbildung wird durch Phagen induziert. Bei intakter sekretorischer Funktion führt die Wirkung der Toxine zu einer Schädigung des Bürstensaumes, einhergehend mit Malabsorption der Kryptenzellen, was die hämorrhagische Enterocolitis bedingt. Von vielen Stämmen wird ein plasmidkodiertes EHEC-Hämolysin gebildet, das bei Kontakt mit Erythrozyten zu deren Lyse führt und eventuell eine gewisse Rolle beim hämolytisch-urämischen Syndrom spielt (HUS).

ETEC-Stämme können sich mittels Fimbrien vom MR-Typ an Rezeptoren von Epithelzellen des proximalen Duodenum anheften; es sind dies die 5 Colonisation Factor Antigene: CFA-1 - CFA-5. Es werden nach heutigem Kenntnisstand zwei Enterotoxine gebildet, ein hitzeempfindliches, dem Choleratoxin ähnliches Protein (LT), sowie ein hitzestabiles Peptid (ST). Diese sekretorischen Toxine führen zu einer Störung des intestinalen Elektrolyt- und Wassertransportes und damit zu Durchfällen. Die Toxine werden von zwei verschiedenen Plasmiden kodiert.

Die EIEC-Stämme zeichnen sich durch die Fähigkeit zur Invasion in die Epithelzellen des Dickdarms aus, in denen sie sich vermehren, horizontal ausbreiten, eine eitrige Entzündung und ein ruhrähnliches Krankheitsbild verursachen. Diese Fähigkeit ist plasmidkodiert. Sie produzieren Toxine, die dem Shigellentoxin ähnlich sind. Die Virulenzeigenschaften der obligat pathogenen E.-coli-Stämme sind genetisch bedingt und miteinander gekoppelt: Fehlt einer der Virulenzfaktoren, so fehlen auch alle übrigen.

EAggEC-Stämme exprimieren die aggregativen Ahärenzfimbrien (AAF), die in einem verklumpten Muster an HEp-2-Zellen adhärieren. Ferner produzieren sie ein hitzelabiles Hämolysin EAST1 und ein hitzestabiles Protein, die eine Interleukin-8-Freisetzung aus intestinalen Epithelzellen bewirken, was eine Anhäufung von Neutrophilen zur Folge hat mit Freisetzung von 5-AMP und nachfolgender Elektrolytsekretion.

Betalaktamasen: Opportunistische E.-coli-Stämme, die Erreger von nosokomialen Infektionen sind, besitzen häufig plasmidkodierte Betalaktamasen, die Penicilline und Cephalosporine inaktivieren können.

\section{Erkrankungen}

\section{Lokalisierte Prozesse}

Häufigster Erreger von Harnwegsinfektionen, Erreger von Wundheilungsstörungen, Pneumonien bei beatmeten Patienten, Cholangitis, Cholezystitis, Appendizitis, Peritonitis (fakultativ pathogene Stämme), Gastroenteritiden (obligat pathogene Stämme). 


\section{Generalisierte Erkrankungen}

Durch Einschwemmen in die Blutbahn, vor allem von einer Harnwegsinfektion ausgehend, kann es zur Sepsis (Urosepsis) kommen. E. coli ist neben Staphylococcus aureus der häufigste Sepsiserreger; bei Neugeborenen und Kleinkindern bis zum 1. Lebensjahr ist E. coli ein häufiger Erreger einer eitrigen Meningitis.

\section{Toxische Prozesse}

Obligat pathogene E.-coli-Stämme sind Erreger von Durchfallserkrankungen. Es werden folgende fünf Gruppen unterschieden:

1. Enteropathogene E-coli-Stämme (EPEC) verursachen die Säuglingsenteritis ( $>1 \mathrm{Jahr}$ ), sind weltweit verbreitet und werden bestimmten O-Antigengruppen zugeordnet.

2. Enterohämorrhagische E.-coli-Stämme (EHEC) verursachen eine hämorrhagische Colitis, ferner kann die Infektion zum hämolytisch-urämischen Syndrom (HUS) führen, einhergehend mit hämolytischer Anämie, Thrombozytopenie und häufig letalem Ausgang. Auch diese Stämme werden bestimmten serologischen Gruppen zugeordnet, hauptsächlich dem Serotyp 0157:H7, Verbreitung ist weltweit, betroffen sind Erwachsene und Kinder. EHEC O104:H4 führt gleichfalls zu epidemischen Ausbrüchen mit zum Teil schwersten Krankheitsverläufen, einhergehend mit HUS und mitunter auch tödlichem Ausgang. Die Übertragung erfolgt durch kontaminierte Nahrungsmittel, z. B. mit Sprossen von aus Ägypten importiertem Bockshornkleesamen.

3. Enterotoxinbildende E.-coli-Stämme (ETEC), häufig Ursache der Reisediarrhoe. Betroffen sind alle Altersgruppen. Verbreitung weltweit, vor allem in warmen Ländern („Montezumas Rache"). Auch diese Stämme sind bestimmten serologischen Ound $\mathrm{H}$-Antigengruppen zugeordnet.

4. Enteroinvasive E.-coli-Stämme (EIEC) verursachen eine Enterocolitis, wobei alle Altersgruppen betroffen sind. Vorwiegend kommen die Erreger in Ländern mit geringem Hygienestandard vor. Auch diese Erreger gehören zu einem engen Spektrum bestimmter O-Antigentypen.

5. Enteroaggregative E.-coli-Stämme (EAggEC) sind Ursache von chronischen Diarrhoen, vor allem bei Säuglingen und Kleinkindern und bei immungeschwächten Personen, einhergehend mit Gewichtsverlust und Entwicklungsstörungen.

Die Übertragung all dieser Erreger erfolgt exogen über Nahrungsmittel, die mit menschlichen oder tierischen Faezes kontaminiert sind, wie beispielsweise ungenügend gekochte Nahrungsmittel, Salate, Eis, Wasser u. a.

\section{Diagnostik}

\section{Untersuchungsmaterial}

Blut, Urin, Stuhl, Abstriche.

\section{Diagnostische Verfahren}

Kulturelle Anzüchtung: Hierbei besteht kein Unterschied zwischen fakultativ und obligat pathogenen $E$.coli-Stämmen; sie können in einfachen flüssigen Nährmedien, wie Nährbouillon, und auf festen Nährböden, wie Blut-, Endo-, MacConkey-Agar, bei $36 \pm 1{ }^{\circ} \mathrm{C}$ sowohl unter aeroben als auch unter anaeroben Bedingungen gezüchtet werden.

Molekularbiologische Differenzierung: Zur Identifizierung und Abgrenzung obligat pathogener E.-coliStämme können PCR-Verfahren eingesetzt werden durch Verwendung passender Primersequenzen von Toxingenen und Genen von Pathogenitätsfaktoren $(\triangleright$ MiQ 9).

Serologische Differenzierung: Zur Zeit sind 171 O-, $103 \mathrm{~K}-, 75 \mathrm{H}$ - und $12 \mathrm{~F}$-Antigene bekannt von E.-coliStämmen, die in der Human- und Veterinärmedizin von Bedeutung sind.

Phagen-Lysotypie: Möglich bei obligat pathogenen E.-coli-Stämmen (Speziallaboratorien).

\section{Befund / Interpretation}

Erregernachweis und Charakterisierung ausschlaggebend.

\section{Therapie}

\section{Therapeutische Maßnahmen}

Bei Erkrankungen, die durch fakultativ pathogene E.coli-Stämme verursacht werden: Nach Möglichkeit nach Antibiogramm, in Frage kommen Aminopenicilline, Ureidopenicilline, Cephalosporine, Carbapeneme, Chinolone, Cotrimoxazol, in Ausnahmesituationen in Kombination mit Aminoglykosiden.

Bei Erkrankungen durch obligat pathogene E.-coliStämme: In der Regel sind die durch diese Erreger hervorgerufenen Gastroenteritiden selbstlimitierend. Bei starkem Flüssigkeitsverlust, insbesondere bei Säuglingen und Kleinkindern, ist ein rascher Ersatz des Flüssigkeits- und Elektrolytverlustes notwendig entsprechend der WHO-Formel: Glukose $20 \mathrm{~g} / \mathrm{l}, \mathrm{Na}^{+}-$ Bicarbonat 2,5 g/l, $\mathrm{Na}^{+}$-Chlorid 3,5 g/l, $\mathrm{K}^{+}$-Chlorid $1,5 \mathrm{~g} / \mathrm{l}$ (Handelsname: Elotrans ${ }^{\circ}$ ). Bei Reisen in warme Länder kann die Schwere und Dauer der Erkrankung durch zweimalige Gabe eines Chinolons (z. B. Ciprofloxacin) über $24 \mathrm{~h}$ bzw. Cotrimoxazol gebessert und verkürzt werden.

\section{Resistenz}

E. coli produziert zahlreiche Betalaktamasen, die bei der Antibiotikaresistenz von Bedeutung sind. 


\section{Epidemiologie}

\section{Verbreitung}

Im Krankenhaus ist eine epidemische Ausbreitung von fakultativ pathogenen multiresistenten E.-coliStämmen im Rahmen von nosokomialen Infektionen bei Nichtbeachtung krankenhaushygienischer Maßnahmen möglich.

Bei obligat pathogenen E.-coli-Stämmen sind epidemische Ausbrüche möglich über kontaminierte Nahrungsmittel. Vor allem bei EHEC-Stämmen sind epidemische Ausbrüche beschrieben worden in Kindergärten, durch Schmierinfektionen oder beispielsweise in ganzen Ortschaften durch kontaminiertes Trinkwasser.

\section{Wirtsbereich / Reservoir}

Fakultativ pathogene E.-coli-Stämme kommen außerhalb des Menschen praktisch ubiquitär bei zahlreichen Tierarten vor. Obligat pathogene E.-coli-Stämme finden sich vor allem im Darm von Milchkühen und Kälbern und können - insbesondere in warmen Klimazonen - auch im Darm des Menschen nachgewiesen werden.

\section{Risikogruppen}

Fakultativ pathogene E.-coli-Stämme: Säuglinge (Meningitis), Wickelkinder (Harnwegsinfektion), bei Patienten mit allgemeiner Abwehrschwäche, Diabetes mellitus, Obstruktionen der ableitenden Harnwege, Dauerkatheterträger, bei Querschnittslähmung, Blasenverweilkatheter (nach drei Tagen bei ca. $90 \%$ der Patienten): Harnwegsinfektionen, beatmete Patienten (Pneumonie) nach dickdarmchirurgischen Eingriffen (Peritonitis), bei Patienten mit Obstruktionen der Gallenwege und Gallensteinen (Cholezystitis), Patienten mit Verbrennungen, nach operativen Eingriffen (Wundinfektion).

Obligat pathogene E.-coli-Stämme: Säuglinge bei EPEC, im Übrigen alle Altersgruppen, vor allem bei Reisen in warme Klimazonen.

\section{Transmission / Vektoren}

Fakultativ pathogene E.-coli-Stämme werden endogen übertragen, obligat pathogene E.-coli-Stämme werden fäkal-oral über die Nahrungsmittelkette übertragen.

\section{Prävention / Impfstoffe}

Fakultativ pathogene E.-coli-Stämme: Einhaltung der krankenhaushygienischen Regeln, vor allem hygienische Händedesinfektion, auf Intensivstationen stets bei Wechsel von einem Patienten zum anderen; suprapubische Harnableitung im geschlossenen System, keine Katheterisierung der Harnblase zur Gewinnung von Urin für mikrobiologisch-diagnostische Zwecke. Obligat pathogene E.-coli-Stämme: in Endemiegebieten Einhalten der 3-S-Regel: schälen, sieden, spülen.

\section{Meldepflicht}

Nach $₫ 7$ Abs. 1 IfSG ist der direkte oder indirekte
Nachweis namentlich zu melden, soweit die Nachweise auf eine akute Infektion: a) E. coli, enterohämorrhagische Stämme (EHEC), b) sonstige darmpathogene E.-coli-Stämme hinweisen.

$\$ 23$ IfSG Abs. 1: Multiresistenz ist zu dokumentieren.

\section{Weiterführende Informationen}

\section{Web-Adressen}

- http://www.rki.de

- http://www.cdc.gov/

- http://www.genome.wisc.edu

\section{Schlüsselliteratur}

1. Blaser MJ, Smith PD, Ravdin JI, Greenberg HB, Guerrant RL (eds) (1995) Infections of the Gastrointestinal Tract, Raven Press New York

2. Frank C et al (2011) Epidemic Profile of Shiga-ToxinProducing-Escherichia coli O104:H4 Outbreak in Germany - Preliminary Report. N Engl J Med 2011:1-11

3. Hahn H, Falke D, Kaufmann SHE, Ullmann U (Hrsg) (2005) Medizinische Mikrobiologie und Infektiologie. 5. Aufl., Springer, Berlin Heidelberg New York

4. Kist M, Bockemühl J, Aleksic S, Altwegg M, Autenrieth IB, Bär W, Beutin L, Gerten B, Heintschel von Heinegg E, Karch H, Lehmacher A, Mehnert F, Sonnenborn U, Tschäpe $\mathrm{H}$, von Eichel-Streiber C (2000) Infektionen des Darmes: MiQ 9. Urban und Fischer, München, Jena

5. Konemann EW, Allen HD, Janda WM, Schreckenberger PC, Winn EC (eds) (1997) Diagnostic Microbiology, 5th edn, Lippincott, Philadelphia, New York

\section{Espundia}

Leishmanien

\section{Eubakterien}

HeIdi Schütt-Gerowitt

\section{Erreger}

\section{Erregerspezies}

Eubacterium (jetzt: Eggerthella) lentum, Eubacterium nodatum und ca. 22 andere Arten

\section{Taxonomie}

In der Gattung Eubacterium wurden - wie in der gesamten Gruppe der anaeroben grampositiven Stäbchen - in letzter Zeit viele taxonomische Veränderungen vorgenommen; einige Eubakterien-Arten wurden eigenen neuen Gattungen zugeordnet.

\section{Historie}

Eubacterium spp. wurden zuerst von Eggerth 1935 aus Stuhlproben isoliert und damals fälschlich der Gattung Bacteroides zugeordnet; die Genusbeschreibung erfolgte 1938 durch Prevot.

\section{Morphologie}

Grampositive kleine Stäbchen, keine Sporenbildung. 


\section{Genom}

Das Genom der Eubakterien ist mittels PCR nachweisbar, 16S rRNA-Vergleiche führten zu der oben angesprochenen taxonomischen Neuordnung.

\section{Vermehrung}

Die Bakterien der Gattung Eubacterium vermehren sich nur unter streng anaeroben Bedingungen.

\section{Pathogenität / Virulenz / Antigenvariabilität}

Nicht bekannt.

\section{Erkrankung}

Abszesse: Nierenabszess, Bartholinischer Abszess, intraabdomineller Abszess, Infektionsprozesse der Orofazialregion, Parodontalerkrankungen, Wundinfektionen, intrauterine Infektionen bei liegendem Intrauterinpessar

\section{Inkubationszeit}

Nicht bekannt, endogene Infektion.

\section{Leitsymptome}

Abszedierende Prozesse.

\section{Symptome}

Unspezifische, abszedierende Prozesse und Wundinfektionen.

\section{Pathophysiologie}

Eubakterien kommen in der Regel in den genannten Prozessen nicht in Reinkultur vor, sondern in Verbindung mit virulenteren anaeroben oder fakultativen Bakterien.

\section{Immunantwort}

Nicht bekannt.

\section{Differenzialdiagnose}

Infektionen durch andere Erreger.

\section{Diagnostik}

\section{Untersuchungsmaterial}

Durch Abszesspunktion gewonnener Eiter, tiefe Wundabstriche.

\section{Diagnostische Verfahren}

Kulturelle Anzüchtung unter anaeroben Bedingungen mit nachfolgender Identifizierung mittels biochemischer Reaktionen oder Gensequenzierung.

\section{Befund / Interpretation}

Wie bei jedem Nachweis von Bakterien der normalen Körperflora ist eine ätiologische Bedeutung nachgewiesener Eubacterium spp. nur bei adäquat entnommenem Untersuchungsmaterial (ohne Kontamination mit der Flora der angrenzenden besiedelten Körperbereiche) anzunehmen.

\section{Therapie}

\section{Therapeutische Maßnahmen}

Eubacterium spp. sind empfindlich für Penicilline. Wegen ihres überwiegenden Vorkommens in Mischinfektionen ist jedoch die Gabe eines Penicillins in Kombination mit einem Penicillinase-Inhibitor (Ampicillin plus Sulbactam, Amoxicillin plus Clavulansäure) zu empfehlen; als Alternativen kommen Clindamycin, Erythromycin oder Tetrazykline in Frage. Die sonst bei Anaerobier-Infektionen vor allem eingesetzten Nitroimidazole (z. B. Metronidazol) sind nicht wirksam.

\section{Resistenz}

Natürliche Resistenz gegen Nitroimidazole (z. B. Metronidazol).

\section{Epidemiologie}

\section{Verbreitung}

Ubiquitär.

\section{Wirtsbereich / Reservoir}

Eubacterium spp. sind Bestandteil der normalen Körperflora des Menschen (Darmflora, Mundflora: vor allem E. lentum, Urogenitaltrakt: E. nodatum) sowie von Tieren.

\section{Risikogruppen}

Frauen mit liegendem Intrauterinpessar.

\section{Transmission / Vektoren}

Nicht bekannt.

\section{Prävention / Impfstoffe}

Keine.

\section{Ausbruchsmanagement}

Nicht erforderlich.

\section{Meldepflicht}

Keine.

\section{Weiterführende Informationen}

\section{Referenzzentren / Expertenlaboratorien}

- Konsiliarlaboratorium für anaerobe Bakterien: Zentrum für Infektionsmedizin, Institut für Medizinische Mikrobiologie und Infektionsepidemiologie, Universität Leipzig, Herr Professor Dr. A. C. Rodloff, Liebigstr. 24, 04103 Leipzig

\section{Schlüsselliteratur}

1. Hahn H, Kaufmann S, Schulz Th (Hrsg) (2009) 6. Auflage Springer Verlag, Heidelberg

2. Mandell GL, Bennet JE, Dolin R (eds) (2009) Principles and Practice of Infectious Disease, $7^{\text {th }}$ ed. Churchill Livingstone Inc, London

3. Murray PR, Baron EJ, Jorgensen JH, Pfaller MA, Yolken RH (eds) (2009) Manual of Clinical Microbiology $8^{\text {th }}$ edn. ASM Press, Washington 


\section{Eumyzetom}

Eumyzetom (Madurella mycetomatis u.v.a.)

- Phaeohyphomycetes

\section{Eumyzetom (Madurella mycetomatis u.v.a.)}

Reinhard Kappe, Dagmar Rimek

\section{Erreger}

\section{Synonym(e)}

Das Eumyzetom wird auch als Maduramykose oder Madurafuß bezeichnet. Es umfasst die subkutanen Erkrankungsformen von Hyalohyphomykose und Phaeohyphomykose.

\section{Erregerspezies}

Acremonium falciforme, Acremonium kiliense, Acremonium recifei, Aspergillus nidulans, Corynespora cassiicola, Curvularia geniculata, Curvularia lunata, Cylindrocarpon destructans, Exophiala jeanselmei, Fusarium moniliforme, Fusarium solani, Leptosphaeria senegalensis, Leptosphaeria tompkinsii, Madurella grisea, Madurella mycetomatis, Neotestudina rosatii, Polycytella hominis, Pseudochaetosphaeronema larense, Pyrenochaeta romeroi, Scedosporium apiospermum

Weitere Erreger sind in den Kapiteln Phaeohyphomyzeten, Scedosporium, Aspergillus und Fusarium als Erreger der jeweiligen subkutanen Erkrankungen gelistet.

\section{Taxonomie}

Die Eumyzetom-Erreger gehören zu den Ascomycetes oder zu den Fungi imperfecti.

\section{Historie}

Die früheste dokumentierte Beschreibung eines Myzetoms wurde 1846 von J. Godfrey gegeben: Er berichtete über vier Fälle von „Morbus tuberculosis pedis“ in Madras (Chennai), Indien.

\section{Morphologie}

Wirtsgewebe: Charakteristisch sind Granula (Drusen) im Eiter. Diese sind je nach Erreger verschieden groß $(50 \mu \mathrm{m}$ bis $>1 \mathrm{~mm})$, sphärisch oder gelappt, hart oder weich und unterschiedlich gefärbt (weiß, gelb, rosa oder schwarz). Eumyzetom-Drusen enthalten 2-6 $\mu \mathrm{m}$ starke Hyphen, die oft große, runde, aufgetriebene Zellen am Rand aufweisen. Die Hyphen sind je nach Erreger entweder dunkel pigmentiert oder hyalin. Die Unterscheidung echter, mykotischer (= Eumyzetome) von bakteriellen (aktinomykotischen) Myzetomen ist aufgrund der unterschiedlichen FilamentDurchmesser mikroskopisch leicht möglich. Aktinomyzeten bilden feine grampositive Fäden von maximal $1 \mu \mathrm{m}$ Durchmesser. Die Artdiagnose ist histolo- gisch oder direktmikroskopisch nicht möglich. Sie erfordert die Isolierung des Erregers.

Kultur: Auf die Kolonie- und Mikromorphologie der einzelnen Eumyzetom-Erreger kann wegen der Vielzahl der völlig unterschiedlichen Erreger aus verschiedenen Familien und Ordnungen hier nicht eingegangen werden. Für einzelne Erreger siehe Phaeohyphomycetes, Aspergillus, Scedosporium und Fusarium.

\section{Genom}

Bei einer Reihe der Eumyzetom-Erreger sind Sequenzen z. B. der ribosomalen Gene bekannt. Auf deren Basis kann eine molekulare Identifizierung erfolgen.

\section{Vermehrung}

Im Reservoir (Pflanzen und Erdboden) findet eine vegetative Vermehrung statt, bei den meisten Erregern von Eumyzetomen mit Ausbildung luftgetragener Konidiosporen, die der Verbreitung dienen. Darüber hinaus sind bei vielen Arten sexuelle Fortpflanzungszyklen bekannt. Im Wirt (humanes und tierisches Gewebe) findet sich ausschließlich eine vegetative Vermehrung, die sich zudem auf myzeliales Wachstum ohne Ausbildung von Sporen beschränkt.

\section{Pathogenität / Virulenz / Antigenvariabilität}

Keine Daten verfügbar.

\section{Erkrankung}

Eumyzetom

\section{Synonym(e)}

Maduramykose, Madurafuß.

\section{Inkubationszeit}

Die Erreger des Eumyzetoms gehören zu den langsam wachsenden Pilzen, was eine sehr lange Inkubationszeit und einen langen Krankheitsverlauf von Monaten bis Jahren bedingt.

\section{Leitsymptome}

Chronisch-proliferativer und -destruktiver, tumoröser und fistelnder Prozess in der Unterhaut, oft auf die Knochen übergreifend. Erreger als Granula (Drusen) im Eiter. Größe, Form, Konsistenz und Farbe der Granula sind charakteristisch für die einzelnen Erreger. Es kommen jedoch sowohl bei den Pilzen (Eumyzetome) als auch bei den Aktinomyzeten (bakterielle Erreger) harte und weiche sowie helle und dunkle Granula vor.

\section{Symptome}

Das Eumyzetom ist eine chronische, nicht schmerzhafte, eitrige Infektion des Subkutangewebes und angrenzender Knochen. Die Läsion beginnt an der Stelle eines Mikrotraumas und breitet sich im Verlauf von Monaten bis Jahren lokal aus. Der Fuß stellt die häufigste Lokalisation dar, fast immer einseitig. Die initiale Läsion ist eine kleine subkutane Schwellung. Am Fuß befindet sich diese Läsion oft zwischen dem 1 . 
und 2. Metatarsalknochen, dorsal oder plantar. Das betroffene Areal ist wenige Millimeter groß, fest oder gummiartig und schmerzlos. Die darüber liegende Haut erscheint normal und zu Beginn frei verschiebbar. In den Folgemonaten breitet sich die Infektion in den Faszienlogen aus, und es entsteht ein größeres, verhärtetes Gebiet. Es bilden sich zahlreiche kleine Abszesse aus, die im Allgemeinen durch Fisteln verbunden sind. Gewinnen diese Fisteln Anschluss an die Hautoberfläche, erscheinen sie als weiche oder blasige Gebiete, die nach Eröffnung serös-blutige Flüssigkeit entleeren. Die Drainageflüssigkeit enthält die charakteristischen Drusen. Auch die Knochenbeteiligung verläuft schmerzlos, selbst bei Belastung. Muskeln, Nerven und Sehnen sind relativ resistent gegenüber der Infektion, sodass die Funktion gut erhalten bleibt. Myzetome sind nicht von systemischen Reaktionen wie Fieber, Leukozytose, Anämie oder Gewichtsverlust begleitet. Regionale Lymphknoten können vergrößert sein, enthalten jedoch nur selten den Erreger. Es besteht keine Tendenz zur hämatogenen Aussaat.

\section{Pathophysiologie}

Destruktives Erregerwachstum per continuitatem in den Faszienlogen.

\section{Immunantwort}

Über eine systemische Immunantwort ist wenig bekannt. Es wurden präzipitierende Antikörper gegen einzelne Erreger im Blutserum von Eumyzetom-Patienten nachgewiesen. Lokal finden sich außer granulozytenhaltigem Eiter keine weiteren Entzündungszeichen.

\section{Differenzialdiagnose}

Bakterielles Myzetom (Aktinomykose z. B. durch Nocardia brasiliensis), Basidiobolomykose, Tuberkulose.

\section{Diagnostik}

\section{Untersuchungsmaterial}

Granula-(Drusen-)haltiger Eiter. Gewebebiopsie.

\section{Diagnostische Verfahren}

Größe, Form, Farbe und Konsistenz von Drusen, zusammen mit der Kenntnis der vorherrschenden Eumyzetom-Erreger einer geografischen Region, führen zur Verdachtsdiagnose.

Direktmikroskopische Untersuchung: Die Drusen werden in $10 \% \mathrm{KOH}$ auf einen Objektträger gebracht und durch Aufdrücken eines Deckgläschens aufgebrochen. Die Mikromorphologie erlaubt die Unterscheidung zwischen einem Pilz-Myzetom (Eumyzetom) und einem bakteriellen (aktinomykotischen) Myzetom.

Kultur: Zur definitiven Identifizierung eines Eumyzetom-Erregers muss dieser isoliert werden. Drusen werden in antibiotikahaltiger Kochsalzlösung gewaschen und auf Sabouraud-Glukose-Agar mit Antibio- tikazusatz ausgespatelt. Die Inkubation erfolgt bei $28^{\circ} \mathrm{C}$ und $37^{\circ} \mathrm{C}$ für sechs Wochen. Die Identifizierung des Erregers geschieht anhand von Kolonie- und Mikromorphologie.

\section{Befund / Interpretation}

Der kulturell nachgewiesene Pilz muss zur Morphologie der Granula passen (Cave: Kontaminanten!).

\section{Therapie}

\section{Therapeutische Maßnahmen}

Eumyzetome sprechen kaum auf antimykotische Chemotherapie an. Berichte über Befundbesserungen durch langdauernde Behandlungen durch Voriconazol, Posaconazol und Terbinafin liegen vor. Die In-vitro Empfindlichkeit der zugrundeliegenden Eumyzetom-Erreger sollte bestimmt werden. Die chirurgische Exzision kleiner, gut abgekapselter Eumyzetom-Herde ist hilfreich. Bei ausgedehnten Fällen ist die Amputation die aussichtsreichste Therapie. Rezidive am Resektionsrand stellen eine bekannte Komplikation dar.

\section{Resistenz}

Eine Reihe von Eumyzetom-Erregern ist resistent gegenüber den gängigen Antimykotika. Nach Anzucht eines Erregers sollte eine In-vitro-Resistenzbestimmung erfolgen.

\section{Epidemiologie}

\section{Verbreitung}

Eumyzetome kommen in den Tropen vor (zwischen $15^{\circ}$ südlicher und $30^{\circ}$ nördlicher Breite). Sie sind endemisch in Indien sowie Ländern Afrikas und Südamerikas. Männer sind viermal häufiger betroffen. Die Erkrankung beginnt oft zwischen dem 20. und 45. Lebensjahr.

\section{Wirtsbereich / Reservoir}

Einige Erreger wurden auf dornigen Bäumen wie Akazien nachgewiesen, andere im Erdboden.

\section{Risikogruppen}

Farmer und Hirten in tropischen und subtropischen Klimazonen, die in ländlichen Gebieten leben und öfter geringfügigen, penetrierenden Verletzungen durch Dornen oder Splitter ausgesetzt sind. Barfuß gehende Bevölkerung.

\section{Transmission / Vektoren}

Die Erkrankung wird durch Inokulation von Pilzmaterial in kleine Verletzungen erworben. Sie ist nicht von Mensch zu Mensch oder von Tier zu Mensch übertragbar.

\section{Prävention / Impfstoffe}

Vermeidung penetrierender Mikrotraumata mit Verschmutzung der Wunden in tropischen Gebieten, z. B. durch Tragen festen Schuhwerks. 


\section{Ausbruchsmanagement}

Die Erkrankung ist nicht von Mensch zu Mensch übertragbar.

\section{Meldepflicht}

Nach dem Infektionsschutzgesetz besteht für das Eumyzetom in Deutschland keine Meldepflicht.

\section{Weiterführende Informationen}

\section{Referenzzentren / Expertenlaboratorien}

- Konsiliarlaboratorium für Pseudallescheria boydii / Scedosporium sp. und Erreger außereuropäischer Systemmykosen, Robert Koch Institut, Mykologie, Fr. Dr. Kathrin Tintelnot, Nordufer 20, 13353 Berlin, Tel.: 01888-7542208, Fax: 01888-754-2614,E-Mail: tintelnotk@rki.de

- Centraalbureau voor Schimmelcultures, PO Box 85167, NL-3508 AD Utrecht, The Netherlands. Phone: +31-302122600, fax +31-30-2512097, email: info@cbs.knaw.nl

\section{Web-Adressen}

- DoctorFungus Corporation: http://www.doctorfungus.org

- Centraalbureau voor Schimmelcultures, Niederlande: http://www.cbs.knaw.nl

- ISHAM Working Group Mycetoma: http://www. isham. org

\section{Schlüsselliteratur}

1. De Hoog GS, Ahmed AOA, McGinnis MR, Padhye AA (2007) Fungi Causing Eumycotic Mycetoma.. In: Murray PR, Baron EJ, Jorgensen JH, Landry ML, Pfaller MA (eds) Manual of Clinical Microbiology, vol 2, $9^{\text {th }}$ edn. ASM Press, Washington DC, Chapter 126
2. De Hoog GS, Guarro J, Gene J, Figuera MJ (2000) Atlas of Clinical Fungi, $2^{\text {nd }}$ edn. Centraalbureau voor Schimmelcultures, Utrecht

3. Kwon-Chung KJ, Bennett JE (1992) Medical Mycology, $2^{\text {nd }}$ edn. Chapter 21: Mycetoma. Lea \& Febiger, Philadelphia, London, pp 560-593

4. Lichon V, Khachemoune A (2006) Mycetoma: a review. Am J Clin Deramatol 7:315-321

\section{Everglades-Virus}

Alphaviren

\section{Exanthema subitum}

- Humanes Herpesvirus 6 (HHV-6)

- Humanes Herpesvirus 7 (HHV-7)

\section{Exophiala jeanselmei}

- Eumyzetom (Madurella mycetomatis u.v.a.)

\section{Extended-Spectrum Betalaktamasen}

$>\mathrm{ESBL}$ 


\section{Fasciola hepatica}

\section{Erreger \\ Synonym(e) \\ Großer Leberegel, liver fluke.}

\section{Erregerspezies}

Fasciola hepatica

\section{Taxonomie}

Phylum: Plathelminhes; Klasse: Digenea; Ordnung: Echinostomatida; Familie: Fasciolidae; Gattung: Fasciola; Art: Fasciola hepatica

\section{Historie}

1379 wurde Fasciola hepatica von französischen Schäfern gekannt (de Brie), 1684 von Redi beschrieben, 1758 von Linne als Fasciola hepatica bezeichnet; damit gehört F. hepatica zu den ersten Helminthen, die taxonomisch eingeordnet wurden. Der Entwicklungszyklus wurde 1881/82 von Leuckart beschrieben.

\section{Morphologie}

Die adulten Leberegel (Zwitter) werden ca. $2-5 \mathrm{~cm} \times$ 4-13 mm groß. Fasciola gigantea kann eine Länge von $7 \mathrm{~cm}$ erreichen. Als charakteristisch gelten das abgesetzte, zugespitzte Vorderende mit Mundsaugnapf und Bauchsaugnapf, die seitlich stark verästelten Darmschenkel und die beiden lateralen Schenkel des Vitellariums. Die Oberfläche ist mit zahlreichen Dornen versehen. Die aus dem Uterus abgesetzten gelbbräunlichen, dünnwandigen Eier sind ca. 130-150 $\mu \mathrm{m} \times 60$ $90 \mu \mathrm{m}$ groß und zählen damit zu den größten der mikroskopisch sichtbaren Helmintheneier. Durch ihre Größe und das vorhandene Operculum sind sie charakteristisch.

\section{Genom}

F. hepatica besitzt im diploiden Zustand 12 Chromosomen.

\section{Vermehrung}

Die Entwicklung der Eier erfolgt im Freien. Wenn sie ins Wasser gelangen, entsteht in ihnen eine bewimperte Larve (Mirazidium). Diese schlüpft und dringt in eine Wasserschnecke (1. Zwischenwirt; Gattung Lymnea) ein, in der binnen 4 Wochen im Hepatopankreas eine starke Vermehrung und Entwicklung über Sporozysten und Redien bis hin zu beweglichen Zerkarien erfolgt. Diese setzen sich, nachdem sie die Schnecke verlassen haben, an Wasserpflanzen („2. Zwischenwirt") fest und enzystieren zur Metazerkarie. Wird diese von Weidetieren (Endwirt; z. B. Schaf) auf sumpfigen Wiesen oder vom Mensch (Zufallswirt) oral (Verzehr von Sauerampfer oder Brunnenkresse Nasturtium officinale) aufgenommen, schlüpft die Metazerkarie im Dünndarm aus der Hülle, durchdringt die Darmwand, penetriert die Leber von außen und wandert binnen 2 Monaten durchs Leberparenchym in die Gallengänge. Nach dem Heranwachsen zum adulten Tier werden die Würmer (als zwittrige Egel) geschlechtsreif und beginnen etwa 3-4 Monate nach der Kopulation mit anderen Zwittern mit der Eiablage. Die ausgeschiedenen Eier gelangen mit der Gallenflüssigkeit in den Stuhl.

\section{Pathogenität / Virulenz / Antigenvariabilität}

Leberegelbefall ist pathogen durch die Beschädigung der Leber bei der Wanderung durchs Leberparenchym wie auch durch die Blockade der Gallengänge. Bereits geringer Befall führt evtl. zu schweren Schäden. Die sezernierten Proteasen induzieren während der Wanderung in der Leber die Symptome.

\section{Erkrankung \\ Fascioliasis, Fasciolose}

\section{Inkubationszeit}

Die Inkubationszeit beträgt 3-12 Wochen; die Präpatenzzeit 3-4 Monate und die Patenzzeit bis zu 20 Jahre.

\section{Leitsymptome}

Hepatitis, Cholangitis.

\section{Symptome}

Das Blutbild weist eine sekundäre Anämie mit deutlicher Eosinophilie (und evtl. Leukozytose) auf. Die Migration des larvalen Egels verursacht nekrotische Abszesse. Ein akutes Krankheitsbild zeigt sich selten (nur bei starkem simultanem Befall) und manifestiert sich dann mit kolikartigen Schmerzen, Übelkeit, Erbrechen, Fieber. Weitere Symptome sind Leberentzündung, Appetitlosigkeit, Oberbauchbeschwerden, Mattigkeit, Lebervergrößerung, Wucherungen, Verkalkungen und Verstopfungen der Gallengänge, Aszites und zirrhotische Erscheinungen. Werden adulte Leberegel z. B. beim Verzehr roher Tierleber aufgenommen, können diese sich im Rachen festsetzen und zu Schluckbzw. Atembeschwerden führen.

\section{Pathophysiologie}

Es findet sich eine Hyperplasie des Gallengangepithels. 
Die Abgabe von Prolin durch die adulten Würmer (stimulieren die Kollagenproduktion) führt zu Fibrosen.

\section{Immunantwort}

Die durch den Leberegel hervorgerufene geringgradige Immunantwort führt weder zur Abtötung des Parasiten, noch schützt sie vor Reinfektion.

\section{Differenzialdiagnose}

Leberstörungen anderer Genese (z. B. Schistosomiasis, Zirrhosen anderer Genese).

\section{Diagnostik}

\section{Untersuchungsmaterial}

Zum Nachweis der charakteristischen Eier ist nativer (unfixierter) oder fixierter Stuhl in geeigneten Transportgefäßen bzw. speziellen Transportsystemen einzusenden. Der Einachweis gelingt evtl. auch im Gallensaft oder im Sekret des Zwölffingerdarms.

\section{Diagnostische Verfahren}

Mikroskopische Stuhl-Diagnostik nach Anreicherungsverfahren.

\section{Befund / Interpretation}

Der Nachweis von F-hepatica-Eiern ist beweisend. Eine Scheininfektion kann beim Verzehr roher Tierleber auftreten (Verschlucken und Ausscheiden von Eiern). Diese ist durch Folgeuntersuchungen auszuschließen.

\section{Therapie}

Therapeutische Maßnahmen

Triclabendazol gilt als wirksames Mittel.

\section{Epidemiologie}

\section{Verbreitung}

Der (seltene) Befall des Menschen kommt überall dort vor, wo mit Metazerkarien behaftete Brunnenkresse oder andere Wasserpflanzen geerntet oder verzehrt werden. F. gigantea bevorzugt warme Gebiete. Endemisch hält sich F. hepatica in Gegenden, in denen Rinder und Schafe die Gewässer kontaminieren können. Hiervon betroffen sind zahlreiche Länder in Europa, Afrika, Asien und Amerika. In Frankreich gab es immer wieder kleinere Epidemien beim Menschen.

\section{Wirtsbereich / Reservoir}

Die Infektion mit Fasciola hepatica ist primär eine Zoonose herbivorer Säugetiere und hat ein weites Wirtsspektrum. Endwirte sind Wiederkäuer. Kaninchen und Ratten dienen als Reservoirwirte. Der Mensch ist eher selten ein Zufallswirt.

\section{Risikogruppen}

Personen, die bei der Nahrungszubereitung solche Pflanzen verwenden bzw. verzehren, die mit Metazer- karien behaftet sind. Kinder sind häufiger betroffen als Erwachsene.

\section{Transmission / Vektoren}

Die infektiösen Stadien von F. hepatica werden beim Verzehr der als "Zwischenwirte" dienenden Wasserpflanzen aufgenommen.

\section{Prävention / Impfstoffe}

Werden die beschriebenen Wasserpflanzen nicht oder nur im abgekochten Zustand verzehrt, kommt es nicht $\mathrm{zu}$ einer Infektion. Die Bekämpfung der Fasciolose muss bei der Behandlung der herbivoren Säugetiere ansetzen, um eine Infektion der Schnecken zu verhindern. Maßnahmen zur Schneckenbekämpfung sind problematisch.

\section{Meldepflicht}

Es besteht keine Meldepflicht.

\section{Weiterführende Informationen}

\section{Referenzzentren / Expertenlaboratorien}

- Als fachlich qualifizierte Ansprechstellen gelten alle parasitologischen und tropenmedizinischen Institutionen.

\section{Web-Adressen}

- Identifikation/Diagnose: www.dpd.cdc.gov/dpdx

\section{Schlüsselliteratur}

1. Mehlhorn H (2007) Encyclopedia of Parasitology, $3^{\text {nd }}$ edn. Springer-Verlag, Berlin

\section{Fascioliasis}

Fasciola hepatica

\section{Fasciolopsiasis}

- Darmegel

\section{Fasciolopsis buski}

- Darmegel

\section{Fasciolose}

Fasciola hepatica

\section{Fasziitis, nekrotisierende}

- Bacteroides

- Bilophila

- Flavobacterium

- Prevotella 
Streptococcus agalactiae

Streptococcus pyogenes

\section{Fatale familiäre Insomnie (FFI)}

Prione

\section{Favus}

Trichophyton mentagrophytes

- Trichophyton schoenleinii

\section{Feigwarze}

Humane Papillomviren (HPV)

\section{Feldfieber}

Leptospiren

\section{Fièvre Boutonneuse}

Rickettsien

\section{Fièvre Pourprée Américaine}

Rickettsien

\section{Filarienfieber}

Brugia

- Wuchereria

\section{Filariose}

Wuchereria

\section{Filoviren}

\section{Erreger}

Stephan Becker, Hans Dieter Klenk

\section{Erregerspezies}

Marburgvirus, Ebolavirus

\section{Taxonomie}

Marburgvirus und Ebolavirus bilden die Familie Filoviridae, die das Genus Ebolavirus mit den Spezies Zaire-Ebolavirus, Reston-Ebolavirus, Cote d'Ivoire-Ebolavirus, Sudan-Ebolavirus und Bundibugyo-Ebolavirus sowie das Genus Marburgvirus mit der Spezies LakeVictoria-Marburgvirus umfasst.

\section{Historie}

Marburgvirus wurde 1967 als erstes Filovirus bei einem Ausbruch von hämorrhagischem Fieber, von dem ca. 30 Patienten in Deutschland und Jugoslawien betroffen waren, isoliert. Infektionsquelle waren grüne Meerkatzen (Cercopithecus aethiops), die aus Uganda stammten. Vereinzelte Marburgvirus-Episoden traten 1975, 1980 und 1987 in Süd- und Ostafrika auf. Zu größeren Marburgvirus-Ausbrüchen kam es 1999 in Zaire und 2005 in Angola. Ebolavirus wurde zum ersten Mal 1976 im Sudan und in Zaire beobachtet. In den gleichen Ländern kam es 1977, 1979, 1995 und $2000 \mathrm{zu}$ weiteren Ausbrüchen, bei denen jedesmal mehrere hundert Personen betroffen waren. Kleinere Ausbrüche traten an der Elfenbeinküste und in Gabun auf. Das vermutlich nicht humanpathogene Restonvirus wurde 1989 bei Affen entdeckt, die aus den Philippinen stammten. In den Jahren 2008/2009 kam es in den Philippinen zu einem Ausbruch von Reston-Ebolavirus unter Schweinen.

\section{Morphologie}

Die Viruspartikel sind filamentös, verzweigt, U-förmig, 6-förmig oder zirkulär. Die Länge kann bis zu $1,4 \mu \mathrm{m}$ erreichen, der Querschnitt beträgt $80 \mathrm{~nm}$. Die Viren besitzen eine Lipidhülle mit Spikes, die $7 \mathrm{~nm}$ lang sind und einen Abstand von $10 \mathrm{~nm}$ voneinander haben. Im Inneren liegt das Nukleokapsid, das eine helikale Struktur mit einer zentralen Achse von $20 \mathrm{~nm}$ Durchmesser besitzt.

\section{Genom}

Das Virusgenom besteht aus unsegmentierter, linearer, einzelsträngiger RNS mit negativer Polarität. Es besitzt eine Gesamtgröße von 19 kD. Die 5'- und 3'-Bereiche des Genoms werden nicht transkribiert und enthalten cis-aktive Signale für Replikation, Enkapsidierung und Transkription. Das Genom kodiert in der Reihenfolge der einzelnen Gene für das Hauptnukleokapsidprotein NP, den Nukleokapsid-assoziierten Polymerase-Kofaktor VP35, das Matrixprotein VP40, das Oberflächenglykoprotein GP, ein weiteres Nukleokapsidprotein VP30, ein zweites Matrixprotein VP24 sowie das Polymeraseprotein L.

\section{Vermehrung}

Monozyten/Makrophagen sind die primären Zielzellen in vivo. Die Infektion befällt zunächst Leber und Milz, breitet sich dann aber schnell systemisch aus. In vitro werden die Viren in Zellkulturen (z. B. Verozellen) vermehrt.

\section{Pathogenität / Virulenz / Antigenvariabilität}

Infektionen mit Marburgvirus und Ebolavirus gehören zu den gefährlichsten übertragbaren Erkrankungen 
beim Menschen. Arbeiten mit diesen Erregern können deswegen nur in Hochsicherheitslaboratorien (S4) durchgeführt werden. Marburgvirus und Ebolavirus sind typische Vertreter der so genannten „emerging viruses".

\section{Erkrankungen}

\section{Ebolavirus-Infektion}

Synonym(e)

Ebolavirales hämorrhagisches Fieber.

\section{Inkubationszeit}

4-17 Tage.

\section{Leitsymptome}

Grippeähnliche Symptome, hohes Fieber, Blutungen, Ödeme, Ikterus.

\section{Symptome}

Mit Ausnahme des Reston-Stammes führt Ebolavirus beim Menschen zu schwerem hämorrhagischem Fieber mit Letalitätsraten zwischen $30 \%$ und $90 \%$. Nach einer Inkubationszeit von 3-16 Tagen kommt es zum plötzlichen Krankheitsausbruch mit Fieber, Kopfschmerz, Schüttelfrost, Übelkeit und Muskelschmerz. In der Folge treten Schwindel, Erbrechen, Bauchschmerzen und Durchfall auf. Bei der Mehrzahl der Patienten treten nach 5-7 Tagen schwere hämorrhagische Erscheinungsbilder mit multiplen Blutungen auf. Am häufigsten betroffen sind der Gastrointestinaltrakt, die Lunge und das Zahnfleisch. Blutungen sind die Vorboten für einen tödlichen Ausgang, der im Allgemeinen nach 7-16 Tagen in einem schweren Schockzustand erfolgt. Filoviren zeigen einen ausgeprägten Tropismus für Zellen des retikuloendothelialen Systems, Fibroblasten und interstitielles Gewebe. Die Infektion breitet sich über den gesamten Organismus aus, wobei Leber, Niere, Milz und Lunge besonders stark befallen sind.

\section{Pathophysiologie}

Eine Infektion mit Ebolavirus führt zu Läsionen in Leber, Milz, Nieren und Lymphknoten. Im Spätstadium der Infektion kommt es zu Hämorrhagien in fast allen Organen, so auch in den Nierentubuli, wo Ablagerungen von Fibrin und Fibrinspaltprodukten festgestellt werden können. Zugleich ist die Blutgerinnung gestört.

\section{Immunantwort}

Eine humorale Immunantwort kann 10-14 Tage nach der Infektion festgestellt werden. Die Antikörper sind hauptsächlich gegen die viralen Oberflächenglykoproteine gerichtet. Die massive Virusvermehrung kommt einer schützenden Immunantwort, die prinzipiell möglich ist, in der Regel zuvor.

\section{Differenzialdiagnose}

Differenzialdiagnostisch sollten bei viral bedingtem hämorrhagischem Fieber Infektionen mit Hanta-Virus, Lassa-Virus, Krim-Kongo-Virus bzw. Gelbfiebervirus ausgeschlossen werden. Darüber hinaus ist auch an Malaria, Typhus, Meningokokken und Kala-Azar zu denken. Selten können auch Herpes Simplex Infektion ein Krankheitsbild hervorrufen, das dem Ebolavirus hämorrhagischen Fieber ähnlich ist.

\section{Marburgvirus-Infektion}

\section{Synonym(e)}

Marburgvirales hämorrhagisches Fieber.

\section{Inkubationszeit}

Wie $>$ Ebolavirus-Infektion (Erkrankung 1).

\section{Leitsymptome}

Wie Ebolavirus-Infektion (Erkrankung 1).

\section{Symptome}

Wie $>$ Ebolavirus-Infektion (Erkrankung 1).

\author{
Pathophysiologie \\ Wie Ebolavirus-Infektion (Erkrankung 1).
}

\section{Immunantwort}

Wie $>$ Ebolavirus-Infektion (Erkrankung 1).

\section{Differenzialdiagnose \\ Wie $>$ Ebolavirus-Infektion (Erkrankung 1).}

\section{Diagnostik}

\section{Untersuchungsmaterial}

Wegen der hohen Pathogenität dieser Viren müssen beim Umgang mit infektiösem Material besondere Sicherheitsvorkehrungen beachtet werden.

\section{Diagnostische Verfahren}

Virus kann aus dem Serum akut erkrankter Patienten in Verozellen angezüchtet werden sowie aus Leber, Milz, Lymphknoten, Niere und Herz von Verstorbenen. Während der virämischen Phase können Viruspartikel elektronenmikroskopisch nachgewiesen werden. Serum-Antikörper lassen sich durch indirekte Immunfluoreszenz und ELISA nachweisen. Zum schnellen Nachweis von akuten Erkrankungen wird heute mittels RT-PCR das virale Genom nachgewiesen.

\section{Therapie}

\section{Therapeutische Maßnahmen}

Es gibt keine spezifischen immuntherapeutischen oder antiviralen Behandlungsmethoden. Die symptomatische Behandlung richtet sich gegen disseminierte intravaskuläre Koagulopathie, Schock, Hirnödem, Nierenversagen, Superinfektionen, Hypoxie und Hypotonie. Bei der Behandlung ist auf strikte Isolierung der Patienten und Schutz des klinischen Personals (Schutzkleidung, Respiratoren) zu achten. 


\section{Epidemiologie}

\section{Verbreitung}

Ebolavirus und Marburgvirus kommen in Afrika und Reston-Ebolavirus auf den Philippinen endemisch vor. Durch Affenexport können die Viren in andere Länder übertragen werden. Bei den afrikanischen Ebolavirus-Ausbrüchen wurde die Infektion von Tieren (Affen oder Flughunden) auf den menschlichen Primärfall übertragen. Pflegende Angehörige waren dann die nächsten Infizierten. Nach der Einlieferung infizierter Patienten in ein Krankenhaus kam es dort in der Regel zu massiver Ausbreitung der Krankheit durch kontaminierte ärztliche Instrumente und direkten Blut- und Sekretkontakt. Durch Verbesserung der hygienischen Bedingungen kam es dann regelmäßig zum Erliegen des Ausbruchs.

\section{Wirtsbereich / Reservoir}

Das Reservoir von Filoviren wird höchstwahrscheinlich durch verschiedene Spezies von Fledertieren gebildet. Nachgewiesen wurde Marburgvirus in Rousettus aegyptiacus, dem Nilflughund. Die Viren können auf Affen (grüne Meerkatzen, Schimpansen, Gorillas) übertragen werden, die dann eine wichtige Infektionsquelle für den Menschen darstellen (Nahrungskette). Als Tiermodelle dienen Primaten, Meerschweinchen und Mäuse, für die die Infektion, u. U. nach mehreren Passagen, in der Regel tödlich ist.

\section{Risikogruppen}

Hierzu gehören in erster Linie Ärzte, Pflegepersonal und Mitpatienten infizierter Patienten, im weiteren Sinne aber auch allgemein Ärzte und Pflegepersonal in endemischen Gebieten.

\section{Transmission / Vektoren}

Filovirusinfektionen sind Anthropozoonosen. Die Übertragung von Mensch zu Mensch, vermutlich aber auch vom Tier auf den Menschen, erfolgt in erster Linie über den Kontakt mit Blut oder Körperflüssigkeiten. Tröpfcheninfektionen lassen sich im Tierexperiment nachweisen, spielen aber für die menschlichen Ausbrüche keine Rolle. Während der Übertragungsweg nur bei wenigen Primärfällen identifiziert werden konnte, haben Sekundärfälle in der Regel nosokomiale Ursachen oder gehen auf engen Kontakt mit Patienten zurück. In einem Fall wurde die sexuelle Übertragung einer Marburgvirusinfektion 60 Tage nach der Erstinfektion beobachtet.

\section{Prävention / Impfstoffe}

Immunisierungsansätze zur prä- oder postexpositionellen Prophylaxe von Filovirusinfektionen sind bislang nur auf experimenteller Ebene verfolgt worden.

\section{Ausbruchsmanagement}

Isolierung der Patienten, strikte Durchführung von Hygienemaßnahmen und Schutz des behandelnden
Personals durch Sicherheitskleidung sind geeignete Mittel gegen die Ausbreitung der Krankheit.

\section{Meldepflicht}

Meldepflichtig bei Verdacht, Erkrankung und Tod.

\section{Weiterführende Informationen}

\section{Referenzzentren / Expertenlaboratorien}

- Nationales Referenzzentrum für Tropische Infektionserreger am Bernhard-Nocht-Institut für Tropenmedizin, Bernhard-Nocht-Straße 74, 20359 Hamburg, Tel.: 040/42818-401, Fax: 040/42818-400, E-Mail: MZD@bnihamburg.de

- Konsiliarlaboratorium für Filoviren, Institut für Virologie, Philipps-Universität, Hans-Meerwein-Str. 2, 35043 Marburg, Tel.: 06421/28-66253, 0171-555 9148, Fax: 06421/28-68962,E-Mail: becker@staff.uni-marburg.de

\section{Web-Adressen}

- Institut für Virologie, Philipps-Universität, Marburg: http://www.uni-marburg.de/fb20/virologie

- Bernhard-Nocht-Institut für Tropenmedizin, Hamburg: http://www.bni-hamburg.de

- Deutsche Vereinigung zur Bekämpfung der Viruskrankheiten e.V: http://www.dvv-ev.de

- Gesellschaft für Virologie e.V.: http://www.g-f-v.org

- Centers for Disease Control and Prevention: http://www. cdc.gov

\section{Schlüsselliteratur}

1. Becker S (2010) Filoviren. in Doerr HW, Gerlich WH (eds) Medizinische Virologie, 2. Ausgabe, Thieme Stuttgart, New York.

2. Sanchez A, Geisbert TW, Feldmann, H (2007) Filoviridae: Marburg and Ebola Viruses. Fields Virology, 5th edn. Lippincott-Raven, New York, pp 1409-1448

3. Tidona CA, Darai G (eds) (2011) The Springer Index of Viruses. Springer Berlin, Heidelberg, New York

\section{Filzlaus}

Läuse

\section{Fischbandwurm}

- Diphyllobothrium

Flaviviren, seltene humanpathogene

GÜNTHER SCHÖNRICH

\section{Erreger}

\section{Erregerspezies}

Der Genus Flavivirus enthält zurzeit mindestens 53 anerkannte Viruspezies. Darunter sind sehr viele seltene humanpathogene Erreger, die hier nur exemplarisch beschrieben werden können. Das Murray-Valley-Enzephalitis-Virus (MVE-V) und St.-Louis-Enze- 
phalitis-Virus (SLE-V) sind dem Japanische Enzephalitis-Virus sehr ähnlich. Dagegen weisen das Kyasanur-Forest-Virus (KFD-V), Omsk-HämorrhagischesFieber-Virus (OHF-V) und Powassan-Fieber-Virus (POW-V) enge Verwandtschaft mit dem Frühsommer-Meningoenzephalitis-Virus (FSME-V) auf. Das Weselsbron-Virus (WSL-V) wiederum gehört zu einer Gruppe von Flaviviren, die dem Gelbfiebervirus sehr nahe stehen.

\section{Taxonomie}

Alle Erreger sind Arboviren und gehören zum Genus Flavivirus der Familie Flaviviridae. Die Bezeichnung "Arbovirus" (engl. arthropode-borne viruses) hat keine taxonomische Bedeutung und verweist nur auf die Übertragung durch Zecken bzw. Moskitos (Arthropoden). Beispielsweise kommen die Enzephalitis-induzierenden Arboviren aus drei unterschiedlichen Virusfamilien: Togaviridae (Genus Alphavirus), Flaviviridae und Bunyaviridae.

\section{Historie}

Die erste Isolierung des KFD-V gelang 1957 aus einem toten Langur, der im Kyasanur-Waldgebiet des heutigen Staates Karnataka (Indien) gefunden wurde. Das MVE-V wurde 1951 von infizierten Menschen erstmals während eines Enzephalitis-Ausbruchs isoliert, der sich hauptsächlich im Murray Valley (Australien) abspielte. Das OHF-V wurde 1947 in der Region Omsk (Sibirien) erstmals als humanpathogener Erreger entdeckt. Die Stadt Powassan im nördlichen Ontario (Kanada) gab dem POW-V seinen Namen. Dort wurde es aus dem Gehirn eines 5-jährigen Jungen, der an Enzephalitis verstorben war, 1958 zum ersten Mal isoliert. Im Jahre 1975 wurde das ROC-V während einer Enzephalitis-Epidemie in der südlichen Küstenregion des Staates Sao Paulo (Brasilien) aus dem Gehirn eines Opfers gewonnen. Im Sommer 1933 wurden Kansas City und St. Louis in den USA von einem Enzephalitis-Erreger heimgesucht und das SLE-V als Erreger identifiziert. In dem Dorf Wesselsbron (Südafrika) wurde 1957 das WSL-V aus einem Schaf isoliert.

\section{Morphologie}

Die seltenen humanpathogenen Flaviviren gleichen morphologisch dem Gelbfiebervirus.

\section{Genom}

Die Genome (GenBank-Nr. in Tabelle 1-3) der seltenen humanpathogenen Flaviviren bestehen aus einzelsträngiger RNA (Länge: 9.000-11.000 Basen) und sind wie das Genom des Gelbfiebervirus organisiert.

\section{Vermehrung}

Spezifische Fakten über die Vermehrung der seltenen humanpathogenen Flaviviren sind kaum bekannt.

\section{Pathogenität / Virulenz / Antigenvariabilität}

Über die Pathogenität und Virulenz der seltenen hu- manpathogenen Flaviviren ist ebenfalls noch wenig bekannt. Vom MVE-V existieren zwei verschiedene Stämme: eine australische Variante und eine Variante, die in Papua-Neuguinea zirkuliert. Beim SLE-V kann mit monoklonalen Antikörpern eine gewisse Heterogenität in der Antigenstruktur festgestellt werden, deren Bedeutung für die Virulenz noch nicht feststeht.

\section{Erkrankungen}

\section{Enzephalitis}

Eine Reihe von seltenen humanpathogenen Flaviviren, die durch Zecken ( Tab. 1) oder Moskitos ( $\triangleright$ Tab. 2) übertragen werden, können neurologische Symptome hervorrufen. Auch einige seltene Flaviviren mit noch unbekanntem Hauptvektor ( $>$ Tab. 3) fallen in diese Kategorie. Hier sollen einige zusätzliche Information zu den wichtigeren Vertretern gegeben werden. Dazu zählt neben MVE-V, POW-V und SLE-V auch das Rocio-Virus (ROC-V), welches als Genotyp des Ilhéus-Virus betrachtet wird.

\section{Inkubationszeit}

Die Inkubationszeit für ROC-V beträgt 7-15 Tage und für SLE-V 4-21 Tage. MVE-V und POW-V besitzen vermutlich ähnliche Inkubationszeiten.

\section{Symptome}

MVE-V: Das Verhältnis von asymptomatischen zu symptomatischen Infektionen wird auf 700:1 bis 1.200:1 geschätzt. Insbesondere junge Kinder zeigen einen symptomatischen Verlauf. MVE-V verursacht ein ähnliches klinisches Bild wie das Japanische-Enzephalitis-Virus, von dem sich MVE-V ableitet. Die Letalität beträgt 20-24\%, wenn neurologische Symptome auftreten.

POW-V: Etwa 70 \% der symptomatischen Fälle manifestieren sich als Enzephalitis. Ungefähr $20 \%$ zeigen das Bild einer Meningoenzephalitis und $10 \%$ imponieren als aseptische Meningitis. Die klinischen Symptome können nicht von anderen virus-induzierten ZNS-Erkrankungen unterschieden werden. Die Letalität ist ca. $10 \%$. Persistierende neurologische Schäden werden in $50 \%$ der Fälle gefunden.

ROC-V: Die Erkrankung beginnt mit Fieber, Kopfschmerzen und Erbrechen. Darauf können Symptome einer Enzephalitis auftreten. Fulminante Verläufe mit letalem Ausgang sind beschrieben. Die Letalität beträgt bei Hospitalisierten etwa $10 \%$. In $20 \%$ der Fälle bleiben nach der Infektion schwere neurologische Schäden zurück.

SLE-V: Über 99 \% der Infektionen verlaufen asymptomatisch. Bei klinisch manifester Infektion treten grippeähnliche Symptome auf mit plötzlichem Fieber, das von anderen unspezifischen Symptomen (Abgeschlagenheit, Schwindelgefühl, Erbrechen und Kopfschmerzen) begleitet wird. Das ZNS kann in Form von aseptischer Meningitis oder Enzephalitis betroffen sein (Nackensteife, Benommenheit, Ataxie, Verwir- 
Tab. 1. Durch Zecken übertragene seltene humanpathogene Flaviviren

\begin{tabular}{|c|c|c|c|c|}
\hline $\begin{array}{l}\text { Virusspezies: } \\
\text { GenBank-Nr. }\end{array}$ & $\begin{array}{l}\text { Natürlicher Wirt / } \\
\text { Hauptvektor }\end{array}$ & $\begin{array}{l}\text { Verbreitungs- } \\
\text { gebiet }\end{array}$ & $\begin{array}{l}\text { Krankheit } \\
\text { beim } \\
\text { Menschen }\end{array}$ & $\begin{array}{l}\text { Vakzine } \\
\text { für Men- } \\
\text { schen }\end{array}$ \\
\hline $\begin{array}{l}\text { Alkhurma-Virus (ALK-V, Subtyp } \\
\text { des KFD-V): AF331718 }\end{array}$ & $\begin{array}{l}\text { Menschen, Schafe, Kame- } \\
\text { le/Ornithodorus savignyi? }\end{array}$ & $\begin{array}{l}\text { Arabische Halb- } \\
\text { insel? }\end{array}$ & $\begin{array}{l}\text { Hämorrhagi- } \\
\text { sches Fieber }\end{array}$ & nein \\
\hline $\begin{array}{l}\text { Kyasanur-Forest-Disease-Virus } \\
(\text { KFD-V)*: X74111 }\end{array}$ & $\begin{array}{l}\text { Affen/Haemaphysalis } \\
\text { spinigera }\end{array}$ & Indien (Kartanaka) & $\begin{array}{l}\text { Hämorrhagi- } \\
\text { sches Fieber }\end{array}$ & ja \\
\hline Langat-Virus (LGT-V): M73835 & $\begin{array}{l}\text { Unbekannt/lxodes gra- } \\
\text { nulatus }\end{array}$ & $\begin{array}{l}\text { Malaysia, Thai- } \\
\text { land, Sibirien }\end{array}$ & Enzephalitis & Nein \\
\hline $\begin{array}{l}\text { Louping ill-Virus (LI-V: britischer, } \\
\text { irischer, spanischer, türkischer } \\
\text { Subtyp)*: D12937, X86784, } \\
\text { X77470, X69125 }\end{array}$ & $\begin{array}{l}\text { Schafe, Moorhuhn, Hasen/ } \\
\text { Ixodes ricinus }\end{array}$ & $\begin{array}{l}\text { Großbritannien, } \\
\text { Irland, Norwegen, } \\
\text { Spanien, Grie- } \\
\text { chenland, Türkei }\end{array}$ & Enzephalitis & nein \\
\hline $\begin{array}{l}\text { Omsk-Hämorrhagisches-Fieber- } \\
\text { Virus (OHF-V)*: X66694 }\end{array}$ & $\begin{array}{l}\text { Bisamratte, Nager/Derma- } \\
\text { centor pictus }\end{array}$ & Westsibirien & $\begin{array}{l}\text { Hämorrhagi- } \\
\text { sches Fieber }\end{array}$ & nein \\
\hline $\begin{array}{l}\text { Powassan-Virus (POW-V)*: } \\
\text { L06436 }\end{array}$ & $\begin{array}{l}\text { Kleine Säugetiere//xodes- } \\
\text { Arten }\end{array}$ & $\begin{array}{l}\text { Russland, Nord- } \\
\text { amerika }\end{array}$ & Enzephalitis & nein \\
\hline
\end{tabular}

Tab. 2. Durch Moskitos übertragene seltene humanpathogene Flaviviren

\begin{tabular}{|c|c|c|c|c|}
\hline $\begin{array}{l}\text { Virusspezies: } \\
\text { GenBank-Nr. }\end{array}$ & $\begin{array}{l}\text { Natürlicher Wirt / } \\
\text { Hauptvektor }\end{array}$ & $\begin{array}{l}\text { Verbreitungs- } \\
\text { gebiet }\end{array}$ & $\begin{array}{l}\text { Krankheit } \\
\text { beim } \\
\text { Menschen }\end{array}$ & $\begin{array}{l}\text { Vakzine } \\
\text { für Men- } \\
\text { schen }\end{array}$ \\
\hline Ilhéus-Virus (ILH-V): AF013376 & Vögel/Culex-Arten? & $\begin{array}{l}\text { Süd- und Zentral- } \\
\text { amerika }\end{array}$ & Fieber & nein \\
\hline $\begin{array}{l}\text { Koutango-Virus (KOU-V): } \\
\text { AF013384 }\end{array}$ & Nagetiere?/Moskitos & Senegal & $\begin{array}{l}\text { Fieber, } \\
\text { Exanthem }\end{array}$ & nein \\
\hline $\begin{array}{l}\text { Murray-Valley-Enzephalitis-Virus } \\
(\text { MVE-V)*: X03467 }\end{array}$ & Vögel/Culex annulirostris & $\begin{array}{l}\text { Australien, Pa- } \\
\text { pua-Neuguinea }\end{array}$ & Enzephalitis & nein \\
\hline Ntaya-Virus: AF013392 & Unbekannt/Moskitos & Afrika & Fieber & nein \\
\hline Rocio-Virus (ROC-V)*: AF013397 & Vögel/Culex-Arten? & Brasilien & Enzephalitis & nein \\
\hline $\begin{array}{l}\text { Spondweni-Virus (SPO-V): } \\
\text { AF013406 }\end{array}$ & $\begin{array}{l}\text { Unbekannt/Aedes circum- } \\
\text { luteolus }\end{array}$ & Afrika & Fieber & nein \\
\hline $\begin{array}{l}\text { St.-Louis-Enzephalitis-Virus } \\
(\text { SLE-V)* }\end{array}$ & Vögel/Culex-Arten & $\begin{array}{l}\text { Nord- und Süd- } \\
\text { amerika, Jamaica, } \\
\text { Haiti }\end{array}$ & Enzephalitis & nein \\
\hline Usutu-Virus (USU-V): AF013412 & Vögel/Moskitos & Afrika & $\begin{array}{l}\text { Fieber, } \\
\text { Exanthem }\end{array}$ & nein \\
\hline Wesselsbron-Virus (WSL-V)* ? & Unbekannt/Aedes-Arten & Afrika, Thailand & $\begin{array}{l}\text { Fieber, } \\
\text { Arthralgien, } \\
\text { Exanthem }\end{array}$ & nein \\
\hline Zika-Virus (ZIK-V): AF013415 & Affen?/Aedes-Arten & Afrika, Asien & $\begin{array}{l}\text { Fieber, } \\
\text { Arthralgien } \\
\text { Exanthem }\end{array}$ & nein \\
\hline
\end{tabular}


Tab. 3. Seltene humanpathogene Flaviviren mit unbekanntem Hauptvektor

\begin{tabular}{|c|c|c|c|c|}
\hline $\begin{array}{l}\text { Virusspezies: } \\
\text { GenBank-Nr. }\end{array}$ & $\begin{array}{l}\text { Natürlicher } \\
\text { Wirt }\end{array}$ & $\begin{array}{l}\text { Verbreitungs- } \\
\text { gebiet }\end{array}$ & $\begin{array}{l}\text { Krankheit bei } \\
\text { Menschen }\end{array}$ & $\begin{array}{l}\text { Vakzine } \\
\text { für Men- } \\
\text { schen }\end{array}$ \\
\hline Apoi-Virus (APOI-V): AF013361 & Nagetiere? & Japan & Enzephalitis & nein \\
\hline $\begin{array}{l}\text { Dakar-bat-Virus (DB-V): } \\
\text { AF013371 }\end{array}$ & Fledermäuse? & Afrika & Fieber & nein \\
\hline $\begin{array}{l}\text { Modoc-Virus (MOD-V): } \\
\text { AF013387 }\end{array}$ & Peromyscus maniculatus & USA & Enzephalitis & nein \\
\hline $\begin{array}{l}\text { Rio-Bravo-Virus (RB-V): } \\
\text { AF013396 }\end{array}$ & $\begin{array}{l}\text { Tatanida braziliensis } \\
\text { mexicana }\end{array}$ & USA, Mexiko & Fieber & nein \\
\hline
\end{tabular}

rungszustände und Desorientiertheit). Die Letalität bei manifest Erkrankten beträgt bei über 50-Jährigen 7-24 \%; bei Personen unter 50 Jahren ist sie kleiner als $5 \%$. Eine protrahierte Rekonvaleszenz bei $30-50 \%$ geht einher mit Müdigkeit, Vergesslichkeit, Konzentrationsstörungen und Ataxie (Dauer bis zu 3 Jahre).

\section{Immunantwort}

Bei Personen, die mit dem SLE-V infiziert wurden, lassen sich wie bei anderen Flavivirusinfektionen IgMund IgG-Antikörper nachweisen. Es ist anzunehmen, dass auch eine T-Zell-Antwort generiert wird. Einzelheiten zur Immunantwort bei Infektionen des Menschen mit MVE-V, POW-V und ROC-V sind nicht bekannt.

\section{Differenzialdiagnose}

Viele andere Viren, die Enzephalitis hervorrufen, müssen in Betracht gezogen werden.

\section{Grippeähnliches Syndrom}

Einige der durch Moskitos übertragenen seltenen Flaviviren - wie z. B. WSL-V - rufen hauptsächlich Fieber, Arthralgien und Exantheme hervor.

\section{Inkubationszeit}

Die Inkubationszeit von WSL-V beträgt 2-4 Tage.

\section{Symptome}

Die meisten Infektionen mit WSL-V bleiben symptomlos oder verlaufen sehr mild, so dass sie diagnostisch nicht weiter abgeklärt werden. Es kann sich jedoch eine grippeähnliche Symptomatik entwickeln mit plötzlichem Fieber sowie schweren Kopf-, Glieder- und Muskelschmerzen. Lichtphobie und Hyperästhesie der Haut sind weitere Symptome. Nicht selten wird ein Exanthem beobachtet. Das Fieber verschwindet bereits nach 2-3 Tagen während die Muskelschmerzen länger anhalten können. Berichte über tödliche Infektionen liegen nicht vor.

\section{Immunantwort}

Antikörper können mit dem Hämagglutinationshemmtest nachgewiesen werden.

\section{Differenzialdiagnose}

Andere Viren, die eine grippeähnliche Symptomatik hervorrufen können.

\section{Hämorrhagisches Fieber}

Seltene humanpathogene Flaviviren, die hämorrhagisches Fieber verursachen, sind KFD-V und OHF-V. Beide werden durch Zecken übertragen ( $\triangleright$ Tab. 1).

\section{Inkubationszeit}

Die Inkubationszeit für KFD-V und $\mathrm{OHF}-\mathrm{V}$ beträgt ca. 3-8 Tage.

\section{Symptome}

KFD-V: Es tritt plötzliches Fieber (bis $40{ }^{\circ} \mathrm{C}$ ) auf mit Kopfschmerzen und Muskelschmerzen (hauptsächlich Rücken, Nacken). Im akuten Stadium können papulovesikuläre Schleimhautläsionen im Bereich des weichen Gaumens und eine zervikale und axilläre Lymphadenopathie beobachtet werden. Außerdem kommt es zu hämorrhagischen Diathesen mit Blutungen aus der Nase und dem Gastrointestinaltrakt. In einigen Fällen werden während der Rekonvaleszenz Symptome einer Meningitis beobachtet. Die Letalität beträgt 5-10\%.

OHF-V: Die erste Krankheitsphase beginnt plötzlich mit Fieber, welches 5-12 Tage andauert. Nach Remission kommt es bei 30-50 \% der Erkrankten zu einer zweiten Fieberphase, die schwerer verläuft und durch Muskelschmerzen, Kopfschmerzen und milde hämorrhagische Diathesen (Epistaxis, gastrointestinale Blutungen, Urogenitalblutungen) gekennzeichnet ist. Eine meningeale Reizung - in der Regel ohne ausgeprägte neurologische Symptomatik und ohne psychomotorische Langzeitfolgen - ist möglich. Meist ist der Verlauf gutartig mit einer Letalität von $0,5-3 \%$. 


\section{Pathophysiologie}

OHF-V verursacht ein hämorrhagisches Fieber, obwohl es genetisch mit dem FSME-V, einem Enzephalitis-Erreger, sehr eng verwandt ist. Im Gegensatz zu FSME-V repliziert sich OHF-V jedoch hauptsächlich in den Endothelzellen der Gefäße. Das erklärt, warum es mit Blutungen assoziiert ist. Über die zugrunde liegenden molekularen Mechanismen ist jedoch noch kaum etwas bekannt.

\section{Immunantwort}

Keine Daten vorhanden.

\section{Differenzialdiagnose}

Andere Viren, die hämorrhagisches Fieber hervorrufen können (z. B. Gelbfiebervirus, Dengueviren) müssen in Betracht gezogen werden. Das Fehlen einer ausgeprägten neurologischen Symptomatik erleichtert die Unterscheidung des Omsk Hämorrhagischen-Fiebers von einer Frühsommer-Meningoenzephalitis. Bei OHF-V-Infektionen tritt eine Leukopenie auf, die bei der Abgrenzung von bakteriell bedingten Erkrankungen hilfreich ist.

\section{Diagnostik}

\section{Untersuchungsmaterial}

Serum, Plasma, Liquor, Autopsiematerial.

\section{Diagnostische Verfahren}

Die Virusisolierung ist zeitaufwändig und erfordert bei manchen Spezies ein Labor der Sicherheitsstufe 3 bzw. 4. Alle serologischen Testverfahren (IFT, ELISA, HHT, KBR) außer dem Neutralisationstest sind aufgrund der Kreuzreaktivität innerhalb des Genus Flavivirus mit Vorsicht zu interpretieren. Eine sichere $\mathrm{Zu}$ ordnung erlaubt die Amplifikation der viralen Nukleinsäure durch RT-PCR mit anschließender Sequenzierung.

KVD-V: Die Virusisolierung aus dem Serum gelingt im Gegensatz zu Infektionen mit anderen Arboviren gut und wird durch Inokulation von Babymäusen oder unterschiedlichen Vertebraten-Zellkulturen erreicht.

MVE-V: Mit Hilfe der RT-PCR kann das Virus früh nach Beginn der Symptomatik detektiert werden. Nach Inokulation von infiziertem Gehirngewebe in Babymäuse, Hühnerembryonen oder geeigneten Zellkulturen kann Virus aus Blut isoliert werden. Die Virusisolierung aus dem Liquor ist meist nicht erfolgreich. In Serum und Liquor können virusspezifische IgM-Antikörper nachgewiesen werden.

OHF-V: Das Virus kann am Anfang der Fieberphase isoliert werden (aus Blut oder Urin). In der Regel wird die Diagnose jedoch serologisch gestellt, wobei die Verwandtschaft zum FSME-V Probleme bereiten kann. ROC-V: Viren können nur nach Inokulation von infiziertem Hirngewebe in Babymäuse oder geeignete Zellkulturen (z. B. Verozellen) isoliert werden.
SLE-V: Virusisolationen aus Serum oder Liquor sind meist nicht möglich, können aber aus Autopsie-Material (Hirngewebe) gelingen. Für die Anzüchtung werden Babymäuse verwendet. Die Diagnose kann serologisch ab dem 3. bis 5. Tag durch den Nachweis von virusspezifischen IgM-Antikörpern im ELISA gestellt werden. Nach etwa 2 Monaten sind die viruspezifischen IgM-Antikörper in der Regel wieder verschwunden; sie können aber in $25 \%$ der Patienten bis zu 1 Jahr persistieren.

WSL-V: Die Diagnose wird in der Regel serologisch gestellt. Eine Virusisolierung aus dem Blut des infizierten Patienten im Fieberstadium kann versucht werden.

\section{Befund / Interpretation}

Die Ähnlichkeit der Antigenstrukturen von Flaviviren ist bei der Interpretation von serologischen Testverfahren zu berücksichtigen (mögliche Kreuzreaktionen).

\section{Therapie}

\section{Therapeutische Maßnahmen}

Eine spezifische Therapie der Infektionen mit seltenen humanpathogenen Flaviviren existiert nicht. Es sind nur supportive Maßnahmen möglich.

\section{Epidemiologie}

\section{Verbreitung}

KFD-V: Die Krankheit ist bis jetzt auf den indischen Bundesstaat Karnataka begrenzt. Es treten jedes Jahr etwa 500 Fälle auf. Laborinfektionen sind in Indien und den USA vorgekommen.

MVE-V: Die durch den Erreger hervorgerufene Enzephalitis ist eine seltene menschliche Erkrankung (weniger als 1000 Fälle), die bisher nur in Australien und Papua-Neuguinea aufgetreten ist. Ausbrüche fanden bisher immer in den Sommermonaten nach Regenzeiten statt und betreffen in der Regel die Eingeborenen Australiens. Die letzte Epidemie wurde 1974 registriert; seitdem wurde nur noch über sporadische Fälle berichtet.

OHF-V: Von 1945 bis 1958 wurden in der Umgebung von Omsk ca. 1.500 Fälle registriert. Später sank dort die Anzahl der Zecken und damit die Inzidenz der OHF-V-Infektionen. In den Jahren 1988-1997 wurden nur noch ca. 165 Fälle beobachtet. Naturherde kommen hauptsächlich in der Waldsteppe in den Regionen Omsk, Novosibirsk und auch in Kurgan und Tyumen (Westsibirien) vor.

POW-V: Nur weniger als 50 Fälle (in Kanada, USA und Russland) wurden bisher weltweit bekannt.

ROC-V: Erkrankungen traten bisher nur in einem Küstenbereich des südöstlichen Teils des Staates Sao Paulo in Brasilien auf. Zwischen 1975 und 1978 wurden ungefähr 1000 Fälle registriert, von denen etwa 100 tödlich verliefen und ungefähr 200 mit bleibenden 
neurologischen Schäden verbunden waren. Seit 1980 sind keine weiteren Erkrankungen vorgekommen.

SLE-V: Dieser Erreger wird in Nord- und Südamerika gefunden. Er verursacht alle 5 bis 15 Jahre Enzephalitis-Epidemien in den USA. In Nordamerika wird die endemische Form der St.-Louis-Enzephalitis jährlich bei ca. 50 Personen pro Jahr diagnostiziert. Die Erkrankung tritt in den Sommermonaten auf. Folgende Gebiete sind betroffen: Ohio-Mississippi-Becken, Osten von Texas, Florida, Kansas, Colorado und Kalifornien. In Zentral- und Mittelamerika können gelegentlich Fälle von St.-Louis-Enzephalitis auftreten. Vor kurzem wurde ein großer Ausbruch von Infektionen mit SLE-V in Cordoba (Argentinien) beobachtet.

WSL-V: Es tritt außer in Südafrika auch in anderen Teilen Afrikas auf: Simbabwe, Kamerun, Nigeria, Zentralafrikanische Republik, Senegal, Elfenbeinküste, Uganda, Kenia und Madagaskar. Darüber hinaus wurde das Virus in Thailand gefunden. Da WSL-V den Tod von neugeborenen Lämmern verursacht, besitzt es - insbesondere in Südafrika - veterinärmedizinische Bedeutung.

- Abb. 1 .

\section{Wirtsbereich / Reservoir}

- Tab. 1 und 2 .

\section{Risikogruppen}

Die meisten OHF-V-Infektionen in Westsibirien betreffen Jäger von Bisamratten und deren Angehörige.

\section{Transmission / Vektoren}

- Tab. 1 und 2.

\section{Prävention / Impfstoffe}

Wichtig ist die Vermeidung von Mückenstichen (Repellentien, Tragen langer heller Kleidung, Moskitonetze, Vermeidung von stehenden Wasseransammlungen etc.). Wegen der relativ geringen medizinischen Bedeutung der seltenen humanpathogenen Flaviviren gab es bisher keinen Anreiz für die Entwicklung von lizenzierten Impfstoffen. Allerdings gab es Impfkampagnen gegen die Kyasanur Forest Disease in Indien. Dabei wurde ein Formalin-inaktiviertes KFD-V, welches in Fibroblasten von Hühnerembryonen hergestellt wurde, als Vakzine verwendet. Möglicherweise schützt die FSME-Impfung wegen der Antigenverwandtschaft der Viren auch vor OHF-V. Ähnlich könnte eine bald erhältliche Vakzine gegen WNF-VKreuzprotektion für das verwandte SLE-V induzieren.

\section{Ausbruchsmanagement}

OHV-V: Vermeidung von Zeckenbissen und Vorsicht im Umgang mit infizierten Tierleichen sind elementar.

SLE-V: Die Bekämpfung der Vektoren stellt die wichtigste prophylaktische Maßnahme dar. Zur Überwachung werden die Moskitos auf virale Nukleinsäuren mit Hilfe der PCR untersucht. Hühner werden als Indikatoren der Virusverbreitung eingesetzt, um dro-

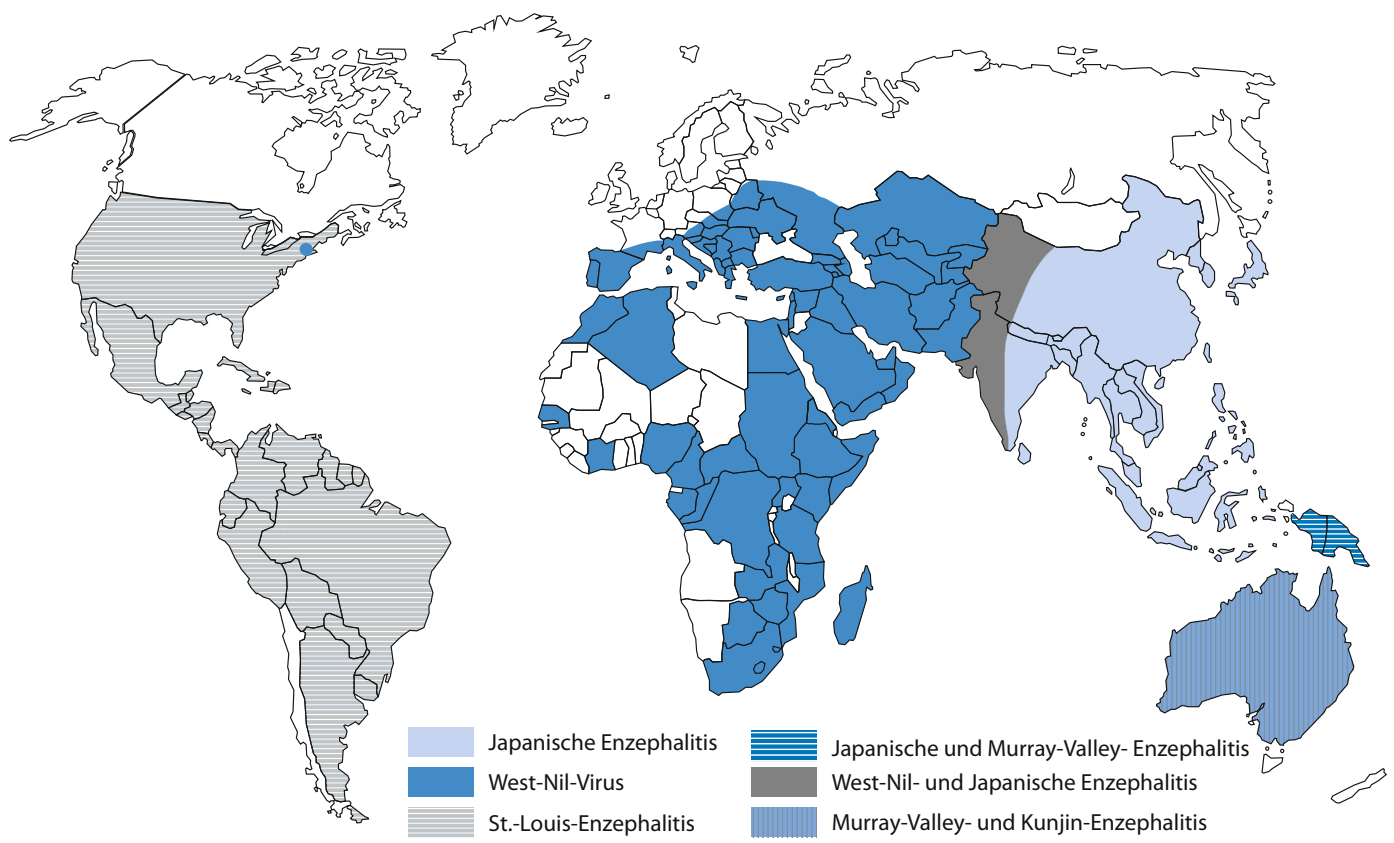

Abb. 1. Verbreitungsgebiet der humanpathogenen Flaviviren, die zum Serokomplex des Japanische-Enzephalitis-Virus gehören: Japanische-Enzephalitis-Virus, West-Nil-Virus, Murray-Valley-Enzephalitis-Virus, St.Louis-Enzephalitis-Virus, Kunjin-Enzephalitis-Virus (Subtyp des Murray-Valley-Enzephalitis-Virus) 
hende Epidemien unter Menschen vorherzusagen. Als persönliche Prophylaxe kommen Schutz vor Mückenstichen durch mückenabweisende Mittel und die Verwendung von Moskitonetzen, insbesondere nachts und in der Dämmerung, in Betracht.

WSL-V: Es gibt keine besonderen Empfehlungen, um menschliche Infektionen zu vermeiden. Besondere Vorsicht ist jedoch beim Umgang mit WSL-V im Labor geboten, um Laborinfektionen zu verhindern.

\section{Meldepflicht}

Nach $₫ 6$ des Infektionsschutzgesetzes (IfSG) ist vom feststellenden Arzt bei Krankheitsverdacht, Erkrankung sowie Tod an virusbedingtem hämorrhagischen Fieber der Patient namentlich dem Gesundheitsamt zu melden (unverzüglich, spätestens innerhalb von 24 Stunden). Diese Meldungen werden entsprechend $\$ 11$ über die zuständigen Landesbehörden an das Robert-Koch-Institut übermittelt. Die seltenen humanpathogenen Flaviviren stellen zwar in Deutschland derzeit keine Gefahr für die Allgemeinheit dar. Nach $₫ 7$ des IfSG besteht jedoch Meldepflicht bei Krankheitserregern, die örtlich und zeitlich so gehäuft auftreten, dass mit einer schwerwiegenden Gefahr für die Allgemeinheit gerechnet werden muss. Mit Hilfe dieser Regelung sollen neu auftretende Krankheitserreger möglichst schnell identifiziert werden, um Gefahr für die Allgemeinheit abzuwenden. Weiterführende Informationen zum IfSG sind auf der unten aufgeführten Web-Adresse des Robert-Koch-Instituts zu finden.

\section{Weiterführende Informationen}

\section{Referenzzentren / Expertenlaboratorien}

- Nationales Referenzzentrum für tropische Infektionserreger, Bernhard-Nocht-Institut für Tropenmedizin, Bernhard-Nocht-Straße 74, 20359 Hamburg, Tel.: +49-4042818-401 bzw. 400, E-Mail: MZD@bni-hamburg.de

\section{Web-Adressen}

- Robert-Koch-Institut (RKI): http://www.rki.de/

- Friedrich-Loeffler-Institut: http://www.fli.bund.de/

- Bernhard-Nocht-Institut für Tropenmedizin (Hinweise auf Tropen-Viruskrankheiten): http://www.bni-hamburg. de/

- Gesellschaft für Virologie: http://www.g-f-v.org/

- Deutsche Vereinigung zur Bekämpfung der Viruskrankheiten e.V.: http://www.dvv-ev.de/

- Centers for disease control and prevention: http://www. cdc.gov/ncidod/dvbid/

- Veterinary Public Health (Tierärztliche Hochschule Hannover): http://www.veterinary-public-health.de/home_d/ aufgaben/zoonosen/

- WHO World Health Organization (Aktuelles über Infektionskrankheiten, Empfehlungen und Programme der WHO): http://www.who.int/

\section{Schlüsselliteratur}

1. Gould EA, Solomon T (2008) Pathogenic flaviviruses. Lancet 371:500-509
2. Gubler DJ, Kuno G, Markoff L (2007) Flaviviruses. In: Knipe, DM, Howly, PM (eds) Fields Virology (5th edition), Philadelphia: Lippincott Williams and Wilkins, pp 1153-1252

3. Schoub BD, Venter M (2009) Flaviviruses. In: Zuckerman AJ, Banatvala JE, Pattison JR, Griffiths PD, Schoub BD, Mortimer P (eds) Principles and practice of clinical virology (6th edition), Chichester: John Wiley, pp 669-698

\section{Flavobacterium}

\section{Erreger}

Michael Hogardt, IsAbel Späth

\section{Erregerspezies}

Die Familie der Flavobacteriaceae umfasst zahlreiche Gattungen und deren Spezies. Die meisten Spezies kommen allerdings ausschließlich in der Umwelt vor und nur die wenigsten besitzen eine medizinische Relevanz. Hierzu gehören die Spezies Bergeyella zoohelcum, Chryseobacterium indolgenes, Elizabethkingia meningoseptica, Myroides odoratus und M. odoratimimus.

\section{Taxonomie}

Familie: Flavobacteriaceae; Gattung: Flavobacterium (Typgenus); Typspezies: F. aquatile; sowie aktuell 47 weitere Gattungen, z. B. Chryseobacterium, Elizabethkingia, Bergeyella, Riemerella, Myroides und Capnocytophaga (wird in einem eigenen Kapitel behandelt) etc.

\section{Historie}

Die 1923 von Bergey vorgeschlagene Gattung Flavobacterium umfasste ursprünglich eine Gruppe gramnegativer, gelb pigmentierte Stäbchenbakterien, die nach standardisierten Methoden der Genotypisierung jedoch sehr heterogen waren (lat. „flavus" = gelb). Die Gattung hat daher in den letzten Jahren mehrere Reklassifizierungen erfahren. Die medizinisch wichtigsten Spezies, F. indologenes und F. meningosepticum, sind heute als Chryseobacterium indologenes bzw. Elizabethkingia meningoseptica in unterschiedlichen Gattungen klassifiziert. F. odoratum wurde in die beiden Spezies Myroides odoratus und M. odoratimimus überführt. Die derzeit definierte Gattung Flavobacterium enthält somit nur noch apathogene Umweltbakterien. Darüber hinaus wurde die gesamte Familie der Flavobacteriaceae in mehreren Revisionen neu strukturiert. Einen Überblick gibt die Homepage des „International Committee on Systematics of Prokaryotes (ICSP)“.

\section{Morphologie}

Unbewegliche, gramnegative Stäbchenbakterien, die mikroskopisch zum Teil, filamentös (4-6 $\mu \mathrm{m}$ ), häufig parallel gelagert und gelegentlich mit aufgetriebenen Enden imponieren. 


\section{Genom}

Genom einiger Erreger teilweise sequenziert, siehe auch www.ncbi.nlm.nih.gov.

\section{Pathogenität / Virulenz / Antigenvariabilität}

Über Virulenzfaktoren bei den oben genannten und v. a. opportunistischen Krankheitserregern ist insgesamt wenig bekannt. E. meningoseptica zeigt das größte Virulenzpotenzial und wurde bisher vor allem mit Meningitiden bei Neugeborenen in Verbindung gebracht. Im Erwachsenenalter kommen darüber hinaus nosokomiale Pneumonien, Bakteriämie, Kathetersepsis und in Einzelfällen Osteomyelitis, Weichteilinfektionen, Meningitis, Augeninfektionen oder Endokarditis vor. Ein vergleichbares Erkrankungsspektrum ist mit $C$. indologenes assoziiert.

$M$. odoratus und $M$. odoratimimus werden als weitgehend apathogen angesehen, in Einzelfällen sind jedoch Bakteriämie, nekrotisierende Fasziitis, Zellulitis oder Weichteilinfektionen beschrieben. Der Nachweis von B. zoohelcum ist eine Seltenheit und tritt hauptsächlich bei Wundinfektionen und Zellulitis nach Tierbissen auf.

\section{Erkrankungen}

Meningitis, Sepsis, Pneumonie, Wundinfektionen, Augeninfektionen, Harnwegsinfekte

\section{Leitsymptome}

Die Symptomatik manifestiert sich in Abhängigkeit der Lokalisation der Infektion.

\section{Symptome}

- Leitsymptome

\section{Diagnostik}

\section{Untersuchungsmaterial}

Liquor, Blutkulturen, respiratorische Materialien, Wundund Augenabstriche, Urin.

\section{Diagnostische Verfahren}

E. meningoseptica wächst auf Blutagar in konvexen, glattrandigen, nicht oder leicht gelbbraun pigmentierten Kolonien von weicher Konsistenz. C. indologenes bildet goldgelb pigmentierte, nach einigen Tagen mukoid werdende Kolonien. Myroides-Kolonien sind sehr variabel, entwickeln häufig einen fruchtartigen Geruch und können ebenfalls ein gelbes Pigment aufweisen. B. zoohelcum wächst in adhärenten, gelb oder braun pigmentierten Kolonien. Die genannten Spezies sind Oxidase-positiv und unbeweglich. Für die biochemische Differenzierung der einzelnen Gattungen und Spezies ist vor allem die oxidative Säurebildung aus Zuckern, die Harnstoffhydrolyse, die Indol- und die Gelatinasebildung von Bedeutung.

\section{Befund / Interpretation}

Der Nachweis von humanpathogenen Flavobacteria- ceae in primär sterilen Materialien wie Blut oder Liquor stellt in den meisten Fällen eine Therapieindikation dar. Bei Nachweis aus anderen Materialien muss die klinische Bedeutung von Fall zu Fall erwogen werden bzw. ist im Falle der apathogenen Vertreter als Kontamination zu werten.

\section{Therapie}

\section{Therapeutische Maßnahmen}

Bei klinischer Relevanz Therapie nach Antibiogramm.

\section{Resistenz}

Die Resistenzmuster der genannten Erregerspezies sind sehr variabel. Für alle Erreger ist daher eine Resistenztestung mit MHK-Bestimmung vor Therapiebeginn unerlässlich. C. indologenes, E. meningoseptica und Myroides spp. sind häufig resistent gegen die üblicherweise für gramnegative Infektionserreger verwendeten Antibiotika, wie $\beta$-Lactame einschließlich der Cephalosporine und Carbapeneme (Bildung von Metallo- $\beta$-Lactamasen), Aminoglykoside oder Tetrazykline. Wirksam sind dagegen meist neuere Gyrasehemmer, Trimethoprim-Sulfamethoxazol und Rifampicin. B. zoohelcum ist typischerweise penicillinempfindlich.

\section{Epidemiologie}

\section{Verbreitung}

Weltweit.

\section{Wirtsbereich / Reservoir}

Die natürlichen Standorte von Chryseobakterien und Myroides spp. sind in der Umwelt v. a. in Erdböden und Wasser zu suchen. B. zoohelcum hat ihren Standort im oberen Respirationstrakt von Tieren (v. a. Hunden).

\section{Risikogruppen}

Hospitalisierte, immunsupprimierte Patienten, Neugeborene und Säuglinge für E. meningoseptica.

\section{Transmission / Vektoren}

Chryseobakterien und Myroides spp. können über verunreinigte Vernebler-, Inkubator-, Respirator- oder Waschflüssigkeiten auf empfängliche Patienten übertragen werden. B. zoohelcum tritt meist nach Tierbissen auf.

\section{Meldepflicht}

Keine Meldepflicht nach IfSG.

\section{Weiterführende Informationen}

\section{Referenzzentren / Expertenlaboratorien}

Keine bekannt.

\section{Web-Adressen}

- http://www.the-icsp.org/default.htm

- http://www.bacterio.cict.fr/ 


\section{Schlüsselliteratur}

1. Mandell GL, Bennett JE, Dolin R (eds) (2009) Mandell, Douglas, and Benett's Principles and Practices of Infectious Diseases. Seventh edition, Elsevier Churchill Linvingstone

2. Neumeister B, Geiss Heinrich K, Braun RW, Kimmig P (Hrsg) (2009) Mikrobiologische Diagnostik: „Nonfermenter: Pseudomonas spp. und verwandte Spezies“. Georg Thieme Verlag, Stuttgart New York

\section{Fleckfieber}

Rickettsien

\section{Fleckfieber, murines}

Rickettsien

\section{Fleckfieber, Neue-Welt-}

Rickettsien

\section{Fliegenmaden}

Myiasis-Erreger

\section{Fliegenmadenkrankheit}

- Myiasis-Erreger

\section{Flinders Island Fever}

Rickettsien

\section{Flöhe}

Ektoparasiten, sonstige (Stechmücken, Trombiculiden, Flöhe, Wanzen, Zecken)

\section{Flussblindheit}

- Onchocerca volvulus

\section{Focale epitheliale Hyperplasie Heck}

- Humane Papillomviren (HPV)

\section{Follikulitis}

- Haarbalgmilben

- Malassezia

- Staphylococcus aureus

\section{Fort-Sherman-Virus}

Bunyaviren

\section{Fournier'sche Gangrän}

- Bacteroides

- Bilophila

- Streptococcus pyogenes

\section{Frambösie}

- Treponemen

\section{Francisella tularensis}

HANS-GÜNTHER SONNTAG

\section{Erreger}

\section{Synonym(e)}

F. tularensis Typ A bzw. F. tularensis subsp. nearctica für F. tularensis subsp. tularensis.

F. tularensis Typ B bzw. F. tularensis subsp. palaearctica für F. tularensis subsp. holarctica Biogruppe I (Erythromycin empfindlich) und Biogruppe II (Erythromycin resistent).

F. tularensis var. palaearctica japonica für F. tularensis subsp. holarctica Biogruppe Japonica.

\section{Erregerspezies}

Francisella tularensis. Hierbei wird unterschieden zwischen F. tularensis subsp. tularensis, F. tularensis subsp. holarctica (Biogruppe I, II und Japonica) und F. tularensis subsp. Mediaasiatica.

\section{Taxonomie}

Der Gattung Francisella werden gegenwärtig außer F. tularensis auch noch die Spezies F. novicida (zunehmend als Biogruppe III von F. tularensis subsp. holarctica diskutiert) sowie die halophile Spezies F. philomiragia (frühere Bezeichnung Yersinia philomiragia) zugeordnet.

\section{Historie}

Durch McCoy und Chapin wurden 1912 aus Organmaterial von im Bezirk Tulare verendeten Erdhörnchen, die pestähnliche Veränderungen aufwiesen, Bakterien angezüchtet und als Bacterium tularense be- 
zeichnet. 1914 isolierten Wherry, Lamp und Vail in Ohio die gleichen Bakterien aus Konjunktivalabstrichen erkrankter Personen. In den folgenden Jahren wurden durch E. Francis die epidemiologischen $\mathrm{Zu}$ sammenhänge zwischen den pestähnlichen Erkrankungen bei Nagern und dem „Deer Fly-Fever“ beim Menschen aufgeklärt. Seit 1974 wird diese Bakterienspezies offiziell als Francisella tularensis bezeichnet und gilt als Erreger der Tularämie (syn. in Japan: Ohara's Disease, Yatobyo; in den USA: Francis Disease, Market Men's Disease, Rabbit Fever, Deer Fly Fever, Pahyvant Valley Plaque und in Norwegen: LemmingFieber).

\section{Morphologie}

F. tularensis ist ein gramnegatives, strikt aerob wachsendes, unbewegliches, kokkoides Kurzstäbchen von der Größe $0,2 \times 0,2-0,7 \mu \mathrm{m}$.

\section{Genom}

F. tularensis enthält nicht nur viele Lipide $(21 \%$ des Trockengewichtes), sondern auch Phosphatdylethanolamin und Phosphatdylglycerol sowie verschiedene ungewöhnliche, langkettige Fettsäuren wie 2-Hydroxyhexadeconat und 3-Hydroxyoctadeconat. Der GC \% beträgt 33-36 \%, im Vergleich $40-45 \%$ bei Pasteurellen, $46-50 \%$ bei Yersinien und $55-58 \%$ bei Brucellen. Das Genom von F. tularensis ist vollständig sequenziert. (siehe auch http://www.ncbi.nlm.nih.gov).

\section{Vermehrung}

Die Vermehrung erfolgt intrazellulär.

\section{Pathogenität, Virulenz, Antigenvariabilität}

F. tularensis bildet neben dem klassischen Endotoxin, das in seiner Wirkung dem der Enterobacteriaceae entspricht, auch ein thermolabiles Toxin. Die Antigene von $F$. tularensis enthalten Lipopolysaccharide, welche die Immunantwort der befallenen Wirte stimulieren.

\section{Erkrankung}

Tularämie

\section{Synonym(e)}

In Japan: Ohara's Disease, Yatobyo; in den USA: Francis Disease, Market Men's Disease, Rabbit Fever, Deer Fly Fever, Pahyvant Valley Plaque und in Norwegen: Lemming-Fieber.

\section{Inkubationszeit}

Die Inkubationszeit beträgt 2-10 Tage, in seltenen Fällen 1-14 Tage.

\section{Leitsymptome}

Hautpapel mit Lymphknotenschwellung (ulzero-glanduläre Form), Konjunktivitis (okulo-glanduläre Form), Lungen- und oder Rippenfellentzündung (pulmonale/thorakale Form).

\section{Symptome}

Erkrankungen durch F. tularensis lassen sich in die so genannte äußere Form (ca. 85-90 \% der beschriebenen Fälle) und in die so genannte innere Form der Tularämie unterscheiden.

Äußere Form: Die an der Eintrittspforte des Erregers entstehende Hautpapel (Primärläsion) schmilzt innerhalb von 2-4 Tagen, begleitet von Fieber, ein und zerfällt geschwürig. Die regionären Lymphknoten schwellen erheblich an, vereitern u. U. und schmelzen ulzerös ein (= ulzero-glanduläre Form). Bei unbehandelten Fällen kann die Letalitätsrate bis zu $5 \%$ betragen. Gelegentlich Fehlen des Primäraffektes möglich, sodass nur Schwellungen der Axillar- oder Inguinallymphknoten auftreten (= glanduläre Form). Dringt der Erreger über die Konjunktiven ein, dann entsteht das Bild der so genannten Parinaud'schen Konjunktivitis (= okulo-glanduläre Form).

Innere Form: Nach Inhalation des Erregers kann es zum Entstehen einer Lungen- und/oder Rippenfellentzündung (= pulmonale oder thorakale Form) kommen. Die orale Aufnahme von F. tularensis kann, je nach Organmanifestation, zu Entzündungen der Rachenschleimhaut (= oropharyngeale Form), zu Milzschwellung oder Durchfall, verbunden mit starken Leibschmerzen (= abdominale Form) führen. Bei der Generalisation treten während des langwierigen Verlaufs intermittierende Fieberschübe (= typhöse Form) auf. Bei unbehandelten Fällen beträgt die Letalitätsrate ca. $30 \%$.

Infektionen mit F. novicida wurden bislang nur sehr selten, insbesondere bei immunsupprimierten Patienten, nachgewiesen.

\section{Pathophysiologie}

Intoxikation durch die Ausbildung klassischer Endotoxine (ähnlich der bei Enterobacteriaceae).

\section{Immunantwort}

Antikörper gegen F. tularensis können jahrelang persistieren.

\section{Differenzialdiagnose}

Bei den vielfältigen klinischen Krankheitsbildern müssen differenzialdiagnostisch vor allem Tuberkulose, Katzenkratzkrankheit, Lymphogranulomatose, Aktinomykose, infektiöse Mononukleose, Virusgrippe, atypische Pneumonie, Typhus, Q-Fieber, Ornithose, Brucellose sowie evtl. auch Rattenbissfieber, Malaria und Pest ausgeschlossen werden.

\section{Diagnostik}

\section{Untersuchungsmaterial}

Serum, für die kulturelle Anzüchtung: Ulkusmaterial der Primärläsion, Eitermaterial, Exzisionsmaterial von vergrößerten Lymphknoten, Konjunktivalsekret, Sputum oder Heparinblut. 


\section{Diagnostische Verfahren}

Die Diagnose der Tularämie erfolgt in den meisten Fällen serologisch.

Antikörpernachweis: Hierbei erweist sich die Mikroagglutination, unter Verwendung eines gefärbten Antigens, zuverlässiger als die Röhrchenlangsamagglutination. Frühestens 8-10 Tage nach erfolgter Infektion fällt die Langsamagglutination positiv aus und die höchsten Titer werden in der 4. bis 5. Krankheitswoche nachgewiesen. Titer von 1:80 und höher oder ein 4 facher Titeranstieg während der serologischen Verfolgsuntersuchung gelten als Hinweis für das Vorliegen einer Infektion mit F. tularensis. Diese Bakterienspezies weist allerdings mit Brucellen, Yersinia enterocolitica 0:9 sowie Proteus vulgaris 0X19 Antigengemeinschaften auf, die zu serologischen Kreuzreaktionen führen und $u$. U. die serologische Diagnostik der Tularämie erschweren können.

Die getrennte Erkennung von Ig A-, IgM- und IgGAntikörpern ist mittels ELISA-Test möglich. Weitere serologische Verfahren sind der indirekte Hämagglutinationstest und die Komplementbindungsreaktion.

Mikroskopie: Die mikroskopische Untersuchung von Ausstrichpräparaten oder Gewebeschnitten, jeweils gefärbt nach Gram, hat keinen großen diagnostischen Wert. Mittels fluoreszierender Antikörper ist dagegen ein Nachweis von F. tularensis möglich.

Kultur: Der kulturelle Erregernachweis erfordert infolge der hohen Infektiosität von $F$. tularensis die strenge Einhaltung besonderer Hygiene-Schutzmaßnahmen vonseiten des Labor Personals und sollte daher nur in entsprechend eingerichteten Laboratorien (L3) durchgeführt werden! Ein Nachweis von F. tularensis ist auch mittels PCR möglich.

Die Anzüchtung von F. tularensis ist nur unter Verwendung von Blut-Glukose-Zystin-Agar oder koagulierten Eidotternährböden möglich. Nach 2- bis 5-tägiger aerober Bebrütung bei $37^{\circ} \mathrm{C}$ bilden sich $1-2 \mathrm{~mm}$ große, runde, feuchte, milchig-weiße Kolonien. Deren erste Identifizierung erfolgt mittels Gram-Färbung (dicht zusammen gelagerte, aber einzeln liegende, schwach angefärbte, gramnegative, zarte, kokkoide Stäbchen) und einer positiven Objektträgeragglutination mit monospezifischem F-tularensis-Antiserum. Die serologische Untersuchung erlaubt keine Unterscheidung der verschiedenen Biogruppen von F. tularensis, dies ist nur mittels Bunter Reihen möglich.

Biochemische Differenzierung: Stämme, die kein Glyzerin spalten (trifft vorwiegend für Isolate in Europa, Iran und Japan zu) werden F. tularensis subsp. holarctica zugeordnet, während Stämme, die Glyzerin spalten (trifft hauptsächlich für Isolate in Nordamerika zu) F. tularensis subsp. tularensis angehören.

\section{Therapie}

\section{Therapeutische Maßnahmen}

Mittel der Wahl ist Streptomycin, täglich $0,5-1,0 \mathrm{~g}$, mindestens 10-14 Tage lang (i.m.) verabreicht u. U. in
Kombination mit Doxycyclin, täglich 0,2 g oral. Auch Gentamicin (3-5 mg/kg/Tag) ist wirksam. Behandlung in jedem Falle bis mindestens 5 Tage nach der Entfieberung durchführen.

\section{Resistenz}

In toten Tieren kann der Tularämie-Erreger mindestens 133 Tage, in Tierhäuten mindestens 40 Tage vermehrungsfähig bleiben. Bis zu 5 Monaten kann F. tularensis in Oberflächenwasser bei $+4{ }^{\circ} \mathrm{C}$ überleben.

\section{Epidemiologie}

\section{Verbreitung}

Das Vorkommen der Tularämie beim Menschen entspricht weitgehend der Verbreitung von F. tularensis bei Tieren. Die epidemiologisch wichtigsten Naturherde sind derzeit in den USA, in Japan und in Gebieten der ehemaligen UdSSR anzutreffen. Europäische Endemiegebiete sind vor allem in Schweden, in der ehemaligen CSSR, in Österreich, in der Schweiz und in Deutschland (Schleswig-Holstein, Mecklenburg, Mainfranken) bekannt. Jährlich werden in den USA ca. 300 Erkrankungen beim Menschen (Inzidenzrate 0,6-1,3/Million Einwohner) erfasst, in Deutschland sind es 2-3 Fälle (Inzidenzrate 0,02-0,06/Million Einwohner) pro Jahr.

\section{Wirtsbereich / Reservoir}

F. tularensis wurde bislang außer beim Menschen bei mehr als 125 Säugetierarten, aber auch bei Vögeln, Reptilien, Fischen und insbesondere bei Arthropoden nachgewiesen. Als die wichtigsten Erregerreservoire gelten vor allem Hasen, Wildkaninchen, Mäuse, Ratten, Biber und Erdhörnchen.

\section{Risikogruppen}

Personen, wie z. B. Jäger, Wildbrethändler, die aufgrund ihrer Tätigkeit intensiven Kontakt mit Wildtieren (Hasen!) haben, sind besonders gefährdet, außerdem Menschen in ländlichen Gegenden.

\section{Transmission / Vektoren}

Die Ansteckung des Menschen mit F. tularensis erfolgt in den meisten Fällen durch direkten Kontakt mit Ausscheidungen, Blut oder Organen beim Aufbrechen, Zerlegen oder Abhäuten infizierter Tiere (Hasen!). Im amerikanischen Schrifttum werden zunehmend infizierte Katzen als direkte Ansteckungsquellen für den Menschen beschrieben. Außerdem ist die Erregerübertragung auf den Menschen durch Bisse oder Stiche blutsaugender Arthropoden möglich; ferner durch Inhalation von erregerhaltigem Staub, z. B. bei Verarbeitung von Getreide, das mit Sekreten und Exkreten infizierter Nager kontaminiert ist. Durch Verzehr von infizierten Hasen oder Wildkaninchen sowie durch Genuss von kontaminiertem Trinkwasser kann es ebenfalls zu einer Infektion mit $F$. tularensis kommen. 


\section{Prävention / Impfstoffe}

Personen, die aufgrund ihrer Tätigkeit besonders gefährdet sind, sollten beim Umgang mit Wildtieren, insbesondere Hasen, stets arbeitshygienische Maßnahmen beachten. Verzehr nur von gekochtem bzw. durchgebratenem Hasen- oder Wildfleisch. Bei Untersuchung von Tularämie verdächtigem Material müssen im L3-Labor unbedingt die gesetzlich vorgeschriebenen Schutzmaßnahmen eingehalten werden. Schutzimpfungen sind möglich mittels LVS, ein attenuierter russischer F-tularensis-Stamm, aber im deutschsprachigen Raum derzeit nicht erforderlich.

\section{Ausbruchmanagement}

Bei Verdacht einer möglichen Ansteckung sind serologische Kontrolluntersuchungen, jeweils im Abstand von 8-10 Tagen angebracht (Titeranstieg). In „Risikojahren" mit extremer Mäuseplage ist in Endemiegebieten die serologische und/oder bakteriologische Untersuchung erlegter Hasen zu empfehlen.

\section{Meldepflicht}

Nach $₫ 7$ des IfSG ist in Deutschland der direkte oder indirekte Nachweis von F. tularensis beim Menschen namentlich zu melden, soweit ein entsprechender Nachweis auf eine akute Infektion hinweist.

Der Nachweis der Tularämie bei Tieren unterliegt nach dem Tierseuchengesetz in Deutschland der Meldepflicht.

\section{Weiterführende Informationen}

\section{Referenzzentren / Expertenlaboratorien}

- Nationales Referenzlaboratorium für die Epidemiologie der Zoonosen, Bundesinstitut für gesundheitlichen Verbraucherschutz und Veterinärmedizin (BgVV), Diedersdorfer Weg 1, 12777 Berlin (Tel.: 030/8412-2220)

- Expertenlaboratorium: Bundesanstalt für Tierseuchenbekämpfung, Robert Koch Gasse 11, A 2340 Mödling/ Österreich

- Konsiliarlabor für Tularämie, Institut für Mikrobiologie der Bundeswehr, Neuherbergstr. 11, D-80937 München (Tel. 089/3168-2806) (Herr Oberfeldarzt Dr. Wolf Splettstößer)

\section{Web-Adressen}

- http://www.rki.de/cln_091/nn_264978/DE/Content/ Infekt/EpidBull/Archiv/2007/07_07.html

\section{Schlüsselliteratur}

1. Ohara Y, Sato T, Fujita, Uenoo T, Homma M (1991) Clinical manifestations of tularemia in Japan - Analysis of 1355 cases observed between 1924 and 1987. Infection 19:14-21

2. Pearson A (1998) Tularemia. In: Palmer SR, Soulsby L, Simpson D (eds)(1998) Zoonoses, Oxford University Press, pp 267-279

3. Wong JD, Shapiro DS (1999) Francisella. In: Murray PR (ed) Manual of Clinical Microbiology, 7th edn ASM Press, Washington, pp 647-651

\section{Frühsommer-Meningoenzephalitis (FSME)}

- Frühsommer-Meningoenzephalitis-Virus und Russisches Frühjahrs-Sommer-Enzephalitis-Virus

\section{Frühsommer-Meningoenzephalitis-Virus und Russisches Frühjahrs-Sommer-Enzephalitis- Virus}

\section{Erreger}

\section{Synonym(e)}

Russische Frühjahrs-Sommer-Enzephalitis-Virus: fernöstlicher Subtyp des Frühsommer-Meningoenzephalitis-Virus.

\section{Erregerspezies}

Frühsommer-Meningoenzephalitis-Virus (abgekürzt: FSME-V)

\section{Taxonomie}

Das FSME-V (engl. tick-borne encephalitis virus) gehört zum Genus Flavivirus der Familie Flaviviridae. Es wird in einen europäischen, fernöstlichen und sibirischen Subtyp unterteilt.

\section{Historie}

Als Krankheitsbild wurde FSME erstmals 1931 in Österreich beschrieben. Dann kam es 1932 im fernöstlichen Teil Russlands zu einem Enzephalitis-Ausbruch. Weitere Fälle traten in den nächsten Jahren auf. Schließlich wurde 1937 das verantwortliche Virus aus menschlichem Gehirn isoliert und der Übertragungsweg (Zecken) aufgeklärt. In den folgenden Jahren wurde die weite Verbreitung des Virus in Europa und Asien erkannt.

\section{Morphologie}

FSME-V gleicht morphologisch dem Gelbfiebervirus.

\section{Genom}

Das Genom des FSME-V besteht aus einzelsträngiger RNA mit einer Länge von 10.477 Basen. Die Organisation des Genoms gleicht derjenigen des Gelbfiebervirus. GenBank-Nr:: M27157 (europäischer Subtyp), X07755 (fernöstlicher, sibirischer Subtyp), L40361 (sibirischer Subtyp).

\section{Vermehrung}

Nach dem Zeckenstich vermehrt sich das inokulierte Virus zunächst lokal in Endothelzellen, Makrophagen, Langerhans-Zellen und Granulozyten. Über das lymphatische System gelangen die Erreger in das Blut (erste Virämie). Nach weiterer Vermehrung im retikulo-endothelialen System (zweite Virämie) kann das Virus über das Gefäßendothel oder durch Infektion 
von mobilen Zellen (Makrophagen, Dendritische Zellen) in das ZNS gelangen.

\section{Pathogenität / Virulenz / Antigenvariabilität}

Innerhalb eines FSME-V-Subtyps variiert die Aminosäuresequenz nicht mehr als bis zu 2,2\%. Dagegen ist diese Variabilität zwischen den Subtypen naturgemäß größer (5,6 \%). In einigen Studien wird dem fernöstlichen Subtyp eine größere Virulenz im Menschen zugeschrieben als den anderen. Tierexperimente unterstützen diese Annahme. Außerdem gibt es Hinweise, dass der sibirische Subtyp einen chronisch-progressiven Krankheitsverlauf verursachen kann, während dies für den europäischen Subtyp nicht beobachtet wird.

\section{Erkrankung}

Frühsommer-Meningoenzephalitis (FSME)

\section{Synonym(e)}

Zentraleuropäische Zeckenenzephalitis (Infektion mit dem europäischen FSME-V-Subtyp); Russische Frühjahrs-Sommer-Enzephalitis (Infektion mit dem fernöstlichen FSME-V-Subtyp).

\section{Inkubationszeit}

Die Inkubationszeit beträgt 7-14 Tage, in Einzelfällen bis zu 28 Tage.

\section{Leitsymptome}

Das klinische Erscheinungsbild von FSME ist nicht charakteristisch, sodass letztlich die Ergebnisse des virologischen Labors für die Diagnosestellung entscheidend sind.

\section{Symptome}

Die meisten Infektionen mit dem europäischen FSME-V Subtyp verlaufen inapparent. Nur bei 5-30 \% der Infektionen treten grippeähnliche Symptome auf mit Fieber $\left(<38{ }^{\circ} \mathrm{C}\right)$, Kopfschmerzen, Schwindelgefühl und Erbrechen („Sommergrippe“). Diese 1. Phase der Krankheit dauert 4-6 Tage. Danach lassen die Beschwerden für ungefähr 2-3 Tage nach (in Einzelfällen bis zu 21 Tage). In der 2. Phase der Erkrankung, die nur 20-30 \% der Patienten erleiden, stellen sich hohes Fieber (bis $>40{ }^{\circ} \mathrm{C}$ ), starkes Krankheitsgefühl und Meningitis-Symptome ein. Es können Zeichen der Enzephalitis hinzu kommen (Meningoenzephalitis, in ca. 30-40 \% der Fälle mit einer 2. Phase). Vor allen Dingen bei älteren Patienten kann sich zusätzlich eine Myelitis oder Radikulitis entwickeln (Gefahr der Bulbärparalyse und Phrenikusparese). In diesen schweren Fällen (ca. $10 \%$ der Fälle mit einer 2. Phase) beträgt die Letalität ungefähr 1-2 \% und die Gefahr von bleibenden Schäden besteht. Extrapyramidale und zerebelläre Symptome können oft noch Monate nach Rekonvaleszenz persistieren. Gewöhnlich kommt es aber selbst bei schweren Verläufen zur völligen Heilung ohne bleibende neurologische Ausfälle. In 10-20\% der schwereren Verläufe muss jedoch mit bleibenden psychomotorischen Defekten gerechnet werden. Paraplegien, Tetraplegien und Paresen der Schultergürtelund Kopfmuskulatur sind als prognostisch ungünstige Zeichen $\mathrm{zu}$ werten. Insgesamt betrachtet, sind die Krankheitsbilder Paresen und bleibenden Schäden bei Erwachsenen ausgeprägter als bei Kindern.

Durch den fernöstlichen FSME-V-Subtyp hervorgerufene Erkrankungen beginnen weniger akut. Die Letalität (5-40\%) ist jedoch wesentlich höher als bei beim europäischen Subtyp. Einen weiteren Unterschied stellt die Tatsache dar, dass hier infizierte Kinder schwerer erkranken als Erwachsene. Auch die Rate der bleibenden neurologischen Schäden ist mit 3060 \% höher. Der sibirische Subtyp des FSME-V verursacht Krankheitsverläufe (Letalität von 1-3 \%), die weniger schwer sind als beim fernöstlichen aber schwerer als beim europäischen Subtyp verlaufen. Ähnlich wie bei dem fernöstlichen Subtyp werden chronische Infektionsverläufe beobachtet.

\section{Pathophysiologie}

Der erste Fieberanstieg ist auf die Virämie zurückzuführen, während der zweite Fiebergipfel dann auftritt, wenn das Stadium der ZNS-Infektion erreicht ist. Das Gehirn verändert sich ödematös. Vereinzelt treten umschriebene Blutungen auf. Die beobachtete Lähmung der oberen Extremitäten lässt sich mit der hohen Empfindlichkeit der anterioren motorischen Rückenmarkszellen im Halswirbelbereich für Virus-assoziierte zytopathogene Mechanismen erklären.

\section{Immunantwort}

Gegen das Glykoprotein der Hülle werden hämagglutinationshemmende und neutralisierende Antikörper gebildet. In der Regel werden zunächst IgM-Antikörper produziert und erst danach IgG-Antikörper. Auch eine zelluläre Immunantwort wird generiert.

\section{Differenzialdiagnose}

Die Differenzialdiagnose der durch Flaviviren hervorgerufenen neurologischen Symptome umfasst viele andere virale Erreger. Häufig sind Enteroviren als Ursache anzuschuldigen. In Nordamerika sind das WestNil-Virus und das St.-Louis-Enzephalitis-Virus wichtige Enzephalitis-Erreger. Auch an die therapierbare Herpes-Enzephalitis (Herpes-simplex-Virus) muss gedacht werden, obwohl sie nur selten auftritt. Andere Herpesviren können vor allem bei immunsupprimierten Patienten eine ZNS-Symptomatik verursachen. Darüber hinaus kommen als Ursache einer Meningitis bzw. Enzephalitis Masern-, Mumps-, Röteln- und Influenzaviren in Betracht. Epidemiologische Hinweise wie Jahreszeit und Wohnort in einem bekannten Endemiegebiet erleichtern die Diagnose. 


\section{Diagnostik}

\section{Untersuchungsmaterial}

Serum, Plasma, Liquor.

\section{Diagnostische Verfahren}

Die Diagnose wird in der Regel aufgrund des Nachweises von virusspezifischen IgM- und IgG-Antikörpern im Serum und ggf. im Liquor (bei ca. 50 \%) durch das ELISA-Verfahren gestellt. Meist sind schon in der ersten Krankheitsphase virusspezifische IgM-Antikörper im Serum nachweisbar. Bei zunächst negativem Test und weiterbestehendem klinischen Verdacht empfiehlt sich die Testwiederholung nach etwa 1 Woche. In der zweiten Krankheitsphase werden dann in der Regel sowohl IgM- als auch IgG-Antikörper gefunden. Andere serologische Testverfahren wie KBR und HHT spielen keine Rolle mehr. Die Virusisolierung aus dem Blut von Infizierten und der Nachweis mittels RT-PCR gelingen nur in der virämischen Phase und sind für die Routinediagnostik daher meist bedeutungslos (bei Arztkonsultation ist die virämische Phase in der Regel schon vorbei). In der zweiten Erkrankungsphase kann eventuell im Liquor mittels RTPCR virale Nukleinsäure gefunden werden.

\section{Befund / Interpretation}

Berücksichtigt werden müssen mögliche Kreuzreaktionen durch Antikörper gegen andere Flaviviren. Diese können durch Neutralisations-Testverfahren ausgeschlossen werden, die allerdings nur Speziallaboratorien durchführen. Bei der Befundinterpretation muss auch daran gedacht werden, dass FSME-Impfungen zu lange Zeit nachweisbaren Spiegeln von FSME-Vspezifischen IgM-Antikörpern führen können. Bei Infektionen mit dem Epstein-Barr-Virus nach FSMEImpfung können FSME-V-reaktive IgM-Antikörper auftreten, die nicht auf eine FSME zurückzuführen sind.

\section{Therapie}

\section{Therapeutische Maßnahmen}

Es kommen nur supportive Maßnahmen (z. B. strenge Bettruhe) in Betracht, da eine spezifische antivirale Therapie nicht zur Verfügung steht.

\section{Epidemiologie}

\section{Verbreitung}

Weltweit treten mehr als 10.000 Krankheitsfälle jährlich auf. Besonders Russland ist betroffen. Damit ist das FSME-V nach dem Japanische Enzephalitis-Virus der zweithäufigste Krankheitserreger unter den neurotropen Flaviviren.

Das Verbreitungsgebiet des europäischen Subtyps erstreckt sich bis zum Ural im Osten, über Finnland und Schweden im Norden, nach Deutschland und Frankreich im Westen bis herunter nach Italien, Griechenland und dem ehemaligen Jugoslawien im Süden. Im
Unterschied $\mathrm{zu}$ den Erregern der Lyme-Borreliose (Borrelia burgdorferi) wird das FSME-V nur in bestimmten Risikogebieten gefunden. Die topographische Darstellung der FSME-Risikogebiete in Deutschland (Angabe auf Landkreisebene) beruht größtenteils auf einer speziellen Fallsammlung von FSME-Erkrankungen und wird ständig aktualisiert (Robert-KochInstitut in Berlin in enger Kooperation mit den betroffenen Bundesländern). Naturherde mit hohem Risiko befinden sich überwiegend in Baden-Württemberg und Bayern. Solche mit niedrigem Risiko liegen in Hessen, Rheinland-Pfalz und Thüringen ( $\triangleright \mathrm{Abb} .1)$. FSME stellt eine endemische Erkrankung dar, die hauptsächlich in den Sommermonaten auftritt. Die hier herrschenden Temperaturen und die Feuchtigkeit fördern die Aktivität der Zecken. Besonders waldreiche Flusstäler sind potentielle Zeckengebiete. Oberhalb von 1.000 Metern ist keine Zeckengefahr mehr gegeben. In Zentraleuropa gibt es zwei Häufigkeitsgipfel der FSME-Infektion: April/Mai/Juni und September/Oktober. Der Erkrankungsgipfel hinkt entsprechend etwa 3-4 Wochen hinterher. Begünstigt wird die Zeckenvermehrung durch milde Winter und feuchte Sommer.

Der fernöstliche Subtyp kommt im asiatischen Russland, nordöstlichen Teil Chinas, nördlichen Teil Japans (Hokkaido) und in Sibirien vor. Der sibirische Subtyp

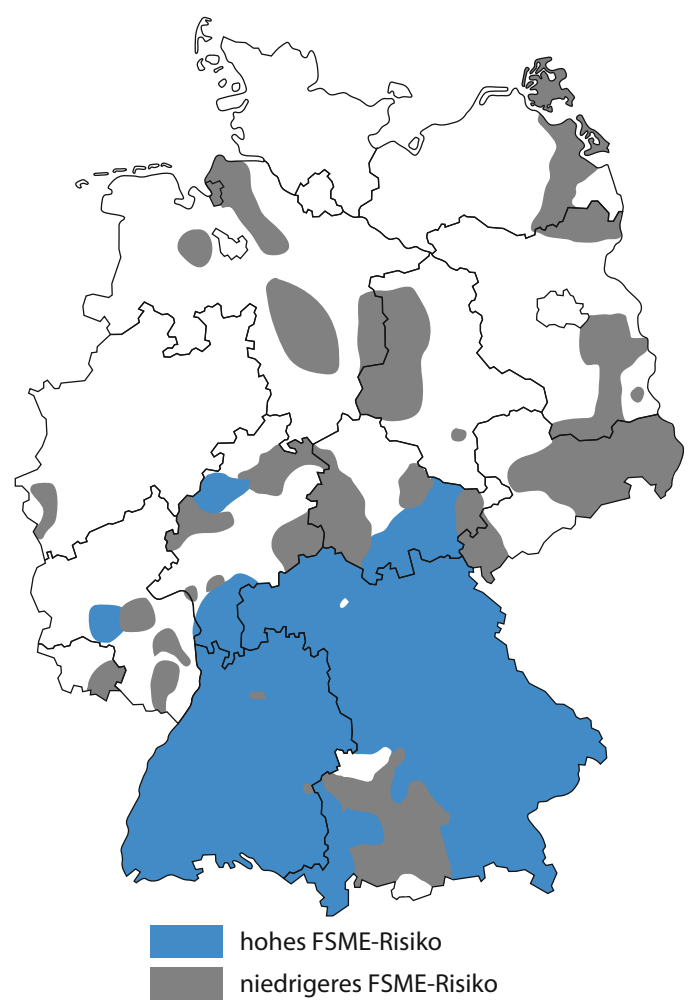

Abb. 1. FSME-Risikogebiete 


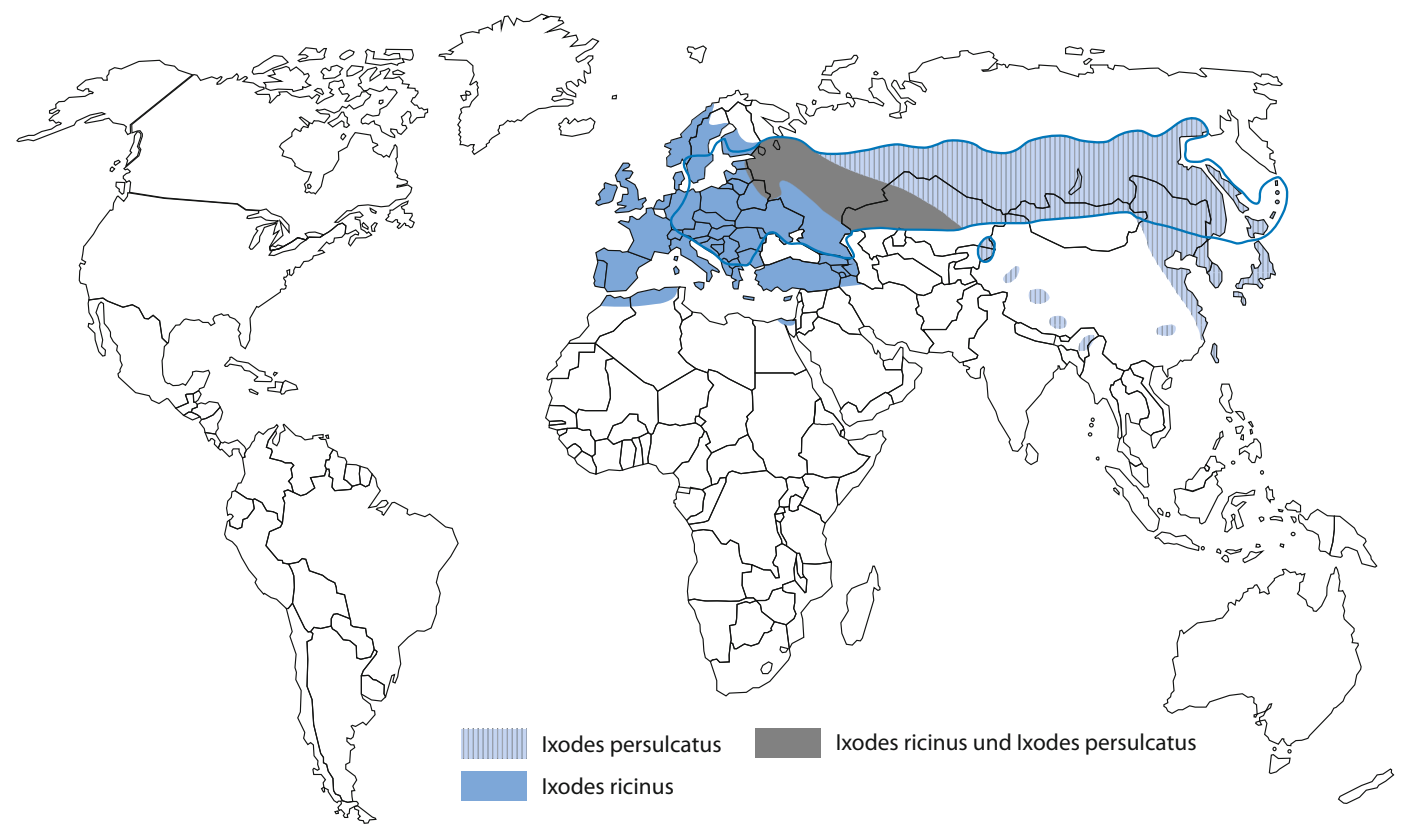

- Abb. 2. Verbreitung von Ixodes ricinus (Vektor des europäischen FSME-V Subtyps) und Ixodes persulcatus (Vektor des sibirischen und fernöstlichen FSME-V Subtyps). Die blaue Linie umgrenzt das Gebiet, in dem fokale Herde von FSME vorkommen.

des FSME-V findet sich im östlichen Teil des europäischen Russlands und in Westsibirien. Damit überlappt sein Verbreitungsgebiet im Westen mit dem des europäischen und im Osten mit dem des fernöstlichen Subtyps ( $\triangleright$ Abb. 2).

\section{Wirtsbereich / Reservoir}

Natürliche Wirte für alle 3 Subtypen des FSME-V sind kleine Nagetiere. Für den europäischen Subtyp sind es vermutlich Mitglieder der Familie Muridae (Apodemus flavicollis).

\section{Risikogruppen}

Das Infektionsrisiko ist für Personen am höchsten, die permanent in FSME-Endemiegebieten wohnen bzw. dort beruflich tätig sind (Land- und Forstwirtschaft). Aber auch Freizeitaktivitäten (Wandern, Campen, etc.) in Endemiegebieten können selbst bei kurzer Aufenthaltsdauer zur Infektion führen. Die Zeckensaison dauert etwa von März bis Oktober. Außerhalb dieser Zeitspanne besteht an warmen Tagen ein geringes Restrisiko.

\section{Transmission / Vektoren}

Das Auftreten der Infektionen mit FSME spiegelt die relativ konstante geografische Verteilung der Hauptvektoren wieder. Der fernöstliche und der sibirische Subtyp werden durch Ixodes persulcatus (Taigazecke) übertragen. Im Falle des europäischen Subtyps der FSME-V ist dies die Schildzecke Ixodes ricinus (ge- meiner Holzbock). Ixodes ricinus hat für jedes Lebensstadium unterschiedliche Wirte (Larvenstadium: Kleinsäuger, Eidechsen, Vögel; Nymphenstadium: Igel, Eichhörnchen, Mäuse, Vögel und der Mensch; adultes Stadium: u. a. Füchse, Ziegen, Schafe, Rehe, Hasen, Rinder). Um einen Wirt zu erreichen, kriechen Zecken an Pflanzen hoch, jedoch in der Regel nicht höher als $50 \mathrm{~cm}$ bis $70 \mathrm{~cm}$. Es trifft also nicht zu, dass Zecken sich aus der Höhe von Bäumen auf ihre Opfer fallen lassen. Außerdem benötigen Zecken für ihren Lebenszyklus eine Mindesttemperatur von $7-8{ }^{\circ} \mathrm{C}$ und eine relative Luftfeuchtigkeit von mehr als $80 \%$. In der Regel entstehen solche Umweltbedingungen in Deutschland im Frühjahr, Frühsommer und Herbst. In Gebieten, in denen das FSME vom europäischen Subtyp endemisch ist, ist etwa 1-5\% der Vektoren durchseucht. Viel häufiger sind Zecken mit dem Bakterium Borrelia burgdoferi infiziert (10-35\%), welches die Lyme-Borreliose hervorruft. Nach dem Zeckenstich gelangen die Viren über den infizierten Speichel in das Blut des Wirtes. Etwa 10-20 \% aller FSME-Infektionen werden nicht durch Zeckenstich, sondern über Rohmilchprodukte von infizierten Kühen, Schafen und Ziegen übertragen. Dieser Infektionsweg ist jedoch in Deutschland ohne praktische Bedeutung. Laborinfektionen kommen ebenfalls vor.

\section{Prävention / Impfstoffe}

Der sicherste Infektionsschutz besteht darin, Zeckenhabitate zu meiden. Bei einem Aufenthalt in Risikoge- 
bieten sollte lange Kleidung getragen werden. Diese sollte hell sein, damit herumwandernde Zecken besser erkannt werden können. Repellentien wie beispielsweise Autan haben eine zeitliche begrenzte Wirkung (2 Stunden) gegen Zecken. Nach Risikoaufenthalten sollte der Körper nach Zecken abgesucht werden (bevorzugte Lokalisationen: unter den Armen, im Nacken, am Haaransatz des Kopfes und generell an dünnen, gut durchbluteten Hautpartien).

Zecken, die sich mit ihrem Halteapparat bereits in der Haut verankert haben, sollten möglichst rasch entfernt werden. Mit einer Zeckenzange oder Pinzette wird die Zecke möglichst hautnah gefasst und vorsichtig - nach leichtem Hin- und Herhebeln - herausgezogen. Danach sollte die Einstichstelle desinfiziert werden. Die Verwendung von Öl, Wachs oder Nagellack, um die Zecke zu ersticken, sind obsolet (Gefahr der vermehrten Erregerausschüttung). Die Wunde sollte sofort nach Entfernung der Zecke desinfiziert werden.

Die FSME-Impfung ist eine Indikationsimpfung für Risikogruppen (s. o.). Zurzeit sind vier Impfstoffe verfügbar. Neben zwei russischen Impfstoffen, die den fernöstlichen Subtyp enthalten, gibt es zwei Vakzine, welche in Europa zugelassen sind und auf dem europäischen Subtyp basieren (FSME-IMMUN von Baxter; Encepur von Novartis). Die Impfung mit dem europäischen Subtyp schützt sehr wahrscheinlich auch vor Infektionen mit dem fernöstlichen Subtyp. Für die Impfung wird ein komplettes, durch Formalin inaktiviertes Virus verwendet, welches in Kulturen von embryonalen Hühnerfibroblasten angezüchtet und anschließend gereinigt wurde. Als Adjuvans enthält der Impfstoff Aluminiumhydroxid. Drei Impfungen sind für einen vollständigen Impfzyklus notwendig, wobei die Effizienz des Impfschutzes bei 95 \% bis 99 \% liegt. Auffrischimpfungen sollten alle 3 bis 5 Jahre durchgeführt werden. Früher beobachtete Nebenwirkungen (Kopfschmerzen, Fieber, Abgeschlagenheit) treten heute kaum mehr auf, da die Vakzine nun durch einen Ultrazentrifugationsschritt hochaufgereinigt wird. An einer weiteren Verbesserung der Impfstoffe wird gearbeitet. Die Durchimpfungsrate der österreichischen Bevölkerung ist die höchste in ganz Europa und beträgt etwa $86 \%$. Dadurch konnte die Die Zahl der FSME-bedingten Hospitalisierungen um 90 \% gesenkt werden.

Die postexpositionelle Gabe von FSME-spezifischem Hyperimmunglobulin (passive Impfung) wird „generell nicht empfohlen" (STIKO) und von Herstellerseite in Deutschland nicht mehr angeboten. Berichte über schwere Krankheitsverläufe nach zu später postexpositioneller passiver Immunisierung liegen vor. Der zugrunde liegende Mechanismus ist möglicherweise eine Verstärkung der Infektion durch die verabreichten Antikörper (Immunoenhancement).

\section{Ausbruchsmanagement}

Wenn FSME in Regionen beobachtet wird, die bislang nicht als Risikogebiet eingestuft wurden, dann müssen weiterführende epidemiologische Untersuchungen eingeleitet werden. Darüber hinaus sollten die Ärzte dieser Regionen ausführlich über FSME informiert und weitergebildet werden.

\section{Meldepflicht}

Nach $₫ 7$ Abs. 1 Nr. 14 Infektionsschutzgesetzes (IfSG) muss das Labor dem Gesundheitsamt jeden direkten oder indirekten (serologischen) Nachweis von FSME$\mathrm{V}$ durch das Labor dann namentlich melden, wenn er auf eine akute Infektion hinweist. Darüber hinaus stellt das Gesundheitsamt gemäß $\$ 25$ Abs. 1 IfSG ggf. eigene Ermittlungen an. Das Gesundheitsamt übermittelt gemäß $\$ 11$ Abs. 1 IfSG an die zuständige Landesbehörde nur Erkrankungs- oder Todesfälle und Erregernachweise der Falldefinition gemäß $₫ 4$ Abs. 2. Weiterführende Informationen zum IfSG und zur Falldefinition sind auf der unten aufgeführten WebAdresse des Robert-Koch-Instituts zu finden.

\section{Weiterführende Informationen}

\section{Referenzzentren / Expertenlaboratorien}

- Konsiliarlaboratorium für Frühsommer-Meningoenzephalitis (FSME), Robert-Koch-Institut, Nordufer 20, 13353 Berlin, Tel. +49 30 18754-2370 oder-2321, E-Mail: niedrigm@rki.de

- Nationales Referenzlabor für durch Zecken übertragene Krankheiten (NRL-ZüK), Friedrich-Loeffler-Institut, Bundesforschungsinstitut für Tiergesundheit, Standort Jena, Naumburger Str. 96a, 07743 Jena, Tel. +49 3641 804248, E-Mail: jochen.suess@fli.bund .de

\section{Web-Adressen}

- Robert-Koch-Institut (RKI): http://www.rki.de/

- Gesellschaft für Virologie: http://www.g-f-v.org/

- Deutsche Vereinigung zur Bekämpfung der Viruskrankheiten e.V.: http://www.dvv-ev.de/

- Centers for disease control and prevention (Informationen zu durch Zecken übertragene Enzephalitiden): http:// www.cdc.gov/ncidod/dvbid/

- Veterinary Public Health (Tierärztliche Hochschule Hannover): http://www.veterinary-public-health.de/home_d/ aufgaben/zoonosen/

- WHO World Health Organization (Aktuelles über Infektionskrankheiten, Empfehlungen und Programme der WHO): http://www.who.int/

\section{Schlüsselliteratur}

1. Gubler DJ, Kuno G, Markoff L (2007) Flaviviruses. In: Knipe, DM, Howly, PM (eds) Fields Virology (5th edition), Philadelphia: Lippincott Williams and Wilkins, pp 1153-1252

2. Mansfield KL, Johnson N, Phipps LP, Stephenson JR, Fooks AR, Solomon T (2009) Tick-borne encephalitis virus - a review of an emerging zoonosis. J Gen Virol 90:1781-1794

3. Schoub BD, Backburn NK (1995) Flaviviruses In: Zuckerman AJ, Banatvala JE, Pattison JR, Griffiths PD, Schoub BD, Mortimer P (eds) Principles and practice of clinical virology, 6th ed (2009) Chichester: John Wiley, pp 669698 


\section{FSME-Virus}

Frühsommer-Meningoenzephalitis-Virus und Russisches Frühjahrs-Sommer-Enzephalitis-Virus

Fünftagefieber
- Bartonella
Rickettsien

\section{Fusariose}

Fusarium

\section{Fusarium}

\section{Reinhard Kappe, Dagmar Rimek}

\section{Erreger}

\section{Synonym(e)}

F. solani, Teleomorph: Nectria haematococca; F. verticillioides $=$ F. moniliforme, Teleomorph: Gibberella moniliformis.

\section{Erregerspezies}

F. solani, F. oxysporum, F. verticillioides, F. proliferatum. Die Gattung Fusarium enthält über 20 weitere, als Infektionserreger in der Humanmedizin weitaus seltenere Arten.

\section{Taxonomie}

Abteilung: Ascomycota; Klasse: Euascomycetes; Ordnung: Hypocreales; Familie: Hypocreaceae; Gattung: Fusarium.

Die Taxonomie auf Spezies-Ebene wurde in den letzten Jahren aufgrund molekulargenetischer Untersuchungen der ITS-rDNA, der 28S-rDNA, der mitochondrialen DNA und der Sequenz des Beta-TubulinGens neu definiert. Danach werden mehr als 20 Spezies unterschieden. Bei F. oxysporum und F. solani wurden mehrere Varianten beschrieben, sodass beide Arten als Spezies-Komplex anzusehen sind.

\section{Historie}

In der ehemaligen UdSSR starben 1944-1947 mehr als 100.000 Menschen an einer Nahrungsmittelvergiftung durch verschimmeltes Getreide. Die Erkrankung war eine Mykotoxikose verursacht durch Toxine von F. sporotrichoides und F. poae.

Der erste Fall einer disseminierten invasiven Fusariose wurde 1973 von Cho et al. bei einem Kind mit einer akuten lymphatischen Leukämie beschrieben.

\section{Morphologie}

Histologisch finden sich bei invasiver Fusariose im Wirtsgewebe radiär wachsende, hyaline, septierte, sich spitzwinklig $\left(30-50^{\circ}\right)$ verzweigende Myzelien einheitlichen Kalibers (3-4 $\mu \mathrm{m})$. Diese sind anfärbbar mit der Grocott-Gomorri-Versilberung oder dem Perjodsäure-Schiff-Reagenz (PAS). Ohne Immunhistologie sind die Hyphen nicht von Aspergillus und Scedosporium (Pseudallescheria) unterscheidbar.

In der Kultur wachsen nach 3-5 Tagen bei $37^{\circ} \mathrm{C}$ auf Sabouraud-Glukose-Agar weißliche Kolonien mit reichlich Luftmyzel.

- F. solani: Rückseite der Kultur grün bis bläulichbraun. Mikroskopische Merkmale: Die Traghyphen (Konidiophoren) entspringen seitlich vom Luftmyzel. Nach wenigen Tagen finden sich massenhaft einzeln terminal an einer Traghyphe gebildete, kleine, längliche Mikrokonidien (1-3 $\mu \mathrm{m})$. Nach 5-10 Tagen treten zahlreiche terminale oder interkalare, glatt- oder rauwandige, einzeln oder paarweise liegende Chlamydosporen auf. Nach 10-30 Tagen werden charakteristische Makrokonidien auf kürzeren, verzweigten Konidiophoren gebildet. Diese sind spindelförmig, leicht gebogen, zugespitzt und 3- bis 5-zellig.

- F. oxysporum: Das weiße Luftmyzel wird meist nach wenigen Tagen purpurfarben. Rückseite der Kultur farblos bis dunkelblau oder dunkelpurpurn. Mikroskopische Merkmale: Die Konidiophoren sind kurze, einzelne, seitliche Monophialiden am Luftmyzel. Mikrokonidien, Chlamydosporen und Makrokonidien unterscheiden sich nicht von denjenigen bei F. solani.

\section{Genom}

Fusarium spp. sind eukaryonte Organismen mit 6-9 Chromosomen (0,4-6,5 Mb) und einer Genomgröße von ca. 27-30 Megabasenpaaren. Da Fusarien in der Pflanzenpathologie eine große Rolle spielen, sind die Sequenzen einer Reihe von Genen und Proteinen bekannt.

\section{Vermehrung}

In vitro zeichnen sich die humanpathogenen Fusarien durch rasches Wachstum aus.

\section{Pathogenität / Virulenz / Antigenvariabilität}

F. solani und F. oxysporum sind in Risikogruppe 2 eingeordnet. Ein Grund für die Humanpathogenität dieser beiden Arten ist ihre Fähigkeit bei $37^{\circ} \mathrm{C}$ zu wachsen. Fusarien sind in der Lage, Gewebe und Gefäßwände zu penetrieren und verursachen hämorrhagische Gewebeinfarkte und Nekrosen. Fusarien können verschiedene Mykotoxine bilden, z. B. Trichothecene. $\mathrm{Ob}$ diese eine Rolle bei der invasiven Fusariose spielen, ist unbekannt. 


\section{Erkrankungen}

\section{Fusariose}

\section{Synonym(e)}

Invasive Fusarium-Infektion.

\section{Inkubationszeit}

Die Inkubationszeit der Fusariose ist unbekannt.

\section{Leitsymptome}

Fieber, knötchenartige, hämorrhagische Hautläsionen, Pneumonie.

\section{Symptome}

Die klinischen Symptome entsprechen weitestgehend denen der invasiven Aspergillose: antibiotikarefraktäres Fieber und Pneumonie. Im Gegensatz zur Aspergillose zeigen sich in ca. $75 \%$ der Fälle multiple schmerzhafte papuläre Hautläsionen z. T. mit zentraler Nekrose. Prädilektionsstellen sind die Extremitäten. In ca. 50 \% werden Fusarien aus Blutkulturen angezüchtet. Seltene Symptome sind Sinusitis, Endokarditis, Myokarditis, Osteomyelitis, Zellulitis, Myositis und Meningoenzephalitis.

Auch Katheterinfektionen können auftreten, die als zentralvenöse Katheterinfektion oder als Peritonitis bei kontinuierlicher ambulanter Peritonealdialyse (CAPD) verlaufen können.

\section{Pathophysiologie}

Die invasive Fusariose beginnt nach Inhalation der Sporen primär in der Lunge, von wo aus der Pilz hämatogen in andere innere Organe und die Haut disseminiert. Auch der Gastrointestinaltrakt oder die Haut können als Eintrittspforten dienen. Die Schwere des Krankheitsbildes hängt vom Ausmaß der Immunsuppression ab.

\section{Immunantwort}

Makrophagen bilden die erste Reihe der Immunabwehr, Granulozyten die zweite. Beide Zelltypen verhindern das Wachstum der Pilzhyphen; die Makrophagen unterbinden darüber hinaus das Auskeimen der Pilzsporen.

\section{Differenzialdiagnose}

Invasive pulmonale und disseminierte Aspergillose, Scedosporiose, Zygomykose. Die Klärung der Differenzialdiagnose wird erst bei erfolgreicher Kultur möglich.

\section{Lokalisierte Fusarium-Infektion}

\section{Inkubationszeit}

Unbekannt.

\section{Leitsymptome}

Keratitis, Onychomykose, Hautläsionen.

\section{Symptome}

Am Auge finden sich Keratitis und Endophthalmitis; an der Haut kutane und subkutane Infektionen bei Verbrennungswunden oder Hautulzera, an den Nägeln eine Onychomykose.

\section{Pathophysiologie}

Bei Immunkompetenten entstehen nach traumatischer Inokulation lokalisierte Pilzherde.

\section{Immunantwort}

Keine Daten verfügbar.

\section{Differenzialdiagnose}

Auge: Keratitis durch andere Schimmelpilze, Herpesvirus-Infektion; Haut: Verletzungsmykosen durch andere Schimmelpilze, Sporotrichose, Eumyzetom; Nagelmykose durch Dermatophyten.

\section{Diagnostik}

\section{Untersuchungsmaterial}

Hautbiopsien, Blutkulturen, Katheterspitzen, Hornhaut vom Auge, Glaskörperpunktat, Nagelmaterial, Peritonealflüssigkeit.

\section{Diagnostische Verfahren}

Mikroskopie: Die histologische Untersuchung von Biopsiematerial befallenen Gewebes erlaubt die Diagnose Hyalohyphomykose (z. B. Aspergillose, Fusariose, Scedosporiose). Auch die Calcofluorweiß-Färbung stellt die Hyphen dar.

Kultur: Das Untersuchungsmaterial wird auf Sabouraud-Glukose-Agar-Platten mit antibakteriellen Zusätzen ausgestrichen und 3 Wochen bei $28{ }^{\circ} \mathrm{C}$ und bei $37^{\circ} \mathrm{C}$ inkubiert. Nach 3-5 Tagen wachsen weißliche Kolonien mit reichlich Luftmyzel. Die Speziesidentifizierung ist schwierig und erfolgt mikromorphologisch oder molekulargenetisch.

Antigen- und Antikörpernachweise sind nicht verfügbar. Über die Entwicklung spezieller Nukleinsäurenachweisverfahren gibt es Berichte, bisher ist aber kein kommerzieller Test verfügbar.

\section{Befund / Interpretation}

Fusarien treten im mikrobiologischen Labor in der Kultur häufiger als Kontaminanten denn als ätiologisch relevante Erreger auf. Daher sind vor jeder Speziesbestimmung eines Isolates der klinische Hintergrund und Ergebnisse weiterer mikrobiologischer Untersuchungen zu berücksichtigen. Der mikroskopische Nachweis von Pilzhyphen erlaubt die Diagnose Hyalohyphomykose. Erst die kulturelle Anzucht bestätigt eine Fusariose. Speziesbestimmung und Sensibilitätstestung haben bei invasiven Fusariosen therapeutische Konsequenzen.

\section{Therapie}

\section{Therapeutische Maßnahmen}

Eine allgemein gültige Therapieempfehlung gibt es nicht. Amphotericin B in hohen Dosen war lange Zeit 
das Standardmittel, Alternativen sind die neueren Triazole Voriconazol und Posaconazol. Die klinische Erfolgsrate ist dennoch gering, die Letalität der invasiven Fusariose liegt bei über $75 \%$.

\section{Resistenz}

Die Fusarien zeichnen sich durch eine geringe In-vitro-Empfindlichkeit gegenüber den meisten Antimykotika aus. F. solani ist die resistenteste Art. Amphotericin B zeigt die höchste Aktivität in vitro. Die neueren Triazole Voriconazol, Ravuconazol und Posaconazol zeigen speziesabhängige, $z$. T. fungizide Aktivität gegenüber non-solani Fusarium-Spezies.

\section{Epidemiologie}

\section{Verbreitung}

Fusarium spp. sind weltweit verbreitete Pflanzenpathogene oder leben als Saprophyten auf abgestorbenen Pflanzenteilen, auf Getreidesamen, im Erdboden und im Wasser. Fusarien stellen zusammen mit Cladosporium-, Alternaria- und Aspergillus-Arten einen Großteil des „Myko-Planktons“ der Luft. Die Fusariose ist mittlerweile bei neutropenischen Patienten der Hämato-Onkologie die zweithäufigste invasive Schimmelpilzinfektion nach der Aspergillose.

\section{Wirtsbereich / Reservoir}

Das größte Reservoir für invasive Fusariosen stellen Fusarium-Sporen in der Luft dar. Quellen können aber auch die besiedelte Haut oder kontaminierte Wassersysteme im Krankenhaus sein. Bei lokalisierten Infektionen spielen besiedelte Pflanzenteile die größte Rolle.

\section{Risikogruppen}

Lokalisierte Infektionen wie Keratitis: Gärtner, Waldarbeiter.

Invasive, disseminierte Fusariose: Immunsupprimierte Patienten, z. B. nach zytotoxischer Chemotherapie oder Steroidbehandlung, mit Agranulozytose, Leukämie, AIDS; Patienten mit intravenösen oder intraperitonealen Dauerkathetern, Verbrennungspatienten.

\section{Transmission / Vektoren}

Infektionen am Auge entstehen nach Mikrotraumata der Hornhaut durch Verletzung mit Pflanzenteilen. Bei invasiven Fusariosen werden aerogen verbreitete Mikrokonidien inhaliert oder sie gelangen nach Besiedlung von Haut oder Kathetern in den Blutkreislauf.

\section{Prävention / Impfstoffe}

Zur Prävention von Augeninfektionen sollten bei Arbeiten mit Verletzungsgefahr durch Pflanzenteile Schutzbrillen getragen werden.

Zur Vermeidung invasiver Fusariosen sollten Hochrisikopatienten, z. B. Knochenmarktransplantierte in der Phase der Neutropenie, die Inhalation von Fusari$u m$-Konidiosporen vermeiden. Dies ist in Räumen, die mit HEPA-Luftfiltern ausgestattet sind, gewährleistet. Bei unumgänglichem Transport für diagnostische Maßnahmen muss die Passage durch stark konidienhaltige Luft (wie sie z. B. bei Baumaßnahmen entsteht) vermieden werden, bzw. die Patienten müssen einen Mundschutz tragen. Sorgfältige Pflege von Langzeitkathetern unter sterilen Kautelen.

\section{Ausbruchsmanagement}

Die Erkrankung ist nicht von Mensch zu Mensch übertragbar. Bei Ausbrüchen im Krankenhaus sollte eine Quellensuche und -elimination erfolgen. Ursache können z. B. Sporen aus der Luft bei Baumaßnahmen oder kontaminierte Wassersysteme sein.

\section{Meldepflicht}

Nach dem Infektionsschutzgesetz besteht für die Fusarium-Infektion in Deutschland keine Meldepflicht. Im Rahmen gehäuft auftretender nosokomialer Infektionen (gleichzeitig in einem Stationsbereich zwei oder mehr Fusariosen) besteht eine nicht namentliche Meldepflicht an das zuständige Gesundheitsamt.

\section{Weiterführende Informationen}

\section{Referenzzentren / Expertenlaboratorien}

- Nationales Referenzzentrum für Systemische Mykosen, Prof. Dr. med. Uwe Groß, Institut für Medizinische Mikrobiologie, Universitätskliniken Göttingen, Kreuzbergring 57, 37075 Göttingen, Tel.: 0551-39 5801/7099, Fax: 0551-39 5861, E-Mail: ugross@gwdg.de

- Centraalbureau voor Schimmelcultures, PO Box 85167, NL-3508 AD Utrecht, The Netherlands. Phone: +31-302122600, fax +31-30-2512097, E-Mail: info@cbs.knaw.nl

\section{Web-Adressen}

- DoctorFungus Corporation: http://www.doctorfungus. org/thefungi/fusarium.htm

- Nationales Referenzzentrum für Systemische Mykosen: http://www.nrz-mykosen.de/

- Centraalbureau voor Schimmelcultures, Niederlande: http://www.cbs.knaw.nl

\section{Schlüsselliteratur}

1. De Hoog GS, Guarro J, Gene J, Figuera MJ (2000) Atlas of Clinical Fungi, 2nd edn. Centraalbureau voor Schimmelcultures, Utrecht, pp 681-705

2. Kappe R, Rimek D (2009) Hyalohyphomyzeten. In: Neumeister B, Geiss HK, Braun RW, Kimmig P (Hrsg.) Mikrobiologische Diagnostik, 2. Aufl. Georg Thieme Verlag, Stuttgart, S 673-687

3. Torres HA, Raad II, Kontoyannis DP (2003). Infections caused by Fusarium species. J Chemother 15 (Suppl 2):28-35

4. Verweij PE, Brandt ME (2007) Aspergillus, Fusarium and other opportunistic moniliaceous fungi. In: Murray PR, Baron EJ, Jorgensen JH, Landry ML, Pfaller MA (eds) Manual of Clinical Microbiology, vol 2, $9^{\text {th }}$ edn. ASM Press, Washington DC, Chapter 121 


\section{Fusobacterium}

Heinrich K. Geiss, Arne C. Rodloff

\section{Erreger}

\section{Erregerspezies}

F. alocis, F. gonidiaformans, F. mortiferum, F. naviforme, F. necrogenes, F. necrophorum (ssp. necrophorum, ssp. funduliforme), F. nucleatum (ssp. animalis, ssp. fusiforme, ssp. nucleatum, ssp. polymorphum, ssp. vincentii), F. periodonticum, F. russii, F. ulcerans, F. varium, (F. canifelinum, F. perfoetens, F. simiae)

\section{Taxonomie}

Phylum: Fusobacteriales; Familie: Fusobacteriaceae; Genus: Fusobacterium

\section{Historie}

In der letzten Dekade des 19. Jahrhunderts wurden von zahlreichen Wissenschaftlern (Bang, Löffler, Miller, Plaut, Schmorl, Vincent, Veillon und Zuber) spindelförmige und fusiforme Stäbchenbakterien aus dem Mund von gesunden und erkrankten Menschen sowie von verschiedenen Tierarten beschrieben. Die meist pleomorphen Bakterien wurden verschiedenen Spezies zugeordnet, bis 1923 von Knorr für obligat anaerobe gramnegative fusiforme Stäbchenbakterien der Gattungsname Fusobacterium innerhalb der Familie der Bacteroidaceae vorgeschlagen wurde. Derzeit gehören zu dieser Gattung 11 humanpathogene Arten (F. perfoetens wurde bislang ausschließlich im Stuhl von Schweinen, F. simiae aus dem Mund von Makaken und F. canifelinum aus dem Oropharynx von Hunden und Katzen isoliert). Bei den beiden Spezies F. necrophorum und F. nucleatum sind zudem mehrere Subspezies beschrieben, deren endgültige taxonomische Stellung ebenfalls noch nicht endgültig geklärt ist. Der ursprünglich beschriebene Biotyp C von F. necrophorum, der zwischenzeitlich als eigene Spezies F. pseudonecrophorum eingeordnet wurde, ist identisch mit F. varium.

\section{Morphologie}

Fusobakterien sind gramnegative, obligat anaerobe, unbewegliche, nicht sporenbildende, schlanke, 0,2$0,3 \mu \mathrm{m}$ breite, spindelförmige Stäbchen mit einer wechselnden Länge von $0,5-10 \mu \mathrm{m}$. F. nucleatum hat spitz zulaufende Enden und zeigt im mikroskopischen Präparat aufgrund zahlreicher intrazellulärer Granula ein gekörntes Aussehen. F. periodonticum hat eine vergleichbare Morphologie, während F. naviforme kahnförmig imponiert. Zellen von $F$. necrophorum sind pleomorph, oft gekrümmt mit teilweise sphärischen Ausstülpungen, es kommt häufig zu filamentösen Formen (bis zu $70 \mu \mathrm{m}$ Länge).

\section{Genom}

F. alocis X55406, F. gonidiaformans X55410, F. mortife- rum AJ867033, F. naviforme, F. necrogenes AJ867034, F. necrophorum (ssp. necrophorum AY372007, ssp. funduliforme AY972049), F. nucleatum (ssp. animalis AJ810279, ssp. fusiforme X55403, ssp. nucleatum NC_003454, ssp. polymorphum AF287812, ssp. vincentii NZ_AABF02000302), F. periodonticum AJ810271, F. russii X55409, F. ulcerans X55412, F. varium AJ867035.

\section{Vermehrung}

Ein Vermehrung von Fusobacterium spp. findet ausschließlich unter anaeroben Bedingungen statt. Entsprechende Bedingungen finden sich im Darm und auf Schleimhäuten von Mensch und Tier. In vitro bietet ein Gasgemisch aus $80 \% \mathrm{~N}_{2}, 15 \mathrm{CO}_{2}$ und $5 \% \mathrm{H}_{2}$ eine hinreichende Atmosphäre. Aufgrund der begrenzten Energieausbeute der anaeroben Glykolyse ist die Generationszeit z. B. gegenüber Enterobacteriaceae verlängert.

\section{Pathogenität / Virulenz / Antigenvariabilität}

Fusobakterien besitzen eine Reihe von Adhäsinen, die es ihnen erlauben, mit anderen Bakterienarten zu interagieren bzw. zu aggregieren. Diese Adhäsine ermöglichen zudem die Adhäsion an Schleimhautepithelzellen, aber auch an künstlichen Oberflächen (Zahnersatzmaterialien) und stellen auf diese Weise einen wichtigen Faktor bei der Plaqueformation dar.

\section{Erkrankungen}

\section{Angina Plaut-Vincent}

\section{Synonym(e)}

Fusospirochätose.

\section{Inkubationszeit}

Unspezifisch.

\section{Symptome}

Die Angina Plaut-Vincent stellt eine Mischinfektion aus Spirochäten (Treponema vincentii) und Fusobacterium nucleatum dar. Sie verursacht meist kein Fieber und nur geringfügige Störungen des Allgemeinbefindens und äußert sich lediglich in meist einseitigen Schluckbeschwerden. Trotzdem finden sich typischerweise erheblich geschwürig und nekrotisch veränderten Gaumenmandeln, die meist fibrinöse übelriechende grau-grünliche Beläge aufweisen. Schwellungen der submandibularen Lymphknoten können oft beobachtet werde.

\section{Pathophysiologie \\ Unklar.}

\section{Immunantwort}

Eine bleibende Immunität nach Infektion entsteht nicht.

\section{Differenzialdiagnose}

Streptokokkenangina, Lues. 


\section{Lemierre-Syndrom}

\section{Synonym(e)}

Nekrobazillose.

\section{Inkubationszeit}

Unspezifisch.

\section{Symptome}

In Folge einer in der Regel durch F. necrophorum hervorgerufenen Pharyngotonsillitis kommt es zu einer Thrombophlebitis der Vena jugularis interna. Metastatische Absiedelungen aus diesem Fokus können alle Organe betreffen und schnell zu schweren Krankheitserscheinungen bis hin zum septischen Schock führen.

\section{Pathophysiologie \\ Unklar.}

\section{Immunantwort}

Eine bleibende Immunität nach Infektion entsteht nicht.

\section{Differenzialdiagnose}

Streptokokkenangina.

\section{Noma}

Synonym(e)

Wangenbrand.

\section{Inkubationszeit \\ Unspezifisch.}

\section{Symptome}

Die Noma ist eine in der Regel durch Fusobakterien hervorgerufene Infektion der Wangenschleimhaut, die im weiteren Verlauf zu einer Zerstörung von Weichgewebe und knöchernen Anteilen des Gesichts führt. Später kommt es zu septischen Absiedlungen, die mit einer hohen Letalität behaftet sind.

\section{Pathophysiologie}

Unklar.

\section{Immunantwort}

Eine bleibende Immunität nach Infektion entsteht nicht.

\section{Differenzialdiagnose}

Staphylokokken- und Streptokokkeninfektionen, Aktinomykose.

\section{Eitrige/septische Infektionen}

Zusammen mit Arten der Bacteroides-fragilis- sowie Porphyromonas-melaninogenicus-Gruppe ist F. nucleatum das gramnegative anaerobe Bakterium, das am häufigsten bei menschlichen Infektionen isoliert wird. Ebenso ist F. necrophorum eindeutig menschenpathogen, in der Vorantibiotikaära war es ein häufiger Erreger von eitrigen Infektionen der Mundhöhle und des oberen Respirationstraktes. Fusobakterien treten typischerweise bei Infektionen mit Nekrosebildung und Ulzerationen auf. Sie sind am häufigsten bei Infektionen im Kopf-Halsbereich, Hirn- und Leberabszessen sowie nach Tier- und Menschenbissen nachweisbar. Finegold fand 1977, dass ein Viertel aller Isolate von anaeroben pleuropulmonalen Infektionen zur Art F. nucleatum gehörten. Weiterhin spielt $F$. nucleatum neben $P$. gingivalis, $P$. intermedia, $T$. forsythus, E. corrodens, Capnocythophaga spp., A. actinomycetemcomitans und Eubacterium spp. eine herausragende Rolle bei Periodontalerkrankungen. Bei einer ganzen Reihe weiterer Infektionen wurden Fusobakterien als Erreger beschrieben, wie Peritonsillarabszesse, Pyomyositis und septische Arthritis, Leberabszesse, intrauterine Infektionen, bakterielle Vaginose, Harnwegsinfektionen, Meningitis sowie Peri- und Endokarditis und schließlich Sepsis. F. necrophorum spielt in der Veterinärmedizin ebenfalls eine außerordentlich wichtige Rolle und wird dort häufig isoliert bei nekrotisierenden und gangränösen Infektionen bei Rindern, Schafen und Schweinen, während Carnivore offensichtlich nicht empfänglich für Infektionen durch diese Erregergruppe sind. Die übrigen Fusobakterienarten werden ebenfalls gelegentlich aus humanen klinischen Materialien isoliert, sind aber offensichtlich von untergeordneter Bedeutung.

\section{Diagnostik}

\section{Untersuchungsmaterial}

Fusobacterium spp können in Blutkulturen nachgewiesen werden. Untersuchungsmaterialien, die mit physiologischer Standortflora kontaminiert sind (z. B. Sputum, oberflächliche Abstriche aus Ulzera) sind ungeeignet. Bioptate und Aspirate müssen ggf. auf, während (weniger geeignete) Abstriche in Transportmedien ins Labor verbracht werden, um die toxische Wirkung des Luftsauerstoffs zu minimieren.

\section{Diagnostische Verfahren}

Die Anzucht und Isolierung aus menschlichem Material erfolgt unter strikt anaeroben Bedingungen. Feste Kulturmedien sollten für gute Wachstumsergebnisse bluthaltig (Kaninchen, Pferd, Schaf) und mit Hämin und Vitamin K1 supplementiert sein (Brucella-Agar, Columbia-Agar, Schädler-Agar) Antibiotikahaltige Selektiv- und Indikatormedien können genutzt werden (Kanamycin-Vancomycin-Agar, Bacteroides-Galle-Eskulin-Agar). Mit Glukose, Proteosepepton, $\mathrm{NaCl}$ $(0,5 \%)$, Cystein, Hämin und Vitamin $\mathrm{K}$ angereicherte Flüssigmedien erlauben ebenfalls eine Anzucht von Fusobacterium spp. Die Differenzierung der einzelnen Spezies erfolgt durch Kombination biochemischer und chemischer Tests (Gaschromatographie der Säuremetaboliten). Eine ausreichend gute Speziesidentifizierung kann mit kommerziellen miniaturisierten Testsystemen nicht immer gewährleistet werden. Die Koloniemorphologie auf Blutagar der einzelnen Arten 
ist unterschiedlich, wobei diese Unterschiede meist nicht für eine eindeutige Identifizierung ausreichen: F. nucleatum bildet flache, unregelmäßige und glänzende Kolonien, F. necrophorum kreisrunde, flache bis konvexe, raue und oft $\beta$-hämolysierende Kolonien mit einem Durchmesser von 1-4 mm, die Koloniefarbe ist je nach Biotyp metallisch-grau (ssp. necrophorum), gelblich (ssp. funduliforme) oder graugelb (Biotyp $\mathrm{AB}$ ). F. varians bildet nach 3-tägiger Bebrütung knopfförmige, am Rand gewellte, raue, gräuliche, durchscheinende Kolonien mit einem Durchmesser von 2-3 mm. Kolonien von F. ulcerans haben ebenfalls einen Durchmesser von $2-3 \mathrm{~mm}$, sind rund, flach, nicht hämolysierend und von cremeweißer Farbe. Metabolische Endprodukte sind vor allem Azetat und Butyrat. Propionat, Succinat, Laktat, Formiat wird in geringeren Mengen und speziesunterschiedlich gebildet. Gemeinsam ist neben dem Vorkommen von geradkettigen, gesättigten und einfach-ungesättigten, langkettigen zellulären Fettsäuren der Aufbau der Peptidoglykanschicht sowie der Glutamatstoffwechsel (Glutamatdehydrogenase positiv). Differenzierende biochemische Charakteristika sind u. a. der Indolabbau (nur F. mortiferum und F. russii sind negativ), Wachstum in Gegenwart von $20 \%$ Galle und Äskulinhydrolyse (nur F. mortiferum ist positiv), Nitratreduktion (F. ulcerans ist positiv) sowie die Hippurathydrolyse (F. periodonticum ist positiv).

\section{Befund / Interpretation}

Der Nachweis von Fusobacterium spp. ist bei entsprechenden klinischen Infektzeichen als relevant zu bewerten.

\section{Therapie}

\section{Therapeutische Maßnahmen}

Neben der chirurgischen Abszessbehandlung muss immer eine Antibiotikatherapie erfolgen. Fusobakterien sind empfindlich gegen eine Vielzahl von Antibiotika wie Penicilline, Cephalosporine, Peneme, Tigecyclin, $\beta$-Laktam/ $\beta$-Laktamaseinhibitor-Kombinationen, Metronidazol, Clindamycin, Linezolid und Chloramphenicol.

\section{Resistenz}

Resistenz besteht gegen Aminoglykoside und Erythromycin. Unterschiedlich ist die Empfindlichkeit gegen Tetrazyklin. Da diese Substanz häufig bei periodontitischen Infektionen eingesetzt wurde, kam es zur zunehmenden Ausbildung von resistenten F.-nucleatum-Stämmen, sodass der Einsatz von Tetrazyklinen nicht mehr uneingeschränkt gerechtfertigt ist. F. nucleatum kann eine $\beta$-Laktamase produzieren, ist aber dann sensibel gegenüber $\beta$-Laktam/ $\beta$-Laktamaseinhibitor-Kombinationen. F. varium und F. mortiferum sind resistent gegen Rifampicin. Es wurden zudem vereinzelt Resistenzen gegen Chinolone und moderne Makrolide beschrieben.

\section{Epidemiologie}

\section{Verbreitung}

Ubiquitär.

\section{Wirtsbereich / Reservoir}

Fusobakterien kommen natürlicherweise bei Menschen und Warmblütern vor, jedoch sind auch Fusobakterien ähnliche Arten im Gastrointestinaltrakt von Wanzen und Heuschrecken beschrieben. Der Standort beim Menschen ist der Oropharynx (F. nucleatum, $F$. alocis, F. naviforme, $P$. periodonticum und F. sulci) und der Gastrointestinaltrakt (F. necrophorum, F. gonidiaformans, F. mortiferum, F. necrogenes, F. russii und F. varium). F. ulcerans wurde bisher lediglich bei chronischen tropischen Ulzera beschrieben, gleichzeitig allerdings auch aus Schlammproben, sodass hier evtl. ein Standort außerhalb des Menschen in Betracht kommt. Im Speichel wird die Keimzahl von Fusobakterien auf $5 \times 10^{4}$ geschätzt und in der Zahnplaqueflora machen sie zwischen 0,4 und $7 \%$ der anzüchtbaren Erreger aus. Allerdings liegen erhebliche individuelle Unterschiede vor und besonders bei fortgeschrittenen chronischen Periodontalerkrankungen und akuter ulzerierender Gingivitis kommt es zum Überwiegen von F. nucleatum mit Keimzahlen zwischen $3,3 \times 10^{7}$ bis $9,5 \times 10^{7}$ pro Gramm Feuchtgewicht. In der Darmflora machen Fusobakterien nur einen kleinen Teil aus, der je nach Diät zwischen $1 \%$ und $7 \%$ beträgt. Hauptvertreter sind F. mortiferum, F. russii. Inwieweit Fusobakterien zur normalen Flora des menschlichen Urogenitaltraktes gehören, ist noch unklar. In verschiedenen Untersuchungen ließen sich $F$. necrophorum bzw. F. nucleatum intravaginal, in der Klitorisregion als auch in Vorhautsekreten isolieren. In ähnlicher Weise wie beim Menschen kommen Fusobakterien im Oropharynx und Gastrointestinaltrakt einer Vielzahl von Tierarten vor und spielen dort wohl auch eine ähnliche Rolle als Bestandteil der Normalflora und als Erreger von endogenen Infektionen.

\section{Risikogruppen}

Von der Angina Plaut-Vincent sind häufiger Jugendliche betroffen. Die Noma tritt bei mangelernährten immunsupprimierten Kindern in Entwicklungsländern auf.

\section{Transmission / Vektoren}

Meist endogene Infektionen.

\section{Prävention / Impfstoffe}

Keine.

\section{Ausbruchsmanagement}

Nicht relevant.

\section{Meldepflicht}

Keine. 


\section{Weiterführende Informationen}

\section{Referenzzentren / Expertenlaboratorien}

- Institut für Medizinische Mikrobiologie und Infektionsepidemiologie des Universitätsklinikums Leipzig, Liebigstr. 21, 04103 Leipzig, Tel. 03419715200

\section{Schlüsselliteratur}

1. Bolstad AK, Jensen HB, Bakken V (1996) Taxonomy, biology, and periodontal aspects of Fusobacterium nucleatum. Clin Microbiol Rev 9:55-71

2. Hofstad T (1991) The genus Fusobacterium. In: Balows A, Trüper HG, Dworkin M, Harder W, Schleifer K-H (Hrsg) The Prokaryotes, 2. Aufl. Springer Verlag, New York Berlin Heidelberg
3. Jacobs JA, Hendriks JJE, Verschure PDMM, van der Wurff AM, Freling Voss GD, Stobberingh EE (1993) Meningitis due to Fusobacterium necrophorum subspecies necrophorum. Case Report and review of the literature. Infection 21:57-60

4. Lawson PA, Gharbia SE, Shah HN, Clark DR, Collins MD (1991) Intrageneric relationships of members of the genus Fusobacterium as determined by reverse transcriptase sequencing of small-subunit rRNA. Int J Syst Bacteriol 41:347-354

5. Ravn T, Huniche B, Breum L, Jorgen Christensen J (2006): Lemierre's syndrome: still an important clinical entity. Scand J Infect Dis 38:299-301 


\section{Gammopathie}

- Hepatitis C Virus (HCV)

\section{GanGan-Virus}

Bunyaviren

\section{Gardnerella vaginalis}

\section{Erreger}

\section{Synonym(e)}

Früher: Hämophilus vaginalis, Corynebacterium vaginale.

\section{Erregerspezies}

Gardnerella vaginalis

\section{Taxonomie}

G. vaginalis ist die einzige Spezies des Genus Gardnerella, das bisher noch keiner Familie zugeordnet wurde.

\section{Historie}

G. vaginalis wurde 1954 von Gardner und Dukes beschrieben und zunächst als "Hämophilus vaginalis“ bezeichnet. Untersuchungen zeigten jedoch, dass das Bakterium weder Hämin (Faktor X) noch NAD (Faktor V) für das Wachstum unbedingt benötigt, sodass von Zimmermann und Turner eine Reklassifikation empfohlen wurde. Hauptsächlich aufgrund morphologischer Kriterien wurde G. vaginalis in den folgenden Jahren dem Genus „Corynebacterium“ zugeordnet und als "Corynebacterium vaginale " bezeichnet. Hybridisierungsexperimente, elektronenmikroskopische Untersuchungen sowie biochemische Analysen (Greenwood und Pickett, 1980) zeigten jedoch, dass "Hämophilus bzw. Corynebacterium vaginale" nur geringe Ähnlichkeit zu anderen Mitgliedern der Genera Hämophilus und Corynebacterium aufweist. Seit Anfang der 80er Jahre wurde dem Bakterium daher (nach Gardner) der Name „Gardnerella vaginalis“ zugeteilt.

\section{Morphologie}

G. vaginalis ist ein pleomorphes, dünnes, fakultativ anaerobes Stäbchen $(0,5 \times 1,5 \mu \mathrm{m})$ mit gramnegativer bis gramvariabler Eigenschaft. Das Bakterium ist unbeweglich und bildet keine Kapseln und keine Sporen.

\section{Genom}

Genom ist vollständig sequenziert, siehe auch www. ncbi.nlm.nih.gov.

\section{Vermehrung}

Aerob unter 5\%iger $\mathrm{CO}_{2}$-Spannung auf Blutagar in 2-3 Tagen.

\section{Pathogenität / Virulenz / Antigenvariabilität}

G. vaginalis kann - wie auch andere Bakterien, die an der bakteriellen Vaginose (BV) beteiligt sind - auch in Vaginalabstrichen gesunder Frauen nachgewiesen werden und ist daher fakultativ pathogen. Faktoren die eine Störung des physiologischen Vaginalmilieus begünstigen, wie z. B. Vaginalspülungen, Antibiotikatherapie, Östrogenmangel, Diabetes mellitus begünstigen eine Vermehrung der an diesem Krankheitsbild beteiligten Keime. Das von G. vaginalis freigesetzte hämolytische Exotoxin (auch: Hämolysin = Gvh, Zytotoxin) ist der einzige bisher identifizierte Virulenzfaktor des Bakteriums. Das Protein (59 kD) bildet Poren in cholesterinhaltigen Membranen und führt so zu einer toxischen Zellschädigung. Darüber hinaus sind von Prevotella bivia, Bacteroides spp. und anderen Mikroorganismen produzierte Sialidasen (syn. Neuraminidasen) für die Entstehung der bakteriellen Vaginose von Bedeutung. Diese Virulenzfaktoren fördern die Bakterienadhärenz und reduzieren eine spezifische, gegen Gvh gerichtete IgA-Immunantwort.

\section{Erkrankung}

\section{Bakterielle Vaginose (BV)}

\section{Synonym(e)}

Gardnerella-vaginalis-Vaginitis, unspezifische Vaginitis. Diese Bezeichnung ist jedoch im eigentlichen Sinn inkorrekt, da die bakterielle Vaginose (BV) zu keiner ausgeprägten Entzündungsreaktion führt.

\section{Leitsymptome}

Übelriechender, dünnflüssiger, weißlicher Fluor vaginalis.

\section{Symptome}

Nach Fisch riechender Fluor vaginalis, gelegentlich Dysurie und/oder Dyspareunie.

\section{Pathophysiologie}

Bei der bakteriellen Vaginose kommt es zu komplexen Veränderungen in der Zusammensetzung der physiologischen Vaginalflora. Neben der Abnahme der Konzentration $\mathrm{H}_{2} \mathrm{O}_{2}$-produzierender Laktobazillen findet sich eine erhöhte Konzentration von G. vaginalis so- 
wie weiterer Keime wie z. B. Mobiluncus spp., Mycoplasma hominis und anaerober Bakterien der Gattungen Prevotella, Porphyromonas, Bacteroides spp., Peptostreptococcus spp., Bacterioides. Als klinisches Korrelat findet sich dabei ein übelriechender, vermehrter, weißlich-grauer, gering-visköser Fluor, bei erhöhten vaginalen $\mathrm{pH}$-Werten von $>4,5$ (normal 4,0-4,5). Der für die bakterielle Vaginose typische Geruch entsteht dabei durch proteolytischen Abbau von Proteinen zu z.T. übelriechenden Aminen (z. B. Trimethylamin) durch Carboxylasen anaerober Bakterien. Die bakterielle Vaginose verläuft zumeist ohne nennenswerte entzündliche vaginale Veränderungen (daher Vaginose statt Vaginitis) oder Juckreiz. Ein asymptomatischer Verlauf ist häufig (50-75 \% der Fälle). Bei 10-15\% der Frauen mit BV tritt eine Zervizitis auf, auch besteht ein erhöhtes Risiko für aszendierende Infektionen (Endometritis). Eine höhere Prävalenz der BV wurde auch bei Patienten mit PID (pelvic inflammatory disease) beschrieben, ob jedoch ein kausaler Zusammenhang vorliegt ist unklar. In der Schwangerschaft stellt die bakterielle Vaginose einen Risikofaktor für Chorioamnionitis, Frühgeburtlichkeit und damit neonataler und perinataler Komplikationen dar. Darüber hinaus weisen Frauen mit BV ein erhöhtes Risiko für Post-partum-Endometritiden und postpartale Wundinfektionen auf. Die bakterielle Vaginose begünstigt, wie auch andere Vaginalinfektionen, die Übertragung von HIV und anderer sexuell übertragbarer Krankheiten.

\section{Immunantwort}

Bei einem Teil der Patientinnen sind im Vaginalsekret Antikörper (IgA, IgM) gegen das G.-vaginalis-Zytotoxin (Gvh) nachweisbar, in über 50 \%der Fälle bleibt jedoch eine spezifische Immunantwort aus. Ursache hierfür ist eine bei diesen Patienten im Vergleich zur ersten Gruppe höhere Sialidase-Aktivität (s. o.). Diese Enzyme spalten Neuraminsäure bzw. deren N-und OAcylderivate (Sialinsäure) von IgA und IgM-Molekülen ab, wodurch die Antikörper einer Spaltung durch Proteasen leichter zugänglich werden. Hierdurch wird eine effektive immunologische Auseinandersetzung mit dem Erreger vermindert. Klinische Studien haben ein 2-11fach erhöhtes Risiko für ein niedriges Geburtsgewicht bei einer BV mit vorhandener Sialidaseund hoher Prolidase-Aktivität ergeben. Dagegen hatte keine der Frauen mit BV und einer starken anti-GvHAntwort einen ungünstigen Schwangerschaftsausgang. Eine Erhöhung von Serumantikörpern (IgM, IgG) ist ebenfalls nachweisbar, diagnostisch aber nicht relevant. Bei einer Vermehrung von G. vaginalis und Prevotella spp., nicht aber bei Lactobazillus und Mobiluncus spp. ist Interleukin- $1 \beta$ in vaginalen Spülproben erhöht. Die Serumspiegel der Zytokine werden jedoch nicht durch die Veränderung der Vaginalflora beeinflusst. Die bakterielle Vaginose hinterlässt keine pro- tektive Immunität, sodass Reinfektionen jederzeit möglich sind.

\section{Differenzialdiagnose}

Differenzialdiagnostisch müssen infektiöse Kolpitiden (z. B. Trichomonas vaginalis, Candida albicans, Neisseria gonorrhoeae) sowie nicht infektiöse Scheidenirritationen oder Entzündungen abgegrenzt werden.

\section{Diagnostik \\ Untersuchungsmaterial \\ Vaginalsekret.}

\section{Diagnostische Verfahren}

Die Diagnose der bakteriellen Vaginose erfolgt zumeist klinisch. Zum Nachweis einer bakteriellen Vaginose müssen dabei mindestens 3 der 4 Diagnosekriterien (nach Amstel et al. 1983) erfüllt sein:

1. Dünnflüssiger, homogener, milchiger Ausfluss,

2. vaginaler $\mathrm{pH}>4,5$,

3. KOH-Test (Amin-Test): Bei Zusatz von $10 \%$ Kalilauge zum Vaginalsekret lässt sich unmittelbar nach Vermischen ein Fischgeruch nachweisen, der auf flüchtige, vermutlich durch anaeroben Stoffwechsel entstehende Amine im Scheidensekret zurückzuführen ist.

4. Nachweis von Schlüsselzellen („clue cells“, > $20 \%$ ). Bei diesen handelt es sich um abgeschilferte Epithelzellen, die bei BV von einer großen Zahl gramnegativer (Prevotella spp., Porphyromonas spp.) und gramvariabler Keime (G. vaginalis) umgeben sind. Üblicherweise im Vaginalsekret nachweisbare Laktobazillen fehlen fast vollständig. Der Nachweis erfolgt mikroskopisch im Flüssigkeitstropfen (wet mount), der aus einer Mischung aus Vaginalflüssigkeit mit Kochsalzlösung besteht.

In etwa $50 \%$ der Fälle, in denen die Kriterien erfüllt sind, liegen keine Beschwerden vor. Vaginale Sekrete können zur Diagnose nach Gram oder PAP gefärbt werden. G. vaginalis kann aerob unter $5 \%$ iger $\mathrm{CO}_{2}$ Spannung auf Blutagar in 2-3 Tagen angezüchtet werden. Die kleinen Kolonien sind auf Human- und Kaninchenblutagar von einem unscharf begrenzten Hämolysehof umgeben, auf Schafblutagar findet keine Hämolyse statt. Selektivsupplemente unterdrücken die Begleitflora. Biochemisch ist neben der Katalaseund Oxidase-Negativität vor allem die positive Hippurathydrolisierung wichtig. Zur biochemischen Differenzierung eignet sich der API 20 Strep. G. vaginalis lässt sich auch über Gensonden nachweisen.

\section{Befund / Interpretation}

Da G. vaginalis bei $50-60 \%$ der gesunden Frauen Bestandteil der vaginalen Flora ist, sind Versuche den Keim bei bakterieller Vaginose zu isolieren, von geringem diagnostischem Nutzen. DNA-Gensonden für G. vaginalis bringen ebenso keinen diagnostischen 
Vorteil. Vergleiche der klinischen Kriterien mit der Gram-Färbung vaginaler Sekrete weisen eine Sensitivität von bis zu $97 \%$ und eine Spezifität von bis zu 95 \% auf, sodass die Gramfärbung als Standard im Laborbereich gilt.

PAP-Färbungen vaginaler Abstriche sind für die BVDiagnose weniger geeignet. Bei Screenings mit $\mathrm{pH} /$ whiff-Test, QuickVue-pH und Amines-Test wurde in mehr als der Hälfte der Fälle eine später nachgewiesene BV nicht erkannt.

Bei asymptomatischen Schwangeren mit Frühgeburtsanamnese sollte die Testung auf BV zu Beginn des zweiten Trimenons stattfinden.

\section{Therapie}

\section{Therapeutische Maßnahmen}

Die Therapie einer Infektion mit G. vaginalis erfolgt mit Metronidazol oder Clindamycin (oral oder vaginal). Alternativ orale Therapie mit Tinidazol.

\section{Epidemiologie}

\section{Verbreitung}

G. vaginalis ist weltweit verbreitet, und die bakterielle Vaginose ist die häufigste Ursache einer Vaginitis bei Frauen im gebärfähigen Alter. Die Prävalenz ist abhängig vom untersuchten Patientenkollektiv: Sie beträgt in der Allgemeinbevölkerung 4-10\%, bei Schwangeren $10-35 \%$ und in Risikogruppen bis zu $65 \%$.

\section{Wirtsbereich / Reservoir}

G. vaginalis kann bei Menschen und bei zahlreichen Säugetieren nachgewiesen werden.

\section{Risikogruppen}

Die bakterielle Vaginose betrifft hauptsächlich jüngere, sexuell aktive Frauen oder Frauen mit häufig wechselnden Partnern. Eine erhöhte Prävalenz der BV findet sich auch bei homosexuellen Frauen. Ein erhöhtes Risiko besteht auch für Frauen mit IUP (Intrauterinpessar).

\section{Transmission / Vektoren}

G. vaginalis kann durch Geschlechtsverkehr übertragen werden, kann jedoch auch bei Frauen ohne sexuelle Kontakte nachgewiesen werden. Eine Übertragung z. B. in Schwimmbädern oder über Toilettensitze ist nicht möglich.

\section{Prävention / Impfstoffe}

Erhalt des physiologischen Vaginalmilieus, Vermeidung unnötiger Irritationen (Antibiotika, Scheidenspülungen, Vaginalcremes etc.).

\section{Ausbruchsmanagement}

Im Allgemeinen ist die antibiotische Behandlung der Erkrankten ausreichend, eine Partnerbehandlung wird nicht zwingend empfohlen.

\section{Meldepflicht}

Weder die Erkrankung noch der Erreger sind im Infektionsschutzgesetz aufgeführt.

\section{Weiterführende Informationen}

\section{Referenzzentren / Expertenlaboratorien}

- Nationale Referenzzentren sowie Konsiliarlaboratorien in Deutschland sind nicht bekannt.

\section{Web-Adressen}

- http://www.cdc.gov/std/bv/STDFact-BacterialVaginosis.htm

\section{Schlüsselliteratur}

1. Amsel R, Totten PA, Spiegel CA, Chen KC et al (1983) Nonspecific vaginitis: Diagnostic criteria and microbial and epidemiologic associations. Am J Med 74:14

2. Cauci S, Monte R, Driussi S, Lanzafame P, Quadrifoglio F (1998) Impairment of the mucosal immune system: IgA and IgM Cleavage detected in vaginal washings of a subgroup of patients with bacterial vaginosis. J Infect Dis 178:1698-1706

3. Sobel JD (2000) Bacterial vaginosis. Annu Rev Med 51:349-356

\section{Gasbrand}

- Clostridien der Gasbrand-Gruppe

\section{Gasbranderreger}

Clostridien der Gasbrand-Gruppe

\section{Gasgangrän}

Clostridien der Gasbrand-Gruppe

\section{Gasödem}

Clostridien der Gasbrand-Gruppe

\section{Gasterophilus spp.}

- Myiasis-Erreger

\section{Gastritis, chronische}

Helicobacter pylori

\section{Gastrodiscoides hominis}

Darmegel 


\begin{tabular}{l}
\hline Gastroenteritis \\
- Adenoviren \\
- Astroviren \\
Blastocystis sp. \\
- Campylobacter \\
- Clostridien der Gasbrand-Gruppe \\
- Coxsackieviren \\
- Echoviren und Parechoviren \\
Edwardsiella \\
- Enterobacter \\
Escherichia coli \\
- Listeria monocytogenes \\
Noroviren \\
Reoviren \\
Rotavirus \\
Salmonella \\
Shigella \\
Trichinella spiralis \\
Vibrio \\
\hline
\end{tabular}

\section{GB Virus C (GBV-C)}

Helga Meisel, Wolfgang Jilg, Detlev H. Krüger

Erreger

Synonym(e)

GBV-C, Hepatitis-G-Virus, HGV.

\section{Erregerspezies}

GB-Virus C

\section{Taxonomie}

GBV-C wurde (bisher ohne Zuordnung zu einem Virusgenus) als eigene Spezies in die Familie Flaviviridae eingeordnet. Innerhalb der Flaviviren ist GBV-C eng mit dem Hepatitis-C-Virus (HCV) verwandt und weist auf Aminosäureebene eine 28 \%ige Homologie zum HCV auf.

\section{Historie}

1967 inokulierten Deinhardt und Mitarbeiter das Serum eines an akuter Hepatitis erkrankten Chirurgen (mit den Initialen GB) in südamerikanische Krallenaffen (Tamarine), das eine akute Hepatitis auslöste. Nach mehreren Serumpassagen in Tamarinen und Marmorsets gelang 1969 die Erstbeschreibung des GBAgens als bisher noch unbekannter Hepatitiserreger. Erst 1995 erfolgte mit Hilfe von repräsentativer Differenzanalyse der Nachweis von zwei als GBV-A und GBV-B bezeichneten Viren aus den mit dem GBAgens infizierten Affenseren. Unter Verwendung von degenerierten Primern, die von GBV-A-, GBV-B- und HCV-Helikasesequenzen abgeleitet worden waren, wurde im Serum eines Westafrikaners mit Non-A-C-
Hepatitis ein als GBV-C bezeichneter Erreger nachgewiesen. Nur kurze Zeit später berichtete eine andere Arbeitsgruppe über die Entdeckung von genetischem Material eines neuen Virus im Plasma eines Patienten mit Non-A-C-Hepatitis, das sofort als Hepatitis-GVirus (HGV) bezeichnet wurde. Es zeigte sich, dass HGV und GBV-C verschiedene Isolate desselben Virus sind ( 86 \% Nukleotid-, 96 \% Aminosäuresequenzhomologie). Da der Erreger jedoch offensichtlich nicht hepatopathogen ist, hat sich der Name GBV-C durchgesetzt und wird auch vom Internationalen Kommitee für Virustaxonomie benutzt (s. o.).

\section{Morphologie}

GBV-C ist ein umhülltes Virus mit einem einzelsträngigen, 9,4 kb langen Positivstrang-RNA-Genom. Elektronenmikroskopisch wurde eine Nukleokapsidstruktur identifiziert. Die exakte Coreprotein-kodierende Region im GBV-C-Genom ist jedoch nicht bekannt. Die Hülle enthält zwei Proteine (E1 und E2).

\section{Genom}

Die Plusstrang-RNA kodiert für ein Polyprotein. Am 5 ' - und 3'-Ende befinden sich regulatorische Elemente. Es werden gegenwärtig fünf verschiedene Genotypen unterschieden, die in ihrer geografischen Prävalenz variieren (Genotyp 2 in Europa und den USA).

\section{Vermehrung}

Nach GBV-C-Exposition ist in der Regel eine bis vier Wochen später GBV-C-RNA nachweisbar. Über den intrazellulär ablaufenden Replikationszyklus von GBV-C ist wenig bekannt. Wie bei HCV wird ein Polyproteinvorläufer posttranslational in verschiedene Proteine (z. B. Oberflächenprotein E2, zwei Proteasen [NS2 und NS3], eine Helikase [NS3]) gespalten. Ein Coreprotein wird nicht oder nur in trunkierter Form exprimiert. Als Orte für die GBV-C-Vermehrung sind periphere mononukleäre Blutzellen und auch Epithelzellen beschrieben worden. GBV-C-Replikation ist zwar in vitro in einer Hepatoma-Zelllinie (PH5CH) nachgewiesen worden, jedoch scheinen im Organismus die Hepatozyten nicht Ort der Virusreplikation zu sein. Die bisher vorliegenden Daten - unter anderem die Kultur in einer humanen T-Zelllinie (MT-2c) - sprechen dafür, dass GBV-C primär ein lymphotropes Virus ist, das sich sowohl in B- als auch T-Lymphozyten vermehrt.

\section{Pathogenität / Virulenz / Antigenvariabilität}

Es liegen keine Beweise für die Humanpathogenität von GBV-C vor.

\section{Erkrankung}

\section{Symptome}

Man geht heute davon aus, dass Infektionen mit GBV$\mathrm{C}$ nicht ursächlich mit der Entstehung akuter oder chronischer Hepatitiden in Zusammenhang gebracht 
werden können. Auch kausale Assoziationen mit anderen, nichthepatischen Erkrankungen gelten als nicht gesichert, so dass GBV-C als ein für den Menschen nicht pathogenes Virus angesehen werden kann.

Koinfektionen von Patienten sowohl mit GBV-C als auch viralen Hepatitis-Erregern (HBV, HCV) oder HIV sind durch den ähnlichen parenteralen Übertragungsweg erklärbar. Eine Reihe von Studien hat gezeigt, dass bei HIV-infizierten Patienten mit einer GBV-C-Koinfektion der Krankheitsverlauf bis zum Stadium AIDS deutlich langsamer erfolgt und mit einer längeren Überlebenszeit verbunden ist. Dieser protektive Effekt ist nicht in allen Studien bestätigt worden, wobei möglicherweise unterschiedliche GBVC-Stämme einen unterschiedlichen Einfluss auf den Verlauf der HIV-Koinfektion haben.

\section{Immunantwort}

Bisher liegen nur Daten über humorale und zelluläre Immunantworten gegen das E2-Hüllprotein vor. Das Erscheinen von anti-E2-Antikörpern korreliert in der Regel mit dem Verschwinden der Virämie und mit einer durchgemachten Infektion. Das Vorliegen von anti-E2-Antikörpern vor orthotroper Lebertransplantation schützt vor einer GBV-C-de-novo-Infektion, was für eine protektive Rolle der anti-E2-Antikörper spricht. Im Gegensatz zur Situation beim HCV ist der E2-Genabschnitt hoch konserviert. Bezüglich der zellulären Immunantwort weisen Patienten mit ausgeheilter oder florider GBV-C-Infektion im Proliferationsassay keine Unterschiede auf.

\section{Differenzialdiagnose}

Entfällt.

\section{Diagnostik}

\section{Untersuchungsmaterial}

Eine Infektion mit GBV-C kann mittels RT-PCR für GBV-C-RNA aus Serum oder Plasma nachgewiesen werden.

\section{Diagnostische Verfahren}

Antikörper gegen das Oberflächenglykoprotein E2 (anti-E2) sind kurz vor oder nach Verschwinden der Virämie mittels ELISA nachweisbar, das heißt, ihr Auftreten korreliert in der Regel mit dem Verschwinden der Virämie. Es gibt jedoch einzelne Fälle von RNA-Elimination ohne Erscheinen nachweisbarer E2-Antikörper.

\section{Therapie}

\section{Therapeutische Maßnahmen}

Eine Indikation zur medikamentösen Behandlung einer GBV-C Infektion liegt nicht vor. Allerdings wurden im Rahmen der Interferon-Therapie von chronischer Hepatitis C bei Patienten mit GBV-C Koinfektion ähnliche Erfolgsraten für die Elimination von HCV und GBV-C gefunden.

\section{Resistenz}

GBV-C kann mit üblichen viruziden Maßnahmen inaktiviert werden.

\section{Epidemiologie}

\section{Verbreitung}

GBV-C ist weltweit verbreitet. Die GBV-C-RNA-Prävalenz bei Blutspendern in Europa und Nordamerika liegt zwischen 1 und $4 \%$, in Risikogruppen (s.o.) und in der Bevölkerung anderer Kontinente kann sie deutlich höher sein. Anti-E2-Antikörper liegen bei bis zu $16 \%$ der europäischen Blutspender vor, was häufiger als der RNA-Nachweis ist und für die hohe Ausheilrate der GBV-C Infektion spricht.

\section{Wirtsbereich / Reservoir}

GBV-C ist bisher nur beim Menschen nachgewiesen worden. Experimentell sind Affen infizierbar. GBV-A und GBV-B sind Affen-spezifische Viren (u. a. Tamarine).

\section{Risikogruppen}

Drogenabhängige, Empfänger von Blutprodukten, Hämodialysepatienten, Transplantatempfänger, Personen mit häufig wechselndem und ungeschütztem Geschlechtsverkehr.

\section{Transmission / Vektoren}

GBV-C kann parenteral über Blut und Blutprodukte, "needle sharing", direkten Kontakt oder auch perinatal von der Mutter auf das Kind übertragen werden. Insgesamt ähnelt die Übertragungsweise sehr stark der für HIV. Im Vergleich zu HCV spielt die vertikale Übertragung eine größere Rolle. GBV-C ist auch in Samenflüssigkeit und im Speichel nachgewiesen worden. Bei GBV-C-positiven (und HCV-negativen) Blutspendern wurden als Risikofaktoren für eine GBV-CInfektion Sexualkontakte und vorangegangene medizinische Eingriffe ermittelt.

\section{Prävention / Impfstoffe}

Angesichts der fehlenden klinischen Relevanz von GBV-C sind besondere Maßnahmen zur Infektionsvermeidung nicht vorgesehen (wie z. B. Screening von Blutprodukten auf GBV-C RNA oder anti-E2-Antikörper). Darüber hinaus gelten die üblichen Verhaltensregeln zur Verhütung parenteral übertragbarer Krankheiten (Einmalspritzen, Handschuhe, Desinfektion und Sterilisation, Kondome).

\section{Ausbruchsmanagement}

Aufgrund der bisher nicht erwiesenen Pathogenität von GBV-C sind keine Strategien zur Krankheitsvorbeugung entwickelt und implementiert worden. Wahrscheinlich greifen aber die allgemeinen Strategien zur Verhütung anderer parenteral übertragbarer Viruserkrankungen ( $\triangleright$ HCV-Infektion). 


\section{Meldepflicht}

Zwar ist die akute Non-A-E-Hepatitis nach $₫ 6$ des IfSG meldepflichtig, jedoch wird diese offensichtlich nicht durch GBV-C ausgelöst. Es sind weder der Nachweis von GBV-C RNA noch von anti-E2 zu melden.

\section{Weiterführende Informationen}

\section{Referenzzentren / Expertenlaboratorien}

- Robert-Koch- Institut, Nordufer 20, 13353 Berlin, Telefon: 030-18754-0, www.rki.de

- Institut für Virologie der Universität Essen, Hufelandstr. 55, 45147 Essen, Telefon: 0201-723 3550, www.uni-essen. de/virologie

\section{Schlüsselliteratur}

1. Alter HJ (2005) Hepatitis G Virus and TT Virus. In: Mandell, Douglas and Bennett's Principles and Practice of Infectious Diseases 6th edition. Churchill Livingstone, pp 1981-1989

2. Lindenbach BD, Thiel HJ, Rice CM (2007) Flaviviridae: The viruses and their replication. In: Knipe DM, Howley PM (eds) Fields Virology 5th edition. Lippincott-Williams \& Wilkins, Philadelphia, pp 1101-1152

3. Reshetnyak VI, Karlovich TI, Ilchenko LU (2008) Hepatitis G virus. World J Gastroenterol 14:4725-4734

\section{Gebirgsfleckfieber}

$\checkmark$ Rickettsien

\section{Geflügelpesterreger}

Aviäre Influenzaviren

\section{Gehörgangsmykose}

Aspergillus

\section{Gelbfieber}

$>$ Gelbfiebervirus

\section{Gelbfiebervirus}

\section{Erreger}

\section{Erregerspezies}

Gelbfiebervirus .

\section{Taxonomie}

Das Gelbfiebervirus ist Namensgeber und Prototyp der Familie Flaviviridae (flavus, lat. gelb), die drei Genera enthält $(\triangleright$ Abb. 1$)$.

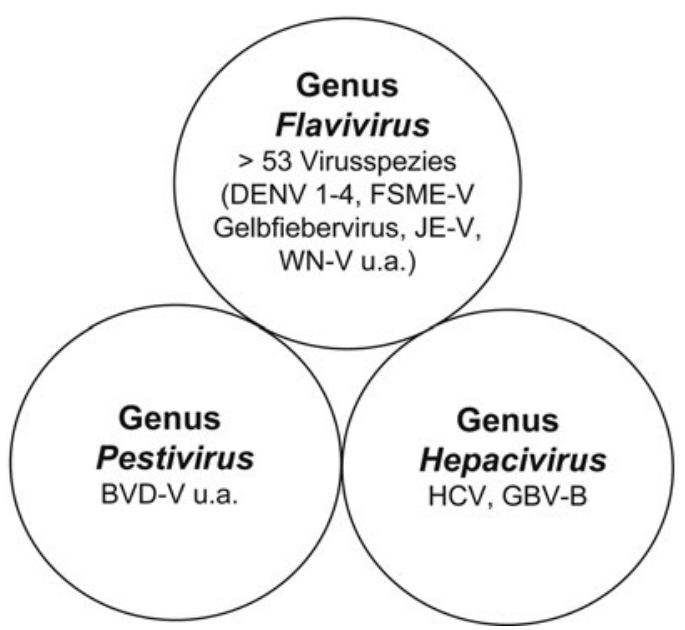

Abb. 1. Familie der Flaviridae

Familie Flaviviridae. Das Gelbfiebervirus (flavus, lat. gelb) ist Namensgeber für die Familie Flaviviridae bzw. das Genus Flavivirus. Letzteres enthält zurzeit mehr als 53 anerkannte Virusspezies (z. B. Denguevirus 1-4, DENV 1-4; Frühsommer-Meningoenzephalitis-Virus, FSME-V; Gelbfiebervirus; Japanische Enzephalitis-Virus, JE-V; West-Nil-Virus, WN-V). Die beiden anderen Genera sind Hepacivirus (HepatitisC-Virus, HCV; GB-Virus B, GBV-B) und Pestivirus, welches tierpathogene Viren enthält (z. B. Bovine Virus-Diarrhoe-Virus, BVD-V)

\section{Historie}

Das Gelbfieber bekam seinen Namen aufgrund der gelben Farbe von Haut und Skleren (Ikterus). Während der Epoche des Sklavenhandels wurde Gelbfieber von Afrika nach Amerika eingeschleppt. Große Gelbfieber-Epidemien folgten während des 18. und 19. Jahrhunderts in den Küstenregionen Amerikas, Europas und Westafrikas. Der Übertragungsweg durch Moskitos wurde 1900 durch Walter Reed aufgeklärt. Er konnte später auch die virale Natur des Erregers zeigen. Das Krankheitsbild fand in der Oper „Der Fliegende Holländer" von Richard Wagner Beachtung. Die verheerenden Gelbfieberausbrüche beim Bau des Panama-Kanals zwischen 1881 und 1914 wurden weltweit bekannt. In Ghana wurde 1927 der PrototypStamm des Gelbfiebervirus (Asibi) isoliert. Max Theiler entwickelte daraus die heute noch gebräuchliche Gelbfieber-Vakzine und gewann für diese Leistung 1951 den Nobelpreis für Medizin.

\section{Morphologie}

Das Virion besitzt einen Durchmesser von 40-50 nm. Eine Lipidhülle umgibt das ikosaedrisch geformte Nukleokapsid (25-30 nm). Dieses besteht aus einem nicht-glykosylierten Kapsidprotein (C-Protein), welches das virale Genom in Form von einzelsträngiger 
RNA umfasst. Die Außenhülle des Virions besitzt spikeartige Projektionen und enthält das nicht-glykosylierte M-Protein und das glykosylierte E-Protein. Das E-Protein ist für die Rezeptorbindung und die Fusion der Virushülle mit der Membran der Wirtszelle verantwortlich. Es trägt die meisten Antigenepitope, an welche neutralisierende Antikörper binden können.

\section{Genom}

Das Genom der Flaviviren besteht aus einzelsträngiger Plus-Strang-RNA mit einer Länge von ca. 9.00011.000 Basen und besitzt einen einzigen offenen Leserahmen (engl. open reading frame, ORF). Am 5 '-Ende findet sich eine Cap-Struktur. Im Unterschied zu den Arboviren der Familie Togaviridae ist das 3'-Ende jedoch nicht polyadenyliert. Wie bei den Viren der Familie Picornaviridae wird der ORF als Ganzes in ein Vorläufer-Polyprotein translatiert, welches während und nach der Translation in insgesamt 10 Proteine (3 Strukturproteine, 7 Nicht-Strukturproteine) gespalten wird ( Abb. 2). Anders als beim Hepatitis-C-Virus ist bei den Mitgliedern des Genus Flavivirus am 5 '-Ende keine IRES-Sequenz vorhanden, welche für die Bindung der Nukleinsäure an Ribosomenuntereinheiten verantwortlich ist. Während das gesamte Genom des sequenzierten Prototyp-Stamms Asibi eine Länge von 10.862 Basen besitzt, hat der darin enthaltene ORF eine Länge von 10.233 Basen (GenBank-Nr. X93700).

\section{Vermehrung}

Im Menschen vermehrt sich das Virus vermutlich primär in Makrophagen, die im lymphatischen Gewebe lokalisiert sind, welches die Stelle der Virusinokulation drainiert. Eine hochkonservierte Region im viralen Glykoprotein E ist für die Bindung des Virus an Heparansulfat und andere bisher kaum bekannte Rezeptoren auf der Zielzelle verantwortlich. Danach wird das gebundene Virus durch Rezeptor-vermittelte Endozytose in das Zellinnere aufgenommen. Die Replikation des Virus findet im Zytoplasma statt und ist eng mit dem Endoplasmatischen Retikulum assoziiert. Die reifen Virionen gelangen schließlich an die Zelloberfläche und werden dort durch Exozytose oder Lyse der Zelle ausgeschleust. Das Gelbfiebervirus vermehrt sich auch in vielen anderen Zelltypen vom Menschen, Kaninchen oder Hamster. Darüber hinaus kann es sich sehr gut in Moskito-Zelllinien replizieren, die daher auch für die Virusisolierung und -vermehrung im Labor eingesetzt werden.

\section{Pathogenität / Virulenz / Antigenvariabilität}

Versuche mit Affen zeigen, dass das Gelbfiebervirus eine extrem hohe Pathogenität aufweist. Das Gelbfiebervirus besitzt sowohl Viszerotropismus (u. a. Infektion der Leber) als auch Neurotropismus (Infektion des Gehirns). Für den Neurotropismus des Virus ist das virale Glykoprotein E verantwortlich. Dagegen ist über die molekularen Mechanismen des Viszerotropismus noch wenig bekannt. Das Gelbfiebervirus ist genetisch sehr stabil und existiert nur als ein einziger Serotyp. Es können jedoch sieben Genotypen unterschieden werden.

\section{Erkrankung}

Gelbfieber

\section{Synonym(e)}

Ochropyra, Schwarzes Erbrechen (Vomito negro, span. schwarzes Erbrechen).

\section{Inkubationszeit}

In der Regel 3 bis 6 Tage, in Einzelfällen bis zu 14 Tage.

\section{Symptome}

Das Spektrum der Symptomatik reicht von unspezifischer fiebriger Erkrankung bis zum tödlichen hämorrhagischen Fieber. Gelbfieber beginnt mit Allgemeinsymptomen wie Fieber, Kopfschmerzen, Rückenschmerzen und Appetitlosigkeit. Eine Bradykardie (ähnlich wie beim Typhus relativ zur erhöhten Temperatur) als Zeichen der Herzschädigung wird registriert. Die meisten Infektionen klingen nach kurzer Dauer (häufig < 48 Std.) ab oder bleiben unbemerkt, sodass die Infektionsrate um ein Vielfaches höher ist als die Zahl der apparenten Infektionen.

Bei etwa 15-25\% der betroffenen Patienten kommt es zu einer 2. Krankheitsphase (toxische Phase), der eine kurzzeitige Remission vorausgehen kann. Fieber, Erbrechen, Dehydratation, Abdominalschmerzen und Ikterus treten auf. Es kann zum Versagen der Nierenfunktion und Hämorrhagien (verminderte Synthese von Blutgerinnungsfaktoren in der Leber) kommen.

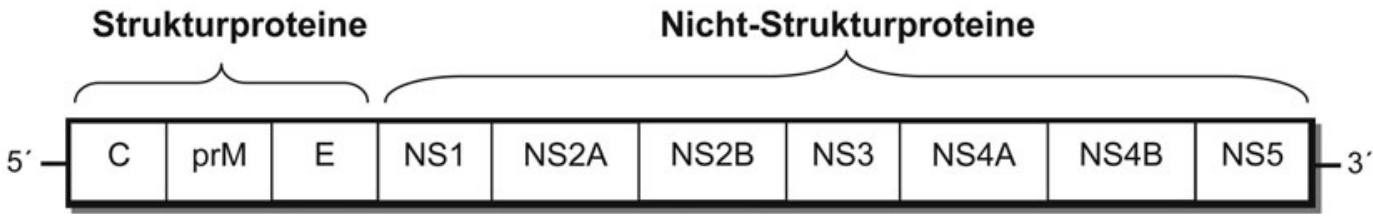

Abb. 2. Aufbau des Genoms von Flaviviren. $C=$ Kapsidprotein; prM = Prä-M-Protein (Vorläufer Molekül des Membranproteins); E = Envelope-Protein (Glykoprotein der Virushülle); NS = Nicht-Strukturproteine (u. a. Bestandteile der RNA-Replikase). 
Hämatemesis („schwarzes Erbrechen“), intraabdominale Blutungen und Hämoptyse sind Bestandteil einer schweren Symptomatik. Fast die Hälfte der Patienten, welche diese 2. Phase erreichen, stirbt zwischen dem 7. und 10. Tag infolge von Nierenversagen, Leberversagen, Schock oder Krampfanfällen. Erhöhte Leberenzymwerte, ein starker Anstieg der Konzentration von harnpflichtigen Substanzen und Gerinnungsstörungen weisen auf ein Multiorganversagen hin.

\section{Pathophysiologie}

Die Schädigung von Leber und Herzmuskel ist durch eine direkte toxische Wirkung des sich replizierenden Gelbfiebervirus bedingt. Blutdruckabfall und Schock im Spätstadium der Erkrankung werden vermutlich durch eine Dysregulation der Zytokin-Sekretion verursacht, ähnlich wie bei anderen Formen des viralen hämorrhagischen Fiebers und der Sepsis. TNF- und weitere Zytokine werden dabei von infizierten Kupfferschen Sternzellen der Leber und von Makrophagen in der Milz freigesetzt und schädigen die EndothelBarriere. Es kommt zu Mikrothrombose, disseminierter intravaskulärer Gerinnung, Gewebe-Hypoxie, Oligurie und Schock.

\section{Immunantwort}

Neutralisierende Antikörper persistieren sehr wahrscheinlich lebenslang, sodass ein sicherer Schutz vor Reinfektion besteht.

\section{Differenzialdiagnose}

Ähnliche Symptome treten bei Leptospirose und Rückfallfieber (Borellia recurrentis) auf. Virale Hepatitiden (z. B. Hepatitis E in der Schwangerschaft) und schwere Verlaufsformen der Malaria müssen ebenfalls abgegrenzt werden. Andere Erreger von hämorrhagischem Fieber sind normalerweise nicht mit einem Ikterus verbunden (bei Denguefieber, Krim-Kongo-Fieber, Lassafieber und Infektionen mit Marburg- und Ebola-Virus kann dies jedoch der Fall sein). Auch Infektionen mit Influenza, Enteroviren und HIV müssen differenzialdiagnostisch evtl. in Erwägung gezogen werden.

\section{Diagnostik}

\section{Untersuchungsmaterial}

Serum, Plasma, evtl. Lebergewebe.

\section{Diagnostische Verfahren}

Der Virusnachweis gelingt in den ersten 3-4 Fiebertagen. Die RT-PCR kann das virale Genom bereits am ersten Krankheitstag detektieren. Bei Biopsie oder Autopsie gewonnenes Lebergewebe ist ebenfalls geeignet für die Detektion des Gelbfiebervirus. Potentiell virushaltiges Material (z. B. Blut) wird für die Virusanzucht in empfängliche Zellkulturen oder in junge Mäuse überimpft. Letzteres Verfahren ist zwar sehr sensitiv, benötigt jedoch bis zu 3 Wochen. Antikörper der IgM- und IgG-Klassen können 5-7 Tage nach Krankheitsbeginn (8-14 Tage nach Infektion) mit konventionellen immunlogischen Verfahren (IFT, ELISA, KBR, HHT, NT) im Serum nachgewiesen werden. Nach 6-12 Monaten verschwinden die IgM-Antikörper wieder. Die KBR wird bereits 3-6 Monate nach Infektion mit dem Wildtyp wieder negativ. Neutralisierende IgG-Antikörper persistieren lebenslang und schützen vor Reinfektionen.

\section{Befund / Interpretation}

Antikörper gegen das Gelbfiebervirus kreuzreagieren mit Dengueviren und anderen Flaviviren. Das voll ausgeprägte klinische Bild verbunden mit der Information über den Aufenthalt in einem Endemiegebiet und die fehlende Gelbfieber-Impfung sollten jedoch die Diagnose ermöglichen.

\section{Therapie}

\section{Therapeutische Maßnahmen}

Eine spezifische Therapie steht nicht zur Verfügung. Es kann nur symptomatisch behandelt werden. Besteht der Verdacht auf Gelbfieber sollte der Patient sofort stationär in eine Klinik mit tropenmedizinischem Know-how und der Möglichkeit zur intensivmedizinischen Behandlung eingewiesen werden. Für Kontaktpersonen müssen keine weiteren Maßnahmen in die Wege geleitet werden. Eine Übertragung von Mensch zu Mensch ohne Beteiligung von Vektoren ist nur in Ausnahmefällen durch Bluttransfusionen denkbar.

\section{Epidemiologie}

\section{Verbreitung}

Gelbfieber tritt heute in tropischen Gebieten auf beiden Seiten des Atlantiks (Westafrika, Ostafrika, Südamerika) auf. Der Nahe Osten, Asien und die Pazifikregion sind frei von Gelbfieber, obwohl dort Aedes aegypti als potentieller Vektor vorkommt. Die Ursache dafür ist unbekannt. In Südamerika wird Gelbfieber in zwölf Ländern einschließlich Bolivien, Brasilien, Kolumbien, Ecuador, Peru, Panama, Venezuela und den Guyana-Staaten beobachtet (100-300 Fälle jährlich). In Afrika ist Gelbfieber südlich der Sahara zwischen 15 Grad nördlicher und ca. 18 Grad südlicher Breite verbreitet. Etwa 600 Millionen Menschen sind durch das Virus bedroht. Bis zu 5.000 Gelbfieber-Fälle werden jährlich in Afrika registriert. Die wirklichen Zahlen sind jedoch vermutlich 10-50fach höher als die offiziellen. Die WHO schätzt weltweit die jährliche Inzidenz von Gelbfieber auf 200.000 und geht von 30.000 Todesfällen jährlich aus. Afrika trägt dabei mit $90 \%$ der Fälle die Hauptlast. In Westafrika sind die endemischen Herde zahlreicher als in Ostafrika. Es können sich außerdem immer wieder unvorhergesehene, explosionsartige Ausbrüche ereignen. Im Südwesten Äthiopiens wütete von 1960-1962 die größte je regis- 


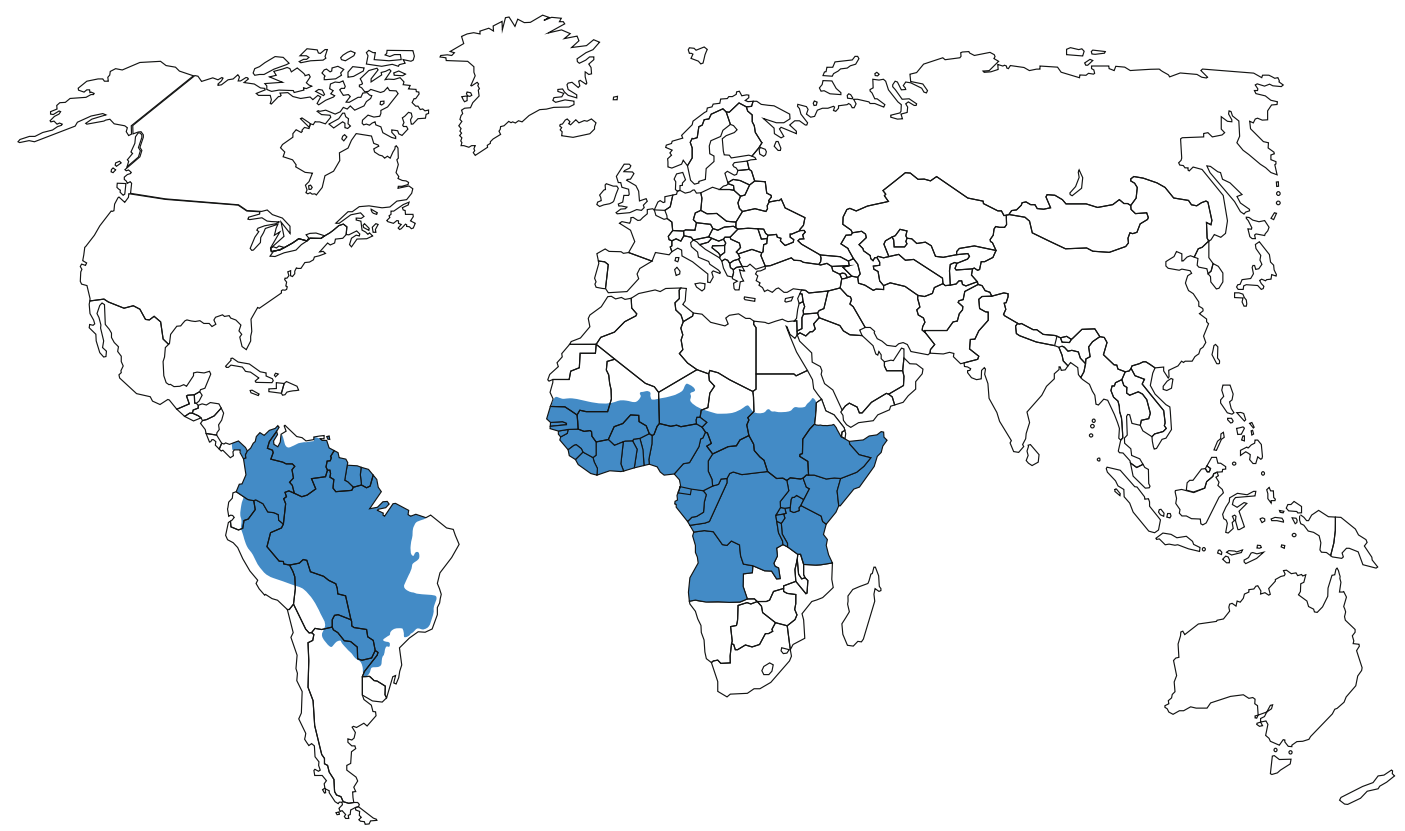

- Abb. 3. Verbreitungsgebiet des Gelbfiebers. Hochrisiko-Länder sind blau markiert.

trierte Gelbfieber-Epidemie aller Zeiten: Etwa 100.000 Personen erkrankten, davon erlagen 30.000 der Krankheit. In Nigeria gab es von 1986-1988 eine größere Epidemie mit ca. 25.000 tödlichen Infektionsverläufen. Weitere Ausbrüche ereigneten sich 2003 und 2005 im Sudan ( $\triangleright$ Abb. 3 ).

\section{Wirtsbereich / Reservoir}

Flaviviren besitzen ein breites Spektrum an potentiellen Wirten. Antikörper gegen Flaviviren sind in vielen verschiedenen Wildtieren nachgewiesen worden. Darüber hinaus wurden Wildtiere experimentell mit Gelbfiebervirus infiziert, u. a. Nagetiere, Fledermäuse und Beuteltiere. Die daraus abgeleiteten Erkenntnisse sprechen jedoch gegen eine Rolle von Nicht-Primaten im Übertragungszyklus der Flaviviren.

\section{Risikogruppen}

Gelbfieber vom Dschungeltyp befällt in Südamerika hauptsächlich junge Erwachsene, die sich zur Holzgewinnung oder Landwirtschaft im Amazonas- oder Orinocobecken aufhalten. In Teilen Afrikas, wo die Bevölkerung in den Dörfern während der Regensaison und der frühen Trockenzeit gegenüber Gelbfiebervirus exponiert wird, sind insbesondere Kinder gefährdet, da sie noch keine erworbene Immunität aufweisen. Es ist essentiell, dass sich Reisende in Gelbfieber-Endemiegebiete impfen lassen. Trotzdem kommt es immer wieder vor, dass ungeimpfte Reisende sich infizieren und an schweren Gelbfieber-Komplikationen versterben.

\section{Transmission / Vektoren}

In Südamerika gibt es zurzeit nur das Dschungelgelbfieber (sylvatischer Infektionszyklus). HaemagogusArten übertragen das Gelbfiebervirus auf niedere Primaten, die darauf eine transiente Virämie entwickeln und als Infektionsquelle für noch nicht infizierte Moskitos dienen. Nur sporadisch wird das Virus auf Menschen übertragen. In Afrika dient Aedes africanus als Hauptvektor für das Dschungelfieber. Im Unterschied zu den Neuweltaffen in Südamerika erkranken jedoch die Altweltaffen nach Infektion mit dem Gelbfiebervirus nicht. Dies ist Ausdruck eines langen Anpassungsprozesses zwischen Erreger und Altweltaffen und verweist auf die Tatsache, dass das Gelbfiebervirus aus Afrika stammt. Epizootische Infektionsherde kommen an den Rändern des Regenwaldes immer wieder vor und können das Infektionsrisiko für den Menschen wesentlich steigern. $\mathrm{Zu}$ Ausbrüchen kommt es, wenn infizierte Moskitos dort befindliche menschliche Siedlungen heimsuchen.

In Westafrika ist der anthropophile Vektor Aedes aegypti verantwortlich für Gelbfieber-Ausbrüche in Städten (urbanes Gelbfieber, Stadtgelbfieber). Moskitos nehmen während einer Blutmahlzeit bei virämischen Menschen den Erreger auf und übertragen ihn auf andere Menschen. In der Zeit vor der effektiven Bekämpfung von Aedes aegypti in Südamerika war dort dieser urbane Infektionszyklus die vorherrschende Übertragungsform des Gelbfiebers. Das Wiederauftauchen von Aedes aegypti in den früheren Ver- 
breitungsgebieten lässt vermuten, dass in Zukunft wieder urbane Epidemien in Südamerika entstehen. In den Savannengebieten bestimmter Regionen Afrikas kommt ein intermediärer Zyklus vor, bei dem verschiedene Aedes-Arten involviert sind. Viele Ausbrüche von Gelbfieber haben ihren Ursprung dort genommen.

\section{Prävention / Impfstoffe}

Aedes-Spezies, die das Gelbfiebervirus übertragen, sind tag- und nachtaktiv. Primär sollte man sich vor Mückenstichen schützen (lange Kleidung, Repellentien, Moskitonetze). Die Impfung der Menschen in den Endemiegebieten ist enorm wichtig. Der an Hühnerembryonen adaptierte 17D-Stamm wird als attenuierte Lebendvakzine eingesetzt. Über 200 Millionen Menschen wurden bisher mit dieser Vakzine geimpft. Eine einzige Dosis des 17D-Impfstoffes subkutan appliziert vermag bei $99 \%$ der Personen eine schützende Immunität $\mathrm{zu}$ induzieren, die vermutlich lebenslang anhält. Die ständige Impfkommission (STIKO) am Robert Koch-Institut empfiehlt die Impfung für Reisende in Gelbfieberinfektionsgebiete. Außerdem müssen die Impfbestimmungen sowohl der jeweiligen Ziel- als auch der Transitländer bei Reisen in tropische Gebiete Afrikas und Südamerikas beachtet werden. In einige Regionen, die bisher frei von Gelbfieber sind, könnte theoretisch diese verheerende Krankheit eingeschleppt werden, da dort geeignete Vektoren und infizierbare Wirte vorkommen (z. B. südlicher Teil der USA, Südafrika, Indien, Südostasien, Australien). Um dies zu vermeiden, können solche Länder von ihren ausländischen Besuchern, die aus Endemiegebieten kommen, ebenfalls eine vorherige Impfung verlangen (Impfbescheinigung erforderlich). Die internationalen Gesundheitsbehörden halten in der Regel eine Auffrischimpfung alle 10 Jahre für erforderlich. Der Gelbfieber-Impfstoff darf nur in Zentren verabreicht werden, die von der WHO oder bestimmten nationalen Gesundheitsbehörden dafür autorisiert wurden. Wie normalerweise jeder andere Lebendimpfstoff auch, sollte die Gelbfieber-Vakzine in der Regel nicht bei Schwangeren und Immunsupprimierten eingesetzt werden.

\section{Ausbruchsmanagement}

Bei Ausbrüchen in Endemiegebieten sollen vor allem ungeschützte Personen rasch geimpft werden (Riegelungsimpfung). Die Bekämpfung der häuslichen Aedes-aegypti-Moskitos durch Insektizide stellt eine wichtige prophylaktische Maßnahme dar. Leider ist der Moskito in viele Gelbfiebergebiete zurückgekehrt, in denen er früher eradiziert worden war. Die Kombination aus Vektorkontrolle und Impfmaßnahmen haben jedoch das urbane Gelbfieber fast vollständig zurück gedrängt.

\section{Meldepflicht}

Nach $₫ 6$ des Infektionsschutzgesetzes (IfSG) ist vom feststellenden Arzt bei Krankheitsverdacht, Erkrankung sowie Tod an virusbedingtem hämorrhagischen Fieber der Patient namentlich dem Gesundheitsamt zu melden (unverzüglich, spätestens innerhalb von 24 Stunden). Außerdem ist nach $\$ 7$ jeder direkte oder indirekte (serologische) Nachweis von Gelbfieberviren durch das Labor dann namentlich zu melden, wenn er auf eine akute Infektion hinweist. Diese Meldungen werden entsprechend $\$ 11$ über die zuständigen Landesbehörden an das Robert-Koch-Institut übermittelt. Zusätzlich ist das Auftreten einer Erkrankung auch nach $₫ 12$ IfSG übermittlungspflichtig. Dies bedeutet, dass - zusätzlich zum Übermittlungsweg nach $\$ 6$ und 7 - bestätigte hämorrhagische Verläufe von Gelbfiebervirus-Infektionen vom Gesundheitsamt aus unverzüglich an die zuständige oberste $\mathrm{Ge}$ sundheitsbehörde und von dort unverzüglich an das Robert Koch-Institut zu übermitteln sind, welches dann die Informationen an die WHO weitergibt. Weiterführende Informationen zum IfSG und zur Falldefinition für Gesundheitsämter sind auf der unten aufgeführten Web-Adresse des Robert-Koch-Instituts zu finden.

\section{Weiterführende Informationen}

\section{Referenzzentren / Expertenlaboratorien}

- Deutschland, Nationales Referenzzentrum für tropische Infektionserreger, Bernhard-Nocht-Institut für Tropenmedizin, Bernhard-Nocht-Straße 74, 20359 Hamburg, Tel.: +49-40-42818-401 oder -400, E-Mail: MZD@bnihamburg.de

\section{Web-Adressen}

- Robert-Koch-Institut (RKI): http://www.rki.de

- Bernhard-Nocht-Institut für Tropenmedizin (Hinweise auf Tropen-Viruskrankheiten): http://www.bni-hamburg.de/

- Gesellschaft für Virologie: http://www.g-f-v.org/

- Deutsche Vereinigung zur Bekämpfung der Viruskrankheiten e.V.: http://www.dvv-ev.de/

- Centers for disease control and prevention (Informationen zu Gelbfieber): http://www.cdc.gov/ncidod/dvbid/ yellowfever/

- Veterinary Public Health (Tierärztliche Hochschule Hannover): http://www.veterinary-public-health.de/home_d/ aufgaben/zoonosen/viren.htm

- WHO World Health Organization (Aktuelles über Infektionskrankheiten, Empfehlungen und Programme der WHO): http://www.who.int/

\section{Schlüsselliteratur}

1. Gubler DJ, Kuno G, Markoff L (2007) Flaviviruses. In: Knipe, DM, Howly, PM (eds) Fields Virology (5th edition). Philadelphia: Lippincott Williams and Wilkins, pp 1153-1252

2. Schoub BD, Venter M (2009) Flaviviruses. In: Zuckerman AJ, Banatvala JE, Pattison JR, Griffiths PD, Schoub BD, Mortimer P (eds) Principles and practice of clinical virology (6th edition). Chichester: John Wiley, pp 669-698

3. Tolle MT (2009) Mosquito-borne diseases. Curr Probl Pediatr Adolesc Health Care 39:97-140 


\section{Germiston-Virus}

Bunyaviren

\section{Gerstmann-Sträussler-Scheinker-Syndrom} (GSS)

Prione

\section{Gianotti-Crosti-Syndrom}

- Hepatitis B Virus (HBV)

\section{Giardia lamblia}

\section{Erreger}

\section{Synonym(e)}

Giardia lamblia, G. intestinalis, G. duodenalis, Lamblia intestinalis.

\section{Erregerspezies}

Giardia lamblia, G. ardeae (Vögel: Reiher) und G. psittaci (Vögel: Papageien), G. intestinalis; G. microtii (Wühlmäuse), G. muris (Nager), G. agilis (Amphibien). G. duodenalis (Mensch, zahlreiche Säugetiere). Besondere zoonotische Bedeutung haben die Genotypen AII, $\mathrm{AI}$ und B von G. duodenalis, die einen Komplex von mehreren Genotypen (A bis F) darstellen. Nur G. lamblia gilt als humanpathogen.

\section{Taxonomie}

Phylum: Metamonada; Klasse: Diplomonadea; Ordnung: Diplomonadida; Familie: Diplomonadidae; Gattung: Giardia

Stamm Sarcomastigophora; Unterstamm: Mastigophora (Flagellata); Klasse: Zoomastigophora; Ordnung: Diplomonadida; Familie: Hexamitidae; Gattung: Giardia

\section{Historie}

Die Trophozoiten der Gattung Giardia wurden 1681 von Antony van Leeuwenhoek entdeckt, nachdem er während einer Durchfallerkrankung den eigenen Stuhl mikroskopisch untersucht hatte und über die Existenz von motilen Trophozoiten berichtete. Die nächste Beschreibung des Einzellers stammt von dem Kinderarzt Wilhelm Lambl aus dem Jahre 1859. Der Gattungsname „Lamblia“, der auf ihn zurückzuführen ist, wird heute nicht mehr verwendet. An dessen Stelle trat der Name „Giardia“. Lambl beschrieb das vollständige Erscheinungsbild des Trophozoiten, aber erst Grassi zeigte nach 1879, dass auch Zysten zum Entwicklungszyklus gehören. Der vollständige Name wurde dann von Stiles im Jahre 1915 festgelegt; er würdigte damit den französischen Zoologen Alfred Giard (1846-1908).

\section{Morphologie}

Giardia lamblia Trophozoiten leben im Dünndarm, wobei diese Stadien sich mit ihrer konkaven Bauchseite an den Mikrovilli der Darmepithelzellen anheften. Sie erreichen eine Länge von 15-20 $\mu \mathrm{m}$, eine Breite von 7-10 $\mu \mathrm{m}$ und sind durch den Besitz von zwei gleich großen Kernen sowie acht freien Geißeln gekennzeichnet. Die Zysten von G. lamblia erscheinen ovoid, besitzen eine relativ dünne, chitinhaltige zweischichtige Wand, enthalten vier Kerne und messen 8-15 $\mu \mathrm{m} \times 7-10 \mu \mathrm{m}$. Im Innern erscheinen im Lichtmikroskop gebogene Filamentstrukturen.

\section{Genom}

Es wurden etwa 10 Genotypen von G. lamblia aus Menschen und verschiedenen Tieren isoliert. Der Mensch kann von verschiedenen Genotypen befallen sein, von denen einige auch bei Hunden, Katzen, Wiederkäuern, Ratten und Bibern auftreten. Hund, Katze und Ratte besitzen zudem eigene Genotypen von Giardien. Somit sind einige Genotypen sehr wirtsspezifisch. Die beiden Trophozoiten-Kerne enthalten gleich viel DNA und sind gleichermaßen transkriptionsaktiv. Man nimmt an, dass Polyploidie vorliegt und etwa 8-50 Chromosomen (in neun Klassen von 0,7-4 Mb) vorhanden sind. Die Größe des haploiden Genoms von Giardia beträgt 1,2 × $10^{7} \mathrm{bp}$, sein GC-Gehalt beträgt $46 \%$ und es besitzt typisch eukaryote Charakteristika. Giardia weist lineare Chromosomen auf, die von Telomeren begrenzt sind. Außerdem besitzt G. lamblia alle vier eukaryotischen Histone, die hohe Sequenzübereinstimmung zu denen anderer Eukaryoten zeigen. Giardien sind polyploid mit zumindest vier Kopien der 5 Chromosomen. In einem Zellzyklus teilen sich beide Kerne je einmal, so dass insgesamt vier Tochterkerne entstehen. Warum Giardia ein polyploides Genom mit zwei offensichtlich identischen Kernen beibehält, ist bis heute vollkommen ungeklärt. Das Giardia-Genom enthält ungefähr 60 Kopien der ribosomalen tandem-repeats. Nahezu alle rRNA-Gene liegen auf dem Chromosom 1. Wie andere parasitische Protozoen weisen G.-lamblia-Trophozoiten variable Oberflächenantigene (VSPs) auf; es wird allerdings immer nur ein Oberflächenantigen exprimiert, wobei dann ein regelmäßiger Switch stattfindet. Es gibt etwa 150 VSP-Gene, deren kodierende Sequenzen $1 \%$ des gesamten Genoms einnehmen, wobei die meisten VSP-Gene auf den Chromosomen 4 und 5 liegen. Seit 1998 besteht ein Genomprojekt, welches die Aufklärung der möglichst vollständigen Sequenz des Giardia-Genoms zum Ziel hat.

\section{Vermehrung}

Wird eine Zyste als überlebensfähiges Stadium außer- 
halb des Wirtes aus kontaminierten Fäkalien oral aufgenommen, so kommt es zur Einleitung der Exzystierung im Magen durch den Magensaft. Im Duodenum erfolgt dann die Zweiteilung des Zysteninhaltes, aus dem zwei doppelkernige Trophozoiten hervorgehen, die sich mit ihrer Ventralseite an den Mikrovillisaum der Epithelzellen des Duodenums anheften. Durch ständige Teilungen kann der Darm schnell stark besiedelt werden. Im Dickdarm angelangte Trophozoiten scheiden eine Zystenwand aus, ziehen die Geißeln ein, und in ihnen teilt sich jeder der beiden funktionsgleichen Nuklei. Damit entstehen vierkernige Zysten, die ausgeschieden werden. Giardia-Trophozoiten leben als aerotolerante Anaerobier, die ihre Energie durch Substratphosphorylierung gewinnen.

\section{Pathogenität/Virulenz/Antigenvariabilität}

Bei gesunden Personen ist die Pathogenität von G. lamblia oft gering; bei Immundefizienten oder bei Kindern treten jedoch häufig massive Symptome auf. Es scheint zudem, dass manche Genotypen unterschiedlich virulent sind. Auf molekularer Ebene wurden intraspezifische Unterschiede in der Zusammensetzung der Oberflächenantigene beobachtet. GiardiaTrophozoiten besitzen die Fähigkeit zur Veränderung ihrer Oberflächenantigene. Offensichtlich spielen Oberflächenantigene mit Cystein-reichen Proteinen eine Rolle für die Pathogenität.

\section{Erkrankung}

Giardiasis

\section{Synonym(e)}

Giardiasis, Lambliasis.

\section{Inkubationszeit}

3-21 Tage.

\section{Leitsymptome}

Malabsorptionssyndrom.

\section{Symptome}

Es kommt zu abdominalen Schmerzen, Abgeschlagenheit, Übelkeit, Erbrechen, Flatulenz sowie intermittierenden, dünnbreiigen Diarrhöen, Malabsorption, Unterernährung bei Kindern und immundefizienten Personen.

\section{Pathophysiologie}

G. lamblia verursacht lokale Darmepithelschäden, Entzündungen der Propria und Störungen des Gallenflusses.

\section{Immunantwort}

Die Entwicklung einer Immunität ist fraglich. Einen Schutz vor Reinfektionen gibt es offensichtlich nicht.

\section{Differenzialdiagnose}

Diarrhoen anderer Genese (Amöbenbefall, Diarrhöen durch Bakterien, Viren).

\section{Diagnostik}

\section{Untersuchungsmaterial \\ Nicht fixierter Stuhl oder Duodenalsaft.}

\section{Diagnostische Verfahren}

Der Nachweis der Trophozoiten erfolgt im Frischpräparat und im gefärbten Ausstrich (Heidenhain-, Trichrom- oder Lawless-Färbung), am besten aus frischem Stuhl. Ist die Untersuchung von Durchfallstühlen nicht innerhalb einer Stunde und von geformten Stühlen nicht am selben Tag gewährleistet, sollte der Stuhl sofort nach dem Absetzen fixiert werden (PVA-, MIF- oder SAF-Lösung), da die Trophozoiten rasch desintegrieren können. Zysten lassen sich im Gegensatz zu Trophozoiten auch in Stuhlproben nachweisen, die nicht frisch gewonnen oder fixiert wurden. Zudem können sie unter Erhaltung ihrer Morphologie effektiv angereichert werden (MIF- oder SAF-Anreicherung). Die Ausscheidung von Zysten variiert jedoch häufig sehr und kann bei akuter Giardiasis mit den flüssigen Durchfällen völlig fehlen. Zum Ausschluss einer Giardiasis sollten daher mehrere (mindestens drei) Stuhlproben von verschiedenen Tagen auf Zysten und/oder Trophozoiten untersucht werden. Gelegentlich lässt sich die Infektion nur durch den Nachweis von Trophozoiten in endoskopischen oder per Sonde gewonnenen Aspiraten bzw. bei Abstrichen (sofortige Untersuchung oder Fixierung wie oben) oder Biopsaten (nach Giemsa gefärbte Tupfpräparate und Histologie) aus dem Duodenum sichern.

Immunologische Nachweisverfahren haben eine geringe Aussagekraft. Molekularbiologische Nachweisverfahren (DNA-Nachweis aus Stuhl oder Duodenalmaterial oder anderen Geweben) sind für den Nachweis von Giardia-Infektionen besonders bei subklinischen, asymptomatischen oder chronischen Verlaufsformen sehr nützlich.

\section{Befund/Interpretation}

Das Auftreten von Zysten oder Trophozoiten ist eine Therapieindikation.

\section{Therapie}

\section{Therapeutische Maßnahmen}

Metronidazol, Quinacrine, Albendazol haben sich gegen Giardia-Infektionen bewährt. Bei Tieren (z. B. Hunden und Katzen, die humanpathogene Giardien ausscheiden) ist Fenbendazol wirksam. Dosis und Dauer der Therapie sind präparateabhängig.

\section{Resistenzen}

G.-lamblia-Infektionen lassen sich oft weder mit Metronidazol bzw. Quinacrine noch mit Kombinations- 
präparaten eliminieren. Es entwickeln sich Resistenzen.

\section{Epidemiologie}

\section{Verbreitung}

Der Erreger tritt weltweit auf und ist wahrscheinlich in unterentwickelten Ländern häufiger vorhanden als in entwickelten Ländern. Die Zahl der Infizierten variiert stark, die Prävalenzen liegen in entwickelten Ländern zwischen 4 und $7 \%$.

\section{Wirtsbereich/Reservoir}

Eine breite Reihe von Tierspezies scheiden Millionen von Zysten aus, die für den Menschen infektiös sind. Bereits die orale Aufnahme von 10 Zysten reicht für eine Infektion und das Auslösen einer Erkrankung aus.

\section{Risikogruppen}

Kinder, landwirtschaftliche Bevölkerungsgruppen, Menschen in Wohnheimen und sonstigen Masseneinrichtungen, Haustierhalter, Vogelzüchter und Reptilienzüchter sind besonders gefährdet. Auch sind einige Berufsgruppen wie Klärarbeiter und Arbeiter in Bewässerungsanlagen einem erhöhten Infektionsrisiko ausgesetzt. In Mitteleuropa sind Kindertagesstätten häufig von Giardiasis-Fällen betroffen. Es kommt immer wieder zu Giardiasis-Epidemien. G. lamblia ist einer der Hauptverursacher von Reisediarrhoen.

\section{Transmission/Vektoren}

Die Giardiasis tritt sporadisch und epidemisch auf und ist eine typische Schmutz- und Schmierinfektion. Zur Infektion und Übertragung reichen bereits 10 Zysten aus. Als Infektionsquellen treten drei Übertragungsmöglichkeiten (fäkal-oral) auf:

- Personenkontakte

- kontaminierte Nahrungsmittel

- kontaminiertes Wasser

Die Zysten bleiben bis zu 3-6 Monate im Freien oder bei niedrigen Temperaturen infektiös. Fliegen, Schaben oder andere Insekten können die Zysten auf die Nahrung oder direkt auf die Menschen verschleppen. Die Verbreitung von Giardia auf dem Wasserweg ist seit 1946 bekannt. Zu diesem Zeitpunkt wurde in Tokio ein Wasserreservoir in einem Hotel durch Abwasser kontaminiert und $86 \%$ aller Hotelgäste mit Giardien infiziert. Giardiasis stellt in den industrialisierten Ländern neben der Kryptosporidiose die wichtigste Trinkwasser-assoziierte Erkrankung dar.

\section{Prävention}

Die Vermeidung des Kontakts mit humanen und tierischen Fäkalien vermindert das Infektionsrisiko. Geeignete hygienische Maßnahmen sind die Desinfektion oder das Abkochen des Trinkwassers sowie die gründliche Reinigung von Obst-, Salat und anderen frisch verzehrten Nahrungsmitteln.

\section{Ausbruchsmanagement}

Zahlreiche Epidemien durch Trinkwasserkontamination mit parasitischen Protozoen wurden weltweit berichtet. Auf nordamerikanische und europäische Krankheitsausbrüche entfielen zusammen $93 \%$ aller beschriebenen Fälle. Über 30 \% aller Ausbrüche wurden in Europa, hiervon allein $24 \%$ in Großbritannien, dokumentiert. G. lamblia war für einen großen Anteil der Epidemien verantwortlich (132; 40,6 \%).

\section{Meldepflicht}

Der Nachweis von Giardia lamblia ist nach $\$ 7$ Infektionsschutzgesetz meldepflichtig.

\section{Weiterführende Informationen}

\section{Referenzzentren / Expertenlaboratorien}

- Offizielle Referenzzentren existieren nicht. Alle parasitologischen und tropenmedizinischen Einrichtungen haben ausreichende Expertise.

\section{Web-Adressen}

- http://www.biologiezentrum.at/pdf_frei_remote/ DENISIA_0006_0133-0143.pdf

\section{Schlüsselliteratur}

1. Garcia CS (2005) Giardiasis. In: Cox FEG, Wakelin D, Gillespie S, Despommier DD (eds) Parasitology. Hodder Arnold, London

2. Plutzer J, Ongerth J, Karanis P (2010) Facts and open questions about Giardia: Int J Hyg Environ Health, in press

\section{Giardiasis}

- Giardia lamblia

\section{Gilchrist's Disease}

Blastomyces dermatitidis

\section{Gingivostomatitis}

- Herpes-simplex-Virus (HSV)

\section{Gnathostoma spinigerum}

- Nematoden, seltene Arten

\section{Gnathostomiasis}

- Nematoden, seltene Arten 


\section{Gonokokken}

Neisseria gonorrhoeae

\section{Gonorrhoe}

- Neisseria gonorrhoeae

\section{Granulomatöse Amöbenmeningoenzephalitis (GAE)}

- Amöben, frei lebende (Naeglerien, Acanthamöben, Balamuthia, Amöben als Vehikel pathogener Mikroorganismen)

\section{Granulomatöse Balamuthia-Enzephalitis}

Amöben, frei lebende (Naeglerien, Acanthamöben, Balamuthia, Amöben als Vehikel pathogener Mikroorganismen)

\section{Granulomatöse Hautinfektion}

Amöben, frei lebende (Naeglerien, Acanthamöben, Balamuthia, Amöben als Vehikel pathogener Mikroorganismen)

\section{Granulomatosis infantiseptica}

- Listeria monocytogenes

\section{Grippe}

- Influenza-Virus

\section{Grippeviren}

- Influenza-Virus

\section{Großer Leberegel}

Fasciola hepatica

\section{Guama-Virus}

Bunyaviren

\section{Guaroa-Virus}

Bunyaviren

\section{Guillain-Barré-Syndrom}

- Campylobacter

$\checkmark$ Cardioviren

- Cytomegalievirus

- Echoviren und Parechoviren

- Leptospiren

- Mycoplasma pneumoniae

- Yersinien

\section{Guineawurm}

- Dracunculus medinensis

\section{Gurkenkernbandwurm}

- Cestoden, seltene Arten

\section{Gürtelrose}

- Varicella-zoster-Virus (VZV) 


\section{Haarbalgmilben}

\section{Erreger \\ Synonym(e)}

RAFAEL SCHWARZENBERGER

Acarus folliculorum, Haarbalgmilbe, Mitessermilbe, eyelash mite.

\section{Erregerspezies}

Demodex folliculorum, Demodex brevis

\section{Taxonomie}

Klasse: Arachnida; Ordnung: Acariformes; Familie: Demodicidae

\section{Historie}

Die Entdeckung von D. folliculorum in Cerumen erfolgte 1841 durch Henle; unabhängig davon beschrieb 1842 Simon die Art unter dem Namen Acarus folliculorum als Bewohner der Haartalgdrüsen. 1843 vermutete Wilson pathogene Eigenschaften. 1963 trennte Akbulatova die Art in zwei Unterarten, denen 1972 Desch und Nutting jeweils einen Artrang zusprachen.

\section{Morphologie}

Haarbalgmilben sind wurmförmig aussehende Milben, deren Abdomen eine feine Ringelung, jedoch keine Segmentierung aufweist. Männchen und Weibchen von $D$. folliculorum werden $0,3-0,4 \mathrm{~mm}$ lang, während D. brevis nur ca. $0,25 \mathrm{~mm}$ misst. Aus den Eiern geschlüpfte Larven besitzen drei stummelförmige Beinpaare. Nach der ersten Häutung sind die Nymphen wie auch die adulten Tiere durch vier stummelförmige Beinpaare gekennzeichnet.

\section{Vermehrung}

Haarbalgmilben leben saprophytär in Haarfollikeln und Haartalgdrüsen wie auch in deren Ausführungsgängen und in den Meibomschen Drüsen. D. folliculorum besiedelt vorwiegend die Haarfollikel, die kleinere D. brevis dagegen die Talg- und Meibom-Drüsen. D. folliculorum soll sich vom Follikelepithel und D. brevis vorwiegend vom Zellinhalt des Talgdrüsenepithels ernähren. Die Parasiten stechen die Zellen an und saugen dann ihren Inhalt aus. Die Entwicklung der Haarbalgmilben dauert ca. 10 Tage. Die geschlechtsreifen Tiere leben nur etwa 5 Tage. Die meisten befallenen Follikel enthalten 2-6 Milben, nicht selten auch deutlich mehr. Die Milbenweibchen legen Eier, aus denen junge Larven schlüpfen, die ihrerseits sehr schnell neue Haarfollikel befallen.

\section{Pathogenität / Virulenz / Antigenvariabilität}

Haarbalgmilben sind Kommensalen, die der physiologischen Hautflora zuzurechnen sind. Im Zusammenhang mit den ihnen zugeordneten klinischen Manifestationen findet man sie stark vermehrt. Gesicherte pathogenetische Hinweise, dass ein verstärkter Befall mit Haarbalgmilben bestimmte Krankheitsbilder hervorruft, fehlen allerdings.

\section{Erkrankung \\ Demodikose}

\section{Synonym(e)}

Pityriasis folliculorum, Demodicosis, Demodex-Follikulitis.

\section{Inkubationszeit}

Eine Inkubationszeit lässt sich nicht definieren.

\section{Leitsymptome}

Gesichtsdermatose, Blepharitis.

\section{Symptome}

Bei Menschen mit seborrhoischem Hauttyp können Haarbalgmilben äußerst zahlreich im Gesicht auftreten. Desgleichen sind sie auch am Schädel, im äußeren Gehörgang, in den Augenlidfollikeln und besonders bei Frauen in der Umgebung der Brustwarzen zu finden. Sie kommen auch an Penis, Mons veneris und Gesäß vor. Die stark befallenen Hautareale, vorwiegend im Gesicht, zeigen follikulär gebundene entzündliche Papeln, gelegentlich auch Papulopusteln und eine pityriasiforme Schuppung. Juckreiz kann auftreten. Bei der ekzematösen Blepharitis finden sich häufig Haarbalgmilben in den Follikeln der Wimpern. Lidrandverkrustungen und Lidrandekzeme sind typische klinische Bilder. Ob allerdings eine Kausalität zwischen Milbenbefall und dem Erscheinungsbild der Blepharitis besteht oder die Blepharitis die Milbenansiedlung begünstigt, wird konträr diskutiert. Nicht eindeutig geklärt ist, inwieweit der Befall mit Demodex das Krankheitsbild einer Rosazea hervorrufen kann. Spekuliert wird z. B. über eine ursächliche Bedeutung bei papulopustulösen Rosazeaformen, die therapeutisch schwer zu beeinflussen sind. Ebenso wird nicht ausgeschlossen, dass Demodex an einer Reihe von Hauterkrankungen wie bestimmten Verhornungsstörungen, areataartigen Alopezien und pyodermieartigen Erscheinungen beteiligt ist. Bei HIVPatienten wurden juckende follikuläre Papeln im Hals-Kopf-Bereich mit Nachweis stark vermehrter Demodex-Besiedlung beschrieben. 


\section{Pathophysiologie}

Bei der Demodikose ist eine übermäßige Besiedlung der Talgdrüsenfollikel gegeben. Eiablage, Milbenkot und der Fremdkörperreiz durch die Milben führen wahrscheinlich zu spongiotischen Veränderungen am Follikelepithel und gelegentlich zur Granulombildung.

\section{Differenzialdiagnose}

Rosazea, seborrhoisches Ekzem, Blepharokonjunktivitis anderer Genese.

\section{Diagnostik}

\section{Untersuchungsmaterial}

Der schnellste Weg eines Milbennachweises besteht in der Biopsie der Hautoberfläche mithilfe von rasch härtenden Polymeren wie Zyanoakrylat (Follikelbiopsie, skin surface biopsy). Eine andere Methode, um Demodex-Milben nachzuweisen, ist die Untersuchung eines in Paraffin-Öl aufgeweichten Hautgeschabsels. Zudem besteht die Möglichkeit Follikelfilamente mit Komedonenquetschern oder Pinzetten auszudrücken oder Pusteln und Papulopusteln zu eröffnen. Bei der Blepharitis können befallene Wimpern herausgezupft werden; gewöhnlich haften der Wimper ein bis mehrere Parasiten an. Nur ausnahmsweise ist eine Hautbiopsie mit histopathologischer Aufarbeitung indiziert, um die Diagnose einer Demodex-Follikulitis zu sichern.

\section{Diagnostische Verfahren}

Der Nachweis der Milben im Untersuchungsmaterial erfolgt mikroskopisch. Im Nativmaterial zeigen sich die Milben recht beweglich. Bei der Demodex-Blepharitis gelingt der Milbennachweis auch mit der Spaltlampe.

\section{Befund / Interpretation}

Die Diagnosestellung beruht gewöhnlich auf dem Nachweis von zahlreichen Milben und der Besserung nach adäquater Behandlung.

\section{Therapie}

\section{Therapeutische Maßnahmen}

Die antiparasitäre Behandlung erweist sich als schwierig. Crotamiton- und Benzylbenzoathaltige 10 \%ige Emulsionen wie auch verschiedene andere Insektizide als Cremegrundlage (Permethrin, Allethrin, Ivermectin) können zur Anwendung kommen. Bei Lidrandbefall können die Haarbalgmilben mechanisch entfernt werden. Zur systemischen Behandlung kann auch Metronidazol wirkungsvoll eingesetzt werden.

\section{Epidemiologie}

\section{Verbreitung}

Es ist davon auszugehen, dass $40-70 \%$ der menschlichen Bevölkerung, unabhängig vom Geschlecht, mit
Haarbalgmilben besiedelt sind. Mit zunehmendem Alter nimmt auch die Milbenbesiedlung zu, um im hohen Alter - allerdings in niedriger Besiedlungsdichte - bei nahezu allen Menschen vorzukommen.

\section{Wirtsbereich / Reservoir}

D. folliculorum und D. brevis sind sehr wirtsspezifisch und bisher nur beim Menschen gefunden worden. Die Übertragung von Haarbalgmilben der Tiere auf den Menschen spielt keine Rolle.

\section{Risikogruppen}

Besondere Risikogruppen sind nicht bekannt.

\section{Transmission / Vektoren}

Durch den engen Kontakt zwischen Mutter und Kind erfolgt die Übertragung wahrscheinlich vielfach schon im frühen Kindesalter. Da Haarbalgmilben sehr beweglich sind, von einem Follikel zum andern wandern können und auch frisch geschlüpfte Larven schnell neue Haarfollikel befallen, ist die Übertragung aber auch in späterem Alter möglich.

\section{Prävention / Impfstoffe}

Wirksame Maßnahmen zur Verhütung des Milbenbefalls sind nicht bekannt.

\section{Meldepflicht}

Eine Meldepflicht nach dem Infektionsschutzgesetz besteht nicht.

\section{Weiterführende Informationen}

\section{Schlüsselliteratur}

1. Jansen T, Plewig G (1996) Demodex-Milben und ihre Bedeutung für Gesichtsdermatosen. Münch Med Wochenschr 138:483-487

\section{Haemophilus aegyptius}

\section{Erreger}

Synonym(e)

Koch-Weeks-Bazillen.

\section{Erregerspezies}

Haemophilus aegyptius

\section{Taxonomie}

Familie: Pasteurellaceae; Gattungen: Pasteurella, Haemophilus, Actinobacillus; Gattung Haemophilus: 16 Arten

$H$. aegyptius hat $\mathrm{zu} H$. influenzae enge genetische und biochemische Verwandtschaft, daher im strengen Sinne $H$. influenzae als Biotyp zuzuordnen.

\section{Historie}

Von Robert Koch 1883 in Ägypten im Eiter von akuter 
Konjunktivitis gesehen, 1886 von J. E. Weeks gezüchtet, bis 1950 als Koch-Weeks-Bazillen bezeichnet.

\section{Morphologie}

Gramnegative kokkoide Stäbchen.

\section{Genom}

Sequenz von 19 Nukleotiden und 34 Proteinen bekannt. Weitere Informationen: http://www.genedb.org.

\section{Vermehrung}

Wachstum auf Kochblutagar.

\section{Pathogenität, Virulenz, Antigenvariabilität}

Nicht näher bekannt. Unterschiede der Lipooligosaccharide (LOS) sowie der äußeren Membranproteine (P1) bei virulenten und avirulenten Stämmen.

\section{Erkrankungen}

Konjunktivitis, Brazilian Purpuric Fever (BPF)

H. aegyptius verursacht eine akute oder subakute eitrige Konjunktivitis bei Kindern, in warmen Ländern (Nordafrika, Südstaaten der USA). Das seit 1984 charakterisierte Brazilian Purpuric Fever (BPF), eine lebensbedrohliche Infektion im Kindesalter, wird von einem besonders virulenten Stamm verursacht.

\section{Inkubationszeit}

Nicht bekannt.

\section{Leitsymptome}

Eitrige Konjunktivitis.

\section{Symptome}

Eitrige Konjunktivitis, hohes Fieber bei BPF.

\section{Pathophysiologie}

Nicht näher bekannt, mögliche/r von $H$. influenzae abweichende/r Virulenzfaktor/en.

\section{Differenzialdiagnose}

Konjunktivitis jeglicher Genese (bakteriell, viral, durch Pilze, allergisch u. a.).

\section{Diagnostik}

\section{Untersuchungsmaterial}

Abstrich, bei Verdacht auf BPF Blut.

\section{Diagnostische Verfahren}

Mikroskopie: schlankes, nicht bekapseltes gramnegatives Stäbchen.

Kultur: anspruchsvoll, wächst auf Kochblutagar.

Biochemische Differenzierung: nach Wuchsfaktoren und biochemischen Kriterien.

\section{Befund / Interpretation}

Keimnachweis und Keimcharakterisierung.

\section{Therapie}

\section{Therapeutische Maßnahmen}

Augentropfen oder -salben mit Chloramphenicol, Rifampicin, Sulfonamiden oder Chinolonen (Norfloxacin, Ciprofloxacin).

\section{Resistenz}

Sehr empfindlich gegen Umwelteinflüsse.

\section{Epidemiologie}

\section{Verbreitung}

Konjunktivitis v. a. in warmen Ländern (Nordafrika, Südstaaten der USA), Brazilian Purpuric Fever (v.a. in Sao Paulo, Brasilien).

\section{Wirtsbereich /Reservoir}

Mensch, Nachweis auch in Stechmücken gelungen.

\section{Risikogruppen \\ Kinder.}

\section{Transmission / Vektoren}

Übertragung durch Kontaktinfektion.

\section{Ausbruchsmanagement}

Unterbrechung durch Kontaktinhibition.

\section{Meldepflicht}

Keine Meldepflicht nach IfSG.

\section{Weiterführende Informationen}

\section{Schlüsselliteratur}

1. Albritton WL (1982) Infections due to Haemophilus species other than H. influenzae. Ann Rev Microbiol 36:199216

2. Kilian M (Hrsg) (1981) Haemophilus, Pasteurella und Actinobacillus. Academic Press, London

3. Read TD, Dowdell M, Satola SW,Farley MM (1996) Duplication of pilus gene complexes of Haemophilus influenzae biogroup aegypticus. J Bacteriol 178:6564-6570

4. The Brazilian Purpuric Fever Study Group (1992) Brazilian purpuric fever identified in a new region of Brazil. The Brazilian Purpuric Fever Study Group, J Infect Dis 165 Suppl 1:16-19

\section{Haemophilus ducreyi}

\section{Erreger}

HANS-GÜNTHER SONNTAG

\section{Erregerspezies \\ Haemophilus ducreyi}

\section{Taxonomie}

Familie Pasteurellaceae; Gattungen: Pasteurella, Haemophilus, Actinobacillus; Gattung Haemophilus: 16 Arten 


\section{Historie}

Von Agosto Ducrey 1889 erstmals in Präparaten aus Ulcus molle nachgewiesen.

\section{Morphologie}

Gramnegative kokkoide Stäbchen.

\section{Genom}

Gesamtgenom sequenziert Weitere Informationen: http://www.genedb.org. bzw http://www.ncbi.nlm.nih. gov.

\section{Vermehrung}

3-14 Tage, in der Regel 3-5 Tage.

\section{Pathogenität, Virulenz, Antigenvariabilität}

Nicht näher bekannt. Unterschiede der Lipooligosaccharide (LOS) bei virulenten und avirulenten Stämmen, Resistenz gegen Phagozytose und Serumbakterizidie. Das äußere Membranprotein „Ducreyi serum resistance A“ (DsrA) vermittelt Serumbakterizidie und spielt eine Rolle bei der pathogenetisch wichtigen Progression von der Papel- zur Pustelbildung.

\section{Erkrankung}

Ulcus molle

Sexuell übertragbare Krankheit mit weichen, meist schmerzhaften Ulzerationen im Genitalbereich mit inguinaler Lymphadenitis.

\section{Synonym(e)}

Weicher Schanker (engl. chancroid).

\section{Inkubationszeit}

3-14 Tage, in der Regel 3-5 Tage.

\section{Leitsymptome}

Schmerzhafte Ulzeration im Genitalbereich mit inguinaler Lymphadenitis.

\section{Symptome}

Leitsymptome, weiche Papel mit erythematösem Hof.

\section{Pathophysiologie}

Nicht bekannt.

\section{Immunantwort}

Vorübergehender Schutz aufgrund der zellgebundenen Immunität (verzögerter Hypersensitivtiätsreaktion vom Typ IV), hinterlässt jedoch keine bleibende Immunität.

\section{Differenzialdiagnose}

Treponema pallidum (Syphillis), Herpes-simplex-Virus (HSV) Typ 1 und 2, Calymmatobacterium granulomatis (Granuloma inguinale).

\section{Diagnostik \\ Untersuchungsmaterial \\ Abstrich, Punktat.}

\section{Diagnostische Verfahren}

Mikroskopie: Gramfärbung, gramnegative kokkoide Stäbchen in Abstrichen fischzugartig angeordnet, Direktpräparat wenig sensitiv (typische Anordnung oft durch Superinfektion verwischt), bei Wachstum in Flüssigkultur Tendenz zur Autoagglutination.

Kultur: schwierig, schneller Transport notwendig, Schaf-Kochblut-Agar (7-8\%) mit Vancomycin (3 mg/l) zur Unterdrückung der Begleitflora, eine Woche Bebrütung bei $31-34{ }^{\circ} \mathrm{C}$ und $5 \% \mathrm{CO}_{2}$; kleine, bräunlich gefärbte, sehr feste Kolonien. Zweites Medium zur Verbesserung der Sensitivität empfohlen (z. B. Gonokokken-Agar mit 2 \% Rinder-Hämoglobin und 5 \% fötalem Kälberserum (GC-HgS) mit Vancomycin $(3 \mathrm{mg} / \mathrm{l})$ und $1 \%$ IsoVitalex oder Gonokokken-Agar mit Fildes-Zusatz.

Biochemische Differenzierung: Abhängigkeit von XFaktor (Hämin), Katalase negativ.

DNA-Amplifikation: Die Kultur war lange Zeit Goldstandard der Diagnostik, zeigt gegenüber DNA-Amplifikationstechniken (PCR z. B. mit groEL-Gen als Primer) jedoch nur eine Sensitivität von $75 \%$. Auch eine Multiplex-PCR (H. ducreyi, T. pallidum, HSV Typ 1 und 2) ist beschrieben.

Sonstige Diagnoseverfahren: Antigennachweis mittels monoklonalen Antikörpern im direkten Immunfluoreszenztest vielversprechend, Hybridisierung (DNA-DNA oder DNA-RNA). Serologie (Antikörpernachweis) für epidemiologische Zwecke im Einsatz.

\section{Befund / Interpretation}

Klinischer Befund für Therapie ausschlaggebend; kultureller Befund und biochemische Charakterisierung des Erregers geben starken Hinweis, PCR-Befund beweisend.

\section{Therapie}

\section{Therapeutische Maßnahmen}

Erythromycin, Cotrimoxazol, Kombination von Aminopenicillinen und Betalaktamase-Inhibitoren, zur Eindosisbehandlung Ciprofloxacin oder Ceftriaxon.

\section{Resistenz}

Betalaktamasebildung regional sehr häufig; Erreger sehr empfindlich gegen Umwelteinflüsse.

\section{Epidemiologie}

\section{Verbreitung}

Nur sporadisch in westlichen Ländern, häufig in Südostasien, Lateinamerika; in Schwarzafrika häufigste Ursache von Genitalulzerationen (genital ulcer disease). 


\section{Wirtsbereich / Reservoir}

Nur beim Menschen, symptomlose Träger (häufig bei Frauen).

\section{Risikogruppen}

Bevölkerungsgruppen mit schlechter persönlicher Hygiene.

\section{Transmission / Vektoren}

H.ducreyi wird über sexuelle Kontakte übertragen, begünstigt durch Läsionen im Genitalbereich.

\section{Prävention / Impfstoffe}

Expositionsprophylaxe (Kondom), Eintrittspforte für HIV, daher von CDC frühe Diagnostik und Behandlung empfohlen. Kein Impfschutz möglich.

\section{Ausbruchsmanagement}

Da Individualerkrankung nicht erforderlich

\section{Meldepflicht}

In Deutschland besteht nach dem IfSG seit 1.1.2001 keine Meldepflicht mehr.

\section{Weiterführende Informationen}

\section{Web-Adressen}

- CDC, HIV Prevention Through Early Detection and Treatment of Other Sexually Transmitted Diseases United States Recommendations of the Advisory Committee for HIV and STD Prevention, MMWR 47 (RR12); 1-24, 1998; http://www.cdc.gov/nchstp/od/mmwr/hiv_ prevention_through_early_det.htm

\section{Schlüsselliteratur}

1. Albritton WL (1982) Infections due to Haemophilus species other than H. influenzae. Ann Rev Microbiol 36:199216

2. Albritton WL (1989) Biology of Haemophilus ducreyi. Microbiol Rev 53:377-389

3. Lewis DA (2000) Diagnostic tests for chancroid. Sex Transm Inf 76:137-141

4. Morse SA (1989) Chancroid and Haemophilus ducreyi. Clin Microbiol Rev 2:137-157

5. Trees DL, Morse SA (1995) Chancroid and Haemophilus ducreyi: an update. Clin Microbiol Rev 8:357-375

\section{Haemophilus influenzae}

\section{Erreger}

HANS-GÜNTHER SonNTAg

\section{Erregerspezies}

Haemophilus influenzae

\section{Taxonomie}

Familie: Pasteurellaceae; Gattungen: Pasteurella, Haemophilus, Actinobacillus

Gattung Haemophilus: 16 Arten; Serotypen: a-f; Biotypen: I-VIII

\section{Historie}

Von Richard Pfeiffer während der Grippepandemie von 1889/92 entdeckt, zunächst als Erreger der Influenza angesehen; nach der Pandemie 1918/19 Zweifel an der ätiologischen Bedeutung; die Entdeckung des Influenzae-Virus (1933) klärt die Frage.

\section{Morphologie}

Gramnegatives kokkoides Stäbchen.

\section{Genom}

Seit 1995 gesamtes Chromosom sequenziert (Science 269:496-512, 1995); Sequenz von 889 Nukleotiden, 6.188 Proteinen und 18 Strukturen bekannt. Weitere Informationen http://www.genedb.org. bzw. http:// www.ncbi.nlm.nih.gov

\section{Vermehrung}

Wenige Tage auf Kochblutagar.

\section{Pathogenität / Virulenz / Antigenvariabilität}

Kapselsubstanz (Polyribitolphosphat) des Typs b als wichtiger Virulenzfaktor fördert die Invasion und blockiert die Phagozytose; daneben Neuraminidase, Endopeptidase, Glykopeptid, Lipopolysaccharid, Endotoxin. Durch Zilien (Pili) und Adhäsine mit hohem Molekulargewicht (HMW1,2) Adhärenz am oropharyngealen und tracheobronchialen Epithel. Häufig endogene Infektionen.

\section{Erkrankungen}

Bei Kindern: durch den Kapseltyp b eitrige Meningitis, Epiglottitis, seltener Otitis, Sinusitis, Pneumonie, septische Arthritis und Weichteilinfektionen.

Bei allen Altersklassen: durch unbekapselte Erreger häufig akute Tracheobronchitis, sekundäre bronchopulmonale Infektionen, akute Exazerbationen der chronischen Bronchitis, seltener Endokarditis, Abdominal- und Genitalinfektionen.

\section{Inkubationszeit}

Nicht genau bekannt, häufig nur wenige Tage.

\section{Leitsymptome}

Epiglottitis, Tracheobronchitis, Meningitis.

\section{Symptome}

Epiglottitis, Sinusitis, Tracheobronchitis, Meningitis, bronchopulmonale Infektion, septische Arthritis, Weichteilinfektionen.

\section{Pathophysiologie}

Kapselsubstanz (Polyribitolphosphat) des Typs b als wichtiger Virulenzfaktor fördert die Invasion und blockiert die Phagozytose.

\section{Immunantwort}

Immunität (gegen Typ b) nach Impfung von unbekannter Dauer, gute Schutzwirkung bei Kindern. 


\section{Differenzialdiagnose}

Invasive Erkrankungen können einer Meningokokken-Meningitis/Sepsis ähneln, ansonsten je nach betroffenem Organsystem.

\section{Diagnostik}

\section{Untersuchungsmaterial}

Alle Materialien von infizierten Organsystemen.

\section{Diagnostische Verfahren}

Mikroskopie: Unbegeißelte gramnegative Stäbchen $(0,3-0,5 \times 0,5-3 \mu \mathrm{m})$, Stämme mit Kapsel meist kokkoid; kapsellose oft auffallend pleomorph mit filamentösen Formen.

Kultur: fakultativ-anaerobe, mikroaerophile Bakterien, relativ anspruchsvoll; Anzüchtung auf Kochblutagar und Nährböden, die spezielle Wuchsfaktoren (X = Hämin, $\mathrm{V}$ = Nikotinamid-Adenin-Dinukleotid) enthalten; Wachstum auch auf Blutagar in der Nähe von Staphylococcus-aureus-Kolonien (Ammen- oder Satellitenphänomen); die Hämolyse setzt NAD frei; Kolonien klein ( $1 \mathrm{~mm} \mathrm{O}$ ), glatt, konvex, hellgrau, bekapselte Stämme wachsen größer, erscheinen opaleszent und glänzen.

Antigennachweis: Nachweis der Kapselsubstanz des Typs b durch Latexagglutination im Liquor bei Meningitis.

Biochemische Differenzierung: Auf Haemophilus verdächtige Kolonien (Ammenkultur oder die nicht so typische Koloniemorphologie) müssen differenziert werden. Die normale Oropharyngealflora birgt verschiedene Haemophilusarten, regelmäßig $H$. parainfluenzae und oft $H$. haemolyticus, $H$. parahaemolyticus, H. aphrophilus sowie H. paraphrophilus. Geprüft wird die Abhängigkeit von X- und V-Faktor (für XFaktor auch Porphyrintest), Haemolyse, Indolbildung, Urease und Ornithindecarboxylase. H. influenzae benötigt sowohl den X-als auch den V-Faktor (Testung mittels supplementierter Blättchen oder Bouillon). Mittlerweile kann die Identifizierung von $H$-influen$z a e$-Kulturisolaten auch mittels DNA-Hybridisierung erfolgen (z. B. Gen-Probe, San Diego, Kalifornien).

Serologische Differenzierung: Kapseltragende $H$. influenzae lassen sich in 6 Typen (a-f) gliedern. Stämme des Typs b verursachen die schweren Infektionen im Kindesalter, die anderen Typen sind pathogenetisch unauffällig. Die Typen lassen sich durch Latexagglutination, direkte Immunfluoreszenz und andere immunologische Methoden bestimmen.

Antikörperbestimmung: Für die Dokumentation einer ausreichenden Antikörperantwort nach Impfung mit $H$. influenzae Typ b kommen Radioimmun- und Enzymimmunassays zum Einsatz.

\section{Befund/Interpretation}

Nachweis des Erregers, bei Meningitis Nachweis der Kapselsubstanz.

\section{Therapie}

\section{Therapeutische Maßnahmen}

Klassische Therapie mit Aminopenicillinen (Ampicillin, Amoxycillin). Schwere Infektionen wegen des Risikos der Ampicillinresistenz parenteral mit Cefotaxim und Analogen. Leichtere Infektionen mit Oralcephalosporinen oder Aminopenicillin mit Betalaktamase-Inhibitor.

\section{Resistenz}

Ampicillinresistenz durch Plasmid kodierte Betalaktamase, in Mittel- und Nordeuropa $10 \%$, USA, Spanien, Italien bis $50 \%$; dabei oft Multiresistenz (Chloramphenicol, Tetrazykline, Cotrimoxazol).

\section{Epidemiologie}

\section{Verbreitung}

Häufungen in Kinderheimen und Krankenhäusern, Epidemien nicht bekannt.

\section{Wirtsbereich / Reservoir}

Nur beim Menschen, vorwiegend Nasopharynx, seltener Mundhöhle, Genitalschleimhaut (H. influenzae Biotyp IV). Keimträger häufig unter Kindern und Erwachsenen. Sehr empfindlich gegen Umwelteinflüsse.

\section{Risikogruppen}

Kleinkinder bis zum 2. Lebensjahr, Patienten mit Virusinfektionen der Atemwege und Defekten der mukoziliären Clearance.

\section{Transmission / Vektoren}

Übertragung durch Kontakt- und Tröpfcheninfektion, begünstigt durch enge Lebensverhältnisse. Hohes Übertragungsrisiko bei Kindern.

\section{Prävention / Impfstoffe}

Aktive Impfung mit Konjugatimpfstoff, empfohlen für Kinder bis zum 6. Lebensjahr und bei funktioneller oder anatomischer Asplenie, gute Schutzwirkung, deutlicher Rückgang der Infektionen durch den Typ b. Chemoprophylaxe bei Meningitis oder Epiglottitis für Kontaktpersonen mit Rifampicin oral (über 4 Tage).

\section{Ausbruchsmanagement}

Ausbrüche nicht bekannt, bei Auftreten der Erkrankung Chemoprophylaxe bei Kontaktpersonen.

\section{Meldepflicht}

Namentlich nach $₫ 7$ Abs.1 IfSG nur für den direkten Nachweis aus Liquor oder Blut (durch das Labor).

\section{Weiterführende Informationen}

\section{Referenzzentren / Expertenlaboratorien}

- Isolate aus invasiven Infektionen an das Nationale Referenzzentrum für Streptokokken, Institut für Medizinische Mikrobiologie, Universitätsklinikum der RWTH Aachen, 52057 Aachen 
- Kapseltypisierung im Labor Prof. Schmitt (Pädiatrische Infektiologie), Universität Kiel möglich

\section{Web-Adressen}

- University of Wisconsin-Madison: Bacteriology 330 Lecture Topics: Haemophilus influenzae von Kenneth Todar: http://www.bact.wisc.edu/Bact330/lectureHflu

\section{Schlüsselliteratur}

1. Deutsche Gesellschaft für Pädiatrische Infektiologie (DGPI) (2000) Infektionen bei Kindern und Jugendlichen, 2. Aufl. Futuramed-Verlag, München

2. Frederiksen WM (1993) Ecology and significance of Pasteurellaceae in man - an update. Zbl Bakt 279:27-34

3. Gilsdorf JR et al. (1997) Role of pili in Haemophilus influenzae adherence and colonization. Infect Immun 65: 2997-3002

4. Kilian M (Hrsg) (1981) Haemophilus, Pasteurella und Actinobacillus. Academic Press, London

5. Peltola H (2000) Worldwide Haemophilus influenzae type $b$ disease at the beginning of the 21st century: Global analysis of the disease burden 25 years after the use of the polysaccharide vaccine and a decade after the advent of conjugates. Clin Microbiol Rev 13:302-317

\section{Hafnia}

\section{Erreger}

\section{Erregerspezies}

Hafnia alvei

\section{Taxonomie}

Familie: Enterobacteriaceae, Gattung: Hafnia

\section{Historie}

Hafnia ist die alte Bezeichnung für den Namen Kopenhagen.

\section{Morphologie}

Gramnegative Stäbchenbakterien, beweglich durch peritriche Begeißelung.

\section{Genom}

Das Genom von $H$. alvei ist vollständig sequenziert. Siehe auch www.ncbi.nlm.nih.gov.

\section{Vermehrung}

Wachstum innerhalb von 24 Stunden.

\section{Pathogenität / Virulenz / Antigenvariabilität}

Nicht bekannt.

\section{Erkrankungen}

1. Lokalisierte Prozesse

Postoperative Wundheilungsstörungen, Pneumonien, Abszesse, Harnwegsinfektionen.

\section{Leitsymptome}

Entsprechend dem jeweiligen Krankheitsbild.

\section{Symptome}

Entsprechend dem jeweiligen Krankheitsbild.

\section{Pathophysiologie}

- Enterobacter

\section{Immunantwort}

- Enterobacter

\section{Differenzialdiagnose}

Ausschluss anderer Infektionserreger.

\section{Generalisierte Prozesse}

Durch Übertritt in die Blutbahn kann es zur Sepsis kommen.

\section{Inkubationszeit}

Nicht bekannt.

\section{Leitsymptome}

Fieber.

\section{Symptome}

Fieber.

\section{Pathophysiologie \\ - Enterobacter}

\section{Immunantwort}

- Enterobacter

\section{Differenzialdiagnose}

Ausschluss anderer Infektionserreger.

\section{Diagnostik}

Kulturelle Anzüchtung: S. fakultativ pathogene E. coli - Escherichia coli.

Serologische Differenzierung: Es wurden 68 O- und $64 \mathrm{H}$-Antigentypen nachgewiesen.

Phagentypisierung: Speziallaboratorien.

\section{Untersuchungsmaterial}

Blut, Eiter, Sputum, Urin.

\section{Diagnostische Verfahren}

- Enterobacter

\section{Befund / Interpretation}

Erregernachweis ausschlaggebend.

\section{Therapie}

\section{Therapeutische Maßnahmen}

- Enterobacter

\section{Resistenz}

Häufig Multiresistenz. 


\section{Epidemiologie}

\section{Verbreitung}

Durch Hafnia alvei bedingte Erkrankungen sind selten und werden allenfalls im Hospital bei krankenhauserworbenen Infektionen nachgewiesen.

\section{Wirtsbereich / Reservoir}

Hafnia alvei kommt im Darm von Menschen, Tieren und Vögeln vor, aber auch in Wasser, Abwasser, Mist sowie im Erdreich

\section{Risikogruppen}

Risikogruppen sind immunsupprimierte und abwehrgeschwächte Patienten.

\section{Transmission / Vektoren}

Mit hoher Wahrscheinlichkeit Schmierinfektion.

\section{Prävention / Impfstoffe}

S. fakultativ pathogene E. coli $\triangleright$ Escherichia coli

\section{Ausbruchsmanagement}

Nicht erforderlich.

\section{Meldepflicht}

$\$ 23$ IfSG Abs. 1: Multiresistenz ist zu dokumentieren.

\section{Weiterführende Informationen}

\section{Web-Adressen}

- http://www.cdc.gov/

\section{Schlüsselliteratur}

1. Blaser MJ, Smith PD, Ravdin JI, Greenberg HB, Guerrant RL (eds) (1995) Infections of the Gastrointestinal Tract, Raven Press New York

2. Hahn H, Kaufmann SHE, Schulz TF, Suerbaum S (Hrsg) (2009) Medizinische Mikrobiologie und Infektiologie. 4. Auflage, Springer Verlag Berlin, Heidelberg, New York, Barcelona, Hongkong, London, Mailand, Paris, Singapur, Tokyo

3. Kist M, Bockemühl J, Aleksic S, Altwegg M, Autenrieth IB, Bär W, Beutin L, Gerten B, Heintschel von Heinegg E, Karch H, Lehmacher A, Mehnert F, Sonnenborn U, Tschäpe H, v. Eichel-Streiber C (2000) Infektionen des Darmes: MiQ 9, Urban und Fischer, München, Jena

4. Konemann EW, Allen HD, Janda WM, Schreckenberger PC, Winn EC (eds) (1997) Diagnostic Microbiology, 5th Ed, Lippincott, Philadelphia, New York

\section{Hakenwürmer}

Erreger

\section{Synonym(e)}

Grubenwurm, „Todeswurm“.

\section{Erregerspezies}

Humanpathogene Arten: Ancylostoma duodenale, $\mathrm{Ne}$ - cator americanus, tierpathogene Arten: A. braziliense, A. caninum u. a.

\section{Taxonomie}

Klasse: Nematoda, Ordnung: Strongylida, Familie: Ancylostomatidae

\section{Historie}

Hinweise auf $A$. duodenale finden sich bereits im $\mathrm{Pa}$ pyrus Ebers (1.600 v.Chr.), später durch Avicenna (980-1037), eine genaue Beschreibung erfolgte jedoch erst durch Dubini (1843). Grassi und Parona wiesen 1878 die Eiausscheidung über den Stuhl nach, Perroncito (1880) stellte die filariformen Larven dar. Wesentliche klinische und epidemiologische Erkenntnisse wurden währen des Baues der St. Gotthard-Tunnels 1879/80 gewonnen. Aber erst 1896/97 gelang A. Looss die Aufklärung des vollständigen Entwicklungszyklus bei seinen Arbeiten in Ägypten. Die Beschreibung von $N$. americanus als zweiter Hakenwurmart des Menschen erfolgte 1092 durch Stiles.

\section{Morphologie}

Hakenwürmer sind rötlich gefärbt und tragen Zähne (Ancylostoma) bzw. Schneideplatten (Necator) in der Mundkapsel. Die Männchen von A. duodenale sind $10 \times 0,45 \mathrm{~mm}$, die von $N$. americanus $7 \times 0,3 \mathrm{~mm}$ groß und tragen eine Bursa copulatrix am Hinterende. Die Weibchen der Hakenwürmer sind etwas größer als die Männchen (A. duodenale $12 \times 0,6 \mathrm{~mm}, N$. americanus $10 \times 0,35 \mathrm{~mm})$

Tierische Hakenwürmer: Beim Menschen treten nur wandernde Larven auf.

\section{Genom}

Für die humanpathogenen Hakenwürmer liegen derzeit Sequenzen von ribosomalen und mitochondrialen Genen sowie von Strukturgenen vor, die für den molekularbiologischen Nachweis verwendet werden können. Daten bezüglich des Gesamtgenoms existieren noch nicht, sind jedoch in Arbeit.

Bei den tierischen Hakenwürmern liegen für A. caninum Sequenzen von ribosomalen und mitochondrialen Genen sowie von Strukturgenen vor, für A. braziliense sind Sequenzen von ribosomalen Genen publiziert.

\section{Vermehrung}

Die Adultwürmer leben im Dünndarm, wo sie sich von Darmzotten ernähren. Ihre Lebensdauer beträgt 4-5 Jahre. Hakenwürmer entwickeln sich ohne Einschaltung eines Zwischenwirts: Ein Weibchen gibt pro Tag etwa 10.000 ( $N$. americanus) bis über 20.000 (A. duodenale) Eier ab, die mit dem Stuhl ausgeschieden werden. Im Freien schlüpfen nach ca. 48 Std. die Erstlarven, die innerhalb von 5-8 Tagen unter 2 Häutungen zu Infektionslarven (L3) heranwachsen. Bei Kontakt mit dem Menschen dringen diese perkutan 
ein und führen über das Blut eine Herz-Lungen-Wanderung durch. In der Lunge wandern sie über die Alveolen in den Bronchialbaum aus und erreichen den Rachen, wo sie abgeschluckt werden. Sie siedeln sich schließlich im Dünndarm an, wo sie zu Adultwürmern heranwachsen. Die Eiablage beginnt 5-6 Wochen nach der Infektion (Präpatenz).

\section{Pathogenität / Virulenz / Antigenvariabilität}

Das wesentliche pathogene Agens stellen die Adultwürmer dar, die sich mit Hilfe von vier Chitinzähnen (Ancylostoma) bzw. zwei sichelförmigen Mundplatten (Necator) an der Schleimhaut festsetzen. Mithilfe ihrer sehr kräftigen Ösophagusmuskulatur saugen sie Darmzotten in ihre Buccalhöhle. Der daraus resultierende tägliche Blutverlust beträgt bei Ancylostoma $0,1-0,5 \mathrm{ml}$, bei Necator ist er mit $0,03-0,25 \mathrm{ml}$ geringer.

\section{Erkrankung \\ Hakenwurm-Infektion}

\section{Inkubationszeit}

Eine Inkubationszeit lässt sich nicht präzise definieren, da das Entstehen von Krankheitserscheinungen von der Zahl der - in der Regel akkumulativ - eingedrungenen bzw. aufgenommenen Larven und der Dauer der Infektion abhängt.

\section{Leitsymptome}

Pneumonie, uncharakteristische gastrointestinale Symptomatik, Eisenmangel-Anämie.

\section{Symptome}

Akute Erscheinungen können kurz nach Infektion bei sensibilisierten Personen in Form juckender erythematöser oder papulöser Hautveränderungen auftreten, die durch wandernde humane oder tierische Hakenwurmlarven verursacht werden; die pulmonale Phase kann sich in Form von Dyspnoe, Husten und anderen pneumonischen Symptomen äußern. Die intestinale Phase geht mit uncharakteristischen gastrointestinalen Beschwerden wie Oberbauchschmerzen, Inappetenz, Völlegefühl, Meteorismus, Flatulenz, Obstipation oder Diarrhoe einher. Chronische Erscheinungen in Form von Anämie-bedingter Blässe, Müdigkeit, Leistungsschwäche und Symptome einer Mehrbelastung des Herzens finden sich bei stärkerem Befall; speziell bei schlechten Ernährungsbedingungen kommt es durch den chronischen Eiweißverlust zu einer Kwashiorkor-artigen Symptomatik mit Ödemen und Depigmentierungen von Haut und Haaren, im Kindesalter mit Wachstums- und Entwicklungsstörungen einhergehend.

\section{Pathophysiologie}

Maßgebend für das Entstehen einer Erkrankung ist die Befallsstärke. Bei Massenbefall und bestehender Sensibilisierung werden durch eindringende Parasiten kutane entzündliche Infiltrationen verursacht. Die durch wandernde Larven verursachte pulmonale Phase ist durch granulomatöse und allergisch-infiltrative Reaktionen mit resultierenden passageren Pneumonien gekennzeichnet. Das wesentliche pathogene Agens stellen jedoch die Adultwürmer dar, die durch Einsaugen von Darmzotten Schleimhauterosionen, vor allem aber Blutungen verursachen; je nach Spezies kommt es dabei zu einer mehr oder weniger ausgeprägten Eisenmangel-Anämie und Hypalbuminämie (intestinale Phase).

Bei Befall des Menschen mit Larven tierischer Hakenwürmer (v. a. von Hund und Katze) kommt es zum so genannten Hautmaulwurf (creeping eruption, Larva migrans cutanea); das Krankheitsbild ist charakterisiert durch entzündliche Reaktionen im Korium, die im Gefolge der im basalen Epithel minierenden Larve auftreten.

Makroskopisch stellt sich der Wanderweg als serpiginöser, erhabener, roter Streifen in der Haut dar, der täglich einige $\mathrm{mm}$ an Länge zunimmt (Lebensdauer der Larve ca. 10 Tage). Beim Verschlucken infektiöser Larven sind auch Wanderungen in inneren Organen möglich.

\section{Immunantwort}

In der Regel hat die durch Hakenwürmer hervorgerufene Immunantwort keine protektive Wirkung. Beobachtungen bei Erwachsenen über eine Abnahme der Befallsstärke trotz kontinuierlicher Transmission lassen jedoch auf die Entwicklung einer Teilimmunität schließen.

\section{Differenzialdiagnose}

Ein eosinophiles Lungensyndrom kann auch durch die Larven von Strongyloides stercoralis und Ascaris lumbricoides verursacht werden. Der intestinale Hakenwurmbefall ist von anderen intestinalen Helminthosen sowie Protozoonosen abzugrenzen; ähnliche Symptome können auch durch chronische bakterielle Enteritiden wie z. B. Yersiniosen ggf. auch durch Magen-Darm-Ulzera hervorgerufen werden. Hypalbuminämien und Ödeme sind gerade in Entwicklungsländern oft eine Folge von Kwashiorkor und/oder nephrotischem Syndrom, letzteres oft auf der Basis einer urogenitalen Bilharziose.

Ein Larva-migrans-cutanea-Syndrom kann auch durch Strongyloides-Arten verursacht werden.

\section{Diagnostik}

\section{Untersuchungsmaterial}

Stuhl: Hakenwurmeier sind widerstandsfähig, sodass der Stuhl versandt werden kann. Achtung: bei längerem Transport und Wärme schlüpfen die Larven!

Serum: Besondere Abnahmebedingungen bestehen nicht. 


\section{Diagnostische Verfahren}

Der Nachweis einer Hakenwurminfektion erfolgt am effektivsten durch mikroskopische Stuhluntersuchung auf die charakteristischen Eier unter Verwendung eines Anreicherungsverfahrens (z. B. SAF-Methode). Hakenwurmeier sind oval, transparent und dünnschalig mit Abmessungen von $60 \times 40 \mu \mathrm{m}$. Sie erlauben keine Differenzialdiagnose zwischen A. duodenale und N. americanus. Eine Speziesdifferenzierung ist jedoch anhand von L3-Larven in Kotkulturen möglich.

\section{Befund / Interpretation}

Ein Nachweis der Eier oder Larven ist für einen Hakenwurm-Befall beweisend. Mit der Ausscheidung von Eiern ist frühestens 5-6 Wochen nach Infektion zu rechnen (Präpatenz).

Antikörper werden ca. 2 Wochen nach Infektion nachweisbar.

\section{Therapie}

\section{Therapeutische Maßnahmen}

Eine ätiologische Therapie in der migratorischen Phase existiert nicht, zur Behandlung der Adulten beider Hakenwurmarten eignen sich in erster Linie Benzimidazolcarbamate (z. B. Mebendazol $2 \times 100 \mathrm{mg} / \mathrm{d}$ für 3 Tage; Albendazol $1 \times 400 \mathrm{mg}$ ). Vor allem bei N. americanus ist auch Pyrantelembonat wirksam $(10 \mathrm{mg} / \mathrm{kg}$ KG/d für 4 Tage). Die Behandlung der Larva migrans cutanea erfolgt durch lokale Anwendung von Benzimidazolen oder Ivermectin.

\section{Resistenz}

Resistenzprobleme treten bei der Behandlung von Hakenwurminfektionen kaum auf.

\section{Epidemiologie}

\section{Verbreitung}

Die Verbreitung von A. duodenale und N. americanus ist primär auf die Tropen und Subtropen beschränkt, A. duodenale wurde jedoch in Mitteleuropa auch in Bergwerken und Ziegeleien sowie bei Tunnelbauten eingeschleppt. Während $N$. americanus ursprünglich in den inneren Tropen und A. duodenale in den Subtropen vorkamen, finden sich beide Arten heute vielfach nebeneinander im gleichen Gebiet. Weltweit rechnet man mit ca. 900 Mio. infizierter Menschen, wobei die Prävalenz lokal bis zu $90 \%$ betragen kann. Begünstigend sind feuchte, schattige, warme Plätze mit sandigem Untergrund; auslösend wirken primitive hygienische Verhältnisse, bei denen die Fäzes wahllos im Freien abgesetzt werden ( $\triangleright$ Abb. 1$)$.

\section{Wirtsbereich / Reservoir}

A. duodenale und N. americanus sind spezifische $\mathrm{Hu}-$ manparasiten und können sich nur im Menschen entwickeln. Die beim Menschen lediglich als Wanderlarven auftretenden Hakenwurmarten der Säugetiere haben in Caniden und Feliden ihre eigentlichen Wirte, der Mensch ist für sie Fehlwirt.

\section{Risikogruppen}

In Endemiegebieten ist generell die arme Bevölkerung

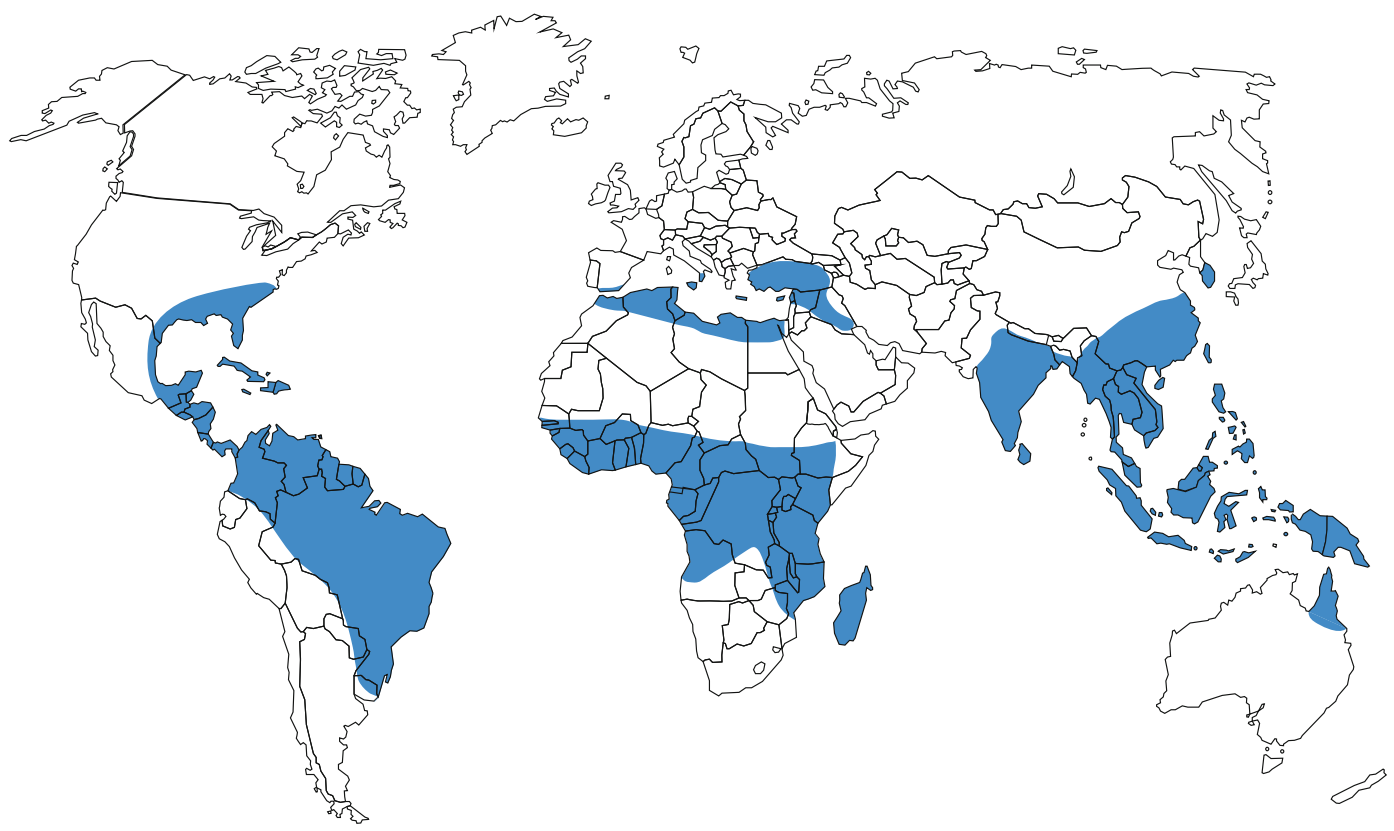


ländlicher Bereiche (Barfußgehen!) exponiert, unter dieser speziell Kinder. In den gemäßigten Breiten gilt die Hakenwurminfektion in Bergwerken als Berufskrankheit (Grubenwurm). Sie kommt in Deutschland jedoch nicht mehr autochthon vor.

\section{Transmission / Vektoren}

Die Infektion erfolgt in erster Linie durch aktives Eindringen der Larven in die intakte Haut, aber auch orale Infektionen durch Aufnahme filariformer Larven sind möglich.

\section{Prävention / Impfstoffe}

Die Prävention besteht generell in der hygienischen Entsorgung menschlicher Fäkalien in Gruben bzw. in dem Verbot einer Verwendung als Dünger. Individuell ist Barfußgehen und Sitzen auf nacktem Boden in Endemiegebieten zu vermeiden.

Ein Impfstoff gegen Hakenwürmer ist derzeit nicht verfügbar. Eine Impfstoffentwicklung auf der Basis rekombinanter Antigene wird versucht.

\section{Ausbruchsmanagement}

Wegen des indirekten Übertragungsweges sind Ausbruchsgeschehen nicht möglich.

\section{Meldepflicht}

Nach dem Infektionsschutzgesetz (IfSG) vom 1.1.2001 ist bei einer Hakenwurminfektion weder die Erkrankung noch der Erregernachweis meldepflichtig. Bei Bergleuten und Tunnelbauern ist die Infektion auch heute noch als Berufskrankheit meldepflichtig.

\section{Weiterführende Informationen}

\section{Referenzzentren / Expertenlaboratorien}

- Offizielle Referenzzentren existieren nicht; als fachlich qualifiziert anzusehen sind sämtliche parasitologischen und tropenmedizinischen Institutionen.

\section{Web-Adressen}

- CDC-Center for Disease Control and Prevention: http:// www.dpd.cdc.gov/dpdx/HTML/Hookworm.htm

- WHO-World Health Organization: http://www.who.int/ vaccine_research/diseases/soa_parasitic/en/index2.html

\section{Schlüsselliteratur}

1. Beaver PC, Jung RC, Cupp EW (1984) Clinical Parasitology. $9^{\text {th }}$ edn. Lea $\&$ Febiger, Philadelphia

2. Burkhardt F (Begr), Neumeister B, Geiss K, Braun R, Kimmig P (Hrsg) (2009) Mikroskopische Diagnostik: Bakteriologie, Mykologie, Virologie, Parasitologie. Georg Thieme Verlag, Stuttgart

3. Gilles HM, Ball PAJ (eds) (1991) Hookworm infections. Human Parasitic Diseases, vol 4. Elsevier, Amsterdam

4. Janitschke K, Kimmig P, Seitz HM, Frosch M, Groß U, Hlobil H, Reiter-Owona I (1998) MIQ, Qualitätsstandards in der mikrobiologisch-infektiologischen Diagnostik. 4, Parasitosen. Gustav Fischer, Stuttgart

5. Löscher T, Burchard GD Hrsg (2010) Tropenmedizin in Klinik und Praxis. 4. Aufl. Georg Thieme Verlag, Stuttgart
6. Schad GA, Warren KS (eds) (1990) Hookworm disease: current status and new directions. Taylor \& Francis, London

\section{Hakenwurm-Infektion}

- Hakenwürmer

\section{Halazoun}

$\checkmark$ Pentastomiden

\section{Hämolytisch-urämisches Syndrom (HUS)}

- Echoviren und Parechoviren

- Escherichia coli (EHEC)

\section{Hämorrhagisches Fieber}

- Bioterrorismus, infektiologische Aspekte

- Bunyaviren

- Dengueviren

- Filoviren

- Flaviviren, seltene humanpathogene

- Gelbfiebervirus

- Hantaviren

- Lassa-Virus

\section{Hämorrhagisches Fieber mit Renalem Syndrom (HFRS)}

- Hantaviren

\section{Hämorrhagisches Krim-Kongo-Fieber}

Bunyaviren

\section{Hand-, Fuß- und Mundkrankheit}

- Coxsackieviren

- Enteroviren 68-71 und andere Entroviren

\section{Handschuh-Socken-Erythem}

- Parvoviren

\section{Hantaan-Virus}

Hantaviren 


\section{Hantaviren}

\section{LOTHAR ZÖLLER, SANDRA EsSBAUER}

\section{Erreger}

\section{Erregerspezies}

Hantaan-Virus, Puumala-Virus, Seoul-Virus, DobravaVirus, Tula-Virus, Sin-Nombre-Virus, Bayou-Virus, Black-Creek-Canal-Virus, New-York-Virus, Andes-Virus, Laguna-Negra-Virus, Prospect-Hill-Virus, Thailand-Virus, Khabarovsk-Virus, El-Moro-Canyon-Virus

\section{Taxonomie}

Familie: Bunyaviridae; Genus: Hantavirus. Unterhalb der Genusebene werden die bisher bekannten Isolate bzw. die mithilfe der Reverse-Transkriptase-Polymerasekettenreaktion (RT-PCR) nachgewiesenen viralen Genome oder Genomfragmente aufgrund des Verwandtschaftsgrades ihrer Nukleinsäure- bzw. der daraus abgeleiteten Aminosäuresequenzen in mindestens 22 verschiedene genetische Gruppen (Genotypen, Spezies) eingeteilt ( $\downarrow$ Tab. 1), die mit den immunologisch definierten Serotypen korrespondieren und mit jeweils spezifischen Nagetierspezies als Reservoiren assoziiert sind. Innerhalb der genetischen Gruppen wurden wiederum verschiedene Subtypen höheren Homologiegrades beschrieben, die zum Teil ebenfalls mit einem bestimmten Reservoirwirt oder aber einer besonderen Krankheitsausprägung beim Menschen assoziiert sind.

\section{Historie}

Während des Koreakrieges erkrankten über 3.000 amerikanische und koreanische Soldaten an einem Krankheitsbild mit hoher Letalität, das als Koreanisches Hämorrhagisches Fieber bezeichnet wurde. Erst 1978 gelang es dem Virologen Ho Wang Lee, das ätiologisch verantwortliche Virus aus dem Lungengewebe der Brandmaus Apodemus agrarius zu isolieren. Es wurde nach dem Grenzfluss zwischen Nord- und Südkorea als Hantaan-Virus bezeichnet. Das Hantaan-Virus wurde dem neugeschaffenen Genus Hantavirus in der Familie Bunyaviridae zugeordnet. Mithilfe seroepidemiologischer Studien wurde nachgewiesen, dass auch die in Nordeuropa bereits Anfang des Jahrhunderts beschriebene Nephropathia epidemica durch Hantaviren hervorgerufen wird. Analysen historischer Fallberichte machen es wahrscheinlich, dass es sich bei der im ersten Weltkrieg beschriebenen Feldnephritis um eine Infektion durch Hantaviren gehandelt hat.

Auf das Hantavirus-Lungensyndrom wurde man aufmerksam, als es im Mai 1993 in der so genannten Four-Corners-Region im Südwesten der USA zu einem zunächst unklaren Ausbruch einer akuten, rasch tödlich verlaufenden Lungenkrankheit kam. Mitarbeiter der CDC erkannten ein bis dahin unbekanntes Hantavirus als Ursache. Als Reservoirwirt konnte die
Hirschmaus (Peromyscus maniculatus) identifiziert werden.

\section{Morphologie}

Es handelt sich um sphärische, behüllte Virionen mit einem Durchmesser von ca. 90-100 nm. Die Viruspartikel enthalten drei separate Nukleokapside, die aus dem viralen Nukleokapsidprotein, jeweils einem der drei Segmente des RNS-Genoms sowie einer RNSPolymerase bestehen. In die Hülle sind zwei Glykoproteine $(\mathrm{G} 1, \mathrm{G} 2)$ integriert, die typspezifische antigene Determinanten tragen (Bunyaviren).

\section{Genom}

Hantaviren besitzen wie alle Bunyaviren ein MinusEinzelstrang-RNS-Genom, das aus drei Segmenten besteht ( $\mathrm{L}=$ Large, $\mathrm{M}=$ Middle, $\mathrm{S}=$ Small). Das $\mathrm{S}$ Segment kodiert für ein ca. $48 \mathrm{kDa}$ großes Nukleokapsidprotein und, wie für einige Hantavirus-Spezies nachgewiesen wurde, für ein Nichtstrukturprotein, das auf die Interferon-Kaskade einwirkt, das M-Segment für die beiden Glykoproteine (ca. $64 \mathrm{kDa}$ und $54 \mathrm{kDa}$ ). Das Genomprodukt des M-Segments wird als Polyprotein translatiert und bei Membrandurchtritt in die einzelnen Strukturproteine prozessiert. Das L-Segment kodiert für die virale Polymerase. Bei den Hantaviren wurde die Fähigkeit zum Austausch von Genomsegmenten zwischen serologisch eng verwandten Virusstämmen (Reassortantenbildung) sowohl in der Natur als auch in vitro nachgewiesen.

\section{Vermehrung}

Hantaviren lassen sich nur in wenigen Zelllinien (z. B. Vero E6) vermehren. Sie verursachen keine Zelllyse. Im Wirtsorganismus findet die Virusvermehrung vorwiegend in Lunge und Niere statt.

\section{Pathogenität / Virulenz / Antigenvariabilität}

Die genetischen Gruppen besitzen eine hohe Spezifität für ihre jeweiligen Nagetier- bzw. InsektenfresserWirte. Aus letzteren, nämlich Spitzmäusen und Maulwürfen, wurde ein neuer Subtyp von Hantaviren isoliert, dessen humanpathogene Bedeutung noch unklar ist. Mit den Arvicolinae (Wühlmäuse) sind die Genotypen Tula, Prospect Hill, Khabarovsk und Puumala, mit den Murinae (echte Mäuse) die Genotypen Dobrava, Hantaan, Seoul und Thailand assoziiert, während die mit dem Hantavirus-Lungensyndrom assoziierten Genotypen in den Mäusearten der neuen Welt vorkommen, die den Sigmodontinae zuzurechnen sind. Die Virulenz der Hantavirus-Genotypen für den Menschen ist sehr unterschiedlich ( $\triangleright$ Tab. 1). Neben hoch pathogenen Genotypen (Hantaan-Virus, Dobrava-Virus, Andes-Virus) gibt es solche mit geringer Pathogenität, deren klinische Manifestationen leichter sind und die nur eine geringe Letalität aufweisen (z. B.Puumala-Virus), oder die nur ein geringes Potenzial haben, Menschen überhaupt zu infizieren (z. B. Tula-Vi- 
Tab. 1. Humanpathogene Spezies des Genus Hantavirus

\begin{tabular}{|c|c|c|c|}
\hline $\begin{array}{l}\text { Genotyp/ } \\
\text { Serotyp/Spezies }\end{array}$ & Klinische Manifestation & Hauptreservoirwirt & Verbreitungsgebiet \\
\hline \multicolumn{4}{|c|}{ Humanpathogene Hantaviren der alten Welt } \\
\hline Hantaan & $\begin{array}{l}\text { HFRS, Koreanisches Hämor- } \\
\text { rhagisches Fieber (KHF) }\end{array}$ & $\begin{array}{l}\text { Apodemus agrarius (Brand- } \\
\text { maus) }\end{array}$ & $\begin{array}{l}\text { Südostasien, Südost- } \\
\text { europa }\end{array}$ \\
\hline Puumala & $\begin{array}{l}\text { HFRS, Nephropathia epi- } \\
\text { demica }\end{array}$ & Myodes glareolus (Rötelmaus) & Mittel- u. Nordeuropa \\
\hline Seoul & $\begin{array}{l}\text { HFRS, KHF, mildere Verlaufs- } \\
\text { form }\end{array}$ & $\begin{array}{l}\text { Rattus norvegicus (Wander- } \\
\text { ratte), } \\
\text { Rattus rattus (Hausratte) }\end{array}$ & weltweit \\
\hline $\begin{array}{l}\text { Dobrava(-Belgrad) } \\
\text { - Aa (Synonym: } \\
\text { Saarema) } \\
\text { - Af }\end{array}$ & HFRS & $\begin{array}{l}\text { - Apodemus agrarius (Brand- } \\
\text { maus) } \\
\text { - Apodemus flavicollis (Gelb- } \\
\text { halsmaus) }\end{array}$ & $\begin{array}{l}\text { - Mitteleuropa, } \\
\text { - Südosteuropa, Balkan }\end{array}$ \\
\hline Tula & $\begin{array}{l}\text { HFRS (geringe Pathoge- } \\
\text { nität, bisher erst ein Fall } \\
\text { beschrieben) }\end{array}$ & $\begin{array}{l}\text { Microtus arvalis (Feldmaus) } \\
\text { Microtus agrestis (Erdmaus) }\end{array}$ & Mittel- und Osteuropa \\
\hline \multicolumn{4}{|c|}{ Humanpathogene Hantaviren der neuen Welt } \\
\hline Sin Nombre & Hantavirus-Lungensyndrom & $\begin{array}{l}\text { Peromyscus maniculatus } \\
\text { (Hirschmaus), } \\
\text { Peromyscus leucopus (Weiß- } \\
\text { fußmaus) }\end{array}$ & $\begin{array}{l}\text { USA (mit Ausnahme } \\
\text { der Ostküste) }\end{array}$ \\
\hline Bayou & Hantavirus-Lungensyndrom & Oryzomys palustris (Reisratte) & USA, Ostküste \\
\hline Black Creek Canal & Hantavirus-Lungensyndrom & $\begin{array}{l}\text { Sigmodon hispidus (Baum- } \\
\text { wollratte) }\end{array}$ & USA, Südosten, Florida \\
\hline New York & Hantavirus-Lungensyndrom & $\begin{array}{l}\text { Peromyscus leucopus (Weiß- } \\
\text { fußmaus) }\end{array}$ & Kanada, USA (Ostküste) \\
\hline Andes & Hantavirus-Lungensyndrom & $\begin{array}{l}\text { Oligorizomys longicaudatus } \\
\text { (langschwänzige Zwergreis- } \\
\text { ratte), } \\
\text { Oligoryzomys sp. }\end{array}$ & $\begin{array}{l}\text { Argentinien, Chile, } \\
\text { Brasilien, Uruguay }\end{array}$ \\
\hline Laguna Negra & Hantavirus-Lungensyndrom & $\begin{array}{l}\text { Calomys laucha (Vesper- } \\
\text { maus) }\end{array}$ & $\begin{array}{l}\text { Paraguay, Argentinien, } \\
\text { Bolivien }\end{array}$ \\
\hline
\end{tabular}

rus). Die Pathogenese der Hantavirus-Infektion ist nur wenig erforscht. Bei der natürlichen Infektion weisen Hantaviren eine Organaffinität zur Lunge und Niere auf. Hantavirus-Antigen lässt sich in den Kapillarendothelien nachweisen. Auch dendritische Zellen werden durch das Virus infiziert. Auf zellulärer Ebene kommt es durch die Infektion nicht zur Lyse. Daher sind die pathologischen Veränderungen vermutlich immunvermittelt. In-vitro-Studien zeigten, dass mit Hantaviren infizierte humane Endothelzellen Interferon- $\beta$ und in der Folge HLA-Klasse-I-Antigene ex- primieren. Diese sind Zielstrukturen für zytotoxische CD8-T-Lymphozyten, die die infizierten Zellen zerstören. Die unterschiedliche Pathogenität der Genotypen kann mit einer unterschiedlich starken Induktion dieser zytotoxischen Reaktion zusammenhängen. In ähnlicher Weise wird auch die Expression des antiviralen MxA-Proteins in den infizierten Zellen durch eine Infektion mit den verschiedenen Genotypen unterschiedlich stark heraufreguliert. 


\section{Erkrankungen}

1. Hämorrhagisches Fieber mit Renalem Syndrom (HFRS)

\section{Synonym(e)}

Nephropathia epidemica, Koreanisches Hämorrhagisches Fieber.

\section{Inkubationszeit}

5-35 Tage.

\section{Leitsymptome}

Fieber, Lumbalgie, Leukozytose, Thrombopenie, Kreatininanstieg, Oligurie.

\section{Symptome}

Unter dem Begriff HFRS fasst man die durch die Genotypen Hantaan, Seoul, Puumala, Tula und Dobrava hervorgerufenen Krankheitsbilder zusammen. Der Genotyp Puumala ist der Erreger der als Nephropathia epidemica (NE) bezeichneten, meist mild verlaufenden HFRS-Variante. Die klinischen Manifestationen des HFRS beginnen meist abrupt mit hohem Fieber, das über drei bis vier Tage anhält. Unspezifische Allgemeinsymptome wie Schüttelfrost, Photophobie, Pharynxerythem, Husten und Konjunktivitis stehen zunächst im Vordergrund. Nach 3-6 Tagen haben die meisten Patienten ausgeprägte Lumbalgien, die auch unilateral auftreten und urologische Schmerzursachen vortäuschen können. Bei einem Drittel der Patienten treten abdominale Schmerzen, Nausea und Erbrechen auf. Bereits während der Fieberphase beginnt der Anstieg der Retentionswerte. Circa 4-10 Tage nach Fieberbeginn erreichen sie ihr Maximum, während die unspezifischen Allgemeinsymptome bereits wieder abgeklungen sind. Im Vordergrund der Symptomatik stehen jetzt die renalen Manifestationen. Typisch ist eine Oligurie, die sich bis zur dialysepflichtigen Niereninsuffizienz entwickeln kann. Die beim schweren HFRS im Anschluss an die Fieberphase meist auftretende hypotensive oder Schockphase fehlt in der Regel bei der Infektion durch den Genotyp Puumala. Eine polyurische Phase leitet schließlich die Rekonvaleszenz ein. Extrarenale Manifestationen des HFRS können in Form einer Begleithepatitis, Myokarditis oder ZNS-Beteiligung auftreten. Das durch Viren des Hantaan-Genotyps verursachte Erkrankungsbild, das in Südostasien als Koreanisches Hämorrhagisches Fieber bezeichnet wird, verläuft schwer. Ausgeprägte hämorrhagische Komplikationen, die letztlich die Prognose bestimmen, sind ebenso häufig ( $80 \%$ der Fälle) wie eine Beteiligung des ZNS. Die Letalität beträgt bis zu $15 \%$. Auch das durch die südosteuropäische Variante des Dobrava-Virus hervorgerufene HFRS weist eine hohe Letalität auf (bis zu $12 \%$ ). Das durch den Genotyp Puumala hervorgerufene Krankheitsbild ist gekennzeichnet durch einen milderen Verlauf. Ausgeprägte Blutungskomplikationen sind selten. Die Letalität beträgt unter $1 \%$. Nur ca. 5-10 \% der Infektionen werden klinisch manifest. Allerdings werden auch bei der Puumala-Virus-Infektion schwere Verläufe beschrieben. Auf die Möglichkeit schwerer Lungensyndrom-ähnlicher Krankheitsbilder durch Infektionen mit diesem Genotyp wurde anhand von Kasuistiken aus Deutschland hingewiesen. Nahezu alle Patienten weisen einen Kreatininanstieg auf, bei ca. der Hälfte erreicht er Werte über $6 \mathrm{mg} / \mathrm{dl}$. Fast immer ist auch eine Proteinurie vorhanden. Eine Thrombopenie lässt sich bei $50 \%$ der in Deutschland erkrankten Patienten nachweisen, nur in $19 \%$ der Fälle erreicht sie jedoch Werte unter $50.000 / \mathrm{mm}^{3}$. Bei ca. $80 \%$ der Patienten wird eine für Virusinfektionen ungewöhnliche Leukozytose beobachtet. In einem Teil der Fälle weist eine Transaminasenerhöhung auf die bestehende Begleithepatitis hin. Prädilektionsalter des HFRS ist das 20. bis 40. Lebensjahr. Männer erkranken häufiger als Frauen. Nur selten werden Erkrankungen bei Kindern beobachtet.

\section{Pathophysiologie}

Das Erkrankungsbild wird bestimmt durch das Ausmaß der Organschädigung, das vom infizierenden Virustyp, wahrscheinlich aber auch von einer genetischen Prädisposition des Infizierten abhängt. So gibt es Hinweise dafür, dass Personen mit bestimmten HLA-Haplotypen schwerer erkranken als andere. Die vaskuläre Dysfunktion aufgrund der Endothelschädigung stellt das zentrale pathophysiologische Geschehen dar. Die Thrombozytopenie, Blutungsneigung und Hypotension können als Ausdruck der Endothelschädigung verstanden werden. Mediatoren wie TNF- $\alpha$, Interleukine und Prostaglandine tragen im Gefolge der immunologischen Reaktion gegen die infizierten Zellen (s. o.) ebenfalls zur endothelialen Permeabilitätssteigerung bei. Das histomorphologische Korrelat der renalen Symptomatik ist eine akute tubulo-interstitielle Nephritis.

\section{Immunantwort}

HFRS-Patienten entwickeln schon sehr früh nach Infektionsbeginn virusspezifische Antikörper vom IgMund IgG-Typ, die hauptsächlich gegen das homologe Nukleokapsidprotein gerichtet sind. Die IgG-Antikörperantwort erreicht ihr Maximum innerhalb einiger Wochen und persistiert über viele Jahre, wahrscheinlich sogar lebenslang. Ebenso setzt bereits früh die Antikörperbildung gegen das virale Glykoprotein G1 ein. Antikörper gegen das Hüllglykoprotein G2 werden hingegen erst in der Rekonvaleszenzphase nachweisbar. Neutralisationsrelevante Epitope befinden sich auf den Glykoproteinen. Antikörper gegen das Nukleokapsidprotein schützen nicht vor Infektion, dennoch erreicht man durch Immunisierung mit Nukleokapsidproteinen gute Schutzraten über die zelluläre Immunität. Zwischen den Genotypen bestehen ausgeprägte, zum Teil aber nur unidirektionale Kreuzreakti- 
onen. Die natürliche Infektion hinterlässt eine homologe (serotypspezifische) Immunität.

\section{Differenzialdiagnose}

Das HFRS ist bei renaler Symptomatik differenzialdiagnostisch gegen nicht infektiöse Nephritiden und Glomerulonephritiden abzugrenzen, bei hämorrhagischen Manifestationen gegen andere virale hämorrhagische Fieber (Expositionsanamnese), die Leptospirose und Rickettsiosen. Liegen nur unspezifische Symptome vor, ergibt sich eine breite Palette möglicher Differenzialdiagnosen. Bei jungen Männern, die abrupt an Fieber erkranken und im Verlauf einen Kreatininanstieg entwickeln, sollte immer an die Möglichkeit eines HFRS gedacht werden.

\section{Hantavirus-Lungensyndrom (HPS)}

\section{Synonym(e)}

Hantavirus Cardiopulmonales Syndrom (HCPS).

\section{Inkubationszeit}

14-32 Tage (Mittel: 18 Tage).

\section{Leitsymptome}

Fieber, Leukozytose, Thrombopenie, interstitielles Lungenödem, respiratorische Insuffizienz.

\section{Symptome}

Beim Hantavirus-Lungensyndrom dauert die Prodromalphase nur 2-3 Tage. Danach entwickelt sich ein rasch fortschreitendes interstitielles Lungenödem, das innerhalb von Stunden in eine akute respiratorische Insuffizienz übergehen kann. Während der Prodromalphase zeigen die Patienten nur unspezifische Symptome. Fieber und Myalgien stehen dabei im Vordergrund. Bauchschmerzen, Übelkeit, Erbrechen und Diarrhoen können auftreten. Bei fast allen Patienten findet man eine typische Trias, bestehend aus einer Leukozytose $\left(20.000-30.000 / \mathrm{mm}^{3}\right)$ mit einer für virale Infektionen ungewöhnlichen Linksverschiebung, dem Auftreten atypischer blastenähnlicher Lymphozyten im Blutbild sowie einer Thrombopenie. Bei den am Hantavirus-Lungensyndrom erkrankten Patienten tritt keine Nierenbeteiligung auf. Ebenso gibt es keinen Anhalt für asymptomatische oder blande Verläufe. Die Letalität des Hantavirus-Lungensyndroms beträgt $40-50 \%$.

\section{Pathophysiologie}

Auch beim Hantavirus-Lungensyndrom steht die endotheliale Infektion durch Hantaviren im Vordergrund. Sie findet hauptsächlich lokalisiert im Kompartiment Lunge statt, wo große Mengen viralen Antigens zu finden sind. Die oben beschriebene immunologische Reaktion führt zur Konzentration zytotoxischer T-Zellen sowie von Entzündungsmediatoren in der Lunge. Durch die kapilläre Leckage kommt es zu einem massiven interstitiellen Lungenödem. Auch in den myokardialen Kapillarendothelien findet man Hantavirus-Antigen.

\section{Immunantwort}

Die humorale Immunantwort gegen die Virusantigene entspricht prinzipiell dem beim HFRS beschrieben Ablauf.

\section{Differenzialdiagnose}

Die Prodromalphase des HPS ist von der anderer Virusinfektionen meist nicht $\mathrm{zu}$ unterscheiden. Die meist bestehende Thrombozytopenie oder eine Leukozytose mit Linksverschiebung können erste spezifischere Hinweise sein. In der kardiopulmonalen Phase der Erkrankung steht das Lungenödem im Vordergrund. Ein stummer Myokardinfarkt ist differenzialdiagnostisch mithilfe eines EKG und eines Echokardiogramms auszuschließen. Ferner sind differenzialdiagnostisch auszuschließen: Leptospirose, Legionellose, Q-Fieber, Chlamydien-Pneumonie, in Endemiegebieten auch Tularämie, Pest, Coccidioidomykose und Histoplasmose. Unter den nicht infektiösen Ätiologien ist das Goodpasture-Syndrom zu berücksichtigen. Bei Immunsupprimierten ist an eine Pneumocystis-carinii-Pneumonie oder an eine Cytomegalievirus-Infektion zu denken.

\section{Diagnostik}

\section{Untersuchungsmaterial \\ Vollblut ohne Zusätze oder Serum.}

\section{Diagnostische Verfahren}

Die Diagnose der Hantavirus-Infektion wird in erster Linie durch den spezifischen Antikörpernachweis gestellt. Dafür stehen verschiedene serologische Verfahren zur Verfügung.

Indirekter Immunfluoreszenztest (IFT): Virusinfizierte Vero-E6-Zellen dienen als Antigen. Der Test ist geeignet zum Nachweis von IgG- und IgM-Antikörpern. Der IgM-IFT besitzt im Vergleich zum ELISA eine etwas geringere Sensitivität und wird rascher wieder negativ. Der IgG-IFT eignet sich auch zur Bestätigung positiver ELISA-Ergebnisse.

Enzymimmuntests (ELISA): Beschrieben wurden IgG- und IgM-ELISAs im Format klassischer indirekter Tests mit viralen Antigenen oder gentechnisch hergestelltem Nukleokapsidprotein an der Festphase. Ein hochempfindlicher IgM-Nachweis gelingt mit Hilfe des $\mu$-capture-ELISA, bei dem ebenfalls native oder gentechnisch hergestellte Hantavirus-Antigene verwendet werden können. Bereits in der frühesten Krankheitsphase reagieren die meisten Patientenseren positiv. Maximale Extinktionen werden zwischen dem 8. und 25. Tag erreicht. Nach 2-3 Monaten sind bei der Mehrzahl der Patienten keine IgM-Antikörper mehr nachweisbar.

Immunblot: Mit diesem Test können Antikörper gegen die Hantavirus-Strukturproteine, hauptsächlich 
gegen das Nukleokapsidprotein, nachgewiesen werden. Im Zweifelsfall kann der Immunblot als Bestätigungstest eingesetzt werden.

FRNT: Beim Fokusreduktionsneutralisationstest (FRNT) wird eine standardisierte Virusmenge mit dem zu untersuchenden Serum inkubiert und nach Verimpfung auf Zellkulturen die Reduktion von Foki infizierter Zellen im Vergleich zum unbehandelten Virus gemessen. Zum Nachweis der infizierten Zellen werden Immunfärbungen mit monoklonalen Antikörpern eingesetzt. Die Methode ist weitgehend genotypspezifisch.

RT-PCR: Bei der Hantavirus-Infektion kommt es in der Initialphase der Erkrankung zu einer kurz dauernden Virämie, deren Ausmaß mit der Prognose der Erkrankung korreliert. Die bisher vorliegenden Studien zeigen, dass die Sensitivität der RT-PCR aus Serum offenbar abhängig ist vom infizierenden Genotyp und somit vom Krankheitsbild. Die Sensitivität wird zwischen 40 und $90 \%$ angegeben und ist bei Patienten mit Koreanischem Hämorrhagischem Fieber am höchsten. Über den Nachweis viraler RNS im Speichel und Urin von Akutpatienten wurde berichtet. Insgesamt ist die RT-PCR für diagnostische Zwecke kaum geeignet.

\section{Befund / Interpretation}

Der IgM-Nachweis beweist eine frische oder kurz zurückliegende Infektion, ein isolierter IgG-Nachweis spricht für eine zurückliegende Infektion. In Mitteleuropa werden in der Routinediagnostik meist kommerzielle Tests eingesetzt, die Puumala- und HantaanAntigene (virusinfizierte Zellen im IFT, auch als Biochip mit mehreren Hantavirus-Typen; rekombinante Nukleokapsidproteine im ELISA oder Immunblot) verwenden. Mit dem Puumala-Antigen werden die weitaus am häufigsten vorkommenden Puumala-Infektionen, mit dem Hantaan-Antigen Infektionen durch Hantaan-Virus, aber auch mit dem hierzulande häufiger vorkommenden Dobrava-Virus erfasst, das dem Hantaan-Virus serologisch verwandt ist. Für die Diagnostik des HPS empfiehlt sich die Verwendung eines Sin-Nombre-Virus-Antigens, obwohl viele Seren auch mit dem Puumala-Virus kreuzreagieren.

\section{Therapie}

\section{Therapeutische Maßnahmen}

Das HFRS wird in erster Linie symptomatisch behandelt. Bei schweren HFRS-Fällen erwies sich die frühzeitige antivirale Chemotherapie mit Ribavirin als erfolgreich, für das Hantavirus-Lungensyndrom fehlt bisher der Nachweis der Wirksamkeit.

\section{Resistenz}

Hantaviren sind in vitro gegenüber Ribavirin empfindlich. Andere wirksame Virostatika sind nicht bekannt.

\section{Epidemiologie}

\section{Verbreitung}

Hantaviren sind weltweit verbreitet. Generell werden die in der Alten Welt vorkommenden Viren, von den in der Neuen Welt endemischen unterschieden ( $\triangleright$ Abb. 1).

Alte-Welt-Viren: Im gesamten südostasiatischen Raum sowie im östlichen Russland herrscht der Hantaan-Genotyp vor. In Zentral- und Nordeuropa ist der Genotyp Puumala endemisch. Sein Hauptreservoirwirt ist die Rötelmaus (Myodes glareolus), Puumala-Virus-ähnliche Viren wurden in nahe verwandten Mäusearten (Myodes rutilus, Microtus fortis) nachgewiesen. Der Genotyp Dobrava kommt auf dem Balkan vor und koexistiert dort mit dem Genotyp Puumala. Allerdings wurde in den letzten Jahren festgestellt, dass eine mitteleuropäische Variante des Dobrava-Virus existiert (mit dem Zusatz Aa bezeichnet), die mit Apodemus agrarius als Reservoirwirt assoziiert ist. In Deutschland kommt sie vorwiegend im Norden und Osten vor. Der Seoul-Genotyp wurde weltweit in Rattenpopulationen nachgewiesen. Die Pathogenität des Seoul-Virus ist umstritten, aber es gibt Berichte über Seoul-Virus-assoziiertes HFRS.

Neue Welt-Viren: Hauptreservoirwirt des Sin-Nombre-Virus ist Peromyscus maniculatus (Hirschmaus), die mit Ausnahme der Ostküste nahezu auf dem gesamten Gebiet der Vereinigten Staaten vorkommt.

Jüngst wurden erstmals auch auf dem afrikanischen Kontinent einheimische Hantaviren nachgewiesen. In der afrikanischen Waldmaus (Hylomyscus simus) wurden Gensequenzen einer neuen Hantavirus-Spezies (Sangassou-Virus) gefunden, die bisher nicht mit Erkrankungen beim Menschen assoziiert wurde. Weltweit beträgt die Inzidenz der Hantavirus-Infektionen bis zu 200.000 Fälle jährlich. Allein in China werden pro Jahr bis zu 150.000 Fälle beobachtet. Jeweils bis zu 2.000 Fälle treten jährlich in Korea und anderen südostasiatischen Ländern auf; in Russland sind es über 10.000. Jeweils einige Hundert klinisch manifeste Erkrankungen können in Zentral-, Nord- und Südeuropa erwartet werden. Die durchschnittliche Antikörperprävalenz in Deutschland liegt nach älteren Seroprävalenzstudien bei $1,7 \%$, nach neueren bei $1 \%$ und reicht von 0,8-3,1\%. Seit der Einführung der Meldepflicht im Jahr 2001 sind bis zum 19.05.2010 dem RKI insgesamt 3.845 klinisch-labordiagnostisch bestätigte Hantavirus-Infektionen übermittelt worden. In drei Viertel der Fälle handelte es sich um Männer. Bei fast 90 \% der Fälle wurde Puumala-Virus als ursächlicher Erreger angegeben. Bei zwischen 1 bis $2 \%$ der Fälle diagnostizierten die Labore Infektionen mit dem Dobrava-Virus. Deutliche Häufungen wurden in den Jahren 2005 und 2007 mit 447 bzw. 1683 gemeldeten Hantavirus-Infektionen beobachtet. Im Jahr 2010 wurden sogar 2000 Fälle gemeldet, was deutlich über der Inzidenz aller bisherigen Meldejahre liegt.

Fälle von Hantavirus-Lungensyndrom wurden aus 


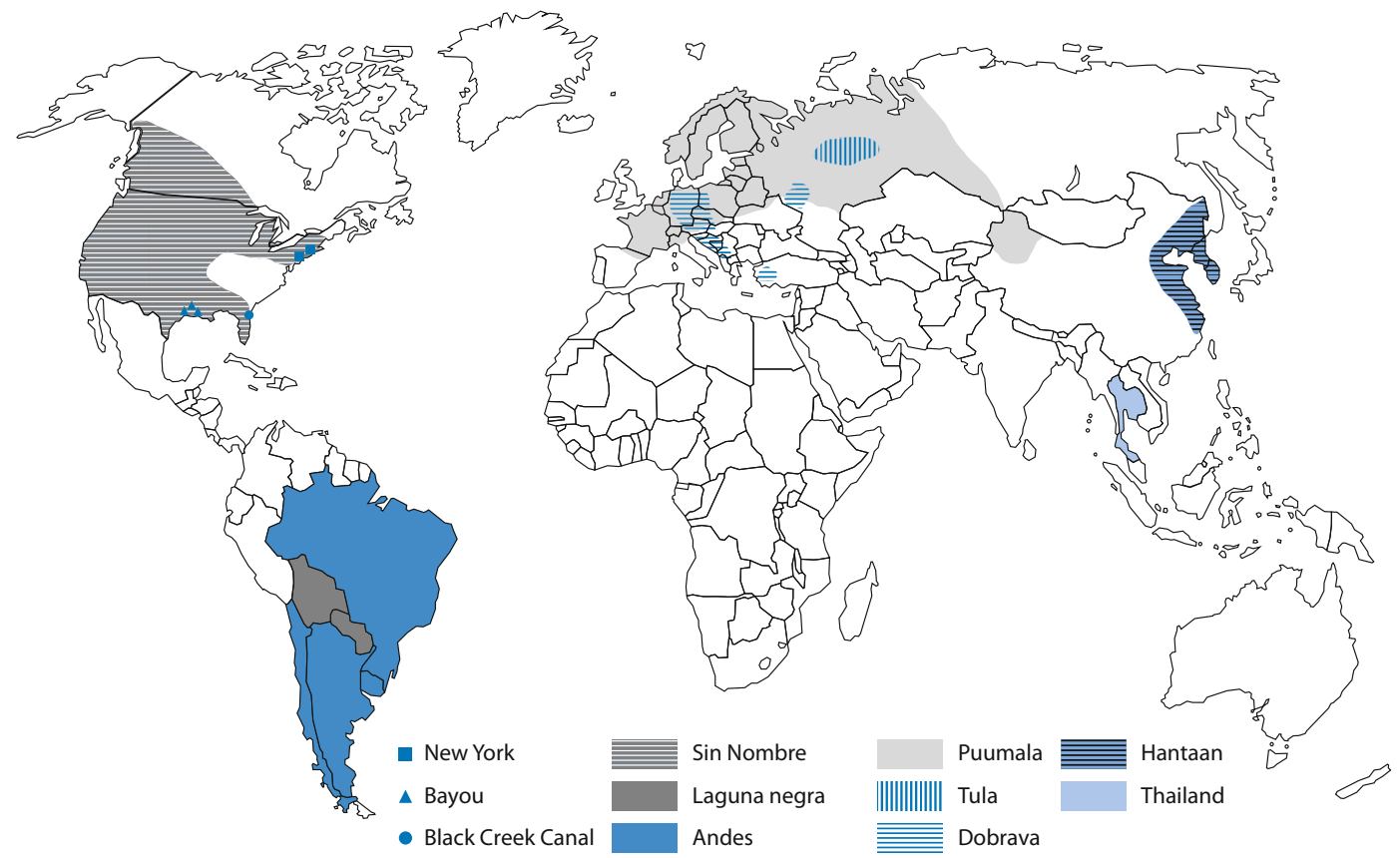

- Abb. 1. Verbreitungsgebiet der Hantaviren (nach Genotypen)

den USA, Kanada, Brasilien, Argentinien, Chile, Bolivien, Paraguay und Uruguay berichtet, sodass man davon ausgehen kann, dass Neuwelt-Hantaviren auf dem gesamten Kontinent endemisch sind.

\section{Wirtsbereich / Reservoir}

Reservoirwirte sind verschiedene Nagetiere und Insektenfresser, wobei die Assoziation zwischen Virus und Wirtsspezies zumeist genotypspezifisch ist $(\triangleright$ Tab. 1$)$.

\section{Risikogruppen}

Ein erhöhtes Erkrankungsrisiko ergibt sich aus vermehrter Exposition gegenüber den Reservoirwirten. Bei Waldarbeitern, Gestütsarbeitern, Soldaten, in der Landwirtschaft Beschäftigten u. a. wurde eine Antikörperprävalenz von bis zu $26 \%$ gefunden. Bei Soldaten wurden immer wieder Ausbrüche von HantavirusInfektionen beschrieben. In Deutschland existieren Endemiegebiete (Schwäbische Alb, Münsterland, Landkreis Osnabrück, Unterfranken, Spessart, Landkreis Würzburg, Odenwald, Nordbaden, Oberschwaben, Fränkische Alb und Bayerischer Wald). Hantaviren werden überdies als potenzielle Biokampfstoffe angesehen.

\section{Transmission / Vektoren}

Hantaviren induzieren in den Nagetierspezies persistierende Infektionen, wobei die Tiere selbst nicht erkranken und die Erreger in Speichel, Urin und Fäzes ausscheiden. Die Übertragung auf den Menschen erfolgt durch Aerosole, kontaminierten Staub oder direkten Kontakt mit den Ausscheidungen der Nager, wobei die Atemwege offenbar als Eintrittspforte fungieren. In proteinhaltigem Material getrocknet bleiben Hantaviren tagelang infektiös. Eine Übertragung von Mensch zu Mensch wurde bei südamerikanischen Hantaviren mehrfach beschrieben.

\section{Prävention / Impfstoffe}

Ein Totimpfstoff aus inaktivierten Virionen gegen den Hantaan-Genotyp (Hantavax) ist seit 1990 in Korea zugelassen. Rund 10 Millionen Dosen wurden bisher verabreicht. Obwohl in Studien gezeigt wurde, dass seit Einführung der Vakzine die Zahl der HFRS-Fälle drastisch zurückgegangen ist, gibt es bezüglich der protektiven Wirksamkeit keine ausreichende Datenlage. In einer Fallkontrollstudie wurde eine Schutzrate von $75 \%$ nach drei Dosen festgestellt. In-vitro-Daten weisen jedoch auf einen raschen Abfall der schützenden Antikörper hin. Neue Impfstoffe auf der Basis rekombinanter Hantavirus-Proteine oder von DNAVakzinen befinden sich noch am Anfang der Entwicklung.

\section{Ausbruchsmanagement}

Das Risiko einer Hantavirus-Infektion kann nur durch Vermeidung der Exposition gegenüber den Reservoirwirten gemindert werden. Nahrungsmittel sollten für Nager unzugänglich aufbewahrt werden. Nagetier-in- 
festierte Örtlichkeiten sollten vor Säuberung mit Desinfektionsmitteln behandelt werden. Bei Ausbrüchen durch hochpathogene Hantaviren sollten bei der Beseitigung von Nagetierbefall als potenzieller Infektionsquelle Schutzanzüge und Atemmasken getragen werden.

\section{Meldepflicht}

Der Nachweis einer Hantavirus-Infektion ist nach $\$ 7$ Abs. 1 Infektionsschutzgesetz durch das Labor namentlich zu melden.

\section{Weiterführende Informationen}

\section{Referenzzentren / Expertenlaboratorien}

Konsiliarlaboratorium für Hantaviren:

- Institut für Medizinische Virologie, Charité-Universitätsmedizin Berlin, Campus Charité Mitte, Helmut Ruska Haus, 10098 Berlin, Ansprechpartner: Herr Prof. Dr. D.H. Krüger, Tel.: 030.450-52 50 92, Fax: 030.450-52 59 07; EMail: detlev.kruger@charite.de

Leistungsübersicht:

- Antikörpernachweis bei Hantavirusinfektion einschließlich serologischer Bestätigungstests (IgM ELISA, IgG ELISA, IFT, Westernblot)

- Fokusreduktionsneutralisationstest zur Typisierung des Erregers (Genotypen Dobrava, Puumala, Hantaan, Seoul, Tula);

- Genomnachweis durch RT-PCR für Hantaviren allgemein (genusspezifisch) sowie für die einzelnen Virustypen (speziesspezifisch), Sequenzanalysen

- Voraussetzungen zur Virusanzucht vorhanden

\section{Web-Adressen}

- Centers for Disease Control and Prevention: http://www. cdc.gov

- Robert-Koch-Institut: http://www.rki.de/DE/Content/ InfAZ/H/Hantavirus/Merkblatt.html

- Merkblatt zur Vermeidung von Hantavirus-Infektionen:

- http://www.charite.de/virologie/hantapraev.pdf,

\section{Schlüsselliteratur}

1. Braun N, Haap M, Overkamp D, Kimmel M, Alscher MD, Lehnert H, Haas CS (2010) Characterization and outcome following Puumala virus infection: a retrospective analysis of 75 cases. Nephrol Dial Transplant. 25(9):29973003

2. Jonsson CB, Figueiredo LT, Vapalahti O (2010) A global perspective on hantavirus ecology, epidemiology, and disease. Clin Microbiol Rev 23(2):412-41

3. Krautkrämer E, Zeier M (2008) Zunehmende Verbreitung der Nephropathia epidemica in Deutschland.Dtsch Med Wochenschr 133(10):476-478

4. Krüger DH, Klempa B (2009) Von der Maus zum Menschen: Gefahren durch Hantaviren. Berl Munch Tierarztl Wochenschr 122(11-12):434-439

5. Schönrich G, Rang A, Lütteke N, Raftery MJ, Charbonnel N, Ulrich RG (2008) Hantavirus-induced immunity in rodent reservoirs and humans. Immunol Rev 225:163189

6. Ulrich RG, Schmidt-Chanasit J, Schlegel M, Jacob J, Pelz HJ, Mertens M, Wenk M, Büchner T, Masur D, Sevke K, Groschup MH, Gerstengarbe FW, Pfeffer M, Oehme R,
Wegener W, Bemmann M, Ohlmeyer L, Wolf R, Zoller H, Koch J, Brockmann S, Heckel G, Essbauer SS (2008) Network „Rodent-borne pathogens“ in Germany: longitudinal studies on the geographical distribution and prevalence of hantavirus infections. Parasitol Res 103 Suppl 1, S 121-129

\section{Hantavirus Cardiopulmonales Syndrom (HCPS)}

$>$ Hantaviren

\section{Hantavirus-Lungensyndrom (HPS)}

\section{Hantaviren}

\section{Harnwegsinfektion}

- Acinetobacter

- Burkholderia, Ralstonia

- Campylobacter

- Citrobacter

- Corynebakterien, sonstige

- Enterobacter

- Enterokokken

- Escherichia coli

- Flavobacterium

- Fusobacterium

- Hafnia

- Klebsiella

- Mikrosporidien

- Proteus mirabilis, Proteus vulgaris

- Providencia, Morganella

- Pseudomonas

- Serratia

- Staphylococcus (koagulasenegativ)

- Stenotrophomonas

- Streptococcus agalactiae

\section{Harnwegsinfektionen}

\section{Definition}

Martin ZeIER

Harnwegsinfektionen sind bakterielle Infektionen des Harntraktes mit oder ohne systemische Begleitreaktion. Sie entwickeln sich in der Regel aufsteigend über die Urethra, Blase und Ureter bis zu den Nieren. Je nach Lokalisation des Infektes wird zwischen unteren Harnwegsinfektionen (Zystitis und Urethritis) und oberen Harnwegsinfektionen (Pyelonephritis) differenziert. Darüber hinaus ist zwischen einer akuten und einer chronischen Verlaufsform zu unterscheiden. Eine Generalisierung des Infektes (Urosepsis) ist möglich. 


\section{Erregerspektrum}

Das Erregerspektrum umfasst hauptsächlich Keime der Darmflora. In mehr als 95\% der Fälle treten sie als Monoinfektion auf.

Ambulant erworbenen Harnwegsinfektionen werden in den meisten Fällen durch gramnegative aerobe Bakterien hervorgerufen. Mit 60-80 \% dominiert Escherichia coli, gefolgt von Staphylococcus saprophyticus, Klebsiella pneumoniae, Proteus mirabilis und Streptococcus faecalis.

Sind die Harnwegsinfektionen nosokomial erworben, gehen sie in 30-40 \% der Fälle auf Escherichia coli zurück. Daneben spielen vor allem Enterococcus spp. und Pseudomonas aeruginosa eine Rolle. Seltener werden Proteus, Enterobacter spp. und Citrobacter spp. sowie Staphylococus aureus nachgewiesen. Ein häufiger Befund im stationären Bereich ist Candida spp. im Urin. Auf Intensivstationen dominieren Harnwegsinfektionen durch Escherichia coli, Enterococus spp. und Candida spp.

$\mathrm{Zu}$ den selteneren Erregern von Harnwegsinfektionen zählen hingegen Chlamydien, Mykoplasmen, Mykobakterien, Trichomonas vaginalis, Gadnerella vaginalis und Haemophilus influencae. Gelegentlich sind Harnwegsinfektionen die Folge einer Virusinfektion. Das Erregerspektrum umfasst hier z. B. Herpes-simplex-Virus, Adenoviren Cytomegalieviren und Polyomaviren. Bei Nierentransplantierten setzt sich das Erregerspektrum bis 5 Wochen nach der Transplantation hauptsächlich aus Pseudomonas aeroginosa, Koagulase-negativen Staphylokokken und Enterobacter cloacae zusammen. Danach überwiegen gramnegative Erreger, insbesondere Escherichia coli.

\section{Epidemiologie}

Harnwegsinfektionen zählen zu den häufigsten zu Behandlungen führenden Erkrankungen sowohl im ambulanten als auch nosokomial erworbenen Bereich. Sie sind zwar gut therapierbar, haben jedoch die Tendenz zur Rekurrenz. Damit sind Harnwegsinfektionen eine wichtige Ursache für Nierenschäden und das Auftreten einer gram-negativen Sepsis. Auch sind sie mit erhöhter Morbidität und Mortalität assoziiert.

Frauen sind aufgrund der kurzen Urethra wesentlich häufiger von Harnwegsinfekten betroffen als Männer. Weiterhin nimmt die Zahl der Harnwegsinfektionen mit dem Lebensalter kontinuierlich zu.

Die akute, unkomplizierte und ambulant erworbene Harnwegsinfektion bei jungen Frauen stellt das häufigste Krankheitsbild dar. Zu den Risikofaktoren zählen Sexualverkehr und vorangegangene Blaseninfektionen. Insbesondere während der Schwangerschaft treten Harnwegsinfekte unter den hormonellen Gewebeveränderungen auf. Unbehandelt entwickeln 3040 \% dieser Frauen eine Pyelonephritis. In der Postmenopause steigt bei Frauen die Inzidenz von Harnwegsinfektionen. Unter der signifikant reduzierten Östrogenproduktion kommt es zu vaginalen Mili- euänderungen, welche die Besiedlung mit Enterobacteriaceae und Aerobiern befördern.

Bei Männern verlaufen Harnwegsinfektionen meistens mit Prostatabeteiligung unter Anstieg des prostataspezifischen Antigens und einer Prostataschwellung. Die Inzidenz nimmt mit dem Lebensalter zu.

Grundsätzlich begünstigen Obstruktionen, die eine Harnstauung zur Folge haben, die Entwicklung von Harnwegsinfektionen. Hierzu zählen Harnabflussstörungen oder Blasenentleerungstörungen $z$. B. infolge von Missbildungen, Steinen, Strikturen oder auch Tumoren. Auch neurogene Blasenentleerungsstörungen können ursächlich sein.

Dauerkatheter sind die Hauptursache nosokomial erworbener Harnwegsinfektionen. Zur Keimbesiedlung kommt es entweder durch Keimeinschleusen beim Einbringen des Katheters oder durch Aszension von Keimen durch das Katheterlumen bzw. zwischen Katheter- und Urethralwand. Die Inzidenz nimmt bei transurethralem Dauerkatheter auch bei geschlossenen Systemen pro Tag um 5-10 \% zu. Auch technische Komplikationen während Ureter-Anastomosen begünstigen die Etablierung von Harnweginfektionen. Bei intensivpflichtigen Patienten ist in $10 \%$ der Fälle eine Bakteriurie mehr als 48 Stunden nach der stationären Aufnahme nachweisbar. Hauptrisikofaktoren bei intensivpflichtigen Patienten sind das weibliche Geschlecht, die Dauer der Intensivbehandlung, die Schwere der Erkrankung und die Dauer der antimikrobiellen Therapie.

Des Weiteren stellen Vorerkrankungen wie der Diabetes mellitus und Zystennieren, Risikofaktoren für die Entwicklung von Harnwegsinfektionen dar. Nierentransplantierte Patienten, vor allem bei vorliegender Verstorbenenspende, sind mit einer Infektionsrate von nahezu $80 \%$ von Harnwegsinfektionen betroffen. Sie machen $50 \%$ aller infektiösen Komplikationen nach Nierentransplantation aus, wobei $74 \%$ im ersten Jahr nach Transplantation diagnostiziert werden. Risikofaktoren sind weibliches Geschlecht, höheres Lebensalter, gehäufte Harnwegsinfekte vor Transplantation, immunsuppressive Therapie, eine akute Abstoßung, einliegender Blasenkatheter, technische Komplikationen während der Ureter-Anastomose, Diabetes mellitus, Reflux in die Eigennieren.

\section{Beschreibung der Krankheitsbilder}

Der unkomplizierte Harnwegsinfekt ohne Fieber manifestiert sich bei einer Zystitis mit Dysurie, Pollakisurie und Algurie. Dazu kann ein lokaler Schmerz über dem mittleren Unterbauch bestehen, zusätzlich Leukozyturie und eventuell Hämaturie.

Der komplizierte Harnwegsinfekt verläuft schwerer mit Fieber und Schüttelfrost. Bei der Pyelonephritis sind die Nieren mit betroffen und es besteht eine einoder beidseitige Flankenschmerzsymptomatik, CRPErhöhung, Leukozyturie, eventuell Hämaturie, Proteinurie, Leukozytose. 
Als Komplikation kann eine Urosepsis mit Tachykardie, Hypotonie und Bewusstseinstrübung auftreten. Eine chronische Pyelonephritis führt zur Vernarbung des Parenchyms, zur Papillenschädigung mit tubulointerstitieller Atrophie und zur Schrumpfniere mit Hypertonie. Bei 2-3 \% der Fälle endet dies nach Jahren mit chronischem Nierenversagen, das zur Dialysepflichtigkeit führt oder eine Nierentransplantation notwendig macht.

\section{Zielorgan(e) und Immunreaktion}

Zielorgane sind Urethra, Blase, Ureter und Niere.

Bei der Immunabwehr spielen lokale Immunmechanismen der Mukosa, die Bildung von sekretorischem Immunglobulin A und die Anwesenheit von TammHorsfall-Protein (THP) eine Rolle. THP bindet uropathogene Erreger und bewirkt so die Ausscheidung mit dem Urin. Bei Kindern, älteren Frauen und Diabetikern ist die THP-Ausscheidung vermindert.

\section{Pathophysiologie/Molekulare Basis der Organschäden}

Ein wichtiger Faktor in der Pathogenese rezidivierender Harnweginfekte ist die Abwesenheit von TollLike-Rezeptoren (TLR). Toll-Like-Rezeptoren sind Teil des innaten Immunsystems. Diese sowohl auf epithelialen als auch nicht-epithelialen Zellen lokalisierte Faktoren erkennen Pathogene und aktivieren das innate Immunsystem sowie inflammatorische Prozesse. Insbesondere der TLR-4 wird mit Harnwegsinfektionen in Verbindung gebracht. Experimentelle Untersuchungen deuten daraufhin, dass dysregulierte TRL bzw. die Defizienz von TRL für chronisch rezidivierende Verläufe von Harnwegsinfektionen verantwortlich sind.

\section{Diagnostische Maßnahmen}

Neben der klinischen Symptomatik stehen als labordiagnostische Verfahren Teststreifen, Urinsediment und Urinkultur zur Verfügung.

Der Urinstatus kann mittels Teststreifen erhoben werden. Das Teststäbchen wird in den Urin getaucht und erlaubt den relativ genauen Nachweis von Leukozyten, Erythrozyten und Protein im Urin. Der Nachweis von Nitrit im Urin ist ein wichtiger Hinweis auf Bakterien, jedoch können nicht alle Bakterien Nitrat zu Nitrit reduzieren. Der Nachweis mit dem Uricult sollte aus Mittelstrahlurin, am besten Morgenurin bzw. Urin mit einer Verweildauer von mindestens 3 Stunden in der Blase geführt werden. Bei Patienten mit Dauerkatheter wird Katheterurin entnommen. Signifikant ist der Nachweis einer Keimzahl $>10^{5} / \mathrm{ml}$. Keimzahlen $10^{4}$, insbesondere bei Mischinfektionen sprechen für eine Kontamination. Keimzahlen zwischen $10^{5}$ und $10^{4} / \mathrm{ml}$ sollten kontrolliert werden. In Urinproben ohne ausreichend lange Verweildauer in der Blase, Katheterurin/Blasenpunktionsurin oder bei chronischer Pyelo- nephritis sind auch niedrigere Keimzahlen signifikant.

Bei Risikopatienten, bei komplizierten Harnwegsinfektionen sowie bei unklarer Symptomatik sollte eine Urinkultur angelegt werden. Diese erlaubt die Keimidentifizierung, die Bestimmung der Zahl kolonienbildender Einheiten pro ml Urin sowie eine Aussage zum Resistenzspektrum des Keims. Anhand des Keimspektrums kann das für die Therapie geeignete Antibiotikum festgelegt werden.

Bei Verdacht auf eine Pyelonephritis sollte darüber hinaus eine Sonografie der Niere durchgeführt werden. Bei ambulant erworbenen unkomplizierten Harnwegsinfektionen ist ein Erregernachweis nicht in jedem Fall notwendig. Bei fieberhafter Begleitreaktion sollte auch eine Blutkultur angelegt werden, um eine Urosepsis auszuschließen.

Liegen chronisch-rezidivierende Harnwegsinfektionen vor, ist die bildgebende Diagnostik (Sonographie, CT, MRT) hinzuzuziehen. Auch eine weitere urologische Diagnostik kann weiterhelfen.

\section{Therapie und Prävention}

Die asymptomatische Bakteriurie sollte in der Schwangerschaft behandelt werden. Eine relative Behandlungsindikation besteht auch bei Diabetikern und immunsupprimierten Patienten.

Für die Behandlung akuter unkomplizierter unterer Harnwegsinfektionen sind die empfohlenen Antibiotika Trimethoprim oder Chinolone. Darüber hinaus kommen Penicilline und Cephalosporine in Betracht. Die Behandlungsdauer der symptomatischen Harnweginfektion sollte mindestens 3 Tage umfassen, häufig ist eine Behandlung von 5 bis 7 Tagen notwendig. Der Behandlungserfolg steigt mit der Behandlungsdauer, wobei der größte Unterschied bei einer Dauer von 3 bis 5 Tagen liegt. Des Weiteren ist unbedingt darauf zu achten, dass Harnabflussstörungen mittels bildgebender Diagnostik ausgeschlossen sind.

Für die Harnwegsinfektbehandlung bei Schwangeren wird die Gabe von Penicillinen und Cephalosporinen empfohlen.

Akute unkomplizierte obere Harnwegsinfektionen können nach vorangegangener Keimbestimmung und Resistenztest ambulant durch eine orale antibiotische Therapie behandelt werden. Als Therapiedauer werden 7-14 Tage empfohlen. Bei ausgeprägter Symptomatik ist die stationäre Aufnahme mit zunächst parenteraler Behandlung angezeigt.

Komplizierten Harnwegsinfektionen liegt häufig eine urologische Grunderkrankung mit Harnabflussstörungen zugrunde, die beseitigt werden muss. Die Antibiotikatherapie erfolgt entsprechend der Keimbestimmung und dem Ergebnis der Resistenzbestimmung mit den bekannten Medikamenten.

Zur Vermeidung von Harnwegsinfektionen sollten im stationären Bereich nach Möglichkeit transurethrale Dauerkatheter vermieden werden, alternativ eine in- 
termittierende Katheterisierung oder ein suprapubischer Blasenkatheter den Vorzug gegeben werden. Beim Legen der Katheter ist größter Wert auf sterile Bedingungen zu legen.

Der Einsatz von Uro-Vaxom ${ }^{\circledR}$ E.-coli-Extrakt (OM89) reduziert signifikant das Harnweginfekt-Rezidiv. Bei Frauen schützt die Absenkung des vaginalen $\mathrm{pH}$ Wertes unter pH5 ebenfalls vor Harnwegsinfektionen. Auch die intravaginale Applikation von Lactobacillus einmal pro Woche für die Dauer eines Jahres reduziert die Harnweginfekt-Häufigkeit um 80 \%.

Grundsätzlich ist zur Rezidivprophylaxe auf eine ausreichende Trinkmenge von ca. 2 1/Tag zu achten, sofern es hierfür keine Kontraindikation gibt. Auch sollte der Harndrang nicht unterdrückt und die Blase vollständige und regelmäßige entleert werden, insbesondere nach Geschlechtsverkehr. Zur Aufrechterhaltung der körpereigenen Vaginalflora ist jedoch von einer übertriebenen Genitalhygiene abzuraten.

\section{Schlüsselliteratur}

1. Girndt M, Wandel E, Köhler H (2006) In: Lehnert H, Werdan K (Hrsg) Nephrologie und Hochdruck. Innere Medizin. essentials, 4. Auflage Stuttgart 2006

2. Heisig, P (2010) Urinary tract infections and antibiotic resistance: Urologe 49: 612-617

3. Schmiemann G, Kniehl E, Gebhard K, Matejczyk MM, Hummers-Pradier E (2010) The diagnosis of urinary tract infection: a systematic review. Dtsch Ärztebl Int 107:361-367

4. Stein, G, Fünfstück, R (2008) Medikamentöse Therapie von Harnwegsinfekten. Internist 48:747-755

\section{Wichtige Webseiten und Links}

- http://www.harnwegsinfekt.de

- http://www.urologielehrbuch.de

- http://www.p-e-g.org/econtext/leitlinien

\section{Hautabszess}

- Bacteroides

- Bilophila

\section{Hautmilzbrand}

Bacillus anthracis

\section{Haverhill-Fieber}

- Streptobacillus

\section{Helicobacter pylori}

\section{Erreger}

\section{Synonym(e)}

Vor 1989: Campylobacter pyloridis, C. pylori.

\section{Erregerspezies}

Campylobacter pylori

\section{Taxonomie}

Familie: Helicobacteraceae; Gattung (Genus): Helicobacter

Weitere Spezies in dieser Gattung u. a.: H. mustelae (Frettchen), H. felis (Katzen, Hunde), H. heilmannii (Mensch) sowie die so genannten enterohepatischen Helicobacterarten (z. B. H. hepaticus, H. bilis), die im Darm und in der Leber verschiedener Tiere gefunden werden und Hepatitis und Leberkarzinome auslösen können.

\section{Historie}

Die Gegenwart spiralförmiger Bakterien in der Magenschleimhaut wurde erstmals Ende des 19. Jahrhunderts (Bizzozero 1893) beschrieben und in jahrzehntelangen Abständen mehrfach wieder beobachtet. Diese Beobachtungen wurden jedoch auf Kontaminationen zurückgeführt und nicht weiter beachtet. 1983 gelang es den Australiern Robin Warren und Barry Marshall durch Anwendung mikroaerophiler Kulturbedingungen aus endoskopisch gewonnenen Magenbiopsien spiralförmige gramnegative Bakterien anzuzüchten, die sie zunächst als Campylobacter pyloridis bezeichneten. Da dieser Name gegen die Regeln der lateinischen Grammatik verstieß, wurden die Bakterien wenig später in Campylobacter pylori umbenannt. Detailliertere taxonomische Untersuchungen zeigten dann, dass der Erreger gravierende Unterschiede zu Campylobacter sp. aufwies, sodass er 1989 in die neue Gattung Helicobacter überführt wurde. H. pylori wurde 1994 offiziell als definitives Karzinogen eingestuft. Warren und Marshall erhielten 2005 den Medizinnobelpreis für ihre Entdeckung von H. pylori.

\section{Morphologie}

Spiralförmige oder einfach gebogene Stäbchen mit 5-6 unipolar angeordneten und von einer Membranhülle umgebenen Geißeln.

\section{Genom}

Die Genomsequenzen von drei $H$.-pylori-Stämmen (26695, J99 und HPAG1) sind komplett entschlüsselt worden. Die Genome bestehen aus ca. 1,6 Mio. Basenpaaren und enthalten ca. 1.500 Gene. Neunzig Prozent der DNA kodieren für Proteine. Der GC-Gehalt des Genoms beträgt $39 \%$. Aufgrund von vergleichenden Genomhybridisierungen mit zahlreichen $H$.-pyloriStämmen umfasst das Kerngenom von $H$. pylori 1.111 Gene, die in allen Stämmen vorhanden sind. Jeder Stamm enthält zusätzlich ca. 400 Gene aus einem Pool von variablen Genen. Viele dieser variablen Gene sind in zwei hochvariablen Bereichen des Chromosoms lokalisiert, die als Plastizitätszonen bezeichnet werden. Etwa 50 \% der Stämme tragen Plasmide, deren Funktion nicht bekannt ist. H. pylori ist in der Lage, DNA 
aus der Umgebung aufzunehmen (natürliche Kompetenz). Die Fähigkeit zum effizienten DNA-Austausch (Rekombination) bei Vorliegen einer Mischinfektion mit mehreren H.-pylori-Stämmen ist die Hauptursache für die extrem hohe genetische Diversität bei verschiedenen $H$.-pylori-Isolaten.

\section{Vermehrung}

$H$. pylori ist ein langsam wachsendes anspruchsvolles Bakterium. Im Labor werden zur Koloniebildung auf komplexen Nährmedien 2-3 Tage benötigt. Die Generationszeit und Vermehrungsgeschwindigkeit in vivo sind nicht bekannt. Da die akute H.-pylori-Infektion in der Regel nicht diagnostiziert wird und der Moment der Infektion nicht genau bekannt ist, sind Inkubationszeiten für die verschiedenen H.-pylori-assoziierten Erkrankungen nicht bekannt. Aus Versuchen an Freiwilligen weiß man, dass eine akute Infektion bei Erwachsenen regelmäßig nach wenigen Tagen dyspeptische Symptome auslöst, die nach 9-12 Tagen ihren Höhepunkt erreichen.

\section{Pathogenität / Virulenz / Antigenvariabilität}

$H$. pylori besiedelt im Körper eine ökologische Nische, die für praktisch alle anderen Bakterien nicht zugänglich ist. Zahlreiche Eigenschaften des Erregers können als spezifische Anpassungen an das Leben in diesem Habitat und damit als Pathogenitätsfaktoren angesehen werden.

Urease: Alle H.-pylori-Isolate bilden das Enzym Urease in großen Mengen. Durch Spaltung von Harnstoff werden Ammoniak und Kohlendioxid freigesetzt. Es wird angenommen, dass so die Mikroumgebung des Bakteriums neutralisiert wird und sich der Erreger während des Aufenthalts im Magenlumen vor der Säure schützt. Außerdem ermöglicht es die Urease H. pylori, Harnstoff als Stickstoffquelle für seine Aminosäuresynthese zu nutzen. Tierexperimente mit Urease-negativen Mutanten haben gezeigt, dass Urease ein für die Pathogenität des Bakteriums essenzieller Faktor ist.

Beweglichkeit: $H$. pylori ist ein stark bewegliches Bakterium. Charakteristisch ist, dass die Beweglichkeit auch unter Bedingungen erhöhter Viskosität erhalten bleibt. Das Bakterium verdankt die Beweglichkeit einem Bündel von Geißeln (Flagellen), die an einem Pol der Zelle entspringen. Jede Geißel ist von einer Membranhülle umgeben, die das Flagellenfilament vor der Desintegration durch Säure schützt. Auch die Beweglichkeit ist für H. pylori ein essenzieller Pathogenitätsfaktor. H. pylori orientiert sich in der Schleimschicht des Magens durch Chemotaxis und nutzt hierfür den $\mathrm{pH}-$ Gradienten im Magenschleim aus.

Adhärenz: H. pylori adhäriert stark an die Zellen des Magenepithels. Die am besten charakterisierten Adhäsine sind die Außenmembranproteine BabA und SabA, die die Bindung an die Blutgruppenantigene Lewis $\mathrm{b}$ und Sialyl-Lewis $\mathrm{x}$ vermitteln. Die Bedeutung von Adhärenz für die Infektion ist noch nicht eindeutig bewiesen.

Zytotoxin (VacA): Etwa die Hälfte aller H.-pyloriStämme bildet ein Zytotoxin (vakuolisierendes Zytotoxin, VacA-Toxin). Gereinigtes Toxin kann im Tiermodell Magenschleimhautulzerationen induzieren und vacA-Mutanten haben in Tiermodellen einen moderaten Fitnessdefekt. Das Toxin wird als ein wichtiger Virulenzfaktor des Erregers angesehen. Das Toxin hat in Zellkultursystemen multiple Effekte wie die Störung der Auslösung von Apoptose durch Freisetzung von Cytochrom C aus Mitochondrien, die Hemmung der Proliferation von T-Zellen, die Auslösung von Signaltransduktionsprozessen und die Bildung anionenselektiver Kanäle in der Endosomenmembran. Die Tatsache, dass sich H.-pylori-Stämme in ihrer Fähigkeit zur Toxinbildung unterscheiden, könnte eine der bakteriellen Ursachen für die unterschiedlichen klinischen Verläufe der H.-pylori-Infektion bei verschiedenen Patienten sein.

cag-Pathogenitätsinsel: Die Induktion der Bildung des potenten Zytokins Interleukin-8 spielt eine Schlüsselrolle in der Pathogenese der H.-pylori-Gastritis. H.pylori-Stämme unterscheiden sich erheblich in ihrer Fähigkeit, die Bildung von IL-8 zu induzieren.

An dieser Induktion ist eine Gruppe von 29 Genen beteiligt, die auf einer so genannten Pathogenitätsinsel (cag-Pathogenitätsinsel) lokalisiert sind. Die Gene erlauben $H$. pylori wahrscheinlich, einen so genannten Typ-IV-Sekretionsapparat zu bilden, mit dem die Bakterien das CagA-Protein in die Magenschleimhautzellen „injizieren“. CagA wird nach der Injektion von zellulären Kinasen phosphoryliert und löst multiple Signaltransduktionsvorgänge aus, die zur malignen Transformation der Zellen beitragen könnten. Beim Kontakt von cag-positiven Stämmen mit Epithelzellen können auch Peptidoglykanbruchstücke in die Zelle eingeschleust werden, die das angeborene Immunsystem über den Musterkennungsrezeptor NOD1 aktivieren.

\section{Erkrankungen}

\section{Folgen der Kolonisation mit $H$. pylori}

\section{Chronische Gastritis}

Alle mit $H$. pylori infizierten Personen entwickeln eine entzündliche Reaktion der Magenschleimhaut, die in der Regel im Magenantrum besonders ausgeprägt ist (chronische Typ-B-Gastritis). Auf dem Boden der durch die H.-pylori-Infektion ausgelösten Gastritis (die selbst entweder asymptomatisch sein oder auch zu uncharakteristischen Oberbauchbeschwerden führen kann) können verschiedene Folgekrankheiten entstehen. Die H.-pylori-Gastritis heilt in der Regel nicht spontan aus, nur im hohen Alter kann es infolge einer Schleimhautatrophie zur spontanen Elimination der Erreger kommen. 


\section{Leitsymptome}

Anämie, Dysphagie, Erbrechen, Gewichtsverlust.

\section{Peptisches Ulcus duodeni}

Das Zwölffingerdarmgeschwür kommt praktisch ausschließlich bei Patienten vor, die mit $H$. pylori infiziert sind. Die Eradikation der H.-pylori-Infektion verhindert Ulkusrückfälle mit großer Sicherheit.

\section{Leitsymptome}

-Chronische Gastritis, Schmerzen, blutiges Erbrechen.

\section{Peptisches Ulcus ventriculi}

Der größte Teil der Magengeschwüre (ca. 70 \%) sind Folge einer H.-pylori-Infektion; Rezidive können durch H.-pylori-Eradikation verhindert werden. Die restlichen $30 \%$ der Magengeschwüre werden durch H.-pylori-unabhängige Noxen ausgelöst (insbesondere die Einnahme nicht-steroidaler Antirheumatika).

\section{Leitsymptome}

- Chronische Gastritis und Peptidisches Ulcus duodeni.

\section{Magenkarzinom}

Die H.-pylori-Infektion ist ein wichtiger Risikofaktor für die Entstehung des Magenadenokarzinoms. Das Karzinomrisiko ist umso größer, je früher die Infektion erworben wurde.

\section{Magenlymphom}

Die Magenschleimhaut ist bei gesunden Personen praktisch frei von lymphatischem Gewebe. Die H.-pylori-Infektion führt häufig zur Bildung von Lymphfollikeln in der Submukosa (sekundäres MALT). Sie ist daher die Voraussetzung für die Entstehung von malignen Non-Hodgkin-Lymphomen des Magens.

\section{Bezug zu Erkrankungen außerhalb des Gastrointestinaltraktes}

Ein Zusammenhang zwischen H.-pylori-Infektionen und Idiopathischer thrombozytischer Purpura, Eisenmangel-Anämie und Asthma wie auch anderen atopischen Erkrankungen wird diskutiert

\section{Immunantwort}

Im Verlauf der H.-pylori-Infektion werden Antikörper gegen H.-pylori-Antigene gebildet, die sich zwar für die serologische Diagnostik eignen, aber nicht zu einer protektiven Immunität führen. Die Reaktion der Magenschleimhaut auf die Infektion ist die Ausbildung einer so genannten chronisch aktiven Gastritis, die durch Infiltration mit neutrophilen Granulozyten und Lymphozyten charakterisiert ist. Eine zentrale Rolle in der Steuerung der Entzündungsreaktion spielt Interleukin-8. Im Infiltrat herrschen T-Lymphozyten vom TH1-Typ vor. Eine ausführliche Darstellung der
Immunpathogenese der H. pylori-Infektion findet sich in der angegebenen Literatur.

\section{Differenzialdiagnose}

Die umfangreichen Differenzialdiagnosen der H.-pylori-assoziierten Magenerkrankungen (z. B. medikamentös induzierte Ulzera) fallen in den Bereich der Gastroenterologie und können im Rahmen dieses Lexikons nicht dargestellt werden.

\section{Diagnostik}

\section{Untersuchungsmaterial}

Biopsien von Magen- oder Duodenalschleimhaut, Serum, Stuhl. Atemtest.

\section{Diagnostische Verfahren}

Infektionsnachweis: Am häufigsten wird der Nachweis der H.-pylori-Infektion im Rahmen einer endoskopischen Untersuchung (Ösophagogastroduodenoskopie) erbracht. Hierzu stehen folgende Methoden zur Verfügung: Biopsie.

Ureasetest („Urease-Schnelltest“): Dieser Test nutzt die starke Ureasebildung des Erregers aus. Eine oder zwei Biopsien werden in ein Ureasetestmedium (verschiedene kommerzielle Anbieter, z. B. CLO-Test ${ }^{\circ}$ ) gegeben. Nach kurzer Inkubationszeit kommt es durch die Wirkung der präformierten Helicobacter-Urease zur Alkalisierung und zur Verfärbung des Testmediums. Der Test ist einfach, preiswert und relativ zuverlässig. Vorbehandlung mit Protonenpumpenhemmern kann die Sensitivität verringern.

Bei entsprechender Erfahrung des Pathologen erlaubt die histologische Untersuchung auch eine Beurteilung über das Vorliegen einer H.-pylori-Infektion. Unter Umständen sind spezielle Färbungen (z. B. WarthinStarry-Versilberungsfärbung) notwendig.

Kultur: Die Kultur erfolgt auf Blutagar- oder Kochblutagarplatten in mikroaerophiler Atmosphäre (z. B. im Anaerobentopf mit Campylobacter-Gasgenerator). Die Verwendung eines Antibiotikasupplements (z. B. Skirrow'sches Supplement) ist sinnvoll. Inkubation 3-7 Tage bei $37^{\circ} \mathrm{C}$. Identifizierung durch charakteristische Kulturmorphologie (bis 1,5 mm große, transparente, glänzende, glatte, konvexe Kolonien), positive Katalase- und Oxidasereaktion und Nachweis von Ureasebildung. Charakteristisch sind außerdem Resistenz gegen Nalidixinsäure und Empfindlichkeit gegen Cephalotin.

Wegen der Empfindlichkeit des Erregers ist rascher Transport ins Labor, u. U. unter Verwendung eines Transportmediums (z. B. Portagerm pylori ${ }^{\circledR}$ ) notwendig. Wegen der langen Kulturzeit und suboptimalen Sensitivität wird die kulturelle Anzüchtung nicht in allen Fällen durchgeführt. Wichtigste Gründe eine Kultur durchzuführen, sind die Notwendigkeit einer Resistenzbestimmung bei therapeutischen Problemen (z. B. nach erfolglosem ersten Eradikationsversuch, - unten) und der Wunsch nach Erregertypisierung 
(Virulenzfaktornachweis, molekulares Fingerprinting). Für die Resistenztestung von $H$.-pylori-Stämmen gibt es keine verbindlichen Richtlinien. Bewährt haben sich die MHK-Bestimmung mit dem Agardilutionstest (die sich nur für die Testung größerer Serien lohnt) und für Einzelisolate die Testung mit Epsilometer-Teststreifen.

Neben diesen Methoden stehen auch nicht-invasive diagnostische Methoden zur Verfügung:

Serologie: Es gibt zahlreiche kommerziell erhältliche serologische Testkits (ELISA, Immunoblot, Schnelltests zur Durchführung durch den Arzt während der Sprechstunde). Die Qualität dieser Tests ist sehr variabel. Sensitivität und Spezifität der besseren Tests liegen zwischen $90 \%$ und $95 \%$. Die Titer fallen nach Eradikation nur langsam ab, daher ist die Serologie nur bedingt zur Verlaufskontrolle geeignet.

Atemtests: Diese Tests machen sich, wie der BiopsieUreasetest, die starke Ureasebildung zunutze. Dem Probanden wird oral Harnstoff zugeführt, der mit dem stabilen (nicht radioaktiven) Kohlenstoffisotop ${ }^{13} \mathrm{C}$ markiert ist. Die Wirkung der Urease führt bei Infizierten zur Freisetzung von ${ }^{13} \mathrm{CO}_{2}$ in die Ausatemluft. Die Auswertung der Atemproben erfolgt durch Massenspektrometrie. Der Test ist sehr zuverlässig und eignet sich sehr gut zur Therapiekontrolle, da er schon kurz nach erfolgreicher Eradikation negativ wird.

Antigennachweis im Stuhl: Diese Tests weisen H.-pylori-spezifische Antigene im Stuhl mit einem ELISAVerfahren nach. Bisherige Studien haben gezeigt, dass die Sensitivität und Spezifität dieser Verfahren mit denen des Atemtests vergleichbar sind. Wie der Atemtest ist auch dieses Verfahren für die Therapieverlaufskontrolle geeignet.

Typisierungsmethoden: Die Spezies $H$. pylori zeichnet sich durch eine ungewöhnlich hohe genetische Variabilität aus. Dies kann zum „Fingerprinting“ von individuellen Isolaten genutzt werden. Zahlreiche Methoden zur molekularen Typisierung von H.-pyloriStämmen sind beschrieben worden. Beispiele sind Restriktionsanalysen genomischer DNA, die Untersuchung von PCR-Restriktionsfragmentpolymorphismen, die so genannte RAPD-PCR und die direkte Sequenzierung von einzelnen oder mehreren PCR-amplifizierten Genfragmenten (z. B. flaB-Flagellingen, ureC-Ureasegen, Multilokus-Sequenztypisierung).

Diese Methoden ermöglichen es, die Identität bzw. Verwandtschaft von Isolaten zu untersuchen und so beispielsweise Infektketten aufzuklären. Möglicherweise wird in der Zukunft auch der Nachweis bestimmter Virulenzfaktoren (z. B. des VacA-Toxins $\checkmark$ unten) eine klinische Bedeutung erlangen, solche Methoden werden zurzeit noch validiert.

\section{Therapie}

\section{Therapeutische Maßnahmen}

H. pylori ist in vitro gegen die meisten Antibiotika empfindlich. Dennoch war es außerordentlich schwierig, effiziente Therapieformen für die H.-pylori-Infektion zu etablieren, wahrscheinlich weil die üblichen Antibiotika im Magen nur eine stark eingeschränkte Wirksamkeit besitzen. Werden Antibiotika als Monotherapie eingesetzt, lassen sich die Erreger zwar während der Therapie nicht mehr nachweisen, werden jedoch nicht vollständig eliminiert, sodass es nach Beendigung der Therapie zur Rekrudeszenz kommt. Monotherapien (wie auch viele Kombinationstherapien) haben daher keinen verlässlichen Effekt. Ziel der Therapie der H.-pylori-Infektion ist die komplette Eradikation des Erregers (definiert als ein negativer Erregernachweis mindestens vier Wochen nach Therapieende). Es sollten außerhalb von klinischen Studien nur Therapieschemata mit nachgewiesener Wirksamkeit eingesetzt werden, da sich aus In-vitro-Daten die klinische Wirksamkeit einer Therapie nicht vorhersagen lässt. Die derzeit effektivsten Therapieschemata sind Kombinationen von zwei Antibiotika (z. B. Clarithromycin kombiniert mit Amoxicillin oder Metronidazol) mit einem Säuresekretionshemmer (bevorzugt einem Protonenpumpenblocker), mit denen sich bei guter Patientencompliance Eradikationsraten um $90 \%$ erreichen lassen. Unumstrittene Therapieindikationen sind peptische Ulkuskrankheit und MALTLymphom, weitere trotz schwächerer Datenlage empfohlene Indikationen sind atrophische Gastritis, $\mathrm{Zu}-$ stand nach Magenkarzinomresektion, Magenkarzinom in Verwandten 1. Grades und starker Patientenwunsch nach Eradikation. Weitere mögliche Indikationen (besonders die zur Eradikation bei nicht ulzeröser Dyspepsie) werden weiterhin kontrovers diskutiert.

\section{Resistenz}

Die Häufigkeit von H.-pylori-Stämmen mit Resistenzen gegen Clarithromycin und Metronidazol hat in den letzten Jahren zugenommen und macht die Therapie zunehmend problematisch. Alternative Therapieformen bei Versagen der Ersttherapie (so genannte Rescue-Therapieformen) sind die Quadrupeltherapieschemata. Andere Therapieschemata sollten auf der Basis von publizierten Effektivitätsdaten und nach Resistenztestung eingesetzt werden.

\section{Epidemiologie}

\section{Verbreitung}

Weltweit.

\section{Wirtsbereich / Reservoir}

Mensch. Ein Reservoir in der unbelebten Umwelt ist nicht bekannt.

\section{Risikogruppen}

Die H.-pylori-Infektion ist weltweit verbreitet. Die lokale Prävalenz der Infektion variiert jedoch stark. In einigen Entwicklungsländern sind über $90 \%$ der Be- 
völkerung infiziert, in den westlichen Industrienationen liegt die Gesamtprävalenz zwischen $25 \%$ und $50 \%$. Da die Infektion normalerweise lebenslang bestehen bleibt, nimmt die altersspezifische Prävalenz mit zunehmendem Lebensalter zu. Diese Zunahme unterliegt einem Kohortenphänomen, weil besonders die Lebensbedingungen in der Kindheit die Infektionswahrscheinlichkeit eines Individuums bestimmen. So sind beispielsweise Alterskohorten, in deren Kindheit ein Krieg geherrscht hat, besonders infektionsgefährdet. Ein berufliches Risiko wurde für Gastroenterologen beschrieben.

\section{Transmission / Vektoren}

Die Epidemiologie der H.-pylori-Infektion ist bisher nur unvollständig untersucht und es gibt viele offene Fragen. Hierzu gehören die Fragen nach dem vorherrschenden Transmissionsweg ( $>$ oben), nach möglichen epidemiologisch bedeutsamen Umweltreservoirs oder nach der Entstehung der Stammheterogenität innerhalb der Spezies H. pylori, um nur einige zu nennen. Alles deutet jedoch darauf hin, dass sowohl in Industrienationen als auch in Entwicklungsländern der größte Teil der Infektionen in der Kindheit erworben wird und dass prophylaktische Strategien bei der Transmission im Kindesalter angreifen müssen.

\section{Prävention / Impfstoffe}

Verbesserung der allgemeinen sozioökonomischen Bedingungen und der Hygiene reduziert die Prävalenz der H.-pylori-Infektion. Da nicht genau bekannt ist, wie die Transmission erfolgt, gibt es zurzeit keine spezifischen Empfehlungen zur Expositionsprophylaxe. Impfungen gegen $H$. pylori befinden sich in der Entwicklung.

\section{Meldepflicht}

Es besteht keine Meldepflicht.

\section{Weiterführende Informationen}

\section{Referenzzentren / Expertenlaboratorien}

- Nationales Referenzzentrum Helicobacter pylori (Leiter: Prof. Dr. Manfred Kist), Institut für Medizinische Mikrobiologie und Hygiene der Universität Freiburg, HermannHerder-Str-11, D-79104 Freiburg, Tel. 0761 203-6514 (-6546), (Fax: -6562)

\section{Web-Adressen}

- NRZ für Helicobacter pylori. www.nrz-helicobacter.de

\section{Schlüsselliteratur}

1. Kandulski A, Selgrad M, Malfertheiner P (2008) Helicobacter pylori infection: a clinical overview. In: Dig Liver Dis 40, Nr. 8, S 619-626

2. Kist M, Glocker E, Suerbaum E (2005) Pathogenese, Diagnostik und Therapie der Helicobacter pylori-Infektion. Bundesgesundheitsbl Gesundheitsforsch Gesundheitsschutz

3. Malfertheiner P et al (2006) Current concepts in the ma- nagement of Helicobacter pylori infection: the Maastricht III Consensus Report. Gut

4. Suerbaum S, Josenhans C (2007) Helicobacter pylori evolution and phenotypic diversification in a changing host. Nat Rev Microbiol

5. Suerbaum S, Michetti P (2002) Helicobacter pylori infection. N Engl J Med

\section{Hendra-Virus}

Christoph Springfeld

\section{Erreger}

\section{Synonym(e)}

Veraltet: Equine morbillivirus.

\section{Erregerspezies \\ Hendra-Virus}

\section{Taxonomie}

Ordnung Mononegavirales, Familie Paramyxoviridae, Genus Henipavirus

\section{Historie}

Das Hendra-Virus wurde erstmals 1994 in Hendra, einem Vorort von Brisbane, isoliert, wo 21 Pferde und zwei Menschen infiziert wurden. Bis 2009 wurden 13 Ausbrüche dokumentiert, alle an der Ostküste Australiens. Von sieben infizierten Menschen starben vier.

\section{Morphologie}

Das Virion ist behüllt und enthält im Inneren ein helikales Ribonukleokapsid. Die virale RNA wird eng vom Kapsidprotein umgeben und ist außerdem mit dem Phosphoprotein sowie der viralen Polymerase assoziiert. Die Lipidhülle enthält zwei Glykoproteine, das Fusionsprotein und das Glykoprotein G. Auf der Innenseite der Membranhülle befindet sich das Matrixprotein, das den Kontakt zwischen den zytoplasmatischen Domänen der Glykoproteine und dem Ribonukleokapsid vermittelt.

\section{Genom}

Das virale Genom besteht aus einem 18234 Nukleotide langen einzelsträngigen RNA-Molekül mit negativer Orientierung (GenBank accession number NC_001906). Es kodiert für sechs Gene in der Reihenfolge N (Nukleokapsid), P (Phosphoprotein), M (Matrixprotein), F (Fusionsprotein), G (Glykoprotein) und $\mathrm{L}$ (large protein, Polymerase). Für jedes Gen wird eine mRNA transkribiert, die mit Ausnahme des P-Gens für ein Protein kodiert. Von der P-mRNA werden zusätzlich zum Phosphoprotein noch die Nicht-Strukturproteine $\mathrm{V}$ und $\mathrm{W}$ (durch RNA-editing) sowie C (durch Initiierung an einem alternativen Startkodon) hergestellt.

\section{Vermehrung}

Das Virus bindet mit dem Glykoprotein G an den Re- 
zeptor EphrinB auf der Wirtszelle. Das Fusionsprotein vermittelt dann die Fusion der Virushülle mit der Zellmembran. Die Replikation des Virus erfolgt im Zytoplasma. Zunächst werden die sechs Gene transkribiert und die viralen Proteine synthetisiert. Danach erfolgt die Replikation der genomischen RNA über ein Positiv-Strang-Intermediat. Die genomische RNA wird sofort enkapsidiert. Die Freisetzung des Virus erfolgt über die Zellmembran. Das Virus kann in vitro unter anderem in Verozellen vermehrt werden. In vivo wurde das Virus vor allem in Endothelzellen nachgewiesen.

\section{Pathogenität / Virulenz / Antigenvariabilität}

Bislang ist nur ein Serotyp des Virus bekannt. Das Virus ist serologisch mit dem Nipah-Virus verwandt.

\section{Erkrankung}

Hendra-Virus-Infektion

Synonym(e)

Keine.

\section{Inkubationszeit}

Vermutlich 7 bis 16 Tage.

\section{Leitsymptome}

Husten, Fieber, meningitische und enzephalitische Symptome, Krämpfe.

\section{Symptome}

Die 7 infizierten Menschen litten zunächst an grippeartigen Beschwerden. Ein Patient verstarb an Lungen-, Nieren- und Kreislaufversagen. Bei zwei 2008 erkrankten Patienten kam es nach den initialen grippeartigen Beschwerden an Tag 5 bzw. 12 zu neurologischen Symptomen in Form von Verwirrung, Ataxie und Krämpfen. Ein Patient verstarb am Tag 40, die andere Patientin erholte sich wieder. 1994 erkrankte ein Patient zunächst nur an einer kurzen aseptischen $\mathrm{Me}$ ningitis, verstarb jedoch dreizehn Monate später an einer schweren Enzephalitis mit fokalen und generalisierten Krampfanfällen.

\section{Pathophysiologie}

Bei infizierten Pferden wurde das Virus vor allem im Endothel der Lungengefäße, aber auch in anderen Organen nachgewiesen. Die Pathophysiologie der menschlichen Erkrankung, insbesondere die Ursache der verzögert aufgetretenen Enzephalitis, ist nicht bekannt.

\section{Immunantwort}

Im Serum infizierter Menschen und Tiere können Antikörper gegen das Virus nachgewiesen werden.

\section{Differenzialdiagnose}

Eine Hendra-Virus-Infektion sollte nach derzeitigem Stand des Wissens nur bei Patienten in Erwägung ge- zogen werden, die Kontakt mit infizierten Pferden hatten. Differentialdiagnostisch kommen andere Erreger von Atemwegsinfektionen und Enzephalitiden in Betracht.

\section{Diagnostik}

\section{Untersuchungsmaterial}

Blut, Serum, Liquor, Abstriche.

\section{Diagnostische Verfahren}

Derzeit sind keine kommerziellen Tests zur Diagnose einer Hendra-Virus-Infektion erhältlich. Bei begründetem Verdacht sollte Kontakt z. B. zum BernhardNocht-Institut aufgenommen werden, um die Diagnostik sowie das notwendige Untersuchungsmaterial zu besprechen. Die Anzucht des Virus sollte nur in Hochsicherheitslabors (S4) durchgeführt werden.

\section{Befund / Interpretation}

Die Untersuchungsergebnisse sollten mit den zuständigen Ärzten im Referenzzentrum und dem Gesundheitsamt besprochen werden.

\section{Therapie}

\section{Therapeutische Maßnahmen}

Ribavirin ist in vitro wirksam, so dass ein Therapieversuch mangels Alternativen gerechtfertigt erscheint. Monoklonale Antikörper zur Postexpositionsprophylaxe werden entwickelt.

\section{Resistenz}

Keine bekannt.

\section{Epidemiologie}

\section{Verbreitung}

Alle 13 Hendra-Virus-Ausbrüche fanden in Australien (Bundesstaaten Queensland und New South Wales) statt.

\section{Wirtsbereich / Reservoir}

Als natürlicher Wirt des Hendra-Virus gelten Flughunde der Gattung Pteropus, die nach Infektion jedoch keine Krankheitssymptome zeigen.

\section{Risikogruppen}

Alle infizierten Menschen hatten Kontakt zu erkrankten Pferden.

\section{Transmission}

Der genaue Übertragungsweg von Flughunden auf Pferde und von Pferden auf Menschen ist nicht bekannt. Es gibt keinen Anhalt für eine Übertragung von Mensch zu Mensch oder von Flughunden auf den Menschen.

\section{Prävention / Impfstoffe}

Nicht vorhanden. 


\section{Ausbruchsmanagement}

Isolierung infizierter Pferde.

\section{Meldepflicht}

Nein.

\section{Weiterführende Informationen}

\section{Referenzzentren / Expertenlaboratorien}

- Bernhard-Nocht-Institut für Tropenmedizin, BernhardNocht-Straße 74, 20359 Hamburg

\section{Web-Adressen}

- http://www.csiro.au/

\section{Schlüsselliteratur}

1. Eaton BT, Broder CC, Middleton D, Wang LF (2006) Hendra and Nipah viruses: different and dangerous. Nat Rev Microbiol 4:23-35

2. Elliott G, McCall B, Smith G, et al (2010) Human HendraVirus encephalitis associated with equine outbreak, Australia, 2008. Emerging Infectious Diseases 16:219-223

3. Murray K, Selleck P, Hooper P et al (1995) A morbillivirus that caused fatal disease in horses and humans. Science 268:94-97

\section{Hepatitis}

- Adenoviren

- Arenaviren

- Brucella

- Bunyaviren

- Coxsackieviren

Dengueviren

Echoviren und Parechoviren

- Ehrlichia

- Enteroviren 68-71 und andere Enteroviren

- Epstein-Barr-Virus

- Fasciola hepatica

- GB Virus C (GBV-C)

- Gelbfiebervirus

- Hantaviren

- Hepatitis A Virus (HAV)

- Hepatitis B Virus (HBV)

- Hepatitis C Virus (HCV)

- Hepatitis D Virus (HDV)

- Hepatitis E Virus (HEV)

- Herpes-simplex-Virus (HSV)

- Histoplasma capsulatum

- Lassa-Virus

- Leptospiren

- Neisseria gonorrhoeae

- Nematoden, seltene Arten

- Parvoviren

- Reisemedizin, Infektionsprävention

- Reoviren

$\checkmark$ Rötelnvirus

- Streptobacillus

- Trichosporon

\section{Hepatitis A}

Hepatitis A Virus (HAV)

\section{Hepatitis A Virus (HAV)}

\section{Erreger \\ HAV}

\section{Erregerspezies}

Hepatitis-A-Virus (HAV)

\section{Taxonomie}

Das Genus Hepatovirus gehört zur Familie der Picornaviridae. Weltweit existiert nur ein Serotyp.

\section{Historie}

Im Jahr 1973 konnten Feinstone et al. das Virus erstmals darstellen. Die Züchtung in Zellkulturen gelang 1979 durch Provost und Hillemann.

\section{Morphologie}

Das Virion besteht aus einem nicht umhüllten Partikel mit einem Durchmesser von ca. $27 \mathrm{~nm}$. Das ikosaedrische Kapsid, welches das virale Genom beherbergt, enthält jeweils 60 Kopien der 3 Hauptstukturproteine VP1, VP2 und VP3.

\section{Genom}

Das Hepatitis-A-Virus besitzt ein einzelsträngiges, lineares (+)Strang-RNA-Genom von ca. 7,5 kb Länge. Accession No. der Nukleinsäure- und Proteinsequenzen: NC_oo1489, No. X7525, No. M16632.

\section{Vermehrung}

HAV wird üblicherweise über den fäkal-oralen Weg übertragen. Eine Replikation des Virus im Oropharynx oder intestinalen Bereich konnte nicht sicher nachgewiesen werden, so dass der Weg, über den HAV die Leber erreicht, bisher nicht identifiziert ist. Bereits 2 Wochen vor Ablauf der Inkubationszeit und Beginn der klinischen Symptomatik wird das in der Leber replizierte Virus über die Gallengänge und den Intestinaltrakt ausgeschieden. Die Virusausscheidung in den Fäzes beläuft sich insgesamt auf ca. 3 Wochen. Eine deutliche Verlängerung der HAV-Ausscheidung findet sich in den protrahierten Verläufen und Infektionen im Neugeborenenalter, wo eine HAV-Ausscheidung über 20 Wochen beobachtet wurde.

\section{Pathogenität / Virulenz / Antigenvariabilität}

Die klinische Symptomatik einer HAV-Infektion und die damit einhergehende Destruktion der Hepatozyten ist nicht die Folge einer zytolytischen Infektion, sondern beruht auf immunpathologischen Mechanismen. Die Pathogenese fulminanter Verläufe ist bisher 
nicht geklärt. Die beschriebenen HAV-Genotypen zeigen keine Unterschiede in ihrer Pathogenität. Es gibt keine Evidenz für Antigenvariabilität.

\section{Erkrankung}

Hepatitis A

\section{Inkubationszeit}

Die Inkubationszeit beträgt 3-5 Wochen (Mittel 27 Tage).

\section{Leitsymptome}

Hepatitis mit Ikterus, Transaminasenerhöhung, dunkler Urin, heller Stuhl.

\section{Symptome}

Die klinische Manifestation reicht von der asymptomatischen Infektion bis hin zur fulminanten Hepatitis mit Todesfolge. Die Prodromi sind gekennzeichnet durch Fieber, Erbrechen, Unwohlsein mit Diarrhoe und Myalgien, häufig einhergehend mit einer schweren Abgeschlagenheit. Der Schweregrad der Erkrankung ist altersabhängig. Die asymptomatische oder zumindest anikterische Infektion findet sich insbesondere im Kindesalter. Schwere Verlaufsformen zeigen sich z. T. auf dem Boden einer vorbestehenden chronischen Hepatitis B oder C oder anderer leberschädigender Vorerkrankungen. Die Hepatitis-A-Virusinfektion wird nicht chronisch.

Protrahierte, relapsierende Hepatitis: Ca. 15 \% der Krankheitsfälle zeigen einen protrahierten und teilweise relapsierenden Verlauf ohne aber in die Chronizität überzugehen. In $>$ Abb. 1 sind beispielhaft solche protrahierten Krankheitsverläufe schematisch dargestellt.

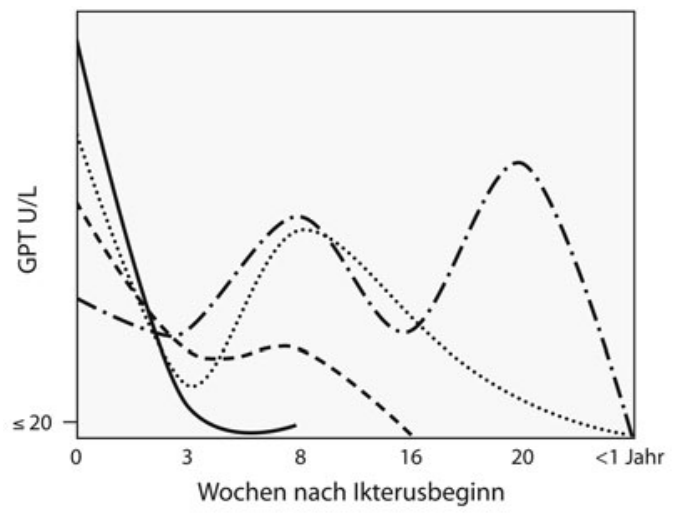

-... normaler Verlauf
$\ldots .$. protrahierter, relapsierender biphasischer Verlauf
- - protrahierter Verlauf
- - protrahierter, relapsierender multiphasischer Verlauf

- Abb. 1. Schematische Darstellung verschiedener Verlaufsformen der klinisch-manifesten Hepatitis-AVirusinfektion
Aplastische Anämie: Neben einem häufig zu beobachtenden transierten Effekt des HAV auf das hämatopoetische System werden seltene Fälle schwerer Panzytopenien beschrieben, die mit einer Letalität von über $90 \%$ einhergehen.

\section{Pathophysiologie}

Eine Replikation des HAV konnte bisher nur in der Leber nachgewiesen werden. Die Destruktion der infizierten Zellen erfolgt über zytotoxische T-Zellen.

\section{Immunantwort}

Anti-HAV-IgM ist bei fast allen Patienten mit Beginn der Symptomatik nachweisbar. Kurz darauf finden sich anti-HAV-IgG Antikörper, die lebenslang persistieren.

\section{Differenzialdiagnose}

Die Hepatitis-A-Virusinfektion ist von anderen Hepatitiden viraler oder nicht viraler Ätiologie mit einer serologischen Labordiagnostik abzugrenzen.

\section{Diagnostik}

\section{Untersuchungsmaterial}

Die Routinediagnostik einer akuten HAV-Infektion erfolgt über den Nachweis spezifischer Antikörper im Serum. In speziellen Fällen kann der Virusnachweis im Stuhl oder Blut angezeigt sein.

\section{Diagnostische Verfahren}

Die Diagnose einer akuten Hepatitis-A-Virusinfektion erfolgt über den Nachweis von anti-HAV-IgM im Serum. Der Nachweis der HAV-RNA über RT-PCR im Stuhl oder Blut kann insbesondere bei unklaren protrahierten Verläufen zur Diagnose-Sicherung herangezogen werden. Zur Feststellung der Immunität wird ein Gesamtantikörpernachweis gegen HAV (antiHAV) durchgeführt.

\section{Befund / Interpretation}

Der Nachweis von anti-HAV-IgM ist Zeichen einer akuten oder in der Regel kürzlich abgelaufenen HAVInfektion. Falsch positives anti-HAV-IgM kommt vor, daher muss ein positives Ergebnis grundsätzlich durch eine Gesamtantikörperbestimmung gegen HAV (antiHAV) ergänzt werden. Bei protrahierten Verläufen findet sich anti-HAV-IgM teilweise über Monate bis Jahre. In diesen Fällen kann häufig der Nachweis der HAV-RNA im Stuhl oder Blut die Diagnose sichern. Immunität gegen HAV wird ab einer anti-HAV Konzentration von $10 \mathrm{U} / \mathrm{L}$ angenommen.

\section{Therapie}

\section{Therapeutische Maßnahmen}

Eine HAV-spezifische Therapie steht nicht zur Verfügung. 


\section{Epidemiologie}

\section{Verbreitung}

Die Epidemiologie der Hepatitis A unterliegt einer kontinuierlichen Veränderung. Obgleich das HAV weltweit verbreitet ist, zeigen sich extreme Unterschiede in der Seroprävalenz von Land zu Land.

\section{Wirtsbereich / Reservoir}

Neben dem Menschen sind nur wenige nicht-humane Primaten infizierbar.

\section{Risikogruppen}

In den westlichen Industriestaaten ist das Risiko einer HAV-Infektion niedrig. Einem erhöhten Erkrankungsrisiko unterliegen aber auch dort bestimmte Berufsgruppen, wie z. B. Personal in Kindertagesstätten und Kliniken oder Arbeiter in Kanal- und Kläranlagen. Ein hohes Risiko einer HAV-Infektion haben Personen, die aus einem Gebiet mit niedriger HAV-Inzidenz in ein Endemiegebiet reisen.

\section{Transmission / Vektoren}

Die Transmission des HAV findet fast ausschließlich über den fäkal-oralen Weg, insbesondere über kontaminiertes Wasser, kontaminierte Nahrungsmittel und Schmierinfektionen statt. Übertragungen des HAV via Bluttransfusion und kontaminierte Blutprodukte sind beschrieben, aber selten.

\section{Prävention / Impfstoffe}

Zur Prävention einer HAV-Infektion stehen gut verträgliche inaktivierte Impfstoffe zur Verfügung, die zu einem sicheren Schutz führen. Als post-expositionelle Maßnahme werden gegebenenfalls Immunglobuline verabreicht.

\section{Ausbruchsmanagement}

Bei infektionsgefährdeten Personen im Umfeld eines Ausbruchs werden Impfungen mit einem Impfstoff, der ein 2-Dosen-Schema zulässt, empfohlen. Bei individuell besonders gefährdeten Personen kann eine passive Immunisierung mit Immunglobulin erfolgen. Eine neuere Untersuchung zeigt, dass zur Unterbrechung der Infektkette auch die Familienangehörigen von geimpften Kontaktpersonen aktiv immunisiert werden sollten. Der aktuelle Stand der empfohlenen Präventiv- und Bekämpfungsmethoden ist im Merkblatt "Hepatitis-A-Erkennung und Verhütung" des Robert Koch-Instituts zusammengefasst.

\section{Meldepflicht}

Nach dem IfSG ist laut $\$ 6$ Abs. 1 der feststellende Arzt verpflichtet, sowohl den Verdacht als auch Erkrankung und Tod an akuter Virushepatitis an das zuständige Gesundheitsamt $\mathrm{zu}$ melden. Leiter von Untersuchungsstellen (Laboratorien) sind verpflichtet $(\$ 7)$, den direkten oder indirekten Nachweis des Hepatitis-
A-Virus zu melden, soweit dieser auf eine akute Infektion hinweist.

\section{Weiterführende Informationen}

\section{Referenzzentren / Expertenlaboratorien}

- Konsiliarlaboratorium für HAV, Prof. Dr. W. Jilg, Institut für Med. Mikrobiologie und Hygiene der Universität Regensburg, Franz-Josef-Strauß-Allee 11, 93053 Regensburg, Telefon: 0941944 6408, Telefax: 0941944 6402, Email: wolfgang.jilg@klinik.uni-regensburg.de

\section{Web-Adressen}

- Robert-Koch-Institut: http://www.rki.de

- Centers for disease control and prevention: http://www. cdc.gov

- WHO World Health Organization: http://www.who.int/

- All the virology on the WWW: http://www.virology.net

\section{Schlüsselliteratur}

1. Blaine Hollinger F, Emerson SU (2001) Hepatitis A Virus. In: Fields Virology. Lippincott Williams \& Wilkins, Philadelphia, pp 799-840

\section{Hepatitis B}

- Hepatitis B Virus (HBV)

\section{Hepatitis B Virus (HBV)}

Wolfgang Jilg, Helga Meisel, Detlev H. Krüger

\section{Erreger}

Synonym(e)

HBV, Humanes Hepatitis-B-Virus.

\section{Erregerspezies}

Hepatitis-B-Virus

\section{Taxonomie}

HBV gehört als einziges humanpathogenes Virus zur Familie der Hepadnaviridae, Genus Orthohepadnavirus. Zurzeit sind 8 Genotypen (A-H) und 8 Serotypen (adr, ayr, ayw1, ayw2, ayw3, ayw4, adw2 und adw4) bekannt, die eine geografische unterschiedliche Verteilung aufweisen.

Hauptcharakteristika der Hepadnaviren sind die besondere Genomorganisation, ein für DNA-Viren bemerkenswerter Replikationsmechanismus über eine reverse Transkription, die hohe Spezies-Spezifität, der Lebertropismus und die Fähigkeit, im infizierten Wirt eine starke und langanhaltende Virämie auszubilden.

\section{Historie}

Baruch Blumberg entdeckte 1963 im Rahmen einer anthropologischen Studie das sphärische HBsAg im Serum eines australischen Ureinwohners. Mit der Identifizierung als Oberflächenprotein von $\mathrm{HBV}$ 
(HBsAg) 1967 begann dessen Erforschung, gefolgt vom elektronenmikroskopischen Nachweis des Viruspartikels (Dane, 1970), der Charakterisierung der viralen DNA und der Aufklärung des Replikationsmechanismus der Hepadnaviren.

\section{Morphologie}

Das Virion (42 nm) besteht aus einem ikosaedrischen Nukleokapsid (Core), in dem sich die virale DNA, die virale Polymerase und eine wirtseigene Proteinkinase befinden. Die lipidhaltige Virushülle mit HBs-Antigenität enthält ein kleines (SHBs), mittleres (MHBs) und großes (LHBs) Oberflächenprotein. Aus der Hülle ragen die PräS-Domänen von MHBs und LHBs als Spikes heraus. Neben den kompletten Virionen liegen im Serum HBV-infizierter Patienten noch leere, ca. $20 \mathrm{~nm}$ große nichtinfektiöse Hüllproteinstrukturen als sphärische und tubuläre HBsAg-Partikel vor.

\section{Genom}

NCBI-Nummer: 001707. Das HBV-Genom ist mit ca. 3.200 Nukleotiden Länge eines der kleinsten bekannten DNA-Genome animaler Viren. Die acht Genotypen $(\mathrm{A}-\mathrm{H})$ weisen untereinander eine Nukleotiddivergenz von mehr als $8 \%$ auf. Im Unterschied zu den anderen Genotypen liegt beim Genotyp G eine 36-Nukleotid-Insertion im C-Gen vor. Das nichtkovalent zirkularisierte, partiell doppelsträngige DNA-Molekül besteht aus einem linearen DNA-Minus-Strang von konstanter Länge, an dessen 5'-Ende die virale DNAPolymerase kovalent gebunden ist. Der komplementäre DNA-Plus-Strang besitzt ein definiertes 5'-Ende, an das ein Oligoribonukleotid-Fragment gebunden ist, sowie ein variables 3'-Ende, wodurch das Genom einen einsträngigen Abschnitt unterschiedlicher Länge aufweist. Die Genomorganisation ist sehr kompakt: Das Genom besteht aus den kodierenden Leserahmen der S-, C-, P- und X-Gene, die sich in allen Leserastern auf dem DNA-Minus-Strang extensiv überlappen. Durch die Verwendung unterschiedlicher Startkodone innerhalb eines kodierenden Leserahmens werden bei der Translation des S- und C-Gens aminoterminal unterschiedlich lange, aber am Carboxylende koterminale Proteine erhalten.

\section{Vermehrung}

Die primären Zielzellen von HBV in vivo sind Hepatozyten des Menschen, in die das Virus durch rezeptorvermittelte Endozytose gelangt. Die PräS1-Domäne des LHBs ist entscheidend für die Interaktion mit den zellulären Rezeptoren. Die sinusoidalen Endothelzellen der Leber scheinen eine Schlüsselrolle bei der Aufnahme von HBV in den Hepatozyten zu spielen. Das virale Genom wird im Zellkern des Hepatozyten durch zelluläre Replikationsenzyme vervollständigt und kovalent zirkularisiert. Die dadurch erzeugte cccDNA dient als Matrize zur Transkription der viralen mRNAs. Mittels einer zellulären DNA-abhängigen
RNA-Polymerase II wird vom Minus-Strang neben vier mRNAs für die Proteinsynthese die prägenomische mRNA synthetisiert, die auch für das Coreprotein und die Polymerase kodiert. Die 3,5 kb lange prägenomische mRNA wird in das Zytoplasma transferiert und mit der viralen Polymerase in das sich aus CoreProtein-Dimeren bildenden Nukleokapsid verpackt. Dort wird von der viralen Polymerase der komplette DNA-Minus-Strang durch reverse Transkription synthetisiert, an die sich die Synthese des DNA-PlusStranges mittels viruskodierter DNA-Polymerase anschließt. Die nun reifen Nukleokapside mit der partiell doppelsträngigen DNA werden am endoplasmatischen Retikulum von den viralen Oberflächenproteinen umhüllt und schließlich von der Leberzelle sezerniert. Ein Teil der reifen Kapside entlässt seine DNA in den Nukleus, was zu einem Anstieg an cccDNA im Kern führt. Für den viralen Vermehrungszyklus ist eine Integration der HBV-DNA in das Wirtsgenom nicht erforderlich.

\section{Pathogenität / Virulenz / Antigenvariabilität}

HBV selbst ist nicht zytopathogen. Mit der Vermehrung und Freisetzung von HBV werden Virusantigene auf der Leberzellmembran präsentiert, die eine zelluläre Immunantwort induzieren, welche zum Zelluntergang führen oder die Virusreplikation unterdrücken. Für die unterschiedlichen Verlaufsformen einer HBV-Infektion werden die individuelle virusspezifische Immunantwort sowie die Zytokinproduktion und -wirkung verantwortlich gemacht. An der Überwindung der akuten Infektion ist primär das adaptive Immunsystem mit HBV-spezifischen zytotoxischen T-Zellen, daneben aber wahrscheinlich auch das angeborene Immunsystem beteiligt. Bei der Zellschädigung im Rahmen einer chronisch aktiven Hepatitis scheinen dagegen nicht virusspezifische Effektorzellen der angeborenen Immunität eine größere Rolle zu spielen. Auch eine Assoziation zwischen Genotyp und klinischem Verlauf der chronischen Hepatitis B wurde beobachtet. So weisen Träger des Genotyps C das höchste Karzinom- und Zirrhoserisiko auf und sind am längsten HBeAg-positiv. HBV ist hochvariabel, da aufgrund des Fehlens einer Korrekturfunktion sowohl der zellulären RNA-Polymerase als insbesondere der viralen reversen Transkriptase die Neusynthese eines HBV-Genoms mit einer hohen Fehlerrate einhergeht. Aminosäureaustausche im kleinen HBsAg können zu so genannten Escape-Mutanten führen, die durch impfinduzierte Antikörper oder diagnostische Teste schlechter erkannt werden. Mutationen im PräcoreBereich gehen mit Verlust der $\mathrm{HBeAg}$-Expression und Auftreten von anti-HBe bei oft hoher Virämie einher. HBV-Varianten mit einem komplexen Mutationsmuster im C-Gen, Core-Promotor und präS1/2-Gen gelten als Risikofaktoren für die Entwicklung einer aktiven Hepatitis und eines Leberzellkarzinoms und sind 
eng mit der Pathogenese der chronischen Hepatitis bei immunsupprimierten Patienten assoziiert.

Bei über 80 \% der Fälle eines HBV-assoziierten Leberzellkarzinoms (HCC) liegt das HBV-Genom im zellulären Genom integriert vor. Die Integration fördert wahrscheinlich die genetische Instabilität der Zelle. Im HBV-Genom ist bisher kein Onkogen gefunden worden. Es gibt indirekte Beweise dafür, dass transaktivierende Effekte von HBV-Proteinen (X-Protein, Cterminal verkürztes MHBs/SHBs) zur Mehrschrittpathogenese von HCC beitragen.

\section{Erkrankung}

Hepatitis B

\section{Synonym(e)}

Virushepatitis B, (Serumhepatitis, Transfusionshepatitis).

\section{Inkubationszeit}

Die Inkubationszeit der Hepatitis B kann in Abhängigkeit vor allem von der Erregerdosis 30-180 Tage (durchschnittlich 70 Tage) betragen.

\section{Leitsymptome}

Bei $30 \%$ der Erwachsenen und 10 \% der Kinder Ikterus, Hepatomegalie, z. T. auch leichte Splenomegalie und Lymphknotenschwellung; im chronischen Stadium: Müdigkeit, Abgeschlagenheit und Leistungsminderung, mäßige Hepatosplenomegalie, evtl. erhöhte Transaminasen, evtl. Zeichen einer Leberzirrhose.

\section{Symptome}

Das ca. einwöchige Prodromalstadium ist durch Fieber, Erbrechen und weitere Symptome ( $\triangleright$ extrahepatische Manifestationen) gekennzeichnet. Die akute Hepatitis B verläuft in zwei Dritteln der Fälle subklinisch. Ein Drittel der Patienten weist einen ikterischen Verlauf auf. Fulminante Verläufe sind selten (1\%), aber oft tödlich.

Die klinischen Manifestationen einer HBV-Infektion sind in erster Linie vom Alter und Immunstatus des Patienten abhängig. Bei Neugeborenen und Kindern unter einem Jahr verläuft die Infektion in der Regel zunächst asymptomatisch. Ca. 70-90 \% dieser Kinder entwickeln einen chronischen HBV-Trägerstatus, und in ca. 30-50 \% der Fälle kommt es zur Ausbildung von chronischen Lebererkrankungen, die zu Zirrhose und Leberzellkarzinom (HCC) führen können. Auch bei immuninkompetenten Patienten wie zum Beispiel Organtransplantierten, HIV-Infizierten oder Dialysepatienten ist die Chronifizierungsrate hoch. Bei immunkompetenten Erwachsenen liegt die Chronifizierungsrate zwischen 1-5\%. Persistenz von HBsAg über mehr als sechs Monate nach der akuten Erkrankung deutet auf einen chronischen Verlauf der HBV Infektion hin. In Abhängigkeit von den Leberzellveränderungen unterscheidet man den so genannten gesunden HBsAg-Träger-Status (Immuntoleranz) und die chronische Hepatitis, die in eine hoch-replikative Form mit entzündlichen, fibrotischen Leberveränderungen und erhöhten Transaminasen und eine niedrig-replikative Form mit nur geringgradiger Leberpathologie unterschieden wird.

Im Verlauf der chronischen HBV-Infektion können drei Phasen durchlaufen werden. Die erste Phase ist in den meisten Fällen durch hohe Infektiosität (hohe HBeAg- und HBV-DNA-Konzentrationen im Serum) gekennzeichnet, wobei häufig Leberzellschädigung und Virämie in einem umgekehrten Verhältnis stehen. Histologisch kann das Spektrum von geringer bis hoher entzündlicher Aktivität und geringem Fibrosierungsgrad bis zur Leberzirrhose reichen. Nach unterschiedlich langer Zeit kommt es bei einem Teil der Patienten zum Aufbau einer Immunantwort mit Übergang in eine nicht-replikative Phase, der in der Regel eine Serokonversion von $\mathrm{HBeAg} z \mathrm{zu}$ anti-HBe vorausgeht. Diese Phase kann durch intermittierende Reaktivierungen unterbrochen sein, die durch medikamentöse Immunsuppression, Kortikoidtherapie, HBVMutanten (im Präcorebereich), Superinfektionen mit anderen Hepatitiserregern bzw. HIV hervorgerufen werden können. Bei nur sehr wenigen Patienten erfolgt Jahre später eine Serokonversion von $\mathrm{HBsAg}$ zu anti-HBs, die mit einer Ausheilung verbunden ist.

Die chronische aktive Hepatitis B hat ohne Therapie in der Regel eine schlechte Langzeitprognose. Fünfzehn bis $40 \%$ aller Patienten mit chronischer Hepatitis B entwickeln eine Leberzirrhose. Das trifft insbesondere für die Patienten mit HBV-Genotyp C zu. In den westlichen Industrienationen versterben ca. 17 \% der Zirrhosepatienten innerhalb von 5 Jahren an hepatozellulärem Karzinom.

Extrahepatische Manifestationen: Insbesondere das Prodromalstadium der akuten Hepatitis B zeichnet sich durch extrahepatische Manifestationen wie Urtikaria, Arthralgien und Hauteffloreszenzen (GianottiCrosti-Syndrom bei Kindern) aus, deren Auftreten hauptsächlich durch zirkulierende Immunkomplexe bedingt ist. 10 bis $20 \%$ der Patienten mit chronischer HBV-Infektion zeigen weitere extrahepatische Manifestationen, wie Arthralgien, Polyarthritis, gemischte Kryoglobulinämie, Myalgien und eine meist membranöse Glomerulonephritis, die ebenfalls hauptsächlich durch Hepatitis-B-Antigen-Antikörper-Immunkomplexe bedingt sind.

Leberzellkarzinom (HCC): Die Assoziation zwischen HBV-Infektion und HCC ist gesichert. Patienten mit allen Formen des HBsAg-Trägerstatus können nach einer Latenz von ca. 20-40 Jahren HCC entwickeln mit einem 100fach erhöhten relativen Risiko gegenüber der Normalbevölkerung. Bei Patienten mit einer hohen Viruslast erhöht sich das relative Risiko auf den Faktor 300. Entscheidender Risikofaktor ist die Dauer des HBsAg-Trägerstatus. 


\section{Pathophysiologie}

Nach Infektion der Leber mit HBV kommt es zur Proliferation der Kupfferschen Sternzellen, Ballonierung der Hepatozyten und Einzelzellnekrosen sowie entzündlichen Reaktionen der periportalen Felder und Einlagerung von Ceroidpigment. Typisch sind Leberzellen mit milchglasartig aufgehelltem Zytoplasma. Bei chronischen Hepatitiden sind die Prozesse in Abhängigkeit von der Krankheitsaktivität auf die Periportalfelder beschränkt und mit wenigen Einzelzellnekrosen verbunden, oder sie überschreiten die Periportalfelder und sind mit so genannten Mottenfraßnekrosen assoziiert. Zur reproduzierbaren Erfassung der entzündlichen Aktivität und des Ausmaßes des bindegewebigen Umbaus wurden Scoring-Systeme eingeführt (Knodell-Score, Ishak-Score, METAVIRScore), die zur Dokumentation des Krankheits-und Therapieverlaufes herangezogen werden.

\section{Immunantwort}

Die humorale Antikörperantwort gegen die viralen Hüllantigene führt zur Elimination zirkulierender Viruspartikel. Daneben werden infizierte Zellen durch die zellulären Immunantworten gegen die Hüll-, Nukleokapsid- und Polymeraseantigene eliminiert. Entscheidend sind die Stärke und Multispezifität der MHC-Klasse I-restringierten T-Zell-Antworten auf das Virus, wobei die T-Zell-Aktivität mit der Ausprägung der Erkrankung sowie der Viruselimination positiv korreliert. CD8-positive aktivierte T-Zellen induzieren über Zytokine eine nicht-zytolytische Hemmung der Virusreplikation und über TNF- $\alpha$ /PerforinFasL die Zerstörung der infizierten Zellen. Die HBVspezifische T-Zell-Antwort persistiert lebenslang nach klinisch und serologisch durchgemachter Hepatitis B.

\section{Differenzialdiagnose}

Die akute Hepatitis-B-Infektion muss von anderen viralen (bei Vorliegen von fulminanter Hepatitis insbesondere von Hepatitis D) und bakteriellen Hepatitiden abgegrenzt werden. Bei der chronischen Hepatitis B kommen differenzialdiagnostisch auch Autoimmunhepatitiden sowie toxische, medikamentöse und alkoholbedingte Hepatitiden in Betracht. Systemische Infektionen vieler Erreger inklusive Protozoen können zu einer Leberbeteiligung führen. Durch serologische, molekularbiologische und histologische Untersuchungen kann eine Diagnose gesichert werden.

\section{Diagnostik}

\section{Untersuchungsmaterial}

Als Untersuchungsmaterial dienen Serum oder Plasma bzw. Lebergewebe.

\section{Diagnostische Verfahren}

Für eine Unterscheidung zwischen akuter und chronischer Infektion sowie Immunität stehen verschiedene
Tab. 1. Serologische Marker im Verlaufe der Hepatitis

\begin{tabular}{|l|l|}
\hline Marker & Erklärung \\
\hline HBsAg & $\begin{array}{l}\text { Oberflächenprotein des HBV, } \\
\text { indirekter Marker der Infektiosität, } \\
\text { Marker zur Früherkennung der } \\
\text { akuten und chronischen Hepatitis } \\
\text { sowie der Prognose }\end{array}$ \\
\hline HBeAg & $\begin{array}{l}\text { lösliche Form des viralen Core- } \\
\text { Proteins, möglicherweise Immun- } \\
\text { modulator, indirekter Marker der } \\
\text { Infektiosität }\end{array}$ \\
\hline HBV-DNA & $\begin{array}{l}\text { Virusgenom, Infektiositätsmarker, } \\
\text { Parameter zur Überwachung } \\
\text { antiviraler Therapien }\end{array}$ \\
\hline HBCAg & $\begin{array}{l}\text { Core-Antigen des HBV (kommt } \\
\text { nicht in freier Form im Serum vor) }\end{array}$ \\
\hline anti-HBc-IgM & $\begin{array}{l}\text { lgM-Antikörper gegen HBcAg, } \\
\text { frühester diagnostischer Antikör- } \\
\text { per, indirekter Replikationsmarker, } \\
\text { hohe Titer nur bei akuter Hepatitis } \\
\text { (bei chronischer Hepatitis in Ab- } \\
\text { hängigkeit von der Aktivität) }\end{array}$ \\
\hline anti-HBs: & $\begin{array}{l}\text { IgG-Antikörper gegen HBcAg, } \\
\text { akute, chronische, abgelaufene } \\
\text { Infektion, Durchseuchungsmarker }\end{array}$ \\
\hline anti-HBe & $\begin{array}{l}\text { zusammen gegen HBsAg, Marker } \\
\text { Marker nach Immuneis auf unvollständige Virus- } \\
\text { vermehrung, Auftreten im akut- } \\
\text { limitierten Verlauf: gute klinische } \\
\text { Prognose }\end{array}$ \\
\hline anti-HBc-IgG einziger \\
\hline
\end{tabular}

Testmethoden zum Nachweis der viralen Antigene und Antikörper zur Verfügung ( $\triangleright$ Tab. 1).

Direkter Nachweis von Viruskomponenten: Elektronenmikroskopie, qualitative und quantitative DNANachweise (Real-time PCR, PCR, DNA-Hybridisierung), ELISA zum Nachweis von $\mathrm{HBeAg}$ und HBsAg. Indirekter Virusnachweis: ELISA zum Antikörpernachweis: anti-HBc-IgM und -IgG, anti-HBe und anti-HBs.

Chemische Laboruntersuchungen: Bestimmung der Aktivitäten der Transaminasen (ALT, AST), der Gamma-GT, der alkalischen Phosphatase, der Bilirubinkonzentration, der Prothrombinzeit und Durchführung einer Serumelektrophorese erlauben Aussagen über Art und Schweregrad der Leberschädigung. Eine 
Tab. 2. Serologische Marker im Verlaufe der Hepatitis B

\begin{tabular}{|l|l|l|l|l|l|l|l|}
\hline HBsAg & HBeAg & $\begin{array}{l}\text { anti- } \\
\mathrm{HBC}- \\
\text { IgM }\end{array}$ & $\begin{array}{l}\text { anti- } \\
\mathrm{HBC}\end{array}$ & $\begin{array}{l}\text { anti- } \\
\mathrm{HBe}\end{array}$ & $\begin{array}{l}\text { anti- } \\
\mathrm{HBs}\end{array}$ & $\begin{array}{l}\text { HBV- } \\
\text { DNA }\end{array}$ & Interpretation \\
\hline+ & $(+)$ & - & - & - & - & + & Inkubationsphase \\
\hline+ & + & + & + & - & - & + & akute Hepatitis B (frühe Phase) \\
\hline+ & $-/+$ & + & + & $+/-$ & - & ++ & akute Hepatitis B (späte Phase) \\
\hline- & - & - & + & + & + & - & $\begin{array}{l}\text { abgelaufene HB-Infektion, frühe } \\
\text { Immunität }\end{array}$ \\
\hline- & - & - & + & - & + & - & Spätrekonvaleszenz \\
\hline- & - & - & - & - & + & - & Immunität nach Impfung \\
\hline+ & $+/-$ & $+/-$ & + & $-/+$ & - & + & chronisch aktive Hepatitis \\
\hline+ & + & - & + & - & - & + & Trägerstatus, hohe Infektiosität \\
\hline+ & - & - & + & + & - & $(+)$ & Trägerstatus, geringe Infektiosität \\
\hline
\end{tabular}

Differenzierung von anderen Virushepatitiden erfordert jedoch die Bestimmung der Hepatitis-B-Antigene und -Antikörper.

\section{Befund / Interpretation}

In $>$ Tab. 2 ist das zeitliche Auftreten der HBV Marker in verschiedenen Phasen der Hepatitis-B-Virusinfektion dargestellt.

Bei Verdacht auf eine Hepatitis-B-Infektion sollte als erster Schritt HBsAg (Nachweis ab ca. 100 pg/ml) und anti-HBc-IgG aus dem Serum bestimmt werden. Die Höhe der anti-HBc-IgM Antikörper geben einen Hinweis auf das Stadium der Erkrankung (Werte > 500 PEI Einheiten sprechen für akute Hepatitis). Der Nachweis von $\mathrm{HBeAg}$ korreliert in der Regel mit einer hohen Virämie $\left(\geq 10^{6}\right.$ Genomäquivalente/ml). Ein akutselbstlimitierter Verlauf ist in der Regel durch den Abfall des HBsAg innerhalb von sechs Wochen um mehr als 50 Prozent mit Verlust von HBeAg und HBV-DNA gekennzeichnet. Anti-HBe verschwindet in der Regel einige Jahre nach der akuten-selbstlimitierten Hepatitis. Bei isoliert anti-HBc-positiven Patienten, insbesondere bei Koinfektionen mit HIV, ist die Bestimmung der HBV-DNA indiziert.

\section{Therapie}

\section{Therapeutische Maßnahmen}

Gegenwärtig sind in Europa für die Therapie der chronischen Hepatitis B Interferon- $\alpha$ (IFN- $\alpha$ ) und pegyliertes IFN- $\alpha$ zugelassen, daneben drei Nukleosidanaloga (Lamivudin, Telbivudin, Entecavir) und zwei Nukleotidanaloga (Adefovir Dipivoxil, Tenofovir Disoproxil).

Eine Therapieindikation besteht in der Regel, wenn
Patient HBV-DNA-positiv ist und zwei der drei folgenden Kriterien erfüllt sind:

- Virusreplikation von $\geq 10^{4}$ Viruskopien $/ \mathrm{ml}$,

- fortgeschrittene Fibrose, Zirrhose,

- erhöhte Transaminasen.

Therapieziele sind das Verschwinden von HBV-DNA und (wenn vorhanden) $\mathrm{HBeAg}$ sowie anhaltende Normalisierung der Transaminasen. Die immunstimulatorische Therapie mit IFN- $\alpha$ über 6 Monate oder pegyliertem Interferon über $1 \mathrm{Jahr}$ ist bei bis zu $40 \%$ der Patienten erfolgreich, bei ca. $10 \%$ verschwindet später auch HBsAg, wobei die Ansprechrate vom Genotyp abhängt $(\mathrm{A}>\mathrm{B}>\mathrm{C}>\mathrm{D})$. Nukleosid- und Nukleotidanaloga hemmen die Virusreplikation direkt und effektiv und sind sehr gut verträglich. Sie werden erfolgreich bei der Therapie chronischer HBV-Infektionen von immunsupprimierten Patienten, nach Lebertransplantation zur Verhinderung einer Reinfektion und jüngst auch bei Patienten mit fortgeschrittener Leberfibrose sowie bei HBeAg-negativen Patienten mit Leberzirrhose zur Verringerung des HCC-Risikos eingesetzt. Da die Behandlung i. d. R. nicht zur Elimination der cccDNA führt, muss sie dauerhaft erfolgen. Problem dabei ist das Auftreten resistenter Virusvarianten, das vor allem bei Behandlung mit Lamivudin ausgeprägt ist, bei Entecavir und Tenofovir aber eher gering zu sein scheint.

\section{Resistenz}

Bei 18 bis $20 \%$ der Patienten treten unter Therapie innerhalb des ersten Jahres bereits Lamivudin-resistente Mutanten auf, und nach vier Jahren liegen sie bei ca. $70 \%$ der Patienten vor. Trotz der Mutanten kann bei 
Fortsetzung der Therapie bei einem Teil der Behandelten eine Serokonversion zu anti-HBe mit Normalisierung der Transaminasen eintreten. Als Alternative kann Adefovir eingesetzt werden, das meist auch bei Vorliegen von Lamivudin-Resistenzen wirksam ist. Adefovir-resistente Mutanten treten später und seltener auf (in $2 \%, 18 \%$ bzw. bis zu $28 \%$ der Patienten innerhalb des ersten, vierten bzw. fünften TherapieJahres). In bis zu $28 \%$ der Patienten mit LamivudinResistenzen kommt es aber unter Adefovir trotz fehlender Adefovir-Resistenzmutationen nur zu einer schwachen oder keiner Antwort. Bei diesen Patienten ist Tenofovir mit Erfolg eingesetzt worden.

\section{Epidemiologie}

\section{Verbreitung}

Die Zahl der jährlichen Neuinfektionen wird weltweit auf 20 Millionen geschätzt, davon allein über 100.000 in Westeuropa. In Deutschland geht die Zahl der gemeldeten Neuerkrankungen kontinuierlich zurück. 2008 wurden dem Robert-Koch-Institut 805 akute Infektionen gemeldet. Aufgrund des hohen Anteils inapparenter Verläufe muss man jedoch von einer wesentlich höheren Infektionsrate ausgehen.

Die Anzahl der HBsAg-Träger wird weltweit auf 350 Millionen geschätzt. In tropischen und subtropischen Ländern Afrikas, Mittel- und Südamerikas sowie Südund Osteuropas sind bis zu $20 \%$ der Bevölkerung chronisch infiziert. In Deutschland sind 0,7 \% der Bevölkerung HBsAg-Träger (ca. 500.000). Ca. eine Million Menschen sterben weltweit jährlich an den Folgen einer Hepatitis-B-Infektion.

Die Genotypen A und D kommen hauptsächlich in Europa und den USA vor, die Genotypen B und C sind in Asien vorherrschend, Genotyp E findet man in West Afrika, Genotypen F und $\mathrm{H}$ sind in Südamerika am häufigsten anzutreffen. Der seltene Genotyp G ist bisher in Frankreich, Georgien und den USA gefunden worden.

\section{Wirtsbereich / Reservoir}

Das natürliche Wirtsspektrum des Virus umfasst nur den Menschen. Schimpansen und Gibbons sowie Spitzmäuse (Tupaia belangeri) können experimentell infiziert werden. Das Reservoir bilden vor allem chronisch HBV-infizierte Personen. Hochvirämische Virusträger, insbesondere unerkannte, stellen eine permanente Infektionsquelle dar und sorgen für die Weiterverbreitung der Hepatitis B in der Bevölkerung.

\section{Risikogruppen}

Risikogruppen sind medizinisches Personal, Empfänger von Blutprodukten, Hämodialysepatienten, immunsupprimierte Patienten und Transplantatempfänger, Drogenabhängige, Strafgefangene, Haushaltsmitglieder und enge Kontaktpersonen von hochvirämischen Virusträgern (in Kindergärten, Schulen, etc.),
Personen mit promiskuitivem Verhalten und Neugeborene von HBsAg-positiven Müttern.

\section{Transmission / Vektoren}

HBV wird horizontal (parenteral, Sexualkontakt) und vertikal (perinatal) übertragen. Im Blut sind hohe Virustiter ( $\geq 10^{10}$ Viruspartikel $\left./ \mathrm{ml}\right)$ möglich, so dass geringste Blutmengen, z. B. nach Nadelstichverletzungen, zu einer Infektion führen können. Bei extrem hoher Virämie kann HBV auch im Speichel, Sperma und Vaginalsekret in Konzentrationen vorliegen, die eine Übertragung durch Schleimhautkontakte ermöglichen. Von HBV-Trägern mit $\leq 10^{5}$ Viruspartikeln $/ \mathrm{ml}$ ist eine Übertragung durch Intim- oder Haushaltskontakte eher unwahrscheinlich, durch medizinisches Personal bei größeren operativen Eingriffen oder von Müttern auf das neugeborene Kind aber möglich. Das Übertragungsrisiko einer HBV-Infektion durch Blutprodukte ist in Deutschland aufgrund der vorgeschriebenen Testverfahren (HBsAg, HBV-DNA, anti-HBc) extrem gering (ca. 1:360.000).

\section{Prävention / Impfstoffe}

Zur Primärprävention wird eine Impfung mit rekombinantem, heterolog exprimierten $\mathrm{HBsAg}$, das an Aluminiumhydroxid adsorbiert ist, eingesetzt. Seit 1995 empfiehlt die Ständige Impfkommission (STIKO) in Deutschland die generelle aktive Hepatitis-B-Immunisierung von Säuglingen, Kindern und Jugendlichen sowie von Risikogruppen. Die Grundimmunisierung erfolgt in der Regel durch dreifache Gabe der Vakzine in dem Zeitintervall von einem Monat zwischen den ersten beiden und sechs bis zwölf Monaten zwischen der zweiten und dritten Impfung. Der anti-HBs-Titer ein bis zwei Monate nach erfolgter Grundimmunisierung gestattet Aussagen über den Impferfolg. Liegt er über $100 \mathrm{IE} / \mathrm{l}$, ist ein Langzeitschutz für zu erwarten. Die genaue Schutzdauer ist nicht bekannt, sie dürfte aber über 15 Jahren liegen. Bei Menschen mit hohem Infektionsrisiko sollte aus Sicherheitsgründen nach 10 Jahren eine Auffrischimpfung durchgeführt werden. Menschen mit Immundefekten, aber auch fünf bis $10 \%$ der gesunden Bevölkerung sprechen auf die Impfung nicht oder schlecht an (Non-Responder, anti-HBs nach 3. Impfung 10 IE/l, und Hypo-Respondern, anti-HBs nach 3. Impfung 10-100 IE/l). Ihnen wird eine erneute Impfung mit Kontrolle empfohlen. Zur Verhinderung von Neuinfektionen sind das Blutspender-Screening auf $\mathrm{HBsAg}$ und anti-HBc, das HBsAg-Screening von Schwangeren, die kontinuierliche arbeitsmedizinische Überwachung von medizinischem Personal (HBV-Serostatus, Impfung) inklusive deren Unterweisung in adäquater Arbeitsweise (z. B. Schutzhandschuhe, Einmalspritzen, Desinfektion von medizinischen Geräten), die Information der Bevölkerung und insbesondere der Risikopersonen (Kondombenutzung, Gefahren des "needle sharings") wichtig. 


\section{Ausbruchsmanagement}

Bei möglicher akzidenteller oder perinataler Übertragung sollte je nach Impfstatus eine Postexpositionsprophylaxe mit Hepatitis-B-Immunglobulin (HBIG) und/oder HB-Impfstoff durchgeführt werden. Äußerst wichtig sind die Aufklärung von Virusträgern, die Immunisierung ihrer Kontaktpersonen sowie die Überwachung von Infektketten durch Virustypisierung. HBV ist gegenüber Detergenzien und organischen Lösungsmitteln empfindlich, gegenüber Umwelteinflüssen und Desinfektionsmitteln jedoch relativ stabil. Bei über $80^{\circ} \mathrm{C}$ sind mindestens zehn Minuten zur Inaktivierung des Virus erforderlich, bei $60{ }^{\circ} \mathrm{C}$ erfolgt eine weitgehende Inaktivierung nach zehn Stunden.

\section{Meldepflicht}

Der Verdacht auf eine akute Hepatitis-B-Infektion, Erkrankung und Tod sind durch den feststellenden Arzt an das Gesundheitsamt zu melden. Darüber hinaus muss auch der Infektionsnachweis durch das Labor gemeldet werden, sofern eine akute Hepatitis B vorliegt ( $\$ \$ 6$ und 7 Infektionsschutzgesetz). In einigen Ländern muss zusätzlich jeder Carrierstatus gemeldet werden, wenn er in der diagnostischen Einrichtung erstmalig festgestellt wird.

\section{Weiterführende Informationen}

\section{Referenzzentren / Expertenlaboratorien}

Konsiliarlaboratorium:

- Institut für Medizinische Virologie der Universität Gießen, Frankfurter Str. 107, 35392 Gießen, Telefon: 0641 9941200, www.med.uni-giessen.de

Expertenlaboratorien:

- Institut für Med. Mikrobiologie und Hygiene, der Universität Regensburg, Franz-Josef-Strauß-Allee 11, 93042 Regensburg, Telefon: 0941944 6401, www.uni-regensburg. de/Fakultaeten/Medizin/MMH

- Institut für Med. Virologie, Helmut-Ruska-Haus, Charité - Universitätsmedizin Berlin, Campus Charité Mitte, Charitéplatz 1, 10117 Berlin, Telefon: 030450 525141, www.charite.de/virologie

\section{Web-Adressen}

- Centers for Disease Control and Prevention: http://www. cdc.gov/ncidod/diseases/hepatitis/b

- Hepatitis B Foundation: http://www.hepb.org

- Robert-Koch-Institut, Merkblatt/Ratgeber HBV und Mitteilungen der Ständigen Impfkommission (STIKO): http://www.rki.de/

- www.kompetenznetz-hepatitis.de

\section{Schlüsselliteratur}

1. Cornberg M, Protzer U, Dollinger MM, Petersen J, Wedemeyer H, Berg T, Jilg W, Erhardt A, Wirth S, Schirmacher P, Fleig WE, Manns MP (2007) Prophylaxis, diagnosis and therapy of Hepatitis-B-Virus-(HBV-) infection: upgrade of the guideline, AWMF-Register 021/011. Z Gastroenterol 45:525-574

2. Ganem D, Prince AM (2004) Hepatitis B Virus infection - Natural history and clinical consequences. N Engl J Med 350:1118-1129
3. Koziel MJ, Siddiqui A (2005) Hepatitis B Virus and Hepatitis D Virus. In: Mandell, Douglas and Bennett's Principles and Practice of Infectious Diseases 6th edition. Churchill Livingstone, pp 1864-1890

4. McMahon BJ (2009) Natural history of chronic Hepatitis B Virus infection. Hepatology 49(suppl):S45-S55

5. Schaefer S, Glebe D, Gerlich WH (2010) Hepatitis-B-Virus (Hepadnaviridae). In: Doerr HW, Gerlich WH (Hrsg). Medizinische Virologie, 2. Aufl, Thieme, Stuttgart, S 345372

6. Seeger C, Zoulim F, Mason W (2007) Hepadnaviruses. In: Knipe, DM and Howley, PM (eds): Fields Virology 5th edition. Lippincott-Williams \& Wilkins, Philadelphia, pp $2977-3029$

\section{Hepatitis C}

- Hepatitis C Virus (HCV)

\section{Hepatitis C Virus (HCV)}

Helga Meisel, Wolfgang Jilg, Detlev H. Krüger

\section{Erreger}

\section{Synonym(e)}

HCV, Humanes Hepatitis-C-Virus, Post-Transfusionshepatitisvirus, Non-A-Non-B-Virus.

\section{Erregerspezies}

Hepatitis-C-Virus

\section{Taxonomie}

Aufgrund von Ähnlichkeiten mit den Flavi- und Pestiviren in Genomorganisation, Replikationsmechanismus und Prozessierung des Polyproteins wurde HCV der Familie Flaviviridae zugeordnet. Im Unterschied zu den humanen Flaviviren (z. B. Gelbfiebervirus, FSME-Virus) und den animalen Pestiviren wird HCV nicht durch Arthropoden übertragen und führt im hohen Maße zu chronischen Verläufen. Aus diesem Grund wurde HCV 1999 als ein eigenständiges Genus (Hepaciviren) in die Familie Flaviviridae eingeordnet. Interessanterweise gibt es auch eine ferne genetische Verwandtschaft von HCV zu pflanzenpathogenen Erregern (Potyviren, Carmoviren).

\section{Historie}

Nachdem klar wurde, dass mindestens ein Erreger von infektiösen Non-A-Non-B-Hepatitiden existieren müsste, wurden aus dem Plasma eines infizierten Schimpansen cDNA-Expressionsbanken hergestellt. Ihre Testung mit dem Serum eines Patienten mit einer chronischen Non-A-Non-B-Hepatitis führte 1989 zum Auffinden des ersten HCV-spezifischen Klons 5-1-1, der wiederum zur Identifizierung eines größeren Genabschnitts diente und mit Hilfe spezieller molekularer „Walking“-Techniken schließlich zur Definition des kompletten Virusgenoms führte. 


\section{Morphologie}

Das Virion wurde bisher nicht zufriedenstellend elektronenmikroskopisch dargestellt. Das 40-60 nm große Virus mit einem ikosaedrischen Nukleokapsid (circa $30 \mathrm{~nm}$ ) enthält in seiner lipidhaltigen Hülle zwei viruscodierte Proteine, E1 und E2. Neben dem Virus kommen im Serum nackte Nukleokapside vor.

\section{Genom}

NCBI-Nummer: NC001433. Das virale Genom ist eine einzelsträngige lineare RNA mit Positiv-Orientierung. Es enthält eine 5'-nichtkodierende Region (5'NCR), die einen internen Ribosomen-Eintrittsort (IRES) birgt, einen langen einzigen offenen Leserahmen und eine kurze 3'-nichtkodierende Region (3'NCR). Die Replikation erfolgt durch die virale Replikase (NS5b-Polymerase) ohne Korrekturmöglichkeit für Basen-Misspaarungen. Die resultierende hohe Mutationsrate bedingt eine große genetische Diversität des Virus. Die Verteilung der Mutationen im HCVGenom ist nicht gleichförmig, sondern es werden konservierte von den variablen und hypervariablen Regionen (im E2-Bereich) unterschieden. Nach gegenwärtigen Kenntnissen wird HCV in sieben Genotypen (1-7) mit mehr als 100 Subtypen (1a, 1b, 1c usw.) unterteilt. Diese Einteilung basiert auf dem Grad der Sequenzdivergenz (Genotypen mehr als $28 \%$, Subtypen zwischen 14 und $25 \%$ und Isolate $>12 \%$ Nukleotiddivergenz).

\section{Vermehrung}

Die Replikation findet in Hepatozyten statt. Für eine Virusreplikation in extrahepatischen Zellen (Lymphozyten) fehlen noch gesicherte Beweise. Die Virusaufnahme wird wahrscheinlich durch die Anheftung des Erregers an Glykosamine der Zelloberfläche und den „Low density lipoprotein“-Rezeptor eingeleitet, -Bindung an den Scavenger-Rezeptor Typ 1 Klasse B (SRB1) - dessen eigentliche Aufgabe die Bindung von „high density lipoprotein“ ist - und CD81 führen zur eigentlichen Infektion durch rezeptorvermittelte Endozytose. Das Ausmaß der viralen Proteinsynthese wird durch positive und negative Translationskontrollelemente in der 5'-nichtkodierenden Region der viralen mRNA beeinflusst. Bei der Translation entsteht ein Polyprotein von etwa 3000 Aminosäuren Länge, das mit Hilfe zellulärer und viraler NS2-und NS3-Proteasen in folgende Proteine zerlegt wird (vom N- zum CTerminus): Coreprotein, E1- und E2-Hüllprotein sowie die Nichtstrukturproteine p7, NS2, NS3, NS4A/B und NS5A/B. Das Protein NS3 besitzt Protease- und Helikase-Funktionen und NS5B ist eine RNA-abhängige RNA-Polymerase. Nach Translation bilden HCVRNA und die Nichtstrukturproteine im Zytoplasma wahrscheinlich einen so genannten Ribonukleoproteinkomplex, in dem Virusreplikation und post-translationale Prozessierung stattfinden. Die 3'-NCR des Genoms spielt eine essentielle Rolle in der Replikation.
Die Verpackung des Genoms scheint am Endoplasmatischen Retikulum stattzufinden. Nach Umhüllung der Nukleokapside am Golgi-Apparat werden die Viren durch Exozytose ausgeschleust.

Wenngleich eine Anzucht von HCV in der Zellkultur bisher nicht möglich ist, lässt sich die Replikation unter bestimmten Bedingungen studieren. Das erste System, das ein Studium der HCV-Vermehrung erlaubte, war das so genannte Replikon-System. Damit konnten subgenomische HCV-Konstrukte, die bestimmte kodierende Regionen enthielten, in humanen Hepatomzellen zur Vermehrung gebracht werden. Ein weiterer wichtiger Schritt war die Entdeckung eines HCV-Isolates, das in humanen Hepatomzellen repliziert und infektiöse Viruspartikel freisetzt.

\section{Pathogenität / Virulenz / Antigenvariabilität}

Die Pathogenese der Hepatitis-C-Infektion beruht zu einem großen Teil auf immunvermittelten Prozessen, die sich durch Aktivität von zytotoxischen T-Lymphozyten (CTLs) und lokale Zytokinproduktion von CD4-positiven T-Zellen und CTLs äußern. Aus klinischen Beobachtungen ist bekannt, dass immunologisch unreife oder immunsupprimierte Personen einen leichteren Krankheitsverlauf im akuten Stadium aufweisen als immunkompetente, andererseits haben immungesunde Personen mit einer symptomatischen Hepatitis C eine höhere Wahrscheinlichkeit der Ausheilung. Allerdings gibt es auch Hinweise auf eine direkte zellschädigende Wirkung des Virus. So soll das Coreprotein zur Entstehung der Steatose (Leberverfettung) beitragen und die Karzinomentstehung begünstigen. Andere virale Proteine können die Fibrogenese fördern, die Interferonantwort der Zelle unterdrücken, Membranveränderungen induzieren und ebenfalls durch Begünstigung der Transformation die Onkogenese unterstützen.

Bei der HCV-Infektion liegen im Serum der Patienten, bedingt durch die fehlende „proof reading“-Funktion der RNA-Polymerase, eng verwandte Virusmutanten (Quasispezies) vor. Das Oberflächenprotein E2 besitzt zwei hypervariable Regionen (HVR 1 und 2), die eine hohe Mutationsrate aufweisen. Die Varianten kommen am ehesten durch Selektionsdruck der humoralen Immunantwort zustande.

\section{Erkrankung}

Hepatitis C

\section{Synonym(e)}

Non-A-Non-B-Hepatitis, Posttransfusionshepatitis, Posttransplantationshepatitis.

\section{Inkubationszeit}

Im Allgemeinen entwickelt sich im Durchschnitt sieben bis acht Wochen nach HCV-Exposition die klinische Symptomatik, obgleich schon nach ca. ein bis zwei Wochen HCV-RNA im Serum nachweisbar ist. 


\section{Leitsymptome}

Vergrößerte und druckschmerzhafte Leber, Ikterus (Dunkelfärbung des Urins, Entfärbung des Stuhls), Hepatomegalie.

\section{Symptome}

Bei zirka 80 \% der Infizierten verläuft die akute Infektion symptomarm oder klinisch inapparent. Abgeschlagenheit, Appetitlosigkeit und Übelkeit gehören zu den am häufigsten beschriebenen Symptomen. Die Transaminasen sind im Gegensatz zur akuten Hepatitis A oder B nur mäßig erhöht. Ikterische Verläufe sind selten (15-20 \%) und lassen sich nicht von einer akuten Hepatitis A oder B unterscheiden. Fulminante Hepatitiden sind eine Rarität. Abhängig von viralen $(\mathrm{Ge}-$ notyp, Infektionsdosis, Replikationsrate) und wirtsspezifischen (Alter, Immunstatus, HLA-Typen) Faktoren entwickelt sich bei 70 bis $85 \%$ der Infizierten eine chronische Hepatitis.

In der Regel verläuft die chronische HCV-Infektion lange Zeit symptomlos oder mit nur wenig ausgeprägten Symptomen wie Müdigkeit, Leistungsschwäche, Appetitlosigkeit oder Muskel- und Gelenkbeschwerden. Transaminasen sind häufig normal oder nur mäBig erhöht, im letzteren Fall sind fluktuierende Transaminasewerte typisch. Häufig finden sich allerdings schon in frühen Stadien deutliche histologische Veränderungen der Leber. Viele Patienten mit einer chronischen Hepatitis C - in manchen Studien mehr als die Hälfte - weisen trotz normaler Transaminasen histologisch Zeichen einer chronischen Hepatitis und eine manchmal bereits ausgeprägte Fibrose auf. Klinische Symptome einer schweren Lebererkrankung werden allerdings oft erst nach jahrzehntelangem Verlauf sichtbar. Wie häufig allerdings ein solcher Fall eintritt, ist nach wie vor nicht genau bekannt. Die Rate der chronisch infizierten Patienten, die eine Leberzirrhose entwickeln, schwankt in verschiedenen Studien zwischen einigen wenigen und über vierzig Prozent. Auf dem Boden der Leberzirrhose kann sich ein hepatozelluläres Karzinom entwickeln.

$\mathrm{Zu}$ den Faktoren, die den Krankheitsverlauf beschleunigen können, gehören männliches Geschlecht, höheres Infektionsalter, Alkoholgenuss, Immunsuppression und Koinfektionen insbesondere mit HIV. Der Grad der Leberfibrose dient als ein prognostischer Marker für den Ausgang der chronischen Hepatitis. Eine spontane Viruselimination und Ausheilung kommt bei Patienten mit chronischer Hepatitis $\mathrm{C}$ praktisch nicht mehr vor.

Hepatitis-C-Infektionen können auch mit extrahepatischen Manifestationen verbunden sein. HCV-Infektionen sind Hauptursache für gemischte Kryoglobulinämien (Typ II), die mit Vaskulitis, Purpura, Arthralgien, membranoproliferativer Glomerulonephritis, Polyneuropathien oder einem Raynod-Phänomen einhergehen können. Ein Zusammenhang scheint auch mit dem Auftreten von lymphoproliferativen Er- krankungen wie Non-Hodgkin-Lymphomen und Gammopathien zu bestehen, ebenso mit Porphyria cutanea tarda und Lichen ruber planus. Mit chronischen HCV-Infektionen in Verbindung gebracht werden auch autoimmune Schilddrüsenerkrankungen, das Sicca-Syndrom und Diabetes mellitus.

Bei Lebertransplantierten ist die HCV-Infektion die zweithäufigste Ursache (nach HCMV-Infektionen) einer Posttransplantationshepatitis. Nahezu alle Patienten, die wegen einer HCV-bedingten Lebererkrankung transplantiert werden, entwickeln kurz nach Transplantation eine HCV-Reinfektion. Diese nimmt zwar in der Mehrzahl der Fälle einen milden Verlauf, dennoch haben diese Patienten ein höheres Risiko eines Transplantatversagens und eine höhere Letalität als HCV-negative Transplantatempfänger. Zehn bis 25 Prozent entwickeln innerhalb von fünf bis zehn Jahre eine Zirrhose.

\section{Pathophysiologie}

Die histologischen Befunde bei der akuten und chronischen Hepatitis $\mathrm{C}$ unterscheiden sich nicht von denen bei anderen Virushepatitiden: Bei akuten Hepatitiden treten hepatozelluläre Nekrosen mit Entzündungszellen (Makrophagen, Lymphozyten) im Leberparenchym und in der portalen Region auf. Die schwere chronische Hepatitis $\mathrm{C}$ ist histologisch durch inflammatorische Destruktion und progressive Fibrose gekennzeichnet. Verschiedene Scoring-Systeme erfassen sowohl die Aktivität als auch das Stadium einer chronischen Hepatitis. Bei der chronischen Hepatitis C bilden sich typischerweise lymphoplasmazelluläre Infiltrate in den Portalfeldern. Daneben treten wie bei anderen chronischen Virushepatitiden auch Nekrosen (Mottenfraßnekrosen, intralobuläre Nekrosen), Leberparenchymverfettung und Fibrose auf.

\section{Immunantwort}

Bei der HCV-Infektion werden Antikörper gegen Struktur- und Nichtstrukturproteine gebildet. Obwohl jene gegen die hypervariable Region 1 (HVR1) von E2 neutralisierend wirken, scheint ihr Auftreten nur im frühen Stadium der Infektion zu einem limitierten Verlauf beizutragen. Neben der angeborenen Immunität (NK-Zellen, IFN) ist während der akuten HCVInfektion eine starke multispezifische Immunantwort von $\mathrm{CD}_{4}^{+}$- und $\mathrm{CD}^{+}-\mathrm{T}$-Zellen für die erfolgreiche Viruselimination entscheidend. Bei chronisch infizierten Patienten wurden abgeschwächte T-Zell-Antworten beobachtet. HCV-spezifische $\mathrm{CD} 4^{+}$-T-Zellen können im Gegensatz zu den Antikörpern und $\mathrm{CD}^{+}{ }_{-}^{-}$ T-Zellen noch Jahrzehnte nach akut limitierter HCVInfektion nachgewiesen werden und stellen somit einen Marker für eine durchgemachte, bereits seronegative Hepatitis C dar.

\section{Differenzialdiagnose}

Das klinische Bild einer Hepatitis kann durch Infek- 
tionen mit verschiedenen Viren (inklusive EBV und $\mathrm{CMV}$ ), Leptospiren oder Rickettsien hervorgerufen werden. Neben Infektionen sind toxische, medikamentöse und alkoholische Ursachen für eine Hepatitis in Betracht zu ziehen. Eine Vielzahl von anderen Infektionserkrankungen kann mit einer Leberbeteiligung einhergehen. Die chronische Hepatitis $\mathrm{C}$ muss von der chronischen Hepatitis B, von der alkoholischen Hepatitis, von chronischen Cholangitiden, Morbus. Wilson und der Hämochromatose abgegrenzt werden. Neben serologischen und molekularbiologischen Untersuchungen ist für die endgültige Diagnose eine Leberbiopsie empfehlenswert, wenn sich daraus Konsequenzen für Verlaufsbeurteilung und/oder Therapie ableiten lassen.

\section{Diagnostik}

\section{Untersuchungsmaterial}

Als Untersuchungsmaterialien werden Serum, EDTABlut und Leberbioptate verwendet.

\section{Diagnostische Verfahren}

Direkter Nachweis von Viruskomponenten: Der Nachweis von HCV-RNA (Virämie) kann in Serum/ EDTA-Blut oder im Leberbioptat erfolgen. Klinisch werden zum Screening qualitative Teste (Real-Time RT-PCR und andere Nukleinsäure-AmplifikationsTechniken, wie Transcription-Mediated Amplification [TMA] und Nucleic Acid Sequence Based Amplification [NASBA]) eingesetzt. Für Verlaufskontrollen kommen quantitative Verfahren zur Anwendung (Real Time RT-PCR [LightCycler, Taqman] und spezielle Hybridisierungen [„Branched“-DNA-signal-amplification-Assay]). Die HCV-Viruslast wird in internationalen Einheiten (IE/ml) der WHO gemessen. Mit einigen kommerziellen Kits zur qualitativen und quantitativen HCV-Bestimmung wird eine untere HCV-RNANachweisgrenze von $15 \mathrm{IE} / \mathrm{ml}$ Plasma erreicht. Die Bestimmung des HCV-Genotyps/Subtyps, die therapeutische Konsequenzen hat, ist über die RT-PCR mittels typspezifischer Primer, Hybridisierung mit spezifische Gensonden, Bestimmung des Restriktionsfragmentlängen-Polymorphismus oder über die Verwendung Typ-spezifischer Antikörper möglich.

HCV-Core-Antigen ist ein weiterer diagnostischer Marker für die Antikörper-negative Frühphase und für das Therapiemonitoring. Seit kurzem steht ein kommerziell erhältlicher ELISA zum quantitativen Nachweis von HCV-Core-Ag zur Verfügung mit einer ähnlichen Sensitivität wie die RNA-Nachweisverfahren. Indirekter Virusnachweis: Für den Nachweis von virusspezifischen Antikörpern aus dem Serum gegen das Coreprotein und verschiedene Nichtstrukturproteine aus dem NS3-, NS4-, und NS5-Bereich stehen kommerzielle ELISA mit hoher Sensitivität und Spezifität sowie Immunoblots zur Bestätigung positiver und „indeterminate“ ELISA-Ergebnisse zur Verfügung.
Chemische Laboruntersuchungen: Die Bestimmung der Transaminasen, der Lebersyntheseparameter oder der Bilirubinkonzentration erlaubt allein keine Diagnose einer HCV-Infektion, liefert aber Hinweise auf das Ausmaß der Leberschädigung und ist nützlich für das Verfolgen des Krankheitsverlaufes.

\section{Befund / Interpretation}

Der HCV-RNA-Nachweis ist unter anderem indiziert bei Verdacht auf eine akute Hepatitis C bei Seronegativität, zur Absicherung der Diagnose einer chronischen Hepatitis, bei Verdacht auf eine perinatale Infektion, zur Beurteilung der Infektiosität von asymptomatischen anti-HCV-Trägern, zur Indikationsstellung und Verlaufskontrolle der antiviralen Therapie, zur Bestimmung des Genotyps und für epidemiologische Untersuchungen. HCV-RNA oder HCV-Core-Ag ohne Nachweis von anti-HCV ist typisch für die Frühphase der akuten HCV-Infektion. Verlaufsuntersuchungen zur Erfassung der Serokonversion werden empfohlen.

Ein bestätigter anti-HCV-Antikörpernachweis beweist einen stattgehabten Kontakt mit HCV. Er erlaubt aber keine Unterscheidung zwischen einer akuten, chronischen oder abgelaufenen Infektion. Bei ca. 90 \% der Patienten mit akuter Hepatitis C sind HCV-Antikörper im Transaminasengipfel nachweisbar. Bei immunsupprimierten Patienten fehlt jedoch häufig in der akuten Phase die Antikörperantwort, so dass der Nachweis der HCV-Infektion nur über die PCR erfolgen kann.

Ein negativer HCV-RNA-Befund schließt eine HCVInfektion nicht aus, weil nicht selten die Virämie fluktuiert. Ein wiederholt negatives HCV-PCR-Ergebnis bei anti-HCV-positiven Personen spricht aber für eine ausgeheilte HCV-Infektion.

Bei chronischen Verläufen ist eine Leberbiopsie zur Beurteilung der Entzündungsaktivität und des Fibrosegrades sinnvoll. Zur alleinigen Beurteilung einer Leberfibrose können auch nicht-invasive Verfahren eingesetzt werden.

\section{Therapie}

\section{Therapeutische Maßnahmen}

Eine akute Hepatitis C kann durch frühzeitige, 24-wöchige Interferon-alpha (IFN- $\alpha$ )-Monotherapie in fast allen Fällen (98 \%) geheilt werden.

Das Ziel der Therapie einer chronischen Hepatitis C ist die dauerhafte Viruseliminierung. Dadurch können die Progression der Lebererkrankung verhindert, extrahepatische Manifestationen geheilt und das Risiko eines hepatozellulären Karzinoms verringert werden. Als Standard-Therapie der chronischen Hepatitis C gilt derzeit die Kombination von pegyliertem IFN- $\alpha$ (Peg-IFN- $\alpha$ ) und Ribavirin über 24 (Genotyp 2 oder 3) oder 48 Wochen (Genotyp 1). Die Erfolgsrate der Behandlung hängt von verschiedenen Faktoren, wie Alter, Geschlecht, Genotyp, Viruslast und Fibrosie- 
rungsgrad ab. Bei Patienten mit HCV-Genotypen 2 oder 3 wird ein dauerhafter Erfolg in $>80 \%$, beim besonders schwer therapierbaren Genotyp 1 in ca. $50 \%$ der Fälle erreicht. Zur Verlaufskontrolle wird die HCVRNA nach 4 und 12 Therapiewochen quantitativ bestimmt, da die Höhe der Viruslast zu diesen Zeitpunkten Vorhersagen über den Therapieausgang ermöglicht. Die Behandlung kann so an die individuelle Situation des Patienten angepasst und verkürzt, verlängert oder auch abgebrochen werden. Wenn nach 3 (Genotypen 2 und 3) bzw. 6 (Genotyp 1) Monaten Therapie HCV-RNA noch nachweisbar ist, wird ein Therapieabbruch empfohlen. Bei Kontraindikation gegenüber Ribavirin kann auch eine Monotherapie mit IFN- $\alpha$ durchgeführt werden.

Bei lebensbedrohlicher Leberzirrhose bleibt die Lebertransplantation als ultima ratio.

\section{Resistenz}

Gegen Interferon und Ribavirin sind keine direkten Resistenzentwicklungen bekannt.

Allerdings kann es zu Therapie-Versagen kommen, das auch von virologischen Faktoren abhängig ist (besonders häufig bei den Genotypen 1 und 4). Die molekularen Ursachen für die unterschiedliche Sensitivität verschiedener HCV-Stämme und -Genotypen sind nach wie vor ungeklärt.

\section{Epidemiologie}

\section{Verbreitung}

Ungefähr $3 \%$ (circa 170 Millionen) der Bevölkerung weltweit sind mit HCV chronisch infiziert; in Deutschland sind es zurzeit ca. 500.000 Personen. Die durchschnittlichen Antikörperprävalenzen variieren zwischen ungefähr $0,4 \%$ in Deutschland und 5,3\% in Afrika. Die Genotypen 1-3 kommen weltweit vor, die Genotypen 4 und 5 findet man hauptsächlich im Vorderen Orient und in Afrika, Genotyp 6 in Asien. Über die Verbreitung des Genotyps 7 ist bisher nichts bekannt. Der Subtyp 1b kommt weltweit am häufigsten vor und ist zurzeit in Deutschland für ca. die Hälfte aller Infektionen verantwortlich. Bei den unter 20-Jährigen dominiert mittlerweile der Subtyp 1a mit etwa $60 \%$ Anteil unter den HCV-Infizierten, während bei den über 50-Jährigen der Subtyp $1 \mathrm{~b}$ am häufigsten auftritt. Nach Angaben des Robert-Koch-Instituts werden in Deutschland jährlich 5.000-9.000 Hepatitis-C-Infektionen erstmals diagnostiziert, mit allmählich abnehmender Tendenz (2009: 5.236). Hohe Antikörperprävalenzen finden sich bei Angehörigen von Risikogruppen. Insbesondere die Durchseuchung von i.v.-Drogensüchtigen ist weiterhin hoch und kann in Kollektiven mit mehrjährigem Drogengebrauch bei über $80 \%$ liegen. Bei den Drogenabhängigen wird häufig der Subtyp 3a nachgewiesen. Die HCV-Ausbreitung in Entwicklungsländern ist wenig verstanden. Möglicherweise geschieht sie hier durch Mehrfachbenutzung kontaminierter medizinischer Instrumente oder durch Gegenstände für rituelle Handlungen. Circa ein Fünftel aller neu auftretenden hepatozellulären Karzinome werden auf eine HCV-Infektion zurückgeführt.

\section{Wirtsbereich / Reservoir}

Der Mensch ist der einzige bekannte natürliche Wirt. Schimpansen lassen sich experimentell infizieren.

\section{Risikogruppen}

Intravenös Drogenabhängige, Hämophiliepatienten und Empfänger von Blut und Blutprodukten, Dialysepatienten, Transplantatempfänger, Personen mit häufig wechselnden Sexualpartnern.

\section{Transmission / Vektoren}

Die Übertragung von HCV erfolgt parenteral, hauptsächlich durch Blut und Blutprodukte und in Deutschland überwiegend durch i.v.-Drogenkonsum. Nach Einführung des HCV-Screenings (PCR) aller Blutspenden im Jahr 1999 zum Ausschluss von Risikogruppen ist in Deutschland das Risiko einer transfusionsbedingten Hepatitis C auf ca. 1:13.000.000 gesunken. Auch die mit Transplantationen übertragenen HCV-Infektionen sind deutlich gesenkt worden. Die Virustransmission durch Intimkontakt, perkutan innerhalb von Familien oder vertikal von der Mutter zum Kind spielt eine weit geringere Rolle. Das Risiko für vertikale Übertragung erhöht sich bei Koinfektion mit HIV. Nosokomiale Infektionen spielen immer noch eine Rolle. Bei einem Teil der HCV-Infektionen sind Infektionsquelle und Übertragungsweg nicht nachvollziehbar.

\section{Prävention / Impfstoffe}

Die Primärprävention besteht zurzeit in der Expositionsprophylaxe, hauptsächlich über die Kontrolle und Virusinaktivierung von transfundiertem Blut und Blutprodukten (inklusive PCR-Screening) und über die Aufklärung von Risikogruppen, insbesondere von i.v.-Drogenabhängigen. Zum einen ist es notwendig, auf globaler Ebene Screening von Blut und Blutprodukten inklusive Standardisierung bei der Auswahl von Spendern, Einhaltung von „Good Laboratory Practice", technischer Unterstützung und Qualifizierung von Personal durchzusetzen. Zum anderen müssen Beschäftigte im Gesundheitswesen (inklusive traditioneller Medizin) über den Übertragungsweg von HCV informiert werden, so dass angemessen Injektionstechniken, Hygieneregeln, Schutzmaßnahmen (z. B. das Tragen von Handschuhen), Sterilisation und Desinfektion beziehungsweise Verwendung von „Einmalmaterialien" angewendet werden.

Eine aktive oder passive Immunisierung existiert nicht. Die Entwicklung eines Impfstoffes ist durch die hohe Genomvariabilität erschwert. Neben Impfversuchen mit E2-Protein werden andere Strategien zur Impfstoffentwicklung verfolgt, zu denen DNA-Vakzi- 
ne, virusähnliche Partikel oder rekombinante virale Vektoren gehören.

\section{Ausbruchsmanagement}

Infektketten sind zu verfolgen und Infektionsquellen zu identifizieren. HCV-infizierte Patienten sollten behandelt werden, um so die Komplikationen Leberzirrhose und HCC zu vermeiden. Nach Nadelstichverletzungen muss engmaschig kontrolliert werden. Bei medizinischem Personal ist die kontinuierliche Überprüfung des HCV-Serostatus erforderlich. Bei antiHCV-positivem Personal wird eine HCV-RNA-Bestimmung mindestens einmal im Abstand von 2 bis 3 Monaten empfohlen.

HCV kann durch Inkubation mit lipidlösenden Detergenzien inaktiviert werden. In wässrigen Medien wird das Virus durch Hitze $\left(60^{\circ} \mathrm{C}\right.$ für zehn Stunden, $100^{\circ} \mathrm{C}$ für zwei Minuten) inaktiviert. Es ist auch empfindlich gegen Frieren und Tauen sowie Aufbewahrung bei Raumtemperatur.

\section{Meldepflicht}

Nach Infektionsschutzgesetz (IfSG $\$ \$ 6$ und 7) müssen akute Hepatitis-C-Infektionen oder der Nachweis einer HCV-Infektion, soweit nicht schon eine chronische HCV-Infektion bekannt ist, gemeldet werden. In einigen Bundesländern ist darüber hinaus jeder antiHCV-Träger nach Länderverordnung meldepflichtig.

\section{Weiterführende Informationen}

\section{Referenzzentren / Expertenlaboratorien}

Nationales Referenzzentrum:

- Institut für Virologie der Universität Essen, Hufelandstr. 55, 45147 Essen,

- Telefon: 0221723 3550, www.uni-essen.de/virologie

Expertenlaboratorien:

- Institut für Medizinische Mikrobiologie und Hygiene der Universität Regensburg, Franz- Josef-Strauß-Allee 11, 93042 Regensburg, Telefon: 09419446401

- www.uni-regensburg.de/Fakultaeten/Medizin/MMH

- Institut für Med. Virologie, Helmut-Ruska-Haus, Charité - Universitätsmedizin Berlin, Campus Charité Mitte, Charitéplatz 1, 10117 Berlin, Telefon: 030450 525141, www.charite.de/virologie

- Institut für Med. Mikrobiologie und Immunologie des Universitätsklinikums, Martinistr. 52, 20251 Hamburg, Telefon: 04047172150

- www.uke.uni-hamburg.de/institute/infektionsmedizin

- Robert-Koch-Institut, Nordufer 20, 13353 Berlin, Telefon: 018887542379

- www.rki.de

\section{Web-Adressen}

- Centers for Disease Control and Prevention: http:// www. cdc.gov/ncidod/diseases/ hepatitis/c/

- Robert-Koch Institut: http://www.rki.de (dort siehe Infektionskrankheiten)

- Medscape: http://id.medscape.com/Medscape/ features/ ResourceCenter/HepC/public/ RC-index-HepC.html

- www.kompetenznetz-hepatitis.de

\section{Schlüsselliteratur}

1. Bartenschlager R (2010) Hepatitis-C-Virus - Grundlagen. In: Doerr HW, Gerlich WH (Hrsg) Medizinische Virologie, 2. Aufl. Thieme, Stuttgart, S. 402-408

2. Dienstag JL, McHutchison JG (2006) American Gastroenterological Association Technical Review on the management of Hepatitis C. Gastroenterology, 130:231-264

3. Lemon SM et al (2007) Hepatitis C Virus. In: Knipe DM and Howley PM (eds) Fields Virology 5th edition. Lippincott-Williams \& Wilkins, Philadelphia, pp 1253-1304

4. Peveling-Oberhag J, Zeuzem S, Sarrazin C (2010) Hepatitis-C-Virus - Klinik und Therapie. In: Doerr HW, Gerlich WH (Hrsg) Medizinische Virologie, 2. Aufl. Thieme, Stuttgart, S. 416-424

5. Roggendorf M, Roß RS (2010) Hepatitis-C-Virus - Diagnostik und Prävention. In: Doerr HW, Gerlich WH (Hrsg) Medizinische Virologie, 2. Aufl. Thieme, Stuttgart, S. 408416

6. Thomas DL, Ray SC, Lemon SM (2005) Hepatitis C. In: Mandell, Douglas and Bennett's Principles and Practice of Infectious Diseases 6th edition. Churchill Livingstone, pp 1950-1981

7. Zeuzem S, Berg T, Moeller B, Hinrichsen H, Mauss S, Wedemeyer H, Sarrazin C, Hueppe D, Zehnter E, Manns MP(2009) Expert opinion on the treatment of patients with chronic hepatitis C. J Viral Hepat 16:75-90

\section{Hepatitis D}

- Hepatitis D Virus (HDV)

\section{Hepatitis-Delta-Virus}

- Hepatitis D Virus (HDV)

\section{Hepatitis D Virus (HDV)}

Wolfgang Jilg, Helga Meisel, Detlev H. Krüger

\section{Erreger}

Synonym(e)

Hepatitis-Delta-Virus, HDV.

\section{Erregerspezies}

Hepatitis-D-Virus

\section{Taxonomie}

HDV verfügt über das kleinste Genom der bisher bekannten animalen Viren und besitzt hinsichtlich seiner Genomstruktur und Genexpression bestimmte Gemeinsamkeiten mit in Pflanzen oder Tieren vorkommenden subviralen Agenzien (Viroide, Satellitenviren). HDV ist ein defektes RNA-Virus, das für die Infektion von Zellen die Hülle des Hepatitis-B-Virus (HBV) oder anderer Hepadnaviren besitzen muss. Das International Committee on Taxonomy of Viruses (ICTV) hat für die Einordnung von HDV das Ge- 
nus Deltavirus kreiert, das den Einzelstrang-RNA-Satelliten zugeordnet ist.

\section{Historie}

1977 wurde vom Turiner Gastroenterologen Mario Rizetto ein neues Antigen (Delta) in den Kernen der Hepatozyten von Patienten mit besonders schweren Hepatitis-B-Verläufen nachgewiesen. Zunächst wurde das Antigen für eine neue Variante des HBV-CoreProteins gehalten. Durch Infektionsexperimente an HBV-infizierten Schimpansen Anfang der 80er Jahre konnte es jedoch als das Nukleokapsid-Protein (HDProtein) eines neuen menschlichen Hepatitiserregers, des Hepatitis Delta Virus (HDV), identifiziert werden. Die Klonierung und Sequenzierung des HDV-Genoms im Jahre 1986 zeigte seine strukturelle Ähnlichkeit mit pflanzenpathogenen Viroiden.

\section{Morphologie}

HDV ist ein sphärisches, umhülltes MinusstrangRNA-Virus mit einem Durchmesser von 36 bis $43 \mathrm{~nm}$. HDV kodiert für ein einziges Protein (HD-Protein, HDAg), welches als kleines (SHD, ca. $24 \mathrm{kDa}$ ) und großes (LHD, ca. $27 \mathrm{kD}$ ) Protein vorkommt. Beide Formen bilden mit der circa 1,7 kb großen genomischen RNA einen Ribonukleoproteinkomplex mit einer sphärischen, core-ähnlichen Struktur (ca. $19 \mathrm{~nm}$ Durchmesser). Das HBs-Antigen in der lipidhaltigen Hülle besteht zu $95 \%$ aus dem kleinen HBs-Antigen (SHBs, Hauptprotein der Hülle des HBV).

\section{Genom}

NCBI: NC001653. Das HDV-Genom besteht aus einer einzelsträngigen zirkulären RNA mit negativer Polarität von etwas weniger als 1,7 kb Länge. Etwa $70 \%$ der Nukleotide paaren miteinander, so dass unter nichtdenaturierenden Bedingungen eine doppelsträngige, stäbchenförmige Struktur entsteht. Die HDV-RNA enthält ein offenes Leseraster (ORF) in der genomischen und anti-genomischen Orientierung, das für das HD-Protein kodiert. Dessen Nukleotidsequenz ist in allen HDV-Isolaten konserviert. Die zweite interessante Eigenschaft der HDV-RNA neben ihrer viroidähnlichen Struktur besteht darin, dass sie während der Replikation als Ribozym (katalytische RNA) wirken kann. Das HDV Genom ist hochvariabel. Bis vor kurzem erfolgte eine Unterscheidung in 3 Genotypen bzw. 7 Stämme, die in ihren Nukleotidsequenzen bis zu $40 \%$ voneinander abweichen. Gegenwärtig werden die weltweit gesammelten HDV-Isolate in 8 Gruppen HDV-1 (früher Genotyp 1), HDV-2 (früher Genotyp 2a), HDV-3 (früher Genotyp 3), HDV-4 (früher Genotyp 2b) und HDV-5 bis HDV-8 klassifiziert.

\section{Vermehrung}

Die Anheftung und der Eintritt von HDV in den Hepatozyten erfolgt sicherlich über das große HepatitisB-Virus-Oberflächenprotein (LHBs) des HBV. Die
HDV-RNA-Replikation ist unabhängig vom Helfervirus HBV. Sie vollzieht sich mit Hilfe zelleigener Polymerasen (RNA-Polymerase II und wahrscheinlich Pol I) im Zellkern über einen „,double-rolling-circle“Mechanismus, in den sowohl der genomische als auch der antigenomische RNA-Strang involviert sind. Dabei werden multimere RNA-Stränge von Genom und Antigenom gebildet, die anschließend in 1,7-kb-Monomere geschnitten, zirkularisiert und kontinuierlich wieder transkribiert werden. Spaltung und Ligation werden durch die HDV-RNA selbst katalysiert. Parallel zur Replikation wird eine lineare antigenomische RNA von 800 Basen Länge transkribiert, von der zunächst SHD translatiert und in den Kern zurücktransportiert wird, wo es die HDV-RNA-Replikation initiiert und aufrecht erhält. Ein RNA-Editing durch die zelluläre RNA-abhängige Adenosin-Desaminase führt dann zur Ablösung der Synthese von SHD durch LHD mit 19 zusätzlichen AS. Dieses Protein hemmt die genomische RNA-Synthese und führt zur Translokation des HD-Ribonukleoproteins zum Endoplasmatischen Retikulum, wo es für die Wechselwirkung mit dem HBsAg während der Virusassemblierung und für die Virussekretion benötigt wird. SHD und LHD werden zu etwa gleichen Anteilen in die Viruspartikel inkorporiert. Insgesamt verläuft die Vermehrung sehr effizient, da bis zu $2 \times 10^{11} \mathrm{HDV}$-Viruspartikel $/ \mathrm{ml}$ während der Inkubationszeit im Patientenserum nachweisbar sein können.

\section{Pathogenität / Virulenz / Antigenvariabilität}

Für die Pathogenität des Virus werden zwei Mechanismen, die direkte sowie die immunbedingte Zytopathogenität, diskutiert. In-vitro-Studien zeigten, dass eine hohe SHD-Protein-Expression mit hoher HDV-Replikation Zytotoxozität induziert. Klinische Studien und Ergebnisse der Leberhistologie von Patienten mit HDInfektion sprechen aber eher gegen einen direkten zytopathischen Effekt des Virus, so dass wie im Falle der anderen hepatotropen Viren spezifische Immunmechanismen für die Schädigung der infizierten Zellen verantwortlich gemacht werden. Für einen immunvermittelten Mechanismus spricht der Nachweis einer CD4-positiven T-Zell-Antwort (Th1 oder Th0) mit Nachweis von Zytotoxizität in bestimmten Assays bei Patienten mit HDV-Superinfektionen. Ähnlich wie das Hepatitis-C-Virus induziert HDV Autoantikörper, wie z. B. gegen eine mikrosomale uDP-Glucuronyltransferase.

Inwieweit die geografisch unterschiedlich vorkommenden Genotypen von HDV eine unterschiedliche Virulenz besitzen, ist ebenfalls unklar. Der nur in Ostasien nachgewiesene Genotyp 2 scheint nur milde klinische Verläufe auszulösen, während bei dem in Südamerika isolierten Genotyp 3 zusammen mit dem Genotyp F von HBV besonders schwer verlaufende Hepatitis-D-Infektionen gesehen wurden. Der weltweit am häufigsten vorkommende Genotyp 1 führt 
dagegen zu in ihrem Schweregrad in weiten Grenzen schwankenden Infektionen einschließlich Fällen fulminanter Hepatitis.

\section{Erkrankung}

Hepatitis D

\section{Synonym(e)}

Virushepatitis D, Deltahepatitis

\section{Inkubationszeit}

In Infektionsexperimenten an Schimpansen wurde die Inkubationszeit von vier bis 20 Wochen bei Simultaninfektion und von drei bis sechs Wochen bei Superinfektion ermittelt.

\section{Leitsymptome}

Ikterus, erhöhte Transaminasen, Hepatosplenomegalie, Oberbauchbeschwerden.

Bei HBV-HDV-Simultaninfektion: analog zur HBVInfektion, z. T. Erkrankungsintensität deutlicher ausgeprägt.

Bei HDV-Superinfektion: Krankheitsexazerbation der chronischen Hepatitis B mit klinischem Bild der akuten Hepatitis.

\section{Symptome}

Das klinische Krankheitsbild und der Verlauf der HDV-Infektion sind von einer bestehenden oder simultanen Infektion mit dem HBV abhängig. Sie kann akut oder chronisch verlaufen. Die ersten Symptome sind durch unspezifische Prodromi wie Müdigkeit, Anorexie und Übelkeit gekennzeichnet. Es schließt sich die eigentliche Hepatitis an, die mit Ikterus und Transaminasen-Anstiegen einhergehen kann.

Simultaninfektion von HDV und HBV: Bei der Koinfektion tritt in der Regel eine akute Hepatitis auf, die im Vergleich zur akuten Hepatitis B klinisch schwerer verlaufen kann. Der typische biphasische Transaminasen-Verlauf ist Ausdruck des Leberschadens durch die beiden Viren bzw. deren ausgelöste Immunantwort. Die klinischen Zeichen und Symptome sind in der Regel innerhalb von drei bis zwölf Wochen rückläufig und enden mit dem Verschwinden beider Viren (auch anti-HDV IgM und IgG gehen üblicherweise innerhalb einiger Monate verloren) sowie der Serokonversion zu anti-HBs. In circa $5 \%$ der Fälle erfolgt jedoch ein Übergang in den chronischen Krankheitsverlauf. Die Simultaninfektion kann zu subfulminanten und fulminanten Hepatitiden (insbesondere bei Drogensüchtigen) führen. Fulminante Verläufe treten aber wesentlich seltener als bei der Superinfektion auf.

Superinfektion eines HBsAg-Trägers: Die HDV-Superinfektion bei chronischen HBV-Trägern verläuft häufig klinisch schwerer als die Koinfektion. In Abhängigkeit vom HDV-Genotyp entwickeln 70-90 \% der Patienten eine chronische Hepatitis D. In der Regel verläuft diese aggressiver als die chronische Hepatitis B ohne HDV und oft progredient. Ursache hierfür ist die bereits etablierte HBV-Infektion, die dem HDV durch Bereitstellung der Virushülle die Verbreitung in der Leber und damit eine hohe Replikation ermöglicht. Je mehr Helfervirus vorhanden ist, umso schwerer scheint die Superinfektion zu verlaufen. In mehr als $30 \%$ der Fälle kann es zu fulminanten Verläufen mit hoher Letalität kommen. Die chronische HDVSuperinfektion führt ca. dreimal so häufig zu einer Leberzirrhose wie eine chronische Hepatitis B. Weiterhin ist bei einer HDV-Superinfektion zum Zeitpunkt einer kompensierten Leberzirrhose (Child-Pugh A) das Risiko für ein Leberzellkarzinom verdreifacht und die Letalität verdoppelt. Neben schweren Verläufen gibt es in seltenen Fällen auch asymptomatische Verlaufsformen der chronischen HDV-Superinfektion. Eine spontane Ausheilung der Superinfektion wird vor allem bei Infektion asymptomatischer HBsAgTräger beobachtet.

HBV-Superinfektion einer klinisch latenten HDVInfektion (selten): Bei Patienten mit HDV-Infektionbedingter Lebertransplantation kann es nach der Transplantation zu einer HDV-Reinfektion kommen, bei der trotz HDV-spezifischen Makromolekülsynthesen keine begleitenden Leberschäden gesehen werden. Zur Lebererkrankung kommt es erst, wenn auch das HBV die neue Leber infiziert und damit eine extrahepatische Verbreitung von HDV ermöglicht.

\section{Pathophysiologie}

HDV repliziert ausschließlich in der Leber, wo direkte pathologische Veränderungen auftreten. Die Schädigungen beinhalten Leberzell-Nekrose und Entzündungsreaktionen (geschwollene Hepatozyten, die eine eosinophile Nekrose durchmachen, Entzündungszellen in Parenchym und portalen Feldern). Sie unterscheiden sich nicht von anderen Formen akuter oder chronischer viraler Hepatitis, außer dass sie zu einer schwereren Ausprägung neigen. > Hepatitis-B-Virus.

\section{Immunantwort}

Sowohl die Simultan- als auch die Superinfektion führt nach Ausbruch der klinischen Symptome zur IgM- und IgG-Antikörperbildung gegen die HD-Antigene. Allerdings kann die humorale Immunantwort bei der Simultaninfektion schwach und kurz sein bzw. gänzlich fehlen. Bei Chronifizierung sind die antiHD-Antikörper in der Regel hochtitrig und langfristig nachweisbar. Die Antikörper scheinen nicht protektiv zu sein. Für die Viruselimination wird eher die zelluläre Immunantwort gegen die HD-Antigene verantwortlich gemacht. So sind bei HDV-Superinfektionen auch Th1- und Th0-Immunantworten beobachtet worden. Das konnte auch bei Versuchen mit HDVDNA-Vakzinen in Mäusen bestätigt werden, wobei hier auch CD8-positive zytotoxische T-Zellen induziert wurden.

\section{Differenzialdiagnose}

Der HDV-Ausschluss gehört nicht zur Primärdiag- 
nostik bei akuter Hepatitis. Eine HDV/HBV-Simultaninfektion kann insbesondere bei fulminanten Verläufen von akuten Hepatitiden durch serologische oder molekulargenetische Untersuchungen von anderen viralen oder bakteriellen Hepatitiden abgegrenzt werden. Bei klinischer Verschlechterung einer chronischen Hepatitis B muss an eine HDV-Superinfektion gedacht werden, wobei in solchen Fällen differenzialdiagnostisch auch HBV-Mutanten oder andere virale Superinfektionen eine Rolle spielen könnten.

\section{Diagnostik}

\section{Untersuchungsmaterial}

Als Untersuchungsmaterialien werden Serum und Lebergewebe eingesetzt.

\section{Diagnostische Verfahren}

Direkter Nachweis von Viruskomponenten: Der Nachweis von HDV-RNA mittels RT-PCR ist bei akuter und chronischer Hepatitis mit HD-Positivität zur Beurteilung der Virusaktivität (unter antiviraler Therapie) und der Infektiosität angezeigt. Der HD-Protein-Nachweis in Lebergewebe mit Immunfluoreszenz oder Immunoblot sowie im Serum in der frühen Phase der akuten Hepatitis (nach Abbau der HBsAg-Hülle mit Detergenzien) mittels ELISA ist möglich. In der Routinediagnostik spielen diese Methoden wegen der Möglichkeit des empfindlichen HDV-RNA-Nachweises keine Rolle.

Indirekter Virusnachweis: Die spezifische Diagnose einer HDV-Infektion basiert im Wesentlichen auf dem Nachweis von IgM- und IgG-Antikörpern gegen das HD-Protein mittels ELISA (anti- $\mu$-capture; GesamtAntikörper-ELISA). Zur Labordiagnostik gehören weiterhin die serologischen Untersuchungen zum Nachweis einer aktiven Hepatitis-B-Infektion.

Chemische Laboruntersuchungen: Erhöhung von Transaminasen, alkalischer Phosphatase und Bilirubin sowie Veränderungen hämatologischer Parameter (wie Leukopenie, Lymphpenie und Neutropenie) ermöglichen keine ätiologische Zuordnung der Erkrankung. Bei akuter HDV-Infektion liegen in der Regel erhöhte Transaminasen (GPT) um 300-400 U/l und Anstiege der Bilirubin-Werte auf ca. 3-6 mg/dl vor.

\section{Befund / Interpretation}

Eine Hepatitis-D-Diagnostik ist hauptsächlich bei neu identifizierten HBsAg-positiven Personen mit erhöhtem HDV-Risiko (z. B. Drogenabhängige oder Personen aus Endemiegebieten) und bei anti-HBc-IgMpositiven Personen angezeigt. Untersuchungen sind allerdings auch bei akuten Schüben einer chronischen Hepatitis ohne HBsAg-Positivität indiziert, da HDV die HBV-Replikation unterdrücken und dadurch das serologische Bild einer HBsAg-negativen Hepatitis entstehen kann.

Der Nachweis von anti-HD-IgM und IgG beweist das Vorliegen einer HDV-Infektion. In der frühen Erkran- kungsphase kann anti-HD aber noch fehlen. IgM-anti-HD ist bei einer aktiven (akuten oder chronischen) Hepatitis D nachweisbar. Rasches Verschwinden von IgM-anti-HD spricht für einen gutartigen Verlauf der Simultan- oder Superinfektion. Die IgG-anti-HDAntwort tritt bei der Simultaninfektion meist nur transitorisch auf, sie persistiert nur wenige Jahre. Der Nachweis gelingt am häufigsten vier bis sechs Monate nach Erkrankungsbeginn. Bei der Superinfektion werden dagegen hohe anti-HD-Titer erreicht, die auch nach Ausheilung persistieren. Bei der Koinfektion ist im Gegensatz zur Superinfektion hochtitrig anti-HBcIgM nachweisbar. Die zusätzliche Bestimmung von anti-HBc-IgM dient zum Nachweis einer Simultaninfektion von HBV und HDV.

Ein positiver HDV-RNA-Nachweis beweist das Vorliegen einer aktiven HCV-Infektion. Untersuchungen von Leberbiopsien sind für die Beurteilung der Entzündung, der Fibrose und des Leberumbaus von Bedeutung.

\section{Therapie}

\section{Therapeutische Maßnahmen}

Hochdosiertes Interferon alpha (IFN- $\alpha$ ) stellt die zurzeit einzig verfügbare Therapie der chronischen Hepatitis D dar. Bei 3-mal 9 bis 10 Mio. IE/Woche über ein Jahr wurde bei mehr als $50 \%$ der Patienten eine (allerdings nur vorübergehende) Normalisierung der Transaminasen sowie eine Verbesserung des histologischen Befundes (Rückgang der Leberfibrose) beobachtet. Die Langzeit-Ansprechrate mit anhaltender Viruselimination liegt allerdings nur bei 10-20\%. Eine kurze Erkrankungsdauer scheint die Wirksamkeit der Therapie zu begünstigen. Andere therapeutische Maßnahmen, wie der Einsatz von Immunsuppressiva, Nukleosidanaloga (z. B. Lamivudin und Famciclovir), Acyclovir, Ribavirin oder Thymosin zeigten keinen Erfolg. Zukünftige, vielversprechende Therapiestrategien beinhalten Antisense-Oligonukleotide und Hemmstoffe der Isoprenylierung. Eine finale Option bei terminalem Leberversagen ist eine Lebertransplantation, deren Ergebnis für eine Hepatitis D günstiger sein kann als bei einer HBV-Monoinfektion, da bei ersterer eine geringere Reinfektionsrate des Transplantats mit HBV beobachtet wurde.

\section{Resistenz}

Gegen Interferon traten bisher keine direkten Resistenzen auf.

\section{Epidemiologie}

\section{Verbreitung}

Weltweit sind etwa 15 Millionen Menschen chronisch mit HDV infiziert. Endemiegebiete sind insbesondere die Länder Nord- und Südamerikas, des Mittleren Ostens und des südeuropäischen Mittelmeerraums. Das globale Verteilungsmuster von HDV entspricht weit- 
gehend dem von HBV. Der Anteil von HDV-Infektionen in Relation zu HBsAg-Trägern ist allerdings von der Prävalenz der chronischen Hepatitis B abhängig. In Ländern mit niedriger HBV-Trägerrate (inklusive Deutschland) spielen HDV-Infektionen nur noch bei Risikopersonen (Drogenabhängige, Hämophiliepatienten) eine Rolle. In Ländern mit einer mäßigen bis hohen Prävalenz ist der Anteil an HDV-Infektionen variabel. Bei asymptomatischen HBV-Trägern kann er zwischen 10 und $20 \%$ und bei Patienten mit HBVassoziierten Lebererkrankungen zwischen 30 und 60 \% liegen. Die Ursache für die in bestimmten Regionen Südamerikas periodisch auftretenden HDV-Epidemien mit fatalem Ausgang bei 10 bis $20 \%$ der Erkrankten ist bisher unbekannt. Im Gegensatz dazu sind in China trotz hoher HBsAg-Durchseuchung HDV-Infektionen selten. In den letzten Jahren haben die Inzidenz und Prävalenz von HDV-Infektionen in vielen Ländern stark abgenommen. So verminderte sich in Südeuropa die Prävalenz von anti-HDV-Antikörpern von $40 \%$ in den 80er Jahren auf circa $12 \%$, wozu u. a. HBV-Impfungen und Verbesserung der sozio-ökonomischen Verhältnisse beigetragen haben.

\section{Wirtsbereich / Reservoir}

Das natürliche Wirtsspektrum ist auf den Menschen beschränkt. Waldmurmeltiere (Woodchucks), wenn sie chronische Träger des Woodchuck-Hepatitis-BVirus (WHBV) sind, und HBsAg-positive Schimpansen lassen sich experimentell mit HDV infizieren. Folgen der Infektion können eine akute, eine chronische Hepatitis sowie die schnelle Entwicklung von Leberzellkarzinomen - speziell bei Waldmurmeltieren sein. Primäre Hepatozytenkulturen von Waldmurmeltieren eignen sich für die HDV-Vermehrung. Wird das HDV-Genom als cDNA künstlich (Transfektion) in Säugerzellen eingeführt, zeigt seine Replikation keine Spezies-Spezifität.

\section{Risikogruppen}

Risikogruppen sind chronische HBsAg-Träger. In Niedrig-Endemiegebieten sind insbesondere Drogenabhängige, Hämodialysepatienten, oder Empfänger von multiplen Blut- oder Blutprodukten einem höheren Risiko für eine HDV-Infektion ausgesetzt.

\section{Transmission / Vektoren}

Die Übertragung erfolgt auf dem gleichen Weg wie von HBV. Die perkutane Inokulation ist die häufigste Infektionsursache. Seltener als HBV wird HDV durch Intim- und Schleimhautkontakt übertragen. Vertikale Transmissionen sind nur vereinzelt beobachtet worden.

\section{Prävention / Impfstoffe}

Bisher existiert weder eine spezifische passive noch eine aktive Impfung. Anti-HBs-Antikörper nach Impfung oder nach durchgemachter Hepatitis-B-Infektion schützen vor einer HDV-Infektion. Daher ist eine Hepatitis-B-Immunisierung der effektivste Weg einer Prävention. Für HBV-Träger ist eine Expositionsprophylaxe wie für HBV-Infektionen angezeigt.

\section{Ausbruchsmanagement}

Strategien, die der Kontrolle und Vorbeugung von HBV-Infektionen dienen, beeinflussen gleichermaßen die HDV-Infektionen. Dazu gehören unter anderem die aktive Immunisierung der Bevölkerung mit HBsAg, das Screening von Blut- und Blutprodukten auf Hepatitis-B-Marker und Aufklärung von Risikopersonen.

Das Virus übersteht trockene Hitze $\left(60^{\circ} \mathrm{C}\right)$ über längere Zeiträume ( $30 \mathrm{~h})$.

\section{Meldepflicht}

Gemäß Infektionsschutzgesetz sind der Krankheitsverdacht, die Erkrankung sowie der Tod an akuter Virushepatitis nach $\$ 6$ und der Labornachweis (HDVRNA und anti-HD-Protein-Antikörper) nach $\$ 7$ meldepflichtig.

\section{Weiterführende Informationen}

\section{Referenzzentren / Expertenlaboratorien}

Konsiliarlabor:

- Institut für Medizinische Virologie der Universität Gießen, Frankfurter Str. 107, 35392 Gießen, Telefon: 0641 / 994 1200, http://www.uniklinikum-giessen.de/viro

Expertenlaboratorien:

- Institut für Virologie der Universität Essen, Hufelandstr. 55, 45147 Essen, Telefon: 0221/7233550

- http://www.uni-essen.de/virologie

- Institut für Medizinische Mikrobiologie und Hygiene der Universität Regensburg, Franz-Josef- Strauß-Allee 11, 93042 Regensburg, Telefon 0941 / 9446401

- http://www.uni-regensburg.de/Fakultaeten/Medizin/ $\mathrm{MMH}$

\section{Web-Adressen}

- Centers for Disease Control: http://www.cdc.gov/ncidod/ diseases/hepatitis/

- Robert Koch-Institut: www.rki.de (dort siehe Infektionskrankheiten)

\section{Schlüsselliteratur}

1. Gerin JL, Casey JL, Purcell RH (2007) Hepatitis D (Delta) Virus. In: Knipe DM, Howley PM (eds): Fields Virology 5th edition. Lippincott-Williams \& Wilkins, Philadelphia, pp 3031-3046

2. Taylor, JM (2006) Hepatitis Delta virus. Virology 344:7176

3. Wedemeyer H, Manns MP (2010) Epidemiology, pathogenesis and management of hepatitis D: update and challenges ahead. Nat Rev Gastroenterol Hepatol 7:31-40

\section{Hepatitis $\mathrm{E}$}

- Hepatitis E Virus (HEV) 


\section{Hepatitis E Virus (HEV)}

\section{Erreger}

\section{Erregerspezies \\ Hepatitis-E-Virus}

\section{Taxonomie}

Die taxonomische Klassifizierung des HEV ist zum gegenwärtigen Zeitpunkt nicht abgeschlossen. Provisorisch wurde es wegen seiner strukturellen und physikochemischen Eigenschaften in den Genus Hepevirus klassifiziert. Neue Analysen seiner Genomorganisation legen eine enge Verwandtschaft zu Rubellavirus und den pflanzlichen Furoviren nahe.

\section{Historie}

Im Jahr 1980 wurde HEV als eigenständiges infektiöses Agens identifiziert, als im Verlauf einer epidemischen durch Wasser induzierten Hepatitisepidemie in Indien durch serologische Methoden festgestellt wurde, dass diese epidemische Hepatitis nicht durch Hepatitis A hervorgerufen wurde. Die Erkrankung wurde als „epidemische Non-A, Non-B-Hepatitis“ bezeichnet. Erst 1990 gelangen die molekulare Klonierung des viralen Genoms und damit die Möglichkeit der genauen Charakterisierung des Virus.

\section{Morphologie}

HEV ist ein nicht verhülltes, sphärisches Partikel von 27-30 nm Durchmesser mit wahrscheinlich ikosaedrischer Symmetrie.

\section{Genom}

Das Genom des HEV besteht aus einer einzelsträngigen polyadenylierten (+)-Strang RNA mit 7,5 kb Länge. Das Genom des HEV-Prototypstammes besteht aus einer 5' nicht kodierenden Region von 27 Nukleotiden, gefolgt von ORF1, der aus 5.079 Basen besteht. Ein zweiter ORF beginnt im 2. Leserahmen 38 Nukleotide 3' der Termination des ORF1 und besteht aus 1.980 Nukleotiden. Ein dritter ORF3 besteht aus 369 Nukleotiden. ORF1 kodiert für Nicht-Strukturproteine, ORF2 kodiert das Kapsidprotein und ORF3 kodiert ein kleines immunogenes Protein von unbekannter Funktion. Da die Virusvermehrung in Zellkultur limitiert ist, sind die genauen Mechanismen der Replikation nicht bekannt. Wahrscheinlich erfolgt das Attachment an Rezeptoren auf der Oberfläche von Hepatozyten. Nach dem Uncoating wird das RNAGenom wahrscheinlich durch zelluläre Faktoren translatiert. Prozessierung des translatierten ORF1Proteins erfolgt durch zelluläre Proteasen. Replikative (-)-Strang-Intermediat-RNA wird wahrscheinlich von der viralen Polymerase synthetisiert. Es sind vier Genotypen bekannt. Die genomische Sequenz des HEV ist unter der Genebank Accession-Nr. AF 076239 erhältlich.

\section{Vermehrung}

Nach Infektion der permissiven Zelle wird die virale genomische RNA im Zytosol translatiert und somit das im ORF1 kodierte Nichtstrukturprotein nsP exprimiert. Da nsP die virale Replikase beinhaltet, wird postuliert, dass es für die Umschreibung des Positivstrangs in einen Negativstrang verantwortlich ist. Dieses Intermediat fungiert, in Analogie zu Alphaviren, als Template für die weitere Herstellung von genomischen Positivstrang-RNA-Molekülen.

\section{Pathogenität / Virulenz / Antigenvariabilität}

Tierversuche an HEV-infizierten Affen legen nahe, dass die Leberschädigung hauptsächlich durch Immunmechanismen hervorgerufen wird, da infiltrierende Lymphozyten einen zytotoxischen SuppressorImmunphänotyp aufweisen. Die Ursache für die erhöhte Schädigungsrate bei schwangeren Frauen ist unbekannt.

\section{Erkrankung \\ Virale Hepatitis}

\section{Inkubationszeit}

30-40 Tage.

\section{Leitsymptome}

Hepatomegalie, Ikterus, Anorexie.

\section{Symptome}

HEV-Infektionen können klinisch nicht von anderen viralen Hepatitiden unterschieden werden. Hauptsymptome sind Hepatomegalie, Ikterus und Anorexie. Anikterische Verläufe sind möglich. Die meisten Patienten klagen über Bauchschmerzen, Übelkeit, Erbrechen und Fieber. Wie auch bei HAV-Infektionen werden bei HEV keine chronischen Verläufe beobachtet. Bei Schwangeren treten jedoch fulminante Verläufe auf.

\section{Pathophysiologie}

Es wird vermutet, dass das Hepatitis-E-Virus nicht zytopathogen ist und die Erkrankung durch immunologische Reaktionen hervorgerufen wird. Dies ist jedoch nicht bewiesen.

\section{Immunantwort}

IgG- und IgM-Antikörper werden gegen antigene Determinanten aller drei ORFs gebildet.

\section{Differenzialdiagnose}

Andere virale Hepatitiden.

\section{Diagnostik}

\section{Untersuchungsmaterial}

Serum. 


\section{Diagnostische Verfahren}

Die Diagnostik der HEV-Infektion beruht auf dem Nachweis von spezifischen Antikörpern der IgM- und IgG-Klasse. Dieser Test wird routinemäßig von den meisten Labors angeboten. Darüber hinaus steht für bestimmte Fragestellungen auch der Nachweis viraler HEV-RNA mittels Nukleinamplifikationstest zur Verfügung.

\section{Befund / Interpretation}

IgM- und IgG-Antikörper gegen HEV können im ELISA untersucht werden. IgM anti-HEV kann 1-4 Wochen nach der Infektion nachgewiesen werden. Etwa 3 Monate nach Beginn der Erkrankung sind die IgM-Antikörper nicht mehr nachweisbar. Auch ein ansteigender IgG-Titer ist beweisend für die floride HEV Infektion.

\section{Therapie}

\section{Therapeutische Maßnahmen}

Es gibt keine spezifische Therapie der HEV-Infektion.

\section{Epidemiologie}

\section{Verbreitung}

Bisherige seroepidemiologische Studien zeigten, dass der Erreger in Südostasien, Indien, dem Nahen Osten, Zentralasien und Mittel- und Südamerika vorkommt.

\section{Wirtsbereich / Reservoir}

Aufgrund des Vorkommens des Erregers bei verschiedenen Tierspezies, wie Schweinen, Affen, Ratten sowie Mäusen, geht man davon aus, dass es sich bei der Infektion um eine Zoonose handelt.

\section{Risikogruppen}

Bei Schwangeren kann es zu fulminanten Verläufen kommen.

\section{Transmission / Vektoren}

HEV wird fäkal-oral übertragen und ist vorwiegend mit kontaminiertem Trinkwasser assoziiert. Ein sexueller Übertragungsweg erscheint ebenso wahrscheinlich, da eine Infektionshäufung im jungen Erwachsenenalter beobachtet wird.

\section{Prävention / Impfstoffe}

Ein Impfstoff wurde in einer Phase-II-Studie erprobt [3] und wird wahrscheinlich bald zur Verfügung stehen.

\section{Ausbruchsmanagement}

Hygienemaßnahmen wie bei anderen viralen Hepatitiden, die fäkal-oral übertragen werden.

\section{Meldepflicht}

Nach dem Infektionsschutzgesetz (IfSG) $₫ 6$ besteht beim Krankheitsverdacht, der Erkrankung sowie beim Tod an einer akuten Hepatitis auch bei Hepatitis E eine namentliche Meldepflicht. Darüber hinaus besteht nach IfSG $\$ 7$ beim Nachweis einer akuten Infektion mit Hepatitis-E-Virus durch das Labor eine namentliche Meldepflicht.

\section{Weiterführende Informationen}

\section{Referenzzentren / Expertenlaboratorien}

Konsiliarlaboratorium für HAV und HEV:

- Erreger: Hepatitis-A-Virus, Hepatitis-E-Virus ; Institution: Institut für Medizinische Mikrobiologie und Hygiene der Universität Regensburg Franz-Josef-Strauß-Allee 11 93053 Regensburg, Ansprechpartner: Herr Prof. Dr. W. Jilg, Telefon: 0941.9 44-64 08, Telefax: 0941.9 44-64 02, E-Mail: wolfgang.jilg@klinik.uni-regensburg.de

\section{Web-Adressen}

- All the virology on the WWW: http://www.virology.net

- National center of biotechnology information: http:// www.ncbi.nlm.nih.gov

\section{Schlüsselliteratur}

1. Aggarwal R, Krawczynski K (2000) Hepatitis E: An overview and recent advances in clinical and laboratory research. Journal of Gastroenterology and Hepatology 15:9-20

2. Emerson SU, Purcell RH (2003) Hepatitis E virus. Rev Med Virol 13:145-154

3. Mrigendra Prasad Shrestha et al (2007) Safety and Efficacy of a Recombinant Hepatitis E Vaccine. New England Journal of Medicine 356: S 895-903

4. Purcell RH (1996) Hepatitis E Virus. In: Fields BN, Knipe DM, Howley PM et al. Fields Virology, 3rd edn. Lippincott - Raven Publishers, Philadelphia, pp 2831-2843

5. Tsarev et al (1992) Characterization of a prototype strain of hepatitis E virus. Proc Natl Acad Sci USA 89:559-563

\section{Hepatitis $\mathbf{E}$}

- Hepatitis E Virus (HEV)

\section{Hepatitis G Virus (HGV)}

$>$ GB Virus C (GBV-C)

\section{Herbstgrasmilben}

- Ektoparasiten, sonstige (Stechmücken, Trombiculiden, Flöhe, Wanzen, Zecken)

\section{Heringswurm}

- Nematoden, seltene Arten

\section{Herpangina (vesikuläre Pharyngitis)}

\footnotetext{
Coxsackieviren
} 


\section{Herpes, generalisiert}

- Herpes-simplex-Virus (HSV)

\section{Herpes genitalis}

- Herpes-simplex-Virus (HSV)

\section{Herpes labialis}

- Herpes-simplex-Virus (HSV)

\section{Herpes neonatorum}

- Herpes-simplex-Virus (HSV)

\section{Herpes-simplex-Virus (HSV)}

\section{Erreger}

Nurith J. Jakob, Michaela Handermann

\section{Synonym(e)}

Herpes-simplex-Virus 1, Humanes Herpesvirus 1 (HSV-1)

Herpes-simplex-Virus 2, Humanes Herpesvirus 2 (HSV-2)

\section{Erregerspezies}

Herpes-simplex-Virus 1, Herpes-simplex-Virus 2

\section{Taxonomie}

Der Genus Simplexvirus ist der Familie Herpesviridae und der Unterfamilie der Alphaherpesvirinae zugeordnet. Anhand von DNA-Homologien, serologischer Typisierung und klinischer Symptomatik unterscheidet man zwei Serotypen: das Humane Herpesvirus 1 (Herpes-simplex-Virus 1, HSV-1) und das Humane Herpesvirus 2 (Herpes-simplex-Virus 2, HSV-2).

\section{Historie}

Herpes bedeutet „kriechen, kribbeln, schleichen“ und wurde von Hippokrates für bestimmte Hautkrankheiten verwendet. Morton (1694) gibt eine genaue Beschreibung des Krankheitsbildes „Herpes febrilis“. Gegen Ende des 19. Jahrhunderts wird die Terminologie Herpesvirus hominis (simplex) eingeführt.

\section{Morphologie}

Das Virion besteht aus einem ikosaedrischen Kapsid $(110 \mathrm{~nm})$ mit 162 Kapsomeren (150 Hexons und 12 Pentons), das das virale Genom beherbergt, dem Tegument, das das Kapsid umschließt und einer äußeren Membranhülle (envelope) aus Lipiden, die an der Oberfläche mit Proteinen (spikes) gespickt sind. Die Hexons enthalten sechs Moleküle des so genannten major capsid proteins (155 kD; VP5 oder UL19). Die Pentons bestehen aus VP5 und 80-100 Kopien des so genannten Verpex-Proteins VP26.

\section{Genom}

Das virale Genom ist ein lineares, doppelsträngiges DNA-Molekül und enthält 152.262 bp (HSV-1 Stamm 17; Accession-Nummer X14112) bzw. 154.746 bp (HSV-2 Stamm HG52; Accession-Nummer Z86099). Das virale Genom besteht aus zwei kovalent miteinander verbundenen Komponenten (long component: L; short component: S). Beide DNA-Abschnitte werden von repetitiven DNA-Sequenzen flankiert und nochmals in die "unique sequences“ der langen Komponente (UL) und in die "unique sequences“ der kurzen Komponente (US) untergliedert. Beide Komponenten sind auf einer ideellen Achse im Bereich der so genannten a-Sequenzen zu- und voneinander drehbar, womit vier isomere Formen des viralen DNA-Moleküls entstehen. Das virale Genom beinhaltet drei Replikationsursprünge (origin of replication). Die DNATranskription erfolgt unter Mitinanspruchnahme der RNA-Polymerase II des Wirtes und unter Beteiligung viraler Faktoren. Das virale Genom weist ca. 70 Translationseinheiten auf, die mit ATG initiiert und mit TAA, TAG oder TGA terminiert werden. Einige der viralen Transkripte werden gespleißt.

HSV exprimiert mehr als 70 individuelle Polypeptide während der lytischen viralen Replikationsphase. Hiervon sind ca. 25 virale Proteine für die Virusvermehrung essenziell. Die viralen Proteine werden entsprechend der drei Kategorien der HSV-Gene $(\alpha-, \beta-$ und $\gamma$-Gene) als $\alpha$-, $\beta$ - und $\gamma$-Proteine, die entsprechend zwischen $2-4 \mathrm{~h}, 5-7 \mathrm{~h}$ und $15-18 \mathrm{~h}$ post infectionem exprimiert werden, bezeichnet. Einige virale Proteine sind phosphoryliert, wie z. B. der a4Transkriptionsaktivator und andere Strukturproteine. Das a4-Protein wird auch durch Uridin-Ribosylierung modifiziert. Die genetische Verwandtschaft zwischen HSV-1 und HSV-2 ist durch starke Homologien der Nukleinsäure (um $50 \%$ ) sowie identische transkriptionelle Strategien und analoge Genprodukte dokumentiert.

\section{Vermehrung}

Die akute Virusvermehrung findet in vivo in den Epithelzellen des Nasen-Rachen-Raumes, der Augen, Genitalien und Nebennieren statt. Im Allgemeinen folgt eine neurotrope Phase, während der das latente Virus in den Nervenzellen der Ganglien lebenslang persistiert. Das latent persistierende Virus ist unter bestimmten Risikofaktoren, wie z. B. UV-Licht, chemische Substanzen, immunsuppressive Therapie und Stress reaktivierbar. Die In-vitro-Vermehrung ist auf Zellkulturen verschiedener Organe (Lungen- und Nierenepithelzellen, Fibroblasten) diverser Spezies möglich. Der zytopathische Effekt (CPE) zeigt sich innerhalb einiger Tage post infectionem, abhängig vom 
Virustiter des Inokulums. Die Virulenz und Kontagiosität des HSV ist nicht sehr hoch und in erster Linie abhängig vom Virusstamm und vom Wirt bzw. dessen Immunstatus. Das HSV ist bei Temperaturen von $-70{ }^{\circ} \mathrm{C}$ und darüber stabil. Eine Inaktivierung erfolgt sehr schnell bei Temperaturen über $50^{\circ} \mathrm{C}$ (z. B. $56^{\circ} \mathrm{C}$, $30 \mathrm{~min}$ ) und nach Behandlung mit Detergenztien wie Natriumhypochlorid und Lipidlösungsmitteln, wie z. B. Ether.

\section{Erkrankungen}

\section{Herpes labialis, Herpes genitalis}

\section{Synonym(e)}

Gingivostomatitis, Vulvovaginitis herpetica, Balanitis herpetica.

\section{Inkubationszeit}

Bei Erstinfektion ca. 2-12 Tage, jedoch handelt es sich meistens um eine Reaktivierung.

\section{Leitsymptome}

Juckreiz und ein Spannungsgefühl an der betroffenen Hautstelle, seltener auch Schmerzen. Fieber, Mundausschlag mit stark schmerzenden Bläschen, Lymphknotenschwellung, allgemeines Krankheitsgefühl.

\section{Symptome}

Erstinfektion im Kindesalter meistens symptomlos, kann aber auch in Form einer Gingivostomatitis herpetica auftreten mit Mundausschlag mit stark schmerzenden Bläschen, Lymphknotenschwellung, Es dominiert die Bläschenbildung mit einhergehender Entzündung der entsprechenden Schleimhautregionen und einer meist begleitenden Lymphadenopathie. Beim Herpes genitales können neben den brennenden Schmerzen an den Geschlechtsteilen und am After auch Probleme beim Wasserlassen auftreten.

\section{Pathophysiologie}

Die mazerierenden und exulzerierenden Bläschen sind blutig und überwiegend sekundär infiziert.

Bei Immunsuppression kann eine ausgedehnte, auf tiefere Schichten übergreifende Mukositis entstehen.

\section{Immunantwort}

Bei Immunkompetenten bleibt die Infektion meistens lokalisiert, da aktivierte Makrophagen und Lymphozyten (INF- $\gamma$-Produktion) und natürliche Killerzellen die Dissemination verhindern. Die T-Zell-vermittelte Abwehr scheint wichtiger zu sein als die humorale $\mathrm{Ab}-$ wehr. Die durch eine Herpes-simplex-Virus-Infektion hervorgerufene Immunabwehr schützt nicht gegen eine Reaktivierung des latent persistierenden Virus bzw. vor einer intra- und intertypischen Reinfektion. So wie eine vorhergegangene HSV-1-Infektion nicht vor einer HSV-2-Infektion schützt.

\section{Differenzialdiagnose}

Orofazialer Herpes: rezidivierende Aphten, M. Behçet,
Erythma exsudativum multiforme, Stevens-JohnsonSyndrom, Enterovirus-Infektionen (Herpangia, HandMund-Fuß-Krankheit), Schleimhautulzera bei Neutropenie bzw. bestimmten Autoimmunkrankheiten. HSV-Ösophagitis: Infektionen durch CMV, Candida spp., Arzneimittelnebenwirkungen.

HSV-Hautläsionen: H. zoster, Impetigo, Paronychie, Hautmykosen, Syphilis.

Der ischämische Insult weist wie die HSV-Enzephalitis bei Beginn ein normales CT auf.

\section{Herpes neonatorum}

\section{Synonym(e)}

Generalisierter Herpes des Neugeborenen.

\section{Inkubationszeit}

Die Inkubationsperiode beträgt beim Herpes neonatorum 9-11 Tage.

\section{Symptome}

Die Manifestation beginnt am 9. bis 11. Lebenstag mit einer lokalen Infektion der Haut, der Mundschleimhaut und der Augen, mukokutanen Bläschen, Keratokonjunktivitis oder Choriorenitis. Anschließend erfolgt das Stadium des Herpes generalisatus mit dem Befall der inneren Organe und einem sepsisähnlichen Bild.

\section{Pathophysiologie}

Die Herpes-Sepsis bei Neugeborenen ist überwiegend die Folge einer Infektion im Geburtskanal. Die Häufigkeit des subklinischen Verlaufs ist unbekannt. Das Herpes neonatorum verläuft mit der Häufigkeit von 1 auf 2.000-5.000 Geburten unbehandelt meistens letal. Die Letalität beträgt ohne Behandlung $80 \%$. Entwicklung einer Enzephalitis meist am 9./10. Lebenstag bei hämatogener Genese, bei retrogradem axonalem Virustransport am 16./17. Lebenstag mit den Symptomen von fokalen oder generalisierten Krampfanfällen, Tremor, Unruhe oder Lethargie.

\section{Differenzialdiagnose}

Andere Infektionen, intrakranielle Blutung.

\section{Enzephalitis, Meningoenzephalitis und Meningitis}

\section{Synonym(e)}

Meningoencephalitis herpetica.

\section{Inkubationszeit}

Stunden bis Tage.

\section{Leitsymptome}

Kopfschmerze, Fieber, Bewusstseinsstörung.

\section{Symptome}

Charakteristischer zweiphasiger Verlauf: 1. Grippales Vorstadium (Kopfschmerz, hohes Fieber), oft mit kurz- 
zeitige Besserung. Dann können 2. aphasische Symptome, Hemiparese, kurze psychotische Episoden, Krampfanfälle (komplex-fokal beginnend mit sekundärer Generalisation) sowie quantitative Bewusstseinsstörungen bis hin zum Koma auftreten.

\section{Pathophysiologie}

Die Herpesenzephalitis repräsentiert 50 \% aller Enzephalitiden in Mitteleuropa. Die Eintrittspforte des Virus in das Gehirn sind die Neuronen des N. olfactorius oder eine Aktivierung von latent im Ganglion gasseri persistierendem HSV. Die Enzephalitis befällt in erster Linie temporale und orbitoparietale Regionen des Gehirns und manifestiert sich meist einseitig als eine hämorrhagisch-nekrotisierende Enzephalitis mit einer Letalität von 70 \% (unbehandelt). Nach einer Genesung können neurologische Restschäden zurückbleiben. Die zerebrale HSV-1-Infektion ist häufiger als eine HSV-2-Infektion, die sich meist in einer lymphozytären Meningitis äußert. Primäre Herpesmeningitis oder Herpesmeningitis infolge einer Exazerbation ist ein ernst zu nehmendes Krankheitsbild.

\section{Immunantwort}

Oft ist eine Aktivierung von CD3- und CD8-positiven T-Lymphozyten sowie CD68-positiven Makrophagen sichtbar, die auch nach Abklingen der akuten Infektion oft noch nachweisbar sind.

\section{Differenzialdiagnose}

Enzephalitis durch andere Viren (z. B. VZV, CMV) bzw. Bakterien (z. B. Tbk, Mykoplasmen), Hirnabszess, Hirntumor, Durchblutungsstörungen, Alkoholentzugssyndrom.

\section{Herpetische Keratokonjunktivitis, Choriorenitis und Keratitis}

\section{Inkubationszeit}

Unbekannt, meist Reaktivierung.

\section{Symptome}

Rötung, Fremdkörpergefühl, „Sand im Auge“, Lichtscheu und Sehverschlechterung.

\section{Pathophysiologie}

Die HSV-Infektion der Kornea und der Bindehaut führt zu Läsionen vor allem auf dem Epithel der Hornhaut. Erwachsene sind am häufigsten betroffen. Wenn Neugeborene betroffen sind, dann meistens nur an einem Auge. Schwere serös-eitrige Konjunktivitis. Trübung und oberflächliche Ulzerationen der Hornhaut. Eventuelles Auftreten von Herpesbläschen im Bereich der Augenlider. Rasche ohthalmologische Behandlung. Choriorenitis bei Generalisation.

\section{Differenzialdiagnose}

Zoster ophthalmicus.

\section{Ekzema herpeticum}

\section{Synonym(e)}

Eccema herpeticatum, Pustulosis acuta varioliformis Juliusberg.

\section{Inkubationszeit}

Es kann sich um eine Erstinfektion oder um eine Reaktivierung handeln.

\section{Symptome}

Monomorphe vesikuloerosive Eruption auf ekzematöser Haut bei teils schweren Allgemeinsymptomen, Fieber und Lymphknotenschwellung.

\section{Pathophysiologie}

Charakterisiert durch eine schwere generalisierte Infektion meistens auf dem Boden einer bestehenden Hauterkrankung (meistens atopisches Ekzem) mit Flüssigkeitsverlust sowie der Gefahr einer bakteriellen Superinfektion und möglicher Sepsis bei Virämien mit nachfolgendem Multiorganversagen. Die Übertragung erfolgt mittels Kontakt- oder Schmierinfektion, die Virusausbreitung im Patienten kann per continuitatem, lymphogen oder hämatogen erfolgen. Es entstehen verdickte Krusten auf der Haut mit Ekzem-Effloreszenzen, die sich diffus und rasch ausdehnen können.

\section{Differenzialdiagnose}

Akute Varizelleninfektion des Neurodermitikers, Eczema vaccinatum, varioliforme Pyodermie.

\section{Herpetische Hepatitis}

\section{Symptome}

Müdigkeit, Abgeschlagenheit, Appetitlosigkeit, Druckgefühl im rechten Oberbauch, Erbrechen, Fieber, Ikterus.

\section{Pathophysiologie}

Ein sehr seltenes Krankheitsbild mit meistens tödlicher Folge.

\section{Differenzialdiagnose}

Infektiöse (z. B. Hepatitis A, B, C) und nichtinfektiöse Hepatitiden (z. B. autoimmun, toxisch).

\section{Diagnostik}

\section{Untersuchungsmaterial}

Als Untersuchungsmaterial dienen Bläschenflüssigkeit, Liquor, Tränenflüssigkeit, Bronchiallavage, Rachenspülwasser.

\section{Diagnostische Verfahren}

Direkter Virus-Nachweis: Elektronenmikroskopie, Immun-Elektronenmikroskopie, Virusisolierung über Zellkulturen, Restriktionsenzymanalyse des viralen Genoms, DNA-Hybridisierungstest und Polymerasekettenreaktion. 
Indirekter Virus-Nachweis: Nachweis von virusspezifischen Antikörpern der Klasse IgM, IgG und IgA durch KBR, Immunfluoreszenztest, ELISA-Anti-HSV und Neutralisationstest, Western-Blot aus dem Serum.

Chemische Laboruntersuchungen: Keine spezifische Testverfahren bekannt; histochemisch können multinukleäre Riesenzellen und intranukleäre Einschlusskörperchen bei Abstrichen (z. B. Zervix-Abstrich) nach Papanicolaou-Färbung nachgewiesen werden.

\section{Therapie}

\section{Therapeutische Maßnahmen}

Als Chemotherapie für die Herpesenzephalitis kommt in erster Linie Acyclovir (Acycloguanosin), AdenosinArabinosid oder die Kombination von beiden in Frage. Weiterhin kann Foscarnet oder Cidofovir gegeben werden. Joddeoxyuridin-Präparate, Dimethylsulfoxyd, Acyclovir, Trifluormethylthymidin (TFT) sind bei Keratitisherpetika angezeigt. Zinkoxydpräparate sind bei Hauteffloreszenzen erfolgreich einsetzbar. Bei der Herpesenzephalitis ist die sofortige i.v. Gabe entscheidend für den Verlauf der Erkrankung.

\section{Resistenz}

Acyclovir resistente Stämme sind sehr selten $(<1 \%$ der Isolate). Jedoch sind bei immunkomprimierten Patienten während der Therapie ca. 5 \% der Isolate resistent.

\section{Epidemiologie}

\section{Verbreitung}

HSV ist weltweit verbreitet und kommt unter natürlichen Bedingungen nur beim Menschen vor. Es sind zwei Serotypen bekannt: Typ 1 (HSV-1) infiziert hauptsächlich Zellen der Mundregion. Die Durchseuchungsrate bis zur Pubertät beträgt ca. $50 \%$ und erhöht sich im Erwachsenenalter auf über 90 \%, abhängig vom sozioökonomischen Status und der regionalen hygienischen Infrastruktur der Population. HSV Typ 2 (HSV-2) ist dagegen überwiegend auf die Genitalregion beschränkt. Die Durchseuchungsrate rangiert hier bei ca. $10-20 \%$ bei den 20- bis 30-Jährigen in Mitteleuropa, wobei eine Beziehung zwischen sexueller Aktivität und niederem sozialen Status besteht.

\section{Wirtsbereich/Reservoir}

Das Wirtsspektrum des Virus umfasst außer dem natürlichen Wirt, den Menschen, auch zahlreiche andere Spezies wie Affen und Nager. Auch in vitro zeigt das Virus einen sehr breiten Wirtsbereich. Verschiedene Zellkulturen von Primaten sind für das Virus empfänglich.

\section{Risikogruppen}

Neugeborene von Müttern mit primärem oder rekurrierendem Herpes genitalis, Personen mit Ekzemen, Immunsupprimierte oder immungeschwächte Perso- nen, z. B. unter zytostatischer Therapie, mit Infekten, mit AIDS.

\section{Transmission/Vektoren}

Das Virus wird durch direkten Kontakt über Speichel, Urin, Stuhl und andere Körperflüssigkeiten übertragen. HSV-2 meist über sexuellen Kontakt oder unter der Geburt im Geburtskanal.

\section{Prävention/Impfstoffe}

Es besteht ein dringender Bedarf zur Entwicklung einer effizienten Prophylaxe gegen die Herpes-simplexVirus-Infektion.

\section{Ausbruchsmanagement}

Prophylaxe des Herpes neonatorum: bei rekurrierendem Herpes genitalis der Schwangeren regelmäßiger Versuch des Virusnachweises. Falls negativ, natürliche Geburt; falls in den letzten Wochen der Schwangerschaft positiv, Schnittentbindung erwägen. Bei sichtbaren Erscheinungen stets Sectio innerhalb von $24 \mathrm{~h}$ nach Blasensprung. Passive Immunisierung des Kindes wirkungslos: Herpes neonatorum tritt auch dann auf, wenn Antikörper der Mutter passiv übertragen wurden. Aciclovir beim Kind bei den ersten Anzeichen einer Herpesinfektion verabreichen. Pflegepersonal mit rezidivierender Herpes-simplex-Infektion nicht auf Neugeborenenstationen beschäftigen.

\section{Meldepflicht}

Enzephalitis ist meldepflichtig.

\section{Weiterführende Informationen}

\section{Referenzzentren/Expertenlaboratorien}

- Konsiliarlaboratorium für Herpes-simplex-Virus (HSV) und Institut für Virologie und Antivirale Therapie, Nordhäuserstr. 78, 99089 Erfurt

Ansprechpartner: Prof. Dr. P. Wutzler, Prof. Dr. A. Sauerbrei, Tel.: 0361/7411-214/ -314, Telefax 0361/7411-114, Email: peter.wutzler@med.uni-jena.de

\section{Web-Adressen}

- Introduction to virology: http://www-micro.msb.le.ac. uk/109/Introduction.html

- All the virology on the WWW: http://www.virology.net

- Virus databases on-line: http://life.anu.edu.au/viruses/

- The big picture book of viruses: http://www.virology.net/ Big_Virology/BVHomePage.html

\section{Schlüsselliteratur}

1. Baringer JR (2008) Herpes simplex infections of the nervous system, Neurol Clin 26:657-674

2. Becker Y, Darai G (eds) (1994) Pathogenicity of Human Herpesviruses due to Specific Pathogenicity Genes, Frontiers of Virology 3. Springer-Verlag Berlin Heidelberg New York

3. Corey L, Wald A (2009) Maternal and neonatal herpes simplex virus infections. N Engl J Med 361: 1376-1385.

4. Whitney RJ (1990) Herpes-simplex-Virus. In: Fields N, Knipe DM et al (eds) Virology, 2nd edn, Raven Press, Ltd. New York, vol 2, pp1843-1888 